MAR : 1971

NBS

PUBLICATIONS

\title{
Hydraulic Research
}

in the United States

\section{8}

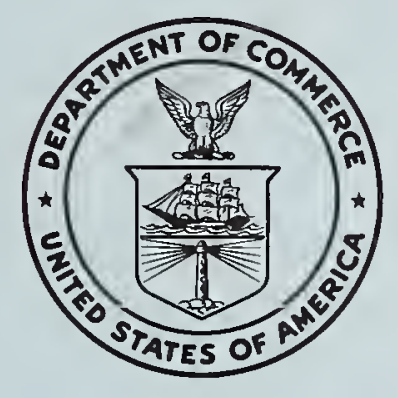

United States Department of Commerce

$Q C$

100

.457

1969
National Bureau of Standards

Special Publication 316 


\section{NATIONAL BUREAU OF STANDARDS}

The National Bureau of Standards ' was established by an act of Congress March 3, 1901. Today, in addition to serving as the Nation's central measurement laboratory, the Bureau is a principal focal point in the Federal Government for assuring maximum application of the physical and engineering sciences to the advancement of technology in industry and commerce. To this end the Bureau conducts research and provides central national services in four broad program areas. These are: (1) basic measurements and standards, (2) materials measurements and standards, (3) technological measurements and standards, and (4) transfer of technology.

The Bureau comprises the Institute for Basic Standards, the Institute for Materials Research, the Institute for Applied Technology, the Center for Radiation Research, the Center for Computer Sciences and Technology, and the Office for In formation Programs.

THE INSTITUTE FOR BASIC STANDARDS provides the central basis within the United States of a complete and consistent system of physical measurement; coordinates that system with measurement systems of other nations; and furnishes essential services leading to accurate and uniform physical measurements throughout the Nation's scientific community, industry, and commerce. The Institute consists of an Office of Measurement Services and the following technical divisions:

Applied Mathematics-Electricity-Metrology-Mechanics-Heat-A tomic and Molecular Physics-Radio Physics "-Radio Engineering "-Time and Frequency "-Astrophysics "-Cryogenics."

THE INSTITUTE FOR MATERIALS RESEARCH conducts materials research leading to improved methods of measurement standards, and data on the properties of well-characterized materials needed by industry, commerce, educational institutions, and Government; develops, produces, and distributes standard reference materials; relates the physical and chemical properties of materials to their behavior and their interaction with their environments; and provides advisory and research services to other Government agencies. The Institute consists of an Office of Standard Reference Materials and the following divisions:

Analytical Chemistry_Polymers-Metallurgy-Inorganic Materials-Physical Chemistry.

THE INSTITUTE FOR APPLIED TECHNOLOGY provides technical services to promote the use of available technology and to facilitate technological innovation in industry and Government; cooperates with public and private organizations in the development of technological standards, and test methodologies; and provides advisory and research services for Federal, state, and local government agencies. The Institute consists of the following technical divisions and offices:

Engineering Standards-Weights and Measures - Invention and Innovation - Vehicle Systems Research-Product Evaluation-Building Research-Instrument Shops-Measurement Engineering-Electronic Technology-Technical Analysis.

THE CENTER FOR RADIATION RESEARCH engages in research, measurement, and application of radiation tis the solution of Bureau mission problems and the problems of other agencies and institutions. The Center consists of the following divisions:

Reactor Radiation-Linac Radiation-Nuclear Radiation-Applied Radiation.

THE CENTER FOR COMPUTER SCIENCES AND TECHNOLOGY conducts research and provides technical services designed to aid Government agencies in the selection, acquisition, and effective use of automatic data processing equipment; and serves as the principal focus for the development of Federal standards for automatic data processing equipment, techniques, and computer languages. The Center consists of the following offices and divisions:

Information Processing Standards-Computer Information - Computer Services - Systems Development-Information Processing Technology.

THE OFFICE FOR INFORMATION PROGRAMS promotes optimum dissemination and accessibility of scientific information generated within NBS and other agencies of the Federal government; promotes the development of the National Standard Reference Data System and a system of information analysis centers dealing with the broader aspects of the National Measurement System, and provides appropriate services to ensure that the NBS staff has optimum accessibility to the scientific information of the world. The Office consists of the following organizational units:

Office of Standard Reference Data-Clearinghouse for Federal Scientific and Technical Information "-Office of Technical Information and Publications-Library-Office of Public Information-Office of International Relations.

\footnotetext{
Headquarters and Laboratories at Gaithersburg, Maryland, unless otherwise noted; mailing address Washington, D.C. 20234. 


\section{Hydraulic Research in the United States 1968}

(Including Contributions from Canadian Laboratories)

Edited by Gershon Kulin

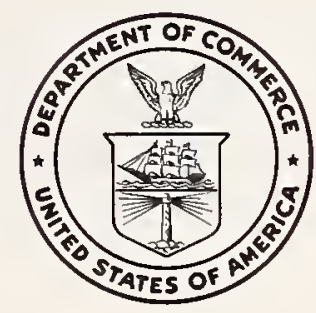

U.S, National Bureau of Standards Special Publication 316,

Nat. Bur. Stand. (U.S.), Spec. Publ. 316, 331 pages (June 1969)

CODEN : XNBSA

Issued June 1969 
PATIONAL E:AT:" OF STA.NDARDS

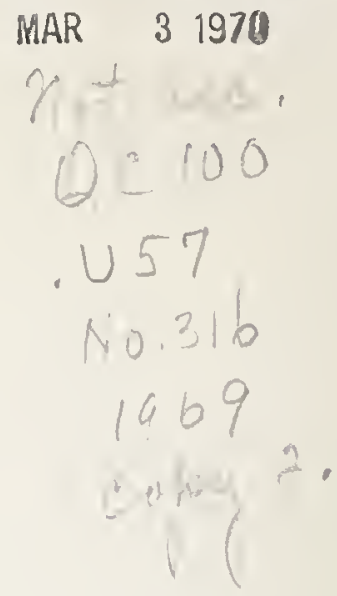

ABSTRACT

Current and recently concluded research projects in hydraulics and hydrodynamics for the years 1967-1968 are summarized.

Projects from more than 200 university, industrial, state and federal government laboratories in the United States and Canada are reported.

Key words: Hydraulics; hydraulic research; hydraulic engineering; hydrodynamies; project summaries

Library of Congress Catalog Card Number: 34-3323 
"Hydraulic Research in the United States" first appeared in 1933 in answer to a need for a publication devoted to keeping hydraulicians aware of pertinent current activity in research laboratories throughout the United States and Canada. With the exception of a few World War II years, it was published annually through 1966, after which publication became biennial.

The National Bureau of Standards appreciates the cooperation of the more than 200 organizations which have contributed to this issue their summaries of hydraulic and hydrologic research and of other fluid mechanics research of interest and usefulness to hydraulicians. Although efforts are made to solicit reports from all laboratories whose work comes to our attention, the National Bureau of Standards cannot assume responsibility for the completeness of this publication. We must depend in the last analysis upon reporting laboratories for the completeness of the coverage of their own programs and upon new laboratories engaged in pertinent research to bring their activities to our attention.

Detailed information regarding the research projects reported here should be obtained from the correspondent listed under (c) or immediately following the title of the organization reporting the work. The National Bureau of Standards does not maintain a file of publications, reports or other detailed information on research projects reported by other laboratories. It is of course understood that laboratories submitting reports on their work will be willing to supply additional information to properly qualified inquirers.

A similar bulletin, "Hydraulic Research," compiled and published biennially by the International Association for Hydraulic Research, contains information on hydraulic research being conducted in all countries other than the United States and Canada. This bulletin is edited by Prof. H.J. Schoemaker, Director, Delft Hydraulics Iaboratory, Delft, The Netherlands, and Secretary of the International Association for Hydraulic Research. Copies are available to nonmembers of the International Association for Hydraulic Research from the Secretary at $\$ 7.50$ each (postage by surface mail included).

There is also available the "Water Resources Research Catalog," prepared by the Science Information Exchange of the Smithsonian Institution for the Office of Water Resources Research, U.S. Department of the Interior. Volume 3 is available from the Superintendent of Documents, U.S. Government Printing Office, Washington, D.C. 20402 , at $\$ 6.75$ per copy. (See also "Key to Projects" on next page). 
Abstract-1.

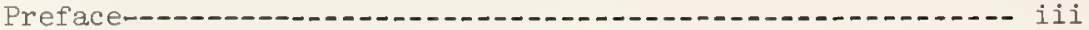

List of Contributing Laboratories-.......... V

Project Reports from

University, State and Industrial Laboratories-.-.-. 1

U.S. Government Laboratories.......................... 155

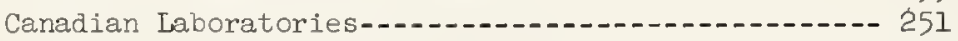

Subject Index-1... 273

\section{KEY TO PROJECTS}

(a) Number and title of project

Project numbers, once assigned, are repeated in each issue for identification purposes until the project is completed. In this issue the numbers 6044 and above refer to projects being reported for the first time. Numbers followed by $W$, e.g. (001W), refer to projects which are included here by title only, but which are completely summarized in "Water Resources Research Catalog." (See "Preface")

(b) Project conducted for

Projects which are not under outside sponsorship are identified here as "laboratory projects."

(c) Correspondent

Where there is no entry here, please see the correspondent cited directly below the name of the contributing laboratory. (See also "Preface")

(d) Nature of project

(e) Description of project

(f) Present status

Absence of an entry here implies that the project was in an active status as of the time of submission.

(g) Results

(h) Publications 
ALARAMA, UNIVERSITY OF, HUNTSVILTE

Research Institute, Huntsville, Ala. 35807

Dr. C.C. Shih, Prof. of Engrg. Mechanics

ARIZONA STATE UNIVERSITY

Dept. of Mechanical Engrg., Tempe, Ariz. 85281

Prof. Warren Rice, Chairman

ARIZONA, UNIVERSITY OF

Dept. of Civil Engrg., Tucson, Ariz. 85721

Dr. Emmet M. Laursen, Head

ARKANSAS, UNIVERSITY OF

Dept. of Civil Engrg.

Fayetteville, Arkansas 72701

Prof. I.R. Heiple, Head

BOEING SCIENTIFIC RESEARCH IABORATORIES

Flight Sciences Laboratory, P.0. Box 3981

Seattle, Washington 98124

A. Goldburg, Head, Flight Sciences Lab.

BROOKLYN, POLYTECHNIC INSTITUIE OF

333 Jay Street, Brooklyn, N.Y. 11201

Prof. Matthew W. Stewart, Civil Engrg.

BUFFAIO, STATE UNIVERSITY OF NEW YORK (AT)

Dept. of Civil Engrg., Buffalo, N.Y. 14214

Dr. Ralph R. Rumer, Chairman

CAITFORNIA INSTITUTE OF TECHIOLOGY

Engrg. Science Dept., Pasadena, Calif. 91109

Dr. Milton S. Plesset, Prof. of Engrg. Science

CAIIFORNTA INSTITUTE OF TECHNOLOGY

W.M. Keck Laboratory of Hydraulics and

Water Resources, Pasadena, Calif. 91109

Dr. Vito A. Vanoni, Professor of Hydraulics

CAIIFORNIA, UNIVERSITY OF, EERKELPY

College of Engineering, Berkeley, Calif. 94720

Prof. J.W. Johnson, Hydraulic Engineering

CAIIFORNIA, UNIVERSITY OF, BERKELEY

Dept. of Naval Architecture

Berkeley, California 94720

Prof. J.R. Paulling, Chairman

CALIFORNIA, UNIVERSITY OF, DAVIS

College of Agriculture, Davis, Calif. 95616

Prof. Verne H. Scott, Chairman

Dept. of Water Science and Engrg.

CALIFORNIA, UNIVERSITY OF, IOS ANGELES

Dept. of Engineering, Ios Angeles, Calif. 90024

C. Starr, Dean, College of Engineering

CAIIFORIIA, UNIVERSITY OF, SAN DIEGO

See Scripps Institution of Oceanography

CATHOLIC UNIVERSITY OF AMERICA, THE

Dept. of Civil Engrg., Wash. D.C. 20017

Dr. B.S. Browzin, Prof. Civil Engrg.

CATHOIIC UNIVERSITY OF AMERICA, THE

Dept. of Space Science and Appl. Physics

Washington, D. C. 20017

Prof. C.C. Chang, Head
CINCINNATI, UNIVERSITY OF

Dept. of Chemical Engrg. and Metallurgical

Engrg., Cincinnati, Ohio 45221

Dr. D. Hershey, Assoc. Prof., Chem. Engrg.

CINCINNATI, UNIVERSITY OF

Civil Engrg. Dept., Cincinnati, Ohio 45221

Dr. Louis M. Laushey, Head

CITY COLIEGE OF NEW YORK

See New York, City College of

CIARKSON COLIEGE OF TECHNOLOGY

Dept. of Chemical Engrg., Potsdam, N.Y. 13676

Prof. William N. Gill, Chairman

COASTAL ENGINEERING RESEARCH CENTER

U.S. Army Corps of Engineers

See U.S. Government

COLORADO STATE UNIVERSITY

College of Engrg., Engrg. Research Center

Fort Collins, Colo. 80521

Dr. D.B. Simons, Assoc. Dean

COLORADO, UNIVERSITY OF

Dept. of Civil Engrg., Boulder, Colo. 80302

J. Ernest Flack, Director, Water Resources

COLUMBIA UNIVERSITY

Dept. of Civil Engrg. and Engrg. Mechanics

New York, N.Y. 10027

Prof. Richard Skalak, Civil Engrg.

COLUMBIA UNIVERSITY

Lamont Geological Observatory

See separate listing

CONNECTICUI, UNIVERSITY OF

School of Engineering, Storrs, Conn. 06268 Prof. C.J. Posey, Civil Engineering

CONRAC CORPORATION

P.0. Box 32, Caldwell, New Jersey 07006

E. Martinez, Manager, Fluidies

CORNELI AERONAUPICAL LABORATORY, INC.

P.O. Box 235, Buffalo, N.Y. 14221

Mr. Harold A. Cheilek, Vice-Pres.-Technical

CORIVELL UNIVERSITY

School of Civil Engrg., Dept. of Hydraulies and Hydraulic Engrg., Ithaca, N.Y. 14850

Dr. J.A. Liggett

DELAWARE, UNIVERSITY OF

Dept. of Civil Engrg., Newark, Del. 19711

Prof. Eugene Chesson, Jr., Chairman

DOUGLAS AIRCRAFT COMPANY, INC.

Dakewood Blvd. Long Reach, Calif. 90801 N.A. Carhart, Vice Pres., Advanced Systems and Technology

FLORIDA, UNIVERSITY OF

Engineering and Industrial Exp. Station

Dept. of Coastal and Oceanographic Engrg.

Gainesville, Florida 32603

Dr. Robert G. Dean, Chairman of Dept. 
GENERAL DYNAMICS, CONVAIR DIVISION

P.O. Box 1128, San Diego, Cal1f.. 92112

M. Dublin, Chief Technical Engr.

Aerospace Technology

GENERAL DYNAMICS, ELECIRIC BOAT DIVISION

Eastern Point Road, Groton, Connecticut 06340

V.T. Boatwright, Jr., Director, Research and Development

GENERAL ELECTRIC COMPANY

Research and Development Center

P.0. Box 8, Schenectady, New York 12301

Dr. William J. Love, Actg. Mgr., Fluids

Branch, Mechanical Technology Laboratory

GENERAL EIECTRIC COMPANY

Space Sciences Iaboratory

P.0. Box 8555, Philadelphia, Pa. 19101

S.M. Scala, Mgr., Theoretical Fluid Physics

GEORGIA INSTITUTE OF TECHNOLOGY

School of Civil Engrg., Atlenta, Ga. 30332

Dr. W.M. Sangster, Director

GEORGIA INSTITUTE OF TECHNOLOGY

School of Engrg. Mechanics, Atlanta, Ga. 30332

Milton E. Raville, Director

GRUMMAN AIRCRAFT ENGINEERING CORP.

Research Dept., Fluid Mechanics Sec.

Bethpage, L.I., N.Y. 11714

Dr. Charles E. Mack, Jr., Dir. of Research

HAWAII, UNIVERSITY OF

Hawaii Institute of Geophysics

Honolulu, Hawaii 96822

Dr. John S. Williams, Civil Engrg. Dept.

HAWAII, UNIVERSITY OF

J.K.K. Look Lab. of Oceanographic

Engineering, Honolulu, Hawaii 96822

Howard P. Harrenstien, Director

HOUSTON, UNIVERSITY OF

Dept. of Mechanical Engrg., Cullen Blvd.

Houston, Texas 77004

Asst. Prof. Charles Dalton

HYDRONAUIICS, INCORPORATED

Pindell School Road, Laurel

Howard County, Maryland 20810

Mr. Phillip Eisenberg, President

IDAHO, UNIVERSITY OF

Engrg. Exp. Station, Moscow, Idaho 83843

R.E. Warner, Associate Director

IIT RESEARCH INSTITUTE

10 West 35 th Street, Chicago, Ill. 60616

Dr. E.H. Schulz, Director

ILIINOIS, STATE OF

Division of Waterways, Dept. of Public

Works and Bldgs., 201 W. Monroe Street

Springfield, Illinois 62706

Mr. John C. Guillou, Chief Naterway Engr.

ILLINOIS STATE WATER SURVEY DIVISION

Box 232, Urbana, Illinois 61802

Mr. William C. Ackerman, Chief
Illinois 61803

Dr. Frank B. Lanham, Head

ILITNOIS, UNIVERSITY OF

Dept. of Chemistry and Chemical Engrg. Urbana, Illinois 61803

Prof. Thomas J. Hanratty, Chem. Engrg.

ILIINOIS, UNIVERSITY OF

Civil Engrg. Dept., Urbana, Ill. 61803

Dr. V.T. Chow, Prof. Hydraulic Engrg.

ILIINOIS, UNIVERSITY OF

Dept. of Theoretical and Applied Mechanics

214 Talbot Laboratory, Urbana, Ill. 61803

Prof. T.J. Dolan, Head

IOWA INSTITUIE OF HYDRAULIC RESEARCH

Univ. of Iowa, Iowa City, Iowa 52240

Dr. John F. Kennedy, Director

IOWA STATE UNIVERSITY

Dept. of Agric. Engrg., Ames, Iowa 50010

Dr. Howard P. Johnson, Professor

IOWA STATE UNTVERSITY

Dept. of Agronomy, Ames, Iowa 50010

Prof'. Don Kirkham

IOWA, UNIVERSITY OF

Dept. of Mechanical Engrg., Iowa City

Iowa 52240

Prof. Thomas P. Anderson, Head

IOWA, UNIVERSITY OF

Iowa Institute of Hydraulic Research

See separate listing

JOHINS HOPKINGS UNIVERSITY

Applied Physics Lab., 8621 Georgia Ave.

Silver Spring, Maryland 20910

B.H. Buckingham, Asst. to Director

KANSAS, UNIVERSITY OF

Dept. of Civil Engrg., Lawrence, Kan. 66044 Prof. Y.W. Yu

41 KENIUCKY, UNIVERSITY OF

Dept. of Civil Engrg., Lexington, Ky. 40506 Don J. Wood, Assoc. Professor

LAMONT GEOLOGICAL OBSERVATORY

Columbia Univ., Palisades, New York 10964

Dr. Takashi Ichiye

IEHIGH UNIVERSITY

Dept. of Civil Engineering

Fritz Engrg. Lab., Bethlehem, Pa. 18015

Dr. W.H. Graf, Chairman, Hydraulic and

Sanitary Engineering Division

LOCKHEED CAITFORNIA COMPANY

Burbank, California 91503

A.J. Carsola, Manager, Oceanics Div.

LOUISANA STATE UNIVERSITY AND A AND M COLIEGE Agric. Engrg. Dept., Baton Rouge, La. 70803 Mr. Harold T. Barr, Head

LOUISIANA STATE UNIVERSITY AND A AND M COLIEGE Dept. of Civil Engrg., Baton Rouge, La. 70803 Dr. F.J. Germano, Head 
LTV RESEARCH CENTER

Ling-Temco-Vought, Inc .

P.0. Box 6144, Dallas, Texas 75222

H.B. Gibbons, Director

MARINE ADVISERS, INC.

P.O. Box 1963, LaJolla, Calif. 92037

R.D. Plunkett, Manager, Stuãies Dept.

MASSACHUSETTS INSTITUTE OF TECHNOLOGY

Dept. of Civil Engrg., Cambridge, Mass. 02139

Dr. Arthur T. Ippen, Head

Hydrodynamics Iaboratory

MASSACHUSETTS INSTITUME OF TECHNOLOGY

Dept. of Mechanical Engineering

Cambridge, Mass. 02139

Prof. Ascher H. Shapiro, In Charge

Fluid Mechanics Division

MASSACHUSETTS INSTITUTE OF TECHNOLOGY

Dept. of Naval Architecture and Marine Engrg.

Ship Model Towing Tank, Cambridge, Mass. 02139

Prof. Martin A. Abkowitz, Director

MASSACHUSETTS, UNIVERSITY OF

School of Engrg., Amherst, Mass. 01003

Dr. Kennerth G. Picha, Dean of Engrg.

MICHIGAN STATE UNIVERSITY

Dept. of Civil Engrg., East Lansing, Mich. 48823

Charles E. Cutts, Chairman

MICHIGAN, UNIVERSITY OF

Dept. of Civil Engrg.

320 W. Engrg. Bldg., Ann Arbor, Mich. 48104

Dr. E.F. Brater

MICHIGAN, UNIVERSITY OF

Dept. of Engineering Mechanics

Ann Arbor, Michigan 48104

Dr. J.W. Daily, Chairman

UNIVERSITY OF MICHIGAN

Dept. of Nuclear Engrg., Lab. for Fluid Flow and Heat Transport Phenomena, Ann Arbor,

Michigen 48104

Prof. F.G. Hammitt, Director

UNIVERSITY OF MICHIGAN

Ship Hydrodynamics Laboratory

Ann Arbor, Michigan 48104

Prof. Finn C. Michelsen, Director

MINNESOTA, UNIVERSITY OF

See St. Anthony Falls Hydraulic Lab.

MISSOURI, UNIVERSITY OF

Dept. of Civil Engrg., Columbia, Mo. 65202

Dr. Adrian Pauw, Chairman

MISSOURI, UNIVERSITY OF, AT ROLIA

Dept. of Chemical Engrg., Rolla, Mo. 65401

Professor Jacques L. Zakin

MISSOURI, UNIVERSTTY OF, AT ROLIA

Dept. of Civil Engrg., Rolla, Mo. 65401

Dr. J.H. Senne, Jr., Chairman

MOEIL RESEARCH AND DEVELOPMENT CORPORATION

Research Dept., P.O. E0\% 300

Dallas, Texas 75221

C.S. Yuhn, Manager, Production Research
Agricultural Exp. Sta., Bozeman, Mont. 59715

Prof. Charles C. Bowman, Head

Agricultural Engineering Dept.

NARRAGANSETT MARINE IABORATORY

See Rhode Island, University of

NEW YORK, STATE UNIVERSITY OF, AT BUFFALO

See Buffalo

NEW YORK, THE CITY COLLEGE OF

Dept. of Civil Engrg., New York, N.Y. 10031

Prof. J.R. Stevens, Director,

$74 \quad$ Fluid Mechanics Lab.

NEW YORK UNIVERSITY

Courant Institute of Mathematical Sciences

251 Mercer St., New York, N.Y. 10012

Prof. C.S. Morawetz

NEW YORK UNIVERSITY

Dept. of Chemical Engrg., University Heights, New York, N.Y. 10453

Prof. John Happel, Chairman

NEW YORK UNIVERSITY

Dept. of Civil Engrg., Water Resources Lab.

University Heights, New York, N.Y. 10453

Dr. William E. Dobbins, Director

NEW YORK UNIVERSITY

Dept. of Meteorology and Oceanography

University Heights, New York, N.Y. 10453

Gerhard Neumann, Prof. of Oceanography

NORTH AMERICAN AVTATION, INC.

Space and Information Systems Div.

12214 Lakewood Blvd., Downey, Calif. 90241

79 W.H.T. Loh, Mgr., Science and Technology

Research, Engineering and Test

NORTH CAROLINA STATE UNIVERSITY

Dept. of Engrg. and Research

Raleigh, North Carolina 27607

N.W. Conner, Asst. Dean for Research

NORTH DAKOTA STATE UNIVERSITY

Agricultural Engrg. Dept., Fargo, N.D. 58103

Prof. W.J. Promersberger, Chairman

NORTHERN MICHIGAN UNIVERSITY

Dept. of Physics, Marquette, Mich. 47855

Dr. Robert T. Wagner, Head

80 NORTHERN RESEARCH AND ENGINEERING CORP.

219 Vassar St., Cambridge, Mass. 02139

Dr. Willem Jansen, Staff Engineer

NORTH STAR RESEARCH AND DEVELOPMENT INSTITUTE

3100 38th Ave. South, Minneapolis,

Minn., 55406

R.Q. Wilson, Vice President

NORTHWESTERN UNIVERSITY

The Technological inst., Evanston, Ill 60201

NOTRE DAME UNIVERSITY

Dept. of Civil Engrg., Notre Dame, Ind. 46556

NOTRE DAME UNIVERSITY

Dept. of Mech. Engrg., Notre Dame, Ind. 46556

Dr. J.W. Jerper, Chai rman 
OAK RIDGE NATIONAL IABORATORY

P.O. Box X, Oak Ridge Tennessee

Dr. Alvin M. Weinberg, Director

37830

OHIO AGRICULTURAL RESEARCH AND DEVELOPMENT

\section{CENTIER}

Dept. of Agricultural Engrg., Wooster, Ohio 44691

Dr. R.E. Stewart, Chairman

OHIO STATE UNIVERSITY

Agronomy Dept., Columbus, Ohio 43210

Prof. George S. Taylor

OHIO STATE UNIVERSITY

Water Resources Center, Colümbus, Ohio 43210

Prof. George S. Taylor

OREGON STATE UNIVERSITY

Engrg. Exp. Sta., Corvallis, Oregon 97331

James G. Knudsen, Asst. Dean of Engrg.

PEC Research Associates, Inc.

P.0. Box 3435, Boulder, Colorado 80302

Donald G. Burkhard, Research Director

PENNSYLVANIA STATE UNIVERSITY

Dept. of Civil Engrg., University Park, Pennsylvania 16802

Prof. Sam Shulits, Head, Hydraulics Lab.

PENNSYLVANIA STATE UNIVERSITY

Ordnance Research Laboratory

University Park, Pennsylvania 16802

Dr. J.C. Johnson, Director

PENNSYLVANIA, UNIVERSITY OF

Towne School of Civil and Mechanical Engrg.

Philadelphia, Pennsylvania 19104

Dr. Iraj Zandi, Assoc. Prof.

PITTSBURGH, UNIVERSITY OF

Chemical and Petroleum Engrg. Dept.

Pittsburgh, Pennsylvania 15213

Asst. Prof. George E. Klinzing

PURDUE UNIVERSITY

Dept. of Agricultural Engrg.

Lafayette, Indiana 47907

Dr. G.W. Isaacs, Head

PURDUE UNIVERSTTY

Dept. of Agronomy, Lafayette, Ind. 47907

Dr. J.B. Peterson, Head

PURDUE UNIVERSITY

School of Chemical Engrg.

Lafayette, Indiana 47907

R.A. Greenkorn, Head

PURDUE UNIVERSITY

School of Civil Engrg.

Lafayette, Indiana 47907

Dr. G.A. Leonards, Head

PURDUE UNIVERSITY

School of Mechanical Engrg.

Lafayette, Indiana 47907

Prof. P.W. McFadden, Head

PURDUE UNIVERSITY

School of Mechanical Engrg., Automatic

Control Laboratory

Lafayette, Ind. 47907

Dr. Rufus Oldenburger, Director
PURDUE UNIVERSITY

102

Center, Lafayette, Indiana 47907

B.A. Reese, Director

RAND CORPORATION, THE

Dept. of Geophysics and Astronomy

1700 Main St., Santa Monica, Calif. 90406

Dr. S.M. Greenfield, Head of Dept.

RENSSELAER POLYTECHIIC INSTITUITE

Dept. of Mathematics, Troy, N.Y. 12181

Professor Richard C. DiPrima

RHODE ISIAND, UNIVERSITY OF

Kingston, R.I. 02881

92 Dr. John A. Knauss, Dean, Graduate School

of Oceanography

ROBERT TAGGART INCORPORATED

3930 Walnut St., Fairfax, Va.

ROCKETDYNE

6633 Canoga Ave., Canoga Park, Calif. 91304

93 S.F. Iacobellis, Dir., Advanced

Projects/Marketing, Large Engines

ROCKY MOUNTAIN HYDRAULIC IABORATORY

Allenspark, Colorado 80510

94 Prof. C.J. Posey, Director (Winter address:

Box U-37, Univ. of Conn., Storrs, Conn. 06268)

ST ANTHONY FALIS HYDRAULTC LABORATORY

University of Minnesota

Mississippi R. at Third Avenue, S.E.

Minneapolis, Minn. 55455

Prof. Edward Silberman, Director

SCRIPPS INSTITUTION OF OCEANOGRAPHY

University of California, San Diego

LaJolla, Calif. 92037

Dr. W.H. Munk, Assoc. Dir., Inst. of

Geophysics and Planetary Physics

SOUTH DAKOTA SCHOOL OF MINES AND TECHNOLOGY

Professor Shu-t'ien Li

SOUTHERN CALIFORNLA, UNIVERSITY OF

Dept. of Mechanical Engrg., University Park,

Los Angeles, Calif. 70007

Prof. Raymond C. Binder

SOUTHERN CALTFORNIA, UNIVERSITY OF

Foundation for Cross-Connection Control

Research, School of Engrg., University Park, Los Angeles, Calif. 70007

Prof. E. Kent Springer, Director of Foundation

SOUTHWEST RESEARCH INSTITUIE

Dept. of Mechanical Sciences

8500 Culebra Rd., San Antonio, Tex. 78206

Dr. H. Norman Abramson, Director of Dept.

STANFORD RESEARCH INSTITUTE

Menlo Park, California 94025

Dale H. Hutchison, Asst. Vice President

STANFORD UNIVERSITY

Dept. of Civil Engrg., Stanford, Calif. 34305 
STANFORD UNIVERSITY

Mechanical Engrg. Dept., Thermosciences Div. Stanford, California 94305

Professor S.J. Kline

STEVENS INSTITUTE OF TECHNOLOGY

Davidson Lab., Hoboken, New Jersey 07030

John P. Breslin, Director

SYRACUSE UNIVERSITY

Dept. of Civil Engrg., Syracuse, N.Y. 13210

Dr. W.-H. Li, Prof. of Civil Engrg.

SYRACUSE UNIVERSITY

Dept. of Mechanical and Aerospace Engrg.

Syracuse, New York 13210

Dr. S. Eskinazi

TAGGART, ROBERT, INCORPORATED

See Robert Taggart

TENNESSEE, UNIVERSITY OF

Dept. of Chemical and Metallurgical Engrg.

Knoxville, Tennessee 37916

H.F. Johnson, Head

TEXAS $A$ and $M$ UNIVERSITY

Dept. of Civil Engrg., College Sta., Texas 77843

Dr. J.B. Herbich, Head, Hydraulic Engrg.,

Fluid Mechanics, and Coastal and Ocean Engrg.

TEXAS $A$ and $M$ UNIVERSITY

Dept. of Oceanography, College Sta.,

Texas 77843

Richard A. Geyer, Head of Dept.

TEXAS $A$ and $M$ UNIVERSITY

Water Resources Institute

College Station, Texas 77843

Ernest T. Smerdon, Director

TEXAS, UNIVERSITY OF

Dept. of Civil Engrg., Austin, Tex. 78712

Dr. Walter L. Moore, Professor

TRACOR, INC.

627 Lof strand Lane

Rockville, Maryland 20850

Roy Whymark, Director, Appl. Physics

TRW SYSTEMS GROUP

Engineering Mechanics Lab.

One Space Park, Redondo Beach, Calif. 90278

Dr. M.V. Barton, Director

UTAH STATE UNIVERSITY

Utah Water Research Laboratory

Logan, Utah 84321

Jay M. Bagley, Director

VANDERBIIT UNIVERSITY

Dept. of Sanitary and Water Resources Engrg.

Nashville, Tennessee 37203

Dr. Peter A. Krenkel, Chairman

VIDYA DIVISION, ITEK CORP

Applied Mechanics Dept.

1450 Page Mill Rd., Palo Alto, Calif. 94304

VIRGINIA POLYTECHNIC INSTITUTE

Dept. of Civil Engrg., Blacksburg, Va. 24061

Dr. H.M. Morris, Head

Dept. of Mech. Engrg., Blacksburg, Va. 24061

Dr. J.B. Jones, Head

WASHINGTON STATE UNIVERSITY

118 The R.L. Albrook Hydraulic Iaboratory

Pullman, Washington 99163

Dr. E. Roy Tinney, Head

122

124
WASHINGTON, UNIVERSITY OF

Dept. of Civil Engrg., Charles W. Harris

Hydraulic Iab., Seattle, Eash. 98105

Prof. T.H. Campbell, Director

WASHINGTON, UNIVERSITY OF

Dept. of Oceanography, Seattle, Wash. 98105

Professor Maurice Rattray, Jr.

WASHINGTON, UNIVERSITY OF

Fisheries Research Inst., Seattle, Wash. 98105

R.L. Burgner, Director

WEBB INSTITUTE OF NAVAI ARCHITECTURE

Glen Cove, New York 11542

Edward V. Lewis, Director of Research

THE WESTERN COMPANY

Research Div., Richardson, Tex. 75080

W.E. Brown, Vice President

WISCONSIN, UNIVERSITY OF

Hydraulic and Sanitary Engrg. Laboratory

Madison Wisconsin 53706

Dr. Arno T. Ienz, Chmn., Civil Engrg. Dept.

WOODS HOLE OCEANOGRAPHIC INSTITUTION

Woods Hole, Massachusetts 02543

Dr. Paul M. Fye, Director

WORCESTER POLYTECHIIC INSTITUTE

Alden Research Laboratories

Worcester, Mass. 01609

Prof. Iawrence C. Neale, Director

WORTHINGTON CORPORATION

Advance Products Div., 401 Worthington

Ave., Harrison, New Jersey 07029

George W. Soete, Chief Engr.

WYLE LABORATORIES

Research Staff, Huntsville, Alabama

Dr. K. McK. Eldred, Director of Research

\section{U.S. GOVERIMENT AGENCIES}

DEPARTMENT OF AGRICULTURE

AGRICULTURAL RESEARCH SERVICE, Soil and

Water Conservation Research Division

CORN BELT BRANCH

108 Soils Bldg., Univ. of Minn.

St. Paul, Minn. 55101

Dr. C.A. Van Doren, Branch Chief

NORTHEAST BRANCH

Plant Industry Sta., Beltsville, Md. 20705

Dr. H.L. Barrows, Branch Chief

NORTHERN PLAINS BRANCH

P.O. Box E, Fort Collins, Colo. 80521

Dr. C.E. Evans, Branch Chief 
NORTHWEST BRANCH

P.0. Box 1187, Boise, Idaho 83701

Mr. Dean C. Muckel, Branch Chief

SOUTHERN BRANCH

P.0. Box 1072, Athens, Ga. 30601

Dr. G.R. Burns, Branch Chief

\section{SOUTHERN PIAINS BRANCH}

Bushland, Texas 79012

Dr. J.R. Johnston, Branch Chief

SOUTINEST BRANCH

P.o. Box 2326, Riverside, Calif. 92506

$\mathrm{Mr}$. W.W. Donnan, Eranch Chief

DEPARTMENT OF AGRICULTURE, FOREST SERVICE

INTERMOUNTAIN FOREST AND RANGE EXP. STA.

Forest Service Bldg., Ogden, Utah 84401

Joseph F. Pechanec, Director

NORTHEASTERN FOREST EXPERIMENT STA.

6816 Market St., Upper Darby, Pa. 19082

R.D. Lane, Director

NORTH CENTRAL FOREST EXPERIMENT STA.

Folwell Ave., St. Paul, Minn. 55101

Robert W. Merz, Asst. Director

PACIFIC NORTHWEST FOREST AND RANGE

Experiment Station

P.0. Box 3141, Portland, Oregon 97208

Mr. Philip A. Briegleb, Director

PACIFIC SOUTHWEST FOREST AND RANGE

FXPERIMENT STATION

P.0. Box 245, Berkeley, Calif. 94701

Mr. Robert D. MeCulley, Director

ROCKY MOUNTAIN FOREST AND RANGE

EXPERIMENT STATION

240 W. Prospect St., Fort Collins, Colo. 80521

Raymond Price, Director

SOUTHEASTERN FOREST EXPERIMENT STATION

Post Office Building, Asheville, N.C.

W.M. Zillgitt, Director

SOUTHERN FOREST EXXPERIMENT STATION

T-10210 Federal Bldg., 701 Loyola Ave.

New Orleans, Louisiana 70113

T.C. Nelson, Director

DEPARTMENT OF THE AIR FORCE, AIR FORCE

INSTITUTE OF TECHNOLOGY

Wright-Patterson AFB, Ohio 45433

Harold C. Larsen, Head, Aeronautical Engrg.

DEPARTMENT OF THE ARMY

ARMY COLD REGIONS RESEARCH AND ENGINEERING

IABORATORY

Hanover, New Hampshire 03755

ARMY INERTIAL GUIDANCE AND CONTROL IAB.

AND CENTER

Redstone Arsenal, Alabama 35809

Mr. Jess B. Huff, Director

CORPS OF ENGINEERS, COASTAL ENGINEERINC

RESEARCH CENTER

5201 Iittle Falls Rd., N.W., Wash.D.C. 20016

The Director
CORPS OF ENGINEERS, LOS ANGELES DISTRICT 186

District Hydraulics Lab., Los Angeles, Calif

CORPS OF ENGINEERS, NORTH PACIFIC DIV.

Division Hydraulic Lab., Bonneville, Oreg.

97008

The Director

CORPS OF ENGINEERS, ST. PAUL DISTRICT

1217 U.S. Post Office and Customhouse

St. Paul, Minnesota 55101

The District Engineer

CORPS OF ENGINEERS, WATERWAYS EXPERIMENT STATION

P.0. Box 631, Vicksburg, Miss. 39181

The Director

DEPARTMENT OF COMMERCE

ATIANTIC OCFANOGRAPHIC IABORATORIES

Environmental Science Services

Administration

901 S. Miami Ave., Miami, Fla. 33130

Dr. Bernard D. Zetler, Actg. Dir., Physical Oceanography Lab.

NATIONAL BUREAU OF STAINDARDS

Fluid Meters Section, Wash.,D.C. 20234

Fillmer w. Ruegg, Chief

NATIONAL BUREAU OF STANDARDS

Hydraulics Section, Wash., D.C. 20234

Dr. G. Kulin, Chief

WEATHER BUREAU

Environmental Science Services

Administration, Silver Spring, Md. 20235

Wm. E. Hiatt, Assoc. Director (Hydrology)

DEPARTMENT OF THE INTERIOR

BUREAU OF RECLAMATION

Division of Engrg. Labs.

Denver Federal Center, Denver, Colo. 80225

Chief Engineer

\section{GEOIOGICAI SURVEY}

Water Resources Div., Wash., D.C. 20242

E.L. Hendricks, Chief Hydrologist

NATIONAL AERONAUTICS AND SPACE ADMINISTRATION

NASA, LANGLEY RESEARCH CENTER

Langeley Station, Hampton, Va. 23365

Dr. Floyd L. Thompson, Director

NASA, IEWIS RESEARCH CENTER

21000 Brookpark Rd., Cleveland, Ohio 44135

Abe Silverstein, Director

DEPARTMENT OF THE NAVY

U.S. NAVAL ACADEMY

Engineering Dept., Annapolis, Md. 21402

Capt. R.W. King, Head

U.S. NAVAI APPIIED SCIENCE IABORATORY

Flushing and Washington Aves., Brooklyn, N.Y. 11251

Capt. T.T. McGillicuddy, USN, Commanding officer and Director 
NAVAL CIVIL ENGINEERING LABORATORY

Port Hueneme, California 93041

Director, Amphibious and Harbor Div.

Code L55

U.S. MINE DEFENSE LABORATORY

Panama City, Florida 32401

U.S. NAVAT OCEANOGRAPHIC OFFICE

Washington, D. C. 20390

U.S. NAVAL ORDNANCE LABORATORY

White Oak, Silver Spring, Md. 20910

Dr. G.K. Hartmann, Technical Director

U.S. NAVAT POSTGRADUATE SCHOOL

Dept. of Aeronautics, Monterey, Calif 93940

C.E. Menneken, Dean of Research Admin.

U.S. INAVAL POSTGRADUATE SCHOOL

Dept. of Mechanical Engrg.

Monterey, Calif. 93940

Dr. Turgut Sarpkaya, Chairman of Dept.

U.S. NAVAL POSTGRADUATE SCHOOL

Dept. of Meteorology and Oceanography

Monterey, Calif. 93940

C.E. Menneken, Dean of Research Admin.

U.S. NAVAL RESEARCH LABORATORY

Washington, D. C. 20390

The Director

NAVAI SHIP ENGINEERING CENTER, PHILA.

DIVISION

Philadelphia, Pa. 19112

Capt. J.D. Working, Officer in Charge

NAVAL UNDERSEA WARFARE CENTER

3202 E. Foothill Blvd., Pasadena, Calif.

91107

The Cormander

NAVAT UNDERSEA WARFARE CENTER, SAN DIEGO

DIVISION

271 Catalina Blvd., San Diego, Calif. 92152

Dr. W.B. McLean, Technical Director

U.S. NAVY UNDERWATER SOUND LABORATORY

Fort Trumbull, New London, Conn. 06320

Captain Richard L. Corkran, Jr.,

Commanding Officer and Director

U.S. UNDERWATER WEAPONS RESEARCH AND

ENGINEERING STATION

Oceanography Branch, Newport, R.I. 02840

Mr. John F. Brady, Head, Research Dept.

U.S. NAVAL WEAPONS IABORATORY

Dahlgren, Va. 22448

Mr. Bernard Smith, Technical Director

NAVY WEATHER RESEARCH FACIIITY

Bldg. R-48, Naval Air Sta.,

Norfolk, Va. 23511

Officer in Charge

\section{TENNESSEE VALLEY AUTHORITY}

TVA ENGINEERING LABORATORY

P.O. Box 37, Norris, Tenn

Mr. Rex A. Elder, Director

Mr. James W. Beverage, Branch Chief

236

236

\section{CANADIAN IABORATORIES}

ALBERTA, RESEARCH COUNCIL OF

Rm. 301, Engrg. Bldg., University of

Alberta, Edmonton, Alberta, Canada

Mr. C.R. Neill

ALBERTA, UNIV. OF

Dept. of Civil Engrg.

Edmonton, Alberta, Canada

Dr. T. Blench, Prof. of Civil Engrg.

BRITISH COLUMBIA, UNIVERSITY OF

Hydraulic Lab., Vancouver 8, Canada

Prof. W.D. Liam Finn, Head

Dept. of Civil Engrg.

BRITISH COLUMBIA, UNIVERSITY OF

Dept. of Mechanical Engrg.

Vancouver 8, B.C. Canada

Dr. J.P. Duncan, Head

ECOLE POLYTECHNIC

2500 Marie-Guyard Ave.,

Montreal 26, Canada

Prof. Raymond Boucher, Dir.

Hydrodynamics Laboratory

GUELPH, UNIVERSITY OF

Hydrology Section, Sch. of Agric. Engrg.

Guelph, Ontario, Canada

H.D. Ayers, Professor-in-Charge

THE HYDRO-ELECTRIC POWER COMMISSION OF ONTARIO

620 University Ave., Toronto 2, Canada

Mr. J.B. Bryce, Hydraulic Engineer

LASALLE HYDRAULIC LABORATORY, LTD.

0250 st. Patrick Street

LaSalle, P.Q. Canada

Mr. E. Pariset, President

MANITOBA, UNIVERSITY OF

Dept. of Civil Engineering

Fort Garry, Manitobe, Canada

Prof. E. Kuiper

MCGILL UNIVERSITY

Department of Civil Engineering and

Applied Mechenics

Montreal 2, P.Q., Canada

Dr. A.J. Reynolds

MCMASTER UNIVERSITY

Chemical Engrg, Dept.

Hamilton, Ontario, Canada

Dr. A.E. Hamielec, Fluid Mechanics Group

NATIONAL RESEARCH COUNCIL

Division of Mechanical Engineering

Montreal Road, Ottawa 2, Canada

Dr. Simon Ince, Head, Hydraulic Section

ONTARIO, HYDRO-ELECTRIC POWER COMMISSION OF 258 See Hydro-Electric Power Commission of Ontario 
Dr. A. Brebner, Head

SASKATCHEWAN, UNIVERSITY OF

Dept. of Civil Engrg.

Saskatoon, Saskatchewan, Canada

C.D. Smith, Assoc. Prof. of Civil Engrg.

TORONTO, UNIVERSITY OF

Department of Mechanical Engineering

Toronto 5, Canada

Prof. G. Ross Lord, Head

WESTERN CANADA HYDRAULIC LABS, LTD

1186 Pipeline Road

Port Coquitlam, B.C. Canada

J.W. sall, Director

WINDSOR, UNIVERSITY OF

Dept. of Mechanical Engineering

Windsor, Ontario, Canada

William G. Colborne, Head 
UNIVERSITY OF ALABAMA IN HUNTSVILLE,

Huntsville, Alabama 35807

(6081) DRAG ON TWO-DIMENSIONAL PLATES IN AN INCOMPRESSIBLE OSCILLATING FLOW AT IOW REYNOLDS NUMBERS.

(b) Laboratory project.

(c) Prof. C.C. Shih, Univ. of Alabama in Huntsville.

(d) Experimental; applied research; thesis.

(e) Drag forces are to be determined for a flat plate oscillating normal to its plane. This study is to provide data for constructing a damping law for antislosh baffles under low Reynolds number conditions. Such an expression for damping could be used to predict the damping of baffles in the tanks of an orbiting vehicle.

(6082) THE EFHECTS OF UNSTEADY FLOW UPON THE PRESSURE DISTRIBUIION AROUND SUBMERGED BODIES.

(b) Iaboratory project.

(c) Prof. C,C. Shih; see (6081 above)

(d) Experimental; applied research; thesis.

(e) Pressure distribution time histories will be measured in a uniformly accelerated incompressible flow that is started impulsively. The object of this experiment is to provide data for vehicle design and for comparison with current theories and numerical experiments. In this area experimental data are sparse or non existent.

ARIZONA STATE UNIVERSITY, Department of Mechanical Engineering, Tempe, Arizona 85281

(6051) UNSTEADY LAMINAR FIOW FIELD ANALYSIS.

(b) Laboratory project.

(c) Warren Rice, Chmn., Dept. of Mechanical Engrg.

(d) Analytical; applied research resulting in theses.

(e) Development of methods for formulating and solving problems in unsteady laminar incompressible flow, particularly in tubes and passages and between rotating cylinders.

(g) Solutions found for flow between plates and in tubes with arbitrary time-varying pressure gradients, and for fluid between rotating cylinders with arbitrary time-varying inner-andouter angular velocity and/or applied torque.

(h) "Duhamel's Theorem for One-Dimensional Unsteady Leminar Fluid Problems," Harry K. Hepworth, MS thesis, Dept. of Mech. Engrg., May 1966. "Iaminar Flow Between Parallel Plates with Arbitrary Time-Varying Pressure Gradient and Arbitrary Initial Velocity, "W.Rice and H.K. Hepworth, Trans. ASME, Jour. Appl. Mechanics, Vol. 34, Series E, No. 1, March 1967.

THE UNIVERSITY OF ARIZONA, Department of Civil Engineering, Tucson, Arizona 85721

(4625) CRITICAL TRACTIVE FORCE OF UNIFORM SANDS.

(b) Departmental.

(c) Dr. Emmett M. Laursen, Head, Civil Engrer.

(d) Analytical and laboratory investigation related to theory; MS and Ph.D. theses.

(e) Analytic and experimental attempts to relate the average boundary shear to the incipient movement of sediment particles composing the boundary.

(g) Distribution of mean velocity near high-density "artificially" roughened surfaces, and corresponding longitudinal turbulent velocity fluctuations, are studied in order to give insight into the measurement and prediction of incipient-motion shear for noncohesive particles. A power velocity law is seen tc represent accurately the mean velocity profile near the surface for a large variation in roughness size and shape in the hydraulically rough regime.

(h) "Surface Shear at Incipient Motion of Uniform Sands," Bruce D. Ward, Ph.D. Dissertation, 1968.

(4626) SCOUR AT REIIEF BRIDGES.

(b) Departmental.

(c) Dr. Enmett M. Iaursen; see (4625) above.

(d) Laboratory investigation.

(e) To find the effect of sediment size and velocity of flow in the limiting depths of clearwater scour in simple relief-bridge geometries. Long contractions and abrupt contractions will be studied. The experimental data will be compared to an approximate solution of the problem previously published by the principal investigator.

(4627) A STUDY OF PARTIALIY SATURATED FIOW IN SANDEPOXY RESIN COLUMNS.

(b) Departmental.

(c) Prof. Richard I. Sloane, Dept. of Civil Engrg.

(d) Lab. study related to theory; Ph.D. thesis.

(e) The flow of water through soils often takes place under conditions of partially saturated flow. The prediction of fluid distribution and pressure under conditions of partially saturated flow will make use of vertical columns made of sand grains cemented together with epoxy resin. The use of this type of sand columns will result in a model for which properties such as void ratio and particle arrangement will remain constant during a series of tests.

(g) The relationship between capillary pressure and degree of saturation was obtained on models one inch in diameter and one inch in length. Pressure distribution in drained columns was obtained on models one inch in diameter and 35 inches in length. The relationship between capillary pressure and partially saturated permeability was obtained using the 35-inch columns for steady-state conditions at various flow rates. A simplified porous model was considered which helps in the explanation of certain relationships but does not provide for the hysteresis effect in the relationship between capillary pressure and the degree of saturation.

(h) "A Study of Partially Saturated Flow in SandEpoxy Resin Columns," John Bryan Carney; Jr., Ph.D. Dissertation, Univ. of Ariz., 1968

(5348) OPEN CHANNEL TRANSITIONS.

(b) Departmental. 
(c) Dr. E.M. Laursen, Head, Dept. of Civil Engrg., University of Arizona.

(d) Laboratory investigation for development; master's thesis.

(e) Both contractions and expansions in canal sections are being studied, looking towerd improvements in design methods. For the contractions various shapes ranging from the abrupt through circular ellipsoidal wells to the free stream line form will be used. Flow patterns, water surface profiles and head losses are being measured. For the expansion, standard warped sections, veined expansions and other shapes are being studied. Flow patterns, water surface profiles and head losses will be measured.

(g) Two M.S. Theses completed:

(h) "Open-channel Expansions for Subcritical Flow," Sayed A.H. Hashimi, Univ. of Ariz., 1966. The results indicate clearly that simple types of transitions with selected inserts can be employed instead of costly, elaborately designed structures.

"Open Channel Contractions for Subcritical Flow," Habib M. Yaziji, Univ. of Ariz., 1968. Results indicate that the abrupt transition causes a significantly greater energy loss than do those either partially or extensively streamlined, and they indicate also that under certain conditions the quarter-ellipse transition (1:4 ratio) causes the least energy loss of all shapes studied, including two based on free-streamline analysis of discharge from a slot orifice.

(5349) EFFECT OF SILT LADEN WATER ON INFTITRATION IN ATIUVIAL CHANNELS.

(b) Departmental.

(c) Dr. Enmett M. Laursen; see (5348) above.

(d) Laboratory and field investigation; doctoral thesis.

(e) In arid regions a large part of the natural recharge is through the bed of intermittent streams. A better understanding of the effect of silt content of the flow is needed in order to predict natural recharge and to evaluate works to promote recharge.

(g) A tilting-bed flume study was made to examine the relationships between velocity, suspended sediment and infiltration rate in alluvial channels for velocities from 2 to 5 feet per second and suspended sediment up to 0.6 percent. Very poor correlation was found between the preliminary permeability and infiltration tests and the flume infiltration rates, but good correlation was obtained for the flume results with the flow losses and natural recharge occurring in the river channels in the Tucs on Area.

(h) "The Effect of Silt-Laden water on Infiltration in Alluvial Channels," William G. Matlock, Ph.D. Dissertation, Univ. of Ariz., 1965.

(6730) DYNAMIC STRUCTURE OF STREAMS.

(b) Departmental.

(c) Dr. Frmett M. Laursen; see (5348) above.

(d) Laboratory and field investigation; doctoral dissertation.

(e) To find the effect on sediment movement of width/depth ratios, channel gradients, flow sequencing, flood-wave attenuation, etc., in streams in general. Ephemeral streams will be studied especially for the conditions of (a) no tributary inflow and (b) an influent stream bed.
(6731) FLOW CHARACTERISTICS OF TWO-DIMENSIONAL EXPANSIONS.

(b) Departmental.

(c) Dr. Thomas Carmody; Dept. of Civil Engrg., University of Arizona.

(d) Laboratory investigation; master's theses.

(e) The influence of approach-slot length/width ratio, expansion ratio, and degree of eccentricity at Reynolds numbers near $10^{5}$ on the flow characteristics of two-dimensional expansions is to be studied.

(g) M.S. Thesis completed:

(h) "Some Factors Influencing Flow Characteristics of a Two-Dimensional Expansion," Steven M. Hindall, Univ. of Ariz., 1968. Some stability criteria and loss coefficients were determined through use of continuity, momentum and energy relationships. Results indicate that for a stable jet, flow can be analyzed two-dimensionally, while for a neutrally stable jet (one that will attach to one wall or another but will not switch without outside stimulus) the flow must be analyzed three-dimensionally.

(6732) PERMEABILTTY DETERMINATION OF A NON-HOMOGENEOUS POROUS MEDIUM.

(b) Departmental.

(c) Dr. Frmett M. Laursen; see (5348) above.

(d) To study the detailed flow patterns in the pore spaces of a porous medium.

(e) A plexiglass flow table will be constructed, representing an idealized, macroscopic model of a porous medium. The model arrangement will allow the study of a wide range of flow regimes and the introduction of prearranged non-uniformities in the matrix. The use of plexiglass will permit visual and/or photographic observation.

UNIVERSITY OF ARKANSAS, Civil Engineering Department, Fayetteville, Arkansas 72701

\section{(6152) WATER QUALITY STUDY.}

(b) Arkansas Pollution Control Commission.

(c) L.R. Heiple, Head, Civil Engrg. Dept., Univ. of Arkansas.

(d) Applied research.

(e) The purpose of this investigation is to make current a previous Report No. 3 of the Engrg. Expmt. Sta., Univ. of Arkansas, "Stream Flow Quantity and Quality Correlations and Statistical Analyses".

(f) Completed.

(g) The results include a detailed correlation of Arkansas stream flows and quality parameters based upon information furnished in U.S.G.S. Water Supply papers and U.S.G.S. Water Quality Reports.

(h) Publication available from Engrg. Expmt. Sta., Univ. of Arkansas. Cost \$2.50. "Water Quality studies for Arkansas Streams," H.M. Jeffus, J.A. Proctor, and I.R. Heiple, Research Report Series No. 11., Engrg. Expmt?. Sta., Univ. of Arkansas.

(OOIW) WATER RESOURCES PIANIING STUDY, ARKANSAS AND OKTAHOMA.

For summary, see Water Resources Research Catalog, Vol. 2, No. 6.0032.

(h) "Interim Progress Report - Water Resources Planning Study for Arkansas and Oklahoma," 
Arkansas Water Resources Research Center, Fayetteville, Oct. 1967, 35 p. Limited publication, not available for general distribution.

BOEING SCIENPIFIC RESEARCH IABORATORIES, Flight Sciences Laboratory, P.0. Box 3981, Seattle, Washington, 98124.

(6393) THE IAMINAR WALL JET ON A CURVED SURFACE.

(b) Laboratory project.

(c) Dr. I.J. Wygnanski, Flight Sciences Lab., Boeing Scientific Research Labs.

(d) Theoretical; basic research.

(e) This problem is one of a class of unsolved problems in classical fluid mechanics with application to many problems in airplane aerodynamics: jet flaps, slots, ejectors. A unique similarity solution of the problem has been obtained for both concave and convex surfaces when the tpcal radius of curvature is proportional to $\mathrm{x}^{3 / 4}$.

(f) Completed.

(g) 3 BSRL reports.

(h) "The Laminar Wall Jet over a Curved Surface," I. Wygnanski and F.H. Champagne, FSL TM No. 49, July 1966.

(6394) THE TWO-DIMENSIONAL TURBULENT JET IN PARALLEL STREAMING FLOW.

(b) Laboratory project.

(c) Dr. I.J. Wygnanski; see (6393) above.

(d) Theoretical basic research.

(e) The turbulent, two-dimensional jet issuing into a uniform parallel stream is of considerable interest in aeronautics as it represents an idealization of the flow in combustion chambers, ejectors, jet-flap wings, etc. Presently, the theoretical methods available for predicting the mean velocity in the jet are of the integral type. The most severe drawback of integral analyses is the inherent assumption of complete self-preservation. It is the purpose of the present analysis to employ newly gained definite knowledge of the turbulent shear stress distribution in the case of a jet in a parallel uniform stream, and to make no additional assumption about the flow. A coordinate-type expansion will be developed and a transformation is sought through which the series converge to their asymptotic value.

(f) Completed.

(g) Three BSRI reports.

(h) "The Two-Dimensional Turbulent Jet in a Uniform, Parallel Stream," I. Wygnanski, FSI TM No. 53, June 1967.

(6395) THE COAXIAL JET MIXING PROBLEM.

(b) Laboratory project.

(c) Dr. F.H. Champagne, Flight Sciences Lab., Boeing Scientific Research Labs.

(d) Experimental; basic research.

(e) How quickly does a turbulent shear layer assume property and velocity distributions of terminal character? The goal of this research is to determine the detailed nature of the procedure by which the fluctuating properties in the turbulent free shear layer go towards asymptotic character.

(f) Completed.

(g) Measurements of mean velocity profiles, rootmean-square turbulent components and shear stress distribution were accomplished. All measurements were repeated while varying the two basic parameters: 1) the area ratio between the external and internal streams, and 2) the velocity ratio of these nozzles. The length of the potential core was obtained for each condition as well as the tendency to self-preservation far downstream. All measurements were done using linearized constant temperature hot-wire anemometers.

(6396) INVESTIGATION OF "BASIC" TURBULENT SHEAR FLOWS.

(b) Laboratory project.

(c) Dr. I.J. Wygnanski; see (6393) above.

(d) Experimental basic research.

(e) There are six basic turbulent shear flows: the planar semi-infinite mixing layer, downstream of a flat plate or a backward-facing step; the planar jet and the planar wake; the axisymmetric jet and the axisymmetric wake. Comprehensive data on the local turbulence characteristics -- mean velocities, RMS values of the turbulent fluctuations, turbulent shear stress distributions, intermittency, power spectral density of turbulent fluctuations, size and directionality of anisotropy of turbulence, space-time correlation and scales, convection velocity and its dependency on frequency, flatness and skewness factors -- are not available. The aim of this work is to complete a definitive experimental study of these six basic turbulent shear flows, and to present the results in a manner useful to the theorist and to the practicing engineer.

(g) The precise results from shear stress distribution and intermittency factor have led to a new concept of eddy viscosity of great potential engineering value. The results from space-time correlations have led to a fundamental question in the derivation of the Kolmogorov scaling law of $\mathrm{k}^{-5 / 3}$.

(6397) INVESTIGATION OF THE STRUCTURE OF HOMOGENEOUS TURBULENT SHEAR FLOW.

(b) Laboratory project.

(c) Dr. F.H. Champagne; see (6395) above.

(d) Experimental; basic research.

(e) The central role of shear in natural and technological turbulent flows derives from the energy transfer interaction of the mean velocity field with the turbulent velocity field. The purpose of the present work is to generate a homogeneous shear flow which has turbulence properties constant in planes normal to the mean flow and to obtain basic data on the detailed fluctuation behavior of such a flow. No such information exists today.

(g) With the achievement of a truly homogeneous turbulent flow with uniform shear, the critical turbulence measurements were made. Data on mean velocity profiles, fluctuating velocity distributions, turbulent shear stress distribution, Taylor microscale values and transverse correlation functions were obtained.

(6611) MAXIMUM ROTATIONAL VELOCITIES IN VORTEXX MOTION.

(b) Laboratory project.

(c) G.K. Tinm, Flight Sciences Lab., Boeing Scientific Research Labs.

(d) Iiterature search and summary.

(e) Little data is available on actual measured 
circumferential velocity distributions in real free vortices in real fluids. The aim of this work was to discover, document and catalogue, data on circumferential velocities in real free vortices.

(f) Completed.

(8) A comprehensive literature search was undertaken to obtain all validated data on circumferential velocity distributions in real free vortices. Over 1,000 papers were examined. Less than twenty had data which could be accepted with confidence. This data is being documented and catalogued in a uniform manner in Boeing Document Dl-82-0683.

(h) "Circumferential Velocity Distributions in Wing Vortices. Appendix: Bibliography on Spiralling Flows," G.K. Timm, Boeing Document D1-82-0683, Nov. 1367.

(6612) FLOWS OF STRATIFIED FLUIDS OVER BARRIERS.

(b) Laboratory project.

(c) Dr. Yih-Ho Pao, Flight Sciences Lab., Boeing Scientific Research Laboratories.

(d) Theoretical and experimental basic research.

(e) Lee waves of mountain ranges and isolated mountain peaks are simulated in the laboratory by towing wedge- and cone- shaped models in a stably stratified liquid. The role of Richardson number in the mountain wave phenomena is examined in detail by varying the towing speed of the models and/or the density gradients. This experimental work is supported by theoretical analysis. By applying the alternating direction method and the extrapolated Liebmann method, one can approximate the unsteady Boussinesq equations of motion with a set of finite difference equations. These resulting equations can be solved numerically.

(h) "Inviscid Flow of a Stably Stratified Fluid over Barriers," Y.H. Pao, Boeing Document D1-82-0646, Sept. 1967. "Laminar Flow of a Stably Stratified Flow Past a Flat Plate," Y.H. Pao, Boeing Document Dl-82-0488, Sept. 1967.

(6613) STRUCTURE OF TURBULENCE.

(b) Laboratory project.

(c) Dr. Yih-Ho Pao; see (6612) above.

(d) Theoretical and experimental basic research.

(e) The aim of this research is to study specially critical characteristics of real turbulence which have not previously been seriously analyzed due to the extreme complexities of the problems.

(h) "Transfer of Turbulent Energy and Scalar Quantities at Large Wave Numbers," Y.H. Pao, FSL TM No. 54, Oct. 1967.

"Structure of Turbulent Velocity and scalar Fields at Large Wave Numbers," Y.H. Pao, Physics of Fluids 8, 1063-1075 (1965).

"Turbulent Mixing With a Second-Order Reaction or a Weak Exothermic First-Order Reaction," Y.H. Pao, Boeing Document Dl-82-0679, Oct. 1967.

"Turbulence in Stably Stratified Fluids," Y.H. Pao (to appear as a Research Note in the Physics of Fluids).

"Turbulent Velocity and Scalar Spectra in Stratified Fluids," Y.H. Pao, Boeing Document D1-82-0680, November 1967.

(6614) INVISCID DENSITY STRATIFIED FLOW.

(b) Laboratory project.

(c) Dr. Beverly B. Graham, Boeing Scientific
Research Laboratories.

(d) Theoretical basic research.

(e) The goal of this work is to obtain linearized results for flows of stratified fluids. Two reports have already been written for the case where gravity forces greatly exceed the inertia forces. An important regime of atmospheric motion is where the inertia forces are of the same order as the gravity forces. Small velocity perturbations and an exponential variation of density with depth are assumed. The resulting linearized equation governing the two-dimensional flow of a density-stratified liquid is then used. Both the dipole (thickness producing) and vortex (lift producing) singularities are introduced. (f) Completed.

(h) "The Effect of Froude Number on the Two-Dimensional Flow of an Inviscid Density Stratified Liquid Past a Slender Body," E.W. Graham and B.B. Graham, Boeing Document Dl-82-0614, April 1967.

"The Effect of a Free Surface on the TwoDimensional Flow of an Inviscid DensityStratified Liquid Past a Slender Body," E.W. Graham and B.B. Graham, Boeing Document Dl-82-0664, October 1967. "Further Notes on the Two-Dimensional Flow of an Inviscid Density-Stratified Liquid Past a Slender Body," E.W. Graham and B.B. Graham, Boeing Document D1-82-0591, December 1966. "The Two-Dimensional Flow of an Inviscid Density-Stratified Liquid Past a Slender Body," E.W. Graham, Boeing Document Dl-82-0550, July 1966.

\section{(6615) MECHANICS OF ROTATING FLUIDS.}

(b) Laboratory project.

(c) Dr. John H. Olsen, Boeing Scientific Research Laboratories.

(d) Theoretical and experimental basic research.

(e) The aim of this work is to understand the coupled orographic-Coriolis effect on intermediate scale atmosphere turbulence. Taylor columns are the limiting case for low Rossby number -- ratio of inertia to Coriolis forces -- of the propagation via inertial waves of orographic features far into a rotating fluid.

(6616) VORTEX BOUNDARY IAYER FLOWS.

(b) Laboratory project.

(c) Dr. John H. Olsen; see (6615) above.

(d) Theoretical and experimental basic research.

(e) The boundary layer beneath a vortex carries most of the radial inflow to the vortex core. An understanding of this boundary layer is important for predicting the performance of vortex devices and for understanding dust devils, tornadoes, and other geophysical vortices.

(g) An experimental vortex was constructed and the resulting boundary layer was seen to exhibit the same roll instabilities as the Ekman layer and the boundary layer on a rotating disk. Photographs of the instabilities have been taken together with streak photographs showing the velocity field outside the boundary layer.

POLYTECHNIC INSTTIUTE OF BROOKLYN, 333 Jay Street, Brooklyn, New York 11201

(6710) STUDY OF FLOWS IN HORIZONTAL DRAINAGE SYSTEMS IN BUILDINGS. 
(b) Dept. of Mechanical Engrg. Laboratory project; partially sponsored by New York State Science and Technology Foundation.

(c) Prof. Clifford A. Wojan, Dept. of Mechanical Engrg., Polytechnic Inst. of Brooklyn.

(d) Experimental and theoretical Master and senior undergraduate level project.

(e) The program is a study of the flow characteristics of a drainage system for a building. In addition to obtaining flow characteristics in drainage systems, the research is oriented towards the study of the interaction between venting and drainage systems. The immediate aim of the program is to determine if venting of drainage systems in high rise buildings can be modified or if the number of vents may be reduced.

(g) The experimental program is in progress.

(h) Initial reports on the program are expected to be issued in late Fall 1968.

STATE UNIVERSITY OF NEW YORK AT BUHFAIO, Dept. of Civil Engrg., Buffalo, New York 14214

(6044) DIFFUSION OF SEDIMENT IN A NON-UNIFORM FIOW FIELD.

(b) Agriculture Research Service, USDA.

(c) Dr. Ralph Rumer, Chairman, Dept. of Civil Engrg., State Univ. of New York at Buffalo.

(d) Experimental and theoretical.

(e) A study of the diffusion process in nonuniform free surface flow as it relates to the entrainment and transportation of mineral sediments. Experiments were conducted in a tilting flume equipped with an elevator system that fed sediment into a clear water inflow. Measurements of the flow and sediment concentration were made and correlated with analytical predictions of the diffusion coefficient. The purpose of the investigation was to correlate sediment processes with the turbulent and diffusive properties of free surface flows, especially through the gross hydraulic and mechanical properties of the fluid, sediment and channel.

(f) Completed.

(g) Prediction of sediment concentration distributions was found to agree with observed distributions based on a simplified form of the convective-diffusion equation in which the diffusion coefficient and the flow velocity were assumed uniform in the flow region. Diffusion coefficients were found to depend on the relative roughness of the erodible bed. Measured sediment loads, extrapolated to an equilibrium, uniform flow condition, were found to agree closely with results of other investigations.

(h) "Diffusion of Sediment in a Non-Uniform Flow Field," R.P. Apmann and R.R. Rumer, Civil Engrg. Report No. 16, State Univ. of New York at Buffalo 14214. (Available from the Dept. of Civil Engrg. at Buffalo at $\$ 1.00$ per copy).

(6045) DYNAMIC MODEL STUDY OF IAKE ERIE.

(b) Federal Water Pollution Control Admin., U.S. Dept. of Interior.

(c) Dr. Ralph Rumer; see (6044) above.

(d) Experimental and theoretical.

(e) A vertically-distorted Froude model of Lake Erie, housed in a rotating laboratory, is being operated. The purpose of the investigation is to study the response of the water movement in the model lake to various physical inputs such as inflows, outflows, and wind stress. The effect of the earth's rotation is included by way of the rotating laboratory.

(g) Results to date include measurements of water level response during mass oscillation, residence time of tracers entering the lake through the Detroit River, and surface circulation patterns for the isothermal lake system with only the inflow of the Detroit River and the outflow of the Niagara River.

(6046) SALT WATER INPRUSION INIO IAYERED STRATA.

(b) Iaboratory project.

(c) Dr. Ralph Rumer; see (6044) above.

(d) Analytical.

(e) Purpose of the study is to determine the position of the salt water - fresh water interface in coastal aquifers composed of several homogeneous layers of differing permeabilities.

(6047) EROSTON OF COHESIVE SOILS AND CHANNEL STABILIZATION.

(b) Agriculture Research Service, U.S. Dept. of Agriculture.

(c) Dr. Enmanuel Partheniades, Assoc. Prof. Dept. of Civil Engrg., State Univ. of New York at Buffalo.

(d) Experimental and analytical.

(e) The purpose of the study is to determine the effect of shear strength, density and structure of a cohesive bed as they affect the initiation and rates of erosion by flowing water. Equipment for consolidation of large clay samples and for the hydraulic testing is under construction.

(6048) DEPOSITION OF FINE SEDIMENTS IN TURBULENT F'LOWS.

(b) Federal Water Pollution Control Admin., U.S. Dept. of Interior.

(c) Dr. Fmmanuel Partheniades; see (6047) above.

(d) Experimental and theoretical.

(e) The purpose of the project is to discover the important flow parameters which control the initiation, the degree and the rates of deposition of cohesive sediments in turbulent flows. Attention will be focused on only one type of cohesive soil. The experimental setup consists of a rotating annular channel containing the water-sediment mixture and a rotating annular ring positioned within the channel and in contact with the water surface. Flow fields are generated by simultaneous rotation of the ring and channel.

(6049) TURBUIENCE CHARACTERISTICS OF FREE SURFACE FIOWS WITH VARIABTE BOTTOM ROUGHNESS.

(b) Agriculture Research Service, U.S. Dept. of Agriculture.

(c) Dr. Emmanuel Partheniades; see (6047) above.

(d) Experimental.

(e) The purpose of the study is to correlate turbulence characteristics measured by hot film probes with bed roughness. Experiments are being conducted in a tilting flume with removable flase bottoms of variable roughness heights and patterns.

CAIIFORNIA INSTITUTE OF TECHRNOLOGY, Division of Engrg. and Applied Science, Pasadena, California Ylla. 
(1548) PROBLEMS IN HYDRODYNAMICS.

(b) Office of Naval Research, Dept. of the Navy.

(c) Prof. Milton S. Plesset, Calif. Inst. of Tech.

(d) Theoretical and experimental; basic research.

(e) Studies of cavitating and noncavitating flow; dynamic behavior of cavitation bubbles; theoretical studies of cavitation damage.

(h) "On the Shock Transition, The Hydraulic Jump, and Vortex Breakdown," Din-Yu Hsieh, Rep. No. 85-39, Calif. Inst. of Tech., March 1967. "Some Hydrodynamic Aspects of Superfluid Helium," Din-Yu Hsieh, Int'1. Shipbldg. Progress, Vol. 14, March 1967, pp. 104-119. "Mrltiple Scattering of Acoustical Waves," David J. McCloskey, Rep. No. 85-40, Calif. Inst. of Tech., May 1967.

"Transmission and Reflection of Sound in a Media Containing Discrete Scatterers," David J. Mccloskey, Rep. No. 85-41, Calif. Inst. of Tech., August 1967.

"Effect of Exposure Time on Cavitation Damage," M.S. Plesset and R.E. Devine, J. of Basic Engrg., Dec. 1966, pp. 691-705.

"Cavitation Damage Measurements with Nickel, Aluminum, and Stainless Steel for the ASTM Round Robin," Milton S. Plesset, Calif. Inst. of Tech. Report No. 85-47, October 1967. "Nonlinear Bubble Oscillations," Iouis P. Solomon and M.S. Plesset, Int'l Shipbldg. Progress, Vol. 14, Mar. 1967, pp. 98-103. "Magnetohydrodynamics of the Earth's Magnetic Field," Giulio Venezian, Int'l. Shipbldg. Progress, Vol. 14, March 1967, pp. 120-126.

CALIFORNIA INSTTTUTT OF TECHNOIOGY, W.M. Keck Lab. of Hydraulics and Water Resources, Pasadena, Calif. 91109

(4075) MECHANICS OF F'LOW IN SAND-BED CHANNEIS AT VERY LOW RATES OF SEDIMENT TRANSPORT.

(b) National Science Foundation.

(c) Prof. V.A. Vanoni or N.H. Brooks, Calif. Inst. of Tech.

(d) Experimental and theoretical research.

(e) Studies are made (1) of the development of dunes with time on a sand bed with flows which produce low rates of sediment transport and of the resulting changes in flow resistance as the dunes grow and (2) on the mechanism of entrainment of sediment by flowing water and (3) of relations of geometric parameters of dunes and the frictional resistance to flow produced by the dunes with a view to predicting resistance from dune dimensions.

(h) "Entrainment of Fine Sediments by Turbulent Flows, " Ph.D. Thesis, Alexander J. Sutherland, 1966, Calif. Inst. of Tech., available from University Microfilms, Ine., Ann Arbor, Mich. Same material available as W.M. Keck, Iab. of Hyd. and Water Res. Report KH-R-13.

"Relation between Bed Forms and Friction in Streams," Vito A. Vanoni and Ii-San Hwang, Jour. Hyd. Div., Proc. Amer. Soc. Civ. Engrs., V. 93, HY3, May 1967, pp. 121-144.

(4561) DYIAMICS OF DEIVSITYY-STRATIFIED RESERVOIRS.

(b) Public Health Service.

(c) Prof. Norman H. Brooks, Calif. Inst. of Tech.

(d) Basic theoretical and experimental research.

(e) (1) In reservoirs having density variation with depth, the pattern of flow toward an outlet may be quite different from the flow in a homogeneous reservoir. The withdrawal pattern has been studied experimentally in a laboratory tank of water having a linear density profile induced either by dissolved salt or heat. Application will ultimately be in management of water quality in rivers by slective withdrawal from reservoirs.

(2) Buoyant discharges into a stratified or flowing ambient fluid have been studied experimentally and theoretically. When a buoyant jet (or plume) is generated from a point or line source in a stratified ambient fluid, it may rise only to some equilibrium level, then spread in a thin cloud.

(f) Completed.

(g) (1) At very low Reynolds numbers there is a distant "withdrawal layer" extending upstream at the level of the outlet. Fluid above and below this layer is not withdrawn through the outlet. Research has been extended from line sinks to point sinks during the past year with good agreement between theory and experiment. The theoretical analysis based on the laminar boundary layer equations and the diffusion equation for the substance causing density variation. An approximate integral theory, valid for somewhat larger flow rates, has also been developed for both the two-dimensional and axisymmetric cases.

(2) Integral type solutions for buoyant jets and plumes have been made following Morton's approach, with initial variables including mass flux, buoyancy flux, and the momentum flux vector.

(h) "Unsteady Stratified Flow into a Sink," R.C.Y. Koh, Jour. of Hyd. Res., Int'l. Assoc. for Hyd. Res., Vol. 4, No. 2, 1966, pp. 21-35. "Turbulent Buoyant Jets into Stratified or Flowing Ambient Fluids, "I. -N. Fan, Ph.D. Thesis, May 1967 (issued as Rep. KH-R-15). "Discussion of "Horizontal Jets in Stagnant Fluid of Other Density," Gerrit Abraham,by I. -N. Fan and N.H. Brooks, Jour. Hyd. Div. ASCE, Vol. 92, No. HY2, March 1966, pp.423429 .

"Selective Withdrawal from Density-Stratified Reservoirs," N.H. Brooks, R.C.Y. Koh and T.W. Kao, ASCE Specialty Conf., Portland, Ore., Jan. 1968 (to be published in J. Hyd. Div., ASCE).

(5013) DYNAMICS OF DENSITY-STRATIFIED GROUND-WATER FLOW.

(b) Federal Water Pollution Control Admin. (research grant).

(c) Prof. Norman H. Brooks, Calif. Inst. Tech.

(d) Basic theoretical and experimental research.

(e) Slight density variations often affect groundwater flow patterns. Water which is recharged artificially may not mix readily with native waters but develops density stratification in the aquifer. Studies include problems such as overturning of unstably layered systems, effects of density difference on fluid dispersion in flow through porous media, and selective withdrawal from continuously stratified fluid.

(f) Completed.

(g) (1) Theory and experiments have shown it possible to have a more dense liquid in quasistable horizontal motion above a less dense liquid in a saturated porous medium. (2) Iateral disporsion in saturatcd porous media has been shown experimentally to be 
dependent solely on the Peclet number, provided the Reynolds number is low enough for laminar flow. At high Reynolds numbers the dispersion becomes independent of the Peclet number.

(3) Selective withorawal from a sink was investigated in a vertical Hele-Shaw cell in which the density gradient in the fluid was linear. Velocity distributions were measured in the flowing withdrawal layer, and compared favorably with theory.

(h) "Lateral Dispersion in Saturated Porous Media," E.J. List and N.H. Brooks, Jour. Geophys. Res., Vol. 72, No. 10, May 15, 1967, pp. 2531-2541. "A Two-Dimensional Sink in a Density-Stratified Porous Medium," E.J. List (now at Univ. of Auckland, New Zealand), submitted to Jour. Fluid Mechanics, Sept. 1967.

(5014) WAVE-INDUCED OSCILUATIONS OF SMALI MOORED VESSELS.

(b) Dept. of the Army, Corps of Engineers.

(c) Prof. Fredric Raichlen and Prof. Vito A. Vanoni, Calif. Inst. of Tech.

(d) Experimental and theoretical research.

(e) The objective of this research is to investigate the nature of wave-induced motions of small boats moored to fixed or floating docks. The study is directed toward understanding the problems of mooring small craft in harbors and providing information that will assist in planning. In this connection the investigation is divided into two phases: the dynamics of mooring and the response of harbors to incident wave systems.

The problem of the response of harbors to waves is under investigation in a wave basin with wave generator and associated measuring and recording equipment. The basin is lined with wave absorbers and wave filters to simulate the condition of open-sea outside the harbor. Analytical and prototype studies are being conducted on the problem of the mooring of small boats, considering the mooring system to be an asymmetrical non-linear system.

(h) "Wave-Induced Oscillations of Small Moored Vessels," F. Raichlen, loth Conf. on Coastal Engrg., Tokyo, Japan, Sept. 1966. Discussion of "The Threshold of Surge Damage for Moored Ships," B.W. Wilson, Paper 7018, Proc. Inst. of Civil Engrs., 1967, 38 (Sept.), F. Raichlen (manuscript submitted for publication).

(5360) MECHANICS OF SLUG FLOW IN STEEP CHANNELS.

(b) Los Angeles County Flood Control District.

(c) Prof. Vito A. Vanoni, Calif. Inst. of Tech., and Prof. Richard R. Brock, Univ, of Calif. at Irvine, Irvine, Calif. 92650.

(d) Experimental and theoretical research.

(e) Experimental data have been obtained on the growth of roll waves in channels as functions of Froude number and distance along the channel. Wave form has been measured and compared with that given by theory and the theory has been modified to take account of the gravity force on the waves.

(f) Completed.

(h) "Development of Roll Waves in Open Channels" Richard R. Brock, Ph.D. Thesis, Calif. Inst. of Tech., 1967, obtainable from University Microfilms, Inc., 313 No. lst St., Ann Arbor, Mich. 48107, or Rep. KH-R-16 of W. M. Keck Lat. of Hyd. and Water Resources covering same material from correspondents.
(5361) EXPERIMENTS ON TURBIDITY CURRENTS.

(b) Petroleum Research Fund.

(c) Dr. Gerard V. Middleton, McMaster Univ., Hamilton, Ontario, Canada.

(d) Experimental research.

(e) Comparative studies were made on the behavior of density underflows composed of salt solutions, clay suspensions, and coarse sediment suspensions. Particular attention was devoted to the movement of the head of the current, and to deposition of sediment from the current.

(f) Completed.

(h) "Experiments on Density Currents and Turbidity Currents," Gerard V. Middleton, Canadian Jour. of Earth Sci., Vol. 3, 1966, pp. 523-546.

(5773) LONGITUDINAL DISPERSION IN OPEN CHANNEL FLOW.

(b) U.S. Geological Survey and laboratory project. (c) Prof. Norman H. Brooks, Calif. Inst. of Tech.

(d) Experimental and theoretical, laboratory and field; basic research for $\mathrm{Ph} . \mathrm{D}$. dissertation.

(e) Contaminants or tracers are dispersed longitudinally in flow in a channel by an interaction of the variable mean flow velocity in the cross section and the transverse turbulent mixing. The purposes of this project are: first, to test the existing theory and determine wherein it fails; second, to identify the dominant mechanisms responsible for dispersion in both laboratory and natural situations; and third, to establish a workable method whereby the dispersion characteristics of a natural system can be more closely predicted from a knowledge of the hydraulic characteristics. The project includes participation in a field study being carried out by the U.S. Geological Survey in the Duwamish River and Estuary in the State of Washington.

(f) Completed.

(g) Large values of dispersion coefficients in rivers are due to effect of horizontal velocity profile as well as vertical velocity profile.

(h) Discussion of "Canal Discharge Measurements with Radio Isotopes," Jack C. Schuster, by Hugo B. Fischer, Jour. of Hyd. Div., ASCE, Vol. 91, HY5, Sept. 1965, pp. 317-319. "A Note on the One-Dimensional Dispersion Model," Hugo B. Fischer, Air and Water Pollution, an International Journal, June/July 1966, Vol. 10, pp. 443-452.

"The Mechanics of Dispersion in Natural Streams," Hugo B. Fischer, Preprint 427, ASCE Environmental Engrg. Conf., Dallas, Tex., Feb. 6-9, 1967.

"Longitudinal Dispersion in Laboratory and Natural Streams," Hugo B. Fischer, Ph.D. Thesis, June 1966 (issued as Rep. KH-R-12). "Analytic Prediction of Longitudinal Dispersion Coefficients in Natural Streams," Hugo B. Fischer, Proc. 12th Congr. Intl. Assoc. for Hyd. Res., Vol. 4, Sept. 11-14, 1967, pp. Il19.

"Mechanics of Dispersion in Natural Streams," Hugo B. Fischer, Jour. Hyd. Div., ASCE, Vol. 93, HY6, Nov. 1967, pp. 187-216.

(6581) DISPERSION IN HYDROLOGIC AND COASTAL ENVIRONMENTS.

(b) Federal Water Pollution Control Admin.

(c) Prof. Norman H. Brooks, Calif. Inst. Tech.

(d) Theoretical and experimental (laboratory and cooperative field studies); basic research, 
including Ph.D. dissertations. The project is a combination and continuation of 4561 , 5013 and 5773.

(e) Hydrodynamics problems of dispersion in hydrologic and coastal environments are being studied theoretically, in the laboratory, and in some instances in the field. The various areas and problems being considered are: (1) Natural rivers: longitudinal dispersion, transverse turbulent diffusion, velocity distributions. (2) Reservoirs and lakes: artificial large-scale mixing and destratification; buoyant plumes in stratified environments. (3) Ground-water basins: source of buoyancy in a current; free and forced convection. (4) Estuaries: longitudinal dispersion. (5) Oceans (nearshore): buoyant plumes in a current; sewage field thickness; large scale diffusion. Turbulent diffusion and density-stratified flow phenomena are common to several areas above.

(g) (See 4561, 5013, and 5773.)

(6582) TURBULZNCE MEASUREMENTS IN WATER.

(b) Iaboratory project.

(c) Prof. Fredric Raichlen, Calif. Inst. Tech.

(d) Experimental.

(e) This study involves the use of a constanttemperature hot-film anemometer to measure the turbulence characteristics in water. The recording and reduction of data has been accomplished using the IBM 7094-7040 digital computing system and its peripheral analogue-todigital conversion equipment located in the Booth Computing Center. The electrical signal from the associated electronics of the hot-film anemometer is connected directly to the Computing Center.

The local temporal mean velocities, root mean squares of the turbulent velocity fluctuations, turbulent energy spectra, and autocorrelation curves were obtained directly from the digital computer.

(f) Inactive.

(g) The results of the initial studies have shown relatively good agreement with the work of others in air. Since a major objective of this research is to develop a reliable method of measuring the turbulence characteristics of water, additional studies are planned.

(h) "Some Turbulence Measurements in Water," F. Raichlen, Jour. Engrg. Mechanics Div., Proc., ASCE, Vol. 93, No. EM2, April, 1967. Discussion of "Some Turbulence Measurements in Water," F. Raichlen, J. J. Lee, Jour. Engrg. Mechanics Div., Proc., ASCE, Vol. 93, No. EM6, Dec. 1967.

(6583) IABORATORY STUDIES OF THE EFHECT OF WAVES ON THE PROPOSED ISIAND SIME FOR A COMBINED NUCLEAR POWER AND DESALIING PIANT IN SOUTHERN CAIIFORNIA.

(b) The Bechtel Corporation.

(c) Prof. Vito A. Vanoni and Prof. Fredric Raichlen.

(d) Experimental.

(e) The objectives of the studies were (1) to develop a design for the island face that will be stable under the attack of storm waves, (2) to determine the heights of the island faces needed to prevent overtopping by storm waves and (3) determine the effect of the proposed island on the littoral drift on the beach near the island. The stability of the island and overtopping by waves were studied by subjecting a one-fiftieth size model of a section of the face to properly scaled waves in a tank 114 feet long and 4 feet wide. Overtopping by obliquely incident waves and the effect of the island on littoral drift were studied in a 1:150 scale model of the island in a basin 145 feet wide by 160 feet long.

(f) Inactive.

(h) "Laboratory Design-Studies of the Effect of Waves on a Proposed Island Site for a Combined Nuclear Power and Desalting Plant, "V. A. Vanoni and F. Raichlen, W. M. Keck Lab. of Hyd. and Water Res. Report KH-R-14, July, 1966.

(6584) WAVE UPLIFT FORCES ON DOCKS.

(b) Sloan Foundation; Bechtel Foundation; National Science Foundation.

(c) Prof. Fredric Raichlen and Mr. Jonathan A. French.

(d) Experimental and theoretical.

(e) A pile-supported pier in an exposed location is occasionally subject to high waves which impinge on its underside. At any particular location on a pier these waves cause a transient pressure consisting of a highintensity portion of short duration followed by a lower pressure of longer duration. This latter portion exists until the rear portion of the wave separates from the dock and may be negative as well as positive. The specific objective of this research is to study theoretically and experimentally this pressure distribution with particular attention being given to the portion of high intensity which coincides with the initial wetting of the underside of the pier. Experiments are being conducted in a wave tank for the case of a solitary wave striking the underside of a dock which is represented by a flat plate located at fixed distance above the water surface. Simultaneous recordings are made of the wave profile and the resultant pressure distribution at locations on the underside of the platform as the wave travels underneath and in contact with it.

UNIVERSITY OF CAIIFORNIA, BERKELEY, Dept. of Civil Engrg., Fluid Mechanics Lab., Berkeley, Calif. 94720

(1554) SEA WATER CONVERSION RESEARCH.

(b) State of California.

(c) Prof. Everett D. Howe, Coordinator, Saline Water Conversion Research, Univ. of Calif., 1301 s. 46th st., Richmond, Calif.

(e) The purpose of this project is to discover whether there is available any method for the large-scale, low-cost demineralization of sea water. The project includes a number of investigations, of which the following have been active during 1965 - 1967: (1) mutipleeffect flash evaporator; (2) vapor compression distillation; (3) vacuum flash distillation; (4) solar distillation; (5) miscellaneous studies of heat transfer, vapor disengagement and scaling in distillation equipment; (6) boundary layer studies in electrodialysis; (7) development of electrodialysis membranes; (8) ion exchange; (9) reverse osmosis pilot plant; (10) thermodynamic and economic analysis; (11) transport phenomena near a liquid-vapor interface; (12) fundamental studies of corrosion processes; (13) submerged combustion studies; and (14) studies of the thermodynamic properties of sea water. 
Investigations are being carried on at the Berkeley, Los Angeles, Riverside, and San Diego Campuses.

(g) Detailed results may be obtained from the progress reports and publications listed under ( $\mathrm{h}$ ) below. This project has been active since 1951 - 52 and previous summaries have listed all reports prior to October 1965.

(h) The following reports and publications have been issued during the period since October 1965, and summarize the work to date:

UNIVERSITY OF CALIFORNIA, IOS ANGELES*

"Saline Water Research Progress Report," Dept. of Engrg. No. 66-1, 62 pp., Jan. 1966. "Cellulose Acetate Membranes As a Means of Removing Scale Forming Ions of Natural Saline Waters," D. I. Erickson, Dept. of Engrg. Rep. No. 66-7, 108 pp., Feb. 1966.

"Mass Transport of Binary Electrolyte Solutions in Membranes," D. N. Bennion, Dept. of Engrg. Rep. No. 66-17, 29 pp., March 1966. "Corrosion Studies - Part VIII - Corrosion Kinetics of Molybdenum in $\mathrm{H}_{\mathrm{SO}}$, "Dept. of Engrg. Rep. No. 66-37, 64 pp.., June 1966. "Corrosion Studies - Part IX - Effect of Chloride Ions on the Corrosion of Nickel and Niobium (Columbium)," L. L. Wilkstrom and K. Nobe, Dept. of Engrg. Rep. No. 66-37, 30 pp., June 1966.

"A Composite Tubular Assembly for Reverse Osmosis Desalination," S. Loeb, Dept. of Engrg. Rep. No. 66-40, 26 pp., June 1966.

"Variation of the Heat Transfer With Length, Pressure, Flow Rate and Temperature Difference in an ITV Falling Film Evaporator," J.E. Kroll, Dept. of Engrg. Rep. No. 66-43, 98 pp.,Aug. 1966.

"Reverse Osmosis Desalination at the Coalinga Pilot Plant," J.S. Johnson and S. Loeb, Dept. of Engrg. Rep. No. 66-53, 16 pp., Oct. 1966. "Fouling Problems Encountered in a Reverse Osmosis Desalination Pilot Plant," J.S. Johnson and S. Loeb, Dept. of Engrg. Rep. No. 66-61, 26 pp., Oct. 1966.

"Turbulent Region Performance of Reverse Osmosis Desalination Tubes I. Experience at Coalinga Pilot Plant," J. Rosenfeld and S. Loeb, Dept. of Engrg. Rep. No. 66-62, 20 pp., Oct. 1966.

"Further Studies on Thin Wiped Film Heat Transfer," V.J. Jusionis and R.I. Perrine, Dept. of Engrg. Rep. No. 66-59, 38 pp. , Nov. 1966.

"Saline Water Research Progress. Report," Dept. of Engrg. Rep. No. 67-1, 83 pp., Dec. 1966.

"Reverse Osmosis Desalination Costs Derived from the Coalinga Pilot Plant Operation," D. Stevens and S. Loeb, Dept. of Engrg. Rep. No. 67-2, 31 pp., 1967.

"Performance of Cellulose Acetate Semipermeable Membrane Under Brackish Water Field Conditions," J.S. Johnson, Dept. of Engrg. , Rep. No. 67-41, 115 pp., Aug. 1967.

"Corrosion Studies - Part X - Corrosion Kinetics of Iron-Nickel Alloys, Part XI Corrosion Kinetics of Antimony, Part XII Corrosion Kinetics of Copper, Part XIII Potentiodynamic Studies of Antimony, Part XIV - Corrosion Kinetics of Iron," R.R. Sayano, I.L. Wikstrom, C.P. Kim, A. Akiyama, R. Patterson and K. Nobe, Dept. of Engrg. Rep. No. 67-45, 193 pp., Aug. 1967.
UNIVERSTTY OF CATTFORNIA, BERKELFY***

"Polarization and Selective Transport Characteristics of Permselective Membranes," S.A. Weiner, Sea Water Conversion Lab. Rep. No. 65-6, 25 pp., Dec. 1965.

"Nocturnal Production of Solar Distillers," E.D. Howe and B.W. Tleimat, Sea Water Conversion Lab. Rep. No. 65-7, 17 pp., Dec. 1965. "1965 Progress Report, Berkeley, Riverside, and San Diego Campuses," Sea Water Conversion Lab. Rep. No. 66-1, 5 pp., Jan. 1966.

"Ion Transport Inside Charged Members," R.A.

Wallace, Sea Water Conversion Lab. Rep. No. 66-2, 48 pp., Sept. 1966.

"1966 Progress Report, Berkeley, Riverside, and San Diego Campuses," Sea Water Conversion Lab. Rep. No. 67-1, 63 pp., Jan. 1767.

"Solar Distillation," E.D. Howe, B.W. Tleimat and A.D.K. Laird, Sea Water Conversion Lab. Rep. No. 67-2, 52 pp., Oct. 1967.

"Multiple-Effect Rotating Evaporator," I.A. Bromley, Water Resources Center Contribution No. 100, 111 pp., April 1965.

"The Demineralization of Water," E.D. Howe, Impact, Vol. XV, No. 3, 13 pp., April 1965.

"The Effect of Temperature on Electrodialytic Demineralization," S.A. Weiner, Bull. Chemical Soc. Japan, Vol. 38, No. 11, 3 pp., May 1965. "Determination of Resistance Factors of Porous Diaphragms and Electrodes," K.S. Spiegler, Jour. Electrochemical Soc., Vol. 113, No. 2, pp. 161-165, Feb. 1966.

"Nocturnal Production of Solar Distillers," E.D. Howe and B.W. Tleimat, Solar Energy, Vol. X, No. 2, 6 pp., June 1966.

"Kinetics of Styrene Homogeneous Polymerization to Atactic Polypropylene," R.A. Wallace and K.I. Hadley, J. Polymer Science $(A-1)$, Vol. 4, pp. 71-82, 1966.

"Sea Water Conversion," E.D. Howe, Advances in Hydroscience, Vol. 3, pp. 191-235, Aug. 1966. "Effect of D.C. Electric Fields on IiquidLiquid Settling," G.I. Sjoblom and S.I. Goren, I and EC Fund., Vol. 5, No. 4, p. 519, Nov. 1966.

"Pacific Island Water Systems Using a Combined Solar Still and Rainfall Collector," E.D. Howe, Solar Energy, Vol. X, No. 4, pp. 175-181, Dec. 1966.

"Solar Distillers for Use on Coral Islands," E.D. Howe and B.W. Tleimat, Desalination, Vol. 2, No. 1, 7 pp., 1967

*Requests for copies should be directed to: Institute of Industrial Cooperation, Dept. of Engrg., Univ. of Calif., Los Angeles, Calif. 90024 .

* Requests for copies should be directed to: Sea Water Conversion Lab., Univ of Calif., 1301 s. 46th st., Richmond, Calif. 94804.

(2265) FORCES ON ACCETHRATED CYIINDERS.

(b) Iaboratory project.

(c) Prof.A.D.K. Laird, 6167 Etcheverry Hall, Univ. of Calif., Berkeley.

(d) Experimental and theoretical; basic research.

(e) Measurement and prediction of drag coefficients and flow configurations about cylinders during accelerated motion in fluids including effects of support flexibility.

(g) Analytical explanation of eddy formation found.

(4562) ANALYSIS OF NONTINEAR SYSTEMS.

(b) Laboratory project and Water Resources Center, Univ of Calif. 
(c) Prof. J.A. Hardex, Hesse Hall, Jniv. of Calif., Berkeley.

(d) Theoretical; basic research.

(e) Given a sufficiently long record of the input and output of a stationary system that may include nonlinearities, the purpose is to develop a predictor for arbitrary inputs.

(8) Computer program has been developed. Applications have been made to the prediction of salinity in estuaries from river flow data. Predictor accuracy is of same order of accuracy as field data (5-10\%).

(h) "The Prediction of Estuary Salinity Using Nonlinear Systems Analysis," J.A. Harder and S. Zand, Univ. of Calif., Berkeley, Nov. 1967.

(4565) MATHEMATICAI MODELS FOR FLOOD ROUTIING.

(b) Laboratory project and Water Resources Center, Univ. of Calif.

(c) Prof. J.A. Harder; see (4562) above.

(d) Theoretical; basic research.

(e) Computer simulation of flood flows through natural channels is compared with actual flows.

(g) Computer prograrns are operating successfully and a generalized theory is being worked out.

(4930) COASTAL SAND MOVEMENT.

(b) Corps of Engrs., U.S. Army, Coastal Engrg. Research Center.

(d) Experimental; laboratory and field.

(e) This investigation is concerned with the transportation of sand by both wind and waves.

(h) "Sand Movement Along a Portion of the Northern California Coast," J.A. Cherry, CERC Tech. Memo. No. 14, Oct. 1965.

"Sand Movement Along Equilibrium Beaches North of San Francisco," J.A. Cherry, Jour. Sed. Pet., Vol. 36, No. 2, June 1966.

"The Erosional and Depositional History of the Coast of Northern California," C.R. Minard, Jr., Univ. of Calif., Hya. Lab. Rept. No. HEL-2-10, Sept. 1964.

"Bed Ioad Function Due to Wave Action," M.M. Abou-Seida, Ph.D. Thesis, Univ. of Calif., Jan. 1965, and Univ. of Calif. Hyd. Lab. Rept. No. HEL-2-11, Jan. 1965.

"A Function for Sand Movement by Wind," A.A. Kadib, Ph.D. Thesis, Univ. of Calif., 1965, and Univ. of Calif. Hyd. Lab. Rept. Ho. HEL-2-12, Jan. 1965.

"Recent Sediments of the Monterey Deep-sea Fan," P. Wilde, Univ. of Calif. Hyd. Lab. Rept. No. HEL-2-13, May 1965.

"Recent Coastal Sediments: Double Point to Point San Pedro, California," D.B. Moore, M.A. Thesis, Univ. of Calif., June 1965, and Univ. of Calif. Hyd. Lab. Rept. No. HEL-2-14, June 1965.

"Coastal Sedimentation: Point San Pedro to Miramontes Point, California," F.I. Sayles, M.A. Thesis, Univ. of Calif., Aug. 1965, and Univ. of Calif. Hyd. Lab. Rept. No. HEL-2-15, Aug. 1965.

"A Reconnaissance Heavy Mineral study of Monterey Bay Beach Sediment," F.I. Sayles, Univ. of Calif. Rept. No. HEL-2-16, Aus. 1966.

"Nearshore Sediment Movement--Central

California Coast," J.W. Johnson, Coastal Engrg.,

ASCE Santa Barbara Specialty Conf., Oct. 1965.

"Mechanism of Sand Movement on Coastal Dunes," A.A. Kadib, Jour. Waterways and Harbors Div., ASCE, May 1966, pp. 27-44.

(4932) GROUND WATER BASIN MAIAGEMENP. (b) Offlce of Water Resources Research; and Water Resources Center.

(c) D.K. Todd.

(d) Experimental and theoretical; applied research.

(e) Study of the physical conditions within a basin so that ground water levels at any point can be predicted for any future time for given recharge and discharge conditions. Subsequently, study of alternate methods for operating the basin to obtain an economically optimal system.

(h) "The Optimum Use of a Ground-water and Surfacewater System: a Parametric Linear Programing Approach," J.A. Dracup, Water Resources Center Contribution No. 107, Univ. of Calif., Berkeley, 134 pp., 1966.

"Theoretical Analysis of Groundwater Basin Operations," W.D. McMillan, Water Resources Centex Contributions INo. 114, Univ. of Calif., Berkeley, $167 \mathrm{pp} ., 1966$. "Cost, Precision, and Value Relationships of Data Collection and Design Activities in Water Development Planning," S.V. Allison, Water Resources Center Contribution No. 120, Univ. of Calif., Berkeley, 142 pp., 1967.

(4933) HYDRAULIC SYSTEMS AITALYSIS.

(b) California Dept. of Water Resources.

(c) Prof. J.A. Harder, Hesse Hall, Univ. of Calif., Berkeley.

(d) Experimental; applied research and design.

(e) Analog model and digital computer methods are being used to predict salinity, tidal amplitudes, tidal elevations, and fresh water flows in the Sacramento-San Joaquin Delta Region.

(f) Completed.

(h) "Analog Modeling the California Delta System," J.A. Harder and J.O. Nelson, Proc. ASCE, Fol. 92, No. HY4, pp. 1-10, July 1966.

(4934) WAVE DIFFRACIION AND REFRACTION.

(b) Corps of Engrs., U.S. Army, Coastal Engrg. Research Center.

(c) Prof. R.I. Wiegel, Univ, of Calif., Berkeley.

(a) Experimental; basic research.

(e) Determination by model tests the diffraction and refraction characteristics of wind waves. Also, model studies of the "Mach-stem" equivalent of water waves.

(g) A study is being made on the directional spectra of wind generated waves, and on their diffraction by a semi-infinite breakwater.

(h) "Diffraction of Wind Generated Water Waves," Ismail Mobarek and Robert L. Wiegel, Proc. Tenth Conf. Coastal Engrg., ASCE, 1966, pp. 185-206.

"Directional Spectra of Laboratory Wind Waves," Ismail E. Mobarek, Jour Waterways and Harbors Div., Proc. ASCE, Vol. 91, No. WW3, Aug. 1965, pp. $91-116$.

"Diffraction of Water Waves over Bottom Discontinuities," Nabil Hilaly, Univ. of Calif., Hyd. Eng. Lab., Tech. Rept. HEL-1-7, sept. 1967, $142 \mathrm{pp}$.

(5437) DEPOSIT OF SILT IN A GRAVEI BED BY WATER FIOWIING OVER THE BED.

(b) U.S. Bureau of Reclamation.

(c) Prof. H.A. Einstein, Dept. of Civil Engrg., Univ. of Calif., Berkeley.

(d) Experimental; basic research.

(e) The rate at which fine sediment is deposited in artificial spawning grounds for salmon and other fish has been determined. The 
sediment carrying flow is recirculated over gravel beds in laboratory flumes.

(f) Terminated.

(g) The fine sediment deposits at a rate that is proportional to the concentration. The concentration decreases exponentially. The "half life" is proportional to the water depth and inversely proportional to the settling velocity.

(h) Final report submitted to the U.S. Bureau of Reclamation.

"Deposition of Suspended Particles in a Gravel Bed," H.A. Einstein, submitted to ASCE for publication in Jour., Hyd. Div.

(5438) SHAPE OF CROSS SECTIONS IN RIVER BENDS.

(b) Laboratory research, supported by the California State Water Resources Center.

(c) Prof. H.A. Einstein; see (5437) above.

(d) Experimental with statistical analysis, $\mathrm{Ph}$.D. thesis.

(e) A circular flume has been constructed in which various flows are established and cross sections established. The cross sections are statistically described by a minimum of parameters and the change of these parameters established in terms of the flow and sediment parameters. River sections are equelly analyzed.

(g) Analysis of 2300 cross sections of the Missouri River shows that cross slope of the bed can be predicted as a function of the channel curvature in the preceding 1.5 miles of river. The statistical analysis is continued.

(5439) WAVE FORCES.

(b) Corps of Engrs., U.S. Army, Coastal Engrg. Research Center.

(c) Prof. R.L. Wiegel, Univ. of Calif., Berkeley.

(d) Experimental and theoretical; basic research.

(e) Determine by model tests the forces exerted by waves on coastal structures. Theoretical studies of statistical properties of wave forces.

(g) Forces exerted by broken waves on vertical wall bulkheads are being studied experimentally. Spectral methods are being developed to study wave forces on piles, both theoretically and experimentally.

(h) "The Spectral Density for Ocean Wave Forces," Ireon E. Borgman, Coastal Engrg.: Santa Barbara Specialty Conf., Oct. 1965, ASCE, 1966, pp. 147-182.

"Ocean Wave Simulation for Engineering Design," Leon E. Borgman, Civil Engineering in the Oceans, ASCE, 1967 (in press).

"Tsunami Surge Forces," Ralph H. Cross, Jour. Waterways and Harbors Div., Proc. ASCE, Vol. 93, No. Ww4, Nov. 1967.

"Wave Forces on Circular Cylindrical Piles Used in Coastal Structures," Yuan Jen, Univ. of Calif. Hyd. Eng. Lab. Tech. Rept. HEL-9-1l, Jan. 1)67, 99 pp.; also, Jour. Waterways and Harbors Div., Proc. ASCE (in press).

"Statistical Prediction of Wave-induced

Responses in Deep-Ocean Tower Structures," Edward Terence Foster, Jr., Univ. of Calif. Hyd. Eng. Lab. Tech. Rept. HEL-9-14; also in "Civil Engineering in the Oceans," ASCE, 1967 (in press).

"Tables of the Statistical Distribution of Ocean Wave Forces and Methods of Estimating Drag and Mass Coefficients," I.J. Brown and L.E. Borgman, U.S. Army, Corps of Engineers,
Coastal Engrg. Research Ctr., T.M. 24, Oct. 1967, $152 \mathrm{pp}$.

(5816) GROUND WATER FIOW IN THE CAPILIARY ZONE.

(b) Water Resources Center.

(c) D.K. Todd.

(d) Experimental; basic research.

(e) A sand model with steady ground water flow was employed to study flow in the capillary zone, its relative magnitude, and its importance in relation to flow in the saturated zone.

(i) Completed.

(h) "Lateral Movement of Water through the Unsaturated Zone of an Unconfined Aquifer," F. Mobasheri, M. Shahbazi, and D.K. Todd, Water Resources Ctr. Contribution No. 106, Univ. of Calif., Berkeley, 39 pp., 1965. Technical paper in preparation.

(5817) SHIP WAVES IN NAVIGATION CHANNELS.

(b) Coastal Engineering Research Center.

(c) Prof. J.W. Johnson, Univ . of Calif., Berkeley.

(d) Theoretical, laboratory and field experimental basic research study.

(e) The characteristics of waves generated by ships moving at various speeds in shallow water are being investigated.

(h) "Investigation of Ship-generated Waves," R.M. Sorensen, Univ. of Calif. Hyd. Lab. Rept. No. HEL-12-1, April 1966.

"Ship Waves," R.M. Sorensen, Ph.D. Thesis, Univ. of Calif., Aug. 1966 and Univ. of Calif. Hyd. Lab. Rept. No. HEL-12-2, Aug. 1966. "Investigation of Ship-generated Waves," R.M. Sorensen, Jour. Waterways and Harbors Div., ASCE, Feb. 1967, pp. 85-93.

"Waves Generated by a Moving Ship," R. M. Sorensen, Shore and Beach, Vol. 35, No. 1, April 1967, pp. 21-25.

"Photometric Definition of a Wave Surface," F.H. Moffitt, Univ. of Calif. Hyd. Lab. Rept. No. HEL-12-3, September 1966.

"Determination of a Ship's Wave Resistance in a Canal from Measurements of Wave Profiles," T. Mizuno and J.V. Wehausen, Univ of Calif. Hyd. Lab. Rept. No. HEL-12-4, Dec. 1966. "Ship Waves in Navigable Waterways," Duncan Hay, Univ. of Calif. Hyd. Lab. Rept. No. HEL-12-5, Sept. 1967.

(5818) TRANSMISSION OF WAVE ENERGY THROUGH RUBBLE MOUNDS.

(b) Laboratory project.

(c) Prof. J.W. Johnson; see (5817)above.

(d) Experimental.

(e) The transmission of wave energy through three scale models of rubble structures wa conducted with rubble size and wave ciaracteristics as the principal variables.

(f) Completed.

(h) "Scale Effects in Wave Action Through Porous Structures," J.W. Johnson, H. Kondo, and R. Wallihan, Proc. Tenth Conf. on Coastal Engrg., 1967, pp. 1022-1024.

(5819) WATER TABLE AND TOPOGRAPHY RELATIONS.

(b) Office of Water Resources Research; and Water Resources Ctr.

(c) D.K. Todd.

(d) Experimental and theoretical; basic research.

(e) Analytic techniques were developed and applied to the study of flow pattern in a two-dimensional steady state ground water basin 
resulting from surface infiltration. The geometry of recharge and discharge zones is a function of ground surface profile, recharge rate, permeability, and geometry of the flow region. The study included cases where the water table was known and also unknown; single and multi-layered systems were analyzed. Results were checked by a Hele-Shaw model.

(f) Completed.

(h) "Analytic Techniques for Determining Ground Water Flow Fields," M. Shahbazi and D.K. Todd, Water Resources Ctr. Contribution No. 117, Univ. of Calif., Berkeley, 139 pp., 1967.

(5820) TRANSPORT OF SILT THROUGH POROUS MEDIA.

(b) National Science Foundation.

(c) Prof. H.A. Einstein, Dept. of Civil Engrg., Univ. of Calif., Berkeley.

(d) Experimental and theoretical basic research.

(e) Silt-carrying water is flowing at various directions through porous media. The deposition, transport and erosion of the silt are studied as a function of silt size, concentration and density, and of the flow velocity.

(g) Iaboratory experiments in a column filled with spheres in geometrically regular arrangement are concluded and show that particles smaller than $1 / 7$ of their diameter are able to enter the pores. Particles between $1 / 7$ and $1 / 14$ their size will in time clog the column. Particles smaller than $1 / 14$ their size will indefinitely pass through the column.

For horizontal or near horizontal motion there exists a relationship between the rate of motion of the fine particles and the fluid velocity.

(h) "A Review of Filtration Theories," S. Irmay and R. Sakthivadivel, Univ. of Calif. Hyd. Lab. Rept. No. HEL-15-4, July 1966.

"Theory and Mechanism of Filtration of Noncolloidal Fines Through a Porous Medium," R. Sakthivadivel, Ph.D. Thesis, Univ. of Calif., Dec., 1966, and Univ. of Calif. Hyd. Lab. Rept. No. HEL-15-5, Dec. 1966, 110 pp. "Theory and Mechanism of Filtration of Noncolloidal Fines Through a Porous Medium to Other Directions Than Vertical," R. Sakthivadivel, Univ. of Calif. Hyd. Lab. Rept. No. HEL-15-6, June 1967, 36 pp. "Clogging of a Granular Porous Medium by Fine Sediments," R. Sakthivadivel and H.A. Einstein (in preparation).

(6221) ENERGY DISSIPATORS FOR IARGE CULVERTS.

(b) California Division of Highways.

(c) J.W. Johnson, Univ. of Ca.lif., Berkeley.

(d) Experimental.

(e) Model studies were conducted to arrive at the best condition for a hook-type dissipator with Froude Numbers up to about 4.

(f) Completed.

(g) "Model Studies of Energy Dissipators for Large Culverts," T.C. MacDonald, Univ. of Calif. Hyd. Iab. Rept. No. HEL-13-5, Nov. 1967.

(6222) FFEDBACK CONIROL OF CANAL GATES.

(b) U.S. Bureau of Reclemation, Region II.

(c) Prof. J.A. Harder, 412 Hesse Hall, Univ. of Calif., Berkeley.

(d) Experimental; applied research.

(e) Canal systems are modeled with electric analogs and digital computer programs, and feedback control systems for maintaining near-constant water levels are developed and evaluated.

(g) A feedback loop filter constructed of hydraulic components has been developed that successfully controls oscillations.

(6223) THE MANAGEMENT OF SURFACE WATHR HYDROLOGIC SYSTEMS FOR WATER QUATITY CONTROL.

(b) Water Resources Center, Univ. of Calif.

(c) Hugo B. Fischer, Asst. Prof. of Civil Engrg., Univ. of Calif., Berkeley.

(d) Experimental and theoretical; basic research.

(e) Basic mechanics of mixing and dispersion of pollutants in river and estuarine systems are studied to improve methods of predicting and managing surface water quality.

(6224) TSUNAMIS.

(b) Corps of Engrs., U.S. Army, Coastal Engrg. Research Ctr.

(c) Prof. R.L. Wiegel, Univ of Calif., Berkeley.

(d) Experimental and theoretical; basic research.

(e) Model and theoretical studies of water waves generated by horizontal fault moving normal to a channel or escarpment.

(g) See (e).

(h) "Long Wave Profiles over a Slope," R.H. Cross and R.I. Wiegel, Univ of Calif. Hyd. Eng. Lab. Tech. Rept. HEL-16-1, Oct. 1966, 17 pp. "Non-linear Wave Effects on Tide Gages," Ralph H. Cross, Univ. of Calif. Hyd. Eng. Lab. Tech. Rept. HEL-16-2, May 1967, $30 \mathrm{pp}$. "Methods for the Analysis of Non-stationary Time Series with Applications to Oceanography," Lloyd John Brown, Univ. of Calif. Hyd. Eng. Lab. Tech. Rept. HEL-16-3, May 1967, 135 pp. "Frequency Response of ride Gages," Ralph H. Cross, Univ. of Calif. Hyd. Eng. Lab. Tech. Rept. HEL-16-4, Aug. 1967, 13 pp.

UNIVERSITY OF CALIFORIIA, BERKELEY, Dept. of Naval Architecture, Berkeley, California 94720.

(5301) SHLP SLAMMING.

(b) U.S. Dept. of Commerce, Maritime Admin.

(c) Prof. H.A. Schade, Dept. of Naval Architecture, Univ. of Calif., Berkeley.

(d) Experimental and theoretical; applied research.

(e) The purpose of the project is to investigate the impact loads (pressures) caused by slaming and the response of the ship structure to these loads. The capacity of the testing equipment is as follows: (a) $1 / 4$ scale models; (b) total model weights up to 40,000 lbs; (c) drop height up to $10 \mathrm{ft}$. above the still water surface.

(g) Preliminary results for an extra stiff flat model indicate that: (a) For lower drop heights the peak pressure varies nearly as the square of the impact velocity; (b) the pressure is proportional to the deceleration ( for the range 10 to $30 \mathrm{~g}$ ). More experiments in preparation.

(h) "The Ship Dynamic Test Machine at the University of California, Berkeley, California," Walter M. Maclean, Univ. of Calif., Berkeley, Coll. of Engrg. Rept. INA 66-1, Jan. 1966.

(4971) SHIP RESISTANCE IN IRREGUIAR WAVES.

(b) Naval Ship Research and Development Ctr., Dept. of the Navy 
(c) Mr. O.J. Sibul, Dept. of Naval Architecture, Coll. of Engrg., Univ. of Calif., Berkeley.

(d) Experimental; applied research.

(e) The previous resistance measurements of ship models in uniform waves will be used to predict the total added resistance in irregular waves of known spectral content. The predictions will be compared with experiments in irregular waves of various spectral contents and severity, combined with a number of model speeds.

(g) The resistance response function was used to predict the resistance of a Series $60, \mathrm{C}_{\mathrm{B}}=$ 0.70 model in irregular waves of known spectral content. The predictions are compared with measurements. The results indicate that the predicted added resistance is approximately 65 to 85 per cent of the measured values, depending upon the severity of the waves and the speed of the ship. This is a similar trend as found earlier for the experiments in waves at two components.

(h) "An Experimental Study of Ship Resistance and Motions in Waves - A Test for Linear Superposition," 0.J. Sibul, Univ. of Calif., Berkeley, Coll. of Engrg. Rept. NA 66-3, Jan. 1966.

"Increase of Ship Resistance in Waves," O.J. Sibul, Univ. of Calif., Berkeley, Coll. of Engrg. Rept. NA 67-2, March 1967.

(4084) SHIPS OF MINIMUM RESISTANCE.

(b) Office of Naval Research, Dept. of the Navy.

(c) Prof. J.V. Wehausen, Dept. of Naval Architecture, Coll. of Engrg., Univ. of Calif., Berkeley.

(d) Theoretical applied research.

(e) The general aim of this work is to find computer designed ships of minimum "total" resistance, subject to various restraining conditions. Here "total" resistance means the Michell wave resistance plus the equivalent flat-plate frictional resistance.

(g) The waves generated by the ship model were measured from stereoscopic pictures of the water surface behind the model. The results were used to calculate the wave-making resistance by Egger's method. The analysis shows that the wave-making resistance coefficient is a minimum at the design speed. Boundary layer separation observed at the stern may be a possible source for higher than expected resistance. Some additional experiments were made in which boundary layer suction was used at the stern. Results indicate reduced form resistance as the rate of the suction is increased.

(h) "Use of Lagrangian Coordinates for Ship Wave Resistance (First- and Second-Order Thin-Ship Theory)" J.V. Wehausen. Univ. of Calif., Coll. of Engrg. Rept. NA 67-4, June 1967. Qualified requesters may obtain copies from DDC. Limited number of copies available from Dept. of Naval Architecture, Univ. of Calif., Berkeley

(5774) HYDRODYNAMICS OF SHIP SIAMMING.

(b) University of California, Berkeley, Dept. of Commerce, U.S. Maritime Admin., and Naval Ship Research and Development Ctr., Dept. of the Navy.

(c) Prof. J.V. Wehausen; see (4084) above.

(d) Theoretical, experimental.

(e) Some experimental results suggest that air trapped under the flat bottom of the falling model, is cushioning the impact and reducing the peak pressures for slamming. A preliminary theory has been developed to take into consideration the entrapped air.

(f) Completed.

(g) The theory shows good general agreement with the experiments, though further work is needed to confirm some of the assumptions made.

(h) "The Effect of Entrapped Air upon the Slamming of Ships' Bottoms," Grant Lewison and Walter M. Maclean. Univ. of Calif., Coll. of Engrg. Rept. INA 66-5, Mar. 1966.

"The Effect of Air Compressibility in the Impact of a Flat Body upon a Free Surface," Robert S. Johnson. Univ. of Calif., Coll. of Engrg. Rept. INA 66-8, Sept. 1966.

(4570) PRESSURE DISTRIBUTION ON SEMI-SUBMERGED OSCIIIATING BODIES.

(b) Naval Ship Research and Development Ctr., Dept. of the Navy.

(c) Prof. J.R. Paulling, Dept. of Naval Architecture, Coll. of Engrg., Univ. of Calif., Berkeley.

(d) Experimental and theoretical.

(e) To determine the response of a floating body in a seaway, it is necessary to know the magnitudes and phases of hydrodynamic forces and moments acting on this body. In the linearized analysis the total pressure at any point takes the form of two terms: (a) exciting pressure dependent upon the waves only: (b) pressure dependent upon the geometry and motion of the body and independent of the waves. These two terms are being measured on: (1) A prolate spheroid; (2) A ship-like form.

First the models are attached rigidly to the dynamometers, towed in waves and the pressure distribution, total forces and moments measured. Then the models are oscillated sinusoidally in still water and again the pressure distribution, total force and moment measured. The results will be compared with theoretical calculations.

(f) Completed.

(g) The results indicated that the wave forces and moments follow the general trend as predicted by the Froude-Krylov Theory. For the oscillating models in still water the results were compared with strip computations using twodimensional cylinder data. In general, the greater discrepancies were found at the ends of the model. At amidships, measured values agreed quite closely with two-dimensional results. At high frequencies forward speed was found to have small effect on added mass. However, at high frequencies and high forward speed, negative damping was found at some sections.

(h) "Measurements of Pressures on a Heaving Prolate Spheroid," Choung Mook Lee and J.R. Paulling, Univ. of Calif. Coll. of Engrg. Rept. NA 66-4, March 1966.

(6298) STEFRING AND DIRECTIONAL STABILITY OF SHIPS.

(b) Naval Ship Research and Development Ctr., Dept. of the Navy.

(c) Prof. J.R. Paulling; see (4570) above.

(d) Theoretical and experimental.

(e) The objective of this research is the experimental and theoretical determination of the steering characteristics of ships.

(1) Completed. 
(g) The change of ship response in a ziz-zag maneuver due to a small variation of each of the coefficients in the equation of motion has been obtained. The non-linear equations were solved by numerical methods. Both dynamically stable and unstable ships were investigated. The relationship between the ship lateral response and harmonically oscillated rudder has been found experimentally. Excellent agreement between experiment and theoretical prediction was obtained.

In separate tests dynamometers were used to measure longitudinal and transverse forces and moments about the centerline of the rudder stock. Results were compared with rudder performance, calculated from airfoil data and results obtained by other experimenters.

(h) "An Investigation of the Sensitivity and the Linearity of Response of a Steered Ship," Hsao-Hsin Chen, Univ. of Calif. Coll. of Engrg. Rept. NA 67-1, Feb. 1967.

"The Experimental Determination of the Rudder Forces and Rudder Torque of a Mariner Class Ship Model," Hsao-Hsin Chen, Univ of Calif. Coll. of Engrg. Rept. NA 67-5, July 1967.

(6299) MOTION OF A "SPAR SHIP" IN WAVES.

(b) Naval Ship Research and Development Ctr., Dept. of the Navy.

(c) J.R. Paulling; see (4570) above.

(d) Experimental, theoretical.

(e) The behavior of a floating body of revolution having a vertical axis and small radius to depth ratio has received considerable attention. This configuration can form the basis for a number of special types of seagoing vehicles such as a stable oceanographic research platform.

In the present study the motions as well as the forces will be measured on a small model of a "Spar Ship" on waves. The experimental results will be compared with theoretical calculation.

(g) The heave, pitch, and surge motions of the "spar ship" have been measured in uniform waves. The results compare fairly well with theoretical calculations. However, more data are necessary, and the instrumentation needs improvement in order to accurately measure the small motions characteristic of this type body.

(6300) FORCES AND PRESSURES ON TWO-DIMENSIONAI BODIES IN FORCED OSCILIATIONS.

(b) Naval Ship Research and Development Ctr., Dept. of the Navy.

(c) Prof. J.R. Paulling; see (4570) above.

(d) Theoretical and experimental.

(e) A potential solution up to the second order is sought for a symmetric horizontal cylinder which oscillates vertically in a free surface. The pressure distribution about the cylinder, the force acting upon it, and the waves generated by it are computed. Theoretical results will be compared with experimental measurements. The results of this study wili be used to help calculate the response of a floating body on a seaway.

(g) The theoretical analysis has been completed. Numerical computations were made for a circular cylinder and for a U-shaped cylinder. -The results indicate that the second-order hydrodynamic forces may become important when the bodies are subject to large amplitude oscillations. The experimental work is under evaluation.

(h) "The Second-order Theory of Cylinders Oscillating Vertically in a Free Surface," Choung Mook Lee, Univ. of Calif. Coll. of Engrg. Rept. NA 66-7, Sept. 1966.

UNIVERSITY OF CAIIFORNIA, DAVIS, Coll. of Agriculture and Environmental Science, Dept. of Water Science and Engrg., Davis, California 95616.

(23) HYDROLOGY OF IRRIGATION SUPPIIES IN CALIFORNIA.

(b) Univ. of California.

(c) Prof. R.H. Burgy, Dept. of Water Science and Engrg., Univ. of Calif., Davis.

(d) Laboratory and field investigation; applied research.

(e) Hydrologic investigations of mountain watersheds are being conducted on pilot watersheds in three areas of the state. Measurements are made of rainfall, surface runoff, erosion, and groundwater storage and outflow. The hydrologic effect of vegetative conversions on the watersheds is under long-term study. Various tracer techniques are used to study groundwater movement and sources of water for native vegetation water uptake. Moisture movement and storage above water tables in fractured rock mantles are measured with neutron scattering meters, combined with seismic and resistivity methods. Micrometeorological techniques and equipment are being tested to provide an independent evaluation of evapotranspiration from the study watersheds.

(h) "Water Use by Native Vegetation and Hydrologic Studies," D.C. Lewis and R.H. Burgy, Annual Rept. No. 7, 1965-66, Dept. of Water Science and Engrg., Univ. of Calif., Davis.

(1819) DRAINAGE IN RELATION TO IRRIGATION.

(b) Univ of California.

(c) Dr.J.N. Iuthin and Mr. J. Woerner, Univ. of Calif., Davis.

(d) Basic and applied research.

(e) Leaching of salts from soil under ponded conditions has been studied in a sand tank. The movement of the "leaching front" (defined as the interface between the added fresh water and the salty soil water) has been followed. Theoretical analyses were made by obtaining solutions to Kirkham's equation. Exit gradients into drain lines were obtained from theoretical analyses.

(h) "Drain Tile Effects on Soil Salinity in the Imperial Valley," F.R. Robinson and J.N. Iuthin, California Agric. 2l, Feb. 1967. "Transient Solutions for Drainage of Sloping Iand," J.N. Iuthin and J.C. Guitjens, Jour. Irrig. and Drainage, ASCE, IR3, 43-5I. "Proposed Drain Spacing Equation and an Experimental Check with the Hele-Shaw Model," M.N. Amer and J.N. Luthin, Intl. Soil Water Symp. ICID Proc., II, 397-422.

(4086) MISCIBLE AND IMMISCIBLE FIUID DISPIACEMENTS IN REIATION TO SOLUTE MOVEMENT IN SOIL AND OTHER POROUS MATERIAL.

(b) Univ of California.

(c) Drs. J.W. Biggar and D.R. Nielsen, Dept. of Water Science and Engrg., Univ. of Calif., Davis. 
(d) Theoretical and experimental; basic and applied.

(e) The simultaneous transport of fluids and solutes through porous media is under investigation. The mixing and spreading of the fluids in the medium, the interaction of the fluids with each other and the medium have been studied. The work will help define the nature of the porous structure of materials, and the coupling between velocity and diffusion in the dispersion process. Leaching phenomena, disposal of industrial and radioactive wastes, and the movement of pesticides in soil water depend upon the dispersion process.

(g) Transient water and salt conditions in columns and field profiles of soil are currently under study. These conditions involve, among other complex processes, the hysteritic moisture content-pressure relation and the rate dependence of this relation. The mixing processes in unsaturated media which have not been understood are also involved. Field experiments demonstrating the importance of mixing in saturated and unsaturated soils have been continued. A computer program for predicting leaching of salts has been improved to include a variable $K$ and mixing processes.

(5145) GENERALIZED ANALYSIS OF SMALI WATEERSHED RESPONSES.

(b) Office of Water Resources Research--Water Resources Center, Univ. of Calif.

(c) Prof. J. Amorocho, Dept. of Water Science and Engrg., Univ. of Calif., Davis.

(d) Theoretical and experimental; basic and applied research.

(e) (I) Studies on the mathematical theory of nonlinear systems with lumped and with distributed parameters. (2) Development of methods for the establishment of inflow-outflow relationships for natural catchments. (3) Laboratory and field investigations related to (2) above.

(g) Several models for the prediction of watershed performance have been developed. Data on California catchments have been analyzed and studies of the conformance of model predictions with field data have been undertaken. A detailed model for the process of snow melt has been completed and tested against field data obtained in the Sierra Nevada of California. Studies on a laboratory system for the verification of theoretical methods for the description of the operation of hydrologic systems with distributed rainfall have been initiated.

(h) "The Role of Infiltration in Nonlinear Watershed Analysis Processes," J. Amorocho, Trans. ASAE 10(3): 396-399, 404, 1967.

"The Nonlinear Prediction Problem in the study of the Runoff Cycle," J. Amorocho, Water Resources Res. 3(3): 861-880, 1967.

(5861) THE MECHANICS OF OPEN CHANNEI FLOW SYSTEMS.

(b) Office of Water Resources Research--Water Resources Ctr., Univ. of Calif.

(c) Prof. J. Amorocho and Prof. T.S. Strelkofe, Dept. of Water Science and Engrg., Univ. of Calif., Davis.

(d) Theoretical and experimental investigation.

(e) Comprehensive analytical and experimental study of phenomena encountered in the operation of complex open channel systems with multiple controls. Development of mathematical models of the systems for steady and unsteady state operation. (g) An air model and a water model of a warped channel transition have been built and are being analyzed with hot-probe anemometer equipment in order to evaluate the various terms of the equations of motion.

(5862) BBHAVIOR OF IARGE PUMPING PLANT SIPHONDISCHARGE LINES.

(b) Dept. of Water Resources, State of Calif.

(c) Prof. J. Amorocho and Mr. A. Babb, Dept. of Water Science and Engrg., Univ. of Calif., Davis.

(d) Hydraulic model studies.

(e) Investigation of energy losses due to air entrapment at the crests of large pumping plant discharge siphons due to the release of air in solution from the water stream due to pressure reduction near siphon crests.

(f) Completed.

(g) The conditions of air entrapment at the crest of large siphons were investigated in various laboratory model configurations and in large siphons at Grand Coulee Dam. The primary cause for head losses in the siphons was found to be the turbulent energy dissipation associated with the creation of hydraulic jumps within the siphons under certain conditions of flow. The conditions of sweepout of air accumulated at the siphon crests were also investigated.

(h) "Flow Behavior in Large Siphons, "A.F. Babb, $\mathrm{J}$. Amorocho, and J. Dean, WS and $\mathrm{E}$ Paper No. 1016, Univ, of Calif., Feb. 1967.

(5863) OVERFIOW AND UNDERFIOW DISCHARGE COEFFICIENIS FOR RADIAI, GATES.

(b) Dept. of Water Resources, State of Calif.

(c) Prof. J. Amorocho and A. Babb; see (5862).

(d) Experimental, applied research.

(e) Theoretical and experimental investigation of discharge coefficients of radial gates under steady and unsteady states for the cases of simultaneous gate overflow and underflow, and for situations of flow reversal. The purpose of the study is to establish the theory and to obtain experimental data applicable to the analysis of surge problems in gate-controlled open channel systems in which flow reversal can be expected.

(f) Completed.

(g) Values of the discharge coefficients of radial gates for a wide variety of conditions including forward and backward free and submerged flow, as vell as gate overtopping were determined. A computer program routine was prepared, to permit the automatic applicatjon of these experimental discharge coefficients to the solution of unsteady state operation problems of open channels with gate controls.

(h) "Discharge Coefficients of Radial Gates," A. Babb, M. Moayeri, J. Amorocho, WS and E Paper No. 1013, Univ. of Calif., July 1766.

(5864) DEL VALTE DAM GLORY HOIE SPILLWAY.

(b) Dept. of Water Resources, State of Calif.

(c) Prof. J. Amorocho and A. Babb; see (5862).

(d) Model studies for design development.

(e) Study of glory hole spillway for a California dam. Investigation of the effect of the asymmetrical flow field created by the topography of the reservoir in the immediate vicinity of the spillway on the overflow capacity. Effects of discharges from the river outlet into the spillway tunnel on the performance of the structure. 
(f) Completed

(g) The effects of topographic configuration in the vicinity of the spillway on the patterms of flow were investigated. The disposition of antivortex and flow directional vanes to improve on these flow conditions was studied, and the configuration of the spillway shaft, including the details of its elbow section was optimized.

(h) "Hydraulic Model Study of the Shaft Spillway for Del Valie Dam," K. Bucher and J. Amorocho, WS and E Paper 1020, Univ. of Calif., 1968.

(5865) MIXING CHAMBER FOR WATERS OF DIFH'ERENT QUALITIES.

(b) Metropolitan Water District of Southern Calif.

(c) Prof. J. Amorocho and Mr. A. Babb; see (5862).

(d) Hydraulic model investigation for design development.

(e) Development of a mixing chamber for obtaining homogeneous quality in the mixture of two dissimilar water supplies. The optimization of this device is sought in terms of mixing qualities and minimum energy losses.

(f) Concluded.

(g) Detailed investigations of a mixing chamber containing a larger inner cylinder with a number of ports were conducted. The chamber performed satisfactorily and the mixing was found to be complete and uniform with respect to time a short distance downstream from the chamber.

(h) "Flow Behavior in Large Pipe-Junction Structures," K.C. Reynolds, J. Amorocho, A. Babb, and B. Cole, WS and E Paper No. 1015, Univ. of Calif., Dec. 1966.

(6657) CASTAIC DAM SPIILWAY.

(b) Dept. of Water Resources, State of Calif.

(c) Prof. J. Amorocho, Dept. of Water Science and Engrg., Univ. of Calif., Davis.

(d) Hydraulic model investigations for design development.

(e) Investigation of flow behavior of spillways and energy dissipators for the Castaic Dam of the California Water Project.

(6658) CASTAIC INTAKE TOWER.

(b) Dept. of Water Resources, State of Calif.

(c) Prof. J. Amorocho; see (6657) above.

(d) Hydraulic and air model investigations for design development.

(e) Investigation of the hydraulic performance of a high intake tower with multiple lateral inlets at various levels. These studies include the investigation of vibrations in the tower due to unsteadiness in the flow, associated particularly with the operation of the lateral intakes at various reservoir elevations.

(6659) CASTAIC DAM DIVHRSION AITD RELEASE SYSTEM.

(b) Dept. of Water Resources, State of Calif.

(c) Prof. J. Amorocho; see (6657) above.

(d) Hydraulic model investigations for design development.

(e) Investigation of diversion scheme for the Castaic Dam during construction and use of elements of the diversion structures for the permanent release system, which includes closed conduit bifurcations and fixed cone values.

(6660) CEDAR SPRINGS SPILLWAY AND OUTLET WORKS.

(b) Dept. of Water Resources, State of Calif.

(c) Prof. J. Amorocho, Dept. of Water Science and Engrg., Univ. of Calif., Davis. (d) Hydraulic model investigation for design development.

(e) Investigation of flow behavior of a spillway and outlet works for Cedar Springs Dam.

(6661) TTEHACHAPI PUMPING PIANT INTAKE.

(b) Dept. of Water Resources, State of Calif.

(c) Prof. J. Amorocho; see (6660) above.

(d) Hydraulic model investigation for design development.

(e) Investigation of flow patterns in the intake area of the Tehachapi pumping plant of the California Water Project.

(ז) Completed.

(g) A variety of transitions and configurations were studied for the linkage between the main supply canal and the pumping plant forebay area. These studies indicate that although the flow could not be directed axially towards the pump intakes of the plant, the transversal velocities past the intakes were relatively low and did not cause any problems with respect to pump suction.

(h) "Hydraulic Studies of the Tehachapi Pumping Plant Intake Channel and Manifold," J. Amorocho, J.J. DeVries, and W. Curry, Proc., Western Water and Power Symp., April 1968, Los Angeles, Calif.

(6662) TEHHACHAPI DISCHARGE ITIE MANIFOLDS.

(b) Dept. of Water Resources, State of Calif.

(c) Prof. J. Amorocho; see (6660) above.

(d) Hydraulic model investigations for design development.

(e) Investigation of the effects of various pump manifold geometries on the energy losses and on the possibility of vibration at the branch junctions due to vortex shedding.

(6663) TEHACHAPI SURGE TANK.

(b) Dept. of Water Resources, State of Calif.

(c) Prof. J. Amorocho; see (6660) above.

(d) Hydraulic model investigation for design development.

(e) Investigation of the discharge characteristics of various alternative types of orifices for a surge tank for the penstocks of the California Aqueduct over the Tehachapi Mountains. The orifice performance will be studied for various conditions of steady and unsteady, forward and reverse flow.

(g) Head losses through various orifice configurations under steady state conditions were determined.

(h) "Hydraulic and Structural Design of the Tehachapi Surge Tank," A. Babb, R.W. Wright, R. Blunden, and R.K. Jain, Proc., Western Water and Power Symp., April 1968, Los Angeles, Calif.

(6664) THEORY OF THE DESIGN OF PRECIPITATION NETWORKS FOR HYDROIOGIC AITALYSIS.

(b) Water Resources Center, Univ. of Calif.

(c) Prof. J. Amorocho; see. (6660) above.

(d) Theoretical and experimental investigation; basic and applied research.

(e) Experimental and analytical studies for the determination of the optimum design of precipitation networks for hydrologic analysis.

(g) A method has been developed for the characterization of precipitation patterns near ground level. This method leads to the description of the distribution of rainfall intensities as a function of space and time and permits quantitative measures of the accuracy of description of the field as a function of 
network density. An experimental network is now in operation in North Central California in connection with this project.

(h) "The Representation of Storm Precipitation Fields Near Ground Ievel," J. Amorocho and A. Brandstetter, J. Geophys. Res. 72(4):1145-1164, Feb. 15, 1967.

"The Effect of Density of Recording Rain Gauge Networks on the Description of Precipitation Patterns," J. Amorocho, A. Brandstetter, and Don Morgan, Proc. Int'1. Assoc. of Scientific Hydrology, Int'l. Union of Geodesy and Geophys. 14th General Assembly, Bern, Switzerland, 1967.

(6665) OPTIMIZATION OF CONJUNCTIVE SURFACE AND GROUND WATER USE.

(b) Univ of California.

(c) Dr. V.H. Scott, Dept. of Water Science and Engrg., Univ. of Calif., Davis.

(d) Theoretical and field research. Applied research including doctoral thesis studies.

(e) The following studies are in progress: (1) Development of an operating schedule of a water distribution system including surface and ground water supplies for the purpose of optimizing long-term benefits; (2) A study of water quality control by progranmed conjunctive use of water supplies of different salt content.

(g) (1) A numerical computer solution of the hydrologic balance in a two-aquifer system including groundwater transfer and infiltration of imported surface water was developed; (2) Numerical solutions for recharge into confined or unconfined aquifers were developed and presented in dimensionless form; (3) Guidelines for determining a cyclic pumping schedule to achieve a desired minimum residual drawdown were developed and presented in graphical form; (4) The theoretical phase of a study on the comparative capacity and cost of recharge wells versus shallow ditches was completed and the results published; (5) A report on ground water conditions and pumping tests performed near the city of Patterson in the San Joaquin Valley, California, was prepared and published. (6) Algorithms are being sought for an approach to optimize a comprehensive system of surface and ground water resources on the basis of long-term benefits with particular attention given to economizing on computer storage requirements.

(h) "The Hydrologic Balance of a Two-Aquifer System under Integrated Use of Surface and Ground Water," N.J.Atallah, D. Eng. Thesis, Univ. of Calif., Davis, 1966.

"A Solution for Determination of Aquifer Characteristics and Unsteady Flow through Injection Wells by Numerical Methods, "H. Esmaili, D. Eng. Thesis, Univ. of Calif., Davis, 1966.

"Cyclic Pumping for Drainage Purposes," G. Aron, V.H. Scott, and M.A. Abu-Zied, NWWA Ground Water Jour. Vol. 5, No. 1, Jan. 1967. "Aquifer Recharge Efficiency of Wells and Trenches," V.H. Scott and G. Aron, NWWA Ground Water Jour. Vol. 5, No. 3, July 1967. "Drainage by Wells - An Investigation in the Patterson Water District," V.H. Scott, M.A. Abu-Zied, J.N. Luthin and G. Aron, Hilgardia, Vol. 30, No. 10, Sept. 1967.
UNIVERSTTY OF CALIFORNIA, LOS ANGELES, Dept. of Engineering, Los Angeles, Calif. 90024

(6733) INVESTIGATION OF TUNNEL DEPOSITS CAUSING OBSTRUCITION TO FLOW IN THE COLORADO RIVER AQUEDUCT SYSTEM.

(b) Laboratory project supported by the Univ. of Calif. Water Resources Center, and the Metropolitan Water District of Southern Calif.

(c) A.F. Pillsbury, A.F. Bush, Andrea Balla, Dept. of Engrg., U.C.I.A.

(d) Applied research.

(e) (g) Research and investigation into the nature of deposits formed on the Colorado River Aqueduct tunnels has been performed and recommendations for control formulated.

The deposit in time becomes thick enough to cause roughness and impede the water flow, thus producing a decrease in flow rate to a point where it becomes necessary to shut down delivery and clean the system, giving economic modification to this research. Deposits near the River were thicker than the deposits closer to the end of the system near Lake Matthews. Analysis of these deposits indicated a highly carbonaceous material precipitated from the water slowly over a long period of time. Some samples showed a heavy involvement of biological activity, such as algae and other minute forms of life. It is still not clear whether the biological growths encountered are the cause of the deposit or the result of being trapped in the deposit as it is being formed.

In the initial stages the deposit is sort, but as it dries out on dewatering, it becomes firm and more difficult to remove. The chemical analyses of deposits indicate calcium carbonate as the predominant material in all cases. Silica was present in varying amounts from 2 to 15\%. Other metallic oxides were present to a small degree. Sulphates were present in only trace amounts. Carbonaceous deposits also occurred in the open channels from the reservoir and on the rocks in the River. They were found on the metal surfaces, on the asphalt coated surfaces, and on the brass surfaces on the pump and impeller. Analysis of the Colorado River water under the conditions encountered in the system showed a positive saturation index with a tendency for precipitation; in other words the water was saturated at the pH-temperature encountered and was capable of producing a deposit. The delicate balance between the conditions for deposition and for dissolving of deposits is worthy of considerable study to determine what can be done to discourage deposition without attacking the concrete surfaces of the tunnels.

Research on the mechanism of carbonate deposition in calcium silicate hyorates is underway and may contribute significantly to our understanding of the deposition mechanism. The mechanism of control for chemical deposition might be the addition of carbon dioxide in the tunnels since this would shift the equilibrium and decrease the tendency of deposition. The second possibility of control would be the addition of acid to shift the pH slightly and thus decrease the deposit. Such chemical control could aid in keeping the tunnel surfaces clean, but would not be practical in removing deposits already accunulated. 
(h) Final report to be published.

UNIVERSTTY OF CAIIFORNIA, SAN DIEGO, see SCRIPPS INSTITUTION OF OCEANOGRAPHY.

THE CATHOLIC UNIVERSITY OF AMERICA, Dept. of Civil Engrg., Washington, D. C. 20017.

(3031) HYDROLOGY OF GREAT IAKES-ST. IAWRENCE RIVER BASIN.

(b) Laboratory project.

(c) Dr.B.S. Browzin, Prof. of Civil Engrg., Catholic Univ. of America.

(d) Basic research.

(e) Research is based on long range flow and meteorologic record. Flow and precipitation data on U.S. and Canada stations were statistically investigated in order to establish basic long range hydrologic characteristics of the basin.

(f) Was completed in 1966. New publications resulted from continuation of the research after 1966.

(g) Coefficients of variation and of asymmetry of monthly and of annual discharges were calculated, and their relation to climatic factors explained. Average, maximum and minimum runoffs for the period of available observations are analyzed. Historical variation of flow and that of climatic factors were investigated.

(h) "Annual Runoff in the Great Iakes-St. Lawrence Basin." Proc., Ninth Conf. on Great Lakes Research, Toronto, 1966, Great Lakes Res. Div., Univ. of Michigan., Publ. No. 15, pp. 203-215.

"Comparative Study of Snow Type Hydrology of Northeastern Canada and of Plains of Russia and Siberia," Proc., XIV General Assembly, Intl. Union of Geodesy and Geophysics, Berne session, Switzerland 1967.

THE CATHOIIC UNIVERSITY OF AMERICA, Dept. Of Space Science and Applied Physics, Washington, D.C. 20017.

(6448) HYDRODYIAMICS OF IIQUID-LIQUID INTIRRFACE.

(b) National Science Foundation.

(c) Assoc. Prof. Timothy W. Kro, Dept. of Space Science and Appl. Physics, The Catholic Univ. of America.

(d) Experimental and theoretical basic research; M.S. and Ph.D. thesis.

(e) Stability and mixing of two liquids in parallel shear flow.

(f) First stage completed; continuing.

(g) The stability of oil and water interface is found to be a manifestation of the instability in the water phase.

(h) "Role of the Interface in the Stability of Stratified Flow Down an Inclined Place," Timothy W. Kao, Phys. of Fluids, 8, 21902194, Dec. 1965.

"Stability of Gravity-motivated Plane Poiseuille Flow of Tho Fluids," Timothy W. Kao and C. Park, Proc. IOth Midwestern Mechanics Conf., Ft. Collins, Colo., Aug. 1967. "Measurements of Mean Flow Profiles and Stability of the Co-current Flow of Two Immiscible Liquids," Timothy $\mathrm{W}$. Kao and $\mathrm{c}$.
Park. Tech Rep. 67-032, Dept. of Space Science and Appl. Physics, The Catholic Univ. of America, Washington, D. C., Nov. 1967. "Role of Viscosity Stratification in the Stability of Two-Layer Flow Down an Incline," Tech. Rept. 67-031, Dept. of Space Science and Appl. Physics, The Catholic Univ. of Amer., Washington, D.C., Nov. 1967.

(6449) EXPERIMENTAL STUDY OF A WEAK TURBULENT FIELD.

(b) National Aeronautics and space Admin.

(c) Prof. S.C. Ling, Dept. of Space Science and Appl. Physics, The Catholic Univ. of America.

(d) Experimental basic research; Ph.D. thesis.

(e) To study decay of turbulence created behind a grid.

(6450) FREE SURFACE PIANING.

(b) National Science Foundation.

(c) Asst. Prof. Paul Rispin, Dept. of Space Science and Appl. Physics, The Catholic Univ. of America.

(d) Theoretical basic research.

(e) Non-linear free surface problem.

(g) Singular perturbation method is applicable.

(6451) DYIAMICS OF ATMOSPHERIC VORTICES.

(b) National Science Foundation.

(c) Prof. C.C. Chang, Head, Dept. of Space Science and Appl. Physics, The Catholic Univ. of America.

(d) Experimental and theoretical basic and applied research; M.S. and Ph.D. thesis.

(e) Vortex motion over a fixed flat boundary.

(g) Measurement of turbulent boundary layer flow created by a vortex over a fixed plat plate. Numerical studies.

(h) "A Numerical Computation of a Confined Vortex," H.P. Pao, Tech. Rep. 67-024, Dept. of Space Science and Appl. Physics, The Catholic Univ. of America, Washington, D. C., April 1967. "On the Stability of a Revolving Conducting Fluid in a Circular Magnetic Field," Proc. loth Midwestern Mechanics Conf., Ft. Collins, Colorado, Aug. 1967.

"Sources and Sinks at the Axis of a Viscous Rotating Fluid," H.P. Pao and T.W. Kao, Tech. Rep. 66-012, Dept. of Space Science and Appl. Physics, The Catholic University of America, Washington, D. C., July 1966.

UNIVERSITY OF CINCINNATI, Department of Civil Engrg., Cineinnati, ohio 45221.

(6460) EROSION AT THE OUTLET OF CULVERTS.

(b) Ohio Department of Highways.

(c) Dr. Louis M. Laushey, Univ. of Cincinnati.

(d) Experimental; applied research; for master's theses.

(e) Experimental study of incipient erosion velocity at the outlet of culverts, the amount scoured, and the time-rate of scour, for granular beds.

(f) Completed, and inactive.

(h) Results published in papers $\mathrm{C}-1, \mathrm{C}-24$, and C-39, Proc. Twelfth Congr., IAHR, Ft. Collins, Colorado, September 1967.

(6461) AERATION OF RIVERS.

(b) In cooperation with Ohio River Division, Corps of Engineers.

(c) Dr. Herbert C. Preul, Univ of Cincinnati. 
(d) Experimental; applied research; laboratory and field measurements.

(e) Study of reaeration of rivers at gated structures. Oxygen uptake is measured with different discharges, gate openings, and submergences. Purpose is to determine optimum operation of gates to maximize reaeration.

(6462) UNSTHADY F'LOW.

(c) Dr. Louis M. Laushey, Univ. of Cincinnati.

(d) Experimental and theoretical; laboratory measurements; for master's thesis.

(e) Measurements in ground water tank and HeleShaw apparatus to confirm equations for unsteady flow and to determine the friction during unsteady flow.

(h) Progress report published in the Proc., Symp. of the IASH, Bern, Switzerland, October 1967.

(6463) GROUNDWATER CONTAMINATION.

(b) U.S. Public Health Service.

(c) Dr. Herbert C. Preul, Univ . of Cincinnati.

(d) Experimental; laboratory and field.

(e) Measurements of amount of contamination and travel velocity of contaminants in ground water under a polluting sanitary land fill.

(6464) MODELS OF RIVER BASINS.

(b) Southwestern Ohio Water Company.

(c) Drs. Herbert C. Preul and Louis M. Laushey.

(d) Experimental and theoretical; laboratory and field; for master's thesis.

(e) Construction of an electrical analogue, a computer solution, and a mathematical model for an aquifer in the Miami River Basin. objective is to develop criteria and methods for the optimum management of the aquifer.

UNIVERSITY OF CINCINNATI, Dept. of Chemical and Metallurgical Engrg., Cincinnati, Ohio 45221.

(6138) BLOOD FIOW PROPERTTES.

(b) Laboratory project.

(c) Dr. Daniel Hershey, Assoc. Prof. of Chem. Engrg., Dept. of Chem. Engrg., Univ. of Cincinnati.

(d) Experimental and theoretical; basic and applied research; M.S. and Ph.D. theses.

(e) Steady and pulsatile flow properties of blood in rigid and distensible tubes.

(h) "Laminar Regime Transition for Blood Flow in Tubes," Biorheology Jour., 4, 61-67, 1967. "Blood Flow in Rigid Tubes:" Thickness and Slip Velocity of Plasma Film at the Wall," J. Appl. Physiol. 21, 27-32 (1966).

"Wall Phenomena for Flow of Suspension (Blood) in Rigid Tubes," Chemical Engrg. Prog. Symp. Series: Chemical Engrg. in Medicine, Vol. 62, No. $66,1366, \mathrm{pp} .139-145$.

"Friction Factors and Pressure Drop for Sinusoidal Laminar Flow of Water and Blood in Rigid Tubes," A.I.Ch.E. Jour., 13, 491-6 (1967).

"Analytical and Experimental Description of Blood Flow," Digest of 7 th Int. Conf. on Med. and Biol. Eng., 374, Stockholm, 1367.

CLARKSON COLIEGE OF TECHNOLOGY, Department of Chemical Engrg., Potsdam, N. Y. 13676.

(6331) MECHAINISMS OF DISPERSION. (b) Office of Saline water.

(c) William N. Gill, Prof. and Chmn. of Chemical Engrg., Clarkson Coll. of Tech.

(d) Combined theoretical and experimental; basic research

(e) One of the purposes of this investigation is to delineate the fundamental mechanisms of dispersion for well defined flows in a variety of physical configurations. This information will then be generalized to describe the dispersion processes in porous media. Another purpose of this work is to establish generalized methods of mathematical analysis for the description of multiphase convective diffusion systems.

(h) Ananthakrishnan, V., W.N. Gill and Allen J. Barduhn, "Laminar Dispersion in Capillaries: Part I. Mathematical Analysis", A.I. Ch.E. Jour., 11, No. 6, 1063-1072(1965).

Gill, W.N., and V. Ananthakrishnan, "Laminar Dispersion in Capillaries, Part II. Effect of Inlet Boundary Conditions and Turner Type of System Capacitance," A.I.Ch.E. Jour., 12, 906-915(1966).

Gil1, W.N., and V. Ananthakrishnan, "Laminar Dispersion in Capillaries, Part IV. The Slug Stimulus," A.I.Ch.E. Jour., 13, 801-807(1967). Gill, W.N., "Analysis of Axial Dispersion with Time Variable Flow," Chemical Engrg. Sci., 22, 1013-1017(1967).

Gill, W.N., "A Note on the Solution of Transient Dispersion Problems, "Proc. Roy. Soc., A298, 335-337(1967).

Reejhsinghani, N.S., Gill, W.N., and A.J. Barduhn, "Laminar Dispersion in Capillaries: Part III. Experiments in Horizontal Tubes Including Observations on Natural Convection Effects," A.I.Ch.E. Jour., 13, 916-921(1967).

COLORADO STATE UNIVERSITY, Civil Engineering section, Fort Collins, Colorado 80521.

Note: The Colo. State Univ. Hydrology Papers may be obtained (at $\$ 3.00$ per copy) by writing to: Hydrology Papers, Civil Engrg. Dept., Foothills Campus, Colo. State Univ., Fort Collins, colo. 80521.

(55) SNOW COURSE MEASUREMENTS AND FORECAST ANALYSIS.

(b) Soil Conservation Service; Colorado Agric. Expmt. Sta.

(c) Mr. Jack N. Washichek, Snow Survey Supervisor, Agricultural Engrg. Section.

(d) Field investigations; applied research.

(e) Systematic measurements of depth and water content of snow are being made at high elevations in Colorado and New Mexico mountain areas for the purpose of forecasting the runoff of the principal rivers in the interest of irrigation, power, domestic supplies and other uses. New snow courses have been established in the headwaters area of the Frying PanArkansas Project. It is hoped that the new snow courses will. enable this office to install automatic sensors in this basin to assist in forecasting water potentials for the project.

(g) Forecasts are now being issued at forty-four gaging stations in Colorado and New Mexico. As forecast procedures improve, additional streams will be forecasted and other areas of potential power and irrigation development will be investigated on the Colorado, San Juan, Animas and Arkansas Rivers. 
(h) Colorado Agric. Expmt. Sta. General Series Papers Nos. 842, 843, 844, 845 covering monthly snow reports for all of Colorado and New Mexico. Nine small basin reports and one two-state bulletin covering the South Platte River watershed; Arkansas River watershed; Rio Grande watershed in Colorado; Rio Grande watershed in New Mexico; Dolores River watershed; San Juan and Animas River watershed; Gunnison River watershed; Colorado River watershed; Yampa, White and North Platte River watershed; Lower South Platte River watershed. Supplemental reports are issued Jan. 1, May 15, and June 1. Progress reports on the Steamboat Springs Project and Progress reports on the Jemez Mountain Project in New Mexico. These are both Atmospheric Research Projects - "Summary of Snow Survey Measurements in Colorado and New Mexico".

(2846) STOCHASTIC HYDROLOGY. (See also No. 2812 in past issues).

(b) National Science Foundation.

(c) Dr. V. Yevjevich, Prof. of Civil Engrg.

(d) Theoretical; basic research.

(e) The studies relate to the stochastic structure of hydrologic time series. Annual, monthly and daily rainfall and runoff data have been studied and water quality parameters are also being studied.

(g) Several statistical methods, including spectral analysis, Markov models, and non-decreasing sample functions have been applied to hydrologic time series studies

(h) "An Objective Approach to Definitions and Investigations of Continental Hydrologic Drought," V. Yevjevich, Hydrology Paper 23, Colo. State Univ., Aug. 1967.

"The Application of Cross-Spectral Analysis to Hydrologic Time Series," I. Rodriguez-Iturbe, Hydrology Paper 24, Colo. State Univ., Sept. 1967.

"Mean Range of Linearly Dependent Normal Variables with Application to Storage Problems," V. Yevjevich, Water Resources Research, Vol. 3, No. 3, 1967, pp. 663-671.

"Reservoir Storage Capacity Required When Water Inflow Has a Periodic and Stochastic Component," P. Sutabutra, Ph.D. Dissertation, June 1967 .

"The Application of Cross-Spectral Analysis to Hydrologic Time Series," I. Rodriguez-Iturbe, Ph.D. Dissertation, Aug. 1967.

"Time Dependent Solutions for Water Storage Problem," R.I. Jeng, Ph.D. Dissertation, Dec. 1967.

"Characteristics of Distributions of Stochastic Variables for Daily and Monthly Runoff and Monthly Precipitation," J.J. Feline, M.S. Thesis, Sept. 1967.

The following papers appear in the Proceedings, International Hydrology Symp., Sept. 6-8, 1967, Ft. Collins, Colo., Vol. I (June, 1967): "Stochastic Description of Daily River Flows," R.G. Quimpo and V. Yevjevich, pp. 290-297. "A Particular Stochastic Process as Applied to Hydrology," Petar Todorovic and V. Yevjevich, pp. 298-305.

"The Statistical Measure of Hydrologic Time Series," Walter G. Knisel, Jr. and V. Yevjevich, pp. 306-313.

"Sunspots and Hydrologic Time Series," K. Rodriguez and V. Yevjevich, pp. 397-405. "Effects of Inconsistency and Non-Homogeneity on Hydrologic Time Series," V. Yevjevich and
R.I. Jeng, pp. $451-458$.

"Applications of Runs to Hydrologic Droughts," Richard N. Downer, M.M. Siddiqui and V. Yevjevich, pp. 496-505.

"Effects of Sampling Interval, Periodicity, Dependence and Skewness on Extreme Values," David F. Kibler and V. Yevjevich, pp. 537-545.

(4099) WAKE CHARACTERISTICS FOR BODIES OF REVOLUTION WITH MOMEITIM ADDITION.

(b) Navy Ship Research and Development Ctr.

(c) Dr. L.V. Baldwin, Dean of Engrg. and Prof. of Civil Engrg., Colo. State Univ..

(d) Experimental, theoretical; basic research.

(e) Trurbulent and mean flow characteristics of wakes formed behind axisymmetric and elliptical bodies have been studied experimentally in a wind tunnel using hot-wire anemometers. Theoretical studies have lead to explanations of all observed phenomena.

(i) Completed.

(h) "Comments on Three Dimensional Effects in Viscous Wakes," Yung-huang Kuo and L.V. Baldwin, AIAA Jour., Vol. 2, 1163-1164, June 1964.

"Instrument for Measuring the Intermittency of Quasi-Steady Signals," C.L. Finn and V.A. Sandborn, Colo. State Univ. Fluid Mech. Paper No. 3, Oct. 1964.

"Three-Dimensional Thurbulent Wakes," Yunghuang Kuo, Ph.D. Dissertation, Colo. State Univ., April 1965.

"The Decay of Turbulence in Axisymmetric Wakes," N.H.C. Hwang and L.V. Baldwin, Trans. ASME, Series D: J. Basic Engrg., Vol. 88, March 1966. "Diffusion and Decay of Turbulent Elliptic Wakes," Yung-huang Kuo and I.V. Baldwin, AIAA Jour., Vol. 4. 1566-1572, Sept. 1966. "The Formation of Elliptical Wakes," Yunghuang Kuo and L.V. Baldwin, Jour. Fluid Mech., Vol. 27, 353-360, 1967.

"Wake 'lurbulence far Downstream from an Axisymetric Body," N.H.C. Hwang, Ph.D. Dissertation, Colo. State Univ., Aug. 1966. "Intermittency of Far Wake Turbulence," L.V. Baldwin and V.A. Sandborn, AIAA Jour. note (pending).

(4106) GROUND-WATER RESERVOIR MANAGEMENT.

(b) Colorado Agricultural Experiment Station.

(c) D.K. Sunada, Asst. Prof., R.A. Longenbaugh, Asst. Prof.

(d) Theoretical and field investigation; applied research.

(e) It is the purpose to study the operating characteristics of ground water reservoirs in Colorado. Specific studies include (1) natural recharge from ephemeral streams, (2) electric analog study of High Plains aquifer, (3) evaluation of natural recharge to aquifers, (4) development of a general mathematical model, for solution on a digital computer, that can be adopted to particular ground water aquifers to relate the effect of the various parameters on the aquifer, and (5) mathematical model of inorganic ion movement in ground water aquifers.

(g) (1) Kiowa Creek data analysis reveals influence of ephemeral stream flow on irrigation wells. (2) Electric analog model has provided preliminary estimates on the quantity of water that can be pumped from the High Plains Aquifer. (3) Mathematical models have shown importance of priority of rights, aquifer characteristics, ground water pumping and consumptive demand on 
management of an integrated surface-ground water system.

(h) "Mathematical Model of a Stream-Aquifer System," R.A. Longenbaugh, presented at Third Amer. Water Resources Conf., San Francisco, Calif., Nov. 1967.

"Distribution of Ground Water Recharge," D.I. Reddell, M.S. Thesis, Colo. State Univ., June 1967.

"Irrigation Water Supply Management," L.F. Land, M.S. Thesis, Colo. State Univ., March 1967.

(5164) FIOW MEASUREMENT.

(b) Colo. Agric. Expmt. Sta.; Civil Engrg. Sect; and Northern Plains Soil and Water Conservation Research Div., ARS, U.S. Dept. Agric.

(c) Dr. H.J. Koloseus, Prof. of Civil Engrg., Colo. State Univ.

(d) Experimental laboratory and basic research which involves staff and graduate student participation leading to M.S. and Ph.D. degrees.

(e) This project has the general objective of developing and improving devices and techniques for the conduction and measurement of irrigation water. The present activities include: (1) Evaluation of head losses for various flow measuring devices, and (2) a further study of the circular hydraulic jump.

(g) Analytical considerations indicated that: (I) the sequent depth for the circular hydraulic jump is less than that for a jump in a rectangular channel. (2) the energy dissipation for the circular hydraulic jump is greater than that for the rectangular hydraulic jump. Preliminary experimental results tend to be in accord with these indications.

(h) "Circular Hydraulic Jump," D. Ahmad, M.S. Thesis, Colo. State Univ., June 1967.

(5165) HYDRAULICS.

(b) Colorado Agriculture Experiment Sta. and Civil Engrg. Section.

(c) Dr. D.B. Simons, Assoc. Dean for Research, Colo. State Univ.

(d) Basic research.

(e) This research is in hydraulics oriented toward agriculture and irrigation. The principal areas under study include fall velocity, sediment transport, resistance to flow in alluvial channels, turbulence and diffusion, and the mechanics of flow in alluvial channels.

(g) Reports covering certain phases of fall velocity in turbulent flows, channel stablization and resistance to flow in alluvial channels have been completed.

(h) "Stablization of Channels with Gravel," Wend, Fred H., Thesis, Dec. 1967.

"Resistance to F'low in Alluvial Channels," Simons, D.B. and Richardson, E.V., U.S. Geol. Survey Prof. Paper, 422-J, 1966. "Effect of Surface Texture on Fall Behavior of Cylinders and Disks in a Quiescent Fluid," Kumar, Ashok, Dissertation, March 1967.

"Fall Velocity of Spheres in Open Channel Flow," Kandala, Abdulahad S., Dissertation, Nov. 1966.

(5395) WATERSHED MANAGEMENT PRACTICES AFFECTING WATER SUPPIIES ON IRRIGATION PROJECTS.

(b) U.S. Bureau of Reclamation.

(c) R.E. Dils and J.R. Meiman, Colo. State Univ.

(d) Field investigation; applied research; and theses.

(e) The objectives of this study are: (I) to evaluate the use of dye solutions as a method of determining water yields from watershed subdivisions,(2) to test snow surface additives for the suppression of evaporation and control of snow melt and (3) to study such additional watershed management measures as are suggested by the work and which offer promise of successful application to Bureau projects.

(g) (1) A volume integration method of measuring weekly flow by the dye dilution technique has been developed. Substantial progress has also been made in developing a continuous recording system. (2) Evaporation suppression from melting snow for short durations has been achieved. Snowmelt has been approximately doubled over a several week period.

(n) Goodell, B.C. et al. 1967. "Streamflow Volumes and Hydrographs by Fluorescent Dyes," Papers: XIV Congress Int I. Union Forest Research Organizations, Munich, Germany, Section $01-02-11$, pp. 325-348.

Megahan, W.F. et al. 1967. "Net All-wave Radiation as an Index of Natural Snowmelt and Snowmelt Accelerated with Albedo Reducing Material," Proc. Int'1. Hydrology Symp., Ft. Collins, Colo. pp. 149-156. Meiman, J.R. 1967. "Iong-chain Alcohol Suppression of Snow Evaporation," ASCE Jour. Hydraulies Div., Vol. 93(HY 6), pp. 271-279.

(5396) EXPERTMENTAI ARTTHICIAL RECHARGE STUDYARICKAREE RIVER.

(b) Colorado Ground Water Commission.

(c) Mr. Robert Longenbaugh, Asst. Research Engr., Colo. State Univ.

(d) Experimental; applied research; design and operation.

(e) The purpose of this study is to determine the feasibility and practicality of artificial ground water recharge with Eastern Colorado ephemeral-stream flood flows using temporary low-cost structures. The project will include the design and evaluation of several different types of recharge structures.

(g) Structures were designed and constructed on two artificial recharge sites. Data were collected for two floods in June prior to the destruction of the project by the July 24 flood. Analyses of data and consideration on reconstruction of the project are underway.

(h) "Artificial Recharge on the Arikaree River Near Cope, Colorado," R.A. Longenbaugh, Dept. of Civil Engrg., Colo. State Univ., CER66RAL35, $12 \mathrm{pp} .1966$.

(5400) CHEMICAL SEAIING OF WATER CONVEYANCES.

(b) State of Colorado.

(c) Mr. R.D. Dirmeyer, Jr.

(d) Experimental and field investigation; applied research and development.

(e) The purpose of this project is to develop practical, fast and low-cost design procedures for utilizing chemicals, such as NaCl and MaCo, for pond sealing purposes. The work is including laboratory evaluations and field trials.

(g) Three field trials have been installed and are being evaluated.

(5404) REIMOTE SNOW MEASURING DEVICE.

(b) Jointly with Soil Conservation Service, Forest Service and U.S. Bureau of Reclamation.

(c) Jack N. Washichek, Snow Survey Supervisor, SCS, U.S. Dept. of Agriculture.

(d) Field investigation; operation and development. 
(e) Six automatic pillow sensors are in operation near steamboat Springs. Two other pillows are in operation at other locations. Different types of pillows as well as transducers are being investigated. The findings will dictate future installations. A new type sensor using the probe theory is also being investigated.

(g) Four of six sites failed last year due to pillow leaks or transducer failures. Some problems were encountered in the telemetry phase; however, most of these were mechanical and readily repaired.

(h) "Progress Report of Steamboat Springs Project"; "Progress Report of Jemez Mountain, New Mexico"; "Progress Report on Berthoud Pass Pillow Site."

(5407) WATERSHED ENVIRONMENT AND MICROBIAI DYMAMICS.

(b) Public Health Service; Federal Water Pollution Control Admin., U.S. Dept. of the Interior.

(c) S.M. Morrison, Prof. of Microbiology, Colo. State Univ., Dept. of Microbiology.

(d) Experimental, basic research.

(e) A study of the effects of physical and biological environmental factors upon the microbial dynamics of mountain water sources with emphasis upon improved laboratory and field methods. To gain information on the subject of surface water pollution by comprehensive study of the physical,chemical, and biological factors which affect the growth, survival, and distribution of bacterial organisms that are potential enteric pathogens or that are potential indicators of water pollution. Study area in field is the Cache Ia Poudre River at elevation 6000/9000 ft. Laboratory studies include refrigerator water-bath simulator of the microbial environment.

(g) In the 1967 study attempting to correlate physical, chemical, and microbiological factors in high mountain waters, accumulated data were statistically analyzed. Two separate mountain watersheds were used in the study for purposes of comparison. In both watersheds the previously reported high positive correlation between numbers of urease-positive organisms and ammonia nitrogen concentration was confirmed. Mean urease-positive numbers were also found to be highly correlated with densities of coliform, enterococcus and especially fecal coliform bacteria. These conmon index organisms and urease-positive numbers appeared to be enhanced by contact of the river waters with terrain highly productive in organic matter. Ureasepositive ammonia nitrogen correlations were sharply reduced in water which had been impounded in a storage reservoir. Enterococcus numbers and total bacteria densities were found to correlate with mean precipitation amounts. Mean turbidity of samples was found to be highest at sites with the highest mean densities of index organisms, total bacteria and unrease-positive bacteria. As previously reported, turbidity and conductivity were inversely related due in part to unchanged organic matter in the water.

A laboratory study showed that glycollic acid secreted by algae supports the growth of bacteria grown in algae-bacteria cultures. Studies on methods for the isolation of Clostridium from water by membrane filter were completed.

(h) Morrison, S.M. and J.F. Fair, "Stream Environment and Microbial Dynamics." A monograph, Colo. State Univ. Hydrology Series No. 13,
1-21, April 1966.

Morrison, S.M. and C.W. Hendricks, "Enteric Bacteria in Very Dilute Media at 16, 10 and $5^{\circ} \mathrm{C}, "$ Bacteriological Proc., 1966, $21-22$. Wendt, T.M. and S.M. Morrison, "UreaseProducing Bacteria in High Mountain Waters," Bacteriological Proc., 1967, p. 47. Hendricks, Charles W. and S.M. Morrison, "Strain Alteration in Enteric Bacteria Isolated from River Water," Canadian J. Microbiol. 13(3):271, March 1967.

Fair, J.F. and S.M. Morrison, "Recovery of Bacterial Pathogens from High Quality Surface Water," Water Resources Research 3(3):799-803, 1967.

Hendricks, Charles W. and S.M. Morrison, "Multiplication and Growth of Selected Enteric Bacteria in Clear Mountain Stream Water," Water Research. (In Press, 1967).

(5413) IMPACT OF IAND USE ON WATER QUAIITY WITHIN A FORESTED MOUNTAIN WATERSHED.

(b) Experiment Station; McIntire-Stennis.

(c) James R. Meiman.

(d) Field investigation; basic research and theses.

(e) The objectives of this study are to assess present water quality characteristics within a forested mountain watershed at varying natural flow regimes under land use conditions of limited development to non-use, and to measure the effects of multiple land use management--including road construction, logging, recreational developments, and grazing--on water quality.

(g) The assessment of present water quality is essentially completed. Road construction, fire, and grazing plus irrigation impacts were investigated during 1967.

(h) Kunkle, S.H. and J.R. Meiman, "Water Quality of Mountain Watersheds, "Hydrology Paper No. 2l, Colo. State Univ., 53 pp., 1967. Meiman, J.R. and S.H. Kunkle, "Land Treatment and Water Quality Control," Jour. Soil and Water Conserv. 22(2): 67-70, 1967.

(5878) DEVELOPMENT OF MATHEMATTCAI METHODS OF EVALUATION OF RESUITS OF ATMOSPHERIC WATER RESOURCES PROGRAMS.

(b) Bureau of Reclamation, U.S. Dept. Interior.

(c) Dx. H.J. Morel-Seytoux.

(d) Theoretical and applied research.

(e) The objectives of this research are: (1) to develop criteria for selecting mountainous drainage basins for general and experimental weather modification procedures; (2) to evaluate the hydrologic characteristics of river flows from basins selected for experimental weather modification purposes; and (3) to develop mathematical and statistical techniques for evaluating the attainments of experimental weather modification programs.

(h) "Statistical Evaluation of Weather Modification Attainments," Radmilo D. Markovic, Colo. State Univ. Hydrology Paper No. 16, 44 pp., Nov. 1966.

"Accuracy of Discharge Determinations," W.T. Dickinson, Colo. State Univ. Hydrology Paper No. 20, 54 pp., June 1967.

"Prediction of Water Yield in High Mountain Watersheds Based on Physiography," R.W. Julian, V. Yevjevich and H.J. Morel-Seytoux, Colo. State Univ. Hydrology Paper No. 22, Aug. 1967.

(5880) STUDY OF CHANGES IN WATER QUAIITY IN A GROUND WATER RESERVOIR. 
(b) Office of Water Resources Research.

(c) D.K. Sunada, Asst. Prof., Colo. State Univ.

(d) Field investigation; theoretical and applied.

(e) A field study was conducted near Severance, Colorado, to determine the extent and cause of their ground water quality problem. Development of research techniques and experience in ground water quality investigations was one of the principal goals.

(g) Ground water quality in the Severance area of Colorado is influenced by geology, fertilizer practices, feedlot contamination, oil field brine disposal and individual influences can not be differentiated.

(h) "Ground Water Quality Study of Severance Basin, Weld Country, Colorado," N.F. White and D.K. Sunada, Dept. of Civil Engrg., Colo. State Univ., 29 pp., April 1966.

(5885) HYDRAULIC INVESTIGATION OF FLEXIBLE TUBES.

(b) Kalium Chemicals Limited.

(c) Mr. B.P. Edmonds, Kalium; and Dr. A.H. Barnes, CSU.

(d) Experimental; development and applied research.

(e) The purpose of this study is to develop a nozzle of such a geometry that the hydrodynamic forces produced thereby will deploy a flexible hose under a free water-surface. The study is ( 1 ) to determine the hydrodynamic properties of various nozzle geometries; and (2) to determine the hose diameter-discharge relationships for a stable hose position.

(g) Nozzle geometries have been determined to produce predictable forces on the end of a hose. Additional field tests are proposed to be made.

(5886) DEVELOPMEIT OF TTELESCOPING TUBES FOR USE IN SOLUTION MINING.

(b) Kalium Chemicals Limited.

(c) George L. Smith (CSU); B.P. Edmonds, Mining Manager (Kalium Chemical Ltd.)

(d) Experimental, theoretical; applied research, design; development.

(e) The purpose of this study is to design, construct and test a telescoping tube with a reactive head at the discharge outlet; the telescoping tube to have an O.D. range from 3-1/4 to 1 in., and to be tested under various conditions of discharge and buoyancy.

(e) Completed.

(g) Development of telescopic tubes and theoretical curves for determining maximum length of the nested tubes for given $t / D$ - thickness/diameterand submergence conditions of fluids of different specific gravities. Maximum deflection of the pipes for given lengths and fluid characteristics has been determined also.

(h) "Theoretical and Experimental Investigation of Telescopic Tubes in Simulated Solution Mining," George L. Smith, Civil Engrg. Section, Colo. State Univ., CER66GLS16, March 1966.

(5887) STUDY OF THE HYDRAUTICS OF FLOW THROUGH SOLUTION CAVITIES.

(b) Kalium Chemicals Limited.

(c) Dr. E.P. Helvingston, Kalium; and Dr. A.H. Barnes, Colo. State Univ.

(d) Experimental and basic research.

(e) This is a basic observational study to (1) determine the characteristic of the fluid motion within a solution cavity; and (2) to identify those parameters relating geometry, discharge rate and specific gravity of the effluent brine from a solution cavity. Two experimental facilities have been constructed to observe the phenomena. Each represents an $18^{\circ}$ cylindrical sector of an assumed solution cavity, one approximately 8 inches high by 24 inches long and the larger 5 feet high by approximately 15 feet long. The ultimate purpose will be to better understand the physical process of solution mining as it applies to water-soluble salts.

(g) Preliminary quantitative studies have indicated the general pattern of circulation as predicted. Certain anomalies are attributed to the character of the salt blocks (livestock) used. Natural rock salt blocks will be used to observe whether or not the same phenomena exist.

(5891) DIFFUSION OF ENPRAPPED GASES IN RESPONSE TO INITERFACIAL ENERGY.

(b) National Science Foundation.

(c) A.T. Corey, Dept. of Agric. Engr., Colo. State Univ.

(d) Experimental and basic research.

(e) A study of the process whereby a gas in isolated pockets (surrounded by liquid) diffuses from porous media under the influence of interfacial energy. The purpose is to develop and to test equations describing the rate of diffusion of entrapped gas from porous media.

(g) Sufficient experimental data have been accumulated to permit an insight into the process whereby an entrapped gas disappears from porous media. Curves have been developed in terms of normalized length, time and liquid saturation which enable one to estimate the time required for full liquid saturation.

(h) A Colo. State Univ. Hydrology Paper is being prepared and should be available by March, 1968.

(5892) FLOW INIO SUB-SOIL DRAINS.

(b) Colo. State Univ. Agric. Exprnt. Sta. and Agricultural Research Service, U.S. Dept. of Agric.

(c) A.T. Corey, Dept. of Agric. Engrg., Colo. State Univ. and H.R. Duke, ARS, USDA.

(d) Experimental, theoretical; applied research and development.

(e) Techniques for modeling systems involving drainage from soils are being developed. These techniques are being used to evaluate present criteria for the design of subsoil drains. The purpose is to develop improved design criteria and, in particular, to develop criteria which will take into account flow in the partially saturated region above the water table.

(g) A theory of similitude for flow in partially saturated media (and applicable to drainage from soils) was developed. The criteria of similitude resulting from this theory were tested experimentally and found to be valid. The theory is now being used to determine design criteria for drains.

(h) "Properties of Porous Media Affecting Fluid Flow," R.H. Brooks and A.T. Corey, Jour. Irrig. and Drainage Div.,Proc. ASCE, Vol. 92, No. IR2, June 1966, pp. 61-88.

"Similitude for Drainage of Soils," G.L. Corey and A.T. Corey, Jour. Irrig. and Drainage Div., Proc. AsCE, Vol. 93, No. IR3, Sept. 1967. pp. 3-23. 
"Hydraulic Properties of Disturbed and UndisSoils," G.E. Laliberte and A.T. Corey, Amer. Soc. of Testing and Materials, Special Technical Publ. No. 417, 1967, pp. 56-71.

"Similitude for Non-Steady Drainage of Partially Saturated Soils," G.I. Corey, A.T. Corey, and R.H. Brooks, Colo. State Univ. Hydrology Paper No. 9, Aug. 1965.

"Properties of Unsaturated Porous Media," G.E. Laliberte, A.T. Corey and R.H. Brooks, Colo. State Univ. Hydrology Paper No. 17, Nov. 1966.

(6204) IAMINAR AND TURBULENT FLOW THROUGH POROUS MEDIA.

(b) National Science Foundation.

(c) Daniel K. Sunada, Asst. Prof.

(d) Theoretical; basic research.

(e) This investigation is conducted to study the influences of the physical properties of the fluid and porous medium on the fllow behavior of fluid flowing through porous media. Theoretical and experimental analyses of both compressible and incompressible fluids are being made for flow through consolidated and unconsolidated porous media.

(f) Active until December 1968.

(g) An equation representing the non-linear relationship between hydraulic gradient and flow velocities was developed from the NavierStokes equation. Two dimensionless parameters were developed from the flow equation and an unique relationship was shown to exist between them.

(h) "Physical Properties of Porous Medium Affecting Laminar and Turbulent Flow of Water, "N. Ahmed, Ph.D. Thesis, Colo. State Univ., June 1967.

(6206) FLOOD PROTECITION OF BRIDGES AND CULVERTS.

(b) Wyoming State Highway Department.

(c) Dr. D.B. Simons, Assoc. Dean for Research, Colo. State Univ.

(d) The project is primarily experimental with recourse to basic hydraulic principles whenever possible. Prototype verification is carried out for most phases of research. The work is primarily applied research. Information obtained will be used for both M.S. thesis and Ph.D. thesis.

(e) The purpose of this research is to develop design criteria and to establish the physical requirements of materials necessary to control erosion downstream of highway culverts, contracted bridge sections and other hydraulic structures. The principal areas under study are:

1. The dissipation rate of energy and velocity distribution downstream of culvert outlets in concrete lined and rip-rapped basins;

2. Prediction of water surface profiles of a free jet discharging from a closed conduit (both circular and rectangular) onto $a$ large horizontal surface;

3. The effect of artificial roughness elements on the rate of energy decay in basins;

4. The magnitude of scour in energy dissipating basins with the floor made up of materials of known gradation;

5. Protective material for bridge abutments and optimum channel training in the vicinity of contractions;

6. Substitute protective materials for regions where conventional rip rap is not economical.

(f) 1. (above) Work nearly complete, Interim Report 1 in preliminary stage.
2. (above) Experimental work $70 \%$ complete, analytic work $90 \%$ complete, one M.S. thesis in preliminary stage;

3. (above) Experimental work $50 \%$ completed;

4. (above) Experimental work $80 \%$ complete, one M.S. thesis in preliminary stage;

5. (avove) Not started;

6. (above) Not started;

(h) Interim Report 1 - preliminary stage; Interim Report 2 - preliminary stage.

(6478) CIAY CREEK MODEL STUDY.

(b) State of Colo. Game, Fish and Parks Cormission.

(c) M.M. Skinner, Asst. Prof. Engrg. Research Ctr., Colorado State Univ.

(d) Experimental; applied.

(e) A 1:36 scale, undistorted, hydraulic model of the Clay Creek Dasn and vicinity near Iamar, Colorado was constructed and tested at the Outdoor Modeling Facility. Approximately 2.6 acres were utilized. Terrain was stabilized with prime coat asphalt. The purpose was to reestablish the flow conditions that existed during the June 1965 Flood in the area and to investigate what flow conditions would have existed during the June 1965 Flood in the area had no dam been constructed.

(f) Completed.

(g) A 16-m movie was prepared to document the testing and construction and to illustrate the flow pattern for various model configurations.

(h) "Hydraulic Model Study of the Clay Creek Dam near Lamar, Colorado," M.M. Skinner.

(6479) IESTTNG OF A 12-INCH STEEL, TWO-STAGE, DEEPWELI, TURBINE PUMP.

(b) Bechtel Corporation.

(c) M.M. Skinner; see (6478) above.

(d) Experimental; appliea.

(e) The purpose of the study was to establish head-capacity, efficiency, and horsepower curves for the pump with certain impeller types and sump configurations.

(f) Completed.

(g) Maximum approach velocities in the relatively small sump arrangement were about $1 / 2$ foot per second. The water surface was quite stable and no visible vortex formation existed.

(h) "Results of the Testing of a 12-Inch Stainless Steel, Two-Stage, Deep-Well, Turbine Pump," J.F. Ruff and M.M. Skinner.

(6480) TESTING OF A 12"-BUTTERFLY VALVE AND A 12" BAIL VALVE.

(b) Santa Clara County Flood Control and Water District.

(c) M.M. Skinner; see (6478) above.

(d) Experimental; applied.

(e) Cavitation characteristics were investigated for both a 12"-Ball Valve and a 12"-Butterfly Valve with an abrupt enlargement downstream. Air and water injections were used in an effort to extend the operating range of each valve for non-cavitating conditions.

(i) Completed.

(g) Air injection proved quite effective in reducing cavitating at certain valve openings.

(h) "Results of the Testing of a 12-inch Ball Valve and a l2-inch Butterfly Valve with an Abrupt Enlargement Section," M.M. Skinner and J.P. Tuliis.

(OO2W) CHANGES IN THE PHYSICAL AND BIOLOGICAL CHARACTERISTICS OF GROUND WATER RESERVOIRS AND ADJACENT SURFACE WATERS (Formerly No. 5890). 
For summary, see Water Resources Research Catalog, Vol. 2, No. 5.0231.

(OO3W) MATHEMATICAL MODEIING OF SMALL WATERSHED FIOODS.

(b) Colorado State Univ. Experiment Station.

(c) Dr: V. Yevjevich, Prof. of Civil Engrg. and Dr. M.E. Holland, Asst. Prof. of Civil Engrg.

For sumary, see Water Resources Research Catalog.

UNIVERSITY OF COLORADO, Dept. of Civil Engineering, Boulder, Colorado 80302 .

(004W) ENGINEERING-HYDROLOGIC ANALYSIS OF WATER RIGHTS. (Formerly No. 5703).

(c) J.E. Flack.

For sumary, see Water Resources Research Catalog, Vol. 2, No. 6.0074.

(OO5W) ANALYSIS OF TOTAL WATER USE BY SELECTED CITTES AND INDUSTRY. (Formerly No. 5704).

(c) J.E. Flack.

For summary, see Water Resources Research Catalog, Vol. 2, No. 6.0075.

(OO6W) REGIONAL ENVIRONMENTS ON THE FAST SLOPE OF THE FRONT RANGE, COLORADO. (Formerly NO. 5702).

(c) J.W. Marr.

For summary, see Water Resources Research Catalog, Vol. 2, 2.0183.

COLUMBIA UNIVERSITY, Dept. of Civil Engrg. and Engrg. Mechanics, New York, N.Y. 10027.

(6054) VISCOUS FLOW IN A CYIINDRICAL TUBE CONIAINING A IINE OF SPHERICAL PARTICIES.

(b) Office of Naval Research.

(c) Prof. Richard Skalak, Dept. of Civil Engrg. and Engrg. Mech., Columbia University.

(d) Theoretical; basic research; doctoral thesis.

(e) Viscous flow in a circular cylindrical tube containing an infinite line of spherical particles equally spaced along the axis of a cylindrical tube is considered neglecting inertial terms, as a model of blood flow in capillary blood vessels.

(g) The results show that the drag and pressure drop for a given size of sphere decrease as the spacing between spheres increases and for spacings more than one tube diameter, there is little interaction between spheres.

(h) "Viscous Flow in a Cylindrical Tube Containing a Line of Spherical Particles," H. Wang and R. Skalak, ONR Proj. NR 062-393, Tech. Rep. No. 1, July 1967.

COLUMBIA UNIVERSITY, IAMONT GEOLOGICAT OBSERVATORY -.---See LAMONT

UNI VERSITY OF CONNECITCUT, School of Engineering, Storrs, Connecticut 06268
(5489) BOUND-ROCK EROSION PROTECTION FOR HIGHWAY DRAIITAGE DITCHES.

(b) Institute of Water Resources; and State Highway Dept.

(c) Prof. C.J. Posey, Box U-37, Univ. of Com.

(d) Experimental; applied.

(e) Develop application of scientific erosionprotection method to highway ditches. Experiments will provide necessary design data and develop construction methods for low-cost installations.

(f) Trial installation on route I-9I under observation.

(5492) DISCHARGE FROM CIRCUMF'ERENIIAL WEIRS.

(b) Department of Civil Engrg.

(c) Prof. C.J. Posey; see (5489) above.

(d) Experimental; master's thesis.

(e) Head measurements and nappe measurements for water flowing out of vertical pipes and spilling out over their horizontal peripheries.

(f) Completed.

(g) M.S. Theses available on loan from Wilbur Cross Library, Univ. of Conn., "Discharge Over a Circumferential Weir, "Chao Song Shu, 1965, and "Flow Over a Circular Weir," Joseph Cliver Elmer, 1967.

(5737) REDUCTION OF RIVER HFAT POLLUTION BY TURBUIENCE STIMUIATION.

(b) Institute of Water Resources.

(c) Prof. V.E. Scottron, Civil Engrg. Dept., Univ. of Conn.

(d) Experimental; applied research for master's and doctoral theses.

(e) The objective of this work is to break up stratification of heated river flows by generation of heavy turbulence. The laboratory program will investigate a variety of turbulence generating devices, including systematic roughness, in low-speed air flows.

(5738) STUDY OF DISTURBANCE ON THE FREE SURFACE OF ROTATING FLUIDS.

(b) Laboratory project.

(c) Dr. J.D. Lin, Civil Engrg. Dept., Box U-37, Univ. of Conn.

(d) Experimental and theoretical; basic research for both master's and doctoral theses.

(e) A theoretical and experimental study of the scattering of the disturbance generated on the free surface of rotating fluids. A rotating tank of $5^{\prime}$ in diameter and $3^{\prime}$ in depth is used for the experiments.

(5739) A STUDY OF VISCOUS FIOW PAST A SHIP.

(b) David Taylor Model Basin, Navy Department.

(c) Dr. J.D. Lin; see (5738) above.

(d) Theoretical, basic; and doctoral thesis.

(e) Calculation of potential flow over the hull of a ship generated by singularity distribution. Calculation of the boundary layer along the streamlines on the hull. Investigation of the wake and wave resistance of the hull form.

(g) Only intermediate results available.

$\left(k_{1}\right)$ "A study of Viscous Flow Past a Ship-like Body," J.D. Lin and R.S. Hall, Jr., Univ. of Conn., Civil Engrg. Rep. No. CE 66-7, 1966. "A Method of Calculation for the Local Disturbance Integral Due to Sources Under Lirearized Free Surface," J.D. Lin and H.D. Liang, Univ. of Conn., Civil Engrg. Rep. No. CE 67-17, 1967.

(5769) FTITER EROSION PROTECTION.

(b) Water Resources Institute. 
(c) Prof. C.J. Posey, Box U-37, Univ. of Conn.

(d) Basic research; experimental.

(e) To determine whether finest-grained noncohesive and/or cohesive materials can be protected by Terzaghi-Vicksburg inverted filter.

(6376) STUDY OF AN OPEN-CHANNEL SURFACE-FIIM PHENOMENON.

(b) Laboratory project.

(c) Prof. C.J. Posey; see (5769) above.

(d) Experimental; doctoral thesis.

(e) When stationary film forms upstream from an object obstructing the free surface of an open channel, does it cause boundary-layerlike velocity deficit?

CONRAC CORPORATION, Fluidics, Fairfield, N.J. 07006

Correspondence on all projects may be addressed to: Mr. Estaban Martinez, Manager, Fluidics, Conrac Corp., New Jersey Div., Sherwood Lane, Fairfield, N.J. 07006.

(6267) THE MECHANISM OF MASS ENIRAINMENT BY A JET IN THE NEIGHBORHOOD OF THE EXIT.

(b) Air Force Office of Scientific Research.

(d) Experimental; conceptual.

(e) A study of the stability of the boundary of a submerged incompressible jet and its effect on the entrainment of the surrounding fluid. Entrainment by the discrete vortices is evaluated and vortex roll-up rates are measured.

( $)$ Completed.

(g) From the theory of stability of the vortex sheet and the rate of growth of the discrete vortices, a simplified parabolic theory for the entrainment has been derived.

(h) "On Mass Entrainment By Jets - Phase I Preliminary Investigations," E. Martinez, AFOSR 660643, June 1966.

(6268) THE EFFECT OF DISTURBANCES OF A JET BOUNDARY ON ITS ENTRAINMENT PROPERTIES.

(b) Air Force Office of Scientific Research.

(d) Experimental.

(e) A study of the effect of sinousoidal disturbances on the entrainment and spreading of a submerged incompressible jet. Mass entrainment was measured directly in the bubble created by a reattaching jet in a rearward facing step, for various frequencies and amplitudes of the disturbances.

(f) Completed.

(g) Substantial augmentation of the entrainment rate of a jet can be accomplished by lowpower stimulation of its boundaries at certain critical frequencies that are a function of the Reynolds number.

(h) "On Mass Entrainment By Jets - Phase II The Effect of Sound on Jets," E. Martinez, AFOSR 67-0337, Jan. 1967.

(6269) THE EFTECT OF VELOCITY PROFILE ON THE FLOW IN A STRAIGHT CHANNEL WITH SECONDARY-FLOW INJECTION.

(b) Air Force Office of Scientific Research.

(d) Theoretical; applied research.

(e) A simplified, two-parameter description of the velocity profile in the channel is used to predict the distribution of momentum downstream of injection of a secondary flow perpendicular to the main flow.

(f) Completed. (h) "The Effects of Velocity Profile on the Flow in a Straight Channel with Injection," W. Selden Seunders, AFOSR 66-0887, Feb. 1967.

(6270) THE MOMENTUM EQUATION OF A SOLTD-FLUID SYSTEM.

(b) Air Force Office of Scientific Research.

(d) Theoretical; basic research.

(e) A derivation of the momentum equation for a solid-fluid mixture from first principles, to account for the varying "effectiveness" of the momentum transfer from the solid to the fluid phase as a function of slip Reynolds number, loading ratio, etc.

(f) Completed.

(g) The application of the momentum equation to a stagnating flow such as a close-ended pipe, shows that a distribution of pressure in excess of the dynamic value exists, due to the presence of solids in the fluid.

(h) "The Momentum Equation of a Solid-Fluid System," E. Martinez, AFOSR 67-0657, Mar. 1967.

(6271) OSCITTATING JETS.

(b) Air Force Office of Scientific Research.

(d) Experimental; applied research.

(e) A study of the mass entrainment and rates of spreading of a submerged oscillating incompressible jet as a function of the frequency and amplitude of the oscillation.

(6272) MINIMIZING PRESSURE LOSSES IN DUCTS AND CHANNELS WITH PERIODICALLY VARYING CROSSSECTION.

(b) Air Force Office of Scientific Research.

(d) Experimental; conceptual.

(e) To determine the mechanism behind the pressure drop in ducts and channels with re-entrant walls and lateral cavities. The influence of the aspect ratio of the cavities on the pressure losses is examined.

(g) The stability of the vortex patterns in the cavities appears to have a strong effect on the overall pressure drop. Vortex patterns are not stable and pressure drops are at a minimum when cavity aspect ratio approach unity.

(6273) SELF-EJECTING BOUNDARY LAYER FLOWS.

(b) Air Force Office of Scientific Research.

(d) Theoretical and experimental; basic research.

(e) A study of internal flows of incompressible fluids with permeable boundaries. The case of a constant cross section pipe with walls of uniform permeability is analyzed and results are compared with experimental data.

(6274) THE CONIROL OF IARGE-SCALE FLOWS WITH SECONDARY FLOWS.

(b) Laboratory project.

(d) Experimental; applied research.

(e) The following applications are investigated: (1) temporary increase in dam or reservoir capacity (2) wave suppression (3) mass transport in a driven vortex in a large body of water (4) portable drydock.

CORNELL AERONAUTICAL IABORATORY, INC. OF CORNELI UNIVERSITY, P.O. Box 235, Buffalo, N.Y. 14221

(5363) UNSTEADY FORCES AND MOMENTS ON A TWODIMENSIONAL FULLY CAVITATED HYDROFOIL.

(b) Naval Ship Research and Development Ctr., and 
Off. of Naval Research, Dept. of the Navy.

(c) Dr. Irving C. Statler, Head, Appl. Mechanics Dept., Cornell Aeronautical Iab., Inc.

(d) Applied research; theoretical.

(e) The purpose of the project is to determine the steady and unsteady forces and moments on a fully cavitated hydrofoil operating near a free surface. The approach being taken is based on a linearized flow model of a fully cavitating flat plate which is in steady or harmonic motion near a free surface. Full account is taken of the gravity waves generated by the motion of the foil and cavity and cavitation numbers greater than or equal to zero are considered.

(h) "A Note on the Problem of an Oscillating Supercavitated Hydrofoil Near a Free Surface," J.M. Grace and I.C. Statler. Cornell Aero. Lab. Rept. No. BB-1935-S-1, October 1965. "A Theoretical Study of the Force and Moment on an Oscillating Supercavitated Hydrufoil Near a Free Surface," C. Tung and I.C. Statler. Cornell Aero. Lab. Rept. No. BB-2395-S-1 (in preparation).

(6177) WATER RESOURCES STUDY: A BENEFIT COST INVENTORY.

(b) Iaboratory project.

(c) Mr. Hans G. Reif, Research Economist, Operations Research Dept., Cornell Aero. Lab., Inc.

(d) Theoretical; operations research.

(e) The purpose of this study was to develop a conceptual methodology leading to the selection of a set of treatments and actions for providing 'good water' at the least cost to users located along a water resource. A condidate set of treatments and actions is defined as one that eliminates interference between successive water users and satisfies the designated water resource standard. Water treatment by the users was based on specified water resource quality requirements at the user locations rather than a uniform code or regulations applicable to all users and along the entire resource. Water quality standards served to define the overall quality of the water resource to be maintained which includes the quality of the water at the terminus or outflow of the water resource region. Thus, the treatment required by users was a function of water use; waste discharge; the location along the water resource; the location, water requirements and waste discharges of other present and anticipated future water users; the current status and assimilative capacity of the water resource; and the established quality standards.

(f) Completed.

(g) A methodological approach for the selection of treatments and actions for providing 'good water' to users along a water resource.

(h) "An Economic Approach to Water Quality Management," H. Reif, Final Rept. RM-2342-0-Z, Cornell Aero. Lab., August 1967.

(6178) A IABORATORY AND FIEID STUDY OF THE EFFECT OF WAVES ON THE EVAPORATION FROM A FREE WATER SURFACE.

(b) Bureau of Reclamation, Dept. of the Interior.

(c) Mr. Calvin Easterbrook, Principal Physicist, Appl. Physics Dept., Cornell Aeronautical Iab., Inc.

(d) Applied research; experimental, laboratory and field. (e) This study has been directed towards evaluating the effects of waves on a water surface on the evaporation rate from that surface. The work began as a laboratory study, wherein measurements were made using a large wavetank and wind-tunnel combination. The apparatus was designed so that both wind speed and wave parameters could be controlled. Waves were generated in the tank by a hydraulically driven paddle, thus permitting simulation of conditions associated with larger bodies of water (fetches up to a mile or more). The project was extended to include field studies at Lake Hefner in Oklahoma. Here wind, wave and evaporation data have been acquired which will permit computation of parameters comparable to those measured in the laboratory work.

(g) Results of the laboratory experiments show that evaporation rates are reduced under certain combinations of waves and wind speed. Preliminary analysis of the field data tend to support the laboratory findings. The influence of waves on evaporation rate appears to be caused by modification of the air flow over the water surface in a manner which reduces the vertical transport of water vapor in the boundary layer.

(h) Final report to be available in Feb. 1968.

(6179) DEEP SUBMERGENCE RESCUE VEHICLE SIUDIES.

(b) Naval Ship Systems Command, Dept. of the Navy.

(c) Mr. T. Haselton, Staff Engr., Applied Mechanics Dept., Cornell Aeronautical Lab., Inc.

(d) Applied research; experimental.

(e) The purpose of this project is to continue the investigation of the performance characteristics of tandem propellers in developing roll control, to verify the theory that increases in vehicle velocity in any direction orthogonal to the propeller axis cause an increase in control force to power ratio, and to investigate the "anti-mud" mode of operation in near silt-bottom hovering operations of underwater vehicles.

(g) A final report of our findings is in preparation.

CORNELI UNIVERSITY, School of Civil Engineering, Ithaca, New York, 14850

\section{(4531) SECONDARY CURRENTS IN NON-CIRCULAR CONDUITS.}

(b) National Science Foundation.

(c) Dr. J.A. Liggett, Hollister Hall, Cornell Univ.

(d) Theoretical and experimental.

(e) Those secondary currents caused by Reynold's stresses in straight, non-circular conduits are being studied. A triangular open channel is being used. Measurements are to be taken by the hot-film anemometer.

(g) A quantitative theory has been developed and is being tester.

(h) "Secondary Currents in a Corner," J.A. Liggett, C.I. Chiu, and L.S. Miao, Jour. Hyd. Div., ASCE, Vol. 91, No. HY6, Nov. 1965, p. 99. "Flow in a Sharp Corner," R.J. Matthews and J.A. Liggett, Jour. Hyd. Div., ASCE, Vol. 93, Nov. 1967.

(5302) SETTIING VELOCITIES OF SUSPENDED SOLIDS IN A TURBULENT ENVIRONMENT.

(b) U.S. Public Health Service.

(c) Dr. J.A. Iiggett, Hollister Hall, Cornell Univ.

(d) Theoretical and experimental; basic and applied research. 
(e) The research concerns the effect of turbulence on suspended solids and the rate of settlement of suspended solids.

(5303) RECESSION HYDROGRAPHS OF IDEALTZED UNCONFINED AQUIFERS.

(b) Laboratory project.

(c) Dr. W.H. Brutsaert, Hollister Hall, Cornell Univ.

(d) Experimental and theoretical.

(e) A Hele-Shaw model has been constructed to study the different parameters affecting drainage from large unconfined geological formations into stream channels. The obtained ground water recession hydrographs are compared with those derived from previous theoretical, but approximate, solutions. New theoretical analyses are being developed.

(h) "Inflow Hydrographs from Large Unconfined Aquifers," H.A. Ibrahim and Wilfried Brutsaert, Jour. Irrig. and Drainage Div., ASCE, Vol. 91, IR2, June 1965, p. 21.

"On the First and Second Linearization of the Boussinesq Equation," Wilfried Brutsaert and H.A. Ibrahim, Geophys. Jour. Roy. Astr. Soc., Vol. 11, 549-554, 1966.

(5305) THE PHYSICAL PHENOMENA INVOLVED IN PAN EVAPORATION.

(b) Laboratory project.

(c) Dr.W.H. Brutsaert; see (5303) above.

(d) Theoretical and experimental.

(e) Evaporation is being measured from a number of insulated shallow pans of different sizes and colors. These experimental results and simultaneous climatological data will be used to check and extend some theoretical models of the hydrodynamics--and also of the energy budget aspects of pan evaporation and evaporation in general.

(h) "Some Mass Transfer Aspects of Pan Evaporation," Wilfried Brutsaert and S.L. Yu, Trans. A.G.U., Vol. 48, 96, 1967.

"Evaporation from Very Shallow Pans," S.L. Yu and W. Brutsaert, Jour. Appl. Meteor, Vol. 6, 265-271, 1967.

"A Model for Evaporation as a Molecular

Diffusion Process into a Turbulent Atmosphere," W. Brutsaert, Jour Geophys. Res., Vol. 70, 5017-5024, 1965.

"Evaporation from a Very Small Water Surface at Ground Level: Three-dimensional Turbulent Diffusion without Convection," W. Brutsaert, Jour. Geophys. Res., Vol. 72, 5631-5639, 1967.

(5306) THE HYDRAULICS OF POROUS MEDIA.

(b) Laboratory project.

(c) Dr.W.H. Brutsaert; see (5303) above.

(d) Theoretical and experimental.

(e) An analysis is being made of moisture characteristic curves of porous media to describe the pore size distribution by mathematical equations. These distributions are used to calculate hydraulic properties of the media.

(h) "Probability Laws for Pore Size Distribution," W. Brutsaert, Soil Sci., Vol. 101, 85-92, 1966. "Some Methods for Calculating Unsaturated Permeability," W. Brutsaert, Trans. ASAE, Vol. 10, 400-404, 1967.

"The Permeability of a Porous Meduim Determined from Certain Probability Laws for Pore Size Distribution," W. Brutsaert, Water Resour. Res., Vol. 4, 1968.

\section{(5307) MECHANICS OF INFILTRATION.}

(b) Laboratory project.

(c) Dr.W.H. Brutsaert; see (5303) above.

(d) Theoretical.

(e) The micro hydrological equations of unsaturated flow in porous media are being investigated and solved for different boundary conditions. The results of the mathematical analysis are extended to develop infiltration equations for larger areas or for an entire watershed.

(n) "The Recovery of Infiltration Capacity After Drainage," H.A. Ibrahim and W. Brutsaert, Proc. Inter. Hydrol. Symp., Fort Collins, Colo. Sept. 1967, Vol. 1, pp. 227-234, 1967. "Intermittent Infiltration into soils with Hysteresis," H.A. Ibrahim and W. Brutsaert, Proc. ASCE, Jour. Hyd. Div., Vol. 93, HYI, 1968.

(5874) MATHEMATICAL FLOW ANALYSIS.

(b) U.S. Dept. of the Interior.

(c) Dr. J.A. Liggett, Hollister Hall, Cornell Univ.

(d) Theoretical.

(e) The equations of continuity and momentum are being solved on a digital computer in order to analyze unsteady flow over surfaces and in channels.

(h) "Difference Solutions of the Shallow-Water Equation," J.S. Liggett and D.A. Woolhiser, Jour. Engrg. Mech.Div., ASCE, EM2, April 1967. "Unsteady, One-Dimensional Flow over a Plane-the Rising Hydrograph," D.C. Woolhiser and J.A. Liggett, Water Resources Res., Vol. 3,1967. "The Use of the Shallow Water Equations in Runoff Computations," J.S. Liggett and D.A. Woolhiser, Proc. Third Amer. Water Resources Conf., San Francisco, Nov. 1967.

UNIVERSITY OF DELAWARE, Dept. of Civil Engineering, Newark, Delaware 19711

(6367) HYDRODYNAMIC MASSES ASSOCIATED WITH FIOATING AND SUEMERGED BODIES.

(b) Laboratory project.

(c) W.S. Gaither, Assoc. Prof. of Civil Engrg.

(d) Theoretical and experimental.

(e) The purpose of these studies is to understand the mechanics of fluid motion which brings about the formation of a hydrodynamic mass associated with floating and submerged bodies with particular reference to ship hulls.'

(6368) F'LOW OF A ROTATING FLUID OVER IRREGUTAR SURFACE TOPOGRAPHLES.

(b) National Science Foundation.

(c) Don L. Boyer, Asst. Prof., Dept. of Civil Engrg.

(d) Experimental and theoretical; basic research.

(e) The flow of a homogeneous incompressible fluid past obstacles located on the upper and lower of two "infinite" parallel planes in a rotating frame of reference is examined; the axis of rotation is perpendicular to the planes.

(g) A study of the flow past a right circular cylinder, the axis of the cylinder being perpendicular to the plane surfaces, has been completed. The resulting flow phenomena are significantly different than those observed in non-rotating systems.

(6369) AMPHIBIOUS VEHTCTE STUDIES.

(b) Office of Naval Research; U.S. Navy and Marine Corps, Quantico, Va.

(c) Dr. Kurt P.H. Frey, Prof. Fmeritus and 
Investigator, Dept. of Civil Engrg., Univ. of Delaware.

(d) Experimental; applied research.

(e) To study the feasibility of increasing the speed of LVTP-5 amphibious vehicles by fluid dynamic analysis and development, flume and tow tank studies were done. The flume studies with a $2 \mathrm{ft}$. long model without moving track concerned stability limits and drag as well as wave and detached flow studies. They were done for bollard test-like arrangements as a function of the Froude number for two water lines: the normal combat load water line and a lower line derived from tow tank tests when the upper track was ventilated after a certain track channel was provided.

(g) The flume tests showed that guide vanes at the bow section are most effective when extended (like fins normal to the hull) through the region of low static pressures, and inclined to produce upward lift for the compensation of downward lift exerted on the model. Guide vanes, a low freeboard, or the lowered water line can be favorable to avoid flooding and sinking of the model at increased speed. The tow tank studies without ventilated upper track demonstrated by dye tests that the propulsion results from flow between adjacent vanes from the inner track region to the outer track region and as the difference of propulsion produced by the lower and the upper track. With ventilated upper track, the upper region may be best compared with a captured air bubble space. The upper track leaves the water at the bow section, runs through air, and re-enters the water at the bow section. Bubbles are produced when the vanes move into the air and into the water, when the air escapes the captured air bubble space, and to some extent at the interphase air-water.

(h) The first movie could be presented concerning the propulsion studies at the 1966 ASME Fluid Engrg. Conf., Chicago, Ill.

(6370) STUDIES ON SWITCHING PHENOMENA OF BISTABLE FIUIDS AND THE EFFECT OF PRESSURE WAVES ON DETACHED FTOW DURING STARTING PHENOMENA.

(b) U.S. Army, Harry Diamond Lab.

(c) Dr. K.P.H. Frey; see (6369 above).

(d) Experimental; basic and applied research.

(e) Ball valves were installed in addition to regular valves and the length of effective overflow reduced to match the reduced need of make-up water by reducing the model width of the 5.5 feet wide flume to 1 inch. The depth of water was varied from 8 to 0.5 inches. The delay of the effects of switching due to the design of boundaries required some phenomena studies in the flume. Interpretations of the hydrodynamic analogy required some additional phenomena studies, particularily with simplified models. Various sudden enlargements were used to study the effect of pressure waves on detached flow during starting phenomena. Finally, a flumitive oscillator of the type of bistable amplifiers with feed back system was used to study the flow, interactions and oscillations, and the recording. The recording techniques became most critical in these studies.

(g) The study of switching phenomena shown in a movie using differently colored power jets and control jets revealed large differences of effectiveness of switching vs. time as a function of designs, and the time dependent progress of phenomena. The feed back oscillator studies revealed oscillations not recorded in literature. They are related to the formation of von Karman vortex trails. The recording of interactions of pressure waves and detached flow phenomena needs improvements which seem to require other methods. For example, the hydrogen bubble method for flow visualization seems to yeild quantitative results at locations which are important but not accessible otherwise. In addition, make-up water is not needed.

(h) The movie on switching phenomena was shown at the 1965 A.SME Fluid Engrg. Conf., Denver, Colorado. Other results from (c).

(6371) STUDIES ON MECHANICS OF FLUID FLOW.

(b) Office of Naval Research; Harry Diamond Lab. (Army); Defense Dept. (joint School of Engrg. project "Themis").

(c) Dr. K.P.H. Frey; see (6369) above.

(d) Experimental; basic and applied research.

(e) The hydrogen bubble method was applied in continuation of work reported in 1966

(Misc. Publ. 280, page 27). Stroboscopic lighting was used for photographic recording of the phenomena.

(g) For Reynolds numbers of 1000 to more than 16,000 and a velocity range from 0.5 to more than $8 \mathrm{in./sec.,} \mathrm{laminar,} \mathrm{turbulent} \mathrm{and}$ transitional flows could be well presented. Pulsed electrolysis was preferred for which, without a special (kinked) wire, streaminelike bubble arrangements could be presented. In addition, their spacing was irregular. However, this was not of concern. Quantitative data obtained revealed in what respect theory needs more realistic assumptions.

(h) "Flume Studies Substantiating Detailed, TimeDependent Phenomena of Detached Flow," accepted for the May 1968 ASME Symp. on Unsteady Flow.

(OOTW) THE GROUND WATER FLOW SYSTEM IN THE DELMARVA PENINSULA.

(b) Office of Water Resources Research, Dept. of the Interior.

(c) Prof. R.D. Varrin, Dir.. Water Resources Ctr., and Prof. J.R. Mather, Chmn., Dept. of Geology.

For sumary, see Water Resources Research Catalog.

DOUGIAS AIRCRAFT CO., Aerodymamics Research Group, 3855 Lakewood Blvd., Long Beach, Calif. 90801

\section{(6546) STABILITY OF WATER BOUNDARY IAYER ON A HEATED SURFACE.}

(b) Laboratory project.

(c) Mr. T.T. Okamura, Aerodynamics Research Group, Douglas Aircraft Co.

(d) Theoretical.

(e) A form of the Orr-Sommerfeld equation, modified to include effects of variable viscosity was solved for velocity profiles of water on a heated flat plate. Neutral stability curves were obtained for various surface temperature to free-stream temperature ratios.

(I) Suspended. 
(g) It is shown that heating increases the stability of the flow up to a point and then there is a reversal. That is, for a fixed free stream temperature the critical Reynolds number increases with surface temperature to a maximum and then decreases.

(h) "The Stability of Water Flow Over Heated and Cooled Flat Plates," A.R. Wazzan, A.M.O. Smith, and T.T. Okamura. Presented at Ninth ASME-AICHE Natl. Heat Transfer Conf., Seattle, Wash., Aug. 6-9, 1967.

(6547) NONLTNEAR INIERACTION OF TWO LIFTING BODIES IN ARBITRARY UNSTEADY MOTION.

(b) Naval Ship Research and Dev. Center.

(c) Mr. J.P. Giesing, Aerodymamics Research Group, Douglas Aircraft Co.

(d) Basic research; theoretical.

(e) A method is developed for the exact calculation of the two-dimensional potential flow about two bodies, either or both of which are lifting, in nonlinear unsteady flight. No restrictions are placed on either the body shapes or their motions. Pressures, forces, moments and vortex-wake shapes are determined by applying a surface singularity method step by step in time.

(i) Completed.

(g) A computer program has been written and checked out. Example cases have been executed which include: a rotor passing a stator, an airfoil with a flap in large amplitude rotational motion, airfoils passing in opposite directions, airfoils in unsteady motion in ground effect.

(h) A Douglas report has been issued: DAC Report No. 33552, March 15, 1967, "Unsteady TwoDimensional Potential Flow for Two Bodies with Lift, " to be presented at 1968 ASME Unsteady Flow symp. and published in the transactions.

(6548) CALCULATION OF POTENTIAL FIOW ABOUT ARBITRARY CONFIGURATIONS.

(b) Laboratory project; and Naval Ship Research and Development Center.

(c) John I. Hess, Aerodynamics Research Group, Douglas Aircraft Co.

(d) Theoretical; applied research.

(e) Develop methods for calculating incompressible flow with no geometrical restrictions on the flow boundaries. Method utilized a source density distribution on the surface of the body about which flow is to be computed and obtains this distribution as the solution of an integral equation. Separate routines exist for different types of geometry--twodimensional, axisymmetric, and three-dimensional, and for different flow conditions.

(h) "Calculation of Potential Flow about Arbitrary Bodies," John L. Hess and A.M.O. Smith, Progress in Aeronautical Sciences, Vol. 8, Perganmon Press, Oxford and New York, 1966. 138 pages. Also available as Douglas Engrg. Paper No. 3327 from (c) above.

(6549) WATER BOUNDARY LAYER OVER A HEATED PLATE.

(b) Iaboratory project.

(c) Mr. Kalle Kaups, Aerodynamics Research Group, Douglas Aircraft Co.

(d) Theoretical investigation.

(e) Numerical solutions to the laminar boundary layer equations for the flow of water over heated axi-symmetric and two-dimensional surfaces were obtained. The effects of heat transfer on velocity and temperature profiles, skin friction and displacement thickness were determined for various surface temperature to free-stream temperature ratios.

(f) Suspended.

(g) Correlations of skin friction and heat transfer coefficients as a function of temperature ratios were obtained. Results indicated heating produced a fuller velocity profile.

(h) "The Iaminar Boundary Layer in Water with Variable Properties," K. Kaups and A.M.O. Smith, presented at the Ninth ASME-AICHE Nat1. Heat Transfer Conf., Seattle, Washington, Aug. 6-9, 1967.

(6550) INCOMPRESSIBLE TURBUTENT BOUNDARY LAYER STUDY.

(b) BuWeps and laboratory project, jointly.

(c) Dr. Tuncer Cebeci, Aerodynamics Research Group Douglas Aircraft Co.

(d) Theoretical research.

(e) The project consists of investigating a method for solving the flow equations governing an incompressible turbulent boundary layer for two-dimensional or axi-symetric flows. An eddy viscosity is employed to eliminate the Reynolds shear stress. The object of the work is the development of a method for predicting skin friction, displacement effects and separation in a turbulent boundary layer.

(g) A rapid numerical method for solving the equations using an implicit finite difference method has been devised. Results are in good agreement with experiment except in the immediate vicinity of separation.

(h) "Study of a General Method of Solution of the Incompressible Turbulent Boundary Layer Equations," A.M.O. Smith, N.A. Jaffe, and R.C. Iind, Douglas Aircraft Co. Rept. No. 1b-52949, November 1965.

(6551) LOAD DISTRIBUTIONS TO PRODUCE MINIMUM INDUCED DRAG FOR NONPIANAR WINGS (OR HYDROFOTLS).

(b) National Aeronautics and Space Admin.

(c) Mr. J.I. Lundry, Aerodynamics Research Group, Douglas Aircraft Co.

(d) Theoretical.

(e) The goal of this project is a method to compute the load distribution on complex, nonplanar lifting configurations to produce minimum induced drag. The basic theory was developed by Munk. A potential flow parallel to the downwash is computed about the Trefftz-plane wake. The required loading is proportional to the potential difference across each element of the wake. The loading will ultimately be used to compute wing twist distributions for experimental studies designed to demonstrate the theoretical reductions of induced drag that can be obtained with nonplanar configurations.

(6552) THE MINIMUM INDUCED DRAG OF NONPLANAR WINGS (OR HYDROFOILS).

(b) The Independent Research and Development (IRAD) Program of the Douglas Aircraft Co.

(c) Mr. J.I. Iundry; see (6551) above.

(d) Theoretical; applied research.

(e) The goal of this project is the development of a method to compute the minimum induced drag of complex, nonplanar lifting configurations. The basic theory was developed by Munk. A potential flow parallel to the downwash is determined about the Trefftz-plane wake. The minimu induced drag is then found by quadrature. The purpose of the project is to analyze complex configurations more accurately than 
they have been treated previously, and to provide engineering data with which to judge previous approximate results.

(f) Completed.

(g) The significant conclusions of this work are: (1) the early, analytical, approximate method of Mangler gives numerical results for minimu induced drag with reliably small error for the simple configurations that were analyzed; (2) the more recent, combined analytical and experimental method of Cone can treat quite general lifting configurations, but sometimes produces significant optimistic errors for minimum induced drag; (3) the present method gives errors of the order of $10^{-4}$ in induced drag efficiency, and can treat complex nonplanar configurations with front view that can be approximated by straight line segments.

(h) "A Numerical Solution for the Minimu Induced Drag of Nonplanar Wings," J.I. Iundry and P.B.S. Lissaman, to be published in AIAA Jour. of Aircraft in early 1968.

UNIVERSITY OF FLORIDA, The Engineering and Industrial Experiment Station, Dept. of Coastal and Oceanographic Engrg., Gainesville, Florida 32603.

Inquiries concerning projects should be addressed to Dr. Robert G. Dean, Chairman, Dept. of Coastal and Oceanographic Engrg., Univ. of Florida, unless otherwise noted under (c).

(3413) INLET STUDIES.

(b) Laboratory project.

(d) Field investigations; applied research.

(e) Study of the stability of coastal inlets.

(4127) FLUORESCENT TRACING OF SEDIMENT IN COASTAL AREAS.

(b) National Institute of Health.

(d) Field investigations; basic and applied research.

(e) Tracing of sediment drift on beach and offshore bottoms by means of injected fluorescent material.

(g) Statistical sampling methods, rapid measurement fluorescent tracer concentration by electronic scanners, a new longshore current theory and a statistical approach to littoral transport mechanism are being developed at the laboratory.

(h) "Longshore Currents and Longshore Troughs," Per Bruun, Jour. Amer. Geophys. Union, Vol. 63, No. 4, Feb. 1963.

"Tracing of Sediments in Coastal Waters by Fluorescent Material," presented by Per Bruun at 17th Annual Industrial Waste Conf., Purdue Univ., May 1962.

"Quantitative Tracing of Littoral Drift," Per Bruun, Proc. Federal Inter-Agency Sedimenta.tion Conf'., Jackson, Miss., Feb. 1963, Misc. Publ. 970, U.S. Dept. of Agriculture. "Summary of the Production and the Scanning of Fluorescent Tracers," Paul Teleki, Appendix I of Misc. Publ. 970 (see preceding reference), Feb. 1363.

"Statistical Analysis of Samples for Determination of Fluorescent Sand Concentration," M. Manohar, (unpublished).

"Tidal Inlets and Littoral Drifts," Per Bruun and J.A. Battjes, presented at Int1. Assoc. of Hydraulic Research, London,
Sept. 1963.

"Quantitative Tracing of Littoral Drift," P. Bruun, Proc. IXth Intl. Conf. on Coastal Engrg., Lisbon 1964, Paper 1.17.

"Quantitative Tracing of Littoral Drift," P. Bruun, Federal Inter-Agency Sedimentation Conf., Proc., Jackson, Miss. Publ. No. 970, U.S. Dept. of Agriculture, 1963.

"Fluorescent Sand Tracers," P.G. Teleki, Jour. Sedimentary Petrology, Vol. 36, No. 2, pp. 468-485.

"Automatic Analysis of Tracer Sand," P.G. Teleki, Jour. Sedimentary Petrology, Vol. 37, No. 3, pp. $743-759$.

(4128) FLUX OF WAVE ENERGY PERPENDICUTAR TO THE DIRECIION OF WAVE PROPAGATION.

(b) National Science Foundation.

(d) Basic research.

(e) Experiments to determine flux of wave energy perpendicular to the direction of wave propagation.

(f) Discontinued.

(h) "Wave Attenuation on a Channel with Roughened Sides," J.A. Battjes, Engrg. Progress at Univ. of Florida, Vol. XIX, No. 7, July 1965. Paper of same title in Coastal Engrg., Proc. ASCE Specialty Conf., Santa Barbara, Calif., 1965, p. 425.

\section{(4I29) INFLUENCE OF SEA LEVEL RISE ON EROSION.}

(b) Laboratory project.

(d) Basic research.

(e) To determine the influence of short-term as well as long-term fluctuation of sea level on erosion and shoreline movements.

(f) Tracer experiment being undertaken on transversal drift in connection with other field projects.

(4474) COASTAL ENGINEERING STUDY AT SOUTH LAKE WORTH INLET, FLORIDA.

(b) South Lake Worth Inlet District Commission.

(c) South Iake Worth Inlet District Commission, c/o K.C. Mock and Associates, 2730 Okeechobee Road, West Palm Beach, Florida.

(d) Experimental field and applied research.

(e) To study distribution of inlet currents, improvement of entrance jetties, and navigation channels and measures against beach erosion. Also study the effect of proposed landfills in the bay.

(f) Completed.

(g) Report submitted to sponsor.

(h) "Coastal Engineering Model Studies of Three Florida Coastal Inlets," P.M. Bruun, J.A. Battjes, T.Y. Chiu, and J.A. Purpura, Engrg. Progress at Univ. of Florida, Vol. XX, No. 6, June 1966.

(4475) COASTAI ENGINEERING STUDY AT HILUSBORO INLET, FLORIDA.

(b) Hillsboro Inlet Improvement and Maintenance District, City of Pompano Beach and Trustees of the Internal Improvement Fund.

(c) Director, Trustees, Internal Improvement Fund, Capitol Bldg., Tallahassee, Florida.

(d) Experimental, field and applied research.

(e) To study methods for inlet stabilization, navigation improvement, and sand bypassing across the inlet.

(f) Completed.

(g) Report submitted to sponsor.

(h) "Coastal Engineering Model Studies of Three Florida Coastal Inlets," by P.M. Bruun, J.A. 
Battjes, T.Y. Chiu, and J.A. Purpura, Engrg. Progress Univ. of Fla., Vol. XX, No. 6, 1966.

(4479) REVIEW OF BEACH EROSION AND COASTAL PROTECTION IN FIORIDA.

(b) Engrg. and Industrial Expmt. Sta., Univ. of Florida.

(d) Field investigation; applied research.

(e) Review of the erosion and protection situation in Florida.

(h) "Withdrawn Dykes and Preservation Lines," P. Bruun, Shore and Beach, Jour. Amer. Shore and Beach Preserv. Association, October 1764. "Offshore Dredging--Influence on Beach and Bottom Stability," P. Bruun, The Dock and Harbour Authority, London, Vol. XLV, No. 530, Dec. 1964, p. 7 .

"Revetments for Coastal Protection--Review of Some Different Types," P. Bruun, Dock and Harbour Authority, Vol. XITV, No. 520, Feb. 1964.

"Modern Trend in Revetment Design," P. Bruun, Consulting Engineer, Feb. 1964.

"Coastal Protection Procedures," Bull. No. 118, Vol. XVIII, No. 12, 1964, Florida Engrg. and Indus. Expmt. Sta.

"Revetments for Coastal Protection," P. Bruun, Jour. Institution on Engrs. in Australia, Vol. 37, No. I-2, Mar. 1965, pp. 17-20.

(4482) EXPERTMENTAL STUDY OF MECHANICS OF DUNE BUIIDING AT CAPE HATTERAS NATIONAL SEASHORE AREA.

(b) Cape Hatteras National Seashore, National Park Service, Manteo, North Carolina.

(c) Same as (b) above.

(d) Experimental and field research.

(e) Study of mechanics of dune building by various types of sand fences and other sand catchment devices under controlled conditions is underway in a laboratory wind tunnel to be later correlated with field tests.

(f) Completed.

(g) Report submitted to sponsor.

(4895) SAND TRANSPORT BY WIND AND MECHANICS OF DUNE BUIIDING.

(b) National Science Foundation.

(c) T.Y. Chiu, Sr. Asst. in Engrg. , Dept. of Coastal and Oceanographic Engrg., Univ. of Florida.

(d) Experimental and theoretical; basic research.

(e) To study the basic mechanics of sand transport by wind under dry and humid conditions, with and without vegetation, uniform and gusty winds and with and without solid and permeable vertical fences.

(f) Completed.

(g) Report submitted to sponsor.

(h) "Sand Transport by Wind," T.Y. Chiu, Dept. of Coastal and Oceanographic Engrg., Univ. of Florida, Tech. Rep. No. 1, 1967.

(4898) BASIC RESEARCH ON LITTORAL DRIFT BY WAVE AND CURRENT ACTION.

(b) National Science Foundation.

(c) Minze Stuiver, Research Assoc., Dept. of Coastal and Oceanographic Engrg., Univ. of Florida.

(d) Experimental and basic research; dissertation.

(e) A laboratory basic research project on friction coefficients and sediment transport by currents and waves running with or against each other and ruming perpendicular to each other.

(f) Completed (g) Report being prepared.

(5281) TRACING OF LITTORAL DRIFT AT CAPE KENNEDY.

(b) U.S. Atomic Energy Commission.

(c) U.A. Purpura, Assoc. Prof., Dept. of Coastal and Oceanographic Engrg., Univ. of Florida.

(d) Field project; applied.

(e) Tracing of simulated debris resulting from a nuclear rocket abort.

(5283) SCRAPER OPERATION, JUPITER ISLAND.

(b) Coastal Engrg. Research Ctr., U.S. Army Engrs; and Florida Board of Conservation.

(c) J.S. Purpura; see (5281) above.

(d) Field project; applied and basic.

(e) To evaluate the effectiveness of an offshore drag-scraper in providing sand for beach nourishment.

(5284) SAND FENCES.

(b) Coastal Engrg. Research Ctr., U.S. Army Engrs.

(d) Applied.

(e) To test various sand fences.

(f) Discontinued.

(g) Report submitted to sponsor.

(5684) SIMILARITY OF BED LOAD TRANSPORT BY CURRENTS.

(b) National Science Foundation.

(c) Mr. J.A. Battjes, Dept. of Coastal Engrg., Univ. of Florida.

(d) Theoretical and experimental development research.

(e) A study of the feasibility of applying specially developed artificial roughness elements in movable bed models.

(f) Completed.

(h) Report in preparation.

(5685) STUDY OF LONG WAVE PENETRATION IN DEEP NARROW FIORDS ( ICELAND).

(b) Office of Naval Research.

(c) Office of Naval Research.

(d) Basic research.

(e) Research on low frequency ocean waves and their penetration in narrow fiords.

(5686) COASTAL ENGINEERING STUDY OF MACQUARIE HARBOR INLET (TASMANIA).

(b) Pickands Mather and Co., Cleveland, Ohio.

(c) Pickands Mather and Co., Cleveland, Ohio.

(d) Experimental, theoretical and field investigation, applied research.

(e) Stability computations for the proposed navigation channel study methods to arrive at a minimum of maintenance dredging.

(i) Completed.

(g) Report submitted to sponsor.

(h) "Water-Level Fluctuations and Flow in Tidal Inlets," Jacobus Van de Kreeke, Jour. Waterways and Harbors Div., Proc., ASCE, Vol. 93, No. WW4, Nov. 1967, pp. 97-106.

(6752) COASTAL ENGINEERING HYDRAULIC MODEL STUDY OF ST. LUCIE INLET.

(b) Martin County Commissioners, Stuart, Fla.

(d) Experimental, theoretical and field investigation, applied research.

(e) Investigate and propose improvements to provide inlet stability, improved navigation and sand bypassing.

(f) Completed.

(g) Report submitted to sponsor.

(6753) A MODEL INVESTIGATION OF EXTREME RUN-UP AT FLORIDA POWER CORPORATION'S CRYSTAL RIVER SITE. 
(b) Gilbert Associates, Inc., Reading, Penna.

(c) T.Y. Chiu; see (4895) above.

(d) Experimental; model investigation.

(e) Determine the adequacy of proposed berm elevations at site of nuclear plant against extreme hurricane storm tide and wave run-up.

(f) Completed.

(g) Report submitted to sponsor.

(6754) WAVE, CURRENT AND STORM SURGE RESPONSE TO FXXTREME WIND SYSTEMS.

(b) National Science Foundation.

(d) Experimental and theoretical; applied research.

(e) Development and evaluation, by field measurements, of a numerical model to predict the waves, currents and surges resulting from an extreme wind system over a coastal area of irregular bathymetry.

(6755) EVALUATION AND DEVELOPMENT OF WATER WAVE THEORIES FOR ENGINEERING APPLICATION.

(b) Coastal Engrg. Research Ctr., U.S. Army Engrs.

(d) Theoretical; basic and applied.

(e) Development of available water wave theories into a form readily applicable for engineering use.

(g) Computer programs have been developed for eight water wave theories and the agreement with the specified boundary conditions has been established. The most valid wave theories have been identified for wide ranges of dimensionless wave characteristics.

(h) "Relative Validities of Water Wave Theories," R.G. Dean, Proc., Amer. Soc. of Civil Engrs. Conf. on Ocean Engrg., Sept. 1967.

(6756) RESIDENCE TIMES OF WATERS BEHIND BARRIER ISIANDS.

(b) Office of Water Resources Research,(Interior).

(d) Theoretical and experimental; basic and applied.

(e) Develop and assess numerical procedures for predicting residence times of waters in lagoons behind barrier islands and in interconnected bay systems.

(6757) SAND TRACING PROGRAM FOR SPECIFIC AREAS ON THE LOWER EAST COAST OF FIORIDA.

(b) Florida Board of Conservation.

(c) J.A. Purpura; see (5281) above.

(d) Field-laboratory; applied and basic.

(e) Uses fluorescent coated sand to evalute natural and artificial bypassing at three inlets and study of long segments of beach behavior between the inlets.

(6758) FURNISH TECHNICAL ADVICE OF COASTAL ENGINEERING NATURE TO THE STATE OF FIORIDA.

(b) Florida Board of Conservation.

(c) J.A. Purpura; see (5281) above.

(d) Field-office; applied.

(e) To furnish advice to the Florida Board of Conservation relating to State problems in coastal engineering.

(6759) COASTAL ENGINEHRING STUDY OF JUPITER INTET, FLORIDA.

(b) Jupiter Inlet Commission.

(c) J.A. Purpura; see (5281) above.

(d) Field-laboratory; applied and basic.

(e) Laboratory model study to improve navigation, bypassing and maintenance of Jupiter Inlet.

(6760) COASTAL ENGINEERING STUDY OF A SPECIAL TYPE OF OFFSHORE BREAKWATER FOR INSTALIATION AT HILLSBORO INLET. (b) Erosion Prevention District Advisory Committee, Board of County Commissioners, Broward County, Florida.

(c) T.Y. Chiu; see (4895) above.

(d) Experimental; applied.

(e) Measurements of wave transmission and force on a few permeable structures with varying permeabilities.

(f) Completed.

(g) Report submitted to sponsor.

(6761) COASTAL ENGINEERING STUDY FOR THE IMPROVEMENT OF THE CURRENT PATTERN AROUND THE HILLSBORO BRIDGE PIER.

(b) Florida State Road Dept.

(c) Minze Stuiver; see (4898) above.

(d) Experimental; applied, design.

(e) To investigate various solutions for improving the cross-current pattern existing in the inlet channel under the bridge, primarily by modifying the square shape of the bridge abutment.

(f) Completed.

(g) Report submitted to sponsor.

(6762) TRANSVIERSAL INLETS IN BOTMOM PROFILES.

(b) Federal Water Pollution Control Admin., U.S. Dept. of the Interior.

(c) Edward B. Thornton, Research Assoc., Dept. of Coastal and Oceanographic Engrg., Univ. of Florida.

(d) Field-theoretical; basic; doctoral theses.

(e) Synoptic field measurements of the entire littoral processes including sand transport, waves, (height and direction), water particle, velocities, wind, tide, bathymetry and sediment characteristics. These measurements are used to gain insight for development of theoretical models.

(6763) COASTAL ENGINEERING STUDY OF THE MOUTH OF THE YAGUEZ RIVER.

(b) Dept. of Public Works, Puerto Rico, via Flavio Acaron and Associates.

(c) Omar H. Shemdin, Asst. Prof., Dept. of Coastal and Oceanographic Engrg., Univ. of Florida.

(d) Experimental applied research.

(e) Model study of the influence of the offshore sand bar on the water surface elevation in the Yaguez River during a flood.

(f) Completed.

(g) Report submitted to sponsor.

(6764) COASTAL ENGINEERING STUDY OF THE MOUTH OF THE CORAZONES WATER CHANNEL.

(b) Puerto Rico Land Administration, via Flavio Acaron and Associates.

(c) Omar H. Shemdin; see (6763) above.

(d) Experimental applied research.

(e) Model and field study to investigate the formation of a sand bar which blocks the mouth of the Corazones water channel in Puerto Rico.

GEIERAL DYNAMICS CORP., CONVAIR DIVISION, P.O. BOX 1128, San Diego, Calit. 22112

(6294) MONOGRAPH ON ANALYTIC REVIEW OF IIQUID DYNAMICS IN FIXED AND MOVING CONTAINERS.

(b) National Aeroanutics and Space Admin. 
Marshall Space Flight Center.

(c) R.E. Martin, Chief of Dynamics, Mail Zone 575-00, General Dynamics/Convair.

(d) Theoretical; applied research.

(e) Monograph, on rigorous mathematical basis, on incompressible liquid sloshing in fixed and moving containers of arbitrary shape. Purpose was to provide foundation for study of propellant sloshing in liquid rockets.

(f) Completed.

(g) Issued as Convair report; will be published as NASA Contractor Report in near future.

(6295) MONOGRAPH ON TESTING FOR BOOSTER PROPELIANT SLOSHING PARAMETERS.

(b) National Aeronautics and space Admin., Marshall Space Flight Center.

(c) R.E. Martin; see (6294) above.

(d) Monograph on experimental approaches.

(e) Summarizes modeling laws and test techniques for scale model testing of sloshing of propellant in liquid rockets.

(f) Completed.

(g) Issued as Convair report; will be published as NASA Contractor Report in near future.

(6296) SURFACE AND NEAR SURFACE EFFECT ON HYDRODYNAMIC RESISTANCE FOR SUEMERSIBLE VEHICLES.

(b) Laboratory project for internal research purposes.

(c) A. Kremm, Project Engr., Marine Vehicles, Mail Zone 510-00, General Dynamics/Convair.

(d) Experimental; design research.

(e) A scale model of a submersible vehicle was towed in a tank at various speeds and depths to determine the effect of depth on hydrodynamic resistance.

(f) Completed.

(g) Data gathered in the model tow basin tests showed that resistance of the particular shape under study increased 59 percent and 73 percent when its operating depth was decreased from a full scale depth of 30 feet to 3 feet and zero (surface), respectively. Towed speed was equivalent to $6 \mathrm{kn}$, full scale.

(h) Available from correspondent (c) above.

GENERAL DYNAMICS CORP., Electric Boat Division, Groton, Conn. 06340

\section{(6373) SERVO VALVE SPOOL EROSION EVALUATION.}

(b) Laboratory project.

(c) G.M. Lefoley, Supervisor of Mechanical Controls, Underwater Development Engrg., Research and Development, Electric Boat Div., General Dynamics Corp.

(d) Primarily experimental; applied research.

(e) A study and experimental program to establish the cause and solution of servo valve spool erosion resulting from the use of high pressure phosphate ester fire resistant hydraulic fluids.

(f) Completed.

(g) The Electric Boat Division of General Dynamics' AGC system utilizes hydraulic power to control all mechanical functions in the systems. Power is generated at a hydraulic power plant and transmitted through servo valves, which control power, to the various mechanical actuators. On applications requiring control on hot strip mills, a fire resistant fluid is required to minimize the fire hazards in the event of a break in a hydraulic line.

During the test phase a problem was experienced with the servo valve and a hydraulic fluid containing certain additives. An abnormal increase in the internal leakage of the servo valve was experienced. This leakage required more power to be generated at the hydraulic plant and ultimately resulted in an efficiency loss in the hydraulic system after 50 hours of operation.

This report describes the efforts expended and the final results achieved in solving this problem. The report covers the work performed by the valve manufacturer, Sanders Associates, the fluid manufacturers, and the Electric Boat division of General Dynamics, and field operating experience at U.S. Steel McDonald mills.

The solution to the problem consisted of changing fluid to Stauffer Chemical, Cellulube 150, which contains no additives, and the addition of a fuller's earth filter to the system. To date, 1500 hours of field operation has resulted in no increase in internal valve leakage while over-all hydraulic efficiency has been maintained.

(h) Distribution of this report is restricted pending final negotiation of current licensing agreements.

(6374) POTENIIAL FLOW COMPUTER PROGRAM.

(b) Laboratory project.

(c) Quentin Wald, Chief Hydrodynamicist, Research and Development, Electric Boat Div., General Dynamics Corp.

(d) Theoretical; applied research.

(e) A computation method is being developed to compute the potential flow field (Neuman problem) exterior to a three-dimensional body with at least one plane of symmetry. The indirect method is employed, a source distribution on a plane of symmetry being assumed. The body shape is developed by a streamline tracing method. The objective is the prediction of the entire field of flow around a surface ship or other submerged body. It is intended eventually to include a free surface and compute wave resistance.

(g) The basic program is operational. A method of treating the free surface is being developed. It has not yet been applied to practical problems.

(6375) THE HYDRODYNAMIC FORCES ON FTN-BODY COMBINATIONS.

(b) Laboratory project.

(c) Quentin Wald; see (6374) above.

(d) Theoretical and experimental investigation of a basic nature with practical applications.

(e) Methods are being developed to facilitate accurate and convenient prediction of the forces on single and paired fins on a slender body of revolution. The results are applicable to the preliminary design and the prediction of the stability of underwater vehicles.

(g) The basic theoretical analysis is complete. Analysis of the influence of the boundary layer and the experimental work have not started. Convenient prediction formulae have been derived with the aid of conformal mapping of the Trefftz plane. 
GENERAL EIECTRIC CO., Research and Development Center, P.0. Box 8, Schenectady, N.Y. 12301.

(6378) SURFACE FIIMS OF GAS MUCLEI (AS REIATED TO CAVITATION AND TENSILE STRENGTH IN WATER.)

(b) Naval Ship Research and Development Center.

(c) L. Bernd, Research and Development Center, General Electric Company.

(d) Experimental applied research.

(e) Study of the variation of water tensile strength and its influence on the inception of cavitation, as affected by organic films in controlling the rate of gas nuclei dissolving in laminar and turbulent flow. This applies to water tunnel investigations of cavitation.

(f) Completed.

(g) Characteristics of dissolving with films established.

(h) "Cavitation, Tensile Strength and the Surface Films of Gas Nuclei," I. Bernd, 6th Naval Hydrodynamics Symp., Sept. 28 - Oct. 4, 1966, Washington, D. C.

"Study Films of Gas Nuclei (As related to cavitation and tensile strength in water) Part 1, 2, 3, and 4, "ONR Contract No. NONR4294(00), Naval Ship Research and Development Ctr., Washington, D. C.

(6379) POLYMERIC FRICTION REDUCPION PROGRAM.

(b) Laboratory project.

(c) W.B. Giles, Research and Development Center, General Electric Company.

(d) Experimental and analytical investigation.

(e) Study of the boundary layer flow of laminar, transition, and turbulent flows with homogeneous and injected friction-reducing additives.

(h) "Similarity Laws for Dilute Viscoelastic Flows," W.B. Giles, AIAA 3rd Propulsion Joint Specialist Conf., July 17-21, 1967, Wash., D.C., AIAA No. 67-485.

"On the Stability of Dilute Viscoelastic Flows," W.B. Giles and W.T. Pettit, Nature Mag., Nov. 4, 1967.

(6380) SPECTRAL ANALYSIS OF PUMP CAVITATION NOISE.

(b) Marshall Space Flight Center, INASA.

(c) R.B. Tatge, Research and Development Center, General Electric Company.

(d) Electronic analysis of experimental data.

(e) Frequency analysis was applied to magnetic tape data of pressure and vibration signals of tuel and oxidizer missile pumps.

(g) Transient events of the centrifugal pump are observed as photographic patterms; such as head loss, rotating stall, impeller and inducer blade frequencies.

(h) "Spectral Analysis of Pump-Cavitation Noise," F.O. Rathbun, Jr., W.B. Giles, D.E. Wood, and C. Miller, 2nd Intl. Cong. of Experimental Mechanics, pp. 497-507.

GENERAL ELECTRIC CO., Space Sciences Lab., Theoretical Fluid Physics Section, P.O. Box 8555, Phila., Pa. 19101

(6541) BLOOD FLOW RESEARCH.

(b) National Inst. of Health, National Heart Inst.

(c) Dr. Sinclaire M. Scala, Mgr., Theoretical Fluid Physics, Space Sciences Lab.

(d) Theoretical and experimental; applied research.

(e) The theoretical studies and experimental measurements of in vitro and in vivo blood flow are directed toward defining blood motion in and adjacent to circulatory assist devices in order to provide guidelines for optimum design of these devices.

(g) Mathematical models based on the time-dependent Navier-Stokes equations are being developed for pulsatile blood flow. Measurements of hemolysis of red blood cells under various shear stress levels have also been made.

(h) "Design of Devices for Optimum Blood Flow," N.R. Kuchar and S.M. Scala, ASME Design Engrg. Conf., Chicago, Ill., April 1968.

(6542) HURRICANE DYMAMICS.

(b) Laboratory project.

(c) Dr. Albert Barcilon, Theoretical Fluid Physics Section, Space Sciences Lab., General Electric Co.

(d) Theoretical; applied research.

(e) The theoretical studies are directed toward developing a complete self-consistent model for the dynamics of a mature hurricane.

(g) The mathematical models are based on the equations of viscous turbulent flow. A model has already been developed for the interfacial boundary layer between the ocean and the atmosphere, and of effects of meridional circulation.

(h) Several laboratory reports have already appeared, which have also been submitted to journals for publication.

(6543) SLOSHING OF LIQUIDS.

(b) Laboratory project.

(c) Dr. Henry G. Lew, Theoretical Fluid Physics Section, Space Sciences Lab., General Electric Co.

(d) Theoretical; applied research.

(e) The theoretical studies are directed toward developing a general theory for the zero gravity liquid sloshing of a partially-filled container in order to predict forces and moments.

(g) Studies have already been carried out of the sloshing of liquid in a filled container which contains two liquids of different density.

GEORGIA INSITUTE OF TECHNOIOGY, School of Civil Engrg. Atlanta, Georgia 30332 .

(5545) ANALYTICAL AND EXPERIMENTAL STUDY OF BED FORMS UNDER WATER WAVES.

(b) Coastal Engrg. Research Ctr., U.S. Army Corps of Engrs.; and laboratory project.

(c) Dr. M.R. Carstens, School of Civil Engrg., Georgia Inst. of Tech.

(d) Theoretical and experimental; basic research which is partly for a doctoral thesis.

(g) Various features of the bed forms which occur with oscillatory flow over a bed of uniform sand were studied experimentally in an oscillatory-flow water tunnel. The amplitude of the water motion was a controlled variable. Three sizes of bed material were used in otherwise duplicate experiments. The period of oscillation was essentially constant in all runs. A flat bed was the initial condition in all runs. Initial and final transients were eliminated from the water motion. The experiments were organized in order to study (a) incipient motion, (b) evolution of a 
duned bed, (c) geometry of equilibrium dunes, and (d) energy dissipation in the flow over a duned bed.

A universal incipient-motion criterion was derived. Analytical study of scour and fill on a two-dimensional dune is currently being done by a doctoral candidate.

(h) "Evolution of a Duned Bed Under Oscillatory Flow," M.R. Carstens and F.M. Neilson, Jour. Geophys. Research, Vol. 72, No. 12, pp. 30533059, June 15, 1967.

(6686) TWO-PHASE FLOW IN A VERTICAL BEND.

(b) Office of Water Resources Research and laboratory (matching-fund grant).

(c) Dr. M.R. Carstens; see (5545) above.

(d) Experimental; basic research for doctoral thesis.

(e) Two phase flow (air-water) down a vertical conduit, through a 90-degree elbow, and thence through a horizontal conduit is being studied in square conduits. Particular attention is being given to the transition from a bubbly mixture in the vertical leg to stratified (open-channel) or plug flow in the horizontal. leg. Flow variables are air concentration and Froude number in the horizontal leg. Geometric variables are radius of curvature of the simple circular bends and length of the horizontal conduit.

(6687) LOCALIZED SCOUR.

(b) U.S. Navy, Mine Defense Lab. (1962-1967); U.S. Army, Corps of Engrs., Coastal Engrg. Research Ctr. (Current).

(c) Dr. M.R. Carstens; see (5545) above.

(d) Theoretical and experimental; basic and applied research part of which is being used as a doctoral thesis.

(e) The unsteady phenomenon of localized scour which occurs in the sand bed as the result of non-uniform flow induced by an object placed in a flowing fluid is being analyzed by means of mass-transport relations. The rates of sand transport out of and into the scour-hole and the scour hole geometry are evaluated separately. The empirically determined functions for the transport functions and the appropriate scour-hole geometric function are substituted into the total differential for scour-hole volume. Integration of the differential equation results in the desired scour depthtime function. The reasons for this approach are (1) division into three parts, that is, discharge out, discharge in, and scour-hole geometry is more manageable, and (2) the range of model studies is definitely limited by the scale effect of dunes. Experimental studies have been completed for a horizontal cylinder lying on a sand bed under oscillatory flow. Current studies involve localized scour around a single vertical pile protruding into a sand bed under oscillatory flow.

(h) "Similarity Laws for Localized Scour," Marion R. Carstens, Jour. Hydraulics Div., Proc. ASCE, Vol. 92, No. HY3, pp. 13-36, May 1966.

(6688) DIFFUSION OF PARTICIES BY TURBULENCE--EFFECT OF PARTICIE SIZE.

(b) U.S. Dept. of the Interior, Federal Water Pollution Control Admin.

(c) Dr. M.R. Carstens; see (5545) above.

(d) Experimental; basic research which is partly for a doctoral thesis.

(e) A diffusion chamber was constructed in which the turbulence was homogeneous and isotropic in a gross sense. The chamber is cylindrical being 13 inches in diameter by 1 -inch in height. Sixty-eight nozzles which are directed vertically downward are arranged in a separating square network with a l-inch spacing between the rows of 0.190 -inch diameter nozzles. Thirty-four nozzles discharge into the chamber while the other thirty-four exhaust from the chamber. An unvalved piston pump is used to force water into and out of the chamber through the nozzles in the roof. The floor of the chamber is plate glass.

In the current experiments, six sizes of nylon spheres are placed in the chamber and motion pictures are taken to determine particle motion. The smallest particle is $3 / 32$-inch in diameter and the largest is $1 / 2$-inch in diameter. Amplitude and frequency of the pump are fixed. The data are analyzed in accordance with the theory of continuous movement using coordinates of individual particles as input data.

(g) The diffusion coefficients and the mixing length of all particles less than $9 / 32$-inch in diameter were the same. If the ratio of particle diameter to mixing length is less than unity, the ratio of particle diffusivityto-fluid diffusivity is also unity. The particle diffusivity decreases to zero if the ratio of particle diameter to mixing length is about three.

(6689) CHARACTERISTICS OF A POSITIVE SURGE IN AN OPEN-CHANNET WITH A CIRCULAR BOTTOM.

(b) Laboratory porject.

(c) Dr. M.R. Carstens; see (5545) above.

(d) Experimental; basic research for master's thesis.

(e) A positive surge was created in a horizontal, transparent, 8-inch-diameter, plastic pipe. A plane-faced piston at one end of the pipe was moved at a constant velocity in order to generate a surge which progressed over stillwater. The single variable in the experiments was still-water depth which, of course, altered the geometry of the cross section. Differential pressure measurements between two stations along the pipe were used to determine the undular surge profile and celerity. Grossstream tube analysis (continuity and linear momentum) was verified in every respect. At the smaller depths, the frictional forces were sufficient to have reached an equilibrium water-surface profile at the measuring stations whereas with the larger depths, the profile was changing as the surge moved up the channel.

(6690) SIMUIATION OF UNSTEADY FLOW IN OPEN CHANNELS BY DIGITAL COMPUTER.

(b) Laboratory project.

(c) Dr. C.S. Martin, School of Civil Engrg., Georgia Inst. of Tech.

(d) Theoretical and experimental; applied research.

(e) The equations of motion for unsteady graduallyvaried flow in open channels are expressed in a finite-difference form suitable for programming on a high-speed digital computer. A discussion of the various finite-difference schemes available for solution to these equations and their relative units for application to engineering problems is given. The staggered-net scheme introduced by stoker is expanded to be applicable to a system of $\mathbb{N}$ interconnected channels, with each of their ends subject to 
one of the following boundary conditions: discharge hydrograph, stage hydrograph, stagedischarge relationship, dead end or junction of channels. The theory and computer program are tested and compared with existing experimental results corresponding to the following situations: (1) flood hydrograph in circular channel; (2) power-load rejection in headrace of trapezoidal canal; (3) power-load acceptance in tailrace of rectangular model channel; and (4) tidal (stage) hydrograph in rectangular model estuary.

(6691) HYDRODYNAMICS OF TIRE HYDROPIANING.

(b) National Aeronautics and Space Admin.

(c) Dr. C.S. Martin; see (6690) above.

(d) Theoretical; basic research.

(f) Completed.

(g) The hydrodynamics of pneumatic tire hydroplaning are explained from a purely analytical standpoint. Lift and drag forces on an assumed planing surface (tire) are obtained for an ideal fluid undergoing two-dimensional motion. For the condition of incipient hydroplaning the theoretical lift coefficient is found to be 0.8 , compared to a value of 0.7 from experiment. The lift and drag coefficients are shown to decrease as the tire lifts further off the runway. The pressure distribution on the pavement from theory compares favorably with the experimental results.

(h) "Hydrodynamics of Tire Hydroplaning," Jour. of Aircraft, AIAA, Vol. 4, No. 2, MarchApril 1967, pp. 136-140.

(6692) EFFECT OF A PERMEABLE BED ON SEDIMENT TRANSPORT.

(b) Office of Water Resources Research; and laboratory project.

(c) Dr. C.S. Martin; see (6670) above.

(d) Experimental; basic research.

(e) The study is a continuation of an investigation that originally was comprised of three phases. In the completed first phase of the study the magnitude of the seepage force on the top layer of sediment particles on a plane slope was determined. This was accomplished by subjecting the plane slope to seepage flow and then measuring the apparent angle of repose and the piezometric-head gradient within the bed at failure. From the experimental results the seepage force on the top layer of bed particles was computed to vary from $1 / 3$ to $1 / 2$ times the corresponding seepage force on sediment particles well within the bed.

The purpose of the proposed second phase of the study will be to determine the criterion governing incipient sediment motion when a plane bed is subject to not only seepage through it but boundary-layer flow over it, as is present in a stream channel. Experiments will be conducted with sand comprising the bottom of a rectangular water channel. The third phase of the study will be a continuation of the second phase in that the same experimental setup will be utilized. In this case the effect of the seepage force on sediment transport will be ascertained. The sand bed will be allowed to move as the flow through the channel and the seepage flow into or out of the bed are varied.

(g) An experimental investigation was performed to determine the seepage force on uniform, cohesionless bed particles (sand) that comprise the top layer of a stream bed. Slope stability tests were conducted for which water was directed normal to the plane of the bed. The most conclusive results were those for which the water flowed vertically upward into a horizontal bed. The seepage force on the grains forming the interface was found to be approximately one-half the corresponding seepage force on grains well within the bed. Further tests were conducted on the rate of erosion following incipient failure with the plane bed in a horizontal position and the flow directed vertically upward into the bed. The rate of erosion was correlated with the rate of seepage (hydraulic gradient). The hydraulic gradient corresponding to an extrapolated rate of erosion of zero was -3.2. The corresponding seepage force on the grains at the interface is then approximately one-third the seepage force on grains well within the bed.

It is concluded that the seepage force on uniform, cohesionless bed particles at the sand-water interface is approximately onethird to one-half the seepage force on particles well within the bed.

(h) "The Effect of a Permeable Bed on Sediment Transport, Phase I: Seepage Force on Bed Particles, Final Report," OWRR Proj. No. B-004-GA, Water Resources Ctr., Gecrgia Inst. of Tech., WRC-0266, June 1966, 60 pages.

(6693) SOLUTIONS OF SEEPAGE THROUGH COMPIFX MEDIA. BY FINITE EIEMENTS.

(b) Laboratory project.

(c) Dr. Paul G. Mayer, School of Civil Engrg., Georgia Inst. of Tech.

(d) Theoretical; basic research.

(e) Seepage through naturally occurring materials frequently requires treatment of media which are seldom isotropic and more often nonhomogeneous. The method of finite elements is a general numerical method by which complicated seepage problems can be effectively conditioned for digital computation.

(h) "Solution of Anisotropic Seepage by Finite Elements," O. Zienkiewicz and Y.K. Cheung, Jour. Engrg. Mechanics Div., ASCE Proc., EMI-4676, Feb. 1966, pp. 111-120.

\section{(6694) TAINTER GATES AS FIOW MEASURING DEVICES.}

(b) U.S. Dept. of Agriculture, Agricultural Research Service; and laboratory project.

(c) Dr. Paul G. Mayer; see (6673) above.

(d) Theoretical and experimental; applied research.

(e) Soil and water conservation practices in the Southern Florida Flatwoods, as elsewhere, have utilized Tainter gates for the purpose of stream flow control. The study of existing control structures in Okeechobee County, Florida, was coupled with hydraulic model studies to enhance the design of Tainter gates, to investigate the use of such gates as flow measuring devices, to adapt remote sensing devices for the recording of pertinent f'ield data, and to develop computer programs which would translate periodic recordings into discharge rates.

(f) Completed.

(h) "Hydraulic Investigations of Tainter Gates as Flow Measuring Devices," Paul G. Mayer and Bruce R. Olmstead, Final Rept., Georgia Tech Research Sta. Proj. A-953, Dec. 1967, 100 pages. 
"Discharge Characteristics of Partially Open Tainter Gates," Paul G. Mayer, Water Power, Sept. 1965.

(6695) UNSTEADY FLOW OF DILUTE AQUEOUS HIGH POLYMER SOLUTIONS IN PIPES.

(b) Laboratory project.

(c) Dr. Paul G. Mayer; see (6693) above.

(d) Theoretical and experimental; basic research.

(e) Small traces of certain long-chain polymeric molecules, dissolved in water, reduce turbulent friction in flow through pipes. Local additions of polymers will change the resistance characteristics almost instantly, and the progress of the fluid slug with changed properties is a time dependent process. A mathematical study of head and velocity changes is to be carried out using numerical procedures and an electronic digital computer. The mathematical problem is to be formulated as an initial value problem. Solutions to simple pipe problems involve the Runge-Kutta procedures and the Adams-Bashforth method. A laboratory study of unsteady pipe flow is to verify the mathematical model. The mathematical procedures are to be extended to parallel pipe systems and to pipe networks.

(g) Experiments carried out in a 2-inch diameter pipe demonstrated that a 40 per cent reduction resulted from admixture of 100 parts per million by weight. Reductions as much as 60 per cent were observed at polymer concentrations of 300 parts per million. The experiments were carried out as steady-state processes.

The basic simple pipe unsteady pipe flow problem has been solved numerically. Laboratory experiments are under way to verify the procedures.

(6696) FLOW CHARACIERISTICS OF SPHERES IN DILUTE AQUEOUS HIGH POLYMER SOLUTIONS.

(b) Laboratory project.

(c) Dr. Paul G. Mayer; see (6673) above.

(d) Experimental; M.S. thesis.

(e) The addition of small amounts of certain longchain polymeric substances to water causes noticeable changes of drag on spheres at certain Reynolds numbers. Glass spheres and steel spheres are used in a study of settling characteristics in tubes containing various concentrations of polymers dissolved in water.

(6697) MURBULENT FLOW ESTABLISHMENT.

(b) Laboratory project; and U.S. Geol. Survey.

(c) Dr. Paul G. Mayer, Sch. of Civil Engrg., Georgia Inst. of Tech.

(d) Experimental and theoretical; M.S. thesis, Ph.D. thesis.

(e) A major assumption made in experimental and in analytical studies of turbulent flow through straight channels and conduits is that the flow is established. The criterion applied to open channel flows is that of constant depth from station to station, and the criterion applied to enclosed conduit fllow is that of a constant pressure gradient. Flow establishment is studied as a development of the turbulence power spectrum. Established flow is defined as the equilibrium state between turbulence energy generation and energy dissipation.

(f) Suspended.

(g) The study demonstrated that pressure gradients and constant depths are the least sensitive and accurate criteria for flow establishment. The establishment of constant velocity distributions as measured by pitot tubes were a more sensitive criterion. The intensity and scale of turbulence, as well as the turbulence power spectrum are the superior criteria for flow establishment when mixing, diffusion, heat and mass transfer are to be studied.

(h) "Flow Establishment in an Open Channel," J.M. Wallace, Jr., M.S. Thesis, March 1964.

"Investigation of the Energy Spectrum of Thurbulence in a Closed Rectangular Channel," G.M. Slaughter, Ph.D. Thesis, July 1965. "Turbulent Flow in a Three-Dimensional Channel," H.J. Tracy, Ph.D. Thesis, July 1964.

"Turbulent Flow in a Three-Dimensional Channel," H. J.Tracy, Jour. Hydraulics Div., ASCE Proc., Vol. 91, HY6, Nov. 1965, p. 9-36.

(6698) OXYGEN TRANSFER TO WATER DROPIETS.

(b) Laboratory project.

(c) Dr. Paul G. Mayer; see (6697) above.

(d) Theoretical and experimental; M.S. thesis.

(e) The re-aeration of oxygen-deficient streams and lakes is of utmost importance to the full utilization of water resources. A possible method for obtaining water with relatively high concentrations of dissolved oxygen is that of spraying oxygen-deficient water into a pressurized tank with pure oxygen or with air. The water would fall through the atmosphere, absorbing oxygen as it did so, and collect in a receiving pool from which water could be withdrawn to enrich oxygendeficient waters. A preliminary theoretical and experimental investigation was conducted with an oxygen atmosphere. A literature survey was made of the basic interphase mass transfer theories. The preliminary experimental study employed a 75 gallon tank into which water was sprayed through whirl-type nozzles. The operating pressures ranged from zero to approximately 10 atmospheres. Oxygen concentrations were measured with galvanic oxygen analyzers. For the pressures applied, a fifteen-fold increase in dissolved oxygen concentration could be obtained.

The present work is carried out with compressed air in an improved reactor. It is proposed to study the cost-efficiency of the method in its application to oxygen-deficient streams and lakes.

(g) The experimental time-average transfer coefficient was similar to that predicted by both the circulating and the turbulent droplet models.

(6699) DYMAMIC RESPONSE FUNCTIONS OF OCEAN STRUCTURES.

(b) Laboratory project.

c) Dr. Paul G. Mayer; see (6697) above.

(d) Theoretical; Ph.D. thesis.

(e) The object of the study is to develop a technique for analyzing the dynamic response of off-shore structures subjected to random wave forces and to the constraints imposed by the foundation medium of the ocean floor. Emphasis is placed on the use of existing models of the forcing functions and the restraining functions to formulate a numerical method of analysis.

The structural model is analyzed for free and random vibrations. Cross-power spectra are developed for random force fields and random wave heights. Consideration is given to fluid 
damping and the effects of vortex shedding. Dynamic resistance of soils to the movements of piles is to be included. The finite element method may be used in the analysis of dynamic foundation response.

GEORGIA INSTITUTE OF TECHNOLOGY, School of Engineering Mechanics, Atlanta, Georgia 30332 .

\section{(6347) INTERACTION OF SLOSHING LIQUID WITH ELASTIC CONTAINERS.}

(b) National Aeronautics and Space Admin.

(c) Dr. Helmut F. Bauer, Prof., School of Engrg. Mechanics, Georgia Inst. of Tech.

(d) Theoretical; applied research.

(e) Coupled oscillations were considered and the influence of flexibility was considered upon the frequencies. Rectangular containers of infinite width and circular cylindrical containers were treated with either flexible bottom or sidewalls.

(f) Completed.

(h) "Liquid Sloshing in Elastic Containers," H.F. Bauer, T.M. Hsu, and J.T.S. Wang, NASA-CR8802 ( 1967).

(6348) MECHANICAL MODEL FOR LONGITUDINALIY EXCITTD SLOSHING MOTION.

(b) National Aeronautics and Space Admin.

(c) Dr. Helmut F. Bauer; see (6347) above.

(d) Theoretical; applied research.

(e) Representation of liquid sloshing due to longitudinal excitation in rigid circular cylindrical containers as a simple nonlinear mechanical model has been performed. Onehalf-subharmonic response is described by the model.

(f) Completed.

(h) "Mechanical Model for Longitudinally Excited Sloshing Motion," H.F. Bauer and J. Villanueva, Jour. Spacecraft and Rockets, Vol. 4, No. 10, pp. 1376-1379.

(6349) NONLTNEAR IATERAL SLOSHING IN AN ANNULAR CIRCULAR RIGID CYLINDRICAL SECIOR CONTAINER.

(b) School of Engrg. Mechanics.

(c) Dr. Helmut F. Bauer; see (6347) above.

(d) Theoretical; applied research; thesis.

(e) Investigate natural frequency dependency as functions of liquid amplitudes, free oscillations, and nonlinear response to sinusoidal transverse tank excitation.

(f) Starting.

(6350) DYNAMICS OF LIQUIDS IN CYIINDRICAL TANKS WITH A FLEXIBLE BOTYOM.

(b) Dept. of Engrg. Sciences and Mechanics, Univ. of Florida, Gainesville, and School of Engrg. Mechanics, Georgia Inst. of Tech.

(c) Dr. Julius Siekmann, Prof., School of Engrg. Mechanics, Georgia Inst. of Tech.

(d) Theoretical research.

(e) Coupled oscillations of system fluid/tank under consideration of weak gravitational and strong capillary effects.

(f) Completed.

(h) "On Liquid Sloshing in a Cylindrical Tank with a Flexible Bottom Under Strong Capillary and Weak Gravity Effects," J. Siekmann and ShihChih Chang, Jour. of the Astronautical Sei., Vol. XIV, No. 4, pp. 167-172, July-Aug. 1967.
GRUMMAN AIRCRAFT ENGINEERING CORP., Bethpage, N.Y. 11714

(5195) THE EFFECTS OF GAS BUBBLES IN LIQUID SHEAR FLOWS.

(b) Laboratory project.

(c) Dr. Richard A. Oman, Head of Gas Dynamics Group, Research Dept., Plt. 25, Grumman Aircraft.

(d) Experimental and theoretical; basic research.

(e) This program is aimed at determining how a suspension of gaseous bubbles perturbs a liquid flow field. Recent work has concentrated on nozzle flows. After a preliminary one-dimensional flow analysis assuming uniform sized bubbles, we are including bubble expansion in varying pressure field. Experimental work is also directed at finding effects of nozzle geometry on mixtures of different quality.

UNIVERSITY OF HAWAII, Hawaii Institute of Geophysics, Dept. of Civil Engrg., Honolulu, Hawaii

(5893) IABORATORY STUDY OF LONG WAVE AMPLIFICATION AT SMALL CIRCUTAR ISLAINDS.

(b) Conducted as a part of the Hawaii Inst. of Geophysics Tsunami Research Program, Dr. W.M. Adams, Principal Investigator.

(c) Dr. John A. Williams, Assoc. Prof., Dept. of Civil Engrg., Univ. of Hawaii.

(d) Experimental; of an applied research nature.

(e) The project is a model study to determine the amplification of long waves on cylindrical islands which have circular "sea mounts" as bases, i.e.,

$$
h=h_{0}\left(\frac{r}{b}\right)^{q}
$$

where $h_{0}$ is the water depth for all $r \geq b, h$ is the water depth for $a \leq r<b$ ( $a$ is radius of cylindrical island), and $\mathrm{q}$ is an exponent which may vary over the range $0<\mathrm{q}<2$. Wave heights at $r=a$ are observed and compared with predicted values based on linear, long wave theory. The limiting case of $a=0$ is included.

(f) Completed.

(g) Theoretical predictions of long-wave ampliÎication by circular cylinders (Havelock, 1940) and by islands (Webster and Perry, 1366; Homma, 1950) were verified for a limited range of frequencies.

Tests on seamounts with peaks submerged to about 12 percent of the undisturbed water depth showed that particular waves are more sharply focused than others over the peak. For a conical seamount this occurred at a wave length of $1 / 2$ times its base diameter, and for the parabolic seamount, at a wave length of $\pi / 1.7$ times its base diameter. The amplification factors for these two cases are 2.1 and 3.5 , respectively. Theoretical predictions (Wong et al., 1963) for the longest wave sharply focused by the conical seamount agree with the experimental results. Predicted amplitudes, however, are generally smaller and not in agreement with experimental results. 
(h) Results are reported in H.I.G. 66-19, Nov. 1966, Hawail Inst. of Geophysics, Univ. of Hawaii.

(6155) IAMINAR, RADIAL FLOW OF A VISCOUS FLUID BETWEEN PARALLEL PIATES.

(b) Laboratory project.

(c) Dr. John A. Williams; see (5893) above.

(d) Theoretical and experimental; basic research.

(e) The purpose of the investigation is to study the effects of the convective acceleration on the velocity profile of a radial flow and the stability of such a profile.

UNIVERSITY OF HAWAII, J.K.K. Look Laboratory of Oceanographic Engrg., 811 Olomehani St., Honolulu, Hawaii.

\section{(5894) HILO HARBOR, HAWAII SEICHING STUDY.}

(b) Laboratory project, in conjunction with Hawaii Inst. of Geophysics.

(c) Jan M. Jordaan, Jr., Assoc. Prof. of Civil Engrg., Univ. of Hawail.

(d) Experimental, model and field data.

(e) Determination of seiching periods and modes of harbor in present and future planned states, due to tsunamis and storm surges. Continuation study by Univ. of Hawaii on existing 1:600 Hor. 1:200 Ver. model of Hilo Bay of U.S. Army Corps of Engrs. (See No. 3903 in 1965 Issue of Hydraulic Research in the United States under W.E.S., Vicksburg, U.S. Army Corps of Engrs.)

(f) Suspended.

(5895) HILO HARBOR, HAWAII, BEACH EROSION AND RESTORATION STUDY.

(b) Laboratory project, in conjunction with Hawaii Inst. of Geophysics.

(c) Jan M. Jordaan, Jr.; see (5894) above.

(d) Experimental, model and field data.

(e) Determination of feasibility of restoring bathing beach along Hilo Bayfront under present and future planned states of harbor. Utilize existing model; see (5894) under (e).

(f) Suspended.

(5896) TSUNAMI RUN-UP AROUND COASTLINE OF OAHU, HAWAII.

(b) Laboratory project, jointly with Hawaii Inst. of Geophysics; funded by National Science Foundation.

(c) Jan M. Jordaan, Jr., Assoc. Prof. of Civil Engrg.; and William M. Adams, Director, Tsunami Research Group, Univ. of Hawaii.

(d) Experimental, model and field data; basic research.

(e) Determination of wave amplification and runup potential, of tsunamis arriving from various directions, at points around Oahu on $1: 20,000$ and $1: 250,000$ scale models, undistorted.

(g) Light-reflection technique devised to show low-steepness wave motion on screen in background of model. Strain gage wave sensors resolve scaled-down tsunamis of amplitudes down to $0.1 \mathrm{rm}$.

(6072) WIND-WAVE CHARACTERISTICS.

(b) Laboratory project, jointly with Hawaii Inst. of Geophysics; funded by National Science Foundation. (c) William M. Adams, Jan M. Jordaan; see (5896).

(d) Experimental data; basic research; development.

(e) Pilot wind wave flume $48 \mathrm{ft}$. long completed. Report in progress of characteristics of wind waves due to winds up to $45 \mathrm{ft} . / \mathrm{sec}$. Major facility $180 \mathrm{ft}$. long by $4 \mathrm{ft}$. wide by $6 \mathrm{ft}$. high. Wind wave flume in final design stage.

(6073) BARBER'S POINT HARBOR MODEI STUDY.

(b) U.S. Army Corps of Engrs., Honolulu District.

(c) Howard Harrenstien, Director, Center for Engrg. Research, Univ. of Hawaii.

(d) Experimental; model and analytic data; applied research.

(e) Determination of optimum design of deep-draft harbor at Barber's Point, Oahu. Model is to 1:100 scale, undistorted, equipped with variable direction, period and amplitude wave generators.

(6074) KUHIO BEACH MODEL STUDY (WAIKIKI).

(b) State of Hawaii, Dept. of Transportation, Harbors Div., Honolulu, Hawaii.

(c) R.Q. Palmer, Consultant, Univ. of Hawaii.

(d) Experimental and field data; applied research.

(e) Determination of optimum beach alignment and protection for Kuhio Beach Section, Waikiki Beach, Oahu.

(f) Completed.

(g) Beach alignment parallel to refracted wave crests recommended.

(6075) WAVE FORCES ON SUBMERGED SPHERES.

(b) Laboratory project.

(c) R.A. Grace, Asst. Prof. of Civil Engrg., Univ. of Hawaii.

(d) Field installation on foreshore; basic research for Master's thesis.

(e) To obtain inertial and drag resistance coefficients for objects in shallow water waves.

UNIVERSTTY OF HOUSTON, Mechanical Engineering Dept., Houston, Texas 77004

(6381) THE DETERMINATION OF VORTEX MOTION AND DRAG ON A CIRCULAR CYIINDER DUE TO VORTEX MOTION.

(b) Laboratory project.

(c) Prof. Charles Dalton, Mechanical Engrg. Dept., Univ. of Houston.

(d) Doctoral dissertation; analytical and basic research.

(e) Investigation of the growth of vortices behind a circular cylinder in an oscillating flow. The vortices are represented by means of the lumped vortex model.

(6382) OBSERVATION OF WAIE VORTICES FOR A CIRCULAR CYLINDER IN AN OSCILIATING FLOW.

(b) Laboratory project.

(c) Prof. Charles Dalton; see (6381) above.

(d) Master's thesis; experimental.

(e) The wake formation and growth of vortices behind an oscillating circular cylinder were observed by means of a flow-visualization technique.

(f) Completed.

(g) The results indicated that the dimensions and characteristics of the cylinder wake depend strongly on the relative amplitude of the oscillatory motion. The frequency (for the range inciuded in the investigation) of 
oscillation had very little effect on this same wake.

HYDRONAUTICS, INCORPORATED, Pindell School Rd., Laurel, Maryland 20810

(6644) RESEARCH ON OCEAN PHENOMENA.

(b) Office of Navial Research, Dept. of the Navy.

(c) Walter P.M. van de Watering, HYDRONAUTICS, Incorporated.

(d) Experimental and theoretical; basic research.

(e) The purpose is to obtain a better understanding of hydrodynamic phenomena in the ocean such as the generation of internal waves in density stratifications, the generation of wind waves and capillary waves and the change in gravity and capillary wave spectra associated with surface currents being superposed on the wind waves.

(h) A large number of technical reports have been issued, e.g.,

"The Upper Ocean Layers," Owen M. Phillips, HYDRONAUTICS, Incorporated, Tech. Rept. 231-1, May 1963.

"On Internal Gravity Waves Generated by Local Disturbances, "K.K. Wong, HYDRONAUTICS, Incorporated, Tech. Rept. 23l-5, Feb. 1965. "Surface Currents Due to a Submerged Disturbance in a stratified Ocean, " HYDRONAUTICS, Incorporated, Tech. Rept. 231-6, Feb. 1765. "Flow Phenomena Caused by the Collapse of a Mixed Region in a Density-Stratified Medium," Jin Wu, HYDRONAUTICS, Incorporated,Tech. Rept. 231-11, March 1966.

"Wind Profile Analysis," J. Wu, HYDRONAUPICS, Incorporated, Tech. Rept. 231-13, June 1967. "Wind Stress and Surface Roughness at the Air-Sea Interface," Jin Wu, HYDRONAUPICS, Incorporated, Tech. Rept. 231-18, in press.

(6645) HYDRODYMAMICS OF DISPERSE SYSTEMS.

(b) Office of Naval Research, Dept. of the Navy.

(c) Marshall P. Tulin, HYDRONAUTICS, Incorporated.

(d) Experimental and theoretical; basic research.

(e) Theoretical: disperse systems in general; considerations of the mechanics of dilute solutions of polymers; the bulk properties of macromolecular solutions; the way the molecular strains relate to flow patterns; the effect of elastic stresses upon turbulent flows and turbulence itself, and, finally, on turbulent flows with radiation damping, which includes pipe flow thickening of the viscous sub-layer.

Experimental: the effect of additive injection and of electrolytic bubble generation on plate resistance; a study of the effect of macromolecular additives on the spreading of a cylindrical cloud of free turbulence, experiments on the decay of turbulence behind a grid in which the dispersion of small buoyant particles was photographed, the effect of polymer concentration on impact tube pressures, and the measurement of the velocity distribution in the laminar sub-layer.

(h) "Experiments on Free Turbulence in ViscoElastic Fluids," Jin Wu, HYDRONAUTICS, Incorporated, Tech. Rept. 353-1, March 1965. "The Effect of Ejected Polymer Solutions on the Resistance and wake of a Flat Plate in a Water Flow, "R. Love, HYDRONAUTICS, Incorporated, Tech. Rept. 353-2, June 1965.
"The Maintenance of Reynolds Stress in Thrbulent Shear Flow," O.M. Phillips, HYDRONAUTICS, Incorporated, Tech. Rept. 353-3, Jan. 1967.

"Hydrodynamic Aspects of Macromolecular Solutions, "M.P. Tulin, HYDRONAUPICS, Incorporated, Tech. Rept. 353-4, May 1967. "Pressure Fluctuation Measurements in Dilute Polymer So 1 utions, " D.N. Contractor, HYDRONAUTICS, Incorporated, Tech. Rept. 353-5, Sept. 1967.

(6646) FUNDAMENTAL STUDIES OF VENPIIATED CAVITY FIOWS.

(b) Naval Ship Research and Development Ctr., Dept. of the Navy.

(c) Virgil E. Johnson, HYDRONAUTICS, Incorporated.

(d) Experimental; basic research.

(e) This research was intended to delineate the effects on ventilated cavity flows of the following parameters:

1. Submergence depth below the free surface;

2. struts in the proximity of the cavity;

3. transverse gravity fields; 4. cavity air supply.

The experimental results were compared to theoretical predictions in those fields for which theory had been developed.

(f) Completed.

(h) "Effects of Ambient Conditions, The Gravity Field, and Struts, on Flows over Ventilated Hydrofoils," R. Altmann and C. Elata, HYDRONAUTICS, Incorporated, Tech. Rept. 605-1, May 1967.

"Choking of Strut-Ventilated Foil Cavities," C. Elata, HYDRONAUTICS, Incorporated, Tech. Rept. 605-2, May 1967.

(6647) BIDOD FLOW HYDROMECHANICS.

(b) Office of Naval Research, Dept. of the Navy. (c) Clinton Brown, HYDRONAUIICS, Incorporated.

(d) Experimental and theoretical; basic research.

(e) The investigation is an effort to expose pertinent hydrodynamic factors which affect the blood flow in the arterial system of man. These studies emphasize theory and experiment pertaining to the hydrodynamic effect of flow on the filtration theory of atherogenesis.

(6648) INVESTIGATION OF A TANDEM ROW, HIGH HEAD PUMP INDUCER.

(b) National Aeronautics and Space Admin., Marshall Space Flight Center.

(c) Virgil E. Johnson, HYDRONAUTICS, Incorporated.

(d) Theoretical and experimental; applied research.

(e) Design and testing of the tandem row concept for pump inducers. The first stage has been designed as a super-cavitating pump, the second stage as a high solidity, high head impeller without cavitation. The inducer is tested in a pump loop. The high suction performance inducer is used as an inlet stage for high speed, high performance rocket engine turbopumps.

(h) "Supercavitating Cascades with Constant Pressure Cambered Blades," B. Yim, HYDRONAUTICS, Incorporated, Tech. Rept. 703-2, July 1767.

(6647) EXPERIMENTAI AND THEORETICAL STUDY OF THE HYDRODYNAMICS OF DISPERSION IN RIVFRS AND ESTUARIES.

(b) Office of Water Resources Research, U.S. Dept. of the Interior.

(c) Walter P.M. van de Watering, HYDRONAUTICS. Incorporated.

(d) Experimental and theoretical; basic research. 
(e) The general aims of the research are: to develop methods enabling the calculation of velocity distributions in streams which may be used to determine the dispersion coefficient; to provide experimentally verified quantitative results relating to dispersion in channels with varying aspect ratio and boundary roughness distribution; to develop quantitative verified theories relating components of the dispersion tensor to the mean flow characteristics; to provide useful and verified information and procedures relating to the scaling and model testing of dispersion in streams.

(h) "On the Theory of Longitudinal Dispersion," C. Elata, Intl. Assoc. Hydraulic Research Congr., Fort Collins, 1967.

(6650) ROCK TUNNELING WITH HIGH SPEED WATER JETS UTIIIZING CAVITATION DAMAGE.

(b) U.S. Dept. of Commerce, Office of High Speed Ground Transportation.

(c) Virgil E. Johnson, Jr., HYDRONAUTICS, Incorporated.

(d) Experimental and theoretical; applied research.

(e) The primary purpose of the research is to determine if high speed cavitating water jets can drill hard rock more effectively than existing tunneling methods. A test facility was designed and constructed which produces a 0.25 inch diameter water jet with a variable velocity up to 500 fps. Cavitation is induced within the jet by means of various inserts which are placed in a specially designed nozzle. The distance between nozzle and specimen is varied as well as the jet angle of attack.

(g) Very intense erosion is produced. Method looks feasible.

(6651) MODEIING CAVITATION EROSION.

(b) Office of Naval Research, Dept. of the Navy.

(c) Dr. A. Thiruvengadam, HYDRONAUTICS, Incorporated.

(d) Experimental and theoretical; basic research.

(e) The purpose of the experiments is to find the scaling laws to model cavitation erosion. Using a magnetostriction device the cavitation damage resistance for various materials was determined. Tests are conducted with foils to determine the cavitation damage over a range of speeds for different foil shapes and depths of submergence (real time test).

(h) A variety of reports have been issued on this subject, e.g.:

"A Comparative Evaluation of Cavitation Damage Test Devices, " HYDRONAUTICS, Incorporated, Tech. Rept. 233-2, 1963. (See also Symp. on Cavitation Research Facilities and Techniques, ASME Fluids Eng. Conf., May 1964). "On Testing Materials for Cavitation Damage Resistance," A. Thiruvengadam and H.S. Preiser, HYDRONAUTICS, Incorporated, Tech. Rept.

233-2, 1964. (Also Jour. Ship Research, Dec. 1964).

"On the Role of Corrosion in Cavitation Damage, "A. Thiruvengadam, S. Waring and H. S. Preiser, HYDRONAUTICS, Incorporated, Tech. Rept. 233-4, 1964. Presented at the 20th Annual Conf., Natl. Assoc. of Corrosion Engrs., March 1964. (Also Jour. Ship

Research, Dec. 1965).

"Mechanical Properties of Metals and Their Cavitation Damage Resistance," A. Thiruvengadam, HYDRONAUTICS, Incorporated, Tech. Rept.
233-5 July 1964. (Also Jour. Ship Research, March 1966).

"High Frequency Fatigue of Metals and Their Cavitation Damage Resistance," A. Thiruvengadam, HYDROIAUTICS, Incorporated, Tech. Rept. 233-6, Dec. 1964. (Jour. of Engrg. for Industry, Trans. ASME, Vol. 88, Series B. , No. 3, Aug. 1966).

"The Concept of Erosion Strength," A. Thiruvengadam, HYDRONAUTICS, Incorporated, Tech. Rept. 233-9, March 1966. (ASTM Publication "Symposium on Erosion by Cavitation or Impingement, "STP 408 March 1967).

"Cavitation Damage in Liquid Metals," A. Thiruvengadam and H.S. Preiser, HYDRONAUTICS, Incorporated, Tech. Rept. 467-Final, NASA, CR-72305, Sept. 1965.

"On Modeling Cavitation Damage," A.

Thiruvengadam, HYDRONAUTICS, Incorporated, Tech. Rept. 233-10, Aug. 1966.

"Theory of Erosion,"A. Thiruvengadam, HYDRONAUTICS, Incorporated, Tech. Rept. 233-11, March 1967.

\section{(6652) EXPERIMENTAL AND THEORETICAI RESEARCH ON} TURBIDITY CURRENTS.

(b) Office of Naval Research, Dept. of the Navy.

(c) Walter P.M. van de Watering, HYDROMAUIICS, Incorporated.

(d) Experimental and theoretical; basic research.

(e) The purpose is to describe quantitatively the growing process of turbidity currents through experiments and theory; to develop a theory describing the steady state, taking into account the actual distributions of velocity and density, the entrainment of ambient fliud, and the erosion and deposition of sediments, verified by experimental results; to obtain useful and verified information and procedures related to the scaling and model laws for turbidity currents.

(6653) THE INCEPTION OF CAVITATION.

(b) Naval Ship Research and Dev. Ctr., Dept. of the Navy.

(c) Virgil E. Johnson, HYDRONAUTICS, Incorporated. (d) Theoretical and experimental; basic research.

(e) The purpose is to find the change in size of entrained gas bubbles in the free stream passing a body. Trajectories of such bubbles are now being calculated. Model tests and the necessary equipment and instrumentation are under preparation. The model tests will consist of measuring the distribution of the bubble size in the free stream and comparing measured trajectories of a bubble passing an actual body with the theoretically predicted trajectories.

(h) "The Influence of the Trajectories of Gas Nuclei on Cavitation, "Virgil E. Johnson and Tsuying Hsieh, 6th Symp. on Naval Hydrodynamics, 1966.

UNIVERSTTY OF IDAHO, College of Engineering, Moscow,

(3057) CONSERVATION OF WATER FOR RANGE STOCK.

(b) Laboratory project; in cooperation with Bureau of Land Management and ranchers.

(c) J.C. Moore, Asst. Prof., Civil Engrg. Dept., Univ. of Idaho.

(d) Field investigation; applied operational 
research.

(e) Field investigation to study hydrology of small desert watersheds, evaporation under field conditions and occurrence of impermeable earth materials has been made. Several small ponds have been constructed using various manufactured lining materials and the effectiveness of evaporation retardants under field conditions has been investigated. It is proposed to construct several small ponds in naturally impermeable sites or lined with local impermeable earth materials.

(f) Completed.

(g) Performance of manufactured lining materials including plastics, combinations of glass fiber and bitumen, and films of asphalt cutbacks and emulsions was investigated under field conditions. Criteria were developed for the estimation of evaporation and seepage. A digital computer program was developed enabling the investigator to determine total pond storage required, volume of earthwork in dam, and area requiring lining for a small dam and reservoir site in terms of desired storage capacity after evaporation, width of stream floodplain, longitudinal slope of floodplain, and transverse slope of terrain to sides of floodplain. Criteria for the selection of size of watershed to supply ponds fed by small intermittent streams were developed. Some work was done on the evaluation of the hydrology of small desert watersheds, site permeability, and location of sources of natural impermeable materials through airphoto interpretation.

(h) "Stock Watering Ponds in Southwestern Idaho," John C. Moore, Univ. of Idaho Engrg. Expmt. Sta. Research Rept. 5, April 1966.

"The Development of Inexpensive Stock Watering Facilities in Semiarid Regions," John C. Moore. Proc. Intl. Conf. on Water for Peace, May 1967.

(5167) TOTAL HYDROELECTRIC RESOURCES IN IDAHO AND DEVEIOPMENT PROBLEMS ON IDAHO STREAMS.

(b) Leboratory project.

(c) Prof. Paul Mann, Elec. Engrg. Dept., Univ. of Idaho.

(d) Experimental; applied research for master's thesis.

(e) A study of streamflow data is being made to determine full water resources capability. The study is designed to develop estimating constants which may give a 90 percent accuracy. New ideas for stream-to-stream diversion will be investigated.

(f) Completed.

(h) "A Study of Hydro Peaking Capacity in Idaho," R.R. Goranson, unpublished M.S. thesis, Univ. of Idaho, 1964.

(5170) CORREIATION FOR THE DISPERSION OF IIQUIDS FIOWING THROUGH PACKED BEDS USING MODIFIED RANDOM WALK MODELS.

(b) Laboratory project.

(c) Dr. R.R. Furgason, Chem. Engrg. Dept., Univ. of Idaho.

(d) Theoretical and experimental; basic research for doctoral thesis.

(e) The random walk equations were used as a model for the horizontal liquid distribution in a packed bed. A study was made of the effect of the liquid properties (surface tension and viscosity) on the horizontal dispersion of the liquid and the horizontal step sizes. A proposed mechanism for liquid flow through packed beds, consisting of a series of pools and vertical steps was evaluated by comparing the residence time for a tracer in the liquid with the apparent residence time for the liquid itself.

(i) Completed.

(g) The dispersion of a liquid in a packed bed was found to be affected by both surface tension and viscosity. A decrease in surface tension caused an appreciable decrease in the horizontal dispersion coefficient while an increase in viscosity caused a lesser decrease for any given size of packing.

(h) "Mechanisms of Liquid Flow in Packed Beds," G.R. Irving, unpublished Ph.D. thesis, Univ. of Idaho, 1966.

\section{(5368) GROUND WATER MOVEMENT IN HIGHWAY IANDSLIDES.}

(b) Laboratory project; cooperative with Idaho Dept. of Highways and Idaho Bureau of Mines and Geology.

(c) Prof. J.J. Peebles, Coll. of Engrg. Univ. of Idaho.

(d) Experimental and field investigation; applied research and development with master's thesis.

(e) To study the flow characteristics of ground water movement in landslides and to ascertain sources of the water. Tracing techniques are being studied using dyes and isotopes as well as other pressure measuring devices. This is an attempt to predict and identify slide behavior in places where slides are apt to occur.

(f) Completed.

(g) Conclusions of this project are that both fluorescein and pentacyl can be advantageously used to delineate ground water movement in relation to landslides. Graphical presentation of fluoriometer readings is essential before definite conclusions can be made. The augerhole method of determining in-situ hydraulic conductivity can be used in some landslide investigations as an aid in planning a tracer program.

(h) "A Study of Groundwater Movement in Landslides," W.V. Jones and John J. Peebles, Engrg. Expmt. Sta., Univ. of Idaho, June 1966.

(5897) FACTORS INFLUENCING THE FIOW OF SUBSOIL WATER IN THE IMMEDIATE PROXIMITY OF AND INTO DRAINAGE FACILITIES.

(b) Western Regional Research Project.

(c) Dr. G.L. Corey, Head, Dept. of Agric. Engrg., Univ. of Idaho.

(d) Experimental; basic.

(e) To develop a dimensionless nomograph for vertical free drainage from various soils.

(g) A transducer system has been used to record pressures in a column during drainage

(h) An M.S. thesis will be completed in 1,68.

(5898) TWO AND THREE-DIMENSIONAL DIFHUSION ANALYSIS OF UNSTEADY FLOW INIO POROUS MEDIA.

(b) Laboratory project.

(c) Dr. G.L. Corey; see (5897) above.

(d) Experimental; basic.

(e) To determine quantity and rates of advance of flow into porous materials with various initial capillary pressures.

(g) A technique for using a tensiometer pressure transducer system for studying transients developed and tested.

(h) "Using a Tensiometer-Pressure Transducer Apparatus to Study Imbibition, "N.C. Young, unpublished M.S. thesis, Univ. of Idaho. 
(5902) TRANSITION BETWEEN IAMLINAR AND TURBULENT FLOW IN POROUS MEDIA.

(b) National Science Foundation.

(c) Dr. G.I. Bloomburg, Agric. Engrg. Dept., Univ. of Idaho.

(d) Theoretical and experimental basic research for master's thesis.

(e) A theoretical and experimental investigation of the transition between laminar and turbulent was conducted.

(f) Completed.

(g) A theoretical development of the relationship between friction factor and Reynolds number for flow in porous media was obtained. This was similar to a development by S. Irmay but the experimental data contradict some of the assumptions made by Irmay.

(h) "Laminar and Turbulent Flow Through Spherical Particles," M.R. Gibbens, unpublished M.S. thesis, Univ. of Idaho, 1968.

"Transition Between Laminar and Turbulent Flow in Porous Media," G.I. Bloomsburg and M.R. Gibbens, Agric. Engrg. Dept., Univ. of Idaho, Jan. 1968.

(5903) EFTECT OF EXTERINAL AIR PRESSURE ON LIQUID FLOW THROUGH POROUS MEDIA.

(b) Laboratory project.

(c) D.W. Fitzsimmons, Asst. Prof.,Agric. Engrg. Dept., Univ. of Idaho.

(d) Experimental and theoretical; basic research.

(e) The effect of changes in external air pressure on flow of a liquid through a porous medium containing trapped air will be investigated in laboratory columns.

(6701) INVESTICATION OF METHODS FOR AUTOMATIC MEASUREMENTI OF SNOW WATTER.

(b) Laboratory and U.S. Army Corps of Engrs.

(c) V.E. Penton, Asst. Prof., Mech. Engrg. Dept., Univ. of Idaho.

(d) Experimental; development work for M.S. thesis.

(e) One portion of the project involves measuring the runoff from snow pillows since this would give a measure of the rate of snow melt. Various designs for the snow pillow will be investigated. Another part of the project involves investigation of a diurnal fluctuation in snow pillow readings which often occurs.

(h) "Experience with the Pressure Pillow as a Snow Measuring Device," V.E. Penton and A.C. Robertson, Water Resources Research,Vol. 3, No. 2, pp. 405-408, 1967. An M.S. thesis will be completed in 1968 .

(6702) A STUDY OF VECTOPLUVIOMETERS.

(b) Agricultural Research Service, U.S. Dept. Agric.

(c) V.E. Penton; see (6701) above.

(d) Experimental; development work for an M.S. thesis.

(e) The objective is to develop a device to measure the horizontal component of wind blown snow, to help in the determination of the vertical component.

(g) Catch efficiencies for various designs have been determined for sawdust in a laboratory wind tumnel.

(h) An M.S. thesis will be completed in 1968.

(6703) RELATIONSHIP OF PUMPING IIFT TO ECONOMLC USE OF GROUNDWATER FOR IRRICATION.

(b) Idaho Water Resources Board; and Office of Water Resources Research.

(c) Dr. G.I. Corey, Head, Dept. of Ag. Engr., Univ. of Idaho. (d) Field investigation; operation; for M.S. thesis.

(e) During the last few years numerous deep well (<500 ft.) pumps have been installed by private developers to irrigate desert land in southern Idaho. This project is to determine the economic aspects of such projects with respect to types of crops grown.

(h) "Relationship of Pumping Lift to Economic Use of Groundwater for Irrigation," R. Cheline and R. Haynes, Idaho Agric. Research Progress Rept. 1No. 130, 1967. An M.S. thesis will be completed in 1968.

(6704) AGRICULITURAL WATERS NEEDS FOR THE STATE OF IDAHO.

(b) Idaho Water Resources Board.

(c) Dr. G.I. Corey; see (6703) above.

(d) Field investigation; operation; for M.S. thesis.

(e) The monthly consumptive use values for 12 crops at 29 weather stations in Idaho will be determined by the modified Blaney-Criddle Method.

(g) A computer program has been developed for the above computations.

(h) A progress report will be issued in 1968.

(6705) PRELIMINARY INVENTORY OF THE WATER RESOURCES FOR THE STATE OF IDAHO.

(b) Idaho Water Resources Board.

(c) J.J. Peebles, Assoc. Prof., Civil Engrg. Dept.

(d) Field investigation; operation.

(e) To provide base information for water resource development of the state.

(h) A final report will be issued in Sept. 1968.

(6706) AN IMPROVED RADIOACITVE SNOW GAGE.

(b) Laboratory; U.S. Bureau of Reclamation; U.S. Corps of Engrs.; Office of Water Resources Research.

(c) Dr. R.E. Warner, Assoc. Director, Engrg. Expmt. Sta., Univ. of Idaho.

(d) Experimental; development.

(e) To develop a scintillation detector which can be used for the determination of water equivalents for snow packs of up to 100 inches of water.

(f) Completed.

(g) A scintillation detector system was developed.

(h) "A. Nuclear Radiation Snow Gage," G.A. McKean, Bull. No. 13, Engrg. Expmt. Sta., Univ. of Idaho, Aug. 1967.

(6707) BUBBLING PHENOMENA IN FLUIDIZED BEDS.

(b) Laboratory project.

(c) Dr. J.B. Romero, Assoc. Prof., Chem. Engrg. Dept., Univ. of Idaho.

(d) Experimental, basic; for M.S. thesis.

(e) Determine characteristics of bubbles in fluidized beds.

(g) An X-ray unit has been calibrated for studies in fluidized beds.

(h) An M.S. thesis will be completed in 1968 .

(6708) ANALYSIS OF STREAMFLOW SEPARATION TECHNIQUES.

(b) Laboratory project.

(c) C.C. Warnick, Director, Water Res. Research Inst., Univ. of Idaho.

(d) Field investigation, operation; for M.S. thesis.

(e) Purpose was to determine whether there is correlation between ground water levels and stream discharge for purpose of refining separation technique. 
(f) Completed.

(g) No relationship was found between ground water level adjacent to the water course and stream flow when a large range of stream flow was plotted.

(h) "An Analysis of Streamflow Separation Techniques," H.T. Davis, unpublished M.S. thesis, Univ of Idaho, Aug. 1967.

(6709) BUBBLING HEAT TRANSFER RESEARCH.

(b) Laboratory project.

(c) W.P. Barnes.

(d) Study of film and nucleate boiling between solid surfaces and various liquids.

(e) Experimental, design and development for M.S. thesis.

See Water Resources Research Catalog, Vol. 2.

(O3IW) PHYSICAL STATE PROPERTIES OF PRECIPITATION. (Formerly No. 5899)

(O32W) MOVEMENT OF WATER FROM CANAIS TO A GROUNDWATER TABLE. (Formerly No. 5900)

(O33W) HYDROLOGY OF FROZEN GROUND FLOODS. (Formerly No. 5901)

(051W) STUDIES ON METHODS OF SOIL WATER DETERMINATION.

IIT RESEARCH INSTITUTE, ' $10 \mathrm{~W}$. 35th St., Chicago, Ill. 60616

(5196) TURBULENT FIOW TRANSITION NEAR SOLID AND FLEXIBIF BOUNDARIES.

(b) Naval Ship Sys. Comm. General Hydromechanics Res. Program, administered by Naval Ship Res. and Dev. Ctr.

(c) Mr. Henry B. Karplus, Research Physicist, IIT Research Inst.

(d) Experimental; basic research.

(e) Transition to turbulence is investigated in a water channel having walls with adjustable rigidity. It is intended to obtain a better understanding of the effect of resilience and damping of the walls on the build up of turbulence in boundary layers. The uitimate objective is the reduction of drag of vessels and the reduction of boundary layer noise in hydrophone domes.

(f) Completed.

(g) Transition to turbulence is affected by wall resilience. Flexible walls may delay turbulence onset over limited flow rate regions.

(h) Final Technical Report No. IIT RI M-6110.

(5904) OPTICAI MEASUREMENTS WITH HIGH TFMPORAI AND SPATIAL RESOLUITON.

(b) Natl. Aeronautics and Space Admin., Marshall Space Flight Ctr.

(c) Mr. M.J. Fisher, IIT Research Inst.

(d) The aim of this project was the development of a technique for measuring the local turbulent properties of shear layers while avoiding the insertion of probes into the flow.

(e) An experimental technique is being developed with the aid of which estimates of local turbulent properties of shear layers may be obtained without the necessity of inserting probes into the flow field. The probe is replaced by two beams of radiation, which pass through the entire flow field in two mutually perpendicular directions. It has been shown that, although each beam independently measures only an integral of the flow properties along the entire light path between the source and detector, the covariance of the two detected signals does yield local turbulent information.

Although the technique is primarily aimed at supersonic or hot turbulent flows a verification study has been performed using a subsonic jet. Good agreement with published hot wire data has been obtained.

(f) Completed.

(g) The results of this study clearly demonstrate the potential of this method for the investigation of many aspects of turbulent flows which have been previously inaccessible experimentally.

(h) "The Crossed Beam Correlation Technique," M.J. Fisher, and F.R. Krause, J. Fluid Mech. Vol. 28, p. 706, 1967.

"Mapping of Turbuient Fields by Crossing Optical Beams," F.R. Krause, 20th Anniv. Mtg., Amer. Phys. Soc., Nov. 1967.

"Optical Measurements with High Temporal and Spatial Resolution," M.J. Fisher and R.J. Damkevala, Final Report on IIASA Contract No. INAS8-11258, Sept. 1967.

(5913) NOISE TRANSMISSION IN FIUID AMPLIFIERS.

(b) Harry Diamond Labs., U.S. Army Materiel Comm.

(c) Mr. Dennis W. Prosser, Research Engr., IIT Research Inst.

(d) Experimental and theoretical.

(e) The objective of this program was to determine the relative importance of stage-produced noise and transmitted noise in two-stage proportional fluid amplifiers.

(e) Completed.

(g) The main results of this program were: (1) The ratio of stage produced to transmitted noise is frequency dependent; (2) stage produced noise predominates over transmitted noise, except when control noise from the first stage is very large or is of a low frequency nature.

(h) "Noise Transmission in Fluid Amplifiers," D.W. Prosser, Nov. 30, 1966, Final Rept. to Harry Diamond Labs. under Contract No. DA-49-186-AMC-196 (D), Mod. No. 5. Contact HDI for copies of the report.

(6118) STUDY OF VIBRATIONS INDUCED IN THIN-WALTED PIPES UNDER VARYING FIOW CONDITIONS. (See no. 5538 in past issues)

(b) Natl. Aeronautics and Space Admin., Marshall Space Flight Ctr.

(c) Dr. J.M. Clinch, IIT Research Inst.

(d) This work involved an experimental and theoretical investigation of the vibrational response of thin-walled pipe sections to the wall pressure field applied by internal turbulent water flow within them.

(e) A continuously operating water flow loop facility capable of producing Reynolds numbers of $2 \times 10^{6}$ was designed and constructed for the investigation. Wall-mounted miniature pressure transducers were also fabricated to record the wall pressure fluctuations. Statistical properties of the wall pressure fluctuations determined from these recordings included the power spectral density and the space-time and spatial correlation of the wall pressures in 1/3-octave frequency bands. The data obtained from these measurements and also from measuring the pipe damping factor were employed to calculate, on the basis of random vibration theory, the pipe wall response to 
fully-developed turbulent flow excitation.

(f) Completed.

(8) Measurements of the vibrational response to fully-developed turbulence of given pipe sections showed very good agreement with the predicted value of the response over a wide range of flow speeds and exciting frequencies. The results obtained from measuring the pipe wall response at various positions downstream of pipe bends and non-cavitating orifice plates were essentially identical to those for fully-developed flow conditions. It was found that the power spectral density of the pipe wall displacement could be expressed as a function of the Strouhal number based on the pipe diameter and mean flow speed. The results indicated that the displacement power spectral density of the pipe wall vibrations decreased at the rate of $15 \mathrm{~dB} /$ octave at low strouhal numbers and $18 \mathrm{~dB} /$ octave at high strowhal numbers.

(h) "Study of Vibrations Induced in Thin-Walled Pipes by Fluid Flow," J.M. Clinch, Final Rept. on IASA Contract No. NAS8-11248, Sept. 1965. "A Miniature Transducer Assembly for Measuring the Properties of the Wall-Pressure Field in Turbulent Flows," J.M. Clinch, J. Acoust. Soc. Amer., Vol. 40, p. 254, July 1966.

"The Vibrations of Thin-Walled Cylinders Arising from Turbulent Fluid Flow," J.M. Clinch, Ph.D. Thesis, Univ of London, May 1967. "Study of Vibrations Induced in Thin-Walled Pipes under Varying Flow Conditions," J.M. Clinch, Final Rept. on INASA Contract No. NAs8-20325, June 1967.

(6119) STAGE PRODUCED NOISE IN FLUID AMPLIFIERS.

(b) Harry Diamond Labs., U.S. Arny Materiel Conm.

(c) Mr. Dennis W. Prosser, Research Engr., IIT Research Inst.

(d) Experimental and theoretical; basic research.

(e) The objective of this program is to investigate the factors producing noise, defined as undesirable fluctuations of flow properties, in a proportional fluid amplifier, and to reduce the noise if possible.

(f) Almost corpleted.

(g) Tentative results indicate that the noise is almost entirely due to the inherent turbulent nature of the power jet. Thus, no simple geometric changes will reduce the noise, with the possible exception of the use of devices with quite small aspect ratios (thin ampliffiers). In that case jet turbulence would be modified to something more like boundary layer turbulence. Even then there would possibly be little improvement, especially when the signal is also decreased by this approach.

(h) Monthly Progress Reports have been submitted to the Harry Diamond Labs.

ILIINOIS DIVISION OF WATERWAYS, Dept. of Public Works and Bldgs., Springfield, IIl. 62706

Address correspondence on all projects to: Mr. John C. Guillou, Chief Waterways Engr., Div. of Waterways, Dept. of Public Works and Bldgs., 201 W. Monroe St., Springfield, Ill. 62706.

(1863) EROSION CONTROI, ILIINOIS SHORE OF IAKE MICHICAN.

(b) State of Illinois.

(d) Field investigation; applied research. (e) To obtain and correlate basic data on the several forces and factors involved in erosion processes along the Illinois Shore of Lake Michigan to the end that future efforts toward the prevention of erosion might be founded upon a more definite and factual basis with a consequent greater degree of assurance that the works will serve the intended purposes.

(g) No significant results since last report.

(5549) ILIINOIS RIVER.

(b) State of Illinois.

(d) Experimental; applied research.

(e) A hydraulic model study is being conducted to determine the effects, on the Upper Illinois River, of various flood relief measures proposed for the Illinois Waterway and Chicago Sanitary and Ship Canal.

(5656) KINKAID CREEK DAM.

(b) State of Illinois.

(d) Experimental; applied research.

(e) A hydraulic model study is being conducted to assist in the design of the spillway and stilling basin for a proposed reservoir to be constructed in Jackson County, Ill.

(6094) NAPERVILIE DAM.

(b) State of Illinois.

(d) Experimentally applied research.

(e) A hydraulic model study is being conducted to assist in the design of the outlet structure and stilling basin for a proposed reservoir to be constructed near Naperville, Illinois, in DuPage County.

(g) No results at this time.

(6095) MONIGOMERY LOCK.

(b) State of Illinois.

(d) Experimentally applied research.

(e) A hydraulic model study is being conducted to determine the filling system for the proposed $23^{\prime} \times 43^{\prime}$ and $23^{\prime} \times 15^{\prime}$ recreational navigation locks to be constructed in the Fox River at Montgomery, Illinois. The two-lock system will be constructed in stage development with the locks having a common filling wall.

ILIINOIS STATE WATTR SURVEY, BOX 232, Urbana, IIl. 61802

A list of publications is available upon request from Illinois State Water Survey at above address.

(1865) HYDRAUIIC DESIGN OF DROP-INLET SPILIWAY STRUCTURES FOR SMATU RESERVOIRS.

(b) Iaboratory project, in cooperation with U.S. Dept. Agric., Agricultural Research Service, Soil Conservation Service; and Illinois Agric. Expmt. Station.

(c) Mr. H.W. Humphreys, Illinois State Water Survey, (Urbana).

(d) Experimental; generalized applied research for development and design.

(e) To determine the most desirable proportions and shapes of drop-inlet spillway structures that have unique flow characteristics and to develop anti-vortex devices. To provide the necessary information on flow relations and discharge coefficients so that these structures may be economically designed. Experimental apparatus and tests conducted 
on the complete spillway. Information is being obtained on discharges, vortex effect on discharge, pressures, head loss coefficients, a flat plate anti-vortex device, and flow conditions.

(g) Model tests were performed on a drop-inlet spillway to determine whether or not a metal grating deck placed above the inlet can control vortices. The results of the tests show that gratings do not prevent or control strong vortices.

(h) Report of investigation in preparation covering circulation effects, flat plate anti-vortex device effect, and vortex effect on model spillway performance.

(2535) FIITERING THROUGH COARSE MATERTALS.

(b) Laboratory project.

(c) Mr. Ralph I. Evans, Peoria Lab., Illinois State Water Survey, Box 717, Peoria, I1l.

(d) Experimental; basic research.

(e) Sma11, coarse media (1/4 - to 3/4-inch) filters are operated at rates comparable to those achieved in field practice. Purpose is to study the effects of coarse media on physical, chemical, and bacteriological properties of recharged water and to evaluate the function of coarse media in protecting aquifer materials.

(g) The results show that the suspended material passing through coarse media is dependent upon gravel size and depth, flow rate, and suspended solids in the applied water.

(4135) CORROSION PREVENTION BY $\mathrm{CaCO}_{3}$.

(b) Laboratory project.

(c) Dr. T.E. Larson or H.W. Humphreys, Illinois State Water Survey, (Urbana).

(d) Experimental.

(e) To determine chemical requirements and velocity requirements to provide protective coating in water pipes.

UNIVERSITY OF IIJINOIS, Dept. of Agricultural Engrg., Urbana, I11. 61803.

Inquiries concerning the following projects should be addressed to Prof. B.A. Jones, 100 Agricultural Engrg., Univ. of Illinois.

(3424) A STUDY OF RAINFAII ENERGY AND SOIL EROSION.

(b) Iaboratory project cooperative with ARS, U.S. Dept. of Agriculture.

(d) Experimental; basic research.

(e) Natural rainstorms are photographed with a raindrop camera so that the number of raindrops, their size and size distribution, and the kinetic energy of a rainstorm may be calculated. Physical measurements will be made of the soil to determine the effect of the kinetic energy of the rainstorm on soil 1oss. The nature and properties of rainstorms that occur in this area of Illinois will also be studied.

(f) Terminated.

(h) "Sources of Error in Calculating the Kinetic Energy of Rainfall," J.S. Rogers, L.C. Johnson, D.M.A. Jones and B.A. Jones, Jr., Jour. Soil and Water Conserv., Vol. 22, No. 4, pp. 140-142, 1967.

(4987) THE EFFECT OF GYPSUM AND DRAINAGE ON SOLONETZIC SOILS (SLICK-SPOTS) IN ILIINOIS. (b) Laboratory project in cooperation with Dept. of Agronomy.

(d) Experimental field investigation.

(e) To test the feasibility of replacing and removing excess sodium from solonetzic soils under field conditions with (a) different methods and rates of applying gypsum (calcium sulphate), (b) different degrees of disturbing the subsoil, and (c) different spacings of tile drains.

Twenty plots were established in a random pattern to compare 3 positions for the application of gypsum and 3 spacings of tile drains with check plots. The tile effluent is measured by recording equipment to determine the rate and volume of flow. Also samples will be taken to determine the amount of sodium in the leachate.

(g) Corn yields have been greatly increased by some applications of gypsum and drainage.

(h) "Natric Soils in Illinois," J.B. Fehrenbacher, R.T. OdelI, P.E. Johnson and B.A. Jones, Jr., Illinois Research, Vol. 8, No. 1, pp. 5-7, 1966.

"Corn Yields on Natric Soils," J.B. Fehrenbacher, T.D. Hinesly, P.E. Johnson and B.A. Jones, Jr., Illinois Research, Vol. 9, No. 3, pp. 14-15, 1967. (Obtain copies from authors.)

(008W) RUNOFF FROM SMALI AGRTCULTURAI AREAS IN ILIINOIS. (Formerly No. 2316)

For summary, see Water Resources Research Catalog 4.0070, Vol. 2.

(h) "Fortran II Program: Watershed Composite Precipitation," J.K. Mitchell, Agric. Engrg. Research Rept., Illinois Agric. Expmt. Sta., Univ. of Ill., Urbana. 1967.

(OO9W) LABORATORY MODEL STUDIES OF CONSERVATION AND DRAINAGE STRUCTURES. (Formerly No. 2789)

For summary, see Water Resources Research Catalog, 4.0067, Vol. 2.

(h) "Scour Hole Development Upstream of a Rectangular Weir with Free Overfall, "A.0. Weiss, M.S. thesis, Univ. of Ill. Library, 1966.

"Factors Affecting Scour Hole Development Upstream of a Rectangular Weir, "A.0. Weiss, B.A. Jones, Jr., R.N. Fenzl, Paper 67-701, Amer. Soc. Agric. Engr., 1367. (Obtain from ASAE, Saint Joseph, Michigan.)

"Investigation of Scour from a Cantilevered Pipe Outlet," J.D. Hendrick, M.S. thesis, Univ. of Ill. Library, Aug. 1767.

"An Inexpensive Electrical Analog for Flow in Porous Media," J.I. Goodenough and R.IT. Fenzl, Jour. Soil and Water Conservation, Vol. 22, No. 2, pp. 72-75, 1967.

(OIOW) HYDROIOGIC CHARACTERIZATION OF SMAII WATERSHEDS. (Formerly No. 5369)

For summary, see Water Resources Research Catalog, 4.0068, Vol. 2.

(h) "Effect of Boundary Conditions on Solutions to the Unsteady Spatially Varied Flow Equations," W.F.G. Brutsaert, M.S. thesis, Univ of Ill. Library, June 1967.

"Iaboratory Verification of Boundary Condition Assumptions for Solutions of the De SaintVenant Equations," W.F.G. Brutsaert and R.N. Fenzl, Paper 67-737. Amer. Soc. Agric. Engr.. 1067. (Obtain from A.S.A.E. Saint Toseph, Michigan.) 
(OIIW) DEVEIOPMENI OF DRAINAGE ASSESSMEIT PROCEDURES BASED ON PHYSICAL FEATURES IN ILLTNOIS. (Formerly 5809)

For summary, see Water Resources Research Catalog, 6.0159, Vol. 2 .

(h) "A Method for Distributing Drainage Assessments," R.L. Bengtson, M.S. thesis, Univ. of I11. Library, June 1967.

UNIVERSITY OF IITINOIS, Department of Chemistry and Chemical Engrg., Urbana, Ill. 61803

(6824) STRUCTURE OF TURBUIENCE CIOSE TO A WALL.

(b) National Science Foundation.

(c) Thomas J. Hanratty, Prof. of Chem. Engrg., 205 East Chemistry Building, Univ. of Illinois.

(d) Experimental and theoretical; basic research; Ph.D. thesis.

(e) Electrochemical techniques are used to study fluctuating wall shear stress, fluctuating mass transfer rates, fluctuating concentrations, and fluctuating velocities. The system is a vertical 8-inch diameter pipe.

(g) New information on the viscous sublayer.

(h) "A Study of Thrbulence Close to a Wall," Physics of Fluids, Nov. 1967.

(6825) FIOW AROUND SOIID OBJECTS AND OVER SOIID WAVES.

(b) Petroleum Research Fund; National Science Foundation.

(c) Thomas J. Hanratty; see (6824) above.

(d) Experimental; basic research, basic Ph.D. theses.

(e) Electrochemical techniques are used to study shear stress variation around the surface of a cylinder and over solid wavy surfaces.

(g) New technique for studying boundary layers provides new information on near wakes.

(h) "Wall Shear Stress Distribution for Flow Around a Circular Cylinder," H.G. Dimopulos and T.J. Hanratty, Rept. 2 to AFOSR, Project 9791-02, Oct. 1967.

(6826) FIOW THROUGH PACKED BEDS.

(b) Petroleum Research Fund.

(c) Thomas J. Hanratty; see (6824) above.

(d) Experimental; basic Ph.D. theses.

(e) Details of the flow around a sphere in a regular bed of spheres are being studied.

(g) A transition to an unsteady flow at a Reynolds number of about 125 is accompanied by only a slight change in the average rate of transport.

(h) "Transition to Thurbulence for Flow Through a Dumped Bed of Spheres," K.R. Jolls and T.J. Hanratty, Chem. Eng. Sci., Vol. 21, 1185, 1966.

(6827) EFHECT OF NATURAL CONECTION ON FLOW THROUGH A HORIZONPAL PIPE.

(b) National Science Foundation.

(c) Thomas J. Hanratty, Prof. of Chem. Engrg. 205 East Chemistry Bldg., Univ. of Illinois.

(d) Experimental, theoretical; Ph.D. thesis.

(e) Secondary flow caused by natural convection is being studied by laboratory and computer experiments.

(g) At large Grashof numbers the secondary flow may be treated by a boundary layer analysis.

(6828) INTERACTION BETWEEN A TURBUTENT AIR AND FIOWING IIQUID.

(b) National Science Foundation. (c) Thomas J. Hanratty; see (6827) above.

(d) Experimental, theoretical; basic, Ph.D. thesis.

(e) Various instabilities can arise at the interface which affect transport rates.

(g) Flow over liquid wavy surfaces is fundamentally different from flow over solid wavy surfaces.

(h) "Effect of Waves at a Gas-Liquid Interface on Turbulent Air Flow," L.S. Cohen and T.J. Hanratty, Jour. Fluid Mech., late 1967 or early 1968.

(6829) EFFECT OF POLYMERS ON DAMPING OF WAVES.

(b) Natural Science Foundation.

(c) Thomas J. Hanratty; see (6827) above.

(d) Experimental; basic; Ph.D. thesis.

(e) Effect of drag reduction polymers on wave damping in tank is being studied.

(6830) NONLINEAR EFTECTS IN CELIUTAR CONVECTION.

(b) National Science Foundation.

(c) Robert I. Sani, 207 East Chemistry Blag., Univ. of Illinois.

(d) Theoretical; basic research; Ph.D. thesis.

(e) Asymptotic perturbation techniques are being used to study surface tension-buoyancy driven flows in a fluid layer heated from below.

(g) Stable cell shapes and the corresponding convective flux are predicted.

(h) "Remarks on the Benard and Related Stability Problems," R.I. Sani, ZAMP, Vol. 17, 1966, pp. 642-645.

"Free Convective Instability," R.I. Sani, to appear in Math. Jap., Vol. 12, 1967.

(6831) COIVECTIVE INSTABITITY OF TRANSIENT SYSTEMS.

(b) Iaboratory project.

(c) R.L. Sani; see (6830) above.

(d) Theoretical; basic research; Ph.D. thesis.

(e) Projection methods are being used to study convective instability of stagnant fluid layers subjected to transient transfer of heat and mass.

(g) A transient linear acceleration field is predicted to have both a stabilizing and destabilizing effect depending on the physical system.

(6832) ABSORPTION INTO A FLUID IAYER: STABILITY AND THE ONSET OF CONVECTION.

(b) U.S. Dept. of the Interior, Office of Saline Water.

(c) J.A. Quinn, 297 East Chemistry Building, Univ. of Illinois.

(d) Experimental and theoretical; basic research for doctoral thesis.

(e) A basic investigation of the transient nature of buoyancy-driven convection. The growth and magnitude of the convection flow accompanying the absorption of a soluble gas into quiescent liquid is measured with a schlieren technique.

UNIVERSITY OF ILITNOIS, Fluid Mechanies and Hydraulies Lab., Dept. of Theoretical and Applied Mechanics, Urbana, Illinois 61801

Address inquiries on projects 2536, 3427, 5777, 5778, 5779, 6139, 6140 to Prof. J.M. Robertson, 125 Talbot Lab.; on projects 4143, 4559, 6142, 6143 to Prof. M. E. Clark, 123 Talbot Iab., Univ. of Illinois.

(2536) STUDY OF HOMOLOGOUS TURBUIENCE.

(b) Iaboratory project; formerly National Science 
Foundation.

(d) Basic research

(e) The nature of turbulence (its production and dissipation) is being studied in the simplest possible shear flow-plane couette flow where the shear is constant and the turbulence homogeneous but not isotropic. Mean-flow studies essentially complete.

(l) Suspended.

(h) Paper in progress.

(3427) STRUCTURE OF TURBULENCE NEAR ROUGH SURFACES.

(b) Naval Ship Systems Comm., General Hydromechanics Research Program.

(d) Basic research; experimental.

(e) Information on mean-flow and turbulence structure near roughnesses being studied in an 8-inch "natural roughness" pipe and in 3-inch sand-roughened pipe.

(h) "Turbulence Structure near Rough Surfaces," J.M. Robertson and J.D. Martin, AIAA Jour., Vol. 4, pp. 2242-2245, Dec. 1966.

(4142) TURBUTENT BOUNDARY-IAYER FIOW TOWARDS A INORMAI SIIEP.

(b) Iaboratory project.

(d) Basic research.

(e) An analytical and experimental study is being made of upstream separation, i.e., the real fluid behavior (separation, mixing, reattachment) in front of a normal step projecting inward from a plate along which fluid is flowing with a turbulent boundary layer. Air is fluid medium being used.

(g) First phase of study completed; in one case rather good agreement was found between theoretical solution and experimental observation of separation streamline.

(4143) HEMODYNAMICS SIMILITUDE STUDY OF AN ARTERIAL DISTRIBUTION SYSTEM.

(b) Public Health Service, National Insts. of Health, Research Grant No. HE08330-02.

(d) Basic research; experimental.

(e) The flow of blood in the Circle of Willis-the arterial distribution system for the brain--is to be studied utilizing large-sized models. Present goal is to fabricate a model which will simulate in as many ways as possible the prototype and its flow.

(g) Solutions to cerebral circulation problems are being sought via simulation techniques using rigid vessel-steady flow and flexible vesselpulsatile flow models. The current aim is to develop a better engineering understanding of pulsatile flow in flexible vessel networks both analytically (via impedance methods) and experimentally (via latex tube networks pulsed sinusoidally). Networks that both branch and loop are being studied to assess the importance of these aspects to physical and physiological problems.

(h) "Simulation Studies of Factors Influencing the Cerebral Circulation," M.E. Clark, W.A. Hinwich, and J.D. Martin, Acta Neurologica Scandinavica, Vol. 43, 189-204, 1967.

"Forerunners of a Pulsatile Flow Flexible Vessel Model of the Circle of Willis," M.E. Clark and M.I. Roller, Digest of the 7 th Intl. Conf. on Medical and Biological Engrg. Sto kholm, Sweden, Aug. 1367.

"The Simulation of Physiological Impedance Using Lumped and Distributed Fluid Elements," M.L. Roller and M.E. Clark, Proc., Engrg. Mech. Div. Spec. Conf., ASCE, pp. 411-440, Oct. 1366.
(4559) FLOW STABILITY AND HEAD LOSS IN BRANCHED TUBES.

(b) Public Health Service, National Insts. of Health, Research Grant No. HE08330-02.

(d) Basic research; experimental.

(e) In conjunction with a model study of the Circle of Willis--the arterial distribution system for the brain--a need was felt for a better understanding of the stability of viscous flows through certain types of junctions as well as the amount of head loss which occurs. A series of bifurcations and fusions of rigid, circular tubes are being studied to gain this understanding.

(f) Suspended.

(5777) THREE DIMENSIONAL EFFECTS IN TURBOMACHINERY.

(b) Caterpillar Tractor Co.

(d) Basic research, experimental and analytical, for Ph.D. thesis.

(e) Radial inward flow system studied in terms of base flow, boundary layer and secondary flow occurrences.

(f) Study completed.

(g) Non-rotating test rig with some features of rotating system simulated by adjustment in blade contours to give same absolute flow paths on assumption of no separation. An unexpected flow separation was found on blade suction surface. This was not predictable by ordinary two-dimensional boundary-layer analysis and was found not to be due to secondary flows, although such were present. Methods of secondary flow prediction are extended to predict their development from growing boundary on channel side walls.

(h) "Blade Channel Flow in a Simulated Radial-Flow Turbomachine," R.C. Hansen, Ph.D. thesis, TAM Dept. Univ. of Illinois, June 1967, TAM Rept. 297, July 1967.

(5778) BODY DRAG AT LOW REYNOLDS NUMBERS.

(b) Laboratory project.

(d) Basic analytical and experimental research.

(e) Except for flat plate, analytical drag relations are available only in the creeping motion and boundary layer regimes. Experimental data is available only for a few other bodies in the intermediate (Navier-Stokes) range. Objective of study is to help fill this gap.

(g) Use of coordinate-type expansions for treating low Reynolds number flow past cylinders is found to be of some utility and promise. Expansions valid near the body and at large distances are joined in terms of a matching parameter and a flow parameter.

(h) "Analytical Study of Flow Past a Circular Cylinder at Iow Reynolds Numbers, "T.J-M Kim, Ph.D. Thesis in TAM, Univ. of Illinois, 1967.

(5779) UNIQUE ASYMPTOTIC EXPANSIONS IN THE THEORY OF HYDRODYNAMIC STABIIITY.

(b) National Science Foundation.

(c) Prof. Leland K. Shirely, 314 Talbot Lab., Univ, of Illinois.

(d) Theoretical; basic research.

(e) Asymptotic approximations of certain functions which occur in hydrodynamic stability are being studied with reference to their uniqueness; error bounds for such approximations are being studied also.

(g) Have obtained explicit representations for functions which satisfy the differential equations pertinent to the stability theory and which have asymptotic approximation identically equal to zero. 
(6139) LONGITUDINAL CURVATURE EFFECTS ON TURBUIENT BOUNDARY IAYER.

(b) Caterpillar Tractor Co. Grant.

(d) Basic; experimental and analytical.

(e) Boundary curvature in flow direction causing pressure difference between wall and edge of layer is known to affect laminar boundary layer and there is some suggestion of its effect on turbulent layers. Flow of a turbulent layer of several thicknesses along a circular surface is being studied to evaluate the occurrences.

(6140) TURBULENT FLOW IN ECCENIRIC ANNULI.

(b) ASCE Research Study for Fed. Water Pollution Control Admin.

(d) Experimental and analytical.

(e) Interest is in effect of "inserted pipe on llow capacity of a sewer." Experiments have involved concentric and eccentrically located 1 in. and 2 in. (OD) pipes in 6 in. line. Analysis involves more details and effects of different surface roughnesses.

(g) Effect of eccentricity is marked. At full eccentricity friction factor may be reduced to 0.65 of concentric value depending on insert size.

(h) "Turbulent Friction in Eccentric Annular Conduits," J.M. Robertson, TAM Report (now being completed).

(6141) VAPOR FORMATION DURING WATER HAMMER.

(b) Ivational Science Foundation.

(c) Prof. C.E. Bowman, 218 Talbot Lab., Univ. of Illinois.

(d) Basic analytical and experimental research.

(e) This research was undertaken to develop a rational explanation for the large difference in amplitude and duration of the positive and negative components of a pressure surge in pipe lines in which the nominal pressure is much less than the amplitude of the surge component.

(g) Thermodynamic concepts are introduced to explain the pressure-time-relationship observed during water hammer when the pressure in the fluid drops to its vapor pressure. The presence of vapor in a laboratory system has been verified experimentally and the volume of the vapor cavity has been compared to the computed value.

(h) Report in preparation.

(6142) WAVE REFLECTIONS IN BRANCHED FIEXIBLE CONDUITS.

(b) National Insts. of Health Grant-HE 08330.

(d) Experimental and theoretical; basic research.

(e) Study of the reflection of oscillatory pressure waves at a bifurcation in a flexible tube filled with a viscous liquid. The analysis is general in nature and is applicable to other types of system discontinuities. Measurements involve a parallel fluid transmission line technique.

(g) Mean flow and kinetic energy contributions are found to be significant in this type of flow situation. Measurements correlate well with theory for several junction configurations including area ratio and angularation changes.

(h) "An Extension to the Theory of Wave Reflections," J.D. Martin, Trans. ASME Biomed. Fluid Mechs. Symp., April 1966.

"Theoretical and Experimental Analyses of Wave Reflections in Branched Flexible Conduits," J.D. Martin and M.E. Clark, Proc., Engrg. Mech. Div. Spec. Conf., ASCE, p. 441-457, Oct. 1966.
"A Viscoelastic Correction to the Complex Propagation Via Pressure-Displacement Experiments," J.D. Martin and M.E. Clark, Proc. 19th Ann. Conf., Engrg. in Med. and Biol., Vol. 14, Nov. 1966.

(6143) ABNORMAIITY DETECTION IN THE CEREBRAI CIRCULATION VIA FLUID IMPEDANCE CHANGES.

(b) St. Paul-Ramsey Hospital, Sț. Paul, Minn.

(d) Experimental and theoretical; applied research.

(e) Diagnostic investigations of the cerebral circulation would be enhanced if not only the presence of system abnormalities but their severity and clinical significance could be evaluated. Such abnormalities give rise to pressure and flow reflections and since fluid impedance relates pulsatile pressure to llow, changes in impedance can be used to detect and evaluate their presence. Experimental and computer models of systems containing stenoses, aneurysms, and other discontinuities have been studied and recognition patterns have been developed from impedance results.

(h) "Abnormality Detection via Impedance Changes," M.E. Clark, S.I. Hawkes, and G.F. Ayala, Proc. 20th Ann. Conf., Engrg. in Med. and Biol., Boston, Nov. 1967.

UNIVERSITY OF IIWINOIS, Hydraulic Engineering Lab., Dept. of Civil Engrg., Urbana, Ill. 61801

Inquiries concerning all projects should be addressed to Dr. V.T. Chow, Prof. of Hydraulic Engrg., Univ. of Illinois, unless otherwise indicated.

(4543) WATER RESOURCES SYSTEM ANALYSIS.

(b) Laboratory project.

(d) Theoretical; basic research.

(e) Operations research techniques are used to optimize water resources systems for the planning and development of water projects. Mathematical models and simulation were used, involving Monte Carlo methods, Markov-chain models, and linear and dynamic programmings. A study on similarity between rail transport system and water resources system has been completed.

(g) A hydroeconomic analysis to optimize a multipurpose project is now being investigated. Study of the reservoir design is made by using queueing theory through the use of the sequentially generated stochastic input flow information.

Additional research during the year was made to investigate the similarity between rail transport system and water resources system. Beginning with the nature of inputs and the physical formation of the systems, the comparable structures in two systems were studied. To each system, basic components such as the dams and reservoirs in the water resources system and the yards in the railroad system, were identified and their uses were compared. The nature of flow in the systems, particularly the different types of flow, was also investigated. Finally modifications and assumptions were discussed in order to equate the two systems for purposes of comparative analysis.

(4906) BASIC INVESTICATION ON WATFRSHED HYDRAULICS.

(b) National Science Foundation research project. (d) Experimental and theoretical; basic research. (e) To investigate the basic laws governing the 
flow of surface water over drainage basins by controlled experiments on geometric basins. By controlling the various factors involved in the mechanics of flow, the experimental data so obtained can be more amenable to theoretical analyses for the determination of the basic laws. A laboratory watershed experimentation system (WES) of integrated hydraulic, electronic, and structural design has been developed to study the relationship of rainfall input and runoff output of an artificial watershed. The WES can produce a storm of variable time and space distribution moving across the watershed in a required direction as programmed on an electronic computer.

(g) During the past two years, the WES has been constructed and improved. The roughness of watersheds and the time of distribution of runoff were investigated.

(h) "Laboratory Study of Watershed Hydrology," Ven Te Chow, Vol. 1, Proc. Intl. Hydrology Symp., Fort Collins, Colo., Sept. 6-8, 1967 , pp. 194-202; also as Univ. of Ill. Civil Engrg. Studies, Hyd. Engrg. Series No. 14, Sept. 1967.

"A Study of the Roughness of Conceptual River Systems or Watersheds, "T.E. Harbaugh and Ven Te Chow, Proc. XIIth Congr., Intl. Assoc. for Hyd. Research, Fort Collins, Colo., Sept. 17-14, 1967, pp. 9-17; also as Univ. of III. Civil Engrg. Studies Hyd. Engrg. Series No. 15, Sept. 1967.

"Time Distribution of Runoff From Watersheds," T.E. Harbaugh, Ph.D. thesis, Univ. of Ill., 1966.

(4908) THE FORCES CAUSED BY WAVES BRFAKTING AGAINST VERTICAI IMPERVIOUS RIGID WALIS.

(b) Laboratory project; cooperative with U.S. Army Engrs. Waterways Experiment Sta.

(d) Experimental and analytical; basic research; doctoral thesis (W.J. Garcia, Jr., directed by Dr. V.T. Chow.)

(e) To formulate relations which will enable one to determine pressures on impervious rigid walls due to breaking waves with sufficient accuracy to afford an economical and safe design for sea walls and breakwaters; also to investigate the variation of pressure on the wall with respect to time and spatial distribution.

(g) During the years the experimental data were analyzed and a final report is in preparation.

(4909) A STUDY OF THE EIFECT OF BASIN STORAGE ON SURFACE RUNOFF HYDROGRAPHS.

(b) Laboratory project.

(d) Theoretical; basic research.

(e) To study the drainage basin taken as a Iumped hydrologic system. Assuming a general nonlinear equation for the basin storage and combining it with the equation of continuity, a differential equation for the system is formulated. The equation is quasi-linearized by assuming that the coefficients are functions of the average inflow and outflow of the system. Solution of the resulting equation produces four possible conceptual system models depending on the nature of the roots of the equation. Storms and the corresponding outflow hydrographs over six natural drainage basins varying from 7.16 to 1 , 141 square miles are analyzed by the proposed equation and theory. From the results of the analysis it is seen that three coefficients of the pro- posed equation vary with the outflow, thus indicating nonlinearity, while the remaining two coefficients do not change much and can be assumed constant. A study of the variation of the three coefficients seems to indicate that they decrease exponentially with the peak runoff. The storage equation derived in this study is shown for use in flood routing and it is proposed also for use in infiltration analysis.

(g) During the past two years, the nonlinear equations are being solved by numerical analysis on digital computers.

(4910) PROBABILITY AND SYNTHETIC HYDROLOGY APPROACH TO THE ANALYSIS OF RAINEALI-RUNOFF FREQUENCY RELATIONSHIP.

(b) Laboratory project.

(d) Theoretical; basic research.

(e) To treat the inflow into a basin as a stochastic input, the basin as a linear system, and the cutflow as the response of the basin to the input and to investigate the stochastic behavior of the system by sequential generation and simulation techniques.

(g) During the past two years, a preliminary study was made to use nonlinear basin systems.

(5289) STOCHASTIC HYDRODYRAMTC ANALYSIS OF OCEAN WAVE ACTIONS ON MOORED PIATFORM FOR UNDERWATER MISSLE LAUNCHING.

(b) Laboratory project; cooperative with U.S. Navy Civil Engrg. Lab.

(d) Experimental and analytical; basic and applied research; doctoral thesis (by B.J. Muga directed by Dr. V.T. Chow).

(e) To analyze the motions and forces induced by irregular waves on a construction type platform as moored in the open Pacific Ocean.

(g) Prototype and model tests are conducted on the platform, named "Fishook," which is of the catamaran design, having a displacement of 850 tons. It is spread-moored by four $2-1 / 2$ in. stud link chains in 165 feet of water. Water level fluctuations, ship rotations and accelerations, mooring forces, and wind speed and directions are measured. Both prototype and model tests data are analyzed in the form of amplitude response operations by the spectrum and cross-correlation analyses of the complex time series histories. The results are compared with the Iinear theory of ship motion. Equations of motion of the system, for sinusoidal waves are formulated on the basis of the slender body theory for 6 degrees of freedom, taking into account both hydrostatic and hydrodynamic effects. The excitation functions and the various coefficients in the equations are obtained for surges, heaves, pitches, sways, rolls, and yaws. Solutions are also given to the forces in the mooring cables and the horizontal force components and the yawing moment induced by the mooring system on the platform.

(h) "Experimental and Theoretical Study of Motion of a Barge as Moored in Ocean Waves, "Bruce J. Muga, Univ. of Ill. Civil Engrg. Studies, Hyd. Engrg. Series No. 13, Jan. 1967.

\section{(5657) HYDROLOGIC ANALYSIS BY ANAIOG COMPUTERS.}

(b) Laboratory project.

(d) Direct and indirect analog computers are used for the analysis of hydrologic problems on surface and ground water. In the analysis of surface water problems, the FAL PACE computer 
of the Analog Computer Laboratory was employed to route floods through linear as well as nonlinear reservoirs. For the analysis of ground water, resistance networks were designed and analyzed for a number of ground water regions. The results will be recommended for use in the design and planning of water resources systems.

(5660) MICROSCOPIC DETERMINATION OF TRACTIVE FORCE DISTRIBUTION IN FREE-SURFACE WATER CONVEYANCES.

(b) Office of Water Resources Research grant.

(c) Prof. H.G. Wenzel, Jr., Dept. of Civil Engrg•, Univ. of Illinois.

(d) Experimental and basic research.

(e) The classical ultramicroscopic approach has been modified and developed for the determination of velocities within the viscous sublayer in open channel flow. The technique consists essentially of using a high-power microscope and dark-field illumination to observe the movement of small neutrally buoyant spheres suspended in the flow. Highspeed photography permits the determination of the velocity of the spheres within the small optical depth of field.

(g) A preliminary study of laminar flow has been completed. Two-dimensional turbulent flow is being studied. Tractive force and turbulence data will be obtained.

(5661) INFLUENCE OF TURBULENCE ON SURFACE REAERATION.

(b) Office of Water Resources Research.

(c) Prof. E.R. Holley, Dept. of Civil Engrg., Univ, of Illinois.

(d) Experimental and basic research.

(e) Turbulence effects on surface reaeration rates are being studied from at least two aspects:

(1) What is the turbulence condition near the free surface of turbulent water, i.e., in the region of the "surface film?" (2) What is the mechanism by which turbulence influences the rate of reaeration?

(g) An effort will be made to combine the theories of molecular diffusion and turbulent diffusion to describe the way that oxygen, which has been absorbed at the free surface, penetrates into the turbulent eddies for subsequent transport away from the surface. The initial phase of the experimental work centers around measurement of turbulence conditions near the free surface, the gross rate of oxygen absorption, and the gradients of dissolved oxygen for some analogous substance near the free surface.

(6187) MECHANICS OF SURFACE RUNOFF.

(b) National Science Foundation.

(d) Experimental and analytical; basic research.

(e) Basic mechanics of flow of surface water over artificial basins was studied by controlled experiments using a watershed experimentation system and by hydrodynamic analysis. The roughness of a conceptual river system was investigated considering the drainage basin as a quasi-linear distributed dynamic system which was represented by a set of quasi-linear partial differential equations based on continuity and momentur. The conceptual roughness was found to be sensitive to depth of flow and raindrop impact on the laboratory basin.

(g) During the past year the analysis of the distributed dynamic system was completed and the results were verified by experimental findings. Under this project a supplemental watershed experimentation system was also designed and constructed for experimental purposes.
(6188) AN INVESTTCATION OF THE REYNOLDS AND WEBER CRITERIA.

(b) National Science Foundation.

(c) Prop. W.H. C. Maxwell, Dept. of Civil Engrg., Univ. of Illinois.

(d) Experimental and basic research.

(e) A modified interpretation of the Reynolds and Weber numbers is being examined analytically and experimentally. Experiments on spilling flows over a variety of vertical channel obstructions are being made, using additives to alter the surface tension and viscosity of water. The goal is to examine the dependence of discharge coefficients on surface tension and viscous effects in order to determine a criterion for the lower limit on the scale of model tests which is independent of geometry.

(g) Preliminary experiments indicated the need for a substantial increase in the accuracy of data used in the determination of discharge coefficients. Consequently, a special channel was constructed, incorporating a movable skimming weir in the head box to minimize fluctuations in water level, and with a diversion system to permit direct weighing of discharges.

(6189) BASIC STUDY OF JET FTOW PATTERNS REIATED TO STREAM AND RESERVOIR BEHAVIOR.

(b) Office of Water Resources Research.

(c) Prof.W.H.C. Maxwell; see (6188) above.

(d) Experimental and basic research.

(e) The velocity patterns and spreading characteristics of a water jet introduced horizontally in the proximity of the free surface of a reservoir are being investigated. The flow pattern represents an idealized model applicable to such problems in reservoir and river mechanics as the design of siphon spillway outlets and discharge outlets for navigation locks, the behavior of sediment-laden streams entering reservoirs, and low-flow augmentation for improving water quality.

(g) The flow patterns were found to be quite different from those for a deeply submerged jet. The maximum velocity moves upward as the flow proceeds downstream and eventually reaches the free surface. The lower part of the velocity distribution closely resembles that for a deeply submerged jet, whereas, the upper part is modified by wave action at the free surface. As a result there is increased spreading of the flow pattern at the free surface. A nearby intake was found to have negligible influence on the flow pattern. The velocities induced in the region of the jet by the intake are very low relative to those in the jet itself. The jet discharge is concentrated in a narrow conical form whereas the intake gathers fluid from all directions. The results may be applied in the design of discharge outlets, siphon spillway outlets, hydraulic breakwaters and in estimating concentrations of pollutants, temperatures or velocity profiles downstream from outlets when density differences are small.

(6190) BOUNDARY EFFECTS ON JET FLOW PATTERRNS REIATTED TO WATER QUALITY AND POTLUTION PROBLFMS.

(b) Office of Water Resources Research.

(c) Prof.W.H.C. Maxwell; see (6188) above.

(d) Experimental and basic research.

(e) This experimental program will be divided into two phases: ( 1 ) Collection and analysis of 
further experimental data on velocity distributions downstream from a water jet introduced horizontally beneath the free surface of a deep reservoir. The diameter of the jet, submergence of the jet and velocity of the efflux from the jet will be varied systematically to determine their influence on the flow pattern. (2) Velocity traverses will be taken of the flow field downstream from a water jet introduced horizontally beneath the free surface of a shallow reservoir. The diameter and submergence of the jet, velocity of efflux and the vertical location and slope of the lower fixed boundary will be varied systematically.

(6191) EFHECT OF RAINDROP IMPACT AND SURFACE ROUGHINESS ON SHEET FIOW.

(b) Office of Water Resources Research.

(c) Prof. H.G. Wenzel, Dept. of Civil Engrg., Univ. of Illinois.

(d) Experimental and basic research.

(e) The general objective of this research is to examine in detail both experimentally and theoretically the mechanics of sheet flow. This knowledge will be useful in improving the design of urban drainage facilities where this type of flow is common. More specifically the individual objectives are: (a) to investigate experimentally the effect of raindrop impact on sheet flow using carefully controlled laboratory rainfall, surface profile, and runoff measurements, (b) to study in detail the pressure fluctuations caused by raindrop impact using pressure transducers and to correlate this work with the results of the first objective (c) to study the effect of roughness on sheet flow on a more thorough basis than has been previously attempted and (d) to review the existing theoretical relationships describing sheet flow in the light of the experimental results so that, if necessary, modified equations can be developed which will reflect the true physical phenomenon.

IOWA INSTITUTE OF HYDRAULTC RESEARCH, Univ. Of Iowa, Iowa City, Iowa 52240

(66) HYDROIOGIC STUDIES, RALSTON CREEK WATEERSHED.

(b) Cooperative with the Agricultural Research Service and U.S. Geological Survey.

(c) Prof. J.W. Howe, Dept. of Mechanics and Hydraulics, Univ. of Iowa.

(d) Field investigation; applied research, and M.S. theses.

(e) Study being made of relation between rainfall and runoff over a small area. Discharge from a 3-square-mile area measured by U.S.G.S.; rainfall records at five automatic recording stations collected by Agricultural Research Service. Continuous records since 1924 of precipitation, runoff, groundwater levels, and vegetal cover.

(g) Yearly records available for examination at Iowa Inst. of Hydraulic Research.

(h) Reports prepared annually since 1924 available in files at the Iowa Inst. of Hydraulic Research. Summary of 33-year record published as Bull. 16 of the Iowa Highway Research Board in 1961; available upon request from Iowa Highway Commission, Ames, Iowa.

(67) COOPERATIVE SURFACE-WATER INVESTIGATIONS IN IOWA. (b) Cooperative with U.S. Geological Survey, Agriculture Research Service, U.S. Weather Bureau, IIHR, Graduate College.

(c) District Chief, Water Resources Div., U.S. Geol. Surv., Iowa City, Iowa.

(d) Field investigation; collection of basic stream-flow data.

(e) Stream-flow and sediment measuring stations maintained throughout the State of Iowa cooperatively on a continuous basis. Records collected by standard methods of U.S.G.S.

(g) Records of stream-flow and sediment discharge computed yearly.

(h) Records contained in open-file reports published annually, and in Water-Supply Papers published at 5-year intervals, are available from U.S. Geological Survey.

\section{(73) MEASUREMENT OF TURBULENCE IN FLOWING WATER.}

(b) Cooperative with Office of Naval Research, Dept. of the Navy.

(c) Dr. John R. Glover, Iowa Inst. of Hydraulic Research.

(d) Experimental and theoretical; basic and applied research.

(e) Instruments, primarily electrical in operation, are being developed to measure the characteristics of turbulent flow over a wide range of laboratory and field conditions. Both sensing and computing elements are involved.

(g) Results obtained from hot wires coated with urethane indicate that coated wires may be used in liquids for a period of approximately one hour before experiencing the usually encountered drift problems. The frequency response of the coated wires has been found to be flat to at least $1 \mathrm{kHz}$. A vortex shedding technique is used for this evaluation.

(h) "Old Gold Model, Type 4-2H Hot-Wire Anemometer and Type 2 Mean-Product Computer," John R. Glover, IIHR Rept. No. 105, July 1967.

(79) CAVITATION.

(b) Cooperative with Office of Naval Research, Dept. of the Navy.

(c) Dr. Hunter Rouse, Iowa Inst. of Hydraulic Research.

(d) Experimental and theoretical; basic research and graduate theses.

(e) Basic information is sought on cavitation for systematically varied boundary conditions. Studies of cavitation in abrupt conduit expansions are now being pursued.

(h) "Fluctuations of Pressure in Conduit Expansions," Hunter Rouse and Vladimir Jezdinsky, Jour. Hyar. Div., ASCE Vol. 92, No. HY3, Proc. Paper 4815, May 1966, pp. 1-12. "Jet Diffusion and Cavitation" (Freeman Memorial Lecture), Hunter Rouse, Jour. Boston Soc. Civ. Engr., Vol. 53 No. 3, July 1766 , pp. 255-271.

\section{(1875) CHARACTERISTICS OF STABLE EDDIES.}

(b) Laboratory project.

(c) Dr. Enzo 0. Macagno, Iowa Inst. of Hydraulic Research.

(d) Experimental and analytical; basic research.

(e) Distributions of pressure have been investigated throughout the vicinity of separation zones produced at abrupt changes in flow section. A study of laminar flow at two-dimensional and axisymmetric conduit expansions has been undertaken by means of computational models.

(g) Analytical evaluations are now being carried out for unsteady flow in an axisymmetric 
flow expansion using implicit finite difference schemes.

(h) "Some New Aspects of Similarity in Hydraulics," E.O. Macagno, Ia Houille Blanche, Vol. 20, No. 8, 1965.

"Effet d'un Changement Instantane de Viscosite sur le Calcul d'un Tourbillon Laminarie, "TinKan Hung, C.R. Acad. Sci. Paris, Vol. 262, March 28, 1966.

"Fluctuation of Pressure in Conduit Expansions," Hunter Rouse and Vladimir Jezdinsky, ASCE Jour. Hydraulics Div., HY3, 4815, May 1966.

"Laminar Flow in Conduit Expansion," Tin-Kan Hung, Ph.D. Dissertation, Univ. of Iowa, Aug. 1966, (available on loan).

"Laminar Eddies in a Two-Dimensional Conduit Expansion," Tin-Kan Hung and E.O. Macagno, Ia Houille Blanche, Vol. 2l, No. 4, 1966.

"Computational Stability of Explicit Difference Form of Equation for Viscous Fluid," La Houille Blanche, No. 1, 1967, E. Macagno and T.K. Hung. "Computational and Experimental study of Captive Annular Eddy," E.O. Macagno and T.K. Hung, Jour. Fluid Mechanics, Vol. 28, Part 1, 1967.

\section{(2091) RESEARCH ON SHIP THEORY.}

(b) Cooperative with Office of Naval Research and Naval Ship Res, and Dev. Ctr.

(c) Dr. Iouis Landweber, Iowa Inst. of Hydraulic Research.

(d) Experimental and theoretical; basic research.

(e) To determine the laws governing the forces, moments, and motions of ships. Work is under way on the following problems: (I) development of procedure for computing potential flow about ship forms; (2) higher-order gravity wave theory for an immersed prolate spheroid; (3) effect of tank size on shipmodel resistance; (4) resolution of viscous and wave drag by means of wake and surfaceprofile measurements; (5) vibration of ships; (6) effect of a dilute solution of guar-gum on resistance.

(h) "Effect of Solutions of Guar-Gum in Water on Shear Stress and Velocity Distributions in Flow Through a Pipe," Jurgen Richter, M.S. Thesis, Feb. 1967.

"Free-Surface Effects on Boundary-Layer Separation on Vertical Struts," S.K. Chow, Ph.D. Dissertation, June 1967.

"Vibration Frequencies of a Free-Free Cylindrical Beam of Finite Length Immersed in an Inviscid Fluid," Antonio Pita-Szczesniewski, Ph.D. Dissertation, Aug. 1967.

"Added Masses of Two-Dimensional Forms by Conformal Mapping," I. Landweber and M. Macagno, Jour. Ship Research, June 1967. "Vibration of a Flexible Cylinder in a Fluid," I. Landweber, Jour. Ship Research, Sept. 1967. "Lagally's Theorem for Multipoles," L. Landweber, Schiffstechnik, Bd. 14, Heft 70, Feb. 1967.

"Examination of Eggers' Relationship between Transverse Wave Profiles and Wave Resistance," H.E. Kobus, Jour. Ship Research, Dec. 1967. 'Experimental and Analytical Determination of the Induced Drag due to Bilge Vortices," J.C. Tatinclaux, IIHR Rept., Nov. 1966.

"Influence of the Radius of Curvature on the Drag Induced by Bilge Vortices," J.C. Tatinclaux, IIHR Rept. No. 102, Feb. 1967. "A. Comparison of Three Methods for Computing the Added Mass of Ship Sections," IIHR Rept. No. 104, April, 1967.
"Determination of the Viscous Drag of a Ship Model," T.S. Tzou and L. Landweber, IIHR Rept. No. 101, March 1967.

"Study of Eggers' Method for the Determination of Wave-making Resistance," L. Landweber and T.S. Tzou, IIHR Rept. 103, April 1967.

(2328) INVESTICATION OF SURFACE ROUGHIESS.

(b) Office of Naval Research.

(c) Dr. Emmett M. O'Loughlin, Iowa Inst. of Hydraulic Research.

(d) Experimental; basic research.

(e) Flow near boundaries covered with uniformly distributed roughness elements exhibits an approximately uniform layer of high-intensity turbulence generated by the discrete roughness elements. The region of high diffusivity is being explored by means of velocity and turbulence measurements to relate the diffusion characteristics of flow to the geometrical configuration of roughened boundary.

(2541) DEVELOPMENT OF INSTRUMENTS FOR USE IN ANALYZING APERIODIC SIGNALS.

(b) Cooperative with office of Naval Research. (c) Dr. John R. Glover, Iowa Inst. of Hydr. Res. (d) Experimental; applied research.

(e) The purpose is to improve the analysis of unsteady-flow variables such as velocity and pressure fluctuations.

(g) An IBM 1801 Data Acquistion and Analysis System has been installed and is currently being used to record and/or process experimental data in real time. Results from preliminary studies indicate that large errors exist in the measured spectral density functions obtained by a spectrum or wave analyzer. A multiplier is being designed in order to provide the instantaneous product of two random signals so that the triple product may be evaluated.

(h) "Mean-Product Multiplier," John R. Glover, Instruments and Control Systems, Vol. 40, No. 8, Aug. 1967.

(3428) MECHANICS OF BANK SEEPAGE IN NATURAL STREAMS DURING FLOOD FIOWS.

(b) Cooperative with Iowa and U.S. Geological Surveys.

(c) Prof. J.W. Howe, Dept. of Mechanics and Hydraulics, Univ, of Iowa.

(d) Field investigation, analytical, applied research, for $\mathrm{Ph} . \mathrm{D}$. dissertation.

(e) Study of the various aspects of mechanics of bank seepage and bank storage during fluctuations in stage of a stream.

(f) Completed.

(g) Six standard methods for determining $\mathrm{T} / \mathrm{S}$ for problems of bank seepage and bank storage were tested and compared. The range of values found was relatively small. An analytical model was developed that can be used to compute ground-water levels, bank seepage, and bank storage from graphs of stream stage.

(h) "Mechanics of Bank Storage During Flood Flows," Earnest Christian Pogge, Ph.D. dissertation, Dept. of Mechanics and Hydraulics, Univ. of Iowa, $241 \mathrm{p} ., 1966$.

(3739) EDUCATIONAL FIIMS ON THE MECHANICS OF FLUIDS.

(b) National Science Foundation.

(c) Dr. Hunter Rouse, Iowa Inst. of Hydraulic Research.

(e) Six 20-minute sound films in color are planned to cover the following material: (1) An 
introduction to the subject, stressing its great breadth of coverage, the necessarily close tie between theory and experiment, the role of the scale model in engineering analysis and design, and methods of flow measurement in laboratory and field. (2) The source and significance of the fundamental principles of continuity, momentum, and energy, and their application to typical problems in many professional fields. (3) Gravitational phenomena, including jets, nappes, channel transitions, waves, surges, and effects of density stratification. (4) Effects of viscosity, examples of laminar flow, characteristics of fluid turbulence, and problems of surface resistance. (5) Form drag and lift, and their application to propulsion and fluid machinery. (6) Compressibility effects water hammer, submarine signaling, gravitywave and sound-wave analogies, and supersonic drag.

(g) First five films of series, "Introduction to the Study of Fluid Motion," "Fundamental Principles of Flow," "Flow in a Gravitational Field," "Characteristics of Iaminar and Turbulent Flow," and "Form Drag, Lift, and Propulsion," now available from Audiovisual Center, Univ. of Iowa, Iowa City, Iowa. Sixth film, "Effects of Fluid Compressibility," in preparation.

(3740) HYDRODYNAMICS OF FLUIDS UNDER CONDITIONS OF RAPID ACCEIERATION.

(b) Rock Island Arsenal, U.S. Army.

(c) Dr. Enzo 0. Macagno, Iowa Inst. of Hydraulic Research.

(d) Theoretical and experimental; basic research.

(e) Analytical techniques which are applicable to systems involving rapid acceleration of fluids through constrictions or of solids through fluids. Results will be expressed as lumpedconstant parameters similar to those used for steady-flow phenomena.

(g) Additional field tests are performed, and the results compared with those of analytical solutions.

(h) "A Preliminary Analysis of the Ml40 Recoil Mechanism," A.D. Newsham, E.O. Macagno, and T.K. Hung, Rept. to the Rock Island Arsenal, Oct. 1966

"Sliding Friction and Steady-Discharge Coefficient Effects on the Analysis of the MX37 Recoil Mechanism," A.D. Newsham, E.O. Macagno, and C.Y. Hung, Rept. to the Rock Island Arsenal, Dec. 1965.

"Significance of Container Deformability in the Analysis of Shock Absorbers," A.D. Newsham. (Submitted for publication).

"A Preliminary Analysis of the MI40 Recoil Mecnanism, "Arthur D. Newsham, Enzo O. Macagno, and Tin-Kan Hung, IIHR Rept. No. 100, Iowa Inst. of Hydraulic Research, Univ. of Iowa, Iowa City, Dec. 1966.

(4145) INTPERFACIAI EFFECTS IN FLUID FLOW WITH DENSITY STRATIFICATION.

(b) Laboratory project.

(c) Dr. Enzo 0. Macagno; see (3740) above.

(d) Theoretical; basic research and graduate theses.

(e) Instability of two fluid layers of different densities and viscosities flowing in the same direction.

(g) Analysis under way.
(4974) TURBULENCE CHARACTHRISTICS OF THE WAKE OF A BODY OF REVOLUTION.

(b) Iaboratory project.

(c) Dr. E. Naudascher, Iowa Inst. of Hydraulic Research.

(d) Experimental; basic research.

(e) Measurements of the turbulence in the wake of an ellipsoid mounted in an air tunnel to investigate the dynamics of the flow and the fine structure of the turbulence.

(f) Completed.

(h) "Jurbulence in the Wake of a Body of Revolution," R. Chevray, Ph.D. Dissertation, Univ. of Iowa, June 1967. (Available on loan).

(5321) PRESSURE FLUCTUATIONS AT GATED OUTTET WORKS.

(b) Cooperative with U.S. Army Corps of Engrs.

(c) Dr. Eduard Naudascher; see (4974).

(d) Experimental, basic research.

(e) Effects of shear-layer instability on the spectral distribution and the intensity of pressure fluctuations that may induce gate vibrations are being investigated for various gate and conduit geometries, including effects of cavitation and hydroelastic control.

(h) "Pressure Fluctuations in the Vicinity of Normal Walls of Variable Thickness," J.C. Tatinclaux, M.S. Thesis, Univ. of Iowa, Feb. 1966 (available on loan).

"Pressure Fluctuations in Cavitating Flow Past a. Wall," Y-H Chu, M.S. Thesis, Univ. of Iowa, Feb. 1967 (available on loan).

"Some Characteristics of Macro-Turbulence in Flow Past a Normal Wall," F.A. Locher and E. Naudascher, Proc. 12th Congr., Intl. Assoc. Hydr. Res., Fort Collins, Colo., 1967, Vol. 2, No. B37.

(5906) SCATE EFFECTS IN MODEL TESTS OF ROCK-PROTECTED STRUCTURES.

(b) Iowa Highway Research Board.

(c) Dr. E.M. O'Loughlin, Iowa Inst. of Hydraulic Research.

(d) Experimental; applied research.

(e) To define quantitatively the influence of the viscous forces which result in imperfect similarity between the behavior in the model and in the prototype of rock protection around structures. Special emphasis is being placed upon observations of the spectral distributions of pressure fluctuations in the scour hole.

(g) Rate of scour caused by a horizontal jet discharging over a movable bed of spherical glass beads has been measured in geometrically similar structures at six different scales. The development of scour may be predicted on the basis of the Froude criterion for dynamic similarity for the larger scales. Viscous effects in the smaller models cause a decrease in the rate of scour.

(5907) SELF-PRESERVATION TENDENCY IN TURBULENT SHEAR FLOWS.

(b) Cooperative with Office of Naval Research, Dept. of the Navy.

(c) Dr. Eduard Naudascher; see (4974) above.

(d) Analytical; basic research.

(e) Shear flows not exhibiting self-preservation in the conventional sense are analyzed on the basis of a new self-preservation concept.

(h) "On a General Similarity Analysis for Turbulent Jet and Wake Flows," E. Naudascher, IIHR Rept. No. 106, 1367. 
(5908) EFFECTS OF TURBULENCE AND CURVILINEARITY ON STRATIFIED FLOW.

(b) National Science Foundation.

(c) Dr. Enzo 0. Macagno, Iowa Inst. of Hydraulic Research.

(d) Experimental and theoretical; basic research and graduate theses.

(e) The effects of curving an otherwise stable density-stratified flow are being investigated experimentally. A layer of fresh water and a layer of salt water are used in a study of a Karman confined flow induced by a rotating disk. Stratified flow through a bend is also under study. A computational model of flow with continuous stratification is being set up.

(g) Experimental observations are being performed with a conductivity probe and a hot-wire anemometer of the flow through a bend.

(h) "Effects of Curvilinearity on Stratified Flows," C.A. Alonso, M.S. Thesis, June 1967, (available on loan).

"The Stability of a Stratified Flow," J.B. Hinwood, Jour. Fluid Mechanies, Vol. 29, Part 2, 11 Aug. 1967.

(5909) ENERGY TRANSPORT AND DISSIPATION IN VISCOUS FLOW.

(b) Laboratory project.

(c) Dr. Enzo 0. Macagno; see (5908) above.

(d) Analytical; basic research and graduate theses.

(e) Analysis of laminar steady and unsteady flows from the viewpoint of the energy transport and dissipation.

(g) A study of computer solutions of flow in a two-dimensional expansion has shown that the integrated form of the energy equation can be reduced to three terms, the other two being negligible.

(h) "Transporte y Disipacion de Energia en Fluidos Viscosos," E.O. Macagno and C. Quevedo, II Iatinamerican Congr. on Hydraulics, July 1966. "Pressure, Bernoulli Sum, and Momentum and Energy Relations in a Laminar Zone of Separation," E.O. Macagno and T.K. Hung, Physies of Fluids, Jan. 1967.

"A Computational Investigation of ImpulsivelyGenerated Eddies, "Tin-Kan Hung, 12th Congr. Intl. Assoc. Hydraulic Res., Vol. 2, p. 315, Fort Collins, Colo., Sept. 1967.

(5910) STUDY OF DYNAMIC FORCES ON FIASHBOARDS.

(b) Laboratory project.

(c) Prof. J.W. Howe, Dept. of Mechanics and Hydraulics, Univ. of Iowa.

(d) Analytical.

(e) Analysis of results of various previous investigations.

(f) Completed.

(g) A family of curves relating a moment parameter and a submergence parameter for flow over a standard parabolic spillway shape, as well as discharge coefficients for the flashboard mounted on such a spillway are presented.

(h) "Overturning Moments on a Flashboard Mounted on a Parabolic Spillway Crest," Alberto Iizarralde, M.S. Thesis, Univ. of Iowa, Feb. 1962.

(5911) EFFECT OF TURBUTENCE CHARACTERISTICS UPON REGISTRATION OF THE PRICE CURRENT METHR.

(b) Laboratory project.

(c) Prof. J.W. Howe; see (5910) above.

(d) Experimental. (e) Correlation of turbulence characteristics with variation of current meter registration.

(r) Completed.

(g) Error due to both intensity and scale of turbulence established in range tested.

(h) "Effect of Turbulence Characteristics upon Registration of the Price Current Meter," Min Hsiung Yang, M.S. Thesis, Univ. of Iowa. Feb. 1967.

(6351) FLOW-INDUCED EXCITATION OF LOW-CREST SPILLWAY.

(b) U.S. Army Corp of Engineers.

(c) Dr. Eduard Naudascher, Iowa Inst. of Hydraulic Research.

(d) Experimental; applied research.

(e) The fluctuating, hydroelastic load that may excite a spillway on elastic foundation to vibrate in a rocking and bobbing mode is being measured for heads between one and five times the spillway height.

(6352) TTE USE OF PROBABILITY IN PREDICTION OF RUNOFF FREQUENCY AND IN PREDICTION OF INFILIRATIONT FREQUENCIES.

(b) Laboratory project.

(c) Prof. J.W. Howe; see (5910) above.

(d) Analytical.

(e) Rainfall and infiltration frequencies combined to produce runoff frequency on basis of probabilities. Comparison with observed runoff frequencies on two streams having rainfall and runoff records of some 60 years.

(f) Completed.

(g) Computed and observed frequencies agree reasonably well except on largest floods.

(h) "The Use of Probability and Statistics in Prediction of Runoff Frequency Based on Precipitation and Infiltration Frequencies," Chun-Yo Shen, M.S. Thesis, Feb. 1967.

(6353) RECESSION CHARACTFRISTICS OF IOWA STREAMS.

(b) Iowa State Water Resources Research Inst.

(c) Prof. J.W. Howe; see (5910) above.

(d) Analytical.

(e) Recession coefficients of Iowa determined for all low-water periods of 10 days or greater duration.

(f) First phase completed.

(g) Recession coefficients for each summer month show good consistency and uniformity.

(6354) SEDIMENT TRANSPORTATION AND RESISTANCE TO FLOW IN ALIUVIAL-CHANNEL BENDS.

(b) Iowa State Water Resources Research Inst.

(c) Dr. Emmett M. O'Ioughlin, Iowa Inst. of Hydraulic Research.

(d) Experimental; basic research for Ph.D. dissertation and M.S. thesis.

(e) The mechenics of sediment transporting flows through an erodible-bed open-channel bend is being studied to determine the relationship between the fluid-flow description, channel geometry, sediment transport rate, and bend resistance. Total sediment load, and the parameters describing the statistical distribution of bed forms throughout the bend and in the straight reaches between successive bends are being measured, and are being compared with data of the same type obtained with nominally identical flow conditions in a straight flume.

A second phase of the study is concerned with the difference which exists between the resistance to flow of an erodible-bed river 
bend and the resistance in a bend of similar planimetric geometry but with a fixed cross section. The longitudinal force associated with the deformed bed configuration is to be analyzed by computing the integral of the pressure forces on the bed and walls of the channel.

(h) "Bed Configuration and Characteristics of Subcritical Flow in a Meandering Channel," Chin-Lien Yen, Ph.D. Dissertation, Univ. of Iowa, Feb. 1967 (available on loan). "Areal Variations of Bed-Form Characteristics in Meandering Streams, "E.M. O'Loughlin and D. Squarer, 12th Congr. Intl. Assoc. Hydr. Res., Ft. Collins, Colo., 1967.

(6355) SIMULATION OF RED CELI DEFORMATION IN THE CAPIITARIES.

(b) National Institutes of Health.

(c) Arthur R. Giaquinta, Research Assoc., Iowa Inst. of Hydraulic Research.

(d) Experimental and theoretical; doctoral dissertation.

(e) Investigations of the deformation of largescale models of red cells in a creeping flow, characterizing the fluid mechanics of capillary blood flow, are being made. This system will also be simulated mathematically, and the numerical results will be correlated with the experimental results with the final goal of obtaining a numerical model of red cell deformation in the capillaries.

(6356) NONLINEAR ORDINARY DIFFERENTTAI EQUATIONS IN TRAINSPORT PROCESSES.

(b) Laboratory project.

(c) Prof. W.F. Ames, Dept. of Mechanics and Hydraulics, Univ. of Iowa.

(d) Theoretical; basic research.

(e) Mathematical investigation of equations resulting from similarity analyses of fluid flow, diffusion, heat conduction and other transport processes. Methods of modern algebra are extensively used.

(g) First integrals of some basic equations have been developed using continuous transformation groups.

(h) "Similarity Variables and First Integrals of Ordinary Differential Equations," Intl. Jour. Nonlinear Mechanics, Vol. 2, 257, 1967. "Nonlinear Ordinary Differential Equations in Transport Processes," Academic Press, 270 pages, Jan. 1968.

(6357) DEVELOPMENT OF SIMIIARITY VARIABIES.

(b) Laboratory project.

(c) Prof. W.F. Ames; see (6356) above.

(d) Theoretical; basic research and graduate theses.

(e) Development of continuous transformation groups and their invariants (which are the similarity variables) for a variety of fluid problems.

(g) The natural similarity variables for source diffusion problems and heat transfer in nonnewtonian (power law) flow have been developed.

(h) "Similarity Solutions for Non-Newtonian Fluids," A.I.Ch.E. Jour., Vol. 12, 700, 1966. "Similarity for the Nonlinear Diffusion Equation," Ind. and Eng. Chem. Fund, Vol. 4, $72,1965$.

(6358) AD-HOC METHODS FOR NONLINEAR PARTIAI DIFFERENTIAL EQUATIONS.

(b) Natl. Science Found. and laboratory project. (c) Prof. W.F. Ames; see (6356) above.

(d) Theoretical; basic research and graduate thesis.

(e) Development and utilization of a "method of splitting" and functional methods for developing new solutions to nonlinear equations of fluid mechanics.

(g) A new solution, applicable to porous flow through a flat plate, of the Navier Stokes equations has been obtained by a method of splitting.

(h) "Ad-hoc Exact Techniques for Nonlinear Partial Differential Equations," in Nonlinear Partial Differential Equations - Methods of Solution (ed.W.F. Ames), p. 55, Oct. 1967, Academic Press.

(6359) TURBULEINCE STRUCTURE OF FIOW BEHIND A GRID.

(b) Office of Naval Research, Dept. of the Navy.

(c) Dr. E. Naudascher, Iowa Inst. of Hydraulic Research.

(d) Analytical; basic research.

(e) Extension of analytical work on grid turbulence contained in the paper: "Flow in the Wake of Self-Propelled Bodies and Related Sources of Thurbulence," E. Naudascher, Jour. Fluid Mechanics, Vol. 22, Part 4, 1965.

(6360) TURBULENCE STRUCTURE OF A JET IN AN AMBIENT STREAM.

(b) Office of Naval Research, Dept. of the Navy.

(c) Dr. E. Naudascher; see (6359) above.

(d) Experimental; basic research.

(e) The turbulence structure of a round jet in a coaxial stream is being investigated experimentally. Use of a high-speed digital computer for real-time evaluation of the autocorrelation function and its Fourier transform, the power-spectral density, will permit a check upon the accuracy of data obtained with standard analog instrumentation.

(6361) COMPUTATIONAI MODELING OF NON-NEWTONIAN FLOWS.

(b) Laboratory project.

(c) Dr. E.0. Macagno, Iowa Inst. of Hydraulic Research.

(d) Analytical; basic research and graduate theses.

(e) Unsteady, uniform, and non-uniform non-Newtonian flows are being studied by means of computational models based on discretizations of the corresponding differential equations.

(g) Unsteady uniform flows between parallel plates and through circular and annular conduits have been analyzed for fluids with time-independent relations between stress and rate of strain. Creeping non-Newtonian flow is also being analyzed for the case of a two-dimensional conduit expansion.

(h) "Ecoulement Uniforme non-Permanent avec Viscosite non Newtonienne," E.O. Macagno, C.R. Acad. Sci. Paris, Vol. 262, May 16, 1966. "Unsteady Non-Newtonian Flow in Conduits, E.O. Macagno, Engrg. Mechanics Div. Specialty Conf., ASCE, Washington, D.C., Oct. 12-14, 1966. (Abstract published, paper under preparation).

"Slow Motion of Non-Newtonian Fluids in a Zone of Separation," Arthur R. Giaquinta and TinKan Hung, submitted for publication.

"Establishment of Non-Newtonian Fluid Flow Between Coaxial Rotating Cylinders," (in French), E.O. Macagno and A. Pujol, Comptes Rendus Acad. Sci., Paris, Vol. 264, Jan. 1967. 
(6362) TURBULENT MIXING OF DENSITY STRATIFIED LIQUIDS.

(b) Office of Naval Research, Dept. of the Navy.

(c) Dr. E. Naudascher and Dr. John F. Kennedy, Iowe Inst. of Hydraulic Research.

(d) Experimental and analytical; basic research.

(e) Density profiles and turbulence intensities are being measured behind a towed grid passing through an initially density-stratified liquid, with the aim of determining the influence of the density stratification on the turbulence intensity and turbulent mixing, the degree of stratification recovery at various distances behind the grid, and the correlation between turbulent velocity and salinity fluctuations.

(g) An instrumentation system has been designed and developed to measure the mean value and turbulent fluctuations of salinity concentration at fixed distances behind the towed grid. Coated hot wires have been developed for measurement of turbulence velocities. Experiments with initially two-layered fluids have show a strong effect of density gradient on lateral mixing.

(6363) COLIAPSE OF MIXED REGIONS IN DENSITY-STRATIFIED IIQUIDS.

(b) Office of Naval Research, Dept. of the Navy.

(c) Prof. William F. Ames and Dr. John F. Kennedy, Iowa Inst. of Hydraulic Research.

(d) Analytical; basic research.

(e) A numerical finite difference scheme is being developed to describe the profile of an initially circular region of constant density as it collapses in a surrounding liquid with arbitrary density stratification. Experimental verification of the solution will be sought.

(g) A numerical solution for the case of linear stratification outside the mixed region and potential flow within it has been obtained. The shape of the initially circular region during collapse is approximately elliptical. The vertical collapse occurs quite rapidly, the height of the mixed region being reduced to half of its initial value in about two characteristic time units (based on the Vaisala frequency) for an external gradient of 0.0155 l/ft. Solutions are now being developed for the case of viscous motion within the mixed region, and for the approximately one-dimensional motion that occurs at the later stages of collapse.

(6364) FREE SURFACE SHEAR FLOW OVER A. WAVY BOUNDARY.

(b) Surface Water Branch, U.S. Geol. Survey.

(c) Dr. John F. Kennedy, Iowa Inst. of Hydraulic Research.

(d) Experimental and analytical; basic research.

(e) Analytical and experimental investigation of the velocity and pressure distributions, surface configuration, and boundary stress distribution of subcritical and supercritical free surface flows over a rigid bed of sinusoidal form.

(g) Experiments have been completed with two different beds, with wave lengths of 1.0 and 1.5 ft., wave heights of 0.068 and $0.05 \mathrm{ft}$. respectively. The predictor developed by Kennedy and Iwasa for the amplitude ratio of and phase shift between the bed and surface waves has been verified. The measured velocity profiles have revealed that the form of the velocity profiles varies widely along each wave length. Phase shifts have been observed between the variation of bed shear stress and the bed amplitude. The ranges of occurrence of the various surface configurations have been delineated.

(h) "Free Surface Shear Flow Over a Wavy Boundary," Y. Iwasa and J.F. Kennedy, J. Hyd. Div., Proc. ASCE, No. HY2, March 1968.

(6365) THE STRUCTURE OF TURBULENT FLOW IN A WAVY BOUNDARY CIRCULAR PIPE.

(b) Office of Naval Research, Dept. of the Navy.

(c) Dr. John F. Kennedy; see (6364) above.

(d) Experimental and analytical; basic research.

(e) An experimental investigation of the turbulence array and the velocity, pressure, and shear stress distributions of turbulent flow in a circular pipe whose diameter varies sinusoidally along its length. The primary aim is to establish the magnitude of the phase shifts between the flow characteristics and the boundary geometry.

(g) Experiments in two different wavy-wall pipes have been completed. The mean pipe diameter is five inches, the wave height 0.220 inches, and the wave lengths of 10 and 20 inches. The form of the velocity profile has been found to vary radically along a wave length, the value of $\mathrm{n}$ in the power-law distribution ranging from about 6 to 22. In a central core both the mean and turbulent quantities appear to be little affected by the boundary waviness; the major effects are confined to the neighborhood of the boundary. The shear-stress variation is shifted about 0.1 wave length upstream with respect to the boundary wave, the exact value depending on the boundary geometry.

(6366) DEVELOPMENT OF A SENSOR FOR SUSPENDED SEDIMENT CONCENTRATION.

(b) Coastal Engrg. Research and Development Ctr.

(c) Dr. John Glover and Dr. John F. Kennedy, Iowa Inst. of Hydraulic Research.

(d) Experimental; applied research.

(e) The development of a small light source and sensor which can be used to measure the turbulent fluctuations of suspended sediment concentration in a turbulent flow. An attempt will be made to obtain simultaneous measurements of the turbulent velocity fluctuations, and to correlate these with the concentration fluctuations.

(6617) FRICTION FACTORS FOR FLOW IN SAID BED CHAINNELS.

(b) Laboratory project.

(c) Dr. John S. Kennedy; see (6364) above.

(d) Analytical; basic research.

(e) A prediction for the friction factor of alluvial channel flows in the flat bed regime is being developed from an examination of field and laboratory data. The goal is to improve the depth-discharge prediction for all regimes of alluvial channel flow.

(g) A graphical relation has been developed for prediction of the friction factor in terms of the relative sand grain roughness and the flow Reynolds number.

IOWA STATE UNIVERSITY, Dept. of Agricultural Engrg., Ames, Iowa 50010

Inquiries concerning projects 015W, 016W, 01TW and O2OW should be addressed to Dr. H.P. Johnson, Dept. of Agricultural Engrg.; and concerning 018W, 019W and 5708, to Dr. C.E. Beer, Dept. of Agricultural 
Engrg., Iowa State Univ.

(5708) SEDIMENT YIEID IN DEHEP IOESS HIIUS IAND RESOURCE AREA.

(b) Cooperative with Soil Conserv. Service and Agric. Research Service, U.S. Dept. Agric.

(d) Field investigation; applied research; design.

(e) Sedimentation surveys have been made on a total of 27 reservoirs in Western Iowa and Missouri. The rate of deposition will be related to watershed, hydrologic and topographic variables by statistical procedures.

(f) Completed.

(h) "Evaluation of Factors Affecting Reservoir Sediment Deposition," C.W. Farnham, C.E. Beer and H.G. Heinemann, Extract of Publ. No. 71, Intl. Assoc. Scientific Hydrology, Symp. of Garda, pp. 747-758, 1966.

"Evaluating Sedimentation Prediction Techniques in Western Iowa," C.E. Beer, C.W. Farnham and H.G. Heinemann, Trans. Am. Soc. Agr. Engr., Vol. 9, 828, 1966.

(015W) FIETD INVESTICATIONS OF SUBSURFACE AND SURFACE DRAINAGE. (Formerly No. 2330)

See Water Resources Research Catalog, Vol. 1, Part 1, 3.170.

(O16W) HYDROIOGIC CHARACTERIZATION OF SMALI WATERSHEDS. (Formerly No. 2331)

See Water Resources Research Catalog, 4.0080, Vol. 2.

(OITW) PHYSICAI AIND ECONOMTC ANALYSIS OF WATERSHEDS AS RELATED TO SOIL AND WATER CONSERVATION. (Formerly No. 2334)

See Water Resources Research Catalog, Vol. 1, Part 2, 3.22.

(O18W) INVESTIGATIONS OF EROSION CONIROL AND WATER CONSERVATION. (Formerly No. 4913)

See Water Resources Research Catalog, 4.0078, Vol. 2.

(O19W) EVALUATION OF FLOOD DAMAGE TO CORN FROM CONTROLIED DEPTH AND FREQUENCY OF FLOODING. (Formerly No. 5707)

See Water Resources Research Catalog, 6.0166, Vol. 2.

(O2OW) PHYSICAL, LEGAL AND ECONOMIC ASPECTS OF COSTS AMONG DRAINAGE DISTRICTS. (To be listed in Water Resources Research Catalog)

IOWA STATE UNIVERSITY, Department of Agronomy,

Ames, Iowa 50010

For summaries of the following projects, refer to Water Resources Research Catalog.

(OI2W) MOVEMENT OF WATER AND GASES IN SOIL. (Formerly No. 3079)

(c) Dr. Don Kirkham.

(O13W) MOISTURE MOVEMENT TO VERTICAI SINKS IN WATERSATURATED SOII. (Formerly No. 5706)

(c) Dr. Don Kirkham.

(O14W) GROUNDWATER SEEPAGE PATTERNS TO WELLS FOR UNCONEINED FTOW.

(c) Dr. Don Kirkham.
UNIVERSITY OF IOWA, College of Engineering, Dept. of Mechanical Engrg., Iowa City, Iowa 52240

(6109) HEAT TRANSPORT IN TURBULENT FTOWS WITH INTERNAL HEAT SOURCES.

(b) University of Iowa.

(c) Prof. J. Merle Trumel, Dept. of Mechanical Engrg., Univ. of Iowa.

(d) Experimental; basic research.

(e) Development of suitable experimental systems permitting measurement of mean temperature distribution, measurements in statistically analogous systems.

(g) Measurements have been made on one flow geometry with chemical internal heat generation and with an analogous system. Measurements also have been made on circular tube flow using the analogy approach.

(h) "Analogy Between Steadily Heated Flow and Flow with Internal Heat Generation," Barry K. Hankins, M.S. Thesis, Univ. of Iowa, Aug. 1965.

(Available in library)

"Mean Temperature Distribution in Reacting Thrbulent Flow with Uniform Internal Heat Generation," J.M. Trumel, Department Rept.

(6I11) LIQUID-VAPOR INIERFACIAL WAVES ON VERTICAILY FIOWING FILMS FORMED BY A CONDENSING VAPOR.

(b) Laboratory project.

(c) Dr. Donald I. Spencer, Dept. of Mechanical Engrg., Univ. of Iowa.

(d) Experimental; basic research.

(e) The Reynolds number at the line of wave inception is being determined experimentally for various conditions of condensation rate, condenser length and surface finish. Condensation is on the outside of a vertical cylinder. The vertical movement of the inception line with changes in total condensation rate is being determined, as well as indications of wave regimes. The object is to determine the effect of the waves on heat transfer.

(g) For a condensing saturated pure vapor, the surface flow condition is divided into an upper smooth, stable region and a lower region of horizontal roll waves. When non-condensables are present, vertical waves occur on the upper region (which is stable for a pure vapor) for sufficiently high condensation rates, and there is a tendency toward damping of the horizontal waves on the lower section. Since the flow feed is distributed along the surface, there are no "leading edge" constraints typical of purely hydrodynamic experiments, and the line of inception of roll waves (critical condition) is different than as determined in the overflow type of experiments.

(6112) INTERACTION BETWEEN VORTEX FTOW AND TWO DIMENSIONAL JET FLOW.

(b) Laboratory project.

(c) Prof. G.M. Lance, Dept. of Mechanical Engrg. Univ. of Iowa.

(d) Experimental; doctoral thesis.

(e) A study is being made of the flow characteristics in the finite vortex and of the deflection of a submerged jet of fluid by finite vortex flow.

(6113) ON THE INSTABIIITY OF TWO PHASE STAGNATION POINT FLOW.

(b) University of Iowa.

(c) Dr. C.J. Chen, Dept. of Mechanical Engrg.. Univ. of Iowa. 
(d) Experimental and theoretical; basic research.

(e) The basic set-up of the experiment is that a gas jet with variable height, speed and diameter is guided to the liquid tank of a variable depth. The measurements of the instability waves are correlated with the theoretical results of various instability mechanisms.

(g) The preliminary results indicate that the basic parameters to characterize the instability are liquid and gas Reynolds number while Froude and Weber serve only to shift the range of the instability.

(h) "On the Instability and the Low Temperature Simulation of Hypersonic Melting Ablation," submitted for publication, 1967.

"Melting Ablation for Two Dimensional and Axisymmetric Blunt Body with Body Force," C.J. Chen, Ph.D. Thesis, Case Inst. Tech., 1967, or Report, Dept. of Mechanical Engrg., Univ. of Iowa, Dec. 1967

UNIVERSITY OF IOWA, Iowe Institute of Hydraulic Research, see IOWA INSTITUIE.

THE JOHNS HOPKINS UNIVERSITY, Applied Physics Iab., 8621 Georgia Ave., Silver Spring, Md. 20910

(2335) APPLICATION OF SWITCHING TECHIIQUES TO HYDRAUIIC CONTROL SYSTEMS.

(b) Bureau of Weapons, Dept. of the Navy.

(d) Theoretical and experimental; applied development and design.

(e) Study the dynamic qualities of an acceleration switching hydraulic servomechanism while operating in a closed loop under the presence of various loads and environmental conditions on the transfer valve, actuator and feedback transducer.

(g) The operation of a broad bandpass servomechanism driving a low resonant frequency linkage has resulted in radical design compromises to prevent instability. Extension of acceleration switching techniques without any mechanical modification has permitted closed loop operation with bandpasses equal to or exceeding the linkage characteristics.

(h) "Design of a Hydraulic Servo with Improved Bandpass Characteristics When Driving a Resonant Mechanical Load," W. Seamone, APL/JHU $\mathrm{CM}-962$.

(3436) ADAPTIVE EIECTRO HYDRAULIC SERVOMECHANISMS.

(b) Bureau of Weapons, Dept. of the Navy.

(d) Theoretical and experimental.

(e) Techniques have been developed for designing linear servomechanisms with a limit cycle instability about a relay type non-linearity. The closed loop aharacteristics of this servomechanism become invariant to any pure gain changes occurring in the linear elements. This servomechanism, categorized as a selfoscillating control servomechanism, appeared to be an evolutionary improvement over the acceleration switching hydraulic servomechanism.

(8) A self-oscillating rate servomechanism has been operated with the loop closed around the valve spool position. Predictable selfoscillation frequency was achieved and dynamic performance bandpass was independent of hydrau- lic supply pressure between 500 and 2000 psi. The bandpass of both servomechanisms exceeded 60 cycles per second with the latter operating a complex mechanical load system.

(6092) IOAD SENSITIVE HYDRAULIC CONIROL SYSTEM.

(b) Bureau of Naval Weapons.

(d) Theoretical and experimental.

(e) Hydraulic servos are noted for their good dynamic performance and high power levels. This is often accomplished at the expense of system power efficiency. Techniques are being studied to improve hydraulic servo efficiency by modulating the hydraulic power system as a function of load.

(g) A hydraulic servo-integrated power package has been operated employing a load sensitive feedback element between the servo and pump to match input power to actual system load demand. This system concept improved power efficiency by a factor of two during the load demand portion of the duty cycle. Performance was not degraded by this feedback loop.

(h) "Feedback Technique Improves Efficiency of Hydraulic Servos," APL Technical Digest, W. Seamone, Nov.-Dec. 1964.

THE UNIVERSITY OF KANSAS, Department of Civil Engrg., Lawrence, Kansas 66044

\section{(5710) INSTABILITY OF NON-NEWTONIAN HELICAL FLOW.}

(b) Laboratory project.

(c) Dr. Y.S. Yu, Dept. of Civil Engrg., Univ. of Kansas.

(d) Theoretical and experimental; basic research.

(e) This study treats the inception of the instability of the laminar motion of a power-law fluid between two concentric cylinders with the inner cylinder rotating and the outer cylinder fixed.

(f) Completed.

g) The characteristic value problem has been solved by using Galerkin's method for the fluid with a flow behavior index $n=0.5$ and for the radius ratio ranging from 1.17 to 2.0 . The critical power-law Reynolds number and the dimensionless wave number at which the instability is pending were computed approximately. Experiments were also conducted for two values of radius ratio. The measured critical Reynolds numbers agree within 10 percent with the computed values.

(h) "The Stability of Laminar Motion of a PowerLaw Fluid Between Rotating Coaxial Cylinders," Dan B. McVicker, Ph.D., dissertation, Dept. of Mechanics and Aerospace Engrg., 1966.

(6466) IIQUID SLOSHING IN A TANK WITH AN ELASTIC BOTTOM.

(b) Laboratory project.

(c) Dr. Y.S. Yu; see (5710) above.

(d) Theoretical; basic research for doctoral thesis.

(e) The objectives of this study are: (1) to formulate the general linear hydroelastic sloshing problem in terms of a variational principle; (2) to use the direct method of calculus of variations to obtain an approximate solution for the eigen value problem; (3) to determine the limitation of the approximate solution.

(f) Corpleted 
(g) The secular equation for liquid sloshing in a rigid tank and a tank with elastic bottoms was obtained. The eigen values appear in nearly every term of the determinantal equation for both cases. A direct iterative procedure on the eigen value itself has been developed to yield the approximate values of the frequencies of the coupled free oscillations and the normalized amplitudes of the free surface oscillation. The numerical results show that the effect of the elastic bottom on the coupled frequency of free oscillations is negligible at certain ranges of a rigidity parameter and an inertial parameter.

(h) "A Variational Approach to a Liquid Sloshing in a Rectangular Tank with an Elastic Bottom," Richard C. Coddington II, Ph.D. dissertation, Dept. of Mechanics and Aerospace Engrg., 1966.

(6467) UNSTTEADY IAMINAR BOUNDARY IAYER ON A BODY OF REVOLUIIION IN AN AXIAL FLOW.

(b) University research grant.

(c) Dr. Y.S. Yu; see (5710) above.

(d) Theoretical and experimental basic research for doctoral thesis.

(e) This study concerns the steady and unsteady laminar boundary layers on a circular cylinder in an axial flow with and without superimposed oscillations.

(t) Completed.

(g) The laminar boundary layers on a circular cylinder in steady and unsteady axial flows with zero mean pressure gradient have been studied experimentally and theoretically.

For the steady case, velocity traverses were made in a wind tunnel on two cylinders with 2.5 in. and $5.5 \mathrm{in}$. outer radius respectively. The free-stream velocity was about $10 \mathrm{fps}$. The measured velocity profiles agree only qualitatively with the existing theory.

For the unsteady case, the free-stream velocity varies sinusoidally with time in magnitude but not in direction. Theoretical solutions for small-amplitude, high-frequency and low-frequency oscillations were obtained.

For high-frequency oscillations, the computed amplitude and phase difference of the velocity oscillations for the cylinder with the frequency parameters a $\sqrt{\omega / v}$ larger than 10 , practically coincide with the shear-wave solution for a flat plate.

For small-amplitude, low-frequency velocity oscillations, the computed velocity in the boundary layer is almost always in phase with the free-stream velocity and the maximum amplitude of the velocity oscillations in the boundary layer is larger than the amplitude of the free-stream oscillations.

The measured amplitude and phase difference of the velocity oscillations agree only qualitatively with theory.

(h) "The Laminar Boundary Layer on a Circular Cylinder in an Oscillatory Axial Flow," Developments in Theoretical and Applied Mechanics, Vol. 3, Pergamon Press, N.Y., 1967.

(6468) UNSTEADY FTOW PARAMETERS IN HYDRAULTC DESIGN.

(b) Kansas Water Resources Research Inst.

(c) Dr. Y.S. Yu; Dept. of Civil Engrg., Univ. of Kansas.

(d) Theoretical and experimental; basic research for doctoral thesis.

(e) The purpose of this study is to investigate the characteristics of unsteady, incompressible flow involving the interaction between a conduit and a reservoir. The test system consists of a reservoir from which water flows through a conduit. Flow is varied by controlling a quick acting valve. The transient velocity and pressure are measured.

Projects also reported in "Water Resources Research Catalog":

(O2IW) RIVER BASIN HYDROLOGY (DEVELOPMENT OF A WATER BUDGET MODEL FOR KANSAS STREAMS).

(O22W) EFFECTS OF BANK SEEPAGE ON FIOOD HYDROGRAPHS.

(023W) THE USE OF ATMOSPHERIC HUMIDITY IN ESTIMATING EVAPOTRANSPIRATION.

(O24W) FURTHER DEVELOPMENT OF THE CLARK METHOD OF UNIT HYDROGRAPH SYNTHESIS.

(O25W) FLOOD FREQUENCY MODIFICATIONS DUE TO IMPOUNDMENTS.

(O26W) DEVELOPMENT AND EVALUATION OF A MATHEMATICAL MODEL OF THE IOWER REACHES OF THE KANSAS RIVER DRAINAGE SYSTEM.

(O2TW) A HYDROLOGIC STUDY OF A MISSOURI RTVER ALLUVIAL AQUIFER.

UNIVERSITY OF KENIUCKY, Department of Civil Engrg., Lexington, Kentucky 40506

(6275) UNISTEADY FIOW OF SOLTD ITQUID SUSPENSIONS.

(b) National Science Foundation.

(c) Don J. Wood, Assoc. Prof., Dept. of Civil Engrg., Univ. of Kentucky

(d) Basic research; MS, Ph.D. theses.

(e) Development of basic relationships for wave velocities and magnitudes in suspended flow. Purpose is to be able to analytically describe unsteady suspended flow.

(g) Many basic relationships developed.

(h) "Unsteady Flow of Solid - Liquid Suspensions," D.J. Wood, T.Y. Kao, Jour. Engrg. Mechanics Div., ASCE, Dec. 1966.

"Generation and Propagation of Pressure Waves in Two Phase Flow," D.J. Wood and T.Y. Kao, Developments in Theoretical and Appl. Mechanics, Plenum Press, 1967.

(6276) THE INFLUENCE OF STRUCIURAL MOTION ON THE DYNAMIC RESPONSE OF HYDRAUIIC F'HED SYSTEMS.

(b) Army Research Office, Durham.

(c) Don J. Wood; see (6275) above.

(d) Analytical and experimental; applied research; M.S., Ph.D. thesis.

(e) Purpose is to integrate structural and fluid dynamic analysis for coupled flow systems.

(g) Periodic flow systems investigated. Attenuation of waterhammer surge due to line movement shown to be gross effect.

(h) "The Influence of Structural Motion in the Dynamic Response of Periodic Liquid Flow Systems, " D.J. Wood, T.Y. Kao, Conference preprint, ASME - AIAA Structural Dynamics, Structures and Materials Conf., Palm Springs, Calif., 1967.

(6277) DESIGN AND ANALYSIS FOR HYDRAULIC TRANSIENT FLOW SYSTHM UTILTZING ANAIOG COMPUTERS.

(b) Laboratory project.

(c) Don J. Wood, Assoc. Prof., Dept. of Civi] Engrg., Univ. of Kentucky.

(d) Development of computing and design techniques; 
M.S. Thesis.

(e) Analysis and design of surge system, flow establishment and waterhammer.

(g) "Waterhamer Analysis by Analog Computer," Don J. Wood, Jour. Hydraulics Div., ASCE, Jan. 1967.

(6278) EVALUATION AND DESIGN OF HYDRAULTC FILIERS FOR SURGE PRESSURES.

(b) Laboratory project.

(c) Don J. Wood; see (6277) above.

(d) Basic and applied research; M.S. thesis.

(e) Develop analytical techniques to analyze characteristics of filters and to test the filters.

(g) Single air chamber filter investigated and shown to give good attenuation.

IAMONT GEOLOGICAL OBSERVATORY of Columbia University, Palisades, N.Y. 10977.

(6084) MIXING, DIFFUSION AND CIRCUIATION RATES IN OCEAN WATTERS.

(b) U.S. Atomic Energy Commission.

(c) Dr. Takashi Ichiye, Senior Research Associate, Iamont Geological Observatory of Columbia Univ.

(d) Theoretical and/or field investigation; basic research.

(e) The work of the portion reported here includes studies of diffusion and circulation in oceans on varieties of scales ranging from several centimeters to a few hundred kilometers. Techniques used for these studies include dye diffusion methods at the surface and subsurface, classical hydrographic methods, different kinds of current meters and electronic temperaturesalinity recorders, aerial photograrmetry and infra-red thermometry.

(g) Structure of Ekman spiral near the surface was determined with dye experiments. Dynamical features of windrows and Langmuir streaks revealed by dye experiments were explained from wave and turbulence theory. Turbulent motion near the bottom was determined from observations of a nepheloid layer. From hydrographic data off Cape Hatteras, mixing between the Gulf stream water and the shelf water through medium scale eddies was studied. Vertical eddy viscosity and vertical currents in the Pacific equatorial current system were determined from analysis of the hydrographic data based on hydrodynamics. Tidal flushing in the South Oyster Bay-Great South Bay was computed and a new analogue system of its prediction was designed.

(h) "Symposium on Diffusion in Oceans and Fresh Waters, Aug. 31 - Sept. 2, 1964." Edited by T. Ichiye, (Available through Lamont Geol. Observ. at $\$ 2.00$ per copy), 1965.

"Some Hydrodynamic Problems for a Nepheloid Zone," T. Ichiye, Pure and Appl. Geophys. (PAGEOH), Vol. 63, 179-195.

"Turbulent Diffusion of Suspended Particles near the Ocean Bottom," T. Ichiye, Deep-Sea Research, Vol. 13, 679-685.

"Hydrographic Structure of an Eddy on the Edge of the Gulf Stream off Cape Hatteras," (Abstract) T. Ichiye, Trans. A.G.U., Vol. 47, No. 1, p. 109.

"Annotated Bibliography on Internal Waves," T. Ichiye, Jour. Oceanogr. Soc. Japan, Vol. 22, No. 5, pp. 201-223, 。
"Vertical Currents in the Equatorial Pacific Ocean," T. Ichiye, Jour. Oceanogr. Soc. Japan, Vol. 22, No. 6, pp. 274-284.

"Hydrographic Structure of an Eddy on the Edge of the Gulf Stream off Cape Hatteras, "T. Ichiye, Annual Rept. 1965-1966 Contract AT(30-1)2663 to U.S. Atomic Energy Comm. by Lamont Geol. Observ., Appendix P, 5 pp., 1966. "Optimum Ratio of Width to Depth of a Channel for Maximum Flow," T. Ichiye, Annual Rept. 1966-1967 Contract AT(30-1)2663 to U.S. Atomic Energy Comm. by Lamont Geol. Observ., Appendix I, 4 pp., 1967.

"Tidal Flushing of South Oyster Bay and Great South Bay, (I) and (II)," ibid T. Ichiye, Appendix $M$ and $N, 8$ pp. and 25 pp., 1967. "Occurrence of Temperature Iversions in the Upper Layer of the Ocean," T. Ichiye, Pure and Appl. Geophys. (PAGEOH), Vol. 67, 1967, 143-155. "Upper Ocean Boundary Layer Determined by Dye Diffusion," T. Ichiye, Physics of Fluids, Vol. 10, 299-306, 1967.

"Photodensitometric Measurement of Dye Concentration in the Ocean "T. Ichiye and N.B. Plutchak, Limnology and Oceangraphy, Vol. 13, No. 3, pp. 364-370, 1966.

(6085) ROTATING MODEL EXPERTMENT ON CIRCULATION IN THE ANTARCTIC OCEAN.

(b) Anarctic Programs, Natl. Science Foundation.

(c) Dr. Takashi Ichiye; see (6084) above.

(d) Experimental and theoretical; basic research.

(e) To study dynamics of wind-driven and convective circulation in the Antarctic Ocean by use of a scale model of the ocean mounted on a rotating table.

(g) The model experiments proved that sinking of the bottom water along the Antarctic continent reduces the pure wind-driven circulation of the Antarctic Circumpolar Current to be a great degree, yielding the zonal transport similar to the observed geostrophic transport. The observed bottom undulations with several kilometer wave lengths in the Argentine Basin can be explained as internal waves in a nepheloid layer.

(h) "Dynamics of the Antarctic Circumpolar Current (A.C.C.) I and II," T. Ichiye, Tech. Rept. No. CU-1-67 and CU-2-67 to the National science Foundation, Contract NSF FA-258, pp. 23 and pp. 19, April 1967.

"Dynamics of the Antarctic Circumpolar Current (A.C.C.) III, T. Ichiye, ibid CU-3-67, pp. 27, June 1967:

(6086) OCEAN SURFACE PHENOMEITA AND TURBULENCE.

(b) Office of Naval Research.

(c) Dr. Takashi Ichiye; see (6084) above.

(d) Theoretical and field investigation.

(e) To study mechanics of turbulence in the upper layer of the ocean and in the shallow waters and also air-sea interaction.

(g) Turbulent heat exchange between the ocean and the air was discussed by use of diffusion equations in case of a cold air outbreak over the Gulf Stream. Mixing of waters by tidal currents in Block Island Sound was studied by field survey and tidal flushing theories.

(h) "Tidal Variation of Hydrography of Block Island Sound Observed in August 1965," T. Ichiye, Tech. Rept. No. CU-15-67 to Office of Naval Research, Contract Nonr 266948) pp. 38, 1767.

"An Example of Heat Transfer at the Air-Sea 
Boundary over the Gulf Stream during a Cold Air Outbreak," T. Ichiye and E.J. Zipser, Jour. Meteorol. Soc. Japan, Vol. 45, No. 3, 261-270. Also most papers listed for the Atomic Energy Comm. Contract (see No. 6084) were prepared under a joint sponsorship with this project.

IEHIGH UNIVERSITY, Dept. of Civil Engrg., Bethlehem, Pennsylvania 18015

Inquiries concerning the following projects and requests for reprints and technical reports should be addressed to Dr.W.H. Graf, Assoc. Prof., Chairman, Hydraulic and Sanitary Div., Fritz Engineering Lab., Iehigh Univ.

(2543) STUDY OF CONDUIT EXIT PORTALS.

(b) Laboratory project.

(d) Experimental; M.S. thesis.

(f) Discontinued.

(g) Tests of square and circular conduit with freejet, horizontal apron, and three different wall flares, have been completed.

(3084) STUDY ON IMPROVING DESIGN OF A HOPPER DREDGE PUMP.

(b) District Engr., U.S. Army Engr. Dist., Marine Div., Philadelphia, Corps of Engrs.

(d) Applied and basic research.

(e) The irmediate purpose of the study is to improve design of a hopper dredge centrifugal pump for pumping silt-clay-water mixtures. The long-term objective is to determine the effect of Bingham Body-type of fluid on pumping characteristics. The project has been divided into four phases: (1) Model test of existing dredge pump; (2) recommendations for design changes of the dredge pump; (3) model investigation of the modified design of the dredge pump; and (4) analysis of the investigation and final recommendations. Phase 1 involved installation in the hydraulic laboratory of a 1:8 scale model of the dredge pump now used on the U.S. Corps of Engineers dredge ESSAYONS. Water as well as slit-clay-water mixtures (Bingham Body-type of fluid) were pumped and complete characteristics of the pump obtained for capacity of 0 to 1200 gallons per minute, speed of 1150 to 1900 revolutions per minute, and liquid concentrations of 1000 and 1380 grams per liter. Phases 2 and 3 involve modifications in the shape of vane and changes in the exit vane angle of the impeller. Experimental tests indicate considerable improvement in pump efficiency. Analysis of the experimental data resulted in recomendations for changes in pump design.

(f) Completed.

(g) Considerable improvement in pump efficiency has been achieved.

(3086A) INVESTIGATION OF DESIGN CRITERIA OF SPUR DIKES. (See also No. 3086, p. 124.)

(b) Modjeski and Masters, Consulting Engrs., Harrisburg, Pa., Lehigh Univ. Inst. of Research.

(d) Analytical and experimental.

(e) The project has been divided into four phases (a) Literature survey; (b) analytical study; (c) experimental study in a fixed-bed model to determine the desired lengths and shapes of spur dikes to provide uniform velocity distribution in the waterway between bridge abutments; (d) experimental study in a movable-bed model to verify findings in part c. A spur dike has been defined as a projection extending upstream from the bridge abutments.

(f) Completed.

(g) Preliminary investigation indicates that a properly designed spur dike can produce a fairly uniform velocity distribution between the abutments.

(h) "Hydraulics of Bridges," J.W. Delleur, D.E. Schneible and H.J. Tracy, Joint Highway Research Project, Amer. Soc. Civil Engrs., Task Force, Purdue Univ., Lafayette, Ind.

(3747) FRICTION HEAD LOSSES IN CIRCULAR PIPES FOR A BINGHAM-BODY FLUID.

(b) Laboratory project.

(d) Experimental and theoretical.

(e) The object of the study is the determination of the pipe flow characteristics of slurries of various concentrations. The slurries do not behave as fluids of constant viscosity so that it is not possible to use conventional methods for prediction of head losses in pipes conveying them. Tests are being conducted in 6-inch, 3-inch, and 2-inch pipelines with velocities from less than 1 fps to over $30 \mathrm{fps}$.

(f) Suspended.

(4154) DREDGE PUMP DESIGN.

(b) National Bulk Carriers, Inc.

(d) Experimental.

(e) The objective of the investigation is to obtain the efficiency and head-capacity curves, to check the effect of the reduced. vane exit angle, and to determine the efficiency of a model dredge pump while pumping silt-clay-water mixture of specific gravity equal to 1.17. The experimental tests were carried out on a $1 / 8$ model pump of the Natl. Bulk Carriers Hopper Dredge, S.S. Zulia.

(f) Completed.

(h) Report in preparation.

(4.155A)WAVE RUN-UP ON COMPOSITE BEACHES. (See also No. 4155, p. 124.

(d) Graduate student's project. Experimental, applied research for design.

(e) The main object of the study is to verify existing equations for determining the height of wave run-up and obtain the limits of application of the equation for long beach berms.

The study is conducted in a $67 \mathrm{ft}$. long, $2 \mathrm{ft}$. wide and $2 \mathrm{ft}$. deep wave channel equipped with pendulum-type wave generator and efficient absorbers.

( 1 ) Completed.

(4645) EFFECT OF LENGTH AND SPACING OF SPUR DIKES.

(b) Laboratory project.

(d) Experimental and theoretical; M.S. thesis.

(e) The object of the study is to determine the effect of length and spacing of spur dikes on the magnitude of scour in uniform flow. The experiments are conducted in a 10-ft. wide, 35-ft. long open channel with movable sand bed. Scour patterns are observed and analyzed.

(f) Completed.

(5172) MEASUREMENT OF SLURRY FLOW BY USE OF $90^{\circ}$ ELBOW METER. 
(b) National Bulk Carrier Inc., New York, N.Y.

(d) Applied and basic research.

(e) A four-inch $90^{\circ}$ elbow meter was calibrated against a magnetic flow meter. A flow range of from 0-1100 gpm was effected in the calibration. Water and fine concentrations of silt-clay-water mixtures are included in the calibration tests. The basic theory of the "elbow meter" is discussed and an empirical mathematical relation between liquid concentration, differential head, and pipe velocity is presented and discussed. The feasibility of use of the elbow meter for flow measurement of slurry type flow is highly possible, but calibration of meter in place is reconmended. Also, the viscous properties of the material metered are believed to play an important role in the meter's performance.

(f) Completed.

(5173) SUCTION DREDGING IITERATURE SURVEY.

(b) Ellicott Machine Corp., Baltimore, Md.

(d) Applied and basic research.

(e) This report is a brief review and summary of selected literature pertaining to equipment and methods associated with dredging practice and laboratory studies of dredge pumps. It consists of four parts: (1) Summary and discussion section; (2) selected abstracts; (3) annotated bibliography; (4) bibliography. The discussion section consists of two parts. Part 1 discusses dredging equipment and dredging in general. Part 2 discusses aredge pumps.

(f) Completed.

(5174) PERFORMANCE STUDY OF A 1:6 MODEL DREDGE PUMP.

(b) Ellicott Machine Corporation, Baltimore, Md.

(d) Applied and basic research.

(e) Performance tests were made on five 1:6 scale model impellers. Each impeller was tested at four constant speeds over a wide range of heads and discharges. Water and two concentrations of a typical dredging mud were tested with each impeller at all four speeds. Various graphs and design application curves were developed for making similarity studies and designs in the homologous series of pumps.

(f) Completed.

(5550) CAVITATION STUDIES ON A MODEL DREDGE PUMP.

(b) Ellicott Machine Corp., Baltimore, Md.

(d) Applied and basic research.

(e) Effect of various pump design parameters on cavitation is being investigated. Water and two concentrations of a typical dredging mud are being used as dredging material in the laboratory. other variables, in addition to geometric characteristics of the pump, include pump speed and rate of flow.

(f) Completed.

(h) "Effect of Impeller Modifications on Cavitation Characteristics," J.T. Cassan, Fritz Engrg. Lab. Rept. 301.4, 1965.

(5552A)SCOUR OF FIAT SAND BEACHES DUE TO WAVE ACTION. (See also No. 5552, p. 124).

(b) Iaboratory project.

(d) Experimental and theoretical.

(e) Research requirement of Master's degree.

(f) Suspended.

(g) Stability of a horizontal sand bed deposited in shallow water in front of an impervious, smooth seawall under conditions in which the waves have not yet begun to break was inves- tigated. Experimental studies have been performed in a two-dimensional wave channel in an effort to determine the rate, extent, and ultimate amount of scour of the flat sand bed for different conditions of water depth, wave height and length, and slope of sea wall.

(h) "Beach Scour Due to Wave Action on Seawalls," B. Van Weele, Fritz Engrg. Rept. No. 293.3, Lehigh Univ., 1965.

"Scour of Flat Sand Beaches Due to Wave Action in Front of Sea Walls," J.B. Herbich and H.D. Murphy, ASCE Coastal Engrg. Conf., Oct. 1965. "Scour of Flat Sand Beaches in Front of Seawalls," Stephen C. Ko, Fritz Engrg. Rept. No. 293.5, Lehigh Univ., 1967 (M.S. Thesis)

(5821) WAVE REFTECTION AND TRANSMISSION FOR CYIINDRICAI PILE ARRAYS.

(b) Laboratory project.

(d) Experimental; Master's thesis.

(i) Completed.

(g) The purpose of the investigation is to determine the relationship between wave reflection and transmission and several pile-group configurations. A total of 16 circular piles were used in different rectangular arrays and one random pattern. In the rectangular arrangements both the spacings transverse to the oncoming wave and the spacings longitidinal to the oncoming wave were investigated. The experimental studies were performed in a twodimensional wave channel.

(h) "Wave Reflection and Transmission for Cylinarical Pile Arrays," B. VanWeele, Fritz Engrg. Lab. Rept. No. 293.4, Lehigh Univ., 1965.

(5822) GAS REMOVAI SYSTEMS ASSOCIATED WITH DREDGE PUMPS.

(b) District Engr., U.S. Army Engr. Dist., Marine Div., Philadelphia, Corps of Engrs.

(d) Applied and basic research.

(e) The overall purpose is to study the effect of gas removal systems on centrifugal dredge pumps. This consists of a program of studies, tests, analysis and reports dealing with ways and means for efficiently removing entrained and dissolved gases from the effluents of oredging with centrifugal pumps in rivers and harbors. The project has been divided into four (4) phases. (a) Iiterature Search and Formulation of a Test Program. (b) Formulation of Specific Test Setup and Schedule of the Tests wich Water. (c) Experimental Study and Analysis of Test Results. (d) Experimental study with Solid-Water Mixtures (mud) and Analysis of Test Results.

(f) Phase (c) active.

(h) "Gas Removal Systems, Part I: Iiterature Survey and Formulation of Test Program, "W.P. Isaacs and J.B. Herbich, Fritz Engrg. Lab. Rept. No. 310.3, 1965.

"Gas Removal Systems, Part II: Development of Facility layout and Formulation of Test Program," A. Shindala, Fritz Engrg. Lab. Rept. No. 310.7, 1965.

(6559) MODEL STUDY FOR NOCKAMIXON DAM.

(b) General State Authority, Pennsylvania.

(d) Applied research.

(e) Studies on a 1:60 scale model were done to check spillway approach conditions and to complete the design of an unusual right angle turn in the spillway channel. 
(f) Completed.

(g) Improved approach conditions. Improved design of turning basin by rounding corners and narrowing discharge channel.

(h) "Model Study of Ninety Degree Spillway for Nockamixon Dam," D.R. Basco, J.B. Herbich, and P.D. Erfle, Fritz Engrg. Lab. Rept. No. 362.2, Lehigh Univ., 1967.

(6560) SUPERCRITICAL TRANSITIONS. (See Texas A and M Proj. No. 6399)

(b) Laboratory project.

(d) Theoretical; basic research.

(e) Application of the method of characteristics to supercritical flow through a simple transition. Characteristics were computed with a digital computer. Several examples are solved.

(f) Completed.

(h) "Transitions in Supercritical Open-Channel Flow," G. Bagge and J.B. Herbich, Proc. ASCE, Jour. Hydraulics Div., Vol. 93, No. HY5, Sept. 1967.

(6561) MODEL TTEST OF TWO LICK CREEK DAM.

(b) Gilbert Associates, Inc., Reading, Pa.

(d) Experimental; applied research.

(e) A 1:40 scale model was tested to check spillway flow conditions, to calibrate flow under the radial gates, and to determine the erosion patterns likely in the sand stone apron below the flip bucket. A sand-cement mixture was developed to model the sand stone.

(f) Completed.

(h) "Model Study of Two Lick Creek Dam," J.R. Adams, A.W. Brune, and S.C. Ko, Fritz Engrg. Lab. Rept. No. 336.1, 1968

(6562) STUDIES ON THE SETPLING VEIOCITY.

(b) Laboratory project.

(d) Applied research.

(e) Model investigation in the determination of the settling velocities of artifical and natural particles.

(f) Completed.

(g) See $(h)$.

(h) "Settling Velocities of Natural Grains," W.H. Graf and E.R. Acaroglu, Bull. Intl. Assoc. Sci. Hydrology, Vol. XI, No. 4, 1966.

"Remarks on the Rubey Equation for Computing Settling Velocities," W.H. Graf and E.R. Acaroglu, VII Intl. Sedimentological Congr. in Great Britain.

(6563) SETTLING VELOCITIES IN TURBUTENT ENVIRONMENT.

(b) Laboratory project.

(d) Theoretical and experimental; basic research.

(e) The influence of the turbulence on a particle's settling velocity shall be studied. Experiments will be conducted.

(6564) THE TRANSPORT OF SOIID SUSPENSION IN CONDUITS.

(b) Fed. Water Pollution Control Admin., U.S. Dept. Interior.

(d) Experimental and theoretical; applied research; doctoral dissertation.

(e) The transport phenomenon of solid-liquid flow in a conveyance system is studied. General relationship between flow parameter and sediment transports are established.

(g) See (h).

(h) "Experimental Apparatus Studies Sediment Transport," H.A. Einstein and W.H. Graf, Civil Engrg., ASCE, 1963.

"The Loop System for Measuring Sand-Water Mixtures," H.A. Einstein and W.H. Graf, Proc.
ASCE, Jour. Hydr. Div., No. HYl, 1966. "A Modified Venturimeter for Measuring TwoPhase Flow," W.H. Graf, Jour. Hydraulic Research, IAHR, Vol. 5, No. 3, 1967. "Designing Conveyance Systems for Solid-Liquid Flow," E.R. Acaroglu and W.H. Graf, Intl.

Symp. on Solid-Liquid Flow in Pipes, Univ. of Pennsylvania, March 1968.

"Homogeneous Suspensions in Circular Conduits," W.H. Graf and E.R. Acaroglu, Proc. ASCE, Jour. Pipeline Div., No. PL2, 1967.

"List of Sources of Information on the Pipeline Design, a Discussion," W.H. Graf, Proc. ASCE, Jour. Pipeline Div., No. PLl, 1968.

(6565) FRICTIONAL EFFECTS IN RIVERS.

(b) Laboratory project.

(d) Applied research.

(e) A careful investigation on the frictional behaviors of various rivers is done.

(f) Suspended.

(g) See (h).

(h) "Gesetze der turbulenten Geschwindigkeitsverteilung in geschlossenen Rohren und offenen Gerinnen, "W.H. Graf, Schweizer Bauzeitung, 82, Jg., No. 53, 1964.

"Manning's Roughness Determination in Navigable Waterways," W.H. Graf, XXIst Intl. Navigation Cong., PIANC, Stockholm, June 1965. "On the Determination of the Roughness Coefficient in Natural and Artificial Waterways," W.H. Graf, Bull. Intl. Assoc. Sci. Hydrology, IASH, XI, No. 1, 1966.

"Velocity Distribution and Boundary Roughness in Open Channels," W.H. Graf, Water Power (London), July 1966.

(6566) THE ELBOW METER, ITS USE FOR MEASURING SOLID LIQUID SUSPENSIONS.

(b) Laboratory project.

(d) Applied research; Master's thesis.

(e) The usefulness of an elbow meter to measure concentration and flow in a liquid-solid mixture is under investigation.

(g) $\operatorname{See}(\mathrm{h})$.

(h) "Dredging Fundamentals, A Discussion," W.H. Graf and R.N. Weisman, Proc. ASCE, Jour. Waterways and Harbors Div., No. WW2, 1968.

(6567) HYDRAULIC INVESTIGATION OF THE ST. CIAIR RIVER.

(b) Laboratory project.

(d) Applied research.

(e) The unsteady and steady effects on the river discharge are investigated. Further on the effect of the ice cover is studied.

(f) Suspended.

(g) See (h).

(h) "Steady and Unsteady Effects on Discharge in a River Connecting Two Reservoirs," J.A. Liggett and W.H. Graf, 9th Conf. on Great Lakes Research, 1966.

"The Effect of Ice on the Roughness Coefficient in the St. Clair River, "L. Yu, W.H. Graf, and G. Levine, llth Conf. on Great Lakes Research, 1968.

LOCKHEED-CAIIFORNIA COMPANY, Oceanies Division, 3380 N. Harbor Dr., San Diego, Calif. 92101

(6409) RESEARCH ON OCEANOGRAPHIC FORECASTING.

(b) Office of Naval Research.

(c) Dr. L. Baer, Lockheed-California Co. 
(d) Theoretical; applied research.

(e) The purpose was to develop a numerical dynamic model for symoptic forecasting in the deep ocean. A model utilizing the vorticity equation was programed and tested, utilizing data from the Gulf of Mexico.

(f) Temporarily discontinued.

(g) Tests utilizing the Gulf of Mexico data were run for extended periods without developing computational instability. Resul.ts were checked against later data from the Gulf of Mexico and fairly good agreement was found, especially near the Yucatan Peninsula.

(h) "Technical Progress Report: Research on Oceanographic Forecasting," Lockheed-California Co. Rept. No. 17747 , April 1964.

"Final Report: Research on Oceanographic Forecasting". Lockheed-California Co. Rept. No. 20333, Feb. 1967.

These reports may be obtained by contacting Office of Naval Research, Code 408, Washington, D.C. 20360. (Contract NOnr 3935 (00)).

(6410) DEEP WATER INTERIAL WAVES.

(b) Office of Naval Research and Lockheed-California Co. (Laboratory project).

(c) Dr. A.J. Carsola, Manager, Oceanics Div., Lockheed-California Co.

(d) Field investigation; basic research.

(e) Studies of temperature fluctuations in the ocean over the continental borderland off Southern California were made both from shiptended thermistor arrays and from an untended taut-wire array in 600 fathoms off San Clemente Island, California. The objective was the generation of the spectra of underwater temperature fluctuations in water offshore from the continental shelf.

(f) Completed.

(g) Significant temperature fluctuations only occurred at frequencies lower than that of the semidiurnal tide. Iog-log plots of frequency vs. energy density show a power law relationship at higher frequencies, suggesting turbulence or advective processes as the cause of temperature fluctuations in that part of the spectrum.

(h) Results have been published in the literature in previous years, but not during 1966 or 1967. Some will be submitted for publication during 1968.

(6411) THE ICOSAHEDRAL-GNOMONIC PROJECTION AND GRID OF THE WORID OCEAN FOR WAVE STUDIES.

(b) U.S. Naval Oceanographic Office under New York Univ. Contract PO/G15886.

(c) Correspondent: Dr. L. Baer, Lockheed-California Co.

(d) Theoretical; applied research.

(e) The World Ocean has been mapped in a special projection which is optimized for wind-wave studies. A world network of grid points representing hexagonal areas was prepared to overlay the map.

(f) Completed.

(g) The new map features segmented straight-line representation of great circles and small, simple distortions of direction and scale. Large parts of the World Ocean can be represented without interruption and a regular, nearly equidistant grid can be fitted over the globe.

(h) "Final Report: The Icosahedral-Gnomonic Projection and Grid of the World Ocean for Wave Studies, " Lockheed-Calfiornia Co. Rept. No. 20157, Oct. 1966 (Availabe from U.S. Naval
Oceanographic Office).

(6412) PACIFIC OCEAN WAVE FORECASTING STUDY.

(b) U.S. Naval Oceanographic Office under New York Univ. Contract PO/G5OIl.

(c) Dr. L. Baer; see (6411) above.

(d) Theoretical; applied research.

(e) This work extends to very large ocean areas, earlier efforts by Lockheed personnel in the area of objective, automated, wind-wave forecasting techniques.

(f) Completed.

(g) A computer program based on the Lockheeddeveloped Icosahedral-Gnomonic Projection and Grid of the World Ocean and incorporating an improved propagation technique was written.

(h) "Pacific Ocean Wave Forecasting Study," Lockheed-California Co. Rept. No. 20856, July 1967. (Available from U.S. Naval Oceanographic office). "Computer-based Procedures for Preparing Global Wave Forecasts and Wind Field Analyses Capable of Using Wave Data Obtained by a Spececraft," W.J. Pierson, Jr., L.J. Tick and L. Baer, Proc. Symp. on Naval Hydrodynamics, 1966 .

LOUISANA STATE UNIVERSITY and $A$ and $M$ COLIEGE, Agricultural Engrg. Dept., Baton Rouge, La. 70803

(5915) FACTORS AFFECTING RUNOFT ON SMALL AGRICULTURAL WATERSHEDS IN IOW, FLAT, ALLUVIAL AREAS.

(b) Louisiana Agric. Experimentation Sta., Louisiana State Univ.

(c) Dr. Jerry L. Chesness, Assoc. Prof., Agricultural Engrg. Dept., Louisiana State Univ.

(d) Field investigation.

(e) Rainfall, runoff, and soil moisture are being measured (on an event basis) on a 50 acre graded watershed (approximately $0.3 \%$ ), located on the Mississippi River alluvial flood plain. The studies' objectives are to determine prediction equations for peak runoff rate and total volume of runoff as a function of rainfall characteristics, soil infiltration, and vegetative cover.

(g) soil infiltration rate equations (as a function of time) have been experimentally derived for the two watershed soil types using large ring infiltrometers. Twenty-four rainfall-runoff events have been processed and the information stored in printed and graphical form through utilization of the digital computer.

LOUISIANA STATE UNIVERSITY AND A and M COLLEGE, Dept. of Civil Engrg., Baton Rouge, La. 70803

(5711) FRESH WATER STORAGE IN SALINE AQUIFERS.

(b) Louisiana Water Resources Research Inst.

(c) Dr. Oscar K. Kimbler, Assoc. Prof., Dept. of Petroleum Engrg., Louisiana State Univ.

(d) Theoretical and experimental; basic research.

(e) To determine whether it is theoretically feasible to store fresh water in saline aquifers: injecting fresh water, then removing it from storage. The relative effects of diffusion, dispersion and differences in specific gravity are being studied mathematically and by means of models. The ultimate importance of the work to cities located in flat marshland areas lacking in surface-water storage sites that 
are underlain by saline aquifers is readily appreciated.

(5713) STUDY OF MEASURES TO BE TAKEN TO ACCOMPIISH PROTECTION OF THE GROUND-WATER SUPPLY OF THE BATON ROUGE ARFA FROM DEGRADATION DUE TO SALINE WATER INTO AREA OF OFFTAKE-ENGINEERING ASPECTS.

(b) Iouisiana Water Resources Research Inst.

(c) Prof. R.G. Kazmann, Dept. of Civil Engrg., Louisiana State Univ.

(d) Field investigation and theoretical study; applied research and design.

(e) Evaluate engineering solutions for providing permanent ground-water supply for Baton Rouge area. Make preliminary feasibility studies of most promising projects.

(h) Interim report issued Sept. 1967. Final report planned Spring 1969.

(6091) A STUDY OF STORM-WATER INLET CAPACITIES.

(b) Louisiana Dept. of Highways.

(c) Prof. William A. Wintz, Jr., Dr. Yung-huang Kuo, Dept. of Civil Engrg., Iouisiana State Univ.

(d) Experimental; applied research and design.

(e) To study six existing Louisiana Dept. of Highways storm-water inlets' capacities as a function of widths of flow in the street, roadway grades, and crown slopes on full scale models constructed in the laboratory.

LTV RESEARCH CEIVTER, Ling-Temco-Vought, Inc.,

P.0. Box 6144, Dallas, Texas. 75222

(6213) BOUNDARY IAYER TRANSITION.

(b) Laboratory project.

(c) Dr. C.S. Wells, Senior Scientist, ITV Research Center.

(d) Experimental and theoretical; basic research.

(e) A study of theoretical models and empirical criteria which may be used to predict transition is being carried out; experimental results from a low-disturbance boundary layer facility are being used in conjunction with the theoretical work.

(g) A transition Reynolds number of about six million has been obtained with a very low disturbance and essentially zero pressure gradient flow. Recent results have shown the effects of standing and traveling acoustic waves and gridproduced turbulence on transition. The data are being analyzed with respect to two proposed criteria for transition prediction.

(h) "Effects of Freestream Turbulence on Boundary Layer Transition," C.S. Wells, AIAA Jour., Vol. 5, No. 1, pp. 172-174, 1967. "Some Effects of Freestream Disturbances on Boundary Layer Transition," J.G. Spangler and C.S. Wells, ITV Research Ctr. Rept. 0-71000/ TR-10, Apr. 1967; to be published in AIAA Jour.

(6214) A STUDY OF TURBUIENT SHEAR IAYER CHARACTERISTICS OF DRAG-REDUCING FLUIDS.

(b) NASA Office of Adranced Research and Technology, Fluid Dynamics Branch; and laboratory project.

(c) Dr. C.S. Wells; see (6213) above.

(d) Experimental and theoretical; basic research.

(e) The objective of this research program is to identify in detail, the effects of drag-reducing additives on the turbulent shear layer, and to study the implications of these effects for other types of flows which depend on turbulent momentum transport.

(g) Experimental results for high Reynolds number turbulent shear flows of very dilute solutions of drag-reducing additives show the major effects to be confined to the region near the wall, i.e., the viscous sublayer and the buffer layer. This means that rather simple correlations are possible for high Reynolds number flows of very dilute solutions. A correlation for friction factor has been developed and found to be very useful. In addition, injection experiments have shown that the presence of the additive in the region near the wall is sufficient to produce large drag reduction. This shows that a more efficient method of drag reduction can be achieved by uniform injection at the wall rather than flooding the shear layer with the additive. A correlation for turbulent heat transfer in drag-reducing fluids also has been developed.

(h) "Anomolous Turbulent Flow of Non-Newtonian Fluids, " C.S. Wells, AIAA Jour., Vol. 3, No. 10, 1965, pp. 1800-1805.

"Investigation of the Turbulent shear Flow of Dilute Aqueous CMC Solutions," W.D. Ernst, AIChE Jour., Vol. 12, No. 3, 1966, pp. 581-586. "A Correlation of the Frictional Characteristics for Turbulent Flow of Dilute Viscoelastic NonNewtonian Fluids in Pipes," W.A. Meyer, AICHE Jour., Vol. 12, No. 3, 1966, pp. 522-525. "Turbulent Flow of an Elasticoviscous NonNewtonian Fluid," W.D. Ernst, AIAA Jour., Vol. 5, No. 5, 1967 , pp. 906-909.

"Turbulence Measurements in a Drag-Reducing Non-Newtonian Fluid," C.S. Wells, J. Harkness, and W.A. Meyer, ITV Res. Ctr. Rept. 0-71000/ 6R-22, Dec. 1966; to be published in AIAA Jour.

"Injection of a Drag-Reducing Fluid into Turbulent Pipe Flow of a Newtonian Fluid," IIV Res. Ctr. Rept. 0-71000/TR-4, Feb. 1767; also Phys. of Fluids, Sept. 1967.

"Turbulent Heat Transfer in Drag-Reducing Fluids, " C.S. Wells, ITV. Res. Ctr. Rept. $0-71000 / 7 \mathrm{R}-5$, Mar. 1967; to be published in AIChE Jour.

MARINE ADVISERS, INC., P.O. Box 1963, LaJolla, Calif. 92037

(6087) PRACTICAL USE OF ELECTRIC NETWORKS TO SIMULATE OR PREDICT SEICHE CONDITION IN HARBORS.

(b) Laboratory project.

(c) Mr. Richard Lao, Physical Oceanographer, Marine Advisers, Inc.

(d) Theoretical; applied research and development.

(e) Title self-explanatory. Passive network configuration originally due to Ishiguro. Developed as a tool to foresee the character of any potential seiche activity in a proposed harbor or marina. Permits possible adjustment of harbor design prior to construction so as to suppress or minimize long wave activity portending adverse ship response motions.

(g) Electrical analogue models have been tested and found to yield results close to those observed in nature. Areas modeled to date under other auspices: Chesapeake Bay; proposed marina in Los Angeles Harbor; Sattahip Bay (harbor), Thailand.

(h) "Practical Use of Electric Networks to Simulate or Predict Seiche Condition in Harbors, "J.W. 
Joy, Proc. Asce Coastal Engrg. Conf., Santa Calif., Oct. 1965.

MASSACHUSETTS INSTITUTE OF TECHNOLOGY, Dept. of Civil Engrg., Hydrodymamics Laboratory, Cambridge, Mass. 02139

Requests for reprints and Technical Reports should be addressed to Dr. Arthur T. Ippen, Ford Professor of Engineering, Hydrodynamics Lab., Massachusetts Inst. of Technology, Cambridge, Mass. 02139

\section{(1609) STUDY OF BEACH PROCESSES IN THE INSHORE AND} FORESHORE ZONES.

(b) Coastal Engrg. Research Ctr., U.S. Army Corps of Engrs.

(c) Prof. P.S. Eagleson, Prof. C.C. Mei.

(d) Experimental and theoretical; basic research (Doctoral thesis).

(e) Study of surface profile and internal kinematics of a shoaling oscillatory wave up to and beyond the breaker.

(g) The program seeks a finite amplitude theoretical solution, along with experimental verification, for wave propagation in varying water depth from deep water up to breaking.

(h) "An Asymptotic Theory for Water Waves on Beaches of Mild Slope," G.A. Tlapa, C.C. Mei, and P.S. Eagleson, M.I.T. Hydrodynamics Lab. Tech. Rept. No. 90, April 1966.

"A Drag Gage for Measuring Particle Orbital Velocity in Water Waves," C.H. Horstmann, S.M. thesis, June 1966.

(3443) COMPUTFR SIMULATION OF THE COMPLETE TRANSIENT PROBLEM IN A HYDROPOWER PIANT.

(b) Missouri River Div., U.S. Army Corps of Engrs.

(c) Prof. F.E. Perkins.

(d) Theoretical, field tests; applied research (Doctoral thesis).

(e) Development of a digital computer program of general utility and proven validity for performing design analyses involving the response of hydro-power plant systems to load fluctuation.

(f) Completed.

(g) Digital computer programs have been written which for a wide range of hydraulic geometries will yield the time variation of the important hydraulic and mechanical variables for an arbitrary time variation in electrical load under the assumption of an isolated system. The results of these programs compare well with field test measurements. Final reports and a user's manual have been prepared.

(h) "An Explicit Finite Difference Approach to Transient Flow Problems," F.E. Perkins, Sc.D. thesis, Feb. 1966.

(3748) DISPERSION IN POROUS MEDIA IN PUMPING AND RECHARGE OPERATIONS.

(b) Federal Water Pollution Control Admin.

(c) Prof. D.R.F. Farleman, Prof. I.W. Gelhar, Hydrodynamics Lab., Mass. Inst. of Tech.

(d) Theoretical and experimental; basic research (Doctoral thesis).

(e) Development of a general numerical method for the solution of ground water dispersion problems in a steady, two-dimensional flow field. Emphasis is on the development of an efficient finite difference scheme for digital computer application. Investigation includes dispersion between separate recharge and pumping wells and pumping and recharge operations in the same well at different periods of time. The research programs also include consideration of dispersion in non-homogeneous (layered) media. Applications are in the field of ground water contamination.

(g) Approximate analytical solutions have been obtained for dispersion in steady, radial flow from a well and for flow between a recharge and a pumping well. The general finite difference formulation for digital computers has been developed. This program may be used for any steady, two-dimensional dispersion problem. The numerical scheme expresses the convective-dispersion equation in curvilinear coordinates consisting of the streamlines and equipotentials. Analytical results have also been obtained Por dispersion in layered, nonhomogeneous aquifers. Current research is concerned with cyclic purming and recharge from the same well and with the effect of small density differences between injected and natural ground water.

(h) "Numerical Solutions for Dispersion in Porous Mediums, "U.Y. Shamir and D.R.F. Harleman, Water Resources Research, Vol. 3, No. 2, 1967. "Dispersion in Radial Flow from a Recharge Well, " J.A. Hoopes and D.R.F. Harleman, Jour. Geophys. Res., Vol. 72, No. 14, July 15, 1967. "Waste Water Recharge and Dispersion in Porous Media," J.A. Hoopes and D.R.F. Harleman, Proc. A.S.C.E., Vol. 93, No. HY5, Sept. 1967. "Dispersion in Layered Porous Media," U.Y. Shamir and D.R.F. Harleman, Proc. A.S.C.E., Vo1. 93, No. HY5, Sept. 1967.

"Numerical and Analytical Solutions of Dispersion Problems in Homogeneous and Layered Aquifers, "U.Y. Shamir and D.R.F. Harleman, M.I.T. Hydrodynamics Lab. Tech. Rept. No. 89, May 1966.

"Behavior of Bacteriophage $\mathrm{T2}^{+}$in Flow Through Porous Media," E. Aikîns-Afful, Sc.D. Thesis, June 1966.

"Lateral Dispersion Along a Dividing Streamline in Porous Media," M. Wathne, S.M. thesis, Feb. 1966.

(3750) WAVE FORCES ON OFFSHORE STRUCTURES.

(b) Shell Development Company.

(c) Prof. D.R.F. Harleman.

(d) Theoretical and experimental; applied research (Doctoral thesis).

(e) Analytical and experimental study of offshore, bottom supported structures in deep water. object is to determine methods of designing for dynamic response in both periodic and random waves. Platform response in terms of the spectrum of deflection or bending stresses are to be related to the wave spectrum in the case of random waves.

(f) Completed.

(g) The structural response of an offshore structure in random waves is developed by a superposition of dymamic response functions for the periodic components of the wave spectrum. For a given wave spectrum, the leg spacing which minimizes the platform deflection has been determined. The analytical methods have been verified by tests on dynamically similar platform models in a wave tank using periodic and random waves. The effect of the direction of approach of the random wave train has also been studied.

(h) "The Dynamic Response of Fixed Offshore Structures to Periodic and Random Waves, "J.H. Nath 
and D.R.F. Harleman, M.I.T. Hydrodynamics Lab. Tech. Rept. No. 102, Jan. 1967.

"The Dynamics of Fixed Towers in Deep Water Random Waves," J.H. Nath and D.R.F. Harleman, Proc. A.S.C.E., Civil Engrg. in the Oceans, San Francisco, Sept. 1967.

(4160) MOTION OF SUBMERGED BODIES IN A STRATIFIED FIUID.

(b) Office of Naval Research, Dept. of the Navy.

(c) Prof. C.C. Mei, Prof. R.H. Cross, III.

(d) Theoretical and experimental; basic research (Master's thesis).

(e) Collapse of a homogeneous fluid mass in a stratified fluid. Dynamics of the wake of a cylinder towed in a stratified fluid.

(g) The collapse of a homogeneous fluid mass immersed in a vertically stratified fluid has been studied analytically. Two approximate theories are constructed for different stages of the process. For the initial stage when the partition between the fluids is just removed, an inviscid long wave theory is worked out with gravity as the only force governing the collapse. For the final stage of decay, a viscous long wave theory is derived. The time variation of the horizontal spreading velocity of the collapsing mass is compared with available experiments with fair agreement.

Photographic evidence of the collapse of twodimensional wakes behind a cylinder moving in a stratified fluid being sought in a glass tank.

(h) "Surface Wave Pattern Due to a Submerged Source Travelling in a Stratified Ocean," C.C. Mei, M.I.T. Hydrodynamics Lab. Tech. Rept. No. 92, April 1966.

"Three-Dimensional Momentumless Wakes in Density Stratified Fluids," P.J. Stockhausen, C.B. Clark, and J.F. Kennedy, M.I.T. Hydrodynamies Lab. Tech. Rept. No. 93, June 1966. "A Method for Generating Linear Density Profiles in Laboratory Tanks," C.B. Clark, P.J. Stockhausen, and J.F. Kennedy, Jour. Geophys. Res., Vol. 72, No. 4, March 1967.

(4648) MECHANICS OF DISPERSION IN ESTUARY POLIUTION.

(b) Federal Water Pollution Control Admin.

(c) Prof. D.R.F. Harleman, Hydrodynamics Lab., Mass. Inst. Tech.

(d) Experimental and theoretical; basic research (Master's and Doctoral theses).

(e) A basic study of estuary dispersion in an oscillating flow with fresh water throughflow superimposed. Extension of Taylor analysis of longitudinal mixing in estuary type flows. Study of similitude of distorted estuary models in regard to distribution of pollutants in fresh water region of the estuary. Numerical solution of the dispersion equation in a variable area estuary.

(g) Experimental and analytical investigations were conducted on longitudinal mixing in a pipeline with a throughflow superimposed on an oscillating flow. Exact solutions to the dispersion equation were found for both instantaneous and continuous injection of pollutants into an estuary-type flow and both were verified experimentally. It was found that the equation representing the concentration distribution of a continuously injected pollutant must include the tidal or oscillating velocity. The similitude of distorted estuary models in which dye is injected as a tracer was investigated. The results indicate that concentration similitude is not obtained in distorted Froude models. Current investigations are concerned with numerical solutions for variable area estuaries which account for non-linear effects in the tidal convective motion.

(h) "Dispersion of Pollutants in Estuary Type Flows", E.R. Holley, Jr., and D.R.F. Harleman, M.I.T. Hydrodynamics Lab. Tech. Rept. No. 74, Jan. 1965.

"Dispersion of Pollutants in a Variable Area Estuary", D. Zargar, S.M. thesis, Feb. 1966. "Interpretation of Water Pollution Data from Tidal Estuary Models", D.R.F. Har leman, E.R. Holley, Jr., and W.C. Huber, Proc. Third Intl. Conf. on Water Pollution Research, Section III, Paper No. 3, Munich, Sept. 1966, (Pergammon Press).

"Numerical Solution of the Unsteady, Estuary Dispersion Equation", D.R.F. Harleman,

C.H. Lee, and L.C. Hall, Proc.A.S.C.E., Natl. Symp. on Estuarine Pollution, Stanford Univ., Aug. 1967.

(4649) TURBULENT TRANSFER MECHANICS OF FLUID SUSPENSIONS OF SOLID PARIICLES.

(b) Pioneering Research Program, Institute of Paper Chemistry.

(c) Prof. A.T. Ippen; Prof. J.F. Kennedy.

(d) Basic research; experimental.

(e) Basic investigation of the effect on the turbulence structure in a shear flow of suspended particles.

(f) Inactive.

(g) Velocity profiles and resistance coefficients have been determined for high concentrations of neutrally buoyant particles in water in a two-inch diameter pipe. Measurements included spherical and non-spherical particles. Experiments established that the particles move in the average 10-15\% faster than the suspending fluid. This was accomplished by particles tagged with a radio-active coating.

(h) "Particle and Fluid Velocities of Turbulent Flows of Suspensions of Neutrally Buoyant Particles", C.P.R. Roberts, J.F. Kennedy, and A.T. Ippen, M.I.T. Hydrodynamics Lab. Tech. Rept. No. 103, Jan. 1967.

(4654) SINGLE AND TWO-PHASE FLOW BETWEEN CONCENTRIC ROTATING CYIINDERS.

(b) National Science Foundation.

(c) Prof. A.T. Ippen; Prof. L. W. Gelhar.

(d) Experimental and theoretical; basic research.

(e) The research program is directed toward improved understanding of the erosion and suspension process in turbulent shear flow. Experiments are made in a system consisting of two concentric cylinders; each of which rotates producing a centripetal acceleration field which simulates the usual gravitational field.

(g) Measurements of mean velocity and turbulence have been obtained in the rotating cylinder system for the case with the two cylinders rotating the same direction. The structure of the mean velocity profiles indicates that the flow is influenced by secondary motions generated at the ends of the cylinders. A theoretical analysis of the secondary motion yields results which agree with the observed mean velocity profiles. Currently measurements are being made for the case of counterrotating cylinders. 
(h) "Secondary Motion and Turbulence in Circular Couette Flow," I.W. Gelhar, W. Schriek, and F.A. Benham, M.I.T. Hydrodynamics Lab. Tech. Rept. No. 97, July 1966. "Boundary Layers in Circular Couette Flow," F.A. Benham, S.M. thesis, May 1967.

(5115) SYSTEMS METHODOIOGY FOR WATER-RESOURCE PIANNING IN A REGIONAL DEVELOPMENT CONTEXT.

(b) M.I.T. Inter-American Program in Civil Engrg.

(c) Prof. R.T. McLaughlin, Hydrodynamics Lab., Mass. Inst. Tech.

(d) Theoretical and analytical; basic research.

(e) Research on the use of mathematical models and systems analysis in planning for comprehensive development of water resources in river basins or other hydrologic units. The relationship of such developments to the social and economic activity of the region in which the unit is located is also being considered.

(g) Simplified mathematical models are being investigated for possible use in obtaining approximate answers in the early stages of a planning study. The results of the simplified models are being checked against results of simulation.

(h) "Linear-Programing Analysis of River-Basin Development," J.R. Wallace, Sc.D. thesis, June 1966.

"Simulation of Political Interaction in Multiple-Purpose River-Basin Development," J.W. Bulkley and R.T. McLaughlin, M.I.T. Hydrodynamics Lab. Tech. Rept. No. 100, Oct. 1966.

"Operating Policies in the Simulation of RiverBasin Development," F. Ibanez, S.M. thesis, Feb. 1967.

\section{(5117) ANALYSIS AND SYNIHESIS OF HYDROLOGIC SYSTEMS.}

(b) M.I.T. Inter-American Program in Civil Engrg.

(c) Prof. P.S. Eagleson.

(d) Experimental and theoretical; basic research (Doctoral thesis).

(e) Development of improved analytical techniques for the prediction of the time variation in stream flow at some point in a drainage basin due to a given temporal and areal distribution of precipitation. Development of the means for synthesizing these predictors in the absence of long term hydrologic records.

(g) The laboratory rainmaker is being used in conjunction with a computer simulation of overland flow to study the errors accompanying the unavoidable lack of dynamic similarity in using scale models of surface runorf. The equipment is also being used in the development and evaluation of analytical methods for separating the surface and groundwater components of streamflow.

(h) "The Synthesis of Short-Time-Increment Rainfall Sequences," R.A. Grace and P.S. Eagleson, M.I.T. Hydrodynamics Lab. Tech. Rept. No. 91, May 1966.

"Construction and Use of a Physical Model of the Rainfall-Runoff Process, "R.A. Grace and P.S. Eagleson, M.I.T. Hydrodynamics Lab. Tech. Note No. 1l, June 1966.

"The Modelling of Overland Flow," R.A. Grace and P.S. Eagleson, Water Resources Research, Vol. 2, No. 3, pp. 393-403, 1966.

"Computation of Optimum Realizable Unit Hydrographs," P.S. Eagleson, R. Mejia-R. and F. March Water Resources Research, Vol. 2, No. 4, pp. 755-764, 1966.

"Scale Model of Urban Runoff from Storm
Rainfall," R.A. Grace and P.S. Eagleson, Proc. A.S.C.E., HY3, No. 5249, pp. 161-176, May 1967. "A Model for Generating Synthetic Sequences of Short-Time-Interval Rainfall Depths," R.A. Grace and P.S. Eagleson, Intl. Hydrology Symp., Fort Collins, Colo., Vol. 1, pp. 268-276, Sept. 1966.

"An Extension of the Role of Linear Systems Analysis in Hydrograph Theory," A. Barrera, Ph.D. thesis, sept. 1967.

"An Extension of the Role of Linear Systems Analysis in Hydrograph Theory," A. Barrera and F.E. Perkins, M.I.T. Hydrodynamics Lab. Tech. Rept. No. 106, Sept. 1967.

"Study of Drainage Design Practices for Highway Bridges," J.P. Vittands, S.M. thesis, Sept. 1967.

(5118) MECHANICS OF SEDIMENT RIPPIES AND DUNES AND THEIR EFFECT ON CHANNEL ROUGHNESS.

(b) Agricultural Research Service, U.S. Dept. of Agriculture.

(c) Prof. J.F. Kennedy.

(d) Theoretical; basic research (Master's and Doctoral theses).

(e) The formation of sediment ripples and dunes by uniform free-surface flow, uniform infinite flow, and oscillating flow has been investigated as a stability problem by using a potential flow solution for fluid motion over a small-amplitude wavy bed and a sediment transport law in which the transport rate at any point is proportional to a power of the velocity near the bed at some distance upstream. The kinematics of the resulting sediment motion are used to determine the conditions for which the bed waves will grow, and the behavior of the resulting bed features.

(f) Completed.

(g) A method for predicting the friction factor of uniform flows over sand beds in alluvial channels has been developed. The friction factor has been related to the flow quantities that have been shown by the theoretical analysis to govern the geometry of the bed configuration. An extensive body of laboratory and field data has been placed on computer cards and computer programs have been develped to evaluate new methods of predicting channel roughness and compare them with existing methods.

(h) "Friction Factors for Flows in Sand-Bed Channels," A.Z. Alam, Sc.D. thesis, June 1766.

(5119) TIDAL, SALTNITY AND SEDIMENTATION PROBLFMS IN IAKE MARACAIBO CHANNEI, VENEZUELA.

(b) M.I.T. Inter-American Program in Civil Engrg; in collaboration with the Instituto Nacional de Canalizaciones and the Universidad del Zulia, in Venezuela.

(c) Prof. A.T. Ippen, Prof. R.H. Cross.

(d) Theoretical and experiment; basic research and field investigation (Master's thesis).

(e) Purpose of basic research: Investigation of flow variables and soil properties controlling rates of erosion and deposition of fine cohesive sediment in a flow field. Purpose of field investigation: To determine the sources and motion of sediment and the time and spatial salinity distribution within the Maracaibo estuary in Venezuela, and to utilize this information for designing remedial works in order to reduce shoaling in the Maracaibo Navigable Channel and control salt water intrusion into Lake Maracaibo. 
(g) Basic research: The special apparatus developed consists of an annular rotating channel and a counterrotating annular ring placed in the channel and in contact with the water surface. The relative motion of channel and ring generates a uniform turbulent flow field. Experiments with kaolinite clay suspensions have revealed two important properties: (1) The existence of a critical flow velocity for clay deposition. (2) For a given flow, the equilibrium concentration is a constant percentage of the initial sediment concentration in the channel.

Field investigations: Results point out that most of the sediment comes from the Gulf of Venezuela transported near the bottom by tidal and salinity currents. Also a bottom layer at high salinity has been found to exist all the way to the entrance to the lake throughout the year.

(h) "Interaction of Tides, Salinity and sediment in the Lake Maracaibo Estuary in Venezuela," L. Corona Chuecos, E. Partheniades and J.F. Kennedy, Preprint A.S.C.E. Structural Engrg. Conf., Miami, Fla., Jan. 1766.

"Salinity Intrusion and Sedimentation in the Straits of Maracaibo," L.F.Corona Chuecos, S.M. thesis, Feb. 1966.

"Corriente Estratificade en Estuarios y su Influencia en la Sedimentacion de Los Canales Navegables, "E. Partheniades, Boletin, Sociedad Venezolana de Ingenieria Hidraulica, Ano V, Numero 8, April 1966.

"Field Investigations to Determine Sediment Sources and Salinity Intrusion in the Maracaibo Estuary, Venezuela," E. Partheniades, M.I.T. Hydrodynamics Lab. Tech. Rept. No. 94, June 1966.

"Investigations of the Depositional Behavior of Fine Cohesive Sediments in an Annular Rotating Channel," E. Partheniades, M.I.T. Hydrodynamics Lab. Tech. Rept. No. 96, June 1966.

"Depositional Behavior of Fine Sediment in a Turbulent Fluid Motion, "E. Partheniades, J.F. Kennedy, Proc. loth Conf. on Coastal Engrg., Tokyo, Japan, Chapter 41, Sept. 1966. "Deposition of Cohesive Sediments," A.A. Ayora, S.M. thesis, June 1967.

"An Analysis of Salinity Distribution in the Straits of Maracaibo," D.R.F. Harleman, L.F. Corona, and E. Partheniades, Proc. 12th Congr., I.A.H.R., Fort Collins, Colo., Vol. 4, Sept. 1967.

(5540) MINIMUM-COST DESIGN OF PIPE NETWORKS.

(b) Laboratory project.

(c) Prof. R.T. McLaughlin, Hydrodynamics Lab., Mass. Inst. Tech.

(d) Analytical; design (Master's thesis).

(e) Marginal analysis by means of a digital computer is used to find the pipe network that delivers prescribed amounts of water at fixed points with a minimum cost of network and pumping.

(f) Completed.

(g) Professional paper in process.

(h) "Minimum-Cost Design of Linear-Restrained Water Distribution Networks," D.V. Smith, S.M. thesis, Sept. 1966.

(5542) CAVITATION NEAR SURFACES OF DISTRIBUTED ROUGHNESS.

(b) U.S. Army Research Office - Durham. (c) Prof. A.T. Ippen.

(d) Experimental and theoretical (Doctoral thesis).

(e) The influence of various distributions of roughness height on cavitation inception in a turbulent boundary layer. Boundary layer and roughness parameters and the role of free stream and boundary layer turbulence have been correlated with cavitation inception.

(g) A significant correlation between the local resistance coefficient and the cavitation inception parameter has been established on the basis of 4 saw-tooth roughnesses of different height. The experiments are being continued with comparable sand-grain roughnesses.

(h) "Cavitation near Surfaces of Distributed Roughness," R.E.A. Arndt and A.T. Ippen, M.I.T. Hydrodynamics Lab. Tech. Rept. No. 104, June 1967 .

"Rough Surface Effects on Cavitation Inception," R.E.A. Arndt and A.T. Ippen, accepted for publication, Trans., A.S.M.E., Spring 1968.

(5544) TECHNIQUES OF MODELIING THERMAL STRATIFICATION IN LAKES.

(b) M.I.T. Solar Energy Fund.

(c) Prof. D.R.F. Harlemen, Hydrodynamics Lab., Mass. Inst. Tech.

(d) Experimental and analytical (Doctoral thesis).

(e) Development of an analytical method for the prediction of the vertical temperature distribution, as a function of time, in a lake or pond. Techniques of modelling a time dependent temperature structure in laboratory tanks using artificial thermal radiation.

(g) A theory for the vertical temperature distribution has been developed. The theory predicts the development of a surface mixed layer of varying temperature and depth. The results are applicable to deep lakes or shallow ponds in which various bottom thermal boundary conditions may be assumed. Experiments were conducted to verify the theory in a laboratory tank using insolation supplied by mercury vapor and infra-red lamps. The experiments indicate that thermal stratification may be reproduced in the laboratory for the study of wind induced circulation or mechanical destratification by pumping. Current investigations are concerned with evaporative heat losses in laboratory tanks.

(h) "Submerged Jets in a Denser Liquid with a Density Gradient," A.S. Kubo, S.M. thesis, June 1965.

"An Analytical and Experimental Investigation of Thermal Stratification in Lakes and Ponds," J.M.K. Dake and D.R.F. Harleman, M.I.T. Hyarodynamics Lab. Tech. Rept. No. 99, Sept. 1966.

"Induced Mixing in a Thermally Stratified Fluid," J.P. Brainard, S.M. thesis, Feb. 1967.

(5823) TURBULENCE STRUCTURE OF FIOW IN ROUGH POROUS CONDUITS.

(b) National Science Foundation.

(c) Prof. I.W. Gelhar, Prof. A.T. Ippen.

(d) Experimental and theoretical; basic research (Master's and Doctoral theses).

(e) The role of turbulence in sediment transport mechanics is being investigated through observations of turbulence structure near rough porous boundaries. Experiments are being made in a ten-inch diameter air flow facility using hot-wire anemometry.

(g) Detailed measurements of turbulence in a 
conduit roughened with 0.13 inch diameter spheres have been completed. The influence of boundary porosity is now being investigated in a 12 " diameter pipe with a $I^{\prime \prime}$ thick layer of porous material on the inside of the pipe. A theoretical analysis of the effects of boundary porosity has been developed.

(h) "Turbulence Characteristics of Rough Boundary Shear Flow," C.D.D. Howard, S.M. thesis, Feb. 1966.

"Response of Turbulent Pipe Flow to Change in Boundary Roughness, " D.D. Moran, S.M. thesis, June 1967.

(5825) OPTIMAL DESIGN OF SEWER AND DRATNAGE SYSTEMS.

(b) Federal Water Pollution Control Admin.

(c) Prof. R.T. McLaughlin.

(d) Theoretical and analytical; basic research.

(e) Unsteady flow in systems of open channels is being analyzed numerically using a digital computer and dynamic programming is being applied to the optimal design of such systems.

(i) Completed.

(g) Report in progress.

(h) "A Generalization of the Characteristic Method for Free Surface Flow," M.S. Clark, S.M. thesis, Sept. 1966.

"Vertical Alignment of Sewer and Drainage Systems by Dynamic Programming," D.A. Haith, S.M. thesis, Sept. 1966.

(5826) MECHANICS OF VISCOUS STRATIFIED FLOW.

(b) M.I.T., Sloan Basic Research Grant.

(c) Prof. L.W. Gelhar, Hydrodynamics Lab., Mass. Inst. Tech.

(d) Theoretical and experimental; basic research (Master's thesis).

(e) General studies of viscous effects in density stratified flows. The present study deals with slow flow of a non-diffusive fluid.

(f) Completed.

(g) A mathematical model for slow viscous nondiffusive flow of a continuously stratified fluid has been developed. The resulting ordinary differential equation has been integrated numerically for a number of flow problems including flow toward a line sink and the developing shear layer between stratified fluids moving at different velocities. Diffusive effects were found to be negligible when density differences are caused by salinity differences.

(h) "Non-diffusive Characteristics of Viscous Stratified Flow toward a Line Sink, "L.W. Gelhar and D.M. Mascolo, M.I.T. Hydrodynamics Lab. Tech. Rept. No. 88, Feb. 1966.

(6413) SURFACE WAVE STUDIES.

(b) Office of Naval Research, Dept. of the Navy.

(c) Prof. A.T. Ippen, Prof. C.C. Mei.

(d) Theoretical and experimental; basic research (Doctoral thesis).

(e) Linear and nonlinear wave propagation past obstacles.

(g) The weak reflection of water waves by bottom changes has been studied for the case of slowly varying depth. Quadrature formulas for quentities of practical interest have been derived by a WKB-iteration method via a Green's function. For long obstacles with a flat center section, it is found that under certain conditions only the sloping ends are responsible for the scattering. Other effects of obstacle shape on the reflection coefficients have also been found. A variational technique is now being applied to the wave transmission over a rectangular bar. This technique, originated by $J$. Schwinger, is an adaption from problems in electromagnetic waveguides with a thick inductive window. Numerical studies are being conducted for nonlinear waves of cnoidal-class over an uneven bottom.

(h) "Note on the Equations of Long Waves over an Uneven Bottom," C.C. Mei and B. LeMehaute, Jour. Geophys. Res., Vol. 71 , No. 2, pp. 393400, Jan. 1966.

"Wave Reflection and Transmission in Open Channel Transitions," E.L. Bourodimos and A.T. Ippen, M.I.T. Hydrodynamics Lab. Tech. Rept. No. 98, Aug. 1966.

"Water Waves Transmission by Overtopping of an Impermeable Breakwater," P.J. Lamarre, S.M. thesis, Sept. 1967.

"On the Weak Reflection of Periodic Water Waves over Bottom Obstacles," C.C. Mei, M.I.T. Hydrodynamics Lab. Tech. Rept. No. 108, Oct. 1967.

(6414) TIDAL COMPUTATIONS IN ESTUARIES AND CANALS.

(b) Tidal Hydraulics Committee, U.S. Army Corps of Engineers.

(c) Prof. D.R.F. Harleman, Prof. A.T. Ippen, Hydrodynamics Lab., Mass. Inst. of Tech.

(d) Analytical; analysis of field data (Master's thesis).

(e) Development of general digital computer techniques for the calculation of tidal motion in estuaries and sea level canals.

(g) An explicit finite difference computer program has been developed for the determination of tidal motion in estauries and canals. The program retains the nonlinear acceleration terms and the nonlinear frictional resistance. Computations have been carried out for the Delaware and Savannah estuaries, Chincoteague Bay, the Cape Cod and Panama Sea Level canals. In the latter case tidal motion has been computed for canals excavated by both conventional and nuclear cratering techniques.

(h) "One-Dimensional Tidal Computations in Estuaries and Canals," C.H. Iee, S.M. thesis, Jan. 1967. "Numerical Computations of Tidal Currents in the Proposed Sea-Level Canal," Harleman, D.R.F. and C.H. Iee, I.O.C.S. Memo JAX-27, 1895.1, Dept. of the Army, Jacksonville District, Corps of Engrs., Jacksonville, Fla., June 1367.

(64.15) SALINITY INTRUSION IN ESTUARIES.

(b) Laboratory project and Tidal Hydraulics Committee, U.S. Army Corps of Engrs.

(c) Prof. D.R.F. Harleman, Prof. A.T. Ippen.

(d) Theoretical and field investigation; applied research (Master's thesis).

(e) Analysis of field data on salinity intrusion and diffusion in estuaries. Development of methods of predicting changes in logitudinal distribution of salinity due to changes in fresh water flow rate, channel depth, tidal prism, etc. Investigation of shoaling phenomena related to salinity intrusion.

(g) Dimensionless correlations of the parameters describing the longitudinal distribution of salinity have been developed for constant area estuaries. Included are data from a laboratory salinity flume at W.E.S., the Rotterdam waterway and the Straits of Maracaibo. Method permits prediction of salinity intrusion changes. W.E.S. data has been analyzed on twodimensional basis for determination of vertical dispersion coefficients in salinity intrusion 
region. A correlation between bottom velocity (averaged over a tidal cycle) and salinity distribution results in the prediction of a "null point" where shoaling is usually heavy. Changes in the longitudinal location of the "null point" may also be predicted due to changes in estuary geometry or flow. Studies on variable area estuaries are currently underway.

(h) "The Effect of Resistance Bars upon an Arrested Selt Wedge," M. Hendrikse, S.M. thesis, Sept. 1965.

"One-Dimensional Analysis of Salinity Intrusion in the Rotterdam Waterway," D.R.F. Harlemen and G. Abraham, Delft Hydraulics Lab. Publ. No. 44, Oct. 1966.

"Salt-Water Fresh-Water Relationships in Tidal Channels," A.T. Ippen, Proc. 2nd Annual Amer. Water Resources Conf., Chicago, Ill, Nov. 20-22, 1966.

"Estuary Hydrodynamics," A.T. Ippen, Proc. Symp. on Hydrology of the Coastal Waters of No. Carolina, Univ. of North Carolina, Rept. No. 5, W.R.R.I., May 1967.

"Two-Dimensional Aspects of Salinity Intrusion in Estuaries: Analysis of Salinity and Velocity Distributions," D.R.F. Harleman and A.T. Ippen, Comittee on Tidal Hydraulics, Corps of Engrs., Vicksburg, Tech. Bull. No. 13, June 1967.

"An Analysis of Salinity Distribution in the Straits of Maracaibo," D.R.F. Harleman, L.F. Corona and E. Partheniades, Proc. 12th Congr., Intl. Assoc. Hydraulic Res., Fort Collins, Sept. 1967.

(6416) EFFECT OF SUBMERGENCE ON DISCHARGE OF BROADCRESTED WEIRS.

(b) Laboratory project.

(c) Prof. D.R.F. Harleman.

(d) Experimental; applied research (Master's thesis).

(e) Study of effect of downstream tailwater on the discharge characteristics of various shapes of broad-crested weirs. Application is to flow over highway embankments.

(f) Completed.

(g) Discharge coefficients were determined for 10 broad-crested weirs for free and submerged discharge conditions. The point of incipient submergence was defined and found to be dependent on the length of the weir crest in the direction of flow.

(h) "Discharge Coefficients for Submerged BroadCrested Weirs," W.A. Thomas, S.M. thesis, Sept. 1966.

(6417) THERMAL STRATIFICATION IN RESERVOIRS.

(b) M.I.T. Solar Energy Fund.

(c) Prof. D.R.F. Harleman.

(d) Theoretical and experimental; basic research (Doctoral thesis).

(e) Determination of analytical methods of predicting the transient temperature distribution in a reservoir having inflow and outflow. Study includes determination of flow through time in reservoir as well as the time variation of the outlet water temperature.

(g) The two-dimensional heat transfer equation has been simplified by making assumptions regarding internal velocities and temperature gradients. The resulting differential equation includes the temperature variation of the inflowing river, solar radiation input, heat losses from the reservoir surface, and outlet flow rate. The equation is solved by means of an implicit finite difference scheme on a digital computer. Experiments have been conducted on a $40 \mathrm{ft}$. Laboratory reservoir model in which solar radiation is simulated by infra-red heat lamps. Internal temperature distributions and outlet water temperatures are compared with predicted values.

(h) "Thermal Stratification in Reservoirs," D.R.F. Harleman, Symp. on Streamflow Regulation for Quality Control, Public Health Serv. Publ. No. 999-WP-30, R.A. Taft Sanitary Engrg. Ctr., Cincinnati, Ohio, June 1965.

"Laboratory Studies on Thermal Stratification in Reservoirs," D.R.F. Harleman and W.C. Huber, A.S.C.E. Specialty Conf., Current Research into the Effects of Reservoirs on Water Quality, Portland, Ore., Jan. 1968.

(6418) DIFFUSERS FOR MIXING OF NUCIFAR POWER PIANT CONDENSER WATER. (See a.lso No. 6715, p. 246).

(b) Tennessee Valley Authority, Engrg. Lab.

(c) Prof. D.R.F. Harleman, Hydrodynamics Lab., Mass. Inst. Tech.

(d) Experimental; applied research (Master's thesis).

(e) Model study of mixing of condenser water from $3300 \mathrm{MW}$ Browns Ferry Nuclear Power Plant into the Tennessee River. Investigation of temperature rise in river upstream and downstream of the plant during steady state river flows. Determination of temperature rise during periods of no flow caused by peak-load operation of down-stream hydroelectric plant.

(g) A two-dimensional model of a multi-port diffuser has been constructed. The diffuser is a $20 \mathrm{ft}$. diameter conduit extending across the main river channel. Heated water is introduced in the diffuser and temperature rises in the river are measured with thermistor probes. Measurements indicate that complete mixing of the heated water and the river flow is obtained in the downstream direction. For low river discharges an upstream wedge of warm water is developed. Current investigations are concerned with the transient temperature rise which occurs during periods of zero river discharge.

(h) "Experimental Model Study of the Diffusion of Hot Water of the Nuclear Power Plant on the Tennessee River at Browns Ferry, Alabama," T.G. Curtis, Jr., B.S. thesis, Sept. 1967.

(6419) PREVENTION OF RECIRCULATION OF HEATED WATER DISCHARGES FROM THERMAI POWER PIANTS.

(b) Stone and Webster Engineering Corp.; Tenn. Valley Authority.

(c) Prof. D.R.F. Harleman.

(d) Analytical and experimental; basic and applied research (Master's thesis).

(e) Development of design methods for skimmer wall structures to prevent recirculation of heated water at condenser water intakes. Investigation of thermal stratification in the river upstream and downstream of the plant site. Effect of condenser water outlet design. Model studies of complex recirculation problems.

(f) Active.

(g) Design equations for plane and semi-circular skimmer walls have been developed. Analytical studies have indicated the conditions under which critical depths may exist in the stratified flow adjacent to either the condenser water intake or outlet channel. Laboratory experiments have extended the range of 
Bata's investigation of recirculation. A model study for the Valley Plant of the Wisconsin Electric Power Co. has been completed. Design procedures have been developed for optimum similitude in distorted models of thermally stratified flows involving gravitational, interfacial friction and heat dissipation similitude.

(h) "Withdrawal from Two-Layer Stratified Flows," D.R.F. Harleman and R.A. Elder, Proc. A.S.C.E., Vol. 91, No. HY4, July 1965.

"The Effect of Outlet and Intake Design on Cooling Water Recirculation," R.J. Wigh, S.M. thesis, Sept. 1967.

"A. Model Study of Thermal Stratification Produced by Condenser Water Discharge," D.R.F. Harleman and K.D. Stolzenbech, M.I.T. Hydrodynamics Lab. Tech. Rept. No. 107, Oct. 1967.

(6420) HYDROLOGIC MEASUREMENT SYSTEMS.

(b) Laboratory project.

(c) Prof. P.S. Eagleson.

(d) Theoretical; basic research.

(e) Use of concepts from information theory to develop generalized criteria for the design and evaluation of hydrologic instruments, networks and measuring programs.

(g) Conventional, tipping-bucket raingages are shown to be inadequate for many problems of urban hydrologic analysis.

When estimating long-term average areal rainfall the error of estimate is often quite insensitive to the use of more than two point measuring stations.

(h) "Some Criteria for the Measurement of Rainfall and Runoff," P.S. Eagleson and W.J. Shack, Water Resources Research, Vol. 2, No. 3, pp. 427-436, 1966.

"Optimum Density of Rainfall Networks," P.S. Eagleson, Water Resources Research, Vol. 3, No. 4, pp. 1021-1033, 1967.

(6421) OPTIMUM IINEAR SYNTHESIS IN URBAN HYDROLOGY.

(b) Office of Water Resources Research, U.S. Dept. of the Interior.

(c) Prof. P.S. Eagleson.

(d) Theoretical; basic research (Master's and Doctoral theses).

(e) Development of a digital computer simulation of surface runoff on urban catchments. The simulation will be used to investigate (1) analytical errors due to lumping of distributed systems (2) analytical errors due to the assumption of linear behavior (3) experimental errors due to sampling of areally variable rainfall, and to develop an optimum linear model for use in hydraulic design.

(6422) COMPUTER-AIDED TEACHING IN HYDRAUIICS AND HYDROIOGY.

(b) National Science Foundation.

(c) Prof. F.E. Perkins, Hydrodynamics Lab., Mass. Inst. of Tech.

(d) Development (Master's thesis).

(e) Development of problem-oriented computer language for use in hydravlics and hydrology courses. Presently concerned with the establishment of flexible data structures and commands for the storage, retrieval and analysis of typical hydrologic data, and for the analysis of flows in closed conduits. Resulting system will be an integral part of M.I.T.'s I.C.E.S. computer system.

(h) "A Program for Computer-Aided Highway Design," A. Silva, S.M. thesis, June 1967.
"I.C.E.S. Subsystem Design-Open Channel Water Surface Profile Computations," T.C. Gamble, B.S. thesis, June 1967.

"Numerical Refraction and Diffraction for Coastal Areas," R.D. Smert, S.M. and C.E. thesis, June 1967.

MASSACHUSETTS INSTITUIE OF TECHNOIOGY, Dept. of Mechanical Engineering, Cambridge, Mass. 02139

\section{(6105) STUDY OF ATMOSPHERIC DISPERSION.}

(b) Laboratory project.

(c) Prof. James A. Fay and Prof. David P. Hoult, Dept. of Mechanical Engrg., M.I.T.

(d) The project consists of laboratory experiments, field investigations, and studies of semiempirical theories.

(e) Aerodynamic motion of buoyant plumes rising from high smoke stacks is the subject under investigation. The purpose of the research is to find simple, accurate methods for computing the trajectory of the plumes, and the ground level concentration of pollutants due to the smoke stack.

(g) A simple entrainment model has been found to give accurate predictions of a plume trajectory.

(6106) DEVELOPMENT OF INTRA-AORTIC BALIOON PUMP.

(b) National Heart Institute, National Inst. of Health.

(c) A.H. Shapiro, Ford Professor of Engrg. and Head, Dept. of Mechanical Engrg., Mass. Inst. Tech.

(d) Experimental and theoretical; applied research.

(e) This is a method for assisting patients in heart failure. It provides, with only minor surgery, a prosthetic ventricle in series with the left ventricle, and is capable of reducing the work load on the heart. A balloon is inserted into the aorta, at the end of a catheter, through either the carotid or femoral artery. The proximal end of the catheter is connected to a gas source. By inflating the deflating the balloon in proper phase with the heart cycle, the maximum pressure against which the heart pumps may be reduced and the workload of the left ventricle may be partially transferred to the aortic balloon.

Regardless of the state of the art of heart replacement, a simple procedure for assisting the heart will always be needed, whether to assist the patient's own heart, until it can recover, or until the patient's condition improves sufficiently so that he can undergo any necessary surgery, or as a permanent or semi-permanent prosthetic device.

(g) Theoretical work is underway and model experimental apparatus has been constructed to investigate the balloon-wall motions, the fluid motions, and the pressure distributions.

(6107) SKIN FRICTION FOR IAMINAR AND TURBUIENT OSCILIATORY FIOW IN A. TUBE.

(b) Office of Naval Research.

(c) Terry J. Vander Werff, Graduate Student, Dept. of Mech. Engrg., Mass. Inst. of Tech.

(d) Experimental; Master's thesis.

(e) The project is an investigation of the skin friction for purely harmonic oscillatory $\perp \perp 0 w$ of an incompressible fluid in a tube. 
Experimentally, the skin friction is found by measuring the pressure gradient in a region of fully developed flow and subtracting off the inertial contribution, which is accurately known from the boundary conditions. The resulting data will be plotted as a function of the two parameters of the flow, the

Reynolds number ( $R e=Q \Delta / A v$, where $Q$ is the magnitude of the volume flow oscillation and A the tube area) and the frequency parameter $\left(\alpha^{2}=\omega R^{2} / \nu\right.$, where $\omega$ is the frequency of oscillation).

The purpose of the experiment is twofold: to provide skin friction data as a function of the two parameters $\alpha^{2}$ and Re; and to map the regions in the $\alpha^{2}$ - Re plane where various theories resonably predict the flow.

(6108) RESEARCH ON PERISTAITIC PUMPING.

(b) Office of Naval Research.

(c) A.H. Shapiro; see (6106) above.

(d) Experimental and theoretical research; Doctoral thesis.

(e) The pumping action of peristaltic waves moving along a flexible tube is studied with special attention given to the presence of reverse flow. A reverse flow may explain how infection passes from the bladder to the kidney in a direction opposite to the main urine flow. The influences of wave shape and tube geometry on the pumping are also investigated.

(g) A theory has been completed when the ratio of wavelength to tube diameter is large and the Reynolds number is zero. An experimental apparatus has ween built to check the theory and its validity range. The predicted flowpressure gradient relation is in good agreement with the experimental values for Reynolds numbers less than one. Both theory and experiment show the presence of a reverse flow near the walls.

(h) "On Peristaltic Pumping," T.W. Latham and A.H. Shapiro, Engrg. in Medicine and Biology, Proc., 19th Annual Conf., 1966, p. 147.

"Pumping and Retrograde Diffusion in Peristaltic waves," A.H. Shapiro, Proc. Workshop on Ureteral Reflex in Children, Washington, D.C., 1967, p. 109.

MASSACHUSETTS INSTITUITE OF TECHNOLOGY, Dept. of Naval Architecture and Marine Engrg., Ship Model Towing Tank, Cambridge, Mass. 02139

(6607) MAINTAINING SHIP SPEED AT SEA - SHIP PERFORMANCE IN A SEAWAY.

(b) U.S. Maritime Administration.

(c) Prof. M.A. Abkowitz, Room 5-319, Mass. Inst. of Tech.

(d) Experimental and theoretical; applied research, development; masters and doctor theses.

(e) The broad aspect of improving ship performance in rough seas is being studied by more specific investigations in the following areas:

1. Improvement in model testing techniques for performance prediction and evaluation.

2. Improvement and consolidation of theoretical methods for prediction of ship responses* in a seaway, including added resistance in a seaway.

3. Development and application of techniques to predict maximum response in a given seaway.

4. Development of consolidated, but extensive computer programs to facilitate the application of these development into the design process.

*Responses are displacements, velocities, accelerations, speed loss, structural loading, slaming, etc.

(h) Some 15 reports over the last six years. Some of the recent ones are:

"Recent Developments in Seakeeping Research and Its Application to Design," M.A. Abkowitz, L.A. Vassilopoulos, F.H. Sellars IV, Trans. Soc. Naval Arch. and Marine Engrgs., 1966.

"The Analysis and Modeliing of Irregular Waves," F. Sellars and T. Loukakis, MIT Dept. Naval Arch. and Marine Engrg., Rept. No. 66-5, 1966.

"The Added Resistance of a Ship Among Waves," R. Beck, MIT Dept. Naval Arch. and Marine Engrg., Rept. No. 67-9, June 1967.

"The Limiting Height of Ocean Waves," F. Sellars, MIT Dept. Naval Arch. and Marine Engrg., Rept. No. 67-10, June 1967.

"The Dynamic Calibration of Shipborne Wave Gages," F. Sellars, MIT Dept. Naval Arch. and Marine Engrg., Rept. No. 67-11, July 1967. "The Motion of Hinged Ships in Regular Head Seas," F. Marbury. MIT Dept. Naval Arch. and Marine Engrg., Rept. No. 67-14, Oct. 1967.

A report on maximum responses of a hull in a seaway is expected in Sept. 1968 and a report on motions and hingeloading of models of hinged ships in a seaway is expected in June 1968.

(6608) MOTION AND STABILITY OF AMPHIBIOUS CRAFT IN WAVES AND SURF.

(b) Marine Corps, through Office of Naval Research.

(c) Prof. M.A. Abkowitz, Dept. Naval Arch. and Marine Engrg., Room 5-319, Mass. Inst. of Tech.

(d) Experimental; applied research; master's thesis.

(e) The project attempts to gain insight into the hydrodynamic phenomena affecting the motion of landing craft in surf in order to predict and evaluate stability and performance in beaching operations. Studies involved the measurement, on models, of stability coefficients, by stepresponse technique in simulated deep and shallow water, excitations in the horizontal plane by waves and surf, and observations of motion response during beaching operation of the model of a landi is craft.

(h) "Stability of Amphibious Craft IVTP-X12 in Waves and Surf," W.R. Patterson. MIT Dept. Naval Arch, and Marine Engrg., Rept No. 68-1, Jan. 1968 (also master's thesj.s).

(6609) MAXIMUM MOTIONS AND BENDING MOMENT LOADINGS OF DESTROYERS IN SEVERE SEA STATES.

(b) U.S. Navy, Naval Ship Res. and Dev. Ctr.

(c) Prof. M.A. Abkowitz; see (6608) above.

(d) Experimental and theoretical; applied research and development.

(e) To use and further develop the technique of generating, in the towing tank, long time samples of random irregular seas of any specified spectral distribution. The specific model testing program involves the determination of maximum responses, especially midship bending moment, of destroyer models, with and without large bow sonar domes, in 
several heavy sea states. Development of the technique involved ( 1 ) the building of a unique beach in the towing tank in order to kill wave reflections to allow long time samples and (2) the generation of purely random seas of given spectral content by means of a white noise generator.

(h) Progress reports to Naval Ship Res. and Dev. ctr. Two reports are expected in 1968: one on the effectiveness of the new beach and the other on the maximum responses of the destroyer hulls in the severe sea states.

UNIVERSITY OF MASSACHUSETTS, School of Engineering, Amherst, Mass. 01002

\section{(2561) HYDROLOGY STUDIES IN MASSACHUSETTS.}

(b) Cooperative with the U.S. Geological Survey, the Massachusetts Water Resources Commission, and the Mass. Water Resources Research Center.

(c) Assoc. Prof. George R. Higgins, Univ. of Mass., Engrg. Bldg.

(d) Experimental; field and laboratory; for hydrologic information to better assess the water resources potential of the Commonwealth.

(e) Flow duration curves and recurrence interval curves were prepared for nearly all the gaged streams in Massachusetts through the water year 1962. Mass curves for storage-yield relationships have been extended through 1965 . Present emphasis is concerned with evaporation studies to determine the effect of evaporation on reservoir yield in New England.

(h) A 250-page "Preliminary Report" was submitted to the Massachusetts Water Resources Commission in 1964 and an updated "Interim Report" was submitted to the Massachusetts Water Resources Center in 1967. Copies are available upon request. Continuing projects are anticipated dealing with reservoir stratification and thermal pollution.

(5371) A PHOTOMICROSCOPIC INVESTIGATION OF NONNEWTONIAN FLOWS AT LOW REYNOLDS NUMBERS.

(b) Naval Ship Research and Development Center.

(c) Dr. Charles E. Carver, Jr., Prof. of Civil Engrg., Univ. of Mass.

(d) Experimental; basic research.

(e) Laminar velocity profiles have been determined from photomicrographs of the motion of polystyrene latex spheres 0.557 microns in diameter dispersed in distilled water and three different aqueous solutions of non-Newtonian additives flowing in a lucite channel of crosssection $13 \times 1.5 \mathrm{~mm}$ at a channel Reynolds number of 0.92 .

(g) Velocity profile for distilled water agrees within $2 \%$ with the theoretical parabolic distribution for laminar flow between parallel flat plates. Profiles for the additives at both concentrations of $0.125 \%$ and $0.25 \%$ were indistinguishable from that of distilled water except near the boundaries, from 20-50 microns, where the velocity was measurably higher. Experiments are being repeated for turbulent flow in a 0.25 -inch circular tube using high speed cinemanicrophotography.

(h) "Measurement of Laminar Velocity Profiles with Non-Newtonian Additives," in Fluid Mechanics Lab. Tech. Rept. No. 1.
(5373) EFFICIENCY OF SPRAY AERATION.

(b) National Institutes of Health, U.S. Public Health Service.

(c) Dr. Charles E. Carver, Jr.; see (5371).

(d) Experimental; basic research.

(e) Overall oxygen transfer coefficients have been measured for deaerated water droplets falling through the atmosphere as a function of drop size and drop distance. The experiments are repeated with a synthetic detergent added to the water. Transfer coefficients are also measured from fully aerated water droplets falling through a pure nitrogen atmosphere as a function of drop size and drop distance and these experiments are repeated with a synthetic detergent added.

(r) Completed.

(h) Report in preparation.

(6666) FEASIBILITY STUDY ON THE USE OF A PNEUMATIC BREAKWATER FOR THE SURFACE IAUNCHING OF A. MANNED SUBMERSIBLE.

(b) Dept. of Defense, Project THEMIS.

(c) Dr. Charles E. Carver, Jr.; see (5371).

(d) Experimental.

(e) Experiments will be conducted in a wave channel in which wind waves will be generated in order to estimate power requirements for reducing wave amplitudes using a pneumatic breakwater. Ultimate aim is to produce a tranquil zone in the vicinity of a mother ship for the safe launching of a small manned submersible.

(6667) RELATIONSHIP BETWEEN DEFORMATION AND NONNEWTONIAN BEHAVIOR OF SUSPENSIONS OF DEFORMABLE PARTICLES.

(b) National Science Foundation.

(c) Dr. D. Chappelear, Dept. of Chemical Engrg., Univ. of Mass.

(d) Experimental; basic research for Ph.D. thesis.

(e) Measurements of deformation and orientation of suspended deformable particles will be made as a function of shear rate and shear stress in an attempt to correlate these phenomena with the non-Newtonian behavior of this type of suspension. The measurements will be made by light scattering techniques employing a special cell to be used in a viscometer for accurate shear data.

(g) Project is in the initial stages of equipment design with the experimental system chosen.

(6668) THEORY OF COAIESCENCE: A MATHFMATICAL MODEL FOR THE APPROACH OF A DEFORMABLE DROP TO AN INTERFACE.

(b) Laboratory project.

(c) Mr. Irwin Feuerstein or Prof. D.C. Chappelear, Chemical Engrg. Dept.. Univ. of Mass.

(d) Theoretical; basic research for Ph.D. thesis.

(e) The model will describe the shape and velocity of a drop as it approaches an interface. Such information it is hoped will lead to a better understanding of coalescence.

(g) The velocity and shape for slightly deformed drops have been determined.

(h) Chappelear, D.C., Jour. Colloid Sci., Vol.16, 186,1961

(6671) THE EVALUATION OF AN EBULITENT BED CATALYTIC RFACTOR.

(c) Dr. R.S. Kirk, Chemical Engrg. Dept., Univ. of Mass.

(d) Theoretial, experimental, technological: 
doctoral investigation with both experimental and theoretical aspects. Major emphasis on the technological facets such as the design and development of an ebullient reactor.

(e) Study the effect of fundamental design parameter variations with respect to capacity, quality of product, and simplicity of design ot an ebullient bed reactor using the oxidation of liquid ethanol as the three-phase heterogeneous catalytic system.

(6672) A MODEL FOR PREDICTING EFFECTIVE THERMAL CONDUCTIVITIES OF HETEROGENEOUS MEDIA.

(b) Laboratory project.

(c) Prof. R.S. Kirk, see (6671) above.

(d) Theoretical, Experimental, Basic.

(e) A model has been proposed to facilitate prediction of the effective thermal conductivity of a multi-phase system from readily measurable characteristics of the componenets of the system.

(6673) DROPWISE CONDENSATION HEAT TRANSFER OF MERCURY.

(b) Chemical Engrg. Dept., Univ. of Mass.

(c) Dr. I.H.S. Roblee, Jr., Chemical Engrg. Dept., Univ. of Mass.

(d) Theoretical and experimental; applied research for doctoral thesis.

(e) Study of heat transfer and flow parameters of condensing mercury, the purpose of which is to contribute data and a better understanding of the phenomena of dropwise condensation of liquid metals.

(6675) DROPWISE CONDENSATION OF STEAM.

(b) Office of Naval Research.

(c) Dr. L.H.S. Roblee, Jr.; see (6673) above.

(d) Experimental; for master's thesis.

(e) High speed motion pictures were taken at elevated pressures and analyzed to obtain factors, if any, which give rise to a maximum in the heat transfer coefficient versus pressure plot.

(g) Three factors have been found which are felt to be the main reason for the maximum in the heat transfer coefficient versus pressure plot. They are overall driving force, free area, and cycle time of the drops on the surface.

(h) "Dropwise Condensation of Steam at Atmospheric and Above Atmospheric Pressures," J.T. O'Bara, E.S. Killian and L.H.S. Roblee., Chemical Eng. Science, Vol. 22, pp. 1305-1314, 1967 (Reprints obtained by writing Dr. L.H.S. Roblee, Jr., Chemical Engrg. Dept., Univ. of Mass., Amherst, Mass.)

(6676) MASS TRANSFER IN SULFUR DIOXIDE-AIR-WATER SYSTEM.

(c) Dr. K. Cashin, Chemical Engrg. Dept., Univ. of Mass.

(d) Experimental; applied research for master's thesis.

(e) A $5 \mathrm{ft}$. high column packed with 3/8-inch Raschig rings is used to scrub sulfur dioxide from air with water. The rate of absorption is calculated from concentration and flow data.

(6677) DEVELOPMENT OF A MOMENT METHOD TO SOLVE THE THREE-DIMENSIONAL BOUNDARY LAYER EQUATIONS.

(b) National Aeronautics and Space Admin.

(c) Prof. J. Fillo, Principal Investigator, or Mr. E. Cheng, Research Asst., Dept. of Mechanical and Aerospace Engrg., Univ. of Mass.

(d) Theoretical.

(e) Utilization of the moment method to solve three-dimensional boundary layer equations.

(h) "Effects of Compressibility and Viscosity in Curved Flows," J.A. Fillo and S.N.B. Murthy, Presented at Fifth Technical Mtg., Soc. of Engrg. Science.

(6678) VISCOSITY MEASUREMENTS AT EXTREME SHEAR IN LAMINAR FLOW.

(b) Laboratory project.

(c) Prof. R.S. Porter, Dept. of Chemical Engrg., Univ. of Mass.

(d) Basic research.

(e) Methods of determining viscosity at extreme shear in the case of pure compounds and polymer solutions.

(6679) PROPELIER AND WAKE NOISE IN DEEP-SEA SUBMERSIBLES.

(b) Dept. of Defense, Project THEMIS.

(c) Prof. G.A. Russell and S.N.B. Murthy, Dept. of Mechanical and Aerospace Engrg., Univ. of Mass.

(d) Applied and technological.

(e) The relation between vorticity and noise in regard to generation and transmission is under study both experimentally and theoretically. Turbulence correlations are also included.

(6680) THRUST-GENERATION BY ELECTRO-MAGNETIC ACCELERATION OF COLLOIDS.

(b) Dept. of Defense, Project THEMIS.

(c) Prof. S.N.B. Murthy and J.G. McGowan, Dept. of Mechanical and Aerospace Engrg., Univ. of Mass.

(d) Applied and technological.

(e) The stability of motion of fluids in which colloid suspensions are used for acceleration of the fluid is under study.

(6681) THREE-DIMENSIONAL LOSSES IN SUBMERSIBIE BODIES AND PROPELLERS.

(b) Dept. of Defense, Project THEMIS.

(c) Prof. J.A. Fillo, D.E. Cromack and S.N.B. Murthy, Dept. of Mechanical and Aerospace Engrg., Univ. of Mass .

(d) Basic research.

(e) Considering the three-dimensional boundary layer effects on submerged bodies, it is proposed to determine experimentally and theoretically the method of obtaining aercdynamic models for hydrodynamic systems.

MICHIGAN STATE UNIVERSITY, Dept. of Civil Engrg., East Lansing, Michigan 48823

(6700) STABILITY AND FLUID FLOW.

(b) Laboratory project.

(c) Dr. C.M. Potter, Dept. of Mechanical Engrg., Mich. State Univ.

(d) Theoretical; Ph.D. thesis.

(e) A study of stability of parallel shear flow subject to rotation.

UNIVERSITY OF MICHIGAN, Department of Civil Engrg., Ann Arbor, Michigan 48104

(4858) WATER HAMMER: RESONANCE IN TRIPIEX PUMP SUCTION AND DISCHARGE LINES.

(b) National Science Foundation; Union Pump Co.

(c) Prof. V.I. Streeter, Prof'. of Hydraulics, Dept. of Civil Engrg., Univ. of Mich.

(d) Theoretical and experimental; basic research. 
(e) Theoretical determination of resonance-free suction lines and experimental study of actual transients.

(f) Excellent agreement obtained with experiment using linearized impedance methods and the nonlinear characteristics method.

(h) "Hydraulic Transients Caused by Reciprocating Pumps, "V.I. Streeter and E.B. Wylie, Paper No. 66-WA/FE-29, ASME Winter Ann. Mtg., New York, Nov. 27-Dec.1, 1966.

(4859) PULSATIIE FLOW THROUGH ARTERIES.

(b) National Institutes of Health.

(c) Prof. V.L. Streeter; see (4858) above.

(d) Theoretical and experimental; basic research.

(e) Computer simulation of portions of the arterial tree; experimental studies of energy dissipation in pulsatile flow through distensible tubes.

(h) "Flow Through Tapered Tubes with Nonlinear Wall Properties," E.B. Wylie, Symp. on Biomechanics, ASME, New York, 1966.

"Unsteady Flows in Lines with Distributed Leakage," David C. Wiggert, Jour. Hyd. Div., ASCE, Vol. 94, No. HY 1, Jan. 1968, pp. 143162 .

"Frequency Dependent Friction in Transient Pipe Flow," W. Zielke, Paper No. 67-Wa/FE-15, ASME Winter Ann. Mtg., Pittsburgh, Pa., Nov. 12-17, 1967.

(4862) WATER HAMMER, LIQUID COLUMN SEPARATION.

(b) National Science Foundation.

(c) Prof. V.L. Streeter; see (4858) above.

(d) Theoretical and experimental; basic research for doctoral thesis.

(e) Study of wall shear under cavitating conditions.

(h) "Column Separation Accompanying Liquid Transients in Pipes," R.A. Baltzer, Paper No. 67-WA/FE-16, ASME Winter Ann. Mtg., Pittsburgh, Pa., Nov. 12-17, 1967.

(4946) RESONANCE IN PIPE LINES.

(b) National Science Foundation.

(c) Prof. E.B. Wylie, Dept. of Civil Engrg., Univ. of Michigan.

(d) Theoretical and experimental.

(e) Study of resonance in complex systems.

(h) "Schwingungen in Druckrohrleitungen Anwendung der Impedenz-Methode unter Berucksichtigung des Reibungsunflusses," E.B. Wylie and W. Zielke, Die Wasserwirtshaft, 57 Jahrgang, Heft 2, pp. 91-96, 1967.

(5558) FLOOD PREDICTION.

(b) Michigan State Highway Dept.; and U.S. Bureau of Public Roads.

(c) Dr. E.F. Brater, Prof. of Hydraulic Engrg., Dept. of Civil Engrg.

(d) Analysis of field data, basic research.

(e) Rainfall and runoff data from small watersheds in southwestern Michigan are being analyzed to determine infiltration capacities and flood hydrograph shapes for the purpose of predicting the frequency of floods on watersheds in various stages of urbanization.

(h) Preliminary results presented in a paper "Steps Toward a Better Understanding of Urban Runoff Processes" to be published in an early issue of Water Resources Research (Amer. Geophys. Un.).

(5916) RAINFALL-RUNOFF REIATIONS ON URBAN AND RURAL AREAS. (b) National Institutes of Health.

(c) Dr. E.F. Brater; see (5558) above.

(d) Analysis of field data, basic research.

(e) Rainfall and runoff data from small watersheds in various stages of urbanization are being studied to determine the effect of such factors as size of basin, the amount of impermeable areas, shape of basin and the nature of the drainage network in storm runoff.

(h) "Steps Toward a Better Understanding of Urban Runoff Processes," E.F. Brater, Water Resources Research, Vol. 4, No. 2, April 1968, p. 335.

(5917) VALVE STROKING TO CONTROL WATERHAMMER.

(b) National Science Foundation.

(c) Prof. V.L. Streeter; see (4858) above.

(d) Theoretical and experimental.

(e) Development of theoretical equations for motion of a valve so that the transient ceases the instant the valve motion ceases; confirmation on 4,000 $\mathrm{ft}$. line with servo-operated valve.

(h) "Valve Stroking for Complex Piping Systems," V.L. Streeter, Jour. Hyd. Div., ASCE, Paper 5238, HY 3, May 1967, pp. 81-98.

(6423) UNSTEADY OPEN CHANNEI FLOW, see p. 154.

(6424) WAVE FORCES ON SUBMERGED STRUCTURES.

(b) National Science Foundation.

(c) Dr. E.F. Brater; see (5558) above.

(d) Experimental; basic research and application to engineering design.

(e) Study of forces on submerged pipe lines.

(g) Instrumentation completed and testing program is being started.

(6425) TRANSIENTS IN GAS DISTKIBUTION SYSTEMS.

(b) National Science Foundation.

(c) Prof. V.I. Streeter; see (5917) above.

(d) Theoretical and experimental (field); basic research, for doctor's degree.

(e) Application of characteristics method for control of gas distribution systems.

(6426) SUCTION LINE DYNAMICS SATURN V ROCKET.

(b) NASA.

(c) Prof. V.I. Streeter; see (5917) above.

(d) Experimental and theoretical.

(e) Study of possible longitudinal oscillation of the structure caused by cavitations in the fuel pump suction lines.

(g) Explanation of coupling cycle for longitudinal (pogo stick) vibrations.

UNIVERSITY OF MICHIGAN, Dept. of Nuclear Engrg., Laboratory for Fluid Flow and Heat Transport Phenomena, Ann Arbor, Michigan 48105

(6144) ASYMMETRIC BUBBLE COLLAPSE.

(b) National Science Foundation; Army Research Office-Durham.

(c) Prof. F.G. Hammitt, Prof. of Nuclear Engrg., Dept. of Nuclear Engrg., Univ. of Michigan.

(d) Theoretical and experimental; basic research for doctoral thesis.

(e) Study of the asymmetric collapse of vapor (and gas) bubbles in fluid streams.

(6145) CAVITATION STUDIES.

(b) Worthington Corp.

(c) Prof. F.G. Hammitt; see (6144) above. 
(d) Experimental, applied research.

(e) Determination of the relative resistances of metals and alloys to cavitation erosion under different conditions of temperature and pressure.

(6146) CAVITATION TESTING.

(b) Birdsboro Steel Corp.

(c) Prof. F.G. Hammitt; see (6144) above.

(d) Experimental development.

(e) Development of a laboratory technique for determining the relative resistances of various stainless steels to cavitation erosion.

(6147) BUBBLE NUCLEARATION, GROWTH AND COLLAPSE PHENOMENA.

(b) National Science Foundation.

(c) Prof. F.G. Hammitt, Prof. of Nuclear Engrg., Dept. of Nuclear Engrg., Univ. of Mich.

(d) Experimental and theoretical; basic research for thesis.

(e) Study of the details of the growth and collapse of vapor and gas bubbles in liquids with particular reference to the problem of sodium superheat.

UNIVERSITY OF MICHIGAN, Engineering Mechanics Dept., Ann Arbor, Mich. 48104

(6169) NON-HOMOGENEOUS AND ROTATING FLUIDS.

(b) National Science Foundation.

(c) Prof. C.S. Yih, Dept. of Engrg. Mechanics, Univ. of Michigan.

(d) Theoretical and experimental basic research.

(e) The investigation of large amplitude flows in non-homogeneous and rotating fluids.

(g) Theoretical solutions have been obtained to a number of problems which are discussed in the publication below.

(h) "Equations Governing Steady Three-Dimensional Large-Amplitude Motions in a Stratified Fluid," Jour. Fluid Mech., Vol. 29, No. 3, pp. 539-544, 1967.

(6170) STABILITY AND SECONDARY FLOWS IN STRATIFIED F'LUIDS.

(b) Army Research Office.

(c) Prof. C.S. Yih; see (6169) above.

(d) Theoretical and experimental research.

(e) Investigation of stability of stratified flows down inclined planes; wind generated waves; and convective instability in flowing fluids.

(g) Theoretical solutions have been obtained to a number of problems which are discussed in the publication below.

(h) "Instability Due to Viscosity Stratification," Jour. Fluid Mech., Vol. 27, No. 2, pp. 337-352, 1967.

(6171) DRAG REDUCTION.

(b) Office of Naval Research.

(c) Prof. W.P. Graebel, Dept. of Engrg. Mechanics, Univ. of Mich.

(d) Theoretical and experimental basic research.

(e) An investigation of the effect of non-Newtonian fluid properties on drag reduction.

(g) Theoretical solutions have been obtained to a number of protlems which are discussed in the publication velow.

(r) "On Determination of the Characteristic Equations for the Stability of Parallel Flow," Jour. Fluid Mech., Vol. 24, No. 3, pp. 497-508,
1966.

(6172) SUPERCRITICAL CIRCULAR COUETTE FLOW.

(b) Laboratory project.

(c) Prof. W.R. Debler, Dept. of Engrg. Mechanics, Univ. of Michigan.

(d) Experimental research.

(e) The investigation of the speed-torque relationship immediately after Taylor instability occurs.

(g) The slope of the speed-torque curve has been obtained for various cylinder diameter ratios ranging from 0.50 to 0.95 . The outer cylinder was constrained by a torsion wire and air bearing.

(6173) INTERNAL WAVES AND WAKES IN A STRATIFIED FLOW.

(b) Office of Naval Research.

(c) Prof.W.R. Debler; see (6172) above.

(d) Experimental research.

(e) The study of the role of stratification of the development of 2 and 3 dimensional wakes; the generation of internal waves by the body and its wake in a stratified fluid.

(g) No final results to date.

UNIVERSITY OF MICHIGAN, Ship Hydrodynamics Laboratory, Ann Arbor, Michigan 48104

(6682) RESISTANCE CHARACTERISTICS OF TRANSOM STERN MERCHANT SHIP HULL FORMS.

(b) Friede and Goldman, Inc.

(c) Prof. F.C. Michelsen, Ship Hydrodymamics Lab., Univ. of Michigan.

(d) Experimental; applied research.

(e) Various ship hull forms have been developed, all of which feature a transom stern, some of which are mathematically describable, and all of which feature large bulbous bows. Basic powering information for this class of hull forms is being established.

(f) Completed.

(g) Within the range of parameters investigated, powering for high speed transom stern merchant ships can be made competitive with that of other, more common hull configurations if careful attention is given to the design of the transom and bulbous bow.

(h) To be published by Soc. Naval Architects and Marine Engrs.

(6683) RESISTANCE COMPONENTS OF BOXIIKE FORMS TRAVELING ON THE FREE SURFACE.

(b) Office of Naval Research.

(c) Mr. J.L. Moss, Ship Hydrodynamics Lab., Univ. of Michigan.

(d) Experimental; basic research.

(e) Boxlike forms with a range of parameters of length to width and width to draft are towed on a straight course through a range of speeds. Forces are measured on the ends of the boxes and wave elevations are measured. The basic resistance components of wave resistance, eddymaking resistance, and frictional resistance can be determined.

(g) Results to be available in mid-1968.

(h) Final report to be prepared.

(6684) EFFECTIVE AND SHAFT HORSEPOWER FOR HIGH SPEED TRANSOM SHIPS.

(b) Maritime Admin., U.S. Dept. of Commerce.

(c) J.L. Moss; see (6683) above. 
(d) Experimental; applied research; design.

(e) Up to 15 different systematically related transoms are being designed and tested for resistance and propulsion characteristics through a broad speed range and under several different loading conditions each.

(g) Results will be available in late 1968.

(h) Final report to be prepared.

(6685) THE VISCOUS DRAG OF SIMPLE BODIES NEAR A FREE SURFACE .

(b) Naval Ship Research and Development Center.

(c) Mr. John C. Gebhardt, Dept. of Naval Architecture, Univ, of Mich.

(d) Theoretical and experimental; basic research; $\mathrm{Ph}$.D. thesis.

(e) The effect of the free surface on the viscous drag of a two-dimensional hydrofoil is being studied both theoretically and experimentally. Variations of skin friction with Froude number are sought.

(g) Significant changes in pressure distributions with changing Froude number are evident.

(h) Report to be prepared.

UNIVERSITY OF MINNESOTA, St. Anthony Falls Hydraulic Iab., see St. Anthony Falls

UNIVERSITY OF MISSOURI, Dept. Of Civil Engrg., Columbia, Missouri 65201

(5827) EFFECT OF AQUATIC GROWTHS ON THE RESISTANCE TO FLOW IN PIPES.

(b) Missouri State Water Pollution Board.

(c) Dr. John J. Cassidy and Dr. Darrel L. King, Civil Engrg. Dept., Univ. of Missouri.

(d) Experimental; basic; M.S. thesis.

(e) Nutrients are being added to water in order to grow algae and other organisms on the walls of pipes through which the water is being pumped. Change in the resistance coefficient with time is being measured.

(f) Completed.

(g) Equivalent sand-grain roughness was correlated with the weight of algae adhering to a unit area of pipe.

(h) "Resistance to Flow in Pipes as a Function of Aquatic Growth," Annual Progr. Rept. on Water Pollution Control 1966, Engrg. Expmt. Station, Univ. of Missouri.

(5828) SPILLWAY DISCHARGE COEFFICIENTS AND PRESSURE DISTRIBUIIONS AS A FUNCTION OF SPILLWAY SHAPE.

(b) Univ. of Missouri, Engrg. Expmt. Sta.

(c) Dr. John J. Cassidy, Civil Engrg. Dept., Univ. of Missouri.

(d) Experimental; basic research; M.S. thesis.

(e) Discharge coefficients and pressure distributions are being determined experimentally for spillways with varying crest shapes.

(g) "Spillway Design," M.S. Thesis by Chii-ell Tsai, Civil Engrg. Dept., Univ. of Missouri.

(5829) DISCHARGE MEASUREMENT IN TWO-DIMENSIONAL FLOWS.

(b) Missouri Water Resources Center.

(c) Dr. Henry Liu, Civil Engrg. Dept., Univ. of Missouri.

(d) Experimental; applied.

(e) A new method of discharge measurement is being studied. The method involves the release of lighter-than-water particles on or near the floor of a channel, and the measurements of the horizontal distance traversed during their rise to the surface.

(g) Parameters influencing the accuracy of discharge measurement in two-dimensional. lowvelocity flows have been available. The method is particularly applicable to such flow.

(h) "Discharge Measurement Using Lighter-Than-Water Particles," M.S. Thesis, Larry D. Martin, Civil Engrg. Dept., Univ. of Missouri.

(6076) THE MOTION OF RIGID SPHERES IN A HIGHLY TURBULENT FIELD.

(b) National Science Foundation.

(c) Dr. John J. Cassidy, Dept. of Civil Engrg., Univ. of Missouri.

(d) Experimental basic research.

(e) A study is being made of the drag on spheres moving in a fluid field in which the turbulence scale is of the order of the sphere diameter.

(6077) IRROTATIONAL POTENTIAL FLOW OVER A SPILLWAY TOE CURVE.

(b) U.S. Army Engrs., Waterways Experiment Sta.

(c) Dr. John J. Cassidy; see (6076) above.

(d) Analytical; applied research.

(e) An analytical method is being developed for the determination of free-surface profiles and floor pressures for flow over a spillway toecurve of given shape.

(6078) IRROTATIONAL POTENTIAL FLOW UNDER A SLUICEGATE.

(b) Laboratory project.

(c) Dr. Charles Lenau, Dept. of Civil Engrg., Univ. of Missouri.

(d) Analytical; basic.

(e) An analytical solution to the free-streamline problem has been undertaken.

(f) Completed.

(6079) DIFFUSION OF SEDIMENT.

(b) Laboratory project.

(c) Dr. Charles Lenau; see (6078) above.

(d) Analytical; basic.

(e) An analytical analysis is being made of the diffusion of sediment in a turbulent open channel flow.

(6080) HYDRAULIC CHARACTERISTICS OF AN ARTIFICIAI HEART.

(b) Missouri Regional Medical Program.

(c) Dr. Allen T. Hjelmfelt, Jr., Dept. of Civil Engrg., Univ. of Missouri.

(d) Experimental; applied.

(e) An experimental design of an artificial heart has been undertaken.

UNIVERSITY OF MISSOURI AT ROLIA, Dept. of Civil Engrg., Rolla, Missouri 65401

(4169) INVESTIGATION OF VERTICAL INIERNAL SPILLWAYS.

(b) Laboratory project.

(c) Prof. C.D. Muir, Assoc. Prof. of Civil Engrg., Univ. of Missouri at Rolla.

(d) Experimental; basic research; master's thesis.

(e) A scale model rockfill dam containing a vertical internal spillway was studied to determine factors affecting stage-discharge relationships.

(f) Completed.

(g) A relationship for weir discharge coefficient as a function of rock size and weir height was developed from the experimental data.

(h) "Investigation of Vertical Internal Spiliways," 
Paul R. Munger, Master's Thesis, Univ. of Missouri at Rolla, 1961.

(4661) A COMPUTER STUDY OF BACKWATER COMPUTATIONS.

(b) Laboratory project.

(c) Prof. C.D. Muir; see (4169) above.

(d) Experimental; basic research for master's thesis.

(e) The effect of some approximations used in backwater calculations on the resulting surface profile was studied by use of a digital computer. Also, several methods of backwater computations were compared.

(f) Completed.

(g) The results of this study indicated that the use of approximations is feasible for curves above critical depth but are dependent on flow regime.

(h) "A Comparison of Backwater Profile Computations," A.C. Young, Master's Thesis, Univ. of Missouri at Rolla, 1962 .

(4662) HYDROLOGY OF SMALI MISSOURI WATERSHEDS.

(b) Laboratory project.

(c) Prof. C.D. Muir; see (4169) above.

(d) Experimental; basic research for master's thesis.

(e) This study was for the purpose of correlating basin characteristics and mean annual flood for Missouri watersheds having a drainage area of less than ten square miles.

(f) Completed.

(g) It was found that mean annual floods could be predicted and correlated to known data from forty-five Missouri watersheds by use of
shape factor (AL2) and basin index $\left(A L^{2} S^{1 / 2}\right.$ )

(h) "A study of Small Watersheds within the State of Missouri," Terence E. Harbaugh, Master's Thesis, Univ. of Missouri at Rolla, 1962.

(4663) FLOW THROUGH A ROCKFILI DAM.

(b) Laboratory project.

(c) Prof. P.R. Munger, Assoc. Prof. of Civil Engrg., Univ. of Missouri at Rolla.

(d) Experimental; basic research for master's thesis.

(e) Model studies are being conducted on a rockfill dam with a sloping internal spillway to determine the characteristics of flow through such dams.

(f) Completed.

(g) A relationship between discharge coefficient, slope of the core, height of core, and rock size was determined from the test results.

(h) "Investigation of Flow Rates through a Rockfill Dam," Jerry R. Bayless, Master's Thesis, Univ. of Missouri at Rolla, 1962.

(5468) INVESTIGATION OF HIGH VELOCITY JETS ON HYDRAULIC JUMP.

(b) Laboratory project.

(c) Prof. Paul R. Munger; see (4663) above.

(d) Experimental; basic research for master's thesis.

(e) Investigation of tailwater depth, length, and wave formation properties of hydraulic jump due to introduction of high velocity jets from apron.

(f) Completed.

(g) Test results indicate: (a) the quantity of water flowing through the submerged jets is a primary factor in determining the specific energy leaving the jump, (b) submerged jets can be more effective than baffle piers in reducing the length of the hydraulic jump, (c) submerged jets are not as effective as baffle piers in reducing the wave formation properties of a jump, (d) submerged jets at any angle tested tend to decrease the specific energy of the water leaving the jump and are more effective than the impulse-momentum principle indicates, (e) submerged jets may be as effective as baffle piers in reducing the length of the jump, ( $f$ ) submerged jets at any angle tend to decrease the required tailwater depth of the hydraulic jump.

(h) "The Effect of Submerged Jets on the Hydraulic Jump," Harvey E. Jobson, Master's Thesis, Univ. of Missouri at Rolla, 1365.

"Modification of the Hydraulic Jump by Submerged Jets," Edward I. Tharp, Master's Thesis, Univ. of Missouri at Rolla, 1965.

(5469) VELOCITY AND KINETIC ENERGY DISTRIBUTION OF A SUBMERGED JET.

(b) Iaboratory project.

(c) Prof. V.A.C. Gevecker, Dept. of Civil Engrg., Univ. of Missouri at Rolla.

(d) Experimental; basic research for master's thesis.

(e) Tests conducted to determine the effect on velocity and kinetic energy by submerging a jet below the surface of a stilling basin.

(f) Completed.

(g) The entraining effect of the submerged jet is of an order of ten or more times the discharge of the jet itself at the section of the jet opening. The major energy dissipation effects occur in the region of the jet itself. The kinetic energy decreases not linearly but exponentially with depth of penetration.

(h) "Velocity and Kinetic Energy Distribution of a Submerged Jet," Patrick S. Couch, Master's Thesis, Univ. of Missouri at Rolla, 1364.

(5740) DISCHARGE CHARACTERISTICS OF SIDE WEIRS.

(b) Laboratory project.

(c) Prof. V.A.C. Gevecker; see (5469) above.

(d) Experimental; basic research for Master's thesis.

(e) An investigation of the division of flow of water in a flume of rectangular cross-section when the flume is provided with a side weir.

(f) Suspended.

(g) An equation is derived so that the quantity of water flowing over the side weir compared to the quantity of water flowing in the main channel can be predicted. This ratio is acceptable only within the ranges of heads. velocities, and weir lengths imposed by the geometry of the system tested.

(h) "Discharge Characteristics of Side Weirs," Edgar Snowden IV, Master's Thesis, Univ. of Missouri at Rolla, 1365.

(6284) CHARACTERISTICS OF THE FLOW OF WATER IN RECTANGULAR CONDUTTS.

(b) Laboratory project.

(c) Jerry R. Bayless, Asst. Prof. of Civil Engrg., Univ. of Missouri at Rolla.

(d) Experimental; basic research for Master's thesis.

(e) Friction factors for use in the Darcy-Weisbach equation were determined experimentally for smooth pipes in laminar and turbulent flow. The criteria for finding an equivalent diameter were investigated, and the effect of the equivalent diameter on the experimental data was investigated.

(f) Completed. 
(g) The use of four times the area divided by the wetted perimeter as the diameter of an equivalent circular pipe is in error for laminar flow and a different length of dimension is necessary to uniquely correlate pipes of noncircular cross section with those of circular cross section. Potential depth, the average viscous shear depth, makes the data correspond more closely with theory. The use of equivalent diameter is satisfactory for turbulent flow.

(h) "Fluid Flow in Pipes of Rectangular Cross Section," Bruce H. Bradford, Master's Thesis, Univ. of Missouri at Rolla, 1966.

(6285) ROUGHNESS IN OPEN CHANNEL FLOW.

(b) Laboratory project.

(c) Dr. T.E. Harbaugh, Civil Engrg. Dept., Univ. of Missouri at Rolla.

(d) Experimental; development.

(e) An experimental study of various surfaces subjected to various slopes and depths of flow.

(h) Publication pending.

(6286) HYDROPLANING: THE EFFECT OF GROOVING ON SURFACE DRAINAGE OF CONCRETE PAVEMENTS.

(b) Laboratory project.

(c) Dr. T.E. Harbaugh; see (6285) above.

(d) Design.

(e) An experimental and analytical study of the depth of water on grooved pavements to improve design of grooved pavements.

(6287) MODIFIED STATION-YEAR METHOD FOR FLOOD FREQUENCIES.

(b) Laboratory project.

(c) Dr. T.E. Harbaugh; see (6285) above.

(d) Design.

(e) Determination of flood peaks for small drainage areas in Missouri based on physiographic data.

(6288) AERATED OPEN-CHANNEL FLOW.

(b) Laboratory project.

(c) Dr. T.E. Harbaugh; see (6285) above.

(d) Experimental; development.

(e) An experimental study of the effect of airentrainment on the frictional characteristics of open-channel flow.

The following projects are summarized in water Resources Research Catalog.

(O28W) INVESTIGATION OF THE SPATIAL BEHAVIOR OF ROUGHINESS IN IAABORATORY WATERSHEDS UNDER CONDITIONS OF SPATIALLY VARIED UNSTEADY FLOW PROJECT B-007-MO.

(O29W) SPATIAL BEHAVIOR OF ROUGHNESS IN LABORATORY WATERSHEDS PHASE II - PROJECT E-O19-MO.

(O3OW) AVAILABILITY, DISTRIBUTION, QUANTITY AND QUALITY OF WATER RESOURCES IN CARBONATE KARST TERRAIN - PROJECT USDI-A-OO1 MO.

UNIVERSTTY OF MISSOURI AT ROLIA, Dept. of Chemical Engrg., Rolla, Missouri 65401

(6404) EFFECT OF POLYMER STRUCTURE ON DRAG REDUCTTON.

(b) Petroleum Research Fund.

(c) Dr. Jacques L. Zakin or Dr. Gary K. Patterson, Dept. of Chemical Engrg., Univ. of Missouri at Rolla.

(d) Experimental; basic research; Ph.D. thesis. (e) The effectiveness of polymer additives in causing drag reduction is being studied in terms of molecular structure.

(g) Previous work has shown that molecular conformation in solution has an important effect on the level of drag reduction. The effect of molecular structure is now being examined.

(h) "Existence of Two Types of Drag Reduction in Pipe Flow of Dilute Polymer Solutions," H.C. Hershey and J.L. Zakin, Ind. Eng. Chem. Fund., Vol. 6, 381-87, 1967.

"A Molecular Approach to Predicting the Onset of Drag Reduction in the Turbulent Flow of Dilute Polymer Solutions," H.C. Hershey and J.L. Zakin, Chem. Eng. Sci., (in press). "Correlation of Drag Reduction with Modified Deborah Number for Dilute Polymer Solutions," J.M. Rodriguez, J.L. Zakin and G.K. Patterson, Jour. Soc. Pet. Eng., Vol. 7, 325, 1967.

(6405) TURBULENCE INTENSITIES IN DRAG REDUCING ORGANIC SOLUTIONS.

(b) National Aeronautics and Space Admin.

(c) Dr. Jacques L. Zakin or Dr. G.K. Patterson: see (6404) above.

(d) Experimental; basic research; Ph.D. thesis.

(e) Details of the turbulence structure of drag reducing and non-drag reducing solutions are being investigated. Turbulence intensities, frequency spectra, integral scales and other turbulence quantities are being compared for drag reducing and non-drag reducing solutions.

(h) "Hot-Film Anemometry Measurements of Turbulence in Pipe Flow: I. Organic Solvents, "G.K. Patterson and J.L. Zakin, Jour. A.I.Ch.E (in press).

(6406) VELOCITY PROFILES IN DRAG REDUCING FLOW.

(b) National Aeronautics and Space Admin.

(c) Dr. G.K. Patterson or Dr. Jacques L. Zakin; see (6404) above.

(d) Experimental; basic research; M.S. thesis.

(e) An anemometry technique is being developed for measuring mean velocity profiles in drag reducing flow for which pitot tubes are not suitable. Accurate profiles should permit a better understanding of the mechanism of drag reduction.

(h) "Velocity Profiles in Viscoelastic Drag Reducing Solutions," L.G.E. Florez, M.S. thesis, Univ. of Missouri at Rolla, 1367.

(6407) DRAG REDUCTION IN ORGANIC SOAP SOLUTIONS.

(b) Laboratory project.

(c) Dr. Jacques L. Zakin or Dr. Gary K. Patterson; see (6404) above.

(d) Experimental; basic research; M.S. thesis.

(e) While prlymer solution drag reduction has been widely studied, little effort has been given to soap additives which may be more effective drag reducers. The effect of soap type and concentration and the influence of flow variables (flow rate and diameter) are being investigated.

(6408) VISCOSITY OF POLYMER SOLUTIONS.

(b) Laboratory project.

(c) Dr. Jacques L. Zakin or Dr. Kenneth G. Mayhan, Dept. of Chem. Engrg., Univ. of Missouri at Rolla.

(d) Experimental; basic research; M.S. thesis.

(e) The effects of polymer concentration, molecular weight, solvent-polymer interactions and polymer structure on viscosity are being investigated.

(h) "The Effect of Concentration on the Viscosities of Solutions of Linear Flexible High Polymers," 
L.Y. Chou and J.L. Zakin, Jour. Colloid and Interface Sci., (in press).

MOBII RESEARCH AND DEVELOPMENT CORPORATION, Field Reser rch Laboratory, P.0. Box 900, Dallas, Texas 75221 .

(6391) TURBULENT FLOW BEHAVIOR OF RHEOLOGICALLY COMPLEX FLUTDS.

(b) Laboratory project.

(c) J.G. Savins, Research Assoc., Mobil Research and Development Corp.

(d) Experimental and theoretical applied research.

(e) The flow stabilization and drag reduction characteristics of solutions of certain species of high molecular weight polymers and low molecular weight micellar-electrolyte systems are investigated over a broad temperature range. Research is done on theories of the origin of drag reduction, and the roles of elastic behavior, particulate and wall effects, and shear dependent viscosity are studied. An instrumented flow system consists of smooth circular tubes, and test sections for velocity probes, annuli, roughness elements, etc. Basic rheological data are acquired with the usual viscometric and rheogoniometric devices. A semiworks facility consisting of a cased $1000 \mathrm{ft}$ bore hole and instrumented circulating system is available.

(g) We find the different fine structure of the flow units in micellar systems, i.e., a network of interlaced rod-like elements, leads to a new and significantly different turbulent flow behavior. For example, in micellar systems drag reduction is a stress controlled phenomenon in that the per cent reduction in drag steadily increases until a critical wall shear stress is reached. Above the critical shear stress, the per cent reduction in drag decreases until the turbulent flow becomes indistinguishable from that of a Newtonian fluid. This effect is not degradation, but rather a temporary network disentanglement induced by turbulent vortices and eddies.

(h) "Drag Reduction Characteristics of Solutions of Macromalecules in Turbulent Pipe Flow," J.G. Savins, Jour. Soc. Petr. Engrs., Vol. 4, No. 3, p. 203, 1964.

"A Stress-Controlled Reduction Phenomenon," J.G. Savins, Rheologica Acta, Vol. 6, p. 323, 1967.

MONTANA STATE UNIVERSITY, Agricultural Experiment Sta., Bozeman, Mont. 59715

(4664) EFFICIENT APPLICATION OF IRRIGATION WATER BY SURFACE FLOODING METHODS.

(b) Laboratory project.

(c) Prof. C.C. Bowman, Head, Agric. Engrg. Dept. Montana State Univ.

(d) This is a study to develop design criteria for more efficient application of irrigation water by flooding method. This is basic research at the present time, but will be applied researcn immediately upon completion of the first phase.

(e) Automation of systems is also included in these studies.

(h) "Manning's Equation for Shallow Flow," C.C. Bowman, ARS-SCS Proc., ARS 41-43, Oct. 1960.
"Dimensional Analysis Leading to Efficient Application of Irrigation Water, " C.C. Bowman, Am. Soc. Ag. Engr., 1763.

"Vegetative Density Meter," C.C. Bowman and R. Stitt, Mont. Agric. Expmt. Sta. Bul. No. 611, 1965.

NARRAGANSETT MARINE IABORATORY, see Univ . of Rhode Island.

THE CITY COLIEGE OF NEW YORK, Dept. Of Civil Engrg., Fluid Mechanics Lab., New York, N.Y. 10031

\section{(6185) CHANGES IN INITIATION OF SEDIMENT MOTION DUE} TO FLOW OBSTRUCTION BY PIERS OR SILLS.

(b) Laboratory project.

(c) Dr. Walter Rand, Dept. of Civil Engrg., The City College of New York.

(d) Theoretical and experimental; applied research; master's thesis.

(e) If hydrodynamic forces acting on an erodible bed reach values at which sediment motion is impending, a critical or threshold condition is reached. A structure (a pier or a sill), if placed in the channel will change flow conditions, and erosion will develop. The principles of a sediment transportation mechanics are used, and experiments with sediment beds of impending motion are conducted, to determine the erosion characteristics as functions of the geometry of the structure, and of the degree of obstruction. Using impending motion conditions as a reference, similarity laws for the erosion pattern will be developed.

(g) Preliminary experiments with a rectangular channel indicate that the erosion length downstream of sills is a function of the Frcude number, provided the impending motion conditions are used as reference.

(6186) A FLEXIBLE APPROACH TO THE DESIGN OF STILLING BASINS.

(b) Laboratory project.

(c) Dr. Walter Rand; see (6185) above.

(d) Theoretical, experimental; development, design.

(e) Adopting a generalized concept, a spillwaystilling basin complex can be considered as consisting of an entrance structure, a main basin and an after-basin.

The present knowledge on flow under gates and over drop structures, spillways, sills, steps, and baffles is applied to development of a design method in which the design of each structural element is determined individually to achieve the best possible solution for a particular set of conditions. The method would be an extension of current design methods for hydraulic jump stilling basins applicable to cases such as very low tailwater, intermittent operation, and rocky channels where the current methods do not offer straightforward solutions. Models are used for verification as the design is evolved.

(g) The approach has been used to analyze some of the current design methods. The agreements found and the interpretations of the current methods indicate that further progress is possible. These analyses are published in $(h)$.

(h) Walter Rand, Discussion of "The Hydraulic Design of Stilling Fasins." ASCE Proc. Vol. 8't. Paper 1616, April 1958: and Discussion of 
"Straight Drop Spillway Stilling Basin," Jour. Hydr. Div., ASCE, Vol. 92, No. HY 1, Jan. 1766.

NEW YORK UNIVERSITY, Courant Inst. of Mathematical Sciences, 251 Mercer St., New York, N.Y. 10012

\section{(6572) THEORETICAL PROBLEMS IN HYDRODYNAMICS.}

(b) Office of Naval Research, Mechanics Branch.

(c) Prof. Cathleen S. Morawetz, Courant Inst. of Mathematical Sciences, N.Y.U.

(d) Theoretical basic research.

(e) The research to be carried out will be, as in the past, in the field of the classical hydrodynamics of incompressible fluids, with particular reference to wave motions in gravitating fluids with a free surface.

NEW YORK UNIVERSITY, Dept. of Chemical Engrg., School of Engrg. and Science, University Heights, New York, N.Y. 10453

\section{(6217) SEDIMENTATION OF TWO PROLATE SPHEROIDS IN} CLOSE PROXIMITY.

(b) Laboratory project.

(c) Prof. John Happel, Dept. of Chem. Engrg., N.Y.U.

(d) Experimental; basic research.

(e) Experiments concerned with rate of fall of two prolate spheroids in close proximity were conducted for two special orientations of the spheroidal particles. Rotational effects were separated from the translational effects by using a tin rod connecting the two particles. The drag effect of the connecting rod was obtained by using an analogous system using spheres. This will ultimately enable us to obtain a correction factor for the interaction effect as a function of the distance between the two particles.

These experiments and theoretical treatment apply only in the creeping motion region (Reynolds No. $\approx 10^{-3}$ ).

(f) Completed.

(g) Quantitative agreement with S. Wakiya's theoretical predictions of the drag of two prolate spheroids for the case in which two prolate spheroids are settling one above the other in the direction perpendicular to their axis of symmetry and for the case in which two prolate spheroids are settling end to end in the same horizontal plane in the direction perpendicular to their axis of symmetry.

(h) "Sedimentation of Two Prolate Spheroids in Close Proximity, "M. Hnatow, R. Pfeffer and John Happel, presented at 17th Canadian Chemical Engrg. Conf., Niagara Falls, Ont., Oct. 18th, 1967. Paper now being reviewed for publication by the Canadian Jour. of Chem. Engrg.

NEW YORK UNIVERSITY, School of Engrg. and Science, Dept. of Civil Engrg., Bronx, N.Y. 10453

\section{(6769) TRANSIENT DISSOLVED OXYGEN PROFIIES IN STREAMS.}

(b) U.S. Public Health Service, Div. of Water Supply and Pollution Control.

(c) Dr. William E. Dobbins, New York Univ. (d) Theoretical; basic research; doctoral thesis.

(e) A study of the temporal and spatial variation of biochemical oxygen demand (BOD) and dissolved oxygen (DO) under steady uniform stream flow conditions.

(f) Completed.

(g) Although the pair of second-order partial differential equations which represent the variation of $B O D$ and $D O$ in natural streams are similar to the heat conduction equation, numerical procedures necessary for their solution are considerably different. Procedures for the numerical solution of the BOD and DO equations for steady stream flows were developed.

(h) "Numerical Analysis of BOD and DO Profiles," Robert Dresnack and William E. Dobbins, submitted to Jour. Sanitary Engrg., Proc. ASCE.

(6770) FINITE-DIFFERENCE MODELING OF RIVER ESTUARY POLUUTION.

(b) Federal Water Pollution Control Admin.

(c) Dr. William E. Dobbins, New York Univ.

(d) Theoretical; basic research; doctoral thesis.

(e) A study of the variations in space and time of BOD and DO in streams and estuaries where the hydraulic parameters experience temporal and spatial variations.

(f) Completed.

(g) Through the use of the finite difference models developed, it is shown that the effect of longitudinal dispersion on the BOD and DO profiles in fresh-water streams become more pronounced when the strengths of pollutant sources vary with time.

(h) "Finite-Difference Modelling of River and Estuary Pollution," David Bella and William E. Dobbins, Proc. Natl. Symp. on Estuarine Pollution, Palo Alto, Calif., Aug. 1967 (in press).

NEW YORK UNIVERSITY, Dept. of Meteorology and Oceanography, Bronx, New York 10453

(3120) OFFICE OF NAVAL RESEARCH ATMOSPHERE INTERACTION AIVD WAVE PROJECT.

(b) Geophysics Branch, Office of Naval Research, Dept. of the Navy.

(c) Prof. Gerhard Neumann, Prof. of Oceanography, Prof. Willard J. Pierson, Prof. of Oceanography, and Prof. A.D. Kirwan,Jr., Assoc. Prof. of Oceanography, New York Univ.

(d) Experimental and theoretical; basic and applied research.

(e) Large-scale oceanographic prediction on numerical integration of the primitive hydrodynamic equations with more realistic boundary conditions.

(g) Detailed surveys of the Tropical Atlantic Ocean circulation have shown that the Equatorial Undercurrent exists throughout the year between about $40^{\circ} \mathrm{N}$ and the inner part of the Gulf of Guinea. Significant seasonal changes of its velocity and of its temperature-salinity structure are observed and related to seasonal changes of the prevailing wind system and to the difference Evaporation-Precipitation in the equatorial zone.

(h) "Importance of the Atmospheric Boundary Layer over the Oceans in Synoptic Scale Meteorology," Willard J. Pierson, Jr., Physics of Fluids Supplement, pp. S203-S205, 1967. "Gravity Waves," W.J. Pierson, Jr., Trans. 
Amer. Geophys. U., Vol. 48, No. 2, June 1967. "Mixed Gravity-Rossby Waves in the Ocean," R. Blantord, Deep Sea Res., Vol. 13, pp. $941-$ $961,1966$.

"Recent Results in Turbulence Studies on Air-Sea Interaction," (with G. McNally and S. Adelfang), A.D. Kirwan, Conf. on Marine (Oceanic) Meteorology, 7-9 sept. 1966. (In press).

"Evaluation of the Thrust Anemometer as an Instrument for Turbulence Measurements in the Air-Sea Boundary Layer," A.D. Kirwan, Jr., Conf. on Marine (Oceanic) Meteorology, 7-9, Sept. 1966. (In press).

"A Theory of Turbulent Eddies," A.D. Kirwan, Jr., Physics of Fluids (in press).

"Some Aspects of Boundary Layer Turbulence over Land and Ocean," (With U.O. Lappe and S. Adelfang), A.D. Kirwan, Jr., Physics of Fluids (in press).

"Laboratory and Field Evaluation of a Thrust Anemometer," (with G. McNally and S. Adelfang), A.D. Kirwan, Jr., N.Y.U. GDI Report, TR-66-10, 1966.

"Oceanography of the Tropical Atlantic," G. Neumann, Anais da Academia Brasileria de Ciencias, Vol. 37, pp. 63-82, 1965.

"The Location of the Termination Area of the Equatorial Undercurrent in the Gulf of Guinea Based on Observations during Equalant III," G. Neumann, M.O. Runke, and P. Sund, J. Geophys. Res., Vol. 7, No. 16, pp. 3893-3901, 1966.

"The Equatorial Undercurrent in the Atlantic Ocean, "G. Neumann, Proc. Symp. on Oceanography and Fisheries Resources of the Tropical Atlantic, Abidjan, Oct. 1966. (In press). "Steady State Interactions among Intersecting Trains of Capillary-Gravity Waves," J.B. Sullivan, N.Y.U. GSL Report TR-66-7, 1967. "An Investigation of the Intermediate Salinity Meximum in the Equatorial Atlantic during Equalant I," R.G. Williams, N.Y.U. Rep. TR-66-44, G.S.L.

(5470) U.S. NAVAL OCEANOGRAPHIC OFFICE PACIFIC WAVE HINDCASTING PROJECT.

(b) U.S. Naval Oceanographic Office.

(c) Prof. Willard J. Pierson, Jr., Prof. of Oceanography, N.Y.U.

(d) Experimental and theoretical; basic and applied research.

(e) Development of ways to hindcast waves by spectral techniques on an oceanwide basis. The North Atlantic has been completed, and the North Pacific is nearly completed.

(f) A file of magnetic tape containing wave spectra for every 6 hours at 519 points on the North Atlentic for 15 months is available.

(h) "Computer Based Procedures for Preparing Global Wave Forecasts and Wind Field Analyses Capable of Using Wind Data Obtained by a Spacecraft," W.J. Pierson, L.J. Tick and I. Baer. Preprint, 6th Naval Hydrodynamics Symp., 1966, Vol. II.

(6767) RADAR SATELIITE OCEANOGRAPHY.

(b) National Aeronautics and Space Admin.

(c) Prof. Willard J. Pierson, Jr.; see (5470) above.

(d) Experimental and theoretical; basic and applied research.

(e) Study of ways to use radar scatterometry and altimeter on a sparecraft to determine wave properties at the ocean surface and features of the geoid.

(g) Aircraft surface truth program well under way.
Results of Pacific Hindcasting studv are being extended to the whole earth and ways to incorporate spacecraft data in improved analyses of the surface wind field over the oceans are under development.

(h) "Windwaves and Swell," W.J. Pierson, Oceanography from Space, Woods Hole Oceanog. Inst. Ref. 65-10, pp. 393-402, April 1965.

"Recommendation of the Panel on Wind Waves and Swell, "W.J. Pierson et al., Oceanography from Space, WHOI Ref. No. 65-10, pp. 351-354, April 1965.

"Some Application of Radar Return Data to the Study of Ocean Phenomena," W.J. Pierson, E.B. Schepps, and D.S. Simonett, Proc. Third Goddard Memorial Symp., Amer. Astronaut. Soc., Wash., D.C., pp. 87-137, 1965.

"Measuring Sea State and Estimating Surface Winds from a Polar Orbiting Satellite," R.K. Moore and W.J. Pierson, GSL Rept. 65-11, N.Y.U., 1965.

"Radar Altimetry from a spacecraft and its Potential Applications to Geodesy and Oceanography," W.J. Pierson, Jr., et al., GSI, Rept. TR-67-3, N.Y.U., 1967.

NORTH AMERICAN AVIATION, INC., Space and Information Systems Div., Downey, Calif. 90241

(6447) FORCED RESONANT NONLINEAR OSCILLATIONS OF A LIQUID IN A CYLINDRICAI TANK.

(b) National Aeronautics and Space Admin.

(c) O.D. DiMaggio and R.N. Salzman, North American Rockwell Corp., Space Div., Dept. 190-200, Downey, Calif.

(d) Applied research.

(e) Determine the forced resonant nonlinear oscillations of a liquid in a cylindrical tank.

(f) Completed.

(g) Finite amplitude forced oscillations of a liquid in a circular cylindrical container have been investigated using a perturbation procedure. The wave amplitude, force, moment on tank walls and c.g. displacement at or near resonance have been obtained and the results are presented graphically in nondimensional form. The nonlinearities in the system tend to make the liquid in the planar mode behave as a soft spring for large depths and a hard spring for shallow depths. The nonplanar or rotary slosh mode behaves as a hard spring for all depths.

(h) "Finite Amplitude Liquid Oscillations II. Forced Resonant Oscillations," O.D. DiMaggio and R.N. Salzman, Final Report, SID 65-853-1. "Forced Resonant Nonlinear Oscillation of a Liquid in a Cylindrical Tank, "O.D. DiMaggio and R.N. Salzman, Southeastern Symp. on Missiles and Aerospace Vehicles Sciences, AAS, Vol. II, Dec. 5-7, 1966.
NORTH CAROIINA STATE UNIVERSITY, Dept. of Engrg.

Research, Raleigh, North Carolina 27606

(6257) STREAMFLOW ROUTING.

(b) Office of Water Resources Research.

(c) Dr. Michael Amein, Dept. of Civil Engrg., North Carolina State Univ.

(d) Theoretical and field observation; basic 
research.

(e) Streamflow routing is carried out by the numerical integration of the equations of unsteady flow on a digital computer. Three methods have been tested for this purpose. They are (1) the explicit fixed mesh method, (2) the implicit characteristic methods, and (3) the implicit fixed mesh method.

(g) Computer programs have been prepared and the methods have been applied to artificial channels. The significant features of the various methods have been compared. The methods are being applied to natural channels, and verified by field observations.

(h) "Some Recent Studies on Numerical Flood Routing," M. Amein, Proc. Third Ann. Conf., Amer. Water Resources Assoc.

(6258) EROSION IN ROADSIDE DRAINAGE CHANNELS.

(b) North Carolina Highway Commission.

(c) Dr. Michael Amein; see (6257) above.

(d) Field observation; applied research.

(e) Field inspection of roadside drainage channels is made with the objective of establishing criteria for the prevention of erosion in roadside drainage channels.

(g) Information on the size of drainage area, the length of channel, the slope of the channel, soil type, surface treatment and intensity of erosion is collected. This information will be used to evaluate factors contributing to the erosion of the channels.

(6259) DIFFUSION AND DISPERSION IN POROUS MEDIA.

(b) Office of Water Resources Research.

(c) Prof. Abdel-Aziz I. Kashef, Dept. of Civil Engrg., North Carolina State Univ.

(d) Experimental and theoretical; basic research.

(e) Salt water encroachment is determined for complex conditions such as in a coastal well field. The individual effects are studied and then the combined effects are evaluated.

(g) A practical simple method was determined for finding the pattern of salt water mounds in coastal well fields.

(h) "Salt Water Encroachment in the Eastern North Carolina Coastal Region," A.I. Kashef, Proc., Symp. on Hydrology of the Coastal Waters of North Carolina, Rept. No. 5, Water Resources Research Inst. of the Univ. of North Carolina, Raleigh, N.C., pp. 24-38, May 1967.

"Fresh-Salt Water Interface in Coastal Groundwater Basins," A.I. Kashef, Proc. Eighth Congr., Intl. Assoc. of Hydrogeologists, Istanbul, Turkey, sept. 1967, (in press).

"Two-Dimensional Gravj,ty Flow Systems of Finite Lengths," A.T. Kashef and D. McDonald, Proc. Natl. Symp. on Groundwater Hydrology, Series No. 4, Sponsored by the Amer. Water Resources Assoc., San Francisco, Calif., Nov. 1967, (in press).

"Salt-Water Intrusion in Coastal Well Fields," A.I. Kashef, Proc. Natl. Symp. on Groundwater Hydrology, Series No. 4, Sponsored by the Amer. Water Resources Assoc., San Francisco, Calif., Nov. 1967, (in press).

(6260) EVALUATION OF HIGHWAY DRAINAGE PROBLEMS IN NORTH CAROLTNA.

(b) North Carolina Highway Comission.

(c) Prof. Abdel-Azia I. Kashef; see (6259) above.

(d) Theoretical; applied research.

(e) The efficacy of subdrains and filters is studied for vertical sumps of interstate highways. The configuration of water flow beneath the highway would determine the proper means of subsurface drainage.

NORTH DAKOTA STATE UNIVERSITY, Agricultural Engrg. Dept., Fargo, North Dakota 58103

(4175) WATER INTAKE RATES AND PHYSIOCHEMICAL PROPERTIES OF IRRIGABLE SOILS:

(b) Joint laboratory project between Dept. of Agricultural Engrg. and Dept. of Soils.

(c) Harold Holmen, Asst. Prof. in Agric. Engrg., Agric. Engrg. Dept., North Dakota State Univ.

(d) Experimental; basic research; Master's thesis.

(e) A study of infiltration measurements was made using inflow-outflow methods and double ring infiltrometers.

(f) Completed.

(g) Infiltration rates and aggregate stability were determined under alfalfa, sugarbeets, barley, and sumerfallow cropping.

(5471) CONCRETE DITCH LINING AND PIPE FOR IRRIGATION SYSTEMS.

(b) Laboratory project.

(c) Prof. Harold Holmen; see (4175) above.

(d) Experimental; applied research; Master's thesis.

(e) Soil moisture content and temperature measurements were made in the soil profile adjacent to concrete lined farm irrigation ditches and 12 inch buried concrete pipe during various periods of the past 12 months. The alignment and elevation of the ditch and pipe is also recorded. The study is being conducted to predict the behavior of these conduits under North Dakota conditions.

(g) Pipe and ditch lining have not shown appreciable deterioration after three years of use. Some hairline cracks have appeared between joints spaced 10 feet apart in the concrete lining formed with the slipform machine.

(6114) EVALUATION OF EXTENSIVE IRRIGATION.

(b) Laboratory project.

(c) Prof. Harold Holmen; see (4175) above.

(d) Experimental; applied research.

(e) Various mechanical sprinkler irrigation systems are to be studied under conditions of extensive irrigation.

(g) Data were obtained on one system manufactured by Valmont Industries, Inc., Valley, Nebraska.

(h) "An Initial Investigation of Irrigation," Lawrence A. Anderson, M.S. Thesis, March 1767.

(6115) IRRIGATION WATER USE EVALUATION.

(b) Joint project between Dept. of Agric. Engrg.; and Bureau of Reclamation, U.S. Dept. of Interior.

(c) Earl C. Stegman, Asst. Prof., Agric. Engrg. Dept., North Dakota State Univ.

(d) Experimental; applied research.

(e) This study was initiated to provide data for estimating irrigation water requirements of farm size units in the Garrison Diversion area. Data obtained includes crop water use, field irrigation efficiencies, and data relative to the operational performance of graded border and furrow irrigation methods.

(g) Crop coefficient curves relating evapotranspiration of various growth stages to estimated potential evapotranspiration are being developed for alfalfa, potatoes, sugar beets, and 
durum-wheat. Other findings indicate parameters affecting the operational performance of surface irrigation systems vary widely.

The following projects are summarized in water Resources Research Catalog.

(034W) A FEASIBIIITY STUDY OF A LIVESTOCK WASTE DISPOSAL SYSTEM INVOLVING REUSE OF WATER.

(O35W) A PHYSICAL AIND ECONOMIC ANALYSIS OF ALTERNATE IRRIGATION METHODS IN A SUB-HUMID CLIMATE.

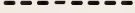

NORTHERN MICHIGAN UNIVERSITY, School of Arts and Sciences, Dept. of Physics, Marquette, Mich. 49885

(6052) A STUDY OF THE ONSET OF WHTTECAPPING WITH INCREASED SURFACE WIND SPEEDS.

(b) Office of Naval Research.

(c) Dr. Edward C. Monahan, Asst. Prof., Dept. of Physics, Northern Mich. Univ.

(d) Field investigation; basic research.

(e) It is the purpose of this study to investigate the onset of whitecapping as a function of wind speed, atmospheric stability, and water temperature, in order to determine whether the concentration of whitecaps increases abruptly with wind speed (in which case it will be of interest to see how this "critical wind speed" varies with atmospheric stability and water temperature) or whether whitecap concentration increases slowly with wind speed. Photographic observations are made from "ships of opportunity" with an automatic photo-system developed for this purpose.

(g) Photo-system field tested, photographic observations made on Great Lakes during past year.

(h) "Lake Superior Studies, Technical Report No. 1, Edward C. Monahan, 30 p., Feb. 1967. (Copies can be obtained from Defense Documentation Center).

(6053) DRIFT-BOTTLE STUDY OF THE SURFACE CURRENTS OF LAKE SUPERIOR.

(b) Laboratory project.

(c) Dr. Edward C. Monahan; see (6052) above.

(d) Field investigation; basic research.

(e) It is the purpose of this study to determine the surface current pattern of Lake Superior as it exists during each of the four seasons of the year.

(g) 162 returns from 1115 drifters released (November 1967).

NORTHERN RESEARCH AND ENGINEERING CORPORATION. 219 Vassar St., Cambridge, Mass. 02139

(6490) FLOW FIELD CALCULATIONS AND ANALYSIS IN WATER TURBINES.

(b) Internally sponsored research.

(c) Dr. Willem Jansen, Staff Engr., Northern Research and Engrg. Corp.

(d) Theoretical studies; applied research.

(e) Studies are made to find velocities and pressure distribution in wheel and draft tube when local losses (induced by separation, cavitation, or friction) are given.

(f) Active (slow).

(g) Performance of draft tube appears to be affected when excessive losses occur at the wheel shroud.
(6491) THE USE OF TWISTED GUIDE VANES TO IMPROVE TURBINE PERFORMANCE.

(b) Internally sponsored research.

(c) Dr. Willem Jansen; see (6490) above.

(d) Theoretical studies; applied research.

(e) Studies are made to determine whether the velocity and pressure distributions in the wheel and draft tube can be improved when the guide vanes are twisted.

(f) Active (slow).

(g) For low flow operation, the draft-tube performance appears to be significantly improved.

NORTH STAR RESEARCH AND DEVELOPMENT INSTITUTE, $310038 \mathrm{th}$ Ave. South, Minneapolis, Minn. 55406

(6088) OPTIMIZATION OF FLOW IN A BLOOD OXYGENATOR.

(b) National Institutes of Health.

(c) Mr. Roy E. Larson, Senior Scientist, North Star Research and Development Inst.

(d) Experimental.

(e) The flow of blood between membranes, membranes and walls, and channels leading to and from a blood oxygenator is measured by a variety of techniques. Design changes are being made and tested. Optimization of the flow will lead to size reduction of the unit.

(g) Blood flow is critical in oxygenation efficiency and can be optimized by appropriate design.

(6089) DEVELOPMENT OF A FLUID CONCENTRATED DISPERSION OF A WATER SOLUBIE POLYMER CAPABLE OF REDUCING THE FRICTION OF WATER UNDER TURBULEIVT CONDITIONS.

(b) Naval Ship Research and Development Ctr.

(c) Mr. Roy E. Larson; see (6088) above.

(d) Experimental; basic research.

(e) The research efforts are directed toward the development of a method for deploying water soluble polymers around ship hulls to reduce the effects of water turbulence. Friction reducing polymers are dispersed in a nonsolvent carrier liquid. The polymer particles are not dissolved, but remain suspended as discrete particles. Fluid slurries containing up to 50 percent of friction-reducing polymers have been utilized.

(g) Prototype ten-percent slurries of various drag reducing polymers were injected into flowing turbulent water streams, and friction reductions as great as 49 percent were noted with mixing times as short as 1.5 seconds. Higher reduction was achieved at somewhat longer times. Fluid slurries containing up to 50 percent of frictionreducing polymers have been tested utilizing an improved injection system. Additional studies are to be carried out in a ten-inch water flow system.

(h) "Development of a Fluid Concentrated Dispersion of a Water Soluble Polymer Capable of Reducing the Friction of Water Under Turbulent Conditions," Ralph E. Forester and Peter S. Francis, Annual Rept., 22 pages, July 1966. Available from Defense Documentation Ctr., Cameron Sta. Alexandria, Va. 22314, (contract Nonr 4827(00)).

NORTHWESTERN UNIVERSITY, The Technological Institute, Evanston, Illinois 60201

(3476) FLOOD WAVE ROUTING.

(b) Northwestern Technological Institute. 
(c) Prof. W.S. Hamilton, Dept. of Civil Engrg., Northwestern Univ.

(d) Theoretical and analytical for doctoral and masters theses.

(e) Finite difference equations based on the method of characteristics have been solved on a digital computer for the case of an irregular channel.

(f) Completed.

(g) Problems of instability have been avoided and reasonable hydrographs obtained.

(h) "Flood Routing in an Irregular Channel," A.G. Fletcher and W.S. Hamilton, Jour. Engrg. Mechanics Div., AsCE, Vol. 93, No. EM 3, June 1967.

(3799) FORCES ON SUBMERGED BODIES IN UNSTEADY MOTION.

(b) National Science Foundation and Northwestern Technological Institute.

(c) Prof. W.S. Hamilton or Prof. I.F. Mockros, Dept. of Civil Engrg., Northwestern Univ.

(d) Theoretical and experimental; basic research; M.S. and Ph.D. theses.

(e) Investigation of the forces on solid spheres accelerating along a rectilinear path through incompressible viscous fluids. The investigation includes ( 1 ) experiments that will be compared with numerical evaluation of theoretical linear solutions, (2) experiments on the general case of large motions, and (3) a study of the effect of the velocity pattern on added mass.

(g) The complex theoretical solution for the creeping motion case has been put into graphical form. This theoretical solution has been used to study the dispersion of particles in a turbulent fluid, the dynamic response of single and two degree of freedom spherical systems in a fluid, the dynamic stability of discrete spherical systems in a fluid, and the limit of validity of Stokes flow theory for an accelerating sphere.

(h) "Motion of Discrete Particles in a Turbulent Fluid," A.T. Hjelmfelt and L.F. Mockros, Appl. Scientific Research, Vol. 16, pp. 149161, 1966.

"Dynamic Response of a Restrained Sphere in a Fluid," A.T. Fjelmfelt, J.F. Carney, I.F. Mockros and S.L. Lee, J. Engrg. Mechanics Div. ASCE, Vol. 93, 4l-56, 1967.

"Dynamic Response of a Two Degree of Freedom Spherical system in a Fluid," J.F. Carney, I.F. Mockros and S.L. Lee, Ingenieur-Archiv, Vol. 35, pp. 351-361, 1967.

"Dynamic Stability of Discrete Spherical Structural Systems in a Fluid Media," J.F. Carney, I.F. Mockros and S.I. Iee, IngenieurArichiv., Vol. 36, 1967

"The Stokes Flow Behavior of an Accelerating Sphere," A.T. Hjelmfelt and I.F. Mockros, Jour. Engrg. Mechanics Div. ASCE, Vol. 93, pp. 87102, 1967.

(5472) DYNAMICS OF THE CIRCULATION IN THE GREAT LAKES.

(b) National Science Foundation.

(c) Asst. Prof. G.E. Birchfield, Engrg. Sciences, Northwestern Univ.

(d) Two year grant, theoretical study; primarily basic research.

(e) Develop mathematical models of wind generated motions in large lakes. Use with recent observational studies to construct model of general circulation.

(g) Some simple analytical models completed. Some observational studies completed. (n) "Wind-driven Currents in a Long Rotating Channel, "G.E. Birchfield, Tellus, Vol. 19, 1967.

"Horizontal Transport in a Rotating Basin of Parabolic Depth Profile," G.E. Birchfield, Jour. Geophys. Res. (In press).

"A Case Study of Coastal Currents in Lake Michigan," G.E. Birchfield and D. Davidson, Proc. 10th Conf. on Great Lakes Res., Toronto Univ., 1967. (In press).

(5474) EXTRACORPOREAI CIRCULATION.

(b) National Heart Institute.

(c) Prof. Lyle F. Mockros, Technological Inst., Northwestern Univ.

(d) Experimental; basic and applied research; Ph.D. thesis.

(e) Investigation of the geometry and fluid dynamies favorable to the circulation of blood outside the animal body. Purpose is to obtain design criteria for heart lung machines.

(g) Experiments indicate a relationship between rate of red cell lysis and rate of mechanical energy dissipation. Low pressure induces red cell lysis. Oxygen and carbon dioxide transfer to blood flowing in gas permeable tubes has to be investigated theoretically and experimentally for both straight and helically coiled tubes.

(n) "Hydrodynamic Hemolysis in Extracorporeal Machines," K.A. Yarborough and I.F. Mockros, Thoracic and Cardiovascular Surgery, Vol. 52 pp. 550-557, 1966.

"Oxygen Transfer to Blood Flowing in Round Tubes," M.H. Weissman and L.F. Mockros, Jour. Engrg. Mechanics Div., ASCE, Vol. 93, pp. 225244,1767 .

(5475) NOISE SPECTRA GENERATED BY FLOW OF A LIQUTD THROUGH VARIOUS ORIFICES.

(b) Bio-Medical Engrg. Center, Northwestern Technological Inst.

(c) Prof. W.S. Hamilton, Dept. of Civil Engrg., Northwestern Univ.

(d) Experimental; applied research; thesis.

(e) Purpose is to identify characteristic flow generated noise in an abnormal heart. The noise spectra generated by steady and pulsating flow through rigid and flexible orifices is being investigated. Water is pumped through aortic valves of sheep's hearts. The flaps are partly sew together to restrict the opening.

(f) Completed.

(g) Equipment and technique for testing sheep hearts were developed to a satisfactory stage. Because of the natural variation of individual hearts, correlation between noise spectra and amount of stenosis was not possible.

(h) "Noise Spectra from Flow Through Aortic Valves," Max Spindler and W.S. Hamilton, ASCE Engrg. Mech. Div. Specialty Conf., Washington, D. C., Oct. 1966.

(5714) YIETD OF A NON-LINEAR ELASTIC AQUIFER.

(b) Northwestern Technological Inst.

(c) Prof. W.s. Hamilton; see (5475) above.

(d) Analytical and experimental; for M.S. and Ph.D. theses.

(e) The drawdown of an aquifer in which the permeability and yield coefficient were functions of drawdown was determined by solving finite difference equations and by testing a sponge-rubber model. The initial condition was one of constant artesian pressure and the 
pumping rate was constant.

(f) Completed.

(g) For variable permeability, the drawdown near the well at a chosen time was greater than for the case when a constant average value was used. The drawdown at a large radius was less. Because of property variations with time and radius, experimental results from the model could not be compared with those calculated.

(h) "Unsteady Flow in an Artesian Aquifer in Which Elasticity and Permeability Depend on Drawdown," Idris Ahmed Mahmoud, Ph.D. Thesis, Feb. 1966.

"Pumping Tests on a Model of a Non-Linear Artesian Aquifer," N.A. Tomaro, M.S. Thesis, June 1967.

UNIVERSITY OF NOTRE DAME, Dept. of Civil Engrg., Notre Dame, Indiana 46556

\section{(6766) HEMOLYSIS INDUCED BY EXTRACORPOREAL} HEMODYNAMICS.

(b) National Science Foundation.

(c) Dr. Keith A. Yarborough.

(d) Experimental and analytical; M.S. and Ph.D. theses.

(e) Breakage of red blood cells in cattle due to shearing and negative pressure stresses.

(h) One M.S. thesis; one Ph.D. thesis.

UNIVERSITY OF NOTRE DAME, Department of Mechanical Engrg., Notre Dame, Indiana 46556

(6101) IAMINAR FIOW SURROUNDING A ROTATING FINITE DISK AT HIGH REYNOLDS NUMBERS.

(c) Prof. K.T. Yang and Asst. Prof. S.T. MeComas.

(e) The detailed flow behavior in the region $r \rightarrow a$, where $a$ is the radius of the rotating disk, is studied analytically by a near waketype of analysis in the region of small $(r-a)$, and by a similarity solution for $r \rightarrow \infty$. Results are now being obtained on the computer.

(6102) ANALYTICAI STUDIES OF FREE TURBULENT SHEAR FLOWS BY THE USE OF A NEW THEORY.

(c) Asst. Prof. V.W. Nee.

(e) The incompressible free turbulent shear flows, particularly those of the turbulent jets and wakes are studied analytically by a new theory developed by the investigator.

(g) The present theory provides a more rational basis for prediction of turbulent effects in such problems as the turbulent diffusion in the atmosphere by explosive release from a rocket.

(6103) ANALYTICAI STUDIES OF THE APPIICATION OF A GENERAL PHENOMENOLOGICAL THEORY FOR WALI TURBULENCE.

(c) Asst. Prof. V.W. Nee; Prof. K.T. Yang.

(e) The non-similar two-dimensional incompressible quasi-parallel turbulent shear flows, particularly those of the turbulent boundary layer with and without pressure gradient, inlet flow and flows with changing roughness are studied analytically by means of a new phenomenological theory with the objective to arrive at a general program in which solutions of a large class of complicated problems with arbitrary pressure gradient and roughness distribution can be obtained in a simple way.

(6104) LAMINAR AND TURBULENT FLOW AT THE ENTRANCE SECTION OF A TWO-DIMENSIONAL CHANNEL.

(c) Asst. Prof. V.W. Nee.

(e) By the introduction of the displacement thickness, the continuity equation can be integrated to give a simple relationship between the central stream velocity and the displacement thickness. Another relation can be obtained by the consideration of the development of the laminar boundary layer. Solutions can then be obtained by solving a set of two algebraic equations.

(6765) NUMERICAL STUDIES OF TIME-DEPENDENT VISCOUS FIOWS.

(c) Assoc. Prof. A.A. Szewczyk.

(e) Numerical solutions of time dependent twodimensional flow of a viscous incompressible fluid over stationary and rotating cylinders are obtained from finite difference approximations to the Navier-Stokes equations. Computer experiments are being performed to determine the influence of such factors as the basic differencing method used, mesh sizing, boundary conditions and stability and convergence criteria used to obtain the solution. Presently attempts are being made at obtaining solutions to a three-dimensional problem, namely, that of an inpulsively started rotating sphere in an infinite medium.

(6768) TURBULENT SHEAR FLOWS OF A NON-NEWTONIAN FLUID.

(c) Asst. Prof. V.W. Nee; Assoc. Prof. A.A. Szewczyk.

(e) A gross effective viscosity is defined as an unknown function which is the sum of the turbulent eddy viscosity and the non-Newtonian viscosity. A secondary differential equation will be introduced to control the variation of the gross viscosity by the consideration of the turbulent mechanism as well as the non-Newtonian behavior of the fluid.

OAK RIDGE NATIONAL LABORATORY, Oak Ridge, Tenn. 37830

(6568) HEAT AND MOMENTUM TRANSFER AT AND NEAR THE WALL FOR TURBULENT FLOW OF WATER IN A PIPE.

(b) Laboratory project.

(c) Dr. J.J. Keyes, Jr., Oak Ridge National Lab., P.O. Box Y, Oak Ridge.

(d) Experimental; applied research.

(e) This project is directed toward determination of the spectral characteristics of turbulenceinduced fluctuations in temperature and in heat-transfer rate at the inside wall of a pipe, and correlation of these fluctuations with velocity fluctuations near the pipe wall. The study is intended to delineate a potential source of thermal fatigue effects in reactor fuel elements and in heat exchangers.

(f) Inactive; to be resumed.

(g) Flush-mounted hot-film sensors were used to determine power spectral density, characteristic frequency, amplitude density, and intensity of heat-transfer fluctuations at a pipe wall for Reynolds numbers from 11,000 to 170,000 . Studies of the relationship between the heat transfer and velocity fluctuations in the vicinity of the wall indicated that a signficant correlation exists. Evidences of a 
periodic component were observed in the auto correlation curves of velocity fluctuation in the vicinity of the wall for a Reynolds number of 52,000 .

(h) "A Study of Wall-Turbulence Phenomena Using Hot-Film Sensors," R.A. Armistead, Jr., and J.J. Keys, Jr., ASME Paper No. 67-WA/HT-11 (to be published in Jour. Heat Transfer. "Hot-Film Sensor for the Study of WallTurbulence Phenomena," R.A. Armistead, Jr., and J.J. Keys, Jr. (to be published in The Review of Scientific Instruments).

Note: The above papers are based on a Doctoral Dissertation submitted to the Carnegie Inst. of Tech. by R.A. Armistead, Jr., April 1967.

(6569) HYDROMAGNETIC STABILITY OF JET-DRIVEN, VORTEXIIKE FLOW.

(b) Laboratory project.

(c) Dr.J.J. Keyes, Jr.; see (6568) above.

(d) Theoretical and experimental; applied research.

(e) The feasibility of utilizing jet-driven, vortex-like flow for separation of fuel and coolant in the plasma-core nuclear reactor concept depends on the development of a means for minimizing turbulence and secondary flows. This project is examining, both analytically and experimentally, the stabilizing effect of magnetic fields on vortexlike flows for this application. In order to simplify the initial phase of the work, incompressibility has been assumed in the analyses, and an aqueous electrolyte has been employed in the experimentation to simulate a plasma from the electrical point of view.

(f) Completed.

(g) Theory. It was found that a conducting, vortex-like flow between coaxial, cylindrical walls can be stabilized against breakdown of laminar motion by means of an axially applied magnetic field of sufficient strength. The effect of radial flow was included in the analysis. A related problem, that of hydromagnetic stability of a tangential-jet injection boundary layer over a concave wall, was also solved; again, the axial magnetic field was found to exert a stabilizing influence. Experiment. The tangential Reynolds number at transition to instability in a jet-driven vortex tube operating with concentrated aqueous ammonium chloride as the conducting fluid was increased (by up to a factor of 15) when a 75,000 gauss axial magnetic field was applied to give a Hartmann number of 172. The data were correlated in terms of parameters appropriate to the boundary layer. Decrease in the ratio of inward radial velocity to tangential velocity in the end-wall boundary layers was also effected by the magnetic field. These results are based on analysis of motion pictures of dye injected into the boundary layers along the concave wall and along the end walls.

(h) "Hydromagnetic Stability of Vortex-Like Flows, " T.S. Chang and W.K. Sartory, USAEC Rept. ORNL-3707, Oak Ridge Natl. Lab., Jan. 1966. "Transition from Stationary to Oscillatory Modes of Instability in Magnetohydrodynamic Couette Flow," T.S. Chang and W.K. Sartory, USAEC Rept. ORNL TM-1404, Oak Ridge Natl. Lab., June 1966

"Hydromagnetic Stabilization of Jet-Driven Vortex Flow," J.J. Keyes, Jr., T.S. Chang, and W.K. Sartory, USAEC Rept. ORNL-TM-1876, Oak Ridge Natl. Lab., Oct. 1967

(Above reports available from Clearinghouse for Federal Scientific and Technical Information, Natl. Bureau of Standards, U.S. Dept. of Commerce, Springfield, Va.) "An Experimental Hydromagnetic Investigation of Jet-Driven, Confined Vortex-Type Flows," Developments in Theoretical and Appl. Mechanics Vol. 2, pp. 277-296, Pergamon Press, 1965 (Edited by W.A. Shaw).

"An Exact Analysis of Magnetohydrodynamic Stability of Nondissipative Couette Flow, T.S. Chang, Quart. Jour. of Mech. and Appl. Math. Vol. XVIII, No. 4, pp. 491-500, 1365.

"Hydromagnetic Stability of Dissipative Flow Between Rotating Permeable Cylinders - Part 1. Stationary Critical Modes, "T.S. Chang and W.K. Sartory, Jour. Fluid Mech., Vol. 27, No. 1, pp. 65-79, 1967.

"On the Onset of Instability by Oscillatory Modes in Hydromagnetic Couette Flow," T.S. Chang and W.K. Sartory, Proc. Roy. Soc. (London), to be published.

(6570) INTERACTION OF A VORTEX WITH A STATIONARY SURFACE .

(b) Laboratory project.

(c) Dr. George J. Kidd, Jr., Oak Ridge Natl. Lab., P.O. Box Y, Oak Ridge.

(d) Experimental and theoretical basic research for doctoral dissertation.

(e) Experimental studies of the flow field produced by a vortex in contact with a stationary surface are being made using a tellurium dye flow visualization technique. Numerical solutions to the equations of motion are being sought for both the complete partial differential equations and a set of total differential equations obtained by means of a similarity transformation. This work is being done to provide a better understanding of the flow in the plasma core vortex nuclear reactor.

(g) The experiments have shown that the flow possesses similarity with respect to the radial and tangential Reynold numbers but does not possess similarity with respect to radial position. Solutions have been obtained to the similarity equations for a limited range of tangential Reynolds numbers.

(h) "Confined Vortex Flow Near a Stationary Disk, Theory and Experiment," George J. Kidd, Jr., USAEC Rept. ORNL TM-1387 (Thesis), Oak Ridge Natl. Lab., April 1966.

(6571) EFHECT OF TURBULENCE PROMOTERS ON HEAT AND MASS TRANSFER.

(b) Office of Saline Water, U.S. Dept. of Interior.

(c) Dr. David G. Thomas, Oak Ridge Natl. Lab., P.O. Box Y, Oak Ridge.

(d) Theoretical and experimental; applied research.

(e) The resistance of a laminar boundary layer to the transfer of mass or heat from a flowing stream to a conduit wall can be reduced if the boundary layer can be disturbed or mixed. One means of promoting this mixing is by turbulence promoters either attached to the wall or separated by a small distance. The promoters can be "tuned" so that vortices shed from the promoter have a maximum effect on the boundary layer.

(g) In mass transfer studies with permeable membranes, detached turbulence promoters increased the transmission of material through the membrance by as much as $60 \%$. Similar 
improvements have been found in the heat transfer of condensing systems.

(h) "Forced Convection Mass Transfer: Part III. Increased Mass Transfer from a Flat Plate Caused by the Wake from Cylinders Located Near the Edge of the Boundary Layer," D.G. Thomas, A.I.Ch.E. Jour, Vol. 12, p. 124, 1966. "Enhancement of Film Condensation Heat Transfer Rates on Vertical Tubes by Vertical Wires," D.G. Thomas, Ind. Eng. Chem. Fundamentals, Vol. 6, p. 97, 1967.

"Enhancement of Forced Convection Heat Transfer Coefficient Using Detached Turbulence

Promoters," D.G. Thomas, Ind. Eng. Chem., Process Design and Development, Vol. 6, p. 385, 1967.

"Forced Convection Mass Transfer, Part IV. Increased Mass Transfer in an Aqueous Medium Caused by Detached Cylindrical Turbulence Promoters in a Rectangular Channel, "J.S. Watson and D.G. Thomas, A.I.Ch.E. Jour., Vol. 13, p. 676, 1967 .

"Reduction of Concentration Polarization in Hyperfiltration by Detached Turbulence Promoters," D.G. Thomas and J.S. Watson, submitted to Ind. Eng. Chem.

"Experiments on Concentration Gradient Driven Convection," D.G. Thomas and R.A. Armistead, submitted to Science.

"A study of Detached Turbulence Promoters for Increasing Mass Transfer Rates in Aqueous Channel Flow, "J.S. Watson, Ph.D. Dissertation submitted to Univ. of Tennessee.

OHIO AGRICULTURAL RESEARCH AND DEVELOPMENT CENTER, Dept. of Agricultural Engrg., Wooster, Ohio 44691

(5033) DRAINAGE INVESTIGATIONS FOR AGRICULTURAL LANDS. (See also Water Resources Research Catalog, Vol. 2, Nos. 4.0162, 4.0163; 4.0164).

(b) Ohio Agric. Research and Dev. Ctr., in cooperation with Agricultural Research Service, U.S. Dept. Agric.

(c) Dr. G.0. Schwab, 2073 Neil Ave., Onio State Univ., Columbus, Ohio 43210.

(d) Field investigation; applied research.

(e) Tile flow, surface runoff, water table levels and crop yields are measured to evaluate various types of drainage systems and to develop improved engineering design criteria.

(g) Sixteen years of tile flow data have been evaluated and probability curves developed which show that tile spacing, time of year (precipitation), and cropping practices were the most important variables.

(h) "Crop Response from Tile and Surface Drainage," G.O. Schwab, G.S. Taylor, J.L. Fouss, and E. Stibbe, Soil Sci. Soc. Amer. Proc. Vol. 30, No. 5, pp. 634-637, 1966.

"Effect of Depth, Spacing, and Cropping Practices on Tile Discharge," James R. Hoover, M.S. Thesis, Ohio State Univ., June 1967. "Tile Flow and Surface Runoff for Drainage Systems with Corn and Grass Cover," G.0. Schwat and J.L. Fouss, to be published in ASAE Trans., Paper No. 66-703, 1966.

"Effect of Tile Depth, Spacing, and Cropping Practices on Drain Discharge," J.R. Hoover and G.0. Schwat, ASAE Paper No. 67-722, 1367. "Transient Solutions for Drainage of Sloping Land, "Harendra S. Chauhan, Ph.D. Dissertation, Orio State Univ., Sept. 1367.
"Analysis of Momentum in Overland Flow," T. Clark Lyons, M.S. Thesis, Ohio State Univ., Sept. 1367.

(5294) HYDROLOGIC CHARACTERIZATION OF SMALI WATER SHEDS. (See also Water Resources Research Catalog, Vol. 2, No. 2.0946).

(b) Laboratory project.

(c) Dr. R. Bruce Curry, Assoc. Prof., Dept. of Agric. Engrg., Ohio Agric. Res, and Dev. Ctr.

(d) Theoretical; basic research.

(e) To investigate the use of mathematical, electrical, and hydraulic models to study hydrologic phencmena of watersheds. (1) To investigate statistical models as a means of identifying and evaluating the pertinent variables in the runoff process. (2) To use these variables together with a mathematical model to predict behavior of a small watershed.

The behavior of small watersheds will be investigated to identify the pertinent variables using the statistical theory. These variables will be combined with the underlying physical and biological phenomena to develop a mathematical model which will permit statements to be made about probable watershed behavior. Data from existing watersheds and runoff plots will be used to test the validity of the model.

(g) Theoretical developments indicate that the nonlinearity of the runoff process makes it unlikely that the phenomenological structure of nonequilibrium thermodynamics can be applied directly to runoff prediction. A mathematical model was obtained for an impermeable watershed surface in terms of a two-parameter stochastic process.

(h) "An Analytic Approach to Overland Flow as Influenced by Stochastic Surface Impressed Forces, "George E. Merva, Ph.D. Dissertation, Ohio State Univ., June 1967.

"Theoretical Consideration of Surface Influence on Watershed Runoff." George E. Merva. Ross D. Brazee, Glenn O. Schwab and R. Bruce Curry, to be presented at Amer. Soc. Agric. Engrs. Mtg., 1968.

(O36W) FLOW OF COLIOIDAL SUSPENSIONS IN POROUS MEDIA. (Formerly No. 5293).

For summary, see Water Resources Research Cata.log, Vol. 2, No. 2.0946.

(03TW) HYDROLOGIC INVESTIGATIONS OF SMALL WATERSHEDS IN OHIO. (Formerly No. 5716).

For summary, see Water Resources Research Catalog, Vol. 2, No. 2.0934.

(O38W) ELECTROKINETIC REMOVAL OF COLIOIDS FROM SUSPENSION. (Formerly No. 5672). For summary, see Water Resources Research Catalog, Vol. 2, No. 5.0826.

OHIO STATE UNIVERSITY, Department of Agronomy, Columbus, Ohio 43210

(5176) SOIL CHARACTERISTICS AND SUBSURFACE DRAINAGE.

(b) Ohio Agricultural Experiment Station.

(c) Prof. George S. Taylor, Dept. of Agronomy, Ohio State Univ.

(d) Experimental investigation, applied research.

(e) Numerical analysis solutions of soil moisture flow problems in subsurface drainage are made with digital computers. Steady-state and 
transient analyses are studied for various parameters of size, depth, and spacing of tile and ditch drains and of soil hydraulic conductivity. Similar studies were initiated in 1965 to analyze water table drawdown around a pumped well. Hillside seepage problems are also evaluated. Field evaluations of hydraulic conductivity are made with the aid of lysimeter-type installations. The principal objective is to interrelate the above factors in rational design of subsurface drainage systems.

(g) Characteristics of water flow into tile drains have been studied for layered soils. An analysis of hillside seepage into open ditches was made. Agreement between analytical and numerical analysis techniques was established.

(h) "Computer Solutions for the Drainage of Sloping Land," J.N. Luthin and G.S. Taylor, Trans. Amer. Soc. Agric. Engr., Vol. 9, No. 4, pp. 546-549, 1966.

"Field Evaluation of Tile Drain Filters in Humid Region Soil," George S. Taylor and Truman Goins, Ohio Agrid. Res, and Dev. Ctr. Research Circular 154, 1967.

THE OHIO STATE UNIVERSITY, Water Resources Center, Columbus, Ohio 43210

(6734) WELL DRAWDOWN IN UNCONFINED AQUIFERS UNDER NONSTEADY CONDITIONS.

(b) Office of Water Resources Research, U.S. Dept. of Interior.

(c) Prof. George S. Taylor, Dept. of Agronomy, Ohio State Univ.

(d) Experimental investigations; applied research.

(e) This study is a numerical analysis study of drawdown around wells in unconfined porous media for transient conditions. The simultaneous flow of water in both the saturated and unsaturated flow regions is evaluated for various pumping rates and boundary conditions. The entire operation is programmed on an IBM 7094 computer. Fulfillment of the project objectives will yield computer techniques for handling complicated water flow problems and additional information on infllow into wells.

(g) Drawdown in the near vicinity of wells has been evaluated for porous media which differ in permeability and specific yield. The feasibility of utilizing computer operation for rapid analysis of complex flow problems has been demonstrated.

(h) A research article entitled, "Procedures for Studying Non-Steady Drawdown in a Pumped Aquifer," is being prepared for publication.

OREGON STATE UNIVERSITY, Engineering Experiment Station, Corvallis, Ore. 97331

(5787) FACTORS INFLUENCING STREAM TEMPERATURES.

(b) Fed. Water Pollution Control Admin.

(c) Assoc. Prof. John Seaders, Dept. of Civil Engrg., Oregon State Univ.

(d) Experimental; field investigation; M.S. thesis.

(e) To-determine evaporation from streams as affected by standing waves, white water, and relative movement of air and water mass. The field investigation is intended to develop an evaporation pan which can be used to estimate evaporation from streams without the necessity of knowing regional correction constants.

(g) Recent work with turbid water indicated that turbidity does not affect the heat absorption rates of a flowing stream.

(h) On present research, two papers are in preparation for submission for publication.

(6774) EFFICIENCY TESTS OF SUBDRAIN PIPE.

(b) Oregon State Highway Dept.

(c) Prof. P.C. Klingeman, Prof. L.S. Slotta, Dept. of Civil Engrg., Oregon State Univ.

(d) Laboratory investigation; applied research.

(e) Laboratory comparison of (1) relative efficiencies of various types of subdrain pipes to draw down the surrounding water; (2) relative tendencies for perforated subdrains to admit the adjacent filter material.

(f) Suspended.

(g) Successive saturation and drying of filter bed permits a progressive increase in subdrain capacity.

(6775) PULP MILL WASTE DISPOSAI IN MARINE ENVIRONMENT.

(b) Fed. Water Pollution Control Admin.

(c) Prof. F.J. Burgess, Head, Dept. of Civil Engrg. Oregon State Univ.

(d) Experimental; applied research for Ph.D. thesis.

(e) The initial phase of the project has been completed. It was a biological study of the effect of pulp mill wastes on marine life. The second phase of the study is just starting and will be an airphoto analysis of the dispersion of wastes from an ocean outfall. It will include the application of photogrammetry and airphoto interpretation for estimating dispersion patterns, diffusion coefficients, waste concentrations, and near shore currents.

(6776) CLIMBING FILM FLOW IN ANNULAR DUCTS.

(b) National Science Foundation.

(c) James G. Knudsen, Prof. and Asst. Dean of Engrg., Oregon State Univ..

(d) Experimental and theoretical.

(e) The project is an experimental and theoretical study of the mechanics of climbing film flow in annular ducts. Measurements of shear stresses and heat transfer coefficients are being made.

(g) "Momentum Transfer in Climbing Film Flow in Annular Duct," Duk H. Kim and James G. Knudsen, AIChE Jour., Vol. 13, No. 2, p. 326-334, March 1967.

(6777) MOMENTUM AND HEAT TRANSFER CHARACTERISTICS OF LIQUID-LIQUID DISPERSION.

(b) National Science Foundation.

(c) Prof. James G. Knudsen; see (6776) above.

(d) Experimental and theoretical.

(e) Determination of the characteristics of turbulent flow of liquid-liquid dispersions with respect to effective viscosity, heat transfer coeficients, and drop size distributions.

(g) "Turbulent Flow of Unstable Liquid-Liquid Dispersions: Drop Sizes and Velocity Distributions," J.P. Ward and J.G. Knudsen, AIChE Jour., Vol. 13, No. 2, pp. 356-365, March 1967.

(6778) STRATIFIED RESERVOIR CURRENTS.

(b) Fed. Water Pollution Control Admin., U.S. Dept. of the Interior.

(c) Assoc. Prof. I.S. Slotta, Dept. of Civil Engrg., Oregon State Univ.

(d) Theoretical, experimental; basic, applied research; M.S. and Ph.D. theses. 
(e) Means by which the quality of water withdrawn from a reservoir can be controlled and best quality maintained by selective withdrawal are to be determined. The investigation consists of a model study and a mathematical study via computer simulation to verify model behavior.

The computer simulation is an extension to the multifluid situation of the MAC method (Marker and Cell) developed by F.H. Harlow, et. al. of the Los Alamos Scientific Laboratory. The model study is directed to the influence of entering or initial water mass on current discharge patterns in the pool and final discharge from the reservoir:

(g) Progress toward computer simulation of problems involving the motion of viscous, incompressible fluids with multidensities and a free surface is continuing. Model studies indicate the importance of submerged topography on flow patterns of density stratified reservoirs by blocking effects.

(h) "Supplement to Part IV of the MAC Method" as a part of "Digital Simulation of NonHomogeneous Fluid Flow," L.S. Slotta, J.D. Hwang, et. al. Northwest Simulation Council Meeting, Oregon State Univ., Corvallis, Ore., 13 pp., January 12, 1968.

(6779) SAND PUMPING EFFICIENCY OF JET-APPARATUS.

(b) Laboratory project.

(c) Assoc. Prof. L.S. Slotta; see (6778).

(d) Basic research; M.S. thesis.

(e) Tests of a water jet apparatus, applicable for dredging sand and also for increasing pressure in suction pipes for pump cavitation preventation, are being conducted. Design data for an efficient apparatus are to be obtained.

(6780) ROTATING CUTTERHEAD EFFICIENCY ON A HYDRAULTC SUCTION DREDGE.

(b) Electric Steel Company, Portland Oregon.

(c) Assoc. Prof. L.S. Slotta; see (6778).

(d) Experimental; applied research.

(e) Flow visulization studies to be used for evaluating rotating dredge cutterhead performance.

PEC RESEARCH ASSOCIATES, Inc., P.0. Box 3435, Boulder, Colorado 80302

(6573) CHARACTERISTICS OF CONFINED DENSE PHASE FLOW OF GRANULAR SOLIDS DRIVEN BY COMPRESSED AIR.

(b) U.S. Army Research Office, (now discontinued); present work is laboratory project.

(c) Donald G. Burkhard, Research Director, PEC Research Associates.

(d) Experimental; plus theoretical analysis.

(e) Condensed granular solids (sands of various sizes) were forced through pipes ranging in diameter from one inch to four inches for distances of 100 feet to 1200 feet. Propelling force: compressed air. Purpose: to determine feasibility of using compressed air to transport heavy granular solids over short distances and to arrive at theoretical formulae permitting design of such systems.

(f) Experimental work discontinued and incomplete since not all conveyance possibilities were investigated. Theoretical work still active.

(g) Efficiency of transport is low but compressed air may serve as an effective means of driving condensed granular solids through pipes over short distances.

THE PENNSYLVANIA STATE UNIVERSITY, Hydraulics Laboratory, Dept. of Civil Engrg., University Park, Penna. 1680?

Inquiries concerning the following projects should be addressed to Prof. Sam Shulits, Head, Hydraulics Lab., 212 Sackett Bldg., The Pennsylvania State Univ., except as noted below.

\section{(5181A) ROUGHNESS COEFFICIENTS OF COBBLE-STREWN STREAMS.}

(b) Laboratory project.

(d) Experimental; applied research; doctoral thesis.

(e) To provide a quantitative means of determining Manning's " $n$ " or the coefficient $K$ in $V=K R$ " $2 / 3$ $\mathrm{s}^{1 / 2}$ in cobble-strewn streams, particularly for use in the slope-area method of computing flood discharge. In a lucite-walled tilting flume, $1 \mathrm{ft}$. wide, $1.5 \mathrm{ft}$. deep, and $25 \mathrm{ft}$. long, roughness patterns were created with small wooden cubes, 1.09 inches on a side. Maximum discharge approximately 2 cfs. A few cylindrical roughness-elements were used.

(f) Completed.

(g) Definite progress has been made towards the ultimate goal of providing the engineer a simple but quantitative means of determining the Manning roughness coefficients for boulderstrewn streams. Criteria relating Reynolds number, Manning $\mathrm{n}$ and the Schlichting roughness parameter are valid throughout a wide range of flume flow rates and depths--from high flows corresponding to flood discharge conditions where the roughness elements are submerged down to low flows with roughnesses protruding through the water surface. The criteria are valid throughout the sub-critical flow regime and the lower range of supercritical flow. A proposed depth-prediction technique is accurate for random distributions of uniform and non-uniform size cubical roughness elements. Thus two major requirements for application to a boulder-strewn stream, a random distribution and varying boulder height, have been met. The prediction technique is within the accuracy required for hydraulic calculations for stream work according to tests in a flume containing three roughness shapes arranged in symmetric patterns. The effect of shape, the third major requirement to be met for application to a boulder-strewn stream, requires further investigation, though so far the intimation is that shape is not of paramount importance. A suggested prediction procedure is outlined to evaluate Manning's $\mathrm{n}$ and compute the fllood discharge in natural streams using the slopearea method. There is much evidence that application of the Prandt-von Karmon concepts of turbulent flow are often not warranted.

(h) "Flume Study of Boulder-Strewn Streams under Flood Discharge Conditions Using Geometric Roughness Elements in Transverse Rows," L.J. Mathers, Doctoral thesis. Available as dissertion No. 67-11, 215 from University microfilms, Ann Arbor, Michigan.

(5181B) ROUGHNESS COEFFICIENTS OF COBBLE-STREWN-EFFECT COBBIE SHAPE.

(b) Laboratory project. 
(d) Experimental; applied research; doctoral thesis.

(e) Same as in (5181A), except for the use of cylinders and rectangular parallelepipeds with various orientations to explore effect of shape, block density and block orientation.

(f) Data being analyzed.

(6207) TRANSITIONS IN SUPERCRITICAL FLOW.

(b) Pennsylvania Dept. of Forests and Waters.

(c) Assoc. Prof. F.L. Blue, Jr., Civil Engrg. Dept., 212 Sackett Bldg., The Penn. State Univ.

(d) Experimental; applied research; design.

(e) Transitions of three different shapes are being tested for Froude numbers varying from 1.2 to 3.0, representing test flows at 0.59 to $4.47 \mathrm{cfs}$. Each transition connects an upstream rectangular channel with a downstream trapezoidal channel, all three parts lying on one straight center line and having constant and continuous invert slopes. One transition shape has warped walls. The other two have plane walls: one with vertical surfaces above sloping surfaces, the other with sloping surfaces above vertical surfaces. Each shape is being tested for three approach-flow depths and for three transition lengths for each flow depth.

(g) Flow depths in and downstream from the transition are being measured.

(6208) BEDLOAD FORMULAS.

(b) Soil and Water Conservation Research Div., U.S. Dept. Agric., Agric. Research Service.

(d) Analytical; applied research.

(e) An attempt to resolve the dilemma of the many existing bedload formulas and an inquiry into their limitations and serviceability. The formulas are being programmed in Fortran IV for the IBM 360, Model 67 and also being plotted with a subroutine to facilitate comparison.

\section{PENNSYLVANIA STATE UNIVERSITY, Ordnance Research}

Laboratory, P.0. Box 30, University Park, Penna. 16801

(2832) MEASUREMENT OF FORCES AND PRESSURES ON A MODEL IN A WATER TUNNEL.

(b) Laboratory project sponsored by the Naval Ordance Systems Command.

(c) Mr. George B. Gurney, Ordnance Research Lab.

(d) Experimental and developmental.

(e) The problem concerns the measurement of thrust, torque body forces, and pressures on various hydrodynamic bodies. Measurements are made on bodies over a range of velocities up to $60 \mathrm{ft} /$ sec and under pressure simulating fully developed cavitating flows.

(g) Strain çaged force balances are used to sense body forces. These balances are capable of completely submerged operation. A Planar Motion Mechanism is available for determining dynamic stability derivatives required in the equation of motion of submerged bodies. The capability of measuring unsteady thrust is also available.

(h) "The Garfield Thomas Water Tunnel," A.F. Lehman, ORL Unclassified External Rept. NOrd 16577-56, Sept. 30, 1959.

( 3807 ) INVESTIGATION OF THE CAVITATION CHARACTERISTICS OF A FEW SIMPLE LIQUIDS.

(b) Laboratory project sponsored by National Aero, and Space Admin. (c) Dr. J. William Holl, Ordnance Research Lab.

(d) Experimental, analytical; basic research.

(e) To investigate experimentally the cavitation characteristics of a few simple (as regards to vapor pressure and handling) liquids under conditions occurring in space and aircraft pumping machinery, and analyze the results so that a reliable basis for theory applicable to these conditions can be formulated. A small high speed water tunnel having test section velocities of 340 feet per second. pressure to 1000 pounds per square inch temperatures to 300 degrees $F$., has been constructed and has been in operation since April, 1962.

(h) "Thermodynamic Effects on Desinent Cavitation in Water," Alain L. Kornhauser, Master's Thesis, Dept. of Aerospace Engrg.. Penna. State Univ., June 1967.

"Cavitation Hysteresis," J. William Holl and A.L. Treaster, Trans. ASME, Jour. Basic Engrg., March 1966, pp. 199-212.

"Description of Film-Cavitation Hysteresis," J. William Holl, reprinted from Cavitation in Fluid Machinery, 1365. Amer. Soc. Mechanical Engrs., 345 E. 47 th St., New York, N.Y. 10017.

(4181) DETERMINATION OF EFFECT OF TUNNEL BOUNDARIES ON THE FORCES ACTING ON A MODEL.

(b) Laboratory project sponsored by Naval ordnance Systems Command.

(c) Mr. Robert E. Henderson, Ordnance Research Lab.

(d) Theoretical and experimental.

(e) Investigation of the errors introduced b; the physical boundaries of tunnel walls on the measured forces on large models. The investigation covers both the axially symmetric case and when the models are at low angles of attack. Establishing the means for correcting these errors is also a part of this investigation.

(g) A method has been developed for the prediction of errors in drag caused by water-tunnel wall deviations. It is shown that small deviations in contour can cause a significant error in model drag measurements. Tunnel wall interference effects on model pitching moment have been investigated and a correction procedure established for models of low attack angle and diameters up to $1 / 3$ tunnel diameter.

(h) "Tunnel Wall Interference Effects on the Drag and Pitching Moment of an Axisymmetric Eody," Ph.D. Thesis, Dec. 1363, Dept. of Engrg, Mechanics, Penna. State Univ.

(4677) THE INVESTIGATION OF TWO-DIMENSIONAL UNSTEADY CAVITY FLOWS ABOUT FIXED SYMMETRIC ELUFF BODIES.

(b) Laboratory project sponsored by Naval Ordnance Systems Command.

(c) Dr. J. William Holl, Ordnance Research Lab., Penna. State Univ.

(d) Experimental and theoretical.

(e) An investigation of the wake region behind supercavitating, two-dimensional wedges at zero degrees angle of attack is in progress with the purpose of determining the wake characteristics, in particular the strouhal number as a function of Reynolds number. cavitation number and wedge apex angle.

(f) Completed.

(h) "Effects of Cavitation on Periodic Wakes Behind Symmetric Wedges," J.O. Young and J. William Holl, Trans. ASME, Jour. of Easic Engrg.. March 1966, pp. 163-176. 
(5106) INVESTIGATION OF TENSIONS IN IIQUIDS.

(b) Laboratory project sponsored by Natl. Aero. and Space Admin.

(c) Dr. J. William Holl; see (4677) above.

(d) Experimental and theoretical.

(e) Investigation of liquid tensions for a variety of liquids under a range of conditions employing a non-flow apparatus. Results will be compared to those obtained in a flowing system.

(f) Discontinued.

(h) "The Behavior of Tap Water Under Dynamic Tensile Stressing in a Non-Flow System," Samuel J. Brown, Jr., Master's Thesis, Dept. of Aerospace Engrg., Penna. State Univ., June 1967.

(5107) INVESTIGATION OF THE KUTTA CONDITION IN UNSTEADY FLOW.

(b) Laboratory project sponsored by Bureau of Naval Weapons.

(c) Dr. Maurice Sevik, Ordnance Research Lab.

(d) Experimental, theoretical; basic research.

(e) The validity of the Kutta-Joukowski criterion is being investigated for the prediction of control-surface hinge moments in steady flow, or instantaneous forces on rapidly oscillating air and hydrofoils.

(5590) INVESTIGATION OF SHED WING VORTICES AND THEIR DECAY.

(b) Laboratory project sponsored by the Army Research Office, Durham, North Carolina.

(c) Dr. Barnes W. McCormick, Jr., Ordnance Research Lab.

(d) Experimental, analytical; basic research.

(e) The vortex sheet shed by a wind tunnel mounted, semi-span lifting wing has been investigated at various angles of attack. and free-stream velocities. The vortex core has been studied by mapping the downstream flow field at distances up to 20 chord lengths. Tangential velocities of vortices have been determined by integrating the vorticity through the vortex core. The local vorticity is measured by a pitchless, cruciform vane which rotates in rotational flow. Rotational speeds of 40,000 rpm have been measured. Similar investigations will be conducted by mounting the vortex probe behind the wing of a full scale flight test airplane. Qualitative characters of shed vortices have been studied by flying an airplane adjacent to a large tuft grid and photographing the motion of the tufts as the vortex moves across the grid.

(g) It is believed that after completion of the investigations it will be possible to predict the vortex geometry of an arbitrary aircraft as a function of the airplane configuration and distances downstream.

(h) "The Effect of Wing Geometry and Lower Surface Eoundary Layer on the Rolled-up Tip Vortex," T.I. Grow, Master's thesis, June 1967, Dept. of Aerospace Engrg., Penna. State Univ.

"A Solution of the Vortex Breakdown Phenomena in a Trailing Line Vortex," A. Logan, Dec. 1966, Master's thesis, Dept. of Aerospace Engrg. , Penna. State Univ.

"Decay of Trailing Vortices," H. Sherrieb. June 1967, Master's thesis, Dept. of Aerospace Engrg., Penna. State Univ.

"Effects of a Porous Wing Tip on an Aircraft Trailing Vortex," H. Smith, Dec. 1767. Master's thesis, Dept. of Aerospace Engrg. Penna. State Univ.
(5592) EXPERIMENTAL INVESTIGATION OF SECONDARY FLOW IN AXIAL FLOW INDUCERS.

(b) Laboratory project sponsored by Natl. Aero. and Space Admin.

(c) Dr. George F. Wislicenus and Dr. B. Lakshminarayana, Dept. of Aeronautical Engrg. Penna. State Univ.

(d) Experimental and theoretical.

(e) A three-foot diameter model of an axial flow inducer for a pump was built and has been tested with air, using smoke for direct observation of secondary motions in long and narrow vane passages. In adition, approximate measurements of the velocity distribution at inlet and discharge have been made to obtain at least a qualitative picture of the fluid motions under the predominant influence of viscous fluid friction. At present a single rotating helical surface is being tested in the same set-up in order to obtain basic data about the flow along the inducer blades.

(5593) INVESTIGATION OF LAMINAR BOUNDARY IAYER AND TRANSITION IN THE VICINITY AND EETWEEN SUCTION SLOTS.

(b) Laboratory project sponsored by the U.S. Naval Ordnance Systems Command.

(c) Mr. J.F. McMahon, Ordnance Research Lab.

(d) Experimental; computational; and applied research.

(e) Calculation and measurement of flow and stability in vicinity of suction slot; optimization of slot form for maximum stability; conducted in attempt to determine reason for extreme sensitivity of boundary layer stabilization by slot suction.

(g) Two-dimensional flow successfully calculated indicates unsteadiness; measurements being conducted to correlate observed frequencies with calculated ones.

(5595) TURBULENCE MEASUREMENTS IN THE VISCOUS SUBLAYER.

(b) Laboratory project sponsored by the U.S. Naval Ordnance Systems Command.

(c) Dr. John Lumley, Ordnance Research Lab., Penna. State Univ.

(d) Experimental; basic research.

(e) Space-time correlations of fluctuating velocities are measured in the viscous sublayer of a flow of glycerine in a closed-loop constant temperature facility, by means of hot-film anemometers.

(f) Suspended.

(g) Correlations of streamwise fluctuating velocities were measured and published (see Bakewell, Lumley in "Physics of Fluids," Sept. 1967). Future work will involve velocities normal to the wall.

(5596) THEORETICAL INVESTIGATION OF TUREULENT FLOW IN NON-NEWTONIAN MEDIA.

(b) Office of Naval Research, Fluid Dynamics Franch.

(c) Dr. Kirtan Singh, Mathematics Dept., St. Mary's Univ., Halifax, Nova Scotia, Canada.

(d) Theoretical; basic research.

(e) By an extension of the Heisenberg method. the form of the turbulent energy spectrum was calculated in the homogeneous turbulent fluw of a second order fluid.

(f) Completed.

(g) A report has been issued which is obtainable from Dr. J.L. Lumley, Dept. of Aeruspace Engrg. The Penna. State Univ.. 153-E Hammond Fldg. 
(6553) INSTRUMENTATION FOR TURBULENCE MEA.SUREMENT IN LIQUIDS.

(b) Laboratory project sponsored by U.S. Naval Ordnance Systems Command.

(c) Dr. John Lumley, Ordnance Research Lab.

(d) Experimental development.

(e) Development of improved instrumentation for the measurement of instantaneous fluctuating velocities in liquids.

(g) Thin film probes utilizing self-heated oxide semi-conductor sensing elements have been fabricated and tested; present work emphasizes improved fabrication techniques for greater stability.

(6554) COHERENT DOPPLER SCATTERING FROM DILUTIE SOLUTIONS OF HIGH MOLECULAR WEIGHT LINEAR POLYMERS.

(b) Laboratory project sponsored jointly by U.S. Naval Ordnance Systems Command and Office of Naval Research, Fluid Dynamics Branch.

(c) Dr. John Iumley; see (6553) above.

(d) Experimental; basic research.

(e) Instantaneous fluctuating velocities are measured in dilute solutions of high molecular weight linear polymers in turbulent flow by means of the doppler shift in scattered coherent light. This is done in an attempt to understand the structure of turbulence in such solutions, in order to explain the mechanism by which such solutions reduce skin friction.

(g) Mean velocity profiles have been measured; present work emphasizes improved line width and signal-to-noise ratio.

(6555) AXI-SYMMETRIC IAMINAR BOUNDARY LAYERS.

(b) Laboratory project sponsored by the U.S. Naval Ordnance Systems Command.

(c) Dr. Hendrik Tennekes, Ordnance Research Lab.

(d) Theoretical; basic research.

(e) Calculations will be made of the growth and stability of laminar boundary layers on a body of revolution.

(6556) ASYMPTOTIC TURBULENT BOUNDARY LAYERS.

(b) Laboratory project sponsored by the U.S. Naval Ordnance Systems Command.

(c) Dr. Hendrick Tennekes; see (6555) above.

(d) Theoretical; basic research.

(e) An examination by the use of asymptotic matching techniques of the structure of the turbulent boundary layer and its dependence on Reynolds number.

(g) The dependence on Reynolds number of the slope in the logarithmic region has been successfully predicted.

(6557) CHARACTERISTIC VIBRATIONS AND ACOUSTIC RADIATION FROM SHELLS OF ARBITRARY SHAPE.

(b) Laboratory project sponsored by Bureau of Naval Weapons.

(c) Dr. Maurice Sevik, Ordnance Research Lab., Penna. State Univ.

(d) Experimental and theoretical.

(e) A study of propuisor blade vibrations.

(g) Propulsor blades have complicated geometries and hence vibrate in modes which are difficult to predict. The characteristic vibrations of such blades are being investigated by means of numerical methods. The effects of the liquid surrounding the blades are also included. The computer results will be verified experimentally.
(6558) MIXING OF GASES IN LIQUID JETS.

(b) Laboratory project sponsored by Bureau of Naval Weapons.

(c) Dr. Maurice Sevik; see (6557) above.

(d) Experimental, theoretical; basic research.

(e) A study of the bubble formation process and resulting acoustic radiation.

(g) When a gaseous jet mixes with a turbulent liquid jet, acoustic radiation is observed. In this study the characteristic bubble size is being determined in terms of the characteristics of the liquid and the gas.

UNIVERSITY OF PENNSYLVANIA, Towne School of Civil and Mechanical Engrg., Philadelphia, Penna. 13104

(6469) TURBULENT FLOW OF NON-NEWTONIAN SUSPENSIONS AND FLUIDS IN PIPES.

(b) National Science Foundation.

(c) Prof. Iraj Zandi, Towne School of Civil and Mech. Engrg., Univ. of Pennsylvania.

(d) Theoretical and experimental.

(e) This investigation is concerned with the study of turbulent flow of non-Newtonian fluids or suspensions in pipes. The primary objective is to formulate analytically and verify experimentally, a method that enables the engineer to predict the head loss of turbulent flow of non-Newtonian fluids or suspensions in a smooth circular tube from the knowledge of the independent variables.

The key to evaluation of head loss in this analysis is the ability to predict, accurately, the velocity profile across the pipe cross section. This equation of velocity profile in combination with the equation of material balance will provide necessary tools for prediction of head loss.

(h) "Governing Equation for Multiphase Flow in Pipes," I. Zandi and G. Govatos, Annual Mtg.. Hydraulics Div., ASCE, Madison, Wisc., Aug. 1966.

"Decreased Head Losses in Conduits," I. Zandi, Jour. Amer. Water Works Assoc., Vol. 59, 2, pp. 213-226, Feb. 1967.

"Visco-Elastic Fluid Flow in the Entrance of a Tube," I. Zandi and A.R. Razaghi, Jour. Engrg. Mechanics Div., ASCE, Vol. 93, EM4, pp. 117-137, Aug. 1767. Also presented to Environmental Engrg. Conf. ASCE, Dallas, Tex., Reprint No. 455, Feb. 6, 1967.

"Turbulent Flow of Non-Newtonian Suspensions

in Pipes," V.R.K. Murthy and I. Zandi, accepted for publication in Jour. Engrg. Mechanics Div., ASCE.

"A Theory of Viscous Interaction in Turbulent Fields, "I. Znadi and V.R.K. Murthy, presented to 38th Ann. Conf., Soc. of Rheology, Washington, D. C., Oct. 25, 1967.

(6470) SOLID WASTE P.PELINE.

(b) U.S. Public Health Service.

(c) Iraj Zandi; see (6469) above.

(d) Both theoretical and experimental.

(e) to investigate the feasibility of applying slurry flow technology (two phase flow, solidfluid) to collection and removal of solid wastes of the community.

The ultimate goal of the project is to combine all types of waste, solid and liquid, and collect them through piping networks under pressure. The slurry may then enter a burner 
in wet condition and the end product may be electricity and fresh water.

The study is progressing along three distinct lines which hopefully at its conclusion will enable the evaluation of the overall performance of solid waste pipeline.

(1) Technological aspects: It appears that the addition of solid waste to water will produce a condition that the carrying medium exhibits non-Newtonian properties. The hydrodynamic behavior of these complex systems are studied.

(2) Generation of solid waste: Design of solid waste pipeline requires the knowledge of continuous generation of solid waste. This information is non-existent. An investigation, sample measurements and a general survey is underway to establish the hourly rate of waste production.

(3) To make the comparison of the present system of removal and disposal of solid waste with the pipe removal of solid waste more realistic, a section of the City of Philadelphia for which the cost of the present system is known was selected. Design of pipeline network for the same section is underway. The study will hopefully enable a comparison of the economics of these systems.

(h) "Solid Waste Pipeline," Iraj Zandi, Solid Waste Res. and Dev., Engrg. Foundation Research Conf., Milwaukee, Wisc., July 1967 , preprint D-4.

"Heterogeneous Solid Transportation in Pipelines," I. Zandi and G. Govatos, Jour. Hydraulics Div., ASCE, Vol. 93, No. HY3, May 1967, p. 145.

"Pressure Drop Suppressant Action of Particulate Matters," I. Zandi, Multi-Phase Flow Session, Annual Mtg. Hydraulics Div., ASCE, Madison, Wisc., Aug. 1966.

"Pipeline Transport of Solid Waste," I. Zandi and J. Hayden, presented to Transportation Engrg. Conf., ASCE, San Diego, Calif., Feb. 19-23, 1968.

UNIVERSITY OF PITTSBURGH, Chemical Engrg. Dept., Pittsburgh, Penna. 15213

\section{(6083) DAMPING OF TURBUTENCE IN FLEXIBLE TUBES BY} USE OF FOAM DAMPENERS.

(b) Laboratory project.

(c) Dr. George E. Klinzing, Chem. Engrg. Dept., Univ. of Pittsburgh.

(d) Experimental and theoretical investigation on basic and applied research for master and doctoral thesis projects.

(e) Polyurethane foam annulus applied to flexible silastic tubing for reduction of energy losses in transporting liquids.

(g) Current data shows as much as a $30 \%$ reduction in drag in reference to rigid wall tubing on the system analyzed. Similar results obtained by use behind artificial heat valve.

(h) M.S. Thesis, J. Marmo, Univ. of Pittsburgh. M.S. Thesis, R. Kubovcik, Univ. of Pittsburgh.

PURDUE UNIVERSITY, Dept. of Agricultural Engrg., Lafayette, Indiana 47907

(3490) INVESTIGATION OF FLOW CHARACTERISTICS IN DRAIN TILF AND THE RELATIONSHTP OF THESE FLOW
CHARACTERISTICS TO SEDIMENTATION.

(b) Agricultural Experiment Sta., Purdue Univ.

(c) Dr. I.F. Huggins, Agricultural Engrg. Dept., Purdue Univ.

(d) Experimental; basic research.

(e) A 60-foot model drain capable of recirculating sediment-laden flow has been constructed. Drain slopes at which incipient deposition occurs are being investigated.

(f) Completed.

(g) The percentage of sediment (100 to 400 microns) in the total discharge at which incipient deposition occurred appears to be a simple function of the slope of the drain. Particle shape (very angular to smooth) and size (100 to 400 microns) did not have an observable effect on the slope attained.

(h) "Sediment Transport Capacity of Circular Drains," C.T. Haan, L.F. Huggins and E.J. Monke, Trans. Amer. Soc. Agric. Engr., Vol. 9, No. 6, 1966.

(3808) DEVELOPMENT AND REFINEMENT OF METHODS FOR ESTIMATING FIEID RUNOFF AND SOIL LOSS.

(b) Soil and water Conservation Research Div., U.S. Dept. of Agric. (See Agric. Research Service, Corn Belt Branch, Project No. 4274); and Agric. Experiment Sta., Purdue Univ.

(c) Mr. Walter H. Wischmeier, ARS-SWC, Agric. Engrg. Dept., Purdue Univ.

(d) Experimental; development.

(e) The relationship of numerous rainstorm characteristics, topographic features, soil characteristics and surface conditions to field runoff and soil erosion are being evaluated from plot data obtained under natural and/or simulated rainfall.

(g) The relations of physical and chemical properties of a soil to infiltration and to its capacity to resist detachment and transport by rainfall and runoff were intensively studied in multiple-regression analyses. Twenty-two soil and surface-condition variables were needed to account for $95 \%$ of the variance in soil losses from identical rains applied to 110 widely distributed fallow plots. An equation was derived which, for medium-textured soils, expresses the universal erosion equation's numerical soil-erodibility equation as a function of physical and chemical properties of the soil.

(h) "Relation of Soil Properties to its Erodibility," W.H. Wischmeier and J.V. Mannering, Agronomy Abstracts, 1967.

(4182) THE MECHANICS OF EROSION BY RATNFALI AND RUNOFF.

(b) Soil and Water Conservation Research Div., Agricultural Research Service, U.S. Dept. of Agric. (See Agric. Research Serv., Corn Belt Branch, Project No. 4275), and Agric. Experiment Sta., Purdue Univ.

(c) Dr. L.D. Meyer, ARS-SWC, Agric. Engrg. Dept., Purdue Univ.

(d) Experimental; basic research.

(e) The influence of slope steepness, slope length, particle size, particle shape, and mulches on erosion and overland flow are being studied in the laboratory. This research is providing mathematical relationships governing soil erosion by water and the mechanics of the processes involved.

(g) Recent studies have shown that small rates of surface mulch are very effective in reducing soil erosion. Erosion rates were closely correlated to overland flow velocities. 
(h) "Effect of Particle Roughness on Soil Erosion by Surface Runoff," G.D. Bubenzer, L.D. Meyer and E.J. Monke, Trans. Amer. Soc. Agric. Engr., Vol. 9(4), 1966.

\section{(4183) SUBSURFACE DRAINAGE OF BOUNT SIIT LOAM.}

(b) Agricultural Expmt. Sta., Purdue Univ.

(c) Dr. E.J. Monke, Agric. Engrg. Dept., Purdue Univ.

(d) Field investigation; applied research.

(e) Various spacings between parallel subsurface drains are under investigation to determine their effectiveness in water removal and crop response. Continuous records of tile discharge are being made and crop yields are determined at harvest time.

(f) Completed.

(g) Both yields and stands were usually best for the 25 foot tile spacing. Tile flow response occurred quickly after the beginning of a runoff producing storm. Peak rates were highest for tile at a 100 foot spacing due primarily to higher antecedent moisture conditions.

(h) "Field Study of Subsurface Drainage on a Slowly Permeable Soil," E.J. Monke, L.F. Huggins, H.M. Galloway, and G.R. Foster, Amer. Soc. Agric. Engr. Paper No. 66-705, 1966.

(5810) TREATMENT OF WATER FROM SMALI RESERVOIRS FOR DOMESTIC CONSUMPTION.

(b) Agricultural Expmt. Sta., Purdue Univ.

(c) Dr. E.J. Monke; see (4183) above.

(d) Experimental; applied and basic research.

(e) Objectives are to study electrophoretic control as an aid for filtration of raw water supplies and to investigate methods for reducing the adverse effects of aquatic weed residues on water treatment processes and water quality.

(g) The filter zeta potential approached an isoelectric condition quickly when the $\mathrm{pH}$ level of the colloidal-laden inflow was around 7.0. Filter efficiency was also much greater than at any of the other pH levels investigated. Evidence was presented that bacteria at the filter surface were positively charged.

(h) "Electrokinetic Measurements of Colloidal-Laden Flow Through a Sand Column "E.J. Monke and D.M. Edwards, Proc. Ind. Acad. of Sci. 76, 1967. "Electrokinetic Studies of the Slow Sand Filtration Process," D.M. Edwards and E.J. Monke, Jour Amer. Water Works Assoc., Oct. 1967.

\section{ANALYSIS OF RAINULATOR INEILTRATION DATA.}

(b) Soil and Water Conservation Research Div., Agric. Research Service, U.S. Dept. Agric.; and Agricultural Expmt. Sta., Purdue Univ.

(c) Mr. G.R. Foster, ARS-SWC, Agric. Engrg. Dept. Purdue Univ.

(d) Experimental and field investigation; applied research.

(e) Overland flow field data from short erosion plots under simulated rainfall are being used to determine a relationship between the rate of surface runoff and depth and to correlate this relationship as well as depressional storage to surface roughness. Infiltration data will be separated from the runoff hydrographs and used to obtain parameters for infiltration equations.

(g) A kinematic overland flow model with a constant Darcy-Weisbach coefficient of friction adequately described overland flow on short, rough slopes. Micro-relief increased recession time of surface runoff by reducing the infiltration area. In cases of variable infiltration rates, retention storage altered the shape of the hydrograph. Retention storage could not be accounted for by a simple time translation of the hydrograph.

(h) "Analysis of Overland Flow on Short Erosion Plots," G.R. Foster, M.S. thesis, Purdue Univ., 1967.

(6093) MATHEMATICAL SIMULATION OF HYDROLOGIC EVENTS ON UNGAGED WATERSHEDS.

See also Water Resources Catalog, Vol. 2, No. 2.0505 .

(b) Office of Water Resources Research; and Agricultural Expmt. Sta., Purdue Univ.

(c) Dr. L.F. Huggins, Agric. Engrg. Dept., Purdue Univ.

(d) Experimental and theoretical; basic and applied research.

(e) Relationships describing the dynamics of the various components of the runoff process for small elemental areas within a watershed will be developed after which fundamental hydrodynamic equations will be utilized to integrate the spatially varied, time dependent outputs from all of the many elements within the watershed to obtain a composite runoff hydrograph.

(g) Preliminary comparisons between hydrographs predicted by the mathematical model and observed hydrographs from very small (two acre) watersheds have been made.

(h) "The Mathematical Simulation of the Hydrology of Small Watersheds," L.F. Huggins and E.J. Monke, Tech. Rept. No. 1, Water Resources Research Center, Purdue Univ., 1966.

"The Application of Simulation Techniques to the Design of Hydrologic Structures," L.F. Huggins and E.J. Monke, ASAE Paper No. 66-724, 1766.

(O4OW) EFFECT OF PESTICIDE RESIDUES AND OTHER ORGANOTOXICANTS ON THE QUALITY OF SURFACE AND GROUND WATER RESOURCES. (Formerly No. 5811)

For summary, see Water Resources Catalog, Vol. 2, No. 5.0383 .

PURDUE UNIVERSITY, Department of Agronomy, Lafayette, Indiana 47907.

(4679) FLOW LAWS FOR THE MOVEMENT OF WATER IN SOIL.

(b) Laboratory project.

(c) Dr. Dale Swartzendruber, Dept. of Agronomy, Purdue Univ.

(d) Experimental and theoretical; basic research, for doctoral thesis.

(e) The validity of basic equations for water relationships in porous media and soils, such as Buckingham's capillary potential function, Darcy's proportionality, and the BuckinghamDarcy equation, is being tested in the laboratory under various conditions.

(g) For horizontal steady-state unsaturated water flow through various mixtures of sand. silt. and kaolinite, improved velocity-gradient measurements have been obtained at single locations from internally positioned tensiometers in such a manner as to eliminate hysteresis. The resulting plots of flow velocity against suction gradient at given suction are essentially proportional, thus validating the Buckingham-Darcy equation for these materials. Similar measurements on 
water-saturated systems, obtained rapidly with sensitive flow meters and differential manometers, also verified Darcian proportionality for mixtures of sand, silt, kaolinite or illite, but the presence of a few percent bentonite in a mixture caused the velocitygradient curves to be sigmoidal in shape. One of the bentonite mixtures was also capable of inducing spontaneously a movement of water against a pressure difference as high as $17 \mathrm{~cm}$. of water. A theoretical study of stratified soils indicated that a least permeable nonDarcian stratum is more effective in limiting the flow through a water-saturated soil profile than is the Darcian counterpart.

(h) "Non-Darcian Movement of Soil Water," D. Swartzendruber, Proc. Intl. Soil Water Symp., Czechoslovak Scientific-Technical Soc. for Water Management, Prague, Vol. II, 207-221, 1967.

"Velocity-Gradient Relationships for SteadyState Flow of Water in Partially Saturated Soil," T.C. Olson, Ph.D. Thesis, Purdue Univ., 1967.

"Velocity-Gradient Relationships for WaterSaturated Porous Media," D.A. Russell, Ph.D. Thesis, Purdue Univ., 1968.

(6166) ELECTRICAL EFFECTS ON WATER INFILTRATION INTO SOILS.

(b) Office of Water Resources Research, U.S. Dept. of the Interior.

(c) Dr. Dale Swartzendruber; see (4679) above.

(d) Experimental and theoretical; basic research.

(e) Electrical streaming potentials developed as a result of water flow through porous materials are being measured for both saturated and unsaturated porous media. Effort will be made both to determine the effects of these potentials on the water infiltration process, and to describe these effects theoretically. Information will be sought on the possibility of using electrical energy to affect the infiltration process.

(g) Difficulty has been encountered in defining and controlling the conditions which will yield a constant electrical streaming potential for steady-state seepage flow of water. Transient changes in the streaming potential appear to be characteristic rather than exceptional. Nevertheless, for flow in water-saturated porous media, a rapid measuring technique has been devised which appears to enable the determination of streaming potential in response to changes in hydraulic head difference. The relationship between these two quantities appears to be one of reasonable proportionality, for the fritted glass and a mixture of sand and kaolinite studied thus far.

(O39W) CHARACTERIZATION OF THE RATE OF WATER INFILTRATION INTO SOIL. (Formerly No. 5788)

For summary, see Water Resources Research Catalog, Vol. 2, No. 2.0509.

(h) "The Applicability of Darcy's Law," D. Swartzendruber, Soil Sci. Soc. Amer., Proc., Vol. 32, Jan-Feb: 1968.

PURDUE UNIVERSITY, School of Chemical Engineering, Lafayette, Indiana 47907

(6781) FLOW REGIMES IN POROUS MEDIA. (b) National Science Foundation.

(c) R.A. Greenkorn, Head, School of Chemical Engrg., Purdue Univ.

(d) Experimental; basic, M.S. and Ph.D. thesis.

(e) Displacement of a fluid in a porous medium by a second fluid was studied in porous medium models and Hele-Shaw cells of greater porosity. Viscous flow, gravity flow, and the phenomenon of "fingering" were investigated, and the results tested against present theory.

(h) "Gravity and Viscous Induced Instabilities in Porous Media Displacements," J.E. Varnon, M.S. thesis, available from Purdue Univ. Library.

(6782) FLOW IN HETEROGENEOUS POROUS MEDIA.

(b) Petroleum Research Fund.

(c) R.A. Greenkorn; see (6781) above.

(d) Experimental, theoretical; basic; M.S. thesis.

(e) A study of the phenomenological, statistical, and mechanistic behaviol of multiphase flow in heterogeneous porous media by measurement on Hele-Shaw and other physical models, and by theoretical calculations on mathematical models.

(h) "Two Fluid Radial Flow in Heterogeneous HeleShaw Models," P.R. Reed, M.S. thesis, available from Purdue Univ. Library.

"A Study of Permeability and Dispersion Phenomena in an Anisotropic Porous Media," E.G. Lenth, M.S. thesis, available from Purdue Univ. Library.

(6783) DISPERSION DURING FLOW IN HETEROGENEOUS POROUS MEDIA.

(b) Dept. of Health, Education, and Welfare.

(c) R.A. Greenkorn; see (6781) above.

(d) Experimental, theoretical; basic; M.S. thesis.

(e) This is a study of the theory and measurement of dispersion in heterogeneous anisotropic porous media. Present statistical models will be extended to include heterogeneity and isotropy. The models will be tested by measurements of dispersion coefficients in linear and radial flow.

(h) "Dispersion During Flow in Linear Heterogeneous Porous Media," R.C. Pleshek, M.S. thesis, available from Purdue Univ. Library.

(6784) SINGLE DROP BREAKUP IN DEVELOPING TURBULENT PIPE FLOW.

(b) Purdue University.

(c) Prof. D.P. Kessler, Assoc. Prof., School of Chemical Engrg., Purdue Univ.

(d) Experimental; basic; M.S. thesis.

(e) The study of the breakup of a single drop in two phase liquid-liquid developing turbulent pipe flow was made and correlated with drop size, drop velocity, distance traveled, and interfacial tension.

(h) "Single Drop Breakup in Developing Turbulent Pipe Flow, "J.E. Swartz, M.S. thesis, available from Purude Univ. Library.

(6785) INTERFACIAL AREA IN TWO PHASE FLOW IN PIPES UNDER CONTINUOUS TURBULENT CONDITIONS.

(b) Purdue University.

(c) J.H. Rushton, Prof., School of Chemical Engrg.. Purdue Univ.

(d) Experimental; basic; M.S. and Ph.D. theses.

(e) A method of producing high interfacial area between two liquids under continuous flow in pipes was investigated.

(g) "Interfacial Area in Pipes Under Continuous Turbulent Flow Conditions, "R.F. Henry, M.S. 
During high floods the river tends to straighten its course.

PURDUE UNIVERSITY, School of Civil Engrg., Lafayette, Indiana 47907

\section{(2841) HYDROLOGY OF SMALI WATERSHEDS IN INDIANA.}

(b) Purdue Water Resources Research Center (since June 1965); State Highway Dept. of Indiana and Indiana State Flood Control and Water Resources Commission (prior to June 1965).

(c) Dr. J.W. Delleur, Hydromechanics Lab., School of Civil Engr., Purdue Univ.

(d) Analysis and field investigation; Ph.D. thesis.

(e) The purpose of the research is to study the hydrology of watersheds less than 300 square miles throughout the State of Indiana to improve the existing methods for estimating the runoff from these watersheds.

(g) Peak discharges were analyzed statistically and a correlation was obtained between the 25 year peak discharge and geomorphological characteristics of the watersheds. Peak discharges for other frequencies may also be obtained. A synthetic design hydrograph was developed on the basis of the instantaneous hydrograph theory. The hydrograph is determined by two parameters which have been related statistically to geomorphological characteristics of the watershed. The theory of overland flow has been investigated from a hydrodymamics standpoint. This study is being extended to include a larger number of watersheds and a larger number of hydrographs. Analysis is being made using linear system theory.

(h) "Design Hydrographs for Small Watersheds in Indiana," I.P. Wu, ASCE, Jour. Hydraulics Div., Vol. 88, 1963.

"Determination of Peak Discharge and Design Hydrographs for Small Watersheds in Indiana," I.P. Wu, J.W. Delleur, and M.H. Diskin, Indiana Flood Control and Water Resources Commission, Ind. State Highway Commission, and Purdue Univ., 106 pp., Oct. 1964. Obtainable from Joint Highway Research Project, School of Civil Engrg., Purdue Univ., at the cost of $\$ 1$ per copy.

(4191) MEANDER FLOOD PLAIN MODEL.

(b) Laboratory project.

(c) Dr. G.H. Toebes, Hydromechanics Lab., School of Civil Engrg., Purdue Univ.

(d) Analytical and experimental research for Ph.D. thesis.

(e) A meander flood plain model is being constructed to replace $5^{\circ} \times 30^{\prime}$ model used in first phase of project. Also data collection equipment is being improved to obtain greatly increased efficiency. Experimental and analytical study of three-dimensional flow patterns in meandering channel with adjacent flood plains. Collection of energy loss data and study of distribution of shear stress and scour. Work applicable to channel protection and flood routing questions, and to problems involving flood plain utilization. Statistical studies of meander geometry are being made for White River system in Indiana.

(g) Energy losses for the geometry considered are larger than the sum of the separate losses in the meandering channel and the flood plains. During overbank flows helicoidal currents are (h) "The Flow in a Meander-Flood Plain Geometry, " A.A. Sooky, Ph.D. thesis, 1363.

"The Hydraulics of Meandering Rivers with Flood Plains," G.H. Toebes and A.A. Sooky, Hydromechanics Lab., Purdue Univ. Tech. Rept. No. 10, 1964.

"Hydraulics of Meandering Rivers with Flood Plains," G.H. Toebes and A.A. Sooky, Jour. of Waterways and Harbors, paper No. 5240, Proc. ASCE, 1967.

(5110) HOT WIRE PHYSICS IN ITQUIDS.

(b) Purdue Research Foundation.

(c) Dr. J.W. Delleur, Hydromechanics Lab., School of Civil Engrg., Purdue Univ.

(d) Theoretical and experimental for Ph.D. thesis.

(e) The purpose of this research is to investigate the heat transfer characteristics of hot wires in liquids, to determine their sensitivity to fluctuations of velocity, temperature and flow direction, and to arrive at an understanding of the physical causes of their limitations.

(f) Complete.

(g) System response equations have been formulated. Heat transfer from hot-wires and cylindrical hot films has been measured in de-ionized water and in ethylene glycol.

(h) "Characteristics of Hot-Wire and Hot-Film Sensors for Turbulence Measurements in Liquids," D.L. Liu, Ph.D. thesis, Purdue Univ. 1967.

Discussion of "Some Turbulence Measurements," C.L. Liu, J.W. Delleur, G.H. Toebes, Jour. Engrg. Mech. Div., ASCE, Dec. 1967. "Some Experiences with Hot-Wire and Cylindrical Hot-Film Anemometers in Liquid," J.W. Delleur, G.H. Toebes, and C.I. Liu, Intl. Symp. on Hot-wire Anemometry, Univ. of Maryland, March 1967.

(5111) FLUIDEIASTIC OPERATORS FOR UNDER-STREAMLINED STRUCTURES.

(b) National Science Foundation.

(c) Dr. G.H. Toebes; see (4191) above.

(d) Experimental and analytical for M.Sc. and Ph.D. Theses.

(e) Analytical and experimental study aimed at correlating the hydroelastic loading of structural components and the turbulent structure of the generated wake and separating boundary layers; study of energy transfer between fluid and structure.

(g) Force, displacement and wake turbulence measurements are being made for variety of cylindrical components and plate-like structures. Reduction of data by means of spectrum analysis equipment.

(h) "Fluidelasticity," G.H. Toebes, Proc. XI Congr. Intl. Assoc. Hyd. Research, Ieningrad, USSR, 1965.

"Flow Induced Structural Vibrations," G.H. Toebes, ASCE, Jour. Engrg. Mech. Div., Vol. 91, EM 6, 1965.

"Fluidelastic Forces on Circular Cylinders," G.H. Toebes and A.S. Ramamurthy, Jour. EM 6-No. 5627, ASCE 1967.

"Fluidelastic Features of Flow Around Circular Cylinders," Proc. Intl. Research Seminar on Wind Effects on Buildings, Natl. Res. Council, Ottawa, Canada, 1967. 
(5112) TURBULENCE MEASUREMENTS IN LITUIDS.

(b) Naval Ship Res. and Dev. Ctr.

(c) Dr. G.H. Toebes; see (4191) above.

(d) Theoretical and experimental; for Ph.D. theses.

(e) Analytic and experimental investigation aimed at optimization of turbulence measurements in liquids using hot-wire and hot-film anemometer equipment. Dynamic calibration of hot-wire probes.

(f) Complete.

(g) Special calibration and test equipment has been built. Spectrum analysis equipment has been adapted for above studies. Special recirculation equipment for laboratory water supply has been built. Liquid Anemometry Data collected.

(h) "Turbulence Measurements in Liquids," T.R. 12 , Hydromechanics Lab., Purdue University, 1965. "The Steady State and Dynamic Heat Transfer from Turbulence Sensors in Liquids, "J.W. Delleur, G.H. Toebes and C.I. Iiu, Intl. Assoc. Hyd. Research, Proc. 12th Congr., 1967.

(5482) URBAN HYDROLOGY FOR SELECTED SITES IN INDIANA.

(b) Indiana Flood Control and Water Resources Commission (Sept. 1964 to Jan. 1966); Indiana Dept. of Natural Resources and Office of Water Resources Research, Dept. of the Interior. (Since Sept. 1967).

(c) Dr. J.W. Delleur, Hydromechanics Lab., School of Civil Engrg., Purdue Univ.

(d) For M.S. and Ph.D. theses.

(e) Rainfall-runoff relationships are studied for selected sites in Indiana in order to test scientific methods of estimating the surface runoff and to obtain design criteria that can be used by practicing engineers.

(g) Two suburban watersheds are instrumented in West Lafayette, Indiana.

(h) Discussion of "Time in Urban Hydrology," G.E. Willeke, by J.W. Delleur and E.B. Vician, Jour. Hyd. Div. ASCE, Sept. 1966, pp. 243-251. "Response of Stage Recorder Systems," J.W. Delleur and D. Blank, Proc. Intl. Hydrology Symp., Fort Collins, Colo., Sept. 1967, Vol. 1, p. 165.

(5484) DESIGN OF INSTRUCTIONAL EQUIPMENT FOR IABORATORY DEMONSTRATIONS IN FLUID MECHANICS.

(b) Engrg. Experiment Sta.; National Science Foundation; Purdue Univ.

(c) Dr. J.W. Delleur and Dr. G.H. Toebes, Hydromechanics Lab., School of Civil Engrg., Purdue Univ.

(d) Developmental; M.S. theses.

(e) Evaluation of the various means of conducting an undergraduate laboratory course in Hydromechanics; evaluation of the subject matter to be investigated, and design of specific equipment.

(f) Complete.

(g) The design of the following apparatuses have been completed: Manometers, rotating cylinder apparatus, radial flow apparatus, small wind tunnel, unsteady flow apparatus, cavitation apparatus, pressure measurement apparatus, viscous flow apparatus.

(h) "Aspects of the Distribution System of the Purdue Hydromechanics Laboratory," G. Sherwin, M.S. thesis, June 1965.

"Selected Experiments in Fluid Mechanics," M.K. Householder, M.S. thesis, Aug. 1965. "Fluid Mechanics: Equipment and Experiments for the Undergraduate Student," W.E. Fite, M.S. thesis, June 1967.
(5830) INSTRUCTIONAT FLUID MECHANICS IABORATORY DEVELOPMENT .

(b) National Science Foundation; Purdue Univ.

(c) Dr. J.W. Delleur and V.W. Goldschmidt.

(d) Developmental.

(e) Curriculum improvement in undergraduate fluid mechanics is sought in part by the use of free hand experiments in which small groups of students are allowed to select, plan, instrument, execute, and present the results of a small scale investigation under the counsel of the instructor.

(g) Equipment has been acquired to implement the objectives of the program.

(h) "Philosophy of Fluid Mechanics Laboratory Instruction," J.W. Delleur, V.W. Goldschmidt, and W.I. Freel, submitted to Jour. of Engineering Education.

(5831) PERFORMANCE CHARACTERISTICS OF IARGE SCALE HYDROMECHANICS LABORATORY EQUIPMENT .

(b) Purdue University, NSF (Traineeship).

(c) Dr. G.H. Toebes, Hydromechanics Lab., School of Civil Engrg., Purdue Univ.

(d) Design, theoretical, experimental; for Ph.D. theses.

(e) Completed are a $35^{\prime} \times 1.5^{\prime} \times 3^{\prime}$ and a $90^{\prime} \times$ $6^{\prime} \times 3^{\prime}$ tilting glass lined flumes. The largest flume accomodates sediment recirculation.

(g) Data collection systems for flumes have been completed and are being tested.

(h) "Design and Performance Characteristics of a Hydromechanics Laboratory Flume and Instrumentation," V.T. Ricca, Ph.D. thesis, Purdue Univ., 1966.

(5832) MEAN VELOCITY VECTOR MEASUREMENTS.

(b) Laboratory project.

(c) Dr. G.H. Toebes; see (5831) above.

(d) Experimental; for M.Sc. thesis.

(e) Optimization of velocity meter based on Pitotsphere principle and associated read out equipment.

(g) Digital data reduction nearly completed. Probe modifications are being evaluated.

(h) "The Development of a Pitot Tube," M.A. Pero, Jr., MS thesis, Aug. 1966.

(5833) WIND TUNNEL DEVELOPMENT.

(b) Laboratory project.

(c) Dr. V.W. Goldschmidt, Hydromechanics Lab., Schonl of Civil Engrg., Purdue Univ.

(d) Theoretical and experimental; M.S. thesis.

(e) A wind tunnel is being designed to provide general purpose flow field for experimental studies.

(g) Model tests of wide angle diffusers have been made, and the performance and design criteria for a low speed tunnel have been investigated.

(h) "Incorporatior of a Wide Angle Diffuser in a Low Speed Wind Tunnel," P.J. Morane, M.S. thesis, 1967.

(6197) INVESTIGATIONS ON FREE SURFACE FLOW AND WAVE PROPAGATION THROUGH CHANNEL-FLOOD PLAIN GEOMETRIES.

(b) Agricultural Research Service, U.S. Dept. Agriculture.

(c) Dr. G.H. Toebes; see (5831) above.

(d) Theoretical and experimental; thesis.

(e) The objectives are to determine improved relationships for energy loss and flood vave velocity for channel-flood plain geometries. 
(g) Several uniform flow energy loss relationships have been determined and reported. Equipment improvement, aimed at processing better detail and measuring dynamic variables, is under way.

(h) "Uniform Flow in Idealized Channel-Flood Plain Geometries," J.W. Delleur, G.H. Toebes, and B.C. Udeozo, Intl. Assoc. Hyd. Research, Proc. 12th Congr., 1967.

(6198) HYDRAULICS OF FLOW IN MEANDERING RIVERS WITH FLOOD PLAINS.

(b) Purdue Water Resources Research Center.

(c) Dr. G.H. Toebes; see (5831) above.

(d) Analytical and experimental; Ph.D. thesis.

(g) Statistical study of river meanders in white River System, Ind. Investigation of sandclay mixtures for use in cohesive, movable boundary meander model.

(h) "Planform Analysis of Meandering Rivers," G.H. Toebes and T.P. Chang, Intl. Assoc. Hyd. Res., l2th Congr., 1967.

"Erosive Behavior of Cohesive Soils," U. Dash, Ph.D. thesis, Purdue Univ., 1968.

(6199) MECHANICS OF SOIL EROSION DUE TO OVERLAND FLOW WITH RAINFALL.

(b) Purdue University; and Agricultural Research Service, U.S. Dept. Agric.

(c) Dr. J.W. Delleur, School of Civil Engrg., and Dr. D. Meyer, School of Agric. Engrg., Purdue Univ.

(d) Theoretical and experimental; for Ph.D. thesis.

(e) A study of the hydrodynamics of overland flow under rainfall as a basis for the understanding of soil erosion.

(6200) NUMERICAL SIMULATION OF A TURBULENCE MODEL.

(b) Laboratory project.

(c) Dr. Aldo Giorgini, Hydromechanics Lab., School of Civil Engrg., Purdue Univ.

(d) Theoretical and numerico-experimental; basic research for $\mathrm{Ph} . \mathrm{D}$. thesis.

(e) A continuous chain of zero-energy impulses is given to the Fourier-amplitude of the velocity field described by Burgers equation. In the long run, ensemble averages are substituted by time averages and the statistical properties of the velocity field are analyzed. The statistics of the stochastic process governed by Burgers equation has a twofold interest: (1) as a term of comparison for hypotheses on turbulence and (2) as the exact mathematical model of the statistics of a random distribution of plain shock waves.

(h) A report on the results of the first part of this research. "A Numerical Experiment on a Turbulence Model," Aldo Giorgini, NCAR PR No. 422, National Center for Atmospheric Research, Boulder, Colo. 86302.

(6201) DEPENDENCE BETWEEN TURBULENT EDDY VISCOSITY AND FLUID VISCOSITY.

(b) Purdue Research Foundation.

(c) Dr. V.W. Goldschmidt, Hydromechanics Lab., School of Civil Engrg., Purdue Univ.

(d) Theoretical and experimental; for Ph.D. thesis.

(e) Eddy viscosity is evaluated from measurement of velocity profiles in liquid jets of which kinematic viscosity is varied.

(6202) DIFFUSION AND IMPACTION OF AEROSOL PARTICLES.

(b) National Science Foundation; and Purdue
Research Foundation.

(c) Dr. V.W. Goldschmidt; see (6201) above.

(d) Experimental and theoretical; Ph.D. thesis.

(e) The dependence of turbulence diffusion on particle size and mass is sought. Diffusion of liquid aerosols in a two-dimensional air jet is being studied using a hot-wire anemometer as a size-concentration sampler. other flow fields such as a submerged twodimensional water jet will be used. The impaction coefficient on circular cylinders is under theoretical and experimental investigation. Knowledge of the impaction coefficient in the interception range is necessary for the calibration of the aerosol size sampler.

(g) A reliable procedure has been designed to modify the hot-wire anemometer to a device which determines the size and concentration of particles in air.

(h) "Measurements of Aerosols by Hot-Wire Anemometry, V.W. Goldschmidt and M.K. Householder, Proc. Int1 Symp. on Hot-Wire Anemometry, March है? 1367.

PURDUE UNIVERSITY, Jet Propulsion Center, Lafayette, Indiana 47909

(6218) ENERGY TRANSFER TO GAS BUBBLES DURING THEIR FORMATION AT SUEMERGED ORIFICE.

(b) National Science Foundation.

(c) M.R. L'Ecuyer, Assoc. Prof., Jet Propulsion Center, Purdue Univ.

(d) Experimental and theoretical; basic research for M.S. and Ph.D. Degrees.

(e) The research program concerns: (i) an experimental study of the basic mechanism of bubble formation at a submerged orifice; (ii) an experimental and theoretical investigation of the energy transfer to the gas during the bubble formation period.

Experiments employing high speed photography and high sensitivity pressure measurements have been conducted by injecting nitrogen into water to determine the conditions required for the initiation of a bubble and the instantaneous rate of gas flow into the bubble. The influence of the mean gas flowrate, the volume of the gas supply chamber, and the orifice geometry has been studied. The theoretical analysis of the energy transfer involves the development of a finite difference solution of the governing equations for describing the flow within an expanding, translating, spherical bubble forming at an orifice for specified conditions on the rate of gas flow into the bubble. The effects of energy transfer to the gas are reflected in experimental measurements of the accelerated growth rate of the bubble due to thermal expansion of the gas.

(g) The experiments on the mechanism of bubble formation have demonstrated the validity of determining the instantaneous rate of gas flow into a bubble from measurements of the transient pressure in the gas supply system. That flow rate was found to be as much as 2 to 10 times greater than the mean gas flowrate through the system. The influence of the orifice geometry and the gas supply chamber volume on the bubble formation process was explained in terms of an excess pressure required for the initiation of bubble formation and the gas stored by the system prior to 
that initiation.

(h) "The Mechanism of Bubble Formation at a Submerged Orifice," H.F. Veldman and M.R. L'Ecuyer, Rept. No. TM-68, Jet Propulsion Center, Purdue Univ., Feb. 1968 (available from Purdue Univ.)

(6219) MASS TRANSFER FROM A THIN LIQUID FILM TO A HIGH VELOCITY HOT GAS STREAM.

(b) Natl. Aeronautics and Space Admin. (initiated by); laboratory project (currently).

(c) M.R. L'Ecuyer; see (6218) above.

(d) Experimental; basic research for M.S. and Ph.D. degrees.

(e) Experiments are conducted for determining the total rate of mass transfer from a thin liquid film (water, methanol, butanol, RP-4) to an air stream (5-10 atm) flowing at 50-450 ft/sec at temperature of 400-700 degrees $F$. The liquid film is formed by injection onto a horizontal flat plate. High magnification photographs are used to characterize the stability of the liquid film. Mass transfer measurements under both hot flow and cold flow conditions enable the isolation of the total mass transfer rate into contributions due to (a) evaporation of the liquid and (b) mechanical entrainment of the liquid by the gas stream. The influence of the gas stream Reynolds numbers ( $10^{6}$ - 107 per $\mathrm{ft}$ ), the rate of liquid injection, and the liquid physical properties is determined.

(g) Experiments show that the magnitude of the liquid entrainment can be as much as 50 percent of the total rate of mass transfer from the liquid film. The entrainment is governed by the momentum flux of the gas stream indicating a dependence on interfacial shear stress. The rate of evaporation of the film is influenced significantly by the roughness of the film. The use of preliminary correlations has demonstrated the ability to predict the total mass transfer rate to within 20 percent of the experimental values reported in previous investigations of liquid-film cooling.

PURDUE UNIVERSITY, School of Mechanical Engrg. , Lafayette, Indiana 47907

\section{(5741) A STUDY OF ROTATING FLUIDS BETWEEN PARALLEL} DISKS.

(b) Laboratory project.

(c) Dr. E.J. Wellman, Assoc. Prof. of Mechanical Engrg., Purdue Univ.

(d) Analytical and experimental; basic research for doctoral thesis.

(e) A system has been constructed which consists of an 18 inch diameter vertical cylindrical tank within which a coaxial circular disk is mounted parallel to the bottom of the tank. The disk may be rotated throughout a range of speeds and the spacing between the disk and the bottom of the tank may be adjusted. Disks are available in a series of diameters, the largest of which is approximately equal to the inside of the tank. Preliminary observations and photographs have been made with the disc rotating in contact with a water surface. The flow was made visible by dye injection or by introduction of neutral density particles. A fine platinum wire has been mounted in the flow and the hydrogen bubkle technique has also been used to observe the flow. This study is being made in an effort to analyze and understand the nature of the flow in such a system, and particularly to try to determine the nature of the vortices which have been reported and the conditions under which they occur. The study should have application to rotating fluid machinery and also to atmospheric flow conditions.

PURDUE UNIVERSITY, School of Mechanical Engrg. Automatic Control Lab., Lafayette, Indiana 47907

\section{(4197) PROPAGATION OF DISTURBANCE IN FLUID LINES.}

(b) Laboratory project.

(c) Prof. Rufus Oldenburger, Director, Automatic Control Center, Sch. of Mech. Engrg., Purdue Univ.

(d) Theoretical; basic research; doctoral thesis.

(e) The purpose of the project was to investigate the phenomena of the decay and dispersion of a disturbance pulse as it travels in a fluid along a pipe. A disturbance has associated with it deviations in the mean velocity and pressure. The disturbance pulse, therefor, may be considered as a velocity or pressure pulse. By decay, we mean here a decrease in the intensity; and by dispersion, an increase in the width of the pulse with time. In an ideal nonviscous fluid contained in a rigid pipe, decay and dispersion do not occur, but are observed in the viscous fluids. A reflection of the pulse from a closed free end of the pipe also causes decay and dispersion. It is observed that for sufficiently low values of the coefficient of friction, the viscous effects may be approximated by a pure decay without dispersion.

(f) Completed.

(g) A disturbance, introduced at some point in a semi-infinite pipe filled with a fluid, travels with the velocity of sound. If the fluid is nonviscous, the disturbance is transmitted ahead and the fluid regains its equilibrium state. In the case of a viscous fluid, the equilibrium state is reached gradually. If the input velocity is such that the coefficient of viscous friction is dominated by $2 / T$ for the duration $T$ of the disturbance, then the influence of viscosity may be approximated by an exponential decay without any distortion in the form of the pulse. A pulse as a result of a reflection from a freely movable end wall of the pipe is dispersed. If the mass of the end wall is neglected and the coefficient of viscous friction satisfies the condition above, the effect may be taken as reduction in the velocity by a factor $\lambda$ where $\lambda$ satisfies a simple equation given in the paper.

(h) "Propagation of Disturbance in Fluid Lines," J.S. Ansari and R. Oldenburger, Trans. Amer. Soc. Mech. Engrs., Vol. 89, series D, No. 2, June 1967, pp. 415-422.

THE RAND CORPORATION, 1700 Main St., Santa Monica, California 90406

Address inquires to Dr. S.M. Greenfield, Head, Dept. of Geophysics and Astronomy, the RAIND Corporation, at above address, unless otherwise noted. 
(6786) GEOPHYSICAL AND ASTROPHYSICAL FLUID DYNAMICS.

(b) U.S. Air Force.

(d) Theoretical; experimental.

(e) An inquiry into the convective processes that occur in sunspots directed toward sunspot prediction; experiments to determine the effect of magnetic Reynolds number on convection and to correlate laboratory flows with sunspots.

(6787) GEOPHYSICAL AND ASTROPHYSICAL FLUID DYNAMICS.

(b) U.S. Air Force.

(d) Theoretical.

(e) An attempt to understand shock, blast, and impact phenomena through the development and utilization of a suitable hydrodynamic model. The primary application of this research is to the determination of free-field motions and pressures following the detonation of a nuclear device in water or air. Currently directed toward improving the present particle-in-cell hydrodynamic model and the determination of the equation of state of water over a wide range of pressures and temperatures.

(g) Construction of an $e-p-v$ equation of state for water over a range of variables suitable for nuclear-burst calculations.

(h) "The Rice and Walsh Equation of State for Water -- Discussion, Limitations, and Extensions," R.A. Papetti and M.C. Fujisaki, RAID Memo. 5050, Dec. 1967.

"Thermochemical Relations for Water at High Temperatures and Pressures," R.A. Papetti and M.C. Fujisaki, RAND Memo. 4969, July 1967.

(6788) GEOPHYSICAL AND ASTROPHYSICAL FLUID DYNAMICS.

(b) National Science Foundation.

(d) Theoretical; applied.

(e) Development and testing of hydrodynamic models of large-scale ocean circulation. Long-term objective: prediction of oceanic behavior and the dynamics of air/sea interaction as part of the weather-modification and -control problem.

(g) The time-dependent behavior of a homogeneous wind-driven ocean has been studied by extended numerical integration. The large-scale currents have been successfully simulated in a uniformly shallow ocean. The shape and depth of the western part of the ocean exert a very strong influence on the shape, location, and intensity of the major currents.

(6789) GEOPHYSICAL AND ASTROPHYSICAL FLUID DYNAMICS.

(b) U.S. Air Force.

(d) Theoretical; applied.

(e) A study of thermal or convective instability in confined regions: thermal instability within a sphere heated from below; convection within a rotating cylinder; convection within the earth's fluid core. Applications to cryogenic storage of liquids in space and to terrestrial induction.

(g) Reports in progress.

(6790) CLOUD PHYSICS.

(b) Naval Research Lab.; National Science Foundation; and Environmental Science Services Admin.

(d) Theoretical.

(e) With the ultimate objective of providing inputs for an atmospheric model for weather-modification studies, this is an attempt to develop a computer model of a cumulus cloud that follows the growth from the start of convection (NRL and ESSA). Other basic-studies include the microphysical effects of clouddroplet coalescence, the force on two spheres in Stokes flow, the force on two spheres in an electric field (NSF) and the mechanism of precipitation.

(g) Programs that model droplet coalescence, condensation, precipitation, and axially symmetric cumulus dynamics have been completed and attempts are being made to merge them into a larger model.

(h) "Theoretical Collision Efficiencies for Cloud Droplets in the Radius Range 10-13 Microns," M.H. Davis, RAIND Memo. 5419, Nov. 1967. "The Force on Two Spheres in Stokes Flow," M.H. Davis, RAND Memo. 5357, Aug. 1967. "On the Computation of Saturation Vapor Pressure," F.W. Murray, RAND Paper 3423, Aug. 1966.

"Ice Multiplication in the Atmosphere," I.R. Koenig, RAND Paper 3623, Aug. 1967. "Numerical Simulation of Cumulus Convection," F.W. Murray, RAIN Memo. 5316-NRL, April 1967. "Cloud Droplet Coalescence: Effects of the Davis-Sartor Collision Efficiency," M. Warshaw, RAIN Memo. 5469-NSF, Oct. 1967.

"Numerical Modeling of Condensation," I.R. Koenig, RAND Memo. 5553-NSF, forthcoming.

(6791) BIOENGINEERING.

(b) Laboratory project.

(d) Theoretical, experimental; applied.

(e) The study of extra-corporeal systems for oxygenating blood, in cooperation with medical staff of the University of California, Los Angeles. Attempt to find ways of predicting the performance of oxygenating devices for open-heart surgery through fluid-mechanics and mass transfer studies and the testing of experimental devices.

(g) Simple theory for oxygen transfer to flowing blood in tubes, channels and films has been developed. Applied to centrifugally driven blood-film.

\section{(6792) BIOENGINEERING.}

(b) Laboratory project.

(d) Theoretical; applied.

(e) An attempt to construct an analytical model of the eye's heat-transport mechanism. The model shows how changes in environmental temperature and humidity affect corneal surface temperature.

(h) Final report in process.

(6793) BIOENGINEERING.

(b) Laboratory project.

(d) Theoretical.

(e) Study of the fluid mechanics of the human microcirculation. Currently directed toward the development of useful engineering models of flow and transport in the capillaries.

(f) Just initiated.

(6794) BIOENGINEERING.

(b) Laboratory project.

(d) Theoretical; applied.

(e) An investigation of the complex structure of the eye, attempting to find a more exact relationship among pressures, deformation, and the calibration of pressure-detecting instruments. High pressure is an early sign of galucoma.

(g) Ocular tension in the various layers of the cornea due to intraocular pressure are determined as a function of corneal parameter. Work is in progress to apply the model to applanation tonometry. 
(6795) DEVELOPMENT OF MODELS FOR NUMERICAL COMPUTATION OF WATER WAVE PROPAGATION.

(b) U.S. Air Force.

(c) Dr. J.J. Leendertse, The RAND Corporation.

(d) Theoretical; applied.

(e) The broad objective is to model water waves generated by nuclear explosions during propagation towards shore. The three-dimensional model should be applicable for areas with complicated bottom contours and include the effect of the vertical accelerations of water particles.

(g) A computational model for long waves has been developed. The model permits modeling in areas with complicated boundaries and is particularly suited for hydraulic engineering research. The basis of computation is the vertically integrated equations of motion and continuity in an Eulerian system. These partial differential equations are approximated by two sets of difference equations which are used in succession. The computation is unconditionally stable. Its accuracy has been tested on tidal computations.

(h) "Aspects of a Computational Model for LongPeriod Water-Wave Propagation, " Jan J. Leendertse, RM-5294-PR, The RAND Corporation, May 1967.

\section{RENSSEIAER POLYTECHRIC INSITUTE, Dept. Of Mathematics,} Troy, New York 12181

(6772) STABILITY OF VISCOUS FLOW OVER CURVED SURFACES.

(b) Office of Naval Research.

(c) Professors R.C. DiPrima and L.A. Segel, Dept. of Mathematics, Rensselaer Poly. Inst.

(d) Theoretical; basic research.

(e) Development and breakdown of Taylor-vortex flow and Benard cells.

(g) Transition from Taylor-vortex flow to a wavyvortex flow is predicted at about $10 \%$ above critical Taylor number for flow between rotating cylinders.

(h) "On the Instability of Taylor Vortices," A. Davey, R.C. DiPrima, J.T. Stuart, J. Fluid Mech., Jan. 1968.

(6773) NONLTNEAR EFFECTS IN HYDRODYNAMIC AND THERMAL INSTABILITY PROBLEMS.

(b) U.S. Army Research Office-Durham.

(c) Profs. R.C. DiPrima and L.A. Segel; see (6772).

(d) Theoretical; basic research.

(e) Numerical procedures for computing supercritical flow; wavenumber selection, pattern formation.

(g) Theory shows why hexagonal convection cells are more likely in thin layers where surface tension is important.

(h) "Finite Amplitude Cellular Convection Induced by Surface Tension," J.W. Scanlon and L.A. Segel, J. Fluid Mech., Vol. 30, 149-62, 1967. AROD Progress Reports since 1 Oct., 1964. (d) Theoretical and field investigation; basic research for M.S. thesis.

(e) To measure and explain the correlation of temperature and velocity records obtained from vertically separated sensors in shallow ocean depths.

(f) Active, just getting underway.

ROCKETDYNE, 6633 Canoga Ave., Canoga Park, California 91304

(6174) EXPERIMENTAL INVESTIGATION OF HYDRODYNAMTCALIY INDUCED SHAFT FORCES WITH A THREE-BLADE INDUCER.

(b) Laboratory project.

(c) Mr.M.C. Huppert, Propulsion Specialist, Rocketdyne.

(d) Experimental applied research.

(e) Investigate unbalanced hydrodynamic forces upon inducers, particularly during partial cavitation.

(f) Completed.

(g) An inducer drive shaft was equipped with bending sensitive and torsion sensitive strain gages to measure inducer hydrodynamic forces during actual operating conditions in an inducer water tunnel. Dynamic data were obtained for step changes in inlet pressure and for various flowrates. The data show that the shaft was subjected to either a steady bending force toward one blade or a rotating bending force rotating about 10 percent faster than the blade. Possible causes of the rotating force were discussed. The influence on the force of gas injection was indicated experimentally.

(h) "Experimental Investigations of Hydrodynam. ically Induced Shaft Forces With a ThreeBladed Inducer," W. Rosenmann, Cavitation in Fluid Machinery, ASME Symp., Nov. 1965, Chicago, Ill., pp. 172-135. Also issued as Rocketdyne internal report (TAMM 4115-34. May 1964) under same title.

(6175) STUDY OF PUMP DISCHARGE PRESSURE OSCILIATIONS.

(b) Natl. Aeronautics and Space Admin., Huntsville, Alabama.

(c) Dr. E.D. Jackson, Member of Technical Staff Rocketdyne.

(d) Theoretical and experimental; applied research.

(e) An investigation of various sources of pumpgenerated pressure oscillations.

(f) Completed.

(g) Some analytical procedures were developed which may be applied in the design and analysis of turbopumps from an oscillation standpoint. The pump blade wake oscillations were studied from the viewpoint of generation, transmission, superposition, and elimination of acoustic waves. Initial studies were made of cavitation oscillations by studying the cavity volume of an inducer and its effect on oscillations. Experimental programs were conducted to verify and supplement certain of the analytical results. A limited experimental study was also made of stall oscillations in an axial and centrifugal pump.

(h) Two Rocketdyne reports were issued: "Summary. Study of Pump Discharge Pressure Oscillations." R6693-1 and "Final Report, Study of Pump Discharge Pressure Oscillations," R6633-2. E.D. Jackson, Oct. 1966.

(b) Office of Naval Research.

(c) Dr. Kern Kenyon, Narragansett Marine Lab., and Dr. Richard Hill, Dept. of Ocean Engrg., Univ, of Rhode Island. 
(6176) TESTING PUMPS IN AIR.

(b) Various programs funded by NASA, Huntsville, Ala., and U.S. Air Force.

(c) Mr. J.A. King, Senior Technical Specialist, Rocketdyne.

(d) Experimental applied research and development.

(e) Investigations of various axial and centrifugal flow turbopumps have been conducted in air as a means of reducing the cost of experimentation.

(f) Certain aspects completed, but effort continues on related problems.

(g) Rocketdyne has tested pumps with air as the working fluid and has found that a very good correlation exists between air test data and liquid test data. Data taken in the air have been compared with data taken in water, IOX, $\mathrm{RP}-1$, and liquid hydrogen. Some of the technical areas that have been investigated include tip clearance effects, volute geometry effects, oscillations generated by the pump, stall, pump inlet and discharge velocity surveys, and others.

(h) "Testing Pumps In Air," J.A. King, Paper No. 67-WA/FE-4, presented at Winter Annual Meeting, ASME, Pittsburgh, Pa., Nov. 1967.

ROCKY MOUNTAIN HYDRAULIC LABORATORY, Allenspark, Colorado 80510

\section{(6377) HOW TO PLACE ROCK SAUSAGES TO OBTAIN EFFECTIVE EROSION PROOFING.}

(b) Water Resources Inst., Univ. of Connecticut.

(c) Prof. C.J. Posey, Director, Rocky Mountain Hydraulic Lab.

(d) Experimental; development or applied research.

(e) This phase of a Water Resources Inst. project was undertaken to develop criteria for failsafe installation of rock sausages.

(g) Simple and practical, but novel, specifications have been developed.

(h) A motion picture film is being prepared which will present essential results to design and maintenance staffs.

ST. ANTHONY FALLS HYDRAULIC LABORATORY, UNIVERSITY OF MINNESOTA, Mississippi River at Third Ave., S. E. Minneapolis, Minnesota 55414

Inquiries concerning projects 2144, 3153, 3502, 3824, $4201,4209,4700$, 5494, 5496-5502, 5792-5796, $5798-$ $5801,5804,5805$, and 6735-6751 should be addressed to the Director, St. Anthony Falls Hydraulic Laboratory at the above address.

Inquiries concerning project Nos. 111, 1168, and 2386, which are conducted by the Agricultural Research Service, should be addressed to Mr. Fred W. Blaisdell, Research Investigations Ieader, Soil and Water Conservation Research Division, Agricultural Research Service, St. Anthony Folls Hydraulic Lab., at above. address.

Inquiries concerning Project No. 194, which is conducted in cooperation with the Corps of Engineers and the U.S. Geological Survey, should be addressed to Engineer in Charge, Mr. John V. Skinner, Federal Inter-Agency Sedimentation Project, St. Anthony Falls Hydraulic Lab., at above address.

\section{(111) CLOSED CONDUIT SPILLWAY.}

(b) Agricultural Research Service, U.S. Dept. of Agric., in cooperation with the Minnesota Agric. Expmt. Sta. and the St. Anthony Falls Hydraulic Lab.

(d) Experimental; generalized applied research for development and design.

(e) A square drop inlet having a hood barrel entrance is being tested to determine entrance loss coefficients for various drop inlet sizes and heights and various barrel slopes. Previous tests have evaluated the performance of this type of inlet. The elbow and transition between the two-way drop inlet and the barrel is being studied to determine the pressures and the best form to minimize the possibility of cavitation.

(g) The theory of closed conduit spillways has been developed, verified, and published. Results of tests on many forms of the closed conduit spillway entrance have been published. Pipe culverts laid on steep slopes may flow completely full even though the outlet discharges freely. Generalized methods for analysis and reporting of the results have been developed. The use of air as the model fluid has been verified by comparing test results with those obtained using water as the model fluid.

The drop inlet with the horizontal anti-vortex device causes the spillway to act as a selfregulating siphon when the headpool level approximates the anti-vortex plate elevation. The height of the anti-vortex plate above the drop inlet crest and the overhang of the antivortex plate determine the effectiveness of the plate as an anti-vortex device. For one form of the inlet, tests have been made to determine the crest loss coefficient, the barrel entrance loss coefficient, the pressures on the plate and the drop inlet, the general performance of the inlet, minimum and maximum permissible plate heights, and the head-discharge relationship for plate control. Variables have been the length of the drop inlet, the barrel slope. the height and overhang of the anti-vortex plate, and the sidewall thickness.

Tests on the hood drop inlet have shown that the hood barrel entrance can be used to reduce the minimum required height of the drop inlet. Minimum sizes of drop inlet and anti-vortex devices have been determined. Tests of lowstage orifices in the two-way drop inlet have shown that improper location and improper proportioning of the orifices can prevent priming of the spillway. The proper location and size of the orifices have been determined. To supplement the experiments, potential flow methods have been used to determine the theoretical coefficient of energy loss at the crest of the two-way drop inlet.

Six shapes of elbow between the two-way drop inlet and the transition were tested. The elbows were evaluated on the basis of high minimum relative pressures and the presence of adverse pressure gradients. The theoretical free streamline elbow had small areas of adverse pressure gradient. The best elbow is an ellipse with semi-major and semi-minor axes of $2 \mathrm{D}$ and $1 \mathrm{D}$. ( $\mathrm{D}$ is the barrel diameter). An elbow made up of two 45-degree circular segments of radii $\mathrm{D} / 2$ and $3 \mathrm{D} / 2$ also has generally satisfactory hydraulic characteristics. Seven transitions between the half-square 
crown - half-circular invert cross section at the elbow exit and the circular barrel were tested. The best transition is warped and ID long. Its top, $1 \mathrm{D}$ above the pipe invert, is an equilateral triangle $1 D$ wide at the elbow exit with its apex at the barrel entrance. The warped sides are the locus of lines run perpendicular to the pipe axis from the edge of the triangular top tangent to the pipe circumference. A conical transition 2D long is also satisfactory. This transition has an isosceles triangle top $1 D$ above the pipe invert. The base of the triangle at the elbow exit is $1 D$ wide and its apex is at the pipe crown at the downstream end of the transition. The sides are vertical right triangular planes $\mathrm{D} / 2$ high at the elbow exit. The hypotenuse drops from $D$ above the pipe invert at the elbow exit to $\mathrm{D} / 2$ above the pipe invert at the downstream end of the transition. Quadrants of circular cones fill the space between the vertical side triangular planes and the nearly horizontal triangular plane top.

The entrance loss coefficients are low and identical within the limits of experimental precision for all elbow-transition combinations.

(h) "The Two-Way Drop Inlet for a Closed Conduit Spillway, "Charles A. Donnelly, Jour. of Soil and Water Conservation, Vol. 20, No. 6, pp. 251-253, Nov.-Dec. 1965.

"Hydraulics of Closed Conduit Spillways, Part XI, Tests Using Air," Fred W. Blaisdell and George G. Hebaus, St. Anthony Falls Hydraulic Lab. Tech. Paper No. 44, Ser. B., 52 pp., Jan. 1966.

"Hydraulic Efficiency in Culvert Design," Fred W. Blaisdell, ASCE, Jour. Highway Div., Vol. 92, No. HWl, pp. 11-22, Mar. 1966. Closing discussion, Vol. 93, No. HW2, pp. 192194, Nov. 1967.

"Flow in Culverts and Related Design Philosophies," Fred W. Blaisdell, ASCE, Jour. Hydraulies Div., Vol. 92, No. HY2, pp. 19-31, Mar. 1966. Closing discussion, Vol. 94, No. HY2, pp. 531-540, Mar. 1968.

(1168) A STUDY OF CANTILEVERED OUTLETS.

(b) Agricultural Research Service, U.S. Dept. Agric. in cooperation with Minnesota Agric. Expmt. Sta. and St. Anthony Falls Hydraulic Lab.

(d) Experimental; generalized applied research for design.

(e) Pipe outlet conduits for small spillways are frequently cantilevered beyond the toe of the earth dam. Attempts are being made to determine quantitatively the size of the scour hole to be expected under various field conditions.

Rectangular cantilever outlets with a deflector at the exit to throw the water away from the structure and move the scour hole further downstream are also scheduled for investigation.

(2144) EXPERIMENTAL AND ANALYTICAL STUDIES OF HYDROFOILS

(b) Office of Naval Research, Dept. of the Navy.

(d) Experimental and analytical; basic research.

(e) Investigation of the unsteady flow characteristics of ventilated hydrofoils of finite span in the vicinity of a free surface.

(f) Completed. (g) Unsteady force measurements were made on a ventilated foil undergoing sinusoidal heaving motions near a free surface, and also on a restrained foil with an oscillatory trailing edge flap.

(h) "Unsteady Force and Cavity Characteristics for Ventilated Hydrofoils," J.M. Wetzel and K.E. Foerster, St. Anthony Falls Hydraulic Lab. Project Rept. No. 85, June 1967.

(2386) GENERAIIZED DESIGN OF TRANSITIONS FOR SUPERCRITICAL VELOCITIES.

(b) Agricultural Research Service, U.S. Dept. of Agric.; in cooperation with the Minnesota Agric. Expmt. Sta. and the St. Anthony Falls Hydraulic Lab.

(d) Experimental; generalized applied research for development and design.

(e) Studies will be made to develop a transition and to determine the rules for its design. The transition will be used to change the flow cross section from circular to rectangular when the velocities are supercritical.

(g) When the flow cross section is changed abruptly from a circular pipe to a rectangular open channel the rectangular channel width must be $1.0 \mathrm{D}$, where $\mathrm{D}$ is the pipe diameter, to prevent excessively high waves and disturbances in the rectangular channel. To provide space for the pipe to expand, an expansion section wider than the outside diameter of the pipe and not longer than $0.5 \mathrm{D}$ can be used between the pipe and the rectangular channel. The channel floor can be lowered below the pipe invert to accommodate pipe expansion and permit drainage of the expansion section. Although there is a diamond-shaped wave pattern with waves of significant height in the $1.0 \mathrm{D}$-wide channel, the transition performance is generally satisfactory at all discharges between Q/D $592=4$ and 20 .

\section{(3153) FLOW ABOUT BODIES AT SMALI CAVITATION NUMBERS.}

(b) Office of Naval Research, Dept. of the Navy.

(d) Experimental and analytical; basic research.

(e) A flat plate and a cambered hydrofoil were tested in free-jet tunnel under supercavitating conditions. The unsteady flow due to the oscillation of a trailing flap as influenced by one or two free surfaces was studied.

(f) Completed.

(h) "A Note on the Effect of a Slot on Force Characteristics of Supercavitating Flat Plates," C.S. Song, $C^{\prime}$. Anthony Falls Hydraulic Lab. Tech. Paper No. ¿8, Series A, June 1966.

(3502) MANGLA SPILLWAY STUDIES.

(b) Harza Engineering Co., Chicago,; Eimnie and Partners, London; Govt. of Pakistan.

(d) Experimental; design and operation.

(e) A l:300 scale section model consisting of half the control structure and basin and a 1:150 scale comprehensive model for study of all important hydraulic features. A 1:216 scale section model consisting of two control structure gates for study of pressures and gate calibration. A 1:300 scale comprehensive approach model for study of flow conditions in approach. Two 1:150 scale section models, one a detailed study of pressures and forces on baffle blocks, one a detailed study of waves on the basin side walls. Typical dimensions of earth fill dam spillway include a drop in water level of $330 \mathrm{ft}$. and a design 
discharge of 900,000 cfs through a two-stage stilling basin energy dissipator.

(f) Completed.

(h) "Hydraulic Studies of the Spillway for the Mangla Dam - A Project of the West Pakistan Water and Power Development Authority," Alvin G. Anderson and Warren Q. Dahlin, St. Anthony Falls Hydraulic Lab. Project Rept. No. 74, Feb. 1968. (Not available for distribution).

(3824) SURFACE CHARACIERISTICS OF AIR ENTRAINED FLOW IN STEEP CHANNELS.

(b) Iaboratory project.

(d) Analytical and experimental investigation of the air concentration, velocity distribution, and surface roughness of water flow in steep open channels, Ph.D. thesis.

(e) Experimental investigation was carried out on the SAF high velocity channel for slopes up to 53 degrees. Velocities were measured by means of a pitot tube and high speed photography. Air concentration was measured by the SAF concentration meter. The surface elevation was measured by a device which measures the average time the surface is above a given elevation.

(f) Experimental work completed.

(h) "Surface Characteristics of Self Aerated Flow in Steep Channels," J.M. Killen (in preparation).

(4201) GURI HYDROELECTRIC PROJECT MODEL STUDIES.

(b) Harza Engineering Co., Chicago; Corp. Venezolano de Guayana.

(d) Experimental, design and operation.

(e) Study for the design of the Guri Hydroelectric development on the Caroni River, Venezuela. using a 1:394 comprehensive spillway model, l:197 spillway section model, and a l:197 comprehensive model. Studies include spillway design, channel closure, and cofferdam studies.

(f) Completed.

(h) "Hydraulic Model Studies for the Guri Hydroelectric Project - Report on the Second Stage Diversion and Flow Characteristics of the Spillway, "Alvin G. Anderson and Arthur L. Charbonneau, St. Anthony Falls Hydraulic Iab. Project Rept. No. 79, Feb. 1966. (Not available for distribution).

(4209) THE INFLUENCE OF ELECTROKINETIC PHENOMENA ON THE HYDRAULIC AND ELECTROOSMOTIC PERMEABILITY OF UNIFORM VERY FINE SANDS.

(b) Laboratory project.

(d) Experimental and theoretical; Ph.D. thesis.

(e) Accurately sized, narrow range, angular quartz particles and spherical glass beads were tightly placed in a permeameter with reversible silver-silver chloride electrodes at the ends of the test section. Streaming potential. streaming current, electrical. resistivity of low conductivity liquid, and filter velocity were precisely measured. Studies include: (1) Flow retardation from return electroosmosis; (2) analysis of electroosmotic permeability factors with respect to particle characteristics and hydraulic permeability, and (3) comparisons of streaming current and filter velocity at varying Reynolds numbers.

(g) It has been found that the streaming currentpotential varies linearly with hydraulic gradient to a slightly higher Reynolds number than the filter velocity. Lack of complete deaeration causes a larger reduction in the filter velocity than the streaming. When "boiling" action takes place anomalous relations between the filter velocity and streaming current occur.

(h) Thesis in preparation.

(4700) OSCILIATORY LIFT AND DRAG FORCES ON VENTILATED HYDROFOIIS IN REGULAR WAVES.

(b) Office of Naval Research, Dept. of the Navy.

(d) Experimental; basic research.

(e) Investigation of the force characteristics of a restrained, naturally ventilated hydrofoil moving through regular waves.

(f) Completed.

(g) Flow visualization studies were conducted to determine the regions of boundary layer separation on hydrofoils with a sharp leading edge near the free surface. The length of the separation bubble was found to vary with velocity, angle of attack, and aspect ratio. Variation of the leading-edge thickness on wedge profiles had little influence on the separation bubble.

(h) "Measurement of the Leading-Edge Separation," J.M. Wetzel and K.M. Foerster, St. Anthony Falls Hydraulic Lab. Project Rept. No. 83, June 1966.

(5494) THERMAL POLLUTION STUDIES OF ST. CROIX RIVER.

(b) Northern States Power Co.

(d) Experimental applied research.

(e) In a first phase of the project, thermal density currents created by the discharge of heated condenser water from a steam power plant into a broad, deep river were studied in a model and isotherm surfaces were calculated. In a second phase of the study the outlet channel between the plant and river was modelled with a view to discharging the warm water in as thin a layer as possible at the river surface.

(f) Completed.

(g) The initial study showed that it would be possible to discharge the warm water as a relatively thin layer on the river surface thereby obtaining maximum heat dissipation to the atmosphere. Probable temperature limits on the water were determined. Structures designed for accomplishing the above purpose were checked and improved in the second phase.

(h) "Model Studies of the Cooling Water outlet Channel from the Allen S. King Generating Plant to Lake St. Croix, "Edward Silberman and Warren Q. Dahlin, St. Anthony Falls Hydraulic Lab. Proj. Rept. No. 86, July 1966. (Not available for distribution).

(5496) STRUCTURE OF TURBULENCE OF NON-NEWTONIAN FLOWS.

(b) Naval Ship Research and Development Center.

(d) Experimental; basic research.

(e) The experiments consisted of the measurement of Taylor vortices in a non-Newtonian fluid placed between two concentric cylinders when the inner cylinder was rotating.

(f) Completed.

(h) "Experimental Investigation of Taylor Instability Using Non-Newtonian Fluids," C.S. Song and F.Y. Tsai, St. Anthony Falls Hydraulic Lab. Proj. Rept. No. 84, June 1966. (Not available for distribution).

(5497) A STUDY OF FLOW NOISE IN A NON-NEWTONIAN FLUID.

(b) Naval Ship Research and Development Center.

(d) Experimental. 
(e) An experimental investigation of the influence of a non-Newtonian additive on the flow noise in the boundary layer of a rotating cylinder is proposed.

(f) Completed.

(g) The effect of dilute solution of drag reducing polymers on radiated flow noise from the boundary layer of a rotating cylinder was studied. Significant reduction in noise level was observed at high frequencies.

(h) "The Effect of Dilute Solutions of Drag Reducing Polymers on Radiated Flow Noise," J. M. Killen and S.D. Crist, St. Anthony Falls Hydraulic Lab. Project Report No. 90, July 1967. (Not available for distribution). (5498) A STUDY OF SURFACE SEAIANTS, TO REDUCE
CAVITATION DAMAGE.

(b) Naval Ship Research and Development Center.

(d) Experimental applied research.

(e) A determination of materials or techniques which will serve to seal cavitating surfaces to either reduce the amount of cavitation of the damage resulting therefrom.

(f) Completed.

(g) Gaseous evolution observed from metallic surfaces but various sealants were unable to withstand erosion under standard ASME vibra-. tory cavitation exposure.

(h) "Non-Newtonian Pipe Friction Studies with Various Dilute Polymer Water Solutions," John F. Ripken and Meir Pilch, St. Anthony Falls Hydraulic Lab. Project Rept. No. 71, June 1964. (Not available for distribution).

(5499) INFLUENCE OF MICRO BUBBLES ON FIOW NOISE.

(b) Naval Ship Research and Development Center.

(d) Experimental.

(e) An experimental investigation of the flow noise intensity and spectra in the boundary layer of a rotating cylinder with the addition of free gas bubbles is contemplated.

(f) Completed.

(g) Intensity spectra of radiated flow noise from the boundary layer of a rotating cylinder were measured. Dissolved gas in the surrounding liquid was controlled so that a variable rate of release of microbubbles occurred in the boundary layers. Iittle effect on radiated flow noise could be observed.

(h) "A Study of the Influence of Microbubbles on Hydrodynamic Flow Noise," John M. Killen and Scott D. Crist, St. Anthony Falls Hydraulic Lab. Project Rept. No. 82, April 1966. (Not available for distribution).

(5500) HYDRODYNAMIC FLUTTER OF SUPERCAVITATING HYDROFOILS.

(b) Naval Ship Research and Development Center, Dept. of the Navy.

(d) Experimental, basic research.

(e) Flat-plate hydrofoils are tested in a freejet water tunnel at supercavitating conditions to determine the critical velocity as a function of the mass density ratio and other variables. The main purpose is to check the existing theories.

(g) Critical speeds for the two-degree of freedom flutter of a two-dimensional flat plate were measured. The critical flutter speed was found to be very sensitive to the location of the separation point. It was also revealed that the cavity may be pinched off when the amplitude of flutter is sufficiently large. (h) "An Experimental Study of the Hydroelastic Instability of Supercavitating Hydrofoils, " C.S. Song and John Almo, St. Anthony Falls Hydraulic Lab. Project Rept. No. 89, Feb. 1967.

(5501) AN ELECTROMAGNETIC VEIOCITY PROBE.

(b) A laboratory thesis study.

(d) Experimental; M.S. thesis.

(e) The study involves the construction, calibration and demonstration of an electromagnetic velocity probe designed for use in the measurement of the axial component of the turbulent velocity in water flow. The magnetic field is provided by permanent magnets placed outside the flow system, which is a $3 / 4$ in. ID lucite pipe. The probes are constructed of .010 in. platinum wire with an electrode gap of .050 in. A total head tube is used in conjunction with the electromagnetic probe in order to obtain mean velocities.

(f) Completed.

(h) "The Construction, Calibration, and Demonstration of an Electromagnetic Velocity Probe," Arthur L. Charbonneau, M.S. Thesis, Univ. of Minnesota, May 1366. (Available on InterIibrary Loan from Univ. of Minn. Library).

(5732) EFFECT OF GAS NUCLEI ON CAVITATION.

(b) Naval Ship Research and Development Center Dept. of the Navy.

(d) Experimental applied research.

(e) Development and use of new instrumentation for correlating the gas nuclei size distribution to the severity of transient cavitation near inception on a test body in a water tunnel.

(g) Definite effects are being found relative to gas nuclei and cavitation severity using the new instrumentation and techniques.

(h) "The Influence of the Gas Nuclei Size Distribution on Transient Cavitation Near Inception," Frank R. Schiebe, St. Anthony Falls Hydraulic Lab. Memo. No. M-110, April 1967 (Not available for distribution).

"Cavitation Occurrence Counting - A New Technique in Inception Research," Frank R. Schiebe, A.S.M.E. Cavitation Forum, Nov. 30, 1966.

(5793) TANK FOR OCEANOGRAPHIC CURRENT METER CALIBRAtion.

(b) U.S. Navy Oceanographic Office.

(d) Experimental; development.

(e) Following completion of the feasibility study, a full-scale facility was constructed and calibrated.

(f) Completed.

(g) The facility consisted of a large semi-portable tank divided into three compartments -- a. head section, a test section, and a receiving section. The nozzle between the head section and test section produced a jet $15 \mathrm{in}$. in diameter at the nozzle and $30 \mathrm{in.}$ long with speeds between 0.01 and 5.0 knots. Speed control was obtained by three pumps, one with three operating speeds, used in various combinations, together with control and by-pass valves. Calibration consisted of measuring the mean velocity profiles and turbulence in the jet at several speeds throughout the range. By judicious use of screens in the head tank, the jet was made symmetrical with marimum deviation within an 11 in. dia. circle at $15 \mathrm{in}$. from the nozzle exit of the order of \pm 2 percent from the average velocity for velocities of 0.5 to 5.0 knots. At lover 
velocities, the deviation increased to somewhat more than \pm 10 percent at 0.01 knots. Repeatability of the velocity measurements at any point in the cross-section was within the same percentages but repeatability of average velocity across the cross-section was much better.

(h) "Description and Operating Instructions for a Calibration Tank", E. Silberman, St. Anthony Falls Hydraulic Lab. Memo. No. M-lll, July 1967. (Not available for distribution).

(5794) JET FLAP STUDIES.

(b) Naval Ship Research and Development Ctr. and Office of Naval Research, Dept. of the Navy.

(d) Experimental basic research.

(e) The utility of a trailing-edge jet flap to increase the lift coefficient of a ventilated hydrofoil of finite span in the vicinity of a free surface was investigated for non-zero cavitation numbers.

(f) Completed.

(g) The increment of lift associated with the jet flap was primarily dependent on the jet momentum coefficient and the flap angle. Measured lift increments were considerably less than those calculated from linearized theory for two-dimensional foils at zero cavitation number in an infinite fluid. Thrust recovery was always greater than the horizontal component of the jet reaction, and was also dependent on the jet momentum coefficient and the flap angle.

(h) "Further Experiments on a Jet Flap Hydrofoil in Ventilated Flow," J.M. Wetzel and K.E. Foerster, St. Anthony Falls Hydraulic Lab., Proj. Rept. No. 92, Dec. 1967. (Not available for distribution).

(5795) NON-NEWTONIAN BOUNDARY LAYER.

(b) Naval Ship Research and Development ctr. and Office of Naval Research, Dept. of the Navy.

(d) Experimental and analytical; Ph.D. thesis study .

(e) Study of boundary layer structure of laminar, transition and turbulent flows with homogeneous non-Newtonian fluids and Newtonian fluids with injected non-Newtonian additives.

(g) Calibration tests of impact tubes in dilute polymer flows have indicated an effect of polymer concentration, type of polymer, and tube size. Polyox WSR 30 was found to require a larger correction than guar gum. Slot injection of concentrated solutions of Polyox. and guar gum into the boundary layer of water indicated that Polyox tended to diffuse less rapidly than guar gum. Changes in the boundary layer profile due to the injected polymer have also been noted.

(5796) IMPACT CAVITATION DAMAGE-II.

(b) Naval Ship Research and Development Ctr. and Office of Naval Research, Dept. of the Navy.

(d) Experimental and analytical applied research.

(e) Utilization of facility previously described under (5495) to clarify fundamental mechanics of failure of solids by erosive impact of liquid drops.

\section{(5798) FLOW CONDITIONS IN SOILS AND FILTERS.}

(b) National Institutes of Health.

(d) Experimental and theoretical; applied research.

(e) A study of the flow of water through unsaturated porous media is being conducted. The variation of the seepage coefficient, $K$, with the characteristics of the porous media and the degree of saturation is being investigated. Knowledge of the variation in the seepage coefficient with porous media characteristics and degree of saturation will aid in the determination of the pressure gradient as a function of velocity and saturation necessary to maintain a given flow rate through filters, natural soil and capillary flow from groundwater tables to the surface.

(f) Completed.

(h) "Unsaturated Flow through Porous Media Experimental Investigation." J.W. Hayden and R.R. Wrucke," St. Anthony Falls Hydraulic Lab. Tech. Paper No. 25, Series A, Nov. 1966.

(5799) REVIEW AND ANALYSIS OF PRECIPITATION AND RUNOFF DATA FOR SELECTED WATERSHEDS IN MINNESOTA.

(b) Office of Water Resources Research, U.S. Dept. of Interior.

(d) Analytical; basic research.

(e) Project involves an analysis of precipitation, infiltration and runoff from selected watersheds in Minnesota. The objective of the study is the procurement of information on peak rates of runoff and infiltration rates for selected storms in watersheds. Also of interest is the correlation of basin-wide loss rates with various parameters characteristic of the basins.

(g) A series of rainstorm floods have been analyzed for each of the six watersheds selected. An optimization program developed by the Corps of Engineers was used to analyze the stormrunoff data and optimize 9 variables associated with the runoff process.

(5800) A STUDY OF THE RELATIONSHIP BETWEEN EROSION AND SOIL PROPERTIES FOR COHESIVE SOIL.

(b) National Science Foundation.

(d) Experimental applied research.

(e) The soil properties and the erosion characteristics of a series of cohesive soil samples are being obtained. A relationship between the erosion characteristics and the soil properties is being obtained.

(f) Completed.

(h) "Properties of Cohesive Soils Related to Erosion," J.W. Hayden, St. Anthony Falls Hydraulic Lab. Proj. Rept. No. 88, Jan. 1967. (Not available for distribution).

(5801) MINNESOTA FLOOD STUDY.

(b) Division of Waters, Dept. of Conservation, State of Minnesota.

(d) Applied research - field investigation.

(e) Project involved motion picture records of the April 1965 flood on the Minnesota River plus the computation of data on discharges, water content of snow and rainfall during the critical runoff period.

(i) Completed.

(g) Of primary interest is the procurement of photographic records of the flood.

(h) "Flood! The Minnesota River, April 1965," C.E. Bowers, St. Anthony Falls Hydraulic Lab. Film No. 77.

(5804) STUDY OF FLOW TUBES.

(b) Automatic Control Company, St. Paul, Minn.

(d) Experimental development.

(e) Selective development of a new form of compact differential pressure meter for pipe line flows. Characteristics were evaluated for a range of sizes. 
(f) Completed.

(5805) GRIT DISTRIBUTION IN GRIT REMOVAL OF SEWAGE TREATMENI PLANT.

(b) Toltz, King, Duvall, Anderson and Associates, Consulting Engineers; and Minneapolis-St. Paul Sanitary District.

(d) Experimental model study, applied research.

(e) The 1 to 12 scale model study was directed at determining causes of uneven distribution of grit among several presently operating removal channels. It was also used to assist in planning future orit channels and in improving operation of the present channels.

(f) Completed.

(h) "A Model Study of the Grit Chamber at the Minneapolis-St. Paul Sanitary District Plant," E. Silberman and A.S. Paintal, St. Anthony Falls Hydraulic Lab. Proj. Rept. No. 87, Jan. 1967. (Not available for distribution).

(6735) SURFACE PRESSURE FLUCTUATION IN DILUTE SOLUTION OF DRAG REDUCING POLYMERS.

(b) Office of Naval Research, Dept. of the Navy.

(d) Experimental.

(e) Measurements were made of the surface pressure fluctuation under the boundary layer developed on a rotating cylinder as influenced by various concentrations and types of drag reducting polymers.

(g) Spectrum measurements were made of the pressure fluctuations under the boundary layer of a rotating cylinder with concentration up to 500 ppmw of Polyox 301, guar gum and separan. Simultaneous measurements were made of drag. Data correlated well on the basis of measured drag.

(6736) STUDY OF CAVITY SEPARATION OF REAL FLUID.

(b) Office of Naval Research, Dept. of the Navy.

(d) Analytical.

(e) Numerical solutions of the Navier-Stokes equations with appropriate mixed boundary conditions for separated flows due to cavitation are being studies.

(6737) SUB-CRITICAL TAYLOR VORTEX.

(b) Office of Naval Research, Dept. of the Navy.

(d) Experimental; M.S. thesis study.

(e) Instability of couette flows is being studied experimentally using Newtonian and Non-Newtonian fluids.

(8) Spiral vortices were observed when the inner cylinder was rotated at subcritical speeds while the outer cylinder was kept stationary. It appears that the subcritical vortices are related to the initial velocity and/or density perturbation.

(h) "Experimental Study of Taylor Instability Using Newtonian and Non-Newtonian Fluids, "Kenneth Keh-Ya Chen, M.S. Thesis, Univ. of Minnesota, June 1967. (Available on Inter-Library loan from the Univ. of Minn. Library).

(6738) FRICTION REDUCTION STUDIES FOR BOUNDARY LAYERS ON A ROTATING DISK.

(b) Office of Naval Research, Dept. of the Navy.

(d) Experimental basic research; M.S. thesis.

(e) Evaluation of principal differences in boundary layer developed on a disk rotating in water and in dilute water solutions of selected polymers.

(6739) CAVITATION DAMAGE REDUCTION BY FORCED SURFACE OUTGASSING. (b) Office of Naval Research, Dept. of the Navy.

(d) Experimental applied research.

(e) An attempt to determine if pre-pitting of a metal specimen subjected to vibratory cavitation would lead to reduction of damage by outgassing from the pits. Test and observations confirmed the objectives.

(f) Tests completed; report being prepared.

(6740) IEADING EDGE SEPARATION STUDIES.

(b) Naval Ship Research and Development Center, Dept. of the Navy.

(d) Experimental basic research.

(e) Measurement of the average and fluctuating values of lift, drag and moment for wedgelike bodies as a function of separation point and other flow parameters.

(6741) DESIGN OF EROSION RESISTANT CHANNELS.

(b) National Cooperative Highway Research Program, Highway Research Board.

(d) Experimental applied research.

(e) To develop design procedures for armoring drainage channels with riprap to prevent boundary erosion. Studies are being made on the leaching process and critical tractive force for mixtures.

(g) A tentative design procedure has been developed and is being further studied.

(6742) STRATIFIED FINW STUDIES.

(b) Federal Water Pollution Control Admin., Dept. of the Interior.

(d) Experimental; applied research.

(e) Determination of three-dimensional spreading patterns and mixing of warm water discharged from a channel near the surface of a colder and stagnant lake; testing of various essentially different outlets.

(6743) DEVELOPMENT STUDY OF AN INSTRUMENT FOR THE MEASUREMENT OF CONCENTRATION OF SUSPENDED SEDIMENT.

(b) Committee on Sedimentation, Water Resources Council, Dept. of the Interior.

(d) Experimental.

(e) A feasibility study of an instrument for the measurement of concentration of suspended sediment through its influence on the electrical impedance of the suspending liquid.

(g) Preliminary results show measurement can be made up to 6000 parts per million by volume over a temperature range of 40 to 90 degrees $F$ and a salinity of $1-10$ gram per 1000 grams of solute.

(6744) FREE STREAMLINE FLOW OVER DISCONTINUITIES IN A BOUNDARY LAYER.

(b) National Science Foundation.

(d) Theoretical and experimental; doctoral thesis.

(e) The purpose of the research is to understand the mechanism of cavity formation at an obstruction in a boundary layer subjected to low pressures. Calculations have been made to describe the boundary cavity formed by various kinds of discontinuities that are often found in hydraulic structures. Experiments are being made to measure the cavity properties.

(6745) GATED CONTROL STRUCTURE - MODEL STUDY.

(b) Harza Engineering Co., Chicago; Metropolitan Water District of Southern Calif., Los Angeles.

(d) Experimental design and operation.

(e) Model studies of the flow through gate 
structures, calibration of gates systems to establish head difference - gate opening curves, and air entrainment release and gate vibrations.

(h) "Model Studies - Foothill Feeder Project, Part I: Regular Gate Structure, "Alvin G. Anderson, David J. Anderson and Roy M. Kuha, St. Anthony Falls Hydraulic Lab. Proj. Rept. No. 91, Feb. 1967. (Not available for distribution).

(6746) DISPERSION OF CHLORINE SOLUTION IN TURBULENT PIPE FLOW.

(b) Harza Engineering Co., Chicago; Metropolitan Water District of Southern California, Los Angeles.

(d) Experimental.

(e) Chlorine concentration profiles are being measured downstream from the point of injection of a concentrated chlorine solution. Injection is normal to the flow at various distances from the pipe wall. A series of tests are being conducted using one, two and multiple injectors to study the relationship between number of injectors used and the "mixing length" required to reach a given degree of concentration uniformly across the pipe.

(6747) MODEL STUDY OF DROP SHAFT FOR DEEP TUNNEL DRAINAGE.

(b) Harza Engineering Co., Chicago; City of Chicago, Ill.

(d) Experimental design.

(e) Experimental design studies of the operation of various drop shaft designs with variations in discharge and tailwater levels. Entrainment of air and impact forces are being measured.

(6748) BREAKWATER FOR PROTECTION OF INTERSTATE HIGHWAY NO. 35 ALONG IAKE SUPERIOR.

(b) Howard, Needles, Tammen and Bergendoff; Minnesota Dept. of Highways; Bureau of Public Roads, U.S. Dept. of Transportation.

(d) Experimental.

(e) A section of Interstate Highway No. 35 near Duluth, Minnesota will be subject to possible damage from waves up to 16 feet high. The objective of the study was to evaluate proposed designs of protective structures which would produce a minimu of spray as well as protect the highway from direct physical damage.

(g) A total of five proposed designs were tested. Two of these were recommended for consideration for a final design. The design producing the minimu spray was of crib-type construction.

(h) "Coastal Engineering Model Study of Interstate Highway 35 at Duluth Minnesota," C. Edward Bowers and Larry Muller. (Not available for distribution).

"Coastal Engineering Model Study of Interstate Highway 35 at Duluth, Minnesota," St. Anthony Falls Hydraulic Lab. Film No. 78.

(6749) PREPARATION OF COMPUTER PROGRAM SIMULATING MAIN INTERCEPTOR SYSTEM FOR MINNEAPOLIS ST. PAUL SANITARY DISTRICT.

(b) Minneapolis - St. Paul Sanitary District.

(d) Analytical.

(e) Objective of the study is the development of a digital computer model of the main interceptor system to assist in predicting the magnitude and distribution of storm runoff. This should assist in the optimum control of trunk sewers which sometimes by-pass to the river, thereby reducing pollution in the river.

(6750) CHARACTERISTICS OF THE AIR ENTRAINED DUE TO THE IMPACT OF A FLUID FREE JET INTO A POOL OF SIMILAR FIUID.

(b) Laboratory thesis study.

(d) Experimental applied research; M.S. thesis.

(e) The study involves the use of photographic and electronic means to determine the shape and consistency (percent air) of the air entrainment region. Certain dimensionless parameters will be varied in an attempt to relate the air entrained in a hydraulic model. to the air which will be entrained in the prototype installation. Velocity profiles, particularly at high jet Reynold's number, will be examined.

(6751) MODEL STUDY OF SUBMERGED OPEN CHANNEL CONSTRICTIONS.

(b) A laboratory thesis study.

(d) Experimental research; M.S. thesis.

(e) This study will try to analyze the relationship between the upstream depth and the constriction depth for an open channel constriction, depending on the degree to which the constriction has been overtopped by the flow. A sediment bed and a recirculating flume will be used.

INTER-AGENCY SEDIMENTATION PROJECT IN COOPERATION WITH ST. ANTHONY FALLS HYDRAULIC ILABORATORY.

(194) A STUDY OF METHODS USED IN MEASUREMENT AND ANALYSIS OF SEDIMENT LOADS IN STREAMS.

(b) Committee on Sedimentation, Water Resources Council; personnel of the U.S. Army Corps of Engrs. and the U.S. Geological Survey are actively engaged on the project.

(c) Engineer in charge, Mr. John V. Skinner, Fed. Inter-Agency Sedimentation Project, St. Anthony Falls Hydraulic Lab.

(d) Experimental; applied research and development.

(e) Drawings and specifications are available to facilitate the manufacture of suspended-sediment and bed-material samplers, particle-size analyzers, and associated laboratory equipment. Approved designs for the measurement of suspended sediment include a single stage sampler, 4-, 22-, and 62-pound depth-integrating samplers, electrically operated point-integrating suspended samplers weighing 100-, 200-, and 300-pounds, and an intermittent purmping type sampler. Samplers for the measurement of bed material include a piston-type hand-operated sampler, 30-pound hand-line sampler, and a 100-pound sampler for cable suspension. Additional items are a sediment samplersplitter, a bottom-withdrawal sedimentation tube for size analysis, and visual-accumulation sedimentation tubes with recording equipment for particle size analyses of sands. The primary objective of the current program is the development of an instrument to automatically record suspended-sediment concentrations in flowing streams.

(g) Testing has continued on the intermittent pumping-type samplers, turbidimeters, filtering devices, electrical and nuclear sensing devices. Results of field tests on bottling-type pumping samplers continue favorable. Preliminary laboratory tests have been started on a compact 
portable prmping sampler unit mounted on two wheels with a 48-pint-size sample bottle storage rack. Tests on the adaptability of the electrical impedance device indicates that the method is a reasonably reliable means for rapidly determining the concentration of suspended-sediments in a stream. Field tests on the radiological sedimentation gauges have produced favorable relationships with some manually procured flood water samples from small streams.

Combination electrical circuits compatible with both suspended-sediment sampling and stream gaging were designed.

A Fisher-Porter water level recorder was modified to include an event marker device which could record on the paper tape the time each pumped sample was taken when used in conjunction with a pumping type sampler. Circuitry available for use with a pumping sampler could also initiate a pumping cycle by a signal from the Fisher-Porter recording unit. Modifications to the 100-pound electrically operated US P-6I suspended-sediment sampler were incorporated to provide for the use of either the quart-size glass pickle jar or the round pint-size milk bottle as the sample container.

(h) "Laboratory Investigation of Pumping-Sampler Intakes, "Report T, Progress Rept. 59-pp, April 1966, price 75 cents per copy.

Catalog- "Instruments and Reports for Fluvial Sediment Investigations, Federal Inter-Agency Sedimentation Project, " 67 pages, Revision Oct. 1966, price $\$ 1.00$ per copy. For sale by the District Engr., St. Paul District, Corps of Engrs., 1217 U.S. Post Office and Custom House, St. Paul, Minnesota 55101.

SCRIPPS INSTITUTION OF OCEAITOGRAPHY, UNIVERSITY OF CALIFORIIA, San Diego, La Jolla, Calif. 92037

(4500) A STUDY OF INTERNAL WAVES IN THE OCEAN.

(b) Laboratory project.

(c) Dr. Charles S. Cox, Scripps Inst. of Oceanography.

(d) The project is theoretical, including field investigation and is basic research.

(g) Internal tides observed off California have energy comparable to surface.

(h) "Energy in Semi-diurnal Internal Waves," C.S. Cox, Proc. IAPO Symposium on Math. Hydr. (in press).

(5926) TIDE PREDICTION.

(b) U.S. Coast and Geodetic Survey.

(c) Dr. Walter H. Munk, Assoc. Director, Inst. of Geophysics and Planetary Physics, Univ. of Calif., San Diego.

(d) Theoretical.

(e) Application of modern time series methods to prediction of tides.

(g) For stations with relatively small shallow water tides the method gives better predictions with fewer station constants.

(h) "Tidal Spectroscopy and Prediction," W.H. Munk and D. Cartwright, Phil. Trans. Roy. Soc., 1965.

(5927) DEEP SEA TIDES.

(b) Office of Naval Research.

(c) Dr. Walter Munk and Frank Snodgrass, Inst. of
Geophys. and Planetary Physics, Univ. of Calif., San Diego.

(d) Field investigation.

(e) A self recording instrument package is dropped freely to the sea bottom and records, in situ, pressure, temperature and currents to a high degree of precision. The instrument is acoustically recalled from a surface vessel. typically after one month.

(g) A one-month record at 2,000 feet with three instruments separated by 1,000 feet horizontally gave clear indications of breaking internal surges.

(h) "A Deep Sea Tide Program," W.H. Munk and B.D. Zetler, Science (in press).

(6287) STUDY OF FINE SCALE OF TEMPERATURE IN THE SEA.

(b) Scripps Institution of Oceanography .

(c) Dr. Charles S. Cox.

(d) Experimental and theoretical; basic research.

(e) Measurements of the spatial distribution of temperature gradient are made from a freely falling instrument. They are related to the rate of entropy increase in the water, the heat flow through the water, the turbulent energy dissipation, and the existence of sharp temperature interfaces and interfacial waves.

(g) The temperature structure off California is found to consist of nearly isothermal layers separated by sharp interfaces. the isothermal layers are in turbulent motion.

SOUTH DAKOTA SCHOOL OF MINES AND TECHNOIOGY, Dept. of Civil Engrg., Rapid City, South Dakota 57701

(6401) DERIVATION OF EASTC HYDRAULIC FORMULAE PURELY BY DIMENSIONAL MATRIX ANALYSIS.

(b) Personal research of (c).

(c) Prof. Shu-t'ien Li, S. Dak. Sch. of Mines and Technology.

(d) 'l'heoretical; basic research.

(e) To demonstrate the complete feasibility of deriving dimensionally consistent hydraulic formulae from their parameters purely by dimensional matrix analysis.

(g) Rational results have been achieved.

(6402) HYDRAULIC DICTTONARY.

(b) Personal research of (c).

(c) Prof. Shu-t'ien Li; see (6401) above.

(d) Compilation; authentication; defining all hydraulic terms in the English language.

(e) To provide a complete hydraulic dictionary, more complete than "Water Resources Thesaurus"; and unlike the "thesaurus," each term will be completely defined.

(g) Plans have been formulated.

(O4IW) INVESTIGATION OF THE WATER RETENTION CHARACTERISTICS OF SOILS USED FOR CONTRUCTION OF WASTEWATER STAEILTZATION PONDS.

For summary, see Water Resources Research Catalog, 8.0272, Vol. 2.

(c) Asst. Prof. Floyd L. Matthew.

UNIVERSITY OF SOUTHERN CALIFORNIA, Dept. of Mechanical Engrg., University Park, Los Angeles, Calif.. 70007

(6796) EFFECT OF HIGH POLYMER ADDITIVES ON DIFFUSER SEPARATION FLOW NOISE. 
(b) Laboratory project.

(c) Prof. Raymond C. Binder and B.M. Ishino, Dept. of Mech. Engrg., Univ. of Southern Calif.

(d) Experimental research for Ph.D. in Mech. Engr. dissertation.

(e) Bench-type apparatus was used to determine the effect of high polymer additives in water on liquid-flow noise. A variable-angle, twodimensional diffuser test section was used with a low velocity blow-down water tunnel.

(f) Completed.

g) Significant reduction in flow noise was found for small concentrations of specific polymers in the region of marginal separation. For the regime of no separation and definite separation no appreciable reduction in flow noise was noted.

(h) Thesis; publication pending.

(6797) AN EXPERIMENTAL INVESTIGATION OF CRITICAL SUBMERGENCE FOR VORTEXING IN A VERTICAL CYLINDRICAL TANK.

(b) Laboratory project.

(c) Prof. E. Kent Springer and F.M. Patterson, Dept. of Mech. Engrg., Univ. of Southern Calif.

(d) Experimental research for Engr. in Mech. Engr. thesis.

(e) Determination of critical submergence for a vertical cylindrical tank with center outlet operating under several flow rates. Data are necessary in process plant design to prevent air or vapor entrainment from a float controlled tank.

(f) First phase completed. Additional work to be accomplished.

(g) Simple draining requires higher submergence than steady-state recirculation at the same net flow rate. The angle of incidence of the inlet flow has a measurable effect on the critical submergence.

(h) Thesis.

UNIVERSITY OF SOUTHERN CALIFORNIA, Foundation for Cross-Connection Control Research, School of Engrg. University Park, Los Angeles, Calif. 90007

(49) FOUNDATION FOR CROSS-CONNECTION CONTROL RESEARCH .

(b) Laboratory project; and Southern California Water Utilities Assoc., Inc.

(c) Prof. E. Kent Springer, Director, Foundation for Cross-Connection Control Research, Univ. Southern Calif.

(d) Experimental and field investigation; basic and applied research; sponsored and thesis (MS, Engr., and Ph.D.)

(e) Sponsored - evaluation of various back-flow prevention devices under both laboratory and field conditions. Laboratory - a new hydraulic research laboratory has been established with capabilities of up to $4500 \mathrm{gpm}$ at $300 \mathrm{ft}$ head. The new facility includes parallel circuits and flow meter calibration capabilities for all sizes up through 16 inches.

(g) Cross-connection control - Standarized laboratory and field test procedures as well as minimum design and operating specifications have been established.

(h) "Manual of Cross-Connection Control Recommended Practice," - available through USC BookStore.
"Cross Talk" - a quarterly publication of news and new development pertaining to crossconnection control.

SOUTHWEST RESEARCH INSTITUIE, Dept. of Mechanical Sciences, 8500 Culebra Rd., San Antonio, Texas 78206

(4927) LIQUID DYNAMIC BEHAVIOR IN TANKS UNDER DYNAMIC OSCILIATION.

(b) Natl. Aeronautics and Space Admin., Marshall Space Flight Ctr.

(c) Dr. D.D. Kana, Senior Research Engr.

(d) Theoretical and experimental; applied research.

(e) Studies of nonlinear liquid motions in rigid and elastic tanks undergoing axial oscillations.

(h) Several SwRI technical reports and three papers in scientific journals.

(5267) MONOGRAPH ON LIQUID DYNAMIC BEHAVIOR IN ROCKET PROPELLANT TANKS.

(b) National Aeronauties and Space Admin.

(c) Dr. H.N. Abramson, Director, Dept. of Mechanical Sciences, Southwest Research Inst.

(d) Theoretical; applied research.

(e) Preparation of a monograph on stated subject.

(f) Completed.

(h) "The Dynamic Behavior of Liquids in Moving Containers," edited by H. Norman Abramson, Natl. Aero. and Space Admin., SP-106, Washington, D. C., 1966.

(5663) MONOGRAPH ON HYDROELASTIC PROBLEMS OF HYDROFOIL CRAFT.

(b) Naval Ship Systems Comm. (Naval Ship Res. and Dev. Ctr. technical supervision), Dept. of the Navy.

(c) Dr. H.N. Abramson; see (5267) above.

(d) Theoretical; applied research.

(e) Preparation of monograph on stated subject.

(f) Completed.

(h) "Hydroelasticity (With Special Reference to Hydrofoil Craft)" by H. Norman Abramson, Wen-Hwa Chu, and Jack T. Irick, U.S. Naval Ship Research and Development Ctr., Govt. Printing Office, washington, D.C. (in press).

(6063) STUDIES OF LIQUID PROPELIANTS IN LOW GRAVITY.

(b) Natl. Aeronautics and Space Admin., Marshall Space Flight Center.

(c) Dr. F.T. Dodge, Senior Research Engr.

(d) Theoretical and experimental; applied research.

(e) Studies of forces on rocket fuel tanks caused by liquid sloshing in simulated low gravity environments.

(h) Several SwRI technical reports and two papers in scientific journals.

(6064) FLUTTER OF THIN PLATES IN NARROW CHANNEL FLOW.

(b) Natl. Aeronautics and Space Admin., Langley Research Center, Langley Field.

(c) Dr. F.T. Dodge, Senior Research Engr.

(d) Theoretical; applied research.

(e) Study of the self-induced vibrations (flutter) of thin elastically supported plates in narrow channel viscous flow.

(6065) FLOW LOSSES AND VIBRATIONS IN EIASTIC TUBES AND BELLOWS.

(b) Natl. Aeronautics and Space Admin., Marshall Space Flight Center.

(c) Dr. C.R. Gerlach, Senior Research Engr. 
(d) Theoretical and experimental; applied research.

(e) Studies of vibration induced in metal bellows and the flow losses in such bellows and in pipe bends.

(6066) HYDRODYNAMICS OF RIGID-BODY WATER IMPACT.

(b) U.S. Naval Ship Research and Development Ctr.

(c) Dr. C.R. Gerlach, Senior Research Engr.

(d) Theoretical and experimental; applied research.

(e) Studies of real fluid effects in rigid-body water impact, with emphasis on the trapped air cushion; later considerations will emphasize scale effects.

(h) One SwRI technical report.

STANFORD RESEARCH INSTITUIE, Menlo Park, Calif. 94025

(6122) TRANSIENT FREE SURFACE FLOW.

(b) Naval Ship Research and Development Ctr.

(c) Dr. C.M. Ablow, Stanford Research Inst.

(d) Theoretical and experimental.

(e) The theoretical analysis of two-dimensional, transient, free-surface, irrotational flows of a perfect incompressible fluid.

(f) Completed.

(g) The analysis has been reduced to a routine determination of terms in series. The method has been applied to find the switching speed of a simple model of a hydraulic switch based on the Coanda effect. Experiments with the model showed that the low Reynolds number needed for stability makes perfect fluid theory inapplicable.

(h) "Free Surface Transients Near a Point of Attachent," C.M. Ablow, Proc. Italian Math. Soc. (In press).

(6123) EFFECT OF CROSS WIND ON RAPID TRANSIT TRAINS.

(b) Bay Area Rapid Transit District, San Francisco.

(c) Dr. Ernest G. Chilton and Mr. T. Dexter Witherly, Stanford Research Inst.

(d) Experimental fluid mechanics.

(e) Wind tunnel tests of train model set at right angles to air flow.

(f) Completed.

(g) Results are shown in parametric form and indicate the trends to be expected if wind velocity, car weight, rail gauge, speed around a curve, and several other factors are varied.

(h) "Rail Gauge and Rapid Transit Stability," E. G. Chilton, IEEE Trans., System Sciences and Cybernetics, Vol. SCC-Z, 1966.

(6124) INVESTIGATION OF ENTRAINMENT SEPARATION.

(b) American Gas Association.

(c) K.T. Semrau, Stanford Research Inst.

(d) Experimental.

(e) Investigation of factors governing breakup of liquid exposed to a gas stream.

(f) Completed.

(g) Established entrainment as a function of liquid and gas rates for specific types of separating elements.

(h) Project NFX12, Final Report, American Gas Assoc., 420 Lexington Ave., New York 17, N.Y.

STANFORD UNIVERSITY, Department of Civil Engrg., Stanford, California 74305

(1946) HYDROLOGIC SYNIHESIS (REVISED). (b) National Science Foundation.

(c) Profs. Ray K. Linsley and N.H. Crawford, Dept. of Civil Engrg., Stanford Univ.

(d) Theoretical and field research.

(e) A detailed digital computer model (Stanford Watershed Model) is used to investigate various interactions in the hydrologic cycle.

(g) Results of research have been published in the following reports listed under $(h)$.

(h) "Hydraulic Behavior of Small Drainage Basins " James R. Morgali, Tech. Rept. No. 30 Oct. 1363.

"An Application of Stochastic Process Theory to Rainfall Runoff Process." J.M. Bagley, Tech. Rept. No. 35, May 1964.

"The Synthesis of Continuous Snowmelt Runoff Hydrographs on a Digital Computer, "Eric Anderson, Tech. Rept. No. 36, June 1964. "Digital Simulation in Hydrology: Stanford Watershed Model IV, "Norman H. Crawford and Ray K. Iinsley, Tech. Rept. No. 39, July 1966.

"Synthesis of Rainfall Data," A. Pattison, Tech. Rept. No. 40, July 1964.

"A Two-Phase Approach to the Prediction of Peak Rates and Frequencies of Runoff for Small Ungaged Watersheds," C.I. Larson, Tech. Rept. No. 53, June 1965.

(4219) SUPERCAVITATING HYDROFOII THEORY.

(b) Naval Ship Research and Development Center, Dept. of the Navy.

(c) Profs. B. Perry and R.I. Street, Dept. of Civil Engrg., Stanford Univ.

(d) Theoretical; basic research; Ph.D. theses and post-doctoral research.

(e) Analyses are being made to develop a method for computing the flow about a supercavitating three-dimensional lifting hydrofoil having arbitrary aspect ratio and arbitrary angle of attack.

(g) Nonlinear solutions for two-dimensional and axisymmetr1c cavitating flows have been obtained.

(h) "Techniques for Solving Free-Streamline, Cavity, Jet and Seepage Problems by Finite Differences," R.W. Jeppson, Dept. of Civil Engrg. Tech. Rept. No. 68, Sept. 1966. "Cambered Bodies in Cavitating Flow -- A Nonlinear Analysis and Design Procedure," R.I. Street and B.E. Larock, Dept. Civil Engrg. Tech. Rept. No. 72, Dec. 1966.

(4916) DISPERSION OF POLIUTANTS IN FLOW THROUGH POROUS MEDIA.

(b) Laboratory project.

(c) Profs. E.Y. Hsu and R.I. Street, Dept. of Civil Engrg., Stanford Univ.

(d) Basic experimental and theoretical research for $\mathrm{Ph} . \mathrm{D}$. thesis.

(e) Study of hydrodynamic dispersion in porous media. Complex variable analysis of flow fields is combined with a convective dispersion equation to define time-space history of pollutant concentrations. Effects of channel boundary shapes and free streamlines on dispersion are to be studied also.

(f) Completed.

(g) Conformal mapping techniques have been applied to seepage from channels in two dimensions; the results were verified by experiments. The classic methods of analysis of secondorder partial differential equations were used to derive a theory to predict the dispersion of a pollutant solution in a porous 
media flow; results were correlated with experiments.

(h) "Studies of Free Surface Flow and Two-Dimensional Dispersion in Porous Media," J.C. Bruch and R.L. Street, Dept. Civil Engrg. Tech. Rept. No. 63, May 1966.

(4917) MECHANISMS INVOLVED IN WIND-GENERATED WAVES.

(b) Fluid Mechanics Branch, Math. Sci. Div., Office of Naval Research.

(c) Profs. E.Y. Hsu and R.L. Street; see (4916).

(d) Experimental and theoretical; basic research for doctoral theses.

(e) Examination, experimental verification, and extension of available theories are being carried out. Several laboratory models of wind-wave phenomena are under study.

(g) The importance of the shear flow instability mechanism in the transfer of momentum from wind to wave has been established.

(h) "Flow Over a Moving Boundary in Relation to Wind-Generated Waves," Dept. Civil Engrg. Tech. Rept. No. 60, Mar. 1966. See also (5454).

(5453) STUDIES OF LARGE WAVES.

(b) Field Projects Branch, Earth Sciences Div., Office of Naval Research.

(c) Prof. R.L. Street, Dept. of Civil Engrg., Stanford Univ.

(d) Experimental investigation; master's and Ph.D. project.

(e) An experimental study of solitary waves is being conducted as a means of establishing the strengths and weaknesses of long wave theory to be used for coastal engineering design.

(g) It has been concluded that present analytical methods do not adequately represent shoaling solitary waves and current design criteria for breaking heights and run-up of waves need to be revised.

(h) "An Investigation of the Deformation and Breaking of Solitary Waves," F.E. Camfield and R.L. Street, Dept. Civil Engrg. Tech. Rept. No. 81, Dec. 1967.

(5454) STUDIES ON WIND-WAVE INTERACTIONS.

(b) National Science Foundation.

(c) Prof. E.Y. Hsu, Dept. of Civil Engrg., Stanford Univ.

(d) Experimental; Ph.D. theses.

(e) The experiments include pressure, velocity, wave form, and spectral measurements in the region of, and at, the interface. They are designed to study the mechanism of energy transfer between the air and the water.

(g) At the present time there appears to be a wellargued wave generation theory, yet the data in hand give only qualitative verification of the theory. Order of magnitude disagreement arises between theory and experiment in the case of wave growth rates.

(h) "Laboratory Simulation of Sea Waves, " J.M. Colonell, Dept. Civil Engrg. Tech. Rept. No. 65, July 1966.

"The Dynamics of Wind in the Vicinity of Progressive Water Waves, "O.H. Shemdin and E.Y. Hsu, Dept. Civil Engrg. Tech. Rept. No. 66, July 1966.

"Response of Gravity Water Waves to Wind Excitation," J.B. Bole and E.Y. Hsu, Dept. Civil Engrg. Tech. Rept. No. 79, July 1967. "Experimental and Analytical Investigation of the Air Velocity Profile Above Progressive
Waves," O.H. Shemdin, Dept. Civil Engrg. Tech. Rept. No. 82, July 1967.

"Spectral Measurements and Growth Rates of Wind-Generated Water Waves," A.J. Sutherland, Dept. Civil Engrg. Tech. Rept. No. 84, Aug. 1967.

(6225) STUDIES OF MASS AND ENERGY TRANSPORT ACROSS AN AIR-WATER INTERFACE.

(b) Laboratory project.

(c) Prof. R.L. Street, Dept. of Civil Engrg. , Stanford Univ.

(d) Experimental, laboratory investigation; basic research for Ph.D. dissertations.

(e) Detailed experimental measurements are to be made to obtain quantitative data on latent and sensible heat transfer and mass transfer due to evaporation and spray formation at an air-water interface.

(3507) STUDY OF INFILTRATION.

(b) Federal Water Pollution Control Admin.

(c) Prof. Joseph B. Franzini, Dept. of Civil Engrg. Stanford Univ.

(d) Theoretical investigation; laboratory and field studies; basic research; Ph.D. theses.

(e) An attempt is being made to develop relations between soil parameters and infiltration capacities. Investigation is being extended to unsteady, unsaturated flow through soils as experienced in capillary rise, drainage and infiltration situations. Various twodimensional flow problems are under investigation.

(g) An analytic approach to the solution of unsteady, unsaturated horizontal flow in soils has been developed. If the soil diffusivity is expressible in exponential form, the method permits prediction of soil moisture movement. An analytical method for the solution of unsteady, unsaturated flow from a cylindrical source has been developed. Results show that the flow rate decreases with time. The effect of an applied pressure on horizontal flow in soils has been investigated; the presence of an ever-growing saturated flow region preceded by an enlarging unsaturated zone was predicted and observed.

(h) "Impedance to Infiltration by Pressure BuildUp Ahead of the Wetting Front," D.D. Adrian and J.B. Franzini, Jour. Geophys. Research, Vol. 71, No. 24, pp. 5857-5862, Dec. 15, 1966. "Unsteady Flow in Unsaturated Soils from a Cylindrical source of Finite Radius," R. Singh and J.B. Franzini, Jour. of Geophys . Research, Vol. 72, No. 4, pp. 1207-1215, Feb. 15, 1967.

"Unsteady and Unsaturated Flow in Soils under the Influence of an Impressed Pressure," William Yeh, Ph.D. dissertation published as Dept. of Civil Engrg. Tech. Rept. No. 77, Stanford Univ., March 1967.

"Coments on Unsaturated Flow from a Cylindrical Source," R. Singh and J.B. Franzini, accepted for publication by Jour. Geophys. Research.

STANFORD UNIVERSITY, Dept. of Mechanical Engrg., Thermosciences Div., Stanford, Calif. 94305

(6798) TURBULENT SHEAR FLOWS AND HYDRODYNAMIC STABILITY. 
(b) Mechanics Div., U.S. Air Force Office of Scientific Research; and National Science Foundation.

(c) Prof. S.J. Kline or Prof. W.C. Reynolds, Thermosciences Div., Dept. of Mech. Engrg., Stanford Univ.

(d) Theoretical and experimental work, primarily fundamental in nature. Includes about six doctoral and three M.S. theses plus work of correspondents.

(e) Emphasizes investigation of the structure of turbulent shear flows (bound and free) and prediction of their properties. Experimental work emphasizes combined visual and quantitative study of instanteneous structures. Predictive studies include improved boundary layer procedures, prediction of turbulence production via hydrodynamic stability calculations, and investigation of stability of free-surface waves. Several dissertations.

(g) Results to be reported early in 1968 provide detailed pictures of turbulence production near smooth walls in turbulent boundary layer. Results verify earlier hypothesis concerning "wall layer flow models" (see first three refs. below). Central result is quantification of the fact that turbulence production arises from local, dynamic, intermittent instability of velocity profile (fourth ref.). Instability is seen to arise from the effect of the "wall model" correlated in first two references. Source of existence of wall model still under study; preliminary stability analyses suggest a predictive method which is now under study.

(h) "An Experimental Investigation of the Flow Structure of the Turbulent Boundary Layer," P.W. Runstadler, S.J. Kline, and W.C. Reynolds, Rept. MD-8, Thermosciences Div., Dept. of Mech. Engrg., Stanford Univ., 1963

(h) "A study of the Structure of the Turbulent Boundary Layer with and without Longitudinal Pressure Gradients," F.A. Schraub and S.J. Kline, Rept. MD-12, Thermosciences Div., Dept. of Mech. Engrg., Stanford Univ., 1965. "The Structure of Turbulent Boundary Layers," S.J. Kline, W.C. Reynolds, F.A. Schraub, and P.W. Runstadler, to be published in Jour. Fluid Mechanics.

"An Experimental Study of Turbulence Production near a Smooth Wall in a Turbulent Boundary Layer with Zero Pressure-Gradient, "H.T. Kim, S.J. Kline, and W.C. Reynolds, Rept. MD-2O, Thermosciences Div., Dept. of Mech. Engrg., Stanford Univ., (to be released).

"Stability of Turbulent Poiseuille Flow with Application to the Malkus Theory of Turbulence," W.G. Tiederman and W.C. Reynolds, Jour. Fluid Mech., Vol. 27, part 2, 1967.

(6799) FIOW IN SUBSONIC DIFFUSERS.

(b) Industrial sponsors: General Electric Co., General Motors Corp., Trane Co., Caterpillar Tractor Co., and AiResearch.

(c) Prof. S.J. Kline or Prof. J.P. Johnston, Thermosciences Div., Dept. of Mech. Engrg., Stanford Univ.

(d) Experimental and theoretical investigation of diffuser flows; M.S. theses and dissertations.

(e) Establishment of flow characteristics including flow regime maps, location of optima for various design criteria, provision of reliable predictive procedures.

(g) Flow regime maps for "Simple Diffusers" ( see below) are established. Optima for a number of cases are thus provided. Calculation procedure for simple cases has been constructed for various geometries and unstalled flow. "Simple Diffuser" is one which: (1) Has straight or nearly straight centerline; (2) Mach number less than choking; (3) Reynolds number high enough to give turbulent boundary layer at or near throat; (4) Potential flow in core plus boundary layer at inlet. Flow maps and correlations for one large class of curved units have also been completed. A method for stabilizing flows to very large angles, using vanes has been established. Current work not yet complete, emphasizes extension into "non-simple" cases of several kinds.

(h) "Performance and Design of Straight, TwoDimensional Diffusers," L.R. Reneau, J.P. Johnston, and S.J. Kline, Jour Basic Engrg., Trans. ASME, Series D, Vol. 89, No. 1, March 1967.

"A Performance Prediction Method for Unstalled, Two-Dimensional Diffusers," L.R. Reneau and J.P. Johnston, Jour. Basic Engrg., Trans. ASME, Series D, Vol. 89, No. 3, Sept. 1967. "The Design and Performance of Two-Dimensional Curved Subsonic Diffusers," C.J. Sagi, J.P. Johnston, and S.J. Kline, ASME Preprint No. 67-FE-6, to be published Jour. Basic Engrg. "Effects of Wall Shape on Flow Regimes and Performance in Straight, Two-Dimensional Diffusers," J.J. Carlson and J.P. Johnston, Jour. Basic Engrg., Trans. ASME, Series D, Vol. 89, No. 1, March 1967.

"The Use of Short Flat Vanes for Producing Efficient Wide-Angle Two-Dimensional Subsonic Diffusers," D.L. Cochran and S.J. Kline, NACA TN 4309, 1958.

(6800) FLOW IN ROTATING SYSTEMS.

(b) National Science Foundation.

(c) Prof. J.P. Johnston (or Prof. S.J. Kline) Thermosciences Div., Dept. of Mech. Engrg., Stanford Univ.

(d) Fundamental experimental and theoretical investigation in flow in rotating systems with particular emphasis on boundary layer effects. Dissertation work.

(e) A large rotating apparatus of flexible design is available to study various configurations. Dissertation and MS theses.

(g) Fully established flow in a channel can be strongly affected by rotation. On "leading" wall a "super turbulence" is produced; on "trailing" wall relaminarization occurs for sufficiently high values of rotation parameter. Flow regimes have been mapped; see first reference below.

Current studies continue work on structure to provide more details. During 1968-69 studies in rotating-diffusing passages are planned.

(h) "The Influence of Rotation on Flow in a Long Rectangular Channel -- An Experimental Study," R.M. Halleen and J.P. Johnston, Report MD-18, Thermosciences Div., Dept. of Mech. Engrg., Stanford Univ., 1367.

"The Laminar Boundary Layer on a Rotating Circular Arc Blade," R.M. Halleen and J.P. Johnston, Jour. Basic Engrg., Trans. ASME, Vol. 88, Series D, No. 1, March 1966.

(6801) USE OF HOT-WIRE ANEMOMETER IN WATER.

(b) Mechanics Div., U.S. Air Force Office of Scientific Research.

(c) Prof. S.J. Kline or Prof. R.J. Moffat, 
Thermosciences Div., Dept. of Mech. Engrg., Stanford Univ.

(d) Experimental work primarily.

(e) Attempts to improve and codify instrument procedures for general use. Will thoroughly test available equipment in special calibration tunnel and report on performance. Will attempt to provide instructions on use in water sufficiently complete to avoid historical errors arising from air practices. Will also attempt to provide improved temperature compensation procedures and a method for primary calibration for fluctuation velocities. Dissertation work.

(g) No final results yet available. Anticipate results circa 1969.

STEVENS INSTITUIE OF TECHNOLOGY, Davidson Laboratory, 711 Hudson St., Hoboken, New Jersey 07030.

(3516) INVESTIGATION OF HULL BENDING MOMENTS IN WAVES.

(b) Ship Structure Conmittee.

(c) Mr. Edward Numata, Davidson Lab., Stevens Inst. Tech.

(d) Experimental; applied research.

(e) Models of the cargo ships WOLVERINE STATE and CALIFORNTA BEAR were instrumented to measure vertical and lateral wave bending moments at the same location used aboard ship for strain gage measurements during actual voyages. The models were run at a range of headings to regular waves with a range of lengths. Prediction of ship bending moments in realistic seas will be made for correlation with bending moment data collected aboard ship.

(f) Completed.

(4226) INVESTIGATION OF SURFACE-PIERCING FULLY VENTILATED DIHEDRAL HYDROFOILS.

(b) Office of Naval Research, Dept. of the Navy.

(c) Mr. P. Ward Brown, Chief of High Speed Craft Div., Davidson Lab., Stevens Inst. of Tech.

(d) Experimental and theoretical; applied research.

(e) A continuing investigation aimed at providing basic design information on three-dimensional hydrofoils operating near a water surface, under conditions of either fully wetted or fully ventilated flow. To date the forces and moments on a series of surface piercing dihedral hydrofoils have been measured and the dynamies of systems employing such foils has been studied, including the problem of a hydrofoil impacting on the water surface and the stability of hydrofoil craft, and their response in waves.

(f) Completed.

(g) Analytical expressions for the forces and moments on surface piercing fully wetted and fully ventilated dihedral hydrofoils, including the effect of flaps, have been obtained and confirmed experimentally. Unsteady problems including those of stability, impact and ventilation of such foils have also been dealt with. The conventional linearized supercavitating foil theory has been extended to cover the entire angle of attack range with simplicity and precision. The response of surface piercing hydrofoil systems in irregular waves has been analyzed and techniques developed and proved experimentally for making predictions of the time history of motion response in irregular waves.
(4229) INTERACTION BETWEEN GRAVITY WAVES AND TURBULENCE FIELDS.

(b) Office of Naval Research, Dept. of the Navy.

(c) Prof. Daniel Savitsky, Davidson Lab., Stevens Inst. of Tech.

(d) Experimental and theoretical; basic research.

(e) The purpose of this work is to study energy loss processes when gravity waves pass through an intense turbulence field.

(g) Project just getting underway.

(5058) UNSTEADY LOADS ON TEED HYDROFOILS IN OBLIQUE SEAS.

(b) Naval Ship Systems Corm., Dept. of the Navy.

(c) Dr. S. Tsakonas, Head, Fluid Dynamics Div. and Dr. Charles J. Henry, Research Engr., Davidson Lab., Stevens Inst. of Tech.

(d) Experimental and theoretical; basic research.

(e) To investigate the forces and moments acting on hydrofoil struts and foils while operating in oblique regular waves.

(f) Completed.

(g) The integral equation relating the unknown time-dependent loading distribution on a lifting-surface of arbitrary shape and orientation to the known downwash distribution has been derived together with the kernal functions for a variety of special cases as well as for arbitrary Froude number. A numerical solution technique is discussed and demonstrated for the case of a deeply submerged, flat, rectangular foil subjected to a traveling gust generated by an oblique regular wave train. The results of the calculations are in very good agreement with those of experiments conducted under similar conditions. For further assessment of theoretical results, a series of experiments have been conducted with a Teed hydrofoil and with each member of this configuration separately, under a variety of conditions of aspect ratio, depth of submergence and wave conditions. The results indicate that interference effects between foil and strut are manifested by a redistribution of the loading on each member of the configuration in such a way as to increase appreciably the roll moment on the foil and the side force on the strut. The measured results demonstrate the paramount importance of including three-dimensional unsteady effects in the design studies of hydrofoil vehicles.

(h) Davidson Lab. Rept. 1118.

(5064) INVESTIGATION OF SHIP MOTIONS.

(b) U.S. Naval Training Devices Center, Dept. of the Navy.

(c) Prof. Daniel Savitsky; see (4229) above.

(d) Theoretical and experimental; basic research.

(e) Development of equations of motion of ships in very low speed maneuvering condition to be applied to a simulator for training.

(f) Completed.

(g) Analysis of general linearized motion equations including terms of importance at very low speeds. Experimental model and full scale program to determine static and dynamic derivatives of importance for inclusion in computer programs for calculating responses to bridge commands.

(h) "Equations of Motion for Mooring and Docking Maneuvers of a Destroyer and a Surfaced Submarine," C.I. Crane, Jr., E.M. Uram and Y.H. Chey, Davidson Lab. Rept. 1157, Sept. 1966. 
(5310) ACOUSTIC PROPERTIES OF BUBBLES IN PRESSURE FIELDS.

(b) Naval Ship Research and Development Ctr.

(c) Prof. Daniel Savitsky; see (4229) above.

(d) Experimental; basic research.

(e) Study of the sound produced by a single gas bubble in the presence of boundaries generating a varying pressure field in the flow direction.

(f) Completed.

(h) Report in preparation.

(5311) STRUCTURE OF TURBUTENT WAKES WITH ASYMMETRIES.

(b) Naval Ship Research and Development Ctr.

(c) Prof. Daniel Savitsky; see (4229) above.

(d) Experimental; basic research.

(e) Determination of turbulent structure of wakes very near bodies of revolution with systematically varied asymmetries. Particular attention to distortion imposed by asymmetries and circumferential eddy structure.

(f) Completed.

(h) Final report being prepared.

(5312) INVESTIGATE GAIN IN WATER SPEED OBTAINED BY COUPLING AMPHIBIOUS CRAFT.

(b) Office of Naval Research, Dept. of the Navy.

(c) Mr. Howard Dugoff, Chief, Vehicle Research Div., Stevens Inst. of Tech., Davidson Lab.

(d) Experimental investigation; applied research.

(e) Towing tank scale model tests were conducted to determine the hydrodynamic drag reduction attainable through coupling of amphibious vehicles in train configuration. Limited tests of directional behavior in waves also were made.

(f) Completed.

(g) Results are extremely encouraging; total resistance for a train of five LVTP-5 amphibians is less than twice as great as the resistance of a single vehicle. Assuming that propulsive efficiency is unaffected by coupling, this represents a potential speed gain of almost 50\%. Insofar as performance at sea is concerned, the tests to date indicate that resistance of the train to broaching is no worse than the very stable single LVTP-5.

(h) "Drag Studies of Coupled Amphibians, "R.I. Van Dyck and I.R. Ehrlich, Davidson Lab. Rept. 1137, July 1966.

(5313) HYDRODYNAMIC TRACK PROPULSION.

(b) Office of Naval Research, Dept. of the Navy.

(c) Mr. Howard Dugoff; see (5312) above.

(d) Experimental and theoretical; applied.

(e) The object of the investigation was to find methods to improve the water propulsion performance of tracked vehicles. Drag measurements were made in a wind tunnel and in a towing tank to investigate the effects of changing the shape and spacing of rectangular track plates.

(f) Completed.

(g) The test results indicate that contrary to common belief all of the cleats on the bottom portion of the track contribute materially to the gross thrust. It is also indicated that the cleat spacing should be made as small as practical, that the influence of cleat aspect ratio is small, and that variation in depth of submergence between about 2.5 and 5.0 chord widths has no noticeable effect.

(h) "Studies in Hydrodynamic Track Propulsion," I.R. Ehrlich, J.A. Mercier and I. Tanaka,
Davidson Lab. Rept. 1136, Sept. 1366.

(5314) HYDRODYNAMIC WHEEL PROPULSION OF FLOATING IAND VEHICLES.

(b) U.S. Army Tank - Automotive Center.

(c) Mr. Howard Dugoff; see (5312) above.

(d) Experimental and theoretical; applied.

(e) The fluid dynamic mechanism by which a floating land vehicle can propel itself through water by spinning its fully submerged wheels is being investigated. Studies are being conducted on two related yet essentially distinct aspects of the problem:

Phase 1-Hydrodynamic Studies of Spinning Disk. Tests are being conducted to determine the thrust force which acts on a disk rotating about an axis parallel to a plane boundary. The experiments are being performed for comparison with a proposed theoretical solution, reported on in the 1964 issue (reference number 5067), intended to provide an insight into the basic elements of the wheel propulsion phenomenon.

Phase 2-Tests on Scale Model of Floating Cargo Truck. Towing tank tests of selfpropelled scale model of a five ton army cargo truck are being conducted in an effort to develop a scale model technique for studying the hydrodynamic performance of wheel-propelled vehicles.

(f) Terminated.

(g) No significant results.

(5928) ROUGH WATER TAKE-OFF RESISTANCE OF HYDROFOIL SHIP HULIS.

(b) Naval Ship Research and Development Center.

(c) Mr. Edward Numata, Davidson Lab., Stevens Inst. of Tech.

(d) Experimental; applied research.

(e) A systematic study of the rough water resistance of hull forms suitable for use with hydrofoils, as a function of wave steepness, and frequency of encounter, with and without a range of foil restoring and damping forces and moments.

(5931) MODEL STUDY OF DOCKING CHARACTERISTICS OF IARC AMPHIBIANS.

(b) U.S. Army Mobility Equipment Center.

(c) Mr. Howard Dugoff; see (5312) above.

(d) Experimental; applied research and development.

(e) Scale model tests have been conducted to determine methods for improving the docking performance of the LARC $V$ amphibian by changing the rudder shape, stern configuration, rudder post location, and mooring line attachment location. Full scale tests are also being conducted by the Army to verify the model results. Davidson Lab. personnel are cooperating in these tests, and also are continuing the model studies in an attempt to extend the present results from the point of view of general applicability to amphibious vehicle design.

(g) It was found in the model tests that the lateral force available to hold the LARC $V$ at dockside could be increased materially, without modification to the hull, by use of a new rudder in the shape of a truncated pyramid with a vertical center plate. The tests also demonstrated that a change in the mooring line attachment location would improve operational performance significantly. 
(h) "Model Study of Dockịng Characteristics of the LARC V Amphibious Vehicle," H. Dugoff and Y.H. Chey, Davidson Lab. Rept. 1090, Jan. 1966.

"A Laboratory Scale Model Technique for Investigating Pneumatic Tire Hydroplaning, " H. Dugoff and I.R. Ehrlich, Davidson Lab. Rept. 1223 (in press).

"Laboratory Scale Model Experiments to Investigate Aircraft Tire Hydroplaning, " $\mathrm{H}$. Dugoff and I.R. Ehrlich, Proc. 7th Ann. Natl. Conf. on Environmental Effects on Aircraft and Propulsion Systems, Sept. 25-27, 1967. (Preprints available soon).

"Hydrodynamics of Aircraft Tire Hydroplaning," S. Tsakonas, C.J. Henry, W.R. Jacobs, Davidson Lab. Rept. 1238 (in preparation).

(5932) HYDROPLANING OF AIRCRAFT TIRES.

(b) National Aeronautics and Space Admin.

(c) I. Robert Ehrlich, Mgr., Transportation Research Group, Davidson Lab., Stevens Inst. Tech.

(d) Experimental and theoretical; applied research.

(e) A systematic experimental study is being made of the various parameters affecting hydroplaning of pneumatic aircraft tires. Model tests are being conducted on the Davidson Iaboratory rolling road facility; tires may be mounted above this rolling road so that with the tire mount stationary, the tire behavior may be studied and the tire loads measured as functions of rolling speed. The model tires are fabricated of polyurethane foam, whose density is varied to simulate variations in pneumatic tire inflation pressure. Static and dynamic tests of these models indicate that they are geometrically similar to the prototype pneumatic tires as they deform under load. A quantitative theoretical description of the hydroplaning phenomenon also is being sought.

(g) Preliminary experiments were made which relate water film thickness, tire size, and applied load to hydroplaning inception speed.

(5933) STUDY OF 1/4-TON TRUCK FLOATING CONCEPTS.

(b) U.S. Army Tank-Automotive Command.

(c) Mr. Howard Dugoff, Chief, or Mr. George M. Warden, Research Engr., Vehicle Research Div., Davidson Lab., Stevens Inst. Tech.

(d) Experimental and theoretical; applied research and development.

(e) This program has two main objectives: (1) To evaluate specific proposed 1/4-ton truck concepts relative to their performance in crossing water obstacles, and (2) to develop general methods for evaluating such vehicles on an objective basis. Specific evaluations include consideration of expected water speed, rough water characteristics, and water entrance and exit problems.

(f) Completed.

(g) Three different modes of locomotion are being investigated in connection with the general stream crossing maneuver; full-floating, fully land-borne, and water-land transition. Common to all is the peripheral study of the variation and distribution of related environmental characteristics. With respect to the full floating condition, methods are being developed to evaluate hydrodynamic resistance, propulsion effectiveness, water speed, height of bow wave, and water shipping rate due to wavelets and/or negative freeboard. Operating techniques such as using guy wires to tether a vehicle and utilizing the stream current to help propel the vehicle across are also being studied. Fully land-borne performance is being investigated particularly in relation to the stream and river bank environment; it is known that vegetation and soil properties are affected adversely by proximity to rivers and streams. The analysis of the water-land transition mode is in the form of dynamic boundary value problem programmed for numerical solution with a digital computer. Input data for the program include water speed, vehicle buoyancy vs freeboard and trim angle, suspension system characteristics, swamping rates for negative freeboard, ground traction coefficients, shore slope, and soil strength. The output is a time history of vehicle motion from time of initial bank contact to time of completion of egress or total immobilization. A start has been made towards categorizing the world hydrological landscape on the basis of available climatic, geological, and other natural scientific data sources.

(h) "Vehicle Egress from Streams -- A Mathematical Model," H. Dugoff, Davidson Lab. Note 765, presented at 5th U.S./Canadian Regional Meeting, Soc. for Terrain-Vehicle Systems at U.S. Dept. of Agric. Natl. Tillage Machinery Lab., Auburn, Alabama, April 18-19, 1967.

"A Computer Simulation of a 1/4-scale $8 \times 8$ XM453 Truck Model Egressing onto a Hard Surfaced Ramp," G.M. Worden, Davidson Lab. Rept. 1242, prepared for U.S. Army Tank-Automotive Command, Contract DA-30-069-AMC-783(T), Oct. 1967. "Wavelet Swamping Study -- A Method for Predicting Rate of Shipping Water, "G.M. Worden, Davidson Iab. Rept. 1254, prepared for U.S. Army Tank-Automotive Command, Contract DA 30-069-AMC-789(T), Nov. 1967.

(5934) INVESTIGATION OF SWIMMING PERFORMANCE OF A PROPOSED $1-1 / 2$ TON MARGINAL TERRAIN VEHICLE.

(b) U.S. Army Tank-Automotive Center.

(c) I. Robert Ehrlich; see (5732) above.

(d) Experimental development.

(e) The object of this program is to optimize the swimming capabilities of a proposed $1-1 / 2$ ton marginal terrain vehicle currently under development for the U.S. Marine Corps by the contractor. To this end, experiments are being made with a 1/4-scale, self-propelled, variable parameter model of this air bag type track vehicle. The tests are intended to permit optimization of two major aspects of the vehicle's hydrodynamic performance, propulsive efficiency and steering ability.

(g) Self-propelled towing tank tests were conducted to determine the effect on propulsive efficien$c y$ of various vehicle parameters including tire diameter, tire (width/diameter) aspect ratio, tire spacing, tire pressure, vehicle load, trim, and track entrance and exit angles.

An initial series of free turning tests demonstrated serious deficiency in steering ability of the vehicle as orginally designed. Subsequent modifications to the vehicle succeeded in correcting the problem without compromising other performance characteristics. Current efforts are primarily directed towards developing general methods for analyzing the performance of the high-flotation type of amphibious vehicle. 
(5935) UNSTEADY LOADS ON DUCTED PROPELLERS AND NOZZLES.

(b) Naval Ship Research and Development Center.

(c) Dr. S. Tsakonas, Head, Fluid Dynamics Div., and Miss W.R. Jacobs, Senior Research Engr., Davidson Lab., Stevens Inst. of Tech.

(d) Theoretical; applied research.

(e) To develop a method of determining the unsteady and steady loading on a ducted propeller and its enshrouding nozzle operating in a three-dimensional non-uniform flow field. The present phase is concerned with derivation of the pair of surface integral equations governing the interaction problem and their reduction to a pair of corresponding line integral equations by the mode approach and lift operator technique.

(g) Theory demonstrates the filtering effect of the propeller on the flow field so that the direct loading is zero at all frequencies not equal to multiples of blade frequency (i.e., blade frequency times $0,1,2 \ldots$. ).

(5936) PROPELLER-SINGING PHENOMENON AS A SELF-EXCITED VIBRATION SYSTEM.

(b) Naval Ship Research and Development Center.

(c) Dr. S. Tsakonas; see (5935) above.

(d) Theoretical; applied research.

(e) To improve the mathematical model introduced in the previous study at Davidson Lab. for the propeller singing phenomenon as a selfexcited vibration system and to develop expressions for the acoustic signal produced by the propeller at the singing stage.

(5937) PROPELLLER-RUDDER INTERACTION.

(b) Naval Ship Research and Development Center.

(c) Dr. S. Tsakonas; see (5935) above.

(d) Theoretical; applied research.

(e) To evaluate theoretically the loading distribution on a rudder of finite aspect ratio in the presence of a propeller operating in three-dimensional non-uniform flow and to determine the rudder torque and side force.

(g) Theory demonstrates the filtering effect of the propeller on the harmonic constituents of the wake which results in the rudder operating in a flow field of frequencies equal to multiples of blade frequency.

(5938) UNSTEADY LOADS ON A MARINE PROPELLER.

(b) Naval Ship Research and Development Center.

(c) Dr. S. Tsakonas, Head, Fluid Dynamics Div., Miss W.R. Jacobs, Senior Research Engr., and Mr. Paul Rank, Research Engr., Davidson Lab., Stevens Inst. of Tech.

(d) Theoretical; applied research.

(e) To determine the loading distribution and vibratory thrust and torque on a rotating propeller operating in a non-uniform threedimensional flow. The resulting integral equation is solved by the mode approach in conjunction with the Glauert lift operator.

(f) Completed.

(g) The surface integral equation has been solved by means of the collocation method in conjunction with the generalized lift operator, for a prescribed set of chordwise modes which reproduce the proper leading edge singularity and fulfill the Kutta condition at the trailing edge. General programs have been developed to accommodate any geometry of propeller operating in a specified nonuniform inflow condition for a large but finite number of chordwise modes. The calculations indicate that the spanwise loading distribution and the steady and time-dependent thrust and torque reach stable values after 3 to 5 chordwise modes, but the chordwise distribution does not converge with a small number of modes, particularly in the neighborhood of the leading and trailing edges. A comparison of theoretical and experimental results for the vibratory thrust shows satisfactory agreement on the whole.

\section{(5939) BOUNDARY IAYER BEHAVIOR ON ROUGH SURFACES.}

(b) Commercial Ship Operator.

(c) Prof. Daniel Savitsky, Stevens Inst. of Tech.

(d) Experimental, theoretical; basic research.

(e) Study of boundary layer growth and turbulence structure on rough surfaces. Includes various geometrically regular roughness elements and distributions and random roughness typical of ship hull plates.

(f) Completed.

(h) Results published in Stevens Inst. of Tech. Doctoral Dissertation, June 1966.

\section{(6535) STEADY AND TIME-DEPENDENT PROPELLER FORCES} AND MOMENTS.

(b) Naval Ship Res. and Dev. Ctr., Naval Ship Systems Command, Dept. of the Navy.

(c) Dr. S. Tsakonas, Head, Fluid Dynamics Div., Davidson Lab., Stevens Inst. of Tech.; Dr. J.P. Breslin, Director, Davidson Lab.; and M. Miller, Physicist, Propeller Branch, Naval Ship Res. and Dev. Ctr., Dept. of the Navy.

(d) Theoretical and experimental; applied research.

(e) To develop a method of determining all steady and unsteady hydrodynamic forces and moments acting on the propeller through use of threedimensional unsteady lifting-surface, and to compare the theoretical results with experiments.

(f) Completed.

(g) The central features of an unsteady, threedimensional, lifting-surface theory for ship propellers are outlined. Comparison of the theoretical predictions obtained from a digital. computer with experimental results show good agreement. To illustrate the applicability of the method, results of comparative calculations are presented: (i) for hulls with moderate U- and moderate $V$ sterns; (ii) for two transom sterns, one with a skeg, the other with a Hogner fairing; (iii) for a large tanker fitted alternately with 4- and 5-bladed propellers. The results show the need for such calculations as a basis for design in regard to the vibratory bearing forces when wake harmonics are sufficiently distinct. The paper concludes with a summary of the attributes of the program which make it attractive to apply to practical design problems.

(h) "Correlation and Application of an Unsteady Flow Theory for Propeller Forces," Paper No. 5, Ann. Mtg. Soc. Nav. Arch. and Marine Engrs., New York, N.Y., Nov. 15-18, 1367.

(6536) STABILIZATION OF MARINE VEHICIES FLOATING IN A SEAWAY.

(b) Naval Air Systems Command, Dept. of the Navy.

(c) Dr. Charles J. Henry, Asst. Head, Fluid Dynamics Div., and Mr. John Mercier, Research Engr., Davidson Lab., Stevens Inst. of Tech.

(d) Experimental; basic research. 
(e) To determine the effect of plate geometry on the damping effectiveness of oscillating plates.

(f) Completed.

(g) The measured damping characteristics of rectangular plates indicated that number of holes and ratio of solid planform area to overall area have very little effect. However, damping increases appreciably with aspect ratio. A cursory study of the wave exciting forces on a fixed vertical cylinder with and without a plate has shown that the added mass force on the plate decreases the wave excitation when the plate is at the end of the cylinder, for the configuration tested. As the plate is moved closer to the free surface, the added mass force increases so that the wave excitation on the plate-float combination becomes greater than that on the float alone.

(h) Devidson Laboratory Report 1183.

(6537) WAVE DECAY AND REFLECTION IN ICE FLOES.

(b) Office of Naval Research, Dept. of the Navy.

(c) Dr. Charles J. Henry, Asst. Head, Fluid Dynamics Div., Davidson Lab., Stevens Inst. Tech., and Prof. T.V. Davies, Head of the Dept. of Mathematics, University College of Wales, Aberystwyth, Wales.

(d) Theoretical and experimental.

(e) To study the pressure field and wave system resulting from the interaction of water-waves with semi-infinite field of ice blocks floating on water of finite depth.

(6538) VIBRATION ANALYSIS OF HYDROFOIL CRAFT WITH THREE-DIMENSIONAL UNSTEADY EFFECTS ON FOIL LOADING .

(b) Naval Ship Systems Command.

(c) Dr. Charles J. Henry, Asst. Head, Fluid Dynamics Div., Davidson Lab., Stevens Inst. Tech.

(d) Theoretical; applied research.

(e) To develop a theoretical procedure for predicting the vibrational performance and stability (flutter) of hydrofoil craft, including the effects of three-dimensional unsteady hydrodynamic forces acting on the foil systems.

(f) Completed.

(g) A theoretical procedure is developed for the prediction of the dynamic response, elastic or rigid body, of a hydrofoil-supported vehicle in the flying condition, to any prescribed transient or periodic disturbance. The procedure also yields the stability indices of the response so that dynamic instabilities such as flutter can also be predicted. The unsteady hydrodynamic forces are introduced in the equations of motion in terms of indicial pressure response functions, which are derived from lifting surface theory. A numerical procedure is presented for obtaining the solution of the downwash integral equations relating the indicial pressure response functions to the elastic mode shapes of the hydrofoil.

(h) Davidson Laboratory Rept. 1202.

(6539) POWER GENERATING CHARACTIERISTICS OF SAVONIUS ROTORS.

(b). Office of Naval Research.

(c) Mr. John Mercier, Research Engr., Davidson Lab., Stevens Inst. Tech.

(d) Experimental; applied research.

(e) To study the dependence of the power generating characteristics of Savonius Rotor models, when used as windmills, on various geometrical features.

(f) Completed.

(g) Savonius rotors are physically simple and have omni-directional stream sensing characteristics but are less efficient at extracting power from a stream of water of given cross section area than ordinary propeller type windmills.

(h) Davidson Lab. LR-1181 (obtain from Defense Documentation Ctr., Cameron Sta., 5010 Duke St., Alexandria, Va. 22314. AD 643 160).

(6540) FORCE MEASUREMENTS ON A ROTATING VARIABLE SWEEP HYDROFOIL.

(b) Naval Air Systems Command.

(c) Mr. John Mercier; see (6539) above.

(d) Experimental; applied research.

(e) To study the dependence of the lift, drag and pitching moment acting on a model hydrofoil on angle of attack, sweep angle and sweep rate.

(f) Completed.

(g) Hydrodynamic forces are only weakly dependent on sweep rate up to reasonably high rates (thirteen foil spans advance for 30 degree sweep).

(h) Davidson Lab. IR-1180 (obtain from Defense Documentation Ctr., Cameron Sta., 5010 Duke St., Alexandria, Va. 22314. AD 804-380).

SYRACUSE UNIVERSITY, Dept. of Civil Engrg., Syracuse, N.Y. 13210

\section{(6215) PRESSURE DEVELOPMEITT FOLLOWING COLIAPSE OF} VAPOR CAVITIES.

(b) National Science Foundation.

(c) Dr. Wen-Hsiung Li, Prof. of Civil Engrg., Syracuse Univ.

(d) Theoretical with experimental verification.

(e) To predict the high pressure generated by collapse of vapor cavities formed by sudden stoppage of flow in a pipe.

(f) Completed.

(g) Solutions have been obtained for the pressure and velocity of flow following the collapse of vapor cavities.

(h) "Mechanics of Pipe Flow Following Seperation," W.H. Ii, Trans. Amer. Soc. Civ. Eng., Vol. 128, p. 1233, 1963.

"Pressure Generated by Cavitation in a Pipe," W.H. Ii and J.P. Walsh, Proc. Amer. Soc. Civ. Eng., Vol. 90, No. EM6, 1964.

"Thermal Eifect on Growth and Collapse of Cavities," W.H. Li, Proc. Symp. on Cavitation and Hyd. Mach. Intl. Assoc. for Hyd. Research, 1962.

"Water Hammer Following Column Separation," J.P. Walsh and W.H. Li, Jour. Appl. Mech., Vol. 34, No. El, p. 234, 1967.

(6216) TRANSVERSE DISPERSION IN GROUND WATER.

(b) Federal Water Pollution Control Admin., U.S. Dept. of the Interior.

(c) Dr. Wen-Hsiung Li; see (6215) above.

(d) Theoretical and experimental.

(e) To predict distribution of contaminant in ground water.

(f) Completed.

(g) Solutions have been obtained for contaminant distribution from sources in nonuniform flow; coefficient of transverse dispersion has been 
determined experimentally for Reynolds number up to 380; solutions have been obtained for concentration distribution at the interface of moving fluids.

(h) "Experiments on Lateral Dispersion in Porous Media," W.H. Li and F.H. Lai, Proc. Amer. Soc. Civ. Eng., Vol. 92, No. HY5, 1966. "Dispersion from Sources in Nonuniform Seepage Flow," W.H. Li and R.P. Canale, Proc. Amer. Soc. Civ. Eng., Vol. 93, No. HY3, 1967. "Band Diffusion with Variable Parameters along Flow," W.H. Li, Trans. Amer. Soc. Civ. Eng., Vol. 132, 1967.

"Dispersion at the Interface of Miscible Liquids in a Soil," W.H. Li and G.T. Yeh, Water Resources Research, Amer. Geophys. Union, (in publication).

SYRACUSE UNIVERSITY, Dept. of Mechanical and Aerospace Engrg., Syracuse, N.Y. 13210

(6263) INVESTIGATION OF TRANSITION IN A PIPE.

(b) National Science Foundation.

(c) Prof. T.H. Hodgson, Dept. Mechanical and Aerospace Engrg., Syracuse Univ.

(d) Experimental and theoretical; basic research for doctoral thesis.

(e) Experimental investigation of the stability of Poiseuille flow in a pipe after the application of three dimensional disturbances.

(6264) MEASUREMENT OF PRESSURE FLUCTUATIONS IN TURBULENT SHEAR FLOWS.

(b) Office of Naval Research.

(c) Prof. T.H. Hodgson; see (6263) above.

(d) Experimental; basic research for doctoral thesis.

(e) A pressure transducer is being developed that should measure static pressure fluctuations in free turbulent shear flows. Also a transducer of high frequency resolution is being used to measure the wall pressure fluctuations beneath a turbulent boundary layer, particularly that part of the spectrum originating in the viscous sub-layer.

(6265) ACOUSTIC RADIATION FROM A TURBUI巴NT BOUNDARY LAYER ON A RIGID PLANE SURFACE.

(b) Laboratory project.

(c) Prof. T.H. Hodgson; see (6263) above.

(d) Experimental and theoretical.

(e) From wall pressure correlation data previously obtained in flight the acoustic radiation from a turbulent boundary layer on a rigid plane surface is being investigated theoretically.

ROBERT TAGGART INCORPORATED, 3930 Walnut St., Fairfax, Virginia 22030

(5189) ACOUSTIC EXCITATION OF FLAT PLATES BY TURBULENT FLOW.

(b) Naval Ship Research and Development Ctr.

(c) Robert Taggart, President, Robert Taggart Inc.

(d) Experimental; applied research.

(e) Tests were carried out in a rectangular water tunnel in which various thin flat plates were mounted flush with the tunnel wall. (1) using a $1 / 16^{\prime \prime}$ thick stainless steel plate, the investigation was directed toward correlation of the boundary layer characteristics with the pressure spectra of a flush-mounted pencilend hydrophone and an accelerometer located on the quarter diagonal point of the plate surface. (2) Experiments were conducted to determine the dimensional effects of cylindrical hydrophones located in a water-filled trunk above the plate. The height above the plate was varied for two hydrophones of different sensitive areas. (3) The effect of damping on the acoustic pressure was examined for two aluminum and two fiberglass plates. Comparison is made between the four plates (damped and undamped) at a maximum flow velocity of $20 \mathrm{ft} . / \mathrm{sec}$. Acceleration levels were measured.

(f) Completed.

(g) (1) It is demonstrated that unsteady flow excitation from a turbulent boundary layer on a thin flat surface, causes vibration of the plate at many natural modes. Chladni figures are shown for a frequency range $170<f<2000$ cps. (2) Both the area of a hydrophone and its distance above a vibrating plate have considerable effect on the dimensionless pressure spectra. (3) Measurements on the four damped plates show that the acoustic response of aluminum plates is lowered more than that of fiberglass plates. The ratio of the thickness of the damping material to the plate thickness is 2 .

(6262) THE WAII PRESSURE SPECTRA IN A THICK TURBULENT BOUNDARY LAYER.

(b) Office of Naval Research, Dept. of the Navy.

(c) Mr. Matthew Stevenson, Hydrodynamicist, Robert Taggart Incorporated.

(d) Experimental; applied research.

(e) Tests were carried out with 1/8" diameter pressure transducers flush-mounted in the wall of a quiet flow water tunnel in which the boundary layer was approximately $3^{\prime \prime}$ thick. The maximum flow velocity was varied between 12 and 22 feet/second.

(f) Completed.

(g) From spectrum levels it is shown that for increasing frequency, the level falls at a rate of $10 \mathrm{db} /$ octave and for any frequency the dependence on velocity is about $2 \mathrm{db} /$ foot per second. Qualitatively, the low frequency results show a tendency for spectral density values to decrease with decreasing frequency. At high frequencies the small wavelength components of the pressure field cannot be properly resolved by the finite sized transducers. An average value of the ratio of root-mean-square pressure to dynamic pressure is found to be $5.2 \times 10^{-3}$ for a zero-sized transducer. In the higher frequency range the data are better represented by scaling the spectral density using wall shear stress and transducer size rather than dynamic pressure and displacement thickness.

(h) "The Wall Pressure Spectra in a Thick Turbulent Boundary Layer," Final Report RT-15101 to the Acoustics Branch, Office of Naval Research, under Contract Nonr-4791(00).

UNIVERSITY OF TENINESSEE, Dept. of Chemical and Metallurgical Engrg., Knoxville, Tenn. 37316

(6492) STUDIES OF CAVITATION. 
(b) Dept. of Chemical and Metallurgical Engrg., The Univ. of Tennessee.

(c) Prof. H.W. Hsu, Dept. of Chem. and Metallurg. Engrg., The Univ. of Tennessee.

(d) Theoretical and experimental; applied research; Master's thesis.

(e) Development of a scaling equation for the incipient cavitation number as a function of the Reynolds number.

(f) Suspended.

(g) The equation agreed favorably with various experimental data.

(h) Proc., Southeastern Symp. on Missiles and Aerospace Vehicles Science, Vol. II, p. 95, 1966.

(6493) EFFECT OF VIBRATION ON FLUID FLOW.

(b) Dept. of Chemical and Metallurgical Engrg., The Univ. of Tennessee.

(c) Prof. H.W. Hsu; see(6492) above.

(d) Experimental; appiied research; Master's thesis.

(e) An experiment of determination of a friction factor for a curved pipe under vibration and without vibration has been performed. Ratio of the friction factor under vibration and without vibration has been correlated in terms of Reynolds number, amplitude, frequency, and curvature-diameter ratio.

TEXAS A and M UNIVERSITY, College of Geosciences, Dept. of Oceanography, College Station, Texas 77843

(4866) MODIFICATION OF TWO-DIMENSIONAL LONG WAVES OVER VARIABLE BOTTOM TOPOGRAPHY.

(b) Coastal Engineering Research Center.

(c) Prof. R.0. Reid, Texas A and M Univ.

(d) Theoretical applied research.

(e) The objective is to investigate the modification of free gravity waves in variable depth, including reflection and transmission etc., with particular attention being given to the interaction of tsunamis with islands. The analysis employs numerical methods.

(g) Studies to date include: (1) The development of modified long-wave equations to allow for vertical acceleration and dispersive character of the waves. (2) The development of a computing system for generating an orthogonal coordinate system for an island of general configuration to be employed in numerical wave diffraction studies. (3) The development of a numerical program for evaluating the diffraction of long waves by islands of general configuration using the special coordinate system. The above system has been tested for several cases of simple geometry where the analytical solution is known. (4) Evaluation of the characteristics of gravity waves of permanent form at intermediate depth for nearly maximum steepness.

(h) "Orthogonal Coordinates for the Analysis of Long Gravity Waves Near Island," R.0. Reid and A.C. Vastano, Proc. Specialty Conf. on Coastal Engrg., ASCE, Oct. 1965.

"Tsunami Response for Islands: Verification of a Numerical Procedure," A.C. Vastano and R.0. Reid, Jour. Marine Res., Vol. 25, No. 2, May 15, 1967, pp. 129-139.
TEXAS A and M UNIVERSITY, Dept. of Civil Engineering, College Station, Texas 77843

Inquiries concerning the following projects and requests for reprints and technical reports should be addressed to Dr. John B. Herbich, Prof. and Head, Hydraulic Engrg. and Fluid Mechanics and Coastal and Ocean Engrg. Divisions, Texas $A$ and M Univ.

(3086) INVESTIGATION OF DESIGN CRITERIA OF SPUR DIKES. (See also No. 3086A p. 63)

(t) Texas $A$ and $M$ University.

(c) Dr. John B. Herbich.

(d) Experimental and analytical.

(e) A spur dike has been defined as a projection extending upstream from bridge abutments. The project has been divided into five phases: (1) Literature survey; (2) analytical study; (3) experimental study in fixed-bed models;

(4) experimental study in movable-bed models; (5) review of design criteria for spur dikes.

(f) Phases (1), (3) and (4) completed, phase (2) re-activated, phase (5) active.

(g) Preliminary investigations indicate that properly designed spur dikes produce uniform velocity between abutments and are extremely effective in reducing scour at the abutments.

(h) "Prevention of Scour at Bridge Abutments," John B. Herbich, Proc., XII Congr. Intl. Assoc. Hydraulic Res., Vol. 2, Paper B9, Sept. 1967.

(4155) WAVE RUN-UP ON COMPOSITE BEACHES. (See also No. 4155A, p. 63)

(b) Texas $A$ and M University.

(c) Dr. John B. Herbich; J. Machemehl.

(d) Experimental and analytical.

(e) The objectives are (1) to verify existing equations for determination of height of wave run-up (2) to determine the limits of application of equations for long beach berms, (3) to develop semi-theoretical equations for wave run-up, and (4) to compare wave uprush data obtained in laboratory using wind-generated and mechanically-generated waves. There appears to be a considerable difference between uprush values obtained by two different methods of wave generation.

(f) Parts e(1) and e(2) completed; parts e(3) and $e(4)$ active.

(g) Agreement between equations and experiments is good for width of berm to wave length ratios equal to or less than 0.15; for higher values there is little agreement.

(h) "Effect of Berm on Wave Run-up on Composite Beaches, "John B. Herbich, R.M. Sorensen and J.H. Willenbrock, Proc. ASCE, Jour. Waterways and Harbors Div., Paper No. 3526, WW2, May. 1963.

(5552) SCOUR OF FLAT SAND BEACHES DUE TO WAVE ACTION. (See also No. 5552A, p. 64)

(b) Texas $A$ and $M$ University.

(c) Dr. John E. Herbich; Dr. R.M. Sorenson.

(d) Experimental and theoretical.

(e) Erosion of sand beaches due to oscillatory water particle motion of non-breaking waves is of importance where such a beach is fronted by a sea wall supported on spread foundation. Laboratory study was conducted in a two-dimentional wave channel for a Master's thesis.

(g) The comparison between theoretically calculated values and experimental results indicates fairly good agreement. Model experiments indicate that depth of scour depends to a large extent on wave character- 
istics and that scour length (distance between scour troughs or crests) is independent of time, but is a function of incident wave length.

(h) "Scour of Flat Sand Beaches Due to Wave Action in Front of Sea Walls," John B. Herbich, H.D. Murphy and V. Van Weele, Coastal Engrg., ASCE, Ch. 29, 1966.

(6398) IARGE-SCALE ROUGHNESS IN OPEN-CHANNEL FLOW.

(b) Texas $A$ and $M$ University.

(c) Dr. John B. Herbich.

(d) Theoretical and experimental.

(e) The most common measures of open-channel roughness, namely Manning's $n$ and Chezy's $C$, are predicted from experience. The study ranges from submerged flow in which the height of roughness elements varied from 0.53 to 1.0 times the depth to submerged flow in which elements protruded through the surface. The project has been divided into three phases: (a) subcritical flow, (b) supercritical flow, (c) design applications.

(f) Phase (a) completed, phase (b) active, phase (c) suspended.

(h) "Large-Scale Roughness in Open-Channel Flow," John B. Herbich, Sam Shulits, Proc. ASCE, Jour. Hydraulics Div., Paper 4145, HY6, Nov. 1964.

(6399) TRANSITIONS IN SUPERCRITICAL OPEN CHANNEL FLOW.

(b) Texas A and M University.

(c) Ir. John B. Herbich.

(d) Theoretical and experimental.

(e) In supercritical open channel flow, changes in wall direction (or any other disturbance in the channel) will set up standing waves which may materially affect the flow profile and the entire character of the flow. There is a need for basic information leading to better design of transitions in supercritical flow. Theoretical analysis of the effects of disturbances on supercritical flows in an inclined channel based on the method of characteristics was proposed. The project has been divided into three phases (a) theoretical analysis, (b) experimental verification, (c) study of application to open channel design.

(f) Phase (a) completed, phase (b) active, phase (c) suspended.

(h) "Transitions in Supercritical Open-Channel Flow," Gurmar Bagge, John B. Herbich, Proc., ASCE, Jour. Hydraulics Div., Paper No. 5417, HY5, Sept. 1967.

(6400) EFFECT OF ENGINEERING PROJECTS ON QUAIITY CHANGES IN SURFACE WATERS.

(b) Texas A and M University.

(c) Dr. John B. Herbich.

(d) Basic research.

(e) There are many water quality problems which were either overlooked or considered of no importance in planning many engineering projects in the past. Some of these problems pertaining to hydraulic engineering are (a) effect of dams and other barriers, (b) effect of tidal power plants, (c) effect of underwater dams or sills in a tidal river, (d) effect of steam electric power plants, etc. Accumulation of information and evaluation of the effect of engineering works is proposed.

(g) No significant conclusions reached to date.

(h) "Quality Changes in Surface Waters Caused by Engineering Projects," John B. Herbich, presented at the Intl. Conf. on Water for Peace, Washington, D.C., May 1967.
TEXXS A and M UNIVERSITY, Water Resources Institute, College Station, Texas 77843

(5478) WATER POLLUTION FROM ERODED SEDIMENTS.

(b) Federal Water Pollution Control Admin.

(c) Ernest T. Smerdon, Director, Water Resources Inst., Texas $A$ and $M$ Univ.

(d) Experimental; basic and applied.

(e) The laboratory study is designed to determine relationships between sediment transport in shallow flow, under specialized conditions where intense rainfall exists, with other hydraulic variables. Sediments used are glass beads. The purpose of the research is to develop equations for transport of sediment in shallow flow with superimposed rainfall. A primary objective is to be able to predict how eroded sediment is transported between the point of origin to deep flowing streams and the effect of rainfall on this transport process. The investigations include detailed studies of turbulence with hot film anemometers.

(g) Rainfall superimposed on shallow flow reduces the sediment transport capacity of streams. Also, the rainfall changes the character of the turbulence and this, in turn, affects the sediment transport capacity.

(h) "How Rainfall Affects Shallow Channel Flow." L. Joe Glass and Ernest T. Smerdon, Agric. Engrg., Vol. 48, No. 10, 558-557, Oct. 1967. "Effect of Rainfall on the Velocity Profile in Shallow Flow," L. Joe Glass and Ernest T. Smerdon, Trans. Amer. Soc. Agric. Engr., Vol. 10, No. 3, pp. 330-332 and 336, 1967.

(5479) EFFECT OF SURFACE IRRIGATION HYDRAULICS ON EFFICIENT APPLICATION OF WATER.

(b) Texas A and M University.

(c) Dr. Ernest T. Smerdon; see (5478) above.

(d) Laboratory and field investigation; applied research.

(e) The objectives are to determine the effect of irrigation stream size, slope, and shape of irrigated surface, hydraulic roughness of irrigated surface, and water intake characteristics of soil on irrigation system design for the most efficient application of water by surface methods. A current objective is to predict the advance and recession of a furrow irrigation stream by hydrodynamic routing.

(g) Field measurements indicate that the mass intake rate of irrigation furrows can often be described by the Kostiakov power equation. Measurements of the advance positions of furrow irrigation streams compare well with the advance positions predicted from either numerical or exact solutions of the LewisMilne continuity equation for the case when intake is described by the Kostiakov equation. A dimensionless graphical representation of that particular exact solution has been prepared. A method for estimating intake rate from advance data using that graphical solution has been developed. A theoretical and measured relationship between water distribution efficiency and the dynamic nature of soil infiltration has been demonstrated. An approximate method for estimating cutback flow rates necessary to prevent tailwater runoff has been derived.

(h) "Surface Irrigation Water Distribution Efficiency Related to Soil Infiltration." E.T. 
Smerdon and L.J. Glass. Trans. Amer. Soc. Agric. Engr., Vol. 8, pp. 76-78, 82, 1965. "A Solution of the Irrigation Advance Problem," O.C. Wilke and E.T. Smerdon. Jour. of Irr. and Drain. Div., ASCE, Vol. 89, No. IR3, pp. 2334, Sept. 1965.

(5940) RESEARCH ON THE MORPHOLOGY OF PRECIPITATION AND RUNOFF IN TEXAS.

(b) Water Resources Inst., Texas A and M Univ.

(c) Dr. Robert A. Clark, Dept. of Meteorology, Texas $A$ and $M$ Univ.

(d) Field and laboratory investigation; applied research.

(e) An investigation of the rainfall-producing mechanism and associated hydrologic regime in Texas. Data obtained from a dense network of recording and non-recording rain gages will be correlated with that obtained from a dualfrequency radar system. This information will then ve related to actual data on surface runoff. The network of rain gages is located over the East Yegua Creek drainage basin, 243 $\mathrm{sq} \mathrm{mi}$, which is approximately 30 to $45 \mathrm{mi}$ west of the radar system. In addition, a network of 40 rain gages in an urban area of $7 \mathrm{sq} \mathrm{mi}$ will be used to study precipitation variation within a small area and the effects of urbanization on surface runoff.

(g) These studies have demonstrated the feasibility of utilizing weather radar in "real-time" flood forecasting. Instrumental accuracy of a weather radar for the measurement of the water concentrations in clouds was investigated also. The results compare favorably with those from more complicated and somewhat more expensive techniques.

(h) "Streamflow Forecasting Based on Statistical Applications and Measurements Made with Rain Gage and Weather Radar," Michael D. Hudlow, Ph.D. Dissertation, Texas A and M Univ., Aug. 1967.

"Applicability of Radar Observations to the Prediction of Storm Runoff," Odell M. Johnson, M.S. Thesis, Texas A and M Univ., May 1967. "On the Feasibility of Precisely Measuring the Properties of a Precipitating Cloud with a Weather Radar," Robert C. Runnels, Ph.D. Dissertation, Texas A and M Univ., Jan. 1968. "A Stochastic Technique for Synthesis of Hourly Precipitation," John P. Huddle, Texas A and M Univ., May 1967.

(6600) ELECTROKINETIC REMOVAL OF POLLUTANTS FROM WATER.

(b) Texas $A$ and $M$ University.

(c) Dr. Edward A. Hiler, Asst. Prof., Dept. of Agricultural Engrg., Texas $A$ and $M$ Univ.

(d) Experimental; basic and applied.

(e) The purpose of this research is to investigate, in the laboratory, the electrokinetic removal of various pollutants from water. The removal of colloidal clay, bacterial, and pesticidal pollutants is to be considered. The general plan of work includes: (1) development of an optimal electrode arrangement based on results of theoretical and basic experimental research, (2) characterization of various contaminants present in natural waters, and (3) evaluation of the efficiency of removal of these pollut. ants by the electrokinetic method. This study is directed toward a critical evaluation of the feasibility of the electrokinetic method in the field of water supply and pollution control.

(g) The experimental system will be completed by
February, 1968. Experimentation and analysis of data will begin at that time.

UNIVERSITY OF TEXAS, Hydraulic Engineering Lab., Dept. of Civil Engrg., Austin, Texas 78712

(2161) CHARACTERISTICS OF A HYDRAULIC JUMP AT AN ABRUPT CHANGE IN BOTTOM ELEVATION.

(b) Univ. of Texas Research Institute and Bureau of Engineering Research.

(c) Dr. Carl W. Morgan, Assoc. Prof. of Civil Engrg., Univ of Texas.

(d) Experimental.

(e) Experimental determinations were made of the flow characteristics at two-dimensional channel drops and rises. The velocity distribution and surface profile were determined throughout the length of the jump for various relative changes in bottom elevation. The longitudinal location of the jump in relation to the change in bottom elevation was varied over a broad range in contrast with previous related investigations in which relative location of the jump was held constant.

(2162) HYDROLOGIC STUDIES, WALIER CREEK WATERSHED.

(b) Cooperative with U.S. Geological Survey.

(c) Dr. Walter L. Moore, Dept. of Civil Engrg., The Univ. of Texas.

(d) Field investigation; applied research.

(e) Measurements of rainfall and runoff for a 4 square mile and a 2 square mile portion of the waller Creek watershed are being made to provide basic information for estimating runoff from small urban watersheds in the Southwest area. Two stream flow stations and a rain gage net are in operation. Studies of the correlation between runoff, rainfall, and the characteristics of the drainage basin are being made by various proposed methods to serve as a base comparison with the data as it is collected.

(g) Data has been collected since 1356 by the U.S.G.S. and for later years is available in special reports listed below. Data has been used in a number of hydrologic studies and its use will continue.

(h) "Hydrologic Data of Waller Creek, Colorado River Basin, Texas, 1961, 1962, 1963." Geological Survey - Water Resources Div., Surface Water Branch, Austin District, Austin, Texas. "Compilation of Hydrologic Data, Waller and Wilbarger Creeks, Colorado River Basin, Texas, 1964." Geological Survey - Water Resources Div., Austin, Texas.

"Compilation of Hydrologic Data, Waller and Wilbarger Creeks, Colorado River Basin, Texas, 1964." Geological Survey - Water Resources Div., Austin, Texas.

(2397) EFFECT OF UPSTREAM DEVELOPMENT ON THE RUNOFF FROM SMALI WATERSHEDS IN THE SOUTHWEST.

(b) Laboratory project.

(c) Dr. Walter L. Moore; see (2162) above.

(d) Field investigation; thesis.

(e) For selected watersheds rainfall-runoff relations are being developed on a storm by storm basis. Multiple correlation diagrams, based on data before changes in the watershed, have been developed and used to compute runoff for later periods. Comparison of these computed runoff values with measured values is 
taken as an index of the effect of watershed development. See also project 5456, p. 128.

(g) The first results were not conclusive because of random error in the computed values. Further studies are being made with an improved method which better accounts for the spatial variation of rainfall.

(h) "Multiple Correlation Estimates of Runoff as Effected by Area Distribution of Rainfall," Stanley P. Sauer, Hydraulic Engrg. Lab. Tech. Rept. HYD 03-6301, June 1963. "Compilation of Hydrologic Data, Mukewater Creek, Colorado River Basin, Texas, 1965," U.S. Geological Survey - Water Resources Div., Austin, Texas.

(2874) AN INVESTIGATION OF THE SCOUR RESISTANCE OF COHESIVE SEDIMENTS.

(b) The University of Texas Research Institute.

(c) Dr. Frank D. Masch, Dept. of Civil Engrg., The Univ. of Texas.

(d) Analytical and experimental (laboratory).

(e) Exploratory tests have been made with two different schemes, one with radially outward flow between a circular disc and the soil sample, and one with a submerged vertical circular jet impinging on a horizontal soil surface. With the first scheme it was not possible to obtain the necessary precision of measurement at low scour rates, but with the second scheme satisfactory measurements were obtained. A correlation based on dimensional analysis gave consistent results in evaluating the relative scour resistance of several materials. Apparatus has been fabricated for a new test which permits direct evaluation of the shear stress at the soil surface. In this test a cylindrical soil sample is submerged in a transparent concentric cylinder which can be rotated at a controlled speed to generate a shear stress on the soil surface. Attempts are being made to relate the scour resistance to other measurable soil properties, and finally to interpret the results in relation to field observations.

(f) Suspended.

(g) Using test procedures previously developed, a series of tests have been run to determine the effect of moisture content on the critical shear stress for Taylor Marl. Tests have been run at nearly constant degree of saturation.

(h) "Measurements of the Shear Resistance of Cohesive Sediments," F.D. Masch, W.H. Espey and W.I. Moore, Proc. Federal Inter-Agency Sedimentation Conf., 1963 Agricultural Research Service Misc. Publ. No. 970, June 1965.

(3522) IONG TIME FLUCTUATIONS IN STREAM RUNOFF.

(b) Laboratory project.

(c) Dr. Carl W. Morgan, Dept. of Civil Engrg., Univ. of Texas.

(d) Analytical and field study.

(e) Values of runoff from selected drainage areas in the lower Mississippi River Pasin and in basins of the rivers emptying directly into the Gulf of Mexico were studied. Variations in the runoff values for each stream were considered and these trends compared with solar variations. The relative sunspot numbers were used as the measure of solar variations and were correlated with the mean annual runoff. Further correlations are being made with different "lag" periods betwe;en solar activity and surfar:s runoff. (f) Completed.

(g) The gradual shifting of the centers of runoff excess and deficiency is consistent rather than random and appears to represent a gradual cyclic change in the runoff pattern. It appears that the locations of the centers of runoff deficiency are following roughly the same path that they did some 22 to 24 years previously. Correlation coefficients of plus 0.2 to plus 0.5 are obtained for selected rivers in Mississippi, Alabama, Georgia, and Arkansas when sunspot numbers in the 11-year sunspot cycle are correlated with runoff. Texas streams do not give significant correlation with the 1l-year sunspot cycle but give better correlation if runoff is compared with the double sunspot cycle in which sunspot numbers are assumed as negative in alternate cycles.

(3524) GROUND WATER FLOW AND SHEPAGE IN NON-HOMOGENEOUS, NON-ISOTROPIC SEDIMENTS.

(b) Laboratory project.

(c) Dr. Walter L. Moore, Dept. of Civil Engrb., The Univ. of Texas.

(d) Theoretical; basic.

(e) A relaxation solution for the Iaplace equation has been developed for application to any specified non-homogeneous, non-isotropic media, and programed for the electronic computer. Additional work is needed to simulate certain boundary conditions. It is then intended that the solutions to select problems obtained by the computer program and by electrolytic tank model be compared.

(4234) EVAPORATION REDUCTION BY CONTROL OF ADVECTED ENERGY.

(b) Partial sponsorship by the Lower Colorado River Authority of Texas.

(c) Dr. Walter I. Moore; see (3524) above.

(d) A Master's thesis involving theoretical and field investigation.

(e) Measurements have been made to determine the temperature field in Lake Travis for the 1962-63 season. A method was developed to estimate the effect of withdrawing water from near the lake surface. Monthly estimates of the resulting temperature field and reduction in evaporation were made.

(4235) TWO-PHASE FLOW IN CONDUITS.

(b) Laboratory project.

(c) Dr. Walter I. Moore; see (3524) above.

(d) Experimental; Master's thesis.

(e) It is apparent that for a two-phase flow system with a liquid and gas, many different types of flow are possible. This investigation explored the use of sound measurements to detect the type of flow present, in a metal pipe. Various types of flow were established in a thin-walled aluminum pipe, 1.66 I.D., with a transparent plastic section at each end. Records of the sound pattern were made with different pick-ups and correlated with the visual observation of the flow type. Magnetic tape records of the sound were also made.

(g) Study of the recorded sound patterns revealed some identifiable characteristics related to the type of two-phase flow in the line. Additional work is needed to refine techniques and try other sound pick-up and recording methods. 
(4716) DRAG FORCES IN VELOCITY GRADIENT FIELDS.

(b) Naval Ship Research and Development Ctr.

(c) Dr. Frank D. Masch and Dr. Walter L. Moore, Dept. of Civil Engrg., Univ. of Texas.

(d) Theoretical and experimental; basic research.

(e) The investigation is being conducted to determine the effect of a velocity gradient on the local and conventional drag coefficients for cylinders of varying $L / D$ ratio and at different Reynolds Numbers. The study will be extended to other shapes.

(f) Completed.

(g) Studies have demonstrated that the velocity gradient along a cylinder affects the drag coefficient. The local drag coefficient decreases along the cylinder in the direction toward the end of the cylinder where the velocity is high. The reduction in drag coefficient is related to a dimensionless measure of the velocity gradient along the cylinder. The angle at which separation occurred was found to increase near the bottom of the cylinder where the free stream velocity is low.

(h) "The Influence of Secondary Flows on Drag Forces," Charles Dalton and Frank D. Masch, Hydraulic Engrg. Lab. Tech. Rept. No. HYD 04-6503, The Univ. of Texas, July 1965.

(4990) WAVE CHARACTERISTICS IN SHOALTNG WATER.

(b) Laboratory project.

(c) Dr. Frank D. Masch, Dept. of Civil Engrg., The Univ. of Texas.

(d) Theoretical; basic and applied research; Master's thesis.

(e) This study is to develop a workable method for computing water wave characteristics in shoaling water using cnoidal wave theory. The method involves evaluating the power transmission for a wave train in shallow water from cnoidal theory and using the concept of constant power between orthogonals on a refraction diagram. The study has been expanded to include computation of velocity, acceleration and pressure fields.

(g) Integrals of the cnoidal functions have been evaluated in terms of elliptic integrals and computer programs have been developed to solve the resulting equations.

(h) "Cnoidal Waves in Shallow Water," Frank D. Masch, Chapter I, Proc. Ninth Conf. on Coastal Engrg., Amer. Soc. Civil Engrs., Lisbon, Portugal, June 1964.

"Velocity and Acceleration Fields," C.Y. Lee, M.S. Thesis, The Univ. of Texas, Auston, May 1966.

(4991) IOCAI SCOUR IN CHANNELS.

(b) Laboratory project.

(c) Dr. Frank D. Masch and Dr. Walter L. Moore, Dept. of Civil Engrg., The Univ. of Texas.

(d) Theoretical and experimental; basic and applied research.

(e) This project is designed to investigate the characteristics of the three dimensional flow patterns at channel obstructions and to study the extent to which these flows affect local scour. It is believed that a more thorough understanding of the fundamentals of the flow at an obstruction would provide the basis to devise methods for controlling scour. The nature of scour at culverts is also under consideration with efforts being devoted to develop methods for dissipating energy and reducing local scours. (f) Suspended.

(h) "The Influence of Secondary Flows in Local Scour at Obstructions in Channels, "W.L. Moore and Frank D. Masch, Proc. Fed. InterAgency Sedimentation Conf., 1963, Agricultural Research Service, Misc. Publ. No. 970, June 1965.

(5455) HYDROLOGY OF SMALL URBAN WATERSHEDS.

(b) Bureau of Engineering Research, Texas Water Commission.

(c) Dr. Carl W. Morgan, and Dr. Frank D. Masch, Dept. of Civil Engrg., The Univ. of Texas.

(d) Field investigation, basic research.

(e) Data from selected watersheds have been collected. These are being studied to evaluate the effects of urbanization on the hydrologic characteristics of the watersheds.

(g) For the Waller Creek Watersheds, Austin, Texas, preliminary results indicate that because of approximately twice as high percent of impervious cover in the lower part it produced yields per unit area approaching twice that of the upper area.

(h) "A Study of Some Effects of Urbanization on Storm Runoff from a small Watershed," W.A. Espey, Jr., Ph.D. Dissertation, The Univ. of Texas, August 1965.

"A Study of Some Effects of Urbanization on Storm Runoff from a small Watershed," W.A. Espey, Jr., C.W. Morgan and F.D. Mesch, Hydraulic Engineering Lab. Tech. Rept. No. HYD 07-6501, The Univ, of Texas, July 1965.

(5456) MATHEMATICAL MODELS FOR RELATING RUNOFF TO RAINEAII.

(b) Office of Water Resources Research.

(c) Dr. Walter L. Moore, Dept. of Civil Engrg., The Univ. of Texas.

(d) Doctoral thesis based on computer analysis of field data.

(e) The study was originally based on multiple correlation analysis of individual storms to obtain storm runoff. The procedure utilized both the temporal and spatial variation of rainfall on the watershed and gave good results for any number of complex storms. The work at present is directed toward application of the Stanford watershed model and developing an improved method to simulate the infiltration and soil moisture accounting portions of the model.

(g) Good results were obtained by the multiple correlation method for predicting runoff hydrographs for individual storms. The Stanford watershed model has been translated into a Fortran program for the CDC 6600 computer and limited runs have checked the output. Modifications to the program will be made as improved concepts for simulating infiltration and soil moisture accounting are developed.

(h) "The Synthesis of Storm Runoff Hydrographs from Unsteady Non-Uniform Rainfall," C.L. Smith, Ph.D. Dissertation, The Univ. of Texas, 1965.

(5457) A NEW TYPE ENERGY DISSIPATOR FOR CULVERT OUTLETS.

(b) Texas Highway Dept. and U.S. Bureau of Public Roads.

(c) Dr. Walter L. Moore; see (5456) above.

(d) Experimental and theoretical thesis work.

(e) A study is being made of a culvert energy dissipator based on the use of a sector of a 
circular hydraulic jump. Apparent advantages of the device are the stability of the jump over a range of discharge and tailwater conditions and the opportunity to spread the culvert discharge back to the original stream width. Problems of practical geometry have been explored and initial designs developed for a structure that performs well for a considerable range of tailwater conditions. The structure is adaptable for use either at the outlet of a box culvert or a circular pipe culvert.

(h) "A Radial Flow Energy Dissipator for Culvert Outlets," Raymundo Aguirre, Ph.D. Dissertation, Jan. 1968, The Univ. of Texas.

"An Energy Dissipator for Culvert Outlets Incorporating Radial Flow and a Transverse Sill," Robert Randle Wear, M.S. Thesis, Jan. 1968, The Univ. of Texas.

(5458) SEDIMENTATION IN GALVESTON-TRINITY BAYS.

(b) Texas Parks and Wildlife Comission and Department.

(c) Dr. Frank D. Masch, Dept. of Civil Engrg., Univ. of Texas.

(d) Experimental, field; applied research.

(e) Field investigation to determine the currents, sources of sediment, and sediment movement in Galveston and Trinity Rays, and to determine the effect they may have on the dredging of mudshell, oysters and oyster production.

(h) "Progress Report on Current and Sediment Movement in Galveston-Trinity Bays," Frank D. Masch, Hydraulic Engrg. Lab. Rept. No. HYD 06-6501, The Univ. of Texas, Jan. 1965. "Shell Dredging as a Factor in Estuarine Sedimentation," Frank D. Masch, Specialty Conf. on Coastal Engrg., Santa Barbara, Calif., Amer. Soc. Civil Engrs., Chapter 25, Oct. 1965. "Shell Dredging - A Factor in Sedimentation in Galveston Bay," Frank D. Masch and W.H. Espey, Jr., Hydraulic Engrg. Tech. Rept. No. HYD 06-6702, The Univ. of Texas, Nov. 1967.

(5459) FINITE-AMPLITUDE GRAVITY WAVES.

(b) Laboratory project.

(c) Dr. I.R. Mack, Dept. of Engrg. Mechanics, Univ. of Texas.

(d) Theoretical; basic research.

(e) In order to obtain better quantitative agreement with the experimental frequency determinations of Fultz and of Edge, the analytical solutions for two-dimensional standing waves have been carried to the fifth order in amplitude. Velocity distribution, free-surface configuration, frequency of oscillation and energy of the wave motion are determined.

(f) Completed.

(g) Surface configuration, frequency of oscillation, maximum amplitude, and the division of energy have been investigated. For a certain range of depths the oscillation exhibits "hardspring" behavior for small amplitudes and soft-spring behavior for larger amplitudes. Close correlation is noted between soft-spring behavior of the frequency and the mean potential energy being greater than the mean kinetic energy. More accurage evaluation has been made of Bessel-function integrals needed in studies of axisymmetric gravity waves.

(h) "On the Maximum Amplitude of Periodic Gravity Waves," Benny E. Jay, M.S. Thesis, Univ. of Texas, June 1966.

"The Partition of Energy in Standing Gravity Waves of Finite Amplitude," Lawrence R. Mack and Benny E. Jay, Jour. Geophys. Res., Vol. 72 , No. 2, pp. 573-581, Jan. 15, 1967.

"Bessel-Function Integrals Needed for Two Classes of Physical Problems," Charles E. McQueary and Lawrence R. Mack, Mathematics of Computation, Vol. 21, No. 99, pp. 413-417, July 1967.

"Standing Gravity Waves of Finite Amplitude," in Developments in Theoretical and Appl. Mechanics, Vol. 3, Pergamon Press, pp. 691712,1967 or 1968.

(5460) WIND WAVE OVERTOPPING OF SHOREIINE STRUCTURES.

(b) Bureau of Engrg. Research, Univ. of Texas.

(c) Dr. Frank D. Masch, Dept. of Civil Engrg., Univ. of Texas.

(d) Experimental; thesis.

(e) This study is designed to compare overtopping from wind waves with that predicted from criteria based on uniform wave trains. Overtopping is being measured under varying wind and wave conditions. Particular study is being given to beach geometry immediately in the front of the structure and its effect on overtopping rates.

(g) Results obtained to date show that the greater the depth of water at the wall, the greater the overtopping rates. The offshore beach profiles appear to have little or no effect on overtopping from wind generated waves.

(5461) ANALYSIS OF UNIT HYDROGRAPHS FOR SMAIL WATERSHEDS.

(b) Laboratory project.

(c) Dr. Carl W. Morgan, Dept. of Civil Engrg., The Univ. of Texas.

(d) Field investigation; thesis.

(e) Characteristic, two-hour unit hydrographs were determined for each of three selected watersheds. The derived dimensionless hydrograph shapes were compared with two widelyused empirical hydrographs. Techniques were studied for using the S-curve hydrograph as an aid in estimating the correct duration of rainfall excess by selecting that duration which caused the least fluctuation in the Scurve.

(g) The dimensionless 2 hour unit hydrographs developed in this study indicate that the falling limbs of the Commons and Mockus hydrograph shapes may need revision in order to be applied to watersheds of less than 100 square miles in area. However, these differences are only minor suggesting that an average dimensionless graph and reliable estimates of only two parameters, period of rise and peak discharge may be sufficient to define the shape of the unit hydrograph. Results indicate the S-curve can be used to estimate by trial and error the rainfall excess duration if rainfall data is not available.

(5753) MIXING AND DISPERSION OF CONTAMINANTS IN RESERVOIRS.

(b) Federal Water Pollution Control Admin.

(c) Dr. Frank D. Masch; see (5460) above.

(d) Basic and applied research; field investigation.

(e) This investigation has been undertaken to study the mixing and dispersion of contaminants in inland fresh waters. The study includes an investigation of the effects of currents, turbulent wave action, and periodic overturning on the disposition of waste 
materials discharged into reservoirs and lakes. The stability effects of temperature and density gradients within the receiving waters are also being determined. Mixing processes in both deep and shallow water reservoirs are being studied in the field.

(h) "Field Investigation of Mixing and Dispersion in a Deep Reservoir," Joe R. Wilson and Frank D. Masch, Hydraulic Engrg. Tech. Rept. No. HYD 10-6701, The Univ. of Texas, June 1967.

(5954) PHYSICAI EXCHANGE CHARACTERISTICS OF TEXAS BAYS.

(b) Center for Research in Water Resources Project.

(c) Dr. Frank D. Masch; see (5460) above.

(d) Analytical; field investigation; applied research.

(e) To evaluate the assimilative capacity of Texas Gulf Coast Bays, studies are being carried out to determine a mathematical model which is descriptive of the mixing, dispersive and exchange characteristics of these bays. Preliminary analysis has proceeded on the basis of a modified tidal prism exchange model. Steps are now under way to improve this type model.

(h) "Estimates of Physical Exchange in Galveston Bay," Lloyd V. Urban, M.S. Thesis, The Univ. of Texas, Aug. 1966.

"Return Flows - Impact on Texas Bays System," Frank D. Masch, et al., Bryant - Currington Technical Rept. to Texas Water Development Board, January 1966.

(5955) PERFORMANCE OF CIRCULAR CULVERTS ON STEEP GRADES .

(b) Texas Highway Department.

(c) Dr. Frank D. Masch; see (5460) above.

(d) Experimental and theoretical research.

(e) This study is concerned with the behavior of the hydraulic jump in circular broken-back culverts. Of particular concern are the conditions under which a jump will form in the culvert. The study is also concerned with methods to insure that the jump forms in the culvert.

(h) "Performance of Culverts on Steep Grades," Bobby Earl Price, Ph.D. Dissertation, The Univ. of Texas, Aug. 1967.

(5956) SPILLWAY MODEI STUDIES - TOLEDO BEND DAM.

(b) Forrest and Cotton Consulting Engineers.

(c) Dr. Frank D. Masch and Dr. Walter L. Moore, Dept. of Civil Engrg., The Univ. of Texas.

(d) Applied research; laboratory investigation.

(e) Model studies on the spillway section of the Toledo Bend Dam were carried out for the purpose of determining the hydraulic performance characteristics of the spillway section of the dam including stilling basin effectiveness, flow behavior in the upstream and downstream channels, and gate operating sequence for a range of discharges including the normal fllood, the design flood, and the maximum probable flood.

(h) "Model Studies - Toledo Bend Dam," Walter I. Moore and Frank D. Masch, Hydraulic Engrg. Lab. Tech. Rept. No. HYD 08-6501, The Univ. of Texas, Oct. 1965.

(6180) TEMPERATURE FIEIDS IN STRATIFIED RESERVOIRS.

(b) Cooperative laboratory project with the Texas Electric Service Company.

(c) Dr. Walter L. Moore, Dept. of Civil Engrg.,
The Univ. of Texas.

(d) Applied research; laboratory investigation.

(e) The temperature field in a stratified reservoir may be influenced by such factors as, temperature and amount of heated inflow, location of inflow, location of outflow, heat input through surface radiation, and wind shear applied at the surface. A generalized laboratory model 8 feet long and a foot wide is being constructed in which these factors can be individually controlled. The temperature field and its change with time will be measured by 100 thermistors located at selected points throughout the model. The model is designed to explore the relative effect of the various factors controlling the temperature field rather than to simulate any specific field conditions. An effort will be made to compare results obtained by computer simulation with those from the model.

(6181) SPIILWAY MODEL STUDIES - DE CORDOVA BEND DAM.

(b) Brazos River Authority and Emmerson Engineering Company.

(c) Dr. Frank Masch, Dr. Walter L. Moore and Dr. Carl W. Morgan, Dept. of Civil Engrg., The University of Texas.

(d) Applied research; laboratory investigation.

(e) Model studies were made on the outlet works for the De Cordova Bend Dam to obtain the design solutions for a critical flow problem. After important modifications to the design including lowering the apron floor, important improvements were obtained.

(h) "Model Studies De Cordova Bend Dam Outlet Works Energy Dissipator, "Frank D. Masch, Carl W. Morgan and Walter L. Moore, March 1967.

(6182) DISPERSION IN SHALIOW ESTUARIES OF IRREGULAT SHAPE.

(b) Office of Water Resources Research.

(c) Dr. Frank D. Masch, Dept. of Civil Engrg.. The Univ. of Texas.

(d) Analytical and experimental research.

(e) This research involves the development and verification of a numerical model to evaluate transport characteristics in shallow vertically mixed estuaries of arbitrary shape. The model is designed to assist in developing water quality requirements and assimilative capabilities of estuaries typical of those found along the Gulf Coast of the United States. The study includes adaptation of an existing numerical model of the two-dimensional, time dependent convective dispersion equation and the evaluation of dispersion coefficients from graphical and analytical considerations of the scale of turbulence and circulation in the estuary.

(6183) REIATION OF PASSES ON PHYSICAL EXHANGE AND SALINITY IN ESTUARIES.

(b) Office of Water Resources Research and Texas Water Development Board.

(c) Dr. Frank D. Masch; see (6182) above.

(d) Experimental and theoretical research.

(e) Most of the estuaries along the Texas Gulf Coast are separated from the Gulf of Mexico by a long thin chain of offshore or barrier islands. The exchange between gulf and bay waters takes place through a few natural and artificial passes through the barrier islands. It is the principle objective of this proposed project to determine whether 
the physical exchange of waters between the bays and gulf can be increased by either dredging new passes, or by enlarging existing passes through thic barrier islands. In particular, the effects of modifications or additions of passes on the volume of physical exchange, the degree of mixing, and on salinity gradients is to be determined.

(6184) NATURAI CONVECTION WITHIN ENCIOSED SPACES.

(b) Laboratory project.

(c) Dr. I.R. Mack, Dept. of Engrg. Mechanics, The Univ. of Texas.

(d) Experimental and theoretical; basic research.

(e) Velocity and temperature distributions and heat transfer.

(g) Visual studies of flow patterns and measurements of temperature profiles and overall heat transfer have been made for concentric spheres with air in the "amulus". Analytical solutions valid for convection between concentric cylinders and that between concentric spheres. Numerical solution for the case of concentric spheres is now underway.

(h) "Convective Heat Transfer Between Concentric Spheres," E.H. Bishop, R.S. Kolflat, L.R. Mack, and J.A. Scanlan, Proc. 1$) 64$ Heat Transfer and Fluid Mechanics Inst., Stanford Univ. Press, pp. 69-80, 1964.

"Photographic Studies of Convection Patterms between Concentric Spheres," E.H. Bishop, R.S. Kolflat, I.R. Mack, and J.A. Scanlan, Soc. Photo-Optical Instrumentation Engrs. Jour., Vol. 3, No. 2, pp. 47-43, Dec. 1764 - Jan. 1965.

"Heat Transfer by Natural Convection Between Concentric Spheres," E.H. Bishop, L.R. Mack and J.A. Scanlan, Intl. Jour. of Heat and Mass Transfer, Vol. 9, pp. 649-662, July 1966. "Natural Convection Within Enclosed Spaces," L.R. Mack, Proc. Symp. on Solid and Fluid Mechanics, p. 8, May 1967 (abstract).

TRACOR, INC., 627 Lofstrand Lane, Rockville, Md. 20850

(6121) AN ANATYTICAT STUDY OF THE MEASURED WALC PRESSURE FIELD UNDER SUPERSONIC TURBULENT BOUNDARY LAYERS.

(b) NASA Langley Research Center.

(c) Roy Whymark, Director, Applied Physics, TRACOR, Inc.

(d) Theoretical; applied research.

(e) Provide a physical interpretation of the structure of supersonic turbulent wall pressure field. Analyze the available wall pressure data on scaling laws derived from the new interpretation of the turbulent pressure field.

(f) Completed.

(g) The turbulent wall pressure field under supersonic shear layers is analyzed in the light of a. new theory of wall turbulence developed by the author. The theory asserts that the turbulent transfer of mass, heat, momentum and energy within the boundary layer are essentially effected within discrete, horseshoevortex structures which are generated and maintained by powerful, localized non-linear instabilities within the sublayer and which move downstream over the wall in a characteristic, quasifrozen, spatial array. In particular, the theory explains the generation of turbulent shear stress in terms of the dynamic interaction between these vortex systems and the basic shear flow through which they move. It further suggests that the turbulent wall pressure field is an essential and integral part of the turbulent shear stress mechanism and hence provides a new analytical basis for the study of boundary layer noise.

On the basis of this theory, new scaling laws are proposed for the turbulent wall pressure field under subsonic and supersonic layers. These laws feature different scaling parameters for high and low frequency portions of the spectra and indicate the effect of pressure gradients on the spectra.

(h) "An Analytical Study of Measured Wall Pressure Field Under Supersonic Turbulent Boundary Iayers," T.J. Black, TRACOR Document No. RL/67-070-U, Oct. 1967.

TRW SYSTEMS GROUP, Engineering Mechanies Lab., One Space Park, Redondo Beach, Calif. 90278

\section{(6290) SONAR DOME STUDY.}

(b) Anti-Submarine Warfare Systems Project, Dept. of the Navy.

(c) Dr. C.T. Molloy and Dr. G.C.K. Yeh, TRW Systems.

(d) Theoretical; applied research.

(e) Studies of uniform and nonuniform radiation from a spherical transducer through sea water and a concentric viscoelastic thick spherical shell to sea water.

(f) Completed.

(g) Depending on the resonance characteristics of the dome and fluid media, the presence of the dome causes an amplification of fluid pressure and velocity for certain radiation frequencies and causes a reduction of fluid pressure and velocity for other radiation frequencies. Numerical solution for the nonuniform radiation problem enables one to determine the effect of the dome upon the directivity pattern of the transducer and the effect of the dome upon the transducer velocity pattern when it is producing a prescribed pressure field.

(h) "Radiation Through Thick Shells - I, "C.T. Molloy and G.C.K. Yeh, Rept. No. 08415-6009Rooo, TRW Systems, July 1967.

"Uniform Spherical Radiation Through Thick Shells," C.T. Molloy and G.C.K. Yeh, presented at 73rd Meeting, Acoustical Soc. of Amer., 21 April 1967, New York, N.Y. and submitted to Jour. Acoustical Soc. of Amer. for publication. "Radiation Through Thick Shells - II, "G.C.K. Yeh and C.T. Molloy, Report No. 08415-6090ROOO, TRW Systems, Nov. 1967.

"Nonuniform Spherical Radiation Through Thick Shells, "G.C.K. Yeh and C.T. Molloy, presented at $74 \mathrm{th}$ Meeting, Acoustical Soc. of Amer., 16 Nov. 1967, Miami Beach, Fla., and to be submitted to Jour. Acoust. Soc. Amer. for publication.

\section{(6291) IIQUTD SIOSHING STUDIES.}

(b) U.S. Air Force and National Aeronautics and Space Administration.

(c) Dr. P.G. Bhuta, TRW Systems.

(d) Theoretical; applied research.

(e) Extensive studies on various aspects of the free and forced motions of a liquid partially filling a rigid or flexible tank.

(g) Results of the studies enable one to estimate the forces, moments and draining characteristics in fuel tanks of missiles and spacecraft 
due to sloshing motions of fuel.

(h) In addition to the over 20 reports on this subject listed in "Engineering Mechanics Reports," Revised Edition, Engrg. Mechanics Lab., TRW Systems, Redondo Beach, Calif. (1965) (most of which have been published in technical journals) typical recent outputs under this effort include:

"Coupled Oscillations of a Liquid with a Free Surface in a Tank Having a Flexible Bottom," P.G. Bhuta and L.R. Koval, Jour. Appl. Mathematics and Physics (ZAMP), Vol. 15, No. 5, oct. 1964, pp. 466-480.

"Liquid Sloshing in a Moving Tank with a Time Dependent Discontinuous Boundary," G.C.K. Yeh, Proc. Ninth Midwestern Mechanics Conf., Univ. of Wisconsin, 1965, pp. 265-276.

"Propellant Slosh Loads," R.E. Hutton and P.G. Bhuta, prepared for NASA-Langley under Contract NAS 7-346, EM 15-10, TRW Systems, 1965. "Sloshing of a Liquid in Connected Cylindrical Tanks Owing to U-Tube Free Oscillations," G.C.K. Yeh, Jour. Acoust. Soc. Amer., Vol. 40, 1966, pp. 807-812.

(6292) FLUID MECHANICS AT LOW GRAVITY ENVIROMMENT.

(b) Laboratory project and National Aeronautics and Space Administration.

(c) Dr. G.C.K. Yeh, TRW Systems.

(d) Theoretical; applied research.

(e) Several aspects of static and dynamic phenommena of a liquid under strong capillary and weak gravity conditions have been investigated.

(f) Completed.

(g) Results of the studies enable one to determine the effects of surface tension, curved free surface and contact angle on sloshing problems in missiles and spacecraft.

(h) "Fluid Mechanics at Low Gravity Environments," G.C.K. Yeh and R.E. Hutton, Em 15-4, TRW Systems, 1965.

"Sloshing of a Liquid in a Draining or Filling Tank under Variable G Conditions, "P.G. Bhuta and L.R. Koval, Proc. AFOSR-Lockheed Symp. on Fluid Mechanics and Heat Transfer under Low G Conditions, Palo Alto, Calif., 1965.

"Static Configuration of the Liquid-Vapor Interface in an Axisymetric Tank in Various Gravitational Fields," G.C.K. Yeh and R.E. Hutton, Proc. Ninth Midwestern Mechanics Conf., The Univ. of Wisconsin, 1965, pp. 291-303. "A Direct Solution for Capillary-Gravity Waves in a Cylindrical Tank, "L.R. Koval and P.G. Bhuta, Proc. Ninth Midwestern Mechanics Conf., The Univ. of Wisconsin, 1965, pp. 277-303. "Free and Forced Oscillations of a Liquid in an Axisymmetric Tank at Low Gravity Environments, "G.C.K. Yeh, Jour. Appl. Mechanics, Vol. 34, 1967, pp. 23-28.

"Forced Oscillations of a Liquid in a Cylindrical Tank at Low Gravity Environments," G.C.K. Yeh, EM 16-8, TRW Systems, 1966.

(6293) DYNAMICS OF A DIELECTRIC LIQUID IN AN ELECTRICAL FIELD.

(b) Laboratory project.

(c) Dr. L.R. Koval, TRW Systems.

(d) Theoretical; applied research.

(e) Studies on the dynamic of a dielectric liquid

(f) completed.

(g) The phenomena of dielectrophoresis can be applied to liquid orientation and slosh control in missiles and spacecraft.

(h) "Dynamics of a Cryogenic Liquid in an Electric Field," L.R. Koval and P.G. Bhuta, presented at 1966 Cryogenic Engrg. Conf., Boulder Colo., TRW Systems, 1766.

"Slosh Control by Dielectrophoresis," L.R. Koval and P.G. Bhuta, Proc. Inst. of Enviromental Sciences, 1766.

(6481) UNIFORM EXPANSION OF A SPHERICAL PISTON IN AN IDEAL COMPRESSIBLE FLUID.

(b) U.S. Atomic Energy Commission.

(c) Dr. G.C.K. Yeh, TRW Systems.

(d) Theoretical; applied research.

(e) Analysis of the pressure wave surrounding a sphere expanding with constant velocity in an ideal compressible fluid.

(f) Completed.

(g) The nonlinear equations of motion and continuity are solved numerically between the expanding sphere and shock wave. Numerical results for water are presented and compared with those according to the incompressible flow theory and the theory of sound.

(h) "Uniform Expansion of a Spherical Piston in an Ideal Compressible Fluid," G.C.K. Yeh, Proc. Fourth U.S. Natl. Congr. Appl. Mechanics, 1962, pp. 1431-1439.

UTAH STATE UNIVERSITY, College of Engrg., Utah Water Research Lab., Iogan, Utah 84321

(3183) DYNAMICS OF FLOW IN STEEP, ROUGH, OPEN CHANNELS.

(b) Laboratory and field projects; National Science Foundation.

(c) Dr. Dean F. Peterson, Dean of Engrg., Utah State Univ.

(d) Experimental, theoretical, field investigation; basic research for doctoral theses.

(e) A basic study of relationships involved in flow in steep, rough channels where the roughness is relatively an appreciable part of the depth, and where channels are sufficiently steep or steeper than a slope such that supercritical flow can occur in connection with contractions caused by the roughness. The work is basic; however, it will have application to steep mountain streams and to hydralic structures.

The objective of the work is to relate descriptive parameters describing the size and configuration of the bed roughness to slope. depth and discharge of channels of this class. Studies began using simple bar and cube elements and have progressed through the use of beds formed by gluing natural gravel elements of various size, gradation and intensity to the bed. Nineteen field sites have been installed in streams, principally in northern Utah in the Wasatch Mountains, but also in New Mexico and Colorado. Piezometric type stilling wells have been installed at thirteen sites and discharge and depth measured. Bed element distribution and size have been studied at all sites. Collection of field data has been completed and analysis is continuing. A laboratory flume study using natural gravel elements glued to the bed, with water as the fluid, was completed. The flume study is being continued using the same beds only in a mirrored effect to eliminate the free surface influence, with air as the fluid.

(f) Completed.

(g) In the flume studies, discharge and slope were varied and depth was measured for each 
of the ten beds. Two sizes of material with five different spacings for each size were used. Experimental results show a continuous change in relative dominance of the factors of gross velocity variation and turbulent mixing as the kineticity and relative depth changes. Six flow zones defined by Froude number and relative depth were suggested. It was not practical to develop a single equation to describe a conductance coefficient, C/g $1 / 2$ to cover all ranges of flow, but one equation for each zone is proposed. $C$ is from Chezy's equation and is based on a roughness spacing parameter, roughness height, and depth of flow. A measure for describing spacing was developed and a method of field application is also discussed.

(h) "The Dynamics of Turbulent Flow in Steep, Rough, Open Channels, "P.K. Mohanty, MS Thesis, Utah State Univ., 1959.

"Flume Studies of Flow in Steep, Rough, Open Channels, "D.F. Peterson, Jr. and P.K. Mohanty, Utah State Univ., 1960.

"A Study of Bed Characteristics in Relation to Flow in Rough, High-Gradient Natural Channels, " Harl E. Judd, Ph.D. Thesis, Utah State Univ., 1963.

"Relation Between the Bed Pavement and the Hydraulic Characteristics of High Gradient Channels in Non-Cohesive Sediments," Davoud Hariri, Ph.D. Thesis, Utah State Univ., 1964. "Flume Study of the Effect of Concentration and Size Roughness Elements on Flow in HighGradient Natural Channels," M.W. Abdelsalam, Ph.D. Thesis, Utah State Univ., 1965. "Flume Studies of Flow in Steep, Rough, Open Channels," D.F. Peterson, Jr. and P.K. Mohanty, Jour. Hydraulics Div. Proc. ASCE, Vol. 86, No. HY9, pp. 55-76, Paper 2653, Nov. 1960.

(3530) WATER REQUIREMENTS OF MARSHLANDS.

(b) Utah State Fish and Game Dept.

(c) Prof. Jerald E. Christiansen, Prof. of Civil and Irrigation Engrg., and Dr. Jessop B. Low, Leader, Utah Cooperative Wildlife Research Unit, Wildlife Resources, Utah State Univ.

(d) Field investigations; applied research; Master's thesis.

(e) Large areas of marshy lands adjacent to Great Salt Lake have been developed and improved by the State Fish and Game Dept., and the Federal Wildlife Service, as Migratory Bird Refuges. Available stream flow from several of the major streams which flow into these areas is impounded behind dikes to create habitats suitable for nesting, feeding, and resting of water fowl. Millions of ducks and geese utilize this area each year during their migratory flights.

(f) Completed.

(g) The basic purpose of the study was to determine the quantities of water necessary for marshlands in order to maintain them in a productive state.

(h) Eight progress reports have been written. Three M.S. theses and one Ph.D. dissertation have been completed. Final report is in manuscript form, and has been submitted to Utah State Fish and Game Dept. for publication.

(3845) WATERSHED MODEI STUDIES.

(b) Agricultural Research Service, U.S. Dept. of Agriculture.

(c) Dr. Calvin G. Clyde, Asst. Director, Utah Water Research Lab., Utah State Univ. (d) Experimental; basic research for Master's and Doctoral theses.

(e) The purpose is to establish techniques and model-prototype laws so that watersheds can be intensively studied in a laboratory. A small watershed has been modeled. A rainfall simulator has been constructed for which design or actual rainfall events can be progranmed to occur automatically over the model. The dominant factors influencing the characteristic shape of the run-off hydrography are being studied. Initial efforts have been aimed at determining effect on modeling relationships resulting from changes in the physical properties of water-chemical mixtures used in the rainfall simulator. Test runs are being made using a physical model with an impervious surface. Subsequent tests will incorporate the relationship between infiltration and run-off by providing for permeability changes in the model.

(g) Satisfactory mechanical performance and electronic control has been achieved. Verification tests to date are highly encouraging. Experimental tests are continuing.

(h) "Construction, Instrumentation, and Preliminary Verification of a Physical Hydrologic Model, "Donald L. Chery, Jr., Utah Water Research Lab. and Agricultural Research Service, U.S.D.A., 152 pp., July 1965.

\section{(5130) FARM IRRIGATION STRUCTURES.}

(b) Office of Water Resources Research.

(c) Mr. Gaylord V. Skogerboe, Research Project Engr., Utah Water Research Lab., Utah State Univ.

(d) Library research combined with design analysis.

(e) A compilation of the material pertaining to the design of small irrigation structures that would be found on a farm. Will also determine gaps in information which will require additional research.

(5131) A STUDY OF THE STRUCTURE AND EDDY DIFFUSIVITY OF TURBUIENT SHEAR FLOWS IN ROUGH OPEN CHAINNELS.

(b) Laboratory project.

(c) Dr. Calvin G. Clyde, Asst. Director, Utah Water Research Lab., Utah State Univ.

(d) Experimental and theoretical; basic research for Ph.D. thesis.

(e) The objectives of the project are: (1) to describe the structure of the turbulent shear flows in rough open channels; (2) to see if local isotrophy exists in the turbulence under study; and (3) to investigate the relationship of the structure of the turbulence to the process of diffusion in the flow. The experimental studies have been conducted in a 3 foot flume artificially roughened on the bottom with expanded metal mesh. A total head tube with barium titanate as the piezoelectric sensor has been used to measure turbulent velocity fluctuations in the direction of the mean flow. The signal was analyzed with a random signal indicator and correlator, a delay line, and a spectrum analyzer. Measurements were made at a section where the boundary layer growth had reached the free surface and the flow was essentially two dimensional.

(f) Completed.

(g) In the outer region of fully developed turbulent flow in the rough open channel, the wave number at which the transition between locally isotropic and anisotropic turbulence 
occurs is independent of Reynolds Number, but varies inversely with the depth of flow. Even in fully developed turbulent flow, local isotropy does not exist near the bed in the presence of steep mean velocity gradients. Hence, the concept of local isotropy is inadequate for obtaining the distribution of the rate of dissipation of energy, notwithstanding its use to evaluate the local rate in the outer region. The structure of the turbulence in the flows studied has been described in terms of longitudinal macroscale and microscale, relative intensity, and energy spectrum. The channel roughness has only an indirect influence on the structure of turbulence by transforming the flow into fully developed turbulent flow at a lower Reynolds Number. A procedure has been developed for estimating the statistical characteristics of the turbulence in fully developed turbulent shear flow in channels from a knowledge of the mean flow quantities.

(h) "A Study of the Structure of Shear Turbulence in Free Surface Flows," M.V. Rao, Ph.D. Thesis, Utah State Univ., 1965.

(5133) UTAH STATE UNIVERSITY STILLING BASIN FOR PIPE TO OPEN CHANNEL FLOW.

(b) Laboratory project.

(c) Mr. Gaylord V. Skogerboe; see (5130) above.

(d) Experimental research for M.S. theses.

(e) The objective of this study is to find an economical and effective means of energy dissipation at the transition of pipe flow to open channel flow.

(f) Completed.

(g) An effective design has been found involving a short dissipator pipe placed on the opposite wall of the stilling basin from the inflow pipe. The best ratios have been found for: the dissipator pipe diameter to inflow pipe diameter, length of dissipator pipe to inflow pipe diameter, slit width to inflow pipe diameter, and center line offset to the inflow pipe diameter. The second MS thesis is studying the effect of changing the inlet pipe diameter and the inlet pipe velocity on the most efficient design described above.

(h) Two M.S. theses have been completed.

(5134) FREE SURFACE EFFECTS ON THE DRAG OF A HEMISPHERE ON A BOUNDARY, IN VELOCITY GRADIENT FLOW.

(b) National Science Foundation.

(c) Dr. Gordon H. Flanmer, Prof. of Civil Engrg., Utah State Univ.

(d) Theoretical and experimental work leading to a doctoral dissertation.

(e) The objectives of this study were to: (1) study the relative effects of the Froude number and the Reynolds number for various relative submergences of an isolated hemisphere in open channel flow; (2) to correlate the total drag coefficient with the Froude number and Reynolds number with calculations based upon flow conditions measured with the hemisphere in place, and with the hemisphere removed; correlation of wave drag coefficient with Froude number for flow conditions measured as in part 1 involving evaluation of the wave drag and the wave drag coefficient in correlation of the wave drag with the Froude number; and (4) analysis of the overall wave patterns and their effect on the drag.

(f) Completed. (h) "Free Surface Effects on the Drag of a Hemisphere on a Boundary in Velocity Gradient Flow, "James P. Tullis, Ph.D. Dissertation, Utah State Univ., 1966.

(5140) ELECTRONIC ANALOG MODEL STUDIES OF RIVER BASINS.

(b) Soil Conservation Serv., U.S. Dept. of Agric.

(c) Dr. Jay M. Bagley, Director, Utah Water Research Lab., Utah State Univ.

(d) Experimental.

(e) An electronic analog model of a river basin is being constructed. The basic hydrologic processes of precipitation, snowmelt, surface and subsurface runoff, groundwater storage and movement, evapotranspiration, streamflow, etc. have been modeled electronically. Model will be used to predict performance of various parts of hydrologic system resulting from proposed water management and developing changes.

(f) Completed.

(g) The completed analog model is being effectively utilized in the Sevier River Investigations of the Soil Conservation Service.

(h) "The Development of an Electronic Analog Device for Hydrologic Investigations and Conservation Planning in the Sevier River Basin," J.M. Bagley, J.P. Riley, and E.K. Israelsen, Utah Water Research Lab., Utah State Univ.

(5442) EVAPORATION AND CLIMATIC STUDIES.

(b) Laboratory project.

(c) Prof. Joel E. Fletcher, Utah Water Research Lab., Utah State Univ.

(d) Experimental; applied research.

(e) Evaporation from land, snow, and water surfaces constitutes the principal losses of water to the United States. The investigation of factors which affect the quantity, quality and timing of these losses from a climatic standpoint are being investigated in order to assist in the more precise formulation of plans of water utilization.

(f) Suspended.

(g) On the basis of dendroclimatic records, it appears that many of Utah's irrigation projects have been designed on the basis of a short, wet cycle.

(5443) MICROCLIMATIC HYDROIOGY

(b) Laboratory project.

(c) Prof. Joel E. Fletcher; (see 5442) above.

(d) Experimental and field investigation; applied research.

(e) Methods for evaluating and measuring the microclimatic factors associated with water supply and use are being investigated.

(f) Suspended.

(5446) THEORY OF INFIITRATION AND FLUID MOVEMENT IN UNSATURATED POROUS MEDIA.

(b) Laboratory project.

(c) Dr. Calvin G. Clyde, Asst. Director, Utah Water Research, Utah State Univ.

(d) Theoretical, experimental; basic research, applied research.

(e) To develop mathematical relationships expressing the phenomena of infiltration. Primary interest is the infiltration of water into the soil. Further development is to extend the developed theory to other fluid and media.

To develop mathematical relationships expressing the fluid movement in unsaturated porous 
media. Primary interest is the movement of water in unsaturated soil.

To evaluate the validity and applicability of the relationships developed from the mathematical analysis by field and laboratory tests.

(f) Discontinued.

(g) Improvements have been made on the developed equations and the solutions.

(h) "One Dimensional Infiltration into Homogeneous Soil," Yu-Si Fok and Vaughn E. Hansen, Jour. Irrigation and Drainage Div., Proc. ASCE, Paper 4912, Sept. 1966.

(5449) HYDRAULICS OF SURFACE IRRIGATION.

(b) Laboratory project.

(c) Dr. A. Alvin Bishop, Head, Dept. of Agricultural and Irrigation Engrg., Utah State Univ.

(d) Theoretical, with field investigation.

(e) To provide fundamental surface irrigation design understanding through the investigation of hydraulic characteristics of surface flows, including (1) further development of mathematical models describing the flows in terms of the many variables involved; (2) laboratory experiments to describe and evaluate the component variables; and (3) a few trials to test the validity of mathematical equations.

(g) Equations have been developed to describe the various relationships in surface irrigation such as length of $r u n$, rate of advance, application efficiency, and intake rate.

(h) "The Influence of Intake Function on the water Advance Function for Surface Irrigation," Charles C.C. Shih, Master's Thesis, Utah State Univ., 1966.

"Analysis of Application Efficiency as Related to Intake Function and Recession Function for Surface Irrigation, "Lam K. Lim, Master's Thesis, Utah State Univ., 1966.

"Analysis of Surface Irrigation Application Efficiency," Lyman S. Willardson and A. Alvin Bishop, Jour. Irrigation and Drainage Div., Amer. Soc. Civil Engrs., IR2, June 1967.

(5450) ELECTROKINETIC POTENTIAL IN SOIL CAPILLARIES.

(b) Laboratory project.

(c) Dr. Calvin G. Clyde, Asst. Director, Utah Water Research Lab., Utah State Univ.

(d) Experimental and theoretical; basic research for $\mathrm{Ph} . \mathrm{D}$. dissertation.

(e) This study was conducted to investigate analytically and experimentally the relationship between the rate of flow of water through porous material and the streaming current and streaming potential induced by this flow. The effect of dissolved salts in the permeating solution, the size of the soil particles, and the temperature of the solution was also investigated.

(f) Completed.

(g) The rate of flow (at a constant salt concentration and soil particle diameter) is directly proportional to the induced streaming current and streaming potential. A decrease in both streaming current and streaming potential was observed with increase of salt concentrate in the permeating solution. A decrease in current and potential was observed with increase of soil particle diameter. Induced streaming potential was found to increase with the decrease in temperature. The analytical relationships developed together with the experimental work form the basis of a method of measuring the rate of flow through porous material. (h) "Streaming Current and Streaming Potential Induced by Water Flow Through Porous Media," Mohamed M.I. Abaza, Ph.D. Dissertation, Utah State Univ., 1966.

(5452) HYDRODYMAMICS OF FREE SURFACE FLOW OVER HYDRAULIC STRUCTURES.

(b) Laboratory project.

(c) Dr. Gary Z. Watters, Assoc. Prof. of Civil Engrg., Utah State Univ.

(d) Theoretical and experimental; for Ph.D. dissertation.

(e) An approximation to real fluid flow over hydraulic structures is being attempted by using a rotational ideal fluid. It is hoped that separation zones can be adequately enough described by this approximation to yield meaningful pressures, velocities, discharge coefficients and free surface locations.

(5747) APPLICATION OF ELECTRONIC AITALOG DEVICES TO SOLUTION OF HYDROLOGIC AND RIVER BASIN PLANIIING PROBLEMS.

(b) Office of Water Resources Research.

(c) Dr. Jay M. Bagley and Prof. Duane G. Chadwick, Utah Water Research Lab., Utah State Univ.

(d) Experimental; design, and development.

(e) Comprehensive study and new development of hydrologic relations employed in current model. Design improvement will be made in order to handle a greater range and variety of problems with more flexibility, reliability, and speed of operation.

(f) Completed.

(h) "Application of Electronic Analog Computer to Solution of Hydrologic and River-Basin-Planning Problems: Utah Simulation Model II, "J.P. Riley, D.G. Chadwick, and J.M. Bagley, Utah Water Research Lab., Utah State Univ., 129 pp., Oct. 1966.

(5748) SEQUENTIAL WATER USE WITHIN A HYDROLOGIC COMPLEX.

(b) Federal Water Pollution Control Admin.

(c) Dr. David W. Hendricks, Assoc. Prof., Utah Water Research Lab., Utah State Univ.

(d) Field investigation, applied research.

(e) The study will utilize data from the Little Bear River Basin in developing guides to the improved administration and management of water in a complex system of sequential uses. The prototype information will provide basis for development and testing of analytical methods of analyzing a variety of sequential water use problems.

(5749) OPTIMIZING CONJUNCTIVE USE OF SURFACE AND GROUNDWATER .

(b) Office of Water Resources Research, Dept. of the Interior; Div. of Water Resources, Dept. of Natural Resources, State of Utah; Utah Water Research Lab., Coll. of Engrg., Utah State Univ.

(c) Dr. Calvin G. Clyde, Asst. Director, Utah water Research Lab., Utah State Univ.

(d) Theoretical; applied research.

(e) Maximum beneficial use of a total water supply in a basin requires that both surface and underground water be utilized. In the past, schemes for conjunctive use of surface and groundwaters have usually involved a selection of the best alternative among a small number of different plans. The purpose of this investigation is to develop a true optimization methodology for conjunctive use schemes and 
involves the following phases: (1) general definition of the problem; (2) development of planning and design guidelines for conjunctive use systems; (3) derivation of a general equation or benefit function which describes the benefit component from each part of the water resource; (4) description of a mathematical model of the hydrologic system composed of equations or inequalities describing the interrelationships among the parts of the system as well as the physical, legal and economic constraints; (5) application of dynamic linear progranming to the mathematical model to maximize or minimize the particular benefit function being considered. The benefit function of primary concern is the amount of water available for beneficial use, but alternative optimization objectives are to minimize the waste of water, to minimize salt accumulation, or to maximize the total economic return; (6) utilization of an actual, but simple, hydrologic complex to test the guidelines and optimization techniques.

(h) "Optimizing Conjunctive Use of Surface Water and Groundwater," Calvin G. Clyde, Bartell C. Jensen, and James H. Milligan, Proc. Symp. on Groundwater Development in Arid Basins, Utah State Univ., Logan, Utah, pp. 59-86, March 1967.

"A Procedure for Determining the Feasibility of Planned Conjunctive Use of Surface and Groundwater," Barry C. Saunders, M.S. Thesis, Utah State Univ., 1967.

(5750) ATMOSPHERIC WATER RESOURCES IN UTAH.

(b) United States Bureau of Reclamation.

(c) Prof. George W. Reynolds, Project Leader, Utah Water Research Lab., Utah State Univ.

(d) Project is primarily experimental, heavily dependent upon field investigations and can be classified as both basic and applied research.

(e) Cloud seeding is to be done along the Wasatch Front to determine the feasibility of increasing water supplies, delineating the areas affected by individual generators, and determing the unique characteristics of the snow producing storm systems. The investigation includes the installation and operation of a dense telemetering precipitation measurement network, meteorological and hydrologic support systems and studies; statistical evaluation.

(h) Project Technical Reports may be obtained by request from the Utah Water Research Iab., Utah State Univ., Logan, Utah.

"Brief Abstracts of Some Papers on Seeding Agents, "Jay D. Schiffman and Joel E. Fletcher, Utah Water Research Lab., Utah State Univ., Feb. 1967.

"Reliability of Can-Type Precipitation Gage Measurements, " C. Earl Israelsen, Utah Water Research Lab., Utah State Univ., 1967. "The Reliability of USU Telemetered Precipitation Data--1," George W. Reynolds and Duane G. Chadwick, Utah Water Research Lab., Utah State Univ., July 1967.

(5752) OVERLAND FLOW.

(b) Laboratory project.

(c) Dr. Calvin G. Clyde; see (5749) above.

(d) Theoretical; basic research.

(e) The general differential equation for overland flow describes a great variety of practical problems such as surface irrigation, the hydrologic analysis of basins and the spreading of water over infiltration areas for groundwater recharge. The objec.. tive of this research is to determine the general solution to the equation by finite difference methods and illustrate the dependence of the solution on the parameters involved by presenting the important phases of the solution in dimensionless form.

(f) Suspended.

(g) Preliminary and simplified studies of the equation reveal that the solution is strongly affected by the inflow and outflow conditions as well as the roughness and slope of the channel.

(h) "Techniques of Border Irrigation by a Hydrologic Method of Routing," Chen-lung Chen, PRWR-11-1, Utah Water Research Lab., Coll. of Engrg., Utah State Univ. "Mathematical Hydraulics of Surface Irrigation, "Chen-lung Chen, PRW-1l-2, Utah Water Research Lab., Coll. of Engrg., Utah State Univ., June 1966.

"Theory and Characteristics of Overland Flow," Cheng-lung Chen and Vaughn $\mathrm{E}$. Hansen, Trans. ASAE, Vol. 9, No. 1, pp. 20-26, 1966.

(5755) PRESSURE, SHEAR AND VELOCITY DISTRIBUTION AROUND A HEMISPHERE ON A BOUNDARY IN A FINITE THREE-DIMENSIONAL FLOW FIEID WITH FREE SURFACE EFFECTS.

(b) National Science Foundation grant.

(c) Dr. Calvin G. Clyde; see (5749) above.

(d) Experimental and theoretical research leading to a doctoral dissertation.

(e) The objectives of this study are to detemine the flow characteristics in the immediate vicinity of a hemisphere located on a boundary in a finite three-dimensional flow field with free surface effects. Such flow characteristics as the velocity distribution, the pressure distribution, the shear stress distribution and boundary layer development and separation patterns will be studied.

(f) Completed.

(h) "Hydrodynamic Forces and Pressure Fluctuations on a Hemisphere on a Boundary in Velocity Gradient Flow Considering Free Surface Effects," Talaat M. Owais, Ph.D. Dissertation, Utah State Univ., 1967.

(5756) TURBULENCE CHARACTERISTICS OF FLOW AROUND A HEMISPHERE IN 'A VELOCITY GRADIENT FIEID WITH FREE SURFACE EFFECTS.

(b) Laboratory project.

(c) Dr. Gordon H. Flammer, Prof., Civil Engrg. Dept., Utah State Univ.

(d) Experimental and theoretical research leading to a doctoral dissertation.

(e) To study such instantaneous properties of the flow field in the near vicinity of the hemisphere as: the measurement of turbulence intensity, space correlations, cross correlations, the auto correlation curve, the instantaneous lift and drag forces on the hemisphere as related to turbulence characteristics near the hemisphere, the effect on the structure of the free stream turbulence of the hemisphere placed in the flow upstream; and to deduce the law of decay of turbulence behind the hemisphere, also, to compare the intensity of turbulence near the hemisphere for the semiinfinite non-uniform flow field, the finite non-uniform flow field without a free surface, 
and a finite non-uniform flow field with a free surface.

(f) Suspended.

(5757) TURBULENCE CHARACTERISTICS OF FLOW AROUND AN ISOLATED CUBE IN A VELOCITY GRADIENT FIELD WITH FREE SURFACE EFFECTS.

(b) Laboratory project.

(c) Dr. Gordon H. Flamer; see (5756) above.

(d) The project is experimental and theoretical in nature leading to a doctoral dissertation.

(e) To study the instantaneous properties of the flow field in the near vicinity of the cube such as intensity of turbulence, space correlations, cross correlations, auto correlation curves, instantaneous drag and lift forces correlated with the turbulence characteristics of the hemisphere, wake turbulence decay; and to compare the intensity of turbulence near the hemisphere for (1) a semi-infinite nonuniform flow field; (2) the finite non-uniform flow field without a free surface; and (3) a finite non-uniform flow field with a free surface.

(f) Suspended.

(5758) LIFT AND DRAG FORCES ON ISOLATED CUBICAL ROUGHNESS ELEMENTS WITH FREE SURFACE EFFECTS.

(b) National Science Foundation and Engrg. Expmt. Sta., Utah State Univ.

(c) Dr. Gary Z. Watters, Assoc. Prof., Civil Engrg., Utah State Univ.

(d) Experimental; for Ph.D. dissertation.

(e) Lift and drag forces on cubical roughness elements are measured with a strain gage dynamometer. The measurements are taken for infinitely deep flow, finite-depth flow without free surface effects, finite-depth flow with free-surface effects, and finite flow with free surface effects and a natural velocity gradient in the flow. This should lead to a more fundamental understanding of energy dissipation due to large roughness elements.

(i) Completed.

(h) Dissertation by James Adamek will be available in 1968.

(5761) DRAG AND SURFACE WAVE CHARACTERISTICS FOR THE ISOLATED SEMI-CIRCULAR DISK IN A FINITE THREEDIMENSIONAL FIOW FIEID WITH FREE SURFACE EFFECTS.

(b) Laboratory project.

(c) Dr. Gordon H. Flammer; see(5756) above.

(d) Experimental and theoretical leading to Ph.D. dissertation.

(e) To study the drag on an isolated disk on a boundary for (1) an infinite uniform flow field; (2) a semi-infinite non-uniform flow field; (3) a finite uniform flow field without a free surface; (4) a finite non-uniform flow field without a free surface; (5) a finite uniform flow field with a free surface; and (6) a finite non-uniform flow field with a free surface. The surface wave characteristics will be studied for items (5) and (6).

(f) Suspended.

(5762) SUBMERGED OPEN CHANNEL FLOW MEASUREMENT STRUCTURES.

(b) Office of Water Resources Research, U.S. Dept. of Interior.

(c) Mr. Gaylord V. Skogerboe, Research Project Engr., Utah Water Research Lab., Utah State Univ.

(d) Experimental; applied research. (e) A hydraulic model study is being undertaken to provide calibration curves. An experimental model is being designed and constructed wherein the lengths of the entrance, throat, and exit may be varied; the width of the throat may be varied; the sides of the model can be placed in various positions to form either rectangular or trapezoidal shapes; and the degree of convergence and divergence may be varied. In addition to the above variable quantities, the effects of conditions in the channel both upstream and downstream from the flume, the scale factor, and roughness of the flume walls and floor will be evaluated.

(f) Completed.

(g) An evaluation of geometry and boundary conditions on both free flow and submerged flow ratings in flumes has been made. The results have shown that the submerged flow analysis can be used for any type of side constriction or floor constriction (weir). In addition, a flat-bottomed flume has been developed, and given the name "cutthroat." The flume was developed primarily as a submerged flow measuring device.

(h) "Design and Calibration of Submerged Open Channel Flow Measurement Structures: Part 1, Submerged Flow," G.V. Skogerboe, M.L. Hyatt, and K.0. Eggleston, Rept. WG31-2, Utah Water Research Lab., Coll. of Engrg., Utah State Univ., Feb. 1367.

"Design and Calibration of Submerged Open Channel Flow Measurement Structures: Part 2, Parshall Flumes," G.V. Skogerboe, M.L. Hyatt, J.D. England, and J.R. Johnson, Rept. WG 31-3, Utah Water Research Lab., Coll. of Engrg., Utah State Univ., March 1967.

"Design and Calibration of Submerged Open Channel Flow Measurement Structures: Part 3, Cutthroat Flumes, "G.V. Skogerboe, M.L. Hyatt, R.K. Anderson, and K.O. Eggleston, Rept. WG31-4, Utah Water Research Lab., Coll. of Engrg., Utah State Univ., April 1967. "Design and Calibration of Submerged Open Channel Flow Measurement Structures: Part 4, Weirs, "G.V. Skogerboe, M.I. Hyatt, and L.H. Austin, Rept. WG31-5, Utah Water Research Lab., Coll. of Engrg., Utah State Univ., May 1967. "Analysis of Submergence in Flow Measuring Flumes, "G.V. Skogerboe and M.L. Hyatt, Proc. ASCE, Jour. Hydraulics Div., Vol. 93, No. HY4, Proc. Paper 5348, pp. 183-200, July 1967. "Subcritical Flow Over Highway Embankments," G.V. Skogerboe and M.L. Hyatt, Proc. ASCE, Jour. Hydraulics Div., Vol. 93, No. HY6, Proc. Paper 5564, pp. 65-78, Nov. 1967. "Rectangular Cutthroat Flow Measuring Flumes," G.V. Skogerboe and M.I. Hyatt, Proc. ASCE, Jour. Irrigation and Drainage Div., Vol. 93, No. IR4, Proc. Paper 5628, pp. 9-13, Dec. 1967.

(5764) MODIFICATIONS TO GATE-PARSHATL FLUME STRUCTURE.

(b) Utah Highway Dept.

(c) Mr. Gaylord V. Skogerboe; see (5762).

(d) Experimental; applied research.

(e) Twin turnout structures have been constructed from the Davis-Weber Canal which employ a gate followed by a four-foot Parshall flume four feet deep. The flow passing through the flume is supercritical. Modifications to the turnout structures will be studied with a prototype structure constructed in the laboratory.

(f) Completed. 
(h) "Modifications to Gate-Flume Structures on the Weber-Davis Canal," by G.V. Skogerboe and M.I. Hyatt, Rept. PR-WG24-4, Utah Water Research Iab., Utah State Univ., Feb. 1966.

(6516) ELECTRONIC ANALOG SIMULATION OF RUNOF'F FROM SMALL WATERSHED AREAS.

(b) Office of Water Resources Research.

(c) Dr. J.P. Riley, Assoc. Prof., Utah Water Research Lab., Coll. of Engrg., Utah State Univ.

(d) Experimental and theoretical; applied research for $\mathrm{Ph} . \mathrm{D}$. thesis.

(e) Simulation by the analog computer of hydrologic processes over small increments of time and space. The model facilitates runoff estimates from storms and snowmelt which occur in short time intervals in the area.

(g) Close agreement has been achieved between observed and computed runoff hydrographs.

(6517) APPIICATION OF ANALOG COMPUTER SIMULATION TECHNIQUES FOR RUNOFF PREDICTIONS WITHIN THE REYNOLDS CREEK WATERSHED.

(b) Agricultural Research Service, U.S. Dept. of Agriculture.

(c) Dr. J.P. Riley; see (6516) above.

(d) Experimental; applied research.

(e) Simulation of basic hydrologic processes on a watershed by the analog computer for establishing runoff predictions.

(6518) A STUDY OF THE INTEGRATION OF THE WATER RESOURCES OF THE BEAR, WEBER, AND JORDAN RIVERS IN NORTHERN UTAH.

(b) Dept. of Natural Resources, Div. of Water Resources, State of Utah.

(c) Dr. J.P. Riley; see (6516) above.

(d) Experimental; applied research.

(e) Analog simulation is being used as a tool to study the feasibility of water exchange between the Bear and Jordan River systems, using the waters of the Weber River as the exchange medium.

(6519) THE SIMULATION OF HYDROLOGIC EVENTS IN ARID REGIONS.

(b) Agricultural Research Service, U.S. Dept. of Agriculture.

(c) Dr. J.P. Riley and Prof. Duane G. Chadwick, Utah Water Research Lab., Utah State Univ.

(d) Experimental and theoretical; applied research for M.S. and Ph.D. theses.

(e) The hydrologic characteristics of watersheds in semi- arid regions are dependent upon many varied and often interrelated factors. A quantitative knowledge of these factors and of their relative influence upon the system as a whole is needed in order to improve the efficiency of watershed management in these areas. A comprehensive analog computer model of a semiarid watershed is being developed. Modeling concepts are based upon the development of basic relationships which describe the various processes which occur within the surface hydrologic system of a semiarid watershed. Once established, the model is applicable to any particular geographic unit by determining the appropriate constants of the hydrologic equations. The analog computer is ideally suited to the many time-dependent differential equations which are encountered in hydrologic systems. To test individual equations and to verify the model, a sub-basin of Walnut Gulch watershed in southern Arizona is being simulated.

(g) In preliminary tests close agreement has been achieved between observed and computed runoff hydrographs for single convective storms. Some progress has also been made in the development of both analog and digital techniques for plotting isohyetal lines corresponding to selected time intervals during the course of a storm.

(h) "Application of an Electronic Analog Computer for the Simulation of Hydrologic Events on a Southwest Watershed," J. Paul Riley, Duane G. Chadwick, and Eugene K. Israelsen, PRWG38-I, Utah Water Research Lab., Utah State Univ., 53 pages, Feb. 1967.

(6520) APPLICATION OF AN ELECTRIC ANALOG COMPUTER TO THE SIMULATION OF THE TOTAI HYDROIOGICECONOMIC FLOW SYSTEM.

(b) Office of Water Resources Research.

(c) Dr. J.P. Riley, Assoc. Prof., Utah Water Research Lab., Utah State Univ.

(d) Experimental; applied research for doctoral thesis.

(e) The purpose of the research is to develop, improve, and evaluate basic relationships which link the hydrologic and economic flow systems and investigate the feasibility of using an electronic analog computer to synthesize fundamental hydrologic and economic processes into a working model of the total hydrologiceconomic flow system.

(6521) ELECTRONIC ANALOG SIMULATION OF THE SALTNITY FLOW SYSTEM WITHIN THE UPPER COLORADO RIVER BASIN.

(b) Federal Water Pollution Control Admin.

(c) Dr. J.P. Riley; see (6520) above.

(d) Experimental; applied research for master's and doctoral theses.

(e) The objective of the research is to simulate the hydrologic and salinity flow systems of a river basin and evaluate various possibilities for a water supply of a given quantity and salinity.

(6522) APPLICATION OF AN ELECTRONIC ANALOG COMPUTER TO THE EVALUATION OF THE EFFECTS OF URBANIZATION ON THE RUNOFF CHARACTERISTICS OF SMALI WATERSHEDS.

(b) Office of Water Resources Research.

(c) Dr. J.P. Riley, Assoc. Prof. and Duane G. Chadwick, Assoc. Prof., Utah Water Research Lab., Utah State Univ.

(d) Theoretical and experimental; applied research for Ph.D. thesis.

(e) The electronic analog computer has several appealing characteristics which suggest exceptional potential for the simulation of the complex flow system of urban watersheds. Under the proposed study the background of experience already gained at Utah State University will be applied to the development of a basic model of urbanized watersheds. In brief, the major objectives of the study are (1) to develop, improve, and evaluate fundamental mathematical relationships for describing the various processes which occur within an urban watershed, and (2) to synthesize these relationships into a dynamic watershed model by means of an electronic analog computer. The model will be verified by simulating urban watersheds. 
6523) FLOW RESISTANCE OVER SCHEMATIC DUNES IN OPEN CHANNELS.

(b) Laboratory project.

(c) Eugene K. Israelsen, Research Engr., Utah Water Research Lab., Utah State Univ.

(d) Theoretical and experimental; for M.S. thesis.

(e) In alluvial streams the flow and the bed interact in a complex flow phenomenon to form a variety of movable beds. This research is an attempt to define the functional relationship between the bed friction factor and other measurable parameters describing the flow and bed characteristics.

(f) Completed.

(g) The relationship appears to be a multiplevalued function so no definite analytical function was derived. Definite tendencies were suggested from the graphic expression of the parameters.

(h) "Effect of the Free Surface on the Resistance to Flow Over Schematic Dunes in Open Channels," Eugene K. Israelsen, Master's thesis, Utah Water Research Lab., Utah State Univ., 91 pages, 1967.

(6524) INCIPIENT MOTION OF LARGE ROUGHNESS ELEMENTS IN TURBULENT OPEN CHAINNEI FLOW.

(b) National Science Foundation.

(c) Dr. Calvin G. Clyde, Asst. Director, Utah Water Research Lab., Utah State Univ.

(d) Theoretical and experimental; basic research; Ph.D. dissertation.

(e) Suitable criteria will be developed for the incipient motion of large roughness elements (hemispheres and spheres varying in diameter between 3 and 12 inches) in turbulent open channel flow under prototype conditions. The parameters to be utilized are time-dependent lift and drag forces, intensity of turbulence, edge velocity, velocity and gradients, flow depths, discharge, and energy gradient.. The flow resistance of large roughness elements will be measured in order to extend present flow resistance data to large elements and, also, to verify whether or not particular criteria developed from research on various smaller roughness elements by other investigators are applicable to the larger roughnesses. The interrelationships between timedependent lift and drag forces, intensity of turbulence, probability of incipient motion, flow resistance, and other hydraulic parameters will be studied.

(g) Beds of spheres (3-3/4 inch and 12 inch diameter) have been prepared and experiments run in the $6 \mathrm{ft}$. by $8 \mathrm{ft}$. by $500 \mathrm{ft}$. flume. Instrumentation has been developed to measure simultaneously the $\mathrm{x}, \mathrm{y}$ and $\mathrm{z}$ components of total fluctuating force on one hemispherical roughness element.

(h) "The Structure of Turbulence in an Open Channel with Large Spherical Roughness Elements, " Farooq Nazir, M.S. Thesis, Utah State Univ., 1967.

(6525) HYDRODYNAMIC FORCES ON NON-COHESIVE EED PARTICLES, INCLUDING SEEPAGE.

(b) National Science Foundation.

(c) Dr. Gary Z. Watters, Assoc. Prof., Civil Engrg. Dept., Utah State Univ.

(d) Experimental; for Ph.D. dissertation.

(e) Fine sand partireles on the berds of alluvial streams are morleled in a recirculating flume. The fluid is oil and spheres 3.75 inches in diameter $r \in p r e s e n t$ the sand particles. The effect of seepage on the forces exerted on the bed particles by the flowing fluid are measured by a strain-gage dyamometer. The object of the study is to determine whether or not seepage does influence the hydrodynamic forces and, if so, to what degree and under what conditions.

(6526) FEASIBIIITY OF RATING CURRENT METERS IN A VELOCITY FIEID.

(b) U.S. Geological Survey.

(c) Mr. Gaylord V. Skogerboe, Research Project Engr., Utah Water Research Lab., Utah State Univ.

(d) Experimental; applied research.

(e) The primary objective of this study is to investigate the feasibility of rating current meters by placing them in a submerged jet emanating from a contracting cone section. Model cones will be constructed based upon both published design criteria and theoretical analysis. The model cones will be evaluated for uniformity of the velocity field and the effects of placing a pygmy meter in the jet. The results of the model studies will form the basis for designing a prototype system, which will be evaluated using the standard current meters used by the U.S. Geological Survey.

(6527) STEADY STATE PLANE SEEPAGE THROUGH NON-HOMOGENEOUS POROUS MEDIA AND AXIAL SYMMETRIC SEEPAGE.

(b) National Science Foundation.

(c) Roland W. Jeppson, Asst. Prof., Utah Water Research Iab., Utah State Univ.

(d) Theoretical applied research.

(e) The objectives of the proposed research are to obtain solutions to the following steady state, free surface seepage problems using appropriate transformations by the methods of finite differences.

1. Two-dimensional plane seepage from channels of arbitrary geometry through nonhomogenous porous media to a drained layer at a specified tinite depth.

2. Axial symmetric seepage from ponds of arbitrary profiles through homogeneous isotropic or anisotropic porous media which may consist of layers of different permeabilities to a drained layer at a specified depth.

3. Axial symmetric flow to a production well (and from a recharge well) which partially or fully penetrates a homogeneous isotropic or anisotropic aquifer.

(h) "Finite Difference So utions to Free-Surface Flow Through Non-Homogeneous Porous Media," Rept. No. WG52-1, Utah Water Researc Iab., Utah State Univ., Sept. 1967.

(6528) WATER QUALITY TELEMETRY.

(b) Federal Water Pollution Control Admin.

(c) Duard S. Woffinden, Research Engr., Utah Water Research Iab., Utah State Univ.

(d) This is a demonstration project.

(e) The purpose of this project is to show the feasibility of telemetering water quality parameters on demand from a remote battery powered monitoring station. The system as developed will transmit any water quality variable which can be transduced into an electrical signal.

(f) Active to May 1968.

(g) To date (December 1967) the necessary equipment and parts have been gathered and the inter- 
facing circuitry designed. The equipment will now be calibrated and is expected to be in full operation by the beginning of 1968.

(6529) WINTER STREAMFIOW CHARACTERISTICS UNDER ICE.

(b) Laboratory project.

(c) Richard Bennett, Water Survey of Canada, Calgary District Office, Calgary, Alberta.

(d) Experimental; applied; Master's thesis.

(e) The objectives are: (1) to examine the accuracy of discharge measurements under ice cover and (2) to develop a method of obtaining reliable winter records.

(6530) FEASIBIIITY STUDY OF A CAPACITANCE-TYPE ELECTRONIC SEDIMENT-SENSING DEVICE.

(b) Soil and water Conservation Research Div., Agric. Research Service, U.S. Dept. Agric.

(c) C. Earl Israelsen, Research Engr., Utah Water Research Lab., Utah State Univ.

(d) Experimental; applied research.

(e) Electrical capacitance between plates submerged in water is proportional to the dielectric constant of the water-sediment mixture. The value of the dielectric constant can be an indication of the sediment present. An investigation is being made to determine the feasibility of this method for measuring sediment concentration.

(h) The progress report to the supporting agency is not available for general distribution.

(6531) HYDROLOGIC ATLAS OF UTAH.

(b) Office of Water Resources Research and Utah Water and Power Board.

(c) Roland W. Jeppson, Utah Water Research Iab., Utah State Univ.

(d) Applied research.

(e) The objective is to analyze and evaluate existing hydrologic and climatologic data of Utah to determine the magnitude of the available water resources and their spatial and time variations. The data will be reduced to maps, charts, graphs, and tables carefully developed for easy understanding and simplicity of use.

(h) "Mass Curve Analysis of Stream Flow for Determining Reservoir Storage Requirements - A Computer Program for Generalized Use," Utah Water Research Lab., Utah State Univ., April 1967.

"Frequency and Magnitudes of Monthly and Annual Flow Rates as Determined by (a) a Normal Distribution, (b) a Log Normal Distribution - A Computer Program of Generalized Use," Utah water Research Lab., Utah State Univ., April 1967.

"Frequency Analyses and Probable Storage Requirements by Frequency Mass Curve Methods A Computer Program for Generalized Use, "Utah Water Research Lab., Utah State Univ., May 1967. "Consecutive Streamflow Averages for 90 Utah Stations, "Utah Water Research Lab., Utah State Univ., June 1967.

(6532) THE EFFECTS OF SNOW COMPACTION ON THE UNDERLYING CROP AND SOIL.

(b) Thiokol Chemical Company.

(c) Joel E. Fletcher, Prof. of Hydrology, Utah Water Research Lab., Utah State Univ.

(d) Project is a field investigation of the effects of compacting the overlying snow on soil moisture and crop growth. It is applied research.

(e) Snow at three locations is rolled with a
Thiokol snow compactor following each major snowfall of the winter. As snow melt occurs the amount of water stored in the soil profile is measured and compared to corresponding areas not compacted. Observations are made on compacted and uncompacted areas for snow mold drainage and other crop responses.

(g) It presently appears that compacting the snow tends to increase the amount of water stored in the soil.

(6533) RANGE SITES AS INDEXES FOR BASIC INFILTRATION PARAMETERS.

(b) Agricultural Research Service, U.S. Dept. of Agriculture.

(c) Joel E. Fletcher; see (6532) above.

(d) The project consists of a theoretical derivation of the parameters involved in the runoff-infiltration relation and its confirmation under field conditions.

(e) A theoretical model of infiltration is to be derived which involve the parameters used in classifying "Range Site and Condition." The model is to be tested under known watershed runoff and conditions.

(6534) FACTORS INFLUENCING THE FLOW OF SUB-SOIL WATER IN THE IMMEDIATE PROXIMITY OF AND INTO DRAINAGE FACIIITIES.

(b) Laboratory project.

(c) A. Alvin Bishop, Head, Dept. of Agricultural and Irrigation Engrg., or S. Abdollah Jenab, Asst. Research Prof., Dept. of Agricultural and Irrigation Engrg., Utah State Univ.

(d) Theoretical with field evaluations.

(e) To analyze and describe the subsurface flow of water and those factors which affect it in the immediate vicinity of the drainage facility (tile line, ditch, drain, well, etc.) for the preparation of improved criterion procedures for the design, installation, and operation of drains.

(g) A drainage function has been developed to describe the relationship of the water table to drainage discharge and aquifer for the transient case.

(h) "The Influence of Exchangeable Ions and Their Concentration in the Pore Fluid on Plastic and Strength Properties of Cohesive Soils," Mahmoud H. Abdel-Aziz, Ph.D. Dissertation, Utah State Univ. Library, 1965.

"Influence of Exchangeable Ions on the Stability of Drain Banks," Mahmoud H. Abdel-Aziz, A. Alvin Bishop, and Irving S. Dunn, Trans. Amer. Soc. Agric. Engrs., Vol. 9, No. 6, 1966. "Shearing Strength of Clay after Soaking in Water, "Tsung-Te Chou, Master's Thesis, Utah State Univ. Library, 1966.

"A Study of Salt Concentrations and Types of Absorbed Ions in the Soils Near an Open Drain," Ming-Hua Chuang, Master's Thesis, Utah State Univ. Library, 1967.

"Stability of Slopes of Open Drain Channels," David C.I. Chung, Master's Thesis, Utah State Univ. Library, 1965.

The following projects have been reported in the water Resources Research Catalog:

( $42 W$ ) STATE WATER PLAN INVESTIGATIONS. (Formerly No. 5138).

(043W) EVALUATION OF REMOTE ELECTRO-MAGNETIC SENSORS FOR DETECTING TRANSPIRATIONAL WATER USE BY PLANTS SUBJECTED TO VARIOUS FOLTAR CHFIMICAL TREATMENTS DESIGIED TO REDUCE TRAINSPIRATION 
LOSSES. (Formerly No. 5751).

(O44W) DEVELOPMENT AND EVALUATION OF IMPROVED TECHNIQUES TO MEASURE WATER-CONIENT OF SNOW.

(045W) CHARACTERISTICS OF UTAH STREAMS.

(046W) HYDROLOGY OF THE GREAT SALT LAKE.

(O4TW) OPTIMIZATION IN THE USE OF VARIABLE QUALITY DESAITED WATER AND AIT ARTIFICIAL UNDERGROUND RESERVOIR TO SUPPLY PEAK MUNICIPAI, WATER DEMANDS.

(O48W) EFFECT OF MINERALIZED SPRINGS ON UTAH'S WATER RESOURCES.

VANDERBIIT UNIVERSITY, Dept. of Sanitary and Water Resources Engrg., Nashville, Tennessee 37203

(5688) TURBULENT DIFFUSION AND RIVER WASTE ASSIMILATIVE CAPACITY.

(b) Federal Water Pollution Control Admin.

(c) Dr. P.A. Krenkel, Prof. and Chariman, Dept. of Sanitary and Water Resources Engrg., Box 1670Sta. B, Vanderbilt Univ.

(d) Field and laboratory observations are used to verify theoretical considerations of the relation between turbulence and gas absorption. The investigations involve basic and applied research and have resulted in $1 \mathrm{M} . \mathrm{S}$. and $2 \mathrm{Ph}$. D. theses.

(e) The project objectives are (a) to determine the applicability of the mathematical models describing turbulent diffusion to river flow, (b) to examine laboratory and field methodology for determination of the various mixing coefficients in the laboratory and field under controlled conditions, utilizing pulse testing techniques, (c) to develop frequency response characteristics of various streams under differing hydraulic conditions, and (d) to correlate turbulent diffusion characteristics of natural streams to the reaeration capacity and, thus, the waste assimilative capacity.

(f) Completed, as of January 31, 1967.

(g) Observations of the mixing coefficients and reaeration characteristics have been made in several TVA rivers and in the laboratory. A new mathematical model describing the exchange of tracer material with "dead zones" has been found to partially account for the discrepancies in theoretical and observed "flow-thru" curves and preliminary relationships have been proposed between the various mixing coefficients.

A new method and formulae have been developed for determination of the reaeration capacity of natural streams which describe the variation in available data better than any other presently used method.

(h) "Longitudinal Mixing and Reaeration in Natural Streams," Edward I. Thackston and Peter A. Krenkel, Tech. Rept. No. 7 in Sanitary and Water Resources Engrg., Vanderbilt Univ., 1966. "Mass Transport Mechanisms in Open Channel Flow," James R. Hays, Peter A. Krenkel, and Karl B. Schnelle, Jr., Tech. Rept. No. 8 in Sanitary and Water Resources Engrg., Vanderbilt Univ., 1966.

"Investigations on Turbulent Diffusion in Inland Waterways," James S. Morris, Peter A. Krenkel, and Edward I. Thackston, Tech. Rept. No. 14 in Sanitary and Water Resources Engrg., Vanderbilt Univ., 1967.
"Least Squares Estimation of Mixing Coefficients," Edward I. Thackston, James R. Hays, and Peter A. Krenkel, Jour. Sanitary Engrg. Div., ASCE, Vol. 93, SA3, 47-58, June 1967.

"Longitudinal Mixing in Natural Streams,"

Edward I. Thackston and Peter A. Krenkel, Jour. Sanitary Engrg. Div., ASCE, Vol. 93, SA5, 67-90, Oct. 1967.

"Application of Frequency-Response Techniques to Analysis of Turbulent Diffusion Phenomena," James R. Hays, Karl B. Schnelle, Jr. and Peter A. Krenkel, Jour. Water Pollution Control Federation, Vol. 38, No. 10, 1669-1682, Oct. 1966.

(6165) TURBUTENT DIFFUSION AND REAERATION IN NATURAL RIVERS.

(b) Federal Water Pollution Control Admin.

(c) Dr. P.A. Krenkel; see (5688) above.

(d) Laboratory and field studies are conducted to test and demonstrate theoretical predictions, previously derived, and to indicate direction for further theoretical work. The project includes both basic and applied research and demonstration of usefulness and applicability of results. Both M.S. and Ph.D. theses may result from the work.

(e) The project objectives are (a) to measure reaeration rates and relevant turbulence parameters in selected rivers under controlled conditions; (b) to test the applicability of recently developed theoretical mathematical models describing reaeration and mixing in natural rivers, and (c) to determine the utility of refined tracer techniques in describing mixing phenomena in unsteady-state flow conditions and stratified flow.

(g) The applicability of a recently developed model of mixing in open-channel flow incorporating tracer technique storage in dead zones to natural streams has been demonstrated. Methods for the prediction of the parameters in the mathematical model from basic hydraulic data have been developed.

The effects of stratified flow regimes on mixing were experimentally studied in the laboratory with heated and cold water as the differing density fluids. Results obtained were similar to those obtained using salt solutions as the denser fluid.

(h) "Mathematical Modeling of Dispersion in Rivers," Karl B. Schnelle, Jr., Edward L. Thackston, and Peter A. Krenkel, Proc. XIIth Congr. Intl. Assoc. Hydraulic Research, Vol. 4, pp. 33-41, June 1967.

VIDYA DIVISION, Itek Corporation, 1450 Page Mill Rd., Palo Alto, Calif. 94304.

(5199) THE EFFECT OF FLOW SEPARATION FROM THE HULI ON THE STABILITY OF A HIGH SPEED SUBMARINE.

(b) Office of Naval Research; Naval Ship Res. and Dev. Ctr. (jointly) under the BuShips Fundamental Hydromechanics Program.

(c) Mr. S. B. Spangler, Nielsen Engrg. and Research, Inc., 3967 East Bayshore, Palo Alto, Calif. 94303.

(d) Theoretical; applied research.

(e) The purpose of the work is to develop methods for predicting the nonlinear portions of the forces and moments on a submarine for motion 
in both the horizontal and vertical plane. The motions considered are steady pitching and yawing angular velocities, high angle of attack, and axial flow. The nonlinear force distributions arise from the wakes shed by forward appendages in crossflow and flow separation from the hull. These wakes are characterized by potential vortices for purpose of computing interference force distributions.

(f) Completed.

(g) For moderate steady pitching or yawing angular velocities, the interference forces in the plane of motion due to the wakes of the forward appendages are small and may be neglected. The cross coupling effects for yawing motion are large and highly nonlinear. No data are available to check the predicted results. For high angle of attack, the interference forces due to forward appendage wake are not appreciably affected by hull flow separation. However, this wake appears to suppress the tail forces induced by the separated wake from the hull. For axial flow the normal force and pitching moment were found to be produced primarily by the loading and wake interference of the bow/ fairwater planes operating in the upwash of the flow over the hull.

(h) "Theoretical Prediction of the Vortex Interference Effects on the Stability of a High Speed Submarine in Pitching and Yawing Motion," S.B. Spangler, Vidya Report No. 238, Dec. 30, 1966. Available through Contract Research Administrator, Code 513, Naval Ship Res. and Dev. Ctr., Washington, D.C. 20007.

(5941) PREDICTED AERODYNAMIC COEFFICIENTS AND DYNAMIC DERIVATIVES FOR DUCTED PROPELIERS.

(b) Bureau of Naval Weapons, Dept. of the Navy.

(c) Mr. M.R. Mendenhall, Nielsen Engineering and Research, Inc., 3967 East Bayshore, Palo Alto, Calif. 94303.

(d) Theoretical investigation; applied research.

(e) The main purpose of this investigation is to express the previous theoretical results (1965 Reference Number 5201) in terms of an arbitrary ducted propeller configuration. The extended analysis will predict the inflow to the propeller, radial variations of blade loading, and duct forces and moments for a specified duct, propeller, and flow condition. Other work includes mutual interference between pairs of ducted propellers and duct lip stall prediction.

(i) Completed.

(g) A computer program for the IBM 7094 has been developed to compute the performance of a specified duct-propeller combination (see item (h)). Comparisons with data on propeller inflow, blade loading and duct thrust for axial flow indicated good agreement. Radial blade loading variations were found to have little effect on duct thrust, but duct normal force increased rapidly when the loading was shifted towards the tips. A criterion was developed to predict duct lip stall which appears to give a good estimate of the advance ratio and angle of attack for the onset of stall.

(h) "Theoretical Study of Ducted Propeller Blade Loading, Duct Stall, and Interference," M.R. Mendenhall, A.R. Kriebel, and S.B. Spangler, Vidya Rept. No. 229, Sept. 1966.

"Computer Programs for Prediction of Ducted Propeller Performance," M.R. Mendenhall, S.B.
Spangler, Vidya Rept. No. 230, Sept. 1966. Available from Commander (Desk V), U.S. Naval Ordnance Lab., White Oak, Maryland 20910.

VIRGINIA POLYTECHNIC INSTITUTE, Dept. of Civil Engrg., Blacksburg, Virginia 24061

(5533) USE OF IARGE ROUGHNESS ELEMENTS FOR HYDRAULIC ENERGY DISSIPATION.

(b) Virginia Council of Highway Investigation and Research; and U.S. Bureau of Public Roads.

(c) Dr. H.M. Morris, Prof. and Head, Dept. of Civil Engrg., Virginia Poly. Inst.

(d) Analytical and experimental, supplemented by field studies; basic and applied research.

(e) Studies are being made to develop general design criteria for flow regimes and energy dissipation in steep channels with large roughness elements. The characteristics of the "tumbling-flow" regime are of special interest. Design applications for chutes, culverts, and other highway drainage structures are in view.

(f) Completed except for final publication.

(g) Final Report, "Hydraulies of Energy Dissipation in Steep Rough Channels" has been submitted to sponsors and will be adapted for publication as a V.P.I. Research Bulletin.

(5534) HYDRAULIC EFFECTS OF BOUNDARY ROUGHNESS.

(b) Laboratory project.

(c) Dr. H.M. Morris; see (5533) above.

(d) Analytical and experimental; basic research for M.S. and Ph.D. theses.

(e) Systematic studies are being made to delineate the various regimes of turbulent flow in rough pipes in terms of each dimension of the boundary roughness geometry, with the aim of attaining comprehensive quantitative criteria for all regimes.

(f) Completed.

(g) Experimental work completed. Turbulent flow regimes have been delineated and quantitative criteria for recognition established.

(h) "Velocity Distribution in Steep, Rough Channel," Tsung-Ting Chang, unpublished M.S. thesis, Virginia Poly. Inst., 1963.

"Study of Flow in Open Channels with Cubical Roughness Elements," Sotirios John Kareliotis, unpublished M.S. thesis, Virginia Poly. Inst., 1967.

(5957) SURGE AND ROIL WAVE PHENOMENA IN STEEP ROUGH CHANNELS.

(b) Laboratory project, supported in part by Virginia Council of Highway Investigation and Research in cooperation with U.S. Bureau of Public Roads.

(c) Dr. H.M. Morris; see (5533) above.

(d) Analytical and experimental; basic research; Ph.D. thesis.

(e) Unsteady flow phenomena in the form of surges and roll waves are experienced under some conditions in steep channels with rough beds. The characteristics of these phenomena and criteria for their formation are being studied.

(f) Completed.

(h) "One-Dimensional Stability Analysis of Unstable Flow in a Steep, Rough Channel, "Eugene Y.T. Koo, Ph.D. Dissertation, Virginia Poly. Inst., March 1967. 
(6279) ANALYSIS OF HYDROIOGIC SYSTEMS.

(b) Office of Water Resources Research.

(c) Dr. J.M. Wiggert, Assoc. Prof., Dept. of Civil Engrg., Virginia Poly. Inst.

(d) Analytical and experimental; basic and applied research; Ph.D. thesis.

(e) This study examines the hydrologic runoff process in terms of fundamental systems analysis. Investigated is the response (discharge) of systems of simple configuration to inputs (rainfall) of simple description. Time constants and amplitude derived from data are used for a synthesis of other flows. Application of the method to data from natural watersheds is also being made.

(6280) MOTION OF A PARTICLE IN POISEUILLE FIOW.

(b) Laboratory project.

(c) Dr. J.M. Wiggert; see (6279) above.

(d) Analytical and experimental; basic research; M.S. thesis.

(e) A study of the transverse forces on and motion of single particles, both leading and lagging fluid flowing laminarly in a tube.

(6281) SURFACE WAVE STUDIES.

(b) Laboratory project.

(c) Dr.R.M. Sorensen, Asst. Prof., Dept. of Civil Engrg., Virginia Poly. Inst.

(d) Experimental; applied research.

(e) Construction of wave generator; studies on wave energy absorption.

VIRGINIA POLYTECHNIC INSTITUTE, Dept. of Mechanical Engrg., Blacksburg, Virginia 24061.

(5537) FLUID JET CONTROL.

(b) National Science Foundation.

(c) Dr. Robert A. Comparin, Assoc. Prof. of Mechanical Engrg., Virginia Poly. Inst.

(d) Analytical and experimental study in part for Master's thesis.

(e) This project is a study of jet reattachment phenomena at low Reynolds numbers. The study will include both parallel and inclined walls and the effects of aspect ratio, offset, and wall angle.

(f) Completed.

(g) Data have been obtained for reattachment distance as a function of Reynolds number for an inclined wall at various angles. Significant three-dimensional effects have been noted with an aspect ratio of ten.

(h) "Jet Reattachment at Low Reynolds Numbers and Moderate Aspect Ratios," R.A. Comparin, R.B. Moore,Jr., W.C. Jenkins, Jr., ASM paper 67-FE-25, available from ASME headquarters.

(6192) IAMINAR JWTS.

(b) Laboratory project.

(c) Dr. Robert A. Comparin; see (5537) above.

(d) Analytical and experimental study for Master's thesis.

(e) This project involves the study of the velocity profiles in laminar jets at low Reynolds numbers. The effects of nozzle design on the velocity profile at the jet exit are being investigated along with the development of the velocity profile in the downstream direction.

(6193) VELOCITY PROFIIE MODELS AND TURBULENT BOUNDARY LAYER FLOWS. (b) Laboratory project.

(c) Dr. F.J. Pierce, Randolph Hall, Virginia Poly. Inst.

(d) Theoretical; basic research.

(e) Several of the more common models proposed for two and three-dimensional turbulent boundary layer flows are examined and compared with a large body of experimental data from a variety of published data.

(6194) LATERAI FIOW REVERSAL IN STRONGLY SKEWED, PRESSURE DRIVEN THREE-DIMENSIONAL TURBULENT BOUNDARY IAYERS.

(b) Army Research Office-Durham.

(c) Dr.F.J. Pierce; see (6193) above.

(d) Experimental; basic research.

(e) The existence and nature of the reversal of lateral or skewed flow in a pressure driven three-dimensional turbulent boundary layer was examined. Lateral flow reversal was obtained in a recurving or $S$ shaped rectangular channel.

(f) Completed.

(h) In preparation.

(6195) A FIUSH MOUNTED DIRECTIONALLY SENSITIVE HOT WIRE WAII SHEAR STRESS METER.

(b) National Science Foundation.

(c) Dr. F.J. Pierce; see (6193) above.

(d) Experimental; basic research.

(e) A length of resistance thermometry wire is suspended between two probe tips and beneath a. mylar film; with the assembly flush mounted in a surface. The device is designed to operate with a Flow Corporation HWB2 anemometer console but any well-regulated DC power supply can be used. Excellent directional sensitivity to limiting wall streamline direction is obtained and the device can be calibrated with power dissipated giving a measure of wall shear stress.

(f) Completed.

(h) "A Directional Hot-Wire Sensor for Measurement of Skin Friction in the Turbulent Boundary Layer, "with R.H. Drinkuth, NSF Report, Sibley School of Mechanical Engrg., Cornell Univ., Ithaca, New York, 1965. Available as DDC Document AD 636248.

"A Directionally Sensitive Heat Meter for Wall Shear Stress Measurements in Turbulent Boundary Layer Flows," with R. Drinkuth, The Review of Scientific Instruments, Vol. 37. June 1966, pp. 740-741.

(6196) WALU SHEAR STRESS DIAGNOSTICS IN THREE-DIMENSIONAL TURBULENT BOUNDARY LAYERS.

(b) Jointly National Science Foundation; Army Research Office-Durham; laboratory project.

(c) Dr. F.J. Pierce; see (6193) above.

(d) Experimental; basic research.

(e) Survey of diagnostic techniques and devices used in two-dimensional turbulent boundary layer flows in an attempt at evaluating the applicability of these for use in threedimensional turbulent boundary layer flows. Comparison is made with direct wall shear force measurements obtained with a floating element wall shear meter in a three-dimensional turbulent bounday layer flow and corrected for pressure gradient effects.

(f) Completed.

(h) In preparation for publication. 
WASHINGTON STATE UNIVERSITY, The R.I. Albrook Hydraulic Laboratory, Pullman, Washington 99163

Inquiries concerning the following projects should be addressed to Dr. E. Roy Tinney, Head, The R.L. Albrook Hydraulic Laboratory, College of Engrg. Research Div., Washington State Univ.

(3848) CALTBRATION OF FLOW METERING FLUMES.

(b) Agricultural Research Service, Boise, Idaho.

(d) Experimental, development.

(e) A standard weir design is being studied to determine whether or not calibration curves can be developed for specific stream gaging stations without requiring extensive field or laboratory experimental calibration.

(r) Completed.

(g) Data analysis indicates that gaging site condition and flume size do not influence the discharge characteristics of the flume at discharges less than a certain percentage of the design capacity. Upstream bed slope and flume orientation affect these characteristics at larger flows if these parameters are greater than given magnitudes.

(h) "Stream Gaging Weirs for Reynolds Creek Experimental Watershed," Howard D. Copp, Bull. 295, Washington State Univ., Coll. of Engrg. Research Div.

(5519) SOUND SUPPRESSOR-HYDRAULIC MODEL TESTS.

(b) George C. Marshall Space Flight Center, NASA.

(d) Experimental; development; analytical, theoretical.

(e) Development of a vane system to produce uniformly distributed flow around a clover-shaped weir was studied. Surges produced by the rocket exhaust at ignition were investigated with a simulated vacuum chamber.

(f) Completed.

(h) "Analytical and Experimental Studies of Sound Suppressor Components for NASA Rocket Engine Test Stands," Edited by E. Roy Tinney, Coll. of Engrg. Research Div., Washington State Univ., August 1967.

(5521) HELLS CANYON HYDROEIECTRIC PROJECT.

(b) Idaho Power Company.

(d) Experimental; applied research.

(e) The objectives of the test program are to measure and analyze the forces which are acting on the left wall and sill during various discharge operating conditions with special reference to those forces causing vibration of the left training wall.

(6156) THE PREDICTION OF WATER QUALITY ASPECTS OF THE WENATCHEE RIVER.

(b) Public Utility District No. I of Chelan County, Washington.

(6157) CIAY SLURRY FLOW CHARACTERISTICS.

(b) J.R. Simplot Co., Bovill, Idaho.

(6158) WASHINGTON STATE WATER RESOURCES ATLAS.

(b) State of Washington.

(d) Compilation; hydrologic analysis.

(e) The water resources Atlas of the State of Washington was completed as a part of an overall study of the state's water needs.

(i) Completed.

(g) A quantification of the water resources of the State of Washington by 50 watershed subdivisions, with physical descriptions by region and watershed.
(6159) HYDRAULIC STUDIES OF FLOATING BRFAKWATERS.

(b) U.S. Forest Service, Seattle, Washington.

(d) Experimental; applied research.

(e) The design and fabrication of a wave basin was completed for the purpose of studying the effectiveness of floating breakwaters.

Investigations are being made with the idea of using floating breakwaters along the southeast coast of Alaska. The log breakwaters are being investigated as opposed to towing more permanent and costly steel floating breakwaters from one loading site to another. Three designs will be tested for maximum and mean wave heights for the vicinity. Mooring forces on the anchors will be determined.

(6160) RESISTANCE OF PLANE BOUNDARY SURFACES.

(b) National Science Foundation.

(d) Theoretical; basic research.

(e) Using various individual geometric shapes, wind tunnel tests have been performed over the past two years to determine the resistance to flow as influenced by the particle shape. Early tests were run in a small demonstration wind tunnel, and during this past year a larger tunnel with more sensitive measuring capabilities was constructed and put in use.

(6161) PHYSICAL CHARACTERISTICS OF BASALT AQUIFERS.

(b) Office of Water Resources Research.

(d) Field and laboratory; basic and applied.

(e) Geophysical logging methods are being used to determine stratigraphic relationships and physical properties of basalts.

(g) Project recently initiated. Preliminary results indicate great value of logging methods.

(6162) METHODS OF ESTIMATING GROUND-WATER RECHARGE NEAR THE MARGINS OF PIATEAU BASALTS.

(b) Office of Water Resources Research.

(d) Field and laboratory; basic and applied.

(e) To evaluate the parameters affecting recharge of basalt aquifers where they impinge on the paleo topography.

(f) Completed.

(g) Primary control of recharge was determined to be associated with buried stream valleys.

(h) "Factor Affecting Ground-Water Recharge in the Moscow Basin, Latah County, Idaho," Chang-Lu Iin, M.S. Thesis, Wash. State Univ., 1967.

(6163) INVESTIGATION OF TECHNIQUES TO PROVIDE ADVANCE WARIING OF GROUND-WATER POLLUTION HAZARDS WITH SPECIAL REFERENCE TO AQUIFERS IN GLACIAL OUTWASH.

(b) Office of Water Resources Research.

(d) Field and laboratory; basic and applied.

(e) To develop techniques for evaluating groundwater pollution hazards so that control measures can be instituted before public health is endangered.

(g) Seismic and gravity surveys of the spokane Valley have been completed. A drilling program was conducted during the past summer and data are being analyzed.

(h) "A Data Acquisition System for Radiation Well Logs," James W. Crosby III and James D. Logan, preprint of paper presented to Amer. Geophys. Union.

(6164) SPILLWAY CHARACTERISTICS FOR FISH PASSAGE.

(b) U.S. Army Corps of Engineers. 
(d) Analytical; applied research.

(e) Analytical studies are being conducted to analyze and momentum flux of water passage over existing spillways and associated stilling basins of hydroelectric power projects. End results are a determination of acceptable and harmful characteristics of said spillways with regard to downstream fish migration.

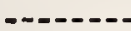

UNIVERSITY OF WASHINGTON, Charles W. Harris Hydraulics Laboratory, Seattle, Washington 98105

(4725) SAIT WATER ENTRAINMENT FOR DILUTION IN SEWER OUTFALIS.

(See also Water Resources Research Catalog Vol. 2, 5.1153).

(b) Federal Water Pollution Control Admin., U.S. Dept. of the Interior.

(c) Prof. R.E. Nece, Dept. of Civil Engrg., Univ. of Washington.

(d) Experimental; basic and applied research.

(e) The mechanism of the entrainment of a fluid from an infinite region of ambient fluid through discrete ports into a conduit flowing full is to be studied experimentally and analytically. One possible application is for pre-dilution in marine sewer outfalls.

(g) Data have been obtained for a range of single circular ports of varying sizes for zero and small density differentials between conduit and ambient fluids. Multi-port data have been obtained for the zero density differential case. Annular port entrainment and mixing data have been obtained for density differentials.

(h) Three M.S. theses completed (available on loan). "Single-Port Suction Manifolds," R.E. Nece, P.P. Goldstern and J.L. Black, Jour.Hydraulics Div., Proc. ASCE, Vol. 92, No. HYl, Jan. 1966, pp. 43-64.

(5532) BED SHEAR AS ANT INDEX OF HYDRAULIC JUMP EFFICIENCY.

(b) Laboratory project.

(c) Prof. R.E. Nece; see (4725) above.

(d) Experimental; basic research.

(e) Boundary shear stresses are used as an index of determining energy dissipation efficiencies of hydraulic jump in rectangular stilling basins; the procedure provides another description of the effective length of the jump as that within which the bed shear is reduced to safe limits.

(g) Data have been obtained for jumps on a horizontal floor and with jumps having approach slopes of 1 in 5, 1 in 3, and 1 in 1.5 . Limited shear data are avajlable for two basin configurations containing end sills and baffle piers.

(h) One M.S. thesis completed (available on loan). "Downstream Bed Shear Stress as Measure of Hydraulic Jump Efficiency," R.E. Nece and K. Mahmood, oral presentation, ASCE Hydraulics Div. Conf., Aug. 1965, Tucson, Ariz.

(OL9W) EFFECT OF DAM CONSTRUCTION ON DOWNSTREAM WATER TEMPERATURE. (Formerly No. 5698).

For sumary, see Water Resuurces Research Catalog, Vol. 2, 6.0422 .
(6148) IINTERNAI CURRENTS RESUITING FROM INIERMEDIATE DENSITY INFLOWS INTO STRATIFIED RESERVOIRS.

(b) State of Washington Water Research Center.

(c) Prof. E.R. Nece; see (4725) above.

(d) Experimental; basic and applied research.

(e) A laboratory study to study the internal currents established by the inflow of intermediate density into a density-stratified reservoir.

(6149) REFLECTED WAVES IN IAKE WASHINGTON.

(b) Washington State Highway Commission, Olympia, Washington; and U.S. Bureau of Public Roads.

(c) Prof. E.P. Richey, Dept. of Civil Engrg., Univ. of Washington.

(d) A field investigation with some theoretical background for the field measurements; applied research.

(e) Some field data were obtained on the excursion and decay of wind-waves in the deep-water category after they reflected from a vertical wall, with the objective to determine what areas of the lake might be influenced by the reflected waves.

(f) Completed.

(g) Meteorological data and a simple analytical model provided a means of determining the frequency and extent of significant reflected wave patterns.

(h) The terminal report has been submitted to the sponsoring agencies.

(6150) ATTENUATION OF DEEP-WATER WAVES.

(b) Washington State Highway Commission, Olympia, Washington.

(c) Profs. E.P. Richey and R.E. Nece, Dept. of Civil Engrg., Univ. of Washington.

(d) Experimental and theoretical applied research for masters' theses.

(e) Experimental and theoretical investigation of the relative efficiencies of hydraulic, pneumatic and fixed structural devices to minimize the energy of the reflected waves.

(6151) SOLUTION OF DUPUTT'S EQUATION FOR THREE-DIMENSIONAL SEEPAGE PROBLEMS.

(b) Laboratory project.

(c) Prof. Bruce Hunt, 305 Hydraulics Lab., Dept. of Civil Engrg., Univ. of Washington.

(d) Theoretical; basic and applied research.

(e) A method is being developed to solve Dupuit's equation for three-dimensional, free-surface seepage problems by a conformal mapping technique.

(g) The method has been applied to a particular seepage problem and a solution has been obtained.

UNIVERSITY OF WASHTNGTON, Department of Oceanography, Seattle, Washington 98105

(6282) ESTUARINE CIRCUTATION STUDIES.

(b) National Science Foundation.

(c) Prof. Maurice Rattray, Jr., Dept. of Oceanography, Univ, of Washington.

(d) Experimental, theoretical and field investigations; basic research which includes thesis problems.

(e) A completed study on the dynamics of estuarine circulations with physical behavior of any estuarine system. 
(6283) BOTTOM CURRENTS AND THE MOVEMENT OF SEDIMENT ACROSS THE CONTINENTAL SHELF.

(b) U.S. Atomic Energy Commission, Div. of Biology and Medicine.

(c) Prof. Joe s. Creager, Dept. of Oceanography, Univ. of Washington.

(d) Experimental and analytical; basic research.

(e) A study of the relationships between boundary layer flow and sediment transport in the marine environment, with emphasis on the effects of unsteady flow features of bottom currents in shallow marine waters and on the flow over dunes as it relates to sediment transport.

(g) An instrument system capable of making measurements of water velocity distribution near the bed, sediment distribution and geometry of the sediment-water interface has been built, tested in the field, and used in data collection. Data from a number of tidal channels have been analyzed. Theoretical analyses of flow over sand waves have been developed.

(h) "An Instrument to Measure Boundary Layer Flow and Sediment Transport over the Sea Floor," Joe S. Creager and R.W. Sternberg, Univ. of Washington, Dept. of Oceanography, Special Rept. No. 36, 31 p., 1964.

"An Intrument System to Measure Boundary Layer Conditions at the Sea Floor," Joe S. Creager and R.W. Sternberg, Marine Geology, Vol. 3, 1965, pp. 475-482.

"Boundary Layer Observations in a Tidal Current," R.W. Sternberg, Jour. Geophys. Res., Vol. 71, 1966, pp. 2175-2178.

"Measurements of Sediment Movement and Ripple Migration in a Shallow Marine Environment," R.W. Sternberg, Marine Geology, Vol. 5, 1967 , pp. 195-206.

"Friction Factors in Tidal Channels with Differing Bed Roughness, "R.W. Sternberg, Marine Geology (in press).

"Stability of a Sand Bed Subjected to a Shear Flow of Low Froude Number," J.D. Smith, submitted to Jour. Fluid Mech.

UNIVERSITY OF WASHINGTON, Fisheries Research Institute, Seattle, washington $9810^{\circ}$

\section{(3535) EFFECTS OF LOGGING ON PINK SALMON IN ALASKA.}

(b) Bureau of Commercial Fisheries, Auke Bay, Alaska.

(c) Dr. Ernest O. Salo, Fisheries Research Inst., Univ. of Washington.

(d) Determination of effects of logging on water quality of Alaska streams, field investigation, applied and basic research.

(e) Determination of rate of flow and quality of water in salmon spawning beds. Purpose of recording the effects of logging on water quality, hence salmon ecology •

(f) Completed.

(g) The relationship of (1) rate of flow, (2) dissolved oxygen and (3) permeability of spawning bed gravel and salmon embryo survival has been established.

(h) "Frequency of Digging Movenents of Female Pink Salmon Before and After Egg Deposition," W.L. Sheridan, Animal Behavior, Vol. 8, No. 3-4. pp. 228-230, 1960.

"Temperature Relationships in a Pink Salmon Stream in Alaska, W.L. Sheridan, Ecology, Vol. 42, No. 1, pp. 91-98, 1961.
"Waterflow Through a Salmon Spawning Riffle in Southeastern Alaska," W.L. Sheridan, USFWS Special Scientific Report, Fisheries No. 407, 20 pp., 1962.

"Red Superimposition and Egg Capacity of Pink Salmon Spawning Beds," W.J. McNeil, Jour. Fish. Res. Bd. Canada, Vol. 21, No. 6, pp. 1385-1335, 1964 .

"A Method of Measuring Mortality of Pink Salmon Eggs and Larvae," W.J. McNeill, USFWS Fishery Bull., Vol. 63, No. 3, pp. 575-588, 1364. "Sedimentation in a Salmon Stream," S. Philip Shapley and Daniel M. Bishop, Jour. Fish. Res. Bd. Canada, Vol. 22, Noo. 4, pp. 919-928, 1365. "Fine Particle Movement Through a Granular Bed, R.D. McIrvin. M.S. Thesis, Univ. Wash., Seattle, 55 pp., 1965.

"Effect of the Spawning Bed Environment on Reproduction of Pink and Chum Salmon, "William J. MeNeil. USFWS Fishery Bull., Vol. 65, No. 2, 495-523, 1766 .

"Study of the Effects of Logging on Pink Salmon in Alaska," Ernest 0. Salo. Proc. Soc. American Foresters, Seattle, Washington, 1966, pp. 59-62, 1967.

(6833) SIMULATION OF A WATER RESOURCE SYSTEM.

(See also Water Resources Research Catalog, Vol. 2, 6.0415).

(b) State of Washington Water Research Ctr.

(c) Dr. Donald E. Bevan, Assoc. Dean, College of Fisheries, Univ. of Washington.

(d) This is a theoretical investigation encompassing both basic and applied research. Three thesis projects are being supported.

(e) The project aims to produce a series of computer simulation models and analytical techniques which will be useful for studying some of the physical, chemical and biological aspects of the Duwamish River and its estuary.

(g) Simulation models of flow conditions and seaward migration of juvenile salmon have been written. A background has been laid towards the development of a simulation model of water quality in the Duwamish Estuary.

(h) "Annual Report - Public Law 88-379, Simulation of a Water Resource System," W.H. Lenarz. Univ. Wash., Fish. Res. Inst., Seattle, Wash., 4 pp., 1967.

"A Modern Approach to the Study of Estuaries, with Specific Reference to the Duwamish River, Washington, "D:M. Miller, J.A. Wetherall, and W.H. Lenarz, Thirty-second N. Amer. Wildl., Trans., 165-173, 1967.

(6834) CHUM SALMON SPAWNING CHANNNEL.

(b) U.S. Bureau of Commercial Fisheries (Anadromous Fish Act funds) and Fisheries Research Inst., Univ. of Washington.

(c) Dr. Ernest O. Salo; see (3535) above.

(d) Experimental field investigation, applied research; one thesis project is being supported.

(e) An artificial spawning channel for chum salmon with areas of varying spawning gravel quality has been built at the University of Washington field station on Big Beef Creek, Hood Canal. Success of chum salmon fry production and fry quality will be measured in relation to physical factors in the natural and controlled environments.

(g) Channel has been completed and spawning has taken place. Fry production still to be measured.

(O5OW) DETERMINATION OF INFLUENCE OF WATER QUALITY ON SAIMON IN THE DUWAMISH ESTUARY (formerly 
No. 5959, ESTUARINE ECOLOGY).

For summary, see Water Resources Research Catalog, Vol. 2, 5.1142.

(h) "A Modern Approach to the Study of Estuaries, with Specific Reference to the Duwamish River, Washington," D.M. Miller, J.A. Wetheral, and W.H. Lenarz, Thirty-second N. Amer. Wildl. Trans., 165-173, 1967.

"Study of the Migration and Spawning Distribution of the Runs of Chinook and Coho Salmon in the Green-Duwamish River System in the Fall of 1965," D.M. Miller and G.D. Stauffer, Univ. Wash., Fish Res. Inst. Circ. 67-4, 21 pp., 1967 .

"Estuarine Ecology Progress Report," Anon. Univ. Wash., Fish. Res. Inst., Seattle, Wash., 52 pp., 1968.

\section{WEBB INSTITUI'E OF NAVAL ARCHITECTURE, Glenn Cove,} Long Island, New York 11542

\section{(5202) DETERMINATION OF SHIP WAVE RESISTANCE.}

(b) Naval Ship Research and Development Center.

(c) Dr. Lawrence W. Ward, Prof. of Engrg., Webb Inst. of Naval Architecture.

(d) Experimental and theoretical; basic research.

(e) Investigation of means for direct experimental determination of ship wave resistance from measurements of the wave pattern during a model test. Purpose includes improvement in scaling model test results to full size as well as basic understanding of nature of ship resistance.

(f) Suspended.

(g) Method utilizing forces exerted by the wave pattern on a long vertical cylinder has been developed and tests run. Results are encouraging and in agreement with other investigators. New method utilizing wave slope records have been investigated and found promising.

(h) "An Assessment of Some Experimental Methods for Determining the Wavemaking Characteristics of a Ship Form," K.W.H. Eggers, S.D. Sharma, and L.W. Ward, Trans. Soc. Naval Arch. and Marine Engrs., 1367.

"Wave Resistance Surveys on a Ship Model of Minimum Resistance," Lawrence W. Ward, Webb Institute, Aug. 1965.

"Experimental Determination of Ship Wave Resistance from the Wave Pattern, "Lawrence W. Ward, Webb Institute, Nov. 1964.

(5203) ASSESSMENT OF SEAKEEPING CHARACTERISTICS OF SHIPS.

(b) Society of Naval Architects and Marine Engrs., Pane $1 \mathrm{H}-7$ of Hydrodynamic Committee.

(c) Prof. Edward V. Lewis, Research Prof. of Naval Architecture, Webb Institute of Naval Architecture.

(d) Theoretical application of available experimental results and confirmation by model tests; applied research.

(e) Application of available knowledge of ship model behavior in regular waves to the prediction of trends of ship performance in realistic irregular wave patterns. Experimental confirmation by means of model tests in waves. Purpose is to provide the ship designer with guidance in the selection of hull characteristics.

(f) Theoretical work is completed; experimental phase is active.

(g) The advantage of a high length/draft ratio in permitting higher speeds before shipping water forward is clearly shown. A corresponding disadvantage in terms of likelihood of slamming is found, requiring a balance to be made in selecting optimum ship characteristics.

(h) "Applying Results of Seakeeping Research," E.V. Lewis, Fifth Symposium of Naval Hydrodynamics, Bergen, Norway, September, 1964, (published by Office of Naval Research, Washington, D.C.).

"Assessment of Seakeepability, " Norman Hamlin and Roger Compton, Webb Institute, June 1965.

(5942) MODEL STUDIES OF SHIP SLAMMING IN WAVES.

(b) American Bureau of Shipping.

(c) Dr. Walter Maclean, Prof. of Engrg., Webb Inst. of Naval Architecture.

(d) Experimental study making use of ship models in waves; applied research.

(e) Two 5-foot models, jointed at amidships for measurement of wave bending moments, are being run in waves to determine the conditions for bottom slamming to occur and to compare with theoretical predictions. Pressure measurements at one point on bottom are being taken.

(g) Fairly good correlation has been obtained between relative vertical velocity at the bow and the occurrence of slamming. However, better correlation is expected when velocity is measured at a point further aft.

(h) "Further Model Tests for the Investigation of Slamming,"W. Maclean, Progress Report No. 11, June 1967.

THE WESTERN COMPANY, Research Division, 2201 Waterview Pkwy., Richardson, Texas 75080

\section{(5291) EFFECT OF POLYMER COILING ON DRAG REDUCTION.}

(b) Naval Ship Research and Development Ctr.

(c) Dr. H.R. Crawford, G.T. Pruitt, B.R. Rosen, The Western Company, Research Div.

(d) Experimental; basic research.

(e) Turbulent friction loss of dilute solutions of polymers in various solvent systems is being determined to relate the degree of polymer coiling to the turbulent drag reduction.

(f) Completed.

(h) "Effect of Polymer Coiling on Drag Reduction," The Western Company, Research Div., contract final report, DDC, Cameron Station, Alexandria, va., 22314.

\section{(5960) TURBULENT HEAT TRANSFER CHARACTERISTICS OF} VISCOEIASTIC FLUIDS.

(b) NASA, Physics of Fluids Branch.

(c) Dr. H.R. Crawford, G.T. Pruitt, N.F. Whitsitt, The Western Co., Research Div.

(d) Experimental; basic research.

(e) Turbulent heat transfer coefficients are being determined for viscoelastic solutions of various polymers in distilled water, to allow prediction of turbulent heat transfer characteristics for this type of fluid.

(f) Completed.

(h) "Turbulent Heat Transfer to Viscoelastic Fluids, "The Western Company, Research Div., contract final report, NASA Scientific and Technical Information Facility, P.0. Box 33, College Park, Md., 20740.

(6261) EFFECT OF BOUNDARY LAYER THICKNESS ON POLYMER DRAG REDUCTION. 
(b) Naval Ship Research and Development Ctr.

(c) N.F. Whitsitt, I.H. Harrington, Dr. H.R. Crawford, The Western Co., Research Div.

(d) Experimental; basic research.

(e) The effect of pipe diameter and boundary layer thickness on turbulent drag reduction is being determined.

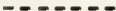

UNIVERSITY OF WISCONSIN, Hydraulics and Sanitary Engrg. Laboratories, Madison, Wisconsin 53706

\section{(3539) MEASUREMENT OF LIQUID VELOCITY AND TURBULENCE.}

(b) Office of Water Resources Research, U.S. Dept. of the Interior.

(c) Dr. J.R. Villemonte, Prof. of Civil Engrg., 1261 Engrg. Bldg., Univ. of Wisconsin.

(d) Theoretical and experimental; basic and applied research for M.S. and Ph.D. theses.

(e) A three-element probe has been developed to permit the simultaneous observation of two components of the instantaneous near-point velocities in liquid flow in closed ducts using an application of the principle of electro-magnetic induction. Reynolds stresses are computed as well as time and space correlations and resulting energy spectra.

(h) "Liquid Turbulent Investigation with an Electro-Magnetic Probe," H.J. Day and J.R. Villemonte, Proc. 9th Midwestern Mechanics Conf., 1965, Univ. of Wisconsin.

"Analog and Digital Computer Analysis of Iiquid Turbulent Flow Measured with a ElectroMagnetic Probe," H.J. Day, J.R. Villemonte, and R. Gratz, presented at 15th Annual Hyaraulics Conf., ASCE, Aug. 1966, Madison, Wisc.

(4252) CHARACTERISTICS OF A DENSTTY STRATIFIED FLUID.

(b) Federal Water Pollution Control Admin.

(c) Dr. P.I. Monkmeyer, 1261C Engrg. Bldg., Univ. of Wisconsin.

(d) Theoretical; basic research for Ph.D. thesis.

(e) Dynamic characteristics of density-stratified fluids are being investigated. Particular emphasis has been placed on a study of the mechanies of Langmuir circulation, in an effort to explain the phenomenon of windrows on lakes.

(f) Completed.

(g) A mathematical model of Langmuir circulation has been developed. The model consists of a shear flow superimposed upon a field of thermal convection cells. Comparison with existing field data shows that the model reproduces many characteristics of Iangmuir circulation.

(h) "A Thermal Model of Langmuir Circulation," P.D. Uttormark, Ph.D. thesis, Univ. of Wisc., 1967.

(4734) FLOW BETWEEN CONCENTRIC ROTATING CYLINDERS.

(b) Wisconsin Alumni Research Foundation; and Fairbanks Morse Co.

(d) Dr. P.I. Monkmeyer; see (4252) above.

(d) Theoretical and experimental; basic research for Ph.D. thesis.

(e) This study is concerned with the characteristics of turbulent flow in an annulus, with rotating inner cylinder. Theoretical prediction and experimental confirmation of shearing stresses, torque, pressure gradients, and frictional resistance are being sought.

(f) Completed.

(g) A theory has been developed to predict the frictional resistance to turbulent flow in a rotating annulus. Experimental confirmation has been obtained over a limited range of flow conditions.

(h) "Turbulent Helical Flow in an Annulus," I.W. Gelhar, Ph.D. Thesis, Univ. of Wisconsin, 1964. A paper has been submitted to ASCE for publication.

(4736) UNSTEADY FLOW IN POROUS MEDIA.

(b) Wisconsin Water Resources Center; Wisconsin Alumni Research Foundation; and National Science Foundation.

(c) Dr. P.I. Monkmeyer; see (4252) above.

(d) Theoretical and experimental; basic and applied research for Ph.D. theses and M.S. projects.

(e) The following problems in unsteady flow through a porous medium are under investigation: use of sound waves to determine permeability; effect of stream bank clogging on unsteady flow of ground water; unconfined. unsteady flow of groundwater toward a surface stream.

(g) A theory, predicting the behavior of sound waves transmitted through an air-saturated porous medium has been developed and verified experimentally. Field data have been used to confirm a new theory which describes the effect of a clogged streambank on the flow of ground water toward a surface stream. The Dupuit-Forchheimer equation for unsteady unconfined radial flow toward a well has been solved by numerical means and the results prepared in the form of type curves.

(h) In addition to those reported earlier: "Unsteady Unconfined Ground Water Flow Toward a Well,"W.A. Murray, Project Rept., Dept. of Civil Engrg., Univ. of Wisconsin, 1966.

(5597) THE HYDRAULIC CHARACTERISTICS OF A DROP INLET.

(b) W.A. Kates Company.

(c) Dr. J.R. Villemonte; see (3539) above.

(d) Experimental; design for an M.S. thesis.

(e) The hydraulic characteristics of a drop inlet typical of a type used by the U.S.D.A. Agricultural Research Service in small headwater control dams have determined by model studies with particular emphasis on the effect of roughness in the outlet pipe under the dam.

(f) Completed.

(g) Internal reports are in the process of preparation presenting the characteristics observed.

\section{(5598) CHARACTERISTICS OF GRAVITY WAVES.}

(b) Laboratory project.

(c) Dr. P.I. Monkmeyer; see (4252) above.

(d) Theoretical; basic research.

(e) Higher order theories for finite height gravity waves are under study.

(g) A higher order non-linear theory for deep water waves of finite amplitude has been developed.

(h) "A Higher Order Theory for Deep Water Waves," by P.L. Monkmeyer and J.E. Kutzbach, Proc. ASCE Coastal Engrg. Conf., Santa Barbara, 1765 .

(5790) DISPERSION IN FLOW THROUGH NON-HOMOGENEOUS POROUS MEDIA.

(b) Wisconsin Water Resources Center.

(c) Dr. J.A. Hoopes, 1212 Engrg. Bldg., Univ. of Wisconsin.

(d) Theoretical and experimental; basic research 
for Ph.D. thesis.

(e) A theoretical description, coupled with experimental confirmation, of the distribution of a conservative pollutant in flow through different patterns of non-homogeneous media is being sought. The purpose of this study is to develop methods for predicting the resulting distribution of a substance introduced into a natural ground water flow.

(g) By treating the media as a continuum with a spatially-varying longitudinal dispersion coefficient, a solution for the distribution of a dissolved substance in one-dimensional flow has been obtained.

(5791) CIRCULATION AND MIXING PROCESSES IN LAKES.

(b) Wisconsin Water Resources Center.

(c) Dr. R.A. Ragotzkie, 425 Science Hall; Dr. J.A. Hoopes, 1212 Engrg. Bldg., Univ. of Wisconsin.

(d) Theoretical, experimental, and field; basic research for M.S. and Ph.D. theses.

(e) This investigation deals with field and laboratory model studies of the current and temperature profiles of Lake Superior. These studies will be integrated and combined with mathematical models in an effort to understand and predict motions within the lake and the resulting distribution of substances introduced at various points in the lake.

(g) A frictionless, mathematical model of the large scale circulation in the Great Lakes (currents and internal waves) has been obtained and compared with observations. A small-scale rotating model of Lake Superior has been constructed.

(h) "Large-Scale Motion in the Great Lakes," G.T. Csanady, Jour. Geophys. Res., Vol. 72, No. 16, pp. 4151-4162, Aug. 15, 1967.

"The Keweenaw Current - a Regular Feature of the Summer Circulation of Lake Superior," R.A. Ragotzkie, Tech. Rept. 29, Dept. of Meteorology, Univ. of Wisconsin, 1966.

(6620) TURBULENCE IN JETS AND STRATIFIED FLOWS.

(b) Wisconsin Water Resources Center.

(c) Dr. John A. Hoopes, 1212 Engrg. Bldg. and Dr. H.H. Lettau, Science Hall, Univ. of Wisconsin.

(d) Theoretical and experimental; basic research for $\mathrm{Ph} . \mathrm{D}$. thesis.

(e) Theoretical expressions for the mean and turbulent velocity fields for a two-dimensional submerged jet are being developed and tested for a two-dimensional water jet. Velocities are determined using an electromagnetic probe (see project 3539).

(6621) INFLUENCE OF TURBULENCE ON OIL-WATER SEPARATION.

(b) American Petroleum Institute.

(c) Dr. John A. Hoopes, 12l2 Engr. Bldg.; Dr. I.B. Polkowski, 3206 Engrg. Bldg.; and Dr. W.C. Boyle, 3230 Engrg. Bldg., Univ. of Wisconsin.

(d) Theoretical and experimental; basic research for M.S. and Ph.D. thesis.

(e) The rates of agglomeration and breakup of oil droplets and the equilibrium droplet sizes are being studied theoretically and in the stationary, turbulent flow field between parallel, oscillating plates as a function of droplet concentration and turbulence level. The purpose of this study is to improve secondary oil recovery in oil refinery, waste water, separation basins.

(6622) INDUCED CIRCULATIONS AND DISSIPATION OF HEAT
FROM CONDENSOR COOIING WATER DISCHARGE.

(b) Madison Gas and Electric Company, Madison Wisconsin.

(c) Dr. John A. Hoopes; see (5790) above.

(d) Theoretical, experimental and field; basic and applied research for Ph.D. thesis.

(e) This is a study of the heat transfer between jets of warm water, discharged horizontally at the edge of Lake Monona by the Company's cooling water outfalls, and the surrounding lake and atmosphere. The investigation involves field measurements of the velocity and temperature patterns induced by the jets throughout the year, mathematical models of the phenomena, and a laboratory model. The purpose of this study is to define the region of the lake affected by the heat and to consider alternate methods of discharging the warm water to reduce this region.

(g) A mathematical model has been developed which describes the induced circulations and the dilution of the heat by the lake. The model describes the field measurements.

(h) A Ph.D. thesis has been completed; it is being prepared for publication.

(6623) DISTURBED IAMINAR FIOW DUE TO PIPE FITTINGS AND BRANCHES.

(b) Laboratory project.

(c) Dr. J.R. Villemonte, Prof. of Civil Engrg., Univ. of Wisconsin, 1261 Engrg. Bldg.

(d) Experimental; applied research for $\mathrm{Ph} . \mathrm{D}$. thesis.

(e) The Reynolds number range is $10<R<30,000$ in pipes using oil. The disturbance due to standard type pipe fittings and combined and divided flows in branches is being studied. The objective of the program is to develop design criteria which can be used for estimating energy losses due to fittings operating in the laminar flow regime.

(6624) THERMOCLINE DEVELOPMENT IN LAKES.

(b) Laboratory project; and Wisconsin Alumni Research Foundation.

(c) Dr. J.A. Hoopes, 1212 Engrg. Bldg., Univ • of Wisconsin.

(d) Theoretical; basic research for M.S. degree.

(e) The transient, vertical distribution of temperature in lakes and reservoirs is being studied, using several models for the vertical transport of heat and momentum. The objective of the work is to develop a model for the temperature structure of a lake which describes the location and stability of the thermocline.

(g) The linearized energy equation has been solved for the vertical temperature distribution due to sinusoidal, surface temperature variation.

(6625) THERMALLY INDUCED MIXING AND OVER-TURNING OF STRATIFIED IAKES AND IMPOUNDMENTS.

(b) Univ. of Wisconsin Geological and Natural History Survey; and the Engrg. Experiment Sta.

(c) Dr. John A. Hoopes; see (6624) above.

(d) Theoretical and experimental; basic research for M.S. thesis.

(e) Two mathematical models, describing the flow pattern and the rate of dilution induced by the discharge of a buoyant plume or jet into a stratified lake, are being investigated and tested in a small circular tank. The purpose of this work is to investigate the feasibility of inducing vertical mixing in stratified 
lakes through the introduction of warm water (power plant or industrial discharge) at the bottom of a lake.

(6626) SMALL WATERSHED RUNOFF BY NUMERICAL MODEL.

(b) Water Pollution Control Administration; and laboratory project.

(c) Dr. Robert F. Carlson, 1214 Engrg. Bldg., Univ. of Wisconsin.

(d) Theoretical; basic research for Ph.D. thesis.

(e) A general numerical model for small basins was developed which computes the direct surface runoff response from excess precipitation input. The components of the model are described by a set of physically based equations, and the structure of the model is based on the stream order method of describing the drainage net.

(f) Completed.

(g) Experimental computer runs were made to verify the model. Observed hydrographs from a small rural watershed were reproduced with fair accuracy. The structure of the model appears to be the most promising aspect of this work.

(h) "Small Watershed Surface Runoff by Numerical Model, "Ph.D. thesis, Robert F. Carlson, 1967.

(6627) THE DYNAMIC RESPONSE OF PILE STRUCTURES SUBJECTED TO WAVE FORCES.

(b) Wisconsin Alumni Research Foundation; and Ford Foundation.

(c) Dr. P.I. Monkmeyer, 1261C Engrg. Bldg., Univ. of Wisconsin.

(d) Theoretical and experimental; basic and applied research for Ph.D. thesis.

(e) The objective of this study is to develop analytical, rather than empirical, expressions for the prediction of the forces on and the response of sea structures, especially piles, when these structures are exposed to deepwater and intermediate-depth progressive waves. Particular emphasis will be placed on pile vibrations of large-diameter piles and pile groups, in deep water. Experimental confirmation of the theory will be sought using a laboratory wave channel.

(6628) SOIL MOISTURE PREDICTION USING THE ANTECEDENT RETENTION INDEX.

(b) Agricultural Research Service; and Wisconsin Agricultural Experiment Station.

(c) Dr. A.T. Lenz, Chairman, Dept. of Civil Engrg., 2203 Engrg. Bldg., Univ. of Wisconsin.

(d) Theoretical study and field investigation for M.S. thesis.

(e) The objective of this study is to examine models for computing Antecedent Retention Index values by comparisons with observed available soil moisture.

(f) Completed.

(g) Two models for calculating antecedent moisture index values are evaluated by comparisons with measured soil moisture. One model is based on the traditional antecedent precipitation index equation and the second uses an evapotranspiration-soil moisture relation. Index values by both models compare favorably with available soil moisture when derived $K$ and $P E T$ values are used.

(h) "Antecedent Retention Indexes Predict Soil Moisture," K.E. Saxton and A.T. Lenz, Jour. Hydraulics Div., ASCE, Vol. 93, No. HY4, Proc. Paper 5351, pp. 223-241, July 1967.

(6629) DYNAMICS OF VISCOUS DENSITY-STRATIFIED FIOW. (b) Federal Water Pollution Control Admin.

(c) Dr. P.I. Monkmeyer; see (6627) above.

(d) Theoretical and experimental; basic and applied research for $\mathrm{Ph} . \mathrm{D}$. thesis.

(e) This study is concerned with the two-dimensional flow of a non-diffusive, viscous, density-stratified fluid toward a point sink. The object of the study is the development of expressions for the shape of the expected withdrawal layer and the form of its associated velocity profiles as a function of spatial coordinates, discharge and characteristics of the density-stratified fluid. A laboratory tank will be utilized to test the theoretical expressions. Application of the results of this study to selective withdrawal from surface impoundments for water quality control will be considered.

(g) Theoretical results have been obtained for the case of a point sink located in the lower corner of a semi-infinite, rectangular flow field.

WOODS HOIE OCEANOGRAPHIC INSTITUIION, Woods Hole, Massachusetts 02543

\section{(4737) HYDRODYNAMICS OF ROTATING LIQUIDS.}

(b) Office of Naval Research, Dept. of the Navy.

(c) Dr. Alan Ibbetson, Mass. Inst. of Tech, Cambridge, Mass. 02139

(d) Experimental and theoretical; basic research.

(e) Hydrodynamics of rotating liquid systems having variable depth, including blocking action by bottom topography ("Taylor columns") and measurements on Rossby waves in an open rotating basin.

(f) Completed.

(g) Measurements on Rossby waves in liquid annulus, including dispersion relationship, damping coefficient, reflection properties.

(h) "The Construction of a One-Meter Diameter Rotating Table," A. Ibbetson and R.E. Frazel, Woods Hole Oceanographic Institution unpublished report, Ref. 65-41, Aug. 1965. "An Experimental Study of "Taylor Columns"," R. Hide and A. Ibbetson, Icarus, Vol. 5, No. 3, May 1966.

"Some Laboratory Experiments on Rossby Waves in a Rotating Annulus," A. Ibbetson and Norman Phillips, Tellus, Vol. XIX, No. 1, 1967 , pp. 81-87.

(6471) THEORETICAI AND HYDRODYNAMIC STUDIES.

(b) Office of Naval Research, Dept. of the Navy.

(c) Dr. Claes Rooth, Woods Hole Oceanographic Institution.

(d) Theoretical; basic research.

(e) Analog computer simulation of a simple hydraulic system, consisting of two containers of wellmixed liquid connected by a pair of insulated tubes at different elevations. The containers are in diffusive contact with exterior baths with prescribed time-variable properties.

(f) Completed.

(g) The system is the simplest possible analog of a thermohaline circulation. By adding a pumping mechanism, the effects of simultaneous driving by density differences and by mechanical forces is simulated. It is shown that multiple equilibrium states may exist, leading to bimodal distribution of states if a random forcing is applied. 
(h) "On the Interaction of Gravitational and Dynamic Forcing in Simple Circulation Models, " Henry Stormel and Claes Rooth, Deep Sea Research, Vol. 15, p. 555, 1967.

WORCESTER POLYTECHIVIC INSITUTE, Alden Research Iaboratories, Worcester, Mass. 01609

Inquiries concerning the following projects should be addressed to Prof. Iawrence C. Neale, Director, Research Laboratories, Worcester Poly. Inst.

(1963) METER CAIIBRATIONS.

(b) Foxboro

(d) Experimental, for design.

(e) Calibration of various sizes of magnetic flow tubes ( $I^{\prime \prime}$ to $36^{\prime \prime}$ diameter) and a variety of nozzle and orifice plate assemblies.

(f) Tests in progress.

(3859) METER CALTBRATIONS.

(b) B-I-F Industries, Providence, R.I.

(d) Experimental, for design.

(e) Calibration of open flow nozzles and flow tubes up to $48^{\prime \prime}$ in diameter. Tests performed in standard test loop and also in mock-up of particular field installations.

(f) Tests in progress.

(4255) METER CALIBRATIONS.

(b) Badger Meter Company, Milwaukee, Wisconsin.

(d) Experimental; for design.

(e) Calibration of open flow nozzles and flow tubes from 2 " to 48 " in diameter in the standard test loop. In addition, tests have been performed to determine operating characteristics in a variety of field installation mock-ups including a number of pipe surface finishes.

(f) Tests in progress.

(4746) METER CALIBRATIONS.

(b) Hagan Chemicals and Controls, Inc., Pittsburgh, Penn.

(d) Experimental, for design.

(e) Calibration of a variety of sizes and designs of flow nozzles and flow nozzle assemblies.

(f) Tests in progress.

(5022) DYNAMIC EFFECTS IN FLOW METER COEFFICIENT PREDICTION.

(b) Laboratory project.

(d) Experimental; for M.S. thesis.

(e) A number of differential producer type flow meters are being studied under different Reynolds Number levels with the same volume flow rate. It is planned to evaluate the dynamic effects on the discharge coefficient.

(f) Suspended.

(5279) METTER CAIIBRATIONS.

(b) ITT General Controls, Warwick, R.I.

(d) Experimental, for design.

(e) Calibration of flow tubes in a range of sizes from 6" to 48" has been carried out. Field piping as well as standard test loop installation have been used.

(f) Tests in progress.

(5962) METER CALIERATIONS.

(b) Eailey Meter Company, Wickliffe, Ohio.

(d) Experimental, for design. (e) Calibration of flow nozzles and flow meters in standard as well as particular metering and piping configurations for a range of sizes from 1" to 16" diameter.

(f) Tests in progress.

(5963) METER CAIIBRATIONS.

(b) Fischer and Porter Company.

(d) Experimental for design.

(e) Calibration of various sizes of magnetic flow tubes from $2^{\prime \prime}$ to $48^{\prime \prime}$ diameter.

(f) Tests in progress.

(5970) WILLOW GIEN STEAM POWER PIANT.

(b) Stone and Webster Engineering Corp.

(d) Experimental for design.

(e) A $1 / 21.8$ scale model was constructed for the Gulf State Utility Co. The model included the discharge flume, stilling basin and river topography in the immediate area of the'still. ing basin. The studies involve evaluation of the effectiveness of the stilling basin for present loads plus future projected loads. Velocity measurements and water surface elevations as well as indications of scour in the river beyond the stilling basin have been recorded.

(f) Tests completed. Report in file.

(5971) WILLOW GIEN STEAM POWER PIANT.

(b) Stone and Webster Engineering Corp.

(d) Experimental for design.

(e) A $1 / 12$ scale model of the proposed circulating water pump intake has been constructed for the Gulf State Utility Company. The model studies are to evaluate the alternative designs for the intake and water passages. Velocities and flow distribution will be measured and other critical phenomena near the pump inlets will be observed.

(f) Tests in progress.

(6499) NORTHFIELD PUMPED STORAGE DEVELOPMENT.

(b) Stone and Webster Engineering Corp., Boston, Mass.

(d) Experimental, for design.

(e) A $1 / 200$ horizontal by $1 / 60$ vertical scale model of the section of the Connecticut River between Vernon Dam and Turners Falls was constructed for the Northeast Utilities Corporation. The model included provision to reproduce both pumping and generating plants at the Northfield Power Plant as well as river flows at Vernon, Ashelot River, Millers River and Turners Falls. Studies involve the effect of various modes of plant operation on the river and the other plants.

(f) Tests in progress.

(6500) NORTHFIELD PUMPED STORAGE DEVELOPMEIT.

(b) Stone and Webster Engineering Corp., Boston, Mass.

(d) Experimental, for design.

(e) A $1 / 46$ scale model of the intake at the upper reservoir was constructed for the Northeast Utilities, Inc. Included in the model was a section of the reservoir, the intake and a section of the penstock below the intake. The purpose was to study the flow patterns in the model during various phases of operation and to develop the structures and excavations in such a way to optimize the operation for both pumping and generating conditions.

(f) Tests in progress. 
(6501) NORTHFIELD PUMPED STORAGE DEVELOPMENT.

(b) Stone and Webster Engineering Corp., Boston, Mass.

(d) Experimental, for design.

(e) A I/25 scale model of a section of the tunnel and penstocks was fabricated in steel and plastic for the Northeast Utilities, Inc. The model was comprised of a section of the large tunnel, the $46^{\circ}$ vertical bend, the bifurcation and sections of the two penstocks beyond the bifurcation. The model was arranged to measure pressures at all critical sections as well as velocity profiles, and windows of clear plastic were installed to permit photographs in the different sections. The study is concerned with determination of the loss coefficients for the various changes in section and alignment and with the minimizing of pressure fluctuations produced by different combinations of flow in the model.

(6502) BIG BEND POWER STATION.

(b) Stone and Webster Engineering Corp., Boston, Mass.

(d) Experimental, for design.

(e) A $1 / 18$ scale model of the discharge channel for condenser cooling water including the outlet and transition structure for the flow from Unit No. 1 was constructed for Tampa Electric Company. The model channel was formed in concrete and the structure in wood and steel. The flow from future units can be introduced through the upper end of the channel. The study involved developing a system of baffles and transitions to produce a uniform velocity into the channel from the unit such that no scour or erosion of side slopes would result.

(f) Tests in progress.

(6503) H.B. ROBINSON POWER PLANT.

(b) Ebasco Services, Inc., New York City.

(d) Experimental, for design.

(e) A $1 / 10$ scale model of the transition and outlet works for the cooling water from the plant is being constructed for the Carolina Light and Power Company. The model is constructed of plastic and steel for the pipe and transition sections and wood and concrete in the areas involving topography of the natural river bed. The model will be a sectional model with the split on the centerline replaced with a sheet of clear plastic to permit observation of flow through the model. The study is designed to allow measurement of velocities at several sections including the exit to insure a uniform distribution at the release to the natural bed.

(f) Model under construction.

(6504) WEBSTER STEAM ELECTRIC STATION.

(b) Ebasco Services, Inc., New York City.

(d) Experimental, for design.

(e) A 1/12.75 scale model of a section of a cooling water discharge canal was constructed for the Houston Lighting and Power Company. The model included the intake and intake drop structure, a section of the canal, a second drop structure and a section of the canal downstream. The study involved evaluating the loss coefficients for the various parts of the model and installing and testing modifications aimed at reducing the head losses in the canal.

(f) Tests in progress.
(6505) PILGRIM NUCLEAR POWER PLANT.

(b) Bechtel Corporation, San Francisco, Calif.

(d) Experimental, for design.

(e) A l/50 scale model of a section of Massachusetts Bay near the Boston Edison Company plant was constructed to evaluate storm protection at the proposed plant. A $4000 \mathrm{ft}$ section of the shore line and the bay for an equal distance off shore were reproduced including the plant cooling water inlet and outlet structures. A $40 \mathrm{ft}$ long variable speed and variable stroke wave maker was installed to generate the storm driven waves. Electronic probes were installed at critical locations to measure and record wave heights and frequencies. A variety of breakwater configuration and combinations are being tested as part of the program.

(f) Tests in progress.

(6506) CAYUGA STEAM POWER PLANT.

(b) Sargent and Lundy Engineers, Chicago, Ill.

(d) Experimental, for design.

(e) A distorted model with scales of $1 / 150$ horizontal and $1 / 20$ vertical has been constructed for the Public Service of Indiana of a 2-1/2 mile section of the Wabash River at the site of the power plant. The model includes sections from $4500 \mathrm{ft}$ upstream of the cooling water intake and $1500 \mathrm{ft}$ downstream of the intake and $1500 \mathrm{ft}$ upstream of the outlet and $4500 \mathrm{ft}$ downstream of the outlet.

(f) Tests in progress.

(6507) CAYUGA STEAM POWER PLANT.

(b) Foster Wheeler Company.

(d) Experimental, for design.

(e) A $1 / 10.8$ scale model of one pump well from section in river through racks and screens to include pump area has been constructed of the Cayuga Steam Power Plant of the Public Service of Indiana. The studies are designed to optimize the pump well arrangement and to determine the flow patterns throughout the structure. The main pump flow is modeled by a siphon passive type of flow system.

(f) Tests in progress.

(6508) POINT BEACH NUCLEAR PLANT.

(b) Sargent and Lundy Engineers.

(d) Experimental, for design.

(e) A $1 / 14$ scale model of the pump well structure has been fabricated for the Wisconsin Michigan Power Company. The model includes the intake pipes, butterfly valves, pump wells and siphon passive type main pumps. The model is of steel and plexiglass with the pump bells modeled in fiberglass. The purpose is to study the flow patterns in the well and to develop a uniform distribution of flow through the screens and to the main pumps.

(f) Tests in progress.

(6509) INDIAN POINT STEAM PLANT.

(b) Consolidated Edison Company, New York.

(d) Experimental, for design.

(e) A I/250 horizontal by $1 / 60$ vertical scale model of a section of the Hudson River is being constructed for the Consolidated Edison Company. A 4.5 mile section of the river including the Indian Point development of units one, two and three will be studied. The model will be operated to reproduce automatically the tide cycle and will be used to study 
the flow patterns of the heated cooling water on return to the river. The measurements will include the flows, detailed velocities and temperature profiles over the river.

(f) Model under construction.

(6510) CORNWALL PUMPED STORAGE DEVELOPMENT.

(b) Consolidated Edison Company.

(d) Experimental, for design.

(e) A 1/150 horizontal by $1 / 75$ vertical scale model of a section of the Hudson River was modeled including the section at the tailrace of the plant. The studies involved determination of optimum shape of the tailrace and flow patterns and velocities for various phases of plant operation and various tide conditions. Protection of marine life in the river was also studied.

(f) Tests completed.

(h) Model held in readiness for additional studies.

(65ll) KINZUA PUMPED STORAGE PROJECT.

(b) Harza Engineering Corporation.

(d) Experimental, for design.

(e) A l/40 scale model of the upper reservoir was constructed for the Cleveland Electric Illuminating Company. The model in addition to the reservoir included the intake, transition and tunnel to beyond the first bend. The study included the intake and reservoir configuration to insure satisfactory flow. Also the flow in the tunnel and vertical shaft was fabricated in clear plastic to allow observation as well as measurements of flow distribution.

(f) Tests completed.

(h) Report on file with client.

(6512) JOCASSEE PUMPED STORAGE DEVELOPMENT.

(b) Duke Power Company.

(d) Experimental, for design.

(e) A 1/50 scale model of the upper reservoir was constructed for the Duke Power Company under the guidance of Charles T. Main, Inc. engineers. Included in the model was a section of the reservoir, the two intake structures, and sections of the tunnel beneath each structure. The study involved the interaction of the local topography and the flow into and out of the structures. Measurements of velocity for a variety of configurations were made both outside the structures in the reservoir and within the structures themselves. In addition a cylinder gate was constructed of fiberglass and instrumented with strain gauges to evaluate dynamic forces on the gate during various modes of operation.

(f) Tests completed.

(h) Report in preparation.

(6513) PEACH BOTTOM NUCLEAR STATION.

(b) Philadelphia Electric Company.

(d) Experimental, for design.

(e) A $1 / 300$ horizontal by $1 / 30$ vertical scale model of the section of the Susquehanna River between Holtwood Dam and Conowingo Dam was constructed. In addition to the Holtwood and Conowingo installations the Muddy Run Pumped Storage Plant is included. At the Peach Bottom site a variety of intake and outlet structures will be studied in evaluating the heat effect on the reservoir of the Peach Bottom cooling water. Weekly cycles of plant operation at all four power stations are modeled during a test and temperature measurements at approx- imately 250 locations are recorded every minute of model operation. The reservoir temperature is varied from $40^{\circ} \mathrm{F}$ to $85^{\circ} \mathrm{F}$ and plant increase has been varied from $8^{\circ} \mathrm{F}$ to $30^{\circ} \mathrm{F}$. (f) Tests in progress.

(6514) MORGANTOWN STEAM POWER STATION.

(b) Potomac Electric Power Company.

(d) Experimental, for design.

(e) A $1 / 400$ horizontal by $1 / 40$ vertical scale model of a $16 \mathrm{mile}$ section of the Potomac River has been constructed. This model includes the section of the Potomac between Upper Cedar Point and Swan Point and is in the tidal range of the river. The controls are designed to automatically produce the selected tide cycle in the model and to produce river temperatures from $40^{\circ} \mathrm{F}$ to $85^{\circ} \mathrm{F}$. In addition the incremental temperature is applied to the plant flow and can be varied over a range from 0 to $30^{\circ} \mathrm{F}$. The study is being conducted to evaluate the heat effect of the condenser cooling water in the river. Instrumentation has allowed approximately 150 temperature probe locations to record data each minute of operation.

(f) Tests in progress.

(6515) CALVERT CLIFFS NUCIEAR POWER PLANT.

(b) Baltimore Gas and Electric Company.

(d) Experimental, for design.

(e) A 1/1000 horizontal by 1/100 vertical scale model is being constructed of an $18 \mathrm{mile}$ section of Chesapeake Bay including the plant site. The limits are from a section above Tilghman Island to below Hooper's Island. The model is designed to reproduce the tidal effects that are present in this section of the Bay and will have a water temperature range of from $40^{\circ} \mathrm{F}$ to $85^{\circ} \mathrm{F}$. The cooling water effluent from the model plant will be heated to reproduce the possible temperatures in the prototype plant. The purpose of the study is to determine the flow patterns and distribution of the heated effluent in the bay.

(f) Model under construction.

(6835) METER CALIBRATIONS.

(b) Ramapo Instruments Company, Bloomingdale, N.J.

(d) Experimental, for design.

(e) Calibration of large type flow meters for application in pipes varying in size from $8^{\prime \prime}$ in diameter to 48" in diameter.

(f) Tests in progress.

WORTHINGTON CORPORATION, Advance Products Div., 401 Worthington Ave., Harrison, New Jersey 07027

(6050) INVESTIGATION OF DISCHARGE PRESSURE OSCILIATIONS IN HIGH PRESSURE PUMPS.

(b) National Aeronautics and Space Admin., Lewis Research Ctr., Cleveland, Ohio.

(c) G.W. Soete, Chief Engineer.

(e) To determine the sources of pressure oscillations within a high pressure pump, the wave patterns throughout the diffuser and scroll, and to provide methods to predict the order of magnitude and the frequency range of these pressure oscillations.

WYLE IABORATORIES, Research Staff, Huntsville, Ala. 
(6545) AERODYNAMIC NOISE RESEARCH.

(b) Nat. Aeronautics and Space Admin., Marshall Space Flight Center, Huntsville, Ala.

(c) Dr. M.V. Lowson.

(d) Experimental and theoretical; basic research.

(e) Fundamental theoretical and experimental studies on the mechanism of boundary layer pressure fluctuations including separated flow and the flow over protuberances. Program includes the definition of models and mechanisms for turbulent boundary layer flow, and the design and completion of experiments to prove out these rypotheses.

\section{ADDENDUM}

\section{UNIVERSITY OF MICHIGAN, Dept. of Civil Engrg.}

See p. 77 for full listings of this department.

(6423) UNSTEADY OPEN CHANNEL FIOW.

(b) National Science Foundation.

(c) Professor E.B. Wylie, Dept. of Civil Engrg., Univ. of Mich., Ann Arbor, Michigan 48104.

(d) Theoretical.

(e) Study of the control of transient conditions in Open Channels. 
U.S. DEPT. OF AGRICULTURE, AGRICUITURAL RESEARCH SERVICE, Soil and Water Conservation Research Div.

CORN BEIT BRANCH, 108 Soils Bldg., Univ. of Minnesota, St. Paul, Minn. 55101, Dr.C.A. VanDoren, Branch Chief.

\section{(1723) HYDRAUIICS OF WATER CONTROL STRUCTURES AND} CHANNELS.

See St. Anthony Falls Hydraulic Lab. Project Nos. 111, 1168, and 2386. See also U.S. Dept. of Agriculture, Agricultural Research Service, Soil and Water Conserv. Res. Div., Southern Plains Branch, Project No. 4335 and Illinois State Water Survey Division, Project No. 1865.

(b) Cooperative with the Minnesota Agric. Expmt. Sta.; the St. Anthony Falls Hydraulic Lab.; and the Illinois State Water Survey.

(c) Mr. Fred W. Blaisdell, Research Investigations Leader, St. Anthony Falls Hydraulic Lab., 3d Ave. S.E. at Mississippi River, Minneapolis, Minnesots 55414 .

(d) Experimental; applied research for development and design.

(e) Research dealing with the design, construction, and testing of structures for conserving and controlling soil and water are carried out. Cooperation with and co-ordination of the tests at the Stillwater, Oklahoma, Outdoor Hydraulic Laboratory and the Illinois State Water Survey are maintained.

A square drop inlet having a hood barrel entrance is being tested to determine entrance loss coefficients for various drop inlet sizes and heights and various barrel slopes. Previous tests have evaluated the performance of this type of inlet.

The elbow and transition between the two-way drop inlet and the barrel is being studied to determine the pressures and the best form to minimize the possibility of cavitation. The transition between a circular pipe and a rectangular cantilevered outlet is being studied to determine the best form of the transition. Studies are also being conducted on a rectangular cantilevered outlet with a deflector at the exit to throw the water away from the structure and move the scour hole further downstream.

(g) If the anti-vortex plate is too low, undesirable orifice flow will control the discharge. If the anti-vortex plate is too high, harmful vortices will form under the plate. Rules for determining acceptable plate heights have been determined. The overhang of the plate must be greater than a certain minimum to insure satisfactory performance. The action of the twoway drop inlet is that of a self-regulating siphon. The tests using air agree with the results obtained from the water tests and are much easier to perform. Air is used as the model fluid only for the condition of full conduit flow.

To supplement the experiments, potential flow methods have been used to determine the theoretical coefficient of energy loss at the crest of the two-way drop inlet.

Six shapes of elbow between the two-way drop inlet and the transition were tested. The elbows were evaluated on the basis of high minimum relative pressures and the presence of adverse pressure gradients. The theoretical free streamline elbow had small areas of adverse pressure gradients. The best elbow shape is an ellipse with semi-major and semi-minor axes of $2 D$ and $D$. ( $D$ is the barrel diameter,) An elbow made up to two 45-degree circular segments of radii $D / 2$ and $3 D / 2$ also has generally satisfactory hydraulic characteristics. Seven transitions between the half-square crown - half-circular invert cross section at the elbow exit and the circular barrel were tested. The best transition is warped and $1 D$ long. Its top, $1 D$ above the pipe invert, is an equilateral triangle 10 wide at the elbow exit with its apex at the barrel entrance. The warped sides are the locus of lines run perpendicular to the pipe axis from the edge of the triangular top tangent to the pipe circumference. A conical transition 2D long is also satisfactory. This transition has an isosceles triangle top 10 above the pipe invert. The base of the triangle at the elbow exit is $1 D$ wide and its apex is at the pipe crown at the downstream end of the transition. The sides are vertical right triangular planes D/2 high at the elbow exit. The hypotenuse drops from $\mathrm{D}$ above the pipe invert at the elbow exit to $\mathrm{D} / 2$ above the pipe invert at the downstream end of the transition. Quadrants of circular cones fill the space between the vertical side triangular planes and the nearly horizontal triangular plane top. The entrance loss coefficients are low and identical within the limits of experimental precision for all elbow-transition combinations. Tests on the hood drop inlet have shown that the hood barrel entrance can be used to reduce the minimum required height of the drop inlet. Minimum sizes of drop inlet and antivortex devices have been determined. Tests of low-stage orifices in the two-way drop inlet have shown that improper location and improper proportioning of the orifices can prevent priming of the spillway. The proper location of the orifices and the sizes of the orifices for satisfactory spillway performance have been determined.

When the flow cross section is changed abruptly from a circular pipe to a rectangular open channel the rectangular channel width must be 1.OD, where $D$ is the pipe diameter, to prevent excessively high waves and disturbances in the reciangular channel. To provide space for the pipe to expand, an expansion section wider than the outside diameter of the pipe and not longer than $0.5 \mathrm{D}$ can be used between the pipe and the rectangular channel. The channel floor can be lowered below the pipe invert to accommodate pipe expansion and permit drainage of the expansion section. Although there is a diamond shaped wave pattern with waves of significant height in the 1.OD-wide channel, the transition performance is greaty satisfactory at all discharges between $Q / D^{5 / 2}=4$ and 20 .

(h) "The Two-Way Drop Inlet for a Closed Conduit Spillway, "Charles A. Donnelly, Jour. Soil and Water Conservation, Vol. 20, No. 6, pp. 251-253, Nov.-Dec. 1965. "Hydraulics of Closed Conduit Spillways, Part XI, Tests Using Air," Fred W. Blaisdell and George G. Hebaus, St. Anthony Falls Hydraulic Lab. Tech. Paper No. 44, Ser. E, 52 pp., January 1966. 
"Hydraulic Efficiency in Culvert Design," Fred W. Blaisdell, ASCE, Jour. Highway Div., Vol. 92, No. HWI, pp. 1l-22, Mar. 1966.

Closing discussion, Vol. 93, No. HW2, pp. 192194, Nov. 1967.

"Flow in Culverts and Related Design Philosophies," Fred W. Blaisdell, ASCE, Jour. Hydraulics Div., Vol. 92, No. HY2, pp. 19-31, Mar. 1966. Closing discussion, Vol. 94, No. HY2, pp. 531-540, March 1968.

"Energy Loss at Pipe Junctions," Fred W. Blaisdell and Philip W. Manson, ASCE, Jour. Irrigation and Drainage Div., Vol 93, No. IR3, pp. 59-78, Sept. 1967.

"Hydraulic Design of the Box Inlet Drop Spillway," Fred W. Blaisdell and Charles A. Donnelly, Agriculture Handbook No. 301, 40 pp., Apr. 1966.

(4271) NEW MATERIALS, EQUIPMENT AND TECHNIQUES FOR DRAINAGE OF AGRICULTURAL IANDS.

(4275) MECHANICS OF SOIL EROSION BY WATER.

(b) Laboratory project, in cooperation with Purdue Univ. Agriculatural Expmt. Sta., (See Project No. 4182, Purdue Univ.).

(c) L.D. Meyer, Agricultural Engr., Agricultural Engrg. Bldg., Purdue Univ., Lafayette, Indiana 47907.

(d) Experimental investigation; basic research.

(e) Laboratory and analytical investigations of (1) mathematical expressions that relate slope length, slope steepness, particle size, mulch rate, etc., to resulting soil erosion; (2) effects of rainfall impact and runoff hydraulics on soil detachment and transportation; (3) relation of soil physical properties to soil surface sealing; and (4) mathematical models of the soil erosion process as basis for improved methods of erosion prediction and erosion control.

(g) (1) Mulch rates less than $1 / 2$ ton per acre were effective in reducing erosion for many conditions; (2) erosion was often very selective in particle sizes transported; (3) raindrop impact reduced the infiltration rate of most fine to medium textured soils by more than 50\%; (4) disturbed slopes that were formed to concave shapes were least erosive; and (5) a general mathematical model describing the soil erosion process was developed.

(h) "The Relation of Some Physical and Chemical Properties of Soils to Surface Sealing," J.V. Mannering and D. Wiersma, Agronomy Abstracts, 1967.

"Effect of Particle Roughness on Soil Erosion by Surface Runoff," G.D. Bubenzer, L.D. Meyer, E.J. Monke, Trans. Amer. Soc. Agric. Engrs., Vol. 9, No. 4, 1967, pp. 562-4.

"Small Amounts of Surface Mulch Reduce Erosion and Runoff Velocity," L.A. Kramer and L.D. Meyer, ASAE Paper No. 68-206, 1968.

U.S. DEPARTMENT OF AGRICULTURE, AGRICULTURAL RESEARCH SERVICE, Soil and Water Conservation Research Division.

NORTHEAST BRANCH, Plant Industry Station, Beltsville, Maryland 20705, Dr. H.L. Barrows, Branch Chief

(4283) PROCESSES OF STREAM CHANNNEL DEVELOPMENT IN THE NORTHEAST.

(b) Laboratory project.

(c) Paul H. Blinco, Civil Engrg.Dept., State Univ. of New York at Buffalo, Buffalo, New York 14212 (d) Field studies; applied research.

(e) Relationships are established between gross flow quantities, such as mean velocities, energy gradients, mean boundary shears, and bed and bank stability as causes for channel deformation. Detailed field measurements of channel geometry and flow parameters are studied and correlated with changes in channel alignment and sediment discharge.

(g) Data were collected on the superelevation of the water surface in open channel bends with the object of developing a method of estimating discharge. An equation which best fits the data is proposed as:

$$
\Delta h=2.2 \ln \frac{r_{0}}{r_{i}} \frac{v^{2}}{2 g}
$$

in which $\Delta \mathrm{h}$ is the maximum superelevation in the bend, $v^{2} / 2 \mathrm{~g}$ is the kinetic energy of the flow at the cross-section being considered, $r_{0}$ is the radius of the outer bank and $r_{i}$ is the radius of the inner bank.

The equation can be rearranged to find discharge as a function of superelevation, cross sectional area, and radii of curvature. Data were collected for a preliminary analysis of the changes of shape at bends in Buffalo Creek, near Buffalo, New York, which is part of the geometry studies of the channel. It was found that unstabilized bends situated on the shale beds widened according to the relation

$$
\frac{W}{W}=\frac{\pi}{2} \frac{W}{r_{0}}+1
$$

in which $W m=$ maximum channel width in a bend, $\mathrm{W}=$ channel width at entrance, and $\mathrm{r}_{\mathrm{o}}=$ radius of outer bank.

The mean value of the product $r_{0} \theta / W$ wa's found to be 3.18 and the probable error of the mean was calculated as 0.16 , so that the data can be said to satisfy the theoretically derived relation, $r / W=\pi / \theta$, in which $\theta$ is the included angle of the bend and the other symbols the same as previously expressed.

(4285) MORPHOLOGY OF STREAM CHANNELS IN NEW ENGLAND.

(4819) DRAINAGE SYSTEMS FOR ST. IAWRENCE - CHAMPLAIN LAND RESOURCE AREA.

(b) Laboratory project.

(c) Mr. Joseph Bornstein, Agricultural Engr., Agricultural Engrg. Dept., Univ. of Vermont, Burlington, Vermont 05401

(d) Experimental, field investigation; basic and applied research.

(e) Twelve drainage treatments established on a wet seepy hillside of Cabot loam soil, including two depths of diversion terrace spacings, two diversion depths, with and without tile at two spacings. Diversion and tile outlets instrumented to record water flow; piezometers determine hydraulic gradient and directional flow; soil moisture monitored by neutron scatter techniques; alfalfa used as test crop. Laboratory studies are needed to evaluate freezing and thawing effects, ice lens formation, and soil temperature effects on soil water retention and transmission values. The research is conducted (1) to develop methods and design criteria for interception drainage systems on wet seepy, sloping lands, (2) to evaluate environmental factors relating to surface and subsurface water flow. 
(g) Analysis of data for six periods of drainage covering parts of 1964,1965 , and 1966 revealed differences related to season of the year, rainfall amounts, and antecedent soil moisture. A correlation exists between incidence of crown rot of alfalfa and inches per acre of water drained from the land. Moisture held between $1 / 10$ and 15 bars of pressure for the 0 to $2.0 \mathrm{~mm}$ size fraction was found to be $24.9 \%$ in the Ap horizon, $16.1 \%$ in the gley horizon, and $13.4 \%$ in the fragipan horizon. Water uptake rates during the freezing of coarse and fine sand at three different constant tension levels of 6,15 , and $30 \mathrm{~cm}$ of water showed that at the higher tension, the rate of uptake was greater for the coarse sand, but the total uptake was greater for the fine sand. At the lower tension, an erratic, modified step function pattern of uptake has been consistently experienced.

(h) "Subsurface Drainage and Diversion Discharge Comparisons on a Sloping Fragipan Soil," J. Bornstein and G.R. Benoit. Amer. Soc. Agric. Engr. Trans., Vol. 10, pp. 590-593, 1967. "Characteristics of Flow to Diversion and Subsurface Drains on a Sloping Fragipan Soil," J. Bornstein, T.J. Thiel, and G.R. Benoit, Amer. Soc. Agric. Engr. Trans., Vol. 10, pp. 586-589, 1967.

"Alfalfa Survival-Indicator of Sloping Land Drainage Effectiveness," G.R. Benoit, K.D. Fisher, and J. Bornstein, Agron. Jour., Vol. 59, pp. 444-447, 1967.

"Soil Drainage - a Key to More Efficient Farming," J. Bornstein and G.R. Benoit, Vermont Farm and Home science, Winter, 1968.

(4820) HYDRODYNAMICS OF CHANNEI SYSTEMS IN AGRICULTURAI WATERSHEDS.

(b) Laboratory project; cooperative efforts on occasion.

(c) Mr. H.N. Holtan, Director, USDA Hydrograph Lab., ARS-SWC, Beltsville, Ma. 20705

(d) Basic and applied research.

(e) Specific objectives of this project are to translate the complete system of hydrodynamics, $i . e .$, the equation of continuity, the equation of state, and the equation of motion of fluids to a system appropriate to steady or unsteady flow (with lateral inflow and outflow) on land surfaces and through open channels; to define appropriate watershed and channel initial values and boundary conditions such as, surface or channel roughness, vegetation, materials and geometry, to insure meaningful watershed solutions to the hydrodynamical equations; to develop feasible numerical methods for solving hydrodynamic equations on analog or digital computers; and to work with other members of the USDA Hydrograph Lab. to verify the surface dynamic aspects of a mathematical model of watershed performance.

(g) A computational watershed surface runoff system is now being utilized which is derived from the watershed topographic map. Treating contour lines as equipotentials, stream lines are drawn normal to the contours, forming flow tubes. Each flow tube starts on the watershed boundary and continues down slope until it intersects a channel. Each flow tube is divided into curvilinear rectangles on which land use and treatment, soil type and precipitation can be superimposed. For each flow tube the input is developed as distributed precipitation excess. Overland flow is routed through each stream tube and is discharged into a channel as lateral inflow. Channel routing computations proceed down each natural channel. The utility of this surface runoff model is twofold. One, inputs can be modified according to soil, cultural practice, as land cover for each incremental area bounded by the contour lines crossing each stream tube.

Second, the natural drainage patterns composed of the overland flow and channel flow system is retained in flow routing computations.

(h) "Kinematic Flood Routing," D.L. Brakensiek, Amer. Soc. Agric. Engr. Trans., Vol. 10, No. 3, pp. 340-343, 1967.

"A Simulated Watershed Flow System for Hydrograph Prediction; A Kinematic Application," D.I. Brakensiek, Proc. Intl. Hydrology Symp., Fort Collins, pp. 18-24, 1967.

"Finite Differencing Methods," D.I. Brakensiek, Water Resources Res., Vol. 3, No. 3, pp. 847$860,1967$.

"The Synthesis of Distributed Imputs for Hydrograph Predictions," D.L. Brakensiek and C.A. Onstad, Water Resources Res., Vol. 4, No. 1, pp. 91-94, 1968.

"Flow Retardance Coefficients for Selected Prismatic Channels," D.E. Overton, Amer. Soc. Agric. Engr. Trans., Vol. 10, No. 3, pp. 327$329,1967$.

U.S. DEPARTMENT OF AGRICULTURE, AGRICULTURAL RESEARCH SERVICE, Soil and Water Conservation Research Division.

NORTHERN PLAINS BRANCH, P.O. BOx E, Fort Collins, Colorado 80521, Dr. C.E. Evans, Branch Chief.

(4826) FLOW IN POROUS MEDIA IN RELATION TO DRAINAGE AND DISPOSAL POLUUTANTS.

(b) Laboratory project.

(c) Mr. Harold Duke, Agricultural Engr., Agricultural Research Service, P.O. Box E, Fort Collins, Colorado 80521

(d) This is an experimental project, which considers the basic theories involved.

(e) A highly instrumented sand tank model of a parallel drain system is being used to determine the potential distribution and contribution of the partially saturated zone to the drain performance. The purpose is to provide an accurate means of drain design in finetextured soil.

(g) Using theories of similitude, the results of the first experiments show promise of modifying existing flow theories to account for the flow contribution of the partially saturated zone.

(4827) DESIGN, PERFORMAINCE, AND AUTOMATION OF SURFACE IRRIGATION SYSTEMS, UPPER COLORADO BASIN.

(b) Laboratory project.

(c) Mr. Dale F. Heermann, Agricultural Engrg. Dept., Colorado State Univ., Fort Collins, Colorado 80521

(d) Field investigations; applied research, design.

(e) Develop and evaliate for efficient water use and crop production facilities, methods, design criteria, and automation for surface irrigation systems including hydraulics of flow in border strips in relation to stream size, slope, crop retardance, soil roughness, and intake rate. Field investigations are conducted to develop relationships of factors involving stream size, slope, soil roughness, crop retardance, etc., that affect flow of water in furrows 
and border strips. Data obtained form the basis for developing equations to predict flow characteristics for design purposes using computer techniques. Automation of various irrigation methods using semi-automatic devices are studied and performance evaluated under a wide variety of soil, crop, and climatic conditions.

(4832) DRAINAGE FOR RECTAMATION OF SAIT-AFFECTED NON-IRRIGATED SOILS IN RED RIVER VALIEY, NORTH DAKOTA.

(5566) DEITA DEVELOPMENT ABOVE FLOODWATER RETARDING AND SEDIMENT DETENTION DAMS.

(b) Laboratory project.

(c) Dr. David A. Woolhiser, Hydraulic Engr., Agricultural Research Service, Engrg. Research Center, Colorado State Univ. Foothills Campus, Fort Collins, Colorado 80521.

(d) Experimental investigations; basic and applied.

(e) Purpose of project is: (1) to investigate the dynamic processes involved in delta (topset bed) development above floodwater or debris storage structures, and (2) to develop equations and graphical representations describing the delta development processes in terms of the variables involved.

(f) Suspended.

(g) The intensity of large-scale motion in the form of secondary currents, surges, and water surface fluctuations was found to be stronger during aggradation of the channel than during degradation and is related to the rate of aggradation. The rate of delta-area growth is a function of sediment inflow and delta thickness. In a study of the size distribution of sediments in a three-dimensional delta it was found that the internal structure of a delta can be related to overall delta geometry.

(h) "Hydraulics of Rivers and Deltas," H.Y. Chang, Ph.D. Dissertation, Colorado State Univ., Fort Collins. 176 pp., 1967.

"Sediment Size Distribution in Deltas," T.A. Reid. MS thesis, Colorado State Univ., Fort Collins. 124 pp., 1967.

"Variation of the Characteristics of Deltaic and Stream Bed Deposits in Laboratory Studies," T.A. Reid, R.H. Brooks and D.B. Simons, Symp. on River Morphology, General Assembly of IUGG, Bern, Switzerland, 1967.

"The Effect of Water Detention Structures on River and Delta Morphology, "H.Y. Chang, D.B. Simons and R.H. Brooks, Symp. on River Morphology, General Assembly IUGG, Bern, Switzerland, 1967.

(5567) AUTOMATION OF WATER DISTRIBUTION SYSTEMS FOR SURFACE IRRIGATION.

(b) Laboratory project.

(c) Dr.H.R. Haise, Soil Scientist, Agricultural Research Service, P.0. Box E, Fort Collins, Colorado 80522

(d) Laboratory and field project; applied research; development, design and operation of automated system.

(e) To develop labor-saving devices for surface application of irrigation water to farm fields for more efficient use of existing water supplies. Study involves development and testing of remote operation of a pneumatic valve (patents pending) capable of controlling water in open ditch and closed pipe systems. (g) Further progress in automation of surface irrigation systems, including both open-ditch and buried concrete pipeline distribution systems, includes the following notable accomplishments: At Wiggins, Colorado, 78 acres of furrow-irrigated field beans, corn and sugar beets were automatically irrigated by the farmer himself utilizing pneumatic butyl rubber O-rings as closures on alfalfa valves and improved remote telemetry controls and timer.

On Maui, Hawaii, 13.4 acres of sugar cane are being automatically irrigated with waterpowered cylinders that operate control gates in an open ditch distribution system. Remote battery-powered electronic gear and soil water sensor is used to over-ride hydraulic actuated gates when sufficient water is applied to field.

(h) "Pneumatic Valves for Automation of Irrigation Systems," H.R. Haise and E.G. Kruse, Proc. 6th Congr. ICID, Spec. Sessions Rpt. No. 1, pp. 51-58, 1966.

"Automation of Surface Irrigation Systems With Inflatable Butyl Rubber Valves, "H.R. Haise and A.T. Corey, Colorado State Univ. Agrarian, Vol. 4, No. 1, pp. 5-12, 1966.

U.S. DEPARTMENT OF AGRICULTURE, AGRICULTURAI RESEARCH SERVICE, SOil and Water Conservation Research Division.

NORTHWEST BRANCH, P.O. Box 1187, Boise, Idaho 83701 , Mr. Dean C. Muckel, Branch Chief.

(3550) SPRINKLER IRRIGATION SYSTEM DESIGN AND OPERATION IN THE NORTHWEST.

(3553) SURFACE IRRIGATION SYSTEM DESIGN AND AUTOMATION IN THE NORTHWEST.

(b) Laboratory project.

(c) A.S. Humpherys, Research Agricultural Engr., Route 1, Box 186, Kimberly, Idaho 83341

(d) Experimental; applied research.

(e) Develop and test mechanical labor-saving devices and structures to control surface irrigation. Determine and compare water application efficiencies, labor requirements and cost on automated and nonautomated portions of irrigation systems.

Various types of gates and tripping mechanisms will be developed and treated including those for cut-back-flow for furrow irrigation. Data on installation procedures, requirements and labor for each automatic structure will be obtained and functional characteristics of automatic control structures will be developed.

(g) A new center-of-pressure, fully automatic gate for use in unlined irrigation ditches has been developed. The gate may be used as a safety gate or as a companion structure to other gates which create a rise in the water surface necessary for releasing this gate. A sinkingfloat border gate, for example, could be used with this gate to provide a fully automatic system for border irrigation. Timers have been used for controlling semiautomatic irrigation structures. Most commercial timers have not been reliable when subjected to normal continuous exposure to dust and moisture. A commercial timer has been modified in cooperation with a manufacturer to provide most of the necessary features of 
a controller of automatic or semiautomatic irrigation structures. It has a corrosion resistant movement and a factory sealed enclosure and escapement release. It is currently being tested using a modified semiautomatic drawstring check (also now available commercially) in unlined ditches. Field tests of an automatic cutback furrow irrigation system near Ault, Colorado indicated that the outlets installed in lined ditches must be constructed to close tolerances and operated as designed because the secondary or cutback flow is very sensitive to variations in the effective head at each outlet.

(h) "Automatic Irrigation Gate," A.S. Humpherys, and J.A. Bondurant, Patent No. 3,300,985, January 1967.

"Surface Irrigation Systems," A.A. Bishop, M.E. Jensen, and W.A. Hall, Chapter 43. Amer. Soc. Agron. Monograph No. 1l, entitled "Irrigation of Agricultural Lands," pp. 865-884, 1967.

"The Development of Automatic Irrigation Structures and Devices," A.S. Humpherys and J.A. Bondurant, 1966 Reports, Hawaiian Sugar Technologists, 25th Annual Meeting, Nov. 1966, Honolulu, Hawaii, 1967.

"Control Structures for Automatic Surface Irrigation Systems," A.S. Humpherys, Amer. Soc. Agric. Engr. Trans., Vol. 10, No. 1, pp. 2l-23, $27,1967$.

"Recent Developments in the Automation of Surface Irrigation," A.S. Humpherys, Agric. Engr. Vol. 48, No. 6, pp. 338-340, 1967.

(5209) DEVICES, METHODS AND STRUCTURES FOR IRRIGATION WATER CONTROL AND MEASUREMENT.

(b) Laboratory project.

(c) A.R. Robinson, Agricultural Engr., Route 1, Box 186, Kimberly, Idaho 83341 .

(d) Experimental; applied research.

(e) Devices and methods for accurate measurement of flow in channels, closed conduits and underground aquifers, and improved designs of dropcheck structures for farm irrigation systems are developed. These devices, methods and structures are tested in the laboratory and in the field to calibrate and determine accuracy, adaptability and field performance.

(g) Efficient water use requires reliable methods of water measurement or volume control of water. Detailed laboratory tests of a standard 7 -inch Parshall flume indicated that the published calibration data for this flume apparently are in error. Parshall flumes with the throat and downstream diverging section removed have been used with the standard calibration for irrigation water measurement. Laboratory studies indicated that there is significant change in the head-discharge relationship with these sections removed, particularly at high flows. This difference is not significant when the discharging jet is supported by the horizontal floor of a lined ditch. Irrigation water measurement in lined concrete ditches can be easily accomplished with cast-in-place concrete trapezoidal flume having side slopes conforming to the standard slipform ditch. The form for casting the flumes, developed at Twin Falls, Idaho, was modified so that the height of the flume above the ditch bottom could be varied. This modification provides free flow conditions and results in greater ease of installation, elimination of feather edges, permits use of a lower slump concrete, and requires less hand finishing.

Commercial prefabricated drop-check structures are being manufactured by many small firms. Field studies of several of these structures indicated that most of them are less stable and tend to wash out easier than more common built-in-place structures. Generally, the prefabricated structures do not provide adequate stilling basins for energy dissipation, or headwall length and depth for structural stability.

(h) "Trapezoidal Flumes for Irrigation Channels," A.R. Robinson, USDA-ARS 4l-140, 15 pp., March 1368 .

"Water Control and Measurement on the Farm," A.R. Robins on and A.S. Humpherys, Chapter 42 , Amer. Soc. Agron. Monograph No. 11 entitled "Irrigation of Agricultural Lands," pp. 828 864,1967

"Discussion: Flow Measurements with Fluorescent Tracers," R.V. Worstell. Amer. Soc. Civil Engr., Jour Hydraulics Div., Vol. 93, No. HY3, pp. 216-220, 1967.

(5570) PRACTICES AND SYSTEMS FOR IMPROVING FARM AND DISTRICT IRRIGATION EFFICIENCY IN THE NORTHWEST .

(b) Laboratory project, cooperative with the U.S. Bureau of Reclamation and Idaho Agricultural Expmt. Sta.

(c) M.E. Jensen, Research Agricultural Engr., Route 1, Box 186, Kimberly, Idaho 8334 l.

(d) Field investigation; applied research.

(e) Evaluate qualitatively and quantitatively factors affecting farm and project irrigation efficiencies. Define, develop, and evaluate farm and project and management guidelines that can improve irrigation efficiencies on existing and proposed projects. Define and develop methods of combining return flow water in distribution systems and develop procedures for predicting stream recession in border irrigation. Test physical and chemical treatments for controlling furrow irrigation intake rates.

(g) A joint study of irrigation practices in southern Idaho indicates that erratic timing of irrigations and applications of excessive amounts of water during irrigations are the major factors affecting farm irrigation efficiencies. Procedures for scheduling irrigations have been developed and are currently being tested throughout southern Idaho. These procedures are based on climatic parameters, soils, and crop characteristics using remote time-sharing computer facilities. The amount of water to be applied is also provided based on attainable field irrigation efficiencies. Results obtained in 1767 indicated that the farmer needs periodic information on soil moisture conditions and probable days before needing to irrigate in order to effectively utilize this information in making management decisions.

Irrigation specialists have advocated the use of cutback irrigation streams in furrow irrigation for many years, but this practice has generally not been adopted because of the problem created with the unused portion of the stream. These studies have shown that a recirculating irrigation system and sump can be used to achieve cutback streams by adding runoff water pumped from storage during the advance of the stream. 
Many companies are now developing and testing new methods of moving sprinkler irrigation pipe without the use of hand labor. One such system is the self-propelled continuous moving lateral. These studies of the water distribution by the self-propelled lateral have indicated that water distribution is more uniform as compared to equivalent laterals operating at a fixed position for a given period of time. One of the major factors affecting the distribution is the fact that sprinkler heads on the moving lateral represent line sources of water for the field as compared to point sources with the standard nonmoving laterals.

(h) "Improving Irrigation Efficiencies," M.E. Jensen, I. Swarner, and J.T. Phelan, Chapter 61, Amer. Soc. Agron. Monograph No. 11 entitled "Irrigation of Agricultural Lands," pp. 1120-1142, 1967.

"Evaluating Irrigation Efficiency," M.E. Jensen. Amer. Soc. Civil Eng. Proc., Jour. Irrig. and Drainage Div., Vol. 93, No. IRI, pp. 83-98, 1967.

(5981) DRAINAGE SYSTEMS FOR IRRIGATED AREAS IN THE NORTHWEST

(b) Laboratory project.

(c) M.E. Jensen; see (5570) above.

(d) Experimental, field investigation; applied research.

(e) Existing approximate solutions for nonsteady state vertical drainage using hydraulic properties of soils determined under steady state conditions in the laboratory are evaluated. An irrigation district with high perched water table problems is being evaluated to determine if restriction of water deliveries will alleviate the problem and if drainage to deeper aquifers is feasible. Equations to describe transient movement of salt, water and heat under conditions associated with simultaneous osmotic, thermal and moisture content gradients in soil are being developed.

(g) A gamma radiation apparatus for automatically scanning more soil columns has been completed. The unit has an Americium 241 gamma source. Some difficulty has been experienced with temperature effects in the scaling system. A water budget was initiated on a southern Idaho irrigation project that has been plagued with high water table problems since the project began 60 years ago and more recently the development of salinity problems. The objective of this study is to develop a representative mathematical model of the project so that management guides can be developed and used to regulate water deliveries to meet evapotranspiration requirements without exceeding natural and artificial drainage capacities. The major difficulty in this study is the lack of water measurement structures. However, preliminary results have delineated areas within the 125 square mile area where excessive water deliveries are made. Natural drainage rates as a function of water table elevation are currently being obtained.

(h) "Experimental Measurements of Soil-Moisture Hysteresis and Entrapped Air," J.W. Cary, Soil Sci., Vol. 104, No. 3, pp. 174-180, 1967. "An Instrument for In Situ Measurements of Soil-Moisture Flow and Suction," J.W. Cary, Soil Sci. Soc. Amer. Proc., Vol. 32, No. 1, pp. 3-5, 1968
"Nonsteady-State Drainage of Fluid from Porous Media," M.E. Jensen and R.J. Hanks, Amer. Soc. Civil Engrs., Jour. Irrigation and Drainage Div., Vol. 93, No. IR3, pp. 209-231, 1967

U.S. DEPARTMENT OF AGRICULTURE, AGRICULTURAL RESEARCH SERVICE, Soil and Water Conservation Research Division.

SOUTHERN BRANCH, P.0. Box 1072, Athens, Georgia 30601, Dr. G.R. Burns, Branch Chief.

\section{(3871) SEDIMENT TRANSPORT IN STREAM CHANNELS.}

(b) Laboratory project, cooperative with Univ. of Mississippi and Mississippi State Univ.

(c) Messrs. Joe C. Willis and A.J. Bowie, Hydraulic Engrs., and Dr. Neil L. Coleman, Geologist, USDA Sedimentation Lab., P.0. Box 30, Oxford, Mississippi 38655.

(d) Experimental; basic and applied research.

(e) Investigate all aspects of sediment transport including: "wash load", bed load, suspended load, bed material transport, and total sediment transport in alluvial channels. Determine by laboratory and field experiments the effects of flow characteristics, physical properties of bed forms and bed material on sediment transport in alluvial channels. Design, develop and test instruments and techniques for measurement of water runoff and sediment discharge.

(g) Two models of the Parametrics X-ray sediment concentration gage were field tested. Model A, although affected by temperature and age, performed satisfactorily over a 2 -month period. Concentrations as low as 1000 p.p.m. were measured over 15-minute periods with a probable error of \pm 330 p.p.m. Model B, which was more sensitive and had none of the shortcomings of its predecessor, performed satisfactorily, with only minor maintenance problems, for several months.

Two methods were devised to utilize the dual channel stream monitor to determine both static and dynamic dune properties for comparison with visual measurements at the flume wall. One uses a single probe to traverse a length of channel and record irregularities. The other method employs two stationary sensing units a fixed distance apart in the direction of flow. Two recordings of bed forms are obtained as they migrate under the units. The attenuation of $x$-rays in passing through sediment laden water from the source to the detector in an experimental sediment sensing gauge was found to differ for a given average concentration depending upon the direction of increase in concentration between the 2 elements of the gauge. Studies are continuing. Examination of suspended sediment concentration profiles from several rivers and laboratory flumes shows that the idea of a suspended sediment boundary layer can be introduced. The relative concentration equation vithin this boundary layer (adjacent to the bed) is in the form of an equilateral hyperbola, indicating that the sediment transfer coefficient in this region varys linearly with distance from the bed. Outside the suspended sediment boundary layer, the relative concentration function is exponential in form, as would be the case if the sediment transfer 
coefficient were constant in this region. An error or Gaussian distribution function has been developed as an approximation to the vertical suspended sediment distribution in open channel flow. This mathematical model has been found to be equally as reliable as the classical equation in predicting the concentration distribution and has the advantage that its integral over the flow depth converges to a reasonable approximation of the total bed material transport rate per unit of channel width.

An even more general method of analysis of sediment transport and channel resistance data has been derived from the equation of motion for a fluid consisting of a sediment-water mixture. Experimental results are shown to be most general when they are expressed as relationships between similitude coefficients derived from the equation of motion and from the boundary conditions of the flow system. The results of analyses, useable in the estimation of bed material transport for known flow and sediment properties are expressed graphically.

(h) "Performance of Nuclear sediment Concentration Gauges," J.R. McHenry et al., Isotopes In Hydrology, IAEA, Vienna, Austria, 1967, pp. 207-225. "Field Tests on the Coshocton-Type Wheel Runoff Sampler, "C.E. Carter and D.A. Parsons, Trans. Amer. Soc. Agric. Engr., Vol. 10, No. 1, pp. 133-135, 1967.

(4316) DESIGN CRITERIA FOR WATER CONTROL STRUCTURES AND CHANNEL STABILTZATION.

(b) Laboratory project, cooperative with Univ. of Mississippi and Mississippi State Univ.

(c) Mr. D.A. Parsons, Hydraulic Engr., and Dr. Neil I. Coleman, Geologist, USDA Sedimentation Lab., P.0. Box 30, Oxford, Mississippi 38655.

(d) Field and laboratory investigations; basic and applied research.

(e) Develop and evaluate techniques and criteria for the design, stabilization, and maintenance of stream channels. Investigate by model and field studies methods and means of channel stabilization and protection. Areas of investigation include: the influence of plan geometry and channel shapes; the spectrum of flood flow values; flow velocities, depths, and slopes; flow reduction schemes; and the use of engineering works, vegetation, etc., to reduce channel boundary velocities and protect the channel lining.

(g) Comprehensive measurements of drag forces on streambed particles, and observations of the mean forces that prevailed at incipient motion have been tabulated and published. The data cover a wide range in liquid viscosities and bed particle densities. Computed lift forces that prevailed at incipient motion are to be checked in future laboratory measurements. A cooperative study with SCS has been initiated to observe and evaluate the effect of floods on channel stabilization measures consisting of piling, waling fencing, and concrete jacks. Installations have been completed on a 4-mile reach of Tillatoba Creek, in north Mississippi.

(h) "A Theoretical and Experimental study of Drais and Lift Forces Acting on a sphere Resting on a Hypothetical Streambed," N.L. Coleman, Proc. XIIth Intl. Assoc. Hydraulic Res. Congr., Fort Collins, Colo., Sept. 1967, Vol. 3, pp. 185192.
(4317) STRFAM CHANNEL MORPHOLOGY AND STABILITY.

(b) Laboratory project, cooperative with Univ. of Mississippi and Mississippi State Univ.

(c) Dr. Earl H. Grissinger, Soil Scientist, Mr. Donald A. Parsons, Hydraulic Engr. and Director, and Dr. Neil L. Coleman, Geologist.

(d) Experimental; applied and basic research.

(e) Investigations of prevailing horizontal and vertical forms of stream channels and the processes and forces that create them, including bed forms and resistance to flow in alluvial channels, to acquire knowledge that will provide engineering solutions to problems of channel stability. Determine by both laboratory and field experiments the effects of various hydraulic and mineralogical parameters on channel geometry and stability; also the influences of horizontal channel geometry on the flow parameters. The latter are interdependent. Hydraulic parameters include: velocity head, boundary shear stress, Froude and Reynolds numbers, and hydraulic gradient. The inherent and the environmental factors affecting cohesiveness of channel periphery materials will be investigated.

(g) Several hundred laboratory soil erodibility tests point to the following conclusions: 1. Water entry into cohesive materials produces mechanical forces, or relieves cohesive forces, which may result in surface particle detachment. In other words, erosion rates increase for a given erosive situation when water enters the channel boundary material. 2. The magnitudes of the internal detaching forces increase with increasing rate of water entry.

3. For a given rate of water entry and flow erosiveness, the erosion rate decreases with decreasing bulk density.

(h) "Resistance of selected Clay systems to Erosion by Water, "E.H. Grissinger, Water Resources Res., Vol. 2, No. 1, pp. 131-138, 1966.

"Sediment Transport Mechanics: Initiation of Motion - A Discussion," Joe C. Willis, Proc. ASCE, Jour. Hydraulics Div., Vol. 73, No. HYl, Jan. 1967, pp. 101-107.

(4331) SOIL DETACHMENT AND MOVEMENT EY RAINDROP IMPACT AND FLOWING WATER IN THE SOUTH.

(b) Laboratory project.

(c) Mr. W. Campbell Iittle, Research Agricultural Engr., Southern Piedmont Conservation Research Center, P.O. Box 555, Watkinsville, Georgia 30677.

(d) Experimental, laboratory; basic and applied.

(e) Basic research on the effects of gradation of sediments on the entrainment and transport. Large gradations (geometric standard deviations from 1.25 to 3.00 ) permit study of the phenomenon of particle segregation and bed armoring. Turbulence measurements are made with the hot film anemometer.

(g) Initial studies are underway. No results to date.

(4332) DRAINAGF SYSTEMS DESIGN AND MAINTENANCT FOR THE LOWER MISSISSIPPI DELTA.

(b) Laboratory project.

(c) Mr. Irwin L. Saveson, Agrigultural Engr., P.O. Drawer U, University Station, Faton Rouge, Louisiana 70803 .

(d) Experimental; basic and applied research. (e) Determine maximum and minimum limits of row 
length and grade, land slope and other land shaping features, and develop criteria for designing surface and subsurface drainage systems. Approximately 80 acres of land have been formed with four different slopes, in two replications of $0.10^{\prime}, 0.15^{\prime}, 0.20^{\prime}$, and $0.25^{\prime}$ and with row lengths of 500', 700', 900', and $1,100^{\prime}$. Characteristics of surface water flow in furrows on agricultural lands will also be determined.

(g) Preliminary data show that peak rate and amount of surface water removal can be predicted from the parameters of maximum rainfall intensity for 35 minutes, land slope and length, and the available soil moisture storage capacity. Prediction equations have been developed.

(b) "Prediction of Surface Runoff from Graded Lands of Low Slopes in Humid Areas" (abstract), J.M. Laflin and I.I. Saveson, Agricultural Engrg., Vol. 47, No. 10, p. 535, Oct. 1966.

(4841) SURFACE AND SUBSURFACE FARM WATER SUPPLIES IN THE SOUTHERN COASTAL PLAINS. (Includes also No. 4842)

U.S. DEPARTMENT OF AGRICULTURE, AGRICULTURAL RESEARCH SERVICE, Soil and Water Conservation Research Division.

SOUTHERN PLAINS BRANCH, Bushland, Texas 79012, Dr. J.R. Johnston, Branch Chief.

\section{(4341) STREAM CHANNEL MORPHOLOGY IN THE SOUTHERN PLAINS.}

(4335) DESIGN AND HYDRAULIC TESTING OF CONSERVATION STRUCTURES AND CHANNELS.

See U.S. Dept. of Agriculture, Agricultural Research Service, Soil and Water Conservation Research Div., Corn Belt Branch, Project 1723, and Illinois State Water Survey Division Project No. 1865.

(b) Laboratory project cooperative with the Oklahoma Agricultural Expmt. Sta.

(c) Mr. G.G. Hebaus, Hydraulic Engr., P.O. Box 551, Stillwater, Oklahoma 74074.

(d) Experimental; applied research.

(e) Develop and test hydraulic structures for soil and water conservation works. Test small scale and full size models of structures and appurtenances in laboratory basins. Determine influence of structure form on head loss coefficients, vortex activity, and performance. Develop vent systems for flow constrictions in closed conduit spillways.

(g) Trash racks proposed for use on closed conduit spillways for detention reservoirs have been tested with clear water flows and with trash laden flows of hay or sticks. Relative efficiencies of the rack have been established. A complex of channels and structures comprising and urban flood water disposal works has been tested. Revisions developed in the testing saved both riprap and right-of-way requirements.

(4336) DEVELOPMENT, DESIGN, AND CALTBRATION OF WATER FLOW MEASURING DEVICES.

(b) Laboratory project, cooperative with the Oklahoma Agricultural Expmt. Sta.

(c) Mr. W.R. Gwinn, Hydraulic Engr., P.0. Box 551, Stillwater, Oklahoma 74074 . (d) Experimental; applied research.

(e) The measuring devices tested are used in the hydrology research program of the Agriculture Research Service. Sites for runoff measuring stations are surveyed and then modeled in the laboratory. Proposed structures are placed in the model and tested to develop a satisfactory design. Consideration is given to scour, backwater, and channel control effects. The final design is calibrated by model tests. Modifications to existing drainage structures to make them suitable for runoff measurement are devised and tested. Current work is on specific sites and no general experiments are done.

(g) Nine large supercritical flow measuring flumes for the flashy, sediment laden flows in southwestern streams have been designed and calibrated. Eight culverts with a V-notch added for low flow measurement have been calibrated. Low flow calibrations for broad-crested Vnotch weirs of different materials and surface roughness have been made.

(h) "Walnut Gulch Supercritical Measuring Flume," W.R. Gwinn, Trans. Amer. Soc. Agric. Engr., Vol. 7, No. 3, pp. 197-199, 1964.

(4337) HYDROMECHANICS OF OVERIAND, CHANNEL AND FLOODPLAIN FLOWS.

(b) Laboratory project, cooperative with the Oklahoma Agricultural Expmt. Sta.

(c) Dr. D.K. McCool, Agricultural Engr., P.O. Box 551, Stillwater, Oklahoma 7407'4.

(d) Experimental; applied research.

(e) Obtain data needed for the design of channels used in soil and water conservation works, for testing theories of the hydromechanics of surface flow, and for developing hydraulic explanations of hydrologic phenomena. Experimental channels are built on the laboratory grounds, planted to grasses or lined with artificial materials and then subjected to controlled flows of water. Test flows can be steady or unsteady, uniform or nonuniform, or in one channel, can be spatially varied as well. Flow retardance coefficients, permissible velcoties, energy and momentum coefficients, and flow profiles are determined.

(g) Manning's $n$ values for vegetation lined channels are a function of depth and velocity of llow as well as the physical characteristics of the vegetation. Permissible velocities are influenced by the physical characteristics of the vegetal cover, the textures of the soil, and by the steepness of the channel. Permissible velocity and $n$-value data are given in a handbook of channel design prepared by the laboratory. Spatially varied flow equations now in use can predict flow profiles accurately only if realistic momentum coefficients are used.

(h) "Spatially Varied Steady Flow in a Vegetated Channel," D.K. McCool, W.R. Gwinn, W.O. Ree, and J.E. Garton, Trans. Amer. Soc. Agric. Engr., Vol. 9, No. 3, pp. 440-444, 1966.

(4844) DRAINAGE REQUTREMENTS OF CROPS AND SYSTEMS DESIGN--RIO GRANDE PLAIN. (Includes also Nos. 4849 and 5578).

(4848) WATER EROSION CONTROL PRACTICES FOR THE TEXAS BLACKIAND PRAIRIE.

(5216) PRINCIPLES, FACILITIES AND SYSTEMS FOR GROUND WATER RECHARGE--SOUTHERN PLAINS. (Includes also No. 5214). 
(5985) SALINE AND SODIC SOIL AND IRRIGATION WATER PROBLEMS--RIO GRANDE PLAIN.

U.S. DEPARTMENT OF AGRICULTURE, AGRICULTURAL RESEARCH SERVICE, Soil and Water Conservation Research Division.

SOUTHWEST BRANCH, P.O. Box 2326, Riverside, California 92506, Mr. W.W. Donnan, Branch Chief.

\section{(2181) GROUND WATER RECHARGE AND MANAGEMENT IN} CALIFORNIA.

(3558) COLLOIDAL MATERIALS FOR CONTROL OF SEEPAGE FROM CANALS AND PONDS IN NEVADA.

(4358) FLOOD WAVE MOVEMENT IN NATURAL EPHEMERAL STREAM CHANNVLS.

(b) Laboratory project, cooperative with the Arizona and New Mexico Agricultural Expmt. Stations, and the USDA Soil Conservation Service.

(c) Mr. K.G. Renard, Hydraulic Engr., 442 East Seventh St., Tucson, Arizona 85705.

(d) Experimental, field investigation.

(e) Water-level recorders are located at 2,000foot intervals in a 2.6-mile reach of natural channel. The reach has a precalibrated flume at the inlet and at the outlet, and the major tributary inflow is measured. Flood waves produced by convective thunderstorms in ephemeral streams are being studied.

(g) The velocity of a wave front on a dry channel bed was found to be relatively independent of the discharge. Peak discharge velocities were considerably higher than the wave front velocities. The pure gravity wave velocity is sometimes less than that of flood waves that have been recorded. The impulse wave overrides the flow, and its absolute velocity is the sum of a (probably somewhat attenuated) gravity wave and the flow velocity.

(h) "Hydrographs of Ephemeral Streams in the Southwest, "K.G. Renard and R.V. Keppel, Jour. Hydraulics Div., ASCE, Vol. 92, No. HY2, pp. 33-52, March 1966.

(4853) SURFACE AND SUBSURFACE IRRIGATION SYSTEMS FOR COASTAL CALIFORNIA. (Includes also No. 5786).

(4854) DRAINAGE SYSTEMS FOR THE IMPERIAL VALLEY.

\section{(5219) IRRIGATION SYSTEMS FOR EFFICIENT WATER USE.}

(b) Laboratory project.

(c) Mr. Lloyd E. Myers, Research Hydraulic Engr. USDA-ARS, U.S. Water Conservation Lab., 4331 E. Broadway, Phoenix, Arizona 85040.

(d) Experimental; applied research.

(e) The purpose of this research is to develop and evaluate principles, methods and design criteria for irrigation systems that will facilitate efficient water use.

(g) Developed elbow meter to measure pipe flow. Evaluated fluorescent tracers to measure flow in channels. Initiated study of erosion reducing outlet structure. Completed study of critical depth measuring flumes.

(h) "Low Pressure Differential Measurements in Liquid Flows," John A. Replogle, Trans., Amer. Soc. Agric. Engr., Vol. 10, No. 1, pp. 84-86, 1367.

"Closure: Flow Measurements with Fluorescent Tracers," John A. Replogle, Lloyd E. Myers, and K.J. Erust, Jour. Hydraulics Div., Proc.
ASCE, Vol. 94, No. HY2, pp. 552-555, March 1968.

(5220) RETATION OF SALINITY TO STATE AND TRANSPORT OF WATER AND IONS IN SOIL AND PLANIS.

(b) Laboratory project.

(c) S.L. Rawlins, U.S. Salinity Iab., P.O. Box 672, Riverside, California 92502.

(d) Experimental and theoretical; basic research.

(e) Principles involving transport and energy status of water and ions in the soil-plantatmosphere continuum are under study. Experiments are conducted in greenhouses and growth chambers to test and improve mathematical models.

(g) Thermocouple psychrometers have been perfected for measurements of total water potential in soils. With use of these experiments, we have shown that water moves through the transpiration stream along the water potential gradient.

(h) "Psychrometric Measurement of Soil Water Potential Without Precise Temperature Control," S.L. Rawlins. Soil Sci. Soc. Amer. Proc., Vol. 31, pp. 297-301, 1967.

"Design Criteria for Peltier-effect Thermocouple Psychrometers, "S.I. Rawlins, Soil Sci., 105: 12-17, 1968.

(5584) MORPHOLOGY AND STABILITY OF STREAM CHANNELS IN SOUTHERN CALIFORNIA.

(6836) MORPHOLOGY AND STABILITY OF STREAM CHANNELS IN SOUTHWESTERN SEMIARID RANGELANDS.

(6837) SOIL WATER MOVEMENT IN RETATION TO CONSERVATION OF WATER SUPPLIES.

(b) Laboratory project.

(c) Mr. Lloyd E. Myers; see (5219) above.

(d) Theoretical; basic research.

(e) The purpose of this research is to determine the significance of physical and chemical processes associated with liquid and vapor phase movement of water in soil as related to water loss from soil and to develop and test means for reducing such loss.

(g) Developed method for measuring soil surface temperature with infrared radiation thermometer. Showed that non-Darcy flow through a fine porous ceramic was by osmotic forces arising from dissolution of the ceramic and not by the physical status of the water. Developed a method for evaluating water repellancy of soils by measuring breakthrough pressures. Studied dispersion of soil as related to electrolyte concentration.

(h) "Radiometric Surface Temperature Measurements and Fluctuations in Sky Radiance Emittance in the 600-1300 $\mathrm{cm}^{-1}$ Waveband," A.W. Conway, and C.H.M. Van Bavel, Agron. Jour. 59(5): 389-390, Sept. - Oct. 1967.

"Evaporation from a Wet Soil surface Calculated from Radiometrically Determined Surface Temperatures," A.W. Conway, and C.H.M. Van Bavel, Jour. Appl. Meteorol. 6(4): 650-655, Aug. 1967.

"Determination of Internal Surface Area, External Water, and Amount of Montmorillonite in Clay-Water Systems," Dwayne H. Fink, C.I. Rich, and G.W. Thomas, Soil Sci. 105(2): 71-77, Feb. 1768.

"Quadrennial Report 1963-1367, Committee on the Physics of Soil Moisture," J.B. Franzini, J.N. Luthin, I. Remson, R.W. Stallman, D. Swartzendruber, and C.H.M. Van Bavel, Trans. 
Amer. Geophys. Union, 48(2): 744-751, June 1967.

"A Drink from the Desert," Ray D. Jackson and C.H.M. Van Bavel, in "Outdoors, U.S.A.," pp. 175-177. (1967 Yearbook of Agriculture). "Solar Still," Ray D. Jackson, in McGraw-Hill Encyclopedia of Sci. and Tech., pp. 362-364, 1967.

"Osmotic Effects on Water Flow through a Ceramic Filter," Ray D. Jackson, Soil Sci. Soc. Amer. Proc. 31(6): 713-715, Nov. - Dec. 1967.

"Calcium Electrode Method for Measuring the Dissociation and Solubility of Calcium Sulfate Dihydrate," F.S. Nakayama, and B.A. Rasnick, Anal. Chem. (Note) 39(8): 1022-1023, July 1967.

Comment on "Soil Moisture Estimation by the Neutron Scattering Method in Britain, "J.P. Bell, and J.S.G. McCulloch, (Jour. Hydrol. 4:254-263, 1966). Jour. Hydrol. 5(4): 360, oct. 1967 .

\section{U.S. DEPARTMENT OF AGRICULTURE, FOREST SERVICE,} Intermountain Forest and Range Experiment Station, Ogden, Utah 84401

\section{(6067) SOIL MANTLE HYDROLOGY.}

(b) Laboratory project.

(c) Mr. Joseph F. Pechanec, Director, Intermountain Forest and Range Expmt. Sta., U.S. Forest Service.

(d) Field investigation, basic research.

(e) The major objectives of this research are: (1) To determine quantitatively the effects of insloped and outsloped roads on soil moisture and seepage flow regimes; (2) to determine quantitatively the extent, if any, to which the effect of roads on soil moisture and seepage flow is modified by the presence of other roads above or below; and (3) to determine quantitatively the effect of timber clearcutting on soil moisture and seepage flow regimes in roaded and unroaded sites.

(g) A statistical model is being developed that will express soil moisture depletion on a roaded, clearcut area. This model is unique, in that it takes into account the important effect of nearness of bedrock to the soil surface.

The schematic equation for volume percent moisture to a soil depth of 3 feet is shown below:

$$
\begin{aligned}
V m= & B_{0}+\left[B_{1} D_{1}-B_{2} D_{1}^{2}+B_{3}(M B / L B)\right. \\
& \left.+B_{4}\left(L B-M B / D_{1}\right)\right]+\left[B_{5}\left(\sum P \cdot P \cdot / T\right)-B_{6} \text { Date }\right] \\
& +\left(-B_{7} D_{2}+B_{8} D_{2}^{3}\right)+\left(-B_{9} D_{3}^{3}+R\right)
\end{aligned}
$$

where $\mathrm{LB}=$ bedrock depth under the soil moisture measuring point; $M B=$ minimum bedrock depth downhill from the measuring point; $D_{1}=$ downhill slope distance from the measurpoint to location of minimum bedrock depth; P.P./T = precipitation from a given storm divided by the time since that storm; Date $=$ chronological date, i.e., May $27=147$; $\mathrm{D}_{2}=$ slope distance downhill from a reference point, 26 feet above the uppermost soil moisture measuring point on the hill; $\mathrm{D}_{3}=$ slope distance from the center of the road to a soil moisture measuring point. $D_{3}$ is + if uphill and - if downhill; $R=$ a road location constant: - for the upper road, $O$ for the middle road, and + for the lower road. In general, with $\mathrm{MB}$ less than $\mathrm{LB}$, soil moisture increases as ground water is forced closer to the surface. Also, as the distance to minimum bedrock depth, $D_{1}$, decreases, soil moisture will increase. ane of the most interesting results of the soil moisture analysis, so far, is that it points out the hydrologic effect of changing bedrock conditions. While the soil moisture data analysis will show the effect of roads on soil moisture, the most important hydrologic effect of roads seems to be the potential for affecting snowmelt flood peaks. The original study was not designed to measure this effect, but cutbank seepage during the snowmelt season has shown the importance of further study of this phenomenon. The original plan called for measurements of cutbank seepage; i.e., subsurface flow of water from the road-cut face. These subsurface seepage flow measurements exclude overland flow that was diverted away from the catchment troughs. The subsurface flow volume for these 25 days (which comprise the 1965 snowmelt season) from 100 feet of road section is 2.56 acre feet. This is almost 73 acre feet per day per square mile of contributing area. By comparison, the Iochsa River (at its mouth) yielded 19.2 and 17.9 acre feet per day per square mile for May and June 1965, respectively.

(h) "Instrumentation and Methodology of Forest Soil Mantle Hydrology Studies, "E.R. Burroughs, Jr., M.S. thesis, submitted to Montana State Univ., 1967.

"Establishment and Progress Report--Methodology of a Soil Mantle Hydrology Study," E.R. Burroughs, Jr., and P.E. Packer, Intermountain Forest and Range Expmt. Sta., Res. Prog. Rept. (processed), 12 pp., 1967.

(6068) SNOWPACK OUTFLOW.

(b) Iaboratory project.

(c) Mr. Joseph F. Pechanec; see (6067) above.

(d) Experimental; basic research.

(e) A need exists for an uncomplicated instrument that will measure directly snowpack outflow in situ, yet be accurate, of low cost, and adaptable to the hydrologic environment of mountainous terrain. Such an instrument-the lysimeter-type snowmelt gage--has been devised and tested.

(g) Simple lysimeter-type snowmelt gages that provide continuous readings of the volume of water flowing from the base of a snowpack, either in the form of atmospheric melt, rain percolate and melt, ground melt, or combinations of these, have been developed and their operation is described. The instruments, located between 3,600 and 4,000 feet MSL in the western white pine-western redcedar type in northern Idaho, detected during a period of clear weather melt a maximum daily outflow of 2.02 inches, water equivalent, on May 16 , 1967; a maximum hourly outflow of 0.23 inch between 1200 and 1300 hours, May 8; and a maximum 2-hour outflow of 0.41 inch between 1200 and 1400 hours, May 16. This type of data shows promise after one season of being readily applicable in the prediction of the timing of peak flow occurrence, which is important to studies of watershed hydrology. 
"Snowpack Outflow as Measured by IysimeterType Melt Gages, "Harold F. Haupt, Intermountain Forest and Range Expmt. Sta., Prog. Rept. (processed), 11 pp., 1967.

U.S. DEPARTMENT OF AGRICULTURE, FOREST SERVICE, Northeastern Forest Experiment Station, 6816 Market St., Upper Darby, Pennsylvania 19082

The following projects are listed by title only; for more details see "Water Resources Research Catalog". Inquiries should be addressed to Mr. R.D. Lane, Director, Northeastern Forest Experiment Station.

(06TW) FLOOD RUNOFF REDUCTION AND WATER YIELD IMPROVEMENT FROM THE GIACIATED MOUNTAIN AREAS OF NEW ENGIAND. (Durham, New Hampshire).

(068W) FIOOD RUNOFF REDUCTION AND WATER YIELD IMPROVEMENT IN THE NORTHERN APPALACHIAN MOUNTAIN REGION. (Parsons, West Virginia).

(069W) CORRELATION AND SYNTHESIS OF WATERSHED RESEARCH RESULTS, COOPERATIVE MUNICIPAL WATERSHED RESEARCH, AND URBAN AND SUBURBAN STUDIES OF TREES AND HUMAN ENVIRONMENT. (Upper Darby, Pennsylvania).

(OTOW) EFHECTS OF DIFFERENT FOREST TYPES AND CONDITIONS ON STREAM REGIMEN AND WATER YIELDS. (Syracuse, New York).

(OTIW) REDUCTION IN SURFACE MINING DAMAGES TO FOREST RESOURCES BY IMPROVING MINING PROCEDURES AND REHABILITATION MEASURES. (Berea, Kentucky).

(OT2W) MANAGEMENT OF STORM RUNOFF. (Columbus, Ohio).

(h) "Measuring Subsurface Stormflow From Simulated Rainstorms," R.Z. Whipkey, U.S. Forest Service Research Note, CS-29, 6 pp., 1965.

"Subsurface Stormflow From Forested Slopes," R.Z. Whipkey, Bull., Intl. Assoc. Sci. Hyd., $\mathrm{X}$ Anne No. 2, pp. 74-85, 1965.

"Theory and Mechanics of Subsurface Stormflow," R.Z. Whipkey, Intl. Symp. on Forest Hydrology, Penn State Univ., pp. 255-260, 1966. "Storm Runoff From Forested Catchments by Subsurface Routes," R.W. Whipkey, Proc. UNESCO Flood Symp., Leningrad, U.S.S.R., 1967 (in press).

U.S. DEPARTMENT OF AGRUCULTURE, FOREST SERVICE,

North Central Forest Experiment Station, Folwell Ave., St. Paul, Minn. 55101

Inquiries concerning the following projects should be addressed to the Director, North Central Forest Experiment Sta., Forest Service, U.S. Dept. of Agriculture, at above address, unless indicated otherwise for a specific project.

(3887) WATERSHED MANAGEMENT RESEARCH IN NORTHERN MINNESOTA.

(b) Iaboratory project.

(d) Experimental and field investigations; basic and applied research.

(e) The project conducts research in the following major areas: (1) The surface and ground water hydrology of small, forested bog watersheds-measurements of rain, snow, runoff, bog water tables, and the deep regional ground water system are carried out on six experimental bogs to determine their natural hydrology and contributions to runoff and ground water, (2) laboratory and field studies of the physical properties of organic soils and their influence on peatland hydrology, and (3) evapotranspiration from peatlands as measured by evapotranspirometers, water balance data, and empirical formulas. The purpose of the project is to develop land management prac. tices, through basic hydrologic studies, which will maintain and improve water yield from northern forested peatlands.

(g) Analyses of water yield data indicate that a major portion of annual runoff occurs during the spring, prior to June 1 . In some years, several of the gaged watersheds produced 80 percent of the annual runoff before June 1 . Because of high water tables after snowmelt, little storage opportunity is available in the spring and any rainfall contributes directly to runoff. High evapotranspiration rates during the summer lower the bog water tables and effectively use normal summer rainfall. Runoff in summer and fall is normally quite low, and during long drying periods streamflow will actually cease.

Studies of the physical properties of peats help explain the total hydrology of bog watersheds. Actual water storage capacity and water movement rates vary considerably for different peat types. Specific yield ranges from nearly 6 gal./cu. ft. in surface mosses to less than $1 \mathrm{gal}$./cu. ft. for well-decomposed peats. Hydraulic conductivities vary from $118 \mathrm{ft}$./day to .02/ft./day for surface mosses and decomposed peats, respectively.

(h) "Hydrologic Characteristics of Organic Soils in Iake States Watersheds," D.H. Boelter, Jour. Soil and Water Consv., Vol. 21, No. 2, pp. 50-53, 1366.

"Evaluation of an Evapotranspirometer for Peat Bogs," Roger R. Bay, Water Resources Res., Vol. 2, No. 3, pp. 437-442, 1366.

"Techniques of Hydrologic Research in Forested Peatlands, U.S.A.," Roger R. Bay, XIV Congr. Intl. Union Forest. Res. Organ., Vol. 1, pp. 400-415, 1967.

"Factors Influencing Soil Moisture Relationships in Undrained Forested Bogs," Roger R. Bay, Intl. Symp. Forest Hydrol., pp. 335-443, Pergamon Press, 1966.

"Ground Water and Vegetation in Two Peat Eogs in Northern Minnesota," Roger R. Bay, Ecology, Vol. 48, pp. 308-310, 1967.

(3889) WATERSHED MANAGEMENT RESEARCH IN THE DRIFTLESS AREA OF SOUTHWESTERN WISCONSIN.

(b) Laboratory project, with some aspects in cooperation with Wisconsin Conservation Dept.

(d) Field investigations; basic and applied research.

(e) Research is conducted on the influence of both natural and planted forests on runoff and erosion (particularly with regard to springthaw floods) and hydrologic effects of soil freezing. The study of forest-land gullies and the reduction of gullying by spreading upland runoff into the lower lying forest zone is included. Overland flow is measured by flumes and recorders at 20 stations, either on natural runoff plots or small watersheds. Factors affecting springflow are also under study. Springflow is measured at 2 stations 
by weirs and recorders. In addition, a number of wells are measured, one with a water level recorder.

(g) A comparison of three indirect methods of measuring frost depth showed that change in resistance of soil moisture blocks could be used to determine frost depth in silt loam soils. Soil temperature and Soiltest Frostmeters, the other methods tested, were less reliable. A simple, automatic stage sediment sampler was developed for use with metal flumes. Advantages over conventional samplers are that it will sample minimum flows and will not catch debris. A chart holder for reading FW-1 streamflow charts by the Copley method was also developed. The instrument makes use of a typewriter platen to turn constant head intervals, reducing chances of error and chart reading time by one-third. Springflow studies have shown that following a primary rise from snowmelt and early spring rains a gradual depletion takes place throughout the summer regardless of the summer rainfall pattern. This is followed by a smaller recharge from fall rains. Heavy fall recharge may influence flow for a full year or more. Short-period fluctuations are caused by changes in barometric pressure, in an inverse relationship. Springflow is a good index of stream baseflow.

Springflow and ground water levels may both rise with winter thaws, even when the ground is frozen. A high soil water content suggests that water moves to the water table through a continuous column of soil water rather than as a wetting front.

Simple practices along the forest edge were found to be effective and economical means of disposing of runoff water from upland fields. Logs placed in a staggered arrangement on a spreading field reducted peak flow by 50 percent. Small contour detention ponds disposed of all the runoff. Rainfall studies showed that the highly dissected terrain of southwestern Wisconsin has only a small effect on point rainfall.

Soil temperature measurements showed that the annual temperature wave at depths to $120 \mathrm{~cm}$. closely followed the air temperature wave. The annual range varied from $30^{\circ} \mathrm{C}$. at $15 \mathrm{~cm}$. to $17^{\circ} \mathrm{C}$. at $120 \mathrm{~cm}$. The lowest soil temperature was $-7^{\circ} \mathrm{C}$.

(h) "Response of Springflow to some Climatic Variables in Southwestern Wisconsin. "Willie R. Curtis, Water Resources Res., Vol. 2, No. 2, pp. 311-314, 1966.

"Rainfall Distribution over Dissected Terrain in Southwestern Wisconsin," Richard S. Sartz, Water Resources Res., Vol. 2, No. 4, pp. 804. 809, 1966.

"Forest Zone Helps Minimize Flooding in the Driftless Area," Willie R. Curtis, Jour. Soil and Water Conserv., Vol. 21, No. 3, pp. 101102, 1966.

"Simple Practices along Forest Edge Reduce Upland Runoff," Willie R. Curtis, Jour. Soil and Water Conserv., Vol. 22, No. 1, pp. 25-26, 1967.

"Annual Soil Temperature Wave at Four Depths in Southwestern Wisconsin," Richard S. Sartz, U.S. Forest Serv. Res. Note $\mathrm{NC}-32,2 \mathrm{pp}$, 1967 .

"Winter Thaws Can Raise Ground Water Levels in Driftless Area," Richard S. Sartz, U.S. Forest Serv. Res. Note NC-35, 2 pp., 1967.
"A Test of Three Indirect Methods of Measuring Depth of Frost," Richard S. Sartz, Soil Sci., Vol. 104, No. 4, pp. 273-278, 1967.

(3890) WATERSHED MANAGEMENT RESEARCH IN LOWER MICHIGAN.

(b) Laborary project.

(d) Field investigation; basic and applied research.

(e) The major projects involved here deal with (1) ground water recharge and evapotrans piration of various cover types in deep sandy soil and (2) streambank erosion and sediment transport on trout streams. Ground water elevations are being measured at 162 wells, 11 of which are equipped with water level recorders. Fifty percent of the trees have been removed in strips in a 35-year-old jack pine plantation to study changes in net water yield and in snowpar:ks. Snow studies are also being made in selectively thinned red pine plantations. Stream sediment budgets are being intensively measured on a trout stream having serious bank erosion. Bank profiles are being measured of one-fourth of the banks to obtain rates of recession and volumes of various sizes of sediments eroded. Total sediment discharge is measured over sills above, in the middle, and below the 20-mile test reach. Effects of sediment on bottom fauna and on trout spawning bed permeability are being studied.

(g) Water yields as ground water recharge and evapotranspiration from ppt-recharge have been determined for 5 years for two deciduous forest types and for two conifer plantations. Results obtained from well-drained locations show the same relationship between conifer and hardwood forests as do shallow water table plots when ET draws water from the saturated zone.

Five-year water yields from well-drained lands as analyzed from regional water table behavior were 14.8 inches per year in pine forests and 17.0 inches in hardwoods. About half the annual difference occurred during the dormant season. Preliminary results indicate that a 50-percent reduction in stocking of pine forests, either by selective thinning or by strip-cutting, results in snowpack water equal to that in deciduous forests.

Sediment discharge below a 20-miles length of stream which has 180 eroding banks appears to be about five times that entering the upper end of the reach. Two-thirds of the sediment in transport is in sand particle sizes and moves on or near the bed of the stream. Attempts to relate bank erosion to suspended sediment levels have been abandoned in favor of measurments of the total sediment budget. Tests of vegetative bank stabilization reemphasized the need for waterline control. Upper bank treatments only increased the rate of revegetation over that occurring naturally.

(h) "Sediment, Streamflow, and Land Use Relationships in Northern Lower Michigan," W. David Striffler, U.S. Forest Serv. Res. Pap. IS-16, $12 \mathrm{pp} ., 1964$.

"Influence of Forest Cover on Snowpack and Ground Water Recharge," Dean H. Urie, Ground Water, Vol. 4, No. 1, pp. 5-7, 1766.

"Influence of Forest Cover on Ground Water Recharge, Timing, and Use," Dean H. Urie, Intl. Symp. Forest Hydrol., Penn. State Univ., Proc.. pp. 313-324, 1966. 
"Forest Cover in Relation to Water Yields on Outwash Sand Soils," Dean H. Urie, Pap. Mich. Acad. Sci., Arts, and Letters 51, pp. 3-11, 1966.

"Waterline Erosion Control Essential to Streambank Rehabilitation," Dean H. Urie, U.S. Forest Serv. Res. Note NC-29, 2 pp., 1967.

U.S. DEPARTMENT OF AGRICULTURE, FOREST SERVICE, Pacific Northwest Forest and Range Experiment Station, P.0. Box 3141, Portland, Oregon 97208

Inquiries concerning the following projects should be addressed to Mr. Philip A. Briegleb, Director, Pacific Northwest Forest and Range Expmt. Sta., at above address.

(4757) WATER YIELD AND EROSION, WENATCHEE, WASH.

(b) Laboratory project.

(d) Field investigations; basic and applied research.

(e) The objectives of the project are to generate information on the relations of moisture disposition and use, and incidence of soil erosion, in forest and range environments to climatic characteristics, vegetative types, soil types, topography, and land uses; and to devise management techniques for ensuring maximum streamflow and minimum erosion and sedimentation in the mid-Columbia River Basin in eastern Oregon and Washington. Studies related to erosion reduction include:

Characteristics of soil related to erodibility; effects of climate, vegetation and parent material on soil development, characteristics of forest humus types; and physical control of erosion by increasing density of vegetation. Factors influencing receipt, disposition, and use of water include: Heat and moisture flux, and partitioning of the solar energy balance over forest canopies; seasonal soil moisture depletion under a lodgepole pine forest; moisture use requirements of six principal conifers; effects of silvicultural treatments, including precommercial thinning and harvest cuttings, on water yields; disposition of intercepted snow and rime ice.

(g) Transpiration rate of potted ponderosa pine, lodgepole pine, Douglas-fir, grand fir, Engelmann spruce, and western larch seedlings were compared at various levels of soil moisture stress under controlled environmental conditions. Studies of stomatal sensitivity to leaf moisture stress were also made on twigs of each of these species.

During the 1965-66 winter, snowpacks were heavier in areas logged by three methods than in undisturbed forest. The greatest increase in water content was on a clearcut block. Snowpacks in alternate clearcut and unlogged strips and in selectively logged stands were similar but intermediate to the large clearcuts and uncut.

Solar radiation data collected at a series of high elevation stations were used to show patterns of insolation in an area of rapid climatic change. Calculations based on this data indicted the need for increasing sample size (sometimes to over 100 stations) when measuring mean daily radiation into this area.
Treatment with foliar sprays of B-995 reduced leaf water deficit and transpiration rate in apple trees but not in sunflower seedlings. However, in sunflower, the treatment enhanced the ability of the plant to recover after severe drought conditions.

(h) "Transpiration of Conifer Seedlings in Relation to Soil Moisture Stress," (Abstr.), William Lopushinsky, Plant Physiol. Proc. Annual Meetings 1966, iv., 1966.

"Increased Water from Forests," R.N. Ross and H.W. Berndt, Oregon Farmer 90(4): 12-13; Washington Farmer 92(4): 24; , Idaho Farmer 85(4): 28-29. Feb. 16, 1967.

"Radiation Sampling in a Mountainous Zone," William B. Fowler, U.S. Forest Serv. Res. Note PNW-49, 5 pp., illus., March 1967. "Effect of N-dimethyl Amino Succinamic Acid (B-995), a Growth Retardant, on Drought Tolerance," George C. Martin and William Iopushinsky, Nature (Iondon), Vol. 209, No. 5019, pp. 216-217, 1966.

(4758) WATERSHED LOGGING METHODS AND STRFAMFIOW.

(b) Laboratory project with some phases in cooperation with City of Portland, Bureau of Water Works and Oregon State University.

(d) Field investigations; basic and applied research.

(e) Research is conducted at three field locations in the Cascade Range of western Oregon: Bull Run Watershed (domestic supply area for Portland), H.J. Andrews Experimental Forest, and South Umpqua Experimental Forest. Studies are confined to two forest types representing major segments of the remaining old-growth forests of the Paciric Northwest: (1) Douglas-fir, western hemlock, western redcedar, and (2) Douglas-fir, sugar pine. Investigations represent an initial effort to study precipitation runoff, erosion, and soil moisture in undisturbed stands, and to follow changes caused by several methods of logging. Included are studies in four categories: (1) Soil movement on logged land and an evaluation of effectiveness of grass seeding on roadbanks; (2) changes in water quality resulting from roadbuilding, two methods of cable logging, two degrees of forest removal--25 percent and 100 percent-- and slash burning; (3) changes in streamflow caused by clear cutting and partial cutting in groups of varying size on matched watersheds in old-growth Douglas-fir and sugar pine-fir. Pretreatment measurements are still being made to provide statistical basis for treatment evaluation; (4) soil moisture movement and disposition and the role of vegetation in evapotranspiration, including measure of seasonal changes in soil moisture under a Douglas-fir stand, vertical movement of water in Douglas-fir soils, rainfall interception by crowns of old-growth Douglas-fir soils, rainfall interception by crowns of old-growth Douglas-fir, and changes in plant succession following logging and slash burning.

(g) Trapezoidal flumes and other instrumentation were used to gather data preliminary to a study of the effect of timber harvesting and road construction on yield, timing, and quality of streamflow from three tributary watersheds in the McKenzie drainage of western Oregon. During the calibration period when the dense Douglas-fir forests remained undisturked. data was collected which described the relationship of geology, soils, vegetation, 
and climate to streamflow.

Recent research results show that after clearcutting minimum streamflow increased significantly with higher flows following heavier cutting. Increased water from land logged in western Oregon and Washington within the last 2 years would supply the daily needs of at least 100,000 people with no additional storage. Floods, following the long duration rainstorms characteristic of the Pacific Northest, are a problem common to the forested areas as well. as the downstrem users. Storms causing damage as great as that which resulted from the 1964 flood are rare, but near record-breaking local storms may occur almost every year. Extensive logging may increase early winter season stormflow but probably does not alter streamflows from major midwinter storms.

Principal damage from severe winter storms results primarily from soil instability. Sur face erosion may be a serious problem in local areas of the Pacific Northwest but massive soil movements are more common to the region. A study of 47 mass movement events, resulting from severe storms during the winter of 1764 65, found that 72 percent were connected with road construction and the great majority occurred in soils derived from pyroclastic parent materials.

On the West Side of the Cascade Range in Oregon there is very little difference in yardingcaused soil disturbance between skyline and high-lead logging methods. The main advantage of skyline yarding is that it necessitates far less road construction than other logging methods.

Before a 450-year-old Douglas-fir forest was logged, summer evapotranspiration from the top 4 feet of soil was about 9.2 inches. The first year after logging, evapotranspiration decreased 4.5 inches and water stored in the soil at the end of the dry season was 4.5 inches greater. Although soils still held half of the available storage capacity at the end of the first year after logging, little of the increased water entered the stream. Because of rapid regrowth of brush and herbs, initial increases in soil water did not persist beyond 2 years after logging. The third year after logging, the concentration of roots in the upper $2-1 / 2$ feet of soil removed more soil water than the trees had, reducing soil moisture to the wilting point.

Organic matter, total nitrogen, and acidity were significantly greater in A horizons under alder and mixed stands than under conifers (Douglas-fir, western hemlock, and Sitka spruce). In A-1l soil horizons of 40-year-old stands, organic content under alder averaged one-third greater than conifer, nitrogen one-third greater and $\mathrm{pH}$ one unit lower. A horizons under conifer stands averaged three times richer in bases than those under alder stands. These effects may indicate greater production of acid decomposition products in alder soils which are richer in organic matter and nitrogen. During certain periods of the year, streamside strips of alder are known to cause an undesirable brown color and musty odor which lowers the quality of water used for domestic purposes. Patch clearcuts, the commonly used logging pattern in the Douglas-fir region, resulted in no significant increase in maximum water temperatures until a slide exposed a section of streambed to direct solar radiation.
Progressive clearcutting of a 237 -acre watershed resulted in increases after 55 percent of the drainage was logged.

(h) "Erodibility and Erosion Potential of Forested Watersheds," C.T. Dyrness, Intl. Symp. Forest Hydrol., Natl. Sci. Found., Advanced Sci. Seminar Proc. 1965, pp. 577-611, Pergamon Press-Oxford and New York, 1766. "Accuracy of Measurement of Runoff from Experimental Watersheds, "Jack Rothacher and Norman Miner, Intl. Symp. Forest Hydrol., Natl. Sci. Found., Advanced Sci. Seminar Proc. 1765, pp. 705-713, Pergamon PressOxford and New York, 1766.

"Chemical Soil Properties under Coastal Oregon Stands of Alder and Conifers," (Abstr.) Jerry F. Franklin, C.T. Dyrness, Duane G. Moore, and Robert F. Tarrant, NW Sci., Vol. 41, No. 1, p. 47, 1767.

"Some Characteristics of Forest Floors under True Fir-Hemlock Stands in the Cascade Range," Carroll B. Williams, Jr. and C.T. Dyrness, U.S. Forest Serv. Res. Pap. PNW-37, 19 pp., illus. Jan. 1967.

"Summer Water Balance Changes on an Old-Growth Douglas-Fir Site After Logging," (Abstr.), R.I. Fredriksen, NW. Sci., Vol. 4l, No. I, p. 50,1767 .

"Experimental Watersheds Used as a Research Tool by the Forest Service," Jack Rothacher, Notes on Unit Source Watershed Conference, U.S. Agric. Res. Serv., Soil and Water Conserv. Res. Div., pp. 1-16 (Appendix H), illus.

"Soil-Vegetation Relationships within the Ponderosa Pine Type in the Central Oregon Pumice Region," C.T. Drymess and C.T. Youngberg, Ecol., Vol. 47, pp. 122-138. "Soil Surface Conditions Following Skyline Logging," C.T. Dyrness, U.S. Forest Serv. Res. Note PNW-55, 8 pp., illus., June 1967.

"Mass Soil Movements in the H.J. Andrews Experimental Forest," C.T. Dyrness, U.S. Forest Serv. Res. Pap. PNW-42, 12 pp., illus. "Hydrologic and Related Characteristies of Three Small watersheds in the Oregon Cascades," Jack Rothacher, C.T. Dyrness, and Richard L. Fredriksen, Pacific NW. Forest and Range Exp. Sta., 54 pp., illus.

"Increases in Maximu Stream Temperatures After Logging in Old-Growth Douglas-Fir Watersheds," Al Levno and Jack Rothacher, U.S. Forest Serv. Res. Note PNW-65, 12 pp., illus., Oct. 1967.

Inquiries concerning the following project should be addressed to Mr. Richard M. Hurd, Director, Institute of Northern Forestry, Box 907, Juneau, Alaska 99801.

(2654) EFFECT OF LOGGING ON PHYSICAL CHARACTERISTICS OF SALMON STREAMS IN SOUTHEAST ALASKA.

(b) Laboratory.

(d) Field investigation, applied.

(e) This work is concerned with the relationships between salmon spawning streams and timber harvesting in Southeast Alaska. Work is concentrated on 3 streams lying 40 miles west of Ketchikan. Two of the watersheds have been logged. The third watershed will remain unlogged.

Study is concentrated on factors that can exert a major influence on pink and chum salmon development and survival in streams in a logged watershed. During 1764 stream discharge and stream temperature measurements 
were obtained.

(f) Completed.

(s) Beginning in 1949 and ending in 1962 to 1766 , depending on the parameter, various stream physical factors were measured before, during, and after logging.

Measurements of streamflow, expressed as a double mass plotting of annual water yield, indicate no evident changes in streamflow in response to clearcutting. Analysis of rainfall in relation to streamflow failed to indicate that clearcutting affected streamflow characteristics during stormflows. According to worldwide experience, it would be reasonable to suppose that clear-cutting increased annual water yield about $4-1 / 2$ inches. This small change would not be detectable by the stream gaging methods used.

Suspended sediment remained at low levels throughout the period of record. For example, the concentration seldom exceeded $25 \mathrm{p} \cdot \mathrm{p} . \mathrm{m}$. (parts per million). Within the limits of our sampling it did not appear that logging significantly affected the relationship between suspended sediment concentration and streamflow. However, we believe that road construction and post logging debris avalanching probably caused increased stream sedimentation. The effects on water quality evidently were small and brief, however.

Timber harvesting apparently caused increased stream temperatures during the summer. The maximum effect was $4^{\circ} \mathrm{F}$. or less in the study streams. The maximum recorded temperature in any of the study streams was $69^{\circ} \mathrm{F}$. (July 1958). Winter streamflow temperatures in both watersheds apparently were not affected by clearcutting. It is possible that removal of streamside timber is the most significant increased solar radiation during the summer and increase solar radiation during the sumer and exposure to colder air during the winter. Timber harvesting doubtless affects a number of stream physical factors that are significant in terms of salmon production. Studies before, during, and after logging show these effects on the measured factors were small or undetectable, perhaps due to a combination of climatic and watershed conditions typical of coastal Alaska, and the small proportion of the watersheds logged. Our conclustion is that in southeast Alaska, timber harvesting, carefully done, can be compatible with salmon production.

U.S. DEPARTMENT OF AGRICULTURE, FOREST SERVICE, Pacific Southwest Forest and Range Experiment Station, P.0. Box 245, 1960 Addison St., Berkeley, Calif. 94701

\section{(4936) WATERSHED MANAGEMENT RESEARCH IN CAIIFORNIA'S SNOW ZONE (SNOW MANAGEMENT RESEARCH).}

(b) Laboratory and the following cooperators: State of California, Dept. of Water Resources; Atomic Energy Commission; and Pacific Gas and Electric Companj.

(c) Dr. James L. Smith, Project Leader, Snow Management Research, Pacific Southwest Forest and Range Expmt. Sta. (Eerkeley).

(d) Experimental; field investigation; basic and applied research.

(e) The okjectjve of this project is to determine metrodology for increasing water yield and changing tre timing of water delivery by vegetation manipulatior, by evaporation suppressants, etc. Its area of interest is confined to the snowpack zone of the Sierra Nevada of California. Present studies emphasize development of methods for management of high elevation snowpacks for yield and control of water; the effects of timber cutting upon soil moisture losses and snow accumulation and melt; and the evapotranspiration from various sites-species combinations.

Project scientists are located in Berkeley with field personnel and studies located at the Central Sierra Snow Laboratory, Soda Springs, California, and studies only located at Teakettle Experimental Forest in the headwaters of the north fork of the Kings River above Fresno, California. Both sites lie at 7,000 to 8,000 feet elevation. In the headwaters of the Feather River a practical sized logging is being tested for snow accumulation and melt effects. Ganma and neutron probes are being tested for measuring hydrologic characteristics of snowpacks. Evaporation suppressants are being tested for reduction of such losses from snowpacks.

(g) Rapid measurement of hydrologic characteristics of snowpack which may permit more accurate appraisal and prediction of delivery of snowmelt water has been possible using gamma and neutron probes. Commercially available probes with gamma source (Troxler Iaboratories SC-10 and SC-20 probes) were tested for the ability to measure snow density of the individual layers in the snowpack. Usable regressions of snow density (I) measured gravimetrically and gamma counts $(\mathrm{Cg})$ in CPM in the snowpack were obtained. Only one calibration curve is needed regardless of how close to the snow-air interface one takes measurements.

A snow gage has been tested with which one may accurately measure snow density in $1 / 2$-inch vertical increments to 1.2 percent accuracy of actual density. With this system a 10-foot snowpack may be profiled in 10 minutes by moving the detector and source through the snowpack at a constant rate. Output was recorded on an analog chart. The system operates on the theory of gamma transmission. Gammas from the source pulse through the snowpack to the crystal detector, thence through a pulse-height analyzer set to pass photo-peak energy only and from there to the ratemeterscaler. Output can be fed to a chart.

Problems of temperature effects upon the crystal are controllable. "Sun-cupping" problems are negligible with use of proper access tubing.

Effect of crystalline structure of snow, ice, and water upon gamma attenuation are shown to be negligible if present at all. Count was shown to be wholly dependent upon density of material between the source and detector. Soil samples were obtained for analysis in a study designed to identify the hydrologic constants of the major soils in the Sierra Nevada of California. Snow accumulation was increased by 45 percent in clear-cut strips 132 feet wide. These strips were cut in virgin red fir at an elevation of 7,000 feet. However, approximately a quantity of snow almost equal to the increase was "stolen" from the bordering forest "downwind" from the cut strjps. Snowmelt in east-west cut strips was shown to be drastically affected by the heating up of the 
tree trunks of mature timber to the north of the cut strips. These in turn radiated heat to the snowpack and melted the pack rapidly from the north edge progressively to the south edge.

Winter surface evaporation from snowpack at high elevation sites was reducted by the addition of the suppressant hexadecanol. It was shown that hexadecanol did not materially increase snowmelt.

\section{(4997) WATER SOURCE HYDROLOGY.}

(b) Laboratory project. Cooperators are: State of California, Dept. of Water Resources; Univ. of California; State of Hawaii, Div. of Forestry.

(c) Mr. Henry W. Anderson, Project Leader, Pacific Southwest Forest and Range Expmt. Sta. (Berkeley).

(d) Experimental and theoretical; basic and applied research.

(e) The objective is through analytical modeling to advance the state of knowledge of watershed hydrology and sedimentation, and particularly, knowledge of the relationship of watershed management and other hydrologic processes at the water sources to water yield, floods, sedimentation, and water quality delivered from wildland watersheds.

(g) In the Central Sierra Nevada of California snow accumulation at individual points in forest openings in forests was studied by selecting 16 periods in the winter of 195758 under different meteorological conditions. Wide differences in topography and forest conditions were obtained by selection of 250 points from 1, 300 available. Snow accumulation was the difference in water equivalent of the snow pack between measurements. Snow accumulation depended strongly on combinations of meteorological and forest variables, and on forest-meteorological interactions. The factors related to snow accumulation were studied by reduced rank procedures of principal components analysis, with varimax rotation of the factors. The results suggest how forest cutting may be modified for greater snow accumulation. If we uniformly remove trees within a dense forest so as to reduce the overhead canopy by 60 percent, the resulting reduction in shading will be only 10 percent, ( $\mathrm{SHADE}=73+0.2 \times$ OVERHEAD CANOPY), with a net increase in snow accumulation of $40 \mathrm{~mm}$ ( 1.5 inches) or 10 percent. On the other hand, if we cut 60 percent of a continuous forest into openings, leaving 40 percent "margins," we change the average snow accumulation in dense forest of $310 \mathrm{~mm}$ (12.1 inches) to 40 percent margin with $400 \mathrm{~mm}$ and 60 percent opening with $470 \mathrm{~mm}$. This forest-opening combination will have $440 \mathrm{~mm}$ (17.4) inches of snow water equivalent, that is 40 percent more snow than the dense forest. The most effective forest cutting will be north slopes (relative energy 0.5), being two times as effective as on south slopes (relative energy 1.5). The major disadvantage on south slopes arose from back radiation, which may be miminized by a wall-and-step cutting pattern and/or by cutting narrow strips which will shade the back wall of trees.

On the Island of Oahu, Hawaii, soil samples were collected along 31 transects in the watershed of the Koolau and Waianae ranges and analyzed in the laboratory for the size distribution of water-stable aggregates and suspension percent. Indices of soil erodibility were related by principal component analyses with varimax rotation to these 7 soil-forming factors: parent material, rainfall, elevation, vegetation type, slope, aspects, and zone. Parent rock material was the most important factor in explaining variation of water-stable aggregates of soils in Hawail. Nevertheless, differences in waterstable aggregates were also associated with differences in vegetation type and other soilforming factors. Most of the soils studied were rated as slightly to moderately erodible under full vegetation cover. However, conversion of the native koa-ohia scrubby forests by planting paperback or silk-oak trees promises to result in development of less erodible soils as well as more useful forest products. In another study, differences in rainfall-runoff relations were found between watersheds with tree-cover, fern-cover and burned vegetation. Prediction equations for hydrologic events developed from one population of observations (watersheds) are often solved for another population that is removed either in time or in space. Factor and discriminant analyses were studied as possible means of determining when it is safe to extend a prediction from one population to another. The methods were found useful for separating probably successful from probably unsuccessful extensions of prediction equations. The classification system is illustrated by a prediction equation for suspended sediment discharge developed from some watersheds in California, and by a discriminant function for marine versus nonmarine sediments based upon microelements.

(h) "An Application of Multivariate Analysis to Sediment Network Design," James R. Wallis and Henry W. Anderson, Intl. Assoc. Sci. Hydrol. Publ. No. 67, pp. 357-378, 1965.

"Snow Accumulation and Melt in Relation to Terrain in Wet and Dry Years," Henry W. Anderson and Allan J. West, Proc., 33rd Western Snow Conf., pp. 73-82, 1965.

"Integrating Snow Management with Basin Management, "Henry W. Anderson, "Water Research," Johns Hopkins Press, Baltimore, pp. 355-373, Dec. 1966.

"Watershed Modeling Approach to Evaluation of the Hydrologic Potential of Unit Areas," Henry W. Anderson, Proc. Intl. Symp. Forest Hydrol., 1965, pp. 735-746, Pergamon Press Ltd., (London).

"Wallyl-A Large Principal Components Regression Program with Varimax Rotation of the Factor Weight Matrix," James R. Wallis, U.S. Forest Serv. Res. Pap. PSW-92, p. 6, 1965.

"Summary of Forests and Soil Stabilization Session, "Henry W. Anderson, Proc. Intl. Symp. Forest Hydrol., pp. 699-700, 1965, Pergamon Press Ltd., (London).

"Watershed Shape as a Hydrologic Parameter," K.L. Bowden and J.R. Wallis, Proc. First Ann. Amer. Water Resources Conf., pp. 222-224, 1965. "When Is It Safe to Extend a Prediction Equetion--An Answer Based Upon Factor and Discriminant Function Analysis," James R. Wallis, Water Resources Res., Vol. 3, No. 2, pp. 375$384,1967$.

"Rainfall and Stream-Flow from Small TreeCovered and Fern-Covered and Burned Watersheds in Hawaii," Henry W. Anderson, Paul D. 
Duffy and Teruo Yamamoto, U.S. Forest Serv. Res. Pap. PSW-34, pp. 10, illus., 1966. "Erodibility Indices for Wildland Soils of Oahu, Hawaii - As Related to Soil Forming Factors," Teruo Yamamoto and Henry W. Anderson, Water Resources Res., Vol. 3, pp. 785-798, 1967.

"The Effect of Random Errors upon the Accuracy of Prediction Made from Reduced Rank Regression Equations," James R. Wallis, temporary file report, pp. 1-8, 1966.

"Abstracted Bibliography of Erosion of Cohesive Materials," Henry W. Anderson, Proc. Amer. Soc. Civil Engrs., Hydraul. Div., Vol. 93, No. HYl, pp. 117-124, 1967. "Important Watershed Characteristics Affecting Water Yield, Flood Peaks, and Erosion and Sedimentation and the Basic Data Needed for Prediction," Howard W. Lull and Henry W. Anderson, Intl. Conf. on Water for Peace, Paper 431, 8 p., 1967.

"Erosion and Sedimentation," Henry W. Anderson, Quadrannial Report (USA) Intl. Assoc. Sci. Hydrol., Trans. Amer. Geophys. Union, Vol 49, No. 2, pp. 697-700, 1967.

"Snow Accumulation Relation to Meteorological, Topographic and Forest Variables in Central Sierra of California, "Henry W. Anderson, Int1. Assoc. Sci. Hydrol., Berne, Symp., 1967. "General Report on Stochastic Hydrology Papers," Henry W. Anderson, Proc. Intl. Hydrol. Symp., Sept. 6-8, 1967, Ft. Collins, Colo., Vol. 2, 9 pp., 1967.

(4998) FIOOD AND SEDIMENT REDUCTION IN THE CONIFER ZONE OF CAIIFORNIA.

(b) Laboratory project. Cooperators are: Calif. Dept. of Water Resources; Calif. Div. of Forestry; East Bay Municipal Utilities District; Calif. Dept. of Fish and Game.

(c) Mr. Robert R. Ziemer, Project Leader, Flood and Sediment Reduction, Pacific Southwest Forest and Range Expmt. Sta. (Berkeley).

(d) Experimental; field investigations; basic and applied research.

(e) This project conducts basic studies of forest hydrology which will suggest methods of land management for improving water quality, preventing floods and controlling sediment in the commercial timber zones of California. A study of soil moisture depletion in the Sierra Nevada concerns the magnitude of soil moisture storage and depletion under different stand and timber cutting intensities. Because soil creep and landslides are prevalent in the zone, a study of gravitational mass movement will form an effort to develop the means of estimating the consequences of mass movement in terms of sedimentation. The ultimate objective is to develop the means of predicting the role of land management practices, such as logging and road building in initiating or accelerating mass movement.

(g) Soil moisture data has been collected at l-foot intervals for an additional summer's depletion period from 84 neutron moisture meter access tubes installed to a depth of 20 feet in a wide range of forest vegetation densities. Distance and bearing to all vegetation within 84 feet ( $1 / 2$ acre) of each access tube has been collected. Soil texture has been determined for each plot to a depth of 50 feet. In addition, 20 access tubes have been installed to a depth of 17 feet around an isolated sugar pine. Thirty access tubes have installed around 2 isolated 30-inch diameter ponderosa pines. Recording water table stage recorders have been installed at 3 locations.

The initial base survey of natural soil creep rates has been completed in holes adjacent to all inclinometer holes. A refraction seismograph survey of soil thickness is at present being carried out at all sites.

The watershed calibration period at Caspar Creek is completed with measurements of streamflow, sediment discharge, and precipitation. A logging access road has been built in the South Fork and measurements of the post treatment period have begun.

(h) "Effects of Neutron Source Type on Soil Moisture Measurement," Irving Goldberg, Norman A. MacGillivray and Robert R. Ziemer, Trans. Amer. Nuclear Soc., Vol. 10, No. 1, pp. 20-21, 1967.

"Mechanics and Rates of Natural Soil Creep," Eugene Kojan, Proc. Ann. Symp. on Engrg. Geology and Soils Engrg., Pocatello, Idaho, April 1967.

"Cooperative Watershed Management Research in the Lower Conifer Zone of California, Progress Report, 1965," R.R. Ziemer, E. Kojan, and R.B. Thomas, Pacific Southwest Forest and Range Expmt. Sta., U.S. Forest Service, processed, 33 pp., 1966.

"Cooperative Watershed Management Research, Flood and Sediment Reduction in the Conifer Zone of California, Progress Report 1766," R.R. Ziemer, E. Kojan, R.B. Thomas, and R.A. Muller, Pacific Southwest Forest and Range Expmt. Sta., U.S. Forest Service, processed, 88 pp. 1967.

(4999) FLOOD AND SEDIMENT REDUCTION FROM STEEP UNSTABIE BRUSHLANDS OF THE SOUTHWEST.

(b) Laboratory project. Cooperators: California Div. of Forestry, Los Angeles County Flood Control District; Los Angeles County Fire Dept., Univ. of California, Berkeley, Los Angeles, and Riverside; Angeles Natl. Forest.

(c) Mr. Raymond M. Rice, Project Leader, Pacific Southwest Forest and Range Expmt. Sta., 110 North Wabash Ave., Glendora, Calif.

(d) Experimental; field investigations; basic and applied research.

(e) Purposes are (1) to determine how watersheds function: what happens to the precipitation, and how water and soil movement are influenced by conditions of vegetation, soil, geology, and topog e 'vy; and (2) to develop methods of watershed anagement, including treatment of areas de uded by fire, to insure maximum yield of usab. ? water and $~$ isfactory flood runoff and soil erosi.n contr... Most of the current research relates to post-fire erosion. Project scientists have identified a fire related hydrophobic condition as an important cause of excessive erosion following brush fires. Laboratory studies are investigating the physical properties of hydrophobic soils and their interactions with wetting agents. Field plot studies are being used to measure the effectiveness of wetting agents and to test modes of application. Work has just been completed on the analysis of the effect of conversion from brush to grass on erosion from mass soil movement. Work is also underway developing equations to predict flood hydrographs using multivariate statistics. 
(g) We compared $143 \mathrm{ha}$. of watershed land converted from brush to grass with $145 \mathrm{ha}$. which were recovering normally from the effects of a fire in 1960 . We found that the soil slip erosion during 1965 - 1966 was $154 \mathrm{~m}^{3} / \mathrm{ha}$. in the converted area while in the naturally recovering area it was only 21 cubic meters per ha. Other than conversion, slope was by far the most important site variable related to soil slips. Though the soil slips were found on terrain which was mapped as having slopes as gentle as 40 percent, all of the 29 slips which were actually visited and surveyed were found to be on terrain steeper than 80 percent. Sixty-two percent of the slips observed were adjacent to stream channels and these slips were, on an average, twice as large as those not adjacent to channels. In the naturally recovering brush areas slips were more prevalent on southfacing slopes. It now appears likely that hydrophobic layers are developed within the soil not by heat treatment in situ but by the vaporization of hydrophobic substances at some upper layer and diffusion and condensation in the deeper layers as a result of the thermogradient created by the heat of the fire's passage. This hypothesis has been supported by laboratory experiments which simulated conditions during a fire. In 1960 field plots treated with a wetting agent produced 40 percent less erosion during the first year after a brush fire. The experience gained here and on our other plots (some of which where the treatment was not effective) indicate that wetting agents will be effective if the burn site is highly erodible, has a coarse-textured soil, and a well-developed hydrophobic layer.

(5000) WATER YIEID IMPROVEMENT FROM THE BRUSHLANDS OF THE SOUTHWEST.

(b) Laboratory project. Cooperators: California Div. of Forestry; Los Angeles County Flood Control District; and Univ. of California at Berkeley, Riverside, and Los Angeles.

(c) Mr. Leonard F. DeBano, Project Leader, Pacific Southwest Forest and Range Expmt. Sta., 110 North Wabash Ave., Glendora, Calif.

(d) Experimental; field investigations; basic and applied research.

(e) The work center is the 17,000-acre San Dimas Experimental Forest in the San Gabriel Mountains of Southern California.

Field investigations include studies concerned with the hydrologic factors of chaparral watersheds, riparian zone hydrology, and evaluation of water yield improvements. Laboratory studies on the movement (saturated and unsaturated), loss and storage of water in brushland soils supplement field studies on chaparral and riparian zone hydrology. Purpose of the work is (1) to establish fundamental plant, soil, water relationships as they influence water losses and water yields; and (2) to develop and test cultural practices aimed at improving water yield.

(g) Abstracts of unpublished material. "Water Repellent Soils and Their Relationship to Wildfire Temperatures," L.F. DeEano and J.S. Krames (to be submitted to the Intl. Assoc. Scientific Hydrology). A naturally occurring water resistent soil was exposed to different burning times and temperatures after which the soil samples were tested for non-wettability.
The less intense treatments produced an extremely non-wettable condition. Temperatures of 800 and 900 degrees applied for 20 minutes completely destroyed the non-wettable property. Heat treatments within the realm of soil temperatures existing during wildfires were capable of producing the extreme non-wettable condition. The increased surface runoff and erosion from burned southern California watersheds could be the result of this relationship.

"Effects of Hydrophobic Substances on Moisture Movement During Infiltration," Leonard F. DeBano (presented to Div. S-1, Soil Science Soc. Amer., Natl. Mtgs. Amer. Soc. Agronomy, Nov. 3, 1965). The effect of a hydrophobic substance on moisture movement was studied during infiltration into soil columns. Physically similar wettable and non-wettable soils were used for the experiments. Data on infiltration rates and soil moisture distributions obtained during horizontal infiltration were used to calculate soil moisture diffusivities for the two soils. Horizontal infiltration rates were used to calculate soil moisture diffusivities for the two soils. Horizontal infiltration rates were reduced 25 fold by the presence of a hydrophobic substance. Also, soil moisture distributions developed in a non-wettable soil during infiltration were different than in the wettable soil. In a non-wettable soil there was a decrease in moisture content between the water source and the wetting front while in the wettable soil the decrease over this interval was smaller. The ratios of soil moisture diffusivities of wettable to those of nonwettable soil increased as relative moisture content decreased. This indicates that the hydrophobic substance has a greater effect on unsaturated soil moisture movement at lower moisture contents. Results of this study taken as a whole suggests a non-wettable soil property may be a significant factor in moisture movement in southern California brushland soils.

"Longevity of a Wetting Agent Treatment for Water Resistent Soils," J.S. Krammes and L.F. DeBano (presented to Div. S-1, Soil Science Soc. Amer., Natl. Mtgs. Amer. Soc. Agronomy, Columbus, Ohio, Nov. 3, 1965.)

Field sampling in burned chaparral watersheds shows a "non-wettable" soil property to be widespread in southern California. Restricted moisture movement and penetration in this soil condition results in high surface runoff and erosion rates during storm periods. A wetting agent treatment has been used to modify the wetting characteristics of these soils on burned watersheds. The longevity of such remedial treatment was evaluated in the laboratory leaching study. Both surface tension measurements of the leachate solution and capillary rise data shows that wetting agent treatment to have a residual effect. It persisted in the soil until an amount of water equivalent to more than 16 inches of natural precipitation was applied.

other experiments.

Preliminary laboratory infiltration experiments were conducted on soil columns containing a layer of non-wettable soil located below the soil surface. The non-wettable layer was 2 inches thick with the upper interface being $21 / 2$ inches below the top of the column. 
Similar textured wettable material was packed above and below the non-wettable layer.

The results of infiltration experiments indicated that a non-wettable layer located in this position reduced total infiltration into columns. Infiltration rates decreased when the wetting front entered and passed through the non-wettable layer. Infiltration rate into the wettable soil overlying the nonwettable layer was similar to those in columns packed with wettable soil. As the wetting front entered the non-wettable layer, infiltration rates dropped below those for columns packed only with non-wettable soil. When the wetting front left the non-wettable layer and passed into the wettable soil, infiltration rates increased slightly and maintained a rate similar to those of the non-wettable soil. The non-wettable layer appeared to influence not only infiltration when the wetting front was located in the non-wettable layer, but also has a residual effect at lower depths in wettable soil.

(h) "Soil Wettability: A Neglected Factor in Watershed Management," Jay S. Krammes and I.F. DeBano, Water Resources Res., Vol. I, pp. 283286, 1965.

\section{(5001) WATER YIELDS IN HAWAII.}

(b) Laboratory project. Cooperators: State of Hawail, Dept. of Land and Natural Resources, Div. of Forestry.

(c) Mr. Robert E. Nelson, Chief, Hawaii Research Center, Pacific Southwest Forest and Range Expmt. Sta., 400 South Beretania st., Honolulu, Hawaii.

(d) Experimental; field investigations; basic and applied research.

(e) The objective is to develop a hydrological and meteorological base in Hawaii's wildland watersheds that will suggest methods of land management for maintaining or improving water yield and water quality and minimizing soil erosion and sedimentation; to obtain adequate understanding of the processes of receiving and discharging water and being able to predict the effects of a wide span of forest land management practices upon water yield and water control; such studies are to suggest ways to manage watersheds that will (1) assure the continued protection of watersheds; (2) improve the distribution of the water yield by modifying the balance between the ground water recharge and surface waterflow; (3) increase water yields by decreasing evapotranspiration losses; and (4) minimize flood runoff and sedimentation.

Major work center is in Honolulu. The principal studies under way are the determination of soil erodibility indices for forest soils in Hawaii, the measurement of evapotranspiration from several selected wildland vegetation types, and a study of rainfall-runoff relations on two small forest watersheds.

(g) A study of rainfall interception and fog-drip was begun in several forest plantations on Maui and oahu. These studies will be expanded to include the effects of size, shape and other characteristics of natural and artificial leaves on water storage and drip under laboratory conditions.

(h) Recent publications available from Institute of Pacific Islands Forestry, 400 So. Beretania St., Honolulu, Hawaii 96813:

"Rainfall and Streamflow from Small Tree-
Covered and Fern-Covered and Burned Watersheds in Hawaii," H.W. Anderson, P.D. Duffy, and T. Yamamoto, U.S. Forest Serv. Res. Paper PSW-34, 10 pp., illus. 1966.

"Erodibility Indices for Wildland Soils of Oahu, Hawaii, as Related to Soil Forming Factors," T. Yamamoto and H.W. Anderson, Water Resources Res., Vol. 3, No. 3, pp. 785-778, 1967.

U.S. DEPARTMENT OF AGRICULTURE, FOREST SERVICE, Rocky Mountain Forest and Range Experiment Station, 240 W. Prospect St., Fort Collins, Colorado 80521

Inquiries concerning the following projects should be addressed to Mr. Raymond Price, Director, Rocky Mountain Forest and Range Expmt. Sta., USDA Forest Service, at above address, unless otherwise noted under (c).

(037W) WATER YIELD IMPROVEMENT IN SNOWPACK TIMEER ZONE, AND REDUCTION OF RUNOFF FROM RANGELANDS IN THE CENTRAL ROCKY MOUNTAINS. (Formerly 377)

For Summary, see Water Resources Research Catalog, Vol. 2, 3.0094.

(657A) WATERSHED MANAGEMENT RESEARCH (CHAPARRAL), TEMPE, ARIZONA.

(b) Laboratory project.

(d) Experimental; basic and applied research.

(e) To study the disposition of precipitation as influenced by vegetation, microclimate, topography, soils, and other physical features of the watershed and to determine the effect vegetation changes brought about by burning, clearing, or herbicide treatment of chaparral has on water, erosion, sediment, autecology, and plant succession of native and introduced vegetation.

To carry out these studies, 15 small watersheds at 4 sites in central Arizona are instrumented with rainfall and streamflow gages and other instruments for measuring climate, and moisture, and sediment. Laboratory and greenhouse facilities are located in Tempe on the Arizona State University campus.

(g) High sediment production and increased water yield followed the destruction by a 1959 wildfire of high density chaparral (25-inch rainfall zone).

Post-fire control by chemicals of resprouting brush and replacement by grass on one 75 -acre catchment has resulted in perennial streamflow for the past 8 years and increases in water yield from 2 to over 10 inches annually depending on rainfall. Chemical control of 6-year-old fire sprouts on 40\% of a nearby catchment in 1765 has produced similar results over the past 2 years. Sediment production appears to have declined to prefire levels on all watersheds.

In medium density chaparral (22-inch rainfall), streamflow persisted throughout the summer and fall months following chemical control of brush within 75 feet of stream courses. This treatment was applied in February 1767; a complete analysis is not yet available. In low density chaparral (less than 20 inches), chemical and mechanical treatment of brush has produced little or no increase in water yield. Experimentation continues to determine vegetation types and areas where greatest potential exists for water yield improvement and to develop management techniques to 
accomplish it.

A watershed treatment of soil-applied picloram pellets for the control of chaparral brush resulted in the movement of detectable amounts of picloram into the stream water. The highest concentration found was $0.37 \mathrm{ppm}$. After 16 months and 40 inches of accumulated rainfall, picloram was no longer detectable in the stream water.

Watershed-vegetation conversion programs depend largely upon adequate brush control techniques. Two herbicides which have been used with considerable success in mixed chaparral, when applied as pellets to the soil, are fenuron and picloram. Fenuron is more effective on the oak species than the other chaparral shrubs (including sugar sumac and birchleaf mountainmahogany), whereas picloram is less effective on the oaks. Fenuron gave better control of the oaks than picloram but poorer control of the accompanying shrubs.

An apparatus for measuring transpiration of intact potted shrubs or individual intact branches has been developed. Water vapor released by the leaves is removed from the airstream by desiccants or refrigerants, and is measured gravimetrically. Initally the method will be used to study relative transpiration rates of potted chaparral shrubs. The possibility of controlling transpiratory water losses from plants by means of chemical treatments is being studied. Sublethal rates of low-volume foliage sprays of picloram temporarily reduced transpiration of shrub live oak by about 25 percent. Repeated applications were necessary to maintain this level of reduction, or to reduce transpiration further.

(h) "A Vegetative Key to Some Common Arizona. Range Grasses," R.F. Copple and C.P. Pase, U.S. Forest Serv. Res. Pap. RM-27, pp.1-72, illus.

"Helicopter-Applied Herbicides Control Shrub Live Oak and Birchleaf Mountainmahogany," C.P. Pase, U.S. Forest Serv. Res. Note RM-84, $1-4 \mathrm{pp}$, illus.

"Increasing Water Yield from Forest, Chaparral, and Desert Shrub in Arizona," C.P. Pase, and Martin M. Fogel, Publ. Proc. of Intl. Conf. on water for Peace, 1967.

"Improving Water Yield and Game Habitat by Chemical Control of Chaparral, "C.P. Pase, P.A. Ingebo, E.A. Davis, and C.Y. McCulloch, Proc. Intl. Union Forestry Res. Organ., presented in Munich, Germany, Sept. 1967. "Moisture-Retention Capacity of Litter under Two Arizona Chaparral Communities, "R.M. Garcia and C.P. Pase, U.S. Forest Serv. Res. Note RM-85, 2 pp., illus.

(657B) WATERSHED MANAGEMENT RESEARCH (RIPARIAN), TEMPE, ARIZONA.

(b) Laboratory project.

(d) Experimental; basic and applied research.

(e) To determine for phreatophytic vegetation (water-loving plants) the amount of water used, methods for reducing water use by phreatophytes or for replacing them with more useful plants.

Methods of determining water losses are being studied. Ecology of Tamarix pentandra and other phreatophytes is under investigation. Germination, seedling survival, sprouting ability, and rate of spread studies are continued.

(8) Initial studies with a portable pressure chamber indicate that this approach may have wide application to watershed management because of the rapidity of measurements and low cost of equipment. It is possible that the technique can be used to determine existing plant-water stresses of individual trees and shrubs on a watershed and from this determine the site where vegetation manipulation would yield the most in returns of increased water.

(657C) WATERSFED MANAGEMENT (PINE-FIR TYPE), TEMPE, ARIZONIA.

(b) Laboratory project.

(c) Project Leader; Forest Hydrology Laboratory, Arizona State Univ., Tempe, Arizona.

(d) Experimental; basic and applied research.

(e) Field and laboratory project to study: Effect of timber and grassland manipulations on water yield improvement; effect of changes in forest vegetation on evapotranspiration, radiation, and snowmelt and accumulation; and determination of the process of infiltration, retention and movement of water in soils, and how frost affects both saturated and unsaturated waterflow. At Sierra Ancha Experimental Forest in central Arizona three pine-fir watersheds (Workman Creek, elev. 7,000 ft.) are currently under experimental treatments. In eastern Arizona two ponderosa pine watersheds (Castle Creek, elev. 8,000 ft.), four mixed-conifer watersheds (Willow-Thomas, elev. 9,200 ft.), and two high elevation grassland watersheds (Seven Springs, elev. 9, $300 \mathrm{ft.}$ ) are in stages of calibration or treatment. Plot studies include measurements of microclimate, radiation, frost, and snow accumulation and melt.

New treatments were initiated on North and South Forks of Workman Creek. On North Fork, all woody vegetation from the area now occupied by merchantable ponderosa pine will be removed and replaced with perennial grass. This treatment clears approximately one-half of the watershed area or two-thirds of the area not already treated. Treatment of South Fork will test the effect of converting the mixed-conifer forest to a pure ponderosa pine stand. The goal is a stand of 40 square feet of basal area per acre when pine trees reach 7 inches d.b.h. Treatment of Castle Creek watersheds was completed. The plan

(5) has been to place five-sixths of the watershed in the best growing condition possible for existing ponderosa pine by removing mature and overmature trees and trees growing in crowded conditions. The remaining one-sixth of the area was clear cut in blocks fitted to existing stands of overmature and mature tree classes.

(g) Water jrield from the treated North Fork of Workman Creek averaged 144 percent of expected on an annual basis. The adjusted values show post-treatment increases every month of the year. Maximum increases 0.32 and 0.30 inch occurred March and February. Increases ranging between 0.07 and 0.14 inch occurred November, December, January, April, and August. The remainder of the months the increase was between 0.04 and 0.05 inch. Eighty percent of the increase occurred during the 8 winter months and 20 percent 
during the 4 summer months (June-September). Adjusted monthly values for South Fork of Workman Creek, where there is a small but nonsignificant increase in annual water yields as the result of treatment indicate only a significant increase in March. For the remaining 11 months, the before and after treatment values are almost exactly the same.

(1969) WATERSHED MANAGEMENT RESEARCH, ALBUQUERQUE, NEW MEXICO.

(b) Laboratory project. Some work in cooperation with the Bureau of Land Management.

(d) Applied research.

(e) Evaluation of range-watershed conditions on small watersheds in the San Luis drainage of the Rio Puerco. Three contiguous watersheds, ranging from 338 to 555 acres located about 8 miles north of the San Luis community and west of the Rio Puerco main channel provide the study area. Water and sediment inflow are measured in small reservoirs formed by earthen dams. Precipitation rates and amounts of vegetation changes are periodically measured over the watersheds. Twelve years of data have been collected under cattle grazing during a 6 month overwinter period (November 1 to April 30).

Work has begun on methods of restoring protective vegetation cover on bare areas of alluvial floodplains found on the Rio Puerco watersheds. These areas serve as sediment traps where vegetation can slow runoff velocities sufficiently to deposit debris loads. Studies of germination, seedling development, soil temperatures, and moisture regimes have been started.

To obtain inventory information on the hydrologic variables of the pinyon-juniper type, five small watersheds with ephemeral streams are being gaged by means of a prefabricated fiberglassed flume.

(g) Summer-deferred grazing significantly increased the ground cover index and reduced sediment yields on the Rio Puerco drainage. Soil ripping also increased forage production. Largest gains in plant cover occurred on alluvial floodplains growing alkali sacaton. Alkali sacaton provides fairly abundant forage, is an effective ground cover, withstands relatively heavy grazing, and may offer possibilities for reseeding.

Tests were conducted to determine optimum temperature requirements for germinating alkali sacaton, galleta, and blue grama, three native grass species that can be used to stabilize soil. Galleta and blue gamma germinate well over a wide range of temperatures whereas alkali sacaton does best at $90^{\circ} \mathrm{F}$ or alternating $68-86^{\circ} \mathrm{F}$ temperatures.

(h) "Deferred Grazing and Soil Ripping Improves Forage on New Mexico's Rio Puerco Drainage," Earl F. Alden, N. Mex. Stockman, Vol. 31, No. 11, pp. 44-46.

"Alkali Sacaton: Its Merits for Forage and Cover," Wayne C. Hickey, Jr., and H.W. Springfield, Jour. Range Manage., Vol. 19, pp. 71-74, illus.

"Influence of Temperature on the fermination of Some Range Grasses," O.D. Knipe, Jour. Range Manage., Vol. 20, pp. 298-299.

(2658) IMPROVEMENT OF WATER YIELDS AND SOIL STABILIZATION IN THE EIACK HILLS.

(i) Laboratory project. (d) Experimental; basic and applied research.

(e) Experimental study of geologic and associated site factors to improve the basis for prediction of watershed behavior; soil moisture in relation to forest stand characteristics to provide criteria for design of forest stand manipulation to improve water yield; effects of valley bottom grassland uses on stream channels and flow characteristics to improve the basis for management design.

(g) Extensive refraction seismograph and electrical resistivity surveys of three small watersheds together with core drilling have provided the basis for delineating probable ground water storage areas and base flow sources in relation to hypsometry and morphology. Geophysical methods appear to have a definite potential for study of the hydrologic properties of substrata.

Thinning from 190 to 80 square feet per acre basal area in second growth ponderosa pine increased the free water seepage yield potential due to the initial reduction of soil moisture depletion as compared with unthinned. Patch clearcutting definitely increased free water seepage.

Under protection from livestock grazing the soil in stream bottom grasslands is slowly recovering from compaction and less summer storm runoff is being produced depending on initial soil density and the lay of the land.

(3569) WATERSHED MANAGEMENT RESEARCH, TARAMTE, WYOMING .

(b) Laboratory project and Bureau of Land Management.

(d) Field investigation; applied research.

(e) (1) To determine the effects of big sagebrush control on total runoff, runoff from snowmelt, snow accumulation and storage pattern. Three high elevation sagebrush watersheds, 60 to 106 acres, in northwestern Wyoming, provide the study area. V-notch weirs gage the runoff, and suspended sediment samples are taken periodically. Snowpack is sampled along permanent transects and at random points. Precipitation is sampled by a network of recording and non-recording gages. (2) To determine the effects of big sagebrush control on total runoff, runoff from snowmelt and summer storms, snow accumulation and storage pattern, and soil movement. Five watersheds, 370 to 1600 acres, mean elevation about 7,700 ft., comprise a 7200-acre study area in southern Wyoming. Instrumentation has just begun, with $V$-notch weirs presently gaging two perennial streams. (3) To determine snow accumulation, disappearance, and disposition of melt water in natural and sprayed stands of big sagebrush. Six 0.7 acre plots have been established within the high elevation sagebrush type in northwestern Wyoming. After sufficient pretreatment study, sagebrush on three of the plots will be eradicated by spraying. Snow water content is sampled periodically throughout the winter and spring, and descriptions of snowpack morphology are made when meaningful. Soil moisture is measured with neutron probe to trace course of soil recharge during snowmelt. Soil frost observations are being related to soil temperature measured with thermistors permanently placed in the upper two feet of soil. (4) To evaluate the effects of inducing snow accumulation on a watershed through use of 
artificial barriers. Three experimental grassland-type drainages, 88 to 144 acres, have been selected for the study in southeastern Wyoming where snow transport by wind commonly occurs. V-notch weirs are installed to measure water yield. Snowpack is sampled in areas of netural accumulation along permanent transects. Summer precipitation is sampled by a network of recording and nonrecording gages. (5) To determine the relationship of snowfence height to snow drift water content. Four replications of five fence heights $(6,8,10,12$, and 16 feet) are being field tested in southeastern Wyoming. Snow drift profile are measured periodically throughout the winter using a dumpy level, and water contents are sampled with a Mount Rose sampler.

(g) (1) Water samples collected between July and October 1965 from four locations at a Wyoming mountain bog were analyzed for radiologic content. The gross alpha and beta content of the water was less than 5 and $10 \mathrm{pc} /$ liter, respectively. Gross beta activity of filterable solids in groundwater collected above the bog reached $400 \mathrm{pc} / \mathrm{gram}$ when the water table was at a seasonal minimum, but on other dates and at bog and stream locations the gross beta activity of filterable solids was less than $100 \mathrm{pc} / \mathrm{gram}$. Radiation levels in waters from snow, overland flow, and stream sources were measured in May, June, or October 1965. Snow water activity was less than 25 pc/liter, but filterable solids had a maximum gross alpha and beta activity of 243 and 1,348 pc/gram, respectively. Standing vegetation, litter, and moss on the bog surface screened radionuclides from snowmelt water. (2) Water samples collected July through October 1965 at a Wyoming mountain bog were analyzed for potability and seasonal changes in calcium, magnesium, iron and silica. Four locations were sampled: effluent stream, fissure and peat locations in the bog, and groundwater. Color and turbidity of peat water greatly exceeded that at other locations and the maximum levels established by the U.S. Public Health Service for drinking water. Dissolved mineral content of all samples was very low, and the waters were of excellent chemical quality. All waters from peat and fissures contained coliform organisms, probably of a non-fecal origin. The concentration of minerals in peat water remained constant through the sampling period. Mineral concentrations in groundwater increased in september when the water table was at a seasonal minimum, but decreased in October following water table recharge. Silica levels were higher than that of other ions at all locations; the highest levels were in peat water. (3) Selected hydrologic characteristics of the organic fill at a Wyoming mountain bog were measured in the laboratory and in the field. Organic materials were collected at depths of $0-13$ and $13-25 \mathrm{~cm}$ in moderately decomposed surface peat, and at a $36-48 \mathrm{~cm}$ depth in decomposed peat. Bulk densities were $0.160,0.208$, and $0.216 \mathrm{~g} / \mathrm{cc}$ at these three depths, respectively. Water yields at these respective depths were $0.233,0.140$, and 0.076 $\mathrm{g} / \mathrm{cc}$ between saturation and 0.10 bar suction, and $0.500,0.458$, and $0.349 \mathrm{~g} / \mathrm{cc}$ between saturation and 1.00 bar suction. Both bulk density and water retention were related to the degree of decomposition and thus to pore size distribution. Surface peat contained large voids which emptied at low suctions, but greater suctions were required to empty the smaller pores of decomposed material. Hydraulic conductivity measured in situ at depths of 46 and $91 \mathrm{~cm}$ was $23.9 \times 10^{-3} \mathrm{~cm} /$ day, and $16.1 \times 10^{-3} \mathrm{~cm} /$ day, respectively.

(h) "Water Quality as Affected by a Wyoming Mountain Bog," David L. Sturges, Vater Resources Res., Vol. 3, No. 4, pp. 1085-1089, 1967.

( 3895 ) WATER YIELD IMPROVEMENI IN ALPINE AREAS AND AVALANCHE PREDICTION AND PREVENIION.

(b) Laboratory project.

(d) Experimental and field investigation; applied research.

(e) To determine methods for controlling the deposition of snow in alpine areas in order to increase summer streamflow from late-lying snowfields. To reduce danger from snow avalanches to winter sports areas, highways, mining operation, and homes by improving the evaluation and forecasting of avalanche hazard and developing methods of stabilizing the snow cover on mountain slopes.

(g) Wind profiles at sites where slat and wire snowfences have been used to increase natural snow accumulation show intermittent separation of the windflow pattern to be important. At sites where separation takes place at or upwind of the fence, snow buries the fence and damages it. At sites where no separation of flow exists upwind of fence site, fences remained unburied and effective all winter. A study of 80 avalanche tracks threatening major highways in Colorado shows that one-half start above timberline; most have a gradient of 27 to 35 degrees and length of 300 to 900 meters. Eighty percent of avalanches ran during storms. Comparison of snow in a small opening in the forest and in the starting zone of nearby avalanches showed depth, grain shape, and strength of snow in the lowest layers to be similar at the two sites. The great difference in strength and thickness of middle layers at the two sites was attributed to wind action at the more exposed avalanche sites.

(h) "The Weather and Climate of a High Mountain Pass in the Colorado Rockies," Arthur Judson, U.S. Forest Serv. Res. Paper RM-16, 28 pp., Nov. 1965.

"Accumulation of Snow in Alpine Areas of Central Colorado and Means of Influencing It, " M. Martinelli, Jr., Glaciology 5(41): 625-636, June 1965.

"Avalanche Technology and Research--Recent Accomplishments and Future Plans, "M. Martinelli, Jr., Weatherwise 19(6): 233-239 and 270-271, Dec. 1966.

"Possibilities of Snowpack Management in Alpine Areas, "M. Martinelli, Jr., Proc. Intl. Symp. on Forest Hydrology, Sopper and Lull (ed.), Pergamon Press, pp. 225-231, 1966.

"New Snow Measuring Instruments," M. Martinelli, Jr., Proc. Intl. Symp. Forest Hydrology, Sopper and Lull (ed.), Pergamon Press, pp. 797$800,1966$.

An Example of Damage from a Powder Avalanche," M. Martinelli, Jr. and K.D. Davidson, Bull. Intl. Assoc. Sci. Hydrology, XI, No. 3, pp. $26-34,1966$.

"Snow Avalanches along Colorado Mountain Highways, Hans Frutiger, U.S. Forest Serv. Res. Paper RM-7, 85 pp., 1964.

"A Manual for Planning Structural Control of 
Avalanches," Hans Frutiger and M. Martinelli, Jr., U.S. Forest Serv. Res. Paper RM-19, 68 pp., 1966.

(3896) GULLY CONTROL METHODS AND REDUCTION OF EROSION FROM MOUNTAIN STREAM CHANNELS.

(b) Laboratory project.

(d) Field investigation; applied research.

(e) Investigation of gully and pipe formation processes and development of methods for control. Determination of hydraulic characteristics of mountain stream channels to develop criteria for stability.

(g) Improved check dams developed and tested. Diversion of water from gully channels to designated waterways also tested with indicated success on steep slopes on soils derived from Wasatch shale and sandstones. Work in natural mountain channels starting.

(h) "Hydraulic Reclamation: A Unique Italian Method in Watershed Rehabilitation, " Burchard H. Heede, Jour. Soil and Water Conserv., Vol 20, INo. 5, pp. 216-219. Sept. - Oct. 1965. "Design, Construction and cost of Rock Check Dams," Burchard H. Heede, U.S. Forest Serv. Res. Paper RM-20, May 1966.

"Gully Development and Control in the Rocky Mountains of Colorado," Burchard H. Heede, Ph.D. Thesis, Colo. State Univ., $285 \mathrm{pp}$., Ft. Collins, Colo. (Thesis available on interlibrary loan from Colo. State Univ.) 1967.

\section{U.S. DEPARTMENT OF AGRICULTURE, FOREST SERVICE,}

Southeastern Forest Experiment Station, P.0. Box 2570, Asheville, North Carolina 28802

Inquiries concerning the following projects should be addressed to Mr. Walter M. Zillgitt, Director, Southeastern Forest Expmt. Sta. at above address.

\section{( 380) WATER RESOURCE AND WATERSHED MAIUAGEMENT} RESEARCH.

(b) Laboratory project. For general public use and information.

(d) Experimental; basic and applied research.

(e) Basic research into forest hydrologic processes governing the disposition of precipitation on forest lands of the southeastern United States. Demonstrations of several cover types and land management, practices and their effect upon the amount, quality, and timing of water yield. Development of watershed management methods pertinent to the region including pilot testing, cooperative trials, and demonstrations of these methods. The work is centered at the 5,600acre Coweeta Hydrologic Iaboratory in the mountains of western North Carolina near Franklin. Located in the zone of maximum precipitation in the eastern United States, the research area receives an average of 80 inches of precipitation each year, mostly coming as rain in about 100 separate climatic events. The basic hydrologic gaging network at Coweeta includes 3 multiple, 16 unit, and 12 standby watersheds ranging from 4 acres to 3 square miles with continuous streamflow records up to 33 years in length; 13 recording and 16 standard rain gages; 1 evaporation pan; 3 metering anemometers; 1 recording pyrheliometer; and 3 hygrothermographs. A small laboratory provides facilities for routine soil moisture work and for turbidity measurement of streamflow. Soil moisture is measured in the field by 3 neutron scattering devices. Moisture and density changes in isolated soil blocks are determined by gamma ray attenuation. Recorder punch tapes and chart traces are translated at the laboratory onto punch cards for computations. Now largely inactive, a unit located near Union, South Carolina, has been the site of considerable work on erosion control, comparative water use by different forest cover types, and soil moisture recharge in the piedmont. Research studies include: (1) forest treatment effects on water yield; the hydrology of mountain unit watersheds under several cover types; (3) movement and storage of soil water on steep slopes; (4) predicting soil moisture in steep terrain for hydrologic purposes; (5) morphology of the soil mantle related to water storage and release to streamflow; (6) structural descriptions of plant communities as related to water yield; (7) effect of forest cover and mountain physiography on the radiant energy balance; (8) rainfall interception by mixed hardwood, white pine, and grass; (9) mechanizing hydrologic data collection and processing; (10) stream diversion to deep soiled slopes to stabilize and increase late summer flows; and (11) pilot testing multiple use of forest for water, timber, recreation, and wildlife on a 365-acre watershed.

(f) Active; as individual studies are completed they are reported via technical reports and publications.

(g) A 22-acre catchment converted from hardwood to grass in 1959-1960 has continued to yield more water each year as the original grass cover declined in vigor. Water yield increases for the past 5 years have been $0,0.9,1.3,4.6$, and 6.9 inches as dry matter production of grass declined from about 3.5 to 1.5 tons/acre year. Both grass vigor and water yield were restored to the 1960 level by heavy fertilization in April 1965. A computer method of separating a continuous streamflow hydrograph into quick and delayed flow components has been developed to facilitate study of streamflow behavior from small catchments. This technique employs a straight line of separation projected forward at beginning of hydrograph rise until it intersects the recession side of the storm hydrograph. All flow above the separation line is quick flow, all below it is delayed flow. Using this technique, 15 forested watersheds in eastern United States were separated into quick and delayed flow by computer and ranked according to mean precipitation, quick flow, and response factors quick flow/precipitation and quick flow/total water yield. The overriding prevalence of subsurface flow was indicated and other important relationships determined by this technique. Use of computer separated components of the hydrograph is continuing to develop new and better streamflow prediction methods and for analysis of forest treatment effects based on the climatic event. A clearcutting experiment on a 40-acre watershed was repeated after 23 years of regrowth since the first cut in 1940. The water yield increase during the first year after the second cut was almost identical with results after the first cut, 14.7 and 14.6 inches respectively. The latest of a series of clearcutting experiments produced a first year yield in. crease of 11 area inches. This is the 
steepest and highest area yet treated at Coweeta; its top elevation exceeds 5200 feet above sea level. A review of worldwide forest cutting experiments reveals that 100 percent reduction of forest vegetation may give water yield increases as large as 18 inches during the first year following treatment, but that most treatments give considerably less, depending primarily on climate and distribution of precipitation throughout the year.

(h) "Man, Water, and the Forest," J.E. Douglass, Forest Farmer 26(5): 6-7, 18, 20, 1967. "Coweeta Lab Selected as Model," Anonymous, Georgia Forestry 20(1): 12, 1967.

"Effect of Leaf Aging on Water Deficit-Water Potential Relationships of Dogwood Leaves Growing in Two Environments, "E.B. Knipling, Physiologia Plantarun 20: 65-72, 1967. "Potential Impact of Forest Fertilization on Range, Wildlife, and Watershed Management," J.B. Hilmon and J.E. Douglass, presented at Symp. on Forest Fertilization, Univ. of Florida, Gainesville, April 18-21, 1967.

"Interception by Eastern White Pine," J.D. Helvey, Water Resources Res. 3(3): 723-729, 1967.

\section{(5813) HYDROLOGY AND MANAGEMENT OF WETLAND FORESTS.}

(b) Laboratory project. For general public use and information.

(d) Experimental; applied and basic research.

(e) Project objective is to develop effective and reliable water control and soil management techniques through increased knowledge of the hydrology, soil properties, and soil-waterplant relations of wetland forests. Research is concentrated on three major problems: Define the natural hydrology of the major physiographic wetland types: bottomlands, bays and pocosins, and wet flatlands; (2) Determine the effects of principal engineering water control measures on area hydrology and soil properties; and, (3) Determine the effects of vegetal manipulation on area hydrology and soil properties. Studies are conducted in wetland forests throughout the southeastern coastal plain from Virginia through Florida. Accordingly much of the program consists of water control and soil research in cooperation with wood-using industries and other wetland forest managers who have made or plan to make capital investments to manage water on their land. In addition, research is conducted on the Santee Experimental Forest, located 32 miles north of Charleston, S.C., which has a small laboratory and three stream gaging stations on watersheds of 400, 1200, and 11 , 000 acres.

(f) Active; as individual studies are completed they are reported via technical reports and publications.

(g) In one study, comparison of diameter growth of 60-year-old loblolly pine on plots where the understory had been eradicated by prescribed summer fires with growth on those where the understory was untreated did not show a meaninful difference. Adequate growing season rainfall and advanced age of the trees could explain the study results. Other research demonstrates that uncontrolled drainage of wet hardwood lands is a problem because water controls the establishment of hardwoods and their subsequent growth rates. On the other hand, controlled drainage of wet slash pine flats in northwest Florida can cause significant improvement in the height growth of slash pine trees. Moreover, diameter and height growth of loblolly pine on drained wetlands is better during wet years than during dry, and on clayey soils than on sandy soils. Variability of soil properties has always created problems in soil sampling in the lower coastal plain of South Carolina where little information is available to guide study designs. Results of another study show the number of sampling locations on test plots needed to estimate the mean of various physical properties within five percent for two probability levels and two common wetland soils. Scientists faced with a soil sampling problem on similar wetlands soils will now have a starting point to determine the magnitude of sampling needed in their work.

(h) "An Overflow System for a standard U.S. Weather Bureau Evaporation Pan," Cortland E. Young, Jr. and James E. Henderson, Research Note SE-60, Sept. 1966.

"Diameter Growth of Mature Loblolly Pine Unaffected by Understory Control," Ralph A. Klawitter, Southern Lumberman, Vol. 213 (2656): 154-155, 1966.

"Drainage," Ralph A. Klawitter, Proc. 1966 Symp. on Hardwoods of the Piedmont and Coastal Plain, Georgia Forest Research Council, pp. 16-17, Oct. 1966 .

"Early Response of Pole-Sized Slash Pine to Drainage, "Ralph A. Klawitter, Research Note SE-63, Sept. 1966.

"Growth Trends of Loblolly Pine on Two Drained Wetlands," Cortland E. Young, Jr., Southern Lumberman, Vol. 213 (2656): 160-161, 1966. "Soil Sampling Small Wetland Forest Plots in the Coastal Plain," Cortland E. Young, Jr., Research Note SE-59, June 1966.

"Waterbalance on a Forested Watershed in the Flatwoods," Cortland E. Young, Jr., Annual Southeast Section Mtg., Amer. Soc. Agric. Engrs., Proc. 63rd Ann. Convention, Feb. 1966, 3 pages.

"Woodland Water Management in Soil and Water Conservation," Ralph A. Klawitter, Proc. Ninth Ann. Meeting of Soil Conserv. Soc. Amer., Vol. V, 8 pates, 1966.

\section{U.S. DEPARTMENT OF AGRICULTURE, FOREST SERVICE,} Southern Forest Experiment Station.

Inquiries concerning the following projects should be addressed to T.C. Nelson, Director, Southern Forest Experiment Sta., T-10210 Federal Bldg., 701 Loyola Ave., New Orleans, Iouisiana 70113.

(2914) WATERSHED MANAGEMENT RESEARCH, OXFORD, MISS.

(b) Laboratory project, in cooperation with Soil Conservation Service, Agricultural Research Service, and Univ. of Mississippi.

(d) Field investigation of runoff and erosion from small experimental watershed on forest and potential forest lands; basic and applied research.

(e) Twelve small natural headwater catchments, two to four acres each, were installed in batteries of three to determine runoff and erosion from old fields, depleted upland hardwoods, pine plantations, and mature upland pine-hardwoods. Four of the six old field and depleted hardwood watersheds were planted to pine in 1764 , after site preparation which included burning. 
Treatments on the pine and pine hardwoods are deferred until after a suitable calibration period. Five additional watersheds in pine plantations are being calibrated prior to testing effects of timber harvesting on runoff, erosion, and sediment flows. Related studies include restoration of depleted watersheds and plant-soil-water relationships.

(f) Data collection on all watersheds is continuing.

(g) Runoff and erosion appear to have increased moderately after prescribed burning.

(h) "Forest Hydrology Research in Mississippi," S.J. Ursic, Proc. Mississippi Water Resources Conf., 1966.

"Mulch Improves Loblolly Pine Survival in Coastal Plain Parent Materials," S.J. Ursic, Jour. of Forestry, 64(11): pp. 728-730. Nov. 1966.

"Survival of Planted Loblolly Pine Seedlings: Moisture, Temperature, and Soil as Influences," D.C. McClurkin, Jour of Forestry, 64(11): 731-734, Nov. 1966.

"Vegetation for Erosion Control in the Southern Coastal Plain of the United States, "D.C. McClurkin, Intl. Symp. on Forest Hyarology, Proc. of a Natl. Science Foundation Advanced Science Seminar, Pennsylvania State Univ., Aug. 29 - Sept. 10, 1965, Pergamon Press Oxford and New York, 1966.

"Throughfall in Pole-Sized Lroblolly Pine as Affected by Stand Density," T.I. Rogerson, Intl. Symp. on Forest Hydrology, Proc. of a Natl. Science Foundation Advanced Seminar, Pennsylvania State Univ., Aug. 29 - Sept. 10, 1965, Pergamon Press - Oxford and New York, 1966.

"Late Planting Improves Loblolly Survival," S.J. Ursic, U.S. Forest Service Research Paper SO-24, 12 pp., illus. 1966.

"Stabilizing Steep Gully Banks with Excelsior Mulch and Loblolly Pine," P.D. Duffy and D.C. McClurkin, Jour. Soil and Water Conservation. 22(2): 70-71. March-April 1967.

"Using Runofi Events to Calibrate Small Forested Catchments," S.J. Ursic and T.W. Popham, Proc., Fourteenth Intl. Union Forest. Res. Organ. Congr., Vol 1, pp. 319-324.

"Longfingergrass Covers Bare Sites Quickly," D.C. McClurkin and V.E. Ahlrich, Crops and Soils Mag., pp. 18-19. Dec. 1967.

"Site Index of Loblolly Pine on Ruston Soils in the Southern Coastal Plain," R.R. Covell and D.C. McClurkin, Jour. of Forestry, 65: 263-264, illus. 1967.

"Improved Standards for Neutron Soil Water Meters," S.J. Ursic, Soil Science, 104(5): 1967.

3225) WATERSHED MANAGEMENT RESEARCH, HARRISON, ARKANSAS.

(b) Laboratory project.

(d) Field investigations on effects of forest type and condition on timing of flows in streams of the Ozark-Ouachita uplands; basic and applied research.

(e) Runoff and sediment from three small mountain watersheds are measured currently. H-flumes and stage recorders were installed on eight additional watersheds ranging from 2 to 40 acres. Cover conditions will be changed after an adequate calibration period. Related studies of soil moisture and erosion are continuing.

(f) Records of runoff and sediment collected currently.

(h) "Throughfall and Stemflow in a Pine-Hardwood
Stand in the Ouachita Mountains of Arkansas," E.R. Lawson, water Resources Res., Vol. 3, No. 3, pp. 731-735, 1967.

"New Neutron Probe System Speeds Logging of Soil Water Profiles," T.I. Rogerson and S.J. Ursic, Proc., Fourteenth Intl. Union Forest. Res. Organ. Congr., Vol. 1, pp. 416-417, illus. 1967.

AIR FORCE INSTITUTE OF TECHINOLOGY, Dept. Of Aeronautical Engrg., Wright-Patterson AFB, Ohio 45433

(6472) HELE-SHAW SOURCE, SINK, AND CIRCULATORY FIOW VISULIZATION

(b) Laboratory project.

(c) Prof. H.C. Larsen, Head, Dept. of Aero. Engrg., Air Force Inst. Tech.

(d) Master's thesis.

(e) The Hele-Shaw flow visualization technique was extended to show sources, sinks, doublets, and combined flows in a uniform stream. A method of contouring one wall enabled circulatory flow to be demonstrated. The flows obtained were compared with analytic solutions to evaluate the validity of flows obtained, and to enable complex flows to be obtained experimentally where no solution exists.

(f) Discontinued.

(g) Useful techniques in analyzing complex potential flows were obtained.

(h) "Hele-Shaw Source, Sink, and Circulatory Flow Visualization," GAM/AE/66B-10 (thesis) may be obtained by writing to correspondent.

(6473) MEASUREMENT OF VELOCITY PROFIIE AND DECAY OF VELOCITY IN RADIAL FLOW JETS.

(b) Laboratory project.

(c) Prof. H.C. Larsen; see (6472) above.

(d) Thesis.

(e) Theoretical equations describing the velocity profile for the near solution, and velocity profile and decay law were obtained for radial flow jets. Experimental data was needed to verify the usefulness of the solutions obtained and to match a transition regime between them. A masters thesis has obtained the necessary data, which was collected by total head pressure measurement and hot wire anemometers.

(g) Agreement between theory and experiment in velocity profile is good, but decay is slower than predicted by the "far" solution.

(h) "Measurement of Velocity Profile and Decay of Velocity in Radial Flow Jets, "Marvin E. Howe, thesis, GAM/AE/68-5.

U.S. ARMY COLD REGIONS RESEARCH AND ENGINEERING LABORATORY, P.O. Box 282, Hanover, New Hampshire $\overline{03755}$

(6383) HYDROLOGY OF A SMALI DRAINAGE EASIN ON THE COASTAL PIAIN OF NORTHERN AIASKA.

(b) Laboratory project.

(c) Dr. Jerry Brown, Research Soil Scientist, USA CRREL.

(d) Field and experimental.

(e) Provides hydrogeological data in support of soils and vegetation processes at farrow. Alaska and obtains information on the water balance in a coastal tundra environment 
underlain by permafrost.

(f) Completed.

(g) Runoff varies widely; hydrograph analyses revealed: (1) lag times generally from 3 to $10 \mathrm{hrs} ;$ (2) recession constants about 50 hrs; (3) runoff from individual storms between $l$ and $70 \%$. Assuming all winter precipitation runs off over the seasonally frozen ground and the data are spatially and temporarily representative, about $50 \%$ of the measured annual precipitation in this region runs off into the Arctic ocean.

(h) USA CRREL Research Report "Hydrology of a Small Drainage Basin on the Coastal Plain of Northern Alaska," Jerry Brown, S. Lawrence Dingman and R.I. Lewellen (in press) and Amer. Geophys. Union, Trans. Vol. 48, p. 93 (abstract).

(6384) RECONNAISSANCE HYDROLOGIC STUDY OF THE DELTA RIVER AND ITS DRAINAGE BASIN, EAST-CENTRAL ALASKA.

(b) Laboratory project.

(c) S. Lawrence Dingman, Research Hydrologist, USA. CRREL.

(d) Field study; basic.

(e) A one-year reconnaissance study of a large braided glacial river and its drainage basin (drainage area - $1665 \mathrm{~m}^{2}$ : elevation range 1000 - 10,000 ft) for which a minimum of hydrometric and meteorologic data existed. Includes estimates of the water-balance, flowduration curves, and sediment characteristics, and descriptions of stream response to glacial melt and rain, channel geometry and channel processes.

(f) Completed.

(g) Mean annual basin precipitation is estimated at $40.4 \mathrm{in}$. and a mean annual loss of permanent glacial storage is about $I$ in. About $30 \%$ of this leaves the basin as evapo-transpiration, $50 \%$ as streamflow, and $20 \%$ as groundwater flow. Characteristics of response to glacial melt are outlined. Flow peaks near the mouth occur within 24 hours of rainfall of greater than $0.5 \mathrm{in}$./day at foothills meteorological stations; rains of less than that amount do not generally produce discernible stream response. Stream channel geometry is described in detail - most channels on the lower floodplain are asymmetrical and are rougly triangular or parabolic, and have high width/depth ratios. At-a-station hydraulic geometry is described. Surveys and ground and aerial photography are used to describe channel changes.

(n) USA CRREL Research Report "The Delta River and Its Drainage Basin - Reconnaissance Hydrological Study," S. Lawrence Dingman et al. (In preparation), 1968. (Available from USA CRREL, Box 282, Hanover, N.H. 03755).

(6385) HYDROLOGIC STUDY OF THE GLENN CREEK DRAINAGE BASIN NEAR FAIRBANKS, AIASKA.

(b) Laboratory project.

(c) S. Lawrence Dingman; see (6384) above.

(d) Field study; basic doctoral thesis.

(e) A study of runoff characteristics and thermal erosion in a sub-artic watershed of $0.7 \mathrm{~m}^{2}$ area, largely underlain by permafrost. Measurements of rainfall, runoff, pan evaporation. moss evaporation, solar radiation, wind, air and water temperature, and relative humidity have been made over parts of four summers.

(g) Rainfall-runoff measurements have shown very slow recessions and long lag-times relative to similar-sized and even much larger watersheds in more temperate regions. The thick moss ground cover over much of the basin is thought to be responsible for their characteristics. Thermokarst features along the stream contribute a large burden of suspended sediment to the stream.

(h) USA CRREL Special Rept. 86 "Hydrologic Studies of the Glenn Creek Drainage Basin Near Fairbanks, Alaska," S. Lawrence Dingman, 30 p., 1966. (Available from USA CRREL, Box 282, Hanover, N.H. 03755).

"Characteristics of Summer Runoff from a Small Watershed in Central Alaska," S. Lawrence Dingman, Water Resources Res., Vol. 2, No. 4, p. 751-754, 1966. (Available from author USA CRREL.

(6386) CHARACTERISTICS OF ALASKAN STREAMS AND BASINS AS RELATED TO MILITARY MOBILITY.

(b) U.S. Army Tank-Automotive Command.

(c) Dr. Jerry Brown; see (6383) above.

(d) Field and experimental; basic and applied.

(e) objective is to evaluate interrelated hydrologic and morphologic characteristics of selected rivers and drainage basins in Alaska, for identifying, understanding and predicting characteristics of arctic and subartic waterway as related to vehicular mobility problems. Basic hydrologic and morphologic data are collected in the Tanana River Basin, Alaska.

(g) Results await further reduction of 1767 data.

(h) Operational Report, Nov. 1767, "Characteristics of Alaska Streams and Basins as Related to Military Mobility, "Capt. C.W. Slaughter, S.L. Dingman, and P.V. Sellmann. This is an interim report and available only upon special request. Final report will be available by 1 July 1968.

(6387) THE EFFECTS OF THERMAL POLLUTION ON RIVER ICE CONDITIONS.

(b) Laboratory project.

(c) S. Lawrence Dingman; see (6384) above.

(d) Theoretical with field experimentation; basic.

(e) Formulation of a steady-state model describing the downstream cooling of river water below a source of thermal pollution and estimation of the length of ice-free reach associated with such pollution under conditions when unaffected portions of the river are ice-covered.

(g) A steady state model was developed relating water temperature $\left(T_{W}\right)$ and distance below the thermal pollution source $(x)$ as $x=C \int_{P_{W O}}^{T} \frac{d T}{Q^{*}}$ where $T_{\text {wo }}$ is water temperature at $x=0, T_{W x}$ is water temperature at $x, Q^{*}$ is heat loss rate from the water surface, and $C$ is a constant including river velocity and depth. $Q^{*}$ is the sum of heat loss rates due to short- and long-wave radiation, evaporation, convection, and in-falling precipitation, and is evaluated from meteorological conditions. Numerical integration is used to evaluate the relation between $x$ and $T_{W}$. The model was successful in predicting lengths of ice-free reaches associated with power plants on the upper Mississippi River. It is shown that properly placed nuclear reactors could keep significant portions of the St. Lawrence River icefree. 
(h) USA CRREL Research Rept. 206 "The Effects of Thermal Pollution on River Ice Conditions," S.L. Dingman, W.F. Weeks, and Y.C. Yen (in press), 1968. (Available from USA CRREL, P.O. Box 282, Hanover, N.H. 03755).

"The Effects of Thermal Pollution on River Ice Conditions," S.L. Dingman, W.F. Weeks, and Y.C. Yen, Water Resources Res. (in press) 1968. (Available from authors, USA CRREL). USA CRREL Research Rept. "Heat Transfer Coefficients for Calculation of Downstream Cooling of a River Below a Thermal Pollution Source," A. Assur and S.L. Dingman (in preparation). (Available from USA CRREL).

(6388) MECHANICS OF ICE, RIVER ICE JAMS.

(b) Laboratory project and Corps of Engineers.

(c) Director, USA CRREL.

(d) Applied research; field investigations.

(e) Several rivers are being investigated for frequency of ice jam formation. Measurements are being made of ice thickness, snow depth and water depth at main channel.

(h) Results of the studies conducted on the White River, Hartford, Vermont area are reported in a Technical Note (internal report) by Garner and Frankenstein.

(O52W) THERMAL CALCULATION TECHNIQUES.

(c) Project Engr., Richard Berg, Research Civil Engr., USA CRREL.

For summary, see Water Resources Research Catalog, Vol. 2, 2.0808.

(O53W) PREVENTION AND CONTROL OF CULVERT AND ROAD ICING.

(c) K.L. Carey, Research Civil Engr., USA CRREL. For summary, see Water Resources Research Catalog, Vol. 2, 2.0805.

(054W) UTILITIES IN PERMAFROST AREAS.

(c) S.C. Reed, Research Civil Engr., USA CRREL.

For summary, see Water Resources Research Catalog, Vol. 2, 5.0665.

(O55W) TECHNICAL SUPPORT, INVESTIGATIONS OF ARTIC CONSTRUCTION.

(b) USA CRREL - laboratory project.

(c) C.W. Fulwider, Research Civil Engr., USA CRREL. For summary, see Water Resources Research Catalog, Vol. 2, 8.0264.

\section{ARMY INERTIAL GUIDANCE AND CONTROL IAB AND CENTER,} AMSMI - RG, Bldg. 5400, Redstone Arsenal, Alabama 35809

(6483) APPLICATION OF THE HYDRAULTC ANALOGY TO SUBSONIC FLOW.

(b) Laboratory project.

(c) Carl Warren, Aerospace Engr.

(d) Experimental and theoretical; applied research; masters thesis.

(e) An experimental study was conducted to determine the quantitative accuracy of the hydraulic analogy when applied to subsonic internal flows such as exist in pure fluid elements. A non-symmetrical flow divider was used as the test model configuration.

(f) Completed.

(g) Under very accurately matched load conditions, air model Mach Numbers corresponded to measured water model Froude Numbers to within $3 \%$.

(h) "Application of the Hydraulic Analogy to Internal Subsonic Flow," Carl H. Warren, U.S. Army Missile Command Rept. No. RG-TR-67-17, 88 pages, Redstone Arsenal, Ala., July 1967, (available through DDC, Cameron Station, Alexandria, Va. 22314).

CORPS OF ENGINEERS, U.S. A.RMY, Coastal Engineering Research Center, 5201 Little Falls Rd., N.W., Washington, D.C. 20016.

Inquiries concerning the following projects should be addressed to the Director, Coastal Enginerring Research Center, unless otherwise noted under (c).

( 181) EQUILIBRIUM PROFILE OF BEACHES AND STUDY OF MODEL SCALE EFFECTS.

(b) Laboratory project.

(d) Experimental; basic research.

(e) Equilibrium beach profiles will be determined experimentally for waves up to 6 feet in height in a prototype tank; the waves will be modeled at a 1 to 10 scale in small laboratory tanks (to determine scale effects) for various median diameter and specific gravity sediments.

(g) Analysis continues of previous test results. Further tests were made with very small-sized ( 115 micron median diameter) glass spheres to simulate beach material under wave action, and data gathered is being analyzed.

( 660) OBSERVED WAVE CHARACTERISTICS.

(b) Laboratory project.

(d) Field investigation; basic research.

(e) To secure a more thorough knowledge of the characteristics of ocean waves. Wave gages have been installed in a number of locations in coastal waters. These wave gages provide a pen and ink strip chart recording and also magnetic tape recordings. The records from the paper chart records are analyzed for significant wave height and wave period. The records from the magnetic tape recorders are analyzed to provide a spectral analysis of wave frequency (or period) versus: (1) linear average wave height; (2) squared average wave height; and (3) peak wave height.

(g) A wave gage telemetering system was installed for transmitting wave height and period data from six wave stations on the east coat of the USA to the Coastal Engineering Research Center laboratory in Washington, D. C. These stations are:

(a) Atlantic City, N.J.; (b) Virginia Beach, Va.; (c) Nags Head, N.C.; (d) Daytona Beach, Fla.; (e) Lake Worth, Fla.; (f) Naples, Fla. Data telemetered from the wave gage at Atlantic City, N.J. is being recorded continuously on a digital magnetic tape recorder. Data from this recorder is compatible with automatic data processing equipment so as to provide wider analyses on the ocean wave climate. A manuscript for an ocean wave gage technical manual has been prepared and should be published by June 1968.

( 975) METHODS OF BY-PASSING SAND PAST INIETS.

(b) Laboratory project.

(c) G.M. Watts, Chief, Engrg. Development Div., CERC.

(d) Field investigation; applied research. 
(e) To study methods and requirements for pumping sand past inlets and to determine the

applicability of the methods in stabilization of beaches adjacent to inlets. Data are being procured on the effect to the shoreline of sand by-passing operations at Port

Hueneme, California and Lake Worth Inlet, Fla. and on the effect to the shoreline of a new harbor constructed at Ventura, California. This latter harbor involves an offshore detached breakwater along with entrance jetties to the new harbor. Data at the three locations include periodic hydrographic surveys south and north of the inlet, wave data, sand samples, detailed records of pumping operations, and detailed records of entrance channel maintenance. A general study is being made of the possibility of adapting commercial instruments utilizing a radioactive source to the discharge line to measure quantity of material pumped in by-passing operations.

(g) Surveys, observation and data compilation are in progress of a submerged weir and deposition basin sand by-passing operation at Masonboro Inlet, $\mathbb{N} . \mathrm{C}$.

(h) "Stabilization of Masonboro Inlet, "A.C. Rayner and N.C. Magnuson, Shore and Beach, Vol. 34, No. 2, pp. 36-41, Oct. 1966.

( 976 ) ESTABLISHMENT OF CRITERIA FOR CONSTRUCTION OF ARTIFICIAL BEACHES.

(b) Laboratory project.

(c) G.M. Watts; see (975) above.

(d) Theoretical; applied research.

(e) To develop criteria for construction of beaches by artificial means. The present continuing phase of this general study involves the measurement of a natural beach slope and attempts to determine its response to the forces normally incident upon the shore such as wave height and period, angle of wave approach, tide, and direction and magnitude of littoral current. By statistical methods the relative importance of the forces or combinations of forces may be evaluated.

(g) Laboratory and experimental field studies were carried out to ascertain stability of oolitic aragonite in comparison with natural beach sand if used for beach fill material.

(h) "A Lognormal Size Distribution Model for Estimating Stability of Beach Fill Material," W.C. Krumbein and W.R. James, Tech. Memo. No. 16, CERC, 17 pp., Nov. 1965.

( 977) DEVELOPMENT OF WAVE HEIGHT AND WAVE DIRECTION GAGES.

(b) Laboratory project.

(d) Experimental; development.

(g) Laboratory tests in which an ultrasonic velocity gage was both towed and tested under wave action were conducted at the Naval Ship Research and Development Center and in the large wave tank at CERC. Data from the tests is awaiting analysis.

(2190) STUDY OF EFFECT OF A GROIN ON THE RATE OF LITTORAL MOVEMENT.

(b) Laboratory project.

(d) Experimental; basic research.

(e) To study the effect of groins on the rate of littoral drift passing a groin system. Initial tests consist of waves generated at a 30-degree angle to the sand beach with measurement of material movement being made at the downdrift end. The tests planned for the immediate future, as have the current season tests, will continue to emphasize the task of collecting and establishing reliable calibration data on the relationship between the littoral transport rate and the wave characteristics. These generalized (not to specific model scale) studies are being made in the Shore Processes Test Basin of the Coastal Engineering Research Center.

(g) Littoral transport tests continue in the Shore Processes Test Basin. Tests were completed at wave periods of 2.18 and 1.25 seconds in further laboratory study of littoral transport and attendant wave diffraction effects. Results show that observable wave diffraction effects on the sand beach were generally less in the shorter wave period tests than in the 1965 longer period test $(T=3.75 \mathrm{sec}$.$) .$

(h) "Correlation of Littoral Transport with Wave Energy Along Shores of New York and New Jersey," John C. Fairchild, CERC Tech. Memo. No. 18, 33 pp., Nov. 1966.

"Laboratory Memorandum of SPTB Littoral Transport Tests - 1964-66", John C. Fairchild (for limited distribution only).

(2192) REGIONAL STUDIES OF THE ATLANIC COAST OF NEW JERSEY; AND THE DELAWARE-MARYLANDVIRGINIA SHORE LINE FROM CAPE HENLOPEN TO CAPE CHARLES.

(b) Laboratory project.

(c) D.B. Duane, Chief, Geology Branch, CERC.

(d) Field investigations; basic research.

(e) To compile all existing data pertinent to shore processes on a regional scale. Reports to consist of three chapters: geomorphology and shoreline histories, littoral forces, and littoral materials. Subject matter to include physiography, geological development of the shore region, sources of littoral material, waves, tides or water level fluctuations, current physical characteristics of the littoral materials, interrelation of sedimentary properties, relation of properties of littoral materials to position in the littoral zone, and changes in shoreline configuration.

(g) The Delaware-Maryland-Virginia shoreline is currently under study. Data compilation for this reach is completed and the preliminary draft of a report has been prepared.

(2193) SHORE PROTECTION PLANNING AND DESIGN.

(b) Laboratory project.

(c) R.A. Jachowski, Chief, Design Branch, CERC.

(d) Design.

(e) To supplement and revise the Coastal Engrg. Research Center's (formerly Beach Erosion Board) Technical Rept. No. 4, "Shore Protection Planning and Design," as new data and techniques are developed for use in the solution of coastal engineering problems.

(g) The third edition of this comprehensive manual is published and available from supt. of Documents, U.S.G.P.O., Washington, D.C. 20025, for $\$ 3.00$ per copy. A cross referenced index for this manual has been prepared for inclusion in possible reprint of present 3 d edition. The outline for complete new format for 4 th edition of this manual has been tentatively formulated.

(h) "Shore Protection Planning and Design, "Tech. Report No. 4 of CERC, 3d Edition, $580 \mathrm{pp}$., June 1966. 
(2195) RE-EXAMINATION OF ARTIFICIALLY NOURISHED AND CONSTRUCTED BEACHES.

(b) Laboratory project.

(c) G.M. Watts, Chief, Engrg. Development Div., CERC.

(d) Field investigation; applied research.

(e) To study the behavior of beach fills placed to restore or nourish a beach sector and the effect of the fill on adjacent shores. A selected number of beach fills are being reexamined.

(g) Follow-up reports prepared but not yet published on beach fill projects at Presque Isle Peninsula, Pa, and at Harmonasset Beach State Park, Conn. Other reports are in preparation for beach fill projects at Key West, Fla. and south of Port Hueneme, Calif.

(h) "Behavior of Beach Fill and Borrow Area at Sherwood Island State Park, Westport, Conn.," W.H. Vesper, Tech. Memo. No. 20, CERC, 25 pp., May 1967.

"Factors Affecting Beach Nourishment Requirements, Presque Isle Peninsula, Erie, Pa.," D.W. Berg, Reprint 3-66, CERC, 25 pp., Feb. 1966.

(2660) STUDY OF QUANTITY OF SEDIMENT IN SUSPENSION IN THE SURF ZONE (INCLUDING TEMPERATURE EFFECTS).

(b) Laboratory project.

(d) Experimental; basic research.

(e) To determine the relationship between wave, water, and sand characteristics, and the amount of material maintained in suspension and, hence, available for longshore transport by currents.

(g) Analysis of suspended sand samples collected at lvags Head, N.C. in 1964 has been completed and a report is now in preparation. Analysis of suspended sand samples collected at Ventnor, N.J. in 1965 continues with preparation of a report. Suspended samples of a 115 micron $M_{d}$. glass beads sand simulant (average specific gravity 2.5) have been made to determine the applicability of the material to laboratory and models studies of wave action in the coastal zone (also, see item $181(\mathrm{~g})$ Sand Simulant Tests).

(h) "A Tractor-Mounted Suspended Sand Sampler," John C. Fairchild, CERC Reprint No. 4-66, June 1966.

(2661) WAVE RUN-UP ON SHORE STRUCTURES.

(b) Laboratory projects.

(d) Experimental; design.

(e) Wave run-up is determined experimentally for various waves for different types of shore structures. Effect of both structure roughness and permeability is being investigated.

(g) Analysis of field measurements taken at Nags Head, N.C. show that there is no one-for-one correlation between wave run-up and the causative waves when a spectrum of waves is present. Therefore statistical correlations are being investigated.

(3228) MODEL TESTS OF WAVE SETUP ON BEACHES.

(b) Laboratory project.

(d) Experimental; basic research.

(e) Measurement of the mean water level of shoaling waves on beaches using damped piezometers buried in the beach. Study is being made in order to (1) check existing theory for setup offshore of breaking; (2) estimate rate of energy supply required to maintain setup in surf zone; and (3) provide engineering criteria for design of coastal structures.

(g) Analysis of setup data showed that setup at the still water line ranged between 15 and $20 \%$ of the breaker height, increasing with the beach slope. The setdown at the breaker point was close to the maximum setdown on the beach and averaged from 1 to $8 \%$ of the breaker height, also increasing with slope. Results of this work were discussed in a talk given at the annual meeting of the American Geophysical Union in April.

\section{(3897) RADIOACTIVE TRACERS FOR BEACH STUDIES.}

(b) Laboratory project.

(c) D.B. Duane, Chief, Geology Branch, CERC.

(d) Experimental; research.

(e) Basic objective of the Radioisotopic sand Tracer (RIST) Study at Point Conception, California is to develop data and knowledge concerning littoral material transport in the vicinity of headlands or supposed barriers to littoral drift utilizing radioactive sand particles. The study will provide data, information, and guidance on development of techniques and necessary hardware for use in studying the characteristics of littoral material movement around headlands and will develop additional information on many other aspects of sediment transport.

(g) Basic tools and techniques have been developed to meet several program objectives, i.e., tracing radioactive sand in the offshore zone and developing qualitative data on the mechanics of transport. Xenon-133 was selected as initial isotope as it does not alter hydraulic behavior of quartz sand and its use does not present a health hazard. A report (see ( $h$ ) below) discussing results of the large and small tests made using fluorescent tracers, reported on previously, was given by the Hydraulics Research Station of England at the Xth Coastal Engineering Conference in 1966.

(h) "Sand Transport due to Wave Action," Rance and Lean, Extended Abstracts, No. Ex-6, Tenth Conf. Coastal Engrg., Tokyo, Japan, Sept. 1966.

(4760) EXPERIMENIAL STUDY OF DUNE BUIIDING WITH SAND FENCES.

(b) Laboratory project.

(d) Experimental; design.

(e) The experimental study consists of the construction of various types and arrangements of sand fences to determine the fence type and arrangement most effective in building a dune by trapping and holding wind-blown sand. Slat-type snow fencing and locally constructed brush fencing have been used in. straight, straight-with-side spurs, and zigzag configurations. The study is being conducted on the Outer Banks of North Carolina between Cape Hatteras and Cape Lookout.

(g) Beach grasses have been shown to be effective sand trappers. Some fabric sand fences have tested and fabric weaves have been found which perform well as sand fences.

(4762) CORRELATION OF STORM WAVE ATTACK AND BEACH EROSION.

(b) Laboratory project.

(d) Field and office investigation to develop quantitative correlation between storm violence and shore erosion.

(e) Repetitive profiles are taken at selected 
beach areas. The storm wave action between surveys is analyzed and correlations between the wave action and observed profile changes are established. Repetitive profile lines were established in September 1962 at nine locations between Delaware Bay and Cape Cod. These profiles were re-surveyed at weekly and bi-weekly intervals. The resurvey interval now is 4 to 6 weeks. Storm wave action is measured by the Coastal Engineering Research Center ocean wave gages and storm surges by U.S. Coast and Geodetic Survey tide gages.

(g) Study is continuing with intensive field effort scheduled for January-March 1968.

(h) An article entitled "The study of Pilot Beaches in the New England Area for the Improvement of Coastal Storm Warnings," by John M. Darling was published in the CERC Bulletin and Sumary Report of Research Projects for Fiscal Years 1965-66, Volume II, 1965-66.

(4763) OFFSHORE SAND SOURCES.

(b) Iaboratory project.

(c) D.B. Duane, Chief, Geology Branch, CERC.

(d) Field investigation; applied research.

(e) For the purpose of delimiting and inventorying sand deposits in Atlantic, Pacific, Gulf or Great Lakes sub-bottom which would be potentially suitable and economic for beach fill at U.S. beaches, field surveys are carried out by contract at selected sites which include geophysical profiles by sonic device to determine stratification and cores to establish material characteristics.

(g) Field work has been completed and processing of available data is underway for selected areas off the New Jersey and Florida coasts. Field work is in progress for the New England area from Long Island, N.Y. to coast of Maine, and for an area of the Mid-Atlantic region just off of Chesapeake Bay entrance. A sand inventory report is nearing completion which covers areas with potential to serve needs in Dade, Broward and Palm Beach Counties, Flordia. Actual field testing conducted off the New Jersey coast with pump-out hopper dredge and experimental hook-up device in the Atlantic Ocean to onshore pipe-line has shown the pumpashore concept to be feasible even for oceanfront operational areas.

(5325) FIELD MEASUREMENT OF IONGSHORE CURRENT VELOCITY.

(b) Iaboratory project.

(d) Field investigation.

(e) Iongshore current velocity was measured by timing the travel of water filled balloons in the surf on the beach near Nags Head, N.C.; breaker angles were measured with a Brunton compass, by triangulation and by measuring the speeds of the crest and plunge point of the breaking wave; beach slope was obtained from profiles through the surf zone; and wave heights and periods were measured from wave gage records.

(f) Suspended.

(g) Additional measurements made at Virginia Beach, Va., Sept. 1966, and Nags Head, March 1967, to study fluctuations in longshore current velocity. For the five sets of data obtained, longshore current velocity is roughly predicted by two of the several equations available to predict longshore current velocity.

(5326) RESONANT EDGE WAVES ON LABORATORY BEACHES. (b) Laboratory project.

(d) Experimental.

(e) An unusual standing wave in the runup on laboratory beaches is under study. The combinations of slope, period, breaker type, standing wave length, and resonant amplification are being measured in order to describe the phenomenon and to understand its effect on laboratory and natural beaches.

(g) A report has been prepared for publication.

(5328) CHARACTERISTICS OF A PLUNGING BREAKER.

(b) Laboratory project.

(d) Experimental and theoretical, basic research.

(e) The wave height, mean water depth, and distance traveled in the breaking process are being measured for waves which break by plunging on a plane concrete beach in a wave tank 96 feet long and 1.5 feet wide. Parallel wire resistance wave gages measure the wave heights, damped piezometers buried flush with the beach surface measure the mean water level and photographs record the distance traveled in breaking. This study is undertaken to increase knowledge of the breaking process, to relate the energy flux of the incoming waves to the resulting wave setup, and to provide engineering criteria for the design of coastal structures.

(g) The horizontal distance between the observed breaking point and the point where the wave crest touches down in the trough before it breaks was measured from movies of plunging waves on 3 plane slopes and from visual observation on a composite slope. Average value of this distance ranges from about twice to more than four times the breaker height as slope decreases from 1 on 5 to 1 on 20 .

(5834) IONGSHORE CURRENT VELOCITY REVIEW.

(b) Laboratory project.

(d) Review of experimental, theoretical, and field investigations.

(e) A search of the literature was made to collect all available data on longshore currents and all published relations for predicting longshore current velocity, for comparison purposes.

(g) Eight equations and 502 sets of data were obtained from the literature. All data were used in all applicable equations and the predicted and measured velocities compared. No single equation predicted well for more than a limited part of the data.

(h) "Longshore Current Velocity: A Review of Theory and Data," Cyril J. Galvin, Reviews of Geophysics, Volume 5, No. 3, pp. 287-304, Aug. 1967.

(5836) FEASIBIIITY STUDY OF A MODEI WAVE-POWERED SAND DREDGE.

(b) Laboratory project.

(d) Experimental investigation.

(e) The model of a wave-powered sand dredge consisted of a float-supported vertical array of check valves. The purpose of these tests was to determine if this device could use the wave energy present to bring sand through the nearshore and surf zones in sufficient quantities to be useful in beach replenishment operations. The tests were conducted on a 1:15 scale in a 65 foot long tank using waves having prototype periods of 5,9 , and 13 seconds. The dredge was floated in the flume (with the valve array parallel to the impinging 
wave crests) over an equilibrium profile having an average 1 on 10 slope, with the bottom material composed of crushed anthracite having an average specific gravity of 1.52 and a median diameter of $0.2 \mathrm{~mm}$. The dredge was placed at various locations along the length of the profile and its valve array was set so that either $1,2,3$, or 4 valves operated, with the deepest valve being close to the bottom surface. Tests were made in which the dredge remained in a single location for the duration of a run, lasting about 13 minutes, as well as where the dredge was moved, by means of a winch and cable system, some distance along the length of the flume at a rate of 0.2 feet per 5 minutes of wave action. A total of 27 runs were completed.

(f) Completed.

(g) The results of the test series indicate that the device is not suitable for use as a dredge in its present form and actually increased the erosion rate by flushing far greater volumes of coal downslope on the seaward side of the dredge than were flushed through the valve array on the upslope side of the dredge.

(h) "A Feasibility Study of a Wave-Powered Device for Moving Sand," Frederick F. Monroe, Miscellaneous Paper No. 3-67, June 1967, U.S. Army Coastal Engrg. Research Center, Washington, D.C.

\section{(5837) NEW BERN STONE STABILITY TESTS.}

(b) Laboratory project.

(d) Experimental; applied research.

(e) A rubble breakwater with an armor layer of clayey limestone on a 1 on $1-1 / 2$ slope is being tested for stability with non-breaking waves. Stone weights for the armor layer vary from 230 to 430 pounds and tests are being made with wave periods of $3.75,5.60$, and 7.87 seconds. Wave heights used vary from 2 to 4.5 feet. The tests are being conducted in a wave tank 635 feet long, 20 feet deep, and 15 feet wide.

(g) Wave tank tests on the stability of a clayey limestone (shell-stone) showed that the stability of the stone is at least as good as that predicted by Hudson's equation. However, weighings before and after the tests indicated that the stones lost weight during the tests. Therefore, field tests are being conducted on a breakwater off Morehead City, N.C. to check on weight losses of this stone under prototype conditions.

(6486) LABORATORY TESTS OF RIPRAP STABTLTTY UNDER WAVE ACTION.

(b) U.S. Army Engr. Div., Missouri River; also CERC laboratory project.

(c) Thorndike Saville, Jr., Chief, Research Div., Coastal Engrg. Research Center.

(d) Experimental; applied research.

(e) Tests are carried out with various sizes and gradations of riprap to study the stability under instant wave action and various slopes of embankment. Tests are being made in three sizes of tanks; with waves varying from 0.2 to 6 feet in height, to show whether or not a scale effect exists. Slopes tested range from 1 on 2 to 1 on 8 . Several of the tests have used actual rock from the Missouri River basin, to properly simulate roughness and interlocking characteristics of rock actually used on some of the large U.S. dams in the Missour River basin. An overlay of tribars has also been tested at the several scales.

(g) Most of the laboratory tests have been completed, and calibration of the waves is underway.

U.S. ARMY ENGINEER DIVISION, NORTH PACIFIC, Division Hydraulic Laboratory, Bonneville, Oregon 97008

(6878) HOWARD HANSON DAM, GREEN RIVER, WASH., MODEL STUDY OF TUNNEL.

(b) U.S. Army Engr. Dist, Seattle.

(c) Director, Division Hydraulic Lab., U.S. Army Engr. Div., North Pacific, Corps of Engrs.

(e) Howard Hanson Dam is a flood-control project located on the Green River approximately 30 miles southeast of Seattle, Wash. It will consist of an earth-filled dam approximately 220 ft high, an uncontrolled spillway, and an outlet tunnel. Ordinary regulation of streamflow will be accomplished by releases through two 10- by 12-ft tainter valves to be installed in an intake structure at the upstream end of a 22- by 22-ft horseshoe-shaped tunnel which will also be used for diversion during construction of the dam. The tunnel is designed to pass 10,000 cfs under a head of $165 \mathrm{ft}$.

The purpose of the study is to determine flow characteristics within the intake structure, transition, horseshoe tunnel, and stilling basin, and to develop design revisions indicated by the tests to be necessary or desirable. In 1967 the studies vere expanded to include: (a) measurements of hydraulic downpull on the emergency closure gates; and (b) satisfactory clearances for installation of rubber side seals on the tainter valves. A 1:25-scale model simulated the intake structure, emergency closure and operating gates, transition section, horseshoe tunnel, stilling basin, and outlet channel. The intake structure gates, transition, and tunnel were molded of transparent plastic, whereas the stilling basin and outlet channel were constructed of waterproofed plywood. The intake structure was connected to a 7-ftdiam. steel pipe that simulated the pool upstream from the dam. A 1:l-scale model, in which 3-ft lengths of typical rubber side seals proposed for use on the operating valves at Howard Hanson Dam could be subjected to performance tests, was constructed of reinforced steel and operated under water pressures equal to heads of from 100 to $200 \mathrm{ft}$. Viewing windows in the test equipment permitted observation of the seal section, especially the end cross section, under test conditions.

(i) Completed.

(g) See (h).

(h) "Outlet Works and Stilling Basin for Howard Hanson Dam, Green River, Washington, " Div. Hydr. Lab. Tech. Rept. No. 88-1, Sept. 1966.

(6879) BONNEVILLE LOCK AND DAM, COLUMEIA RIVER MODEL STUDY OF NAVIGATION CHANNEL IMPROVEMENT.

(b) U.S. Army Engr. Dist., Portland.

(c) See (6878) above.

(e) The purpose of the investigation to study methods of improving navigation conditions in the approaches to Fonneville navigation lock. A 1:130-scale, fixed-bed model reproduced 
5.6 miles of the Columbia River at Bonneville Iram, existing structures of the project, and present features of the riverbed (survey made in summer and fall of 1958). Provision was made for accurate measurement of discharge, water-surface elevations, and velocities. A remote-controlled model of an ore ship or other typical seagoing vessel that would be likely to navigate the river upstream to The Dalles, Oreg., was used to assist in evaluating various improvement plans.

(f) Completed.

(g) See (h).

(h) "Navigation Channel Improvement at Bonneville Dam, Columbia River, Oregon and Washington," Div. Hydr. Lab. Tech. Rept. No. 100-1, May 1966.

U.S. ARMY ENGINEER DISTRICT, LOS ANGEIES, District Hydraulics Laboratory, Los Angeles, Calif.

(6880) LOS ANGELES COUNTY, CALTF., FLOOD CONTROL PROJECT, MODEL STUDY OF SAN GABRIEL RIVER IMPROVEMENT.

(b) U.S. Army Engr. Dist., Los Angeles.

(c) Director, District Hydraulics Lab., U.S. Army Engr. Dist., Los Angeles, Corps of Engrs.

(e) The reach of San Gabriel River improvement between Whittier Narrows Dam and Firestone Blvd., a distance of 34,450 ft, consists of a trapezoidal channel having an earth invert and 1-on-2 stone revetted side slopes. The channel base width ranges from 240 to $300 \mathrm{ft}$. Seven concrete drop structures ranging in height between 6 and 10 ft are placed at intervals, thus reducing the channel gradient and velocity of flow to prevent degradation of the streambed. The drop structures consist of a rectangular weir over which the flow passes onto a concrete stilling basin. The design discharge for this reach of channel varies from 13,500 to 19,000 cfs.

The purpose of the study is to verify the design and criteria used for those drop structures in the Upper San Gabriel River under hydrologic and topographic conditions applicable to this reach of channel. Previous study was reported as "Model Study of Upper San Gabriel River Improvement." Two models were used in the study: one a sectional model constructed in a glass-sided flume to an undistorted scale ratio of $1: 16$, consisting of a single drop structure; and the other a general model constructed to an undistorted scale ratio of 1:42. About 3000 ft of San Gabriel channel, which included two of the proposed drop structures, was reproduced. The trapezoidal cross section in this reach of channel has a base width of $300 \mathrm{ft}$ and depth and velocity of flow of about $8 \mathrm{ft}$ and $6 \mathrm{fps}$, respectively, for a discharge of 14,000 cfs. The drop structures were constructed of plywood and the river channel was molded of sand. Gravel was used to simulate the stone-revetted side slopes.

(f) Completed.

(g) $\operatorname{See}(\mathrm{h})$.

(h) "Drop Structure for San Gabriel River Improvement," Rept. No. 1-108, May 1966.
U.S. ARMY ENGINEER DISTRICT, ST. PAUL, CORPS OF ENGINEERS, 1217 U.S. Post Office and Customhouse, St. Paul, Minn. 55101

( 194) A STUDY OF METHODS USED IN MEASUREMENT AND ANALYSES OF SEDIMENT LOADS IN STREAMS. (See St. Anthony Falls Hydraulic Laboratory, page 112).

U.S. ARMY ENGINEER WATERWAYS EXPERTMENT STATION, CORPS OF ENGINEERS, P.0. BOX 631, Vicksburg, Miss. 39181 .

Inquiries concerning the following projects should be addressed to the Director, U.S. Army Engineer Waterways Experiment Station, Corps of Engineers.

\section{( 236) MISSISSIPPI RASIN MODEL.}

(b) Office, Chief of Engrs., Dept. of the Army.

(d) Experimental; for design.

(e) The project provides for construction and operation of a model of the Mississippi River watershed including the Missouri, Ohio, White, Arkansas, and Red Rivers and their principal tributaries. All existing and proposed floodcontrol reservoirs as well as levees, dikes, floodwalls, and other pertinent works are reproduced.

The model area comprises 200 acres, and measures $4500 \mathrm{ft}$ east and west, and $3900 \mathrm{ft}$ north and south. Completed construction consists of the Upper Mississippi River from Hannibal, Mo., to Baton Rouge, La.; the Missouri River from Sioux City, Iowa to the mouth; the Arkansas River from Blackburn Dam site, Okla., to the mouth; the Ohio River from Louisville, Ky., to the mouth; the Cumberland River from Old Hickory Dam, Tenn., to the mouth; the Tennessee River from Pickwick Dam to the mouth; and the Atchafalaya River to the Gulf of Mexico. The topography of the streams and floodplains is being reproduced to a horizontal scale of 1:2000 and vertical scale of 1:100. Water-surface elevations are measured by electrically operated stage devices with the recorders located in central control buildings. Streamflow is introduced and controlled by automatic instruments called inflow controllers. The purpose is to study the coordination of releases from reservoirs, investigate the effect of reservoir operation on flood stages, check the routing of project and other floods, establish and check levee grades, predict stages, and determine the effect of floodways on stage reduction. The extent of model operation each year is determined by the testing programs directed by the Mississippi Easin Model Board and Chief of Engineers and requested by Divisions and Districts that have operable sections on the model. The model was operated as an integrated unit for comprehensive (basinwide) tests. Tests were conducted of the three hypothetical floods-M 52-A, M 56, and M 58-AOR--from Memphis to the lower end of the model using inflows modified by those reservoirs (EN) scheduled for completion in the near future (approximately 1970), and with ultimate reservoirs (END) operated under both the approved regulation procedures and to full capacity to store flows that affect crest stages on the Lower Mississippi River. Tests were also 
conducted of the four historical floods-1937, 1943, 1945, and 1950--from Memphis to the lower end of the model using inflows as they occurred and with inflows modified by $\mathrm{EN}$ and END reservoirs operated under approved regulation procedures. In addition, tests of the 1943 flood were conducted on the model below Memphis using inflows modified by EN and END reservoirs operated to full capacity to store flows that affect crest stages on the Lower Mississippi River. Tests were conducted also for several U.S. Army Engineer Districts.

( 425) COMPREHENSTVE MODEL STUDY, DELAWARE RIVER, PENNSYLVANIA.

(b) U.S. Army Engr. District, Philadelphia.

(d) Experimental; for design.

(e) The project provides for a navigation channel about 96 miles long from Trenton, N.J., to Delaware Bay. As modified in 1954, the project provides a $40-\mathrm{ft}$ depth generally $800 \mathrm{ft}$ wide along the west side of the channel from the bay to the upper end of Philadelphia, a 40-ft-deep by 400-ft-wide channel between Philadelphia and the upper end of Newbold Island, thence a 35-ft-deep by 300-ft-wide channel to Trenton. Included in the project are provisions for constructing dikes and training walls for regulation of tidal flows, and dredging to provide turning basins and adequate anchorage at several points. The purpose is to develop and test plans for reduction of shoaling in several ranges of the navigation channel; and to determine the probable effect on the hydraulic and salinity regimen in the estuary that would result from modifications of channel depth and alignment and flow regulation.

The model is of the fixed-bed, silt-injection type with linear-scale ratios of $1: 1000$

horizontally and 1:100 vertically, and reproduces the entire tidal portion of Delaware River and Bay from the Capes to Trenton, including tidal portions of major tributaries. Tides and tidal currents are reproduced by automatic tide control mechanisms, and freshwater discharges of the Delaware River and significant tributaries are introduced by means of Van Leer weirs. Observed prototype salinities are reproduced in the Delaware Bay portion of the model, and provisions have been made for the injection of silt into the model, and for measuring silt deposits on the bed of the model. Studies of the dispersion of various contaminants are made by releasing permanent dyes and tracing their movement and concentrations with time after release and distance from the release points.

(g) The model was revised to include a widened navigation channel deepened to $-50 \mathrm{ft} \mathrm{mlw}$ between Philadelphia and the sea, dikes around all available spoil disposal areas, and enlarged and deepened anchorage areas. Tests to determine the effects of widening and deeping the navigation channel on tides, currents, and salinities throughout the estuary and on channel shoaling were completed. The model was restored to existing conditions, and tests were undertaken to determine the effects of an extensive dike scheme extending between Artificial Island and Philadelphia on tides, currents, salinities, and shoaling. A study of currents at the mouth of the Chesapeake and Delaware Canal was made in an attempt to relocate the canal entrance range to benefit navigation. Results of completed tests were analyzed, but no important conclusions were reached concerning the deepened channel and the spoil disposal areas. None of the entrance range alignments tested at the mouth of the Chesapeake and Delaware Canal would benefit navigation.

\section{( 993) CAVITATION RESEARCH.}

(b) Office, Chief of Engrs., Dept. of the Army.

(d) Experimental; applied research.

(e) This is a general study, by means of model tests, of the cavitation characteristics of various elements of hydraulic structures, and of the resistance of construction materials to cavitation damage. Further, the investigation includes a review of literature to evaluate the many variables that affect cavitation results.

The purpose is (a) To study cavitation characteristics of such elements as baffle piers, steps in stilling basins, spillway and conduit gate slots, and offset joints. This program will include tests to determine the conditions for dynamic similarity of the cavitation phenomenon. (b) To determine the resistance to cavitation damage of construction materials with particular emphasis on materials suitable for patching concrete. The cavitation characteristics of the various elements are investigated in a variable pressure water tunnnel with a 12-by 12-in. test section. Velocities in the test section can be varied from 8 to 35 fps. Resistance-todamage tests are conducted in apparatus in which cavitation is induced in velocities of 90 fps by an alignment change.

( 994 ) EFEECTS OF MODEL DISTORTION ON HYDRAULIC ELEMENTS

(b) Office, Chief of Engrs., Dept. of Army.

(d) Experimental; applied research.

(e) This is a general study of similitude relations in distorted models.

The purpose is to determine the hydraulic effects of various types and degrees of model scale distortion on velocity distribution and other hydraulic conditions, with the ultimate aim of establishing limits of permissible distortion for the various types of models. Tests have been conducted in a 5 -ft-wide masonry flume having a 90-degree bend of 10ft radius, with a straight approach channel $20 \mathrm{ft}$ long and exit channel $60 \mathrm{ft}$ long, in which can be reproduced a hypothetical stream to a horizontal scale of $1: 200$ and variable vertical scales to produce distortions up to 1:10. The flume was provided with three venturi meters of different sizes for the control of discharge and a tailgate for the control of tailwater elevation.

(f) Suspended. Work is expected to be resumed in 1968.

\section{( 938 ) WAVE FORCE ON EREAKWATERS.}

(b) Office, Chief of Engrs., Dept. of the Army.

(d) Experimental and theoretical; applied.

(e) This is a general investigation to (a) study existing literature and adapt or acquire testing equipment; (b) verify experimentally the clapotis pressure theory; (c) determine maximum shock-type pressures caused by breaking waves, and delineate the critical conditions necessary to create the extremely high shock pressures; and (d) determine the 
magnitude of pressures due to partially breaking waves.

The purpose is to conduct theoretical and experimental investigations of wave pressures and impact forces on vertical-wall and composite breakwaters from which the magnitude, duration, and location of forces on these structures, caused by breaking waves, can be determined with sufficient accuracy to ensure the design of safe and economical structures. A 3- by 3- by 6-ft steel tank was used for the experiments on shock pressures caused by the impact of an accelerated plate with a water body. Plastic, aluminum, and steel plates of different masses were dropped into water in the tank and the shock pressures developed were measured and recorded electrically. A 2- by 5.5 - by 140-ft concrete wave flume will also be used for conducting experiments on shock pressures and total impact forces caused by waves breaking against vertical-wall breakwaters.

(g) A report on wave pressures on seawalls and breakwaters was prepared. The report included (a) methods for selection of design waves reflected by waves breaking against a structure, (b) method for selection of wave reflection coefficient of a structure (c) equations developed to the second order of approximation, for calculating wave pressures on seawalls and breakwaters caused by waves totally or partially relfected by a structure, (d) discussion of formulas for calculating shock pressures caused by waves breaking against seawalls and breakwaters, and (e) presentation of analytical aspects of a shock pressure formula developed at wES. A draft of a report on shock pressures resulting from the impact between solids and liquids was prepared. This report included a critical review of different approaches suggested for evaluating shock pressures, results of basic experiments on shock pressure conducted at WES indicating validity of WES formula, and recommendations for future research.

\section{( 999) STABILITY OF RUBBLE-MOUND BREAKWATERS.}

(b) Office, Chief of Engrs., Dept. of the Army.

(d) Experimental; applied research.

(e) A general study of rubble-mound breakwaters to determine weight, specific weight, and shape of armor units required for stability under wave attack. The purpose of the study is to develop design procedures and formulas, supported by experimental data, from which the design of safe and economical rubble-mound breakwaters can be determined. In addition to quarrystone, the investigation includes tests of tetrapods, tetrahedrons, tribars, quadripods, modified cubes, and other specially molded armor units. Tests are being conducted in a 5- by 4- by 119-ft wave flume. Preparation of the first draft of a final report describing the results of tests conducted on breakwater trunks constructed of quarrystones, tetrapods, tetrahedrons, quadripods, modified cubes, hexapods, and tribars using nonbreaking waves in deep water was completed. This report also described the results of tests on breakwater heads constructed of quarrystones, tribars, and quadripods using nonbreaking waves in deep water. The results of these stability tests are represented with good accuracy by the formula: $w_{r}=\frac{\gamma_{r} H^{3}}{K_{\Delta}\left(s_{r}-1\right)^{3} \cot \alpha}$

The value of the experimental coefficient $\mathrm{K}_{\Delta}$ is dependent primarily upon the shape of the armor unit, number of layers of armor units, and the method of placement of armor units. For similar conditions, breakwater heads are less stable than breakwater trunks. Flume tests to determine the limiting breaking and nonbreaking waves on rubble-mound breakwaters were completed. Tests were conducted on breakwaters constructed of two layers of random placed quarrystones and tribars. Side slopes tested were $1: 1-1 / 2$ and $1: 3$. The bottom slopes were $1: 10,1: 50$, and flat. Water depths at the toes of the test sections ranged from 0.5 to $1.5 \mathrm{ft}$, and the relative depths used were increased in increments of $0.05 \mathrm{ft}$ from 0.05 to $0.5 \mathrm{ft}$. The wave steepnesses (H/L) of breaking and nonbreaking waves were plotted against relative depths $(\mathrm{d} / \mathrm{L})$. The plotted data showed the influence of relative depth, breakwater slope, bottom slope, and shape of armor unit on the wave steepnesses of both breaking and nonbreaking waves. Analysis of test data showed that wave steepness was influenced more by relative depth and bottom slope than by the slope of the breakwater face and the porosity (shape of armor unit and manner of placement) of the armor layer.

( 1002) EFFECTS OF SCALE AND OPERATING TECHNIQUES ON HARBOR WAVE ACTION AND BREAKWATER MODELS.

(b) Office, Chief of Engrs., Dept. of the Army.

(d) Experimental; applied research.

(e) A general study is being conducted to determine effects of various model scales and distortion on wave characteristics in harbor and breakwater stability models. The effects on test results of various model-testing techniques are also being investigated. The purpose is to obtain information which will allow more accurate determination of optimum scales for wave models, and the effects of different scales and operating techniques on the accuracy of model results.

(g) Screen filter tests were conducted in a 1 - by 1.5 - by 85 -ft steel wave flume in which waves are generated by a hinged-plate type wave generator and are measured and recorded electrically. Further tests to determine the design criteria for wave filters to be used in harbor models and wave flumes to prevent unwanted reflection from model boundaries and wave-making apparatus were conducted. The final draft of a report, "Wave Damping Effects of Screens," describing the use and effectiveness of wire screens as wave filters was completed, and was being prepared for publication. Preparation of the first draft of another report dealing with wave filters, "The Damping Effects of Permeable Materials," was in progress.

\section{(1004) INSTRUMENTATION.}

(b) Office, Chief of Engrs., Dept. of the Army.

(d) Experimental; development.

(e) To develop various types of measurement and control equipment for use in hydraulic models and in the field.

(g) Development of a hawser stress transducer, a 
spherical-head turbulence meter, and a waterlevel indicator for tests of prototype locks was continued. A study to determine the feasibility of using low-range pressure transducers to measure water-surface elevations was continued.

(1467) DEVELOPMENT OF HYDRAULIC DESIGN CRITERIA.

(b) Office, Chief of Engrs., Dept. of the Army.

(d) Analytical; for design.

(e) The purpose is to analyze hydraulic data, theories, and procedures, to develop design criteria therefrom, and to disseminate this information in the form of Hydraulic Design Criteria to insure adequate capacity, economy of design and construction, and safe and satisfactory operation of the large hydraulic structures being designed, built, and operated by the Corps of Engineers.

(g) A study of resistance coefficients for unlined tunnels resulted in a design chart relating design diameter $\mathrm{D}$, tunnel overbreak $\mathrm{K}$, and the Darcy resistance factor $f$. A study of the hydraulic jump resulted in several design charts relating the characteristics of the jump, including the undular jump occurring with Froude numbers less than 1.7. The study showed that application of the solitary wave theory to undular jumps results in a first wave height appreciably greater than that obtained with the classical jump-height equation.

(1986) INVESTIGATION OF SALINITY INTRUSION AND RELATED PHENOMENA.

(b) Committee on Tidal Hydraulics, Corps of Engrs.

(d) Experimental; applied research.

(e) The project consists of the following three broad phases: (a) analysis of prototype data to define the range of conditions for which investigations appear desirable; (b) flume tests to study the effects of the various factors involved; and (c) analytical studies aimed at establishment of fundamental laws describing the phenomena involved, and preparation of the data for use in application to specific prototype problems. Dr. Donald Harleman, consultant, has been engaged to assist in phase (c) above. The purpose of the study is to determine the effects of physical and hydraulic features of estuaries such as tidal prism, tidal range, fresh-water discharge, channel depth, channel width, etc., on the extent of salinity intrusion, the nature of salinity intrusion, the magnitudes and durations of current velocities, and other factors considered essential to proper solution of estaurine problems encountered by the Corps of Engineers.

The flume studies under phase (b) above are being carried out in a transparent flume 327 $\mathrm{ft}$ long, $1.5 \mathrm{ft}$ deep, and $0.75 \mathrm{ft}$ wide. One end of the flume is connected to a tidal basin $25 \mathrm{ft}$ square and $5 \mathrm{ft}$ deep, which is equipped with a tide generator capable of producing tides of any desired range, period, or other characteristic. The opposite end of the flume is connected to a circular headbay equipped with weirs for measuring and introducing fresh-water inflows. Salt water to fill the tidal basin and flume is supplied from an adjacent underground sump equipped with the necessary appurtenances to $\mathrm{mix}$ salt and fresh water and control the salinity of the mixture. The tidal basin is equipped with skimming weirs to maintain a constant basin salinity during tests. Current velocities are measured in the flume by timing the travel of indicators over measured ranges, and salinity measurements are made either by withdrawing samples for chemical titration or by means of a recording salinity meter which operates on the electrical conductivity principle.

(g) A tentative detailed program for study of the movement and deposition of sediments, based on a general program prepared by Dr. Harleman, was prepared. The flume was modified as necessary to permit tests to define the effects of fresh water entering a saltwater canal connecting two tidal seas. This work was being conducted for the Nuclear Cratering Group, with tests being initiated late in 1967.

(h) "Two-Dimensional Aspects of Salinity Intrusion in Estuaries: Analysis of Salinity and Velocity Distributions," Tech. Bull. No. 13, June 1967.

(1987) RIPRAP PROTECTION AT HYDRAULIC STRUCTURES.

(b) Office, Chief of Engrs., Dept. of the Army.

(d) Experimental; applied research.

(e) The erosion characteristics of various sizes of riprap and gravel material are being studied with a view to securing adequate protection at minimum cost. Measurements of velocity and turbulence at which movement of material begins are being made.

The purpose is to develop design criteria for riprap at hydraulic structures.

(1988) WATER TEMPERATURE EFFECTS ON BED FORMS AND ROUGHNESS.

(b) Office, Chief of Engrs., Dept. of the Army .

(d) Experimental; applied research.

(e) It has long been known that water temperature variations caused marked variations in the nature and rate of bed movement, which are of major significance in movable-bed model studies. The onset of cold weather produces excessive riffling of bed surfaces, resulting in sharp increases in roughness values and changes in volumes of material transported. The investigation of this phenomenon is being conducted in existing laboratory flumes, in which water temperatures can be varied to simulate normally experienced summer and winter temperatures.

The purpose is to determine the effects of water temperature on streambed forms and bed roughness of various types of bed material.

(g) Testing with fine sand bed material completed; testing with a coarse sand is in progress.

(2681) SCALE-EFFECT TESTS OF RUBBLE BREAKWATERS.

(b) Cooperative with Coastal Engrg. Research Ctr.; for Office, Chief of Engrs.

(d) Experimental; applied research.

(e) The purpose is to investigate the effects of model scale on the results of experimentally determined criteria for design of rubble-mound breakwaters.

(g) Stability tests were made of a breakwater slope of 1 on $1-1 / 2$ using wave periods of $2.61,3.75$, 7.87 , and $11.33 \mathrm{sec}$. Tests in the CERC wave flume ( 15 by 20 by $635 \mathrm{ft}$ ) were conducted using a linear scale of 7.5 to 1 based on the tests conducted in the WES 5- by 4 - by 117 -ft wave flume. Additional stability tests were conducted in the WES 5- by 4- by 117 -ft wave flume using linear scales of 0.5 to 1 , and 1 to 1 , and following the same testing procedure used in the tests conducted in the CERC wave 
flume. Therefore, data on the stability of rubble-mound breakwaters were available for three different linear scales, 0.5 to 1 , 1 to 1 , and 7.5 to 1 . Test data from the CERC wave flume were correlated with data from the WES flume.

(h) Preparation of final report in progress.

(2678) MCALPINE LOCKS AND DAM, OHIO RIVER, MODEL STUDY OF NAVIGATION CONDITIONS.

(b) U.S. Army Engr. Dist., Louisville.

(e) The purpose of the study is to (a) determine the effect of composition and location of dam on water-surface elevations and currents within the upper pool; (b) study the effect of location, size, and alignment of a new approach canal on navigation and surges in the lock approach; (c) investigate navigation conditions in the lower approach as affected by flow through dam, powerhouse, and lockemptying systems; (d) determine the effect of each design on lock filling and emptying and on operation of the powerhouse; and (e) develop such design modifications as might be necessary to eliminate conditions unfavorable to navigation. A 1:120-scale, fixed-bed model was used for the investigation. The model reproduced the reach of the Ohio River from about mile 602 to about mile 608 below Pittsburgh, $\mathrm{Pa}$., including adjacent overbank areas to an elevation of approximately $445 \mathrm{ft} \mathrm{msl}$, the locks and dam structures, and all bridges and other structures that might affect flow conditions.

(f) Completed.

(g) See (h).

(h) "Navigation Conditions at McAlpine Locks and Dam, Ohio River; Hydraulic Model Investigation," Rept. TR 2-749, Nov. 1966.

(3243) LOCKS AND DAM NO. 4 (RECONSTRUCTED), MONONGAHELA RIVER, MODEL STUDY OF NAVIGATION CONDITIONS.

(b) U.S. Army Engr. Dist., Pittsburgh.

(e) The purpose of the study is to determine the effect of the proposed reconstructed dam on flow conditions in the lock approaches with the existing and ultimate locks and for the development of modifications which might be required to provide satisfactory navigation conditions. A 1:120-scale, fixed-bed, comprehensive model reproduced about 2.5 miles of the Monongahela River and the locks and dam structures.

(f) Completed.

(g) See $(h)$.

(h) "Navigation Conditions at Locks and Dam No. 4, Monongahela River, Pennsylvania; Hydraulic Model Investigation," Rept. TR 2-736, Aug. .1966.

(3590) EAST PASSAGE, NARRAGANSETT BAY, R.I., MODEL STUDY OF EFFECTS OF HURRICANE EARRIER ON NAVIGATION CONDITIONS.

(b) U.S. Army, Corps of Engrs., New England Div.

(e) A barrier across East Passage, Narragansett Bay, has been proposed to limit the quantity of water entering the bay from hurricane surges.

The purpose of the study is to examine ship navigation conditions with respect to barrier location and its navigation opening under current, wave, and wind conditions created by astronomical tides and hurricane surges. Also, to investigate the discharge characteristics of the navigation opening.
A 1:150-scale model of East Passage was used in the study of navigation conditions.

Currents, wave, and wind effects were simulated. A self-propelled, radio-controlled, model aircraft carrier, constructed dynamically similar to its prototype, was used in the tests. In the study of the discharge characteristics of the navigation opening, two section models, reproducing the barrier to scales of $1: 50$ and $1: 150$, were used to determine the effects of approach depth, roughness of the barrier, model scale, and weir design on the discharge characteristics. In addition, the 1:150-scale, three-dimensional model was used to determine the discharge characteristics of two weir plans.

(f) Completed.

(g) $\mathrm{see}(\mathrm{h})$.

(h) "Effects of Hurricane Barrier on Navigation Conditions in East Passage, Narraganset Bay, Rhode Island; Hydraulic Model Investigation," Rept. TR 2-754, Jan. 1967.

(3903) HILO HARBOR, HAWAII, MODEL STUDY OF TSUNAMIS AND NAVIGATION IMPROVEMENTS.

(b) U.S. Army Engr. District, Honolulu.

(e) Hilo Harbor is on the northeast coast of the Island of Hawaii, about 135 nautical miles Southeast of Honolulu. The project provides for an entrance $35 \mathrm{ft}$ deep; a harbor basin $1400 \mathrm{ft}$ wide, $2300 \mathrm{ft}$ long, and $35 \mathrm{ft}$ deep; combined breakwaters and seawalls on the east and west sides of the harbor, 10,570 and 4000 ft long, respectively; and a land dike $6600 \mathrm{ft}$ long, to provide protection against tsunamis and high seas.

Primary purposes of the study were to determine the technical feasibility of proposed tsunami control works for Hilo and to establish the relative degrees of protection afforded by different barrier plans.

The model was about $62 \mathrm{ft}$ wide and $92 \mathrm{ft}$ long with vertical scale of $1: 200$ and horizontal scale of $1: 600$, and was contoured from $200 \mathrm{ft}$ above to $300 \mathrm{ft}$ below mean lower low water. This model area of $2286 \mathrm{sq} \mathrm{ft}$ was comprised of 12. by 12-ft sections with jacked supports to compensate for differential settlement of the foundation, and also included a 1809-sq-ft concrete slab in the wave generator pit. The wave generator was comprised of eight pneumatic chambers, each being 6 by 8 by $10 \mathrm{ft}$. A programmer operated the generator to simulate tsunami waves.

(f) Completed.

(g) The tests showed that tsunami barriers in Hilo Harbor are technically feasible and that effective protection of the harbor and city can be achieved only with barriers that are continuous, except for a necessary navigation opening; no practical means were found to control tsunamis by a series of short reflectors of wave energy traps.

(h) "Study of Proposed Barrier Plans for the Protection of the City of Hilo and Hilo Harbor, Hawaii," TR 1, 1967.

(3906) GARRISON AND OAHE DAMS, MISSOUR RIVER, N. DAK. AIND S. DAK., POWER-PLANT TRANSIENTS TESTS.

(b) U.S. Army Engr. District, Omaha.

(d) Field studies; applied research.

(e) The purpose is to evaluate results of a comprehensive digital computer study made by the Missouri River Division, Omaha District, and Massachusetts Institute of Technology and to 
determine extent operation corresponds to design, in order to develop a solution of the entire problem of power-plant transients, with primary emphasis on governing stability.

Hydraulic prototype measurements of power-plant transients for different plant loadings, and instantaneous pressure values at a number of locations in the power tunnel, the surge tank system, turbine scroll case, and draft tube were obtained simultaneously with instantaneous values of tunnel flow velocity, reservoir and tailwater elevations, turbine speed and gate opening, power output, and other elements (including governor system). Pressure and water-level measurements were made with electrical pressure transducers, velocities were measured with pressure transducers mounted in probes projecting into the flow and connected to pitot-static tubes on cross struts in the penstock, and mechanical and electrical values were obtained with appropriate transducers. Measurements were recorded on about 90 channels of oscillograph and magnetic tape recorders, and digitized for use in the digital computer analyses by the Omaha District and Massachusetts Institute of Technology.

(f) Testing completed. Final report on test operations in progress.

(3907) SHOALING PROCESSES.

(b) Office, Chief of Engrs., Dept. of the Army.

(d) Experimental; for design.

(e) The annual cost to the Federal Government of maintaining navigable channels in tidal waterways is estimated to be of the order of $\$ 60,000,000$. The Committee on Tidal Hydraulics has concluded that a thorough study of shoaling processes in tidal waterways would lead to improvements in channel design, dredging, and spoiling practices, and other maintenance techniques which would reduce this large expenditure. The Committee concludes that the following program of research is essential in arriving at the objective of reducing maintenance cost: (a) flume studies to determine the basic laws involved in the movement and deposition of muddy sediments; (b) flume studies to determine effects of repetitive scour and deposition on sedimentation; (c) the development of techniques for using radioactive tracers for observing the movement and deposition of sediments in nature; (d) the development of a simple and accurate instrument for in-place measurement of turbidity; (e) a study of the physical, chemical, and hydraulic factors involved in the stabilization of deposits in navigable channels; (f) determination of the effects of flocculation on shoaling; ( $\mathrm{g}$ ) prototype studies aimed at correlation of sedimentation phenomena in tidal waterways with physical, chemical, hydraulic, salinity, and other significant factors; and (h) classification of the sediments which consitute all major repetitive shoals in tidal waterways.

(g) Item (a) above has been completed under terms of a contract between the University of California and the San Francisco District, and all pertinent reports have been published; item (c) has been completed under terms of a contract between the University of California and WES; under item ( $f$ ) plans were developed for a field study of flocculation phenomena in Savannah Harbor, agreements were reached as to participation by the several $\mathrm{CE}$ offices involved, and instrumentation required for the study was constructed and/or obtained on loan.

(h) "A Study of Rheological Properties of Estuarine Sediments," Tech. Bull. No. 7, Committe on Tidal Hydraulics.

\section{(3908) ARKANSAS RIVER NAVIGATION MODEL.}

(b) U.S. Army Engr. District, Little Rock.

(e) The purpose is to study flow conditions in the lower Arkansas and White Rivers to determine: (a) the effects on navigation and flood flows of the Arkansas-White, Sawmill Bend, and Avenue Ianding Cutoffs both individually and collectively; (b) the most favorable location of the Arkansas River entrance to the navigation canal and of Dam 2; (c) the remedial works which might be needed to eliminate undesirable navigation conditions at the Arkansas River entrance to the canal; (d) the adequacy of the proposed flood-control plan; and (e) the need for special studies.

Tests were conducted on a fixed-bed model reproducing to scales of 1:600 horizontally and 1:100 vertically about 33 miles of the Mississippi River near the mouths of the White and Arkansas Rivers, 57 miles of the lower Arkansas River, 12 miles of the lower White River, and the major portion of the WhiteArkansas River backwater area.

(f) Completed.

(g) Described in (h).

(h) "Arkansas River Navigation Entrance; Hydraulic Model Investigation," TR 2-795, Sept. 1967.

(3909) HANNIBAL (FORMERLY OPOSSUM CREEK) LOCKS AND DAM, OHIO RIVER - GENERAI MODEL STUDY.

(b) U.S. Army Engr. District, Pittsburgh.

(e) The Hannibal Creek Lock and Dam to be located at about mile 126 on the Ohio River will involve construction of a nonnavigable-type dam and twin parallel locks. The riverward lock will have clear dimensions of 110 by $1200 \mathrm{ft}$ and the auxiliary lock, 110 by $600 \mathrm{ft}$. The locks will provide a maximum lift of about $2 \mathrm{ft}$. The purpose of the study is to study navigation conditions in the approaches to the locks, determine suitability of the selected site, and develop modifications required to overcome any undesirable conditions found.

Tests were conducted in a 1:120, fixed-bed, comprehensive model reproducint about 4 miles of the Ohio River and the lock and dam structures.

(f) Completed.

(g) See (h).

(h) "Navigation Conditions at Hannibal Locks and Dam, Ohio River, Ohio and West Virginia; Hydraulic Model Investigation, "TR 2-796, Sept. 1967.

(3911) MATAGORDA SHIP CHANNEL, TEX., MODEL STUDY.

(b) U.S. Army Engr. Dist., Galveston.

(e) The Matagorda Ship Channel project calls for a channel $38 \mathrm{ft}$ deep at $\mathrm{mlt}$ by $300 \mathrm{ft}$ wide from the Gulf into Matagorda Bay, a channel $36 \mathrm{ft}$ deep at mlt by $200 \mathrm{ft}$ wide through Matagorda and Lavaca Bays to Point Comfort, Tex., and includes provisions for jetties extending into the Gulf.

The purpose of the study if to determine (a) the best location for the entrance channel; (b) the best route for the channel from the entrance to Point Comfort; (c) design of protective works for the channel; and (d) the effects of the deep-draft navigation 
channel on the hydraulic and salinity regimens of the bay system.

The fixed-bed model, constructed to scale ratios of $1: 1000$ horizontally and $1: 100$ vertically, reproduced about 800 square miles of prototype area, including all of Matagorda Bay, part of the connecting bay system, and a portion of the Gulf of Mexico adjacent to Pass Cavallo. Tides and tidal currents were reproduced by one primary tide generator and one secondary tide generator, and freshwater discharges of tributaries, together with the rainfall over the area, were introduced by means of weirs and flowmeters. Salt water was used in the model gulf to reproduce the prototype salinity regimen, and provisions were made for the injection of silt in the model for measurements of deposits on the bed of the model.

(f) Completed.

(g) See $(h)$.

(h) "Matagorda Ship Channel Model Study, Matagorda Bay; Hydraulic Model Investigation," Rept. TR 2-711, Jan. 1966.

(3912) GALVESTON BAY (HARBOR), TEXAS, MODEL STUDY.

(b) U.S. Army Engr. District, Galveston.

(e) Connecting Galveston Bay and the Gulf of Mexico is a jettied entrance channel, 36 to 38 ft deep, $800 \mathrm{ft}$ wide, and about 7 miles long. The north and south sides of the channel are protected by rock jetties about 5 and 7 miles long, respectively. Annual shoaling rates are of the order of $600,000 \mathrm{cu}$ yd on the inner bar and a like amount on the outer bar. The scour area between the channel and the central portion of the north jetty has deepened from about $-30 \mathrm{ft}$ in 1916 to $-40 \mathrm{ft}$ or more at the present time, and since old surveys indicate this jetty to be founded in depths of less than $-20 \mathrm{ft}$, there seems to be grave danger that the jetty may be undermined and partially destroyed in the near future.

The purpose of this study is to determine: (a) plans for relocation and stabilization of the jetty channel on an alignment and depth suitable for navigation of supertankers; (b) means of protecting the north jetty from undermining action of tidal currents; (c) shoaling characteristics of the relocated and deepened jetty (inner bar) channel and plans for minimizing shoaling; and (d) shoaling characteristics of the deepened outer bar channel. A movable-bed model, with scale ratios of l: 500 horizontally and $1: 100$ vertically, reproduces about 174.5 square miles of prototype area, including a small portion of Galveston Bay and a portion of the Gulf of Mexico extending 8 miles north of the north jetty, $6-1 / 2$ miles south of the south jetty, and offshore to about the 50-ft contour of depth. Tides, tidal currents, littoral currents, and wave action in the Gulf of Mexico are being reproduced.

(f) Tests completed.

( $g$ ) The results of channel realignment tests indicated that the plan 2 realignment was the most favorable of those tested in relation to both maintenance dredging cost and ease of navigation. The results of jetty modification tests indicated that the outer $3000 \mathrm{ft}$ of the north jetty can be allowed to deteriorate to about elevation -12 ft mlt without detrimental effects on the shoaling characteristics of the entrance. The results of spur dike tests showed that total shoaling would be reduced about 23 percent by locating a spur dike normal to the north jetty, $3000 \mathrm{ft}$ long with a crest elevation of $-12 \mathrm{ft} \mathrm{mlt}$. Closing the Galveston Harbor channel would increse total shoaling by about 60 percent. Total shoaling would be reduced about 15 percent by reducing the width of the plan 2 channel from $800 \mathrm{ft}$ to $600 \mathrm{ft}$. The results of proposed deepwater anchorage area tests indicated that anchorage area $B$, located on the north side of the inner bar channel, would require annual maintenance dredging of about 250,000 cu yd whereas the addition of area $\mathrm{C}$ would increase total dredging to 1,463,000 cu yd (anchorage area $\mathrm{C}$ is located on the south side of the channel). The tracer tests indicated that waves from south of about $545^{\circ} \mathrm{E}$ cause bottom sediments to move from the northeasterly one-third of the disposal area toward and into the outer shoal area.

(3914) MCALPINE LOCKS, OHIO RIVER, MODEL STUDY FOR MODERNIZATION OF EXISTING LOCK.

(b) U.S. Army Engr. District, Louisville.

(e) Modernization of the filling and emptying system of the 100-ft-wide by 600-ft-long existing McAlpine Lock is part of the McAlpine Locks and Dam project. The existing lock has a 37-ft lift and is filled and emptied through sidewall ports in both walls. Intake manifolds located in both walls immediately upstream from upper miter gates serve circular culverts, each discharging into the chamber through 10 filling ports. Circular emptying culverts, separate from the filling culverts, receive water through 10 emptying ports in each wall and discharge into the lower lock approach through manifolds located just downstream from the lower miter gates. Because of hydraulic conditions the present system is not used to fill the lock in the fastest possible manner.

The purpose of the study is to develop feasible modifications which will improve prototype performance. Tests were conducted in a 1:25 model which reproduced the filling and emptying system.

(f) Completed.

(g) Tests demonstrated that major improvement in performance of the filling and emptying system would result from connecting the filling and emptying culverts and plugging certain of the ports in the existing filling system.

(h) "Modernization of Filling and Emptying System, Ixisting McAlpine Lock (old No. 4l), Ohio River, Louisville, Kentucky; Hydraulic Investigation," TR 2-778, May 1967.

(3915) GERING VALLEY PROJECT, GERING VALIEY, NEER., MODEL STUDY OF DROP STRUCTURE.

(b) U.S. Army Engr. District, Omaha.

(e) The Gering Valley project in western Nebraska will consist of low rectangular drop structures designed for alluvial channels, a series of which will be located in the main Gering drain as well as in the tributaries. Structure widths will vary from 6 to $33 \mathrm{ft}$ and lengths from 16 to $47 \mathrm{ft}$, with drop heights of 5 and $10 \mathrm{ft}$.

The purpose of the study is to examine the hydraulic performance of the drop structures with particular interest in basin performance, discharge capacity, and the extent and size of riprap required upstream and downstream of structure. 
A 1:12-scale model and a 1:35-scale model were used in the investigation. Each model reproduced a typical drop structure, adjacent overbank areas, and about 300 ft of the approach and exit areas. The smaller scale model permitted more rapid modifications of the structure.

(f) Completed.

(g) Families of curves were developed that permitted drop structure design based on drop height and discharge conditions. Design criteria based on investigation of structures having a 5-ft drop height were applicable to structures with drop heights up to $10 \mathrm{ft}$. A satisfactory plan for placement of riprap material in the vicinity of the structure was developed.

(h) "Drop Structure for Gering Valley Project, Scottsbluff County, Nebraska; Hydraulic Model Investigation," TR 2-760, Feb. 1967.

(3917) GENERAL SPILLWAY MODEL TESTS.

(b) Office, Chief of Engrs., Dept. of the Army.

(e) The purpose is (a) To study hydraulic characteristics of spillway crest shapes with heads greater than the design head, including the effects of approach depth, crest piers and gates, elevation of downstream floor of spillway, and of downstream slope of spillway, and (b) to establish general rules for design of roller-type energy dissipators. A flume $70 \mathrm{ft}$ long by $6 \mathrm{ft}$ wide and $6 \mathrm{ft}$ high comprises the test facility. Section models designed for study of particular elements of spillways are installed in the test flume.

(4382) HYDRAULIC PROTOTYPE TESTS.

(b) Office, Chief of Engrs., Dept. of the Army.

(e) Assistance is given to Districts in planning and making hydraulic field tests, including: Planning and design of test facilities, making available personnel and equipment for tests, and analyzing data and preparing reports. The purpose is to coordinate the hydraulic prototype testing program of the corps in order to ensure complete coverage of needed testing, prevent unnecessary duplication of testing facilities and tests, recommend instrument installations at projects where physical and hydraulic conditions will be suitable for obtaining data, and investigate hydraulic performance.

(g) Assistance in planning prototype instrumentation and tests was furnished to 12 District and for 15 projects. Other hydraulic prototype tests related to and conducted partly under this study are described in detail under: $(3906),(5643),(5243),(6850),(6035),(6032)$.

(4383) TURTLE CREEK CHANNEI IMPROVEMENT MODEL STUDY.

(b) U.S. Army Engr. District, Pittsburgh.

(e) The purpose of the study is to check computed head losses and determine the adequacy of the proposed alignment and channel cross section; to determine the effects of low bridges, piers, and alutments on flow conditions; and to evaluate various modifications to the proposed improvement plan. The model reproduced the lower $7800 \mathrm{ft}$ of the Turtle Creek channel to a scale of 1:50. Provisions were made to test the lower $1500 \mathrm{ft}$ of the creek in existing and improved conditions.

(i) Completed.

(g) See $\left(r_{1}\right)$.

(h) "Turtle Creek, Pennsylvania, Channel Improve- ment; Hydraulic Model Investigation," TR 2-765, March 1967.

(4385) BELIEVILIE LOCKS AND DAM, OHIO RIVER, GENERAL MODEL STUDY.

(b) U.S. Army Engr. Dist., Huntington.

(e) The purpose of the investigation is to study the adequacy of the proposed design, to determine the best location for the locks under various flow conditions, and to develop measures to overcome or minimize the effects of any adverse conditions.

A 1:120-scale, fixed-bed model, reproducing about 3 miles of the river, adjacent overbank area, and the locks and dam structures, was used for the investigation. The model included sufficient piezometer-type gages to permit an accurate study of the effects of the installation on stages at the dam, at the ends of the lock walls, and upstream and downstream from the ends of the walls.

(f) Completed.

(g) $\operatorname{See}(h)$.

(h) "Navigation Conditions at Belleville Locks and Dam, Ohio River; Hydraulic Model Investigation," Rept. TR 2-738, Sept. 1966.

(4386) HOLT LOCK AND DAM, WARRIOR RIVER, ALA., GENERAI MODEI STUDIES.

(b) U.S. Army Engr. Dist., Mobile.

(e) The purpose is to study navigation conditions in the lock approaches, performance of the spillway, the feasibility of lock culvert intakes and outlets on the river side of the riverward lock wall, and flows through the first and second construction stage diversion channels.

Tests were conducted on a 1:80-scale model reproducing the structures, 4800 ft of the approach channel, and 4800 ft of the exit channel, and a 1:36-scale section model reproducing one full bay and two adjacent half bays of the spillway and stilling basin.

(f) Completed.

(g) See $(h)$.

(h) "Spillway and Navigation Conditions, Holt Iock and Dam, Warrior River, Alabama; Hydraulic Model Investigation," Rept. TR 2-745, Oct. 1966.

(4390) CANNELTON LOCKS AND DAM, OHIO RIVER, IND. AND KY., MODEL STUDIES.

(b) U.S. Army Engr. District, Louisville.

(e) The project involves the construction of a nonnavigable dam approximately 721 miles below Pittsburg, $\mathrm{Pa}$., with parallel locks, the main lock to have usable dimensions of 1200 by 110 ft and the auxiliary lock to be 600 by $110 \mathrm{ft}$. The dam will consist of twelve 100-ft-wide gate bays and will replace three existing low-lift locks and dams. The locks and dams will have a lift of $26 \mathrm{ft}$, creating a pool up to the McAlpine Locks and Dam at Louisville, Ky. The purpose of the study is to investigate navigation conditions in the lock approaches and effects of the structures on flood stages; to obtain data for development of rating curves; and to determine the effect of powerhouse installation on flow and navigation conditions.

A 1:120-scale model reproduces about 9 miles of the river and sufficient overbank areas to permit the reproduction and study of flows up to the maximum of record (1937 flood). The model includes the locks and dam structures with provisions for the installation of 
powerhouse facilities. Also, 20 piezometertype gages are provided to permit study of swellheads as affected by the locks and dam and the powerhouse facilities.

(

(4391) LOCK AND DAM NO. 3, ARKANSAS RIVER, ARK., MODEL STUDY OF NAVIGATION CONDITIONS.

(b) U.S. Army Engr. Dist., Little Rock.

(e) The purpose is to determine the suitability of the proposed site for the lock and dam structure, the effects of proposed regulating works in the vicinity including a cutoff, and modifications which might be required to provide adequate channel depths in the lock approaches and safe navigation conditions with minimum maintenance. A movable-bed model reproducing about 13 miles of the Arkansas River and adjacent overbank area, constructed to a scale of 1:120 horizontally and 1:80 vertically, was used.

(f) Tests completed; report in progress.

(g) The investigation has resulted in the development of channel alignment and regulating structures required for the development of adequate depths and satisfactory navigation conditions in the reaches upstream and downstream of the lock and in the lock approaches and conditions which can be expected with cofferdams for various stages of construction. Results also indicated that shoaling in the lower lock approach can be reduced by selected operation of the lock gates and the installation of training dikes in the channel upstream of the dam.

\section{(4396) COLUMBIA RIVER ESTUARY, MODEL STUDY.}

(b) U.S. Army Engr. Dist., Portland.

(e) The existing authorized project in Columbia River provides for a channel 48 ft deep and one-half mile wide from the entrance to about river mile 3.0 , and thence $40 \mathrm{ft}$ deep and 600 ft wide to Portland, Oreg. The north and south jetties at the river mouth are 2.4 and 6.6 miles long, respectively. Jetty $A$, inside north jetty, is 1.1 miles long.

To determine the need for and to develop optimum plans for rehabilitation of existing jetties and proposed additional improvements; to investigate future shoaling developments in the entrance channel and in the reach between the entrance and Oak Point, and means of alleviating such shoaling; and to investigate existing and proposed spoil-disposal areas to establish locations that will not permit movement of material back to the channel. The model reproduces the lower 52 miles of the Columbia River and pertinent off-shore areas to linear scales of 1:500 horizontally and 1:100 vertically. Tides and tidal currents, density currents, waves, and other phenomena significant to the movement and deposition of sediments are reproduced and studied. All portions of the model have been, heretofore, of the fixed-bed type. During the year the entrance and surrounding area were converted to the movable-bed type.

(g) Two separate checks of tidal prism were made for conditions of mean tide and spring tide, and it was concluded that the results obtained were directly applicable to the prototype. Construction of Jetty $B$ would reduce shoaling in the entrance area by about 28 percent; however, other data indicated that more detailed studies (movable bed) should be made to determine optimum design of Jetty $B$. The closure of Sand Island gap affects tides in Baker Bay very little except to delay the time of low water about $1 / 2 \mathrm{hr}$. All flow through the gap would be diverted around the east end of Sand Island, increasing velocities in that area as much as 4.0 fps. The effects of the rehabilitation of Jetty A would be slight and of a local nature and would not significantly affect the chacteristics of the entrance as a whole. It was also found that the relocation of the entrance channel would not significantly reduce the requirements of maintenance, except for a possible short-term reduction of undetermined amount.

(4593) MILTERS FERRY LOCK AND DAM, ALABAMA RIVER, ALA., GENERAL MODEL STUDIES.

(b) U.S. Army Engr. District, Mobile.

(e) The project is located 142.2 miles above the mouth of the Alabama River and is part of the development program of the Alabama River waterway. It will include a nonnavigable dam with a gated and an overflow section, a lock on the left bank having usable dimensions of 600 by $84 \mathrm{ft}$ and a maximum lift of $48 \mathrm{ft}$, and a powerhouse. The filling and emptying system for the lock will comprise two intake ports in the river side of the upper gate block, 10-ft-square culverts in each wall, a lateral crossover culvert at the midpoint of the lock leading to four longitudinal floor culverts with side ports, and culvert outlets which empty riverward of the lock in the common outlet basin. Reverse-mounted tainter valves will control flow in the system.

The purpose of this study is to investigate navigation conditions through an existing bridge and in the lock approaches, the effects of the structures on flood stages, and the effects of powerhouse operations on navigation conditions; and to determine flow characteristics over the spillway and verify the adequacy of the stilling basin design. A $1: 100$ scale general model reproducing about 3.1 miles of river was used to study navigation conditions.

(f) Completed.

(g) See $(h)$.

(h) "Navigation Conditions at Millers Ferry Lock and Dam, Alabama River, Alabama," Rept. TR 2-775, April 1967.

(4595) COLUMBIA LOCK AND DAM, OUACHITA RIVER, La., GENERAL MODEL STUDY.

(b) U.S. Army Engr. District, Vicksburg.

(e) The project involves construction of a cut-off channel about $5600 \mathrm{ft}$ long with a bottom width of $522 \mathrm{ft}$, a gated structure (consisting of four tainter gates, each $50 \mathrm{ft}$ wide and $26 \mathrm{ft}$ high) located about midway of the cutoff, a 200-ft-wide navigable pass on the right of the dam, and a 600-by 84 -ft lock on the left. The purpose of this study is to investigate navigation conditions in the approaches to the lock and navigable pass, and the effects of the structures on flood stages. The investigation was conducted on a 1:100-scale model that reproduced about 2.6 miles of the ouachita River and cut-off channel, including the lock and dam structures.

(f) Completed.

(g) See $(h)$.

(h) "Navigation Conditions at Columbia Lock and Dam, Ouachita River, Louisiana; Hydraulic Model Investigation," Rept. TR 2-756, Feb. 1967. 
(4594) SHEIBYVILLE DAM, KASKASKIA RIVER, ILL., MODEL STUDY OF SPILLWAY.

(b) U.S. Army Engr. Dist., St. Louis.

(e) The purpose is to study the overall hydraulic performance of the spillway and outlets of the sluices, verify chute and stilling basin designs, and develop an exit channel protection plan.

The investigation was conducted on a 1:40scale model that reproduced the spillway and allied structures, a portion of the earth embankment on each side of the spillway, $1550 \mathrm{ft}$ of the approach channel, and $1150 \mathrm{ft}$ of the exit channel.

(f) Completed.

(g) See $(h)$.

(h) "Spillway and Outlet Works, Shelbyville Dam, Kaskaskia River, Illinois; Hydraulic Model Investigation," TR 2-719, June 1966.

(4599) IITTLE SIOUX RIVER PROJECT, LITTLE SIOUX, IOWA, MODEL STUDY OF CONTROL STRUCTURES.

(b) U.S. Army Engr. District, Omaha.

(e) The structure will consist of a low rectangular drop with a width of $50 \mathrm{ft}$ and crest at el 1020 located in the control channel with rock protection downstream of the structure and on adjacent berms. The purpose of the investigation is to study the placement of riprap materials in the vicinity of the structure, and discharge capacity of the structure, and effectiveness of concrete drop.

The 1:30-scale model reproduced about $700 \mathrm{ft}$ of the channel and berms upstream of the structure, the drop structure, and about 1300 ft of the channel and berms below the structure. Portions of the levees containing the structure were reproduced adjacent to the berms. The approach channel and berms were initially molded in sand; subsequent tests were conducted with this area molded in cement mortar to sheet-metal templates. Prototype roughness was simulated by installing expanded metal mesh (7/8-in.) on the upstream berms. The concrete area of the drop structure was fabricated of plastic-coated plywood.

(f) Completed.

(g) See $(h)$.

(h) "Control Structure, Little Sioux River, Iowa; Hydraulic Model Investigation," Rept. TR 2-762, Feb. 1967.

(4602) LOCK FILLING AND EMPTYING SYSTEMS.

(b) Office, Chief of Engineers.

(d) Analytical and model; applied.

(e) To provide new or improved design information and procedures to assist in the design of navigation lock filling and emptying systems. Flumes with required appurtenances are available for testing, at scales of 1:25, filling and emptying systems of locks as large as $110 \mathrm{ft}$ by $1200 \mathrm{ft}$ with lifts of $100 \mathrm{ft}$.

(g) Two different crossover culvert designs were tested with a floor culvert arrangement which utilized only two discharging floor culverts in each half of the lock chamber. Iimited data were obtained with each of the basic arrangements tested. These data are to be used with similar data for other arrangements (scheduled for testing in 1968) to develop planning information showing the relative effect of the different crossover culvert designs and floor culvert arrangements on performance. Data are being collected at lifts ranging to $100 \mathrm{ft}$.
(4603) LOW-LIFT LOCKS, ARKANSAS RIVER, ARK., MODEL STUDY OF FILLING AND EMPTYING SYSTEM.

(b) U.S. Army Engr. Dist., Little Rock.

(e) The Little Rock District sponsored the first phase of the tests in which a 12- by 12-ft culvert was used; tests of other size culverts will be sponsored by the Little Rock District or other interested Corps of Engineers offices for the purpose of standardizing lock design for 600- by 100 -ft locks. An intake was developed for use in all tests. Then optimum shape, size, number, spacing, and location of the ports in the lock chamber as related to culvert size were determined. The purpose of this study is to determine an optimum port arrangement for the filling and emptying system for low-lift locks.

The investigation was conducted on a 1:25scale model which reproduced $700 \mathrm{ft}$ of lock approach channel, intake manifolds, a $670-$ ft-long lock chamber, culvert, sidewall port manifolds, outlet manifold, and 700 ft of downstream channel.

(f) Completed.

(g) $\operatorname{See}(\mathrm{h})$.

(h) "Navigation Conditions at Lock and Dam No. 4, Arkansas River; Hydraulic Model Investigation," Rept. TR 2-746, Oct. 1966.

(5228) CRITERIA FOR THE DESIGN OF SMALL-BOAT HARBORS. See No. 5014, Calif. Inst. Tech., p. 7.

(5227) GENERAL COASTAL INLET STUDIES.

(b) Office, Chief of Engrs.

(c) Experimental; laboratory and field; applied.

(e) This is a general study to develop means for computing discharge and velocity distribution through tidal inlets, leading to determination of tidal prisms and water-surface elevations in inner bay systems; and to determine the factors involved in both inner and outer bar formation, the shoaling of inlet channels, and the stability of inlet shape and location. The project will consist of the following three phases: (1) tests in four generalized test facilities, three of which (Facilities $A, B$, and C) will be located at the Waterways Experiment Station and the fourth at the Coastal Engineering Research Center; (2) analysis of results of these tests by the Waterways Experiment Station, the Coastal Engineering Research Center, and the Committee on Tidal Hydraulics; and (3) field observations under sponsorship of the Committee on Tidal Hydraulics to confirm the principles developed.

(g) A series of tests of structures designed for hurricane surge reduction were conducted in Facility A for the Galveston District. Modification of the flow measuring system for Facility $A$ was completed, and restoration of the facility basin was completed to allow testing of the first of the general inlets. Construction of models to allow testing for the New York District and the Nuclear Cratering Group was completed in Facility $B$, and tests for the Nuclear Cratering Group were initiated. Tests to determine the ability of obtaining desired littoral drift rates were initiated in Facility $\mathrm{C}$ early in the year. These tests were then interrupted for the construction of the model of Moriches Inlet. Adjustment and verification of Moriches Inlet were initiated the latter part of the year. 
(5230) IOCK AND DAM NO. 4, ARKANSAS RIVER, ARK., MODEL STUDY OF NAVIGATION CONDITIONS.

(b) U.S. Army Engr. Dist., Little Rock.

(e) The purpose of the study is to (a) demonstrate flow conditions in the lock approaches in the vicinity of the Rob Roy Bridge; (b) determine the effect of various guard wall designs on forces affecting tows in the upper lock approach; (c) determine optimum location of the harbor and dock, and mooring facilities; (d) measure distribution of several different flows throughout the model; and (e) furnish information to be used in developing modifications of the approaches and structures to improve navigation conditions. The investigation was conducted on a 1:120-scale, fixedbed, comprehensive model, reproducing about 5 miles of the Arkansas River and adjacent overbank areas, the lock and dam structures, and all bridges and other structures that might affect flow conditions.

(h) "Nevigation Conditions at Lock and Dam No. 4, Arkansas River; Hydraulic Model Investigation," Rept. TR 2-746, Oct. 1966.

(5231) OZARK LOCK AND DAM, ARKANSAS RIVER, MODEL STUDY OF NAVIGATION CONDITIONS.

(b) U.S. Army Engr. District, Little Rock.

(e) The purpose of this study is to determine the suitability of the proposed site for the lock and dam structures, and to develop modifications which might be required to overcome any undesirable navigation conditions. The investigation was conducted on a l:120-scale, fixed bed, comprehensive model, reproducing about 3 miles of the Arkansas River, adjacent overbank areas to an elevation of approximately $385 \mathrm{ft} \mathrm{msl}$, the lock and dam structures, and all bridges and other structures that might affect flow conditions.

(f) Test completed.

(g) Tests have resulted in modifications in the lock approaches and in the excavation in the approach to the powerhouse, and in the development of suitable plan for spoil disposal.

(5232) HUNTINGTON RESERVOIR, WABASH RIVER, IND., MODEL STUDY OF STILLING BASIN.

(b) U.S. Army Engr. District, Louisville.

(e) The Huntington Reservoir, a proposed floodcontrol project to be constructed on the Wabash River about 85 miles northeast of Indianapolis, Ind., includes an earth dam $4700 \mathrm{ft}$ long and $89 \mathrm{ft}$ high, and a gated spillway with six conduits through the spillway section.

The purpose of the study is (a) to insure good energy dissipation in the stilling basin at low and intermediate flows, and safe conditions at high flows; (b) to study the effect of the flatter-than-usual downstream spillway slope (10 horizontal to 12 vertical) on basin action; and (c) if the originally proposed basin design was found to be unsatisfactory, to make revisions necessary to secure the desire results. The 1:60-scale model of the stilling basin reproduced $400 \mathrm{ft}$ of the approach area, a 60 ft-wide section of the spillway and stilling basin, and $500 \mathrm{ft}$ of the exit channel. The spillway gate piers and conduits through the spillway were not reproduced; however, the model was adjusted to simulate the increased head that would have obtained with crest piers and abutments present. (f) Completed.

(g) $\operatorname{See}(h)$

(h) "Stilling Basin, Huntington Reservoir Spillway, Wabash River, Indiana; Hydraulic Model Investigation," Rept. MP 2-876, Feb. 1968.

(5233) ST. CLAIR RIVER, MODEL STUDY OF SUBMERGED SILLS.

(b) U.S. Army Engr. District, Detroit.

(e) The St. Clair River project, proposed for the head of the St. Clair River, will involve construction of submerged sills in an effort to raise the level of Lake Huron. The purpose of the investigation is (a) to study effects of number and location of submerged sills on discharge characteristics, navigation conditions, and sedimentation; and (b) to investigate effects of shape of weir of discharge characteristics.

The comprehensive model reproduced the st. Clair River from Lake Huron to a point about 3.1 miles downstream to a scale of 1:60; this model was of the fixed-bed type with provisions for the study of sediment movement and for the study of shoaling in the critical area.

(f) Tests suspended.

(5243) NOLIN DAM, NOLIN RIVER, KY., PROTOTYPE TESTS, GATED INTAKE AND TUNNEL.

(b) U.S. Army Engr. District, Louisville.

(e) Nolin Dam is a rock-fill dam, $169 \mathrm{ft}$ in height, used for flood control. The outlet works, consisting of a three-gated intake structure and semielliptical-shaped tunnel, has a 16,000cfs capacity. An uncontrolled saddle-type spillway is located on the right abutment. The purpose of the study is to measure the tunnel hydraulic grade line and gate-hoist cylinder pressures. From these measurements, tunnel friction and intake losses can be evaluated and gate forces computed. Test facilities included five pairs of sidewall piezometers connected to a manifold. Pressures at full tunnel flow were measured by means of the air-purge technique, using a mercury manometer and a pressure gage. Pressure taps were provided in one of the operating gate-hoist cylinders and measurements of gate hydraulic cylinder pressures were made with pressure gages.

(5234) TEXAS CITY, TEX., MODEL STUDY OF SEAWALL.

(b) U.S. Army Engr. Dist., Galveston.

(e) The purpose of the study is to develop designs for (a) vertical-faced seawalls, (b) rubblemound structures to protect the natural ground at the base of a vertical wall on its bayside, and (c) rubble-mound armor layers to protect the bayside slope and crown of an earth levee. Tests were conducted in a concrete wave flume $119 \mathrm{ft}$ long, $5 \mathrm{ft}$ wide, and $4 \mathrm{ft}$ deep on section models of the proposed structures constructed to a linear scale of $1: 35$. Model waves were generated by a plunger-type wave machine, and measured and recorded electrically.

(f) Completed.

(g) See (h).

(h) "Stability of Seawall, Texas City, Texas; Hydraulic Model Investigation," Rept. TR 2-728, May 1966.

(5242) GREENUP LOCKS AND DAM, OHIO RIVER, PROTOTYPE CULVERT PRESSURE TESTS.

(b) U.S. Army Engr. Dist., Huntington.

(e) The project, located on the Ohio River 341 miles downstream from Pittsburgh, Pa., consists 
of a 110- by 600-ft auxiliary lock, a 110- by 1200-ft main lock, and a nine-bay, 1287-ftlong spillway dam. The lift of the locks is 32 ft at present, but will be $30 \mathrm{ft}$ when additional downstream development is completed. The filling and emtpying system of the main lock consists of two culverts and a splitlateral system.

The purpose of the study is to measure prototype pressures in the filling and emptying system of the main lock and water-surface elevations in the lock chamber for comparison with model results and for further development of lock design criteria.

Electrical transducers connected to piezometers by air-purged lines were used to measure pressures in the lock culverts and water-surface elevations in the lock. Circular potentiometers were used to indicate the positions of the filling and emptying valves. All data, accompanied by a common time indication, were recorded on light-beam oscillographs. Other data included photographic records of flow conditions and staff gage readings.

(f) Completed

(g) See (h).

(h) "Culvert Pressures, Greenup Lock, Ohio River, Kentucky; Hydraulic Prototype Tests," Rept. TR 2-734, July 1966.

(5245) HOUSTON SHIP CHANNEL, TEX., MODEL STUDY.

(b) U.S. Army Engr. District, Galveston.

(e) Houston Ship Channel comprises a 52-mile reach which starts at Bolivar Roads, traverses Galveston Bay, and includes the lower portion of the San Jacinto River and Buffalo Bayou to confluence of White Oak Bayou. The cost maintenance dredging in the ship channel, including new work such as easing of bends and other routine improvements, has averaged more than $\$ 1,000,000$ per year over a period of several years. The purpose of the study is to determine if the present cost of maintenance dredging can be reduced by proposed plans of channel realignment, partial or complete diking of connecting bays, sediment traps, dikes in Galveston Bay, local contractions, enlargements, and other remedial measures.

The model reproduces a portion of the Gulf of Mexico outside the entrance to Galveston Bay; all of Galveston and Trinity Bays; Dickinson Bay and Clear Creek to the head of project; the tidal portion of Trinity River; the Houston Ship Channel in its entirety; and Buffalo Bayou from the Turning Basin to the confluence of White Oak Bayou. The model is of fixed-bed construction with scale ratios, model to prototype, of $1: 600$ horizontally and $1: 60$ vertically. Tides and tidal currents are reproduced by a tide generator located in the Gulf of Mexico portion of the model, and the salinity of the model Gulf is reproduced to scale so that the effects of salinity differences on the vertical distribution of current velocities, as well as salinity concentrations throughout the model, accurately reproduce those of the prototype. The model will be used to establish the effects of all proposed improvement works on tidal current velocities, current patterns, and salinities in all critical areas. All hydraulic and salinity data obtained from the model will be quantitative and can be applied directly to the prototype. Shoaling studies are made by injecting finely ground gilsonite into the model to reproduce the patterns of shoaling as observed in the prototype, following which the effects of proposed improvement plans on shoaling patterns may be observed and evaluated from a qualitative viewpoint.

(g) Results of the radioisotope tracer tests in the prototype indicated that sediment moves upstream at a fairly rapid rate and that little movement of sediment occurs in the downstream direction. Ships passing through the channel appear to contribute to suspension and further movement of the sediment as found in an observation made in one traverse made behind a moving ship.

(5250) FORT RANDALL DAM, MISSOURI RIVER, S. DAK., PROTOTYPE SPILLWAY TESTS.

(b) U.S. Army Engr. Dist., Omaha.

(d) Field studies; applied research.

(e) The purpose is to obtain vertical velocity distribution and water-surface depths on the spillway chute for use in checking design resistance coefficient assumptions and computing discharge over the spillway. These data will assist in eliminating a deficiency in the information on full-scale chute spillway flows used in design of such structures. Two pitot piers were fabricated and installed on the spillway chute. The pitot piers instrumentation consisted of eight total-head tubes to measure vertical velocity distributions. Water-surface measurements along the spillway length were made with wire-weight gages. Visual observations and photographic records of flow conditions were also made.

(f) Completed.

(g) See $(h)$.

(h) "Flow in Chute Spillway at Fort Randall Dam; Hydraulic Prototype Tests," Rept. TR 2-716, Apr. 1966.

(5251) ROBERT S. KERR LOCK AND DAM, ARKANSAS RIVER, MODEL STUDY OF NAVIGATION CONDITIONS.

(b) U.S. Army Engr. District, Tulsa.

(e) The Robert S. Kerr Lock and Dam, to be located at about mile 395 on the Arkansas River, will involve construction of a nonnavigable-type dam, a 110- by 600-ft lock, and a powerhouse. The lock will provide a maximum lift of about $48 \mathrm{ft}$. The purpose of the investigation is to study navigation conditions in the approm aches to the lock, determine suitability of the selected site, and develop modifications required to overcome any undesirable conditions. The model reproduced about 3.2 miles of the Arkansas River and the lock and dam structures to a scale of 1:120. It was a fixed-bed model with provision for a movable-bed section below the dam for use in the development of channel configurations in the reach.

(f) Tests completed; final report in progress.

(g) Results of the investigation revealed that a 3000-ft-long dike landward of the upper guard wall would be necessary to eliminate a strong crosscurrent at the end of the upper guard wall. A shorter transition in the right bankline downstream of the powerhouse and the addition of a 400-ft dike at the end of the guard wall with initial conditions or a 550-ft dike if the channel downstream of the dam degrades to rock would be necessary to minimize the effect of the large eddy that would develop with all flow through the powerhouse. 
(5634) DANA POINT HARBOR, CAIIF., MODEL STUDY OF BREAKWATER .

(b) U.S. Army Engr. Dist., Los Angeles.

(e) This harbor is to be constructed at a site which is exposed to ocean waves. The harbor will be protected by rubble-mound breakwaters which are permeable and allow some of the wave energy to pass through the structures into the protected area. The purpose of the study is to determine the effectiveness of the proposed breakwater sections in reducing transmitted wave energy, and the stability of the breakwaters to provide a basis for the design of the proposed harbor; and to add to the available basic data on the transmission of wave energy into artificial harbors. Tests were conducted in a concrete wave flume $119 \mathrm{ft}$ long, $5 \mathrm{ft}$ wide, and $4 \mathrm{ft}$ deep on section models of the proposed structures constructed to linear scales of 1:50 and 1:100. Model waves were generated by a plunger-type wave machine and measured and recorded electrically.

(f) Completed.

(g) See $(h)$.

(h) "Designs for Rubble-Mound Breakwaters, Dana Point Harbor, California; Hydraulic Model Investigation," TR 2-725, June 1966.

(5635) INVESTIGATION OF WAVE REFLECTING AND TRANSMITTING CHARACTERISTICS OF RUBBIE-MOUND BREAKWATERS, RUBELE WAVE ABSORBERS, SAND BEACHES, WAVE TRAPS, AND RESONATORS.

(b) Office, Chief of Engrs.

(d) Theoretical and experimental; applied.

(e) A comprehensive study is being conducted to critically review the theoretical aspects of wave absorbers and show their application to practical situations; to develop more accurate methods of measuring wave reflection-absorption characteristics of short-period waves; to investigate the energy transmitted through and over rubble-mound structures; and to determine the wave absorbing characteristics of sand beaches, wave traps, resonators, and certain types of floating breakwaters. The purpose of the study is to establish design criteria (a) for rubble breakwaters with respect to their wave reflecting-transmission characteristics, and (b) for different types of wave absorbers (natural sand beaches, wave traps, resonators, and rubble mound). A 2by 4.5 - by 149-ft concrete wave flume equipped with a flat-type wave generator and electrical wave measuring apparatus was used to conduct tests of the flexible floating breakwater investigation.

(g) Data from tests to determine the ratio of transmitted to incident wave heights and the ratio of reflected to incident wave heights for rubble-mound structures were analyzed and a draft of the final report was begun. Model tests were conducted on ilexible floating breakwaters consisting of used rubber tires (Wave Maze) and spherical shaped units to determine their wave attenuation characteristics. The data were analyzed and a first draft of the final report, "Investigation of Flexible Floating Breakwaters Made of Tires and Spheres,"was completed. The results of the investigation indicated that a wave transmission coefficient $\left(\mathrm{H}_{t} / \mathrm{H}_{j}\right.$ of 0.20 could be otained in situations where the breakwater length is twice the wavelength and the breakwater depth extends one-third of the water depth below the surface. Therefore, this type breakwater is primarily best suited for short-period, high-steepness waves in relatively deep water.

(5636) FLUSHING STUDIES OF VICTORIA CHANNEL, Tex.

(b) U.S. Army Engr. Dist., Galveston.

(e) The Gulf Intracoastal Waterway, Channel to Victoria, Tex., is located along the Gulf coast in south-central Texas. The navigation channel extends northwesterly from the Gulf Intracoastal Waterway in San Antonio about 35 channel miles to a turning basin about 7 miles south of Victoria, Tex. The channel when completed will have a controlling depth of $10 \mathrm{ft}$ below mean sea level over a bottom width of $100 \mathrm{ft}$ and $1-0 \mathrm{n}-3$ side slopes. The proposed turning basin and flushing system will be located at the end of the navigation channel. The flushing system is to consist of a freshwater intake ditch, flushing canal, gate structure, underground conduit, and stilling basin. It is anticipated that the navigation channel will require two flushings per year to eliminate objectionable surface debris, oil, and foul water. Although an average annual inflow of 14,400 acre-ft can be expected to enter the channel from local runoff, the unpredictable magnitude of storms and the distribution of the inflow throughout the length of the navigation channel may not ensure two thorough flushings per year. Flushing will be accomplished with fresh water taken from the Guadalupe River which will be conveyed through the intake ditch, control gates, conduits, and stilling basin and introduced near the head of the navigation channel. Since most of the Guadalupe flow is used for irrigation and other purposes, it is likely that diversion will only be possible during flood peaks lasting two to three days and occurring once or twice per year.

The purpose of the study is to determine the flow requirements of the flushing system to replace the stagnant water in the navigation channel.

The tests were made in the Waterways Experiment Station salinity flume which is $327 \mathrm{ft}$ long, 0.75 ft wide, and 1.5 ft deep. Duplicate tests were made for two depth scales $(1: 15$ and $1: 30)$ to determine if the test data contained any significant scale effects. In both series of tests, the horizontal scale for length along the channel was $1: 323$, and that for width across the channel was $1: 173$. Use of different horizontal scales for length and width was necessary to make the existing flume dimensions conform to those of the landlocked portion of the channel. The salinity scale used for the tests was $1: 1$.

(f) Completed.

(g) See ( $h$ ).

(h) "Flushing Studies, Victoria Channel, Victoria, Texas; Hydraulic Model Investigation," Rept. MP 2-812, Apr. 1966.

(5638) LOCK AND DAM NO. 9, ARKANSAS RIVER, MODEL STUDY OF NAVIGATION CONDITIONS.

(b) U.S. Army Engr. District, Little Rock.

(e) The project involves construction of a gated dam and lock. As proposed, the dam will contain 14 gate bays (60-ft span) with sill at el 253. The lock will have clear dimensions of 110 by $600 \mathrm{ft}$. The maximum lift will be $19 \mathrm{ft}$. The purpose of the study is to 
investigate navigation conditions with the proposed structures, to determine the effects of modifications in the composition and arrangement of the structures, and to develop such modifications as might be considered desirable.

The investigation was conducted on a 1:120scale model reproducing about 6 miles of the Arkansas River and adjacent overbank area near Morrilton, Ark. The model was of the fixed-bed type with provisions for changes in the channel based on the effects of the proposed regulating structures.

(f) Tests completed; report in progress.

(g) Results have indicated the modifications required to produce satisfactory navigation conditions in the upper and lower lock approach.

(5639) LOCK AND DAM NO. 7, ARKANSAS RIVER MODEL STUDY OF NAVIGATION CONDITIONS.

(b) U.S. Army Engr. District, Little Rock.

(e) The purpose of the investigation is to study navigation conditions in the lock approaches, the design of the upstream guard wall, and location and design of any training works needed to improve navigation conditions and distribution of flow to the spillway. The investigation was conducted on a 1:120 scale, fixed-bed, comprehensive model, reproducing about 7 miles of the Arkansas River, adjacent overbank areas, the lock and dam structures, and other structures that might affect flow conditions.

(f) Tests complete; report in progress.

(g) Results indicated that moving the right pier to increase the width of the navigable span would reduce the hazard to navigation through the bridge during the higher flows.

(5640) CHARLESTON HARBOR, S.C., POLLUTION STUDY.

(b) U.S. Army Engr. Dist., Charleston.

(e) The purpose is to provide data on dispersion and transport of wastes in the harbor under various conditions of freshwater inflow along with data on tides, currents, and salinities for all inflow conditions studied.

The Charleston Harbor model reproduced about 17 miles of the South Carolina shoreline, 230 square miles of the Atlantic Ocean, and the entire tidal portions of the Cooper, Ashley, and Wando Rivers and their tributaties. The model was of the fixed-bed type and was constructed to scales of 1:100 vertically and l:2000 horizontally. Provisions were included for reproducing tides and tidal currents, upland freshwater flows, ocean salinities, and salinity intrusion. Conservative-type fluorescent dyes were introduced to simulate industrial and municipal waste, and the effects of variations in the upland flow on the dispersion and flushing characteristics of the dyes were determined.

(f) Completed.

(g) See $(h)$.

(h) "Reduction of Shoaling in Charleston Harbor and Navigation Improvement of Cooper River, South Carolina; Hydraulic Model Investigation," Rept. TR 2-733, July 1966.

(5641) FREMONT DROP STRUCTURE, SANDUSKY RIVER, OHIO, MODEL STUDY.

(b) U.S. Army Engr. Dist., Euffalo.

(e) Tre project provides for widening, deepening, and streamlining the main channel of the
Sandusky River in the vicinity of Fremont, Ohio. The purpose of the study is to determine the adequacy of a drop structure or friction channel in the dissipation of the kinetic energy developed when the water-surface profile drops from existing levels upstream of the proposed improved channel to levels within the improved channel.

Model tests were conducted on a 1:36-scale model reproducing the drop structure and 800 ft of the channel upstream and $900 \mathrm{ft}$ downstream. Tests were also conducted on a 1:40scale rocklined channel which reproduced about $2000 \mathrm{ft}$ of the proposed channel.

(f) Completed.

(g) See $(h)$.

(h) "Fremont Drop Structure and Friction Channel, Sandusky River, Ohio; Hydraulic Model Investigation," Rept. TR 2-752, Dec. 1966.

(5642) DANA POINT HARBOR, CALIF., MODEL STUDY, DESIGN OF SMALL BOAT HARBOR.

(b) U.S. Army Engr. Dist., Los Angeles.

(e) The inner-harbor basin will be enclosed by a mole and will be accessible through 200-ftwide navigation entrances, one at each end of the 3500-ft-long inner basin. The inner harbor, which will accommodate about 2200 small boats, will be protected by two arms of rubble-mound breakwater having a total length of about $7700 \mathrm{ft}$.

The purpose of the study is to study the effects of storm-wave action on the proposed harbor design and to determine in advance of prototype construction what, if any, design modifications are necessary to ensure that wave heights during storms do not exceed (a) $1.5 \mathrm{ft}$ in the inner-basin anchorage, (b) $4 \mathrm{ft}$ in the approaches to the entrances of the inner-harbor east basin berthing area and the inner-harbor west basin berthing area, (c) $5 \mathrm{ft}$ in the fairway channel paralleling the proposed west breakwater, and (d) $2.5 \mathrm{ft}$ in the ramp basin area in the eastern sector of the inner harbor.

The 1:100-scale model was of the fixed-bed type, and was molded of concrete except for the breakwaters and inner-harbor mole section which were constructed of rubble, sized to simulate that required for prototype construction. The model reproduced sufficient area along the shoreline east and west of the harbor site and oceanward to ensure that propagation of waves toward the problem area was adequately simulated. The model had an area of about $11,000 \mathrm{sq} \mathrm{ft}$, equivalent to 4 square miles in nature. Waves were generated by a 60-ft-long, plunger-type wave machine. Electrical printed-circuit-type wave measuring rods were used in connection with automatic recording equipment to obtain necessary waveheight data.

(f) Completed.

(g) See (h).

(h) "Design for Optimum Wave Conditions, Dana Point Harbor, California, Hydraulic Model Investigation," Rept. TR 2-724, June 1966.

(5643) SUMMERSVILLE DAM, ACOUSTIC FLOWMETER INSTALLATION AND PROTOTYPE TESTS.

(b) U.S. Army Engr. District, Huntington.

(e) Summersville Dam is a rock-fill dam, 375 ft in height, used for flood control. The outlet works consists of an intake structure, 29ft-diam operating tunnel, three ll-ft-diam 
outlet conduits, and one 3-ft-diam low-flow outlet pipe. An uncontrolled, saddle-type spillway is located $3500 \mathrm{ft}$ west of the right abutment. The purpose of the study is to gage operational discharges with an acoustic flowmeter, and to measure pressure gradients through the three-branch manifold connecting the 2)-ft tunnel to the three 1l-ft conduits; from these measurements, to evaluate tunnel resistance and intake and manifold losses. The acoustic flowmeter included a pair of transducers in the tunnel and each conduit and the accompanying circuitry to indicate the discharage from the effects of the flow rates on the acoustic signals. The pressure test facilities consisted of six pairs of piezometers along the tunnel and three pairs along each conduit.

(g) Prototype tests of an acoustic flowmeter system were made in a 24-ft-diam power penstock at Oahe Dam to evaluate the system prior to permanent installation in the outlet works at Summersville Dam. Comparative discharge measurements included acoustic, penstock, pressuremomentum (Gibson), turbine model test ratings, scroll-case pressure differential (WinterKennedy flowmeter), and surge tank volume changes. The acoustic flowmeter measurements were very consistent and many of the compari-sons were within 1 percent. The location of the measuring section for a single-path acoustic flowmeter must be selected to give a known or measurable relation between the flow pattern of the whole section and that along the acoustic path.

(5644) IITTIE ROCK REACH, ARKANSAS RIVER, MODEL STUDY OF NAVIGATION CONDITIONS.

(b) U.S. Army Engr. District, Little Rock.

(e) The purpose of the study is to study navigation conditions through six bridges at wittle Rock, Ark., to determine modilications required in the existing bridges; and to develop a plan of regulating structures required to provide satisfactory navigation conditions. The investigation is being conducted on a fixed-bed model reproducing about 3 miles of the Arkansas River and adjacent overflow areas to a scale of 1:100, including six railroad and highway bridges.

(f) Suspended.

(g) A plan producing satisfactory navigation conditions has been developed and involves modifications to five bridges and training structures along the right bank.

(5646) HANNIBAI DAM, OHIO RIVER, SECTION MODEI STUDY OF SPIIIWAY.

(b) U.S. Army Engr. Dist., Pittsburgh.

(e) The spillway will consist of a concrete sill surmounted by eight 110-ft-wide tainter gates and a conventional horizontal stilling basin with baffle piers and end sill. The purpose of the study is to investigate the adequacy of the proposed stilling basin for a full range of tailwater elevations at which the structure will be required to operate.

A 1:36-scale section model reproduced approximately 500 ft of the approach area, one central gate bay and the adjacent half-bays of the spillway, a 2l6-ft-wide section of the stilling basin, and approximately $500 \mathrm{ft}$ of the exit area.

(f) Completed.

(g) See $(h)$.

(h) "Spillway, Hannibal Locks and Dam, Ohio River,
Ohio and West Virginia; Hydraulic Model Investigation," TR 2-731, June 1966.

(5647) GATE VIBRATION TESTS.

See University of Iowa, No. 5321, p. 55, Iowa Institute of Hydraulic Research.

(5648) BRUNSWICK HARBOR, GA., MODEL STUDY.

(b) U.S. Army Engr. District, Savannah.

(e) The purpose of the study is to determine if the present high rate of shoaling in East River can be reduced by either changing the distributions of flows, creating turbulence, increasing bottom velocities, or by reducing the tidal prism of East River to a minimum. The investigation was conducted in a model reproducing the following areas: (a) from vicinity of Jekyll Island and St. Simons Island on the downstream end to the upper limits of Turtle River and Brunswick River on the upstream end; (b) East River in its entirety; (c) Jekyll Creek from Brunswick River to Highway 84 Bridge; and (d) all marsh areas surrounding the rivers, creeks, and tributaries of the system. The model was of the fixed-bed type molded of concrete to linear scale ratios, model to prototype, of $1: 100$ vertically and 1:500 horizontally. Automatic tide generators reproduced tides and tidal currents throughout the harbor. Shoaling studies were made by injecting finely ground gilsonite into the model to reproduce the patterns of shoaling observed in the prototype, and to determine the effects of proposed improvement plans on shoaling patterns. Changes in shoaling patterns as effected by each proposed improvement plan were determined and evaluated.

(f) Tests completed; report in progress.

(g) Results of tests of the plans to reduce shoaling in Jekyll Creek indicate that plan $4 \mathrm{~A}$ will reduce shoaling by about 30 percent. Construction of the required training wall can probably be justified since it will also serve to confine the dredge spoil from channel maintenance. The results of the dye diffusion tests were furnished to the Federal and State water pollution agencies concerned for their analysis and evaluation.

(5650) CORDELI HULL LOCK, CUMBERLAND RIVER, TENN., MODEL STUDY OF FILLING AND EMPTYING VALVES.

(b) U.S. Army Engr. Dist., Nashville.

(e) The purpose of the study is to evaluate the overall performance of the multiport system with particular emphasis given to determining the optimum number, size, and arrangement of chamber ports. Tests also were scheduled to investigate methods of controlling pressures below the filling valves.

The investigation was conducted on a 1:25scale model which reproduced only the portion of Cordell Hull Lock between filling and emptying valves. This action was necessitated by an unusually tight design schedule. other model features remained as they were in an earlier model study.

(f) Completed.

(g) $\operatorname{See}(h)$.

(h) "Filling and Emptying System, Cordell Hull Navigation Lock, Cumberland River, Tennessee; Hydraulic Model Investigation," Rept. TR 2-739, Sept. 1966.

(5651) JAMES RIVER, Vh.., MODEL STUDY. 
(b) U.S. Army Engr. Dist., Norfolk; and State of Virginia.

(e) The purpose is to determine the effects of channel improvement upon hydraulic and salinity conditions in and adjacent to the oyster beds located within the James River estuary and its tributaries.

The model covered approximately $25,000 \mathrm{sq}$ ft (900 square miles in prototype) and reproduced 300 square miles of the Atlantic Ocean, the James River estuary, and all its principal tributaries from Norfolk, Va. to Richmond, Va. The model was of the fixed-bed type with scale ratios, model to prototype, of 1:1000 horizontally and l:100 vertically. Tides and tidal currents were reproduced by a tide generator located in the Atlantic Ocean portion of the model. The ocean salinity was reproduced in the model so that the effects of salinity differences on the vertical distribution of current velocities, as well as salinity concentrations throughout the model, accurately reproduced those of the prototype. The freshwater discharge of the James River and its tributaries was introduced into the model by means of Van Leer weirs.

(f) Completed.

(g) It was concluded that the proposed improvement of the James River navigation channel between Newport News and Richmond would have no significant adverse effects on tides, currents, or salinities in the important seed oyster bed areas.

(5652) WEBBERS FALIS LOCK AND DAM, ARKANSAS RIVER, MODEL STUDY OF NAVIGATION CONDITIONS.

(b) U.S. Army Engr. District, Tulsa.

(e) The Webbers Falls Lock and Dam, to be located about mile 432.2 on the Arkansas River, will involve the construction of a nonnavigabletype dam, a 110- by 600-ft lock, and a powerhouse. The lock will provide a maximum lift of about $30 \mathrm{ft}$. The purpose of the investigation is to study navigation conditions in the approaches to the lock, determine the adequacy of the design, and develop modifications required to overcome any undesirable conditions. The model reproduced about 3.1 miles of the Arkansas River and the lock and dam structures to a scale of $1: 120$. It was of the fixed-bed type with provisions for anticipated changes.

(f) Test complete; report in progress.

(g) Modification of the entrance to the upper lock approach canal would make entrance into the canal easier. A reduction in the length of the upper guard wall from 600 to $450 \mathrm{ft}$ could be made without affecting navigation conditions appreciably. The originally proposed plan for the lower lock approach would be satisfactory.

(5653) LAKE ERIE - LAKE ONTARIO WATERWAY MODEL STUDIES.

(b) U.S. Army Engr. District, Buffalo.

(e) The project will provide a second navigation passage from Lake Erie to Lake Ontario to supplement the existing Welland Canal. The plan includes a control structure at the head of the Niagara River, a new lock to replace the Black Rock Lock at Buffalo, and improvements to the existing navigation channel around Grand Island to the entrance of the proposed overland canal downstream of Tonawanda Island. The canal (with locks) will connect the Niagara River and Lake Ontario.
An existing Niagara River model was used to investigate control structure and lock arrangements and navigation channel features including compensating excavations or structures required to maintain existing stagedischarge relations. It may be desirable when the project advances from the survey report stage to the design stage to refine features of the lock plan in an undistorted model. Navigation conditions at the entrance to the overland canal were studied in a second model. The initial phase of the study utilized an existing distorted-scale model which reproduced the Niagara River from approximately 11,500 ft above the Peace Bridge at Buffalo to Rainbow Bridge below the falls. The upper limit extended into Lake Erie. The model was constructed to scale ratios of $1: 360$ horizontally and $1: 60$ vertically, and was of the fixed-bed type with all channel and overbank areas molded in concrete. An undistortedscale model of a reach of the river at the overland canal entrance was constructed for studying navigation conditions in this area. The model was of the fixed-bed type, constructed to a scale of $1: 120$.

(f) Tests complete; report in progress.

(g) of the five lock plans tested in the distorted model, lock plans $I$ and $I B$ appeared to be the most feasible. Lock plans $I$ and $I B$ are the only plans tested which can be used without a control structure at the mouth of the river. These plans also require less excavation. Current patterns in the improved channel near the canal entrance, as shown in the undistorted model, indicated the need for widening of the improved channel between Tonawanda Island and and the canal entrance. A 100-ft widened channel reduced the severity of currents across the channel.

(60l1) SAINTA BARBARA, CALIF., MODEL STUDY OF HARBOR DESIGN.

(b) U.S. Army Engr. Dist., Los Angeles.

(e) The enlarged harbor, to be enclosed by the protective breakwater system, will have an area of about 188 acres. Of this area, three moles and their perimeter wave-absorber slopes will occupy about 48 acres, leaving about 140 acres within the west, center, and east basins and the access channels leading thereto. New breakwater required under the project plan will aggregate about 5700 lin ft, $1600 \mathrm{ft}$ of which would be a detached structure about 1600 ft long protecting the harbor entrance. The purpose of the investigation is to study the effects of storm wave action on the proposed harbor design and to determine in advance of prototype construction what, if any, design modifications are necessary to ensure that (a) wave heights in the berthing areas do not exceed specified criteria during storms, and (b) these criteria are met while using the minimum amount of protective breakwater positioned to provide minimum requirements for navigation to and from the harbor by pleasure craft and also commercial fishing boats.

The 1:100-scale was of the fixed-bed type and was molded of concrete except for the breakwaters and absorbers flanking the innerharbor moles which were constructed of rubble, sized to simulate that required for prototype construction. The model reproduced sufficient area along the shoreline east and west 
of the harbor site and oceanward to ensure that propagation of waves toward the problem area was adequately simulated. The model had an area of about $10,700 \mathrm{sq}$ ft, equivalent to about 3.84 square miles in nature. Waves were generated by a 60-ft-long, plunger-type wave machine. Electrical printed-circuittype wave-measuring rods were used in connection with automatic recording equipment to obtain necessary wave-height data.

(f) Completed.

(g) $\operatorname{See}(\mathrm{h})$.

(h) "Expansion of Santa Barbara Harbor, California; Hydraulic Model Investigation," Rept. TR 2-805, Dec. 1967.

(6014) SANTA BARBARA HARBOR, CALTF., MODEL STUDY OF BREAKWATER STABILITY.

(b) U.S. Army Engr. Dist., Los Angeles.

(e) The purpose of the study is to determine the effectiveness of the proposed breakwater sections in reducing transmitted wave energy and to develop a breakwater section at a 1:100 scale that will transmit the same amount of energy as transmitted at a 1:33 scale. Wave transmission tests were conducted in a concrete wave flume $119 \mathrm{ft}$ long, $5 \mathrm{ft}$ wide, and 4 ft deep on section models of the proposed structures constructed to linear scales of $1: 33$ and 1:100. Model waves were generated by a plunger-type wave machine and measured and recorded electrically.

(f) Completed.

(g) See $(h)$.

(h) "Expansion of Santa Barbara Harbor, California; Hydraulic Model Investigation," Rept. TR 2-805, Dec. 1967.

(6015) NOYO HARBOR, CAIIF., MODEI STUDIES OF HARBOR DESIGN.

(b) U.S. Army Engr. Dist., San Francisco.

(e) The plan of harbor improvement will entail construction of two arms of rubble-mound-type breakwater. One arm would stem from shore on the south side of Noyo Cove and extend 1100 ft or more in a northwesterly direction while the companion arm would stem from the north side of the cove. A navigation entrance into the harbor not less than $400 \mathrm{ft}$ in width, measured at $-35 \mathrm{ft} \mathrm{mllw}$, would be required. Inside the harbor local interests would construct a lumber-loading pier or wharf about 1050 ft long.

The purpose of the investigation is to study the effects of storm wave action and characteristics of the Noyo area on the proposed harbor design and determine in advance of any prototype construction what, if any, design modifications are necessary to ensure that (a) wave heights during storms do not exceed the selected criterion of $2 \mathrm{ft}$ along the outer 600 ft of the proposed inner-harbor pier, and (b) the minimum system of breakwater necessary to satisfy finalized criteria for the harbor. The 1:100-scale model was of the fixed-bed type and was molded of concrete except for the breakwaters which were constructed of rubble, sized to simulate that required for prototype construction. The model reproduced sufficient area along the shoreline north, south, and oceanward of the harbor site to ensure that propagation of waves toward the problem area. was adequately simulated. Special emphasis was placed on reproducing all wave-reflecting and wave-absorbing characteristics of the prototype in all plan elements. A weir to permit simulation of Noyo River flood flow was also an element of the model. The model had an area of $5500 \mathrm{sq} \mathrm{ft}$, equivalent to about 2 square miles in the prototype. Waves were generated in the model by a plunger-type wave machine, and electrical, printed-circuit-type rods in connection with automatic recording equipment were used to obtain necessary waveheight data.

(f) Completed.

(g) $\operatorname{See}(\mathrm{h})$.

(h) "Wave Action and Breakwater Location, Noyo Harbor, California; Hydraulic Model Investigation," Rept. TR 2-799, Nov. 1967.

(6016) NOYO HARBOR, CALIF., MODEL STUDY OF BREAKWATER STABILITY. (See also No. 6015).

(b) U.S. Army Engr. Dist., San Francisco.

(e) The harbor will be protected by rubble-mound breakwaters which are permeable and allow small amounts of energy to pass through the structure into the protected area. The purpose of the study is to develop stable rubble-mound breakwaters using quarrystone and molded concrete armor units. Also the effectiveness of crown elevation of a concrete cap will be investigated with respect to overtopping and transmission of wave energy through the breakwater.

Tests were conducted in a concrete wave flume $119 \mathrm{ft}$ long, $5 \mathrm{ft}$ wide, and $4 \mathrm{ft}$ deep on section models of the proposed structures to a linear scale of $1: 61.4$. Model waves were generated by a plunger-type wave machine and measured and recorded electrically.

(f) Completed.

(g) See $(h)$.

(h) "Designs for Rubble-Mound Breakwater, Noyo Harbor, California; Hydraulic Model Investigation," Rept. MP 2-841, Aug. 1966.

(6017) EAU GALIE OUTLET STRUCTURE, SPRING VAILEY, WISC., MODEL STUDY.

(b) U.S. Army Engr. Dist., St. Paul.

(e) The purpose of the study is to ensure satisfactory performance of the intake structure and appurtenances. Of primary concern was the performance of the morning glory intak? under anticipated heads up to $80 \mathrm{ft}$. A 1:20scale plastic model reproduced a portion of the approach area, the morning glory intake, the elbow below the intake, the horseshoe conduit, a stilling basin, and about $400 \mathrm{ft}$ of the exit channel. The morning glory intake was housed in a headbay which reproduced appropriate entrance conditions.

(i) Completed.

(g) See $(h)$.

(h) "Outlet Structure for Eau Galle Reservoir, Eau Galle River, Wisconsin; Hydraulic Model Investigation," Rept. TR 2-774.

(6018) MONTEREY HARBOR, CALIF., MODEL STUDY.

(b) U.S. Army Engr. Dist., San Francisco.

(e) The approved project entails extension of the existing rubble-mound-type breakwater about $1600 \mathrm{ft}$ in an easterly direction to the west side of a proposed 400-ft-wide navigation entrance which would be formed by construction of a companion dogleg-aligned east breakwater about 2150 ft long that would extend in a southeasterly direction to shore. This expanded enclosure will provide increased protection for the fishing fleet operating 
from this basin and will permit development of greatly expanded recreational facilities associated with boating and other water sports. The purpose of this investigation is to study the efiects of storm wave action on the harbor assuciated both with the surge-type waves having periods ranging from about 25 to 300 sec and short-period waves considered to range from about 5 to $20 \mathrm{sec}$. Determination of the effect of this range of wave conditions on the approved harbor expansion is required in advance of actual construction to ensure that (a) selection of an optimum navigation entrance to the harbor is possible both with respect to width and position, (b) the minimum amount of breakwater is used in satisfying wave-protection requirements for proposed inner-harbor development, and (c) any resonance characteristics an otherwise satisfactory harbor boundary may have are fully investigated to permit optimum positioning of inner-harbor anchorage areas.

The 1:120-scale model was of the fixed-bed type and was molded of concrete except for the breakwaters which were constructed of rubble, sized to simulate that required for prototype construction. The model reproduced sufficient area along the shoreline northerly, easterly, and oceanward to ensure that propagation of waves shoreward was adequately simulated. The model had an area of $7800 \mathrm{sq} \mathrm{ft}$, equivalent to about 4 square miles in nature. Waves were generated by two sections of a vertical-bulkhead plunger-type wave machine which can be aligned so as to reproduce the average curvature of a wave front bent by refraction as it travels through shallow water. The generators, by use of couplings, operated from a single motor power source. Electrical printed-circuit-type wave measuring rods were used in connection with automatic recording equipment to obtain necessary wave-height data.

(f) Tests complete; report in progress.

(g) It was found that either of the two proposed improvement plans tested would offer an improvement over existing conditions in the harbor, and both of the plans would offer approximately the same amount of protection to the harbor. The harbor basins responded to some extent to several of the long-period waves tested; however, no serious resonance was noted. Wave and current conditions in the newly formed basins of the proposed improvement plans compared favorably with those in the existing small-boat marina.

(6019) FORT SMITH REACH, ARKANSAS RIVER, MODEL STUDY.

(b) U.S. Army Engr. Dist., Little Rock.

(e) The purpose is to study navigation conditions at the mouth of Poteau River and the two bridges at Fort Smith, Ark., to determine modification required in the existing bridge; and to develop a plan of regulating structures required to provide satisfactory navigation conditions. The investigation was conducted on a l:120-scale, semifixed-bed model, reproducing about 3.3 miles of the Arkansas River and adjacent overflow areas, the mouth and about 1.4 miles of the Poteau River, one railroad and one highway bridge, and other structures that might affect flow conditions.

(f) Tests complete; report in progress.

(g) Results indicated that: the navigation spans in the two existing bridges would have to to be modified; the flow from the Poteau River would have little effect on navigation except at maximum flow in the Poteau River and little or no flow in the Arkansas River; the stone-fill revetment along the right bank above the mouth of the Poteau River should be raised to prevent Arkansas River flows from moving into the Poteau River channel; and additional dikes would be required along the left bank to provide sufficient depth for navigation.

(6020) LOCK AND DAM NO. 1't, ARKANSAS RIVER, MODEL STUDY OF NAVIGATION CONDITIONS.

(b) U.S. Army Engr. Dist., Tulsa.

(e) The purpose is to investigate navigation conditions with the proposed structures, to determine the location and width of a navigation channel, and to develop a plan of regulating structures required to provide satisfactory navigation conditions. The investigation is being conducted on a 1:120-scale semifixed-bed model, reproducing about 4.25 miles of the Arkansas River, Bruce Island, Cherokee Chute, and adjacent overbank area near old Fort Coffee on the right bank and Wilsons Rock on the left bank. The model also includes the lock and dam structure and existing channel regulating structures.

(f) Suspended.

(g) Results indicate that satisfactory navigation conditions can be developed with the locks and dam at the site selected.

(6021) LOCK AND DAM NO. 17, VERDIGRIS RIVER, OKIA., MODEL STUDY OF NAVIGATION CONDITIONS.

(b) U.S. Army Engr. District, Tulsa.

(e) The purpose is to determine the adequacy of the proposed channel dredging and realignment, and to develop modifications which might be required to overcome undesirable navigation conditions. The investigation was conducted on two 1:120-scale, fixed-bed comprehensive models. One model reproduced about 1.7 miles of the Verdigris River and adjacent overbank area in the vicinity and upstream of Lock and Dam No. 17. The second model reproduced about 2.1 miles of the Verdigris River and adjacent overbank area downstream of Lock and Dam No. 17.

(f) Tests complete; report in progress.

(g) Results indicated that realignment of the banks at the confluence of the navigation canal and river would be required to provide satisfactory navigation nditions.

(6022) LOCK AND DAM NO. 8, 3KANSAS RIVER, MODEL STUDY OF NAVIGATION C. JNDITIONS.

(b) U.S. Army Engr. District, I, ttle hu.

(e) The purpose is to investigate various plans of regulating structures and to develop modifications as required for the development of a channel of adequate dimensions and satisfactory navigation conditions in the approaches to the lock. The investigation is being conducted on a movable-bed model reproducing about 10 miles of the Arkansas River and adjacent overbank areas to a scale of $1: 120$ horizontally and 1:80 vertically.

(g) Plans developed produced satisfactory channel dimensions except in a few troublesome reaches.

(6023) LOCK CULVERT DISCHARGE BASINS, MODEL STUDY.

(b) U.S. Army Engr. District, Huntington. 
(e) The purpose is to provide information on possible outlet basin information which could be used to reduce the residual head across the lower miter gates at completed projects or obviate it at projects proposed or under construction.

A l:25-scale model of the lock culvert outlet basin was constructed in an existing flume. The model reproduced a l25-ft-wide section of rectangular river channel. A 25-ft-wide by 75-ft-long tank located outside the channel simulated a portion of the lock chamber. The single culvert outlet basin located in the channel section was conncected to the tank by a 16- by 18-ft culvert. The shape and size of the outlet basin were based on an outlet design used at the Cannelton Locks.

(f) Completed.

(g) See (h).

(h) "Lock Culvert Outlet Basins; Hydraulic Model Investigation," Rept. MP 2-794, Feb. 1966.

(6024) JONES BLUFF LOCK AND DAM, ALABAMA RIVER, MODEI, STUDY OF NAVIGATION CONDITIONS.

(b) U.S. Army Engr. District, Mobile.

(e) The project involves the construction of a dam, a 68,000-kw power plant, and a 45-ft-lift, 84by 600-ft lock 245.4 miles above the mouth of the Alabama River. The project will provide 9-ft navigable depths for 80 miles upstream. The purpose of the study is to investigate conditions with the proposed plan and to develop modifications which might be required to overcome any undesirable navigation conditions.

The investigation was conducted on a 1:100scale, fixed-bed comprehensive model that reproduced the proposed structures and about 3.6 miles of the Alabama River and adjacent overbank area.

(f) Test complete; report in progress.

(g) Results indicated that it would be necessary to modify dredging along the left bank above the lock in the upper lock approach, and ports would be required in the upper guard wall to provide satisfactory navigation conditions during high flows. Alignment of the right bank below the powerhouse and modification of the lower guard wall would be required to overcome the effects of powerhouse flow with no flow through the spillway. A rapid increase in powerhouse flow could cause difficulty for upbound tows approaching the lock. No difficulty was indicated for normal powerhouse start. Lock emptying should not generate velocities high enough to cause damage on the riverbank opposite the lock discharge outlet.

\section{(6025) THXAS COAST HURRICANE SURGE MODEL STUDIES.}

(b) U.S. Army Engr. Dist., Galveston.

(e) The purpose is to determine the effectiveness of hurricane surge protection plans for the Galveston Bay complex. Other studies of bay circulation patterns, salinity, shoaling regimens, deep- and shallow-draft navigation, fish and wildlife, and pollution will be conducted in other available models and general test facilities.

The Galveston Eay hurricane surge model reproduces the coast from Freeport on the south to High Island on Bolivar Peninsula on the east. The model includes an average width of the Gulf of Mexico of about 25 miles, measured normal to the Gulf; all of the barrier islands in the bay interior, including its many connecting arms, lakes, and lagoons; and the coastal area within this sector up to a maximum elevation of $20 \mathrm{ft} \mathrm{msl}$. The model reproduces normal tides as well as Gulf surges created by hurricane forces. The model is of the fixed-bed type molded of concrete to linear scale ratios, model to prototype, of l: 100 vertically and 1:3000 horizontally. Automatic tide generators reproduce normal tides and tidal currents throughout the model. the hurricane surges will be reproduced by a horizontal-displacement type surge generator.

(g) Analysis of the results of tests conducted during the year was not completed. However, it was apparent that either of the two major hurricane protection plans would provide protection for the area inland from the barrier when the navigation openings were closed. The Alpha plan, located on the coastline of the Gulf of Mexico, would provide protection for a greater area since it shelters practically the entire area inland from the coastline. The Gamma plan leaves unprotected a major portion of West Bay, the entire city of Galveston, and all of East Bay. The Texas City, LaMarque-Hitchcock system, when completed, will provide protection for these towns from surges not in excess of $20 \mathrm{ft} \mathrm{msl.}$

(6026) UMPQUA RIVER ESTUARY, OREG., MODEI STUDY.

(b) U.S. Army Engr. District, Portland.

(e) The existing authorized project in the Umpqua River entrance provides for a channel $26 \mathrm{ft}$ deep at mllw with no specified width for about $5000 \mathrm{ft}$ across the entrance bar, and thence $22 \mathrm{ft}$ deep and $200 \mathrm{ft}$ wide to Gardiner and Reedsport. The north and south jetties at the river mouth are about 7800 and 3800 ft long, respectively. A training jetty inside the south jetty is $5500 \mathrm{ft}$ long. The purpose of the study is (a) to obtain the optimum layout of a jetty system or other structure to reduce crosscurrent action and maintenance dredging of the entrance to a minimum, and (b) with the optimum for a guide, to adapt the existing jetty system to approach the optimum to the limit allowed by economic considerations.

The model reproduces the lower 14 miles of the Umpqua River and pertinent offshore areas to linear scales of 1:300 horizontally and 1:100 vertically. An additional 14 miles of the Umpqua River and 20 miles of the Smith River are reproduced schematically in order to include the upstream tidal reaches. All portions of the model are initially of the fixed-bed type, with provisions for converting the entrance area to a movable-bed type if movable-bed studies are required. Tides and tidal currents, freshwater inflow, density currents, waves, and other phenomena significant to the movement and deposition of sediments are reproduced and studied.

(g) Sixed-bed shoaling tests and tests to reduce cross-channel currents indicated that the best improvement plan tested would involve extension of the training jetty to the outer end of the south jetty (plan 1). Although the model indicated that no appreciable improvement in shoaling was obtained for this plan, the cross-channel currents were practically eliminated.

(6027) GASTINEAU CHANNEL, ALASKA, MODEL STUDY. 
(b) U.S. Army Engr. District, Alaska.

(e) The existing authorized project in Gastineau Channel provides for a channel 75 ft wide with a depth of $0.0 \mathrm{mllw}$ from Fritz Cove to naturally deep water near Juneau, Alaska. The navigation channel is flanked by continuous tidal flats having elevations as much as $15 \mathrm{ft}$ above the channel bottom for a distance of about 3 miles.

The purpose of the study is to reduce shoaling in order to maintain a suitable navigation channel; various dike layouts which will isolate the channel cut from the surrounding area will be investigated.

The model reproduces the westernmost 8 miles of Grstineau Channel and Fritz Cove to linear scales of $1: 500$ horizontally and $1: 100$ vertically. Tides, tidal currents, and freshwater inflow significant to the movement and deposition of sediments are reproduced and studied. All portions of the model are of the fixedbed type.

(g) Fixed-bed shoaling tests indicated that the best plan for improvement would consist of a 17,250-ft-long impermeable dike located along the north side of the navigation channel. This plan indicated a 90.5 percent in shoaling for the 4- by $75-\mathrm{ft}$ channel, a 91.5 percent reduction for the 12-by 150-ft channel, and an 84.5 percent reduction for the 30 - by 300-ft channel.

6028) FIRE ISIAND INLET, LONG ISIAND, N.Y., MODEL STUDY.

(b) U.S. Army Engr. Dist., New York.

(e) Fire Island Inlet, located on the south shore of Long Island, N.Y., connects the Atlantic Ocean with Great South Bay. The inlet is about 3 miles long and approximately $1 / 2 \mathrm{mile}$ wide, extending generally east and west between Oak Beach on the north and the western end of Fire Island on the south. Great South Bay, the inland waterway to which Fire Island is the main entrance, is a tidal body 25 miles long and 2 to 5 miles wide with a general depth of about 6 to $25 \mathrm{ft}$ at mlw. Attempts have been made to stabilize an entrance channel through Fire Is land Inlet with little success. The purpose of the study is to provide quantitative data on the direction and velocity of tidal currents under existing conditions and with various proposed training structures installed, and by qualitative movable-bed tests to determine probable areas of erosion and deposition.

A movable-bed model, with scale ratios of $1: 500$ horizontally and 1:100 vertically, reproduces all of Fire Island Inlet and a portion of the Atlantic Ocean. Tides, tidal currents, and wave action in the Atlantic Ocean are reproduced.

(g) It was tentatively concluded that the optimum locations and dimensions of the littoral reservoir, the deposition area, and the cunnecting channel have been determined; however, the comprehensive testing program was not completed and definite conclusions could not be made.

6029) EFFECTS OF PNEUMATIC BARRIERS ON SALINITY INTRUSION, MODEL STUDIES.

(b) U.S. Army Engr. Dist., Philadelphia.

(e) Prolonged drought conditions, plus diversion of water from the Delaware Easin to supply New Yorr. City, resulted in reduced upland flows into the Delaware estuary. Upland flow is the controlling factor in preventing the upstream advance of the salinity front in the estuary to the extent that the Philadelphia water supply is contaminated. Other means for retarding the advance of salt water up the Delaware are being sought.

The purpose of the study is to determine if the additional agitation provided by pneumatic barriers would displace the salinity front in a downstream direction for steady-state conditions, or retard the rate of advance of the salinity front during periods of decreasing upland flow. The work was accomplished on the existing Delaware River model. (See No. 425).

(f) Completed.

(g) The results of tests in the Delaware model indicated that pneumatic barriers would have no significant effects on salinity intrusion for either steady-state of transient conditions. This is attributed to the fact that salt and fresh water in the Delaware are well mixed vertically by existing tidal forces, and additional mixing by supplemental means has little effect on the phenomena. The results of the one test in the New York Harbor model indicate that the pneumatic barriers would be very effective in reducing the extent of salinity intrusion for steady-state conditions. Additional testing to determine such things as the number of barriers required and the best barrier locations is indicated.

(6030) WEST POINT DAM, CHATTAHOOCHEE RIVER, GA., GENERAL MODEL STUDY.

(b) U.S. Army Engr. District, Savannah.

(e) The project calls for a gravity-type concrete spillway with crest gates across the main river channel, a penstock intake section and powerhouse, and a concrete nonoverflow section along the right riverbank. Earth embankments extend to high ground on each side of the structure. The structure will provide hydroelectric power, flood control, and more dependable streamflow for navigation and recreational uses.

The purpose of the study is to determine the performance of the structure as affected by flow conditions in the approach channel and the development of a satisfactory energy dissipator below the spillway. Particular emphasis was placed on the selection of a basin which would operate satisfactorily under conditions of a high unit discharge and with tailwater depths insufficient for ideal performance of either a roller-bucket or hydraulic-jump type basin.

The model tests were conducted on a 1:60-scale general model that reproduced about $1700 \mathrm{ft}$ of the approach, the spillway, powerhouse, and $1500 \mathrm{ft}$ of the exit area. Sufficient overbank areas on each side of the structure were provided to reproduce expected flow conditions. Initial study of the enery dissipator was conducted on a 1:60-scale section model of the spillway and stilling basin which was installed in a l-ft-wide glass-sided flume. This permitted observation of subsurface flow conditions in the basin and facilitated modifications of the basin.

(f) Tests complete; report in progress.

(g) The model study indicated that due to insufficient tailwater depth the bucket-type energy dissipator of original design was inadequate. A jump-type basin was developed which gave 
satisfactory performance although the jump was not contained in the basin. Partial energy dissipation within the basin was acceptable because of sound rock below the structure. Although the capacity of the spillway was less than expected, modifications to the spillway abutments furnished desired capacity. Tests also indicated that the presence of submerged cofferdikes upstream of the structure had little effect on discharge capacity.

(6031) WALNUT CREEK, CALIF., MODEL STUDY OF DROP STRUCTURE.

(b) U.S. Army Engr. District, Sacramento.

(e) The purpose of the study is to determine the optimum size and configuration of the stilling basins for drop structures 2 and 3, the stability of the riprap downstream from the stilling basins, and the adequacy of the inlet transition upstream from drop structure 2 . A 1:20-scale model reproduced approximately $570 \mathrm{ft}$ of the trapezoidal channel downstream from drop structure 2, the structure, $1300 \mathrm{ft}$ of the concrete-lined channel upstream from the structure, the inlet transition, and 200 ft of trapezoidal channel upstream from the transition. A second model, scale 1:20, reproduced approximately $580 \mathrm{ft}$ of the trapezoidal channel downstream from drop structure 3 , the structure, and $1400 \mathrm{ft}$ of the concretelined channel upstream from the structure.

(f) Completed.

(g) See $(h)$.

(h) "Drop Structures for the Walnut Creek Project, Walnut Creek, California; Hydraulic Model Investigation," TR 2-730, June 1966.

(6032) OLD RIVER CONTROL STRUCTURE, LA., PROTOTYPE TESTS.

(b) U.S. Army Engr. Dist., New Orleans.

(d) Field study; applied research.

(e) The project, located on the Mississippi River approximately 50 miles downstream from Vidalia, La., consists of an ll-bay, 484-ft-long gated spillway. Flood control is obtained by diverting through the structure approximately onefourth of the flow in the Mississippi River. The purpose of the study is to measure vibration of the structure during periods of high discharge and determine the magnitude of the resulting displacements. Utilizing these data, stresses caused by the dynamic response of the structure will then be computed. Accelerometers to measure vibration in the principal directions were located on the piers, gate guides, and crane rail of bays 6 and 10 as well as the left downstream wing wall and the bridge walkway. Data were recorded on both magnetic tape and oscillograms.

(6033) KAYSINGER BLUFF DAM, OSAGE RIVER, MO., GENERAL MODEL STUDY.

(b) U.S. Army Engr. Dist., Kansas City.

(e) Plans call for an earth-fill dam about $5000 \mathrm{ft}$ long with a height of $97 \mathrm{ft}$ above the valley floor, a 4-bay gated overfall, a hydraulic jumptype stilling basin and an adjacent power facility in the right terrace. The purpose of the investigation is to study the adequacy of the spillway and the performance of the hydraulic jump-type stilling basin with and without diversion through the powerhouse, flow conditions in the outlet channel, and adequacy of various sizes of riprap in the outlet channel.
A 1:60-scale undistorted model that reproduced $1400 \mathrm{ft}$ of the approach and $1900 \mathrm{ft}$ of the exit areas, the spillway, powerhouse, nonoverflow sections, and portions of the earth embankment was utilized to conduct the study.

(f) Tests complete; report in progress.

(g) The discharge capacity of the original design spillway was slightly less than expected; however, the capacity was increased by increasing the radius of the abutments. An unstable surging of flow that occurred on the upstream side of the spillway gates with the original design during operation with large partial gate openings was eliminated by decreasing the length of the gate piers upstream from the gates. Although the original design stilling basin performed satisfactorily, a more economical and efficient design was developed. The discharges at which failure of the riprap placed on the slopes of the outlet channel will occur were determined.

(6034) BRANCHED OAK DAM, NEBR., MODEL STUDY OF OUTLET WORKS.

(b) U.S. Army Engr. Dist., Omaha.

(e) The outlet works will consist of a rectangular intake structure with two inlets ( 3.5 by $12 \mathrm{ft}$ ) and a 6 - by 12-ft riser shaft $30 \mathrm{ft}$ high, followed by an elbow and transition, a 6-ftdiam circular conduit 370 ft long, a flared transition with a parabolic invert, an SAF stilling basin, and an exit channel. The purpose of the study is to verify the performance of the structure, and particularly to ensure against undesirable characteristics such as surging during transition from weir control to pressure flow or excessive vibration under pressure flow.

A 1:10-scale plastic model reproduced the outlet works including the intake structure, the elbow, the transition, the circular tunnel, the outlet transition, the stilling basin, and about $150 \mathrm{ft}$ of exit channel. Pressures in the model were determined by piezometers located in appropriate areas of the model. The intake structure was installed in a baffled headbay which reproduced the approximate geometry and conditions at entry .

(f) Completed.

(g) Discharge characteristics, entrance losses, flow conditions, and pressures throughout the original design outlet works for Branched Oak Dam were found to be satisfactory. The SAF stilling basin provided adequate energy dissipation, and a practical scheme of riprap protection for the exit channel was determined. Although undesirable conditions were observed with an increased height of the riser shaft, it is considered that a balanced design for a similar structure with a relatively high riser shaft can be obtained provided the length and size of the conduit are such that the resistance offered by the conduit is sufficient to raise the hydraulic gradient in the riser shaft to an elevation essentially the same as that of the weir crest before the upper pool elevation exceeds that of the bottom surface of the cover plate.

(6035) BARREN RIVER DAM, BARREN RIVER, KY., STILWING BASIN PROTOTYPE PRESSURE TESTS.

(b) U.S. Army Engr. District, Louisville.

(d) Field study; applied research.

(e) Barren River Dam is a 146-ft-high earth dam used for flood control, recreation, and low 
flow augmentation. The outlet works are a three-gated intake structure and a 17-ft, elliptically shaped tunnel with a 10,000-efs capacity. An uncontrolled, saddle-type spillway is located on the right abutment. The stilling basin is 40 ft wide with a single row of streamlined baffle blocks and an end sill.

The purpose of the study is to measure average and fluctuating pressures against the stilling basin sidewall and on a baffle block. The sidewall pressure magnitude and areal extent will give useful data for the design of similar stilling basins. Baffle pressures will provide full-scale data on turbulence pressure fluctuations and possible cavitation. Prototype test facilities include four slots for pressure transducer carriages and ten embedded pressure transducer boxes on and near a baffle block. A pressure transducer will be installed on each carriage and measurements made at various flow depths. Data will be recorded on oscillographs and magnetic tape for later electronic correlation.

(6036) BANKHEAD DAM, BLACK WARRIOR RIVER, ALA., SECTION MODEL STUDY OF SPILLWAY.

(b) U.S. Army Engr. District, Mobile.

(e) The existing spillway at John H. Bankhead Lock and Dam, Black Warrior River, Ala., which has served its useful life, is to be modified to provide an adequate structure and, under present criteria, extend its economic life 50 years.

The purpose of the investigation is to study pressure conditions and discharge characteristics of the existing and modified spillways and qualitatively evaluate the effectiveness of an air-vent system. A 1:30-scale section model reproduced a 49-ft-wide gate bay, and two adjacent half bays (net spillway length $98 \mathrm{ft}$ ), and sufficient length of approach and exit channels.

(f) Tests completed.

(g) Test results indicated that cavitation-range pressures would be encountered with future conditions on both the existing and modified spillways. Aerating the low-pressure zones by means of air vents failed to raise pressures out of the cavitation range as the air introduced (even compressed) did not spread sufficiently in a lateral direction.

(6037) NEW BUFFALO HARBOR, NEW BUFFALO, MICH., MODEL STUDY.

(b) U.S. Army Engr. District, Chicago.

(e) The proposed small-boat harbor at New Buffalo is located at the mouth of Galien River on the southeast shore of Lake Michigan. This project is cosponsored by the Corps of Engineers and local interests. The harbor will be protected by the north and south breakwaters which converge westward toward the entrance in the form of an arrowhead to furnish an enclosed area of about 8 acres. The proposed 200-ft navigation opening faces west and is located about $800 \mathrm{ft}$ northwesterly from the mouth of the Galien River. The entrance channel is 80 to $180 \mathrm{ft}$ wide by $10 \mathrm{ft}$ deep and $800 \mathrm{ft}$ long. New Buffalo Harbor is used as a base or port of call for light-draft recreational and commercial fishing sessels. The purpose of the study is to determine: (a) the relative effects of waves of various magnitudes that approach the problem area from the most critical storm directions; (b) the relative efficiency of the several separate proposed plans of improvement in protecting the harbor against storm-wave action; and (c) whether design modifications should be made to improve navigation and harbor conditions during storms.

The harbor model tests were conducted on a 1:75-scale, undistorted, fixed-bed model, constructed of concrete except for the breakwaters which simulated the stone characteristics of the proposed breakwaters. The model reproduced all the inner-harbor area, the breakwater system, and sufficient beachline and offshore hydrography to permit simulation of waves propagated toward the harbor from the directions between north-northeast and west. The model covered an area of $5600 \mathrm{sq}$ ft, approwimately 1.1 square riles in nature. Waves were generated by a 40-ft-long plungertype wave machine. Wave heights at selected locations in the model were measured with electrical printed-circuit gages, and were recorded electrically with a multichannel oscillograph.

(f) Completed.

(g) (See $(h)$.

(h) "Selection of Optimum Alignment, Length, and Height of Breakwaters, New Buffalo Harbor, Michigan; Hydraulic Model Investigation," Rept. TR 2-761, Feb. 1967.

(6038) MAGIC ISLAND COMPLEX, HONOLULU, HAWAII, MODEL STUDY.

(b) U.S. Army Engr. District, Honolulu.

(e) Magic Island is a land-reclamation project. Fronting Ala Moana Park in Honolulu, approximately 120 acres of shallow coral reef will be filled in to create new land for recreational and associated commercial use. Ala Wai Boat Harbor, a pleasure-boat harbor, lies to the east of the project; Kewalo Basin, the home of Hawaii's commercial fishing fleet, lies to the west. The purpose of the investigation is (a) to study wave action in Kewalo Basin for existing conditions and following the proposed construction; (b) to develop remedial plans for alleviation of undesirable navigation conditions and wave action in Kevalo Basin; (c) to determine extent of pollution in inner lagoon and develop a satisfactory circulation system therein; and (d) to study wave action in Ala Wai Harbor before and after proposed revisions to that harbor.

The three-dimensional, 1:100-scale model was molded in cement mortar, and reproduced the entire problem area and underwater contours to an offshore depth of $80 \mathrm{ft}$. Sufficient additional offshore area was included to permit generation of test waves from all critical direction. Waves in the model were generated by an 85-ft-long wave machine; waveheight data were secured by use of electrical measuring and recording apparatus. Model appurtenances also included a system for manual reproduction of tide levels in the area.

(f) Completed.

(g) See $(h)$.

(h) "Magic Island Complex, Including Kewalo Basin and Ala Wai Boat Harbor, Honoluzu, Oahu Hawaii; Hydraulic Model Investigation," Rept. TR 2-767, April 1967. 
(6039) HILO HARBOR ISUNAMI BARRIER, HAWAII, STABILITY TEST OF NAVIGATION OPENING STRUCTURE.

(b) U.S. Army Engr. District, Honolulu.

(e) The project will provide a breakwater or barrier across the entrance to Hilo Harbor, Hawaii, to protect the harbor and the city of Hilo against the attack of damaging tsunami waves. A navigation pass will be provided through the barrier. Passage of tsunami waves will result in several minutes of high-velocity flow through the navigation opening. The purpose of the study is to determine the effect of tsunami-induced high-velocity currents through the navigation opening on stability of the barrier heads. Two model arrangements were used during the test program. Tests designed primarily to provide data on the stone size required for stability of the barrier heads were conducted in a 1:60-scale model which reproduced onehalf of the navigation opening. Tests conducted to provide information on channel bottom or barrier toe protection were made with the full navigation opening reproduced at a scale of $1: 72$. Steady flow through the opening with a head differential of $28 \mathrm{ft}$ across the barrier was the basic test flow; this represented the peak flow condition caused by the design tsunami.

(f) Completed.

(g) $\operatorname{see}(h)$.

(h) "Steady Flow Stability Tests of Navigation Opening Structures, Hilo Harbor Tsunami Barrier, Hilo, Hawaii; Hydraulic Model Investigation," TR 2-742, Oct. 1966.

(6040) HILO HARBOR, HAWAII, MODEL STUDY OF BREAKWATER STABIIITY.

(b) U.S. Army Engr. Dist., Honolulu.

(e) Hilo Harbor is on the northeast coast of the Island of Hawaii, about 195 nautical miles southeast of Honolulu. The proposed plan to protect the harbor against seismic waves (tsunamis) and short-period wind waves (sea and swell) consists of extending the existing breakwater westward to a total length of about 10,570 ft, providing a navigation opening $600 \mathrm{ft}$ wide and $35 \mathrm{ft}$ deep, and constructing a breakwater about 4000 ft long on the west side of the harbor, extending eastward. The breakwaters are to be constructed of quarrystone and concrete armor units. The purpose of the study is to develop a breakwater trunk section that will be stable against the attack of seismic waves (tsunamis) and short-period wind wave (sea and swell). Stability tests of the breakwater trunk when subjected to seismic waves (tsunamis) were conducted at a 1:50 scale in a steel flume $230 \mathrm{ft}$ long, $6 \mathrm{ft}$ wide, and 4 ft deep. Model seismic waves (bores) were generated by a pneumatic-type bore generator, and measured and recorded electrically. Stability tests of the breakwater trunk when subjected to short-period waves were conducted at a $1: 50$ scale in a concrete wave flume 119 ft long, 5 ft wide, and 4 feet deep. Model waves were generated by a plunger-type wave machine, and measured and recorded electrically.

(f) Completed.

(g) Described in $(h)$.

(h) "Stability of Rubble-Mound Tsunami Barrier, Hilo Harbor, Hawaii; Hydraulic Model
Investigation," Rept. TR 2-792, Aug. 1967.

(6041) CRESCENT CITY, CALIF., MODEL STUDY OF HARBOR

(b) U.S. Army Engr. District, San Francisco.

(e) The purpose of the investigation is to study the effects of storm wave action involving short-period waves, 5 to $20 \mathrm{sec}$, on the existing harbor and with various proposed plans of improvement installed in the model. These proposed plans of improvement involve determination of (a) optimum arrangements for an enlarged breakwater system, (b) effects on harbor wave action within an area inside the harbor which would be dredged to and maintained at increased project depths necessary to satisfy navigation requirements for deeper draft vessels, and the effects of wave action on the small craft in existing marina areas and also the feasibility of possible marina expansion should such action become desirable in the future.

The 1:125-scale model was of the fixed-bed type, and was molded of concrete except for the breakwaters which were constructed of rubble, sized to simulate that required for prototype construction. The model reproduced sufficient area along the shoreline north, south, and oceanward of the harbor site to ensure that propagation of waves toward the problem area was adequately simulated. The model had an area of about $7800 \mathrm{sq} \mathrm{ft}$, equivalent to about 4.4 square miles in nature. Waves were generated by a 60-ft-long, plungertype wave machine. Electrical printed-circuittype wave measuring rods in connection with automatic recording equipment were used to obtain necessary wave-height data.

(f) Tests complete; report in progress. The testing program was completed, and preparation of the final report and filming of motion picture sequences of the model tests were initiated.

(g) Results of the model tests indicate that (a) wave action could be reduced to a satisfactory level in the inner harbor basin by installation of a 400-ft-long westerly extension of the inner breakwater; and (b) a 2000-ft extension of the existing outer breakwater along its original alignment in conjunction with a 1200-ft-long companion breakwater extending from Whaler Island would substantially improve navigation and mooring conditions in the harbor.

\section{(6042) LABORATORY RESEARCH ON DIKE DESIGN.}

(b) U.S. Army Engr. Districts, Memphis, Vicksburg and New Orleans.

(d) Experimental; applied research.

(e) The purpose of the study is to determine the relative effectiveness of various factors, such as alignment, elevation, length, permeability, etc., in stablizing low-water channels and in providing the required increase in depth.

The investigation is being conducted in a flume $230 \mathrm{ft}$ long by $20 \mathrm{ft}$ wide, including two bends and a relatively long, straight reach between bends. The study is of the movable-bed type with a fine, uniform sand used for bed material.

(g) Results indicated that use of vane-type dikes with spur dikes would produce better results than use of spur dikes only at considerably lower cost in the closure of back channels. Plans using vane-type dikes were developed 
for use in two reaches of the Mississippi River. The most promising dike designs are being built and tested in the field.

(6838) BELTZVILLE DAM, POHOPOCO CREEK, PA., MODEL STUDY OF OUTLET WORKS.

(b) U.S. Army Engr. District, Philadelphia.

(e) The outlet works consist of an inlet channel, a controlled-type intake tower, a rectangular conduit, stilling basin, and an outlet channel. The purpose of the study is to investigate the hydraulic characteristics and develop the optimum design of a selective withdrawal outlet works.

A 1:20-scale model is being used in the study. The model reproduces a sufficient area of the reservoir to obtain natural conditions at the intake, the intake structure and conduit, the stilling basin, and about $100 \mathrm{ft}$ of the outlet channel. Fresh and salt waters are being used to simulate anticipated conditions of stratification in the reservoir and evaluate the effectiveness of the proposed structure to selectively withdraw from the desired levels of the reservoir.

(g) The flood-control intake and conduit performed satisfactorily. However, subatmospheric pressures were detected in the original design of the water quality conduit, and modifications to the conduit were made in an effort to eliminate these conditions.

(6839) CHATFIELD DAM, SOUTH PLATTE RIVER, COLO., MODEL STUDY OF OUTLET WORKS.

(b) U.S. Army Engr. District, Omaha.

(e) The project calls for an ungated chute spillway in the left abutment for return of high flows released from the reservoir to the river approximately 0.7 mile downstream of the dam axis. The outlet works are located through the earth embankment about $2000 \mathrm{ft}$ to the right of the spillway. Discharges from the outlet works will reenter the river downstream of the dam through a discharge channel approximately $0.8 \mathrm{mile}$ long. The purpose of the study is to verify the performance of the structure with emphasis on the performance of the duckbill crest under submerged conditions and the study of head loss due to the duckbill and intake structure. A 1:25-scale model reproduces a sufficient portion of the reservoir area to obtain natural conditions at the intake, the duckbill crest, the intake structure, the conduit, the stilling basin, and about 200 ft of exit channel.

(f) Suspended.

(g) The original design stilling basin provided adequate enery dissipation for the full range of discharges anticipated without excessive scour in the downstream exit channel.

(6840) COPAN DAM, LITTLE CANEY RIVER, OKLA., MODEL STUDY.

(b) U.S. Army Engr. District, Tulsa.

(e) The project provides a flood-control reservoir about 2 miles southwest of the town of Copan, Okla. The spillway will be on the right abutment of the dam and will contain four 50- by 35.5-ft tainter gates. The weir crest will be at elevation 696.5. The stilling basin will consist of a 132.5-ft horizontal apron at elevation 665.5. The purpose of the study is to investigate stilling basin performance, exit flow conditions, flow con- ditions over the retaining dike, and the stability of riprap on the dike and dam embankments.

The investigation is being conducted on a 1:60-scale model that reproduces the spillway, 1600 ft of the exit area, and sufficient overbank area on each side of the structure.

(g) Tests indicated that the original basin can be shortened.

(6841) HUGO DAM, KTAMTCHI RIVER, OKIA., MODEL STUDY OF SPILLWAY.

(b) U.S. Army Engr. District, Tulsa.

(e) The project provides for a flood-control reservoir on the Kiamichi River approximately 150 miles south of Tulsa, Okla., and will include a gated spillway with a gross crest length of $290 \mathrm{ft}$ at an elevation of 387.5 . Earth embankments with tops at el 452.5 extend to high ground on each side of the structure. The structure will provide flood control and more dependable streamflow. The purpose of the study is to investigate approach flow conditions, exit flow conditions, optimum elevation of the stilling basin apron, discharge characteristics of the structure, and flow conditions in the vicinity of two bridges located downstream of the structure. The investigation was conducted on a $1: 60$ scale general model that reproduced $1600 \mathrm{ft}$ of the approach, the spillway, $1600 \mathrm{ft}$ of the exit area, and sufficient overbank area on each side of the structure.

(f) Tests complete. Final report in progress.

(g) Tests indicated that the original design spur dikes and abutments created an undesirable periodic surging of flow and fluctuations of the upper pool water-surface elevation as great as $15 \mathrm{ft}$ in the vicinity of each abutment. The undesirable flow condition was eliminated by removing the spur dikes near the abutments.

(6842) KAW DAM AND RESERVOIR, ARKANSAS RIVER, OKIA., MODEL STUDY OF SPILLWAY.

(b) U.S. Army Engr. District, Tulsa.

(e) The ogee spillway (crest elevation of 797.5) consists of eight 50-ft-wide by 47-ft-high tainter gates. The purpose of the study is to investigate approach and exit flow conditions, discharge characteristics of the structure, and wave heights in the vicinity of the downstream embankments.

The investigation is being conducted on a l:100-scale general model that reproduces $3000 \mathrm{ft}$ of the approach, the spillway, $2500 \mathrm{ft}$ of the exit, and sufficient overbank area on each side of the structure.

(g) Tests of the original spillway design were conducted to obtain approach and exit velocities, water-surface profiles, spillway calibration data, and wave heights in the vicinity of the downstream embankments. Various basins were tested. Scour tests were conducted to determine the design of the left training wall. The right training wall was modified to reduce the wave heights in that area. Tests indicated that approach flow conditions and discharge characteristics with the original design were satisfactory. The length and height of the left training wall were increased in order to reduce the scour hole downstream from the basin and wave heights along the embankments. 
(6843) MERAMEC PARK RESERVOIR, MERAMEC RIVER, MO., MODEL STUDY OF OUPLET WORKS.

(b) U.S. Army Engr. District, St. Louis.

(e) The project provides a vertical-faced weir upstream of the proposed gated intake structure for control of the temperature of water discharged downstream. Releases will pass over the weir and through the intake structure and 14-ft-diam, concrete-lined tunnel into a conventional stilling basin and the exit channel. The purpose of the investigation is to evaluate the effectiveness of the proposed water temperature control weir to selectively withdraw surface and near-surface waters from a stratified reservoir.

A 1:40-scale model is being used to reproduce an 800-ft-long by 500-ft-wide portion of the reservoir, the approach channel, weir, and the intake structure. Overbank areas are molded in concrete to prototype contours. The outlet works and water quality control weir are constructed of sheet metal. Salt and fresh waters are used for simulating a two-layer stratified reservoir.

(6844) NEW HOPE DAM, CAPE FEAR RIVER BASIN, N.C., MODEL STUDY OF OUTLET WORKS.

(b) U.S. Army Engr. District, Savannah.

(e) The structure will be constructed across the Haw River immediately below the mouth of the New Hope River and will include a multilevel intake structure and the adjoining outlet works consisting of a 19-ft-diam conduit approximately $330 \mathrm{ft}$ long and a conventional hydraulic-jump type stilling basin. The purpose of the investigation is to determine the hydraulic characteristics of the proposed intake structure and outlet works including pressure conditions, discharge capacity, flow conditions, and stilling basin performance. Flow conditions through and discharge capacities of the multilevel intakes are of particular interest since they are related to water quality interests.

A 1:20-scale model that reproduced a 200-ftwide, 300-ft-long portion of the reservoir, the intake structure and conduit, the stilling basin and a 350-ft-wide, 500-ft-long section of the exit channel was used for conduct of the study.

(f) Tests completed. Final report in progress.

(g) The adequacy of the original design multilevel intake structure was confirmed. Discharge characteristics and pressures throughout the outlet works were satisfactory for all conditions and the plan of operation anticipated in which releases will be provided through either the flood-control conduit intakes or the multilevel intakes. Selective withdrawal characteristics through the multilevel intakes indicated that the proposed structure will provide effective regulation for control of the quality of water released downstream of and from the stratified reservoir. Performance of the original design stilling basin was inadequate and the model was used to develop a satisfactory stilling basin as well as a plan of protective stone for the side slopes of the downstream exit channel.

(6845) REND IAKE RESERVOIR, BIG MUDDY RIVER, ILL., MODEL STUDY OF SPILLWAY.

(b) U.S. Army Engr. District, St. Louis.

(e) The project provides for a flood-control reservoir on the BiE Muday River approximately
50 miles north of Cairo, Ill., and will include an uncontrolled spillway with a gross crest length of $435 \mathrm{ft}$ at el $410 \mathrm{msl}$. Initial plans provided a 25-ft-wide notch with crest elevation of 405 in the center of the structure for the purpose of releasing flows up to 1000 cfs, the bank-full capacity of the downstream channel. The purpose of investigation is to study the adequacy of the spillway, stilling basin, and exit channel protective stone.

Model tests were conducted with a 1:16-scale section model that reproduced $120 \mathrm{ft}$ of the spillway (approximately 30 percent of the total) including the notched section and two adjacent 52-ft-wide portions of the spillway with crest elevation of 410 . Approach and exit channels were reproduced for distances of 250 and $300 \mathrm{ft}$, respectively. Upon completion of tests of the notched portion of the spillway, the model was revised to investigate flow conditions in the vicinity of the right abutment.

(f) Tests complete. Final report in progress.

(g) Tests indicated that the original, 25-ft-wide, ogee-shaped notched section should be revised to a broad-crested notched section of 31-ft width and that the impact-type stilling basin (32 ft long by $40 \mathrm{ft}$ wide) downstream of the notched section should be recessed 2 ft lower than the main stilling basin. Elements in the stilling basin were revised to provide more efficient energy dissipation. Flow conditions in the vicinity of the right abutment and in the approach and exit channels were satisfactory, and the exit channel riprap remained stable throughout all tests.

(6846) STUDIES OF SELECTIVE WITHDRAWAL FROM STRATIFIED RESERVOIRS.

(b) U.S. Army Engr. Districts, Savannah and Philadelphia.

(d) Experiment and analytical; applied.

(e) Research initiated to assist in the design of multilevel intake structures for the purpose of selectively withdrawing quality water from various levels of a stratified reservoir. The purpose is to determine the effect of the size and shape of an orifice on selective withdrawal characteristics from a stratified reservoir and to determine the limits of the zone of withdrawal, which will aid in locating monitoring systems.

The model facilities consist of a l-ft-wide by $20 \mathrm{ft}-\mathrm{deep}$ by $24-\mathrm{ft}$-long transparent plastic flume connected to a 15-ft-wide by 42.5-ftlong forebay. Fresh water and salt water are used to simulate a two-layer stratification of a given density differential. An orifice located in a removable plastic plate is installed across the flume. The flow through the orifice is regulated by setting up various head differentials across the plate. Instrumentation consists of a digital thermometer and several thermistors for keeping a record of temperatures throughout the system and a conductivity probe for determining the density profile.

(g) Basic data obtained with a number of different density differentials and various elevations of the interface relative to the square orifice confirmed the general form of the equation developed by A. Craya for a circular orifice and indicated the value of the constant of proportionality to be 1.90 . 
6847) TOCKS ISLAND DAM, DELAWARE RIVER, PA., GENERAL MODEL STUDY.

(b) U.S. Army Engr. District, Philadelphia.

(e) The project is part of a comprehensive plan for development of water resources of the Delaware River Basin. The proposed structure is located approximately 5 miles upstream of the Delaware Water Gap and 7 miles northeast of Stroudsburg, $\mathrm{Pa}$. The project calls for a chute spillway (gated) in the left abutment to return high flows released from the reservoir to the river approximately $1050 \mathrm{ft}$ downstream of the dam axis. An intake structure and powerhouse together with outlet works are included in the same general area. Discharges from the outlet works will reenter the river downstream of dam through a separate stilling basin. The purpose of the study is to verify the performance of the structure with emphasis on approach conditions to the spillway, stilling basin performance as affected by outlet works releases, and the location of the outlet works stilling basin. Two models are being used in the study. (a) A 1:60-scale general model reproduces the entire spillway and outlet works and about $2200 \mathrm{ft}$ of approach and $3000 \mathrm{ft}$ of the exit area. Sufficient overbank area is reproduced to simulate expected flow conditions. (b) A 1:64-scale spillway model was used to determine the possibility of combining energy dissipation features of the spillway and outlet works.

(g) The model study indicated that with anticipated tailwater depths the original basin design was unsatisfactory. A jump-type basin at a 10-ft lower elevation was developed which gave satisfactory performance although the jump was not contained in the basin. Sound rock below the structure made partial energy dissipation in the basin acceptable. The capacity of the spillway was acceptable and modifications to the spillway abutments reduced contractive effects and turbulence in the approach. Periodic surging in the gate bases was eliminated by widening the spillway bays. Satisfactory rock protection was developed along the downstream toe of the nonoverflow embankment.

6848) TIDES AND CURRENTS IN TIDAL WATERWAYS. (See also No. 6414, Mass. Inst. of Tech., p. 72).

(b) Office, Chief of Engrs., Dept. of the Army.

(d) Analytical; applied.

(e) The project involves evaluating of the various methods used or proposed for computation of tides and currents in estuaries and tidal canals. The study will be carried out in three phases: (a) A quantitative analysis of the effect of various approximations used in the "Erown's Reflected Wave Theory" and "Pillsbury's Slope Method," the two existing methods in common use for the prediction of vertical rise and fall of the tide and tidal flow patterns, to ascertain which (if either) of the various approximations may best be applied in any specific problem, and to pave the way, if possible, to other methods of calculation that would eliminate any shortcomings that may be revealed in the existing calculation methods. (b) Check of the calculations of the first phase with data determined from existing tidal estuaries and/ or canals, and from experiments conducted in laboratory models or other apparatus; work under this phase will include recommendation for the aforementioned laboratory investigation, close liaison therewith, and full use of data derived therefrom. (c) Final development of a method of calculating tides and tidal currents in canals and estuaries. The purpose is to develop an accurate method for computing tides and currents in estuaries and tidal canals.

(g) The computer program developed by MIT, under contract to WES, for predicting tides and currents in tidal waterways was applied to several routes for the proposed Isthmanian Sea-Level Canal, for a wide variety of tidal conditions, at the request of the U.S. Army Engineer District, Jacksonville. Work by MIT was continued on preparation of a report describing the method developed and the related computer program.

(6849) CHESAPEAKE BAY, MODEL STUDY.

(b) U.S. Army Engr. Dist., Balitmore.

(e) The purpose is to provide assistance in developing plans to improve the hydraulic, salinity, pollution, shoaling, and hurricane tide conditions that exist in the Chesapeake Bay Basin.

The model will be of the fixed-bed, siltinjection type with linear scale ratios of $1: 1000$ horizontally and $1: 100$ vertically, and will reproduce a portion of the Atlantic Ocean, all of Chesapeake Bay and the tributaries up to the limit of tidal action. The model will reproduce adjacent overbank areas up to the t20-ft msl contour. Tides and tidal currents will be reproduced in the model by automatic tide control machines and the appropriate freshwater inflow will be introduced into all major tributaries entering the bay. Observed prototype salinities will be produced in the ocean and by portion of the model, and provisions will be made for injecting silt into the model to simulate shoal deposits in the prototype. Studies of the dispersion of various contaminants will be made by releasing permanent dyes and tracing the movement of concentration with respect to time after release of the dye.

(6850) HOUSTON SHIP CHANNEL, RADIOACTIVE SEDIMENT TRACER TESTS. (See also No. 5245, p. 197).

(b) U.S. Army Engr. Dist., Galveston.

(c) Field study; applied research.

(e) The purpose is to trace the movement of radioactive sediment in order to determine how shoals are formed in the prototype so that the model can be adjusted, if necessary, to react in a similar fashion.

Various pieces of equipment were used for activating, placing in the channel, and tracing the sediment. The isotope gold 198 was utilized in the activation phase. The isotope was mixed with sample sediment in a special tank from which it was removed and placed on the channel floor by water pressure. A scintillation detector was attached to a sled pulled along the bottom for measuring activity. The activity was received and recorded by electronic equipment on the test boat.

(g) Rapid movement of sediment upstream was observed in the channel and very little movement occurred downstream. Very little sediment was detected moving out of the channel up into tributaries of the channel.

(6851) MATHEMATICS OF FLOW IN TIDAL INIETS. 
(b) Office, Chief of Engrs., Dept. of the Army.

(e) The project involves development of methods for computing current velocities and flow distribution in tidal inlets. All work on this project was accomplished by G.H. Keulegan and J.L. French of the National Bureau of Standards, and technical supervision of the work was accomplished by the Committee on Tidal Hydraulies.

(h) "Tidal Flow in Entrances; Water-Level Fluctuations of Basins in Communication with Seas," G.H. Keulegan, Tech. Bull. No. 14, Comittee on Tidal Hydraulics.

(6852) SAN DIEGO BAY, CAIIF., MODEL STUDY.

(b) U.S. Army Engr. Dist., Los Angeles.

(e) The proposed second entrance is needed to alleviate navigational hazards and delays, harbor congestion, and pollution problems. The purpose is to determine the effects of a second entrance to the bay across the southern portion of Silver Strand on the hydraulic regimen, circulation, pollution, and shoaling patterns of the Bay and adjacent areas.

The san Diego Bay model is of the fixed-bed type with a vertical scale of 1 ft (model) to $100 \mathrm{ft}$ (nature) and a horizontal scale of I ft (model) to $500 \mathrm{ft}$ (nature). The area covered by the model extends from just north of Point Loma to just south of the southern extremity of the bay and oceanward to the 100-ft contour of depth, representing approximately 108 square miles of prototype area. The model itself covers an area of about $12,000 \mathrm{sq} f t$. The model reproduces to scale all the hydrualic factors present in nature, such as tidal heights, current velocities, and circulation patterns.

(6853) SHOOTERS ISIAND, N.Y., MODEL STUDY OF NEW YORK AND NEW JERSEY CHANNELS.

(b) U.S. Army Engr. District, New York.

(e) The purpose of the study is to determine the effects of the removal of Shooters Island and widening Arthur Kill to provide terminal berthing areas on tides, currents, circulation patterns, and shoaling in adjacent navigation channels.

The study was conducted in the existing comprehensive, fixed-bed model of New York harbor which reproduces Lower and Upper New York Bays; Jamaica, Raritan, and Newark Bays; a portion of Long Island Sound; the East, Harlem, Hackensack, Passaic, and Raritan Rivers; and Hudson River from The Battery to Hyde Park, N.Y. The model scale ratios, model to prototype, were 1:1000 horizontally and 1:100 vertically. Tides and tidal currents were reproduced by tide generators located at the downstream limits of Lower New York Bay and Long Island Sound. Ocean salinities were reproduced to scale along with upland freshwater inflows so that the effects of salinity differences on the vertical distribution of current velocities and salinities throughout the model accurately reproduced those of the prototype. Shoaling tests were made by injecting finely ground gilsonite into the model, allowing the material to be distributed by the currents, retrieving the shoal material from predetermined areas, and determining the volume retrieved from each area.

(f) Completed.

(B) It was concluded that construction of the ter- minal, including removal of Shooters Island, would have no adverse effects on navigation conditions, maintenance of the Kill Channels, or circulation patterns in the Kills and lower Newark Bay.

(h) "Effects of Removal of Shooters Island and Shore Modifications on Tides, Currents and Shoaling in the Kill Channels; Hydraulic Model Investigation," Rept. MP 2-953, Dec. 1967.

(6854) DARDANELLE LOCK, ARKANSAS RIVER, ARK., MODEL STUDY OF FILLING AND EMPTYING SYSTEM.

(b) U.S. Army Engr. District, Little Rock.

(e) The filling and emptying system for the lock will comprise two intake manifolds, a 14.5-ftwide by l3-ft-high culvert in each wall, a lateral crossover culvert at the midpoint of the lock leading to four longitudinal culverts with side ports, and culvert outlets which empty riverward of the lock in the common outlet basin. Reverse-mounted culvert valves will control flow in the system. The purpose of the study is to investigate the suitability of a longitudinal floor culvert system for filling and emptying the lock under heads and submergences which will obtain at Dardanelle Lock site.

A 1:36-scale test facility was used to develop the crossover culvert entrance. A 1:25-scale general model reproducing the 670 - by $110-\mathrm{ft}^{\mathrm{t}}$ lock chamber, the culvert system, and outlets was used to study filling and emptying at the Dardanelle Lock.

(f) Tests completed; report in progress.

(g) Tests of 15 longitudinal floor culvert arrangements resulted in the selection of the type 13 arrangement as the most satisfactory. With a 54-ft lift, this arrangement permitted the lock to be filled by normal two-valve operation in $8.4 \mathrm{~min}$ ( 1 -min valve) with a maximum hawser stress of about 5 tons. Pressures downstream from the filling valves and turbulence in the lock chamber also were satisfactory with these operating conditions. Results of single valve operation tests indicated that an 8-min valve time, resulting in an 18.2-min filling time, was required to obtain satisfactory hawser stresses and reasonable pressures downstream from the valve during this type operation.

(6855) KASKASKIA RIVER ILL., NAVIGATION PROJECT MODEL STUDY.

(b) U.S. Army Engr. District, St. Louis.

(e) The project provides for 50 miles of channel enlargement and realignment from Fayetteville, Ill., to mouth; alterations to bridges to obtain proper clearance; and construction of a low, gated dam surmounted by two 60-ft-wide by $30-f t-h i g h$ tainter gates, and a 600-ft-long by 84 -ft-wide navigation lock located at mile 0.8 . Purpose of the investigation is to study navigation conditions in the approaches to the lock, and flow conditions in the vicinity of the dam and to develop modifications which might be required to overcome any undesirable conditions.

The investigation was conducted on a 1:120scale, fixed-bed, comprehensive model, reproducing 2 miles of the Kaskaskia River and adjacent overbank to the levee on the right side and to the railroad embankment on the left side, 1.8 miles of the main Mississippi River channel, and the lock and dam structures. 
(f) Tests completed; report in progress.

(g) Results indicated the need for modification of channel alignment in the reach upstream of the lock and dam.

(6856) LOCK AND DAM NO. 13, ARKANSAS RIVER, MODEL STUDY OF NAVIGATION CONDITIONS.

(b) U.S. Army Engr. Dist., Little Rock.

(e) The purpose of the investigation is to study navigation conditions in the lock approaches, determine the effects of existing and proposed channel rectification works and additional works that may seem desirable to produce satisfactory navigation conditions, and determine effects of a proposed bridge crossing at the lock and dam.

The investigation is being conducted on a 1:120-scale, semifixed-bed, comprehensive model, reproducing about 7 miles of the Arkansas River, adjacent overbank areas, the lock and dam structures, and other structures that might affect flow conditions.

(g) The study has resulted in the development of some of the modifications required to improve channel dimensions and navigation conditions through the reach.

(6857) LOCKS AND DAM NO. 26, MISSISSIPPI RIVER, MODEL STUDY.

(b) U.S. Army Engr. Dist., St. Louis.

(e) The project involves the improvement of navigation conditions on the Mississippi River in the vicinity of Alton, Ill., through modification of the existing locks and dam or relocating the locks and dam about 2 miles downstream of the existing dam, and maintaining navigation project depths of at least $9 \mathrm{ft}$ for all flows.

The purpose of the study is to determine the arrangement of the locks at the existing site and at a new location about 2 miles downstream, which would provide the best navigation conditions in the upper and lower lock approaches. The investigation is being conducted on a l:120-scale, fixed-bed, comprehensive model, reproducing about 6.8 miles of the Mississippi River, adjacent overbank areas, the locks and dam structures, a railroad and highway bridge, and other structures that might affect flow conditions.

(6858) NEWBURGH LOCK, OHIO RIVER, MODEL STUDY OF FILIING AND EMPTYING SYSTEM.

(b) U.S. Army Engr. District, Louisville.

(e) The purpose of the study is to determine whether the flow distribution through the chamber ports is affected by the relative location of the first port and the filling valve.

A 1:25-scale model which reproduced only the portion of the main Newburgh Lock between filling and emptying valves is adequate for the purpose of the model investigation. The 1270- by 110-1t lock was reproduced. The model includes 14-ft-wide by 16-ft-high culverts, sidewall port manifold, and reversemounted culvert valve to control flow. Other features of the system remained as they were in an earlier study.

(f) Tests completed; report in progress.

(g) General conclusions drawn from the study were: (a) Minimum pressure occurred when the valve was 40-60 percent open. (b) The low pressure area downstream from the filling valve extended about 105-110 ft ( 7 times culvert height) and was essentially independent of lift and valve time. (c) The first port of the manifold must be at least this far from the valve before it can be expected to discharge near its share of the total flow during the valve opening period. (d) Hawser stresses measured with the port manifold at three different positions with respect to the valve showed no appreciable difference in maximum stresses for the same hydraulic conditions and valve time.

(6859) SMITHLAND LOCKS AND DAM, OHIO RIVER, GENERAL MODEL STUDY.

(b) U.S. Army Engr. District, Nashville.

(e) The Smithland Locks and Dam is a part of the overall navigation improvement project on the Ohio River to replace all of the original movable dams and their locks with modern highlift locks and gated dams. The purpose of the study is to determine the optimum location and alignment of the locks and dam; to investigate shoaling and erosion tendencies; and to develop modifications which might be required to overcome any undesirable conditions. A 1:150-scale comprehensive model, which can be converted from fixed to movable bed, reproduces the proposed structures and about 8.5 miles of the Ohio River and adjacent overbank area to the bluff lines. The model also reproduces a short reach of the Cumberland River above its junction with the Ohio River.

(g) Results indicate that satisfactory navigation conditions could be developed at the site selected for the locks and dam structures. Improvements in navigation conditions could be obtained by widening the upper lock approach and revising the dike along the right bank, and by dredging a portion of the right bank and realigning the dike along the right bank in the lower lock approach.

(6860) ANSONIA-DERBY LOCAL PROTECTION PROJECT, HOUSATONIC AND NAUGATUCK RIVERS, CONN., MODEL STUDY.

(b) U.S. Army Engrs., New England Division.

(e) The project will provide flood protection to properties on both sides of the rivers in the event of the standard project flood. The purpose of the study is to ensure adequacy of floodwall and dike grades, to determine channel velocities for use in design or riprap protection, and to determine if and where economies can be affected in construction of the project.

A 1:120-scale model is being used to reproduce approximately $4000 \mathrm{ft}$ of the Housatonic River and $16,000 \mathrm{ft}$ of the Naugatuck River including 10 bridges, a floodwall approximately $4500 \mathrm{ft}$ long, and riprap-lined dikes along the rivers.

(f) Tests completed; report in progress.

(g) Flow conditions were poor and water surfaces were higher than expected in the upper reach of the project. Several alternative designs and a satisfactory design were developed for this area. Water-surface profiles and bottom velocities were obtained throughout the full reach of the project for the final design with both the design and maximum capacity discharges.

(6861) ARKANSAS, VERDIGRIS, AND GRAND RIVERS CONFLUENCE, MODEL STUDY.

(b) U.S. Army Engr. District, Tulsa.

(e) The project involves the improvement of the Arkansas River for navigation from the vicinity of Tulsa, Okla., to its junction with the 
Mississippi River. The 9-ft-deep channel will be provided by a system of locks and dams and channel regulating and stabilization works. The channel will have a minimum width of $250 \mathrm{ft}$ in the Arkansas River reach and $150 \mathrm{ft}$ in Verdigris River reach with lock chambers 110 by $600 \mathrm{ft}$.

The purpose of the study is to investigate various plans of regulating structures and to develop modifications required for the development of a channel of adequate dimensions and satisfactory navigation conditions in the vicinity of the confluence of the three rivers. A movable-bed model with scale ratios of 1:120 horizontally and 1:80 vertically reproduces the Arkansas River from about river mile 457 to 462.5 , plus about 4000 ft each of the Verdigris and Grand Rivers and adjacent overbank areas.

(6862) VAN BUREN REACH, ARKANSAS RIVER, MODEL STUDY OF NAVIGATION CONDITIONS.

(b) U.S. Army Engr. District, Little Rock.

(e) The purpose of the investigation is to study navigation conditions at the three bridges at Van Buren, Ark., to determine modification required in the existing railroad bridge, the interstate highway bridge under construction, and the proposed relocation of the highway bridge, and to develop a plan of regulating structures to provide satisfactory navigation conditions.

The investigation is being conducted on a l:120-scale, semifixed-bed and movable-bed model, reproducing about 4.2 miles of the Arkansas River and adjacent overflow areas, the mouth of Lee Creek, one railroad, and two highway bridges, and other structures that might affect flow conditions.

(g) The results indicated the best alignment for the channel through the reach and the need for additional regulating structures.

(6863) BURNS WATERWAY HARBOR, IND., MODEL STUDY OF STABILITY OF PROPOSED BREAKWATER.

(b) U.S. Army Engr. District, Chicago.

(e) Burns Waterway Harbor will be located on the south shoreline of Lake Michigan about 10 miles east of Gary, Ind. The proposed harbor will be exposed to storm-wave action from directions between north and $\mathrm{N} 33-1 / 2^{\circ} \mathrm{E}$. The harbor will be protected by a rubble-mound breakwater which is permeable and will allow some wave energy to pass over and through the breakwater into the protected area. The purpose is to determine the stability of the proposed breakwater designs, develop alternate designs, if necessary, and investigate the effectiveness of the proposed breakwater in reducing transmitted energy. Tests were conducted in a concrete wave flume 119 ft long, $5 \mathrm{ft}$ wide, and $4 \mathrm{ft}$ deep on section models of the proposed structures constructed to a linear scale of 1:35. Model waves were generated by a plunger-type wave machine and measured and recorded electrically.

(i) Completed.

(g) Described in ( $h$ ).

(h) "Stability of Proposed Breakwater, Burns Waterway Harbor, Indiana; Hydraulic Model Investigation," Rept. TR 2-766, March 1967.

(6864) CHAGRIN RIVER, EASTLAKE, OHIO, MODEL STUDY OF WAVE PROTECTION STRUCTURES.

(b) U.S. Army Engr. Dist., Buffalo. (e) The project provides for revision of river channel and installation of protective structures to minimize wave action generated in Lake Erie and allow satisfactory passage of flood flows through the river, which will enhance navigation of recreational small craft. The purpose of the study is to determine the optimum size, location, and orientation of proposed wave protection structures at the Chagrin River entrance with respect to wave action and the free passage of flood flows through the river.

A 1:75-scale undistorted model, molded in cement mortar, will be used in the investigation. The model will include the lower portion of the river channel and connected slips and basins and adjacent areas of Lake Erie. Underwater contours will be reproduced to a prototype depth of about $25 \mathrm{ft}$ and sufficient additional area will be included for generation of storm waves from the significant directions of approach. A 40-ft-long wave machine and electrical wave-height measuring apparatus will be utilized in model operation. A water-circulating system will be included for simulation of the river flows.

(6865) CRESCENT CITY CALIFORNIA, THEORETICAL STUDY OF TSUNAMIS.

(b) U.S. Army Engr. Dist., San Francisco.

(d) Theoretical; applied.

(e) The study consists of (a) the preparation of refraction diagrams of tsunamis which affect Crescent City, Calif., and (b) the estimation of the frequency of occurrence of tsunamis of different amplitudes from the different directions of approach to Crescent City, Calif. The wave refraction diagrams will provide information for a proposed hydraulic model study by showing the wave patterns and directions as the tsunami approaches Crescent City from various point sources in the Pacific. The frequency-of-occurrence study should provide part of the information necessary for determining the feasibility of various proposed protective schemes.

(6866) HUMBOLDT BAY, CALIF., MODEL STUDY OF DESIGNS FOR JETTY REPAIRS.

(b) U.S. Army Engr. District, San Francisco.

(e) The purpose of the study is to determine the stability of designs proposed for repairing the head or seaward ends of the existing damaged jetties.

Stability tests are proposed in the WES threedimensional flume. A scale of $1: 50$ has been tentatively selected. Model waves will be generated by a paddle-type wave machine, and will be measured and recorded electrically.

(g) The results of the preliminary tests showed that model waves of sufficient size to displace 100-ton blocks could be generated in the three-dimensional flume. On the basis of the information obtained from the preliminary tests, a model scale of $1: 50$ was tentatively selected for use in testing prototype cubes weighing 100 tons.

(6867) KAWAIHAE HARBOR, HAWAII, MODEL STUDY.

(b) U.S. Army Engr. District, Honolulu.

(e) It is proposed that the present harbor be expanded by widening the entrance channel, enlarging the turning basin, and constructing a small-boat basin in the rear of the harbor. It is expected that these revisions will 
improve navigation conditions in the harbor and provide a safe anchorage for small craft. The purpose of the investigation is to: (a) study wave action in the harbor for existing conditions and following the proposed harbor revisions; (b) develop remedial plans for alleviation of undesirable navigation conditions and wave action in the harbor basin and entrance channel as necessary; and (c) study wave action in the proposed small-craft basin for several design variations.

The three-dimensional wave-action model was molded in cement mortar to an undistorted scale of 1:100, model to prototype, and reproduced the entire harbor area and underwater contours to an offshore depth of $90 \mathrm{ft}$. Sufficient additional offshore area was included to permit generation of test waves from all critical directions. The total area reproduced in the model was approximately 7500 sq ft, representing about 2.7 square miles in nature. Waves in the model were generated by a 52-ft-long wave machine, and wave-height data were secured by the use of electrical measuring and recording apparatus.

(f) Completed.

(g) Described in $(h)$.

(h) "Expansion and Revision of Kawaihae Harbor, Hawaii; Hydraulic Model Investigation," Rept. TR 2-806, Dec. 1967.

(6868) MISSION BAY, CALIF., MODEL STUDY OF HARBOR DESIGN .

(b) U.S. Army Engr. District, Los Angeles.

(e) The purpose of the study is to determine the relative effects inside the harbor of waves of various magnitudes that approach the harbor site from the more significant storm directions, and to develop remedial plans as required to relieve any undesirable wave action in the harbor basins.

The three-dimensional wave action model is molded in cement mortar to an undistorted scale of 1:100, model to prototype. The model reproduces the entrance channel, Quivera Basin, Glen Rick Cove, and the underwater contours to an offshore depth of $60 \mathrm{ft}$. Sufficient additional offshore area is included to permit generation of waves from all critical directions. The total area reproduced in the model is approximately 15,500 sq $\mathrm{ft}$, representing about 5.6 square miles in nature. Waves in the model are generated by a 60-ft-long, plunger-type wave machine. Electrical printed-circuit-type wave-measuring rods are used in connection with automatic recording equipment to obtain necessary waveheight area.

(6869) PORT SAN LUIS, CALIF., MODEL STUDY OF HARBOR MODIFICATIONS.

(b) U.S. Army Engr. District, Los Angeles.

(e) It is proposed that the existing harbor be modified to provide a safe, year-round, smallcraft mooring area for approximately 1500 pleasure craft and 240 commercial fishing boats. The proposed mooring area would be protected by four breakwater structures with a total length of approximately $6600 \mathrm{ft}$, and access to the harbor would be through two 400-ft entrances.

The purpose of the investigation is to study wave action in the harbor for existing conditions and with the proposed harbor revisions installed, and to develop remedial plans for alleviation of undesirable wave action and navigation conditions in the inner harbor and entrance channels as found necessary. The three-dimensional wave-action model is molded in cement mortar to an undistorted scale of 1:100, model to prototype. The model reproduces the entire harbor area and underwater contours to an offshore depth of $60 \mathrm{ft}$. Sufficient additional offshore area is.included to permit generation of test waves from all critical directions of wave approach. The total area reproduced in the model is approximately 12,250 sq ft, representing about 4.4 square miles in nature. Waves in the model are generated by a 60-ft-long wave machine, and wave-height data are secured by the use of electrical measuring and recording apparatus.

(6870) VERMILION HARBOR, OHIO, MODEL STUDY.

(b) U.S. Army Engr. District, Buffalo.

(e) The purpose of the study is to determine the optimum size, location, and orientation of proposed wave protection structures at the entrance to Vermilion Harbor. A 1:75-scale undistorted model, molded in cement mortar, will be used in the investigation. The model will include the harbor and adjacent areas of Lake Erie. Underwater contours will be reproduced to prototype depth of about $25 \mathrm{ft}$, and sufficient additional area will be included for generation of storm waves from the significant directions of approach. A 50-ft-long wave machine and electrical waveheight measuring apparatus will be utilized in model operation.

(6871) BOEUF RIVER, BIG AND COLEWA CREEKS, ARK. AND IA., MODEL STUDY OF LOW WATER WEIRS.

(b) U.S. Army Engr. District, Vicksburg.

(e) The project involves enlargement of the Boeuf River channel and two cutoffs from mile 32.6 to its junction with Big and Colewa Creeks at mile 45.8, enlargement of $\mathrm{Big}$ and Colewa Creeks from mile 0.0 to mile 75.3 , and construction of 11 low-water control weirs in the channel of Big and Colewa Creeks. The purpose of the study is to test several plans to develop an effective, economical drop structure; to study flow conditions and determine protective stone requirements. A 1:20-scale model reproducing one-half the channel section through a low water weir was used to test different drop structures. The weir was constructed of sheet metal. Limestone rock with specific gravity of 2.63 was used to simulate riprap. The downstream channel was molded in sand during early tests and in coal during later tests. A second $1: 20$-scale section model was constructed in a 2.5-ft wide glass flume for more general riprap tests.

(f) Test complete; report in progress.

(g) Critical flow conditions were defined. Two basic drop structure plans were found to provide satisfactory operating characteristics and effective protection against damage to the structure. General design data, relating unit discharge and required tailwater elevations, were developed for two different riprap sizes. 


\section{(6872) CANAL DENSITY CURRENTS.}

(b) USAE Nuclear cratering Group.

(d) Experimental; applied research.

(e) The purpose is to determine if density currents will be a significant parameter to be considered in presently proposed sea-level canals. The study, complemented by theoretical predictions based on the results of the laboratory study, is directed to determining velocity conditions resulting from density differences within the canal and how the velocities relate to navigation requirements for the canals.

The study is being conducted in a plastic flume connecting two tidal basins with a side channel located at the center of the flume to simulate a freshwater river intercepting the canal. Test procedure includes the adjustment of the desired tides in each basin to simulate the desired flows in the flume, and the introduction of the freshwater flows of interest into the side channel and monitoring the resulting salinities, velocities, and tidal heights throughout the system. The results form the basis for prediction of the resulting velocity profiles of the prototype for specific tidal and freshwater inflow conditions.

\section{(6873) NUCLEAR EXCAVATED CHANNELS.}

(b) USAE Nuclear Cratering Group.

(d) Theoretical and experimental; research.

(e) When nuclear explosives are used to excavate a desired navigation channel through terrain of varying elevation, the size and charge placement will result in a channel of varying widths and depths. These resulting and contractions of the channel become significant when the hydraulics of the channel are considered. Problems result in predicting the head loss through the channel as well as velocity distribution throughout the channel. The purpose of this study is to define the extent of head loss in channels with the range of expansions and contractions of present interest, and in addition, the effect of the expansions and contractions on the resulting velocity profiles.

The study will be conducted in two flumes constructed within WES Coastal Inlet Research Facility B. The first flume will be used to define the head loss and velocity distribution within a straight uniform channel of cross-sectional shape similar to a channel resulting from a nuclear explosive. The second flume will be used to define the head loss and velocity distribution of a channel with expansions and contractions of interest. The channel in the second flume will have a mean hydraulic radius and mean cross-sectional area duplicating the same parameters of the straight uniform channel. The resulting difference between the tests in the straight channel and the nonuniform channel will provide a basis for predictions of the effects of expansions and contractions. All work will be conducted in model dimensions with the model results extended to prototype ranges for a final prediction.

(6874) SUMMERSILIE DAM, MODEL STUDY OF HOWELIBUNGER VALVE.

(b) U.S. Army Engr. District, Huntington. (e) The Summersville Dam outlet works consist of a 29-ft-diam tunnel 1700 ft long discharging through a manifold system of three ll-ft-diam conduits averaging $210 \mathrm{ft}$ in length. The outflow is controlled by a 9-ft Howell-Bunger valve at the downstream end of each ll-ft conduit. Flow from the valve is confined by a 20-ft-diam hood.

Operation of the prototype valve resulted in a portion of the conical jet being turned upstream into the valve pit after its impingement on the hood. Model tests are being conducted to study the adequacy of various schemes in eliminating or reducing the undesirable backsplash.

The investigation was conducted on a 1:20.6scale model that reproduced the valve, valve pit, hood, and $100 \mathrm{ft}$ of the approach tunnel. Piezometers were located in the approach tunnel to determine pressures in the area of the upstream butterfly valve. The valve pit and hood were constructed of clear plastic to permit observation of the backsplash.

(f) Tests completed; report in progress.

(g) Tests indicated that approximately 60 percent of the backsplash could be eliminated by installing 3-ft-long lOWF 49 beams on 10degree centers around the inside periphery of the hood. The beams reduced backsplash by intercepting the jet, creating turbulence, and increasing the demand and entraiment of air. Various collector rings located upstream of the beams were found to be beneficial in reducing the backsplash to a satisfactory degree as well as a scheme which utilized the beams in a diverging, conical arrangement. Less backsplash was observed as the hood diameter was increased.

\section{(6875) RIPRAP REQUIREMENTS IN CHANNELS.}

(b) Office, Chief of Engineers.

(e) Theoretical and experimental investigations regarding the adequacy of various sizes of crushed stone and gravel in resisting flow in straight and curved reaches of trapezoidal channels of varying hydraulic radii will be conducted to obtain basic data for development of a satisfactory theory and appropriate design criteria regarding the stability of stone in flowing water.

(6876) SUMMERSVILTE IAKE, PROTOTYPE VALVE TEST.

(b) U.S. Army Engr. Dist., Huntington.

(c) Field study; applied.

(e) Summersville Iake is impounded by a rockfill dam, $375 \mathrm{ft}$ in height, and is used for flood control. The outlet work consists of an intake structure, 29-ft-diam operating tunnel, three ll-ft-diam outlet conduits, and one 3-ft-diam low-flow outlet pipe. The outlet conduits are controlled by $132-i n$. butterfly and 108-in. Howell-Bunger valves in tandem. An uncontrolled, saddle-type spillway is located $3500 \mathrm{ft}$ west of the right abutment. The purpose of the study is to evaluate the nature and magnitude of vibrations which had previously resulted in severe damage to the Howell-Bunger valves in order to set limits for safe operation, and to measure vibration conditions in the valves as rebuilt with heavier components.

Radial vibrations of the Howell-Bunger valve body and the radial gate were measured on two of the Howell-Bunger valves. Average piezometric pressures upstream from the butterfly 
valves, fluctuating pressures just downstream from the butterfly valves, and fluctuating pressures at the upstream side of the HowellBunger valves also were measured. The rebuilt Howell-Bunger valves will incorporate pressure transducers in the vanes and body, strain gages on the vanes and body to indicate the nature of the vibrations, and accelerometers in the cone at the downstream end of the valve.

(g) Results During Year -- Some relation appeared to exist between the pressure fluctuations and the valve vibrations. Any vortex trail from the butterfly valve seemed to be too low in frequency to contribute significantly to the vibration. The indicated vibration displacements were very low, but their relation to displacements and stresses in other parts of the valve was not known.

U.S. DEPARTMENT OF COMVERCE, NATIONAL BUREAU OF STANDARDS, Fluid Meters Section, Washington, D.C. 20234

(6881) DECAY OF SWIRLING, TURBUTENT FLOW OF INCOMPRESSIBLE FLUIDS IN INNG PIPES.

(b) Naval Ordnance Systems Command; in cooperation with Dept. of Mech. Engrg., Univ. of Maryland.

(c) Dr. David w. Baker, Research Engr., NBS.

(d) Experimental; basic research; doctoral thesis.

(e) Purpose: to study the decay of swirling flow fields in steady, incompressible flow from measurements made in two cylindrical, unobstructed, smooth pipes. In one pipe, 5.75 inches ID by 270 inches long and flowing water, mean point velocities, static pressures and wall pressures were measured at several stations along the pipe. In the other pipe, 1.180 inches ID by 120 inches long and flowing liquid hydrocarbons of kinematic viscosities of about 1.2 and 3.5 centistokes, measurements were made of wall pressure and the swirling motion of the fluid, as sensed by a vaned rotor having a diamter nearly that of the pipe. For the vortex flows generated, the product $K / M D$ varied from 0 to 0.9 , where $\mathrm{K}$ is the angular momentum flux or swirl level, $M$ is the axial momentum flux, and $D$ is the pipe inside diameter. Reynolds number (based on $\mathrm{D}$ and the mean axial velocity) ranged from 12,500 to 200,000 .

(f) Completed.

(g) Tangential velocity and angular momentum profiles verified that an initial forced vortex motion develops toward a free vortex field as caused by the action of viscosity at the wall. The radial static pressure gradient was verified to vary nearly directly with the centripetal acceleration. For two stations spaced an axial distance $\Delta x / D$ diameters, it was found $K / K_{0}=e^{-\beta \Delta / D}$, where $\beta$ is a swirl decay parameter and $K_{0}$ is the angular momentum flux at the upstream station. A definite dependency of $\beta$ on Reynolds number was noted ranging from $\beta=0.020 \pm 0.005$ at $\operatorname{Re}=200,000$ to $\beta=0.040 \pm 0.005$ at $\mathrm{Re}=12,500$. However, this scatter of 0.005 and larger values of $\beta$ ranging to 0.07 at $\mathrm{Re}=15,000$ for data from additional sources demonstrate dependence of $\beta$ on the inlet geometry and, possibly, the angular momentum flu\% and turbulence characteristics. The ratio of the differential wall pressure $\Delta \mathrm{P}_{W}$ during swirling flow relative to non-swirling flow varied primarily with the initial angular momentum flux and was essentially independent of Reynolds number. A value of the pressure ratio greater than unity will indicate presence of swirling flow, and when $\Delta \mathrm{P}$ as a function of the initial angular momentum flux is known for a system, $\triangle \mathrm{P}$ may be used as measure of the swirl level.

(h) Thesis available at the Library, Univ. of Maryland, and from University Microfilms, Inc., Ann Arbor, Michigan.

\section{U.S. DEPARTMEIVT OF COMMERCE, NATIONAL BUREAU OF} STANDARDS, Hydraulic Section, Washington, D.C. 20234

\section{(2435) HYDRAULICS OF CULVERTS.}

(b) Bureau of Public Roads, U.S. Dept. Of Transportation.

(c) Mr. John L. French, Hydraulic Engr., NBS.

(d) Experimental; applied research.

(e) To detemine hydraulic characteristics of various types of culvert entrances and to develop inlets of improved design.

(f) Completed.

(g) Inlets of improved hydraulic capacity were developed.

(h) "Tapered Inlets for Pipe Culverts," John L. French, Jour. Hydraulics Div., A.S.C.E. Vol. 90, No. HY2, Proc. Paper 3845, pp. 255-299, Narch, 1964.

The following progress reports have been issued to the Bureau of Public Roads, and are distributed only by that agency:

"First Progress Report on Hydraulies of Culverts - Hydraulic Characteristics of Commonly Used Pipe Entrances," John L. French, Natl. Bu. Standards Rept. No. 4444, Dec. 1955. "Second Progress Report on Hydraulics of Culverts - Pressure and Resistance Characteristics of a Model Pipe Culvert," John L. French, NBS Rept. 4911, Oct. 1956.

"Third Progress Report on Hydraulics of Culverts - Effect of Approach Channel Characteristics on Model Pipe Culvert Operation," John L. French, NBS Rept. 5306, June 1957. "Fourth Progress Report on Hydraulics of Culverts - Hydraulics of Improved Inlet Structures for Pipe Culverts," John L. French, NBS Rept. 7178, Aug. 1961.

"Fifth Progress Report on Hydraulics of Culverts - Nonenlarged Box Culvert Inlets," John L. French, NBS Rept. 9327, June 1966. "Sixth Progress Report on Hydraulics of Culverts - Tapered Box Culvert Inlets, "John L. French, NBS Rept. 9355, June 1966. "Seventh Progress Report on Hydraulics of Culverts - Tapered Box Culvert Inlets with Fall Concentration in the inlet Structure," John L. French and Herbert C. Bossy, NBS Rept. 9528, July 1967.

\section{(4400) MOTION AROUND A BODY IN A STRATIFIED FLUID.}

(b) Office of Naval Research, Dept. of the Navy.

(c) Mr. Karl Lofquist, Physicist, NBS.

(d) Theoretical and experimental; basic and applied research.

(e) A study is made of the internal waves produced by the horizontal motion of spheres through a stably stratified liquid.

(g) Experiments and analysis completed; final report in progress. 
(h) "On Spheres and Doublets in Stratified Flows," Karl Lofquist, presented at Intl. Conf. on Stratified Flow, Univ. of Michigan, Ann Arbor, April 1967 and to be issued as NBS Report covering aspects of the theoretical work.

(4892) TURBULENT SHEAR FLOW THROUGH COMPLIANT WALLED TUBES.

(b) Office of Naval Research, Dept. of the Navy.

(c) Dr. G. Kulin, Hyäraulic Engr., NBS

(d) Experimental; basic research.

(e) Investigation of effect of compliancy of boundaries on a turbulent flow with a view toward possible damping of turbulence and potential reduction in wall shear stress.

(f) Suspended.

(5613) RESPONSE OF A DENSITY-STRATIFIED LIQUID TO A SOURCE OR SINK IMPULSE.

(b) Office of Naval Research, Dept. of the Navy.

(c) Mr. Karl Lofquist, Physicist, NBS.

(d) Theoretical and experimental; basic research.

(e) A study of the internal waves produced by the sudden inflation or contraction of a small spherical membrane situated within stratified liquid.

(g) Some theoretical work has been completed.

(5614) INTERACTION BETWEEN IONG WAVES AND SUPERPOSED SHORT WAVES.

(b) Office of Naval Research, Dept. of the Navy .

(c) Dr. G. Kulin, Hydraulic Engr., NBS.

(d) Experimental; basic research.

(e) Investigation of the change of form of the shorter waves, and of the effect, if any, on damping of the longer waves.

(g) Experiments in progress.

(5615) INTERCOMPARISON OF TOWING TANKK AND WATER TUNNEL CALIBRATIONS OF CURRENT METERS.

(b) Laboratory project.

(c) Mr. John L. French, Hydraulic Engr., NBS.

(d) Experimental; basic and applied research.

(e) Investigation of wall interference and turbulence effects on current meter calibrations in water tunnels.

(g) Calibration of 20-inch diameter working section is under way.

(6013) DAMPING OF SHALLOW-WAVES: SUMMARY OF AVAILABLE INFORMATION.

(b) Office of Naval Research, Dept. of the Navy.

(c) Dr. G. Kulin, Hyäraulic Engr., NBS.

(d) Analytical; basic research.

(e) A state-of-the-art review of viscous damping of waves, with analysis of available theoretical and experimental results.

(g) Report in progress.

U.S. DEPARTMENT OF COMMERCE, WEATHER BUREAU, Environmental Science Services Administration, Washington, D. C. 20235

\section{(5664) STREAMFLOW FORECASTING RESEARCH.}

(b) Laboratory project.

(c) Mr. William E. Hiatt, Assoc. Director of Weather Bureau (Hydrology).

(d) Theoretical and field; applied research.

(e). In Washington, D.C., and at River Forecast Centers throughout the U.S., phenomena are being investigated for improved objective forecasts of stream-flow. These phenomena include (1) storage and movement of rain and snowmelt through the soil, including the influence of evapotranspiration, and (2) routing of flow in natural channels.

(g) Major results are adaptation of field procedures to digital computer operation at several River Forecast Centers, using a more sophisticated model than was possible earlier. Computer operations have been expanded to two additional River Forecast Centers.

(h) "General Estimates of Free-Water Evaporation," M.S. Kohler and L.H. Parmele, Water Resources Research, Vol. 3, No. 4, pp. 997-1005, 1967. "Estimating Incident Terrestrial Radiation Under All Atmospheric Conditions," E.A. Anderson and D.R. Baker, Water Resources Research, Vol. 3, No. 4, pp. 975-988, 1967.

(6154) HYDROMETEOROIOGICAL RESEARCH FOR DESIGN CRITERIA.

(b) Several Federal agencies engaged in water management programs.

(c) Mr. William E. Hiatt; see (5664) above.

(d) Largely theoretical; basic and applied.

(e) Preparation of estimates of probable maximum precipitation, meteorological conditions for maximum snow accumulation and melting, hurricane wind fields, and rainfall intensityfrequency for design of spillways and other water-control structures and programs.

(g) Detailed description and results are reported in the Water Resources Research Catalog.

(h) "Meteorological Conditions for the Probable Maximum Flood on the Yukon River Above Rampart, Alaska," Hydromet. Rept. No. 42, 97 pages, May 1966.

"Probable Maximu Precipitation, Northwest States," Hydromet. Rept. No. 43, 228 pages, Nov. 1966.

"Meteorological Estimation of Extreme Precipitation for Spillway Design Floods," Vance A. Myers, WBTM Hydro-5, 29 pages, Oct. 1967. "Normal Monthly Number of Days with Precipitation of $0.5,1.0,2.0$, and 4.0 Inches or more in the Conterminous United States," John F. Miller and R.H. Frederick, Tech. Paper No. 57, 52 pages, 1966.

"Rainfall Frequency Maps for Arizona, New Mexico and Colorado," prepared by Special Studies Branch, Office of Hydrology, Weather Bureau (individual maps), 1967.

U.S. DEPARTMENT OF COMMERCE, ATLANTIC OCEANOGRAPHIC IABORATORIES, Environmental Science Service Administration, 901 South Miami Ave., Miami, Fla. 33130.

(6055) SHALIOW WATFR TIDE PREDICTIONS.

(b) Laboratory project jointly with Coast and Geodetic Survey.

(c) Bernard D. Zetler, Acting Director, Physical Oceanography Lab., Atlantic Oceanographic Labs.

(d) Experimental; applied research.

(e) To develop technique for predicting more accurately tides in Cook Inlet, Alaska, for navigational requirements of deep-draft oil tankers.

(f) Completed.

(g) Improved tide predictions for times of high and low waters, range of tide and shape of curve.

(h) "A Harmonic Method for Predicting Shallowwater Tides," B.D. Zetler and R.A. Cummings, Jour. Marine Res., Vol. 25, No. 1, pp. 103-117, Jan. 15, 1967. 
U.S. DEPARTMENT OF THE INTERIOR, BUREAU OF RECLAMATION, Div. of Engineering Laboratories, Denver Federal Center, Denver, Colorado 80225

Inquiries concerning the following projects, unless otherwise indicated, should be addressed to:

Office of Chief Engineer, Bureau of Reclamation, Denver Federal Center, Denver, Colo. 80225.

\section{(2959) STILLING FASINS FOR SIIDE GATE CONTROILED} OUTLET WORKS.

(b) Laboratory project.

(d) Experimental; for design.

(e) Data from several models of hydraulic jump basins were used to develop tentative design curves for an efficient, economical stilling basin for use with slide gate control for high head outlet works and a general purpose model facility was used to develop design curves for a plunge-type basin.

(f) Suspended.

(g) The plunge basin indicates an advantage over the hydraulic jump basin in the necessary length to contain the hydraulic jump. Impact forces on the floor of the plunge basin may be a controlling factor in the design. Recommendations for continuing work in this study are presented.

(h) "Progress Report VII--Research Study on Stilling Basins, Energy Dissipators, and Associated Appurtenances--Section 13, Stilling Basins for High Head Outlet Works With Slide-gate Control (Preliminary Studies)," D.L. King, Rept. No. Hyd-544, May 1965.

(3278) CAVITATION OF CONCRETE SURFACE IRREGUTARITIES.

(b) Laboratory project.

(d) Experimental; applied research and design.

(e) Into-the-flow offsets with abrupt edges, chamfered edges, and rounded edges were tested to determine the velocity-head relationships for incipient cavitation.

(f) Inactive.

(3612) DISCHARGE COEFFICIENTS FOR RADIAL GATES.

(b) Laboratory project.

(d) Experimental, laboratory and field investigations; applied research.

(e) Radial gates are used extensively in irrigation systems for discharge and water surface level control. Intelligent operation of the systems requires that the rate of flow passing the gated structure be known. Literature research resulted in an analytical approach and adjusted equation for the gate capacity with unsubmerged flow.

(f) Suspended.

(g) Analysis of model data for several USER lowhead radial gate installations resulted in design curves for determining discharge capacity. Curves are grouped according to number of gates.

(h) Report in preparation.

(3994) HYDRAUIIC JUMP CHU'T BLOCK AIND BAFFLE BLOCK PRESSURES.

(b) Laboratory project.

(d) Experimental; applied research.

(e) A spillway stilling basin model has been constructed to study chute block and baffle block pressures and to relate these pressures to the Froude number of the entrance flow and to tailwater depth.

(f) Suspended.

(g) An analytical expression for determining the average minimum instantaneous pressure on chute blocks in one particular type of stilling basin was determined.

(h) "Progress Report VI-Research Study on Stilling Basins Energy Dissipators--And Associated Appurtenances: Section 12--Stilling Basin Chute Block Pressures (Basin II)" G.I. Beichley, Rept. No. Hyd-514, May 8, 1963.

(4791) HIGH-VELOCITY JET ON PROTECTIVE COATINGS.

(b) Laboratory project.

(d) Experimental; for operation and maintenance.

(e) A 100-fps, 1-inch-diameter jet was impinged at 45 degrees on protective coverings proposed for application on concrete surfaces to be subjected to high-velocity flow.

(f) Completed.

(g) All protective coatings tested, in which the surface was unbrcken, withstood the jet for 4 hours. All coatings tested in which a broken or cut surface extended to the concrete were ripped from the concrete test blocks in less than 5 minutes.

(h) "Resistance of Selected Protective Coatings for Concrete to High Velocity Water Jets," D. Colgate, Rept. No. Hyd-543, April 1965.

(4792) CANADIAN RIVER AQUEDUCT CHECK TOWERS.

(b) Laboratory project.

(d) Experimental; for design.

(e) Laboratory tests were made to determine the hydraulic losses and air-entrainment potential of check towers to be installed in the 125-mile-long Canadian River Aqueduct. The aqueduct consists of 54-, 60-, and 66-inchdiameter concrete conduit. The check towers are so designed that the top of each is slightly below the hydraulic grade line when the aqueduct is flowing full. Each check tower consists of a 90 degree vertical bend to direct the conduit upward, a 180-degree return bend at the top of the tower, and a 90-degree bend at the bottom of the downstream leg to return the conduit to the original alinement. There is a 22-inch air vent at the top of each tower.

(f) Completed.

(g) Head loss was determined for each size check tower. During filling or evacuating the tower, air was entrained in the downstream leg and carried into the horizontal conduit. A 36inch-diameter vent was installed 120 feet downstream from each tower to release the entrained air.

(h) "Hydraulic Model Studies of the Flow Characteristics and Air Entrainment in the Check Towers of the Main Aqueduct, Canadian River Project, Texas, " D. Colgate, Rept. No. Hyd-555, June 1966.

(4794) VERTICAI STILIING WEII.

(b) Laboratory project.

(d) Applied research.

(e) The purpose is to obtain the optimum size, depth, and internal configuration of vertical stilling wells for high-head discharges. The test installation has a 4-foot by 4-footsquare well 6 feet deep, followed by a canal with a 4-foot bottom width and 1-1/2:1 side slopes. An adjustable downspout is symmetrically located in the well and discharges against the flat floor. Piezometers are 
located in the floor and lower sidewalls of the well. Adjustable corner fillets provide a means for determining optimum fillet angle, size, and height.

(g) Optimum well dimensions have been determined for a range of wave heights in the downstream canal.

(h) Preparation of report temporarily suspended.

(4802) STUDIES ON ORIFICES FOR AUTOMATIC RADIAI GATE CONTROLS.

(b) Laboratory project.

(d) Experimental; for design.

(e) The studies are for the purpose of determining flow characteristics and discharge coefficients for various size orifices in floatwell intakes of automatic radial gate controls. A 1:1 scale model of a floatwell intake structure was constructed to determine discharge coefficients of the irregular orifice configuration in the regulating structure.

(f) Suspended.

(g) Although the test arrangements differed substantially from arrangements for which data are presently available, measured coefficients compared closely with existing data.

(h) Report in preparation.

(4807) MORROW POINT DAM SPILLWAY AND OUTLET WORKS.

(b) Laboratory project.

(d) Experimental; for design.

(e) A 1:24 scale model was constructed to aid in the development of the unusual design of the spillway and outlet works for the thin-arch concrete dam. The original design, consisting of a free overfall spillway and an outlet works located near the bottom of the dam, was abandoned because of undesirable flow conditions in the artificially formed stilling pool at the base of the dam. The present design includes four fixed-wheel gate controlled conduits near the top of the dam which discharge $34,400 \mathrm{cfs}$, allowing it to fall approximately 400 feet to the stilling pool. The small slide-gate-controlled outlet works in the lower portion of the dam and the underground powerplant tailrace channels are also included.

(f) Completed.

(g) Model studies have proven the acceptability of the present design. Design of the control weir which forms the stilling pool was modified and the two inside spillway conduits were tipped downward to provide more even distribution of impact of the free-falling jets. Revisions were made to the topography of the downstream river channels to improve flow conditions in those areas.

(h) Hydraulic Model Studies of Morrow Point Dam Spillway, Outlet Works, and Powerplant, " D.L. King, Rept. No. Hyd-557, April 1966.

(4954) SAN IUIS FOREBAY PUMPING PLANT INTAKE TRANSITIONS.

(b) Laboratory project.

(d) Experimental; for design.

(e) A 1:15 scale model was used to compare head loss, velocity distribution, and flow patterns in various configurations of canal transitions to pumping plant intakes.

(f) Completed.

(g) On the basis of velocity distribution and surface flow patterns in the transition and pump intake bays a symmetrical transition was found to be more desirable than an angled transition. Head losses were too small to justify comparison on this basis. The angled transition was chosen for the final desien after consideration of economic factors. Numerical methods and a digital computer were used to analyze the large volume of velocity data.

(h) "Hydraulic Model Studies of the Canal Transition at the Forebay Pumping Plant, "D.L. King, Rept. No. Hyd-542, June 1965.

"Comparison of Intake Transition Designs for a Large Pumping Plant," D.L. King, Conference Preprint 371, ASCE Water Resources Engrg. Conf., Denver, Colo., May 1966.

(4958) AIR DEMAND TESTS ON 84-INCH JET FLOW GATE-TRINITY DAM, CAIIFORIIA.

(b) Laboratory project.

(d) Field investigations.

(e) Field measurements were obtained to compare model and prototype air demand for the complete range of gate openings at maximum operating head ( 369 feet) on the gate. A laboratory model study was made to obtain centerline velocity coefficients for the prototype air duct to provide for quantitative analysis of field measurements.

(f) Completed.

(g) Maximum velocity in the air supply conduit was within design limits.

(h) Publication not anticipated.

(4959) FLAT BOTTOMED TRAPEZOIDAI VENTURI FLUMES.

(b) Laboratory project.

(d) Experimental; for design.

(e) A pilot study of a single flume is being conducted to determine the best approach to a comprehensive program to generalize the design and calibration of this type of water measuring device.

(g) The model study has demonstrated that the particular pilot flume tested is an adequate measuring device.

(h) Report in preparation.

(4960) PROTOTYPE PIEZOMETRIC AND AIR DEMAND MEASUREMENTS OF 4- BY 4-FOOT TANDEM GATE--NAVAJO DAM, NEW MEXICO.

(b) Iaboratory project.

(d) Field investigation.

(e) To compare the model and prototype, piezometric measurements were obtained for the complete range of gate openings with a head of 164.5 feet. Prototype air demand measurements were made simultaneously with piezometric values to evaluate adequacy of the air supply system. Further tests are planned at heads of about 230 feet and 300 feet to more fully evaluate the hydraulic characteristics of this gate and to check the model scaling.

(f) Inactive pending prototype measurements at higher heads.

(4962) LABORATORY INVESTIGATION OF THE REMOVAL OF SALT WATER FROM A TWO-PART AQUIFER USING TILE DRAINS INSTALTED IN THE UPPER MEMBER, AND PUMP WELLS INSTALIED IN THE IOWER AQUTFER. (See also Water Resources Research Catalog, 2.0196, Vol. 2).

(b) Laboratory project.

(d) Applied research.

(e) Tests were performed on a 16-foot-long 1:40 scale model containing two-part and singlepart aquifers to determine the hydraulic action of simulated tile ground-water drains 
placed 0.2 foot below the model surface. The lower aquifer was composed of coarse sand 50 times more permeable than the fine sand in the upper aquifer. For initial conditions the model was charged with salt water, concentration 6,000 ppm $\mathrm{NaCl}$, dyed blue for visual identification. Tests are continuing using vertical pump wells in the lower aquifer as drains.

(g) For the given prototype conditions, tile ground-water drains will not intercept and discharge fresh water if the lower aquifer contains salt water. The fresh water tends to drive the salt water ahead of it to the drain.

(h) "Removal of Saline Water from Aquifers," E.J. Carlson, Research Rept. No. 13, 1968.

(5335) HIGH PRESSURE SLIDE GATE STUDIES FOR RUEDI AND MORROW POINT DAM OUTLET WORKS.

(b) Laboratory project.

(d) Experimental; for design.

(e) A 1:9 scale model is being used to determine operating characteristics and pressure conditions on slide gates to be used for regulation at heads up to 355 feet. The flow passages of the gates slope downward $30^{\circ}$ in the direction of flow, and the gate leaves and bonnets are vertical. Effects of flaring the sidewalls inmediately downstream from the leaf are being studied.

(f) Suspended.

(g) Preliminary studies show that a gate slot design used very successfully on gates with horizontal flow passages and vertical leaves is not satisfactory for gates with $30^{\circ}$ sloping passages and vertical leaves. Also, flaring the downstream walls in the normal fashion just downstream from the leaf leads to extremely subatmospheric pressure conditions and cavitation. By offsetting the walls abruptly 3 or 4 inches outward a very short distance downstream from the leaves, an excellent design with either parallel or diverging downstream walls is apparently obtained.

(h) Publication not anticipated in near future.

(5336) BUTTERFIY VALVE STUDIES WITH CAVITATION OCCURRING

(b) Laboratory project.

(d) Experimental; for design.

(e) A commercial 8-inch, 125 psi butterfly valve is being tested under prototype head to determine the effects on cavitation characteristics, air demand, and discharge coefficients that result from discharging the valve directly into sudden enlargements, or through short conduits into the enlargements. Tests are made with and without the admission of air, and quantities of air needed to just quiet the cavitation are being obtained. Effects of air admission on the discharge coefficient are also being obtained.

(f) Suspended.

(g) Preliminary results show that satisfactory pressure reducing stations for high differential heads and low back pressures can be obtained with butterfly valves if the valves discharge directly into a 2.0 dia. enlargement. Air in sufficient quantities to relieve cavitation when the discharge enters the enlargement directly, or through short sections of pipe, has little effect upon the discharge coefficient.

(h) Publication not anticipated in near future.
(5338) LABORATORY TESTS OF GATE SEALS UNDER PROTOTYPE HEADS.

(b) Iaboratory project.

(d) Experimental; for design.

(e) A facility for testing gate seals under heads of up to 600 feet was used on 16 specimens of seals having various combinations of fluoro-carbon and brass cladding bonded to the rubber. The tests included measuring the seal bulb extension and photographing and observing the general behavior of the seal under load during opening and closing cycles of the gate.

(g) Of the seals tested, the one best suited for high-head applications was of the clamp-on type having a fluoro-carbon cap extending over the bulb and both stems and a brass backing. This seal successfully withstood opening and closings cycles under heads of up to 600 feet.

(h) A report is being prepared.

(5339) MODEL-PROTOTYPE CORRELATION OF AIR DEMAND.

(b) Field tests and laboratory project.

(d) Theoretical and experimental; applied research.

(e) Basic parameters are being developed to correlate model results with prototype measurements for the flow of air in a closed conduit partially filled with moving water. Prototype measurements are essentially complete. Iaboratory tests are beginning in a variable slope, enclosed, rectangular channel. The mean air velocity and turbulence intensity of the air stream will be measured for various water velocities, various water depths and various pressure gradients.

(f) Suspended.

(g) Methods to be used in modeling air demand have been determined. The Froude scale relationship seems to be valid for converting rodel data to prototype dimensions.

(h) "Hydrodynamic Pressures in Conduits Downstream from Regulating Gates," H.T. Falvey, Paper 53, 12th Congr., Intl. Assoc. Hydraulic Res., 1967.

(5343) STRATIFIED FIOW.

(b) Iaboratory project.

(d) Experimental and theoretical; applied research.

(e) A laboratory flume is being used to study the mechanism of selective withdrawal from stratified reservoirs. Temperature difference, monitored with thermistors, is being used to induce stratification.

(g) Results of the laboratory tests have shown the feasibility of using a temperature model.

(h) "Hydraulics of Stratified Flow--First Progress Report--An Analysis of the state of the Art and a Definition of Research Needs," D.I. King, Rept. No. Hyd-563, June 1966.

(5346) GLEN ELDER DAM SPILLWAY

(b) Iaboratory project.

(d) Experimental; for design.

(e) A 1:72 scale model is being used to study the hydraulic features of the spillway. The model contains 12 radial gate controlled spillway bays, the approach channel, surrounding topography, the hydraulic jump stilling basin and concrete lined apron, and a portion of the downstream channel.

(I) Completed.

(g) The flow in the approach area, through the 
bays, and in the downstream channel is smooth. The operation of the stilling basin is efficient. There is no excessive erosion of the downstream channel. No major changes to the initial design were recommended as a result of the model study.

(h) "Hydraulic Model Studies of the Spillway--Glen Elder Dam--Missouri River Basin Project, Kansas," W.F. Arris, Report No. Hyd-561, June 1966.

(5347) LITTLE PANOCHE CREEK DETENTION DAM OUTLET WORKS INTAKE STRUCTURE.

(b) Laboratory project.

(d) Experimental; for design.

(e) A 1:15 scale model was built to study the flow conditions in a square, submerged vertical inlet and bend when stop logs are used to control the flow into the inlet.

(f) Completed.

(g) Smooth operation and near atmospheric pressures were attained in the throat and elbow of the intake by using vertical flow splitters between the horizontal structural beams of the trashrack stoplog structure to aerate the undernappe of the jets flowing over the stoplogs.

(h) "Hydraulic Model Studies of the Intake Structure for the Outlet Works of Little Panoche Creek Dentention Dam--San Luis Unit--Central Valley Project, California," T.J. Rhone, Rept. No. Hyd-560, June 1966.

(5844) PORTAGE MOUNTAIN DAM LOW LEVEL OUTLET WORKS.

(b) British Columbia Hydro and Power Authority, W.F. Miles, General Manager.

(c) International Power and Engineering Consultants, Ltd., 570 Dunsmuir Street, Vancouver 2, Canada.

(d) Experimental; for design.

(e) The outlet works will utilize two of the three 48-foot-diameter horseshoe-shaped diversion tunnels and will consist of two conduits through each of the two diversion tunnel plugs. An 84-inch Howell-Bunger valve at the downstream end of each conduit is used to control the flow. Each conduit is designed to discharge 2,500 cfs at an approximate head of 450 feet but may discharge twice this amount in emergencies. A 1:14 scale model of the valves and the horseshoe-shaped tunnel has been constructed to develop the design of the air supply system to the valves, the optimum location of the valves, and the energy dissipating devices required in the diversion tunnel.

(f) Completed.

(g) The fixed-cone valve and ring deflector combination that was developed for the prototype provides a relative simple and effective device for flow control and energy dissipation. A recirculating air supply tunnel was developed to provide near atmospheric pressures within the cone-shaped jet as well as upstream of the jet surrounding the valves.

(h) "Hydraulic Model Studies of Portage Mountain Development Low-Level Outlet Works--British Columbia, Canada," G.L. Beichley, Rept. No. Hyd-562, 1966.

(5845) PATILIAS DAM SPILLWAY.

(b) Puerto Rico Water Resources Authority.

(c) Rafael V. Urrutia, Executive Director, Puerto Rico Water Resources Authority, San Juan, Puerto Rico. (d) Experimental; design.

(e) The existing spillway has operated over the years and a considerable amount of erosion has occurred in the natural channel at the downstream end of the spillway. Numerous modifications to the original spillway have been ineffective in reducing the erosion. A $1: 36$ scale model is being constructed to develop the required modifications to eliminate this adverse operating condition.

(f) Inactive.

(5846) CRYSTAL DAM SPILLWAY.

(b) Laboratory project.

(c) Experimental; design.

(e) A 1:40 scale model of the spillway will be tested to investigate overall flow conditions. In addition, a structure at the end of the spillway tunnel will be developed which will function as a stilling basin for flows up to 11,000 efs and as a flip bucket for higher discharges. Determination of discharge coefficients for a tainter gate on the spillway crest and the development of an atmospheric pressure spillway crest will be accomplished through the use of a 1:24 sectional model.

(f) Suspended.

(g) The preliminary design was found to be satis iactory.

(h) Publication not anticipated.

(5847) CRYSTAL DAM OUTLET WORKS.

(b) Iaboratory project.

(d) Experimental; design.

(e) A 1:12 scale model will be tested to evaluate the operation of the outlet works stilling basin. Two 3-foot 3-inch-square high-pressure slide gates discharge a maximum of about 2,000 cfs into the stilling basin under a. head of approximately 200 feet. The energy dissipating efficiency of the basin and the downstream flow conditions will be investigated. Special attention will be given to the measurement and evaluation of hydrodynamic forces acting on various parts of the structure, particularly the cantilevered vertical concrete wall which separates the flow from the two gates.

(f) Suspended.

(5848) EL VADO DAM OUTLET WORKS.

(b) Iaboratory project.

(d) Experimental; design.

(e) A 1:30 scale model was used to develop a flip bucket which would minimize river channel erosion by dispersing sizable releases, and would allow small releases to be bypassed through an offset opening in the right wall. The model contained a section of the dual gate controlled outlet works tunnel, the flip bucket, a section of the existing spillway, and a section of river channel.

(f) Completed.

(g) The recommended flip bucket contained two vertical confining walls and two sloping plane surfaces to intercept and direct the flow to the lip of the bucket. The best flow dispersion occurs for normal releases of from 2, 000 to 4,000 cfs. Small releases are passed through an offset opening in the right wall.

(h) Publication pending.

(6301) RADAR PUMPING PLANT INLET TRANSITION. 
(b) Laboratory project.

(d) Experimental; for design.

(e) Limited tests were performed with a 1:18 scale model to compare the hydraulic characteristics of an angled transition with the characteristics of a symmetrical transition, and to determine the configuration of appurtenances required to improve the flow distribution in the angled transition.

(f) Completed.

(g) The angled transition was made to operate satisfactorily by the addition of curved guide walls near the upstream end of the transition. However, the symmetrical transition was recommended.

(h) "Hydraulic Model Studies of the Inlet Transition at Radar Pumping Plant," D.I. King, Rept. No. Hyd-547, Arpil 1965.

(6302) LOWER TWO MEDICINE DAM SPILLWAY AND OUTLET WORKS.

(b) Laboratory project.

(d) Experimental; for design.

(e) A 1:24 scale sectional model of the uncontrolled spillway, the outlet works passin through the spillway section, and the stilling basin common to both features were studied to determine hydraulic characteristics.

(f) Completed.

(g) Baffle piers were added to the USBR Type II basin to improve energy dissipation and reduce the tendency for riverbed material to move upstream.

(h) "Hydraulic Model Studies of the Spillway and Outlet Works for Lower Two Medicine Dam," D.L. King, Rept. No. Hyd-554, January 1366.

(6303) REJECTION SURGES IN TRAPEZOIDAI CHANNELS.

(b) Laboratory project.

(d) Experimental and theoretical; applied research.

(e) Exact and approximate theoretical equations were presented for determination of size, velocity, and shape of surge waves in a trapezoidal channel following complete rejection of the flow. The equations were compared with each other and with experimental data.

(f) Completed.

(g) The approximate form was found to be essentially equal to the exact form. Generally, agreement between theory and experiment was quite good. The greatest deviation between theory and experiment occurred in the determination of the peak surge height.

(h) "A Theoretical and Experimental study of Rejection Surges in Trapezoidal Channels," D.L. King, Master's Thesis, Univ. of Colorado, June 1966.

(6304) MODIFIED OUTLET WORKS STILLING BASIN, NAVAJO DAM.

(b) Laboratory project.

(d) Experimental; for design.

(e) A 1:12 scale model was used to investigate the causes of damage to the stilling basin for the hollow-jet-valve outlet works.

(f) Completed.

(g) The tests showed that abrasion damage in the stilling basin was caused by circulation of large rocks and gravel. Damage was duplicated in the model. Modifications were developed to $r \in d u c e$ turbulence in the basin and to prevent streambed material from entering the basin. The tests also showed that the center dividing wall was subjected to fluctuating pressures which could result in structural damage due to vibration.

(h) "Hydraulic Model Studies of the Modified Outlet Works Stilling Basin, Navajo Dam," D.L. King, Rept. No. Hyd-573, June 1967.

(6305) FONTENELIE POWERPIANT DRAFT TUBE AND TATLRACE.

(b) Laboratory project.

(d) Experimental for design.

(e) During rehabilitation of the river outlet works, stilling basin flow was diverted through the powerplant. To prevent untimely breakdown of the untested mechanical parts in the powerplant, the turbine runner was removed. Diversion flows were controlled with the turbine wicket gates.

(f) Completed.

(g) A trivane flow splitter and two baffle walls placed in the draft tube were necessary to reduce flow concentrations in the tailrace. The orientation and dimensions of these appurtenances are given.

(h) "Hydraulic Model Studies of the Fontenelle Powerplant Draft Tube and Tailrace," H.T. Falvey, Rept. No. Hyd-571, Aug. 1967.

(6306) ATTALYSIS OF PRESSURE FLUCTUATIONS IN STILLING BASINS.

(b) Laboratory project.

(d) Experimental; applied research.

(e) Pressure fluctuations in models of two distinct types of energy dissipators (hydraulic jump stilling basin and free-fall impact pool) were inspected with a commercial spectrum analyzer to estimate dynamic forces acting on hydraulic structures. Data from a prototype stilling basin is being similarly analyzed.

(g) The analysis indicates that pressure fluctuations have a frequency range of approximately $0-50$ Hertz. Amplitudes generally increase with decreasing frequency; no isolated regions of high amplitude are apparent. The analysis has shown that resonance in piezometer lines can give erroneous results. Flush-mounted transducers are recommended.

(h) "Analysis of Random Pressure Fluctuations in Stilling Basins," D.L. King, Paper B25, 12th Congr. Intl. Assoc. Hydr. Res., Sept. 1967.

(6307) ATTENUATION OF SURGE WAVES BY A SIDE WEIR.

(b) Laboratory project.

(d) Experimental and theoretical; applied research.

(e) Two theoretical equations for attenuation by a side weir were compared with each other and with experimental data for complete rejection of flow in a trapezoidal canal. Wave heights were measured with capacitance-type probes. Digital computers were used for solution of the theoretical equations.

(f) Completed.

(g) Good agreement between theory and experiment was obtained. Iimits of application of each of the two theories were determined. Some general characteristics of surges in trapezoidal channels were observed.

(h) "Attenuation of Surge Waves by a Side Weir in a Trapezoidal Channel," $\mathrm{S}$. Rungrongtaanin and D.L. King, Rept. No. Hyd-575, April 1767.

(6308) BARTLETT DAM SPILLWAY.

(b) Laboratory project.

(d) Experimental; design. 
(e) Hydraulic studies were made on a 1:100 scale model of the existing structure to determine corrective measures needed to prevent additional erosion damage in the discharge channel near the existing concrete-lined spillway chute.

(f) Completed.

(g) Concrete fill and pneumatically placed concrete anchored to the rock was recommended rather than any channel alinement or excavation work.

(h) "Hydraulic Model Studies of the Bartlett Dam Spillway, Salt River Project, Arizona," G.I. Beichley, Rept. No. Hyd-576, October 1967.

\section{(6309) IMPACT-TYPE STIIIING RASINS.}

(b) Laboratory project.

(d) Experimental; applied research.

(e) Model studies were conducted on a 1.6- and 2.4-foot-wide $(48.76$ and $73.15 \mathrm{~cm})$, impact, USBR Type VI, stilling basins to modify and standardize existing procedures in the design of this basin.

(g) The basin dimensions in relation to discharge and velocity entering the basin and the amount, size, and location of riprap in the channel were standardized. The reduction in velocity and energy through the basin was determined.

(h) "Progress Report No. XIII--Research Study on Stilling Basins, Energy Dissipators, and Associated Appurtenances--Section 14, Modification of Section 6 (Stilling Basin) for Pipe or Open Channel Outlets No Tailwater Required-Basin VI, "G.I. Beichley, Rept. No. Hyd-572, 1968.

(6310) TEHAMA-COLUSA CANAI FISH CONCENTRATOR.

(b) Fish and Wildlife Service.

(d) Experimental; design.

(e) A 1:2.5 scale model was used to develop the design of the fish concentrator through which the fingerlings are to be concentrated from a discharge of $140 \mathrm{cfs}$ into a discharge of 5 cfs flowing to an electronic counting device.

(f) Completed.

(g) A fish concentrator was developed consisting of a sloping perforated plate screen 10 feet wide by 16 feet 3 inches long with adjustable orifices beneath the screen to control the flow through it to $135 \mathrm{cfs}$.

(n) "Hydraulic Model Studies of the Tehama-Colusa Canal Fish Concentrator, Central Valley Project, California," G.L. Beichley, Rept. No. Hyd-581, 1968.

(6311) TEHAMA-COLUSA CANAL VELOCITY BARRIER FOR FISH CONTROI.

(b) Fish and Wildlife Service.

(d) Applied research.

(e) A 1:1 scale model study was conducted to determine the depth to which a vertical slide gate (baffle gate) that spans the fish spawning canal section should be lowered into the canal to produce a 5 fps velocity barrier beneath the gate. The new born fish will not swim through this barrier; and, therefore, can be crowded downstream by providing a carriage for movement of the gate in that direction.

(f) Completed.

(g) The baffle gate can be adjusted to produce a water velocity of 5 feet per second at a point 0.3 foot above the gravel bed without scouring the gravel.

(h) "An Artificially Produced Velocity Barrier for Controlling Fish Movement: Tehama-Colusa Canal," E.R. Zeigler, Rept. No. Hyd-579,
Nov. 1967.

(6312) KANSAS RIVER BASIN SEDIMENT TESTS ON PROTOTYPE DIVERSION DAM.

(b) Laboratory project.

(d) Field investigation; applied research.

(e) Field test at various diversion dams in the basin were conducted to determine the efficiencies of sediment control structures (curved guide walls) for excluding sediment from the canal systems. Data were also obtained at Cambridge Diversion Dam where a sediment control structure had not been constructed but where a problem existed.

(f) Completed.

(g) Curved guide walls provide an efficient means for flushing sediment deposits either by continuous sluicing or by intermittent sluicing.

(h) "Interim Report--Sediment Tests on Prototype Diversion Dams, Kansas River Basin, KansasNebraska," E.I. Pemberton and E.J. Carlson, Rept. No. Hyd-550, Dec. 1964.

(6313) TEHAMA-COLUSA CANAL SPAWNING BED CLEANING DEVICE.

(b) Fish and Wildlife Service.

(d) Experimental; design.

(e) A sectional model was used to develop a device for cleaning the salmon spawning bed in the canal.

(g) The Bureau of Reclamation's Tehama-Colusa Canal in the California Central Valley Project is the first known dual-purpose canal being used both as a spawning grounds for salmon and also as a conveyance structure to supply water to irrigated lands. Several gravel cleaning methods, including underdrains, water and air jets, and mechanically cleaning the gravel were studied before the baffle gate was developed to clean fine sediment from gravel. The adjustable baffle gate is mounted on a carriage spanning the 140-foot-wide canal and is lowered into the water sufficiently to increase the velocity beneath the baffle gate to scour the gravel to the concrete bottom. Model tests were made to provide a basis for designing the field size cleaning device.

(h) "Baffle Gate Method for Cleaning Salmon Beds in Canals," E.J. Carlson, Proc. 12th Congr. Intl. Assoc. Hydr. Res., Fort Collins, Colo., Sept. 1967.

(6314) DENSITY CURRENTS AND TURBIDITY.

(b) Laboratory project.

(d) Field investigation; applied research.

(e) A limited investigation of turbidity and density flows in a prototype reservoir was conducted.

(f) Completed.

(g) Visual observations, field measurements, and laboratory analyses indicated that turbid releases from Trinity Reservoir were caused by withdrawal from a turbid density current which originated during the December 1964 flood. Very fine particles of clay were suspended in the cool lower layers of Trinity and Whiskeytown Reservoirs. The particles were identified by petrographic examination as primarily montmorillonite and kaolinite with a size considerably less than one micron. The turbidity disappeared as the reservoir cooled to a nearly uniform temperature during the winter season of 1965-66.

(1) "Investigation of Turbid Releases from Trinity 
Reservoir," D.L. King, Rept. No. Hyd-566, Aug. 1966.

(6315) DETERMINATION OF SEEPAGE BY ELECTRICAL IOGGING. (See also Water Resources Research Catalog, 3.0066, Vol. 2).

(b) Laboratory project.

(d) Experimental; applied research.

(e) Oil and water well electrical logging equipment was tested for detecting seepage from an earth-lined canal 75 feet long, 2 feet deep, and 12 feet wide at the top. A 5- by 11-by 4-foot-deep hole was excavated in the canal bottom and a grid system of perforated pipe surrounded by a reversible filter was placed in the hole. The remainder of the hole was filled with sand to the level of the canal invert and a pump connected to the pipe system. With the test canal filled with water, seepage from the sand section was varied by pumping different discharges from the pipe grid while operating the electrical logging equipment. Seepage meter measurements were made at different points in the canal to help establish a datum for interpreting the electrical logging charts.

(f) Completed.

(g) Tests showed there was no correlation between the electrical logging chart diagrams and the seepage measurements. The electrical logging equipment did not successfully detect seepage or seepage areas in the canal test facility.

(h) "Electrical Logging and Seepage Tests in a 75-foot-long Canal--Denver Federal Center, Lower Cost Canal Lining Research Program," E.R. Zeigler, Rept. No. Hyd-564, 50 pages, March 1967.

(6316) FARWELL MAIN CANAL--OPEN AND CLOSED CONDUIT SYSTEM PROGRAM.

(b) Laboratory project.

(d) Experimental; applied research.

(e) Hydraulic model discharge calibrations were made of three differently shaped trapezoidal weirs operating under submerged flow conditions.

(f) Completed.

(g) An electronic digital computer was used in making a least square fit analysis of the test data to obtain discharge equations for each weir.

(h) Report in preparation.

(6317) DRAINAGE FROM SLOPING IRRIGATED IAND.

(b) Laboratory project.

(d) Experimental; applied research.

(e) Drainage tests are being made on fine sand in a 60-foot-long by 2-foot-wide by 2-1/2-footwide flume that can be tilted up to approximately 15 percent grade. Recharge simulating irrigation water is applied through a sprinkling system which distributes the water uniformly over the sand surface. Water discharging from tile drains placed horizontally and at right angles to the slope is measured to determine the distribution of the drainage water discharge down the slope. Fewer drains could probably be used if the knowledge can be obtained to determine the optimum drain spacing.

(g) The flume is constructed and preliminary tests have been conducted.

(6318) MODEL TESTING OF BRTNE PIPING BETWEEN EVAPORA'TORS. (b) Office of Saline Water.

(c) Mr. P.G. Tomalin, Office of Saline Water, Distillation Division, U.S. Dept. of the Interior, Washington, D. C. 20240.

(d) Experimental; design.

(e) A 1:2.33 scale model study was conducted to determine the driving force required to discharge a given quantity of $118^{\circ} \mathrm{F}, 5$ percent salt saturated brine through the most critical of the interstage module piping and to develop design modifications as dictated by the results of the tests.

(g) Pipeline losses including entrance and exit losses exceed the available driving force between the last two modules and a loss coefficient curve for the system was determined for a range of Reynolds numbers.

(6319) MANIFOID STUDIES FOR FIASH DISTILIATION DESAIINATION PLANT.

(b) Office of Saline Water.

(c) Mr. P.G. Tomalin; see (6318) above.

(d) Experimental; design.

(e) A 1:8.93 model is being used to study flow conditions in the downstream end of a flash distillation test module. Vortex formation and vapor entrainment in the manifold connecting the evaporation trays to the pump suction are being investigated because of critical pressure conditions in the recirculating pump.

(g) Tests have resulted in several flow-improving modifications.

(6320) AIR VENT COMPUTATIONS--MORROW POINT DAM, COLORADO.

(b) Iaboratory project.

(d) Applied research; basic research.

(e) The development of a computer program to determine the magnitude of the reduced pressure in the intake gate chamber and the air flow rates through the vents during an emergency closure of the intake gate.

(g) The program has been developed for the quasisteady state condition. The effects of inertia are being investigated.

(h) Report in preparation.

(6321) DRAFT TUBE SURGE STUDIES.

(b) Laboratory project.

(d) Experimental, theoretical, and field investigation classified as both basic and applied research.

(e) The causes of draft tube surges or power swings are being examined through laboratory tests on a schematic model, theoretical considerations, and prototype testing. Preliminary investigations involve a literature survey and analysis of the resonant characteristics of a generalized penstock system.

(g) A comprehensive bibliography has been assembled.

(h) An annotated bibliography is in preparation.

(6322) GRAND COULEE DAM AND THIRD POWERPIANT.

(b) Laboratory project.

(d) Experimental; design.

(e) Tests are being conducted on a 1:120 scale model of the Third Powerplant and all existing features at Grand Coulee Dam. Details of the forebay channel and tailrace of the plant, which will have an ultimate capacity of 72,000 kw from 12 units, are being investigated and modified where necessary.

(g) An economical, hydraulically efficient shape of the forebay channel was developed with the 
aid of the model for 12-unit operation. Tests have shown satisfactory flow conditions in the tailrace for 6-unit operation.

(6323) GRAND COULEE THIRD POWERPIANT PENSTOCKS.

(b) Laboratory project.

(d) Experimental; for design.

(e) A 1:41.75 scale model is being used to evaluate different entrances and elbows for the 40-foot-diameter penstocks.

(g) A penstock entrance that is much smaller and shorter than entrances designed by current criteria was found to have satisfactory flow and pressure conditions and a very small head loss coefficient. The tests also indicate that an accelerating elbow just upstream of the generator entrance will be equally efficient with a curvature radius equal to either $2-1 / 2$ or $3-1 / 2$ times the penstock diameter.

(6324) INTAKES, ENTRANCES, AND TRANSITIONS. (See also Water Resources Research Catalog, 8.0117, Vol. 2).

(b) Laboratory project.

(d) Experimental; for design.

(e) Investigations are being performed to determine optimum configurations for intakes, entrances, and transitions for penstocks and outlet pipes. Tests will be made to determine the actual losses at entrances of different sizes and configuration. These tests will be extended to include studies of pressures and of vortex formation and to determine minimum submergence required to maintain adequate pressures and to prevent vortices.

(g) Tests to date have indicated that penstock entrances can be greatly reduced in size with a minimum amount of streamlining without significantly increasing head losses or causing poor flow conditions.

(6325) CONCONULIY DAM SPILLWAY.

(b) Laboratory project.

(d) Experimental; for design.

(e) A 1:18 scale sectional model is being used to develop a baffled chute as an energy dissipator for a 70-foot-high spillway having a unit discharge of about $78 \mathrm{cfs}$ per foot of width.

(g) The tests indicated that the baffled chute is very effective in preventing acceleration of the flow down the spillway. Tests are being continued to determine the erosion tendencies at the end of the chute.

(6326) AZOTFA TUNNEL INLET JUNCTION.

(b) Laboratory project.

(d) Experimental; design.

(e) Hydraulic model studies were performed on a 1:12 scale model of the Azotea Tunnel Inlet Junction to find a configuration which would minimize head losses through the junction, to determine critical dimensions of the structure, and to establish canal water depths. The purpose of the junction is to combine the flow from a feeder canal with that from the Oso Tunnel inverted siphon and direct this combined flow into the Azotea Tunnel.

(f) Completed.

(g) The recommended design minimized head losses between the siphon and the tunnel by means of a bearing wall placed in the flow stream which accelerated the flow leaving the canal, thereby making the uniting flow velocities from the canal and the siphon almost equal. This significantly reduced eddy formation and tended to eliminate retardation of the siphon flow. The bearing wall also reduces the span length of a roof over the inlet junction.

The flow conditions with this configuration were good over a large range of siphon, canal, and tunnel discharges. Fairly accurate estimates of losses through a system which is not geometrically similar to the Azotea inlet junction can be obtained by application of momentum and energy equations over two control sections. An example of this procedure is given in the appendix to the report.

(h) "Hydraulic Model Studies of the Azotea Tunnel Inlet Junction, San Juan-Chama Project, Colorado, "H.T. Falvey, Report No. Hyd-551, 45 p., Nov. 1965.

(6327) GLEN CANYON DAM DIVERSION TUNNEL OUTLETS.

(b) Laboratory project.

(d) Field investigation and experimental; operational and applied research.

(e) Operational history and performance of the left diversion tunnel outlets was investigated to determine the cause of damage to the concrete and steel surfaces.

(f) Completed.

(g) Extensive abrasive damage to the concrete was experienced due to foreign material circulating in a hydraulic jump that formed in the tunnel during relatively small releases. Progressive cavitation damage was experienced downstream from the gate slots and at surface irregularities in the conduit steel liners. Precautions to be considered in designing future similar structures were determined.

(h) "Glen Canyon Dam Diversion Tunnel Outlets," W.E. Wagner, Jour. Hydraulics Div., ASCE, Vol. 93, No. HY6, Proc. Paper 5573, 21 p., Nov. 1967.

(6328) TIBER DAM AUXIIIARY OUTLET WORKS.

(b) Laboratory project.

(d) Experimental; design.

(e) A 1:17.53 scale model is being used to develop the design of a drop inlet from the existing canal outlet tunnel to the new auxiliary outlet.

(g) A curved deflector in the crown of the canal tunnel directly over the drop inlet has been developed to intercept the swirling motion of flow entering the drop inlet; and, thus, improve the flow pattern throughout the outlet tunnel downstream from the slide gate control.

(h) A report will be prepared.

(6329) YELLOWIAIL DAM SPILIWAY REPAIRS.

(b) Laboratory project.

(d) Experimental; for design.

(e) A model tunnel spillway has been constructed to study means of admitting air to the high velocity, open channel flow to cushion the forces of cavitation collapse thereby preventing damage to the concrete spillway surfaces.

(f) Testing in progress.

(6330) FOLSOM DAM SPILIWAY REPAIRS.

(b) Laboratory project.

(d) Experimental; for design.

(e) A sectional model of the Folsom spillway with 
one outlet works tunnel was constructed and tested to determine a means of preventing cavitation damage during simultaneous operation of the spillway and outlet works.

(f) Completed.

(g) An eyebrow-type deflector with a splitter pier to assure aeration of the upper tier outlets, and an eyebrow with adequate aeration piped from the present air ducts for the gates, will assure satisfactory simultaneous operation of the spillway and outlets at Folsom Dam.

(h) Report in preparation.

The following projects are reported in the Water Resources Research Catalog.

(O56W) QUALTTY OF WATER AS AFFECIED BY STRATIFIED FLOW, 5.0197.

(05TW) INSTRUMENTATION, DATA ACQUISITION, AND COMPUTER TECHNIQUES, 7.0019 .

(058W) FACTORS AFFECTING STABILITY OF ARTIFICIAL AND NATURAI CHANNETS, 8.0047.

(O59W) FLOW SURFACE PROTECTION, 8.0050.

(O6OW) PIPELINE AND TUNNEL HYDRAULICS, 8.0054.

(O6IW) RADIOISOTOPF: WATER FLOW MEASUREMENT IN HIGHHEAD TURBINES AND PUMPS, 8.0072.

(062W) OPEN CHANNEL HYDRAULICS, 8.0132.

(063W) WATER MEASUREMENT, 8.0133.

(064W) RADIOISOTOPE STUDIES IN METHODS OF DISCHARGE MEASUREMENTS, HIGH-HEAD TURBINES AND PUMPS, 8.0134 .

(065W) GATES, VALVES, AND ORIFICES, 8.0141.

(O66W) ENERGY DISSIPATORS, 8.0146.

U.S. DEPARTMENT OF THE INIERIOR, GEOLOGICAL SURVEY, Water Resources Division, Washington, D. C. 20242

(2950) SEDIMENT TRANSPORT AND CHANNEL ROUGHNESS IN NATURAL AND ARTIFICIAI CHANNELS.

(b) Laboratory project.

(c) Mr. Thomas Maddock, Jr., U.S. Geol. Surv., Tucson, Ariz.

(d) Basic research.

(e) Field and laboratory studies, original and other investigations will be analyzed in terms of sediment movement, channel roughness, shear distribution in channel prism and other effects on shape of natural channels.

(g) Relations between velocity and sediment load have been developed. Relations involving slope are shown to be indeterminate within certain limits.

(h) "The Behavior of Straight Alluvial Channels," U.S. Geol. Survey Prof. Paper now in stage of final review.

(3263) SPECIFIC YIEID AND RELATED PROPERTIES.

(b) Cooperative with the State of California.

(c) Mr. A.I. Johnson, Chief, Hydrologic Lab., U.S. Geol. Surv., Denver, Colo. or Mr. Walter Hoffman, District Chief, WRD, U.S. Geol. Surv., Menlo Park, Calif.

(d) Laboratory and field investigation; basic and applied research.

(e) Theoretical, laboratory and field study of specific yield, and related properties, such as moisture equivalent, field capacity, moisture tension, unsaturated permeability and time-drainage relationships, as related to ground-water storage. Evaluation of existing, and possible development of new methods for determining these properties.

(g) Library research, laboratory study in progress or completed of factors affecting column drainage, centrifuge moisture equivalent, moisture tension and unsaturated permeability.

(h) "Compilation of Specific Yields for Various Materials," A.I. Johnson; U.S. Geol. Surv. open-file report, 1365.

"Specific Yield--Laboratory Experiments Showing the Effect of Time on Column Drainage," R.C. Prill, A.I. Johnson and D.A. Morris, U.S. Geol. Surv. Water-Supply Paper 1662-B, 1965. "Specific Yield--Column Drainage and Centrifuge Moisture Content," A.I. Johnson, R.C. Prill and D.A. Morris: U.S. Geological Survey open-file report; also U.S. Geological Survey Water-Supply Paper 1662-A (1963). "Centrifuge Technique for Determining TimeDrainage Relations for a Natural Sand," R.C. Prill and A.I. Johnson: U.S. Geological Survey Prof. Paper 450-E (1963).

"Research on Specific Yield," (abstract) by A.I. Johnson and D.A. Morris, California Association Engineering Geologists Meeting, October 1961: U.S. Geological Survey openfile report (1961).

(4787) MECHANICS OF FLUID FLOW IN POROUS MEDIA.

(b) Laboratory project.

(c) Dr. Akio Ogata, U.S. Geol. Surv., P.0. Box 657, Honolulu, Hawaii.

(d) Experimental and theoretical study; basic research.

(e) Theoretical and laboratory study of microscopic and macroscopic aspects of flow through porous media.

(5075) DOPPIER VELOCITY METER.

(b) Laboratory project.

(c) Mr. G.F. Smoot, U.S. Geol. Surv., WRD, Washington, D. C. 20242.

(d) Experimental; instrument development.

(e) The objective is to measure the instantaneous local velocity by means of the Doppler frequency shift of an ultrasonic signal reflected by minute particles of suspended sediment.

(g) Models undergoing laboratory and field tests.

(5599) RESFARCH ON PERMEABILTTY.

(b) Cooperative with State of California.

(c) A.I. Johnson and Walter Hoffman; see (3263) above.

(d) Laboratory and field investigation; basic and applied research.

(e) Theoretical, library, laboratory, and field study of permeability, mainly as related to water movement through rock and soil materials, both as saturated and unsaturated flow. Evaluation of existing laboratory and field methods and development of new or improved methods.

(g) Library research leading to an annotated bibliography on permeability (manuscript in preparation). Laboratory study of factors affecting saturated permeability measurements in progress. Laboratory study of relation between particle-size parameters and permeability. Laboratory evaluation of unsaturated permeability methods. 
(5600) MOVING BOAT TECHIIQUE FOR MEASUREMENT OF OPEN-CHANNEL DISCHARGE.

(b) Laboratory project.

(c) Mr. G. F. Smoot; see (5075) above.

(d) Experimental; instrument and technique development.

(e) The purpose of this research is to provide the instrumentation and to develop the technique needed to rapidly, accurately and inexpensively measure flow, especially unsteady flow, in rivers and tidal estuaries.

(g) A Doppler navigator, Doppler velocity meter, and a sonic sounder are being coupled together to provide channel discharge. The navigator provides the transverse distance traveled across the channel, the sonic sounder provides the cross-section depth, and the velocity meter provides the flow vector from which the discharge may be electronically integrated.

(h) Manual in preparation.

(5604) MECHANICS OF FLUID RESISTANCE.

(b) Laboratory project.

(c) Dr. H.J. Tracy, U.S. Geol. Surv., WRD, Rm. 164 Peachtree Seventh Bldg., Atlanta, Georgia 30323.

(d) Theoretical and laboratory investigation; basic research.

(e) The objective of this study is to attempt to describe the effects of the boundary on fluid resistance in terms of dimensionless ratios characterizing the physical size and shape of the roughness.

(g) The experimental aspect of the work is being conducted in an artifically roughened, closed circular, air tunnel using hot-wire anemometer equipment to determine velocity profiles, turbulence, and energy spectra. The work consists of tests in which roughness element size, density of spacing, and shape are systematically varied. The resulting turbulence spectra are being analyzed in order to correlate the physical dimensions of the roughness with the energy and momentum transfer mechanisms in turbulent flow.

(5606) MUITIPLE CHANNEL DIGITAL RECORDING SYSTEM.

(b) Laboratory project.

(c) Mr. G.F. Smoot; see (5075) above.

(d) Instrument development.

(e) The objective of this project is to develop a reliable, battery powered, sensing instrument for field operation which is capable of positioning a punched paper-tape digital recorder. The instrument would be used to provide a variety of hydrologic parameters in rapid sequence for recording on tape.

(g) A transistorized system incorporating an A-C Wheatstone bridge balanced by a D-C servo system of minimum power requirements has been developed and is undergoing field testing.

(h) "New Instrumentation for Watershed Investigations," G.F. Smoot, Proc. Symp. on Experimental and Representative Areas, Intl. Assoc. Scientific Hydrology, 1365.

(5607) EVALUATION OF DEPENDENT AND INDEPENDENT VARIABLES IN OPEN CHANNEL FLOW.

(b) Laboratory project.

(c) C.F. Nordin et al.

(d) Experimental; basic research.

(e) The objective is to identify and evaluate the dependency characteristics of flow and sediment measures of alluvial channel flow. The experiments are designed to (l) determine mean flow parameters and channel adjustments when bed material is an independent variable; (2) determine the importance of depth as a scale parameter and as a driving force; (3) determine the time for change when an independent variable is changed; (4) determine the variance of slope, depth, velocity, sediment transport, and bed conditions in time and space.

(5610) MECHANICS OF FLOW STRUCTURE AND FLUID RESISTANCE--MOVABLE BOUNDARY.

(b) Laboratory project.

(c) Dr. E.V. Richardson, U.S. Geol. Surv., c/o Engrg. Research Ctr., Foothills Campus, Colo. State Univ., Fort Collins, Colo. 80521

(d) Experimental, theoretical and field investigation; basic research.

(e) The objective is to measure the internal flow field of turbulent shear flow in an open channel in order to obtain a fundamental understanding of the mechanics of fluid resistance. Further knowledge of the mechanics of flow structure will give a better understanding of the phenomena of energy dissipation, velocity distribution, shear distribution and the transport and dispersion of solutes and sediment.

(g) The velocity djstribution for flow over a plain sand bed with appreciable bed material transport has an inner and outer zone. The distribution is logarithmic in both zones. In the inner zone the parameters for the distribution vary with the size, density and concentration of the bed material, whereas in the outer zone they are constant. The coefficients of a general resistance to fllow equation for equilibrium flow in a sand channel vary widely because (1) the flow may be steady or unsteady, uniform or nonuniform depending on the bed configuration; (2) there are four types of energy dissipation; (3) there is a range of shear stress where the bed configuration may range from dunes to plain bed or antidunes.

(h) "Resistance to Flow in Sand Channels," E.V. Richardson, Ph.D. dissertation, Colo. State Univ., Fort Collins, Colo. 1965.

(5839) MECHANICS OF GROUND-WATER FLOW.

(b) Laboratory project.

(c) Mr. H.H. Cooper, Jr., U.S. Geological Survey, Washington, D. C.

(d) Theoretical investigations with field applications; basic and applied research.

(e) Analysis of ground-water flow problems for which practical need has developed out of field investigations or other sources.

(g) (1) A solution for the response of wellaquifer systems to seismic waves as a function of well geometry, aquifer constants, and frequency of seismic wave was derived and checked by an electric analog model. (2) A technique for determining the rate of ground-water flow through semiconfining beds from the earth's thermal profile was devised. (3) Solutions for the nonsteady radial flow toward a well pumping from (a) an infinite two-layered aquifer, and (b) an infinite anisotropic aquifer were derived.

(h) "Rates of Vertical Groundwater Movement Estimated from the Earth's Thermal Profile," J.D. Bredehoeft and I.S. Papadopulos, Water 
Resources Res., Vol. 1, No. 2, pp. 325-328, 1965.

"Seismic Fluctuations in an Open Artesian Water Well," J.D. Bredehoeft, H.H. Cooper, Jr., I.S. Papadopulos and R.R. Bennett. USGS Prof. Paper 525-C, pp. C51-57, 1965.

"The Response of Well-Aquifer Systems to Seismic Waves," H.H. Cooper, Jr., J.D. Bredehoeft, I.S. Papadopulos and R.R. Bennett. Jour. Geophys. Res., Vol. 70, No. 16, pp. 3915-3926, 1965.

(5841) DENVER MUITIPHASE FLOW.

(b) Laboratory project.

(c) E.S. Samuel, U.S. Geol. Surv., Denver Federal Ctr., Denver, Colo.

(d) Theoretical and field investigation.

(e) Devise and test methods of measuring flow in, and hydraulic properties of, the unsaturated zone in the field. Measure velocities of fluids underground by analysis of temperature profiles. Develop and test methods of predicting the nature of flow in the unsaturated zone. Improve, and develop new techniques for field measurement of evapotranspiration.

(g) Measurement of the time lag and attenuation of fluctuations in gas pressure due to barometric changes as functions of depth below the land surface were made in the unsaturated zone near Cuba, New Mexico, for determining permeability of the unsaturated zone.

Although the field tests were successful, improvement in the instrumentation adopted is indi cated.

Type curves for analyzing drawdowns observed in well fields having variable discharges at scattered locations were developed for the New Mexico ground-water district through the Geological Survey Computations Unit. The computer program evolved is available for calculating the hydraulic properties of aquifers in areas where intensive use of ground-water is monitored at observation wells. Underground temperature profiles were observed in the field near Globe, Arizona and Roswell, New Mexico to test the possibility of using the temperature profile for indicating vertical velocities of ground water through beds having low permeability. Indications are that vertical velocities as small as $0.1 \mathrm{ft}$. per year can be identified by analysis of the steady-state temperature profile observed in beds about 100 feet or more in thickness.

The relation between losses from ground water and evapotranspiration is being studied with the aid of the field offices of the Water Resources Division, U.S. Geological Survey, in Colorado. Measurements of ground-water levels, soil moisture tension and content, and temperature are being made at four 25 acre sites in the Arkansas River Valley. Lateral contribution to ground-water loss, due to spatial changes in flow through the aquifer, is monitored by finite-difference analysis of the shape of the water table. Project interest lies in testing of field techniques of measuring the hydraulic properties of the unsaturated zone, and defining the relation between evapotranspiration and depth to the water table. Field installations were completed in May 1965, and rebuilt by Octoker 1365 after destruction by floods.

(h) Discussion of "Analysis of Data from ivonequilikrium Pumping Tests Allowing for
Delayed Yield from Storage, by N.S. Boulton," Robert W. Stallman, Inst. Civil Engrs. Proc. (British) Vol. 28, pp. 603-604, 1364.

"Multiphase Fluids in Porous Media--a Review of Theories Pertinent to Hydrologic Studies," Robert W. Stallman, U.S. Geol. Surv. Prof. Paper 4ll-E, 51 p., 1364.

"Effects of Water Table Conditions on Water Level Changes near Pumping Wells," R.W. Stallman, Water Resources Res., Vol. 1, No. 2, p. 295-312, 1365 .

"Steady One-dimensional Fluid Flow in a Semiinfinite Porous Medium with Sinusoidal Surface Temperature," R.W. Stallman, Jour. Geophys. Res., Vol. 70, No. 12, p. 2821$2827,1965$.

(5842) THE MOVEMENT OF RADIONUCLIDES IN THE COLUMBIA RIVER ESTUARY.

(b) U.S. Atomic Energy Commission.

(c) Mr. D.W. Hubbell, Project Chief, U.S. Geol. Surv., P.0. Box 3202, Portland, Oregon 97208.

(d) Experimental and theoretical; applied research.

(e) Certain radionuclides enter the Columbia River from the Hanford installation of the U.S. Atomic Energy Commission. Part of the radionuclides remain in solution, part are sorbed by fluvial sediments, and part are sorbed by biota. In order to insure that no dangerous condition prevails or develops in the Columbia River estuary, it is important to know the distribution of radionuclides in time and space, and the processes by which the distribution is altered. The purpose of this investigation is to study the movement of radionuclides in the Columbia River estuary as it is affected by flow, sediment transport, and chemical processes; to assess the distribution of radioactivity in the estuary; to develop measurement methods and techniques for large estuaries; and to contribute knowledge of estuarine processes.

(g) Measurement equipment and techniques have been developed for collecting necessary data in the estuary. The equipment includes systems for measuring water discharge rapid$\mathrm{ly}$, for collecting large-volume water and suspended-sediment samples, for filtering large-volume samples rapidly, for collecting 6-foot long bed-material cores, and for monitoring radioactivity in situ. The areal distribution of radioactivity in the estuary varies markedly and, in general, high activities are associated with fine sediments.

(h) "A Sampler for Coring in Rivers and Estuaries," E.A. Prych and D.T. Hubbell, Bull. Geol. Soc. Amer.

"Measurement Equipment and Techniques Used in Studying Radionuclide Movement in the Columbia River Estuary," E.A. Prych, D.W. Hubbel and J.L. Glenn, Proc. ASCE Coastal Engrg. Conf., 1966.

(5843) THE OCCURRENCE, TRANSPORT, AND DISPOSITION OF RADIONUCLIDES AS SOLUTES AND ASSOCTATED WITH FLUVIAL SEDIMENTS IN THE IOWER COLUMEIA RIVER.

(b) U.S. Atomic Energy Commission.

(c) Mr. W.L. Haushild, Project Chief, U.S. Geol. Surv., P.0. Box 3202, Portland, Oreg. 97208.

(d) Field investigation; applied research.

(e) Small amounts of minerals in the water used for cooling the reactors at the Hanford installation near Richland, Wash. are acti- 
vated and subsequently discharged into the Columbia River in the controlled release of the cooling water. The purpose of the project is to determine the disposition of these radionuclides in and along the channel and the mechanics of transport of the radionuclides by the water and sediment in the river. The investigation is intended to supply information from the 330-mile reach of the Columbia River between Hanford and the head of the estuary.

(g) The transport and retention of radionuclides correlates with ( 1 ) the flow characteristics of the river system, and (2) the influence of the chemical and physical composition of the environment system. The radionuclides affixed to the sediments varies for specific radionuclides and correlates with the physical and mineral characteristics of the sediments. There is a differential transport of these affixed radionuclides because of the differences in the fall velocity of the sediments, and this difference in transport affects the retention of radionuclides in the study reach. The digital computer solutions of a mathematical model for transient river flow have been successfully applied to the production of continuous discharge data for tidal-affected flows of the Columbia river at Vancouver, Wash.

(h) "An Electric-Powered Vehicle for Large River Measurements," H.H. Stevens, Jr., and G.R. Dempster, Jr., Civil Engrg., Vol. 34, No. 6, p. 74, June 1964.

A discussion of "Annual Variation of Stream Water Temperatures," J.C. Ward; by W.L. Haushild and G.R. Dempster, Jr., ASCE Proc., Vol. 90, No. SA4, pp. 90-92, Aug. 1964. "Concurrent Collection of Hydraulic and Sediment Data in Rivers," G.R. Dempster, Jr. and H.H. Stevens, Jr., Jour., Arn. Water Works Assoc., Vol. 57, No. 9, pp. 1135-1138, Sept. 1965.

(6069) GRAIN SIZE DISTRIBUTION AND BEDLOAD TRANSPORT.

(b) Laboratory project.

(c) G.P. Williams, U.S. Geol. Survey (WRD) Wash., D.C.

(d) Basic research.

(e) Experimental flume studies relating bedload transport rate to various channel factors, and especially variations resulting from changes in size distribution keeping median grain size constant.

(h) "Flume Experiments on the Transport of a Coarse Sand," U.S. Geol. Survey Prof. Paper 562-B, Sept. 1967.

"Particle Roundness and Surface Texture Effects on Fall Velocity," Jour. Sed. Petrology, March 1966.

(6070) HYDRAULIC STUDIES OF OVERLAND FLOW.

(b) Laboratory project.

(c) W.W. Emmett, U.S. Geol. Survey (WRD), Wash., D.C.

(d) Basic research; field study.

(e) Determine magnitude and evaluate effectiveness of hydraulic characteristics of overland flow as a landscaping agent and its role in the hydrologic cycle.

(6071) REAERATION IN OPEN CHANNEL FLOW.

(b) Laboratory project.

(c) W.W. Sayre, U.S. Geol. Survey, Ft. Collins,
Colo.

(d) Basic research.

(e) Investigation of processes by which dissolved oxygen is assimilated by flowing water in an open channel, and to develop improved criteria for predicting rate of assimilation as a function of flow, channel, and other measurable environmental characteristics.

NATIONAL AERONAUTICS AND SPACE ADMINISTRATION, Langley Research Center, Langley Station, Hampton, Virginia 23365

\section{(6654) WATER LANDING IMPACT OF SPACECRAFT AIND} AIRCRAFT.

(b) NASA and other govermment agencies.

(c) Head, Impacting Structures Section, Mr. Lloyd J. Fisher, Mail Stop 347, Langley Research Center, NASA.

(d) Experimental and analytical applied research.

(e) Experimental landing impact investigations are made with scaled dynamic models. Various landing attitudes, speeds, and body configurations are simulated. Hydrodynamic force and pressure distribution data on either relatively rigid or partially elastic models are obtained for comparison with theory. Specific energy dissipation capabilities are determined for various impact systems and materials using structural testing procedures and drop model techniques.

(g) See $(h)$.

(h) "Dynamic Model Investigation of the Apollo Spacecraft Water Pressure and Accelerations Encountered Juring Landings," Sandy M. Stubbs, NASA TN-3980, Sept. 1767.

"Water Landing Characteristics of a $1 / 10$ Scale Model of a Winged Missile," Lloyd J. Fisher and John 0 . Windham, NASA TN D-3793, April 1967.

"Dynamic Model Investigation of the Rough Water Landing Characteristics of a Gemini Type Vehicle," William C. Thompson, INASA TN D-3774, April 1967.

"Landing Characteristics of the HL-10 Manned Lifting Entry Vehicle," Sandy M. Stubbs, NASA TN D-3570, Nov. 1366.

"Landing Characteristics of the Apollo Spacecraft With. Deployed Heat Shield Impact Attenuation Systems," Sandy M. Stubbs, INASA TN D-3059, Jan. 1966.

Publications may be obtained from the Scientific and Technical Information Division, National Aeronautics and Space Administration, Washington, D. C. 20546.

(6655) SIMULATION AND SCALING OF LOW-GRAVITY FUEL SLOSH.

(b) Laboratory project.

(c) Mr. David G. Stephens, Mail Stop 244, INASAIangley Research Center.

(d) Experimental, applied research.

(e) Development of laboratory methods for simulating low-gravity fuel slosh phenomena.

(f) Completed.

(g) The frequency and damping of the fundamental slosh mode was found to be dependent upon both the Bond number and Galileo number. By using relatively small tanks under one-G laboratory conditions, it is possible to obtain values of these nondimensional parameters in the range encountered by launch vehicles operating in a low-G environment. 
(h) "Simulation and Scaling of Low Gravity Slosh Frequencies and Damping," Leonard V. Clark and David G. Stephens, ASTM/IES/AIAA second Space Simulation Conf., Sept. 1967.

(6656) ANTI-SLOSH BAFFLE PRESSURE LOADS.

(b) Laboratory project.

(c) Mr. David G. Stephens; see (6655) above.

(d) Experimental and analytical; applied research.

(e) Determination of pressure loads and pressure distribution on large scale anti-slosh baffles.

(g) The oscillatory acceleration as well as the velocity of the liquid contribute significantiy to the total pressure loads. Highest pressures may result from the slapping action which occurs when the mean level of the liquid is below the baffle.

NATIONAL AERONAUTICS AND SPACE ADMLNISTRATION, Lewis Research Center, 21000 Brookpark Road, Cleveland, Ohio 44135

(6336) STUDY OF OUTFLOW RESIDUALS FOR INTERCONINECTED SPHERICAL TANKS.

(b) Iaboratory project.

(c) Robert J. Boyle, Aerospace Engr., NASA-Lewis Research Center.

(d) Theoretical and experimental applied research.

(e) The project consists of a study of the liquid residuals in a set of interconnected spherical propellant tanks having individual outflow lines flowing into a common line. Liquid residuals are affected by total outflow rate, initial mass imbalance in tanks, differences in outflow line characteristics, size of tank interconnect lines, and for a flight vehicle, the vehicle acceleration history during outflow.

(f) Completed.

(g) Results of one-dimensional, incompressible flow analysis agreed well with experimental tests outflowing water from multiple interconnected tanks.

(h) TASA TN in preparation.

(6337) ATLAS ILAUNCH VEHICLE FEED SYSTEM DYNAMICS.

(b) Laboratory project.

(c) Carl F. Lorenzo, Aerospace Engr., NASA-Lewi.s Research Center.

(d) Theoretical and experimental applied research.

(e) Study is to demonstrate the ability to predict the behavior of the complex feedline system for a full-scale vehicle. The line flows water with vibration inputs to the vehicle. Termination impedances have been simulated. A similar study is being made to obtain a simple, but more accurate, method of predicting feedline inlet pressure in longitudinally oscillated thin wall tanks. Small scale experimental tank is being used to evaluate proposed methods.

(6338) THE EFFECT OF WEIGHTLESSNESS ON THE CONFIGURATION OF THE LIQUID-VAPOR INTERFACE.

(b) Laboratory project.

(c) Donald A. Petrash, Chief, Space Environment Branch, NASA-Lewis Research Center.

(d) Experimental; applied research.

(e) To investigate the effect of a zero-gravity environment on the behavior of solid-liquidvapor systems with primary consideration to space vehicle propellant tanks and life support system tankage.

(f) Completed.

(g) The effects of liquid properties, tank size, filling and tank geometry have been determined for typical tank shapes. Results have been obtained in both zero- and low-gravity environments and can be scaled to full size vehicle tankage.

(h) "Experimental Study of the Effects of Weightlessness on the Configuration of Mercury and Alcohol in Spherica.l Tanks," D.A. Petrash, R.F. Zappa, E.W. Otto, NASA TNN D-1197, April 1962.

"Effect of Contact Angle and Tank Geometry on the Configuration of the Liquid-Vapor Interface During Weightlessness," D.A. Petrash, R.C. Nussle, E.W. Otto, NASA TN D-2075, Oct. 1963.

"Behavior of Liquid-Vapor Interface of Cryogenic Liquids During Weightlessness," C.E. Siegert, D.A. Petrash, E.W. Otto, NASA TN D-2658, Feb. 1965.

"Slosh Dynamics Study in Near Zero Gravity," H. Gold, J.G. McArdle, D.A. Petrash, NASA TN D-3985, May 1967.

(NASA TNS available from NASA Scientific and Technical Information Facility, College Park, Maryland).

(6339) STABILITY CHARACTERISTICS OF THE LIQUID-VAPOR INTERFACE.

(b) Laboratory project.

(c) Donald A. Petrash; see (6338) above.

(d) Experimental; applied research.

(e) To investigate the stability of the liquidvapor interface when subjected to adverse (negative) acceleration type disturbances.

(i) Completed.

(g) Results show that the ratio of acceleration to capillary forces expressed as a Bond number scaling parameter will predict the interface stability characteristics.

(h) "Effect of the Acceleration Disturbances Encountered in the MA-7 Spacecraft on the Liquid-Vapor Interface in a Baffled Tank during Weightlessness," D.A. Petrash, R.C. Nussle, E.W. Otto, NASA TNV D-1577, Jan. 1763. "Hydrostatic Stability of the Liquid-Vapor Interface in a Gravitational Field," W.J. Masica, D.A. Petrash, E.W. Otto, NASA TN D-2267, May 1964.

"Hydrostatic Stability of the Liquid-Vapor Interface in a Low-Acceleration Field," W.J. Masica, J.D. Derdul, D.A. Petrash, NASA TN D-2444, Aug. 1964.

(NASA TNs available from NASA Scientific and Technical Information Facility, College Park, Maryland).

(6340) THE EFFECT OF WEIGHTLESSNESS ON OUTFLOW OF LIQUIDS FROM SPACE VEHICLE TANKAGE.

(b) Laboratory project.

(c) Donald A. Petrash; see (6338) above.

(d) Experimental; applied research.

(e) To investigate the effect of a zero-gravity environment on the behavior of the liquidvapor interface during outflow or pumping with primary consideration to space vehicle propellant tanks.

(f) Completed.

(g) The effects of liquid properties, tank size and tank geometry on the outflow phenomenon have been determined in zero-gravity. Results have also been obtained on the effect of inlet 
and outlet baffling and outflow termination.

(h) "Photographic Study of Propellant Outflow From a Cylindrical Tank During Weightlessness," R.C. Nussle, J.D. Derdul, D.A. Petrash, INASA TN D-2572, Jan. 1965.

"Experimental Investigation of Liquid Outflow from Cylindrical Tanks During Weightlessness," J.D. Derdul, Lymn S. Grubb, D.A. Petrash, NASA TN D-3746, Dec. 1966.

"Experimental Investigation of Interfacial Behavior Following Termination of Outflow in Weightlessness," L.S. Grubb, D.A. Petrash, NASA TN D-3897, April 1967.

(NASA TNs available from NASA Scientific and Technical Information Facility, College Park, Maryland).

(6341) SLOSH DYNAMICS IN REDUCED GRAVITY ENVIRONMENTS.

(b) Laboratory project.

(c) Donald A. Petrash; see (6338) above.

(d) Experimental; applied research.

(e) To investigate the natural frequency and damping of lateral slosh in space vehicle propellant tanks.

(f) Completed.

(g) The natural frequency and viscous damping charateristics of liquids in cylindrical tanks have been determined in both low - and zerogravity environments.

(h) "Motion of Liquid-Vapor Interface in Response to Imposed Acceleration," W.J. Masica, D.A. Petrash, NASA TN D-3005, Sept. 1765.

"Slosh Dynamics Study in Near Zero Gravity," H. Gold, J.G. McArdle, D.A. Petrash, NASA TN D-3985, May 1967.

"Experimental Investigation of Liquid Surface Motion in Response to Lateral Acceleration During Weightlessness, "W.J. Masica, NASA TN D-4066, July 1967.

"An Experimental Investigation of the Frequency and Viscous Damping of Liquids During Weightlessness," J.A. Salzman, T.L. Labus, W.J. Masica, NASA TN D-4132, Aug. 1967.

(6342) IIQUEFIED-GAS FLOW MEASUREMENT.

(b) Laboratory prouect.

(c) Isidore Warshawsky, Chief, Instrument Research Branch, NASA-Lewis Research Center.

(d) Experimental basic research.

(e) The program consists of development, test, and evaluation of techniques and equipment for accurately measuring the flow of liquefied gases. Precise measurement of flow is essential in most research and development programs.

(h) A NASA report on performance parameters of turbine-type flowmeters in liquid hydrogen, TN D-3770, was published.

(6343) STUDY OF HIGH HEAD RISE INDUCER STAGES.

(b) Laboratory project.

(c) Donald M. Sandercock, Head, Analys is Section, Fluid System Components Div., Lewis Research Center, NASA.

(d) Experimental applied research.

(e) The study of a tandem-row inlet stage to replace two conventional inlet stages of a multistage axial flow pump. The tandem-row experimental work includes cavitation performance, the head characteristic, and matching with a succeeding main stage door.

(f) Completed.

(g) The tandem-row inducer stage produced a head rise coefficient $\left(\mathrm{g} \Delta \mathrm{H} / \mathrm{U}_{t}{ }^{2}\right)$ of approximately 0.3 at a suction specific speed of 26500 in water.
The single stator blade row, which returned the flow to the axial direction, was highly looded and resulted in high losses.

(h) "Design and Overall Performance of a TwoStage Axial-Flow Pump with a Tandem-Row Inlet Stage," Donald M. Sandercock and James E. Crouse, NASA TN D-2873, 1965.

"Blade-Element Performance of a Two-Stage Axial-Flow Pump with Tandem-Row Inlet Space," James E. Crouse and Donald M. Sandercock, NASA TN D-3962, 1967.

(6344) HYDRODNNAMIC JOURNAL BEARING PERFORMANCE IN WATER AND LIQUID SODIUM.

(b) Laboratory project.

(c) William J. Anderson, MS 23-2, NASA - Lewis Research Center.

(d) Experimental and theoretical applied research.

(e) Investigations of the stability characteristics of tilting pad, herringbone, lobed and stepped journal bearing configurations are being carried out. Analyses of lobed and stepped bearings are being made and experiments are being conducted with all of these bearing types in water at high speeds and low loads.

(g) Experiments with 1.5 inch diameter tilting pad, herringbone grooved, and two and three axial cylindrical bearings have been conducted in liquid sodium at temperatures to $800^{\circ} \mathrm{F}$ and speeds to $12,000 \mathrm{rpm}$. Tilting pad bearings were most stable with herringbone bearings next best.

Several material combinations for use in sodium have been evaluated. A cobalt alloy performed well running against several nickel alloys, as did a molybdenum alloy against a nickel bonded titanium carbide cermet.

(6345) HELICAL AND SPIRAL GROOVE SEAL PERFORMANCE IN SEALING OIL, WATER AND LIQUID SODIUM.

(b) Laboratory project.

(c) R.I. Johnson, MS 23-2, NASA - Lewis Research Center.

(d) Experimental and theoretical applied research.

(e) Analysis of velocity and pressure fields (including inertia effects) within the helical and spiral groove geometry. Measurements of sealing effectiveness, pressure gradients and gas ingestion when sealing various fluids over a wide speed range.

(g) The pressure field within the helical groove viscoseal was mapped. The end of the seal was found to be ineffective in producing pressure.

Viscoseals with grooved rotors had increasing gas ingestion rates with increasing Reynolds numbers. Seals with grooved housings showed no gas ingestion when sealing water sodium at Reynolds numbers above 8400 . Sealing capacity of various viscoseal geometries was determined for sealing liquid sodium to $635^{\circ} \mathrm{F}$. Leakage loss was neglipible. Secondary grooves on viscoseal land areas improved sealing capacity and reduced power absorption. Conventional face contact seal performance was significantly improved by incorporation of the spiral groove geometry. Spiral grooved seals had negligible leakage and wear sealing sodium to $7 \ni$ feet per second and to $20 \mathrm{psig}$. A set of two-dimensional equations that include both convective inertia and viscous forces was formulated for parallel groove geometries. Consideration of convective inertia effects reveal that fluid density, groove to land 
width ratio and number of groove-land pairs are additional parameters of pressure generation not considered in existing published studies. It is argued that zero leakage is due to convective effects.

Spiral groove seal concepts are presented. Supporting experimental studies indicate negligible leakage in sealing oil. Seal torque and sealing gap height were measured. Photographic evidence of positive sealing interface separation (seal gap) is presented. Studies in sodium showed negligible leakage.

(h) "Experimental Study of End Effect and Pressure Patterns in Helical Groove Fluid Film Seal (Viscoseal)," L.P. Ludwig, T.N. Strom and G.P. Allen, NASA TN D-3096.

"Gas Ingestion and Sealing Capacity of Helical Groove Fluid Film Seal (Viscoseal) Using Sodium and Water as Sealed Fluids, "I.P. Ludwig, T.N. Strom and G.P. Allen, NASA TN D-3348.

"Improving Performance of Face Contact Seal in Liquid Sodium $\left(400^{\circ}\right.$ to $1000^{\circ} \mathrm{F}$ ) by Incorporation of Spiral-Groove Geometry, "L.P. Ludwig, T.N. Strom, G.P. Allen and R.I. Johnson, NASA TN D-3942.

"Analysis of the Flow Field and Pressure Generation in Parallel Groove Geometry for an Isothermal Incompressible Fluid with Convective Inertia Effects," J. Zuk, I.P. Iudwig and R.L. Johnson, NASA TN D-3635.

"Spiral Groove Face Seal Concepts; Comparison to Conventional Face Contact Seals in Sealing Liquid Sodium," T.N. Strom, L.P. Ludwig, G.P. Allen and R.I. Johnson, ASME Paper 67-WA-Lub17 .

(6346) EFFECTS OF FLOW ACCELFRATION ON THE TURBUTENT BOUNDARY LAYER.

(b) Laboratory project.

(c) Dr. Robert W. Graham, Head, Experimental Section, NASA-Lewis Research Center.

(d) Experimental and theoretical.

(e) An investigation of the effects of accelerated flow history on the nature of turbulent boundary layer for incompressible flow.

(g) Level of turbulence intensity affected by upstream flow history.

(h) "Effect of Uncooled Inlet Length and Nozzle Convergence Angle on the Turbulent Boundary Layer and Heat Transfer in Conical Nozzles Operating With Air," D.R. Boldman, J.F. Schmidt, and R.C. Ehlers, Jour. Heat Transfer, Vol. 89, p. 34l, Nov. 1967.

UNITED STATES NAVAL ACADEMY, Engineering Department, Annapolis, Maryland. 21402

(6126) CIRCULATION PRESERVING ROTATIONAL FLOWS.

(b) Office of Naval Research, Fluid Dynamics Branch.

(c) Assoc. Prof. Robert A. Granger, Engrg. Dept., U.S. Naval Academy.

(d) Theoretical; basic research.

(e) An investigation into unsteady three-dimensional rotational flow with vortex stretching but no diffusion. A mathematical model of the transition between stable and unstable flow is found and verified by experiment.

(f) Completed.

(h) Results presented at the Amer. Physical Soc., Fluid Dynamics Div., Nov. 1967.
(6127) UNSTFADY THREE-DIMENSIONAL FLOWS.

(b) Office of Naval Research, Fluid Dynamics Branch.

(c) Assoc. Prof. Robert A. Granger; see (6126).

(d) Theoretical and basic research (Ph.D. thesis).

(e) An investigation into unsteady three-dimensional rotational flows with vortex stretching and diffusion. Numerous classical studies are discussed as well as new solutions.

(f) Completed.

(h) Paper submitted to Jour. Fluid Mechanics, entitled "Waves in Vortices."

(6128) SPEED OF A SURGE IN A BATHTUB VORTEX.

(b) Office of Naval Research, Fluid Dynamics Branch.

(c) Assoc. Prof. Robert A. Granger; see (612ó).

(d) Experimental and basic research.

(e) The speed of a surge propagating along the centerline of a bathtub vortex is influenced by sink geometry and circulation of the flow. The origin of the surge is also investigated.

(f) Completed.

(h) A paper has been written and submitted to Jour. Fluid Mechanics.

(6129) BREAKDOWN OF A SPHERICAI DISTURBANCE.

(b) Office of Naval Research, Fluid Dynamics Branch.

(c) Assoc. Prof. Robert A. Granger; see (6126).

(d) Experimental and basic research.

(e) Experimental evidence is presented lending support to finite transition theory for vortex breakdown.

(f) Completed.

(h) Paper submitted to ASME.

(6130) THE NATURE OF A PULSE IN VORTEX SINK FLOW'S.

(b) Office of Naval Research, Fluid Dynamics Branch.

(c) Assoc. Prof. Robert A. Granger; see (6126).

(d) Experimental and basic research.

(e) Experimental evidence supports theory that a pulse with origin at the sink behaves as a ring vortex and that such behavior might occur in shear flow.

(6131) ON THE SOLUTION OF A CLASS OF THREE-DIMENSIONAI UNSTEADY FLOWS.

(b) Office of Naval Research, Fluid Dynamics Branch.

(c) Assoc. Prof. Robert A. Granger; see (6126).

(d) Theoretical and basic research.

(e) Application of group theory to three-dimensional unsteady flows. Evaluation of wave theory, and its applicability for unsteady vortex sink flows.

(6132) ON A MODEL FOR ANALYZING TSUNAMIS.

(b) Office of Naval Research, Fluid Dynamics. Branch.

(c) Assoc. Profs. Robert A. Granger, C. Wu.

(d) Experimental and theoretical applied research.

(e) Feasibility study for using hydro-electric analogs for studying wave motion and tsunamis.

(6133) OPTICAI INVESTIGATIONS OF DENSITY GRADIENTS NEAR A WATER-AIR INTERFACE.

(b) Office of Naval Research and U.S. Naval Academy .

(c) Assoc. Prof. J.A. Adams, Engrg. Dept., U.S. Naval Academy. 
(d) Experimental; basic research.

(e) The project is being carried out to obtain a better understanding of the transport processes that occur across a water-air interface. A Mach-Zehnder interferometer which utilizes a gas laser for the light source is being used to measure density gradients near the interface. Evaporation rates can be determined from the measured liquid density gradients at the interface. The effects of submerged heated surfaces and infrared radiation on the gradients will be studied.

(g) The feasibility of the experimental technique has been proven and initial measurements of evaporation rates are being obtained.

(h) "Optica.l Investigations of Heat Transfer Near an Air-Water Interface" (a preliminary report), James A. Adams, U.S. Naval Acad.,Engrg. Dept. Rept. 67-7, June 1967.

(6134) A COMPARISON OF RANDOM SIGNAL ANALYSIS TECHNIQUES FOR TURBULENCE AND FIOW NOISE MEASUREMENTS.

(b) Hydromechanics laboratory project.

(c) Assoc. Prof. Bruce Johnson.

(d) Trident Scholar Thesis.

(e) The project will investigate the effects of sampling time, filter band width, sweep time, averaging time, and influence of the slope of the power spectral density curve on the characteristics of turbulent signals obtained from testing in the Naval Academy tow tank. The relatively short sample time associated with tank testing results in a non-stationary, pseudorandom set of statistical data to be analyzed in the amplitude, frequency and time domains. Various analog techniques will be compared to gain an optimum characterization of the physical meaning of the turbulent signals. In addition, recently developed digital techniques using the fast Fourier transform will be investigated.

(6135) THE EFFECT OF DRAG-REDUCING ADDITIVES ON BOUNDARY LAYER TURBULENCE.

(b) Hydromechanics laboratory project.

(c) Assoc. Prof. Bruce Johnson.

(d) Trident Scholar Thesis.

(e) A preliminary investigation was made concerning the effects of poly-ethylene oxide on the spectral density of turbulent fluctuations in a boundary layer. The folyox solution was injected into a two-dimensional boundary layer along a flat plate which was towed at 9.5 fps in the Naval Academy's 85-foot tow tank. Measurements of the mean and fluctuating components of the velocity near the wall were made with conical hot film sensors.

(f) Completed, 1966.

(g) Polymer injection resulted in an increase in rms level of the fluctuations and in an increase in spectral density below $200 \mathrm{~Hz}$. Above this frequency, the spectral density decreased, the effect being more pronounced at higher frequencies and at higher polymer concentrations. Measurements of the mean and fluctuating components of the wall shear stress were made with flush mounted hot film sensors submerged in the viscous sub-layer. Polymer injection resulted in a decrease in mean shear, in rms level, and in spectral density of the fluctuating wall shear stress. The latter effect increased with increasing frequency and all effects increased with higher molecular weight of the additives.
All results suggest the polymer shifts the scale of turbulence away from the energydissipating small eddies.

(h) AIAA Preprint No. 67-459, presented at 3rd Propulsion Joint Specialist Conference.

(6136) MEASUREMENT OF VELOCITY FLUCTUATIONS IN A TURBULENT BOUNDARY LAYER WITH AND WITHOUT THE INJECTION OF A POLYMER ADDITIVE.

(b) Hydromechanies laboratory project.

(c) Assoc. Prof. Bruce Johnson.

(d) Trident Scholar thesis.

(e) Conical hot film sensors were used to measure both mean and fluctuating components of the velocity profile at two positions along a flat plate, towed in the Naval Academy's 85-foot tow tank. The effects of polymer injection were found to be dependent on the speed, distance from the wall, and the position of the sensor along the plate. At the wall, the rms level of the fluctuations increased, while the turbulence energy spectra decreased above $200 \mathrm{~Hz}$ aft and $100 \mathrm{~Hz}$ forward. Near the injection point, as distance from the wall and speed increased, the effect of the polymer was to increase rms level and shift the turbulence spectra to higher frequencies.

(f) Completed, 1967.

(g) Experimental results indicated a thickening of the boundary layer and reduction of mean shear with injection. Effectiveness of the polymer injection suggests that the turbulence scale shifts away from the small, energydissipating eddies. Further analysis using normalized energy spectra also indicated this effect.

(6137) THE DEVELOPMENT OF CAIIBRATION TECHNIQUES FOR A FLUSH-MOUNTED HOT-FILM ANEMOMETER IN THE STUDY OF TURBULENT BOUNDARY LAYERS.

(b) Hydromechanics laboratory project.

(c) Assoc. Prof. Bruce Johnson.

(d) Trident Scholar thesis.

(e) A preliminary investigation has been made concerning the calibration of flush-mounted hot-film sensors in fully developed pipe flow. Whereas most hot-film sensors measure the time-average and fluctuating components of velocity, the flush-mounted sensors have been found to measure the mean and fluctuating components of the wall shearing stress. The flush-mounting permits qualitative flow observations in addition to measurements of turbulent quantities without obstructing the flow. Four methods of calibration are presented and compared: a graphical technique, a three-point fit, a least squares determination and derivative technique. Each involves a fitting of the generalized King's Iaw equation to sensor calibration curves.

(f) Completed, 1967.

(g) The calibration variables were found to be functions of the individual sensors, thus no universal King's law fits this type of sensor. Measurements were also made of the normalized fluctuating wall shear spectra.

(6209) SOME THEORETICAL AND EXPERIMENTAL STUDIES ON THE PROPULSION OF SWIMMING FLEXIBLE BODIES.

(b) National Science Foundation and Iaboratory projects.

(c) Assoc. Prof. J.P. Uldrick, Engrg. Dept., U.S. Naval Academy.

(d) Theoretical and experimental; basic research. (e) Three problems are currently under investi- 
gation:

(1) A theoretical determination of the propulsion efficiency of swimming flexible hydrofoils of finite thickness in two-dimensional flow and an experimental investigation of the thrust produced by the undulating body. This phase of the project is essentially complete.

(2) A theoretical and experimental investigation into the propulsion of slender fishlike bodies. Senior research thesis.

(3) A study of the viscous effects on the drag generated by an undulating flexible thin hydrofoil in two-dimensional flow. Senior research project.

(g) In problem (1) a theoretical analysis has been carried out showing the energy exchange between a swimming flexible two-dimensional hydrofoil of finite profile thickness and the inviscid incompressible fluid in which the body swims. The rate at which kinetic energy is transferred to the fluid by the undulating hydrofoil, the power required to maintain the prescribed motion, and the resulting power available for propulsion have been calculated in terms of the thickness, displacement and rate of displacement of the hydrofoil. Recent numerical results reveal that a very large percentage of the power required to maintain the motion is used in the generation of the wake whereas a very small percentage of the prower available for propulsion comes from the wake.

(h) "On the Swimming of a Flexible Plate of Arbitrary Finite Thickness," J.P. Uldrick and J. Siekmann, Jour. Fluid Mech., Vol. 20, pp. 1-33, 1964.

"On the Propulsion Efficiency of Swimming Flexible Hydrofoils of Finite Thickness," J.P. Uldrick, Proc. 5th Natl. Conf. Appl. Mech., 1966.

"On the Propulsion Efficiency of Flexible Hydrofoil of Finite Thickness," J.P. Uldrick, accepted for publication in Jour. Fluid Mech., 7 Nov. 1967.

(6210) A METHOD FOR THE EVALUATION OF TSUNAMI ENERGY FROM TIDE GAUGE RECORDS USING COMPARATIVE ANALYSIS.

(b) Laboratory project.

(c) Midshipman Herman L. Dantzler, Jr., I/C; advisor is Assoc. Prof. Jerome Williams, Naval Science Dept., U.S. Naval Academy.

(d) The project is theoretical, applied research utilizing available data. It is a portion of the Trident scholar program.

(e) The project is attempting to establish a program whereby the energy and shoaling heights of a tsunami may be estimated. Energy values calculated from past tsunamis at Hilo, Hawaii are being utilized after correction for dispersion and epicenter distance are applied. An attempt will be made to develop a forecasting technique to estimate tsunami relative energy utilizing these previous data.

(6211) USE OF NON-LINEARITIES FOR IMPROVED HYDRAULIC SERVO SYSTEM PERFORMANCE.

(

(c) Assoc. Prof. Donald Haber, Weapons Dept., U.S. Naval Academy.

(e) This project is an investigation into improving hydraulic servo systems by the introduction of new or amplification of existing non- linearities. By use of such non-linear elements, a superior design may result. That is, a design which improves response time, error and settling time while still maintaining economy and power requirements.

(g) By use of certain numerical methods, a method has been obtained to identify the nonlinearities present in hydraulic or other servo components. This method has now been extended to use of these non-linearities in design.

(6212) USE OF ANALOG AND DIGITAL COMPUTERS IN WATER BUDGET STUDIES.

(b) Weapons Dept., U.S. Naval Academy.

(c) Assoc. Prof. John F. Foffman, Weapons Dept., U.S. Naval Academy.

(d) Experimental; applied research for further application in another research project "The Effect of Bank Storage on Reservoir Yield" (Ph.D. Dissertation).

(e) Water budget equation is solved for research in order to determine ground water contribution to reservoir storage. Data processing, curve fitting, and data extrapolation are involved. Transient effect of drawdown in reservoir level on ground water in storage simulated by means of a passive analog model. Practical application is being made to data from Fontana Reservoir (TVA) and Pepacton Reservoir (N.Y. City Board of Water Supply).

U.S. NAVAL APPLIED SCIENCE IABORATORY, Flushing and Washington Aves., Brooklyn, N.Y. 11251

\section{(6428) MATERIALS FOR HIGH SPEED FLUID FLOW APPLICA-} TIONS.

(b) Naval Ship Systems Command, Dept. of the Navy .

(c) A. Rufolo, Coatings Branch Head (Code 937), U.S. Naval Applied Science Lab.

(d) Experimental; applied research and development.

(e) Development of coatings and overlay materials which can provide corrosion, erosion and antifouling protection in severe hydrodynamic environments; of structural materials which can resist erosion, primarily that produced by cavitation. Studies are concerned with screening of erosion resistant metallic and elastomeric materials; with development of high strength adhesives; with application techniques; and with field evaluations. Studies are performed in a "Cavitation Laboratory" which compris es "1) A Rotating Disk Apparatus, (2) Magnetc striction Equipment, (3) A High Speed Ventu i Nozzle Faci? ity and (4) A High Sonic Energy Test Tank. j eld trials have included experimental applications on propellers and on Navy hydrofoils.

(g) Attachment, demonstrated to be a critical problem, has been achieved with moderate success on hydrofoils, through special attachment techniques and high strength adhesives. Materials (metallic and elastomeric) with high resistance to cavitation erosion have been evaluated and catalogued.

(h) "Cavitation Damage Design Handbook," J.Z. Lichtman and E.R. Weingram, Lab. Proj. 9300-17, Final Rept., 30 sept., 1364, DDC Distribution AD 460524.

"Cavitation Erosion Performance and Related Properties of Cured Sheet Elastomeric Coating Systems," J.Z. Lichtman, Jour. of Materials, 
Vol. 2, No. 3, ASTM, 1967.

"Erosion Resistance of Coatings," J.Z. Lichtman and D.H. Kallas, Materials Protection, Vol. 6, No. 4, pp. 40-45, NACE, April 1967.

"Foil Weight Saving and Hydrofoil Performance," A. Rufolo, Naval Engrs. Jour., pp. 905-913, Oct. 1966.

"Cavitation Erosion Facilities and Developments at U.S. Naval Applied Science Lab.," J.Z. Lichtman, D.H. Kallas and A. Rufolo, Trans. Symp. on Testing Techniques in Ship Cavitation Research 31 May - 2 June 1967, Norwegian Ship Model Experiment Tank, Technical Univ. of Norway, Trondheim, Norway. Available from NASL, above address, code 937.

NAVAL CIVIL ENGINEERING IABORATORY, Facilities Engineering Command, U.S. Navy, Port Hueneme, California 93041.

Inquiries concerning the following projects should be addressed to Director, Amphibious and Harbor Div., Code L55, Naval Civil Engrg. Lab.

(6332) RUN-UP ON A BEACH OF IMPULSIVELY GENERATTD SURFACE GRAVITY WAVES FROM A NEAR-SHORE DISTURRANCE.

(b) Defense Atomic Support Agency.

(d) Primarily experimental; basic and applied research.

(e) Investigation, primarily through measurements in a 90- by 90- by 3-foot basin, of the height of run-up of the leading waves of a dispersive train, as a basis for prediction.

(g) Data analysis in progress.

(6333) RUN-UP ON PLANE-FACED WALLS OF IMPULSIVELY GENERATED SURFACE GRAVITY WAVES FROM A NEARSHORE DISTURBANCE.

(b) Defense Atomic Support Agency .

(d) Primarily experimental; basic and applied research.

(e) Measurements in a 90- by 90- by 3-foot basin of the height of run-up of the leading waves of a dispersive train on plane-faced, vertical and inclined walls mounted on a sloping bottom at varying distances from shore; to provide a basis for prediction.

(g) Data analysis in progress.

(6334) WAVE PRESSURE ON THE UNDER SIDE OF A HORIZONTAL PIER.

(b) Defense Atomic Support Agency .

(d) Experimental and theoretical; basic and and applied research.

(e) The hydrodynamic pressure on a flat plate 6 feet long by 1 foot wide, with long dimension normal to the wave crests, was analyzed theoretically and studied experimentally in a 90- by 90- by 3-foot basin, where the plate was mounted over a sloping (1:14) bottom near the shore and over a horizontal bottom far from shore, and was subjected to dispersive wave trains.

(f) Completed.

(g) The pressure histories contained slow-rise and fast rise (impact) components. The former varied from one to two times the hydrostatic value. For the latter, an upper limit of 4.5 was found for the parameter

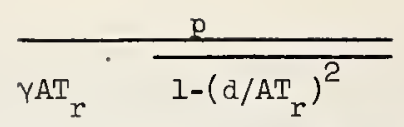

in which is specific weight, $T$ is the transmissibility (ratio of wave height after attenuation by plate to incident wave height), d is height of plate above the still water level, and $A$ is incident.wave amplitude.

(h) "Estimating Wave Pressures on a Horizontal Pier," H. Wang, Naval Civil Engrg. Lab. Tech. Rept. R-546, 69 pp., Oct. 1367 (available from CFSTI, Springfield, Va. 22151.)

(6335) HYDRODYNAMIC PRESSURE ON A VERTICAI WALI DUE TO AN INCIDENT DISPERSIVE TRAIN OF SURFACE GRAVITY WAVES.

(b) Defense Atomic Support Agency.

(d) Experimental; basic and applied research.

(e) Measurement of pressure histories on wall with incident breaking and non-breaking waves.

(g) Data analysis in progress.

U.S. NAVY MINE DEFENSE LABORATORY, Panama City, Florida 32401

(6297) SHALLOW WATER WAVE RESEARCH.

(b) Laboratory project.

(c) Mr. G.B. Austin, Attn.: Code 713, U.S. Navy Mine Defense Lab.

(d) Experimental field investigation; applied research.

(e) A field investigation to measure the variability of the wave element pressure in shoaling water between two offshore platforms is conducted, using arrays of sensors near each of the two platforms. The ability to predict the modification and variability of the wave element pressure in the nearshore ocean is a goal of this investigation. The statistical techniques for estimating power spectra, cross power spectra and the directional spectra of waves are fundamental tools employed in the study.

(g) Estimates of directional spectra for different boundary conditions of depth, sea state, surface wind and time have been mapped for waves in the frequency band $0.15 \mathrm{~Hz}$ to 0.005 $\mathrm{Hz}$. Results include examples of shallow water wave measurements from conditions of the very calm environment to those of hurricances of the Northeast Gulf of Mexico.

(h) "A Data Processing System for Multiple Time Series Analysis of Ocean Wave Induced Bottom Pressure Fluctuations," C. Bennett, E. Pittman, and G. Austin, Proc. Ist U.S. Navy Symp. on Military Oceanography, Washington, D.C., Vol. 1, pp. 379-415, June 1964. "An Annual Distribution of the Power Spectra of Ocean Wave Induced Bottom Pressure Fluctuations in the Near-Shore Gulf of Mexico," C.M. Bennett, Trans. Amer. Geophys. Union 48th Ann. Mtg., Vol. 48, No. 1, Abstract, Mar. 1967, Published as USNMDL $R$ and D Rept. 344, Nov. 1767 .

U.S. NAVAL OCFANOGRAPHIC OFFICE, Washington, D. C. 20390

(6452) OCEANOGRAPHIC CURRENT METER CALIBRATION. 
(b) Laboratory project.

(c) Mr. Gilbert Jaffe, Instrunentation Dept., Naval Oceanographic Office.

(d) Experimental, development.

(e) To develop and provide an environmental laboratory facility for the study of improved instrumentation methods in measuring ocean current flow, and for testing and calibrating of ocean meters under non-turbulent flow conditions.

(g) Non-turbulent flow is obtained in a recirculating water current system through the lowvelocity range from 0.01 to 5.0 knots. The undisturbed space inside the flow tank provides the necessary water volume for test and calibration of presently used rotor-type current meters and for metrological investigation of flow measurement techniques.

(h) "Very Low Speed Water Current Facility," A. Carnvale and W.S. Wong, Instrumentation Dept., Naval Oceanographic Office (in preparation).

(6454) WAVE FORECASTING RESEARCH.

(b) Laboratory project.

(c) Mr. John J. Schule, Jr., Acting Director, Research and Development Dept. (Code 70).

(d) Applied research involving field experiments with wind-generated ocean waves.

(e) Development of automated wave prediction techniques on an ocean-wide basis; present emphasis is directed to measurement of directional spectra in deep and shallow water by airborne techniques and study of low level winds and temperature from ARGUS ISLAND Tower.

(h) "Preliminary Investigation of Ocean Wave Height as Obtained from Stereo Wave Photographs," L.S. Simpson, NAVOVEANO Informal Manuscript, No. 67-1, Jan. 1967.

"On the Interpretation of Fetch-Limited Wave Spectra as Measured by an Airborne sea-Swell Recorder," T.P. Barnett and J.C. Wilkerson, NAVOCEANO Tech. Rept. TR-191, May 1967. (Also see: Jour. Marine Research, Vol. 25, No. 3, Sept. 1967, pp. 292-328).

U.S. NAVAL ORDNANCE LABORATORY, White Oak, Silver Spring, Maryland 20910

\section{(4867) HYDROBALIISTICS RESEARCH.}

(b) Naval Ordnance Systems Command, Dept. of the Navy.

(c) Dr. A.E. Seigel, Chief, Ballistics Dept., U.S. Naval Ordnance Lab.

(d) Experimental, theoretical; basic and applied research.

(e) The purpose is to study high velocity water entry as related directly or indirectly to the behavior of missiles. The study includes the stability and forces during the entry, cavity development and pressure, and the missile trajectory. A wide range of developmental and research configurations and of experimental conditions are investigated. The missiles are launched from gas or powder guns.

A large tank facility was completed near the end of 1966. This facility, which was designed for use with large, high-speed missiles, is supplemented by a smaller, lower-speed tank. Both tanks are suited to such experimental projects as water entry, water exit, and trajectory studies, and both permit atmospheric pressure reduction for water-entry scaling. Current programs involve: axial impact forces, pressure in the water-entry cavity, propulsion and stability of nonbuoyant missiles, and prevention of vortex shedding.

(g) Results of recent studies include: verification of hydrodynamic shocktube predictions, water-impact drag coefficients for cones; prevention of vortex shedding by means of splitter plates; simulation of underwater rocket behavior.

(h) "A Preliminary Study of the Mechanism of Water-Entry Whip of $20^{\circ}$ Cone Nosed Models, " J.0. Gurney, Jr., NOLTR 66-148, 1966.

"A Doppler Radar System to Obtain Water Impact Drag Coefficients," D.F. Gates, R.J. HaisImaier, and I.I. Hill, Second Intl. Congr. on Instrumentation in Aerospace Simulation Facilities, Stanford Univ., 1966. "The Water Entry Problem with Bibliography, " W.E. Parr, NOLTR 66-173, 1966.

"Hydrodynamic Pressure Measurements of the Vertical Water Entry of a Sphere," W.R. Hoover and V.C.D. Dawson, NOITR 66-70, 1966. "Cavity Shapes at Vertical Water Entry--A Comparison of Calculated and Observed Shapes," H.I. Abelson, NOLTR 67-31, 1967.

U.S. NAVAL POSTGRADUATE SCHOOL, Dept. of Mechanical Engineering, Monterey, California 93940.

(6058) JET ATTACHMENT TO OFFSET CONVEX COANDA WALIS.

(b) Dept. of the Army, Harry Diamond Labs.

(c) T. Sarpkaya, Prof. and Chairman, Dept. of Mechanical Engrg., U.S. Naval Postgraduate School.

(d) Theoretical and experimental study of the pressure and velocity distribution over a convex wall set back relative to the power jet. Basic research for M.S. thesis.

(e) Primary objectives of the research are to determine the size of the attachment bubble and to establish the significance of the wall curvature on the coanda effect.

(g) Preliminary studies show that a convex-walled bistable amplifier has a relatively higher pressure recovery.

(h) "Ferformance Characteristics of Straight, Concave, and Convex Walled Vented and Unvented Bistable Amplifiers," T. Sarpkaya, Internal Report to Harry Diamond Laboratories, July 1967.

(6059) SWIRLING FLOWS IN TUBES AND VORTEX BREAKDOWN.

(b) Dept. of the Army, Harry Diamond Labs.

(c) Dr. T. Sarpkaya; see (6058) above.

(d) Theoretical and experimental work for master's thesis.

(e) To determine the circulation distribution in tubes and the effect of the adverse pressure gradient on vortex breakdown.

(h) "Forced and Periodic Vortex Breakdown," T. Sarpkaya, Jour. Basic. Engrg., Trans. ASME, Sept. 1967, pp. 607-616.

(6060) A THEORETICAI AND EXPERIMENTAL INVESTIGATION OF WIND-INDUCED OSCILLATIONS OF ELASTIC BODIES.

(b) National Aeronautics and Space Admin.

(c) Dr. T. Sarpkaya; see (6058) above.

(d) Theoretical and experimental work for M.S. and $\mathrm{Ph} . \mathrm{D}$. theses.

(e) Lift and drag forces and the frequency of the 
oscillations of slender bodies subjected to wind forces are determined through the use of discrete vortices and potential flow theory.

(g) Preliminary studies show that the potential flow analysis may be used to accurately predict the drag forces and to establish an appropriate scale factor.

(6061) A THEORETICAI AND EXPERIMENTAL INVESTIGATION OF VIRTUAI MASS IN STRATIFIED FLUIDS.

(b) Departmental project.

(c) Dr. T. Sarpkaya; see (6058) above.

(d) Theoretical and experimental work for master's thesis.

(e) To determine the virtual mass and the forces acting on a body inmersed in a uniformly stratified fluid.

(g) Experiments are being conducted using salt water solution in a rectangular tank with circular cylinders of various diameters. The cylinder is oscillated with frequencies ranging from 0.5 to 6 cps. The forces are recorded with the help of a strain gage transducer.

(6062) THRUST CONTROL IN A TRANSONIC NOZZLE WITH SWIRLING FLOW.

(b) Departmental project.

(c) Dr. T. Sarpkaya; see (6058) above.

(d) Theoretical and experimental study of the velocity and pressure distribution and the thrust in a transonic nozzle. Applied theoretical and experimental research for master's thesis.

(e) Primary objectives of the research are to determine the relationship between the mass flow used in the generation of the vortex motion to the thrust provided by the nozzle and to develop a non-moving system of thrust control through the use of the vortex motion.

(g) Preliminary studies show that the magnitude of the thrust may be varied from $100 \%$ to $60 \%$ with a swirled mass flow to nozzle mass flow ratio ranging from 0 to $20 \%$.

U.S. NAVAL POSTGRADUATE SCHOOL, Dept. of Meteorology and Oceanography, Monterey, California 93940

\section{(6593) OCEAN STUDIES.}

(b) Naval Oceanographic Office, Ocean Prediction Div.

(c) Dr. G.H. Jung, Prof. of Oceanography, Dept. of Meteorol. and Oceanog., Naval Postgraduate School.

(d) Field and theoretical investigation; applied research and development.

(e) Intensive field studies are analyzed for contributions toward development of an ocean forecasting model (both subjective and objective); theoretical ocean model study results are incorporated as well.

(g) Four intensive survey areas have been analyzed; recent numerical ocean model results have been reviewed and portions of the synoptic surveys and the ocean model findings are being synthesized into a prediction model.

(h) "An Examination of Synoptic Oceanographic Data," Glenn H. Jung, Naval Oceanographic Office Tech. Rept. T-197 (ASWEPS Rept. No.13), 21 pp., May 1967. (60 cents from Naval Oceanog. Off., Washington, D. C. 20390.
In Press: Naval Oceanographic Office Informal Manuscripts:

"Further Analyses of Upper Ocean Variability," Glenn H. Jung, May 1967;

"Synoptic Data Analyses of the 1966 USNS

Gilliss Cruises 403-67 and 404-67 and Related Art Observations," Glenn H. Jung, Aug. 1967;

"Certain Ocean Models and Their Application Toward a Numerical Gulf Stream Forecasting Model," Glenn H. Jung, Dec. 1967.

(6594) NEARSHORE WAVE REFRACTION STUDIES.

(b) Laboratory project.

(c) Dr. Glenn H. Jung; see (6593) above.

(d) Theoretical; for Masters thesis.

(e) Tide level and bottom friction effects on wave refraction as determined by numerical wave refraction procedures.

(f) Suspended.

(g) A uniform increase in water level, as caused by tidal fluctuations can cause a significant change in the wave refraction pattern for a given nearshore region. Computing procedure is developed to permit numerical refraction programs to account for bottom friction. Reduction in wave height caused by bottom friction depends primarily on bottom slope (relation is shown in table and graph).

(h) "Tide Level and Bottom Friction Effects on Wave Refraction as Determined by Numerical Wave Refraction Procedures," Charles A. Farrell, Jr., Master's thesis, NPGS, Dept. of Meteorol. and Oceanog., 60 pp., June 1967. Available from DDC, except to foreign governments or foreign nationals who should contact Librarian, NPGS).

(6595) TURBULENCE MEASUREMENTS.

(b) Naval Ordnance Test Sta., China Lake.

(c) Dr. T. Green and Warren W. Denner, Asst. Prof's. of Oceanography, Dept. of Meteorol. and Oceanog., NPGS.

(d) Experimental; basic research.

(e) Turbulence measurements are made and examined within a few inches of the surface of a pond.

(6596) CONVECTION.

(b) Office of Naval Research.

(c) Dr. T. Green, Asst. Prof. of Oceanography, Dept. of Meteorol. and Oceanog., NPGS.

(d) Numerical; theoretical.

(e) Various cases of Benard convection are examined with rapidly varying fluid properties.

(6597) OCEAN CURRENT CAICULATIONS.

(b) Fleet Numerical Weather Facility, Monterey, Calif.

(c) Warren W. Denner, Asst. Prof. of Oceanography, Dept. of Meteorol. and Oceanog., NPGS.

(d) Field investigation; applied research.

(e) Calculation of surface circulation from driving forces.

(6598) DEVELOPMENT OF A RESISTANCE TIDE GAUGE.

(b) Laboratory project.

(c) Warren W. Denner; see (6597) above.

(d) Experimental and field investigation.

(e) Develop a simple resistance element tide gauge.

(g) Preliminary investigation shows design feasible.

(h) "A Simple Resistance Tide Gauge," Norman Pigeon and Warren W. Denner, Marine Science Instrumentation, Vol. IV, Jan. 1968. 
(6599) CHARACTERISTICS OF GRAVITY WAVES OF PERMANENT FORM.

(b) Coastal Engineering Research Council.

(c) Dr. Joseph J. von Schwind, Assoc. Prof. of Oceanography, Dept. of Meteorol. and Oceanog., INPGS; Robert O. Reid, Dept. of Oceanography, Texas A and M Univ., College Station, Texas 77843 .

(d) Theoretical; applied research for doctoral dissertation.

(e) Determine fourier type coefficients for description of the wave profile, the surface particle velocity, and the surface particle trajectory from a conformal mapping approach.

(g) Procedure applies for a wide range of relative water depths and relative wave heights.

U.S. IIAVAI POSTGRADUATE SCHOOL, Dept. of Aeronautics, Monterey, California 93940

(6588) COMPUIER SIMULATION OF TURBULENCE.

(b) Naval Radiological Defense Lab.

(c) Prof. T.H. Gawain, Dept. of Aeronautics, Code $57 \mathrm{Gn}$, Naval Postgraduate School.

(d) Theoretical; basic research for $\mathrm{PhD}$.

(e) The energy transfer from a shear flow to turbulence is being investigated using a computer.

(g) Reports forthcoming in 1968.

(6589) UNSTEADY AERODYNAMICS.

(b) Laboratory project.

(c) Assoc. Prof. L.V. Schmidt, Dept. of Aeronautics, Code 57 Sx, Naval Postgraduate School.

(d) Experimental and theoretical; basic research at $\mathrm{PhD}$ level.

(e) Unsteady pressures are being measured using multiple arrays of static pressure orifices. The bluff body is moved to permit correlation between pressure variations and motion. Data are being assessed for application to calculation of flutter boundaries.

(6590) LTGHT SCATTERING IN TWO-PHASE FLOW.

(b) Office of Naval Research.

(c) Asst. Prof. D.C. Wooten, Dept. of Aeronautics, Code 57 Wf, Naval Postgraduate School.

(d) Experimental; applied research at MSAE level.

(e) By measuring scattered light at several wavelengths of laser radiation $\left(\mathrm{H}_{\mathrm{e}} \mathrm{N}\right.$ and Argon lasers) the average particle volume and surface area can be determined. Extinction or attenuation measurements are also being conducted.

(6882) HOLOGRAPHIC INTERFEROMETRY.

(b) Office of Naval Research.

(c) Prof. Allen E. Fuhs, Dept. of Aeronautics, Code 57 Fu, Naval Postgraduate School.

(d) Experimental and theoretical; applied research for MSAE and $\mathrm{PhD}$.

(e) Three dimensional distributions of density are to be measured using holographic interferometry.

(f) New project.

(g) See Technical Note in Journal of Applied Physics, Jan. 68.

(6883) HELICOPTER BLADE STALL.

(b) Laboratory project.

(c) Assoc. Prof. J.A. Miller, Dept. of Aeronautics, Code 57 Mo, Naval Postgraduate school. (d) Experimental; applied research for $\mathrm{PhD}$.

(e) Using a wind tunnel which provides harmonic variation in velocity stall of helicopter blades is being investigated using pressure taps, tufts and hot wire anemometers.

NAVAL RESEARCH IABORATORY, Washington, D.C. 20390

(6484) FLOW ACOUSTICS.

(b) Laboratory project.

(c) Mr. Charles W. Votaw, Code 8134, Naval Research Lab.

(d) Experimental; applied research.

(e) Study the vibrational response and radiated sound of an elastically supported cylinder at low Reynolds number, and to study the von Karman vortex street behind such a cylinder.

(g) The limits of vibration amplitude and frequency necessary to align the vorticity parallel to the cylinder have been reported. The strength of these aligned vortices has been determined from photographs of the streak lines using a Hamel-Oseen vortex model. The oscillating lift coefficient has been found for an oscillating circular cylinder at low Reynolds number.

(h) "The Vortex Wakes of Vibrating Cylinders at Low Reynolds Numbers," G.H. Koopmann, Jour. Fluid Mech., Vol. 28, Pt. 3, pp. 501-512, 1967.

(6485) SUBMERGED WAKE COLILAPSE IN A STRATIFIED FLUID.

(b) Laboratory project.

(c) Dr. Allen H. Schooley, Code 8303, Bldg. 208, Naval Research Lab.

(d) Experimental exploratory research.

(e) Models have been used to demonstrate and obtain quantitative data on the novel phenomenon of vertical collapse of the turbulent wake of a self-propelled body moving in a fluid with a vertical density gradient.

(f) Low level of activity.

(g) The time between turbulent mixing and maximum vertical expansion of the wake before vertical collapse starts if $0.44 \mathrm{~T}$, where $T$ is the local Vaisala-Brunt period. Time after mixing for the maximum rate of horizontal spreading to occur is about 2.OT. The collapsing vertical wake has been shown to be an efficient generator of internal waves.

(6389) WIND FIEID NEAR A DISTURBED WATER SURFACE.

(b) Laboratory project.

(c) Dr. Allen H. Schooley; see (6388) above.

(d) Experimental exploratory research.

(e) Small, substantially neutrally buoyant soap bubbles have been used in a small waterwind tunnel to measure the movement of many particles of air as they generate short fetch wind waves.

(f) Low level of activity

(g) Data have been obtained to show the statistical distributions of horizontal, vertical, and lateral movements of air particles above the trough, crest, and intermediate points along a wave generated by a medium velocity short fetch wind.

(6390) SURFACE EFFECTS OF NATURALLY OCCURRING INTERNAL WAVES.

(b) Laboratory project. 
(c) Dr. Allen H. Schooley; see (6388) above.

(d) Experimental field exploratory research.

(e) Experiments are being conducted in Georgia Strait $\left(49^{\circ} \mathrm{N}, 123^{\circ} \mathrm{W}\right)$ using instrumentation on a small float that follows the waves and makes near surface temperature difference and water current measurements.

(f) Low level of activity.

(g) Measurements have shown horizontal velocities $10 \mathrm{~cm}$ below the undulating surface of the sea of about $\pm 25 \mathrm{~cm} /$ second associated with the passage of natural internal waves in late June and early August.

NAVAL SHIP ENGINEERING CENIER, PHILADELPHIA DIVISION (Formerly, Naval Boiler and Turbine Lab.), Phila., Pennsylvania 19112

\section{(3623) HIGH PRESSURE-TEEMPERATURE WATER FLOW METER CAIIBRATION.}

(b) Naval Ship Engr. Center.

(c) Mr. J.W. Murdock, Head, Appl. Physics Dept., Naval Ship Engrg. Ctr.

(d) Experimental; applied research.

(e) A facility is available for calibrating with water at pressures and temperatures up to 2500 psi and $600 \mathrm{~F}$ respectively. Capacity is $100 \mathrm{gpm}$ at maximum pressure and temperature and greater at lower pressures and temperatures. After flowing through the metering section the water is cooled and weighed. The facility is also used to investigate and verify orifice meter coefficients at pressures and temperatures above those at which the coefficients in use were established. A number of flow meters which measure the flow in nuclear reactor loops have been calibrated.

(f) Inactive.

(g) A limited amount of test data indicate good agreement between orifice flow rates obtained by calibration at high pressures and temperatures and those obtained by extrapolating from cold water calibrations. Other meter tests show the need to include suitable corrections for change in shape, size, density, etc.

(4001) HIGH PRESSURE STEAM AND WATER FLOW TESTS.

(b) American Soc. of Mechanical Engrs.

(c) Mr. J.W. Murdock; see (3623) above.

(d) Experimental; applied research.

(e) Although the ASME Research Committee on Fluid Meters has sponsored many fundamental research programs dealing with the development of basic constants used with primary elements, hardly any of this work has been done on steam flow at high pressures and temperatures. Neither has research been done on high temperature water flow. Analysis of many tests indicate that the basic calibration obtained with low temperature water (air and gas) could be extrapolated with high accuracy to the measurement of high pressure and temperature steam and water flow provided suitable corrections were made for the change in the shape and size of the primary element, the pipe and the fluid. This procedure has been experimentally verified for steam up to $2000 \mathrm{psi}$ and $1050 \mathrm{~F}$ and for water to $2500 \mathrm{psi}$ and $600 \mathrm{~F}$.

(f) Completed.

(g) Nozzles and orifices were calibrated with water at $240 \mathrm{~F}$, $2200 \mathrm{psia}$, and with steam at
1050 F, 2000 psia. Pipe Reynolds numbers averaged 600,000 for the water and 4,000,000 for the steam. Coefficients were generally in agreement with ASME predicted coefficients. Two and a quarter percent (2 1/4\%) chromemolybdenum steel proved unsatisfactory for the steam nozzles showing rusting and pitting after less than 10 hours. Type 430 stainless steel was substituted and was satisfactory.

(h) "ASME Research on High Pressure-High Temperature Steam and Water Flow Measurements, "J.W. Murdock, ASME Jour. Basic Engrg., Vol. 87, 1965.

(5286) MEASUREMEIT OF ACOUSTIC VELOCITY OF STEAM.

(b) Jointly with Office of Naval Research.

(c) Mr. J.W. Murdock; see (3623) above.

(d) Experimental; basic research.

(e) Objective is to obtain precise knowledge of acoustic velocity values for steam in liquidvapor and vapor phase. Data will be obtained at conditions up to $5000 \mathrm{psi}$ and $800^{\circ} \mathrm{F}$.

(f) Completed.

(g) A research facility was designed and erected to determine the velocity of sound in superheated steam at pressures and temperatures to 5000 psi and $800^{\circ} \mathrm{F}$. A vibrating quartz crystal was used to set up a series of standing waves in cylindrical acoustic chamber. Frequency and wave length were determined at steam conditions up to 3400 psia and $719^{\circ} \mathrm{F}$. Experimental results show close agreement with velocities computed from the 1967 international formulations for steam. Velocity of sound in high pressure steam can be determined more accurately by ultrasonic methods than from calculated values based on currently available tables of thermodynamic steam properties.

(h) "Measurement of Acoustic Velocity in Steam," J. Woodburn and Y.J. Fostyk, NAVSECPHIIADIV Rept. A-547, 31 Oct. 1967 (obtain from DDC, Cameron Station, Alex., Va. 22314).

U.S. NAVAL UNDERSEA WARFARE CENTER, 3202 E. Foothill Blvd., Pasadena, Calif. 91107

(4434) SHROUDED PROPELLER DESIGN.

(b) Naval Ordnance Systems Command, Dept. of the Navy .

(c) Commander, Naval Undersea Warfare Center, Attn: Mr. J.F. Reynolds, Code P2542.

(d) Theoretical; applied research.

(e) Perturbation velocities induced by shroud and propeller are determined analytically. A solution to these equations representing the perturbation velocities is presented as a series of computer programs which describe the velocities at any location including solutions at the singularities. This study provides information to solve the fluid boundary problem for a shrouded propeller configuration with any blade circulation, shroud and central body shape. Accounting for all fluid boundary interactions and their resulting effect on the perturbed flow will give an improved estimate of the propeller inflow required in the design of the shroudpropeller blade system.

(g) A computer program describing induced propeller radial velocities has been extended to include the effect of a moderately loaded propeller on a specified non-uniform inflow. 
To accomplish this an iteration scheme using Lerb's subroutine was incorporated in the program. Solutions to radial and axial perturbation velocities induced by the shroud are available as computer programs. The computer programs describing the axial velocities include velocities off the propeller plane. Separate solutions are being obtained to des cribe velocities in the neighborhood of and on the cylindrical vortex surface representing the shroud.

(4868) NON-NEWTONIAN FLUIDS.

(b) Naval Ordnance Systems Cormand.

(c) Commander, Naval Undersea Warfare Center, Attn: Dr. A.G. Fabula, Code P254.

(d) Experimental; basic research.

(e) A study is being made of viscoelastic stresses due to rapid elongational deformation of dilute polymer solutions. The work may lead to better understanding of the friction reduction which many polymer solutions display in turbulent flows through pipes and past submerged objects.

(g) "Suspended outlet" and orifice flows can be used to study the stresses and energy transfer or dissipation which occur when fluids are subjected to rapid elongational deformations. In suspended outlet flow, fluid is pulled by viscoelastic stresses out of a quiet pool up to a low-pressure outlet. In orifice flow, fluid is forced through a small hole into a free jet. Results indicate that viscoelastic properties can be investigated in these ways for more dilute solutions than possible heretofore. Aqueous solutions of poly (èthylene oxide) and guar gum behave very differently in these flows, although both additives are effective friction reducers.

(6585) TURBULENT BOUNDARY LAYER STUDIES WITH POLYMER ADDITIVES USING BUOYANTLY PROPELIED VEHICLES.

(b) Naval Ordnance Systems Command, Dept. of the Navy

(c) Commander, Naval Undersea Warfare Center, Attn: H.V.L. Patrick, Code P2542.

(d) Experimental; basic research.

(e) Static wall pressure fluctuations beneath turbulent water boundary layers, with and without high-molecular-weight polymer ejection, are being investigated using buoyantly propelled vehicles with vertical trajectories. Power spectral density and space-time correlation analysis are being performed on the data to determine the effect of certain polymer additives on the fundamental structure of turbulent boundary layer flow.

(g) Information collected in plain water is very similar to data published by other investigators.

(h) "Flow Noise Inside Boundary Layers of Buoyancy - Propelled Test Vehicles, "C.R. Nisewanger and B.F. Sperling, NAVWEPS Rept. 3511, Apri1 1965.

(6586) THRUST DEDUCTION CALCULATION FOR PROPELIER DRIVEN AXISYMMETRIC BODIES.

(b) Naval Ordnance Systems Command, Dept. of the Navy.

(c) Commander, Naval Undersea Warfare Center, Attn: David M. Nelson, Code P2542.

(d) Theoretical.

(e) A method for calculating the thrust deduction of axisymmetric bodies driven by single or counter-rotating propeliers has been developed.
This method accounts for the radial distribution of bound circulation of the propellers and the radial distribution of inflow velocity to the propellers. The calculation has been reduced to an integration over the propeller disc involving the velocities induced there by the body. Hence, the Douglas potential flow computer program for axisymmetric bodies can be used as the principal tool for carrying out the calculation.

(6587) WALL PRESSURE FLUCTUATIONS BENEATH TURBULENT WATER BOUNDARY LAYERS WITH POLYMER ADDITIVES.

(b) Naval Ordnance Systems Command, Dept. of the Navy.

(c) Comander, Naval Undersea Warfare Center, Attn: H.V.L. Patrick, Code P2542 or J. Caraher, Code P254l.

(d) Experimental; basic research.

(e) The wall pressure fluctuations of fully established turbulent pipe flow will be measured; power spectral density and spacetime correlation analysis will be performed on the data. Boundary layer profiles and wall skin friction will also be measured. Studies will be performed with a blow down pipe flow test facility using plain water and various high-molecular-weight polymer solutions. The tunnel will consist of a very smooth 4-inch diameter stainless steel test section 120 diameters in length and will coyer a test Reynolds number range of $0.7 \mathrm{x}$ $10^{6}$ to $2.2 \times 10^{6}$. The results will help determine the structure of turbulent boundary layer flow with polymer additives.

U.S. NAVY UNDERSEA WARFARE CENIER, SAN DIEGO DIVISION, 271 Catalina Blvd., San Diego, Calif. 92152.

(6125) ADVANCED TOWED SYSTEMS.

(b) Iaboratory project.

(c) C.N. Miller, Program Mgr., U.S. Navy Undersea warfare Ctr., San Diego Div., Code D602.

(d) Theoretical and experimental.

(e) The main objective of the project is to develop rigorous design procedures for high speed towed systems through correlation of both model and full scale tests and computer simulations.

(g) Experimental results to date have indicated good agreement with the computer simulation.

(h) "Experimental Determination of the Dynamic Coefficients Applicable to Faired Cables," A. Goodman, T.T. Huang and R.J. Etter, Hydronautics, Inc. Tech. Rept. 530-2, $28 \mathrm{pp}$.

"An Experimental Investigation of the Static Hydrodynamic Characteristics of Several

Simulated Faired Cables Having Symmetrical NACA Airfoil sections," R.J. Etter and T.T'. Huang, Hydronautics, Inc. Tech. Rept. 530-1, $267 \mathrm{pp}$.

"Boundary-Iayer Flow Visualization on Several Simulated Faired Cables Having Symmetrical NACA Airfoil sections," T.T. Huang and R.J. Etter, Hydronautics Inc., Tech. Rept. 530-3, $70 \mathrm{pp}$.

"Cable-Towed Underwater Body Design," P.0. Laitinen, NEL/REPORT 1452, $94 \mathrm{pp}$.

"Tests and Investigations of a High speed Towed Sonar Cable - Final Report," J.N. Brion, H.R. Franch and A. Kawad, Boeing No. D2-1330061, Cont. No. 53213A. 
"Faired Towcable Divergence Criteria," G.A. Hegemier, NEL/CR-24, NEL Contractor Rept. prepared for NEL High Resolution Sonar Div., $24 \mathrm{pp}$.

"Body of Revolution Drag Calculations in Response to Navy Electronic Laboratory P.O. 953/14002/64," Bruce H. Carmichael, MOL-BHC-6430, 21 pp., Marine Ordnance Lab., Space and Information Systems Div., North American Aviation, Inc.

"Computer Study to Establish the Lower Limit of Length-to-Diameter Ratio Advisable for LowDrag Bodies," Bruce H. Carmichael and Oswin Niehuss, Final Rept. SID 64-1938, 32 pp. "Boundary Layer Calculations for some specific Two- and Three-Dimensional Bodies," Harry B. Bowers and Bruce H. Carmichael, Final Rept. Contract No. Noo 123-67-c-0590, C7-875/020, $37 \mathrm{pp}$.

"Two-Dimensional Airfoil Literature survey,"

B.H. Carmichael and Dallas Meggitt, Rept. C6-1796/020, $62 \mathrm{pp}$.

\section{(6372) OCEANOGRAPHIC AND INTERITAL WAVE RESEARCH.}

(b) Naval Ship Systems Command.

(c) Dr. Eugene C. LaFond, Head, Marine Environment Div., Naval Undersea Warfare Ctr.

(d) Projects are experimental, theoretical, and field investigative; and some are basic research and applied research.

(e) Investigate and report on factors in physical oceanography which pertain to underwater sound, including physical properties such as sound velocity, thermal structure, water motion; and chemical properties such as salinity and oxygen. Results apply to convoy, submarine and amphibious operations; and submarine detection. Provide oceanographic consultation and assistance for other problems.

To investigate experimental developments and theory of internal waves in the ocean. Design and perform experiments to obtain needed military information.

(g) See $(h)$.

(h) "Chemical Nutrient Concentrations and Their Relationship to Internal Waves and Turbidity Off Southern California, "F.A.J. Armstrong and E.C. IaFond, Limnol. and Oceanog., Vol. 1l, pp. 538-547, Oct. 1966.

"Precise Positioning for Deep Mooring," E.C. Buffington, U.S. Naval Institute Proc., Vol. 93, pp. 139-143, Aug. 1967.

"Depth and Strength of the Seasonal Thermocline in Shallow Water off Southern California," J.L. Cairns, Proc. 3rd U.S. Navy Symp. on Military Oceanography, Vol. 2, pp. 27-38, May 1966, Naval Electronics Lab.

"Asymmetry of Internal Tidal Waves in Shallow Coastal Taters," J.L. Cairns, Jour. Geophys. Res., Vol. 72, pp. 3563-3565, 15 July 1967. "Periodic Motion of the Seasonal Thermocline Along the Southern California Coast," J.L. Cairns and E.C. LaFond, Jour. Geophys. Res., Vol. 71, pp. 3903-3915, 15 Aug. 1966.

"Shallow Water Sound Transmission Paths from the USNEL Oceanographic Research Tower off Mission Beach, "P.G. Hansen and O.S. Lee, Nav. Electronics Iab., Proc. 3rd U.S. Navy Symp. on Military Oceanography, Vol. 2, pp. 263-274, May 1966.

"Internal Waves," E.C. LaFond, Encyclopedia of Oceanography, pp. 402-408, Reinhold, 1966. "Upwelling," E.C. LaFond, Encyclopedia of Oceanography, Reinhold, 1966, pp. 957-959. "Upwelling," E.C. LaFond, Encyclopedia of
Science and Technology, McGraw-Hill, 15 vol., 1966.

"Internal Thermal Structures in the Ocean, E.C. LaFond and K.G. LaFond, Jour. Hydronautics, Vol. 1, pp. 48-53, July 1967. "Temperature Structure in the Upper 240 Meters of the Sea, "The New Thrust Seaward: Trans. Third Ann. MTS Conf. and Exhibit, June 1967, San Diego, Calif., Marine Technology Soc., 1967.

"Deep Submergence Log No. 3, for Period 4 September through 23 December 1966." Navy Electronics Lab., Feb. 1967.

"Sea-Surface Temperature Estimation--Use of Regression Models for Time/Space Interpolation of Sea-Surface Temperature Observations, "E.R. Anderson, Navy Electronics Lab. Rept. 1427 , 9 March 1967.

"Sea-Surface Temperature Estimation; Time Series Length Necessary for Long-Time Estimation of Sea-Surface Temperature," E.R. Anderson and C.J. Van Vliet, Navy Electronics Lab. Rept. 1429, 17 Jan. 1967.

"Internal Tides off Southern California," W. Krauss, Navy Electronics Lab. Rept. 1389, 6 July 1966.

"Interaction Between Surface and Internal Waves in Shallow Water," W. Krauss, Navy Electronics Lab. Rept. 1432, 30 Jan. 1967. "U.S. Navy Electronics Laboratory's Oceanographic Research Tower: Its Development and Utilization," E.C. IaFond, Navy Electronics Lab. Rept. 1342, 22 Dec. 1965.

"Vertical and Horizontal Thermal Structures in the Sea," E.C. LaFond and K.G. LaFond, Navy Electronics Lab. Rept. 1335, 27 July 1966.

"Physiological Dynamics of Siphonophores From Deep scattering Layers, "G.V. Pickwell, Navy Electronics lab. Rept. 1369, 20 April 1366. "A Predictive Horizontal-Temperature-Gradient Model of the Upper 750 Feet of the Ocean," E.L. Smith, Navy Electronics Lab. Rept. 1445, 17 March 1967.

"Sea-Surface Temperature Estimation: Autocorrelation, Regression, and Trend Analysis of Six Sea-Surface Temperature Time-Series, " C.J. Van Vliet and E.R. Anderson, Navy Electronics Lab. Rept. 1428, 17 January 1967. "Similitude Conditions for Modeling Icebreaker Operations," C. Richardson, Naval Engrs. Jour., Vol. 78, pp. 1039-1044, Dec. 1966.

"Materials for Deep Submergence," J.C. Thompson and R.K. Logan, Oceanology Intl., Vol. 2, pp. 24-27, March/April 1967.

U.S. NAVY UNDERWATER SOUND LABORATORY, Fort Trumbull, New London, Connecticut 06321

\section{(6266) HYDRODYNAMIC NOISE.}

(b) Laboratory project.

(c) Experimental and theoretical; applied research.

(d) Dr. Howard H. Schloemer, U.S. Navy Underwater Sound Iab.

(e) Experimental investigations are being conducted in both acoustic wind and water tunnels to determine the statistical properties of boundary pressure, such as power spectrum, longitudinal and lateral cross-spectra, diagonal correlations, convection speeds and space-time correlations. This work is accomplished in both zero and mild gradients with 
smooth and varying degrees of wall roughness. All sensors are mounted flush to the wall. Experimental results are compared to theoretical predictions. With these studies it is hoped to be able to more completely describe the noise field produced by turbulent flow.

(g) Convective velocity of pressure fluctuations in the turbulent boundary, which are the sources of noise, are traveling at about the same velocity as the mean flow and are frequency dependent. In the frequency range of $500 \mathrm{~Hz}$ to $10 \mathrm{kHz}$, the noise is uncorrelated after a distance of one inch along flow direction. Data taken in both acoustic-wind and water tunnels showed excellent agreement. The effect of an adverse (positive) gradient on the nondimensionalized spectral density was an increase in the low frequency content without influencing the high frequency portion appreciably; a sharp decrease in the high frequency portion was observed for the favorable (negative) pressure gradient. At similar nondimensionalized longitudinal separations and frequencies the convection velocity ratio was higher in the favorable and lower in the adverse pressure gradients. The longitudinal decay of a particular eddy was more rapid in the adverse and slower in the favorable pressure gradients. No differences were found in the lateral cross-spectral density for the different pressure gradients. Experimentation has shown that the viscous sub-layer can not be considered as a passive, viscously dominated region but that it plays an active role in the generation and maintenance of a turbulent shear flow. The streamwise fluctuating velocity exhibits an instantaneous linear behavior in the coordinate direction normal to the wall, which is further confirmed by the appropriate nondimensionalization of the energy spectra of the streamwise fluctuating velocity. In addition, the instantaneous streamwise fluctuating velocity continues to exhibit a behavior very similar to the mean velocity throughout the transition region between the sublayer and the fully developed part of the flow. Secondly, the dominant structure of the flow within the wall region consists of randomly distributed counterrotating, eddy pairs of elongated streamise extent. The occurrence within the viscous sublayer and the adjacent transition region of this dominant nonlinear process of vortex stretching of counter-rotating eddy pairs of elongated streamwise extent thus indicates that linearized theory of the sublayer can not fully describe the flow in this region. A theoretical investigation of the acoustic pressure spectral density and cross spectral density in a closed space behind a rectangular, simply supported, flow excited flat plate has been completed.

Simplified expressions have been derived to predict the maximum acoustic pressure spectral density for a given set of input parameters over a portion of the frequency range of interest.

Analytic solutions for the plate velocity cross spectral density and spectral density of turbulent flow excited flat plates have been obtained using Corcos' model of the turbulent pressure statistics. Agreement between computer results and existing experimental data was good. Based on these data, a simple mathematical expression has been derived to predict the maximum plate velocity spectral density for given input parameters over a portion of the frequency range of interest.

(h) "Wall Pressure Correlation in Turbulent Pipe Flow, " H.P. Bakewell, Jr., G.F. Carey, J.J. Libuha, H.H. Schloemer and W.A. VonWinkle, USL Rept. No. 559, 30 Aug. 1962.

"Longitudinal Space-Time Correlation Function in Turbulent Airflow," H.P. Bakewell, Jr., Jour. Acoust. Soc. Amer., Vol. 35, No. 6, pp. 936-937, June 1963.

"Narrow-Band Investigations of the Longitudinal Space-Time Correlation Function in Turbulent Airflow," H.P. Bakewell, Jr., Jour. Acoust. Soc. Am., Vol. 36, No. 1, pp. 146 148, January 1964.

"A Unified Theory of Turbulent Wall Pressure Fluctuations, "F.M. White, USI Rept. No. 629, 1 December 1964.

"Experimental Hydrophone-Size Correction Factor for Boundary-Layer Pressure Fluctuations, " R.B. Gilchrist and W.A. Strawderman, Jour. Acoust. Soc. Amer., Vol. 38, No. 2, pp. 298-302, Aug. 1965.

"Effects of Pressure Gradients on Turbulent Boundary-Layer Wall-Pressure Fluctuations," H.H. Schloemer, USL Rept. No. 747, $1 \mathrm{July}$ 1966.

"An Experimental Investigation of the Viscous Sublayer in Turbulent Pipe Flow," H.P.

Bakewell, Ph.D. dissertation, The Pennsylvania State Univ., Sept. 1966.

"Acoustic Turbulent Water-Flow Tunnel," Jour. Acoust. Soc. Amer., Vol. 41, No. 2, pp. 373-379, Feb. 1967.

"The Acoustic Field in a Closed Space Behind a Rectangular, Simply Supported Plate Excited by Boundary Iayer Fluctuations," W.A.

Strawderman, USI Rept. No. 827, 11 May 1967.

NAVAL UNDERWATER WEAPONS RESEARCH AND ENGINEERING STATION, Research Dept., Oceanography Branch, Newport, Rhode Island.

\section{(6465) OCEAN TURBULENCE PROJECT 81932.}

(b) Laboratory project.

(c) Dr. David H. Shonting, Oceanographer, Naval Underwater Weapons Res. and Engrg. Sta.

(d) Field investigation; basic research.

(e) To study fundamental processes of turbulent diffusion of momentum and heat in the near surface layers (upper $200 \mathrm{~m}$ ) of the oceans. To relate these processes to the time and spatial variability of temperature and the speed of sound in the upper layers and thus to better describe the thermal and acoustic structure and predict its change.

To examine the similarities and differences between natural tidal or wind generated wave turbulence and artifically induced turbulence such as is associated with a vessel's bow waves or screw waves.

To develop instrumentation in which to better study ocean turbulence and microstructure.

(g) See (h).

(h) "A Preliminary Investigation of Momentum Flux in Ocean Waves," D.H. Shonting, Pure Appl. Geophys., Vol. 57 (I), pp. 149-152, 1964.

"Observations of Short Term Heating of the Surface Layers of the Ocean, "D.H. Shonting, NUWS TM No. 308, 1964. 
"The Seasonal Distribution of Oceanographic Variables Measured in Rhode Is land Sound During 1963-64," D.H. Shonting, G.S. Cook and F.G. Wyatt, Jr., A Data Report, NUWS CONSEC 423, 1966.

"Ocean Wave Turbulence Measurements: Some Instrument Problems," D.H. Shonting, NEREM Record, 56-57, 1966.

"Measurements of Particle Motions in Ocean Waves," D.H. Shonting, Jour. Marine Res., Vol. 25, No. 2, pp. 162-181, 1967.

"Autospectra of Observed Particle Motions in Wind Waves," D.H. Shonting, Jour Marine Res., in press.

"The Thermiprobe: A system for Measuring Thermal Microstructure in the Sea," D.H. Shonting and A.L. Kadis, Marine Sciences Instrumentation, Vol. 4, ISA, Plenum Press, N.Y., 1968.

\section{U.S. NAVAL WEAPONS IABORATORY, Dahlgren, Virginia} 22448

\section{(6427) FLOW OF IIQUID THROUGH MUTTIPLE ORIFICES.}

(b) Joint Technical Group for Munitions Effectiveness.

(c) Dr. William G. Soper, Technical Asst., Code TX, U.S. Naval Weapons Lab.

(d) Experimental and theoretical; applied research.

(e) The project objective is a mathematical model for predicting the leakage rate for a liquid container with an arbitrary number of perforations of arbitrary size and shape.

(g) A simple model, incorporating two empirical curves, has given good results for gasoline, water, and diesel fuel, and for circular and rectangular orifices.

(h) "Flow of Liquid Through Multiple Orifices," W.G. Soper, U.S. Naval Weapons Lab. Tech. Memo. No. T-1l/67, Sept. 1967 (copies available from $\mathrm{DDC}$ ).

U.S. NAVY WEATHER RESEARCH FACIIITY, Building R-48, Naval Air Station, Norfolk, Virginia 23511

(6474) AIR-SEA INITERACTIONS (NAVWEARSCHFAC TASK 36).

(b) Naval Air Systems Command.

(c) Officer in Charge, Navy Weather Research Facility.

(d) Applied research.

(e) A study of air-sea interactions of significance to the prediction of atmospheric effects upon variations in the surface-mixed layer, and of oceanic effects upon maritime weather phenomena.

(6575) EVALUATION OF SYNOPTIC OCEANOGRAPHIC ANALYSES (NAVWEARSCHFAC TASK 36).

(b) Naval Air Systems Command.

(c) Officer in Charge, Navy Weather Research Facility.

(d) Applied research.

(e) A study to determine the scale at which synoptic analysis (hence operational prediction) of oceanographic surface and mixed-layer thermal features is feasible, and to resolve thereform differences among analytical procedures currently employed operationally.

(f) Temporarily suspended.
(6476) SEA, SWELL, AND SURF PREDICTION AIND CLIMATOIOGY (NAVWEARSCHFAC TASK 36).

(b) Naval Air Systems Command.

(c) Office in Charge, Navy Weather Research Facil.

(d) Applied research.

(e) Research in cooperation with the Naval Postgraduate School: to resolve discrepancies between operational observations of sea, swell, and surf and characteristics derived from existing wave/surf development/decay theories; to develop improved objective operational techniqurs for sea, swell and surf prediction, to include emphasis on enclosed seas; and to prepare improved wave and surf climatologies for planning purposes from historical wind field analyses.

(6477) STORM SURGE (NAVWEARSCHFAC TASK 36).

(b) Naval Air Systems Command.

(c) Officer in Charge, Navy Weather Research Facility.

(d) Applied research.

(e) A study of methods for objective prediction of storm surges, and the development of a computer program for their issuance.

(6488) HURRICANE INDUCED UPWELLING (NAVWEARSCHFAC TASK 36).

(b) Naval Air Systems Command.

(c) Officer in Charge, Navy Weather Research Facility.

(d) A coordinated field and applied research investigation in cooperation with U.S. Navy Weather Reconnaissance Squadron FOUR.

(e) A network of expendable bathythermographs will be dropped ahead of, inside and following the passage of hurricanes to provide data necessary for the determination of changes in the oceanic temperature-depth structure induced by hurricane wind and pressure fields.

TENNESSEE VALIEY AUTHORITY, Engineering Laboratory, P.0. Box 37, Norris, Tenn. 37828

Inquiries concerning the following projects should be addressed to $\mathrm{Mr}$. Rex A. Elder, Director, TVA Engrg. Lab. at above address.

(3629) LOW POWER VHF RADIO GAGES FOR REPORTING RAINFALL AND STREAM IEVEL DATA.

(d) Development.

(e) Transistorized radio components powered from nickel cadmium batteries, which will be charged by thermoelectric generators and/or solar cells, will be used. Data in gray code will be transmitted by audio tone pulses. Unattended operation of long duration is a primary objective in the design of these stations.

(g) Installation now in progress; will be completed this year.

(4441) MEASURING OF KAPIAN TURBINE DISCHARGES USING OTT COMPONENT CURRENT METERS.

(d) Equipment development and field measurement operation.

(e) Turbine discharge rating equipment, using the ott component type current meters, has been developed to measure the discharge of turbine units. Twenty-seven current meters mounted on three frames are used to simultaneously measure velocities in the three intakes of each unit 
by either the step or integration method. Measurements made at several fixed loads are employed to calibrate the Winter-Kennedy scroll case pressure taps. The Winter-Kennedy taps are used with suitable measuring equipment to determine the discharge for any turbine loading.

(g) Measurements have been taken at four main river hydro dams, Wilson, Kentucky, Guntersville, and Wheeler. Forty-one turbine units at these facilities have been measured. The project is presently dormant.

(4881) BASIC STREAM HEAT BUDGET STUDIES.

(d) Experimental; for basic and applied research.

(e) This is a study to develop the basic temperature prediction equations for a stream into which water at a temperature other than natural temperature flows. All known variables such as stream flow characteristics, meteorological conditions and thermal characteristics will be included. Theoretical studies, field tests, and possible laboratory studies will be combined to produce verified equations.

(g) As a first step, solutions for fully mixed conditions have been obtained, involving the equilibrium temperature concept, from the basic set of differential equations governing water and heat flow in open channels. An intensive study of individual heat budget terms has been made to determine proper computational methods. Five sets of field data hare been collected for checking the accuracy of the prediction equations.

(5004) NICKAJACK PROJECT.

(d) Experimental; for design.

(e) Studies using the 1:150 horizontal by 1:90 vertical scale distorted model of the Nickajack Project were completed and a 1:100 scale undistorted model constructed to study the apron development problems. The 1:100 scale model represents an area of approximately 2 miles in length by $1 \mathrm{mile}$ in width of the river site. In addition to the apron studies, the 1:100 scale undistorted model was used to develop information on the training wall dimensions, bank protection designs and the design of various other features in the river areas immediately upstream and downstream from the dam structures.

(f) Completed.

(h) A number of internal reports giving the basic test results were issued.

(5386) NICKAJACK PROJECT--IOCK MODEL.

(d) Experimental; for design.

(e) A 1:25 scale model of the $800^{\prime} \times 110^{\prime}$ main Nickajack lock was used to adapt the multiport filling and emptying system to this size chamber. The proposed intake and outlet structures for both the main and 600' $x$ 110' auxiliary lock was also tested by incorporating them with the main chamber model and a simplified model of the auxiliary chamber.

(f) Completed.

(h) A number of internal reports giving the basic test results were issued.

(5387) NICKAJACK PROJECT--VALVE-CULVERT MODEL.

(d) Experimental; for design.

(e) A 1:10 model of an existing lock filling valve, with related culvert appurtenances, was used to determine the nature and origin of the hydrodynamic forces which act on reversed tainter lock filling valves. The model was specifically designed to reproduce the transient conditions existing while the valve is opening. Two valve designs were compared with respect to their reaction to hydrodynamic forces.

(i) Completed.

(h) A number of internal reports giving the basic test results were issued.

(5388) NICKAJACK PROJECT--SPILLWAY MODEL.

(d) Experimental; operations.

(e) Model tests were conducted to develop a spillway discharge rating using a 1:35 scale model duplicating three of the ten spillway bays. Tests were made for (1) free and submerged ungated flow through a series of spillway bays, and (2) free and submerged flow under a series of tainter gates set at various gate opening positions.

(h) A discharge rating table was prepared giving the discharge for specified arrangements of the spillway gates.

(5943) NICKAJACK PROJECT--TURBINE INTAKE GATE STUDIES.

(d) Applied research; operations.

(e) Tests on multi-leaf gates have indicated an interdependence of the design of the lifting beam and gate when the gates are to be positioned in fllowing water. A $1: 36$ scale model of a complete three-bay turbine intake and a 1:12 scale model of one bay were used in tests conducted to develop an operable lifting beam and gate design for the Nickajack Project. Double leaf gates $18^{\prime} \times 18^{\prime}$ are to be used.

(f) Completed.

(g) A lifting beam and gate design was developed which solved the basic problems of successfully lowering and releasing the gate and beam in flowing water.

(h) A number of internal reports giving the basic test results were issued.

(5392) MODEL FLUME TO BE USED TO STUDY THERMAL DENSITY RECIRCULATION PROBLEMS.

(d) Experimental; operations and basic research.

(e) A model flume was constructed of transparent material and equipped with circulating pumps to simulate a typical steam power plant's condensate intake and outlet system. The flume is approximately 100 feet in length and 9 iinches deep by 12 inches wide. The basic intent is to develop and prove the analytical equations for flows in the vicinity of a steam plant or in similar areas.

(g) Data on lengths and depths of warm wedges near the intake and outlet, for various river and intake flows and for various intalie density differences have been obtained, but have not been analyzed.

(5945) TIMS FORD PFOJECT.

(d) Experimental; for design.

(e) A 1:100 scale model will be used to determine the characteristics of the proposed flip bucket spillway. Particular attention will be given to erosion patterns and means of limiting scour.

(f) Completed.

(g) A flip bucket spillway, with corresponding training walls and paved areas, was develcped to minimize erosion at the structure.

(h) Three internal reports were issued. 
(6711) TIMS FORD PROJECT--SPILLWAY.

(d) Experimental; for design.

(e) Foundation conditions at the construction site necessitated changing the spillway design to a chute type. A l:100 scale model was used to develop the superelevation in the chute and other aspects of the chute design. Particular attention was given to scour patterns downstream from the chute.

(f) Completed.

(h) Three internal reports were issued.

(6712) WATER QUALITY STUDY--HYDRODYNAMICS OF A DENSITY STRATIFIED RESERVOIR.

(d) Field investigation; basic research.

(e) Effective and optimum water resource development requires knowledge of the yearly cyclic changes of the various properties of the water in deep, stratified reservoirs. Dissolved oxygen content, temperature, conductivity and density as a function of depth were measured at various stations in Fontana Reservoir and in its inflows and outflows during 1966. Current velocities were measured from a securely moored barge with a deep water isotopic current analyzer which is capable of measuring velocities of $0.005 \mathrm{ft} / \mathrm{sec}$.

(f) Data evaluation and analysis are in progress.

(h) "Evaluation of Fontana Reservoir Field Measurements," Walter 0 . Wunderlich and Rex A. Elder, presented at ASCE Specialty Conf. on Current Research into the Effects of Reservoirs on Water Quality, Jan. 21-24, 1968, Portland.

(6713) BROWNS FERRY PROJECT.

(d) Experimental; for design.

(e) A filter-demineralizer system consisting of an ion exchange resin, settling tank, and dewatering apparatus will be used at this project to remove radioactive contaminants from the condenser cooling water. When the resin becomes exhausted, the filter will be backwashed and the backwash slurry will be pumped to the settling tank which is designed to contain the accumulation from several backwash operations. Each backwash volume will settle and the supernatant liquid decanted through a pipe located in the side wall above the sludge layer before the next backwash is received. To provide design information, laboratory tests were made to determine settling and sludge handling characteristics of the resin, and to determine the rate at which the supernatant liquid could be decanted without entering settled sludge.

(g) The mechanism responsible for sludge entrainment was found to be vortex, the formation of which could be described as a function of the Reynolds number of the flow in the outlet pipe and the ratio of the height of the outlet pipe from the sludge layer to the diameter of the outlet pipe.

(h) Two internal reports have been issued.

(6714) HALES RAR PROJECT-DEMOLITION.

(d) Experimental; for construction.

(e) A l:100 scale model of the existing Hales Bar Dam was used to determine the best basic approach to removing the spillway and nonoverflow section, and how much removal is required to meet navigation and flood control criteria. The Hales Bar Dam will be removed after the new downstream project, Nickajack, has been closed and no differential head exists across Hales Bar.

(f) Suspended until after demolition--may be reactivated to check need for final underwater cleanup.

(h) Three internal reports have been issued.

(6715) BROWNS FERRY PROJECT--CONDENSER COOLING WATER DIFFUSER.

(d) Applied research.

(e) The heated condenser cooling water from the nuclear powered generating station is to discharge into Wheeler Reservoir through a diffusing structure so as to mix the heated water with the flowing reservoir water and to limit the temperature rise in the reservoir. The mixing structure consists of three large corrugated steel pipes with multiple small side ports, laid on the bottom across the reservoir. The heated discharge jets through the ports and is mixed with the cooler river water due to the turbulent jet action of the buoyant plume. A model study was conducted to obtain discharge coefficients for the small side ports in the corrugated wall, and a digital computer study was made to iterate the hydraulic equations for flow through the pipe such that uniform port discharge could be obtained for a specified total head.

(f) Completed.

(g) Information was obtained for the design of the diffuser pipes, i.e., the pipe diameters and lengths, the port diameter and spacing and number of ports were decided.

(6716) WHEELER PROJECT--UNITS 9-11 VIBRATION STUDIES.

(d) Field investigation.

(e) The three new 35 MW fixed-blade propeller hydroturbines vibrate excessively at certain gate openings. A study was made to explain the nature of the vibrations in order to prescribe modifications to eliminate the problem. One unit was instrumented and measurements were made during synchronous speed at various loads and at varying speeds at no-load for the following: scroll case pressure fluctuations; draft tube pressure fluctuations; shaft bending strain; shaft torsional strain; turbine blade bending strain; wicket gate bending strain; stay vane bending strain; vertical shaft deflections; lateral shaft deflections; vertical thrust bearing bracket deflection. Data were recorded on analog magnetic tape and are being analyzed with an analog computer. Mean squared amplitudes, power density spectra, and correlations are being obtained.

(g) Preliminary results indicate that there are two main forcing functions: (1) A precessing draft tube instability at 50-60 percent gate opening, and (2) A pulsation at the "blade frequency" close to resonance with a couplea torsional-lateral mode of shaft vibration, at 80-100 percent gate opening.

(6717) BEAR CREEK PROJECT--INTAKE AND DISCHARGE STRUCTURES.

(d) Experimental; for design and applied research.

(e) A combination of intake tower with slide gates and an uncontrolled morning-glory type spillway were proposed to control headwater elevations when below the emergency spillway. The flow from both structures joined into a common tunnel which was terminated by a still ing structure. A l:20 scale model was used to 
evaluate the efficacy of each component and the system. Measurements of air demand were made and will be compared to future prototype measurements.

(f) Suspended.

(g) The morning-glory spillway was eliminated primarily due to flow problems at the tunnel junction. A cylindrical intake tower was recommended since it minimized surface vortices. A complex stilling basin design was required at the end of the tunnel due to unsymmetrical approach flow into the basin.

(h) Two internal reports were issued.

(6718) BEAR CREEK PROJECT--SPILLWAY.

(d) Experimental; for design.

(e) An emergency chute spillway will be provided for flows in excess of the intake structure capacity. A 1:100 scale model is being used to develop the wall layout which will minimize flow depths and standing waves in the chute, to check the spillway capacity, and to determine erosion tendencies downstream from the chute.

(g) The originally proposed crest did not permit sufficient spillway capacity, and a new design was developed. A revised chute layout was recommended to minimize the required wall heights.

(h) Two internal reports were issued.

(6719) FIXED CONE DISPERSION VALVES--CONTAINMENT STRUCTURE.

(d) Experimental; applied research.

(e) Numerous future projects will have a fixed cone dispersion valve located at the end of a tunnel. To confine the flow from the valve to a limited area, the valves will discharge into a structure. This structure must produce good flow distribution so as to produce acceptable downstream scour without interfering with the reaeration capability of the valves. If possible, one basic structure geometry will be used for a wide variety of valve sizes and operating heads.

(g) A structure meeting the above requirements was developed.

(6720) PARADISE STEAM PLANT--COOLING WATER FLUMES.

(d) Experimental; for design.

(e) Cooled condenser water will be returned from two new cooling towers via open channel flumes to the intake tunnels of two existing units. A 1:30 scale model was used to evaluate the performance of the collection troughs at each tower, and to minimize flow disturbances at the junction where the rectangular flumes from each tower join into a common trapezoidal flume.

(f) Completed.

(g) The original collection troughs were modified to prevent over-topping the walls at the base of the towers, and baffle blocks were used to provide a smooth flow transition at the flume junction.

(h) Three internal reports were issued.

(6721) PARADISE STEAM PLANT--EMERGENCY GATE FOR COOLING WATER CONDUITS.

(d) Experimental; for design.

(e) Each of the three underground conduits from the cooling towers to the condensers will have vertical lift, gates which must be capate of a 30 second closure under fllowing water conditions. Due to the unusual geom- etry at the gate, a 1:11 scale model was used to check the ability of the gate to perform the required closure.

(f) Completed.

(g) The tests showed the gate will perform satisfactorily.

(6722) TIMS FORD PROJECT--TURBINE INTAKE GATE.

(d) Experimental; for design.

(e) The turbine will have a single-leaf vertical lift gate at the intake in the face of the concrete dam. This gate must be capable of closing the intake under flows up to turbine runaway discharge. A l:20 scale model was used to determine whether the gate would close and the magnitude of forces in the lifting cables. The normal load on the gate was measured directly and electric analog components were used to determine the hydrodynamic force as a function of time and gate position.

(f) Completed; project design changed to earth dam.

(g) The original intake design produced upward hydrodynamic forces at small gate openings which would have prevented the prototype gate from closing. A revised intake geometry proved acceptable; the gate geometry was changed to reduce cable loads.

(6723) RACCOON MOUNTAIN PUMP-STORAGE PROJECT--INTAKE IN UPPER RESERVOIR.

(d) Experimental; for design.

(e) A 1:100 scale model of the upper reservoir is being used to study flow patterns at the intake during the turbine operating mode. Special attention is being given to the occurrence of vortices and their effect on setting a minimum pool elevation and on the requirements of an intake structure.

(f) Suspended.

(g) Tests with a simple intake showed that objectionable vortices occurred over a wide range of reservoir water surface elevations.

(6724) TELLICO PROJECT--SPILLWAY.

(d) Experimental; for design.

(e) Model studies are being conducted to develop a design for the spillway apron. A distorted scale model, $1: 156$ vertical and $1: 324$ horizontal, was used to determine the flow patterns downstream from the spillway. Scour patterns are determined from a 1:72 scale undistorted scale model, constructed to simulate the complex flow patterns observed in the distorted scale model.

(g) Tests with the distorted scale model showed that two stable flow patterns can exist downstream from the spillway. The scour patterns produced by these flow patterns were quite different. An apron with baffle blocks and steeply sloping training walls was found to produce optimm results.

(6725) PARADISE STEAM PLANT--UNITS 1 AND 2 GAS DUCT STUDIES.

(d) Experimental; development model studies.

(e) For the efficient operation of the new electrostatic fly-ash collectors recently installed at the two existing units, it is required that the combustion gases and the $f l y$-ash particles be uniformly distributed across the inlet section of the precipitator. To this end the proposed duct configuration was model tested, 
and baffle plates and guide vanes were designed as needed to obtain good gas-flow distribution. Hot wire anemometry and smoke trails were used in the transparent model to measure and observe the flow patterns.

Field measurements were made on the prototype gas flow to verify the results of the model studies.

(f) Completed.

(6726) PARADISE STEAM PIANT--UNIT 3 AIR AND GAS DUCT STUDIES.

(d) Experimental; development model studies.

(e) For the efficient operation of the electrostatic fly-ash collectors, the forced-draft fans, and the air preheaters at the new unit under construction at Paradise Steam Plant, it is required that the air and/or gas flow be uniformly distributed across these various appurtenances. This large unit, has large ducts with sharp bends and rapid expansions making uniform flow distribution difficult to obtain. The proposed air and gas ducts were, therefore, model tested. The duct configuration was changed in places and internal guide vanes, perforated plates, and baffles were installed as needed to obtain satisfactory flow distribution.

(f) Completed.

(6727) SHAWNEE STEAM PLANT--GAS DUCT STUDIES.

(d) Experimental; development model study.

(e) Electrostatic fly-ash precipitators are to be installed in series with the existing mechanical collectors at all ten units at Shawnee Steam Plant. Efficient performance of these precipitators require uniform gas delivery at the precipitator entrance.

Field studies were made to determine the distribution of the flue-gas flow leaving the mechanical collectors, and this distribution was simulated in a 1:18 scale model of the proposed new ducts and precipitators. Results of the model study will indicate which of several possible duct geometries is superior in performance relative to gas distribution, head-loss, and premature flyash precipitation. Hot-wire velocity traverses and smoke trails are used in the model to measure and observe the flow patterns, and suitable guide vanes are installed where needed to create an acceptable gas-flow distribution.

(6728) GALTATIN STEAM PLANT--GAS DUCT STUDIES.

(d) Experimental; development model study.

(e) Electrostatic fly-ash precipitators are to be installed in series with the existing mechanical collectors at all four units at Gallatin Steam Plant.

(6729) AFRATION CHARACTERISTICS OF FIXED-CONE DISPERSION HOWELI-BUNGER VALVES.

(d) Field investigation; applied basic research.

(e) Tests were initiated to investigate the aeration characteristics of fixed-cone dispersion Howell-Bunger valves when discharging water having low dissolved oxygen concentrations. A field test facility was constructed at Nottely Dam in North Georgia where low DO water supply is available during July, August and September. Two valve sizes were used: 24 -inch and 12-inch diameter. The test program was divided into three phases: (I) Free discharge into the atmosphere; (2) discharge into a containment structure; and (3) discharge into a tunnel. DO concentrations are measured upstream from the valve, and from the catchment area downstream from the valve.

(g) Phases 1 and 2 have shown that fixed-cone dispersion Howell-Bunger valves are effective aeration devices. An internal report is being prepared.

TENNESSEE VALLEY AUTHORITY, Hydraulic Data Branch, Knoxville, Tennessee 37902

Inquiries concerning projects should be addressed to Mr. James W. Beverage, Chief, Hydraulic Data Branch, Tennessee Valley Authority.

\section{( 765) EVAPORATION IN THE TENNESSEE BASIN.}

(d) Field investigation; applied research.

(e) To provide data for estimating reservoir losses and derive a general rule, applicable to the Basin, permitting computation of evaporation from pans at six locations in Basin, together with standard meteorological readings.

(h) Results published in monthly and annual bulletins, "Precipitation in Tennessee River Basin" (Project 768).

( 768) PRECIPITATION IN TENNESSEE RIVER BASIN.

(d) Field investigation; basic research.

(e) A comprehensive study of rainfall and other weather phenomena for purposes of water dispatching and improvements in water control; storm studies as related to maximum precipitation, rainfall-runoff, spillway design and operation, etc.

(h) Monthly and annual bulletins, "Precipitation in Tennessee River Basin."

( 769 ) RESERVOIR AND STREAM TEMPERATURES.

(d) Field investigation; basic research.

(e) Study of water utilization and water movement as concerns industrial and steam plant locations and stream pollution. Variations in temperature from surface to bottom in selected reservoirs are determined by soundings, and by continuous recording gages in selected natural streams. Periodic observations are made at gaging stations.

(h) "Water Temperature of Streams and Reservoirs in the Tennessee River Basin," Tennessee Valley Authority, Hydraulic Data Branch Rept. No. 0-6608, Sept. 1966, 417 pp.

( 771 ) GALLERY DRAINAGE IN LARGE DAMS.

(d) Field investigations; design.

(e) Weirs are placed in main galleries and drainage measured as check on tightness and stability .

( 779) MAXIMUM POSSIBLE PRECIPITATION IN TENNESSEE VALTEY.

(b) Cooperative with U.S. Weather Bureau.

(d) Theoretical; applied research.

(e) Hydrometeorological analysis of large storms with upward adjustments of controlling factors to maximum limits as applied to the Tennessee Valley and subdivisions.

(g) Results to be published as one of current series of hydrometeorological reports by the U.S.W.B. and cooperating agencies. 
(h) "Probable Maximum Precipitation over the Tennessee River Basin above Chattanooga," Hydrometeorological Rept. No. 4I, U.S. Weather Bureau, 1965.

( 780) PERIODIC EVALUATION OF GROUND-WATER STORAGE.

(d) Theoretical; operation.

(e) By analysis of current records of stream discharge, the volumes of runoff in groundwater and channel storage are determined for use in operation of multi-purpose reservoirs.

(g) Results reported weekly within the organization.

(h) "Uncontrolled Storage Evaluation in the Tennessee Valley," Paul C. Sodemann, paper for AGU meeting, April 1963.

( 785 ) SEDIMENTATION OF EXISTING RESERVOIRS.

(d) Field investigation; basic research.

(e) Selected ranges in reservoirs are probed and sounded, volumetric samples are collected and analyzed, quantity and distribution of sediment are computed to determine deposition by stream, probable life of reservoir, effect of sediment storage on navigation channels and sedimentation of down-stream reservoirs, and probable sedimentation in future reservoirs.

(h) Data is reported in Misc. Publ. No. 964 , "Summary of Reservoir Sediment Deposition Surveys Made in the United States," U.S. Dept. of Agriculture, Feb. 1965.

"The Lack of Sediment Deposition in TVA Reservoirs," Robert Forbes, paper prepared for presentation at Hydraulies Div. Conf., ASCE, Madison, Wisc., Aug. 1966.

(3306) COOPERATIVE RESEARCH PROJECT IN WESTERN NORTH CAROLINA.

(b) Project conducted in cooperation with North Carolina State University.

(d) Field investigation, basic research.

(e) To determine water-plant-soil relationship on some of the principal soils used for agricultural purposes in western North Carolina under important vegetative covers. Four crops are rotated on four small watersheds under a "Latin-Square" statistical design. Observations include rainfall, runoff, ground-water levels, soil moisture, evaporation, potential and actual evapotranspiration.

(f) Active; hydrologic measurements completed on two of four watersheds. Interflow studies conducted on one watershed in 1965-66.

(g) Results to date are summarized in annual reports on the project.

(3308) WHITE HOLLOW WATERSHED.

(d) To study the effect of changes in the vegetal cover on a watershed taken out of cultivation on the hydrologic factors of runoff and soil erosion.

(e) Continuous record from 1935 of rainfall, runoff, and suspended sediment, and periodic determination of vegetal cover indexes.

(f) Active; logging road system constructed in 1964-65. Selective pulpwood cutting completed in 1966, and sawtimber cutting began in 1967.

(g) During the 24-year period 1935-1958, the forest cover improvement in the watershed resulted in greater watershed protection with no measurable change in water yield, no change in volume of either surface runoff or groundwater runoff, marked reduction in summer peak rates of discharge with lesser reduction in winter rates, a prolongation of the period of draining of surface runoff from the channel system, and a 76 percent reduction in the sediment load.

(h) "Effects of Forest Cover Upon the Hydrologic Characteristics of a Small Watershed in the Limestone Region of East Tennessee," Paul C. Sodemann and Jones E. Tysinger, paper prepared for presentation at Symposium sponsored by UNESCO, Oct. 1365 .

"Forest Cover Improvement Influences Upon Hydrologic Characteristics of White Hollow Watershed" - 1935 to 1958.

(3309) PINE TREE BRANCH WATERSHED.

(d) To determine the effects upon the hydrology of the watershed by reforestation and erosion control measures.

(e) Continuous record from 1941 of rainfall, runoff, ground water, and sediment loads.

(f) Active; selective pulpwood cutting completed in 1966. Watershed reinventoried.

(g) During the 20-year period 1941-1960, the cover improvement and erosion control in the watershed resulted in a decrease in surface runoff volumes and an increase in ground water discharges, marked reductions in summer and winter peak flood discharges, a reduction in overland surface velocities, a prolongation of the period of draining of surface runoff from the channel system, an appreciable decrease in water yield, and a 96 percent reduction in sediment load.

(h) Project reports, "Reforestation and Erosion Control Influences Upon the Hydrology of Pine Tree Branch Watershed"-1941-60, TVA, 1962.

(4011) NORTH FORK CITICO CREEK RESEARCH WATERSHED.

(b) Project conducted in cooperation with U.S. Forest Service.

(d) Field investigation; basic research.

(e) To determine the effects of normal, highstandard National Forest Multiple-use management upon the hydrology of the area. Observations include rainfal1, runoff, air and water temperature, and humidity. Timber inventories, soil surveys, wildlife inventories, and evaluations of soil disturbances will be made. Project activities are divided into calibration, development, and evaluation phases.

(f) Active; calibration period completed. "Action" phase started with access road construction into watershed to site of first timber sale.

(g) Results are published in annual reports distributed to cooperating agencies.

(h) "North Fork Citico Creek Watershed Study," Annual Water Year Reports 1361-66, Tennessee Valley Authority, U.S. Forest Service, and Tennessee Game and Fish Commission.

(4884) UPPER BEAR CREEK EXPERIMENTAL PROJECT.

(b) TVA Tributary Area Development project cooperative with U.S. Forest Service and Auburn Univ.

(e) Quantitative detemination of the effect of soil type, slope, and vegetative cover upon runoff, peak discharge, and erosion on small watershed progressing to large watersheds. Development of procedures to make data usable in projecting effects from small watersheds to larger drainage areas and to transfer 
results of the study to ungaged areas.

Four general types of land cover and use will

be considered in the study of the watersheds

that progress downstream from areas of several hundred acres through intermediate-sized

watersheds to a drainage area of 143 square

miles.

(f) Active; hydrologic condition surveys made in March, August, and November 1967. Bacteriological sampling at selected stations February 1965 to May 1966. TVA and U.S. Forest Service adopted plans for two small forested watersheds to study effects of timber management. Logging roads constructed on one of these watersheds in fall of 1967.

(g) Results are published in quarterly and special reports on the subject.

(h) "Upper Bear Creek Experimental Project Research in Area-Stream Factor Correlation," Water Resources Research Paper No. 1, TVA, February 1965.

"The Upper Bear Creek Experimental Project," 1962-64 and 1964-65, TVA, U.S. Forest Service, May 1965, July 1966. 
RESEARCH COUNCIL OF ALBERTA, Rm. 301, Engrg. Bldg., University of Alberta, Edmonton, Alberta, Canada

(6818) STABIIITY OF COARSE BED MATERIAI IN OPENCHANNVEL FLOW.

(b) Research Council of Alberta; Alberta Dept. of Highways.

(c) Mr. C.R. Neill, Research Council of Alberta.

(d) Laboratory study; field investigations.

(e) Concerned with a design criteria for hydraulic stability of gravel and rip-rap material.

(g) A design nomogram is presented relating competent mean velocity to grain size, specific gravity and depth of flow.

(h) "Mean-Velocity Criterion For Scour of Coarse Uniform Bed-Material," C.R. Neill, Proc. I2th Cong., Intl. Assoc. Hyd. Res., Vol. 3, 1967.

(6819) COMPARISON OF BED-IOAD MEASUREMENT TECHNIQUES.

(b) Research Council of Alberta; Univ. of Alberta; Alberta Dept. of Agriculture; Water Survey of Canada.

(c) Mr. C.R. Neill; (see 6818) above.

(d) Field investigations.

(e) Comparison of estimates of bed-load discharge in gravel rivers using portable bed-load samplers, continuous tracer injection, refilling rates of river bed excavations and formulae.

(h) "Measurements of the Bed-Load Discharge of the Elbo River," A.B. Hollingshead, M. Sc. Thesis, Univ. of Alberta, 1968.

(6820) STUDIES OF REGIME HYDRAULICS AND GEOMORPHOIOGY OF RIVERS OF VARIOUS TYPES.

(b) Research Council of Alberta; Alberta Dept. of Highways; Alberta Dept. of Agriculture.

(c) Mr. C.R. Neill, Research Council of Alberta.

(d) Field studies.

(e) Collection of hydrologic data and study of channel processes of Alberta rivers.

(h) "Observed Forms of Bed Roughness in an Unstable Gravel River," V.J. Galay, Proc. Twelfth Congr., Intl. Assoc. Hydraulic Res., Vol. 1, 1967.

(6821) ICE IOADS ON BRIDGE PIERS.

(b) Alberta Dept. of Highways; Research Council of Alberta.

(c) Mr. C.R. Neill; see (6820) above.

(d) Field measurements.

(e) Measurements of the dynamic ice load on a bridge pier.

UNIVERSITY OF ALBERTA, Dept. of Civil Engrg., Edmonton, Alberta, Canada

(5666) ALBERTAN CO-OPERATIVE STUDIES OF RIVER REGIME.

(b) University; and Alberta Research Council.

(c) Dr. T. Blench, Dept. of Civil Engrg., Univ. of Alberta.

(d) Field study; Master's thesis; basic research.

(e) Tracer studies of initiation and distribution of movement of bed particles. Attempt to check formulas and normality of distributed stones.

(h) "Observations on Gravel Transport in Four Rivers in Western Alberta, "N. Van der Giessen, M.Sc. thesis, Univ. of Alberta, 1966.

(5667) ALBERTAN CO-OPERATIVE STUDIES OF RIVER REGIME. (b) University with Natl. Research Council Grant.

(c) Dr. T. Blench; see (5666) above.

(d) Lab. study; Master's thesis; basic.

(g) A purely bed-load delta in a flume of constant width appears to move far upstream of the original backwater curve as a surge, so bed rises approximately parallel to itself.

(h) "River Aggradation Upstream of a Barrier," W.J. Stolte, M.Sc. thesis, 1966.

(6630) ALBERTAN CO-OPERATIVE STUDIES OF RIVER REGIME.

(b) T. Blench and Associates, Ltd.

(c) Dr. T. Blench; see (5666) above.

(d) Applied research.

(e) Text collating field and laboratory research by regime theory principles to answer major problems of "Evolution of River Bed" and related portion of "Influence of Man on Continental Waters". Problems outlined in UNESCO Note NS/NR/17 dated Paris 15th October 1962 in anticipation of International Hydrologic Decade.

(f) To be revised periodically.

(h) "Mobile-bed Fluviology," 1966, Available Univ. of Alberta Bookstore, 16 Chapters, 21 photo plates, 22 diagrams, 24 worked problems.

(6631) ALBERTAN CO-OPERATIVE STUDIES OF RIVER REGIME.

(b) University with Natl. Research Council Grant.

(c) Dr. T. Blench; see (5666) above.

(d) Lab. study; Master's thesis; basic.

(f) Completed.

(g) Ice cover simulated by articulated plywood. Mainly quantitative study of surges. Celerity reduced by cover. Waves through cover advance beyond those in water.

(h) "Effect of a Surface Cover on Open Channel Surges," R.H. Cooper, M.Sc. thesis, 1966.

(6632) FIOW IMMEDIATELY BEIOW SUBMERGED SLUICE GATES.

(b) University on NRC grant.

(c) Dr. N. Rajaratnam, Dept. of Civil Engrg., Univ. of Alberta.

(d) Basic problem with practical application; experimental in nature.

(e) To study the flow immediately below submerged sluice gates with regard to the nature of velocity and pressure distribution.

(g) A vena contracta has been defined; the diffusion of the jet has been successfully treated as a plane free jet boundary problem. Also the boundary layer growth in this region has been studied.

(h) "Flow Immediately Below Submerged Sluice Gate, "N. Rajaratnam and K. Subramanya, Jour. Hydraulics Div., Amer. Soc. Civil Engrs., Vol. 93, No. HY4, pp. 57-77, July 1967.

(6633) A FIOW EQUATIONS FOR THE SLUICE GATE.

(b) University on NRC Grant.

(c) Dr. N. Rajaratnam; see (6632) above.

(d) Basic problem with practical application; experimental and theoretical in nature.

(e) To develop a general flow equation for sluice gates located in rectangular channels.

(g) A general flow equation has been derived analytically and evaluated experimentally for both free as well as submerged flow. Also direct solutions have been constructed for some of the practical problems connected with the sluice gate. 
(h) "A Flow Equation for the Sluice Gate," N. Rajaratnam and K. Subramanya, Jour. Irrig. and Drain, Div. Amer. Soc. Civil Engrs., Vol. 93, No. IR3, pp. 167-186, Sept. 1967. "Some Practical Problems Concerning Sluice Gate Flow," N. Rajaratnam and K. Subramanya, Water Power, London. (in press)

(6634) PLANE TURBULENI REATTACHED WALI JETS.

(b) University on NRC Grant.

(c) Dr. N. Rajaratnam; see (6632) above.

(d) Basic problem with practical application; experimental.

(e) To study the mean flow characteristics of plane turbulent reattached wall jets under zero pressure gradient.

(g) It has been found that after a certain distance from the reattachment line, the transverse velocity distribution is similar and agrees well with that of the classical wall jet. The variation of the velocity and length scales has been studied. Some interesting results have been obtained concerning the longitudinal distribution of the bed shear stress. This study has been extended to the case of the flow emerging from a sluice gate located at the drop.

(h) "Plane Turbulent Reattached Wall Jets," N. Rajaratnam and K. Subramanya, Jour Hydraulics Div., Amer. Soc. Civil Engrs., Jan. 1968. "Diffusion of Submerged Sluice Gate Flow Over a Drop," N. Rajaratnam and K. Subramanya, Proc. 12th Congr. Intl. Assoc. for Hydraulic Research, Fort Collins, Colorado, Vol. 4, pp. 156-163, sept. 1967.

(6635) HYDRAULIC JUMPS BELOW ABRUPT SYMMETRICAL EXPANSIONS.

(b) University on NRC Grant.

(c) Dr. N. Rajaratnam; see (6632) above.

(d) Basic problem with practical application; experimental.

(e) To study the jump formation below abrupt symmetrical expansions in rectangular open channels.

(f) Completed.

(g) The R-jump and $S$-jump occurring below abrupt expansions have been studied. A new length parameter has been introduced which correlates successfully most of the mean flow characteristics of the S-jumps. The S-jump has also been treated as a three dimensional turbulent wall jet.

(h) "Hydraulic Jumps Below Abrupt Symmetrical Expansions," N. Rajaratnam and K. Subramanya, Jour. Hydraulics Div., Amer. Soc. Civil Engrs., March 1968.

(6636) DIFFUSION OF RECTANGULAR WALT JETS IN WIDER CHANNELS.

(b) University on NRC Grant.

(c) Dr. N. Rajaratnam, Dept. of Civil Engrg.

(d) Basic experimental research.

(e) To study the diffusion of deeply submerged rectangular turbulent wall jets in wider rectangular channels.

(f) Completed.

(g) On the plane of symmetry the mean flow characteristics have been measured and analyzed in two parts, that is the boundary layer region and the free mixing region. The variation of the bed shear stress has also been studied.

(h) "Diffusion of Rectangular Wall Jets in Wider Channels," N. Rajaratnam and K. Subramanya. (under publication).

(6637) THREE DIMENSIONAI FREE JETS.

(b) University on NRC Grant.

(c) Dr. N. Rajaratnam; see (6636) above.

(d) Analytjcal research.

(e) To find out some simple method of correlating the mean flow characteristics of three dimensional turbulent free jets.

(f) Completed.

(g) A new length equal to the cross sectional area divided by the perimeter of the fluid interface of the jet has been found to be very useful in correlating the velocity scale of circular, square, triangular and certain other non-circular jet shapes.

(h) "Three Dimensional Free Jets," N. Rajaratnam and K. Subramanya, Jour. Royal Aero. Soc., London. (In press)

(6638) ANNOTATED BIBIIOGRAPHY ON WALI JETS.

(b) University on NRC Grant.

(c) Dr. N. Rajaratnam; see (6636) above.

(d) Historical research on wall jets.

(e) To prepare a consolidated annotated bibliography on wall jets.

(f) Completed.

(g) All the available publications concerning wall jets in the fields of aeronautical, mechanical, chemical and hydraulic engineering are collected in one report.

(h) "An Annotated Bibliography on Wall Jets," N. Rajaratnam and K. Subramanya, Tech. Rept., Dept. of Civil Engrg., Univ. of Alberta, 1367.

(6639) PROFIIE OF THE HYDRAUIIC JUMP.

(b) University on NRC Grant.

(c) Dr. N. Rajaratnam; see (6636) above.

(d) Analytical.

(e) To develop a simple method to predict the mean flow profile of the hydraulic jump.

(f) Completed.

(g) By properly choosing horizontal and vertical length scales, the mean flow profile of the jump was reduced to a simple but general similarity curve.

(h) "Profile of the Hydraulic Jump," N. Rajaratnam. K. Subramanya, Proc. ASCE, Vol. 94, HY3, 1968.

(6640) FIOW CHARACTERTSTICS OF THE RECTANGULAR FREE OVERFALI.

(b) University on NRC Grant.

(c) Dr. N. Rajaratnam, Dept. of Civil Engrg., Univ, of Alberta.

(d) Basic research; experimental and analytical.

(e) To study the velocity, pressure and bed shear stress fields of the rectangular free overfall.

(f) Completed.

(g) The distribution of the pressure and mean velocity at the brink for a large range of slopes, has been studied. The variation of the normal acceleration at the brink has been evaluated. Further these observations have been continued upstream of the brink and the bed shear stress variation has also been studied.

(h) "Flow Characteristics of the Rectangular Free Overfall, "N. Rajaratnam and D. Muralidhar. (Under publication)

(6641) YAW, PITCH AND SCREW DRIVER PROBES.

(b) National Research Council, Canada (NRC).

(c) Dr. N. Rajaratnam; see (6640) above.

(d) Instrument research.

(e) To develop suitable instruments for the 
measurement of pressure, velocity and boundary shear stress in hydraulic engineering.

(g) Yaw and pitch probes have been constructed and calibrated. A yaw-type Preston probe has been developed for the measurement of boundary shear stress in three dimensional turbulent boundary layers. The performance of the Screw Driver Probe under three dimensional flow conditions has been tested. The Prandtl tube has successfully been used for the measurement of the boundary shear stress.

(h) "Yaw Probe Used as Preston Tube," N. Rajaratnam and D. Muralidhar. (Under publ.) "Yaw and Pitch Probes," N. Rajaratnam and D. Muralidhar, Tech. Rept., Dept. of Civil Engrg., Univ. of Alberta, 1967.

(6642) DIFFUSION OF A SUPERCRITICAL STREAM ON A STAGNANT POOL.

(b) University on NRC Grant.

(c) Dr. N. Rajaratnam; see (6640) above.

(d) Basic experimental research.

(e) To study the diffusion of a supercritical stream discharged on the surface of a stagnant body of water.

(f) Completed.

(g) It was found that this problem could be considered as the diffusion of a surface jet. The main difference between this surface jet and the corresponding half plane free jet was in the growth of the length scale.

(h) "The Diffusion of a Supercritical stream on a Stagnant Pool," N. Rajaratnam. (Under Publication)

(6643) HYDRAULIC JUMPS ON ROUGH BEDS.

(b) Univ, on NRC Grant.

(c) Dr.N. Rajaratnam; see (6640) above.

(d) Experimental basic research.

(e) To study the effect of bed roughness on the characteristics of hydraulic jumps in rectangular channels.

(f) Completed.

(g) It has been found that the ratio of the subcritical sequent depth to the supercritical depth is a function of the supercritical Froude number and the relative roughness of the bed. One other significant finding was that the bed roughness reduces the length of the jump considerably.

(h) "Hydraulic Jumps on Rough Beds," N. Rajaratnam. (Under publication)

UNIVERSITY OF BRITISH COLUMBIA, Dept. of Civil Engrg., Hydraulics Lab., Vancouver 8, B.C., Canada

(4451) HEAD LOSS IN SPHERICAL AND CONVENTIONAL WYES.

(b) Laboratory project.

(c) Dr. E. Ruus, Dept. of Civil Engrg., Univ, of Eritish Columbia.

(d) Applied research. Much of the experimental work is being done by an M.A.Sc. student.

(e) Lucite models of spherical and conventional type of wyes were constructed and the head losses measured. For all wyes the inside diameter of the main pipe and the branch pipes are $51 / 4$ and $33 / 4$ inches respectively. Several modifications such as tierods, tapered outlets, rounded corners and different sphere diameters are keing investigated.

(h) M.A.Sc. Thesis, Hua Wang, Sept. 1967.
(5994) TFE USE OF AIR BUBBLERS TO PREVENT SHOALING AT A WHARF IN A NAVIGABIE, ALLUVIAL, TIDAL RIVER.

(b) Iaboratory project.

(c) Prof. E.S. Pretious; Dept. of Civil Engrg., Univ. of British Columbia.

(d) Laboratory experiments and field tests. Applied research to aid operation and development. Project used for master's thesis.

(e) A grain elevator wharf owned and operated by the Fraser River Harbour Commission on the left bank of the Fraser River at New Westminister, B.C., is subject to severe shoaling annually, inmediate following a freshet. This shoal is removed by conventional dredging which is inconvenient for shipping using the wharf. If dredges are not immediately available the wharf has to close, resulting in serious financial loss. The shoal is composed of fine sand having a median diameter of about $0.1 \mathrm{~mm}$. which may be carried in suspension during the freshet. By creating a curtain of air bubbles it might be possible to deflect the sediment deposition away from the wharf; in the manner of an underwater deflecting groin, except that it would not constitute a hazard to shipping. Compressed air will be forced through perforations in plastic pipe anchored to the river bed in the vicinity of the wharf, which is 1,129 feet long parallel to the bank.

(f) Completed.

(g) Results show that air bubblers cannot prevent shoaling unless there is a fairly strong river current to carry the agitated sediment outside of the project area. Suspended sediment, being finer than bed load, is relatively easily kept in suspension. Air bubblers would probably be ineffectual in agitating coarse bed load, because the upward flow induced in the surrounding water by the curtain of rising air bubbles is weakest where it is most needed, viz. near the river bed.

(h) The results of the study are given in a Master's thesis, "The Use of Air Bubblers to Prevent Shoaling at Wharves in Navigable Rivers," A.B. Ages, April 1967. A Dept. of Civil Engrg. Rept., "The Precise Measurement of Small Water-Surface Slopes in Open Channels," by Professor E.S. Pretious, March 1967, describes particular aspects of the field and laboratory studies of the air bubbler.

(5995) A GENERAL-PURPOSE, LABORATORY WAVE GENERATOR.

(b) Laboratory project supported by Natl. Research Council of Canada.

(c) Prof. E.S. Pretious; see (5994) above.

(d) Design and construction of a wave generator and wave absorbers to provide laboratory facilities for wave research.

(e) The short length of the existing laboratory flumes precludes long spending beaches and also makes it necessary to generate the type of wave desired (shallow-water, deep-water or transitional type) right at the generator. By a suitable linkage the wave generator can act as a hinged paddle, a plunger, or as a combination of the two, depending on the water-particle motion desired. This wave research facility will be available for demonstration and graduate research.

(f) Completed. The same type of wave generator, 
with modifications and improvements, is beirg planned for a much larger flume in the Hydraulics Laboratory. A theoretical analysis will be made of its design and will form the subject of a thesis for a Master's degree.

(g) The results of the completed wave generator showed back-lash in the gear train and belt slap in the drive when maximum acceleration of the crank occurred, which produced irregulatities in the large amplitude waves. This will be remedied in the proposed new wave generator.

(h) A Dept. of Civil Engrg. Rept., "A GeneralPurpose Wave Generator to Produce all Types of Water-Waves in Short Flumes," by Prof. E.S. Pretious, July 1967, describes the completed pilot installation.

(5997) RIVER FLOOD FORECASTIIIG.

(b) British Columbia Disaster Relief Fund.

(c) Dr. M.C. Quick, Dept. of Civil Engrg., Univ. British Columbia.

(d) Applied research (mostly theoretical).

(e) To study hydrometeorological forecasting of floods from snowmelt. This study is coupled with another study of the ripening processes within a snow pack.

(h) "River Flood Flows: Forecasts and Probabilities," M.C. Quick, Proc. ASCE, Jour.

Hydraulics Div., Vol. 91, No. HY3, pp. 1-18, May 1965.

"A Comparison of Measured and Theoretical Snowpack Temperatures," Jour. Hydrology, Vol. 5, pp. 1-20, April 1967.

(5997A) RIVER FLOOD FORECASTING.

(b) British Columbia Disaster Relief Fund.

(c) J.F. Muir, Prof. Emeritus, Dept. of Civil Engrg., U.B.C.

(d) Theoretical; applied research.

(e) To derive a formula for predicting the flood discharge of the Fraser River at Hope.

(g) Report being prepared.

(6096) OPTIMUM PUMP SUMP DESIGN.

(b) Laboratory project.

(c) Dr. M.C. Quick, Dept. of Civil Engrg., U.B.C.

(d) Experimental and theoretical; applied research.

(e) A basic investigation of vortex behavior coupled with a study of flow patterns in sump configurations is being made. Conclusions arising from these studies are being used to develop an optimum design procedure for pump sumps.

(h) Report in preparation.

(6097) WATER HAMMER IN IRRIGATION PIPE SYSTEMS.

(b) Laboratory project.

(c) Dr. E. Ruus, Dept. of Civil Engrg., U.B.C.

(d) Theoretical; applied research; for Master's thesis.

(e) To study water hammer wave motion in irrigation pipe networks by the method of characteristics using a digital computer. In addition to pipe friction, many boundary conditions such as reservoirs, surge tanks, air chambers, sprinklers, valves and centrifugal pump are considered. Networks up to one thousand pipes of varying diameter, wall thickness and material can be handled.

(f) Completed.

(g) Very good agreement was found between results obtained from computer analyses by method of characteristics and results by the graphical method. Sprinkler discharge has a large influence in dampening of water hammer water.

(h) The findings will be presented in a Master's thesis.

(6098) INFLUENCE OF IARGE OSCILIATIONS ON SURGE TANK STABILITY.

(b) Iaboratory project; Natl. Research Council.

(c) Dr. E. Ruus; see (6097) above.

(d) Theoretical, for Master's thesis.

(e) To find the stability criteria for large oscillations of a simple surge tank. The continuity and momentum equations are used with either (1) the constant power output equation or (2) the constant turbine gate opening equation, depending on whether the momentary net head is greater or lower than the rated head of the turbine.

(f) Completed.

(g) Results are significantly different from previous findings based on constant power output criterion only.

(h) M.A.Sc. Thesis by J.P. Wei, Dec. 1767.

(6099) DIMENSIONLESS RATIOS FOR SURGES IN OPEN CANALS.

(b) Laboratory project.

(c) Dr. E. Ruus; see (6097) above.

(d) Theoretical; for Master's thesis.

(e) To arrange the variables involved in open canal surges into groups of dimensionless ratios.

(h) The findings will be presented in a Master's thesis.

(6100) RIVER-BED SCOUR AT BRIDGE PIERS AND OBSTRUCTIONS.

(b) Laboratory project suppor a National Research Council of Canada Operating Grant.

(c) Professor E.S. Pretious, Dept. of Civil Engrg., U.B.C.

(d) Experimental and theoretical for a Master's thesis.

(e) To find a rational expression for calculating scour of river beds at bridge piers, abutments, groin heads, piles and other obstructions: based on theory, laboratory experiments and field studies of existing local bridges.

(g) Past methods have relied heavily on empirical methods for determining scour, aided by hydraulic models.

(h) The results will be presented in a Master's thesis.

UNIVERSITY OF BRITISH COLUMBIA, Dept. Of Mechanical Engrg., Vancouver 8, B.C. Canada.

(6574) UNSTEADY AERODYNAMICS OF STATIONARY ELLIPTIC CYIINDERS IN SUBCRITICAI FIOW.

(c) Dr. V.J. Modi.

(d) M.A. Sc. thesis.

(e) To study the aerodynamics of two-dimensional elliptic cylinders in separated flow with an organized wake character.

(g) The Strouhal number, fluctuating pressures, and wake geometriẻs associated with a set of stationary two-dimensional elliptic cylinders having an eccentricity of 0.8 and 0.6 are being studied during the organized wake condition. Dynamic calibration of the pressure transducer used in the measurements has been completed. The effect 
of the Reynolds number (30,000 - 100,000) on the fluctuating pressure is also being examined. The results indicate substantial dependence of the unsteady forces on the Reynolds number at zero angle of attack (up to $60 \%$ variation). The basing of the Strouhal number on the projected width reduced its dependence on the angle of attack of the models. The existence of a large phase angle between fluctuating pressures was of particular interest. The wake geometry study indicated a gradual reduction in the ratio of the lateral to the longitudinal spacing with increase in the angle of attack.

(6575) AEROELASTIC INSTABILITY OF A STRUCTURAL ANGLE.

(b) Dr. V.J. Modi.

(d) Ph.D. dissertation.

(e) To study the aerodynamics and dynamics of a structural angle during vortex induced and galloping types of oscillations.

(g) The study of the Strouhal number, unsteady forces, and wake geometry as a function of the angle of attack during static and vortex resonance conditions of a structural angle has been completed. The measurements indicate that for the most part the fluctuating pressures on the oscillating model are larger than those associated with the stationary angle. The existence of a large phase angle between the fluctuating pressures and the capture of the vortex frequency by the model frequency near the resonance condition is of interest. The wake geometry study suggests a considerable increase in wake during vortexinduced oscillations of the model with very little effect on the longitudinal vortex spacing.

The results of galloping motion study are being analyzed at present. The similar study in two-degrees of freedom (plunging and torsion) is being planned.

(6576) VORTEX-EXCITED OSCILTATION PHENOMENA FOR D-SECTION AND CIRCULAR CYLINDERS.

(c) Dr. G.V. Parkinson.

(d) M.A. Sc. thesis.

(e) To learn more of the kinematics and dynamics of the organized vortex systems in the wake of bluff, two-dimensional bodies in the Reynolds number range $10^{4}-10^{5}$. In particular, the interactions between the vortex systems and elastically mounted cylinders caused to oscillate by the vortices are of interest in the region of capture of the vortex frequency by the cylinder frequency.

(g) Data obtained by N. Ferguson on the surface pressure and wake characteristics of a D-Section cylinder at rest and in vortexexcited oscillation have been analyzed, and further measurements, including spanwise correlations by hot wire anemometer, are being prepared.

(6577) NON-IINEAR VIBRATION IN HYDRAULIC POSITIONING SYSTEMS.

(c) Dr. C.A. Brockley.

(d) Ph.D. dissertation

(e) To investigate non-linear vibration in hydraulic positioning systems which is associated with frictional and hydraulic fluid compressibility effects.

(g) Numerical solutions of the governing equations have been obtained, using experimentally derived parameters for the static-friction coefficient versus time relationship and using a linear relation for kinetic friction versus sliding speed. The results agree reasonably well with experimental observations, but a better description of the frictional behavior appears desirable.

Investigations are being made into microslip during the stick portion of the stickslip cycle and into obtaining the frictionvelocity relationship during unsteady sliding by using appropriately scaled acceleration to subtract inertia forces from the driving force.

(6578) AN INVESTIGATION OF PROBLEMS OF HAEMODIALYSER DESIGN.

(c) Dr. G.V. Parkinson; Dr. C.A. Brockley.

(d) $\mathrm{Ph} . \mathrm{D}$. dissertation

(e) To investigate experimentally, supported by some theoretical analysis, different configurations of dialysis chamber, flow inlet ducting, and transition chamber, with the purpose of achieving a more efficient flow distribution system within the constraints of available pressure differential and blood flow rate, and the requirements of a high ratio of membrane surface to blood volume for dialysis.

(g) A new theoretical analysis for dialysis of blood flow through a circular tube has been made. A new flow meter designed for pulsatile blood flow measurement has been calibrated for steady flow, and is being calibrated for unsteady flow. Components for the experimental dialysis unit are being designed.

(6579) FLOW SEPARATION IN PROSTHETIC HEART VALVES.

(c) Dr. Zeev Rotem; Dr. V.J. Modi.

(d) M.A. Sc. thesis.

(e) It is of great practical importance to obtain detailed understanding of flow phenomena through prosthetic valves. These valves will sometimes fail after several years of satisfactory operation in vitro, and there is reason to believe that at least some of the failures may be explained by inadequate hydrodynamic design.

The project involves in its preliminary stages the testing of enlarged models of valves at present commonly used, under conditions of both steady and pulsating flows.

(g) Literature survey has been undertaken. Test valves are being manufactured.

(6580) QUALITATIVE STUDY OF SEPARATED FLOW BEHIND BLUEF BODIES.

(c) Dr. Zeev Rotem; Dr. V.J. Modi.

(e) It is intended to study, visually, the wake geometry behind several stationary bluff bodies using a glycerol solution tunnel and Schlieren apparatus.

(g) The glycerol solution tunnel as well as the Schlieren apparatus have been constructed. The calibration of the turnel is in progress. Several circular cylindrical models have been constructed to study the wall effects on the Strouhal number and wake geometry. The model of a prosthetic heart valve has been designed and is under construction.

ECOLE POLYTECHNIC, Dept. of Civil Engrg. Hydrodynamics Lab., 2500 Marie-Guyard Ave., Montreal 26, 
P.९. Caneda.

(14043) STUDY OF TIES RELTABTLITY AND OPERATTON OF BACK-WAITE VALVES ON PLUMBING SYSTEMS AGAINST FLOODING BY PURLIC SEWERS.

(b) City ol Montreal. Permits and Inspections Dept.

(c) Pror. Raymond Boucher, Director. Hydrodynamics Lub. Ecole Polytechnique.

(d) Experimental: applied research.

(e) A ful scale three-story plumbing system has been erected in the Hydrodynamics Laboratory of Ecole Polytechnique. The diameter of the pluvial column and of the drain is 4 inches: experiments were conducted with soil stacks of 3 and 4 inches in diameter. The drain has many sections of pyrex glass to permit observations a critical points. A system oi valves and of cross-comnections on the vents lends to various combinations of tests. The back-water valves have a transparent lucite cover to enalule visual observations. As air entraiment has a great importance on the venting capacity, the rate of aix entrained in the vertical colunus is measured at the inlet by means ot a hot-wire air-meter. Various llooding conditions of the public severs are slmulated by a tank in which the water level cau bo controlled by gate valves. This research is aimed at determining whether back-water valves can offer home dwellers a reliable protection against llooding due to any overload ol combined sewers.

(t) Experiments completed, amalys is of results in progress.

(g) The mechrnism of ail entrainment has been studied and tests have revealed the best position for some of the vents. Recent tests have been conducted with a soil stack of 3 inches and with new positions of the vents.

(h) Two interim reports entitled "Etude expér:imentirle des souprpes de sûreté contre les surcharges d'égout". André Leclerc, Roger. Limonté and Raymond Boucher, Dec. 1963 and Dec. 1067. submitted to sponsor. Final report in preparation.

(5513) HYDRAULIC MODEL STUDIES OF INTAKES FOR THE MANICOUAGAN 5 HYDROELECTRIC PROJECT.

(b) Quebec Hydro-Electric Comission.

(c) Prot. Raymond Eoucher: see (4043) above.

(d) Experimental: tor design.

(e) A comprehensive model built to an undistorted scale of 1:60 reproduced the forebay topography. the intake canal and intake structures. This investigation was conducted to examine the overall pertormance of the structures and to verily the design. A second model of the intake structures of a dilferent design was also built to the same scale. In order to eliminate the formation of vortices near the entrance or the intakes, it was necessary to modify the geometry or the structures.

(i) Completed.

(h) "Etude sur modẻle réduit des prises d'eau de I'usine Manicousgan 5", Laboratoire d'Hydrodynamique, Ecole Polytechnique. décembre 1766.

(5946) HYDRAULTC MODEL STUDY OF LOG-PASSING DEVICES AT DAMS.

(b) Quebec Hydro-Electric Comission.

(c) Prof. Andre Leclerc. Assoc. Director, Hydrodynauics Lab.. Ecole Polytechnique.

(d) Theoretical and experimental for design: applied research for M.S. Theses. (e) The study is conducted to determine the best geometry of intakes, transitions, flumes and chutes to prevent log jamming and ascertain efficient flow especially in vertical and horizontal bends of chutes. The main purpose of this study is to design an intake that will pass the largest flow of logs of 4,8 , 12 and 16 feet with the minimum of water per log. Consideration must be given to the lact that the water level upstream of the dam may vary with time up to 35 feet at some locations. The elevation of the intake structure nust be varied accordingly to control the rate of flow.

(f) Active. Other aspects of the problem are actually under study.

(g) An intake has been designed and tested on a 1:16 scale model. The prototype width of the intake is only 8 leet and it can pass logs 4, 8, 12 and 16 feet long without any danger of jaming. Two other models have been operated to study the influence of the length and of the diameter of the logs on their uniform velocity. A study has also been made of the velocity ol the logs when they pass through circular buckets as usually provided for at the downstream end of chutes. The influence of the radius of ciuvature of these buckets has been determined.

(1) "Le passage des billots aux barrages - Etude sur modèle réduit, partie I: Etudes des tabliers d'entrée: partie IT: Etudes des échelles mécaniques." Joint report prepared by the Quebec Hydro-Electric Commission and Ecole Polytechnique, janvier 1767.

"Etude sur modèle réduit du comportement des billes en canal prismatique." Pierre Dumas. M.S. Thesis, Ecole Polytechnique, septenbre 1767 .

"Ttude à échelle réduite du passage des billots dans des canaux rectangulaires avec courbure dans le plan vertical." Norman McNeil. M.S. Thesis. Ecole Polytechnique, septembre 1967.

(5047) HYDRAULIC MODEI STUDY OF HEAD LOSSES THROUGH VARTOUS RESTRTCTED ORTFTCES FOR THE SURGE TANISS OF MNICOUAGAN 5 HYDROELECTRIC PROJECT.

(b) Quebec Hydro-Electric Conmission.

(c) Prof. Raymond Eoucher: see (4043) above.

(d) Experimental; applied research: M.S. thesis.

(e) A first model has leen built to a scale of $1: 107.3$. Herd loss coefficients of various orifice shapes have been studied for the two llow directions under steady rlow conditions. To obtain a given loss coericient ratio for the two flow directions, a final rorn of the orifice to be installed in the surge tanks has been determined. A second model has been built to a scale of $1: 72$. No appreciable scale efrect has been observed.

(i) Completed.

(h) "Etude sur modèle réduit de différents etranglements pour les chambres d'équilibre de I'usine Manicoumgan 5." Alexandre Godin and Rrymond Roucher, juin 1066. "Etude sur modèle réduit de diftérents étrangelements pour les chambres d'équilitre de l'usine Manicourgan 5." Supplément No. 1 . Iaboritorie d'Hydrodynamique, Ecole Polytechnique, mars 1067.

(5948) THEOREIICAL STUDY ON THE TTDAL MOTION TN THE ST. LAWBENCE ESTUARY.

(b) National Research Council: laboratory project. 
(c) Dr. H.W. Partenscky, Prof. of Hydraulics, Ecole Polytechnique, Hydrodynamics Lab.

(d) Theoretical and field investigation; applied research for M.S. thesis.

(e) Investigation of the tidal characteristics of the St. Lawrence Estuary by means of a. mathematical model. Empirical determination of geometric and roughness effects on tidal amplitudes and velocities. Calculation of tidal discharges. Study of geostrophic effects. Comparison of computed tidal velocities with field measurements.

(f) Completed.

(g) Theoretical results showed good agreement with field measurements for average tidal amplitudes and velocities.

(h) Tidal Motion in the St. Lavrence Estuary," H.W. Partenscky and R. Vincent, Proc. Xth Conf. on Coastal Engrg., Extra.9, Tokyo, 1966. "Tidal Characteristics of the St. Lawrence Estuary Determined by Means of a Linearized Approximation," H.W. Partenscky and R. Vincent, Report prepared for the National Research Council in Ottawa, Sept. 1965, Ecole Polytechnique, Hydraulics Div., Montreal, Canada.

(5949) SAIINITY INTRUSION STUDY FOR THE ST. LAWRENCE ESTUARY.

(b) National Research Council; laboratory project.

(c) Dr. H. Werner Partenscky; see (5948).

(d) Theoretical and field investigation.

(e) One-dimensional study on the salinity intrusion in the St. Iawrence Estuary based on mean tidal velocities obta.ined from theoretical investigations and field measurements. Comparison of computed salinity values with prototype data.

(f) Completed.

(h) "Etude sur la variation cyclique de la salinité moyenne dans l'estaire du SaintLaurent," H.W. Partenscky and L. Louchard, Report prepared for the National Research Council in Ottawa, sept. 1967, Ecole Polytechnique, Hydraulics Div., Montreal, Canada. "The Intrusion of Salinity into the Estuary of the St. Iawrence River," H.W. Partenscky and L. Iouchard, prepared for XIth Conf. on Coastal Engrg., London, Sept. 1968.

(5950) STUDY ON THE OSCILIATION OF FLAP GATES.

(b) National Research Council; laboratory project.

(c) Dr.W. Werner Partenscky; see (5948).

(d) Experimental; fundamental study; M.S. thesis.

(e) The excitation of flap gates to oscillate has been investigated by means of systematic measurements. Tests were carried out with a. fixed flap gate. The excitation of the nappe under different operating conditions has been studied and frequencies and amplitudes of the oscillating nappe have been determined. Critical conditions for the excitation at water bands have been found.

(P) Tests completed; report in final stage.

(g) Characteristics of the mean periodic pressure forces acting on the flap gates in the initial phase of excitation could be determined.

(h) "Oscillations de lanes déversantes non-aérées," H.W. Partenscky and I. Sar Khloeung, Proc. XIIth Congr. Intl. Assoc. Hydraulic Res., Paper S-6, Vol. 4, Sept. 1967, Fort Collins, Colo.
"Supplement a la publication S-6," H.W. Partenscky and I. Sar Khloeung, Proc. XIIth Congr. IAHR, Vol. 5, Sept. 1967, Fort Collins, Colo.

(6822) SYSTEMATIC MODEL STUDY OF HFAD LOSSES THROUGH RESTRICTED ORIFICES FOR SURGE TANKS.

(b) National Research Council; laboratory project.

(c) Prof. A. Godin, Assoc. Prof. Hydrodynamics Lab., Ecole Polytechnique.

(d) Experimental; applied research.

(e) The purpose of this research is to complete the model study commenced under project (5947). A model built to a scale 1:72 has been used to verify effects of diameter and shape on head-loss coefficients of restricted orifices.

(f) Laboratory work completed.

(h) Final report in preparation.

(6823) TWO DIMENSIOINAL JET IN A STREAMING FLOW.

(b) Iaboratory project.

(c) Luc Robillard, Asst. Prof. Hydraulics Div., Ecole Polytechnique.

(d) Theoretical and experimental; basic research.

(e) Experiments and theory concern velocity field and the diffusion of a turbulent jet opposite to a streaming flow.

(g) Apparatus under construction.

UNIVERSITY OF GUELPH, School of Agricultura, Engrg., Hydrology Section, Guelph, Ontario, Canada.

(2740) MAIN TILE DRAIN SIZES FOR COMPOSITE DRAINAGE.

(b) La,boratory project.

(c) Prof. F.R. Hore, Univ. of Guelph.

(d) Field investigation; applied research.

(e) Measurements of tile discharge from several field laterals have been made during the April-October period over a ten year period. During the past five years additional lines placed at the mid-spacing have also been measured to determine the effect of closer spacing.

(f) Discontinued.

(g) No analysis has yet been performed.

(5508) TRANSIENT PRESSURE AND WATER CONTENT DISTRIBUTIONS IN SOIL-WATER FIOW SYSTEMS.

(b) Iaboratory project.

(c) Prof. W.N. Starmers, Univ of Guelph.

(d) Experimental; basic research; Masters' degree.

(e) Soil columns initially sa.turated are permitted to drain by gravity under various outplow impedances. The water table position with time is determined by pressure transducers and the measured flux of water is checked against the steady-state form of the flux equations.

(g) The moving water table condition invalidates the steady-state form of the flux equation for flow of water through a saturated medium.

(6604) HYDROLOGY OF BLUE SPRINGS EASIN, ONTARIO.

(b) Laboratory project.

(c) Prof. H.R. Writeley, Univ. of Guelph.

(d) Field investigation; basic research.

(e) Comprehensive monitoring of several components of the hydrologic system on this $20 \mathrm{sq}$. mile 
basin will provide the basis for development of a mathematical model from which synthetic stream flow data may be generated for basins formed from glacial moraine deposits.

(g) Two years observations indicate large contributions of groundwater flow and considerable variability in source area contribution.

(6605) STREAMFIOW SYNIHESTS BY WATER BALANCE AND ROUTING METHODS.

(b) Laboratory project.

(c) Prof. H.D. Ayers, Univ. of Guelph.

(d) Experimental; development.

(e) Existing hydrometeorological information is examined and by the use of rainfall and temperature inputs on an hourly basis, water balance computations are carried out on a watershed basis. Surface runoff and groundwater flow components are computed and routed through storages to generate an hourly discharge hydrograph.

(g) A model has been developed for the South Branch Thames River, Canada, based on continuous water balance computations through the entire year. Considerable difficulty is experienced in simulating the winter and transitional season events.

(h) "Derivation of a General Flood Wave Hydrograph from a Continuous Watershed Water Balance," H.D. Ayers and J. Balek, UNESCO Symp. on Floods, Leningrad, 1967.

"An Hourly Water Balance Model as a Basis for Continuous Water Resources Assessment on a Watershed," H.D. Ayers and J. Balek, Intl. Assoc. Scientific Hydrology, IUGG, General Assembly of Bern Switzerland, 1967.

(6606) DRAINAGE OF AGRICULTURAL AND URBAN ARFAS.

(b) Laboratory project.

(c) Prof. R.W. Irwin, Univ. of Guelph.

(d) Field investigation; applied research.

(e) Hydrologic elements including precipitation, soil moisture, groundwater and streamflow are being monitored on a small catchment which is now predominatly agricultural. It is anticipated that the land use will change to urban-industrial over the next ten years. The hydrologic influences of these changes will be determined.

THE HYDRO-ELECTRIC POWER COMMISSION OF ONTARIO, Hydraulic Model Iab., Toronto 2 , Ontario, Canada

Inquiries concerning the following projects should be addressed to Mr. J.B. Bryce, Hydraulic Engr., Hydraulic Development Dept., Hydro-electric Power Commission of Ontario, 620 University Ave., Toronto 2, Ontario, Canada.

\section{(4026) NIAGARA RIVER MODEL.}

(b) Ontario Hydro.

(d) Experimental; for design and operation.

(e) An existing 1:250 x 1:50 scale model reproducing five miles of the Niagara River from Buckhorn Island to below the Cataracts is being used to determine the operational characteristics of the Niagara River Control Structure under developed conditions. This model was previously used to investigate the remedial works necessary for the Preservation and Enhancement of Niagara Falls and for the location of the intakes and necessary river improvements of both Ontario Hydro and the Power Authority of the State of New York. To fully realize the terms of the 1950 Niagara Treaty, additional remedial works have been designed. These include a five-gate extension to the existing 13-gate control structure as well as a system containing an upstream accelerating wall, a downstream training wall and overflow weir for the safe passage of ice past the various intakes along the Canadian shore of the river above the Falls. The sequence of construction of these works and the conditions during their construction were determined in the model. Rating of the structure under cofferdammed conditions was obtained. An echo-sounding survey with electronic fixing was made in the field in 1962 and portions of the model re-contoured. Certain river improvements were designed and executed to assist in the passage of ice floes.

(f) Design completed, but model still operational.

(4455) ARROW LAKES DAM - COLUMBIA RIVER.

(b) British Columbia Hydro and Power Authority.

(d) Experimental; for design and operation.

(e) An 1:80 scale model of the Arrow Lakes and dam and environs was built to detemine the detailed location and adequacy of the water passages in a concrete structure and the energy-dissipating works necessary to ensure the protection of an associated earth dam. Numerous tests have been made with a movable bed of fine sand to determine erosion characteristics and navigation velocities upstream and downstream of a lock situated between the concrete structure and the earth dam.

A 1:50 scale model was tested in a flume to determine the hydraulic design of the tunnel ports in the concrete structure and to develop the associated energy-dissipating works. Rating of these ports was obtained as well as the hydraulic loadings on the port gates. A 1:60 scale model of one of the four sluiceways has been tested in the flume to determine the rating of the sluice and the hydraulic loadings on the sluice gate. Piezometers were used to determine under varying conditions of flow, the rollway pressures as well as the pressures at selected locations in the energy dissipating bucket and associated tooth-like projections of the dissipator.

(f) Design completed, but site model still active.

(5516) SIR ADAM BECK-NIAGARA GENERATING STATIONS.

(b) Ontario Hydro.

(d) Experimental; for design.

(e) A 1:80 scale model was built of the two canals leading to the plants including the crossover, in order to determine the performance with the increased flow of Sir Adam Beck No. I canal due to its enlargement.

(f) Work completed and model inactive but operational.

\section{(6167) AUBREY FALLS GENERATING STATION.}

(b) Ontario Hydro.

(d) Experimental; for design.

(e) A 1:80 scale model was constructed of the power site including a sluice discharge dam, a power dam and associated tailrace. Hydraulic studies were made of the unwatering procedure, cofferdams' location, sluice 
discharge capacities, and high water discharge channel wall design, and economical tailrace excavation to reduce tailwater levels at the plant.

(f) Design completed, but model still active.

(6168) NANTICOKE GENERATING STATION.

(b) Ontario Hydro.

(d) Experimental; for design.

(e) A 1:36 model has been constructed of the submerged intake in a lake, leading to a tunnel and forebay for a fossil-fired four-unit 2,000 Mw plant. The water pumped through the intake will be required for service water, condenser cooling water and tempering water for the discharge channel in the summer. The accepted design will be used for a second intake for a four-unit addition at a later date.

(f) Model is active, design proceeding.

IASALTE HYDRAULIC IAABORATORY, 0250 St. Patrick, Lasalle, P.2., Canada

(5428) PEACE RIVER TAIIRACE.

(b) International Power and Engineering Consultants Lta.

(d) Experimental and theoretical, design.

(e) Study on a 1/96 scale model of the head losses and surge waves in the tailrace manifold and tunnel.

(f) Completed.

(h) Report submitted to sponsor.

(5720) QUEBEC ATOMIC POWER REACTOR.

(b) Atomic Energy of Canada Ltd.

(d) Theoretical and experimental, design.

(e) Study on scale models of the hydraulic problem involved by the emergency dumping process of the heavy water moderator.

Dump port shape was first studied on a $1 / 4$ scale two-dimensional model to maximize the discharge capacity of the dump port. Then a l:9.46 model of the reactor vessel was used to study problems pertaining to the dumping process.

(f) Completed.

(h) Report submitted to sponsor.

(6226) TIDAL POWER PRODUCTION - BAY OF FUNDY.

(b) Atlantic Tidal Power Programming Board, Halifax, N.S.

(d) Theoretical (a computer study).

(e) Development of a computer program for determining optimum power and energy generation for various tidal power developments. The following parameters can be introduced in the program: six way operations of the unit (turbining, pumping or sluicing in both directions) with of course real turbine characteristics for all type of operations. Sluiceway capacity - Generator rating - Backwater effect in the basin - Variation of cost of energy with the hour of production (peaking problem) - Limit due to levels or gradient of discharges (wave protlems), etc.

operation of the program for determining power and energy generation of selected tidal power development sites, optimization of operation and equipment.

(g) Several sites are under investigation.

(6227) TIDAL PROPAGATION IN THE FAY OF FUNDY. (b) Atlantic Tidal Power Programing Board, Halifax, N.S.

(d) Theoretical - mathematical model.

(e) Development and adjustment of a mathematical model (using an IBM 360-50) reproducing accurately existing tidal regime in the whole Bay of Funday.

Operation of the model to analyze effect on tidal regime, of building and operating various possible tidal power plants.

(g) Very satisfactory agreement has been obtained between observed and computed values of tidal elevations, amplitudes and phases.

(6228) IAKE ST. PETER.

(b) Department of Transport, Canada.

(d) Experimental.

(e) Study of the effect of dyking the Ship Channel in Lake St. Peter between Montreal and Quebec. Study carried out on a model built to scales of $1 / 75$ vertically and $1 / 600$ horizontally.

(f) Suspended.

(g) Report submitted to sponsor.

(6229) MATANE HARBOUR.

(b) Dept. of Public Works of Canada (Harbours and Rivers Engrg. Branch); Menard, Marsan and Thibeault, Consulting Engineers, Rimouski; Sotramer, Grenoble (France).

(d) Experimental; theoretical.

(e) Flume tests and analytical study aimed at defining breakwater profiles of the new deep water harbour. Tetrapod and rubble-mound armour coverings were retained in the design.

(f) Completed.

(h) Report submitted to sponsor.

(6230) P.E.I. CAUSEWAY.

(b) Dept. of Public Works of Canada; Northumberland Consultants Ltd., Sotramer, Grenoble (France).

(d) Experimental.

(e) Flume tests at scale $1 / 39$ to investigate the stability of the causeway profiles against wave action. Tetrapods were used as armour units.

(f) Completed.

(h) Report submitted to sponsor.

(6231) ABU DHABI L-SHAPED SMALL VESSEL DOCK (TRUCIAL STATES).

(b) Cansult, Consulting Engineers, Montreal.

(d) Theoretical.

(e) The main intent of this short study was to arrive at an appropriate orientation for the protective structures so as to provide effective shelter to small boats. Refraction and diffraction wave diagrams were traced in order to achieve this purpose.

(f) Completed.

(h) Report submitted to sponsor.

(6232) WAVE FORCES ON A DRILIING PIATFORM.

(b) Dufresne Construction Co., Ltd., Montreal.

(d) Theoretical.

(e) Calculation of forces exerted by waves on pipe spuds of Dufresne's Drill Towers M9O and M9I in water depths from 60-100 ft for wave heights from 2-12 ft.

(f) Completed.

(h) Report submitted to sponsor.

(6233) CHAFHEYS IOCK NO. 37 (RIDEAU CANAL).

(b) Dept. of Transport, Canals Div., Ottawa.

(d) Experimental. 
(e) Improvement of the filling system of this small lock (10.6 foot lift) by refining the outlet shape of the two lateral filling culverts which are discharging directly below the upstream mitre gates, one against the other. The desired modifications have been evolved under steady flow conditions, at a scale of $1 / 20$.

(f) Completed.

(h) Report submitted to sponsor.

(6234) NEWBORO IOCK NO. 36 (RIDEAU CANAI).

(b) Dept. of Transport, Canals Div., Ottawa.

(d) Experimental.

(e) Improvement of the filling conditions in this small lock (12 foot lift) which is filled through valves in the upper mitre gates. Very worthwhile results were obtained by using a dual baffle arrangement in front of the filling openings, on the upper mitre gate sill. The tests were conducted for steady flow conditions, at a scale of $1 / 20$.

(f) Completed.

(h) Report submitted to sponsor.

(6235) ST. LAMBERT ST. LAWRENCE SEAWAY IOCK.

(b) The St. Lawrence Seaway Authority, Montreal.

(d) Model investigation.

(e) Hydraulic testing of cross-culverts discharging directly below the upstream mitre gates, so as to produce a positive flow for flushing the ice and providing longitudinal hydraulic assistance to the ships as they leave the lock (scale 1/20).

(f) Completed.

(h) Report submitted to sponsor.

(6236) UPPER AND IOWER BEAUHARNOIS ST. IAWRENCE SEAWAY IOCKS.

(b) The St. Lawrence Seaway Authority, Montreal.

(d) Model investigation.

(e) Hydraulic testing of an ice flushing - hydraulic assist system similarly as for the St. lambert Lock (scale 1/20).

(6237) WELIAND LOCKS - MODEL STUDY OF PORTS.

(b) The St. Lawrence Seaway Authority, Montreal.

(d) Theoretical and experimental.

(e) Basic study on the hydraulic performance of various types of ports in view of repair and rehabilitation of lock chamber walls. The model produces a single port connecting a culvert and a lock chamber (at a scale of $1 / 18$ ) and computations enable the data from the model to be applied to an entire lock.

(6238) EROSION OF FOUNDATIONS AT JUNCTIONS OF CONCRETE CRIB BREAKWATERS.

(b) Dept. of Public Works of Canada (Design Directorate).

(d) Theoretical and experimental.

(e) This wave flume study was aimed at obtaining a qualitative knowledge of the performance of a key inserted in the joint, either at the harbour face, the seaward face or the middle of the cribs, resting on top of the foundation or being driven some distance into it. The rather disappointing results obtained with a single key defence suggested to use a double key defence placed at the seaward and harbour faces of the cribs, driven into the foundation and used in conjunction with a given height of fill material in the joint. Prevention of "piping" was treated both experimentally and theoretically. (h) Report submitted to sponsor.

(6239) ICE TESTS ON THE ST. LAWRENCE RIVER MODEL.

(u) Department of Transport.

(d) Theoretical and experimental; design.

(e) Ice tests are under way on $1 / 150$ vertically and $1 / 600$ horizontally scale model of the St. Lawrence River in the reach of Laprairie Basin - Lanoraie in order to study the ice conditions and the solution to improve them in regard to flood risks during winter.

(6240) MONTREAL CITY WATER INTAKE.

(b) City of Montreal.

(d) Theoretical and experimental; design.

(e) Study of the water intake protection against ice intrusion. A study carried out on a $1 / 12$ scale model showed that the maximum capacity of the existing water intake can be reached before ice floe intrusion appears. As protection against frazil ice intrusion by modification of the intake shape would be costly and incertain, and as this intrusion hazard is of a short duration (during the ice cover formation in the forebay), recommendations were made for melting the ice frazil by injection of hot water in front of the intake.

(f) Completed.

(h) Report submitted to sponsor.

(6241) POLPITIYA DIVERSION DAM (CEYLON).

(b) T. Ingledow and Associates Itd.

(d) Theoretical and experimental; design.

(e) Study on a $1 / 48$ scale model of the spillway and of its protection against resulting scours.

(c) Completed.

(h) Report submitted to sponsor.

(6242) DUNCAN IAKE DEVEIOPMENT.

(b) Montreal Engineering Company Ltd.

(d) Theoretical and experimental; design.

(e) Study on a 1/60 scale model of the spillway stage discharge curves for symmetric and dissymmetrical gate openings.

(f) Completed.

(h) Report submitted to sponsor.

(6243) PEACE RIVER SPILLWAY.

(b) International Power and Engineering Consultants Ltd.

(d) Experimental and theoretical; design.

(e) Study on a $1 / 96$ scale model of the outlet shape of the spillway tunnel. Various shapes and settings of the bucket were tested in order to minimize the scouring and the resulting head losses for the power plant tailrace.

(f) Completed.

(h) Report submitted to sponsor.

(6244) FRAZER RIVER (CAREY'S POINT - ROSEDALE REACH).

(b) Department of Public Works.

(d) Model investigations; design.

(e) Studies on a movable bed model of the solutions to stabilize and maintain a minimum draught in the main channel which tends to divagate.

(f) Completed.

(h) Report submitted to sponsor.

(6250) VANCOUVER HARBOUR.

(b) National Harbour Board.

(e) Investigation on a scale model of the water level and tidal current modifications 
resulting from local dredging in the first and the second narrow and from plugging of the Indian Arm by a causeway .

(6245) IDDIKI POWER INTAKE.

(b) Surveyer, Nenniger and Chenevert, Consulting Engineers.

(d) Theoretical and model investigation.

(e) Investigation of a submerged vertical shaft intake. Determination of optimum diameter and height with regard to velocity distribution and head losses.

(f) Completed.

(h) Report submitted to client.

(6246) OUTARDES 4 - POWER INTAKE.

(b) Hydro-Quebec.

(d) Model investigation.

(e) Development of anti-vortex system upstream of a large power intake in an elbowing canal. Vortices were successfully suppressed by withdrawing the inert fluid against the vertical wall of the structure through a series of small culverts connected to the gate wall.

(f) Completed.

(h) Report submitted to client.

(6247) SCOUR ACTION DOWNSTREAM FROM A DAM.

(b) Dept. of Public Works of Canada.

(d) Model investigation.

(e) Development of adequate protection downstream of a dam where discharge under 20 feet of head flows with a fine sand estuary.

(f) Completed.

(h) Report submitted to client.

(6248) OUTARDES 3 - SPILLWAY.

(b) Hydro-Quebec.

(d) Model investigation.

(e) Investigation of a spillway with large upstream velocities. Determination of maximum allowable discharge coefficient with regard to cavitation danger. Investigation of flow stability in two branching channels with large difference in velocity.

(f) Completed.

(g) Report submitted to client.

(6249) OUTARDES 2 AND MANICOUAGAN 5 SURGE TANKS.

(b) Hydro-quebec.

(d) Theoretical and model investigation.

(e) Investigation of general performance of surge tanks. Determination of optimum throttling orifice and surge shaft dimension. Surge tank stability analysis. Verification of variation of orifice loss with acceleration.

(f) Completed.

(h) Report submitted to client.

(6251) HEAVY WATER CIRCULATTON IN NUCIFAR REACTOR.

(b) Atomic Energy of Canada Ltd.

(d) Theoretical and model investigation.

(e) Investigation of means to withdraw evenly moderator fluid along the periphery of a $250 \mathrm{MW}$ (e) nuclear reactor. Manifold and vortex problems.

(f) Completed.

(h) Report submitted to client.

(6252) BROMPIONVILIE ICE JAM PROBLEM.

(b) Dept. of Natural Resources of quebec.

(d) Model investigation.

(e) Model investigation of large ice floe jamming in Bromptonville, Que. Development of ice jam flushing system.

(f) Completed.

(h) Report submitted to client.

(6253) BACK FIIIIING IN THE RIVIERE DES PRAIRIES.

(b) City of Montreal.

(d) Theoretical and design.

(e) Study to determine the influence of back filling in the vinicity of an island; effect on water levels in free water conditions as well as with ice conditions prevailing in the region.

(f) Completed.

(h) Report submitted to sponsor.

(6254) NORTHERN MONTRFAL WATERSHED SEWER INTERCEPTOR.

(b) City of Montreal.

(d) Theoretical and design.

(e) Study of a 15 miles long interceptor designed to collect water from a territory of 38,000 acres. Design of the overflow appurtenances taking into account the storage capacity of the interceptor in order to limit the outflow to a certain rainfall probability which, by the way, fixed the maximum discharge at the treatment plant located at interceptor end.

(f) Completed.

(h) Report submitted to sponsor.

(6255) LIFAPING WEIR REGULATING DEVICE.

(b) City of Montreal.

(d) Theoretical; experimental and design.

(e) Study, at scale model, of a regulating device which could intercept a fixed amount of flow independently of the total discharge involved. This device, for example, could be integrated in a sewer collector at its crossing over an interceptor when it is wished that a maximu discharge (so many times the dryweather flow) be intercepted. This device has no moving part.

(f) Completed.

(h) Report submitted to sponsor.

(6256) NORTHERN MONTREAL SALABERRY SEWER COLIECTOR.

(b) City of Montreal.

(d) Theoretical and design.

(e) Study of the modifications to be made on an existing sewer. Design of an overflow spillway and connection to the interceptor.

(i) Completed.

(h) Report submitted to sponsor.

UNIVERSTTY OF MANITOBA, Hydraulics Laboratory, Winnipeg, Manitoba, Canada.

Inquiries concerning the following projects should be addressed to: Asst. Prof. V. Galay, Dept. of Civil Engrg., Univ. of Manitoba.

(5999) HELICOIDAL FLOW IN RIVER EENDS.

(b) Laboratory project.

(d) Basic research in the hydraulics laboratory towards a Masters degree.

(e) The study was conducted in a fixed bed channel, $40 \mathrm{ft}$. long, 1.0 feet wide and 0.5 feet deep with four curves of different radii. The helicoidal flow phenomenon was studied for different depths of flow.

(f) Tests completed.

(g) The tests showed that helicoidal flow can take place in a curved laboratory flume. 
Direction of bottom currents and transverse water surface slope were in agreement with the theory.

(h) "A Laboratory study of Flow Around Bends and Bank Stabilization," D. Pashniak, M.Sc. Thesis, Univ. of Manitoba, 1966.

(6000) RIVER BANK STABILIZATION.

(b) Laboratory project.

(d) Basic research in the hydraulics laboratory towards a Masters degree.

(e) Tests have been conducted in a movable-bed channel, $40 \mathrm{ft}$. long, $10 \mathrm{ft}$. wide, and 0.5 ft. deep with four curves of different radii. Basic stabilization measures consisted of spur dikes, jetties and revetments.

(f) Tests completed.

(g) The effect of stabilization measures on the natural erosion patterns was studied and recorded. The findings were in general agreement with established theories.

(h) Report completed.

(6618) HYDROLOGIC MODEL.

(b) Iaboratory project.

(d) Basic research in the hydraulics laboratory.

(e) To assess the accuracy of models in reproducing hydrologic conditions, namely precipitation, infiltration and runoff, that exist in watersheds. Field information from the Wilson Creek Experimental Watershed will be used to correlate model information.

(f) Model under construction.

(6619) ENGINEERING INTERFERENCE WITH RIVERS.

(b) Laboratory project.

(d) Basic restarch in the hydraulics laboratory.

(e) To qualitatively and quantitatively assess the effects of engineering interference, such as dams and diversions, upon the behavior of a river channel.

(f) Model under construction.

MCGILL UNIVERSITY, Dept. of Civil Engineering and Applied Mechanics, Montreal 2, P.Q., Canada.

\section{(4546) CAVITATION AT HIGH-HEAD SLUICE GATES.}

(b) National Research Council, Canada.

(c) Dr. A.J. Reynolds, Dept. of Civil Engrg. and Applied Mechanics, McGill Univ., presently at Mechanical Engrg. Dept., Brunel Univ., Uxbridge, Midalesex, England.

(d) Experimental; applied research, for Doctoral degree.

(e) Study of pressure fluctuations on wall behind an obstruction which produces cavitation.

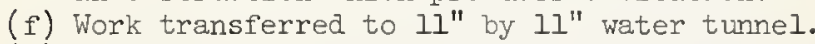

(g) The flow was established in a syphon tunnel of section $3^{\prime \prime}$ by $3^{\prime \prime}$. Mean pressure distributions were measured for a wide range of blockage ratios, with and without air addition. Overall pressure recovery was found to be accurately predicted by momentum balance assuming one-dimensional flow. Length of eddy behind gate (without air addition) agreed with previous measurements of Rouse and Forthmann. The length of the eddy was found to be as much as twice that of the eddy formed in the very similar flow at a sluice gate beyond which there is a nearly level free surface.

(h) "Pressure Fluctuations in Re-Attaching Flow", R. Narayanan, M. Eng. Thesis, 1967.
"Reattachment Downstream of a Control Gate," A.D. Kapur and A.J. Reynolds, Jour. Hydraulic Research, Vol. 5, No. 1, p. 1, 1967.

(4923) DIVISION OF OPEN-CHANNEI FIOW.

(b) National Research Council, Canada.

(c) Dr. A.J. Reynolds; see (4546) above.

(d) Experimenta, ; basic research, for Master's degree.

(e) Detailed examination of flow at junction between straight channel and a branch at $90^{\circ}$.

(f) Completed.

(g) All three sections of the experimental channel are $8^{\prime \prime}$ wide, the walls and bottom being plexiglas and painted steel. The features noted in several earlier studies of such flows have been fitted into a consistent pattern. Simple mathematical models have been found to describe almost every feature of the flow well away from the junction.

(h) "Dividing Flow in Open Channel," S.W. Law and A.J. Reynolds, Jour. Hydraulics Div., Proc. Amer. Soc. Civ. Engrgs., Vol. 92, No. HY2, p. 207, 1966.

(4924) WAVES IN AND NEAR PACK ICE.

(b) Defence Research Board, Canada.

(c) Dr. A.J. Reynolds; see (4546) above.

(d) Theoretical and experimental; basic and applied research, for Master's degree.

(e) Study of fundamental mechanical processes of interaction between surface waves and floating elastic bodies.

(f) Completed.

(g) The dependence of reflection and transmission coefficient on wave-length, wave steepness, and the nature of the edre of the floating sheet has been determined experimentally. Wave celerity and damping in the system composed of sheet and water have also been determined.

(h) "Laboratory Simulation of Waves in an Ice Floe," A.O. Ofuya and A.J. Reynolds, Jour. Geophys. Res., Vol. 72, No. 14, 1967.

(5280) UNIFORM DISTORTION OF TURBULENCE.

(b) Defence Research Board, Canada.

(c) Dr. A.J. Reynolds; see (4546) above.

(d) Experimental; basic research for Doctoral thesis.

(e) Study of uniformly distorted turbulence to investigate the approach to equilibrium structure and the nature of that structure.

(g) Several distorting ducts have been constructed, to allow both planar and three-dimensional irrotational straining of grid turbulence. The case of plane straining has been studied in detail, the turbulence being found to respond in two respects in a manner markedly different from that reported by Townsend. The degree of anisotropy attainak is much greater; the relaxation of anisotropy upon release of the strain is much more abrupt.

(h) "The Distortion of Turbulence by Plane, Rotationless Strain," H.J. Tucker and A.J. Reynolds, Jour. Fluid Mechanics (in press).

(5669) GENERATION OF SURGES AND SOIITARY WAVES.

(b) National Research Council, Canada.

(c) Dr. S.B. Savage, Dept. of Civil Engrg. and Appl. Mech., McGill Univ.

(d) Experimental and theoretical; basic resear for doctoral thesis. 
(e) Study of the generation and development of waves by a single stroke of a piston at uniform velocity.

(g) Time histories of channel bed pressures and free surface elevations are being measured. The higher-order equations accounting for the effects of nonlinearity and dispersion are being integrated by the method of characteristics.

(6610) CAVITATING DELTA WING.

(b) Iaboratory project.

(c) Dr. S.B. Savage; see (5669) above.

(d) Experimental and theoretical; basic research.

(e) Study of the flow about a cavitating deltawing.

(g) Models are being constructed for 3-component measurements in the $28 \mathrm{~cm}$. by $28 \mathrm{~cm}$. water tunnel.

\section{MCMASTER UNIVERSITY, Chemical Engrg. Dept., Fluid} Mechanics Group, Hamilton, Ontario.

(6056) VISCOUS FLOW THROUGH PARTICLE ASSEMBLAGES.

(b) National Research Council of Canada.

(c) Dr. A.E. Hemielec, Assoc. Prof. of Chemical Engrg., Dept. of Chemical Engrg., McMaster Univ.

(d) Theoretical and experimental; basic research for doctoral thesis.

(e) Project is aimed at developing computer solutions of the Navier-Stokes equations for transient, incompressible flow through particle assemblages (fluidized and packed beds and bubble swarms) at intermediate Reynolds numbers. New techniques are being developed to account for particle interaction.

Experimental work involves the measurement of the surface pressure distribution on a test sphere in a packed bed.

(g) Numerical solutions have been obtained for incompressible, Newtonian flow through sphere assemblages for the Reynolds number range, $0-1000$, and the porosity range, 0.4-1.0. The numerical results show the effects of variation in Reynolds number and porosity on: (1) surface vorticity and pressure distributions; (2) form, function, and total drag coefficients; (3) standing vortex ring dimensions. The agreement of predicted and measured drag coefficients for packed and fluidized beds is satisfactory.

(h) "Viscous Flow Through Particle Assemblages at Intermediate Reynolds Numbers, Part I Steady-state Solutions for Flow through Assemblages of Spheres," B.P. LeClair and A.E. Hamielec, - unpublished paper. Paper is available through I and EC Research Results. "Numerical Studies of Viscous Flow Around Circular Cylinders," A.E. Hamielec and J.D. Raal - unpublished paper. May be obtained by writing Dr. A.E. Hamielec, see (c).

(6057) VISCOUS FIOW AROUND BLUNT BODIES IN THE TRANSITION FLOW REGIME.

(b) Laboratory project.

(c) Dr. A.E. Hamielec; see (6056) above.

(d) Theoretical and experimental; basic research for doctoral thesis.

(e) Computer solutions for transient, 3-dimensional flows around blunt object at high Reynolds numbers are being developed. Dis- turbances are introduced and the effects on local flow behaviour are predicted theoretically. Disturbance parameters such as position, wave form, frequency, amplitude, and damping factor are being considered. This investigation may lead to techniques for drag reduction. The experimental program is now being planned.

NATIONAL RESEARCH COUNCI.L, Div. of Mechanical Engrg., Hydraulics Section, Montreal Rd., Ottawa 7, Canada

\section{(4525) FORMATION OF ICE IN RIVERS.}

(b) Laboratory project.

(c) Dr. S. Ince, Head, Hydraulics Section, Natl. Research Council.

(d) Experimental; field investigation.

(e) Water temperatures are being recorded in the St. Lawrence River between Kingston, Ontario, and Three Rivers, Quebec, to obtain information on heat losses.

(g) Preliminary calculations show satisfactory agreement between measured and computed heat losses. For closer correlation more precise measurement of meteorological conditions particularly radiation - will be necessary.

(h) "Observations on the Winter Temperature Structure of the St. Lawrence River," S. Ince and G.W.T. Ashe, Proc. Eastern Snow Conference, Utica, New York, Feb. 1964.

(5766) CHURCHII工 HARBOUR, MANITOBA.

(b) National Harbours Board, Canada.

(c) Mr. T.M. Dick, Hydraulics Section, Natl. Research Council.

(d) Field investigation.

(e) Surveys are conducted to determine ice formation and movement in the estuary to detemine means of extending the navigation season.

(f) Completed.

(g) River ice and ebbing currents in the estuary combine to create a concentrated band of ice that in passing along the dock face, effectively prevents ships from using the Port. It was concluded that simple obstruction and diversion of the ice by training walls or jetties would probably lead to the best solution.

(h) "Limits to Navigation by Ice in the Port of Churchill," T.M. Dick, Jour. Waterways and Harbors Div., Vol. 93, No. WW4, pp. 11-26, Nov. 1967.

(5767) WAVE CLIMATE STUDY, LAKE SUPERIOR.

(b) Dept. of Transport, Canada.

(c) Mr. J. Ploeg, Hydraulics Section, Natl. Research Council.

(d) Field investigation.

(e) Accelerometer type wave recorders are installed at four locations in Lake Superior to measure waves and correlate with the wind field.

(6601) WAVE CLIMATE STUDY, GULF OF ST. IAWRENCE.

(b) Department of Transport, Canada.

(c) Mr. J. Ploeg; see (5767) above.

(d) Field investigation; applied research.

(e) Accelerometer type wave recorders were installed at eight locations in the Gulf of St. Lawrence to measure waves and correlate with the wind tield. 
(6602) TIDAL HYDRAULIC MODEL OF THE ST. LAWRENCE RIVER AND ESTUARY.

(b) Department of Transport, Canada.

(c) Mr. J. Ploeg; see (5767) above.

(d) Experimental, applied research.

(e) A hydraulic model of the tidal reach of the river has been constructed to study navigation improvements.

(6603) MATHEMATICAL MODEL OF THE ST. IAWRENCE RIVER AND ESTUARY.

(b) Laboratory project.

(c) Dr. W. Kamphuis, Hydraulics Section, National Research Council.

(d) Theoretical.

QUEEN'S UNIVERSITY AT KINGSTON, Hydraulic Labs., Dept. of Civil Engrg., Kingston, Ontario, Canada

(4057) THE TRANSPORT OF MATERIAL IN PIPE-IINES.

(b) The National Research Council of Canada.

(c) Dr. A. Brebner, Ellis Hall, Queen's Univ. at Kingston.

(d) Iaboratory investigation.

(e) Pipes of differing shapes being used to study the parameters affecting the critical velocity of deposition.

(h) "Derivation of Regime Equations etc." J.I.C.E. Vol. 36, pp. 47-62, Jan. 1967, and Vol. 37, pp. 775-782, Aug. 1967.

(5673) THE ATTENUATION OF WATER WAVES BY A FLOATING PULPWOOD BREAKWATER.

(b) The Pulp and Paper Research Institute of Canada.

(c) Prof. R.J. Kennedy, Queen's Univ. at Kingston.

(d) Experimental and field project.

(e) The attenuation of waves of various size and steepness by log masses of different characteristics was measured in the laboratory and in the field.

(f) Completed.

(g) Substantial dissipation of wave energy was achieved, a paper is being prepared.

(5674) STUDIES OF FLOW-THROUGH VORTICES.

(b) The National Research Council of Canada.

(c) Dr. J. Boadway, Queen's Univ. at Kingston.

(d) Experimental and theoretical project for master's and doctoral theses.

(e) Velocities, pressures and turbulence characteristics in a series of closed flow-through vortex chambers are being measured by photographic and electronic techniques.

(g) A departure from free vortex form has been observed most of which has been explained by analysis using Reynolds equation in cylindrical co-ordinates.

(h) Both Masters and Doctoral theses have been accepted. One paper has been written and accepted for publication in "The Review of Scientific Instruments". Two other papers are in preparation.

(6494) FLOATING AND SUBMERGED BREAKWATERS.

(b) National Research Council of Canada; and Federal Dept. of Public Works.

(c) Dr. A. Brebner; see (4057) above.

(d) Experimental and laboratory.

(e) Attenuation of waves by sundry floating structures and by submerged structures of various configurations. (g) Preliminary reports given to sponsoring authorities.

(6495) MAGNITUDE AND PROBABILITY OF PEAK FLOWS ON SMALI DRAINAGE BASINS IN SOUTHERN ONTARIO.

(b) The National Research Council of Canada.

(c) Prof. R.J. Kennedy; see (5673) above.

(d) Experimental and theoretical project; applied research for master's and doctoral theses.

(e) Development of a procedure for evaluating the peak flow which corresponds to a particular return period for small ungauged drainage basins.

(h) "The Relationship between Iag Time and the Physical Characteristics of Drainage Basins in Southern Ontario," R.J. Kennedy and W.E. Watt, I.H.D. Symp. on Floods and Their Computation, Leningrad, 1967.

(6496) DIFFUSION OF CONTAMINANTS IN FREE TURBULENT SHEAR FLOWS.

(b) Laboratory project.

(c) Dr. W.E. Watt, Queen's Univ, at Kingston.

(d) Experimental and theoretical project; basic research for master's and doctoral theses.

(e) A study of the behaviour of simple contaminated shear flows. Initial studies were concerned with dynamically passive contaminants in a velocity mixing zone.

(h) "The Velocity-Temperature Mixing Zone," W.E. Watt, Univ. of Toronto, Mech. Engrg. Dept. IP 6709, 1967.

(6497) THE CONTROL OF VELOCITY DISTRIBUTION IN A VORTEX.

(b) The National Research Council of Canada.

(c) Dr. J.D. Boadway; see (5674) above.

(d) Experimental and theoretical project; applied research for a master's thesis.

(e) An attempt to develop a hydraulic design to produce a vortex with the best sedimentation characteristics.

(6498) WATER CTARIFICATION.

(b) Dept. of University Affairs of the Province of Ontario.

(c) Dr. J.D. Boadway; see (5674) above.

(d) Experimental and theoretical project; applied research for a master's thesis.

(e) A study of sedimentation with centrifugal acceleration.

UNIVERSITY OF SASKATCHEWAN, Hydraulics Lab., Dept. of Civil Engrg., Saskatoon, Saskatchewan, Canada.

(6392) SCOUR IN STONE BEDS.

(b) Laboratory project.

(c) D.K. Strang, Hydraulic Engrg., G.E. Crippen and Associates Limited, North Vancouver, British Columbia, Canada.

(d) Theoretical and experimental; M.Sc. thesis.

(e) The study was concerned with the detemination of the ultimate stable bed shape for the case of water discharge over a vertical weir into a stone bed, when tested under repeated hydrograph conditions. Dimensionless plots were prepared to facilitate application of the results to field situations.

(f) Completed.

(h) "Scour in Stone Beds," C.D. Smith and D.K. Strang, Proc. 12th Congr., Intl. Assoc. 
Hydraulic Research, Vol. 3, pp. 65-73, Sept. 1967, Fort Collins, Colorado.

(6482) SIDE CHANNEL SPIILWAYS.

(b) Laboratory project, sponsored by National Research Council of Canada.

(c) Lorand K. Szojka, Hydraulic Engr., P.F.R.A., Motherwell Bldg., Regina, Saskatchewan, Canada.

(d) Theoretical and experimental; M.Sc. thesis.

(e) The project involves the determination of the water surface profile in the channel, and the discharge capacity of a side channel weir, when the weir is placed at various angles with respect to the axis of the channel.

(6483) FLOW MEASUREMENT USING TRIANGULAR WEIRS AND FLUMES.

(b) Laboratory project, sponsored by National Research Council of Canada.

(d) Theoretical and experimental; M.Sc. thesis.

(e) (i) To determine the effect of the proximity of the floor and sidewalls on a V-notch weir coefficient. (ii) To investigate the efficacy of using a V-notch flume for water measurement.

UNIVERSITY OF TORONTO, Department of Mechanical Engineering, Toronto 5, Canada.

(1298) DISCHARGE CHARACTERISTICS OF WEIR-TYPE SPIILWAYS.

(b) Laboratory project.

(c) Prof. L.E. Jones, Univ. of Toronto.

(d) Experimental; applied research for master's theses.

(e) A long-term research carried out with a view to systematizing discharge characteristics for spillways having various pier spacings and proportions.

(f) Significant correlations obtained via special plotting techniques.

(h) Report in preparation.

(2252) HYDRAULIC FLOW IN OPEN CHANNELS OF VARIABLE SLOPE.

(b) Laboratory project.

(c) Prof. L.E. Jones, Univ. of Toronto.

(d) Experimental; fundamental and applied research.

(e) A doubly-tilting, variable-section flume facility of $160 \mathrm{ft}$. length is under construction. Provision is being made for a wide range of experimental conditions.

(3003) ROUGHNESS PHENOMENA IN OPEN CHANNEL FLOW.

(b) Laboratory project.

(c) Prof. L.E. Jones, Univ. of Toronto.

(d) Experimental and analytical; basic research for doctoral thesis.

(e) Critical analysis of the hydraulic radius concept and the effect of cross-section geometry on the resistance to flow in conduits. Detailed evaluation of mean flow parameters such as friction coefficients, static pressures, velocities, and wall shear stresses. The channel under study was 70 feet long and had a variable rectangular cross-section of $3 \times 1,3,9$ inches, respectively, and used air as the fluid medium.

(f) First project completed; others in progress.
(4889) UNSTEADY LAMINAR FLOW IN SHORT, CLOSED CONDUTTS.

(b) Iaboratory project.

(c) Prof. H.J. Leutheusser, Univ. of Toronto.

(d) Experimental and analytical; basic research for master's thesis.

(e) Various cases of unsteady (oscillating) laminar flow as encountered in typical viscous damping devices have been investigated.

(f) Completed.

(g) A friction coefficient has been developed which accounts for the additional pressure drop due to oscillating flow.

(h) "Oscillating Flow in Closed Conduits," G. Parato, M.A.Sc. thesis, Univ. of Toronto, 1966.

(4890) CHARACTERISTICS OF FLOW OF FLUID-SEDIMENT MIXTURES.

(b) Laboratory project.

(c) Prof. H.J. Leutheusser, Univ. of Toronto.

(d) Experimental; basic research.

(e) Evaluation of mean flow parameters such as friction coefficients, static pressure, velocities and wall shear stresses in a two-dimensional closed conduit of 1:10 aspect ratio, for pure air flow.

(f) Suspended.

(g) Laufer's results have not been verified in several details.

(h) "Characteristics of the Turbulent Mean Flow in a Two-Dimensional Channel," R.S. Chow, M.A.Sc. thesis, Univ. of Toronto, 1366.

(5256) OPTIMUM HEIGHTS OF CHIMNEYS.

(b) The Municipality of Metropolitan Toronto, Dept. of Public Works.

(c) Prof. G.R. Lord, Univ. of Toronto.

(d) Experimental; applied research for design information.

(e) Determination, in wind tunnel, of thickness distribution of zone of separate flow on roofs of various building shapes.

(f) Completed.

(g) Chimneys on building roofs should be at least equal in height to the thickness of the separation zone.

(h) "Minimum Stack Heights for Apartment Buildings, "G.R. Lord and H.J. Leutheusser, Univ. of Toronto, Mech. Engrg. Tech. Publication Series TP 6602, June 1966.

(5624) OPEN-CHANNEL PROFILE ANALYSIS.

(b) Laboratory project.

(c) Prof. I.E. Jones, Univ. of Toronto.

(d) Analytical; basic research.

(e) Fundamental computational projects are being reviewed and investigated by computer analysis

(g) Improved extrapolation procedures indicate that significant accuracy of integration can be achieved with confidence and economy.

(5626) FLOW IN A WEDGE WITH POROUS WALLS.

(b) Laboratory project.

(c) Prof. W.D. Baines, Univ. of Toronto.

(d) Experimental and theoretical; basic research for doctoral thesis.

(e) The flow of a fluid with a narrow wedge (less than 10 degrees included angle) is being investigated for walls made of screen. Pressure gradients and velocity distributions are being studied.

(g) Peculiar characteristics have been found for flow approaching a screen at a small angle. Pressure drop is much greater than that 
predicted by simple theory.

\section{(5627) BUILDING AERODYNAMICS.}

(b) Laboratory project.

(c) Prof. H.J. Leutheusser, Univ. of Toronto.

(d) Experimental; for design purposes.

(e) Determination of aerodynamic loading on highrise buildings provided with exterior ribs and other architectural features.

(h) "Aerodynamies of a Star-Shaped Building," H.J. Leutheusser and B.D. Pratte, Univ. of Toronto, Mech. Engrg. Tech. Publication Series TP 6603, July 1966.

"Similitude Problems in Building Aerodynamics," H.J. Leutheusser and W.D. Baines, Proc. ASCE, Jour. Hydraulics Div., Vol. 93, No. HY3, May 1967, pp. 35-49.

(5628) WATER-FLOW-INDUCED AIR CURRENTS.

(b) Laboratory project.

(c) Prof. H.J. Leutheusser, Univ. of Toronto.

(d) Experimental; basic research for master's thesis.

(e) Using a covered 50-foot tilting flume, air motion as induced by uniform open-channel flow has been studied.

(f) Suspended.

(g) Facility developed provides very simple means for studying turbulent plane-Couette flow.

(h) "A Study of Turbulent Plane-Couette Flow," V.H. Chu, M.A.Sc. thesis, Univ. of Toronto, 1966.

(5629) DYMAMICS OF A TURBULENI LINE-VORTEX PAIR.

(b) Laboratory project.

(c) Prof. J.F. Keffer, Univ. of Toronto.

(d) Experimental and theoretical; basic research for doctoral thesis.

(e) Counter-rotating turbulent line vortices are convected by a free stream. The characteristics of the turbulence, entrainment, velocity profiles and vortex interaction are being determined by conventional hot-wire anemometer equipment and visual techniques.

(f) Completed; thesis and publications in preparation.

(5630) MOTION OF BODIES IN STRATIFIED FLUIDS.

(b) Laboratory project.

(c) Prof. J.F. Keffer, Univ. of Toronto.

(d) Experimental and theoretical; basic research for doctoral thesis.

(e) The initial wake formation and asymptotic turbulent wake are being examined for various shaped bodies. A heated wind tunnel is being used to obtain stratification.

(f) Completed; thesis and publications in preparation.

(h) "Research in Stratified Flows," J.F. Keffer, Univ. of Toronto, Mech. Engrg., Tech. Publication Series, TP 6605, sept. 1966.

(5631) INVESTIGATION OF PERIODICITY IN TURBULENT WAKES.

(b) Laboratory project.

(c) Prof. J.F. Keffer, Univ. of Toronto.

(d) Experimental and theoretical; basic research.

(e) With hot-wire anemometer and flow visualization techniques, characteristics of a turbulent wake are examined. The wake has been strained laterally to amplify turbulent motions.

(g) Results indicate that the large eddy motions have a definite periodicity, not directly related to von Karman frequency. Indications are that large motions are initiated by interaction of von Karman street with lateral periodic motions. A more detailed investigation of conditions during the breakdown into turbulence is under way.

(h) "The Uniform Distortion of a Turbulent Wake," J.F. Keffer, Jour. Fluid Mechanics, Vol. 22, Pt. 1, 1965, pp. 135-139.

"A Note on the Expansion of. Turbulent Wakes," J.F. Keffer, Jour. Fluid Mechanics, Vol. 28, Pt. 1, 1967, pp. 183-193.

(6001) TRANSITIONS FROM PRESSURE TO FREE-SURFACE FLOW.

(b) Laboratory project.

(c) Prof. H.J. Leutheusser, Univ. of Toronto.

(d) Experimental and theoretical; basic research for doctoral thesis.

(e) Fluid separation from ceiling of closed twodimensional conduit has been studied. Motion was laminar and steady.

(f) Completed.

(g) Characteristics of laminar sheet flow in the entrance zone to free-surface flow have been evaluated both theoretically and experimentally.

(h) "The Transition of Laminar Flow from ClosedConduit to Free-Surface Conditions in a TwoDimensional Channel," R.N. Ingle, Ph.D. thesis, Univ. of Toronto, 1967.

(6002) EFFECTS OF SKIN FRICTION ON PERFORMANCE OF HYDRAULIC JUMP.

(b) Laboratory project.

(c) Prof. H.J. Leutheusser, Univ. of Toronto:

(d) Experimental; basic research for master's thesis.

(e) Effects of floor roughness on stationary hydraulic jumps in rectangular channels is being studied.

(f) Continued.

(g) Most significant effect of boundary roughness on jump performance has been traced to changes in the upstream velocity profile.

(h) "The Influence of Bed Roughness on the Hydraulic Jump in a Horizontal Rectangular Channel," E.J. Schiller, M.A.Sc. thesis, Univ. of Toronto, 1966.

(6003) SMOKE DIF'FUSION FROM STACKS.

(b) Contract research.

(c) Prof. H.J. Leutheusser, Univ. of Toronto.

(d) Experimental; applied research for design purposes.

(e) Wind-tunnel study of stack discharge as affected by surrounding buildings.

(g) Studies have proved effective means for determining chimney heights to prevent aerodynamic downwash of stack effluents.

(6004) JET SHEETS WITH IATERAL PRESSURE.

(b) Laboratory project.

(c) Prof. W.D. Baines, Univ. of Toronto.

(d) Experimental; basic research for master's thesis.

(e) Measurements are made of the shape, velocity and pressure distribution of a two-dimensional jet sheet across which a pressure difference exists. Comparisons are made with elementary theory.

(f) Completed.

(g) For low pressures the jet shape obeys the one-dimensional momentum equation and the velocity distribution is not affected. The 
shape is strongly affected by downstream obstacles.

(h) "The Influence of Static-Pressure Differences on the Two-Dimensional Turbulent Jet," F.T. DeAbreu, M.A.Se. thesis, Univ. of Toronto, 1966.

(6005) STRATIFIED FLOW THROUGH CURVED SCREENS.

(b) Laboratory project.

(c) Prof. W.D. Baines, Univ. of Toronto.

(d) Experimental and theoretical; basic research for doctoral thesis.

(e) Uniform flow with a small lateral temperature gradient passes through a screen of arbitrary shape. Downstream velocity and temperature profiles are being studied.

(f) Completed.

(g) Theory has been developed which indicates shape required to produce linear velocity distribution. Preliminary tests confirm theory.

(h) "The Flow of Stratified and Homogeneous Fluids Through Curved Sereens," Y.L. Lau, Univ. of Toronto, Mech. Engrg. Tech. Publication Series, TP 6604, Sept. 1966.

(6006) REYNOLDS STRESS IN TURBUIENT STRATIFIED FIOW.

(b) Laboratory project.

(c) Prof. W.D. Baines, Univ. of Toronto.

(d) Experimental; applied research for doctoral thesis.

(e) Measurements are being made of spread of temperature and velocity discontinuities in otherwise uniform flow of a temperaturestratified fluid, as well as of Reynolds stress ard turbulent heat transfer.

(f) Completed.

(g) "The Velocity-Temperature Mixing Layer," W.E. Watt, Univ. of Toronto, Mech. Engrg. Tech. Publication Series, IP 6705, Sept. 1967.

(6007) FLOW-INDUCED VIBRATION OF CANTILEVER BEAMS.

(b) Laboratory project.

(c) Prof. W.D. Baines, Univ, of Toronto.

(d) Experimental and theoretical; applied research for doctoral thesis.

(e) Cantilevered vertical eylinders are mounted on elastic bases in an air stream. Reaction to the von Karman vortex trail produces a vibration which interacts with the trail. Fluid force produced on such an elastic body is being studied.

(6008) PUMP AND PIPE SYSTEM TRANSIENTS.

(b) Laboratory project.

(c) Prof. L.E. Jones, Univ. of Toronto.

(d) Analytical; applied research.

(e) Computer solutions of equations for various combinations of pump and pipe characteristies.

(g) Results to date indicate a significant effect caused by shape of characteristic curves.

(h) "Effect on Flow Establishment of Shape of Pump and System Characteristics," I.E. Jones and K.B. Elgohary, A.S.M.E.-E.I.C. Fluids Engrg. Conf., Denver, April 1966.

(6009) MATHEMATICAI STUDIES IN HYDROLOGY.

(b) Laboratory project.

(c) Prof. L.E. Jones, Univ. of Toronto.

(d) Analytical; applied research.

(e) Various methods of analysis are under study: deterministic and probabilistic methods, stochastic processes, synthetic flow series, regulation procedures over short and long time periods, ete. (h) "Certainty of Stream-Flow Control within a Limited Period of Time," Vit Klemes, Proc. Intl. Assoc. Scientific Hydrology, Garda Symp., Vol. 2, No. 71, Oct. 1966, pp. 711-719. "Reliability of Water Supply Performed by Means of a Storage Reservoir within a Iimited Period of Time," Vit Klemes, Jour. of Hydrology, Vol. 5, No. 1, March 1967, pp. 7092.

"Reliability Estimates for a Storage Reservoir with Seasonal Input," Vit Klemes, Intl. Hydrology Symp., Fort Collins, Colo., Sept. 1967.

"The Effect Upon Reservoir Performance Due to the Form of Distribution Model Fitted to the Mean Annual Flows," Vit Klemes and L.E. Jones, Univ. of Toronto, Mech. Engrg. Tech. Publication Series, TP 6703, sept. 1967. "Basic Methods for Streamflow Regulation," Vit Klemes, Univ. of Toronto, Mech. Engrg. T'ech. Publication Series, TP 6704, Sept. 1967. "The Relationship between Effective Precipitation and Runoff as Expressed in the Distribution Parameters," E.O. Frind, M.A.Sc. thesis, Univ. of Toronto, 1967.

(6010) LEAST-SQUARES FITIING OF RIVER RATING-CURVES.

(b) Laboratory project.

(c) Prof. L.E. Jones, Univ. of Toronto.

(d) Analytical; applied research.

(e) Proper attention to statistical weighting requires involved computing techniques. Suitable simple alternatives have been developed which have a wide applicability.

(h) Report in progress.

(6802) FLOW-INDUCED VIBRATION OF CANTILEVER BEAMS.

(b) Laboratory project.

(c) Prof. W.D. Baines, Univ of Toronto.

(d) Experimental and theoretical; basic research for doctoral thesis.

(e) The interaction between a uniform flow field and a spring-mounted cantilevered cylinder is being studied.

(f) Nearing completion.

(g) Detailed measurements of the cylinder amplitude, frequency, etc., have been made for a range of cylinder aspect ratios, tip shapes, spring stiffness and damping ratios. Results show a characteristic jump in the amplitude response and a "lock in" of the cylinder and wake frequencies.

(h) Report in preparation.

(6803) CONVECTION IN A UNIFORM WATER LAYER BENEATH AN ICE SHEET.

(b) Laboratory project.

(c) Prof. W.D. Baines, Ur v. of Torontr

(d) Experimental and theoretical; bas. research for doctoral thesis.

(e) It is attempted to conduct laboratory experiments on the conduction of heat between and ice layer and a parallel solid boundary through an intermediate layer of water and to produce an analysis of the situation.

(f) Nearing completion.

(g) Measurements of the temperature profiles throughout the water layer have been made and are compared with the results of a twodimensional numerical analysis. The results are in good agreement.

(h) Report in preparation.

(6804) STUDIES OF SEPARATED FLOW WITH RESPECT TO BLUFF BODIES. 
(b) Laboratory project.

(c) Prof. W.D. Baines, Univ. of Toronto.

(d) Analytical; basic research for master's thesis.

(e) The free convection across a two-dimensional square cavity is investigated by numerical solution of the Navier-Stoles equations. A preliminary study involved a steady vortex generated in a slot by a surface moving over the open top of the slot.

(f) "Numerical Solutions for an Isolated Vortex in a SIot and Free Convection across a Square Cavity," J.T. Han, M.A.Sc. thesis, Univ. of Toronto, 1967.

(6805) FREE CONVECTION IN A VERTICAL CHANNEL.

(b) Laboratory project.

(c) Prof. I.G. Currie, Univ. of Toronto.

(d) Experimental; basic research for master's thesis.

(e) Temperature and velocity measurements are being made in a vertical two-dimensional channel having heated walls. It is intended to establish profiles in the accelerating region of the flow.

(6806) ANALYSIS OF UNIFORM-SECTION HEADERS.

(b) Iaboratory porject.

(c) Prof. I.G. Currie, Univ. of Toronto.

(d) Theoretical; applied research.

(e) Analytical studies of the pressure-versusflow rate characteristics of headers having uniform cross-sections are made with a view to predicting their performance.

(f) Almost completed.

(g) Closed-form analytic solutions have been obtained for predicting the head versus flow rate of uniform headers in which the flow may be in either direction.

(h) Report in progress.

(6807) CONVECTION PATTERNS IN LIQUIDS.

(b) Laboratory project.

(c) Prof. I.G. Currie, Univ. of Toronto.

(d) Experimental; basic research for master's thesis.

(e) Measurements of temperature and velocity profiles across convecting liquid layers are being made with a view to obtaining a better understanding of the structure of the flow.

(h) "The Stability of a Horizontal Fluid Layer whose Lower Surface Temperature is Time Dependent, "I.G. Currie, Proc. First Can. Congress of Appl. Mechs., Vol. 2, May 1967, p. 56.

"The Effect of Heating Rate on the Stability of Stationary Fluids," I.G. Currie, Jour. Fluid Mech., Vol. 29, Pt. 2, 1967, pp. 337347.

(6808) WAKE OSCILLATIONS ON A VIBRATING CYLINDER.

(b) Laboratory project.

(c) Prof. I.G. Currie, Univ. of Toronto.

(d) Experimental; basic research for master's thesis.

(e) Tests are being performed with a cantilivered circular cylinder which is vibrating in a uniform flow field. Measurements of the separation point locations are being made and compared with the cylinder motion.

(6809) FIOW AROUND A SUBMERGED POROUS PLATE.

(b) Laboratory project.

(c) Prof. D.F. James, Univ. of Toronto. (d) Experimental and theoretical; basic research for doctoral thesis.

(e) The flow around and through a screen partially occupying a two-dimensional channel is being studied.

(6810) QUANTITATIVE EVALUATION OF HYDROGEN-BUBBLE FIOW VISUALTZATION TECHNIQUE.

(b) Laboratory project.

(c) Prof. L.E. Jones, Univ. of Toronto.

(d) Experimental; applied research.

(e) Quantitative assessment of method for use in determining velocity distribution data.

(g) Discussion of "An Evaluation of the Hydrogen Bubble Technique for the Quantitative Determination of Fluid Velocities within Clear Tubes," W. Davis and R.W. Fox (I.E. Jones and R.N. Ingle), Trans. ASME, Jour. Basic Engrg., Dec. 1967, p. 778. Other report in preparation.

(6811) ENERGY IOSSES IN TWO-PHASE FLOW.

(b) Laboratory project.

(c) Prof. L.E. Jones, Univ. of Toronto.

(d) Experimental and theoretical for doctoral thesis.

(e) Concerns flow of flashing fluid in horizontal circular pipe, to gain insight into development of two-phase single-component flow by studying pressure gradients, local void fractions and phase-velocities. Hot-film anemometer and high-speed photography to be used.

(f) Experimental equipment under design.

(6812) WALL JET FIOWS.

(b) Iaboratory project.

(c) Prof. J.F. Keffer, Univ. of Toronto.

(d) Experimental and theoretical; basic research for master's thesis.

(e) Mean flow and wall shear characteristics for a jet discharging parallel to a wall are being investigated. In particular the effect of a step-wise suction is being considered.

(6813) GRID-PRODUCED TURBULENCE.

(b) Laboratory project.

(c) Prof. J.F. Keffer, Univ, of Toronto.

(d) Experimental and theoretical; basic research for doctoral thesis.

(e) The early decay period for the turbulent flow generated by a grid of parallel cylinder: is being investigated. The mechanism by which the flow changes from non-homogeneous to a homogeneous structure is under study.

(6814) POLUUTION FROM CHIMNEY STACKS.

(b) Contract research.

(c) Prof. J.F. Keffer, Univ. of Toronto.

(d) Experimental; applied research for design purposes.

(e) Wind tunnel studies of stack discharge as affected by complex array of surrounding buildings. Model measures 18 feet in d:ameter, with 1 inch $=20$ feet.

(f) Completed.

(6815) DISCHARGE OF JETS INTO CROSS-WINDS.

(b) Laboratory project.

(c) Prof. J.F. Keffer, Univ. of Toronto.

(d) Experimental and theoretical; basic research for master's thesis.

(e) A mathematical model has been devised to predict the trajectory of a jet discharging 
at various angles into a uniform stream.

(f) Completed; thesis and publications in preparation.

(h) "Profiles of the Round Turbulent Jet in a Cross Flow," B.D. Pratte and W.D. Baines, Proc. ASCE, Jour. Hydraulies Div., Vol. 93, No. HY6, Nov. 1967, pp. 53-64.

"An Entrainment Theory for Deflected Jets," J.I. Platten, M.A.Sc. thesis, Univ. of Toronto, 1967.

(6816) WIND TUNNEL MODELTNG.

(b) Iaboratory project.

(c) Prof. H.J. Leutheusser, Univ. of Toronto.

(d) Experimental; basic research.

(e) Development of boundary-layer-type velocity fields of significant size in wind tunnel to facilitate aerodynamic investigations of buildings and stack-gas discharge under realistic conditions.

(g) Tests of smoke dispersion in non-uniform fields indicated effect of degree of boundarylayer immersion on plume behaviour.

(6817) TURBUIENCE MEASUREMENTS IN WATTER.

(b) Laboratory project.

(c) Prof. H.J. Leutheusser, Univ. of Toronto.

(d) Experimental; basic research.

(e) Application of hot-film anemometer to evaluation of turbulent quantities in openchannel flow phenomena.

WESTERN CANADA HYDRAULIC IABORATORIES LTD., 1186 Pipeline Road, Port Coquitlam, B.C., Canada

Address inquiries on all projects to Mr. J.W. Ball, Director, Western Canada Hydraulic Iaboratories Ltd., at above address.

(6429) MODEL SIUDY OF PONTOON-TYPE FLOATING BREAKWATER.

(b) Swan Wooster Engineering Company Ltd.

(d) Experimental for design and operation.

(e) The models were constructed of sheet plastic to a scale of $1: 75$, each representing a basic unit 20 feet by 120 feet and designed to permit coupling to form a maximum size of breakwater 60 feet by 360 feet. Each section formed a rectangular box, with a raised bulwark along one face, decked over and divided into compartments. Ballast was added to achieve drafts according to test requirements. Models were subjected to a single chosen design wave and their wave attenuating effectiveness was recorded electronically.

(f) Completed.

(h) Report issued to client.

(6430) MODEL SIUDY OF FLOATING BREAKWATER PROTECTIONHORNBY ISLAND.

(b) British Columbia Dept. of Highways.

(d) Experimental for design and operation.

(e) A 1:48-scale compartmented breakwater was tested both as an individual form of wave protection and in conjunction with a rockmound breakwater as protection for a ferry ramp. Individual units were joined to represent breakwaters of various sizes, from 30 feet by 60 feet to 30 feet by 180 feet and subjected to waves of varying characteristics. Comparison tests were made with previously tested floating breakwaters. (f) Completed.

(h) Report issued to client.

(6431) MODEL STUDY OF CAISSON-TYPE FLOATING BREAKWATER.

(b) Dept. of Public Works, Canada.

(d) Experimental for design.

(e) The basic unit, to a scale of 1:24, represented breakwaters 6 feet wide by 50 feet long which were coupled to form units 18 feet, 24 feet and 30 feet wide. Wave attenuation to leeward effect was measured electronically as were forces on the anchor chains.

(f) Completed.

(h) Report submitted to client.

(6432) MODEL STUDY OF A-FRAME FLOATING BRFAKWATER.

(b) Dept. of Public Works, Canada.

(d) Experimental for design.

(e) 1:23.4-scale models of an A-frame-braced, floating wall breakwater were tested, representing units 15 feet, 25 feet and 35 feet wide by 50 feet long. Wave attenuation to leeward and forces on the anchor chains were measured electronically.

(f) Completed.

(h) Report submitted to client.

(6433) MODEL STUDY OF BREAKWATER PROTECTION FOR DOCKING FACILITIES.

(b) Swan Wooster Engineering Co. Ltd.

(d) Experimental for design.

(e) Tests were carried out on a 1:20-scale model of a docking area with a proposed rock breakwater in place. Studies were made of the effect of storm waves on the harbour for various tidal conditions; also with the added effect of a river discharge entering the docking basin during adverse conditions of tide and waves. Wave attenuation in the docking area was investigated for the most prevalent wind directions and the breakwater location adjusted to give optimu results.

(f) Completed.

(h) Report issued to client.

(6434) MODEL STUDIES OF MICA DAM DIVERSION WORKS, RIVER CLOSURE AND LOW-LEVEL OUTIET FIOW.

(b) Caseco Consultants Ltd. for British Columbia Hydro and Power Authority.

(d) Experimental for design and operation.

(e) The I:80-scale erodible-bed model represented 1.5 miles of the upper Columbia River at the site of the 650-foot-high earthfill dam, 75 miles north of Revelstoke, B.C. Purpose of the studies was (1) to investigate the hydraulic characteristics of the two 45-foot diameter diversion tunnels and related structures, up to the design flow of 150,000 cfs., (2) to investigate proposed methods of river closure and flow diversion and (3) to examine flow conditions for low-level outlet discharges through a diversion tunnel exit structure.

(f) Completed.

(h) Report issued to client.

(6435) MODEL STUDIES OF MICA DAM LOW-LEVEL OUTLET AND DIVERSION FLOWS.

(b) Caseco Consultants Ltd. for Eritish Columbia Hydro and Power Authority.

(d) Experimental for design and operation.

(e) Tests were continued on the existing 1:80scale model to (1) chech the performance of redesigned diversion tunnel exit structures. 
(2) develop a stilling basin or flip bucket for low-level outlet flows up to 30,000 efs using a diversion tunnel exit structure, (3) determine whether the design of exit structure would perform satisfactorily for both outlet and diversion flows, (4) check design of rock-cut approach and exit channels to diversion tunnels and (5) check performance and losses for tunnel plug serrations.

(f) Completed.

(h) Report issued to client.

(6436) MODEL STUDIES OF MICA DAM - APPROACH CHANNEL, SPILLWAY, SPILIWAY CHUTE AND FLIP BUCKET, AND HIGH-LEVEL OUTLET WORKS.

(b) Caseco Consultants Ltd. for British Columbia Hydro and Power Authority.

(d) Experimental for design and operation.

(e) The existing 1:80 model of Mica Dam was enlarged to include the spillway with its appurtenances and the high-level outlet works. Development of the rock-cut spillway approach channel, with consideration given to the economics of excavation, as well as to the most efficient hydraulic performance, was followed by refinement of the spillway design. Particular attention was paid to the effect of pier nose and tail design on depth of crest flow near the trunnion axis and flow conditions in the spillway chute. The flip bucket, located above the diversion tunnel exit structures, was required to accomodate flows up to $175,000 \mathrm{cfs}$ and to direct the flow so as to avoid concentration of the jet on the rock-cut exit channels, or on the river bed in such a way that a high-velocity return eddy would attack the downstream toe of the dam or carry bed material into the powerhouse exits to be located on the opposite side of the river. The study of the highlevel outlet works, a twin-gate unit, required development of an approach channel, trash grill and a 700-foot inclined tunnel, which dropped 400 feet to its outlet in a diversion tunnel. Special attention was given to vortex action at the entrance and aeration of the tunnel flow.

(e) Completed.

(h) Report issued to client.

(6437) MODEL STUDIES OF MICA DAM - EXPANSION CHAMBER ENERGY DISSIPATOR FOR LOW-LEVEL OUTLET WORKS.

(b) Caseco Consultants Ltd. for British Columbia Hydro and Power Authority.

(d) Experimental for design and operation.

(e) The low-level outlet works at Mica Dam are contained in one of the two diversion tunnels and will require a capacity of 30,000 cfs at 450-foot head. Since outlets of conventional design would impose velocities of up to $170 \mathrm{fps}$ on the flow downstream of the regulating gates, with serious possibility of cavitation erosion of the concrete tunnel lining, consideration was therefore given to ways of reducing the head on the control gates. Of these, the principle of suddenenlargement energy dissipation was the most promising.

A 1:56.6 model of the upstream tunnel plug, three gate-controlled passages, and the downstream sudden enlargement was constructed of transparent plastic and tested at greater than scaled heads in the laboratory and later at almost full prototype head in a special high head connection. Pressure cells were located along the enlargement wall and recordings made to determine the existence of pressure surges and high frequency fluctuations. To establish the validity of using a cavitation number as the criterion for testing, preliminary tests were conducted by adjusting upstream and downstream pressure relationships to produce incipient, moderate and severe cavitation, thus demonstrating that the cavitation number $K$ was dependent on the pressure relationship rather than actual pressure values. Model designs tested consisted of three main types; a single circular conduit, concentric with the expansion chamber; 3 conduits in trifoil formation and a three-in-line circular conduit pattern. Variants of the above were also tested. Tests were also conducted on concrete-lined enlargements with conditions of incipient, moderate and severe cavitation to determine erosion effects.

(f) Completed.

(g) A final satisfactory design was evolved and conclusions were that ( 1 ) the sudden-enlargement is an effective means of dissipating the energy of an appreciable part of the 450-foot head at Mica Dam (2) the performance of such dissipators is dependent on the geometry of the sudden-enlargement but can be evaluated by model studies using the cavitation number as a criterion (3) rapid pressure flluctuations will occur in the expansion chamber, but there will be no significant pressure surges (4) rapid pressure fluctuations at frequencies up to $250 \mathrm{cfs}$ and magnitudes of more than 110 feet of water will not damage concrete of normal strength.

(h) Report issued to client and published as "Sudden-Enlargement Energy Dissipator for Mica Dam," S.O. Russel and J.W. Ball, Jour. Hydraulies Div., Proc. ASCE, July 1967.

(6438) PORTAGE MOUNTAIN DAM POWER PLANT INTAKES.

(b) International Power and Engineering Consultants Ltd.

(d) Experimental for design and operation.

(e) This 1:70-scale model, represented the approach channel and power plant intakes of the 600. foot high dam at present under construction on the Peace River in northern B.C. Purposes of the study were: (1) to determine the excavation limits for the approach channel to the low-level power intakes to give minimum rock excavation with minimum head loss (2) to establish limits of overburden excavation for satisfactory approach conditions to the high-level outlets and (3) to evaluate the performance of the power plant for various reservoir elevations.

(f) Completed.

(g) Report issued to clients.

(6439) PORTAGE MOUNTAIN DAM SPILLWAY.

(b) International Power and Engineering Consultants Ltd.

(d) Experimental for design and operation.

(e) Tests were performed on a 1:72-scale model which represented part of the reservoir, approach channel, spillway and components, the transition from crest to the channel and approximately 1500 feet of the trapezoidal channel. Tests were conducted to (1) establish the most economical size and alignment of the spillway approach channel to 
to provide satisfactory flow at the control structure (2) to evaluate flow conditions in, pressure distribution on, and capacity of, the gate-controlled crest section (3) to assure that alignment of the walls of the transition from the spillway to the downstream channel would minimize shock waves and establish near-uniform flow, giving minimum wall height and satisfactory flow to the flip bucket chute.

(6440) MODEL STUDY OF DUNCAN DAM.

(b) Montreal Engineering for British Columbia Hydro and Power Authority.

(d) Experimental for design and operation.

(e) Duncan Dam forms part of the development of the Columbia River Basin. The outlet works model to a scale of 1:42, included part of the reservoir, the approach channel, one outlet tunnel with gate structures, flip bucket and a short portion of river bed down stream. Tests were conducted to develop the required hydraulic performance of the outlet works with particular attention to effect of trash racks on vortex action, elimination of objectionable flow circulation in the emergency gate shaft at high flows and gate shaft air venting.

(f) Completed.

(h) Report issued to client.

(6441) OPERATION TESTS OF PRESSURE REGULATING VALTE STATION.

(b) Vancouver City, B.C., Canada.

(d) Field investigation for operation.

(e) Operation tests were conducted on a valve station comprising 2.5 -inch, 6 -inch and 10-inch pressure regulating valves to evaluate the individual and combined valve operating characteristics, control accuracy and station response to changing upstream conditions.

(f) Completed.

(h) Report submitted to client.

(6442) MODEL STUDY OF SOUTH SASKATCHEWAN DAM TAILRACE CHANNEI.

(b) Saskatchewan Power Corporation.

(d) Experimental for design and operation.

(e) A 1:100-scale model representing spillway and outlet stilling basins, tailrace conduits, flow channels for these structures, downstream toe of the dam, and approximately 6000 feet of river channel. Tests were conducted to investigate flow conditions, scour action and bed material movement in the tailrace area for various power plant, outlet, spillway and diversion discharges.

(f) Completed.

(h) Report issued to client.

(6443) MODEL STUDY OF SEDIMENT DEPOSITION.

(b) Dept. of Public Works, Canada.

(d) Experimental for design.

(e) A method of reducing the heavy shoaling which interfered with operations in a log-booming area in a side channel of the Fraser River was studied in a 1:150-scale erodible-bed model. The model was subjected to filows representing discharges up to 350,000 cfs and the deposition pattern of the finer bed material was duplicated using Gilsonite, which was introduced as bed load.

(f) Completed.

(h) Report submitterl to client.
(6444) MODEL STUDY OF SEWER INTERCEPTORS.

(b) Greater Vancouver Sewerage and Drainage District.

(d) Experimental for design.

(e) 1:15.3-scale models of two sewer interceptor units were constructed of clear plastic to study proposed alterations to existing structures. Studies were made of gates, drop pipe and interceptor connections with a view to improving flow conditions for automatic control

(f) Completed.

(h) Report submitted to client.

(6445) MODEL STUDY OF OVERFLOW SPILLWAY OF KETTLE DAM.

(b) Crippen Acres Limited for Manitoba Hydro.

(d) Experimental for design and operation.

(e) Two models were constructed for studies of Kettle Dam on the Nelson River in northern Manitoba. The 1:96-scale comprehensive model represented part of the reservoir, the spillway, powerhouse, dam abutments and a section of the downstream river channel. A 1:48 sectional model represented a section of the spillway crest, two of the eight gates and a section of downstream river channel. Purpose of the study was to develop an efficient economical spillway design that would perform well under all conditions, particularly during the severe winter freezeup and spring break-up of ice on the Nelson River and reservoir. Items of particular concern included the cofferdam in the spillway approach channel; gate design and operation; pier, spillway crest and flip bucket design; the retaining walls downstream of the spillway and erosion conditions in the downstream river channel.

(f) Completed.

(h) Report issued to client.

(6446) MODEI STUDY OF NEW DON PEDRO DAM.

(b) Bechtel Corporation.

(d) Experimental for design.

(e) The 1:42.5 comprehensive model of the 570-foot high New Don Pedro Dam on the Tuolumne River in California represented the tunnel outlet works with its three sudden-enlargement energy dissipators and its slide gates located in the diversion tunnel, the diversion tunnel from outlet control structure to exit portal, the trimmer valve at the powerhouse, powerhouse draft tubes and a 1150foot section. of downstream river channel. A separate 1:42.5 model of an individual sudden enlargement was identical to the corresponding part of the comprehensive model. This model was placed in the supply system where heads up to 150 feet were available. Purposes of the model were (1) to determine cavitation characteristics, flow conditions and transient pressure conditions for the sudden enlargement (2) examine conditions of flow at the outlet works gate in the tunnel bend in the river at the outlet works (3) to determine the ejector action on the tailrace water surface due to operation of the outlet works, trimmer valve and power plant.

(f) Completed.

(h) Report issued to client. 

ing, Windsor, Ontario, Canada

(6455) EFFECTS OF AN INTTIAL GAP ON THE FLOW IN A WALL JET.

(b) Defence Research Board of Canada; and National Research Council of Canada.

(c) Dr. K. Sridhar, Assoc. Prof., Dept. of Mech. Engrg., Univ. of Windsor.

(d) Experimental; basic research for M.A.Sc.

(e) Aim is to study the effects of an initial gap on the turbulent jet flow over plane and curved walls. A gap is introduced between the nozzle lip and the leading edge of the wall. The jet flow over the wall is probed.

(g) Region close to the leading edge of the wall could be described as a settling region where the type of flow changes from a free jet to a wall jet. In the case of curved wall jets there is an hysteresis phenomenon associated with initial gap and the angular position of the jet separation decreased with in increase of the gap size.

(h) "Effects of an Initial Gap on the Flow in a Turbulent Wall Jet," K. Sridhar and P.K.C. Tu, Jour. Royal Aeronautical Soc., Vol. 70, No. 666, pp. 669-673, June 1966.

"Effects of an Initial Gap on the Turbulent Jet Flow over a Curved Wall," S.C. Paranjpe and $\mathrm{K}$. Sridhar, Jour. Royal Aeronautical Soc. (accepted for publication).

The following M.A.Sc. theses have been submitted to the Dept. of Mechanical Engrg., Univ. of Windsor:

"An Experimental Investigation of the Flow in a Plane Wall Jet with an Initial Gap," P.K.C. Tu, 1965.

"An Experimental Investigation of the Effects of an Initial Gap on the Jet Flow over a Curved Wall," S.C. Paranjpe, 1966.

"An Experimental Investigation of the Hysteresis Phenomenon and Effects of Gap on Curved Wall Jet Separation," P.K. Arora, 1967.

(6456) EFFECTS OF CURVATURE ON JET ENTRAINMENT AIND HEAT TRANSFER.

(b) National Research Council of Canada.

(c) Dr. K. Sridhar; see (6455) above.

(d) Experimental, theoretical; basic research for M.A.Sc and Ph.D.

(e) Aim is to investigate the effects of the wall curvature on the jet entrainment and heat transfer. The jet flow over walls of different radius and at different temperature is probed to get the velocity and temperature profiles. Correlations will be obtained.

(6457) JET FLOW OVER A MOVING WALL.

(b) National Research Council of Canada.

(c) Dr. K. Sridhar; see (6455) above.

(d) Experimental; basic research for M.A.Sc.

(e) object is to study the effects of rotating a cylinder on the flow of a jet over it, especially the effects on the velocity profile, jet growth and angular position of separation.

(6458) FLOW IN AN ANNULUS.

(b) National Research Council of Canada.

(c) Dr. K. Sridhar; see (6455) above.

(d) Experimental, theoretical; basic research for M.A.Sc.

(e) Aim is to investigate the flow in the settling length and the fully developed flow in smooth concentric annuli of different diameter ratios. The range of Reynolds number is from 10,000 to 50,000 .

(6459) BOILING HEAT TRANSFER FROM A ROTATING CYLINDER

(b) National Research Council of Canada.

(c) Dr. T.W. McDonald, Dept. of Mechanical Engrg., Univ. of Windsor.

(d) Experimental; applied research for doctoral thesis.

(e) The purpose is to investigate the effect of rotative speed of the cylindrical heater element on the boiling heat transfer coefficient. If the increase in the coefficient is significant, then heat exchangers having rotating elements may be feasible in cases where weight or size are important factors. A previous worker on this project used water as the fluid while the present worker is using "Freon". High speed photography is being used to study the bubble formation.

(g) Abstract: A cylindrical horizontal heating element was rotated about its axis at speeds of $0-800 \mathrm{rpm}$. A maximum increase in the rate of heat transfer of approximately $100 \%$ was found to occur at a rotational Reynolds number of 14,500. For rotational Reynolds numbers greater than this value, the rate of heat transfer was decreased to values less than those occurring at very low speeds of rotation.

(h) "Nucleate Boiling Heat Transfer from a Rotating Horizontal Cylinder to Saturated Water," Todd McLean, Master's Thesis, Univ. of Windsor Library. 
ABSORPTION

Convective flow accompanying absorption of soluble gas into a quiescent liquid (6832)--- 48 ACOUSTICS

Research activity at Naval Undersea Warfare Center (6372)

Sound waves used to determine porous-medium

See also AERODYNAMIC NOISE

See also FYDRODYNAMIC NOISE

ACOUSTIC EXCITATION

Flat plates in turbulent flow (5187)-.....-.-. 123

ACOUSTIC FLOW METER

SEe HYDRAULIC MEAS., FLOW METERS

ACOUSTIC RADIATION

During mixing of liquid and gas jets (6558)---- 96

From shells of arbitrary shape (6557)-...... 96

From spherical shell to sea water (6290)-...-.- 131

From turbulent boundary layer on rigid plane

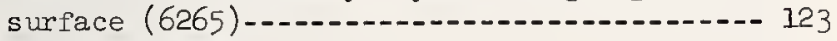

ACOUSTIC VELOCITY

In upper ocean layers (6465)

Measurements in steam (5286)

Transmission, reflection and scattering of sound waves by discrete scatterers (1548)-.-- 6

ADDED MASS

SEe VIRTUAL MASS

AERATION

Efficiency of spray aeration (5373)-..-.-.-.-. 76

Oxygen transfer to water drops (6698)-.......-. 38

See also OXYGEN, DISSOLVED

AERATION, RIVER

See REAERATION

AERODYNAMIC NOISE

Turbulent boundary-layer pressure-fluctuation

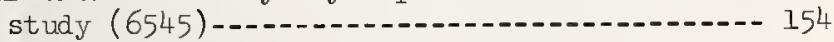

AEROSOLS

Diffusion of liquid aerosols in air jet (6202)- 102

Impaction coefficient on circular cylinder

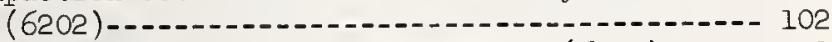

Measurement by hot-wire anemometry (6202)-.-.-- 102

AIR BUBBIES

See BUBBIES

AIR DEMAND

Jet flow gate tests, Trinity Dam (4958)--.---.- 220

Model-prototype scaling for air demands in partly full water conduits (5339)-.....-.-.-.- 221

Prototype measurements, tandem gate, Navajo

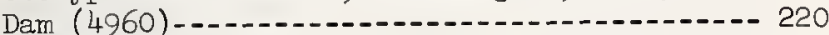

AIR ENTRATNMENT

During impact of free jet into pool of similar

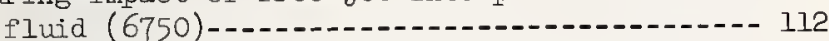

Effect on open-channel flow resistance (6288)-- 82

In check towers, Canadian River aqueduct (4792) - - 219

Mechanism of entrainment in vertical building drains (4043)-........-256

Surface characteristics of air entrained flow

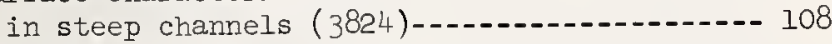

AIRFOILS

Two airfoils passing in opposite directions (6547)

See also LIFTING SURFACE THEORY

See also WINGS

AIR-SEA INIERACTION

A.tmospheric boundary layer turbulence measured

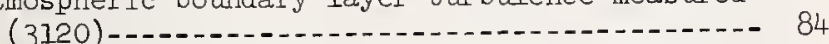

Atmospheric effects on variation in surfacemixed layer $(6474) \ldots \ldots$

Mechanism of energy transfer between wind and waves (5454)
AIR-SEA INTERACTION (continued)

Study of dynamics of interaction as part of weather-modification problem (6788)-........- 104 Turbulent heat exchange (6086)-_.........-.-. 62 Wind field near disturbed water surface (6389)- 239 Wind stress and surface roughness (6644)-....- 41 See also AIR-SEA INIERFACE

See also AIR-WATER INTIERFACE

See also WAVES, WIND

AIR-SFA INTERFACE

Research on various ocean upper-layer phenomena (6644)............................. 4

See also AIR-SFA INTERACTION

See also AIR-WATER INTERFACE

AIR VENT

Air flow after emergency intake-gate closure

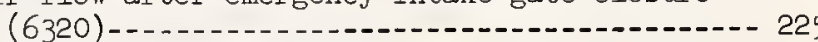

AIR-WATER INTERFACE

Evaporation, see EVAPORATION

Mass and energy transport due to evaportion

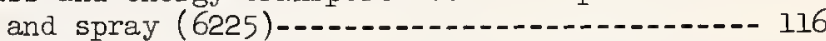

Optical investigation of density gradients near interface (6133)-.................... 233

Turbulence within a few inches of a pond

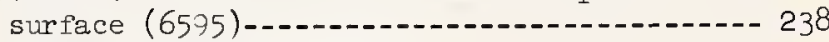

See also AIR-SEA INTERFACE

See also AIR-SEA. INTERACTION

ALGAE

Effect on pipe wall roughness (5827)-.......- 80 AILUVIAI CHANNELS

Bed Forms, see BED FORMS

Flow resistance (5165) -..................... 21

Friction factors for sand bed channel (6617)--- 58

Identification and evaluation of dependency

characteristics of flow and sediment

measures (5607) -..........

228

Meanders, see RIVER CHANNELS

Regime theory; text collating field and lab research (6630)-............................. 251

Roughness and sediment transport in natural and artificial channels (2950)......-.-.-. 227

Silty-water effect on infiltration (5349)-..-- 2

Temperature effect on bed forms (1988)-......-. 189

See also BED FORMS

See also RIVER CHAIVNELS

AMPHIBIOUS VEHICIES

Docking characteristics of IARC V (5931)-.-.-.- 119

Floating truck investigation (5933)-...-.-.-. 120

Flume tests on LVTP-5 (6369)-............. 28

Gain in speed by coupling vehicles (5312)-.---- 119

Motion and stability in waves and surf (6608)-- 75

Propulsion in water by spinning wheels (5314)-- 119

Propulsion in water by track motion (5313)-...- 119

Swimming performance of marginal-terrain vehicle (5934)-1... 120

ANEMOMETERS

SEe HYDRAUIIC MEASUREMENTS

ANNUTAR CONDUITS

See PIPE FLOW, ANNULAR

ANTARCTIC OCEAN

Rotating model for circulation study (6085)---AQUTFERS

Electric analog model, Miami Basin, Ohio

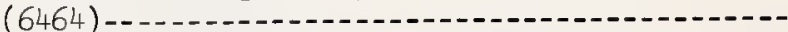

Feasibility of storing fresh water in saline

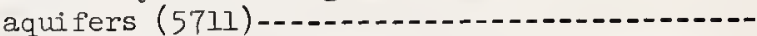

Hydraulic study of a Missouri River aquifer

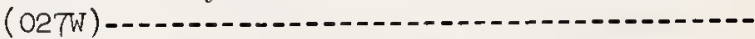

Mathematical model of stream-aquifer system

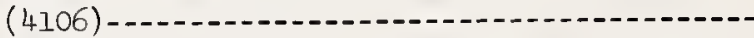

Recession hydrographs for unconfined, idealized aquifers (5303) 
AQUTFERS (continued)

Page

Response of well-aquifer system to seismic waves (5839)--..- 228

Salt water intrusion into layered strata in coastal aquifers (6046)-.................. 5

Salt water removal with tile drains and pump wells (4962) -...... 220 Yield of a nonlinear elastic aquifer (5714)--.- 88 See also GROUNDWATER

AQUTFERS, BASALT

Methods of estimating recharge (6162)-..-.-.-.- 144

Physical characteristics; stratigraphic relations (6161)-........... 144 ARTERIES

See BIO-MEDICAL HYDRODYNAMICS

ASH COLIECTOR

Gas duct flow pattern studied to provide good distribution of ash and gas at inlet (6725)-- 247 $(6726)(6727)(6728)$ ASTROPHYSICS

Geophysical and astrophysical fluid dynamics

$(6786)(6787)-\ldots 4$ $-\mathrm{B}-$

BACKWATER CURVES

See OPEN-CHANNEL FLOW

BAFELES, ANTI-SLOSH

See SLOSHING

BARRIER ISLANDS

Residence times of water in lagoons behind islands (6756)

Role of passes in gulf-bay water exchange BEACHES

Texas Gulf Coast (6183)

Criteria for construction of artificial beaches (976)-182

Equilibrium profile of beaches and study of model scale effect (181)-..... 181

Re-examination of artifically nourished and constructed beaches (2195)-................ 183 Wave-absorbing characteristics (5635)-...-.-.- 198 BFACH EROSION

See EROSION, BEACH

BEACH SAND

Inventory of offshore sand sources (4763)------ 184

see also COASTAL SEDIMENT

BED FORMS

Observed forms of bed roughness in an unstable gravel river (6820)-_... 251

Water temperature effect on bed forms and roughness (1988)-_...... 189

BED FORMS, DUNES

Dune and free surface effects on flow resistance (6523)

Duned bed under oscillating flows (5545)-.-.-. 35

Prediction of friction factor for duned beds (5118)-10

Relation of dune geometry to friction factor (4075) -

BEDS, PACKED AND FLUIDIZED

Characteristics of bubbles in fluidized beds (6707)--... 44

Dispersion in packed bed, using random-walk model (5170)

Ebullient bed catalytic reactor (6671)-...... 70

Transition to turbulence in packed bed of spheres (6826)

Viscous flow through sphere assemblages (6056)- 263 BELLOWS

Flow losses, vibrations in elastic pipes bellows, bends (6065) BENARD CONVECTION

Development and breakdown of Taylor vortices and Benard cells (6772)-_-105
BENARD CONVETION (continued)

Nonlinear effects in cellular convection

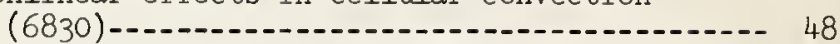

With rapidly varying fluid properties (6596)--- 238 BENDS

See PIPE FLOW; OPEN CHANNEL FIOW

BINGHAM FLUIDS

SEe NON-NEWTONIAN FLOWS

BIO-MEDICAL HYDRODYNAMICS

Analytical model of heat transfer in the

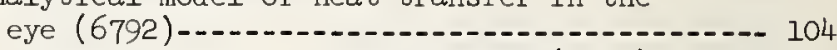

Arterial system for brain; model (4143)-...-. 49

Artificial heart, hydraulic characteristics (6080)-........ 80

Blood flow; breakage of red cells due to shearing and negative pressure stresses (6766)-1.

Blood flow; extra-corporeal systems for oxygenating blood (6791)-_.-...- 104

Blood flow; hydrodynamic effect on filtration theory of atherogenesis (6647) 41

Blood flow in and near circulatory-assist

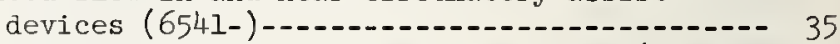

Blood flow, laminar regime transitions (6138)-- 19

blood flow; models of flow and transport in

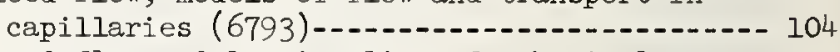

Blood flow model using line of spherical particles in tube (6054)..... 25

Blood flow; Navier Stokes eqs. for pulsatile flow (6541)-.... 35

Blood flow optimization to an oxygenator (6088) -

Blood flow problems connected with dialysis (6578)-

Blood flow, steady and pulsatile in rigid and distensible tubes (6138)-................. 19

Cerebral circulation, abnormality detection via fluid impedance changes (6143)-........ 50

Effect of branches on flow stability in brain arteries (4559)

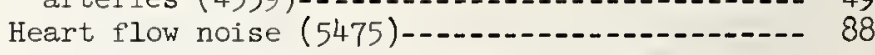

Hydrodynamic hemolysis in extracorporeal

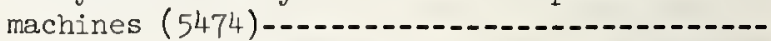

Intra-aortic balloon pump (6106)

Model for intraocular pressure-deformation relations (6794)-... 104

Oxygen transfer to blood flowing in round tubes (5474)

Peristaltic-pumping research (6108)-.........

Prosthetic heart valves; flow separation (6579)-_-_- 255

Pulsatile flow in distensible tubes (4859)-.-.- 78

Simulation of red cell deformation in capillaries (6355)

Wave reflection in branched flexible conduits (6142) BLOOD FLOW

See BIO-MEDICAL HYDRODYNAMICS

BOUNDARY LAYER

Calculation along ship hulls (5739)-

Development of large boundary-layer type velocity profiles in a wind tunnel, for modeling (6816)-... 269 BOUNDARY IAYER, CONTROL

Optimum suction slot form for laminar boundary layer stability (5593)

See also DRAG REDUCTION

BOUNDARY IAYER, LAMINAR

Inlet length for two-dimensional channel (6104)-1.....

In water with variable properties (654))-.-.-.-

Mixing induced by turbulence promoters to improve heat transfer (6571) -

On body of revolution; steady and unsteady flow (6467) 55 57

.


BOUNDARY IAYER, LAMINAR (continued) Page

On rotating circular arc blade (6800)-....... 117

Theory for axi-symmetric layers (6555)-...... 96

Water boundary layer over heated plate

(6549) -

BOUNDARY IAYER, NON-NEWTONIAN

Laminar and turbulent layers in non-Newtonian fluids and luids with polymer additives

(5795) -

See also DRAG REDUCTION, ADDITIVES

BOUNDARY LAYER, PERMFABLE WALT.

Self-ejecting boundary layer flows (6273)-.--- 26

BOUNDARY IAYER, ROTATING DISK

Disk rotated in water and dilute polymer

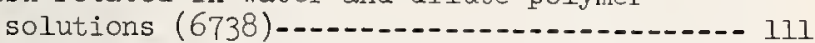

BOUNDARY LAYER, SEPARATION

Free surface effects on vertical strut (2091)- 54

On ventilated hydrofoil rear free surface

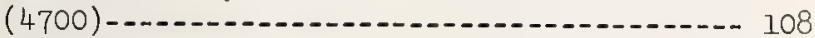

See also SEPARATED FLOW

BOUNDARY LAYER, SKEWED

Lateral flow reversal in skewed threedimensional layers (6194).................... 143

BOUNDARY IAYER, STABILITY

On bodies of revolution (6555)

Water boundary layer on heated surface (6546)- 29

See also BOUNDARY IAYYR, TRANSITION

BOUNDARY LAYER, SUBTAYER

Turbulence measurements in viscous sublayer

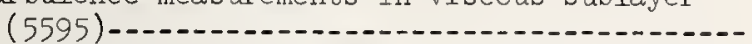

Turbulence structure near wall studied with electrochemical technique (6824)..........- 48

BOUNDARY IAYER, THREE-DIMENSIONAL

Moment method to solve equation (6677)-...... 77

On submersible bodies and propellers (6681)-.- 77

BOUNDARY IAYER, TRANSITION

Effects of free-stream turbulence (6213)--.---

Effects of acoustic waves (6213) -............

Flexible-wall effect (5196) -................

Optimum suction slot form for laminar

boundary layer stability (5593)-.......... 95

Production of turbulence near smooth wall;

visual and quantitative study (6798)......-. 116

BOUNDARY LAYER, TURBUTENT

Acoustic radiation from rigid plane surface

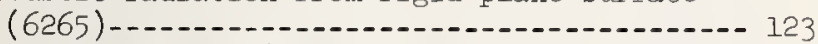

At a normal step (4142)

Experimental investigation of flow structure

(6798)-_... 116

Flow-acceleration effect (6346)-............. 233

General method of solution (6550)-......... 30

General phenomenological theory for wall

turbulence (6103)

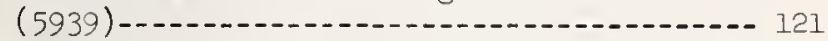

Lateral flow reversal in skewed three-dimen-

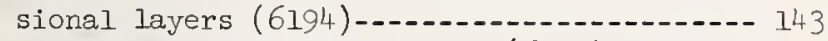

Longitudinal curvature effects (6139).......- 50

Polymer-additive effects on turbulence and shear stress (6135) (6136)-.......... 234

Pressure-fluctuation mechanism including separated flow and flow over protuberances

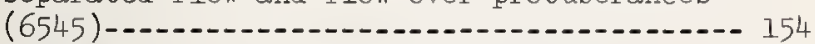

Scaling laws for wall pressure field in subsonic and supersonic flows (6121)

Turbulence measurements in sublayer (5595)---- 95

Use of asymptotic matching techniques (6556)-- 96

Velocity-profile models compared with

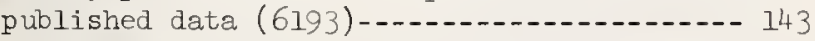

Wall-pressure fluctuations in dilute polymer solutions (6735)-......................... 11

Wall-pressure fluctuations obtained on buoyantly propelled vehicles (6585)-.......-.- 241

Wall-pressure spectra in thick layers (6262)-- 123
BOUNDARY LAYER, TURBULENT (continued)

Page

Wall shear stress measurements, survey

of devices and techniques (6196)........... 143

BOUNDARY IAYER, UNSTEADY

On body of revolution; laminar (6467).......- 61

BOUNDARY LAYER, VORIEX

Boundary layer beneath vortex (6616)-........ 4

Layer created by vortex over flat plate

(6451) -....-

BRANCHED CHANNNELS

In spillway flow, model study (6248)-....-.-.- 261

BRANCHED PIPES

See PIPE FLOW

BREAKERS

See WAVES, BREAKING

BREAKWATERS

Erosion of foundation at junctions of

concrete-crib breakwaters (6238)-.......-.-. 260

Force of breaking waves and clapotis (978)-.-- 187

Protection of Interstate Route 35 along

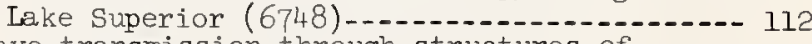

Wave transmission through structures of

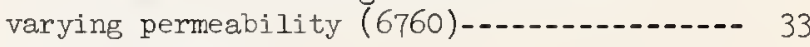

See also MODELS

BRFAKWATERS, FLOATING

A-frame type; model study (6432)-.........- 269

Caisson-type; model study (6431)-.-.-.-.-.-- 269

Ferry-ramp protection, Hornby Island,

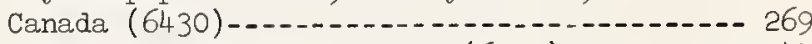

Log breakwater investigation (6159)-........ 144

Pontoon-type; model study (6429)-..-.-.-.-26c

Structures of various configurations (6494)--- 264

Wave transmission through breakwaters

made of used tires and spheres (5635)-....- 198

BRFAKWATERS, PNEUMATIC

For surface launching of manned submersible

(6666) -

BREAKWATERS, RUBBLE

Laboratory stability tests with breaking and non-breaking waves (999)-............. 188

Laboratory stability tests with non-breaking

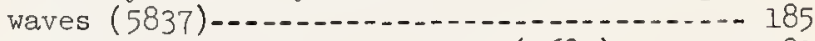

Scale-effect on stability tests (2681)-.....- 189

Stability, Noyo Harbor, Calif.; Model (6016)-- 202

Tetrapod and rubble-manned covering; flume and analytical study (6229)-................. 259

Stability; model tests for Burns Waterway

Harbor, Ind. (6863)-........ 214

Transmission and reflection of waves (5635)--- 198

Transmission of waves through rubble (5814)-.- 11 (5634) - 198

BREAKWATERS, SUBMERGED

Structures of various configurations (6494)--- 264 BRIDGE PIERS

Current pattern at bridge across Hillsboro

Inlet channel, Fla. (6761).............. 33

Dynamic ice loads on piers (6821)-..........- 251

Hydraulics of spur dikes (3086)-........... 124

(3086A) - 63

See also SCOUR

BUBBLES

Characteristics of bubbles in fluidized beds

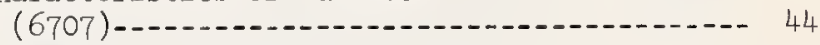

Formed during mixing of liquid and gas jets

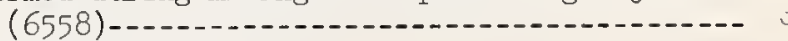

BUBBLES, CAVITATION

SEe CAVITATION

BUBBLES, GAS AND VAPOR

Acoustic properties in pressure field (5310)-- 11)

Air bubbles to prevent shoaling at wharf

(5994) -

Asymmetric collapse in fluid streams (6144)--- 78

Effect of buble suspensions on nozzle flow

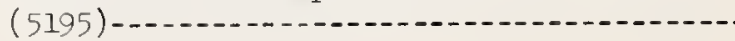
西

\section{.}


BUBBLES, GAS AND VAPOR (continued)

Formation mechanism at submerged orifice

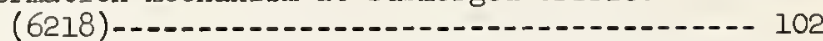

Micro-bubble effect on flow noise (5499)-...-- 109

Nuclearation, growth and collapse in problem

of sodium superheat (6147)

BUIIDING DRAINS

SEe DRAINAGE

BUIIDING AERODYNAMICS

Development of large boundary layer type velocity profiles in a wind tunnel (6816)--- 269

$$
-\mathrm{C}-
$$

CABIES, TOWING

See SUBMERGED BODIES

CANALS

Capacities of large concrete canals on flat

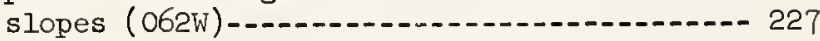

Head loss in irregular channels made by nuclear excavation (6873) -.............. 216

See also OPEN CHANNEL FLOW; SHIP CHANNELS

CANALS, FARTH

Colloidal materials for seepage control in

Nevada ponds and canals (3558)
Use of electrical logging to determine

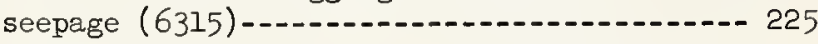

Water movement from canal to groundwater (O32W)

CANALS, SEA-IEVEL

Consideration of importance of density

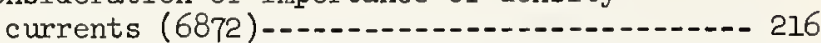

Tidal motion computation (6414)-........- 72 CANALS, SURGES

sEe SURGES

CANAL SYSTEMMS

Feedback gate control to keep constant water level (6222)

CAPIIIARY FIOW

SEe PIPE FLOW, CAPIIIARIES

CASCADES, SUPERCAVITATING

With constant pressure cambered blades (6648)- 41 CAUSEWAY

Stability against wave action, P.E.I. Causeway, Canada (6230)

CAVITATION

Cavitation characteristics of a few simple

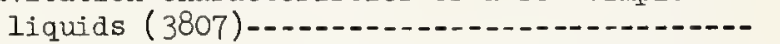

Cavitation characteristics of baffle piers, gate slots and other hydraulic structure components (993)

Cavity formation at obstruction in boundary layer (6744)

In abrupt pipe expansion (79)-......... 53

of butterfly valves discharging into sudden enlargements (5336)............................ 221

Vapor cavities formed by sudden flow stoppage in pipe (6215) ....... 122 CAVITATION, BUBBTES

Asymmetric collapse in fluid streams (6144)--- 78

Change in size and trajectories of bubbles passing a body (6653)

Non linear bubble oscillations (1548) ........ 6

Nuclearation, growth, collapse in problem

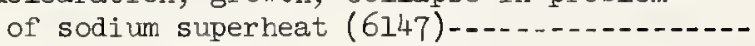

See also CAVITATION, GAS NUCIEI

CAVITATION, DAMAGE

See CAVITATION, EROSION

CAVITATION, EROSION

Erosion-resistant coatings, development

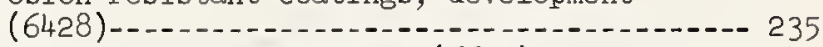

Evaluation of test devices (6651)-.......-. 42

Exposure-time effect (1548)-.............. 6

Liquid drop impact on high-speed target in vacuum (5796) -........ 110
CAVITATION, EROSION (continued)

Measurement on nickel, aluminum and stainless steel (1548)

Reduction of damage by forced surface

outgassing (6739)

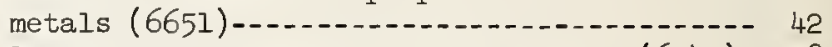

Relative resistances of metals, alloys (6145)- 78

Resistance, of concrete patching materials (993)-_... 187

Rock tunneling with high speed water jets utilizing cavitation damage (6650)-.......- 42

Scaling laws for models (6651)............ 42

Surface sealants studied for damage

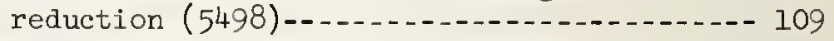

Techniques for determining resistance of

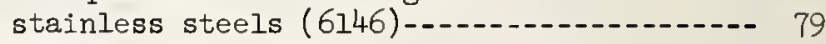

CAVITATION, FUEL LINE

Suction line dynamics, Saturn V rocket (6426)

CAVITATION, GAS NUCLEI
Effect on cavitation

Effect on cavitation severity near inception ( 5792 )

Surface-film effect on tensile strength

(6378)
CAVITATION, INCEPTION

At concrete surface irregularities (3278)----- 219

At surface misalignments in high-speed flow (059W) - 227

Effect of gas nuclei size on severity near inception ( 5792 ) - 109

Influence of gas-nuclei trajectories (6653)-.- 42

Influence of roughness of various distributions (5542)-_... 71

Organic-film effect on tensile strength (6378)-(n 35

Scaling equation for incipient cavitation no. as function of Reynolds no. (6492)-...- 123

CAVITATION, NOISE

Spectral analysis, pump cavitation noise (6380)

CAVITATION, PIPE FLOW

Mechanics of pipe flow following column

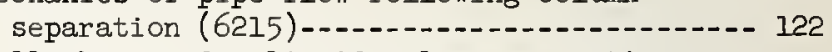

wall shear under liquid column separation (4862)

See Pumps

CAVITATION, SPIILWAYS

See SPIIIWAYS

CAVI'TY FLOWS

Cavity formation at obstruction in boundary layer (6744)-...- 111

Numerical solutions of Navier-Stokes equations for separated flows due to cavitation (6736)

Supercavitating cascades with constant

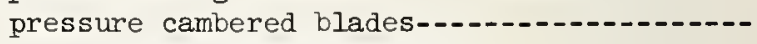
See also FREE STRFAMLINE THEORY

See also SUPERCAVITATING FLOWS

See also HYDROFOILS

CAVITY FLOWS, VENIIIATED

Effects of free surface, gravity, struts and air supply $(6646)$

see also HYDROFOILS

CHAINNELS, DRAINAGE

See DRAINAGE

CHANNELS, ENHEMERAL

See EPHEMERAL STREAMS

CHANNELS, EROSION $Q F$

See EROSION; SE CHANNELS, STABILIZATION

CHAINELIS, IMPROVEMENT OF

Channel improvement model study, Turtle Creek, Pa. (4383)- 
CHANNELS, IMPROVEMENT OF (continued)

James R., Va., channel improvement effect on

Page

hydraulic and salinity conditions in

estuary; model (5651)

Laboratory research on spur and vane dikes

(6042) - 208

Sandusky River near Fremont, Ohio (564l).....- 199

CHANNELS, IABORATORY

See FACIIITIES

CHANNEIS, RIVER

See RIVER CHANNELS

CHANNELS, SHIP

See SHIP CHANNELS

CHANNELS, SPAWNING

See FISH

CHANNELS, STABIIIZATION OF

Armoring drainage channels with riprap

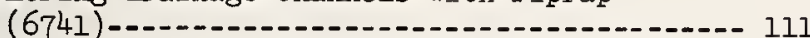

Effect of floods on stabilization measures (4316)--..- 161

Erosion of cohesive soils, flume study (6047)- 5

Riprap stability in straight and curved trapezoidal channels (6875)-......-.-.-- 216

With gravel (5165)-........ 21

See also RIVER CHANNELS

CHANINELS, VARYING SECTION

Head loss in irregular channels from nuclear excavation (6873)-...-.- 216

Minimizing pressure losses in ducts with re-entrant walls and cavities (6272)-.....-- 26

See also OPEN-CHANNEL FIOW

CHECK TOWERS

Flow and air entrainment in check towers of main aqueduct, Canadian River Project (4792)-19.-2 219

CHESAPEAKE BAY

Comprehensive model (6849)

CHIMNEY DISCHARGE

See POLLUTION, ATMOSPHERIC; See PLIMES

CIRCULATION, Estuaries

Estuarine circulation dynamics (6282)-.----.-- 145

CIRCULATION, HUMAN BODY

See BIO-MEDICAL HYDRODYNAMICS

CIRCULATION, LAKES

Induced circulation and temperatures from cooling-water discharge (6622)-..........- 149

Mathematical model for circulation and and mixing in Great Lakes (5791)-.......-.- 149

Mathematical model for Langmuir circulation to help explain windrows (4252) -......... 148

Wind-driven motions in Great Lakes (5472)-.-. 88

CIRCULATION, OCEAN

Calculation of surface circulation from driving forces (6597)-_... 238

Hydrodynamic models of large-scale ocean wind-driven circulation (6788)-_........ 104

Mjxing, diffusion and circulation rates in ocean waters; windrows, Iangmuir

streaks $(6084)$
Rotating model, Antaretic Ocean $(6085) \ldots \ldots-1$

CIRCULATION, THERMO-HALINE

Analog simulation of thermo-haline circulation system (6471)-150

CIRCULATION, WIND-DRIVEN

SEE CIRCUIATION, IAKES, OCEAN

CIAFOTIS

SEE WAVES

COANDA EFFECT

Hydraulic switch, theory and experiment

(6122)-1........ 115

Jet attachment to offset Coanda walls (6058)-- 237

Sfee also FLUID AMPLIFICATION

SEE also FLIJIDIC DEVICES

COASTAL ENGINEERING

Advisory services to State of Florida (6758)--
COASTAL ENGINEERING (continued)

Manual for shore protection planning and

design (2193) -......... 182

See also COASTAL SEDIMENT

See also EROSION, BEACH

See also ESTUARIES

See also INLETS, COASTAL

See also LITTORAL PROCESSES

See also SHORE PROTECTION

See also TIDAL HYDRAULICS

See also WAVES

COASTAL INLETS

SEe INLETS, COASTAI

COASTAL SEDIMENT

Currents and sediment movement in Galveston Trinity Bays, Texas (5458)-......- 129

Effect of groin system on rate of littoral movement (2190)

Field study of quantity of sediment suspended in surf zone (2660)

Fluorescent tracer methods (4127)-........ 31

Influence of sea-level changes on shore

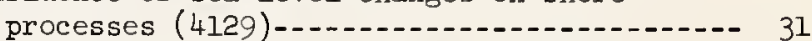

Inventory of offshore sources for beach sand (4763)

Littoral drift by combined wave and current action (4898)

Littoral drift traced, Cape Kennedy, Fla. (5281) -........ 32

Methods of by-passing sand past inlets (975)-- 181 Offshore drag-scraper to provide beach sand (5283)

Radioactive tracers for beach studies (3897)-- 183

Sand bypass and navigation, St. Lucie

Inlet, Fla. (6752)-... 32

Sand movement by wind and waves (4930)-..... 10

Synoptic field measurements of entire littoral processes (6762) -...... 33

Tracing program to evaluate natural and artificial bypassing (6757)-............. 33

See also EROSION, BEACH

See also INIETS, COASTAL

See also LITTORAL PROCESSES

See also WAVES, SEDIMENT

COATINGS

Erosion resistant materials for severe hydrodynamic environment (6428)-...-...-.-- 235

For concrete subjected to high-velocity jets (4791)

COLTECTION TROUGHS

See OPEN-CHANNEL FLOW

COLIOIDS

See SUSPENSIONS

COLORADO RIVER AQUEDUCT

Deposits causing flow obstruction in tunnel (6733) -

COLUMN SEPARATION

See CAVITATION, PIPE FLOW

CONDENSATE

Dropwise condensation of steam (6675)--1----- 77

Flow parameters for condensing mercury (6673)- 77

steam plant condensate circulation model (5392) -

CONDENSER WATER (POWER PIANT)

SeE COOLING WATER

CONTAMINATION

SEE POLLUTION

CONTRACTIONS, OPETT CHANNEL

See OPEN-CHANNEL FLOW, TRANSITIONS

CONTROLS, HYDRAUIIC

Feedback controls for canal gates keep water level constant (6222)

Load-sensjtive hydraulic control system (6092) 
CONTROLS, HYDRAULIC (continued)

Nonlinear vibrations in hydraulic

See also FLUIDIC DEVICES

CONVECTION

Convective flow accompanying absorption of soluble gas into a quiescent liquid (6832)- 48

Convective instability of transient systems

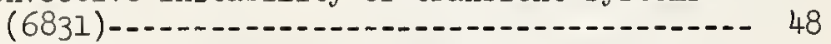

Convective processes in sunspots correlated with laboratory flows (6786).............. 104

Effect of natural convection on horizontal pipe flow (6827)-.... 48

Flow patterns in concentric spheres and

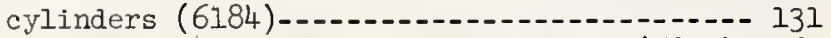

Free convection across a square cavity (6804)- 267

Free convection in a vertical two-dimensional channel with heated walls (6805)-.........- 268

In a uniform water layer beneath an ice

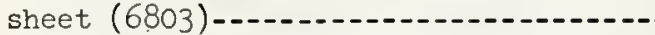

Measurements of temperature and velocity profiles across convecting liquid layers (6807)-

CONVECTION, BENARD

See BENARD

CONVECTION, CELIS

Induced by surface tension (6773)-...-.-.-.-105

See also BENARD CONVECTION

COOLTNG WATER DISCHARGE

Channel design to permit uniform velocity

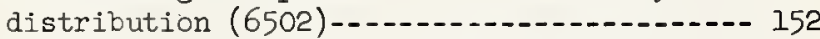

Chesapeake Bay as affected by Calvert Cliffs nuclear plant; model (6515).............. 153

Diffuser for mixing cooling water with

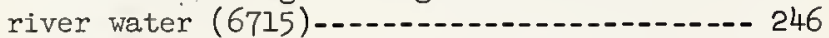

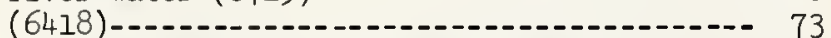

Effect on Susquehanna R. near Conowingo; Peach Bottom plant model (6513)-.........- 153

Effect on Wabash R. at Cayuga plant;

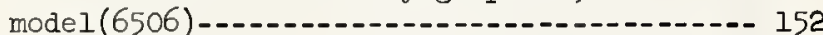

Emergency gate for cooling-water conduits at Paradise Steám Plant (TVA) (6721)-.-.-.-.-- 247

Head loss in channel, intakes and drop structure $(6504)-$

Induced circulation and temperatures from cooling-water discharge, Lake Monona, Wisc. (6622)--..- 149

Open flume design for returning water from cooling tower to intake (6720)-.........- 247

outlets to insure uniform velocity distri-

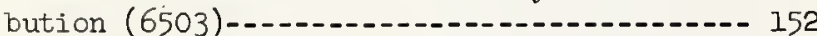

Potomac R. tidal effect on Morgantown steam plant discharge; model (6514)...........- 153

Prevention of recirculation to intake (6419)-- 73

Tidal effect on heated water, Hudson R.

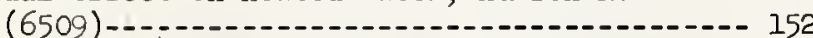

Treatment for removal of radioactive

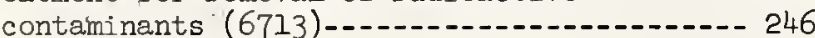

See also MODEIS

See also POLLUTION, THERMAL

See also STRATIFIED FIOW

CORIOLIS FORCE

Coupled inertial-Coriolis effects on atmospheric turbulence (6615)-........... 4 CORROSION

Pipe protection with $\mathrm{CaCO}_{3}$ coating (4135)--.-- 47

Problems in sea-water conversion (1554)-....- 8

COUETTE FIOW

Hydromagnetic stabilization (6569)--.--1-.-- 90

Supercritical circular couette flow (6172)---- 79

See also CYLTNDERS, CONCENTRIC ROTATING

CREEPING FLOW

Sedimentation of two prolate spheroids in

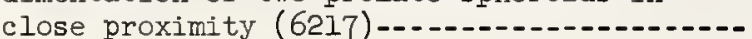

CRITICAL TRACTIVE FORCE

See SEDIMENT TRANSPORT, INITIATION

Page

CROSS CONNECTION CONTROI (49)--20-2.

CRYOGENIC IIQUIDS

Cryogenic storage of liquids in space; convective stability problems (6789)-..-.-- 104

Hydrodymamic aspects of superfluid helium (1548)-1 6

Weightlessness effect on liquid-vapor CULVERTS

interface (6338)

Erosion at outlets (6460) Hydraulic efficiency in design (1ll)-......-. 106 Hydraulic efficiency in design (1723)-.....-.- 156 Hydraulic-jump energy dissipator for culvert outlet (5457)

Hydraulics of various culvert inlets (2435)--- 217 Model study of energy dissipators (6221).....- 12 Performance of "broken-back" culverts on steep grades (5955)

Prevention and control of culvert and road

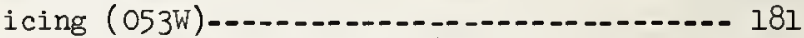

Scour protection at outlets (6206)-......-.-. 24

Used for low-flow measurements with added $\mathrm{V}$-notch (4336)-

CULVERTS, NAVIGATION LOCKS

See IOCKS

CURRENT METERS

SEe HYDRAULIC MEASUREMENTS

CURRENTS, LAKE

Drift-bottle study of surface currents of

Lake Superior (6053)-_........ 87

Dynamics of circulation in Great Lakes (5472)- 88 See also CIRCULATION

CURRENTS, IONGSHORE

Field measurements of longshore velocity

Nags Head, N.C. (5325) Review of available data and theory (5834)-.-. 184

Theory for longshore currents (4127) -...... 31 See also IITIORAI PROCESSES

CURRENTS, OCEAN

Atlantic equatorial undercurrent (3120)-....- 84

Bottom currents and sediment motion (6283)-.-- 146

Prediction of currents resulting from extreme wind system over coastal area (6754)-..-.- 33

Surface currents due to submerged disturbances in stratified ocean (6644)............. 41

CURRICULUM

See INSTRUCTION

CURVATURE EF'FECTS

Longitudinal curvature effect on turbulent boundary layer (6139)

CYLINDERS, CONCENTRIC ROTATING

As related to turbulent helical flow in annulus (4734)

Flow patterns and convection $(6184) \ldots \ldots$

Secondary flow and turbulence in circular couette flow (4654)

Speed-torque relations immediately after Taylor instability (6172)

Stability of a power-law fluid (5710)-.....-. 60

Taylor instability in Newtonian and non-Newtonian fluids (6737)............... 163

Taylor vortices in non-Newtonian fluids (5496) -

Unsteady laminar-flow analysis $(6051)$........ 1 See also TAYLOR VORTICES

\section{- D -}

DAMS

Demolition of Hales Bar dam, TVA; model (6714)--.-... 246 Design, construction and costs of rock check dams (3896) 
DAMS (continued)

Effect on downstream water temperature

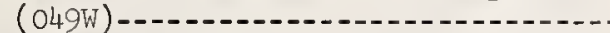

Experiments on flow through rockfill dams (4663)

Gallery drainage in large dams (771)-..-.-.- 248

Riprap stability under wave action (6486)-...- 61

Scour protection, see SCOUR

Thermal regimes in and beneath dams in artic regions (O55W) -.......................... 181

DATA ACQUISITION

Instrumentation compatible with computer analysis (O5TW) - 227

See also HYDRAUTIC MEASUREMENTS

DELTAS

Bed-load delta formation upstream of

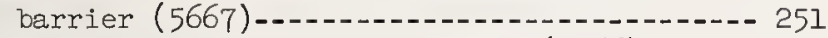

Development above detention dams (5566)-..-.-- 158

DENSITY CURREITIS

See STRATIFIED FLOW

DENSITY GRADIENTS

At air-water interface, measured optically (6133) -

See also STRATIFIED FIOW

DESALINATION

Manifold studies, flash distillation plant

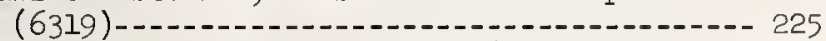

Sea-water conversion research (1554)-......-. 8

DIĆTIONARY

Hydraulic dictionary, English language (6402)- 113 DIELECTRIC LIQUID

Dynamics of, between electrodes (6293)--.-.--- 132 DIFFERENTIAL EQUATIONS

Ad hoc methods for nonlinear partial diff. eqs. (6358) 57

Nonlinear ordinary diff. eqs. in transport processes (6356)

\section{DIFFUSERS}

Effect of polymer additives on diffuser separation flow noise (6796)-...........- 113

Flow in two-dimensional subsonic diffusers (6799) - 117

For mixing condenser water in river (6418)---- 73

Pipe with wall ports for mixing condenser cooling water in river (6715)-........... 246

wide angle diffuser for low speed wind DIFFUSION

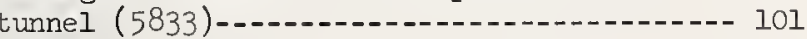

of a supercritical stream on a stagnant

pool (6642) contaminants in free turbulent shear

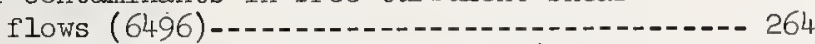
of entrapped gas in porous media (5891)------ 23

of liquid aerosols in air jet (6202)-.....-.- 102

See also DISPERSION

Turbulence structure and diffusion in rough channels (5131) - 133

DIFFUSION, EQUATIONS

Nonlinear ordinary differential equations in

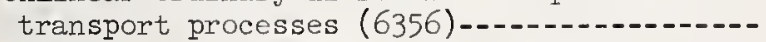

Similarity solutions for non-Newtonian flow (6357)-.... 57

DIFFUSION, GROUNDWATER

Salt water in coastal well rields (6259)......

DIFFUSION, OCEAN

Mixing, diffusion and circulation rates in ocean waters; windrows, Langmuir streaks (6084)

DIFFUSION, PARTICLE

Particle-size effect on turbulent diffusion (6688)-..... 36

See also DIFFUSION, SEDIMENT

DIFFUSION, RIVER

Mathematical model for turbulent diffusion (5688)
DIFFUSION, RIVER (continued)

Mixing of nuclear power plant condenser

water in Tennessee R. (6418) -............... 73

Stratification effects, natural rivers (6165)- 141

Turbulent diffusion, reaeration in natural

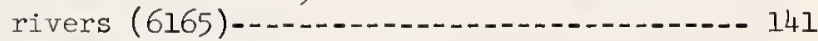

See also DISPERSION, RIVER

DIFFUSION, SEDIMENT

Particle-size effect on turbulent diffusion (6688)-.... 36

Sediment diffusion in non-uniform flow

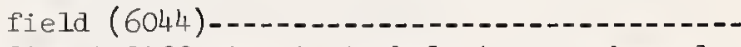

Sediment diffusion in turbulent open-channel flow (6079) -...

DIKES, SPUR

Design to provide uniform velocity between bridge abutments (3086) -.................. 124

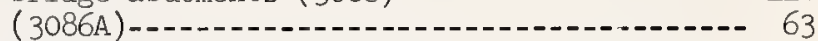

Effect of length and spacing on scour (4645)-- 63

Laboratory research on dikes for channel stabilization (6042)

DISKS, ROTATING

Thrust developed by spinning disk (5314)------ 119

Laminar flow surrounding finite rotating disk at high Reynolds No. (6101).......... DISPERSION

Airphoto analysis of waste dispersion from

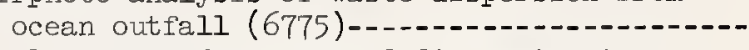

Field study of mixing and dispersion in

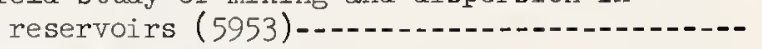
36 5

DISPERSION, ATMOSPHERIC

Buoyant plumes from high smokestacks (6105)---

Smoke dispersion modeled in a wind tunnel

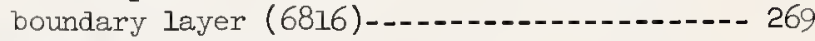

DISPERSION, CAPILIARIES

Dispersion mechanism in capillaries (6331)-.-. DISPERSION, ESTUARIES

In rivers, estuaries, lakes, oceans and

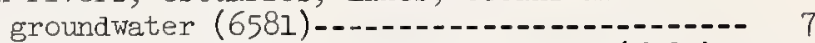

In shallow, irregular-shape estuaries (6182)-- 130

Numerical solution of unsteady estuary

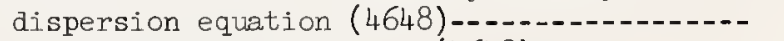

of pollutants in estuaries (4648)-.........-. 69

See also ESTUARIES

DISPERSION, PIPE FLOW

Chlorine solution injected into turbulent pipe flow (6746)

DISPERSION, POROUS MEDIA FLOW

See POROUS MEDIA FIOW, DISPERSION IN

DISPERSION, RIVER

Experimental and theoretical study of hydrodynamics of river and estuary dispersion (6649)

Longitudinal dispersion in open-channel flow and natural streams (5773)-.....-...-

Mechanies of pollutant dispersion in rivers and estuaries (6223)..............-. DISPERSIONS

Momentum and heat-transfer in liquid-liquid

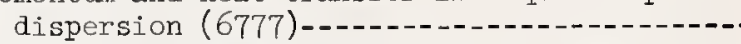

Single drop breakup in developing turbulent pipe flow (6784) See also LIQUID-IIQUID FIOWS

DISPERSION VALVES

See VALVES

DISSOLVED OXYGEN

See OXYGEN

DIVERSIONS

Castaic Dam, Calif., diversion and release system (6659)-16 DOCKS

Small-vessel I-shape dock protection (6231)--- 259 Wave uplift forces on dock (6584) see also PIERS 


\section{DOPPLER METER}

SEe HYDRAULIC MEAS., VELOCITY

SEe HYDRAULIC MEAS., TURBULENCE

DRAFT TUBES

Bibliography of causes of surges in draft

tube (6321)

Splitters and baffles to avoid flow

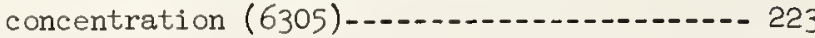
DRAG

Single particles in laminar tube flow (6280)-- 143

Wall roughness size and shape effect on drag

in circular air tunnel (5604)................... 228

Wind tunnel tests on particles of various shapes with plane-boundary surfaces (6160)-- 144

See also SUBMERGED BODIES

DRAG, CUBES

Lift and drag on a cube in a velocity-gradient finite flow field with free surface effects (5758) -

DRAG, CYLINDERS

Analytical drag relations for low Reynolds

No. (5778) -

Forces on accelerated cylinders (2265)-.-.--- 9

Shear stress distribution around cylinder by

electrochemical methods (6825)-..........-. 48

Velocity-gradient effect (4716)-.-.-.-.-.-.- 128

Wake-vortices effect in oscillating flow (6381)

DRAG, Hemispheres

Free surface effects on hemisphere on a

boundary in a velocity gradient (5134)-...- 134

DRAG, INDUCED

See LIFTING SURFACE

DRAG, PIATES

Flat plate oscillating normal to its plane (6081) -

DRAG REDUCTION

Electrolytic bubble generation effect (6645)-- 41

Foam dampeners in flexible tubes (6083)..... 97

DRAG REDUCTION, ADDITIVES

Boundary layer on disk rotating in dilute polymer solution (6738)-................. 11

Deployment methods for polymers around

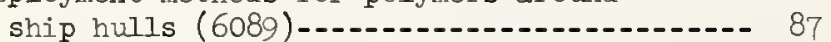

Effect of additive on impact tube (5795)-.-.-- 110

Effect of boundary layer thickness on

polymer drag reduction (6261)-..........- 147

Effect of dilute polymer solution on flow

noise (5497)-_.- 108

Effect of drag reducing polymers on wave damping in tank (6829)......................... 48

Effect of guar-gum solution on ship drag (2091)

Effect of location of additive injection (6214) -

Effect of non-Newtonian properties on drag

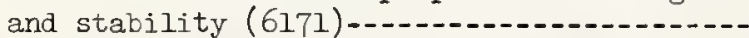

Effect of polymer additives on diffuser separation flow noise (6796)-............ 113

Effect of polymer coiling (5291)-.-.-.-.-.-- 147

Effect on turbulent shear layer (6214)--.---- 67

High polymer and low mol. wt. micellar-

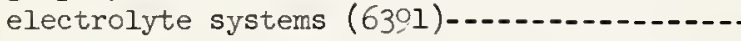

Laminar and turbulent flow with homogeneous and injected additives (6379) -

Polymer effect on boundary-layer turbulence

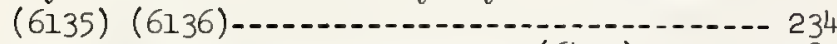

Organic soap-solution additives (6407)-.....-. 82

Polymer effects on resistance and wake of flat plate (6645)

Polymer effects on wall-pressure fluctuations

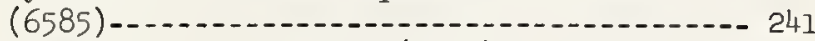

Polymer-structure effect (6404)-........... 82

Skin friction to be measured in pipe flow of

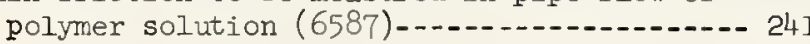

DRAG REDUCTION, ADDITIVES (continued) Page

Spheres falling in polymer solutions (6696)-.- 38

Surface pressure fluctuations in dilute polymer solutions (6735)-................ 11

Turbulence structure in drag-reducing organic solvents (6405)-................... 82

Turbulence structure studied using Doppler

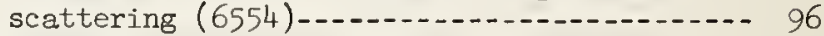

Unsteady pipe flow of polymer solutions (6695) - 38

Viscoelastic stresses in dilute polymer solutions (4868)-......................... 241

Viscosity of polymer solutions (6408)....... 82

See also NON-NEWTONTAN FIOW

See also POLYMERS

DRAG REDUCTION, COMPLIANT WALI

Experiments in water channel (5196)-......-.- 45

Experiments on turbulent pipe flow (4892)-..-- 218

DRAG REDUCTION, FLOW MEAS.

Anemometry technique for accurate velocity profiles (6406) --.-

Optimum suction slot form for laminar boundary

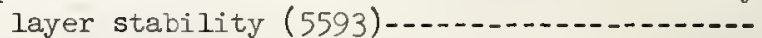

DRAG, SAND GRAINS

Seepage effect on bed forces (6525)-...-.-.-. 139

See also SEDIMENT TRANSPORT, INITIATION

DRAG, SEMI-CIRCULAR DISK

Drag and surface waves in flow around disk in finite 3-dimensional field (5761)-....- 137 DRAG, SLENDER BODIES

Wind-induced oscillations of elastic slender

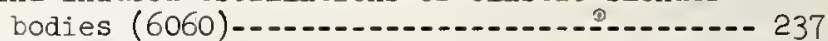

DRAG, SPHERES

Falling in dilute polymer solutions (6696)-..- 38

Force on two spheres in Stokes flow (6790)---- 104

Forces on large roughnesses in open-channel

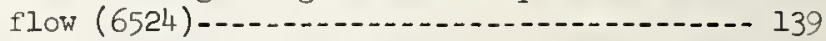

Sphere resting on hypothetical streambed

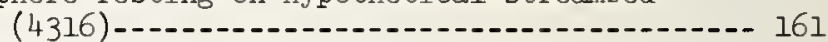

Wave forces on submerged spheres, field study

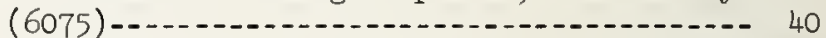

Motion of spheres in highly turbulent field (6076)-....... 80

Sphere assemblages in packed and fluidized beds (6056) -................................. 263

Stokes flow around accelerated sphere (3799)-- 88

Viscous flow in cylindrical tube containing

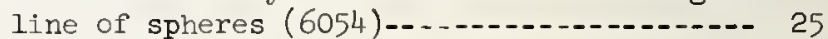

DRAG, STOKES

Force on two spheres in Stokes flow (6790)--.- 104 DRAG, UNSTEADY FLOW

Circular cylinder in oscillating flow (6381)-- 40 Flat plate oscillating normal to its plane

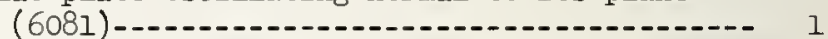

Forces on accelerated cylinders (2265)-.-.-.- 9

Pressure-distribution time history for bodies in uniformly accelerating fllow (6082)-...-. 1

Stokes flow around accelerated sphere (3799)-- 88 See also SUBMERGED BODIES

DRAG, VEHICLES

Cross-wind effect on rapid-transit train (6123) -

Lift, drag and moment for wedge-like bodies as function of separation point (6740)-......- 111 DRAINAGE

Approximate solutions for non-steady vertical drainage of soils (5981) -............... 160 Assessment procedure for drained land (011W)-- 48 Contribution of partially saturated zone in drainage of fine-textured soil (4826)-...-.- 157

Dimensionless nomograph for vertical free drainage from various soils (5897)-.......- 43 
DRAINAGE (continued)

Effects of gradual urbanization of originally

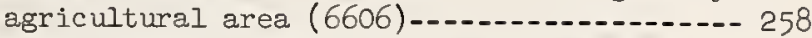

Factors affecting flow of subsurface water near drains (6534)............................... 140

Field study of surface and subsurface

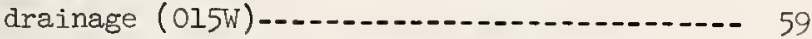

Gravity drainage of initially saturated

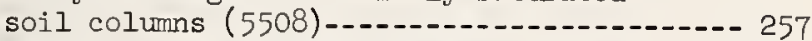

Methods for interception drainage on wet, seepy, sloping land (4819)-_............. 156

New materials, equipment and techniques for drainage of agricultural land (4271)-...-.-. 156

Reclamation of salt-affected non-irrigated soils in N. Dakota (4832)

Relation of water table to drainage discharge and aquifer for transient case (6534)-...-.- 140

Removal of excess soil sodium by gypsum and

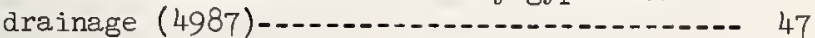

Similitude for flow into subsoil drains (5892) -........ 23

Subsurface drainage of blount silt loam (4183)-........ 98

DRAINAGE, BUIIDING

Flow in horizontal building drainage systems (6710)

Mechanism of air entrainment in vertical drains, and reliability of backwater valves (4043) (6710)

DRAINAGE, DRAINAGE CHAINELS

Armoring channels with riprap; design procedures (6741) - 11$]$

DRAINAGE, DRAINAGE SYSTEMS

For irrigated areas of the northwest (5981)--- 160

For St. Lawrence-Champlain area (4819)-------- 156

For the Imperial Valley (4854)-............ 163

Optimal design of systems (5825)-.......-.-. 72

Physical, legal and economic aspects of costs among drainage districts (020W)-........ 59

Systems design for lower Mississippi Delta (4332) -...... 161

Systems design in Rio Grande plain (4844)-..- 162 DRATNAGE, DRAIN PIPES

Efficiency tests of perforated subdrain pipe (6774)

DRAINAGE, GALLERY

See DAMS

DRAINAGE, HIGHWAY

Bound-rock ditch linings (5489)--.-.-.-.-.-- 25 Computer-aided highway drainage design (6422)- 74

Efficiency tests of perforated subdrain pipe (6774)-.---non

Erosion prevention in roadside channels

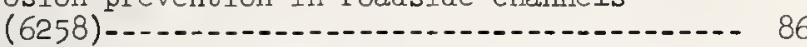

Evaluation of problems in N. Carolina (6260)-- 86

Heat transfer calculations for degradation of permafrost under highways (052W)-...-.--- 181

DRAINAGE, PAVEMENT

Effect of surface grooves (6286)-.-.-...-.-. 82

DRAINAGE, TILE DRAIINS

Computer solutions for subsurface drainage

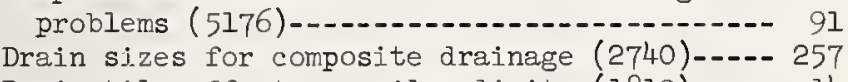

Drain tile effect on soil salinity (1819)-.--- 14

Effect of spacing, cropping practice and

time of year (5033)

Optimu drain spacing for sloping irrigated

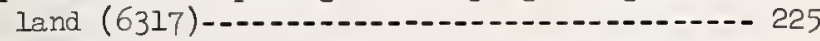

Sediment transport capacity of circular drains (3490) - -

DRAINAGE BASINS

See WATERSHEDS
DRAINING TANKS

Page

Critical submergence for vortexing (6797)-.-.- 114

DRAWDOWN, WELLS

See WELLS

DREDGE PUMPS

See PUMPS, DREDGE

DREDGING

Feasibility study of wave-powered sand dredge (5836)

Rotating cutterhead efficiency on hydraulic suction dredge (6780)

Test of water-jet apparatus for sand pumping (6779)

DRILLING PIATFORM

Theoretical study of wave forces (6232)--.--.-- 259

DROP INLETS

See INLETS

DROPIETS

See DROPS

DROP SHAFTS

For deep tunnel drainage; model study (6747)- 112 DROPS

Mechanics of cloud droplet coalescence (6790)- 104

Oxygen transfer to water drops (6698)....... 38

Shape and velocity of drop approaching an

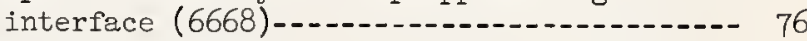

Single drop breakup in developing turbulent pipe flow $(6784)$

DROPS, IMPACT

SEe IMPACT

DROP STRUCTURES

Hydraulic performance studied in model for Gering Valley Project, Nebraska (3915)-.-.-- 192

Prefabricated units for irrigation water control (5209) -..-.-.-.-.

See also MODELS, DROP STRUCTURE

DUNES, BED

See BED FORMS

DUNES, SAND

Dune building with sand fences (4760)-......- 183

Mechanics of dune building at Cape Hatteras

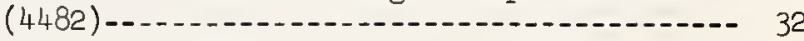

See also SEDIMENT TRANSPORT, BY WIND

- E -

EDDIES

See VORTEX MOTION

EDDY VISCOSITY

See TURBULENCE

EDUCATION

See INSTRUCTION

ELBOW METER

See HYDRAULIC MEASUREMENTS

ELECTROKIIETICS

Influence on permeability of fine sand (4209)- 108 Streaming potential in soil capillaries (5450) - potential in soil capillaries 135

Use in removal of pollutants from water (6600) -

ELECTRO-MAGNETIC EFFECTS

Thrust generation by electro-magnetic acceleration of colloids (6680) ENERGY DISSIPATORS

Baffled chute for Conconully Dam (6325)--.---- 226 Design rules for roller dissipators (3917)---- 193 Expansion-chamber type for Mica Dam (6437)--.- 270 Expansion-chamber type, New Don Pedro Dam

(6446)-_............ 271

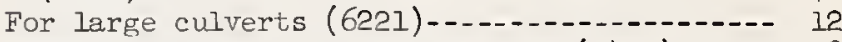
Hydraulic-jump for culvert outlet (5457)-.-.-- 128 Investigation of many dissipator types (066W) - 227 Use of large roughness elements for energy

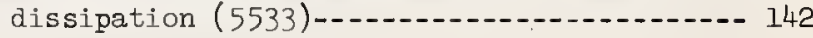


ENERGY DISSIPATORS (continued)

See also HYDRAULIC JUMP

See also MODELS, ENERGY DISSIPATORS

See also STIIIING RASINS

ENTRATMMENT, AIR

See AIR

ENTRAINMENT, IN PIPE FIOW

See PIPE FIOW

ENTRAINMENT, JETS

See JETS

ENIRAINMENT, SAND

SEe SEDIMENT TRANSPORT

ENTRANCE IENTGTH

SEE INLET LENGTH

ENTRAINMENT SEPARATION (6124)

EPHEMERAL STREAMS

Flood wave movement in natural ephemeral

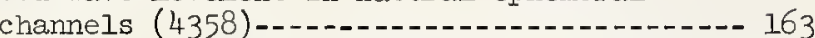

Used for groundwater artificial recharge (5396)

EQUTVATENT DTAMETER

Rectangular-conduit experiments (6284)-.....-. 81

EROSION

Criteria for rock-sausage placement for erosion prevention (6377)-_..........-.-106

Erosion characteristics of riprap and gravel

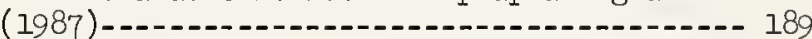

Inverted filters to protect fine-grain

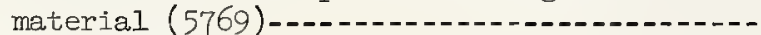

See also SCOUR

EROSION, BEACH

Coastal erosion and protection in Florida. (4479) -

Correlation of storm wave attack and beach erosion (4762) - 183

Hilo Bay, Hawaii, beach model study (5895)-..- 40

Influence of sea-level changes (4129)-......- 31

Lake Michigan field study (1863)............. 46

Manual for shore protection planning and design (2193) -........ 182

Model study for protection of part of Waikiki

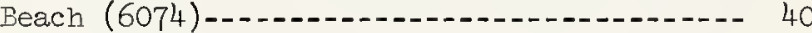

Revetment design and other protection methods (4479)

Scour in front of sea walls (5552) -........ 124

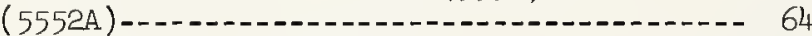

See also COASTAL SEDIMENT

See also IITTORAL PROCESSES

See also WAVES, SEDIMENT

EROSION, CAVITATION

See CAVITATION

EROSION, DRATNAGE CHAINNEL

Armoring channels with riprap; design

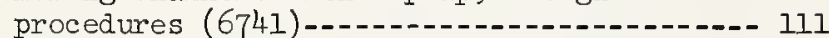

Criteria for erosion prevention in roadside channels (6258)............................. 86

EROSION, GULLY

Gully control and erosion reduction from mountain stream channels (3896)-........-. 177

EROSION, SCOUR

See SCOUR

EROSION, SOIL

Cohesive-soil erosion and channel stabilization

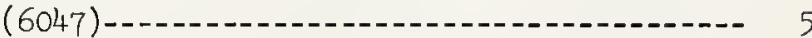

Control of erosion in areas denuded by fire

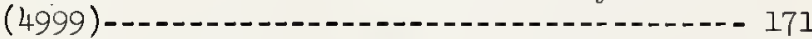

Control practices for Texas blackland

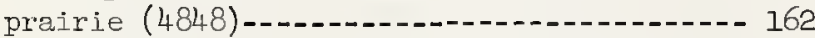

Detachment by raindrop impact and flowing

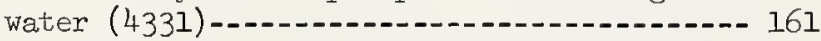

Effect of forest cover control, Mississippi (2914) - 178

Effects of physical and chemical soil

properties (4275)

Effects of surface mulches (4182)-.-------.- 97
EROSION SOIL (continued

Page

Erodibility of some Hawaii soils (4997)-.....- 170

Erosion-control effects on Pine Tree Branch

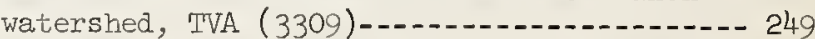

Hydrodynamics of overland flow with rainfall

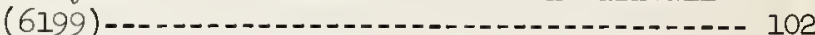

Investigations of erosion control and water

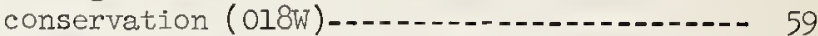

Mathematical models of erosion process (4275)- 156 Mechanics of erosion by surface runoff (4182)- 97

Mechanics of erosion by surface runoff and rainfall impact (4275) -................ 156

Properties of cohesive soil related to

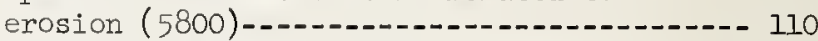

Relation to rainfall kinetic energy (3424)-..- 47

Relation to soil properties, rain and surface characteristics (3808) -................ 97

Resistance of cohesive soils (4317)-........- 161

Soil type, slope and vegetation effects, Upper Bear Creek, TVA (4884)-..........-.- 249

Water yield and erosion, mid-Columbia River

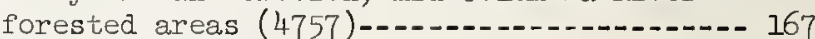

See also EROSION, GULLY

EROSION, STREAMBANK

Effect of erosion and sediment transport on trout streams (3890)-..................... 166

\section{ESTUARIES}

Computer simulation models of physical, chemical and biological aspects of Duwamish River (6833)-........................... 146

Dispersion, shallow estuaries of irregular

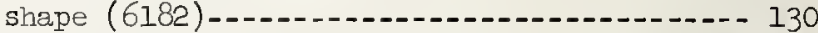

Dynamics of estuarine circulation (6282)-..-.- 145

Estuarine ecology studies (O5OW)-.-.-.-.-.-. 146

Experimental and theoretical study of hydrodynamics of dispersion (6649)............. 41

Finite-difference modeling of river and estuary pollution (6770)-............... 84

Flume studies of salinity intrusion as affected by physical and hydraulic features of estuaries (1986)-_-_-_-_-_-..-. 189

James R., Va. channel improvement effect on hydraulic and salinity conditions in

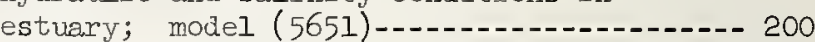

Mechanism of pollution dispersion (4648)-.-.- 69

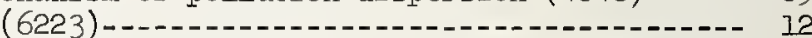

Rheological properties of estuarine sediments

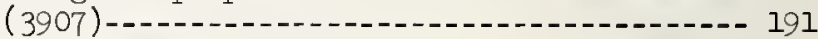

Role of passes in gulf-bay water exchange, Texas Gulf Coast (6183)-.............. 130 St. Lawrence River Salinity intrusion (5949)- 257 Salinity intrusion and diffusion (6415)-...-. 72 Salinity intrusion, see also SAIINITY

Salinity prediction using nonlinear systems

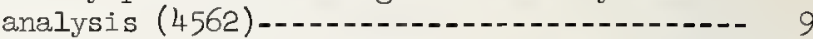

Shoaling model study, Umpqua R., Oreg. (6026)- 204 Shoaling in Columbia estuary; model (4396)-.-. 194

St. Lawrence River and Estuary; mathematical model (6603)

Tidal computations in estauries and canals

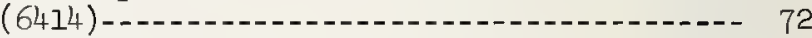

Tidal motion in St. Lawrence estuary,

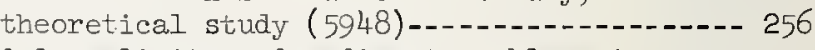

Tidal, salinity and sediment problems in Maracaibo estuary (5119)--.-.-.-.-.-.-.-- 70 See also DISPERSION, ESTUARIES

See also MODELS, RTVER

EVAPORATION

Additives for snow evaporation control (5395)- 21

Data for Tennessee Valley (765)............. 248

Effect of waves, white water, turbidity on losses from streams (5787)-...-........ 92

Effect on reservoir yield in New England

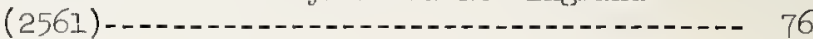

Estimates of free-water evaporation (5664)---- 218 
EVAPORATION (continued)

From small stock-watering ponds in desert areas (3057) -..... 43

Losses, from a climate standpoint (5442)-..-.- 134

Pan evaporation; hydrodynamics and energy budget (5305) -...... 28

Reduction by selective withdrawal from

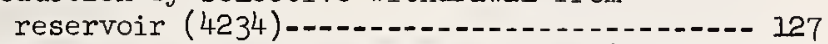

Suppressants to reduce snowpack loss (4996)--- 169

Surface-wave effects (6178) -............ 27

EVAPORATORS

Brine-piping model study (6318)

EVAPOTRANSPIRATION

Evaluation of an instrument for peat bogs (3887) - 165

Use of atmospheric humidity in estimating (OR3W) -

EXITS, PIPE

See PIPE FLOW, EXITS

EXPANSIONS

Energy relations in laminar flow at twodimensional expansion (5909) - 56

Influence of approach slot length-width ratio, expansion ratio and eccentricity on twodimensional expansions (6731) -

Stability criteria, two-dimensional expansion

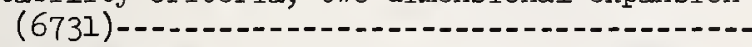

Stable eddies at abrupt expansions in pipe flow (1875) -....

See also OPEN CHANNEL FLOW, TRANSITIONS

See also PIPE FLOW

EYE

See BIO-MEDICAL HYDRODYNAMICS

$$
-\mathrm{F}-
$$

\section{FACIIITIES}

Hydroballistics tank (4867)

Laboratory equipment for undergraduate

courses (5484) -

Electronics Lab. (6372)-.... 242

Performance of large laboratory flume (5831)-- 101

Ship dynamics test machine (5301)-......- 12

FACILITIES, WATER TUNNEL

Blowdown type for pipe-flow tests (6587)--.--- 241

For current-meter calibration (6452)-.-.---- 237

The Garfield Thomas Water Tunnel (2832)-....- 94

FACILITIES, WAVES

General purpose laboratory generator (5995)--- 253

Generator and absorber studies (6281) -...... 143

Wind-wave flume (6072)

See also WAVES

FACILITIES, WIND TUNNEL

Design of low-speed general-purpose tunnel

(5833)--- 101

FALL VELOCITY

Cylinders and disks; effect of surface

texture ( 5165$)$

Of spheres in open-channel flow (5165)
Particles in turbulent environment (5302)-..(6563)-

Two prolate spheriods in close proximity,

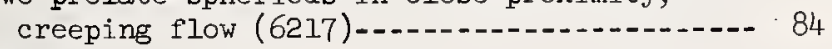

\section{FIIM FLOW}

Mass transfer from liquid film to hot gas

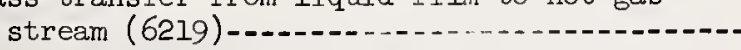

Momentum transfer in climbing film flow in annular duct (6776)

See also CONDENSATE

See also OVERLAND FIOW

See also SHEET FLOW

FILMS

Fluid mechanics, educational films (3739)-.---
FILMS, SURFACE

Effect of stationary surface film upstream

Page of object in free-surface flow $(6376) \ldots 26$

Film on gas nuclei; effect on water tensile strength (6378) FIITERS

Coarse media effects on properties of recharged water (2535)-_... 47

FIITERS, INVERTED

For fine-grain material (5769)

FIITRATION

Silt-carrying water flowing through porous media (5820)

See also POROUS MEDIA FIOW

FIN-BODY COMBINATIONS

See SUBMERGED BODIES

FISH CONTROL STRUCTURES

Artificial spawning channel for chum salmon (6834)-...- 146

Canal fish concentration for counting purposes (6310) -

Canal velocity barrier for spawning-fish control (6311)

Silt deposited by flow in artificial spawning grounds (5437) 10

Spawning-bed cleaning device for canal (6313)- 224

Spillway and stilling-basin fish passage characteristics (6164)-... 144

\section{FISH RESEARCH}

Effect of logging on water quality of Alaska pink salmon streams (3535)-..........-146

Effect of streambank erosion on trout streams (3890)

Influence of water quality on salmon in
Duwamish estuary (O5OW)

Logging effect on Alaska salmon streams (2654) also FISH CONTROL STRUCTURES

See also FISH
ISH PROPULSION

Swiming-body theory and experiment (6209)---- 234 FITTINGS

See PIPE FLOW

FLASHBOARDS

Forces on flashboard mounted on parabolic spillway crest (5910)

FIIP BUCKET

See MODELS, ENERGY DISSIPATORS

FIOATING BODIES

Hydrodynamic mass for floating and submerged

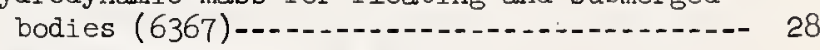

See also WAVES, FLOATING BODIES

FLOOD CONTROL

Ansonia-Derby flood protection project, Conn. (6860) - 213

Clay Creek, Colo., effect of dam on 1965. flood (6478)-... 244

Illinois River model study (5549)-........ 46

Los Angeles County; San Gabriel River. improvement; model study (6880)--.---186

See also MODELS, RIVER

FLOOD DAMAGE, to corn (Ol9W)

FLOOD PLAIN FLOW

SEe OPEN CHANNEL FLOW, OVERBANK

FLOOD ROUTING

Analog computer used to route floods through reservoirs (5657)

Computer models for Weather Bureau river forecast centers (5664) - 218

Computer simulation (4565)-...-...- 10

Numerical integration of unsteady-flow equations by three methods (6257)........ 85

Tests on Mississippi Basin model (236) -.....- 186

See also FLOOD WAVES

FLOOD WAVES

Flood routing in irregular channel (3476)....- 
FIOOD WAVES (continued)

Velocity through channel-flood plain geometries (6197) - -

see also FLOOD ROUTING

FIOODS

Bank seepage effect on hydrograph (022W)-...-- 61

Bank storage in natural streams (3428)-.....-. 54

Forecasting snowmelt floods (5997)-.......-.- 254

Forecasts for Fraser River, Canada-.-.-.-.--- 254

Hydrographs for ephemeral channels (4358)....- 163

Hydrology of frozen ground floods (033W)------ 45

Hydrometeorological research for design-flood criteria (6154)-... 218

Mathematical models of small watershed

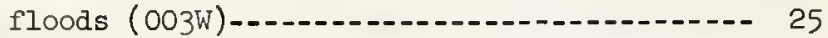

Mean channel flood related to basin characteristics for small Missouri basins (4662).... 81

Minnesota River, 1965 flood study (5801)-.-.-- 110

Peak floods, small Missouri basins (6287)-..-- 82

FLOODS, FREQUENCY

Frequency modification due to impoundments

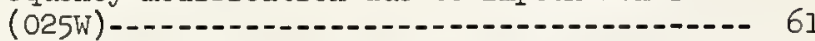

Modified station-year method (6287)-.-.-.-.-. 82

Urbanization effects on frequency (5558)-...- 78

FLOW LOSSES

Channels with periodically varying section

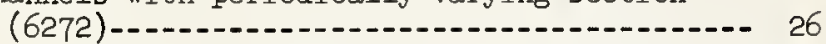

Elastic pipes, bellows, bends; vibrations

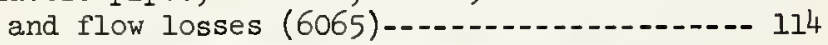

See also OPEN-CHANNEL FIOW, RESISTANCE

See also PIPE FIOW, IOSSES

FLOW METERS

See HYDRAUIIC MEASUREMENTS

FLOW NOISE

See HYDRODYNAMIC NOISE

FIOW TUBES

See HYDRAULIC MEAS., FIOW METERS

FLOW VISUALIZATION

Hele-Shaw source, sink and circulatory

flow (6472)

Separated flow behind bluff bodies studied in glycerol-solution tunnel (6580)-.........-. 255

FLOW VISUAIIZATION, HYDROGEN BUBBLES

Applied to flow in fluidic devices (6371)-...- 29

Evaluation of use for quantitative velocity determination (6810)

FLUID AMPLIFIERS

Hydrodynamic noise transmission in amplifiers (5913)-.......... 45

Jet attachment to offset Coanda walls (6058)-- 237

Stage produced noise (6119)-_............... 46

Switching and starting phenomena of bistable

fluid devices (6370)

See also FLUIDIC DEVICES

FLUIDELASTICITY

See HYDROELASTICITY

FLUIDIC DEVICES

Flow visualization with hydrogen bubbles

in fluidics (6371)

Jet reattachment at low Reynolds No. (5537)-.- 143

See also FLUID AMPLIFIERS

See also HYDRAULIC SWITCH

FLUIDIZED BEDS

See BEDS

FLUID IINES

Propagation of disturbances in fluid

lines (4197)

See also PIPE FIOW

FLUME, IABORATORY

See FACILTTIES

FLUME, MEASURING

See HYDRAUIIC MEAS.

FLUSHING SYSTEM

For Victoria ship channel, Tex. (5636)-...-.- 198
FLUTTER

See VIBRATIONS

Page

FORMULAS, HYDRAULIC

Derivation by dimensional matrix analysis (6401) -...-.

FREE SHEAR FLOWS

See TURBULENCE

FREE STREAMLINE FIOW

Finite-difference techniques for cavity, jet and seepage problems (4219)-_...- 115

Over discontinuities in boundary layer (6744)-

See also CAVITY FIOWS

See also SEPARATED FLOW

FREE-SURFACE FLOW

Non-linear free surface planing theory

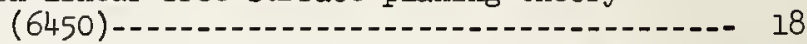

Shear flow characteristics over sinusoidal

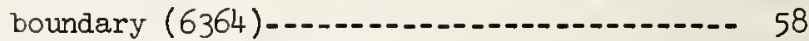

See also OPEN CHANNEI FLOW

FRICTION

See DRAG

SEe OPEN CHANNEI FLOW, RESISTANCE

See PIPE FIOW, IOSSES

See ROUGHINSS

FRICTION REDUCTION

See DRAG REDUCTION

FUEL SLOSHING

See SIOSHNG

$$
-G-
$$

GAGES

See Hydraulic Measurements

GAS DUCT

Flow distribution studied, for inlet to electrostatic ash collectors (6725)-....-.- 247

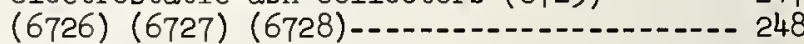

GAS NUCLEI

See CAVITATION

GATES

Air demand and piezometric measurements of tandem gate, Navajo Dam (4960).......-. 220

Air demand tests, Trinity Dam, Calif. (4958)- 220

Automatic control of radial gates (4802) -..-- 220

Calibration of gate systems by models (6745)- 111

Closure forces on turbine intake gate, Tims Ford (TVA) (6722)-_... 247

Flap-gate oscillation tests (5950)-...-...-.- 257

Gate-hoist cylinder pressures measured at Nolin Dam, Ky. (5243)

High-pressure slide gate, Morrow Point Dam outlet works (5335).....................-. 221

Pressure fluctuations at gated outlet works (5321) - 55 (5647)

Quick-closing emergency gate for cooling-water conduits at Paradise Plant (TVA)(6721)-..-- 247

Seals studied at prototype head in laboratory (5338)

See also MODELS, GATES

GATES, RADIAL

Automatic gate control with orifices (4802)-- 220

Discharge coefficients for radial gates (5863)-......... 15

(3612)

GATES, SLUTCE

Development of general flow equations for gates in rectangular channels (6633)...... 251

Flow immediately below submerged sluice gates (6632) -...-..... 251

Irrotational potential flow under a sluicegate $(6078)$ 
As flow measuring devices (6694)

GREAT IAKES

Hydrology of Great Lakes - St. Lawrence

basin (3031) - 18

see also IAKES

GREAT SAIT IAKE, Hydrology of (O46W)-...-.-.-.- 141

GRID TURBULENCE

See TURBULENCE, GRTD

GROINS

Effect of groin system on rate of littoral movement (2190) also COASTAL SEDIMENT

See also

Analytic techniques for determining flow fields (5819) -.... 1

Basin management and optimum ground/surface water use (4932)

Flow in the capillary zone (5816) -.......-. 11

Flow system in Delmarva peninsula (ooTw)-...- 29

Geophysical methods employed to find hydrologic properties of substrata (2658)-_..-.-. 175

Mathematical model of stream-aquifer

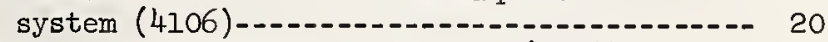

Movement, in highway landslides (5368)-.....- 43

Optimizing conjunctive use of surface and groundwater (5749) -......... 135

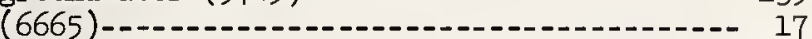

Periodic evaluation of storage, TVA (780)-.-.- 249

Physical and biological changes resulting from man's activities (002W) -........... 24

Protection from saline intrusion in Baton Rouge area (5713)-.... 67

Quality change at Severance, Colo. (5880)--.-- 22

Regions analyzed by analog computer (5657)-..- 51

Relation of pumping lift to economic use of groundwater for irrigation (6703)-.....- 44

Seepage patterns to wells for unconfined flow (014W) -.......... 59

Transient effects on groundwater storage due to reservoir drawdown (6212)

vertical movement estimated from earth's thermal profile (5839)

See also AQUIFERS

See also POROUS MEDIA FLOW

GROUNDWATER, POIJUTION

Advance-warning techniques (6163)-......-.-. 144

Lateral dispersion of contaminants in porous media (6216)

Travel velocity of contaminants (6463)-...-.- 19

GROUNDWATER, RECHARGE

Coarse media effects on properties of recharged water (2535)

Dispersion in pumping and recharge (3748)-.-- 68

Effect of forest cover (3890)-...-166

Estimation methods near margins of plateau

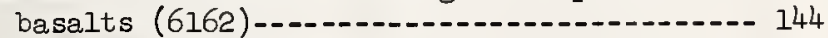

From ephemeral streams (4106)-..........- 20 (5396) -............. 21

Management and recharge in California (2181)-- 163

Principles, facilities and systems for recharge in southern plains (5216)-.......- 162

Silty-water effect on infiltration in alluvial channels (5349)

GROUNDWATER, STRATIFIED

See STRATIFIED FLOW, POROUS MEDIA

GUIF STREAM

Numerical forecasting model (6593)-....... 238

GUULY EROSION

See EROSION

$$
-\mathrm{H}-
$$

HARBORS

Barber's Pt., Oahu, model (6073)-...- 40

HARBORS (continued)

Breakwaters, see BREAKWATERS

Brunswick, Ga., shoaling model study (5648)-- 200

Docks, see DOCKS

Hilo Harbor, Hawaii, seiching study (5894)--- 40

Pollution dispersion and shoaling, Charleston Harbor, S.C. (5640)

Seiche prediction and simulation with

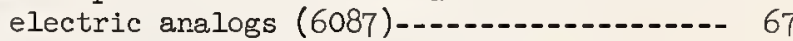

Tidal current changes due to dredging and causeway, Vancouver (6250)-_......-.-. 260

Wave action in small-boat harbor, Dana Point, Calif., model (5642)-.....- 199

Wave-induced oscillations of small moored vessels (5014) (5228) - 195

HAWSERS

Development of hawser stress transducer (1004) -

HEADERS

Pressure-flow rate characteristics of headers having uniform cross-sections (6806)-....- 268

HEART, ARTIFICIAL

See BIO-MEDICAL HYDRODYNAMICS

HEART LUNG MACHINES

See BIO-MEDICAL HYDRODYNAMICS

HEAT TRANSFER

At and near wall in turbulent pipe flow (6568)---1.--

Boiling heat transfer from rotating cylinder (6459)-..... 272

Calculation techniques for change in permafrost level (O52W)-.....- 181

Effect of turbulence promoters on transfer through laminar boundary layer (6571)-..-.- 90

Film and nucleate boiling between solid and various liquids (6709)................ 45

From warm water jets discharged into lake (6622)-_..-149 149

In dropwise condensation of mercury (6673)--- 77

In dropwise condensation of steam (6675)-.--- 77

In turbulent viscoelastic flows (5960)-...-.-. 147

In turbulent pipe flow with internal heat sources (6109)-.... 59

Jet fllow on curved wall (6456)-..........- 272

See also CONVECTION

HELE-SHAW FLOW

Source, sink and circulatory flow visualization (6472)-_..- 179

HEAVY WATER

Circulation in nuclear reactor; manifold and vortex problems (6251)

HIGHWAYS

Culverts, see CULVERTS

Drainage, see DRAINAGE, HIGHWAY

Prevention and control of culvert and road HOSE icing (053W) -... 181

See PIPE FLOW, FLEXIBLE TUBE

HOT WIRE/FIIM

SEe HYDRAUIIC MEASUREMENTS

HURRICANE

Mathematical model based on equations of viscous turbulent f'low (6542)

HURRICANE BARRIER

See HURRICANE SURGE

HURRICANE SURGE

Effect of barrier on navigation in East

Passage, Narragansett Bay, R.I. (3590)--.-- 190

Galveston area, Texas, surge model (6025)---- 204 HYDRAUIIC ANALOGY

Application to intemal subsonic flow (6489)- 181 HYDRAUTIC CONTROLS

See CONIROLS 
HYDRAULIC FEED SYSTEMS

Structural-motion effect on dynamic

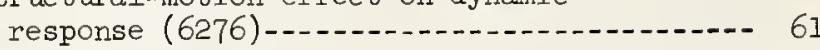

HYDRAUIIC FILTERS

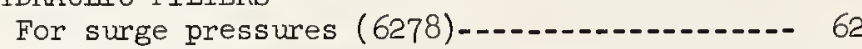
HYDRAUIIC JUMP

At abrupt bottom-elevation change (2161)-.... 126

Bed roughness effect (6643)-............... 253

Bed shear as index of efficiency (5532)-.-.-.- 145

Below abrupt symmetrical expansion (6635)-.... 252

Characteristics of circular jump (5164)-..... 21

Chute and baffle block pressures (3994)-.-.--- 219

Design charts relating jump characteristics

(1467)-..-189

Effect of submerged jets (5468)-_........-. 81

General similarity curve for jump profile

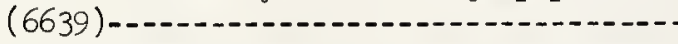

Insuring jump formation inside steep-grade

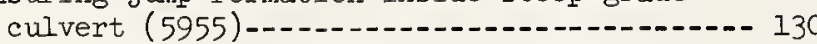

Sector of circular jump used at culvert outlet (5457)-128

Shock transition, hydraulic jump and vortex breakdown (1548) -

Solitary wave theory applied to undular jump (1467) -.... 189

HYDRAULIC MEASUREMENTS

Data acquisition systems compatible with computer analysis (O5TW)

HYDRAULIC MEASUREMENTS, AIR-WATER INTERFACE

Density-gradient near interface measured with interferometer (6133)-.............- 233

HYDRAULIC MEASUREMENIS, CURRENT METERS

Calibration facility for oceanographic

meters ( 5793 )
Calibrations compared between towing tank and water tunnel (5615) - 218

Effect of proximity of fittings (063W)-.-.---- 227

Feasibility of rating meters in a velocity

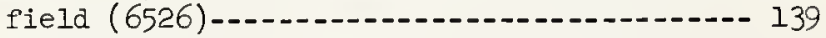

Oceanographic current-meter calibration

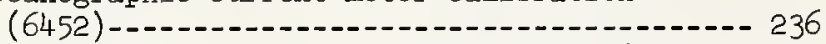

Ott-type meters for turbine discharge (4441)-- 244 Turbulence effect on Price meters (5911)..... 56 HYDRAUIIC MEASUREMENTS, DISCHARGE

Acoustic flow meter tested at Sumersville Dam outlet works (5643)......... 199

ott-type current meters for turbine discharge

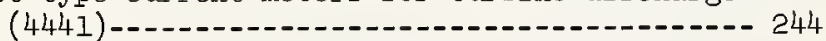

Radioisotope flow measurement in high-head

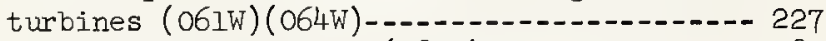

Using buoyant particles (5829)-........... 80

See also HYDRAULIC MEAS., CURRENT METERS

See also HYDRAULIC MEAS., FLOWMETERS

See also HYDRAUIIC MEAS., STREAMFIOW

HYDRAULIC MEASUREMENTS, DOPPLER METER (5075)--.- 227

HYDRAULIC MEASUREMENTS, ELBOW METER

For silt-clay-water slurry (5172)-...-.-.-. 63

Irrigation-system measurements (5219)-.....-. 163

To measure suspension flow and concentration

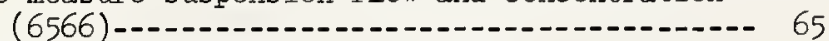

HYDRAULTC MEASUREMENTS, FLOW METERS

Acoustic flow meter tested at Summersville

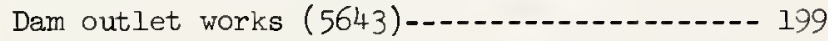

Calibration facility for high pressuretemperature water (3623)-......- 240

Calibration for high pressure steam and water (4001)-...- 240

Calibrations of large ( 8 to 24 inch) meters (6835)-...... 153

Calibration of magnetic flow tubes (5963)-.--- 151

Calibration of magnetic flow tubes, nozzles

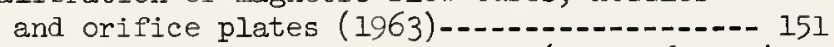

Calibration of nozzles and meters ( 1 to 16-inch)

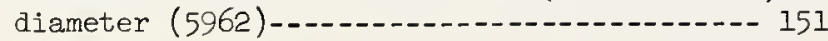

HYDRAULIC MEASUREMENTS, FLOW METERS (continued) Page

Calibration of open flow nozzles and flow tubes (3859) (4255)-_............. 151

Calibration of 6 to 48 -inch flow tubes (5279)-1...-151

Dynamic effects on discharge coefficient (5022) -......- 151

New form of compact differential pressure meter for pipe lines (5804) HYDRAULIC MEASUREMENTS, FLOW NOISE

Random signal analysis techniques (6134)-...- 234 HYDRAULIC MEASUREMEIVT, FLOW TUBES

SEe HYDRAULTC MEASUREMENTS, FLOW METERS

HYDRAULIC MFASUREMENTS, FLOW VISUALIZATION

See FLOW VISUALIZATION

HYDRAULIC MEASUREMENTS, FLUID PROPERTIES

Tensions in liquids (5106)

See also VISCOSITY

HYDRAULIC MFASUREMENTS, FLUMES

Calibration of open flow nozzles (3859)(4255)- 151

Effect of flume size, orientation and site on discharge (3848)

Gate modification effect on gate-Parshall

flume structure (5764)--.-1-137

Generalized design for trapezoidal venturi

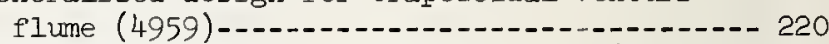

Parshall flumes for irrigation water (5209)-.- 159

Roughness effects on venturi flumes (063W)-.-- 227

Submerged measuring flumes (5762)........... 137

Supercritical-flow flumes for flash

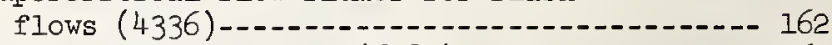

V-notch flume studies (6483)-.............- 265

HYDRAULIC MEASUREMENT, GATES

Tainter gates flow measuring devices (6694)- 37 HYDRAULIC MFASUREMENTS, HOT FILM

Applied to open-channel flow (6817)-.....- 269

Calibration techniques for flush-mounted hot-film anemometers (6137).............-234

Flush-mounted film for wall turbulence study (6568).................................. 89

Improved apparatus for liquid use (6553)-.-.-- 96

Pipe flow of organic solvents (6405)-..-.-.-- 82

Turbulence measurements in water (6582)-.-.-- 8

See also HYDRAULIC MFAS., TURBUIENCE

HYDRAULIC MEASUREMENTS, HOT WIRE

Heat transfer characteristics of hot wires

in liquids (5110)

Improvements for use in water (6801)-.....-. 117

Wall shear stress meter, flush mounted (6195)- 143

Used in liquid aerosols (6202)-..........- 102

Use of hot wires and films in liquids (5112)-- 101

Use of urethane-coated wires (73)-........- 53

HYDRAULIC MEASUREMENTS, IMPACT TUBES

Effects of polymer additives (5795)-...-.-.-. 110

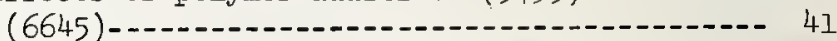

HYDRAUTIC MEASUREMENTS, INTERFEROMETER

Density-gradient at air-water interface

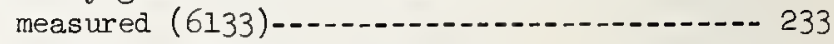

HYDRAULIC MEASUREMENTS, IRRIGATION

Head loss in flow measuring devices (5164)-.-- 21

See also HYDRAULIC MEAS., FLUMES

HYDRAULTC MEASUREMENTS, LIQUEFIED GAS

Turbine-type flowmeters (6342)-...........-. 232

HYDRAULIC MEASUREMENTS, MICROPHOTOGRAPHY

To obtain shear stress in free-surface

flow (5660) (5371)

Non-Newtonian flow effects on impact tubes

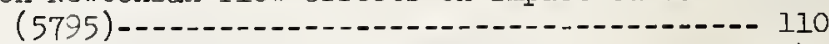

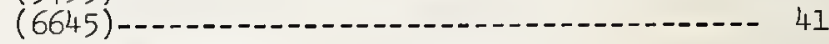

HYDRAULIC MEASUREMENTS, OCEANOGRAPHIC

Calibration tank for oceanographic current meters (5793) - 109 
HYDRAULIC MEAS., OCEANOGRAPHIC (continued) Page Current meter calibration (6452)-.....-...- 236 Instruments for ocean turbulence and microstructure (6465) -.......... 243

Instrument for sea-floor boundary layer measurements (6283).......................... 146 HYDRAULIC MEASUREMENTS, POROUS MEDIA FLOW

Instruments for in situ measurements of soil moisture flow and suction (5981)-........- 160

Nulltensiometer development (032W)-......... 45

Tensiometer pressure transducer system for studying transients (5898)-............... 43

Use of sound waves to determine permeability

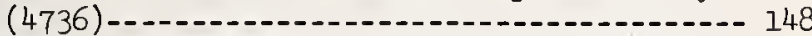

HYDRAUIIC MEASUREMENTS, PRESSURE FLUCTUATIONS

Miniature transducer for wall-pressure field in turbulent flows (6118)............. 45

Very high frequency transducer (6264)-......- 123

HYDRAULIC MEASUREMENTS, PRESTON TUBE

Yaw-type tube for shear stress in 3-dimensional boundary layer (664l).............. 252

HYDRAULIC MEASUREMENTS, SEDIMENT TRANSPORT

Comparison of various bed-load measurement

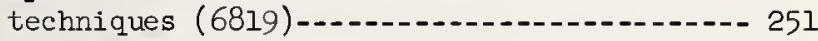

Development of instrument for in-place measurement of turbidity (3907)-.-.-.-.-.- 191

Elbow meter to measure flow and concentration (6566)

Feasibility of capacitance-type concentration probe (6530)

Instrument for suspended-sediment concentration measurement (6743)

Loop system for measuring sand-water mixture (6564)

Methods used in measurement of stream sediment loads (194)

Modified venturi meter for two-phase flow

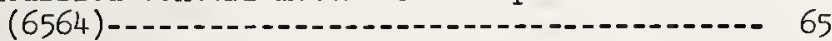

Nuclear and electrical sensing devices for sediment loads (194)................... 112 Samplers for suspended and bed loads (194)-..- 112 Sensor for turbulent concentration fluctuations (6366)-..................... 58

Tests of nuclear concentration gauges (3871)-- 160

Tractor-mounted suspended sediment sampler for surf zone (2660)

HYDRAULIC MEASUREMENTS, SHEAR STRESS

Electrochemical techniques for shear stress distribution around cylinder (6825) -........

Flush mounted hot film, calibration

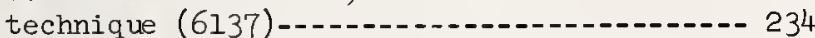

Hot wire, flush mounted and directionally

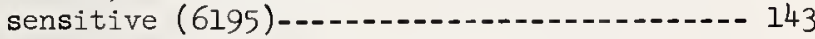

Microphotography used in open-channel

Survey of techniques and devices used in turbulent boundary layers (6196)..........- 143 Yaw, pitch and screw-driver probes (6641)----- 252 HYDRAULIC MEASUREMENTS, SLURRIES

Using elbow meter ( 5172$)$

HYDRAULIC MEASUREMENTS, STREAMFIOW

Measurements under ice cover (6529).......... 140

Moving-boat technique for discharge (5600)--.- 228

VHF radio gage for stream level data (3629)--- 244

See also HYDRAUIIC MEAS., CURRENT METERS

See also HYDRAULIC MEAS., DISCHARGE

See also HYDRAULTC MEAS., FLUMES

See also HYDRAULIC MEAS., WEIRS

HYDRAULIC MEASUREMENTS, SUBMERGED BODIES

Methods of measuring thrust, torque, pressures, in water tunnel (2832)

Tunnel wall interference effect on measured force on axisymmetric body (4181) ..........
HYDRAULTC MEASUREMENTS, SUSPENSIONS

Elbow meter to measure flow and concentration

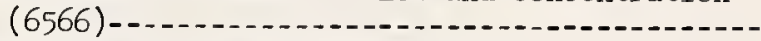

HYDRAULTC MEASUREMENTS, TIDE GAGES

A simple resistance gauge (6598)-

Frequency response and non-linear effects (6224)

12
1

Instrument for deep-sea tides (5927)-...-.-.-.- 113

HYDRAULTC MEASUREMENTS, TRACERS

Diffusion of radioisotopes injected into pipe flow $(064 \mathrm{~W})$

Dispersion in selected rivers (6165).........-. 141

Fluorescent tracers for channel flow in irrigation systems (5219)-......-...-163

For water yield determination on watershed subdivisions (5395)-...-....... 21

Movement of soil water (Ol2W)-_......... 59

Radioactive tracers for beach studies (3897)--- 183

Radioisotope flow measurement in high-head turbines (061W) (064W)

Techniques for studying radionuclide movement in Columbia estuary (5842) -.............. 229

Tracers for coastal sediment (4127)-.........-. 31 See also SEDIMENT TRANSPORT

HYDRAULIC MEASUREMENTS, TURBULENCE

Doppler-scattering technique (6554)-........-. 96

Electrochemical techniques for near-wall studies (6824) ......... 48

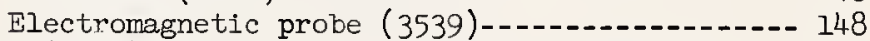
(5501)-_-_._.-. 109

Hot wire and hot film equipment (5112)-.....- 101 Instrumentation for use in liquids (6553)-..--- 96 Instruments for analyzing aperiodic signals (2541)

Optical method of high resolution (5904)-..... 45 Random signal analysis techniques (6134)-..-.-. 234 Spherical-head turbulence meter (1004)-.......- 188 Thrust anemometer for use in air-sea boundary layer (3120)--

See also HYDRAUIIC MEASUREMENTS, HOT WIRE AND HOT FILM

HYDRAULIC MEASUREMENTS, TWO-PHASE FLOW

Scattered laser light used for particle-volume determination (6590)-....... 239

HYDRAULIC MEASUREMENTS, VELOCITY

Anemometry technique for accurate velocity profiles in drag-reducing flow (6406)-...-.- 82

Pitot-sphere probe development (5832)-...-.-.- 101 Ultrasonic Doppler-effect meter (5075)-..-.-.-. 227 Ultrasonic meter tested under waves (977)-...-- 182 HYDRAUIIC MEASUREMEITS, VISCOSITY See VISCOSITY

HYDRAULIC MEASUREMENTS, WATER IEVEI

Feasibility of pressure-transducer measurement of water surface elevation (1004)-.......... 188 HYDRAUUIC MEASUREMENTS, WAVES

Calibration of shipborne wave gages (6607)----- 75 Development of height and direction gage (977)- 182 Drag gage for orbital velocity (1609)-.....-- 68 Ocean surface wave properties measured by

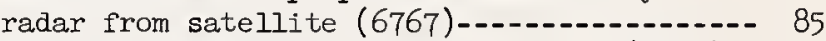

Photometric definition of wave surface (5817)-- 11

Soap bubbles measure wind field near water

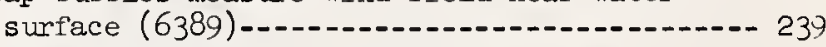

System for collecting field data at east coast stations in U.S. (660) HYDRAULIC MEASUREMENTS, WEIRS

Culverts with added $V$-notch for low flows

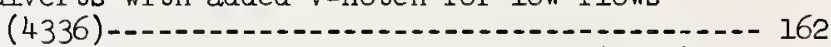

Discharge from circumferential weirs (5492)--.- 25 Standard weir design for stream gaging (3848)-- 144 Submergence effect on broad-crested weir (6416)-.... 73

Trapezoidal weir calibration for submerged flow $(6316)$-........... 225 
HYDRAULIC MEASUREMENTS, WEIRS (continued)

$V$-notch brosd-crested weirs for low flows

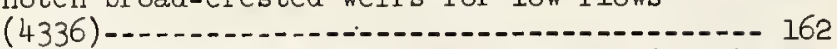

V-notch weir; floor and sidewall effect (6483)- 265 HYDRAULIC MODEL STUDIES

See MODELS

HYDRAULIC PROTOTYPE TESTING (4382)

HYDRAULIC RADTUS

Rectangular-conduit experiments (6284)-...... 81

HYDRAULIC STRUCTURES

Development of hydraulic design criteria

(1467)

See also DAMS, etc.

HYDRAULIC SWITCH

Application of switching techniques to control

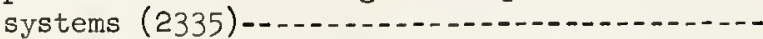

Perfect-flluid theory used to obtain switching speed (6122) - 115

Switching and starting phenomena of bistable

fluid devices $(6370)$-.--

See also SERVOMECHANISMS

HYDROBALITSTICS

Tank for water entry-exit study (4867)-..-.-.-- 237

See also WATER ENIRY

HYDRODYNAMIC NOISE

Effect of addition of drag-reducing polymer (5497)-... 108

Effect of polymer additives on diffuser

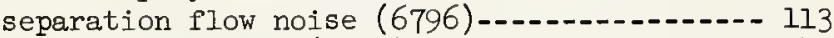

In fluid amplifiers (5913)

In heart valves (5475)

In two-phase gas-liquid flow (4235)-...-.-.-. 127

Micro-bubble influence (5499) -...........-. 109

Propeller and wake noise in deep-sea

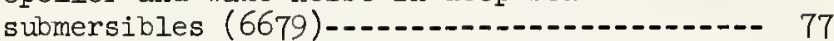

Sound produced by gas bubble in pressure

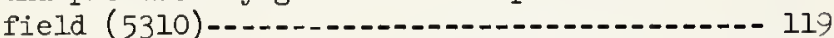

Statistical properties of boundary pressures in acoustic wind and water tunnel (6266)-.-.- 242

See also ACOUSTIC RADIATION

HYDRODYNAMICS, CIASSICAL

Theoretical problems in hydrodynamics (6572)--- 84 HYDROELASTICITY

Fluidelastic features of flow around circular cylinders (5lll)-............... 100

Flutter of supercavitating flat-plate hydrofoils (5500)-109 HYDROELECTRIC RESOURCES

Of Idaho streams (5167)

HYDROFOIL CRAFT

Rough-water take-off resistance (5928)--.------ 119

Vibrational analysis with 3-dimensional unsteady effects on foil loads (6538)-.....-. 122 HYDROFOILS

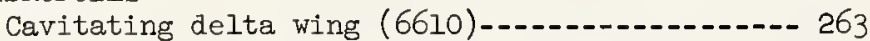

Dependence of lift and drag on sweep angle

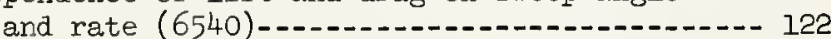

Free-surface effect on viscous drag (6685)-.-.- 80

Investigation of Kutta condition in unsteady flow (5107)-1....... 95

Leading-edge separation on wedges (6740)...... 111

Load distribution for minimum induced $\operatorname{drag}(6551)$

Minimum induced drag of non-planar surfaces (6552)

Thrust and drag on undulating foils (6209)-..-- 234 HYDROFOILS, JET FLAPS

Lift increase for ventilated foils (5794)-.-.-- 110 HYDROFOILS, SUPERCAVITATING

Effect of oscillating trailing flaps (3153)-.-- 107

Flutter of flat-plate foils (5500)-......- 109

Theory for three dimensional lifting foils

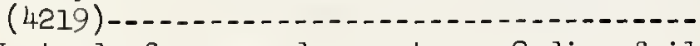

Unsteady forces and moments on 2-dim. foil oscillating near free surface (5363)-.-.-.-- 26
HYDROFOILS, TEED

Page

Loads in oblique regular waves (5058)-......- 118 HYDROFOILS, VENTILATED

Dynamics of surface-piercing dihedral foils and response in irregular waves (4226) -...- 118

Jet flap studies (5794)................. 110

Study of boundary layer separation (4700)-...- 108

Unsteady flow characteristics near free surface (2144)-........ 107

HYDROGEN BUBBIE TECHNIQUE

See FLOW VISUALIZATION

HYDROGRAPHS

Analysis of unit hydrographs for small

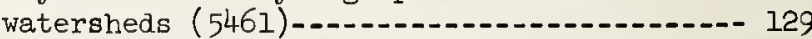

Computer method for separation into quick and delayed flow from small catchments (380)-.-- 177

Design hydrographs for small Indiana watersheds (2841)

Extension of role of linear systems analysis in hydrograph theory (5117)............. 70

Further development of Clark method of unit hydrograph synthesis (024W)-........... 61

Hydrodynamic equations for surface runoff from agricultural watersheds (4820)-......- 157

Mathematical simulation of hydrologic events on ungaged watersheds (6093)-............. 98

Recession hydrographs for unconfined, idealized aquifers (5303) -....... 28

Shallow-water equations used in runoff computations (5874)......... 28

Short erosion plots under simulated rainfall (6771)

Synthesis by water balance and routing methods (6605) - on wa

Synthesis of storm runoff hydrographs from unsteady non-uniform rainfal1 (5456)-...-.- 128

See also HYDROLOGIC ANALYSIS

See also RUNOFF

HYDROLOGIC ANALYSIS

Analog computer use in surface and groundwater problems (5657) -....... 51

Blue Springs Basin, Ontario (6604)-.......-.- 257

Computer simulation of semi-arid watershed

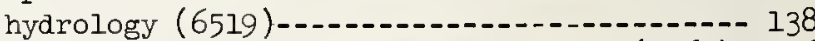

Data for Waller Creek Watershed, Texas (2162)- 126

Delta River (Alaska) basin (6384)-..-...-.-.- 180

Detailed digital computer model used to investigate various interactions in hydrologic cycle (1946)-_... 115

Drainage basin as a lumped hydrologic system

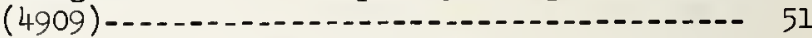

Effect of vegetal manipulation on hydrology and soil properties, southeast U.S. forests (5813) -

Electronic analogs applied to river basin

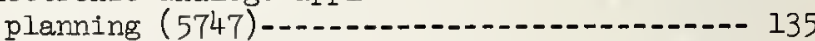

Electric analog computer simulation of total hydrologic-economic flow system (6520)-...-. 138

Electronic analog model of river basin (5140)- 134

Electronic analog simulation, upper Colorado Basin (6521)

Great Lakes - St. Lawrence basin (3031)-.-.-. 18

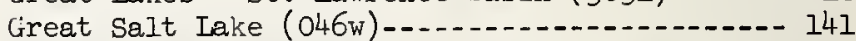

Mathematical modeling of small watersheds (OlOW) -

Mountain watersheds in Calif. (23)

Probability and synthetic hydrology approach to rainfall-runoff frequency relationship (4910) - 51

Regional environments on east slope, Colo.

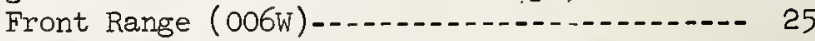

Related to military mobility in Alaska

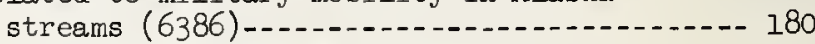

Several statistical methods applied to hydrologic time series studies (234)

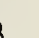
8 . 8 . 
HYDROIOGIC ANALYSIS (continued)

Small desert watershed; for stock watering

ponds (3057)

Small drainage basin, northern Alaska (6383)-- 179

Synthesis of hydrologic data (1946) -......-. 115

Theory of design of precipitation

networks (6664)

Urbanization effects on small watersheds

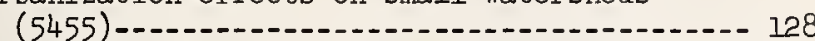

Water budget model for Kansas Streams (O2lW)-- 61 HYDROLOGIC CYCLE

Role of overland flow (6070) HYDROLOGIC MEASUREMENTS

Electromagnetic sensors for transpirational water use by plants (043W)........... 140

Generalized criteria for design and evaluation of instruments and networks (6420)-....... 74

Improved standards for neutron soil water meters (2914)

Multiple-channel digital recording system

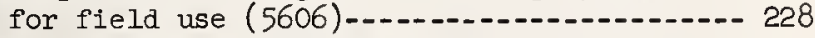

New neutron probe system speeds logging of soil water profiles (3225)

Psychometric measurement of soil water potential without precise temperature control (5220) -........................... 163

Studies on methods of soil water determination (OSIW) -

Tracer methods for water yield determination on watershed subdivisions (5395)........... 21

See also SOIL WATER

HYDROLOGIC MEASUREMENTS, EVAPOTRANSPIRATION

Evaluation of an instrument for peat

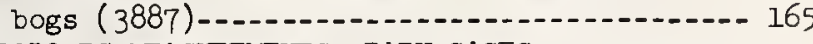

HYDROIOGIC MFASUREMENTS, RAIN GAGES

Effect of gage-network density on precipitation description (6664)-...................... 16

Reliability of can-type precipitation gages

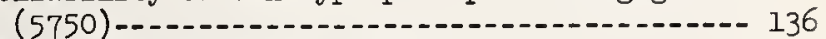

VHF radio gage transmitters (3629)-.......-.- 244 HYDROIOGIC MFASUREMENTS, SNOW

Lysimeter-type gage for in-site use on

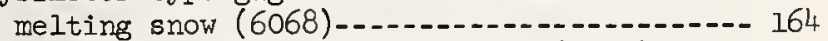

Methods for automatic measurement (6701)..... 44

New techniques to measure water content (044W) -

Nuclear-radiation snow gage (6706) ......... 44

Pressure pillow as snow measuring device

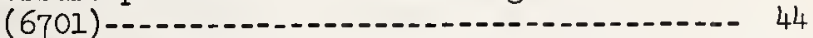

Probes to measure snowpack density (4996)-...- 169

Remote measuring device (5404).............- 21

Vectopluviometer for horizontal component of wind-driven snow (6702) HYDROLOGIC MODEL

Accuracy of models in reproducing hydrologic

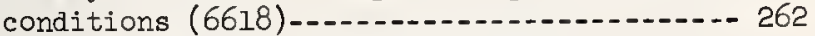

A physical model for rainfall-runoff processes (5117) - 70

Techniques and model laws for laboratory watersheds (3845)

See also MODEIS, ANALOG

See also HYDROLOGIC ANALYSIS

HYDROLOGIC SYSTEMS

Systems analysis of runoff process (6279)-...- 143 HYDROLOGY

Hydrologic atlas of Utah (6531)................. 140 HYDROIOGY, MICROCLIMATIC (5443) HYDROLOGY, STOCHASTIC

Several statistical methods applied to hydrologic time series studies (2846) -......... 20 HYDROLOGY, URBAN

Optimum linear synthesis in urban hydrology (6421) HYDROMAGNETIC FLOW

Couette flow stabilized hydromagnetically (6569) 90
HYDROMETEOROLOGY

Maximum precipitation, floods, etc. for Page

design criteria (6154)_................... 218

HYDROPLANING

Grooved-pavement effect on drainage (6286)--- 82

Of aircraft tires (5932) -............. 120

Pneumatic-tire hydroplaning (6691)-.........- 37

See also PIANING

HYDROPOWER PLANTS

See MODELS

See TRANSIENTS

ICE

Convection in a uniform water layer beneath an ice sheet (6803)-.... 267

Dynamic ice loads on piers (6821) -.........- 251

Effect of floes on wave damping (6537)-..-.-. 122

Ice-cover effect on channel surges (6631)---- 251

In locks, see MODELS, LOCKS

Prevention and control of culvert and road icing (053W) ICE, RIVER

Effected by thermal pollution (6387)---.----- 180

Effect on roughness coefficient (6567)...... 65

Intrusion of Montreal water supply intake; model study (6240)

Mechanics of ice jams-.....................- 181

Model study, Bromptonville, Quebec (6252)-.-- 261

Model study of St. Lawrence ice conditions

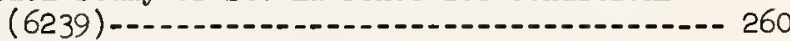

Streamflow measurements under ice (6529)-..-- 140 IDEAL-FLUID FLOW

Flow over hydraulic structures approximated

by rotational ideal fluid (5452) -........- 135

See also POTENTIAL FIOW

IMPACT

Hydrodynamics of rigid-body water impact

(6066) -

Landing impact of spacecraft and aircraft

(6654) - 230

Liquid drop impact on high-speed target

( 5796$)$ -

See also WATER ENTRY

IMPACT TUBES

See HYDRAULIC MEASUREMENTS

INDUCERS

Hydrodynamically induced shaft forces in

three bladed inducer (6174)........... 105

Secondary flow in axial flow inducers (5592)- 95

Study of high rise inducer stages (6343) ..... 232

See also PUMPS

INERTIA COEFFICIENT

See VIRTUAL MASS

INFILTRATION

Analytic approach to unsteady unsaturated horizontal flow in soils (3507)-........- 116

Electrical effects on water infiltration into soils (6166)

Impedance by pressure build-up ahead of wetting front (3507)-........ 116

Infiltrometer measurements under various

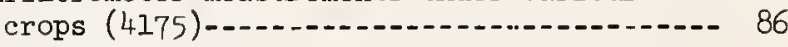

Prediction of field infiltration rates (O39W) - 99

Recovery of infiltration capacity after

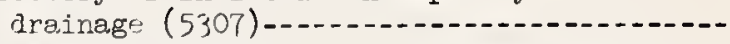

Role of infiltration in nonlinear watershed

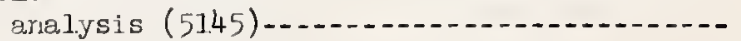

Short trosion plots under simulated

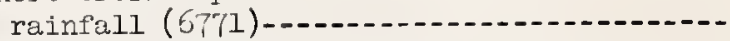

Silty-water effect on infiltration in alluvial channels (5349)

Theory for unsaturated porous media (5307)--- 
INFILTRATION (continued)

Theory for unsaturated media (5446) -........ 134

Theory of runoff-infiltration relation (6533)- 140

See also POROUS MEDIA FLOW

See also SOIL WATER

INJECTION

Velocity-profile effect on flow in straight channel with perpendicular flow injection (6269) -

INLET LENGTH

Laminar and turbulent flow, entrance of twodimensional channel (6104) ...............

See also PIPE FLOW

INLETS

Pumping-plant inlet transition design (6301)-- 222

See also MODELS, INLETS

INLETS, COASTAL

Bypassing and navigation study of Jupiter

Inlet, Florida (6759)

Coastal engineering study, Macquarie

Harbour, Tasmania (5686) -........

Field study, Hillsboro Inlet, Fla. (4475)---.-

Field study, Lake Worth, Fla. (4474).......-.

Fire Island, N.Y., inlet channel stablization

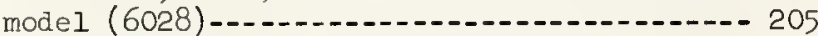

General studies of inlet velocities and

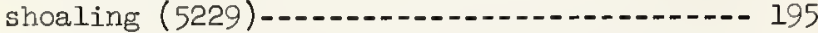

Navigation and sand bypass, St. Lucie Inlet,

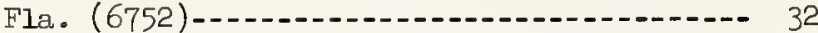

Sand by-passing methods past inlets (975)-..-- 181

Sand tracing program to evaluate natural and artificial bypassing (6757)-........- 33

Stability of inlets; field study (3413)-..-. 31

Tidal flow in basins in conmunication with

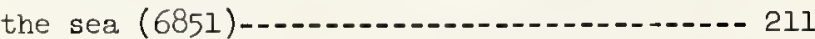

See also MODELS

INLETS, DROP

Closed-conduit spillway inlets (1723)-.-.-.-- 156

Hydraulic characteristics (5597).......... 148

INLETS, STORM-WATER

Capacity as function of road grade, crown

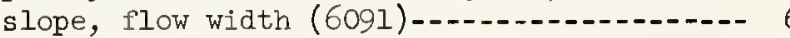

INLETS, TUNNEL

See TUNNELS

INSTRUCTION

Computer-aided teaching in hydraulics and

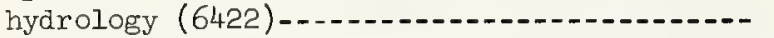

Experiments for undergraduate fluids

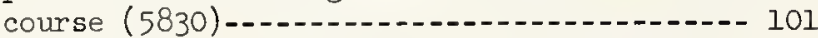

Fluid mechanics films (3739)-............- 54

Laboratory equipment for undergraduate course (5484) 101

INTAKES

Air-vent computations for emergency closure (6320) -........ 225

Performance of high towers with multiple laterals (6658)

INIAKES, POWER PLANI

Optimum diameter and height for submerged

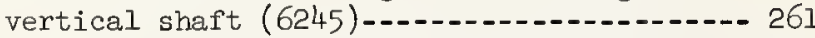

Optimum shape and submergence of penstock

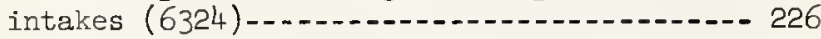

Vortex suppressors for Outardes 4 project,

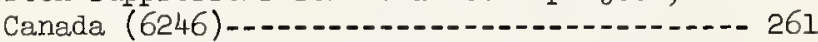

INTAKES, PUMPED-STORAGE PIANT

Flow patterns during various phases of operation; model (6500)-...........-151

Vortex development at turbine intakes; model (6723)

INTAKES, PUMPING PIANT

Flow patterns at Tehachapi, Calif., plant (6661)

Intake transition design comparison (4954)---- 220
INTAKES, WATER SUPPLY

Page

City of Montreal, protection of intake from ice intrusion (6240)

INTERFACE, AIR-SEA

See AIR-SEA

INTERFACE, LIQUID-VAPOR

See TWO-PHASE FLOW

INTERNAL CURRENTS

SEe STRATIFIED FLOW

INIERNAL WAVES

See WAVES, INTERNAI

IRRIGATION

Advance and recession of furrow irrigation stream predicted by hydrodynamic

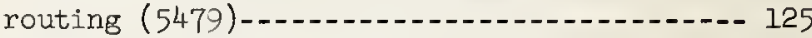

Automation of water distribution for surface irrigation (5567)-.............. 158

Compilation of information on small farm irrigation structures (5130)-.......... 133

Design, performance and automation of surface systems, upper Colo. basin (4827)-.......-.- 157

Efficient application by surface flooding (4664)

Flow measurement with flumes, tracers, elbow meters (5219) -.......... 163

Head loss in flow measuring devices (5164)-..- 21

Hydraulics of surface irrigation (5449)-...... 135 (5479)-...-.-.-125

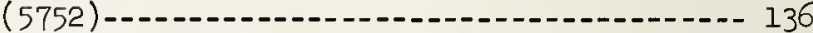

Methods of water measurement and control (5209)

Physical and economic analysis of alternate irrigation methods in a sub-humid climate

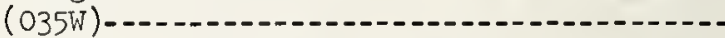

Practices and systems for improving farm and district irrigation efficiency in the northwest (5570) - 159

Relation of pumping lift to economic use of groundwater for irrigation (6703)-........ 44

Saline and sodic soil and irrigation water problems, Rio Grande plain (5985).........- 163

Sprinkler system design and operation in the northwest (3550)

Surface and subsurface systems for coastal California (4853)............................... 163

Surface system design and automation in the

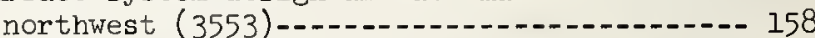

Watershed management practices affecting irrigation water supplies (5395)-.......-. 21

Water requirements and use, farm-size

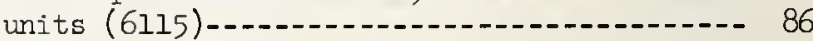

IRRIGATION, DITCHES

Durability of concrete lining (5471)-..-.-.-. 86

IRRIGATION, DRAINAGE

Drain tile effect on soil salinity (1819)-..-- 14

Optimum drain spacing for sloping irrigated land (6317) -........ 225

IRRIGATION, PIPES

Durability of pipe and concrete ditch

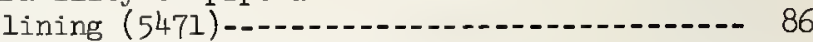

water harmer in pipe systems (6097)-...-.-.-. 254 IRRIGATION, SPRINKLERS

Sprinkler system design and operation in the

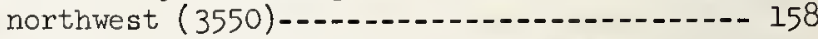

Sprinkler-system evaluation in extensive irrigation (6114)

$$
-J-
$$

JET FLAPS

See HYDROFOILS

JETS

Boundary effects on jets introduced horizontally near reservoir free surface

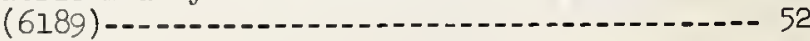


JETS (continued)

Effect of jet oscillation on spreading (6271)

Erosion of concrete by high-velocity jets (4791) -

Gas jet impinging on liquid surface (6113)---- 59

Mixing of gases in liquid jets (6558)-......- 96

Necessity for three-dimensional analysis of

neutrally stable jets (6731) -............ ?

Reattachment at low Reynolds No. (5537)-.---.- 143

Reattachment, see also FLUID DEVICES

Velocity and kinetic energy distribution of

jet submerged in stilling basin (5469)

Vortex-flow influence on jet deflection (6112)

JETS, BUOYANT

SEe PLUMES

JETS, COAXIAI

Coaxial jet mixing problem (6395) -

JETS, ENTRAINMENT IN

Air entrained during impact of free jet into pool of similar liquid (6750)-.........- 112

As effected by boundary disturbances (6268)--- 26

Mass entrainment mechanism near the exit

(6267)---1.-- 26

Oscillation of jets; effect on spreading

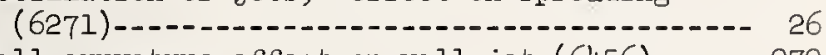

Wall-curvature effect on wall jet (6456)------ 272 JETS, HIGH SPEED

Rock tunneling with high speed water jets utilizing cavitation damage (6650)-.......- 42 JETS, IN AMBIENT FLOW

Diffusion of two-dimensional jet in opposing stream (6823)--1 257

Round turbulent jets discharged into cross flow (6815) - 268

Turbulence structure of jet in coaxial

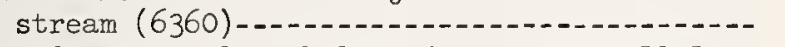

Two-dimensional turbulent jet in a parallel flow (6394) JETS, LAMINAR

Laminar wall jet on curved surfaces (6393)-----

Velocity profile as function of nozzle

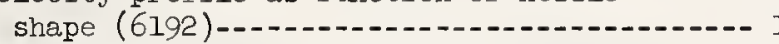

JETS, RADIAL

Velocity profile and decay measurements in radial jets (6473)

JETS, STABILITY

Boundary stability and its effect on entrainment (6267)-

JETS, THREE-DIMENSIONAL

Mean flow of non-circular jets (6637)--.-.---- 252 JETS, TURBUTENCE

See TURBUTENCE

JETS, WALI

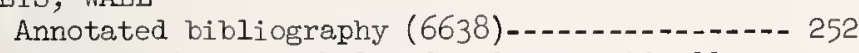

Boundary layer stabilized hydromagnetica.lly

(6569)

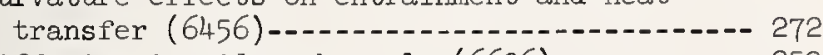

Diffusion in wider channels (6636)-.-.-.-.- 252

Effect of initial gap on flow over plane and

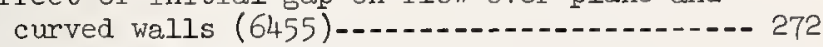

Effect of step-wise suction on mean flow and wall shear (6812)

Flow immediately below submerged sluice

glow over moving wall (rotating cylinder) (6457)--... 272

Laminar wall jet on curved surface (6393)-..-- 3

Plane turbulent reattached wall jets (6634)--- 252 JETTIES

Model tests of jetty stability, Humboldt

Bay, Calif. (6866)

See also BREAKWATERS
JOURNAI BEARINGS

SEe LUBRICATION

Page 26 19

6

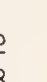

\section{KARMAN VORTICES \\ SEe WAKES, VORTICES \\ KUTMTA CONDITION}

Rapidly oscillating hydrofoils (5107)---------

$$
\text { - L - }
$$

IABORATORY EQUIPMEIN

See FACILITIES

IAKE ERIE

Dynamic model study (6045)

IAKE HURON

Level control with sills in st. Clair

River (5233)-..... 196

IAKE MICHIGAN

Erosion study, Illinois shore (1863)-...-.-. 46

IAKE SUPERIOR

Drift-bottle study of surface currents (6053)- 87

Methematical model for circulation (5791)----- 149

Relation of whitecapping to wind speeds

LAKES

(6052)

Circulation, see CIRCULATION

Hydrology of Great Salt Lake (O46w)-...-.-.-- 141

Model for thermocline development (6624)-...- 149

Overturning induced by introducing warm water at bottom (6625)-.-.-149

Techniques of modeling thermal stratification (5544)

\section{LAMINAR FLOW}

Energy transport and dissipation in separation

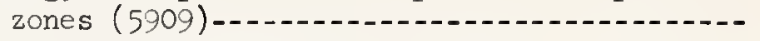

Laminar flow surrounding finite rotating disk at high Reynolds number (6101) -.........-.

Radial flow between parallel plates (6155)-.--

Unsteady flow between plates, rotating

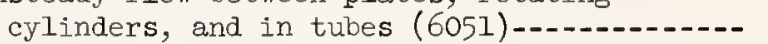

See also BOUNDARY IAYER, LAMINAR

See also VISCOUS FIOW

LANDSLIDES

Groundwater movement in landslides (5368)-...-

LAINGMUIR CIRCUIATION

See CIRCUTATION, LAKES

IEE WAVES

See WAVES, INIERITAL

LIFTING BODIES

Nonlinear interaction of two lifting bodies

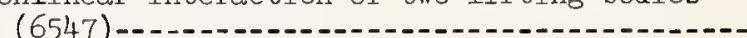

IIFTING SURFACE THEORY

Load distribution on non-planar surfaces to produce minimum induced drag (6551)-......-.

Minimum induced drag of non-planar surfaces

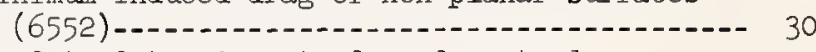

Used to determine steady and unsteady propellor forces (6535)......

see also HYDROFOILS; WINGS

LIQUEFIED GAS

Turbine flowmeters, liquid hydrogen (6342)--.- 232

LIQUID-LIQUID FLOWS

Interfacial area in two-phase flow in pipes under continuous turbulent conditions

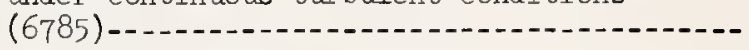

Single drop breakup in developing turbulent pipe flow (6784) see also DISPERSIONS

LIQUID METALS

Bubble growth and collapse in problem of

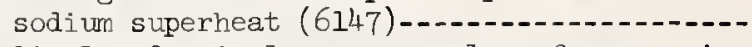

Helical and spiral groove seal performance in

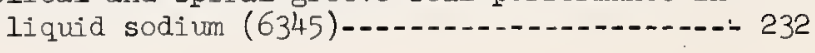

\section{5}


LIQUID PROPEIIANTSS

Atlas vehicle feed system dynamics (6337)---- 231

Outflow residuals for interconnected

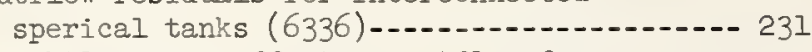

Weightlessness effect on outflow from

tanks (6340)

See also SIOSHING

LIQUID SLOSHING

See SLOSHING

IIQUID SODIUM

SEE IIQUID METALS

IIQUID-VAPOR

See TWO-PHASE FIOW

IITTORAI PROCESSES

Effect of groin system on rate of littoral movement (2190)

Field measurements of longshore velocity, Nags Head, N.C. (5325)

Iittoral drift by combined wave and current action (4898)

Iittoral drift traced, Cape Kennedy, Fla. (5281)-..... 32

Regional studies of Atlantic coast, New Jersey to Cape Charles, Va. (2192)-......- 182

Review of available theory and data on longshore currents (5834)................ 184

Symoptic field measurements of entire littoral processes--sand, waves, tides, winds (6762)

See also BEACH EROSION

See also COASTAL SEDIMENT

LOCKS, (FILTTNG AND EMPTYING SYSTEMS)

Culvert outlet basin investigations (6023)-.- 203

Prototype culvert pressure tests, Greenup Locks, Ohio R. (5242)

Studies to provide new culvert design

information (4602)

see also MODELS, LOCK

IOCKS, (NAVIGATION CONDITIONS AT)

SeE MODELS, LOCKS

LOGGING

Effect on streamflow, Oregon Cascades (4758)- 167 Effects on Alaska salmon streams (2654)-...-- 168

Iog-passing devices at dams (5946).......-.- 256

IOGGING, HYDROIOGIC EFFECTS

SEe HYDROLOGIC AIALYSIS; SOIL WATER; STRFAMFLOW; WATER YIETD; WATERSHED MANAGEMENT

IONGSHORE CURRENTS

SEe CURRENTS

LOW-GRAVITY ENVIRONIENT

See WEIGHTLESSNESS

LUBRICATION

Journal-bearing hydrodynamics, water and liquid sodium $(6344)$

$$
-\mathrm{M}-
$$

\section{MAGNETOHYDRODYNAMICS}

See ELECTROMAGNETIC FLOW

MANIFOIDS

Flow in Plash-distillation plant manifold

(6319)---1a-- 225

Heavy-water circulation in reactor (6251)-..- 261

Pumping-plant discharge line studies (6662)-- 16 MASS TRANSFHR

Across air-water interface by evaporation

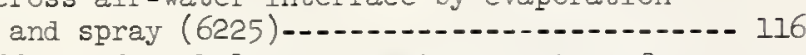

Effect of turbulence promoters on transfer through laminar boundary layer (6571)-...- 90

From liquid film to hot gas stream (6219)---- 103

In $\mathrm{SO}_{2}$ - air-water system (6676)-....... 77
METERS

SEe HYDRAULIC MEASUREMENTS

MINING

Development of telescoping tubes for solution

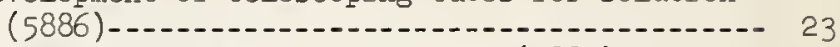

Hydraulics of solution cavities (5887)-...-...- 23

Reduction in surface mining damage to forest resources (OTIW)

MIXING

Grid towed through stratified liquid (6362)---- 58

Mathematical model of exchange characteristics of Texas bays (5954) -.......................... 130 See also DISPERSION; DIFFUSION

MIXING CHAMBER

For waters of different qualities (5865)-.-.-.- 16 MODEL LAWS (FOR)

Air demand in partly full water pipes (5339)--- 221

Artificial roughness in movable bed models (5684)-..... 32

Cavitation damage (6651)

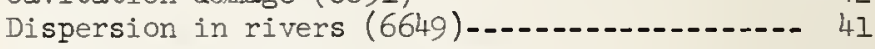

Equilibrium profile of beaches and study of model scale effect (181) -................. 181

Flow into sub-soil drains (5892)-......-.-.-. 23

Laboratory watershed models (3845)-.........-. 133

Liquid-sloshing experiments (6295)-......... 34

Permissible limits of model distortion (994)--- 187

Scale and distortion effects in wave models (1002) - 188

Scale effects in rock protective structure (5906)-.... 55

Scale effects in wave passage through porous

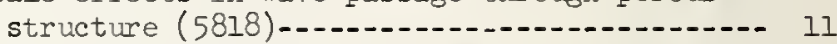

Scale effect on rubble-breakwater stability tests (2681) -...... 189

Simulation of low-gravity slosh (6655)-...-.-.- 17

Techniques of modeling thermal stratification in lakes (5544)

MODELS, ANATOG

Aquifer in Miami Basin, Ohio (6464)-......- 19

Canal system model for feedback control of

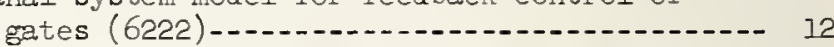

Electronic analogs applied to river basin planning (5747) -........ 135

Electronic analog model of river basin (5140)-- 134

Reservoir-drawdown effect on groundwater

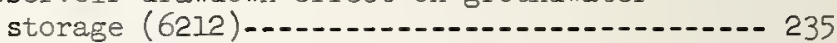

Runoff from small watershed areas (6516)-...-.- 138

Runoff prediction, Reynolds Creek Watershed (6517) -....... 138

Seiche simulation and prediction for harbors

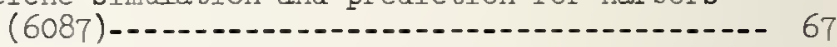

Simulation of effects of urbanization on small-watershed runoff (6522)-_.........- 138

Simulation of salinity flow system, upper Colorado Basin (6521)..................... 138

Simulation of semi-arid watersheds (6519)-.-.-- 138

Simulation of total hydrologic-economic flow system (6520)-...- 138

Stream-aquifer system (4106)-...-...-. 20

Tsunami analysis by electric analog (6132)-.-.- 233

Water exchange feasibility between Eear and

Jordan rivers, Utah (6518)..................... MODEIS, EAY

Chesapeake Bay comprehensive model (6849)--.--- 211

San Diego Bay model (6852) -

MODELS, BEACH

Beach alignment study, Waikiki, Oahu (6074)---- 40 MODEIS, BLOOD FLOW

Arterial system for brain (4143)

MODELS, EREAKWATER

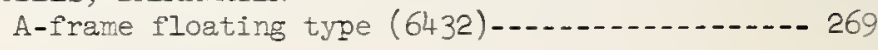


MODELS, BREAKWATER (continued)

Caisson-type; floating (6431) 269

Ferry-ramp protection, Hornby Island,

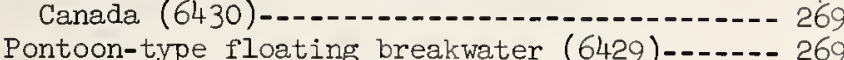

Protection of Interstate Route 35 along

Lake Superior (6748)-.....- 112

Rubble-mound stability at Burns Waterway

Harbor, Indiana (6863)-_................ 214

Rubble stability, Hilo Harbor tsunami

barrier (6040)-........ 208

Scale effect on rubble-breakwater stability tests (2681) -..-189

Stability of navigation opening structure, Hilo Harbor tsunami barrier (6039)-......-.- 208

Stability of rubble breakwater, Noyo Harbor,

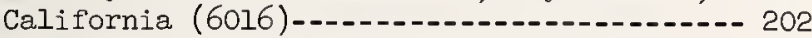

Tetrapod and rubble-mound coverings (6229)---- 259

Transmission of waves through rubble, Dana Point harbor, California (5634)-.........- 198

Wave transmission through breakwater at Santa Barbara Harbor, California (6014)-.--- 202

MODELS, BRINE PIPING

Between evaporators (6318)-.............-. 225

MODELS, CAUSEWAY

Stability against wave action, P.E.I.

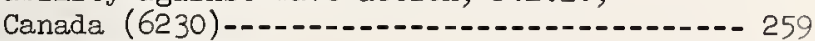

MODELS, CHECK TOWER

See CHECK TOWER

MODELS, COASTAL INLET

Bypassing and navigation study of Jupiter Inlet, Florida (6759)

Fire Island, N.Y., inlet channel stabilization (6028)--..-205

Navigation and sand bypass, St. Lucie, Florida (6752)-...... 32

MODELS, COOLING-WATER DISCHARGE

Chesapeake Bay as affected by Calvert Cliffs

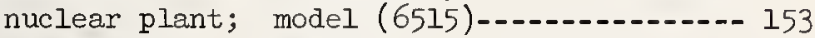

Discharge canal, head loss in intake and

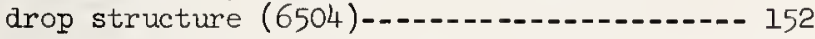

Discharge channel at Big Bend power station (6502)

Discharge channel into Lake St. Croix (5494)-- 108

Effect on Susquehanna R. near Conowingo; Peach Bottom nuclear plant (6513)-........- 153

open flume design for returning water from cooling tower to intake (6720)..........- 247

outlets to insure uniform velocity distribution (6503)

Potomac R. tidal effect on Morgantown plant cooling water (6514)-.-.-.-.-.-153

See also COOIING WATER

See also POLIUTION, THERMAL

MODELS, DAM

Castaic Dam, California, diversion and release system (6659)-.........

Clay Crk., Colo., dam effect on 1965 flood

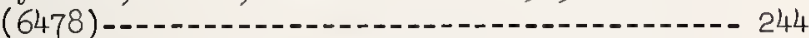

Comprehensive model, New Don Pedro Dam,

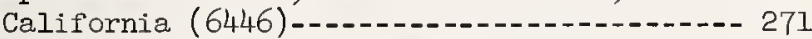

Demolition of Hales Bar dam, TVA (6714)------- 246

Duncan Dam (Canada) components (6440)-...-.-.- 271

Kaysinger Bluff Dam, Osage R., Mo. (6033)-..-- 206

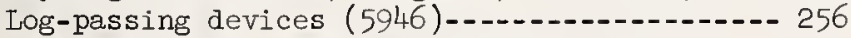

Mica Dam (Can.) spillway, approach channel, chute and outlet works (6436)-.--.-.-.-.-.- 270

Nickajack Project overal1 model (5004)-......- 245

Tocks Island Dam, Delaware R., Pa., general

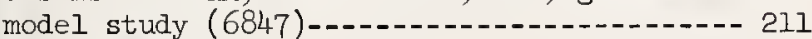

MODELS, DIFFUSER

For mixing of condenser water in river (6418)- 73

MODELS, DIVERSION TUNNEL

Mica Dam (Can.) river diversion and closure (6434)
MODELS, DIVERSION TUNNEL (continued)

Mica Dam (Can.) tunnel exit structures

(6435) (Can 269

MODELS, DREDGE PUMP

Cavitation studies (5550)

Performance studies (5174)

MODELS, DROP SHAFT

Various shaft designs with variations in

discharge and tailwater (6747)-.-.-.-.-- 112

MODELS, DROP STRUCTURE

Control structure on Little Sioux R., Iowa (4599)-_-195

Gering Valley Project, Nebraska (3915)-.-.-.- 192

Low-water weir tests for riprap stability,

Boeuf R., La. (6871)-_._-_. 215

On San Gabriel River, Los Angeles County

Flood Control (6880)-_...........-.-186 Sandusky River improvement, Ohio (5641)-.---- 199

Walnut Creek, Calif., project (6031)--.---.-- 206 MODELS, ENERGY DISSIPATOR

Baffled chute, Conconully Dam (6325)-.-.-.-.-- 226

Bucket and jump types considered for West

Point Dam, Georgia (6030)-_.-.-. 205

DeCordova Bend, Erazos R. (6181)-.---.---.-- 130

Flip bucket, ElVado Dam outlet works (5848)-- 222

For large culverts (6221)-................-. 12

See also ENERGY DISSIPATORS

See also MODELS, STILIING BASINS

See also SIILLING BASINS

MODELS, FISH CONTROL

Tehama-Colusa Canal fish concentrator (6310)- 224

Velocity barrier in canal for spawning-fish

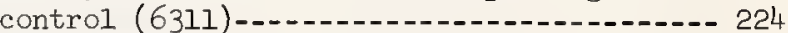

MODELS, GATES

Closure forces on turbine intake gate (6722)- 247

Flow through gate structures; calibrations and vibrations (6745)-....................... 11

High-pressure slide gate, Morrow Point Dam

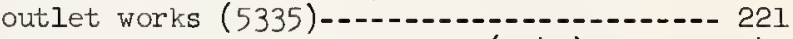

Nickajack turbine intake gates (5943)-..-.-.- 245

Quick-closing emergency gate for coolingwater conduits at Paradise Plant (TVA)

(6721) -...... 247

MODELS, GRIT-REMOVAL CHANINEL (5805)-.......- 111

MODELS, HARBORS

Barber's Pt., Oahu, deep draft harbor (6073)- 40

Breakwater protection of docking facility

(6433)-_- 269

Brunswick, Ga., shoaling study (5648)-.-.-.- 200

Charleston, S.C., pollution study (5640)--.-- 199

Crescent City, Calif., wave action (6041)---- 208

Expansion of Kawaihae Harbor, Hawaii (6867)-- 214

Hilo Bay beach erosion study (5895)-....... 40

Hilo Harbor, Hawaii, seiching study (5894)--- 40

Kewalo Basin and Ala Wai Harbor, Hawai i,

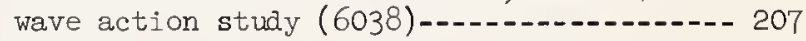

Mission Bay, Calif., wave action study

Modifications at Port San Luis, Calif. (6869)-

Navigation and wave action at Monterey,

Calif. (6018)-...- 202

New Buffalo, Mich., wave action study (6037)- 207

Santa Barbara, Calif., breakwater system

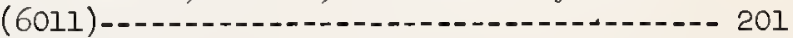

Shooters Island removal, New York Harbor

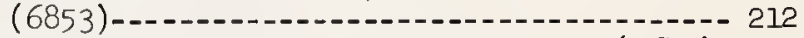
Small-boat harbor, Dana Point, Calif. (5642)- 199 Stability of navigation opening structure Hilo Harbor tsunami barrier (6039)-......- 208

Vancouver, B.C. tidal current changes due to dredging and causeway (6250)-..-.-.-.-260 Wave action at Noyo Harbor, Calif. (6015)---- 202 Wave protection for Vermilion Harbor, Ohio

(6870) - 215 
For aquifer recession hdyrographs (5303)..... 28

MODELS, HURRICANE SURGE

Effect of barrier on navigation in East

Passage, Narragansett Bay, R.I. (3590)-..--- 190 Galveston Bay area, Texas (6025)-........-. 204 MODELS, HYDROELECTRIC PROJECTS

Aubrey Falls dam and tailrace (6167)......-.-. 258

Guri project, Venezuela (4201)-.........- 108

Hells Canyon training-wall vibration (5521)--- 144

Nanticoke Generating Sta., Canada (6168)--.--- 259

MODELS, HYDROLOGIC

See HYDROIOGIC MODELS and MODELS, ANAIOG

MODELS, ICE JAM

Bromptonville, Que., flushing system (6252)--- 261

MODELS, INLET

Canal-tunnel junction, optimum inlet geometry $(6326)$-........... 226

Hydraulics of drop inlets (5597) -.......- 148

Pumping-plant inlet transition design (6301)-- 222

MODELS, INTAKES

Bear Creek (TVA) intake towers (6717)-.-.-.-.-- 246

Circulating water pump intake, Willow Glen steam plant (5971)

Flow patterns at Tehachapi (Calif.) pumping plant (6661)

High intake tower performance, Castaic Dam, California (6658)-...-16

Iittle Panoche Crk. detention dam outlet works (5347) -............. 222

Manicouagan 5 hydroelectric project (5513)---- 256

Montreal water supply intake; ice protection (6240) - - 260

Nanticoke Generating Station (6168)-.-...-.-. 259

Northfield pumped-storage plant (6500)-.....- 151

Portage Mt. Dam (Can.) power plant (6438)-..-- 270

Sen Iuis Forebay pumping plant inlet canal transition (4954) -....... 220

Submerged vertical shaft, Iddiki plant (6245)- 261

Turbine intake flow patterns, Raccoon Mt.

project (TVA) (6723)

See also MODELS, OUTLET WORKS

MODELS, JETTY

Stability tests, Humboldt Bay, Calif. (6866)-- 214 MODELS, IAKES

Dynamic model study of Lake Erie (6045) -...-. 5 MODELS, LOCKS

Ice-flushing and hydraulic-assist flows, Beauharnois Iocks, Canada (6236)-..-...-.-.- 260

Ice-flushing and hydraulic-assist flows

St. Lambert Lock, Canada (6235)-..-.-.-.-.-- 260

MODELS, LOCKS (FIIIING AND EMPTYING SYSTEMS)

Chaffeys Lock No. 37, Rideau Canal, Canada (6233) -

Cordell Hull Iock, Cumberland R., Tenn.

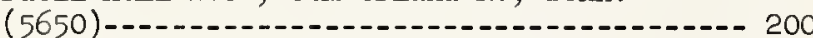

Dardanelle Lock, Arkansas R. (6854)-.-.-.-.--- 212

Lock culvert outlet basin study (6023)-..-.-.- 203

Modernization of McAlpine Locks, Ohio R. (3914)-_-_- 192

Montgomery Lock, Fox R., Illinois (6095)-.... 46 Newboro Lock No. 36, Rideau Canal, Can. (6234)-_........... 260

Newbury Lock, Ohio R. (6858)-.......-.-.-- 213

Nickajack Project filling valve-culvert (5387)--.-1 245

Nickajack Project main lock (5386)-_.......- 245

Optimum port arrangement for low-lift locks,

Arkansas River (4603)-_._-_._- 195

Ports for Welland Locks, St. Lawrence

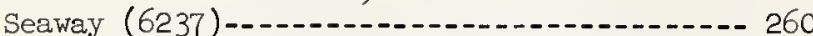
MODELS, IOCKS (NAVIGATION CONDITIONS)

Belleville Locks and Dam, Ohio R. (4385)--.-.- 193

Cannelton Locks and Dam, Ohio R. (4390)-.....- 193

Hannibal Locks and Dam, Ohio River (3909)-.-- 191 Holt Lock and Dam, Warrior R., Ala.,

including spillway performance (4386)-..-.- 193

Jones Bluff Lock and Dam, Alabama R. (6024)-- 204 Kaskaskia R., Ill., navigation project

(6855)-12

Kerr Lock and Dam, Arkansas River (5251)--.-- 197

Lock and Dam No. 3, Arkansas River (4391)-.-- 194

Lock and Dam No. 4, Arkansas River (5230)-.-- 196

Lock and Dam No. 4, Monongahela River (3243)- 190

Lock and Dam No. 7, Arkansas River (5639)--.- 199

Lock and Dam No. 8, Arkansas River (6022)-.-- 203

Lock and Dam No. 9, Arkansas River (5638)-..- 198

Lock and Dam No. 13, Arkansas River (6856)--- 212

Lock and Dam No. 14, Arkansas River (6020)--- 203

Lock and Dam No. 17, Verdigris R., Okla.

(6021)-_. 203

Lock and Dam No. 26, Miss. River (6857)-..--- 213

McAlpine Locks and Dam, Ohio River (2678)---- 190 Millers Ferry Lock and Dam, Ala. R. (4593)--- 194 Ozark Lock and Dam, Arkansas R. (5231)-..-.-- 196 Smithfield Locks and Dam, Ohio R. (6859)--.-- 213 Webbers Falls Lock and Dam, Arkansas R. (5652) - 201 MODELS, MANIFOID

Flow in flash-distillation plant manifold (6319) - 225

Tehachapi (Calif.) pumping plant (6662)-..-.- 16 MODELS, MOVABLE BED

Artificial roughness in movable bed models (5684)--..-.- 32

Frazer R., Canada, navigation draft needs (6244)-...... 260

Shoaling on Frazier River (6443)--.--.--.-- 271

MODELS, OCEAN

Rotating model, Antarctic Ocean circulation (6085)-1..... 62

MODELS, OUTLET WORKS

Auxiliary outlet at Tiber Dam (6328)-..-.-.-- 226

Beltzville Dam, Pa.; selective withdrawal

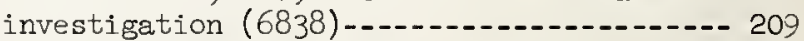

Branched Oak Dam, Nebraska (6034)-.-.....-.-- 206

Chatfield Dam, S. Platte R., Colorado; performance of duckbill crest (6839)--.---- 209

Intake, tunnel and stilling basin, Howard

Hanson Dam, Washington (6878)-.......-. 185

Lower Two Medicine Dam (6302).............- 223

Mica Dam (Can.) low level outlet (6435)-.-.-. 269

Morning glory intake, Eau Galle, Wisc.

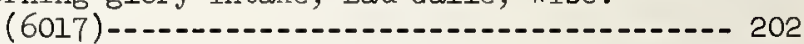

Morrow Point Dam spillway, outlet works (4807) - 220

Naperville Dam, Illinois (6094)-_........-. 46 New-Hope Dam, Cape Fear Basin, NN.C. (6844)--- 210 Selective withdrawal weir, Meramec Park

Reservoir, Mo. (6843)-_.... 210

Summerville Dam, W. Va., Howell-Bunger valve $(6874)$

MODELS, PENSTOCK

For third Grand Coulee powerplant (6323)----- 226 Northfield pumped storage plant (6501)-...-.- 152 MODELS, POWERPLANI

Third plant, Grand Coulee (6322)-.......-.- 225

MODELS, PUMPED STORAGE PLANT

Cornwall Plant, Hudson R. (6510)-........-.- 153

Intake and tunnel flows, Jocassee Plant

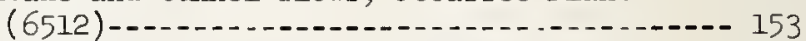

Intake and tunnel flows, Kinzua Project

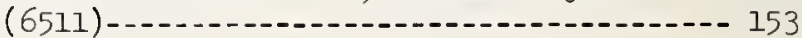

Northfield plant, Connecticut R. (6499)-.---- 151 
MODELS, RIVER

Arkansas R. navigation model (3908) -........- 191

Columbia $R$. near Bonneville Dam, navigation condition study (6879) -.....................

Confluence of Arkansas, Verdigris and Grand

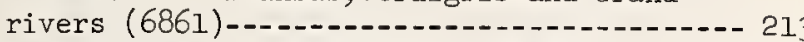

Connecticut R. between Vernon Dam and

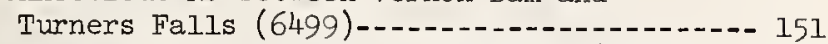

Delaware River, from bay to Trenton (425)--.-- 187

Frazer R., Canada, movable bed model for navigation draft needs (6244)-.......-.-.-260

Housatonic-Naugatuck rivers at Ansonia-Derby, Conn. (6860) -..... 213

Hudson R. cooling-water effect from steam plant (6509)-..- 152

Ice conditions on st. Lawrence (6239)-....-.-260

Illinois River flood relief (5549)-.......-.-. 46

Improvement of San Gabriel R. for Los Angeles County flood control (6880)-.............- 186

James R., Va., channel improvement effect on hydraulic and salinity conditions in

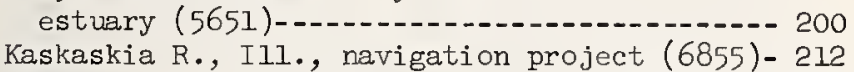

Mississippi Basin model, flood tests (236) -..- 186

Navigation conditions, Arkansas R. near Little Rock (5644)-_.................... 200

Navigation conditions, Ft. Smith reach, Arkansas R. (6019) -

Navigation conditions in Van Buren reach, Arkansas R. (6862)-_........ 214

Pneumatic-barrier effect on salinity

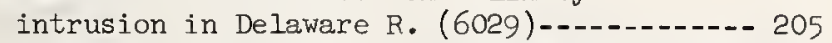

Potomac R. tidal effect on cooling water from Morgantown steam power plant (6514)-...... 153

Sand bar formation blocks mouth of Corazones water channel, Puerto Rico (6764)-......

Sand-clay mixtures for cohesive-bed meander model (6198)

Shoaling in Columbia R. estuary (4396)

Shoaling study, Frazer River (6443)-.-.-.---. 271

Submerged sills in St. Clair $R$. to raise Lake Huron level (5233)-_... 196 Tidal reaches of the St. Lawrence (6602)------ 264 Turtle Creek, Pa., channel improvement (4383)- 193

Umpqua R. estuary, Oreg., shoaling (6026)....- 204

Wabash R., power-plant cooling-water effect (6506)

Yaguez River, Puerto Rico; effect of offshore sand bar near mouth on flood flow (6763) -..--

MODELS, RIVER BASIN

Electric analog, Miami R. Basin, Ohio (6464)-See also HYDROLOGIC MODELS

MODELS, SAND DREDGE

Feasibility study of wave-powered dredge (5836) - 184

MODELS, SEAWALL

Stability of seawall, Texas City, Tex. (5234)- 196

MODELS, SEWER

Vancouver, B.C., interceptor sewers (6444)--.- 271

MODELS, SHIP

Bending moments on cargo ships in waves (3516)

MODELS, SHIP CHANNEL

Channel-diking effect in Lake st. Peter ketween Montreal and Quebec (6228)-...-.-.-. 259

Flusing system to remove oil and debris, Victoria Channel, Texas (5636)........... 138 Gastineau Channel, Alaska, shoaling (6027)---- 204 Houston Ship Channel, Texas (5245)-...-.-.- 197 Lower Columbia River, shoaling (4396)-.-.-.-- 194

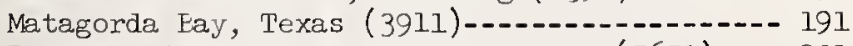
Proposed Lake Erie-Ontario waterway (5653)---- 201 Shoaling at entrance channel to Galveston Eay, Texas (3912)
MODELS, SHIP CHANNEI (continued)

Shoaling in Delaware $R$. channel to Trenton

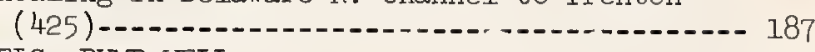
MODELS, PUMP WELL

Cayuga Steam Power Plant, Ind. (6507)-------- 152 Point Beach (Mich.) nuclear power plant

(6508) - RACTORS

MODELS, REACTORS
Heavy-water ci

Heavy-water circulation (6251)--...-.-.-.-- 261 MODELS, SPILLWAY

Apron design for Tellico project, TVA (6724)--- 247 Bankhead Dam, Ala., cavitation study (6036)--- 207 Bear Creek (TVA) morning glory (6717)-.-.---.- 246 Bucket shapes and settings tested, Peace

River (6243)-.-... 260

Castaic Dam, California (6657)-_.......... 16

Cedar Springs, Calif., spillway and outlet

works (6660)-............ 16

Crystal Dam, overall flow conditions (5846)--- 222 DeCordova Bend, Brazos, R. (6181)-.-.-.-130 Duncan Lake Development, Canada; stage-dis-

charge curve for various gate openings

(6242)-.....- 260

Emergency chute for Bear Creek (TVA) (6718)--- 247 Erosion at Patillas Dam, Puerto Rico (5845)--- 222 Erosion studies for Eartlett Dam (6308)-....-. 223 Flow with large upstream velocity, Outardes 3

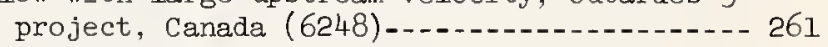
General hydraulic studies of various crest shapes (3917) Glen Elder Dam, hydraulic performance (5346)-- 221 Glory-hole type, Del Valle Dam (5864)-....- 15 Guri project, Venezuela (4201)-...-108 Hugo Dam, Okla., spillway, stilling basin

and effect of downstream bridges (6841)--.-- 209 Huntington Reservoir, Wabash R., Ind. (5232)-- 196 Kaw Dam, Arkansas R., Okla. (6842)-.....- 209 Kettle Dam, Manitoba (6445)-_..-..-.-271 Kinkaid Creek Dam, I11. (5656)-........... 46 Lower Two Medicine Dam (6302)-..........-.- 223 Mangla Dam, Pakistan (3502)-............... 107 Morrow Point Dam spillway, outlet works

(4807)-...-...... 220

Nickajack Project discharge rating (3588)----- 245 Ninety degree spillway, Nockamixon Dam (6559)- 64 Polpitiya (Ceylon) dam spillway and scour protection studies (6241) Portage Mt. Dam, Canada (6439)-...- 270 Rend Lake reservoir, Bi⿱乛⿻ Muddy R., IIl.

(6845)-...... 210

Shelbyville Dam, Kaskaskia River, Ill. spillway and outlet wor's (4594)-........-. 195

Tims Ford flip-buc'ret spillway (5945)-.-.-- 245

Tims Ford Project chute-type spillway (6711) 246

Toledo Bend Dam (5956)-_l 130

Two Lick Creek Dam spillway, radial gates and

erosion patterns below spillway (6561)----- 65

West Point Dam, Ga., concrete overflow (6030)- 205

Yellowtail Dam tunnel-type (6329)-.......-.- 226

MODELS, STILIING BASINS

Abrasion at Navajo Dam (6304)-............. 223

Copan Dam, Okla., stilling basin and riprap

stability (6840) - 209

Crystal Dam outlet works (5847)

Design procedures for USBR Type VI (6309)--.-- 224

Kinkaid Creek Dam, Ill. (5656)-_......... 46

Naperville Dam, Illinois (6094)

Lower Two-Medicine Dam (6302)-_..........- 223

South Saskatchewan Dam (6442)

Spillway and stilling basin, Hannibal Dam,

Ohio R. (5646)-... 200

Tocks Island Dam, Delaware R., Pa. (6847)--.- $2 \perp 1$

Willow Glen steam plant (5970)............ 151

See also MODELS, ENERGY DISSIPATROS 
MODELS, SURGE TANK

For California Aqueduct penstocks (6663)-.-.-- 16 Head losses through restricted orifices (6822)

Head losses through restricted orifices, Manicouagan 5 project (5947) -........... 256

Performance of Outardes 2 and Manicouagan 5 surge tanks (6249).............................. 261 MODELS, TAILRACE CHANNEL

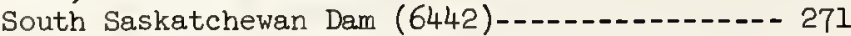

MODELS, TRAINS

Cross-wind effect on train in wind tunnel (6123) -

MODELS, WAVE ACTION

Design criteria for wave filters in harbor

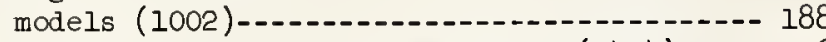

Laboratory simulation of sea waves (5454)-..- 116

On proposed island site for combined nuclear reactor and desalting plant (6583)-......-. 8

Protection against wave and surge runup at nuclear plant site (6753)-............... 32

Scale and distortion effects (1002)-...-.-.-. 188

Section of Mass. Bay modeled to protect nuclear power plant from storm waves (6505)- 152 Tsunami-barrier plans for Hilo, Hawaii (3903)- 190 Tsunami run-up at Oahu, Hawaii (5896)-......- 40 Wave-protection structures for Chagrin River,

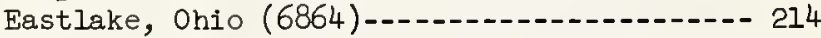
See also MODELS, HARBOR; MODELS, BREAKWATER MOMENTUM EQUATION

For solid-fluid systems (6270) MORPHOLOGY, RIVER

See RIVER CHANNELS

MOUNTAIN WAVES,

SEe WAVES, INTERNAL

MULTI-PHASE FLOW

Thermal conductivity predicted from values for each component (6672) See also TWO-PHASE FLOW

$$
-\mathrm{N}-
$$

NEUTRON METERS

See SOII WATER

See HYROLOGIC MEASUREMENTS

NOISE

See ACOUSTICS

SEe HYDRODYNAMIC NOISE

NONLINEAR SYSTEMS ANALYSIS (4562)-...-..-.-.-. NON-NEWTONIAN FLOWS

Bingham fluids in pipes (3747)

Computational models based on discretizations of diff. eqs. (6361)

Drag reduction effects; stability theory

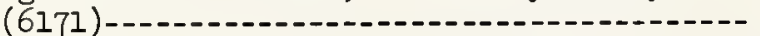

Effect of Bingham-Body fluid on pumping (3084)

Elastic-behavior and wall effects on drag reduction; high polymers and micellarelectrolyte systems (6391)................

Head loss of non-Newtonian suspensions and fluids in pipes (6469)

Laminar and turbulent boundary layer

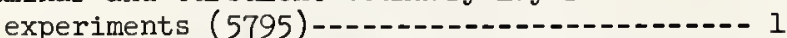

Relation between deformation of suspended particles and non-Newtonian behavior (6667)-

Similarity solutions developed (6357)-...-.-.-

Slurry flows in pipes (3747)

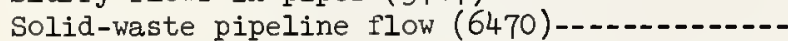

Stability, between rotating coaxial cylinders (5710) -.....

Taylor instability in Newtonian and non-

Newtonian fluids (6737)-................. 111

Taylor vortices between concentric rotating

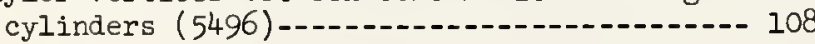

NON-NEWTONLAN FLOWS (continued)

Turbulence theory for second-order fluid-...- 95

Turbulent heat transfer in viscoelastic fluids (5960)

Turbulent shear flow analyzed using gross effective viscosity (6768)-_...... 89

Uniform unsteady flow between plates, in pipes and annuli (6361)................ 57

velocity-distribution measurements at low Reynolds numbers (5371)

NON-NEWTONIAN FLOW, VISCOEIASTIC

Experiments on free turbulence in viscoelastic

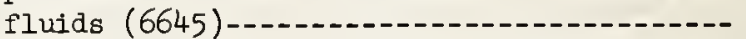

Similarity laws and stability (6379)-..-.-.-.

Visco-elastic flow in tube entrance (6469)---

Viscoelastic stresses in dilute polymer

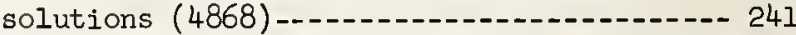

NOZZLES

Hydrodynamic forces on submerged hose-nozzle

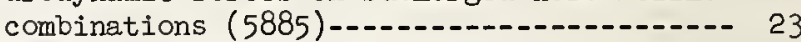

Transonic nozzle, thrust control with swirling flow (6062) -...................... 238

See also HYDRAULIC MEAS., FLOW METERS NUCLEAR EXCAVATION

See CANALS

NUCLEAR REACTOR

Heavy-water circulation, manifold and vortex

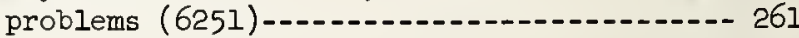

$$
-0-
$$

OCEANOGRAPHIC INSTRUMENTS

See HYDRAULIC MEASUREMENTS, OCEANGRAPHIC OCEANOGRAPHY

Determination of scale at which synoptic analysis is feasible (6475) Mixing and diffusion, see DIFFUSION

Ocean circulation, see CIRCULATION

Ocean currents, see CURRENTS

Oceanographic research tower at Navy Electronic Lab. (6372)-_...... 242

Sea-bottom boundary layer and sediment transport (6283)-...-.-146

Study of fine scale of sea temperature (6289)-....... 113

Thermoclines, see THERMOCLINES

Turbulence in ocean, see TURBULENCE

Upper layers, see AIR-SEA INTERFACE

Use of satellites for obtaining data (6767)-- 85

See also AIR-SEA INIERACTION

See also BEACHES

See also TIDES

See also WAVES

OCEANOGRAPHY, FORECASTTNG

Field studies for development of ocean forecasting model (6593)

Numerical dynamic model for deep-ocean

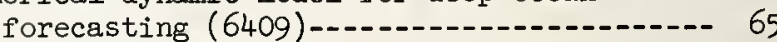

OCEAN STRUCTURES

See STRUCTURES

OIL-WATER INTERFACE

Stability of immiscible liquids (6448)-....- 18

OIL-WATER SEPARATION

Influence of turbulence (6621)

OPEN-CHANNEL FLOW

Analysis of complex systems (5861)-.-.-.-.- 15

Capacities of large concrete canals on flat slopes (O62W) - 227

Collection-trough design for condenser cooling water (6720)-.................. 247 Division by side weirs (5740)............ 81 Dynamics of flow in steep, rough channels

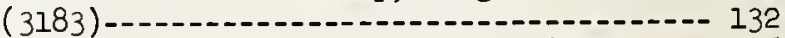

Effect of stationary surface film (6376)-.-- 26 Ice cover effect on surges (6631)-........-251 
OPEN-CHANNEL FLOW (continued)

Permissible limits of model distortion (994)

Rainfall effect on turbulence and sediment capacity in shallow flows (5478)-...-.-.- 125

Reaeration as function of channel, flow, and

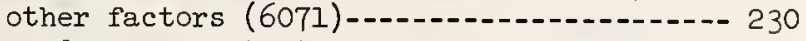

Secondary currents in corner of triangular channel (4531)-_...- 27

SIug flow, steep channels (5360)-.-....-.-. 7

Surface characteristics of air entrained flow in steep channels (3824)

OPEN-CHANNEL FLOW, BACKWATER CURVES

Computer analysis of effects of approximations (4661)-

OPEN-CHANNEL FLOW, BENDS

Resistance differences between fixed and erodible beds (6354)

River bend cross-sections statistically related to flow and sediment parameters

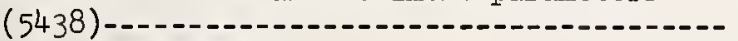

See also MEANDERS

See also RIVER CHANNELS

OPEN-CHANNEL FLOW, CONSTRICTIONS

Relation between upstream depth and constriction depth (6751)-

OPEN-CHANNEL FLOW, DISPERSION

See DISPERSION, RIVER

OPEN-CHANNEL FLOW, FIOW MEASUREMENT

SEe HYDRAUTIC MEASUREMENTS, FLUMES

OPEN-CHANNEL FLOW, OVERBANK

Hydraulics of meandering rivers with flood plains (4l9l)-...... 100 (6198)-_.-...- 102

Manning $n$ for vegetation-lined flow (4337)--- 162

Uniform flow and flood waves in channel-

flood plain geometries (6197)-..-.-.-.-.- 101

OPEN-CHANNEL FLOW, RESISTAINCE

Air entrainment effect on friction (6288)---- 82

Bend resistance-channel geometry-sediment transport relations (6354)-_............ 56

Cobble-strewn stream roughness; effect of cobble shape (5181B)-..... 93

Dune and free surface effects (6523)-.-.-.-- 139

Flow with cubical roughness elements (5534)-- 142

Friction factors for sand bed channels (6617)-_.... 58

Head loss in irregular channels from nuclear excavation (6873)-1...- 216

In alluvial channels (5165)-............ 21

Large roughnesses in steep channels (3183)--- 132 (5533)-...- 142

Large-scale roughnesses (6398)-.......... 125

Large spheres used as roughness elements

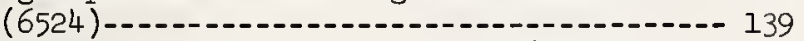

Manning $\mathrm{n}$ for cobble-strewn beds (5181A-B)--- 93

Manning $\mathrm{n}$ for vegetation-Iined flow (4337)--- 162

Prediction of friction factor for duned

beds (5118)

Relation of bed forms to friction (4075)-..-- 6

Roughness in natural and artificial

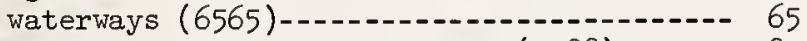

Temperature effect on bed forms (1988)-...-.- 189

Turbulent flow structure related to resistance

for movable boundary case (5610)--.--.-.-. 228

Various rough surfaces at different slopes

and depths (6285) -...-.-.

See also ALLUVIAL CHANNELS

See also BED FORMS

See also ROUGHNESS

OPEN-CHANNEL FLOW, ROLL WAVES

Development of roll waves in steep open channels (5360)

Surges, roll waves in steep, rough channels (5957) - 142
OPEN-CHANNEL FLOW, SHEAR STRESS

Page

Distribution obtained by microphotography (5660)

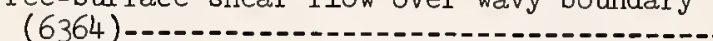

See also OPEN-CHANNEL FIOW, RESISTANCE

OPEN-CHANIEL FLOW, SUPERCRITICAL

Design of transitions (6207)

Diffusion of a supercritical stream on a

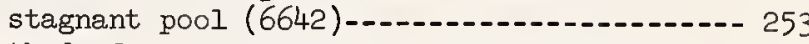

Method of characteristics applied to simple transition (656́o)-....... 65

Transitions, theory and experiment (6399)-...- 125 OPEN-CHANNEL FLOW, SURGES

See SURGES

OPEN-CHANNEL FLOW, TRANSITIONS

Air and water models of warped transitions (5861)--.-.-.-.

Circular pipe flow to rectangular supercritical open channel (2386)--..- 107

Experiments on subcritical-flow expansions

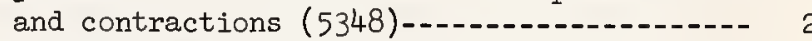

Method of characteristics applied to simple supercritical-flow transition (6560)--..---

Rectangular-to-trapezoidal supercritical channel flow (6207) (6399)

Use of simple expansions with selected inserts $(5348)$

OPEN-CHANNNEL FLOW, TURBULENCE IN

See TURBULENCE

OPEN-CHANNEL FLOW, UNSTEADY

Flow in channel systems analyzed numerically

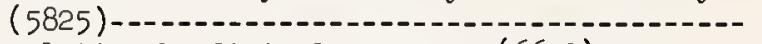

Simulation by digital computer (6690)-------- 36

Steady and unsteady effects on discharge in river connecting two reservoirs (6567)......

OPEN-CHANNEL FLOW, WAVY BOUNDARY

Shear flow characteristics over sinusoidal

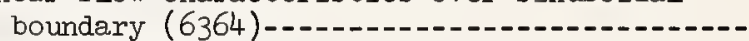

OPERATIONS RESEARCH

Benefit-cost inventory for water-resource analysis (6I77)

ORIFICES

Flow through multiple orifices of arbitrary size and shape (6427)

Flow through wall ports in corrugated metal pipe (6715)-... 246

Head losses through restricted surge tank orifices (5947)-..- 256

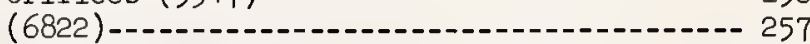

Used in automatic gate control (4802)--.---.-- 220 OSCILIATING BODIES (AT FREE SURFACE)

Forced oscillations of circular and U-cylinders (6300)-.--

OSCILIATIONS, FLOW INDUCED

SEe VIBRATIONS

OUTLET WORKS

Auxiliary outlet at Tiber Dam using drop inlet from existing outlet (6328)-...-.-.-- 226

Prototype measurements on gated intake and tunnel, Nolin Dam, Ky. (5243)-_...-.-.-196 See also MODELS, OUTIET WORKS

OVERBANK FLOW

See OPEN-CHANNEL FLOW, OVERBANK OVERFALIS

Flow characteristics of rectangular free overfall (6640)

OVERLAND FLOW

Difference solutions of shallow-water

equation ( 5874$)$ agents (5294)-...-

Mannings equation for shallow flow (4664)-..-15 (1) 
OVERIAND FLOW (continued)

Manning $n$ for vegetation-lined flow (4337)--- 162

Modeling urban runoff (5117)-............. 70

Rainfall effect on turbulence and sediment

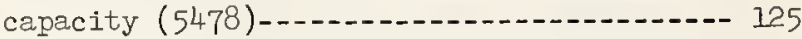

Rainfall effects on flow as factor in soil

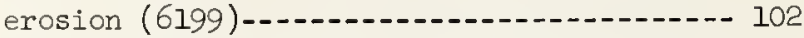

Role in hydrologic cycle; effectiveness as a landscaping agent (6070)-.-.-.-.-.-.-.-230

Short erosion plots under simulated rainfall

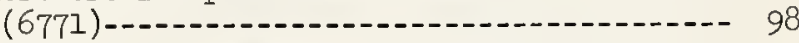

Solution to unsteady spatially varied flow

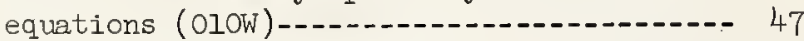

Spatial behavior of roughness in laboratory watersheds (028W)(029W) -................ 82

Theory, as related to surface irrigation (5752) See also SHEET FLOW

OXYGEN, DISSOLVED

Reaeration in open-channel flow (6071)-.-.--- 230

Temporal and spatial variation of dissolved oxygen and b.o.d. in steady, uniform

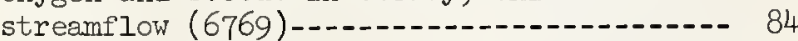

Temporal and spatial variations when hydraulic parameters vary with space and time (6770)- 84 See also AERATION; REAERATION

OXYGEN TRANSFER

See AERATION

See BIO-MEDICAL HYDRODYMAMICS

$$
-\mathrm{P}-
$$

\section{PARSHALI FLUME}

See HYDRAULIC MEAS., FLUMES

PAVEMENT

See DRAINAGE

PENSTOCKS

Entrances, elbows for third Grand Coulee

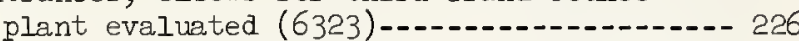

Intakes, entrances, transitions; optimum

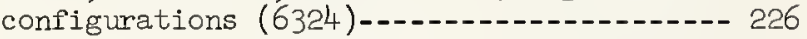

Losses for various alignments and section

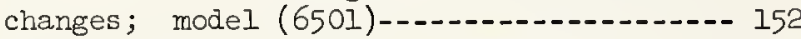

Resonant characteristics of generalized

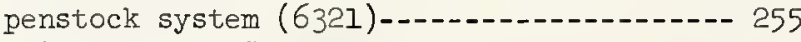

\section{PERISTALTIC PUMPING}

See BIOMEDICAL HYDRODYNAMICS

PERMAFROST

Construction of water supply and sewage facilities in permafrost areas (054W)-.-.-- 181

Thermal calculation techniques for change in frost level (052W)-..... 181

\section{PERMEABILITY}

Annotated bibliography (5599) -..........- 227

Electrokinetic effects in fine sand (4209)--- 108

Evaluation of lab. and field methods (5599)-- 227

Flow table study of flow patterns in nonhomogeneous porous medium (6732)-..-.-.-. 2

Use of sound waves to determine porous-medium

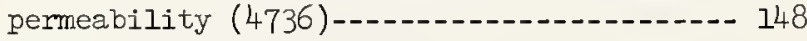

See also POROUS MEDIA FLOW

\section{PESTICIDES}

Effect on surface and groundwater quality (O40W)-....

PHREATOPHYTES

Determining water use by phreatophytes (657B) 174 PIERS

Wave pressure on underside (6334)-..-.-.-.- 236 See also DoCKS

PIFRS, BRIDGE

See BRIDGE PIFRS

PIIES

SEe WAVES, FORCES
PIPE FLOW, ANNULAR

Concentric annuli of different diameter ratios (6458)

Turbulent flow in concentric and eccentric annular conduits (6140)-................. 50

Turbulent helical flow in an annulus (4734)--- 148 PIPE FLOW, BENDS

Flow losses and vibrations in elastic pipes,

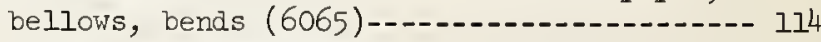
PIPE FIOW, BRAINCHED PIPES

Disturbed laminar flow due to branches (6623)- 149

Effect of branches on laminar stability

(4559)-_-n-n 49

Wave reflections in branched flexible

conduits (6142)-1...- 50

PIPE FLOW, CAPILLARIES

Dispersion mechanism in capillaries (6331)-..- 19 PIPE FLOW, CAVITATION

See CAVITATION

PIPE FLOW, COMPLIANT WALLS

Experiments on drag reduction in turbulent

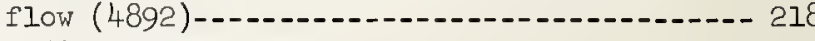
PIPE FLOW, DISPERSION IN

See DISPERSION

PIPE FLOW, ENTRAIMMENT IN

Entrainment of ambient still fluid through ports in submerged pipe flowing full (4725)- 145 PIPE FIOW, EXITS

Effects of free jets, aprons, and wall flares (2543)-...... 63

Pressure fluctuations at abrupt expansion (79)-1.-1 53

Stable eddies at abrupt expansions (1875)-... 53 PIPE FLOW, FITTINGS

Disturbed laminar flow due to fittings (6623)- 149

Head loss in spherical and conventional wyes (4451)-

PIPE FLOW, FLEXIBIE TUBES

Hydrodynamic forces on submerged hose-nozzle

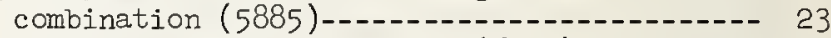

Peristaltic-pumping research (6108)--.-.-.-. 75

Pulsatile and steady blood flow (6138)-.....- 19

Pulsatile flow in distensible tubes (4859)-.-- 78

Turbulence damping with foam dampeners (6083)- 97

Wave reflections in branched flexible pipes (6142) -

PIPE FIOW, GAS DUCT

See GAS DUCT

PIPE FLOW, HEADERS

See HFADERS

PIPE FLOW, INTET LENGTH

Turbulence properties used to determine start of established flow (6697).............. 38

Visco-elastic flow in tube entrance (6469)--.- 96 PIPE FLOW, JUNCTIONS

Flow in large pipe-junction structures (5865)- 16 PIPE FLOW, IAMINAR

Disturbed laminar flow due to fittings (6623)- 149

Immersed single-particle drag and motion in pipe flow (6280)-........................- 143

Friction factors and pressure drop for sinusoidal flow of blood and water in rigid tubes (6138)

Poiseville flow stability to three-dimensional disturbance (6263)........................ 123

Tube containing line of spherical particles

PIPE FIOW, IOSSES

See PIPE FLOW, RESISTANCE

PIPE FLOW NON-NEWTONIAN

See NON-NEWTONIAN FLOW

PIPE FLOW, OF SOLIDS

Solid waste pipeline hydrodynamics (6470)--..- 96 PIPE FIOW, OSCILIATORY

See PIPE FLOW, UNSTEADY 
PIPE FLOW, PERMEABLE WAII

Self-ejecting boundary layer flows (6273)-..- 26

PIPE FIOW, RECTAINGULAR PIPE

Friction factor and equivalent diameter

(6284)

PIPE FIOW, RESISTANCE

Concentric and eccectric annular conduits;

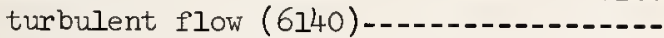

Effect of vibrations on friction factor

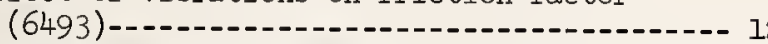

Flow losses and vibrations in elastic pipes, bellows, bends (6065)-.................. 114

Flow of non-Newtonian suspensions and fluids (6469)-....... 96

Friction factor, equivalent diameter for rectangular conduits (6284)-............-

Laminar, sinusoidal flow of blood and water

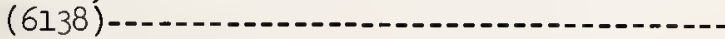

Oscillatory laminar and turbulent flow in a tube (6107)

Roughness due to aquatic growth (5827)-..-.-.

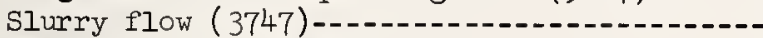

PIPE FLOW, ROTATION EFFECTS

Influence of rotation on flow in long rectangular channel (6800)-..................

PIPE FLOW, SECONDARY FIOW

Effect of natural convection on horizontalpipe flow (6827)

PIPE FLOW, SUSPENSIONS

See SUSPENSIONS

PIPE FLOW, SWIRLING

Decay of swirling turbulent, imcompressible flow in long pipes (6881)-............... 217

Swirling flow in tubes and vortex breakdown, adverse pressure gradient (6059)-......-. 237

PIPE FIOW, TRAINSIENTS

Characteristics methods applied to control of gas distribution systems (6425)--.---.-- 78

Computerized surge computations for pipeline

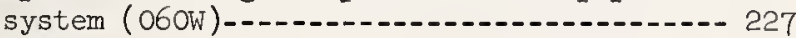

Propagation of disturbance in fluid lines (4197)--.-.-103

Reservoir-conduit interaction with quickacting valve (6468)

Resonance in complex pipe systems (4946)-...See also SURGES, PRESSURE; WATER HAMMER

PIPE FIOW, TRANSITION

Stability of Poiseuille flow to 3-dimensional

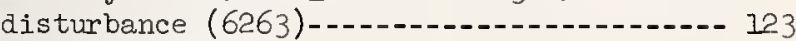

PIPE FIOW TURBULENT

Dispersion of injected chlorine solution

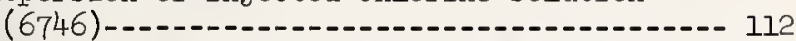

Heat and momentum transport at wall (6568)--- 89

Heat transport with internal heat sources (6109)-...- 59

Regimes of rough-pipe flow delineated in terms of roughness geometry (5534)-.-.-.-- 142

Turbulence structure in rough porous conduits (5823) - 71

Wall-pressure fluctuations in pipe flow of polymer solution (6587)

Wall-pressure fluctuations, measurement and analysis (6266)

Wall-roughness effects on turbulence

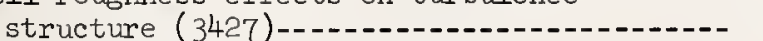

With sinusoidal boundary (6365)-........... 58

See also TIRBUIENCE, PIPE FLOW

PIPE FIOW, UNSTEADY

Frequency-dependent friction in pulsatile

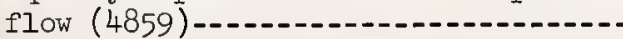

Friction factors and pressure drop for sinusoidal flow of blood and water in rigid tubes (6138)

Laminar flow with varying pressure gradient, analysis (6051)
PIPE FIOW, UNSTEADY (continued)

Local unsteadiness from polymer injection

(6695)-...... 38

Skin friction for laminar and turbulent

oscillatory flow in a tube (6107)-.-.-.-. 74

PIPE FLOW, VIBRATIONS

See VIBRATIONS

PIPE FLOW, WAVY BOUNDARY

Structure of turbulent flow (6365)-........-. 58 PIPELINES

Resonance in complex systems (4946)--.--.-.- 78

Wave forces on submerged pipes (6424)--.---.- 78

PIPE NETWORKS

Minimum-cost design (5540)-_............ 71

Water hammer in irrigation systems (6097)---- 254

PIPE SYSTEMS

Model of brine piping between evaporators

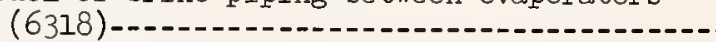

PIPES, CORROSION

See CORROSION

PLANINC

Pneumatic-tire hydroplaning (6691)-.-.-.-.-.-

Non-linear free-surface planing theory

(6450) - - - - - - -

See also HYDROPLANING

PLUMBING

Cross-connection control research (49)--.-.-- 114

Reliability of backwater valves in plumbing

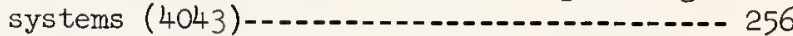
PIUMES, BUOYANT

Discharge into flowing or stratified ambient

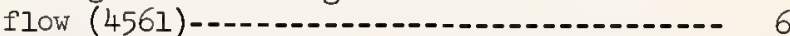

Dispersion of buoyant smoke plumes from high

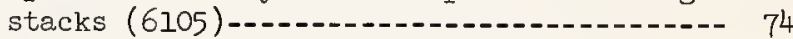

Mixing induced by introducing warm-water

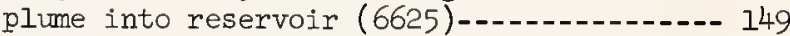

Smoke dispersion modeled in wind tunnel boundary layer (6816)-.................. 269

Spreading of warm water discharged from channel near surface of cold lake (6742)--- 111 POISEUILIE FIOW

See PIPE FIOW, LAMINAR POLIUTION

Charleston Harbor, S.C., model study of waste dispersion (5640) -...............

Dispersion of pulp mill wastes at ocean outfall (6775)

Effect of pesticides on water quality (O4OW)- 98

Electrokinetic removal of pollutants from water (6600) -.... 126

Flushing system to remove oil and debris, Victoria Channel, Texas (5636)-.......... 198

Theory for dispersion in porous media (4916)- 115

See also RADIOACTIVE WASTE

POLLUTION, ATMOSPHERIC

Buoyant plumes from smokestacks, dispersion

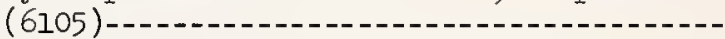

Chimney stack discharge; wind tunnel

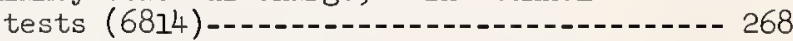

Smoke dispersion modeled in wind tunnel

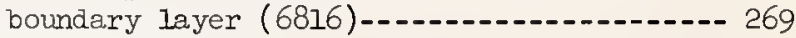

POIUUTION, ESTUARY

Numerical solution of unsteady estuary dispersion equation (4648)

See also ESTUARIES

POIIUTION, GROUNDWATER

See GROUNDWATER

POLUUIION, RADIOACTIVE

See RADIOACTIVE WASTE

POLIUTION, RIVER

Finite-difference modeling of river and

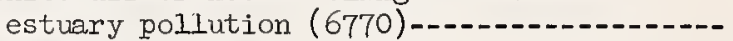

Mechanics of river and estuarine dispersion (6223) 
POLLUTION, THERMAL

Cooling-water discharge into St. Croix River (5494)

Diffusion and exchange of heat discharged

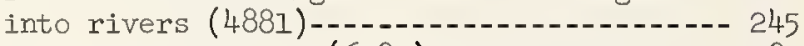

Effects on river ice (6387)-.................. 180

Reduction by turbulence stimulation in

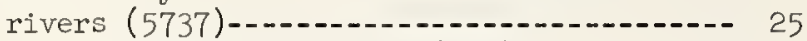

Stream temperatures in IVA (769)-.-.-.-.--- 248 See also COOLING-WATER DISCHARGE

See also MODELS, COOLING-WATER DISCHARGE POLYMERS

Effect of additives on impact tubes (5795)--- 110

Effect of dilute polymers solution on flow noise (5497) - 108

Effect of drag-reducing polymers on wave damping in tank (6829)-.... 48

Effect of polymer additives on diffusion separation flow noise (6796)-........- 113

Effect of polymer coiling on drag reduction (5291) - 147

Effect on impact-tube measurements and grid

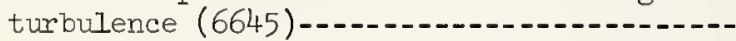

Hydrodynamics of polymer solutions; bulk properties of macromolecular solutions

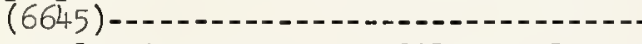

Viscoelastic stresses in dilute polymer solutions (4868)---1.--

Viscosity measurement of polymer solutions at extreme shear (6678) -

Viscosity of polymer solutions (6408)---.-- 82

See also DRAG REDUCTION, ADDITIVES

See also NON-NEWTONIAN FIOW

PONDS

Colloidal materials for seepage control in Nevada canals and ponds (3558)--.-.-....- 163

Properties of soil used for bottoms of wastewater stabilization ponds (04IW)-....- 113 See also RESERVOIRS; IAKES

PONDS, STOCK-WATERING

See RESERVOIRS

POROUS-MEDIA FIOW

Contribution of partially saturated zone in drainage of fine-textured soil (4826)----- 157

Diffusion of entrapped gas in response to interfacial energy (5891) -

Displacement of a fluid by a second fluid, observed in models (6781)

Effect of external air pressure when medium contains trapped air (5903)-.............

Electrical streaming potential developed in

porous media water flow (6166) (5450)-135

Flow of colloidal suspensions in porous media (036w) -

Friction factor vs. Reynolds number (5902)-.. From canals to groundwater table (032W)-.-.-. Gravity and viscous-induced instabilities in porous media displacements (6781)-.....-

Influence of physical properties of fluid and medium; laminar and turbulent flow (6204)

Movement of water and gases in soil (012W)--.
Non-Darcian movement of soil water (4679)--.-

Permeability determination in non-homogeneous media; flow-table study (6732)-.........-.

Probability laws for pore size distribution (5306) -

Relaxation solution for non-homogeneous nonisotropic media (3524)

Seepage patt,erns to wells for unconfined

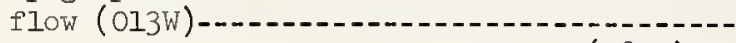

Silt-carrying water in porous media (5820)--- 12
POROUS-MEDIA FIOW

Solution of Dupuits equation for threedimensional free-surface seepage (6151)-.-.- 145

Solutions for steady-state free-surface seepage in non-homogeneous media (6527)-.--- 139

Solutions of seepage through complex media by finite elements (6693)-............... 37

Subsoil water flow into drainage facilities

Theory and experiment on microscopic and macroscopic aspects of flow (4787)--..-.---- 227

Theoretical, lab. and field study of specific yield and related properties (3263)-...-.-.- 227

Theory of flow into vertical sink (013W)-...- 59

Two-fluid radial flow in heterogeneous media ( 6782 )

Conservative pollutant in non-homogeneous media ( 5790$)$

Diffusion and dispersion of coastal groundwater (6259)-...- 86

Dispersion and permeability in antisotropic media (6782)

In heterogeneous anisotropic porous media

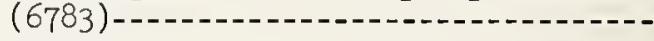

In packed beds, using random-walk model (5170)

Lateral dispersion of contaminants (6216) -...-

Mixing and spreading of fluids and solutes (4086)-...- 14

Stratification effects (5013)-.-.-.-.-.-. 6

Theory for pollutant dispersion in two

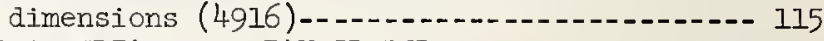

POROUS MEDIA FIOW, PAKCED BEDS

See BEDS

POROUS MEDIA FIOW, PERMEABIIITYY

See PERMEABILITY

POROUS MEDTA FIOW, STRATIFIED

SEe STRATIFIED FLOW

POROUS MEDIA FIOW, TRANSITION

Laminar-to-turbulent transition (5902)--.--.-. 44

Turbulence initiation in bed of spheres

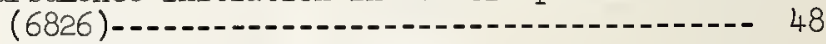

POROUS MEDIA FIOW, UNSATURATED

Analytic approach to unsteady horizontal flow in soils (3507) 116

Effect of external air pressure when medium contains trapped air (5903)

Groundwater flow in capillary zone (5816)-.-.- II

Infiltration theory, unsaturated media (5446)- 134

Methods of measuring flow and hydraulic properties in unsaturated zone (5841)-.-.--- 229

Model laws for partially saturated flow (5892) 23

Movement of water and gases in soil (O12W)-.-- 59

Partially saturated flow in sand-epoxy resin columns (4627) ......... I

Relation between capillary pressure and degree of saturation in sand colums (4627) -.....- 1

Unsaturated flow in soils and filters (5798)-- 110

Variation of seepage coefficient with degree of saturation (5798)--

POROUS MEDIA FIOW, UNSTEADY

Approximate solutions for non-steady vertical drainage of soils (5981)

Effect of bank clogging on flow into a stream (4736) -

Effect of initial capillary pressure (5898)--. 43

Gravity drainage of initially saturated

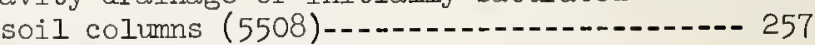

Measurements in ground-water tank and HeleShaw apparatus (6462)-..... 19

Radial flow toward well for 2-layered and anisotropic -1 quifers (5839)-............-. 228 
POROUS MEDIA FLOW, UNSTEADY (continued)

Unconfined flow toward a well (4736)-.......- 148

Unsaturated flow under influence of impressed

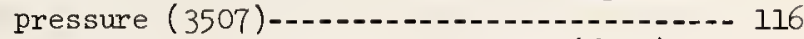

Well drawdown in unconfined aquifer (6734)-.-- 92 POTENTIAL FLOW

Around bodies of arbitrary configuration

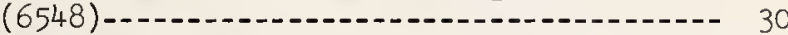

Around ship forms (2091)-................ 54

Computer program for flow around 3-dimensional body (6374)-_...... 34

Nonlinear interaction of two lifting bodies in arbitrary unsteady motion (6547)--.---- 30

Sluicegate, irrotational potential flow

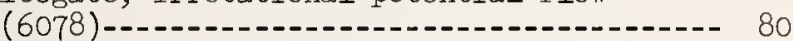

Spillway, irrotational potential flow over toe curve (6077)-1..- 80

Transient, two-dimensional flow of perfect incompressible fluid in free surface flow (6122) -........ 11

See also LIFTING SURFACE THEORY

POWERPLANTS

Third plant for Grand Coulee, model (6322)---- 225

See also HYDROPOWER

See also MODELS, HYDROEIECTRIC

PRECIPITATION

Analysis of physical state properties of precipitation (O3IW)-........ 45

Cloud-seeding experiments, Utah (5750)-.-.-.- 136

Data analysis by computer (008W)-...-...-.-- 47

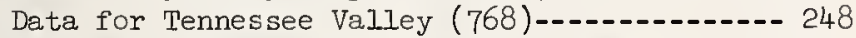

Hydrometeorological research for design

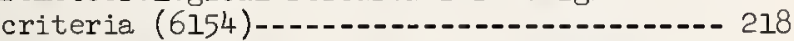

Maximum possible precipitation in Tennessee

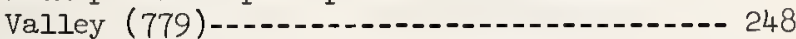

Review of data for selected Minnesota

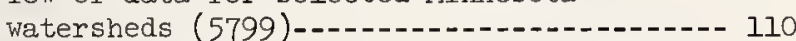

Theory of design of precipitation networks (6664)-1.-.-16

Use of weather radar to predict storm runoff (5940)-...-..- 126

See also RAINFALI

PRESSURE WAVES

In solid-liquid suspensions (6275)--.-.-.-- 61 Surrounding expanding sphere in water (6481)-- 132

See also SHOCK WAVES

See also SURGES, PRESSURE

PRESTON TUBE

See HYDRAULIC MFAS.

PROPETIANTS

SEe LIQUID PROPELIANTS

PROPELLERS

Aerodynamic coefficients and dynamic derivatives for ducted propellers (5941)-.-.-.-. 142

Performance of tandem propellers in roll control of underwater vehicles (6179)-...-- 27

Rudder-propeller interaction (5937)-......-. 121

Self-excited vibration theory for propeller singing (5936)-..... 121

Shrouded propeller theory (4434)-...-.-.-.-.- 240

Steady and time-dependent forces and moments from lifting-surface theory (6535)-...-.-- 121

Three-dimensional boundary layer study (6681)- 77

Thrust deduction calculation for axi-

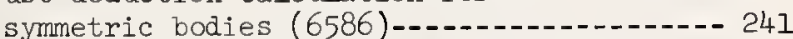

Unsteady loads in non-uniform three-dimen-

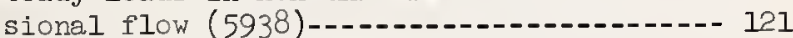

Unsteady loads on ducted propellers and nozzles (5935) -........ 121

PROPELLER- BODY INTERACTION

Thrust deduction calculation for axisymmetric bodies (6586)

PROPULSION

Propellers, see PROPEITERS

Savonius rotor, see SAVONIUS
PROPULSION (continued)

Swimming bodies, see FISH PROPULSION

Page

PROPULSOR BLADES

Effect of surrounding liquid on blade

vibrations (6557)-.... 96

PUT.P WASTE

Dispersion at ocean outfalls; airphoto study $(6775)$

PUMP WELLS

Cayuga (Ind.) steam power plant; model (6507)- 152

Point Beach (Mich.) nuclear power plant; model (6508)-.-... 152

PUMPED STORAGE DEVELOPMENT

Cornwall Plant (Hudson R.) operation related

to tides; model (6510)-1..-153

Effect on river of modes of plant operation; model (6499)-.............................. 151

Intake and tunnel flow, Jocassee project model (6512)

Intake and tunnel flow, Kinzua model (6511)--- 153

Intake flow pattern during various phases of operation (6500) 151 PUMPING PLANTS

Tehachapi (Calif.) plant models (6662)---.--- 16 PUMPS

Axial-flow two-stage pump with tandem-row

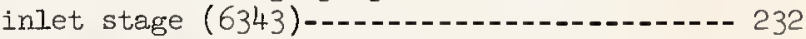

Discharge-pressure oscillations in high pressure pumps (6050) 153

Discharge pressure oscillation, study of

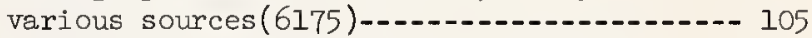

Radioisotope flow measurement (061W)(064W)--.- 227

Testing in air to reduce costs (6176)-...-.-.- 106

Testing 12-in. two-stage deep-well turbine pump (6479)

PUMPS, CAVITATION IN

Effect of impeller modifications on dredge-

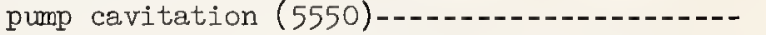

Spectral analysis, pump cavitation noise

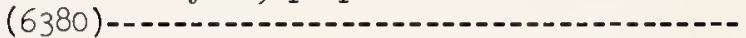

Water-jet apparatus for increasing suctionpipe pressures (6779)

PUMPS, DREDGE

Effect of design parameters on cavitation

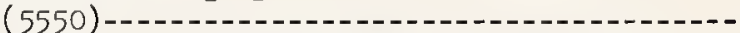

Efficiency of silt-clay-water pump (4154)--.-. Gas removal systems for centrifugal pumps (5822) -........

Improving design for pumping silt-clay-water mixtures (3084)-.-.-.

Literature survey on suction dredging (5173)--

Performance tests on scale model (5174) -...-. PUMPS, HEART

See BTO-MEDICAL HYDRODYNAMICS

PUMPS, INDUCERS

Tandem row, high-head pump inducer (6648)-.-.-See also INDUCERS

PUMPS, SUMPS

See SUMPS

- $\mathrm{R}$ -

\section{RADIAL FIOWS}

Laminar radial flow of viscous fluid between

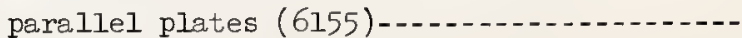

Radial jets, see JETS

RADIOACTIVE WASTE

Occurrence, transport, and disposition of radionuclides in Columbia River (5843)-

Removal from condenser cooling water at Browns Ferry project, TVA (6713)-..-.-.-.- 246

Techniques for studying radionuclide movement

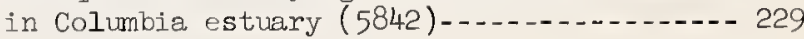


RAINDROPS

See RAINFALL, RAINDROP EFFECTS

See DROPS

RAINEALT

Environmental effects, Colo. Front Range

(006w) -....... 25

Synthesis of rainfall data (1946)-...-.-.-.- 115

Synthesis of short-time-increment rainfall sequences (5117).......................... 70

see also PRECIPITATION

RAINFALI, RAINDROP EFFECTS

Effect on overland flow (6199)--.-.-.-.-.-.- 102

Effect on turbulence and sediment capacity

of shallow flows (5478)-............... 125

Impact effect on sheet flow (6191)-......-.- 53

Raindrop size and energy related to soil

erosion (3424)

RAINFALL-RUNOFF RELATIONS

SEe RUNOFF

RAIN GAGES

SEe HYDROLOGIC MEASUREMENTS

RANDOM SIGNAL ANALYSIS

Comparison of techniques (6134)-.........-. 234

REACTORS

Ebullient bed catalytic reactor (6671)-...--.- 76

REAERATION

Characteristics of fixed-cone dispersion valves (6729)

Containment structure for fixed-cone

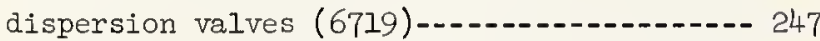

Correlation of turbulent diffusion character-istics with river reaeration capacity (5688) 141

Open-channel flow reaeration as function of flow, channel, and other factors (6071)----- 230

River reaeration at gated structures (6461)--- 18 Selected natural rivers (6165)-............-. 141

Turbulence effect on surface reaeration

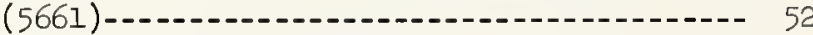

See also OXYGEN, DISSOLVED

RECESSION, STREAM

See STREAMFIOW

RECHARGE, GROUNDWATER

SEe GROUNDWATER

RECOIL

Hydrodynamics of rifle recoil (3740)-......- 55

RECTANGULAR CONDUIT

See PIPE FIOW, RECTANGULAR PIPE

REFRACTION

See WAVES

REGIME THEORY

Regime hydraulics and geomorphology of rivers of various types (6820) -.................. 251

Text collating field and lab. research (6630)- 251 RESERVOIRS

Chemical sealing methods (5400)-........-.- 21

Field study of mixing and dispersion (5953)--- 129

Flow patterns induced by jet introduced horizontally near free surface (6189)(6190)- 52

Linings for desert stock-watering ponds (3057) 43

Sedimentation of TVA reservoirs (785)-......-. 249

Sediment deposition in western Iowa and

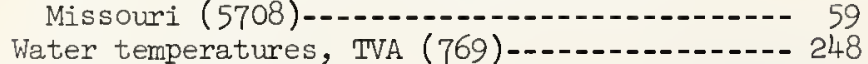

RESERVOIRS, DRAWDOWN

Transient effects on groundwater storage

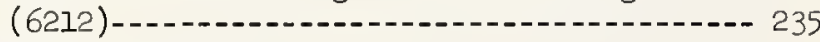

RESERVOIRS, EVAPORATION

SEe EVAPORATION

RESERVOIRS, SELECTIVE WITHDRAWAI

SEe RESERVOIRS, STRATUFIED

SEe STRATIFIED FIOW, SEIECTIVE WITHDRAWAL RESERVOIRS, STRATIFTED

Computer simulation for selective withdrawal

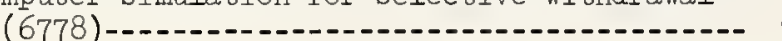

RESERVOIRS, STRATIFIED

Page

Effect of size and shape of orifice on selective withdrawal (6846)

Internal currents from intermediate-density inflow to stratified reservoir (6148)-.....- 145

Measurements of cyclic changes of various water properties in deep stratified

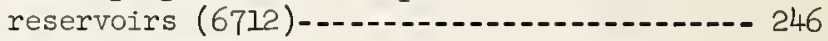

Model for temperature structure of lakes

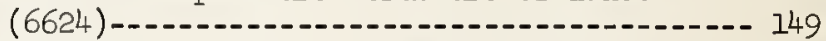

Stratified flow effect on water quality

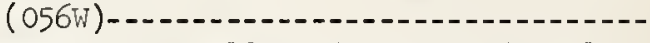

Temperature field as function of inflow, outflow and other factors (6180)

Turbid releases associated with thermal stratification (6314)

Thermal stratification as affected by inflow

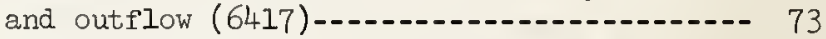

Vertical mixing by introducing warm water at bottom (6625) (4561)REVETMENTS

See EROSION, BEACH

RIPPLES, SAID BED

See BED FORMS

RIPRAP

Design nomogram for stability (6818)-.-.-.--- 251

Erosion characteristics of riprap and gravel (1987)--.-189

Stability under wave action (6486)--.------.-- 185

Stability at Copan Dam, Okla.; model (6840)--- 209

Stability in straight and curved trapezoidal

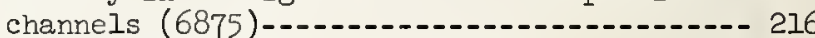

See also BREAKWATERS, RUBBLE-MOUND

See also JETTIES

RIVER BASINS

Electronic analogs applied to river basin planning (5747)-... 135

Electronic analog river-basin model (5140)-.-- 134

Systems analysis and mathematical models

in basin development (5115)

See also WATERSHED ANALYSIS

RIVER CHANNELS

Assessment of effects of engineering

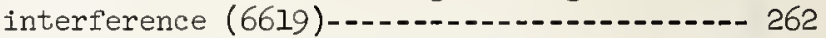

Bank seepage effect on flood hydrograph (022W) 61

Bank storage during floods (3428)-.........-. 54

Bend cross-section statistically related to flow and sediment parameters (5438)-...- 11

Channel morphology in the southern plains (4341) -

Discharge as function of bed geometry and superelevation (4283)-_..... 156

Factors affecting stability of artificial. and natural channels (O58W)-.......-.-.- 227

Improvement, see CHAINNEL IMPROVEMENT

Morphology and stability of southern California channels (5584)..............- 163

Morphology and stability of stream channels in southwestern semiarid rangelands (6836)-...- 163

Morphology of stream channels in New England

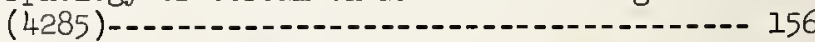

Processes of stream channel development in the northeast (4283) -..... 156

Relations between gross flow properties and channel deformation (4283)-156

Roughness, sediment transport and shear distribution in natural channels (2950)-.-.- 227

Stream channel morphology and stability (4317) 161 See also CHANNELS, STAEIIIZATION OF

RIVER CHANNELS, MEANDERS

Bend resistance-channel geometry-sediment transport relations (6354) -.............. 56

Statistical field study of meanders (6198)---- 102 
RIVER CHANNELS, MEANDERS (continued)

Hydraulies of meandering rivers with flood plains (4191)-100

RIVER FIOW

Breakup of heat stratification by turbulence stimulation (5737)-1..-25

Computer simulation models of physical, chemical and biological aspects of Duwamish River (6833)-_...... 146

Delta development above detention dams

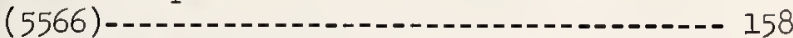

Discharge as function of bend geometry and

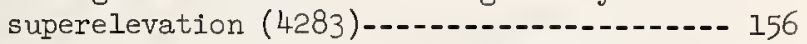

Effect of back filling near an island,

Riviere des Prairies, Canada (6253)-....---. 261

Effect of ice on St. Clair R. roughness (6567)-.... 65

Offshore sand bar near mouth--effect on water elevation of river in flood (6763)-.......-

Regime theory; text collating field and laboratory research (6630)--..-1-25]

Relation of bed forms to friction (4075)---- 6

Roughness in natural waterways (6565)-------- 65

Sand bar formation blocks mouth of Corazones water channel, Puerto Rico (6764)-.-.-.-.-- 33

Steady and unsteady effects on discharge

in river connecting two reservoirs (6567)-- 65

Turbulent mixing in natural streams (5689)-.. 141

See also MODELS, RIVER

See also OPEN-CHANNEL FIOW

See also STREAMFIOW

RIVER FIOW, DISPERSION IN

See DISPERSION

RIVER FLOW, OVERBANK

See OPEN-CHANNEL FLOW, OVERBANK

RIVER FIOW, REGIMES

See REGIME THEORY

RIVER ICE

See ICE, RIVER

RIVER MODELS

See MODELS, RIVER

ROCK SAUSAGES

Criteria for use in erosion proofing (6377)-- 106 ROLI WAVES

See OPEN CHANNEL FLOW, ROLI WAVES

ROTATING DISK

See BOUNDARY LAYER

See LAMINAR FIOW

ROTATING FLOWS

Between parallel disks (5741) 103

Coupled inertial-Coriolis effects on atmospheric turbulence (6615)-...-.

Influence of rotation on flow in long rectangular channel (6800)-........... 117

Large-amplitude motions in non-homogeneous

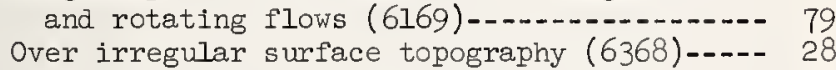

Rossby waves in a rotating annulus (4737)---- 150

Scattering of disturbance on free surface of rotating liquid (5738)

Stability of parallel shear flow subject to

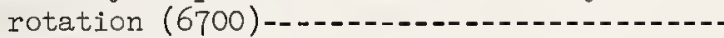
CATIONAL FLOW THEORY

Circulation-preserving rotational flow (6126) 233

Unsteady three-dimensional rotational flow with vortex stretching but no diffusion (6126)

Unsteady three-dimensional rotational flow with vortex stretching and diffusion (6127) 233 ROUGHNESS

Artificial roughness in movable bed models (5684)

Bed Forms, See BED FORMS

Bottom-roughness effect on turbulence in free-surface flow (6049)
ROUGHNESS (continued)

Boundary layer growth on ship-hull plates

(5939)

Cobble-strewn stream roughness studied using

eylinders, parallelepipeds (5181B)........ 93

Effect on open-channel turbulence (5131)-...- 133

Effect on regime of turbulent pipe flow

(5534)-...- 142

Friction factors for sand bed channels

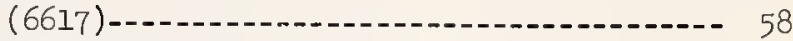

In natural and artificial channels (6565)---- 65

Large scale roughness in open-channel

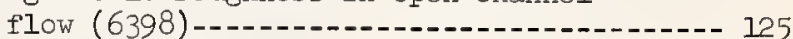

Lift and drag on isolated cubical roughness elements (5758).......... 137

Mean velocity and fluctuations near sandroughened surface (4625)-.............. 1

Observed forms of bed roughness in an unstable gravel river (6820)-.-.-.-.-.-.- 251

Of watersheds and conceptual river systems (4906)-...- 50

Open-channel flow experiments on various rough surfaces (6285)-............ 82

Size and shape effect on drag observed in circular air tunnel (5604)-..........-.- 228

Spatial behavior of roughness in laboratory watersheds (028W)(029W) -.............. 82

Turbulence structure near rough porous

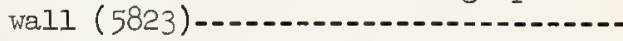

Wind stress and ocean surface roughness (6644) -

See also OPEN-CHANNEL FIOW, RESISTANCE

See also PIPE FIOW, RESISTANCE

ROUGHNESS, WAVY

Free-surface shear flow over wavy boundary (6364)-1... 58

Shear stress distribution along waves by electrochemical methods (6825)-............ 48

Turbulent pipe flow, wavy boundary (6365)---- 58 RUNOFF

Effect of forest-cover control, Mississippi

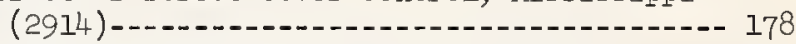

Effects of sagebrush control, Wyoming watersheds (3569) -........ 175

Flood runoff reduction from glaciated mountain areas of New England (06TW)-..........-.-165

Flood runoff reduction in northern Appalachian Mt. region (068W) ..................... 165

From small watershed in Mississippi River flood plain (5915)

Great Lakes - St. Lawrence basin (3031)------ 18

Long-time fluctuations in stream runoff correlated with sunspots (3522)-.--------- 127

Methods of estimation being developed from plot data obtained under natural and/or simulated rainfall (3808)............... 97

Nonlinear prediction problem in study of

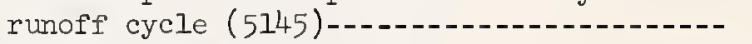

Peak flows, small drainage basins in southern Ontario (6495)-..-.-.-.-264

Probability and synthetic hydrology approach to rainfall-runoff frequency relationship (4910)-- 51

Reduction of runoff from rangelands in central Rocky Mts. (O73W)-_.............. 173

Reynolds Creek Watershed predictions by computer simulation techniques (6517)----- 138

Runoff-infiltration relation theory (6533)--- 140 Semi-arid watershed hydrographs (6519)......- 138

Small agricultural areas, Illinois (008w)-..- 47

Small urban watersheds, analog computer simulation (6522) ....... 138

Small watershed areas; electric analog simulation (6516)-.... 138 
RUNOFF (continued)

Soil type, slope and vegetation effects,

Upper Bear Creek, TVA (4884)-................ 249

Synthesis of storm runoff hydrographs from

unsteady non-uniform rain (5456)-.......-.- 128

Systems analysis of runoff process (6279)--.--- 143

Urbanization effects (5558) ................ 78

Urbanization effects on small watershed

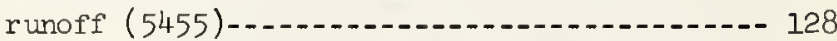

Use of probability in frequency prediction, based on rainfall and infiltration

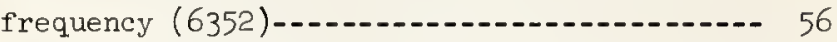

Use of weather radar to predict storm runoff (5940) -..--

See also HYDROGRAPHS

See also RUNOFF-RAINFALI

RUNOFF, SUBSURFACE

Mechanics of subsurface stormflow (O72W)--.-.-- 165

Storm runoff from forested land (OT2W) -....... 165 RUNOFF, SURFACE

Basic mechanics studied using artificial basins (6187)-1... 52

Basin-storage effect on hydrographs (4909)---.- 51 Computer simulation of urban runoff (6421)-..-- 74

Effect of natural and planted forests (3889)--- 165

Hydrodynamic equations for runoff from agricultural watersheds (4820)-_.......- 157

Influence of stochastic surface impressed agents (5294)

Iaboratory watershed system used for basic study of watershed hydraulics (4906)--.---- 50

Modeling urban runoff (5117)

Numerical model for small watershed (6626)-.-.- 150

On low-slope graded land in humid areas (4332)-.-10.-161

Overland-flow hydraulics; its role in hydrologic cycle (6070)-.... 230

Shallow-water equations used in runoff

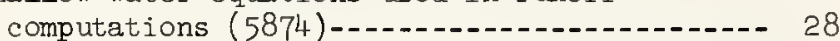

Short erosion plots under simulated rainfall

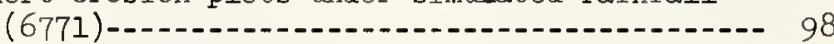

Urban watersheds in Indiana (5482)-.......-. 101

See also OVERLAND FIOW

See also SHEET FLOW

RUNOFF-RAINFALL RELATIONS

Application of stochastic process theory

Effect of areal distribution of rainfall (2397)-1.-126

Effect of type of vegetation cover, Calif. and Hawaii (4997)-.....- 170

Effect of upstream development on small southwest watersheds (2397)-...-...-.-126 Glen Creek (Alaska) drainage basin (6385)-.... 180

Mathematical model (5456) -................. 128

Mathematical models for small Ohio watershed

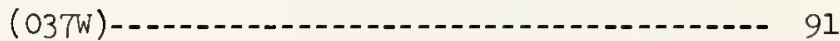

Probability and synthetic hydrology approach to rainfall-runoff frequency relationships (4910)-_.-.-51 Ralston Creek Watershed, Iowa (66).......... 53 Selected Minnesota watersheds (5799)-......-.- 110 Selected urban sites in Indiana (5482)-...-.-.- 101 Small drainage basin, northern Alaska (6383)--- 179

small watersheds in various stages of urbanization (5916)

$$
-\mathrm{S}-
$$

\section{SALINITY, RIVER}

Analog simulation of salinity flow system in upper Colorado Basin (6521)-.............. 138

\section{SALINITY INTRUSION}

Effert of pneumatic barrier on Delaware $R$. salt intrusion; model (6029) 205
SALINITY INTRUSION (continued)

Effects of physical and hydraulic features of estuaries; flume studies (1986)......... 189

Estuarine intrusion and diffusion (6415)-.-.- 72

Into coastal well fields (6259)-.........-. 86

Maracaibo estuary, Venezuela (5119)-...-.-.-. 70

Protection of groundwater in Baton Rouge

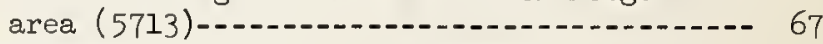

Salt water intrusion into layered strata

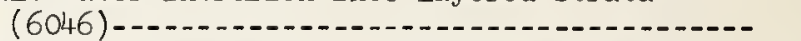

Salt-water removal from two-part aquifers (4962) -

Theory for St. Lawrence estuary (5949)--.-.-.- 257 SAIT WEDGE

See STRATIFIED FLOW

SAND BAR

Formation blocks mouth of Corazones water

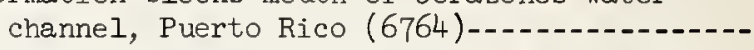

offshore sand bar affects river mouth, Yaguez

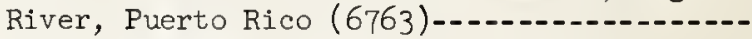

See also SEDIMENT TRANSPORT, SHOALING

SAND BED CHAINNEL

See ALLUVIAL CHANNEL

SAND BYPASS

Methods of by-passing sand past inlets (975)-- 181

St. Lucie Inlet, Fla., model (6752) ......... 32

See also COASTAL SEDIMENT

See also INLETS, COASTAL

SAND DREDGE

See DREDGING

See PUMPS, DREDGE

SAND DURES

See DUNES

SAND FENCES

See SEDIMENT TRANSPORT, BY WIND

SAND PUMPING

See DREDGING

SAND TRANSPORT, WIND

See SEDIMENT TRANSPORT, BY WIND

SATELLITES

For obtaining oceanographic data (6767)-.-.-.- 85

SAVONIUS ROTOR

Power-generating characteristics (6539)-....-. 122 SCALE EFFECTS

Criterion for lower limit on scale of model

tests independent of geometry (6188)-.....- 52

Weber and Reynolds criteria examined by

experiments (6188)

See also MODEL LAWS

SCALING

See MODEL LAWS

SCOUR

At pipe outlets and upstream of weirs (009W)-- 47

At simple relief-bridge geometries (4626)-..-- I

Cantilevered outlet conduits to prevent scour at small spillways (1168)-107

Culvert-outlet erosion (6460)

Effect of spur dike geometry (4645)-....... 63

Erosion at bridges and culverts (6206)-.....-. 24

Erosion downstream of Patillas Dam (5845)----- 222

Erosion downstream of piers and sills (6185)-- 83

Erosion of foundations of concrete-crib

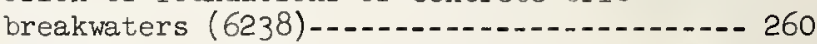

Influence of secondary flows at obstructions (4991) - 128

Localized scour analyzed by mass-transport

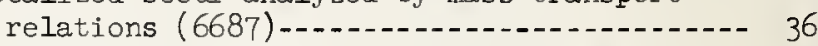

Protection for dam situated with fine sand downstream (6247)......................... 261

Resistance of cohesive sediments (2874)-..-.-. 127

Resistance of cohesive soils (4317) River-bed scour at briage piers (6100)-----.-- 254 Scale effects in scour experiments (5906)-..- 55 Stone beds under weirs (6392) -............. 264 See also EROSION 
SCOUR, INITIATION

See SEDIMENT TRANSPORT, INITIATION

SCREENS

Flow around and through a screen partially

occupying a two-dimensional channel (6809)-- 268

SCRUBBING COLUMN

Mass transfer in $\mathrm{SO}_{2}$-air-water system (6676)-- 77 SEA BOTTOM

Boundary layer and sediment transport (6283)-- 146

SEA-LEVEL CANAL

See CANALS

SEALING

Chemical, for ponds (5400)

SEA WATER CONVERSION (1554)

SEALS

Gate seals studied at prototype head in

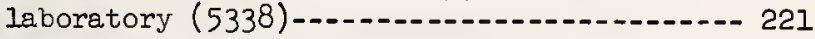

Helical and spiral groove seal performance in oil, water and liquid sodium (6345)-.......- 232 SEAWALI

Model study of seawall stability, Texas City, Texas (5234)

SECONDARY FLOW

Currents in a corner of triangular open channel (4531)

Effect of natural convection on horizontal pipe flow (6827)-...- 48

In axial flow inducers (5592)

Used to control large-scale flows (6274)-.-.-. 26

Velocity-profile effect on straight channel flow with perpendicular secondary flow injection (6269)

\section{SEDIMENT}

Rheological properties of estuarine sediments

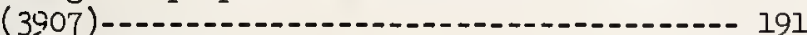

SEDIMENT TRANSPORT

Current and sediment movement in Galveston-

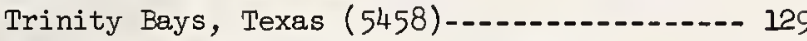

Dependency characteristics of flow and sediment measures in alluvial channel flow (5607)

Diffusion of sediment in a non- uniform flow field (6044)

Diffusion of sediment in turbulent open channel flow (6079)- 80

Effects of permeable bed (6692)-.......... 37

Laboratory study of all aspects of alluvial channel sediment transport (3871)-......- 160

Mechanism of entrainment of fine sand by turbulent flow (4075)-.-............... 6

Records for Iowa Streams (67)-.......... 53

Rotating drum research facility (4654)-...... 69

Roughness and sediment transport in natural and artificial channels (2950)-.-.-.-.-.-- 227

Sedimentation with centrifugal acceleration (6498)--.---n 264

Silt-carrying water flowing through porous media (5820)...... 12

Temperature effect on rate and nature of movement (1988)

SEDIMENT TRANSPORT, ALL
See AILUVIAL CHANNELS

SEDIMENT TRANSPORT, BED FORMS

See BED FORMS

SEDIMENT TRANSPORT, BEDLOAD

Comparis on of measurement techniques (6819)--- 251

Existing formulas--limitations and

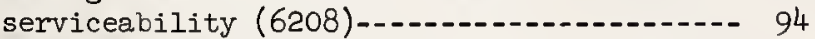

Grain-size distribution and channel factor effects on transport (6069)

SEDIMENT TRANSPORT, BY WIND

Dune building with sand fences (4760)-.....- 183

Effects of vegetation, humidity, gustiness and fences on sand transport (4895) -......- 32
SEDIMENT TRANSPORT, BY WIND (continued)

Page

Mechanics of dune building at Cape Hatteras (4482)

Sand-fence effects on transport (4895)-....... Sand-fence tests (5284)

SEDIMENT TRANSPORT, DEPOSIT REMOVAL

Guide walls constructed to flush sediment at diversion dam (6312)

SEDIMENT TRANSPORT, DEPOSITION

Air bubblers to prevent shoaling at wharf (5994) -...-253

Behavior of fine cohesive sediments in annular

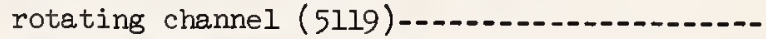

Cohesive-sediment deposition in turbulent

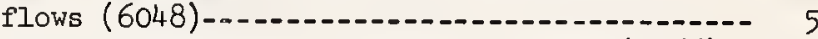

Delta development above detention dams (5566)-- 158

In tile-drain flow (3490)................. 97

Sedimentation field study, Iowa and Missouri

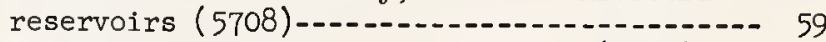

Silt deposit in flow over gravel bed (5437)-..- 10

See also FALL VELOCITY

See also SEDIMENT TRANSPORT, SHOALING

SEDIMENT TRANSPORT, FALL VELOCITY

See FALL VELOCITY

SEDIMENT TRANSPORT, INITIATION

Bed armoring effect of size gradation (4331)--- 161

Critical conditions for sediment mixtures in drainage channels (6741)-................. 111

Critical tractive force for uniform sand (4625)-.-.-.-1

Detachment by raindrops impact and flowing water (4331) - 161

Effect of piers and sills on threshold

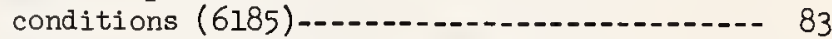

Forces on bed particles at incipient motion (4316)-.....- 161

Gravel material of various sizes (1987)...-.-.- 189

Gravel river bed motion, field study (5666)-..- 251

Incipient erosion, culvert outlets (6460)-.-.-. 18

Large roughness elements in open-channel flow, incipient motion (6524)-...................... 139

Mean-velocity criteria for scour of course,

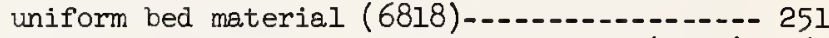

Resistance of cohesive soils to erosion (4317)- 161

Resistance of riprap to erosion in channels

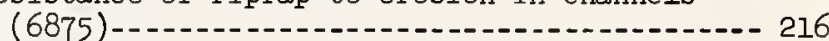

Seepage effect on forces on sand-bed particles

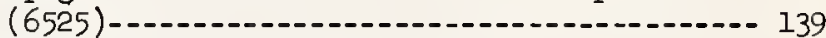

Seepage-force effect on incipience (6692)-....- 37 SEDIMENT TRANSPORT, MEASUREMENT

SEe HYDRAULIC MEAS., SEDIMENT

SEDIMENT TRANSPORT, OCEAN

Bottom currents and sediment motion across continental shelf (6283)

SEDIMENT TRANSPORT, PIPES

Loop system for measuring sand-water mixtures (6564)

SEDIMENT TRANSPORT, SAMPLERS

See HYDRAULIC MEASUREMENTS

SEDIMENT TRANSPORT, SEDIMENTATION

Two prolate spheroids in close proximity (6217) 84

SEDIMENT TRANSPORT, SETTLING VELOCITY

See FALI VELOCITY

SEDIMENT TRANSPORT, SHOALING

Air bubblers to prevent shoaling at wharf

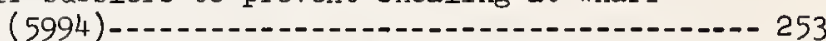

Brunswick Harbor, Ga., model study (5648)-.-.-.- 200 Columbia River estuary model (4396)

Comprehensive study of shoaling in tidal

waterways ( 3907$)$ Alaska, shoaling model (6027)--..... 204

Model study of Delaware River shoaling (425)--- 187 Shoaling on Frazer River; model (6443)-.-.-.-- 271 Umpqua River Estuary, Oreg.. Model (6062)-.-.-- 204 
SEDIMENT TRANSPORT, SUSPENDED

Erosion and deposition by turbidity currents $(6652)$

Instrument for concentration measurement

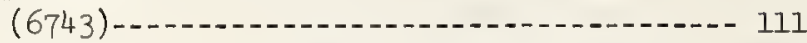

Rainfall effect on sediment capacity of

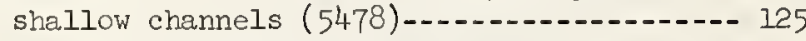

Sensor for turbulent concentration

fluctuations (6366).................... 58

Tests of concentration gauges (3871) ....... 160

SEDIMENT TRANSPORT, TRACERS

Houston ship channel radioactive sediment tracer tests (6850)

SEDIMENT TRANSPORT, TURBIDITY CURRENT

See STRATIFIED FLOW, TURBIDITY CURRENT

SEDIMENTATION

See SEDIMENT TRANSPORT

SEDIMENT YIEID

Cattle-grazing effects, N. Mex. watershed (1969)-1.... 175

Flood and sediment reduction in California conifer zone (4998).......... 171

Prediction techniques for western Iowa (5708) 59

See also WATERSHED ANTALYSIS

SEEPAGE

Attempts to use electrical logging to determine canal seepage (6315) ......... 255

Bank seepage effect on flood hydrograph (022W) -

Bank seepage in natural streams during flood flows (3428)

Colloidal materials for seepage control in Nevada ponds and canals (3558)........... 163

Effect on forces on sand-bed particles

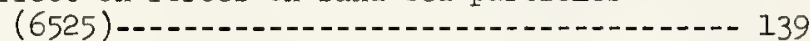

Effect of roads on soil moisture and seepage

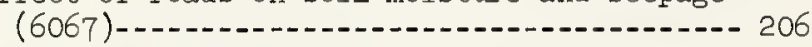

Finite-difference techniques for seepage problems (4219)-15

Finite-element solutions for complex-media

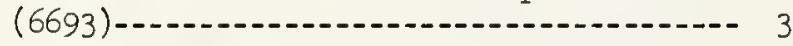

Groundwater seepage patterns to wells for unconfined flows (Ol4W)

Seepage-force effects on sediment transport

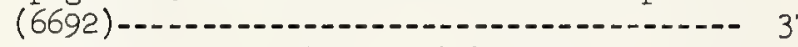

Seepage force on interfacial bed grains (6692)

dimensional free-surface seepage (6151)--.- 145

See also POROUS MEDIA FLOW

SEICHES

See WAVES, SEICHES

SELECTIVE WITHDRAWAL

See STRATIFIED FLOW

SEPARATED FLOW

Boundary layer separation on ventilated hydrofoil (4700)......................... 108

Flow past a two-dimensional cavity (6804)---- 267

Fluidelastic operators for under-streamlined

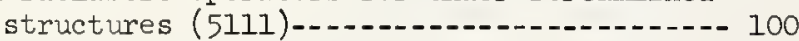

Leading-edge separation on wedges; effect on lift and drag (6740)

Numerical solutions of Navier-Stokes equations for separated flows due to cavitation

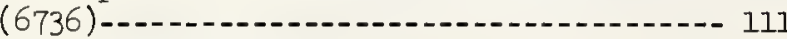

See also CAVITY FLOW

See also BOUNDARY IAYER, SEPARATION

See also FREE STREAMLINE FLOW

SEPARATIORS

SEe OIE-WATER

SERVOMECHANISMS, HYDRAULIC

Application of switching techniques to control systems (2335)

Load-sensitive hydraulic control system (6092) -
SERVOMECHANISMS, HYDRAULIC (continued)

Page

Self-oscillating control type (3436)-......- 60

Servo valve spool erosion (6373)

Use of non-linearities for improved

performance (6211) -...... 235

See also CONTROLS, HYDRAULIC

See also FLUIDIC DEVICES

See also HYDRAULIC SWITCH

SETILING VELOCITY

See FALL VELOCITY

SEWAGE FIOW

Pre-dilution at outfalls by entrainment of water through ports in pipe (4725)-......- 145

SEWAGE TREATMENT

Construction of facilities in permafrost

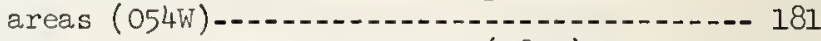

Model of grit-removal channel (5805)-........ 111 SEWERS

Computer program simulating main interceptor system for Minneapolis-St. Paul Sanitary

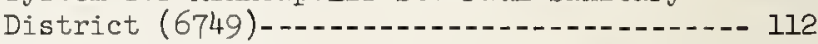

Leaping weir regulator intercepts fixed flow amount (6255) -............................... 261

Model study of Vancouver interceptor (6444)--- 271

Northern Montreal Salaberry sewer collector (6256)

Northern Montreal watershed sewer

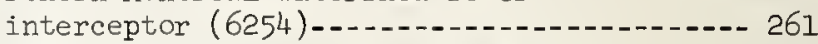

Optimal design of sewer systems using

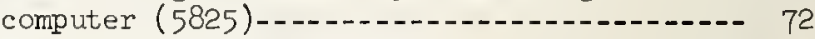

See also DRAINAGE, BUIIDING

SHEAR FLOW, TURBULENT

SEe TURBULENCE

SHEAR STRESS, WALI, MFASUREMENTS

See HYDRAULIC MEAS.

SHEET FLOW

Raindrop-impact and surface roughness effects (6191) -..... 53

See also OVERLAND FLOW

SHIP CHANNELS

Comprehensive study of shoaling in tidal waterways (3907)-...... 191

Effect of channel diking in Lake St. Peter between Montreal and Quebec (6228)-......-.- 259

Flushing system to remove oil and debris, Victoria Channel, Texas (5636)-_........... 198

Houston channel, radioactive sediment tracer

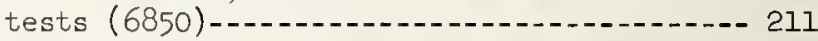

Proposed Lake Erie-Ontario waterway; model

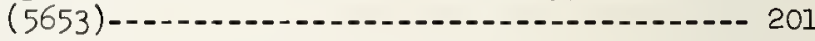

Shoaling in Delaware Basin, model study

(425) -

See also SEDIMENT TRAINSPORT, SHOAIING SHIPS, HULLS

Bending moments on cargo ships in waves (3516)

Bending moments on destroyers in severe seas (6609)

Hydrodynamic masses for floating bodies

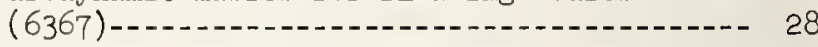

Plate roughness effect on boundary layer (5939)-...... 121

Potential flow and added mass (2091)-....... 54

Transom-stern bulbous-bow merchant ships (6682) -... 79

SHIPS, MOORED

Wave-induced oscillations of small moored vessels (5014) (5228)-1..- 195 SHIPS, MOTIONS

Amphibious craft in waves and surf (6608)--.-- 75

Destroyers in severe sea states (6609)---.-.- 75

Effect of hull flow separation on stability of high speed submarine (5199)-......- 141 
SHIPS, MOTIONS (continued)

Entrapped air effect in slamming (5774)-...-.

Equations of motion for very low-speed

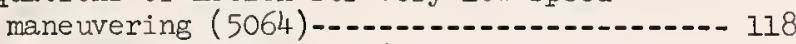

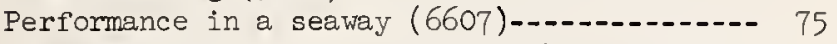

Pressure distribution on ship-like form in a

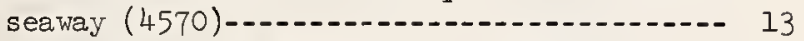

Stabilizing marine vehicles in a seaway

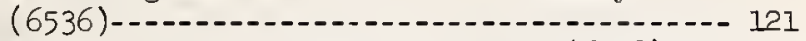

Steering and directional stability (6298)-..- 13

See also SHIPS, SFAKEEPING

See also SHIPS, SLAMMING

SHIPS, POWERING

Horsepower for high-speed transom ships (6684) -

SHIPS, RESISTANCE

Added resistance among waves (6607)-.-.-.-.--

Boxlike forms, resistance components (6683)--

Design for minimum total resistance (4084)---

Drag reduction with polymers, deployment

methods (6089)

Effect of guar-gum solution on drag (2091)--High-speed transom ships (6684)-........-. Induced drag due to bilge vortices (2091)-..In irregular waves (4971) -....... Ship waves in navigation channels (5817)....-

Transom-stern high-speed merchant ships

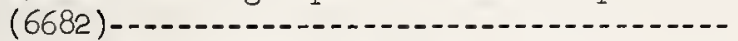

Viscous flow past ship-hull form (5739)------

Wave drag determined from wave pattern

Wave resistance by Eggers' method (2091)-... 54

SHIPS, SEAKEEPING

In irregular waves, theory and models (5203)- 147

See also SHIPS, MOTIONS

SHIPS, SLAMMING

Hydrodynamics of rigid-body water impact

(6066)-..- 115

Laboratory drop tests (5301)-............ 12

Model studies in waves (5942)-...........- 147

see also SHIPS, MOTIONS

SHOALIIKG

See SEDIMENT TRANSPORT, DISPOSITION

See SEDIMENT TRANSPORT, SHOALING

See SHIP CHAINNELS

See MODELS, RIVER

SHOCK WAVES

Equation of state for water over wide range of pressure and temperature (6787)-.....- 104

Hydrodynamic model for shock, blast and impact phenomena (6787)-................. 104

SHORE PROCESSES

Manual for shore protection planning and

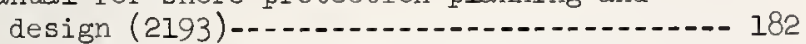

Regional studies of Atlantic coast, New Jersey to Cape Charles, Va. (2192)--.-.--- 182

See also BEACH EROSION

See also COASTAL SEDIMENT

SILLS

Submerged, for Lake Huron level control (5233) -..... 196

SILT DEPOSITION

See SEDIMENT TRANSPORT, DEPOSITION

SIMILARITY SOLUTIONS

For non-Newtonian Flows (6357) - . 57

SIPHONS

Air entrapment in large pumping-plant discharge siphons (5862)-...- 1

SIAMMING

See SHIPS, SLAMMING

SLOSHING

Anti-slosh baffles, damping laws from plates in oscillating flow (6081)........ 1

Anti-slosh baffle, pressure loads (6656)-.-.- 231

Control by dielectrophoresis (6293)-........ 132
SLOSHING (continues)

Cylindrical tanks with flexible bottom under low gravity (6350)

Page

Elastic-bottom tank, variational approach

(6466) -

Filled container with two liquids of different

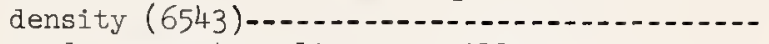

Forced resonant nonlinear oscillations of

liquid in cylindrical tank (6447)...........

Interaction of liquid with elastic containers

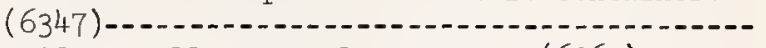

Liquid propellants in low gravity (6063)-.-.-.- 114

Mechanical model for longitudinally excited

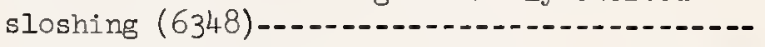

Monograph, mathematically rigorous, on sloshing in fixed and moving tanks (6294)...........

Monograph on experimental approaches (6295)--.-

Nonlinear lateral sloshing in annular tank (6349)-.....

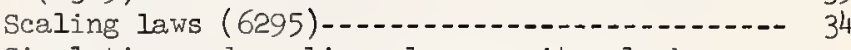

Simulation and scaling, low-gravity slosh

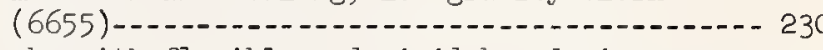

Tanks with flexible and rigid boundaries

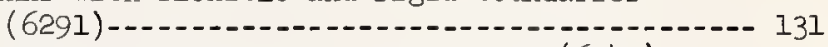

Under low gravity and zero gravity (6341)--.--- 232

Under variable gravity environment (6292)-.-.-. 132

Zero-gravity sloshing in partly filled

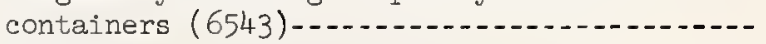

SLUG FLOW

See OPEN-CHANNEL FLOW, ROII WAVES

SLUICE GATES

See GATES

SLURRY FIOW

Clay-slurry flow charactoristics (6157)--.--.-- 144

Flow measurement with elbow meter (5172)-...-.- 63

Head loss in pipe flow (3747) ................. 63

Solid-waste pipeline flow (6470)-..........- 96

SMOKESTACK DISCHARGE

See POITUTION, ATMOSPFERIC

See PLUMES

SNOW

Accumulation control with fences, Wyoming

watersheds (3569)-_._-_._-175

Avalanche prediction and prevention, Colorado

alpine areas (3895)-........................... 176

Measurements for streamflow forecasts in

Colorado and New Mexico (55)-_..........- 19

Remote measuring device (5404)-..........- 21

Snow management by forest cover control (4997)- 170

Water yield control in Calif. snow zone (4996)- 169

SNOW, MEASUREMENT

See HYDROLOGIC MEA SUREMENTS, SNOW

SNOW, MELTING

Additives for evaporation control (5395)-..-.-. 21

Forecasting snowmelt floods (5997)-........-. 254

Lysimeter-type gage for in-situ snowmelt SOAP

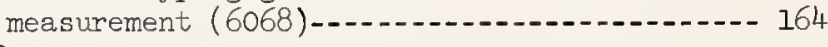

Soap solutions as drag reducers (6407)-......- 82

SODIUM, LIQUID

See LIGUID METALS

SOIL

Properties of soil used for bottoms of wastewater stabilization ponds (O4IW) .......... 113

SOIL EROSION

See EROSION, SOIL

SOIL MOISTURE

SEe SOIL WATER

SOIL SAIINITY

Dispersion of solutes in porous media (4086)--- 14

Drain tile effect on salt leaching (1819)-.-.-. 14

SOIL TREATMENT

Removal of excess soil sodium by gypsum and drainage (4987) 
Effect of roads on moisture and seepage

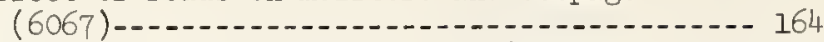

Effect of timber cover control (4998)-......-. 171

Effect of snow compaction (6532)-...........- 140

Hydrologic effects of soil freezing (3889)---- 165

Improved standards for neutron soil water

meters (2914)

Instrument for in situ measurement of soil

moisture flow and suction (5981)..........- 160

Measurements, see HYDROLOGIC MEAS.

Methods of soil water determination (051W)---- 45

Moisture prediction using antecedent

retention index (6628)

Movement of water and gases in soil (Ol2W)-... 59

Movement to vertical sink in saturated soil (Ol3W)-.... 59

New neutron probe system speeds logging of soil water profiles (3225)-............- 179

Physical and chemical processes associated with liquid and vapor phase movement of water in soil as related to water loss (6837) - 163

Relation of salinity to state and transport of water and ions in soil and plants (5220)---- 163

Soil mantle hydrology (6067)-...........-.-. 164

Soil water movement in relation to conservation of water supplies (6837)-.........-163

Studies on methods of soil water determi-

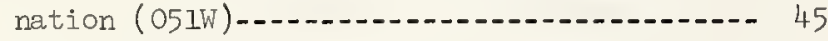

Timber clearcutting effects on moisture

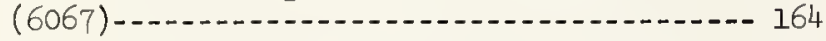

Water-plant-soil relationships in western No. Carolina (3306)

Wetting agent treatment effect on water resistant soils (5000)................... 172

SOLID-FLUID SYSTEM

See TWO PHASE FLOW

SOLIDS TRANSPORT

Granular solids driven by compressed air

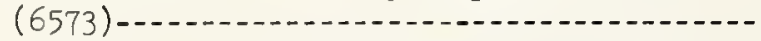

Transport of solid suspensions in conduits

(6564) -

SOLUTION CAVITIES

See MINING

SONAR DOMES

Acoustic radiation studies (6290).........- 131

SOUND SUPPRESSION

Hydraulic model study of rocket sound

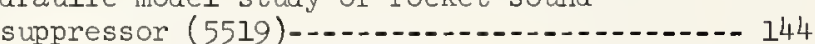
See also HYDRODYNAMIC NOISE

SOURCES-SINKS

Hele-Shaw flow visualization (6472)-..-.-.--- 179

SPAWNING CHANNEI

See FISH CONTROL

SPECIFIC YIELD

Theoretical, field and lab. study of specific yield and related properties (3263)-.....-. 227 SPHERES, CONCENTRIC

Flow patterns and convection (6184)........- 131 SPILLWAYS

Apron design for Tellico project; model (6724) 247 Branched channels with large velocity

difference (6248)............................. 261

Channel with right-angle turn; model (6559)-- 64

Chute design for Tims Ford, TVA (6711)-...-.-. 246

Discharge coefficients and pressure distribution as functions of shape (5828)-......- 80

Erosion at Bartlett Dam; model (6308)-...... 223

Erosion downstream of Patillas Dam, P.R., model (5845) -......... 222 Fish-passage characteristics (6164)-.-.-.-.-.- 144

Forces on flashboard mounted on parabolic spillway crest (5910).................... 56
SPILLWAYS (continued)

Hydraulic behavior of various crest shapes at heads greater than design (3917)-........- 193

Hydrometeorological research for design criteria (6154)-............................. 218

Irrotational potential flow over a spillway toe curve (6077)

Prototype tests on chute spillway, Fort

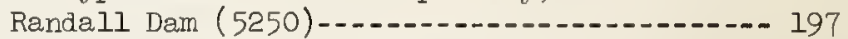

Standing waves and downstream erosion in Bear Creek (TVA) model (6718)

SPILLWAYS, CAVITATION

Aeration to prevent damage during simultaneous operation of spillway and outlet (6330)--.--- 226

Air admitted to cushion cavitation collapse,

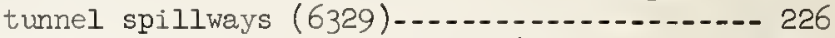
Bankhead Dam, Ala., model study (6036)--.-.-.-.- 207

Model study, Outardes 3 project, Canada (6248)- 261 SPILIWAYS, CIOSED CONDUIT

Air admitted to cushion cavitation in tunnel

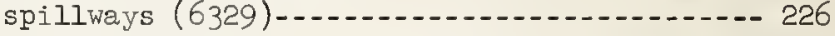

Cantilevered pipe outlet conduits to prevent scour (1168)-...-107 107

Drop inlet for closed conduit spillways (1ll)-- 106

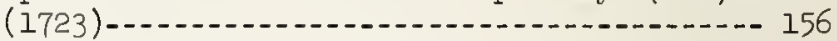
Drop-inlet spillway characteristics (1865)-... 46

Hydraulics of closed conduit spillways (11l)--- 106

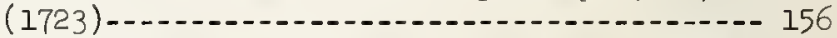

Stage-discharge relations for vertical internal

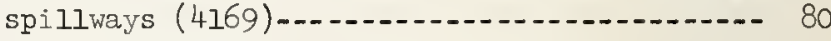

Trash racks tested for closed-conduit

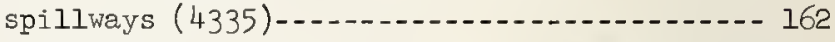

Vent systems for constrictions in closed conduit spillways (4335)-162

SPILIWAYS, MORNING GIORY

Eau Galle, Wisc.; model (6017)-...........- 202

Evaluation by model for Bear Creek project

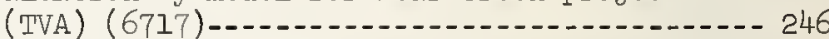

SPILLWAYS, SIDE CHANNEL

Weir at various angles with channel axis

SPILLWAYS, VIBRATIONS

Flow-induced excitation of low-crest spillway (6351) -.......................... 56

Vibration investigations at Old River control structure, La. (6032)-10 206 SPRINGS

Effect of mineralized springs on Utah's water

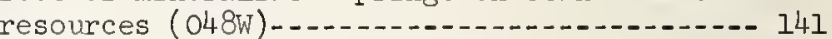

\section{SPRINKLERS}

See IRRIGATION

SPUR DIKES

See DIKES

ST. LAWRENCE RIVER

Mathematical model of river and estuary (6603)- 264

STABILITY

Characteristic equations, parallel non-

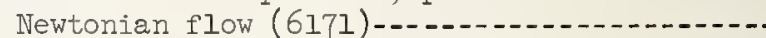

Convective instability in flowing fluids

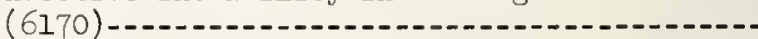

Convective instability of transient systems (6831)

Film flow, see FIIM FIOW

Heated wall effect on boundary layer (6546) -... Laminar vortex-like flows stabilized

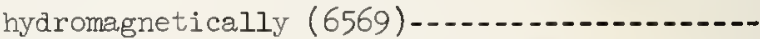

Liquid-surface instability under gas jet (6113) - 59

Nonlinear effects in hydrodynamic and thermal

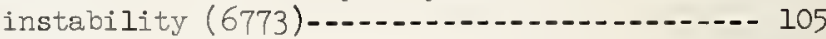

Non-Newtonian fluids between rotating coaxial

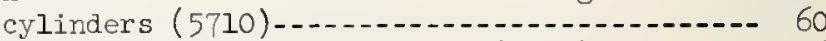

of a turbulent Poiseuille flow (6798)-.......-. 116

of horizontal fluid layer whose lower surface temperature is time dependent (6807) -........- 268 
STABILITY (continued)

of laminar flow, see also TRANSITION

of two fluid layers of different density

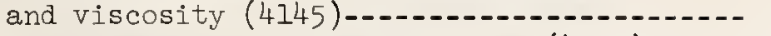

of viscous flow in branched pipes (4559)-...-.

Parallel shear flow subject to rotation

(6700)-

scattering of disturbance on free surface of

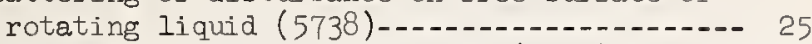

Spherical disturbance breakdown (6129)-------- 233

Thermal or convective instability in

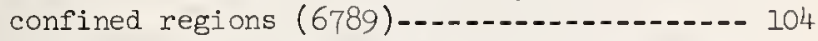

Unique asymptotic expansions in hydrodynamic stability theory (5779)-..... 49

Viscosity-stratification effects (6170)_..... 79

Viscous flow over curved surfaces (6772)-.-.-- 105

See also CYLINDERS, CONCENTRIC ROTATING

STABILITY, CHANNELS

See RIVER CHANNELS

See CHANNEL STABILIZATION

STABILITY, INTERFACE

Liquid-vapor interfacial stability under weightlessness $(6338)(6339)(6340) \ldots \ldots-\ldots-231$ (6341)-......- 232

STABILITY, STRATIFIED FLOW

See STRATIFIED FLOW

STABILITY, TAYLOR

See TAYLOR VORTICES

See CYLINDERS, CONCENTRIC

STEAM

Acoustic velocities in steam (5286)-...-.-.-.- 240

Flowmeter calibrations for steam (4001)-...--- 240

Heat transfer in dropwise condensation (6675)-.-

STILLING BASINS

Abrasion due to gravel and rocks (6304)--.---- 223

At pipe to open-channel transition (5133)-.-- 134

Fish-passage characteristics (6164)-...-.-.-- 144

Flexible approach to design (6186)-.-.-.-.-- 83

Impact type; design procedures for USBR

Type VI (6309)-..... 224

Plunge and jump basins compared for slide-

gate high-head outlet works (2959)-...-.-.-- 219

Pressure-fluctuation analysis (6306)-.......-. 223

Prototype pressure tests, Barren River

Dam, Ky. (6035)

Vertical stilling wells for high-head

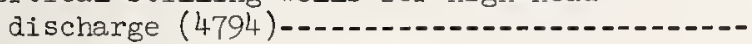

219

See also ENERGY DISSIPATORS

See also MODELS

STILLING WELLS

See STIIIING BASINS

STOCHASTIC HYDROLOGY

See HYDROLOGY

STORM SURGE

SEe SURGES, STORM

See HURRICANES

STORM-WATER INLETS

See INLETS

STRATIFIED FIOW

Breakup of river heat stratification by turbulence stimulation (5737) -..........-

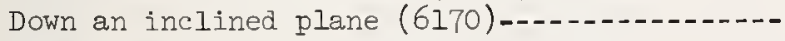

Equations for three dimensional largeamplitude motions (6169)-...............-.-

Generating linear density gradient in

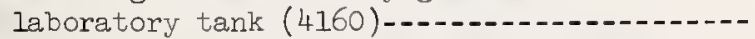

Instability due to viscosity stratification (6170)

Overturning induced by introducing warm

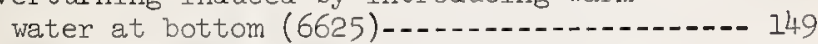

state-of-the-art report and research needs

(5343)-............. 221

Unsteady, into a sink (4561)................. 6
STRATIFIED FLOW (continued)

Virtual mass of cylinders oscillating in

uniformly stratified fluid (6061)-..-

Viscous non-diffusive flow toward line

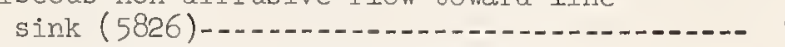

Withdrawal from two-layer flows (6419)-..... 73 STRATIFIED FLOW, DENSITY CURRENTS

Computer simulation of selective withdrawal from stratified reservoirs (6778)-........-

Discharge of heated water into broad deep

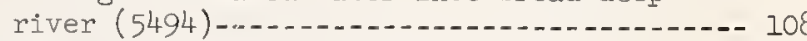

Dynamics of lake circulation (4252)-....-.-. 148 Importance of density currents in sea-level canal (6872)-...-. 216

Intermediate-density inflows into stratified

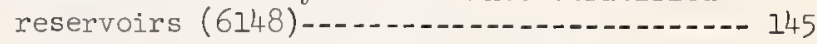

Prevention of recirculation of heated

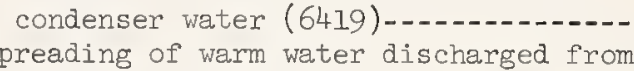
channel near surface of cold lake (6742)--.- 111

Steam plant condensate circulation, model (5392)

Turbidity current underflow experiments (5361)

Turbid reservoir releases associated with thermal stratification (6314) .............

See also MODELS, COOLING-WATER DISCHARGE

See also STRATIFIED FIOW, SELECTIVE WITHDRAWAL See also TURBIDITY CURRENTS

STRATIFIED FLOW, IN POROUS MEDIA

Fresh-salt water interface in coastal

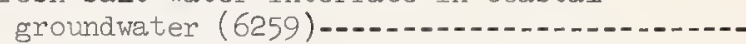

Lateral dispersion, effect of stratification

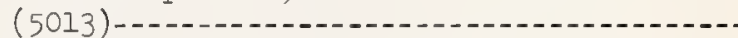

Overturning of unstably layered systems

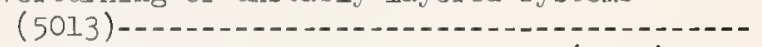

Two-dimensional flow toward a sink (5013)----STRATIFIED FLOW, INTERNAL WAVES

See WAVES

STRATIFIED FIOW, OCEAN

Hurricane induced upwelling (6488)-........-. STRATIFIED FIOW, PLUMES

See PLUMES

STRATIFIED FLOW, RESERVOIRS

SEe RESERVOIRS, STRATIFIED

STRATIFIED FIOW, SALINITY INTRUSTION

SEe SALINITY INTRUSION

STRATIFIED FIOW, SALT WEDGE

Estuarine salinity intrusion and diffusion (6415) -

See also SALINITY INTRUSION

STRATIFIED FIOW, SEIECTIVE WITHDRAWAL

Effect of size and shape of orifice on stratified-reservoir withdrawal (6846)-.-.--

From reservoir with linear density gradient (4561) - . .

Laboratory model using thermal stratification

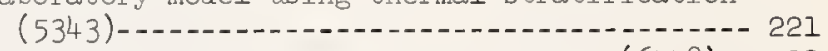

Model studies and computer simulation (6778)-- 92

Outlet-works weir, Meramec Park Reservoir, Missouri, (6843) -............................ 210

Two-dimensional viscous flow toward a point sink (6629)-... 150 STRATIFIED FIOW, STABILITY Curvilinearity and turbulence effects (5908)-- 56

Immiscible liquids in two-layer flow down

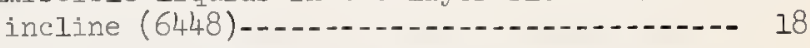

of two fluid layers of different density and viscosity (4145) -....................... 55

Viscosity-stratification effects (6448)--.-.- 18

STRATIFIED FIOW, SUBMERGED BODIES IN

Free-surface and Froude No. effects in stratified flow past slender body ( 661 ).-.--

Internal waves generated by spheres moving through linear density gradient (4400)......

See also WAVES, INTERHAL 244 55

6
92 10

8


STRATIFIED FLOW, THERMOCLINES

See THERMOCLINE

STRATIFIED FLOW, TURBIDITY CURRENTS

See STRATIFIED FLOW, DENSITY CURRENT

See TURBIDITY CURRENTS

STRATIFIED FLOW, TURBUIENCE IN

Mixing behind towed grids (6362)-........... 58

See also TUREULENCE, STRATIFIED FLOW

STRATIFIED FLOW, WAKES IN

Collapse of mixed regions in stratified

liquid (6363) ........................... 58

Collapse of wake of self-propelled body

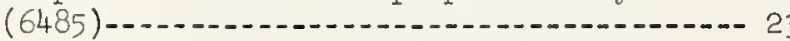

Flow phenomena caused by collapse of mixed

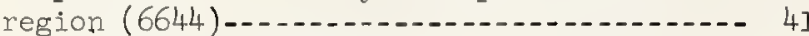

Three-dimensional momentumless wakes (4160)--- 69

See also WAKES, COLIAPSE

see also WAKES, STRATIFIED

STREAM CHANNELS

See RIVER CHANNELS

\section{STREAMFLOW}

Analysis of separation techniques (6708)-...- 44

Characteristics of Utah streams (045W)-...-.-. 141

Data for Iowa streams (67)................ 53

Data for Massachusetts streams (2561)-.-.-.-.- 76

Data for Utah streams (6531)-..........-.-.- 140

Effect of different forest types on stream

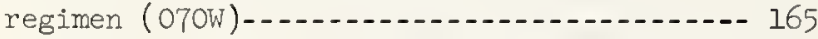

Forecasting research for Weather Bureau river

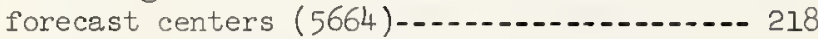

Glacial-river analysis (Delta R., Alaska)

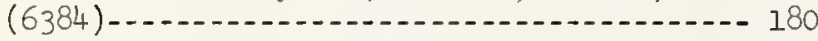

Idaho streamflow data studied for water-

resource capability (5l67)-................. 43

Logging effects on flow, Oregon Cascades

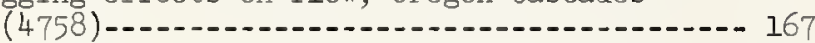

Logging effect on Alaska salmon streams

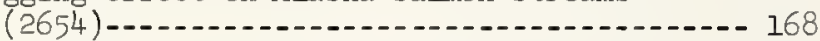

Long-time fluctuations in stream runoff correlated with sunspots (3522)-........-.- 127

Measurements under ice cover (6529)-.....-.-. 140

Recession characteristics of Iowa streams

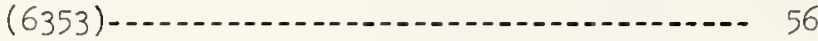

Relation of streamflow to adjacent ground-

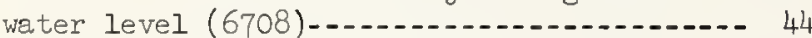

Routing, see FLOOD ROUTING

Synthesis by water balance and routing methods (6605) -......... 258

Use of weather radar in streamflow forecasts (5940) - 126

STREAMFIOW, EPHEMERAL

See EPHEMERAL STREAMS

STREAMFLOW, MEASUREMENT

SEe HYDRAULIC MEASUREMENTS

STREAM GAGINT

See HYDRAULIC MEASUREMENTS

STRUCTURES, OCEAN

Dynamic response functions (6699)-.......... 38

See also WAVES, FORCES

SUBMARINES

Effect of hull flow separation on stability of high speed submarine (5199)-.......... 141

SUBMERGED BODIES, ADDED MASS

See VIRTUAI MASS

SUBMERGED BODIES, BLUFF BODIES

Flow-disturbance effect on local viscous flow around $3-\alpha$ blunt bodies in transition regime (6057) - 263

Flow visualization study of separated flow in glycerol-solution tunnel (6580)-...-.-.-.-- 255

Pressure variation around body correlated with unsteady motions (6589)-................ 239

See also SUBMERGED BODIES, CYIINDERS, PLATES, SPHERES
SUBMERGED BODIES, CAELES

Hydrodynamic performance of faired cables for high-speed towed systems (6125).......- 241 SUBMERGED BODIES, CUBES

Turbulence in flow around cube in a velocity gradient with free surface effects (5757)-- 137

SUBMERGED BODIES, CYLINDERS

Flow around accelerated cylinders (2265)-...- 9

Flow past circular cylinders at low

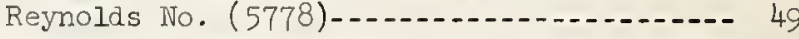

Fluidelastic features of flow around circular cylinders (5ll1)............................... 100

In a rotating fluid (6368)................ 28

Numerical solutions for time-dependent viscous flows around stationary and rotating

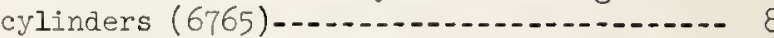

Strouhal No. and fluctuating pressures for elliptic cylinders (6574)-.............. 254

Velocity-gradient effect on drag (4716)-.... 128

Vibrations at low Reynolds No. (6484)-......- 239

Vortex-excited oscillation of D-section and circular cylinders (6576)................ 255

Wake oscillations and separation points of vibrating circular cylinder in uniform flow field (6808)-........... 268

Wake vortices in oscillating flow

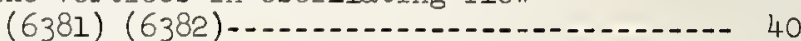

SUBMERGED BODIES, DRAG ON

See DRAG

SUBMERGED BODIES, FALL VELOCITY

See SETTLING VELOCITY

SUBMERGED BODIES, FINS

Hydrodynamic forces on fin-body combinations

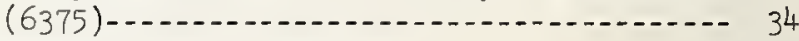

SUBMERGED BODIES, FORCES ON

Methods of measuring thrust, torque, pressures, in water tunnel (2832)-.......- 94

Tunnel wall interference effect on measured force on axisymmetric body (4181)-......- 94 See also DRAG

SUBMERGED BODIES, HEMISPHERES

Flow around hemisphere on a boundary in a finite 3-dimensional field with free surface effects (5755)-136

Free-surface effects on hemisphere on a boundary in a velocity gradient (5134)-..-- 134

Turbulence in flow around hemisphere in a velocity gradient field with free surface

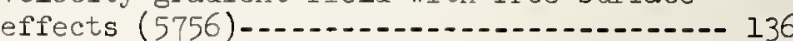

SUBMERGED BODIES, IN PIPE FLOW

Single particles in laminar tube flow (6280)- 143

SUBMERGED BODIES, IN STRATIFIED FLOW

See STRATIFIED FIOW

SUBMERGED BODIES, IN WAVES

See WAVES, FORCES

SUBMERGED BODIES, OF REVOLUTION

Steady and unsteady laminar boundary layers

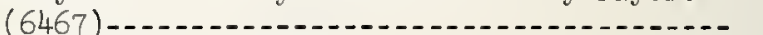

SUBMERGED BODIES, PLATES

Flow around and through a submerged porous plate (6809) - 268

Turbulence characteristics in flow past normal wall (5321)-........ 55 (5647)-........ 200

SUMBERGED BODIES, POTENTIAL FIOW

Computation for bodies of arbitrary configuration (6548)...................... 30

Computer program for flow around 3-dimensional body $(6374) \ldots \ldots$

SUBMERGED BODIES, PRESSURE DISTRIBUTION

Uniformly accelerating flow; pressuredistribution time history around body (6082) 
SUBMERGED BODIES, SPHERES

Flow characteristics in dilute polymer

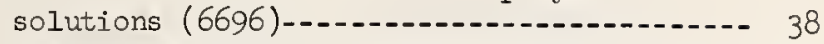

Horizontal motion through water with linear

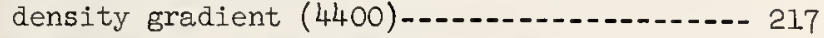

Impulsively started rotating sphere in infinite medium; numerical solution (6765)- 89

Motion of rigid spheres in highly turbulent

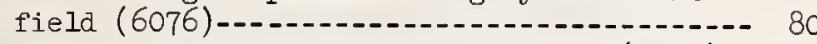

Stokes flow around accelerated sphere (3799)-- 88

SUBMERGED BODIES, STRUCTURAI ANGLE

Unsteady forces and unsteady oscillations

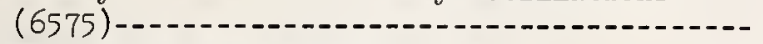

SUBMERGED BODIES, SUPERCAVITATING

See SUPERCAVITATING FLOWS

SUBMERGED BODIES, UNSTEADY FLOW

Circular eylinder, oscillating flow (6382)-..- 40

Flow around accelerated cylinders (2265)-...-. 9

Pressure variations around bluff body correlated with body motion (6589)--.--.---- 239

Stokes flow around accelerated sphere (3799)-- 88

SUBMERGED BODIES, VEHICIES

See SUBMERSIBLE VEHICIES

SUBMERGED BODIES, WAKES

See WAKES

SUBMERSIBIE VEHICLES

Propeller and wake noise in deep-sea submersibles (6679)-1. 77

Surface and near-surface effects on SUMPS resistance (6296)

Optimum design from study of vortices and flow patterns (6096)

SUNSSPOTS

Convective processes in sunspots correlated with laboratory flows (6786)

SUPERCAVITATING FIOWS

Wake behind two-dimensional cavitating wedge (4677)

See also CAVITY FLOWS

SUPERCRITICAI, FLOW

SEe OPEN-CHANNEL FLOW

SURGES

Propagation over dry ephemeral-channel bed

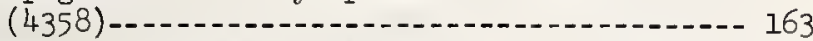

Speed of surge along bathtub vortex (6128)-.-- 233

SURGES, DRAFT TUBE

Literature survey and bibliography (6321)--.-- 255 SURGES, HURRICANE

See HURRICANE

SURGES, OPEN CHAINIEL FLOW

Attenuation by side weir (6307)-_...-..-- 223

Canal surge profile and speed (062W)-.-.-.-.- 227

Dimensionless ratios for canal surges (6099)-- 254

Ice-cover effect on celerity and damping (6631)

Positive surge in circular-bottom channel

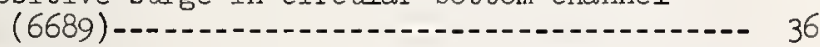

Rejection surges in trapezoidal channels (6303) -.......... 223

Surges, roll waves, in steep, rough channels

(5957) -

SURGES, PRESSURE

Hydraulic filters for surge pressures (6278)-- 62

Vapor formation during water hammer (6141)--.- 50

see also PIPE FLOW, TRANSIENTS

See also WATER HAMMER

SURGES, STORM

Berms for protection of nuclear plant site

(6753)-... 32

Computer programs for surge prediction (6477)- 244

Prediction of surge resulting from extreme

wind system over coastal area (6754)-.....- 33

See also HURRICANE SURGE
SURGE TANKS

General performance, stability, etc.;

theory and model study (6249) -..........-261

Model study of head losses through restricted orifices for surge tanks (6822)-_........ 257

Stability as influenced by large

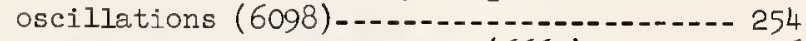

Various orifice types studies (6663)-..-.-.- 16

See also MODELS, SURGE TANK

SUSPENSIONS

Gas-bubble effect on liquid flow through nozzles (5195) -.....

Particle and fluid velocities in turbulent

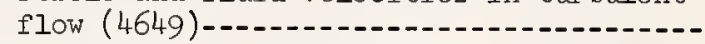

Relation between deformation of suspended particles and non-Newtonian behavior (6667)-

Resistance of neutrally buoyant suspension in pipe flow (4649)

Settling velocity of particles in turbulent

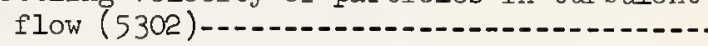

Transport of solid suspension in conduits; design of conveyance systems (6564)

Unsteady solid-liquid flows (6275)...........

See also COLLOIDS

See also TWO-PHASE FLOW

SUSPENSIONS, COLLOIDAL

Electrokinetic measurements of colloid-laden flow through a sand column (5810)......- 98

Electrokinetic removal of colloids (038W)---- 91

Flow of colloidal suspensions in porous

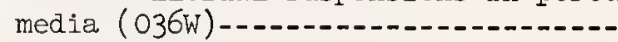

Thrust generation by electro-magnetic acceleration of colloid suspensions (6680) -.

SWIMMING BODIES

See FISH PROPUISION

SWIRLING FLOW

Transonic nozzle thrust control with swirling flow (6062)

See also PIPE FTOW, SWIRLING

- $\mathrm{T}-$

TAINTER GATES

See GATES

TAYLOR VORTICES

Development and breakdown of Taylor vortices

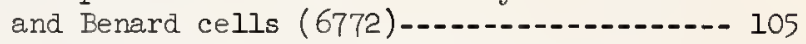

speed-torque relations immediately after

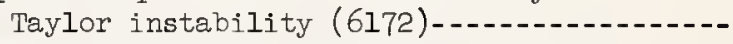

Taylor instability in Newtonian and non-

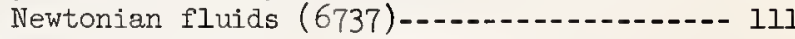
See also CYLINDERS, CONCENTRIC ROTATING See also STARILITY

TEACHING AIDS See INSTRUCTION

TENSILE STRENGTH Organic film effect on gas nuclei $(t, 18)-----35$

TENSION, IN LIQUIDS Measurements in a variety of liquids (5106)-- 95

THERMAL CONDUCTIVITY

For multi-phase systems (6672)

THERMAL POLLUTION See POLLUTION

THERMOCLINES

Model for temperature structure of lakes (6624) -..... 149 Structure in shallow coastal waters (6372)--- 242 THERMO-HALINE CIRCULATION See CIRCUIATION

THRUST

Generated by electro-magnetic acceleration of colloids (6680) 
THRUST (continued)

Page

Thrust control in transonic nozzle with

THRUST, PROPELIER

See PROPELTERS

TIDAL HYDRAULICS

Comprehensive study of shoaling in tidal

Mathematical model of exchange characteristics

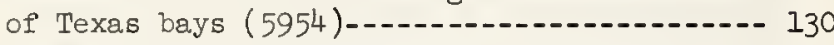

Sacramento-San Joaquin delta analog methods for tidal predictions (4933)-.....- 10

See also COASTAL SEDIMENT

See also ESTUARIES

See also INLETS, COASTAL

TIDAL POWER

Computer program for optimum power generatjon, Bay of Fundy (6226)

Power plant effect on tide regimes, Bay of Fundy (6227) -

TIDES

Application of modern time series methods to tide prediction (5926)-................... 113

Bay of Fundy tide regimes (6227)-......-.-...- 259

Computation methods for tides and currents

in estuaries and canals (6848)...........- 211

Computations in estuaries and canals (6414)-... 72

Effects of dredging and causeway placement

on tidal currents, Vancouver Harbor,

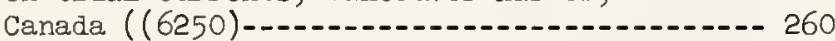

Internal tides off California (4500)--------- 113

Internal tides off Southern Calif. (6372)-...-- 242

Mathematics of flow in tidal inlets (6851)-.-.- 211

Mixing in tidal currents in Block Island

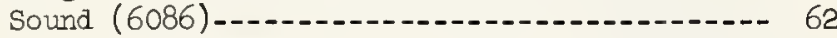

St. Lawrence estuary tidal motion, theoretical

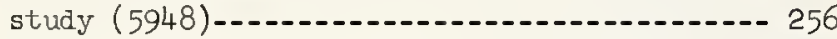

Shallow-water tide predictions, Cook Inlet,

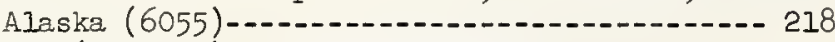

Storm (or wind), see SURGES, STORM

TIDES,GAUGES

Development of resistance gauge (6598)-..-.-.-- 238

Instrument for recording deep-sea tides (5927)- 113

See also HYDRAULIC MEASUREMENTS

TIDES, TIDAL POWER

SEe TIDAL POWER

TIMBER HARVESTING

See IOGGINC

TIRES

See HYDROPLANING

TOWED SYSTEMS

Development of design procedures for high-

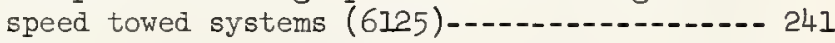

TRACERS

SEe SEDIMENT TRANSPORT

SEe HYDRAUIIC MEASUREMENTS

TRAINS

Cross-wind effect on rapid-transit train

TRANSIENTS, POWER PIANT

Computer simulation of hydropower transients

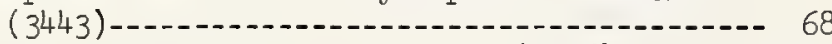

Tests at Garrison and Oahe dams (3906)-..-.-.-- 190

See also PIPE FIOW

See also WATERHAMMER

TRANSITION

Iaminar-to-turbulent porous media flow (5902)-- 44

Turbulence initiation in packed bed of

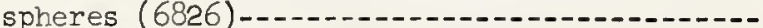

TRANSITION, BOUNDARY IAYER

SEe BOUNDARY LAYER

TRANSITIONS

Canal-tunnel junction, optimum geometry for (6326)
TRANSITIONS ( continued)

Page

Circular pipe to rectangular supercritical

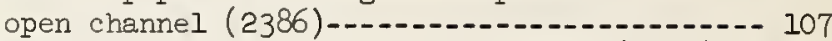

Pumping-plant inlet transition design (4954)--- 220

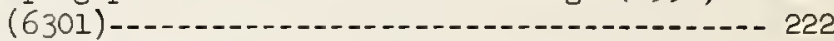

stilling basin for pipe to open channel (5133)- 134

See also OPEN CHANNEL FLOW, TRANSITIONS

TRANSPORT PROCESSES

Nonlinear ordinary differential equations in transport processes (6356)-........... 57

Tests for closed-conduit spillways (4335).....- 162

TSUNAMIS

See WAVES, TSUNAMIS

TUNNELING

Rock tunneling with high speed water jets TUNNELS

utilizing cavitation damage (6650)-........- 42

Deposits causing obstruction to flow in

Colorado River aqueduct system (6733)-.....- 17

Friction factors for unlined tunnels (1467)--.- 189

Tunnel friction measured at Nolin Dam, Ky., outlet works (5243)

TUNNVELS, DIVERSION

Abrasion problems at Glen Canyon Dam tunnel

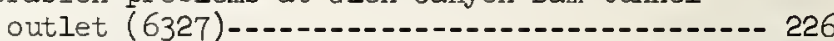

Mica Dam (Can.) river diversion and closure; model $(6434)$

TUNNELS, INLETS

Optimum configuration for Azotea Tunnel inlet junction (6326)

UNNELS, WATER

See FACILITIES

TURBIDITY

Development of instrument for in-place measurement of turbidity (3907)-...-...-.-191 TURBIDITY CURREITS

Experimental and theoretical research on turbidity currents (6652)

See also STRATIFIED FIOW, DENSITY CURRENT

TURBIIES (HYDRAUIIC)

Discharge measured with current meters (4441)-- 244

Internal flow field and pressure distribution, theory (6490)-....... 87

Radioisotope flow measurement (061W)(064W)-...- 227

Twisted guide vanes to improve performance

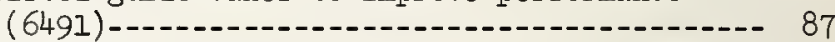

Vibrations analysis on Wheeler Project (TVA) turbines (6716) -........ 246

TURBOMACHINERY

Three-dimensional effects on flow (5777)-.-.-.- 49 TURBUTENCE, BOUNDARY ILAYER

Influence of rotation on flow in long rectangular channel (6800)-........-.-.-.- 117

Turbulence promoters used to improve heat transfer through laminar layer (6571)....... 90

Very high frequency transducer for fluctuating

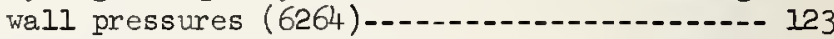

Wall-pressure fluctuations in dilute polymer

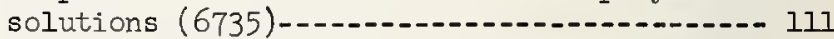

Wall-pressure fluctuations investigated in acoustic wind and water tunnels (6266)--.--.- 242

Wall-pressure fluctuations obtained on buoyantly propelled vehicles (6585)-.-.-.-.- 241 Wall-pressure spectra in thick layers (6262)--- 123 TURBULENCE, DAMPING OF

Foam dampeners used in flexible tubes (6083)--- 97 TURBULENCE, DECAY OF

Decay of grid turbulence (6449)-........-.- 18

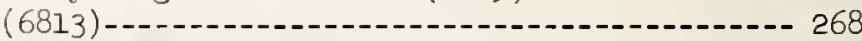

In axisymmetric wakes (4099)-...-........-. 20

TUREULENCE, DRAG REDUCING FLOW

Hot-film measurement and turbulence structure in organic-solvent pipe flow (6405)-........

See also DRAG REDUCTION, ADDITIVES 
TURBULENCE, DRAG REDUCING FIOW (continued)

See also TURBULENCE, NON-NEWTONIAN FIOW

See also TURBULENCE, POLYMER EFHECTS

TURBULENCE, EDDY VISCOSITY

Dependence between eddy and fluid

viscosity (6201) -.....

TURBULENCE, FREF SHEAR FLOW

Analysis by use of new theory (6102)-......- 89

Contaminant diffusion in mixing zone (6496)-.- 264

Self-preservation tendency in jets and wakes (5907) -

Transducer to measure static pressure fluctuations (6264)-..... 123

TURBULENCE, GRID

Analytical treatment of grid turbulence

$\begin{array}{rr}\text { (6359) } & 57 \\ \text { Decay of turbulence behind grid (6449) } & \end{array}$ (6813)-...-. 268

Effect of polymers on turbulence decay (6645)- 41

Mixing behind grid towed through stratified liquid (6362)

TURBULENCE, JETS

Turbulence structure of jet in coaxial

stream (6360)

submerged jet (6620)

TURBULENCE, IAKES

Measurements within a few inches of a pond surface (6595) -...... 238

TURBULENCE, MEASUREMENT

See HYDRAULIC MEASUREMENTS, TURBULENCE

TURBULENCE, NON-NEWTONIAN FIOW

Turbulent shear flow analyzed using gross

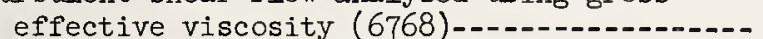

See also TURBULENCE, POLYMER EFFECTS

TURBULENCE, OCEAN

Fine-scale temperature related to turbulence dissipation and other factors (6289)-.....-. 113

Mechanics of turbulence in upper layers of ocean and in shallow water (6086)

Momentum and heat diffusion in upper ocean (6465)--..- 243

Natural turbulence compared with ship-screw turbulence (6465) -

TURBULENCE, OPEN CHANNEL FLOW

Application of hot film anemometer to evaluation of turbulent quantities (6817)--- 269

Correlation of turbulence characteristics with bottom roughness (6049) ................

Mathematical models for diffusion in natural

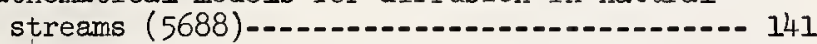

Rainfall effect on turbulence in shallow flow (5478)-...... 125

Turbulence properties used to determine start of established flow (6697)-............. 38

Turbulence structure and diffusion in rough

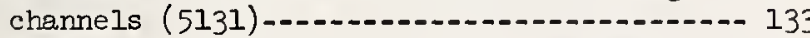

Turbulence structure with large roughness

elements (6524) -

Turbulent flow structure related to resistance for movable boundary case (5610) -...-.-.-- 228

TUREULENCE, PIPE FIOW

Turbulence properties used to determine start of established flow (6697)

Turbulence structure near porous, rough wall (5823) -

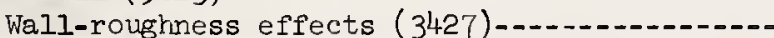

TURBULENCE, POLYMER EFFECT

Boundary-layer turbulence, additives effect on r.m.s. fluctuation, spectral density (6135) (6136) -...- 234

Turbulent shear-layer characteristics (6214)-- 67

Turbulence structure studied with Doppler scattering (6554)
TURBULENCE, POLTMER EFFECT (continued) Page

Wall pressure fluctuations in dilute polymer

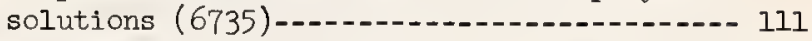

Wall pressure fluctuations in fully established pipe flow of polymer solution (6587)- 241

Wall pressure fluctuations obtained on buoyantly propelled vehicles (6585)........-241 TURBULENCE, ROUGH WAIL

Investigation of layer of high-intensity

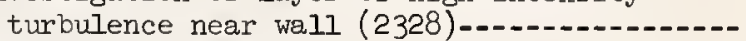

Wall-roughness effect in pipe flow (3427)-...- 49 TURBULENCE, SHEAR FLOW

Production, dissipation in Couette flow (2536) -......

Six basic shear flows studied (6396)-...-...-.

Structure of homogeneous turbulent shear

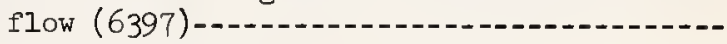

Visuel and quantitative study of turbulence structure (6798) -

See also TURBULENCE, FREE SHEAR FLOW

TURBULENCE, STRATIFIED FLOW

Mixing behind towed grids (6362)-...- 58

Turbulence in stably stratified fluids (6613)- 4 TURBULENCE, THEORY

Computer simulation of energy transfer from shear flow to turbulence (6588)-...-...-. 239

Energy spectrum for second-order fluid (5596)- 95

Free turbulent shear flows analyzed with new theory (6102)-....... 89

General phenomenological theory for wall

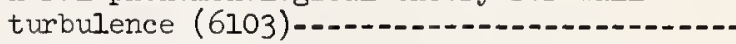

New wall-turbulence theory for subsonic and supersonic flow (6121)-.... 131

Numerical simulation of turbulence model (6200) -...- 102

Transfer of turbulent energy at large wave numbers (6613)

TURBULENCE, WAKE

Behind body of revolution (4974)

TURBULENCE, WALL PRESSURES

Measured with flush hot-film sensors; pipe

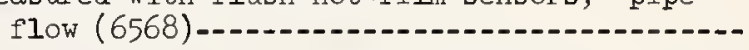

Turbulence structure near wall studied with electrochemical techniques (6824).......-. 48

In pipe flow of polymer solutions (6587) -.... 241 See also TURBULENCE, BOUNDARY LAYER

TWO-PHASE FIOW, IIQUID-GAS

Air-water flow in vertical bend; transition from bubbly to plug flow (6686)

Breakup of liquid exposed to gas stream (6124) -

Effect of waves at interface on turbulent air flow (6828)-..... 48

Gaseous bubble effects on nozzle flow (5195)-- 39

Gas jet impinging on liquid surface (6113)--.- 59

Mass transfer from liquid film to hot gas stream (6219)-_.-.-103

Mixing of liquid and gas jets (6558)........ 96

Sound generated by various types of flow (4235)

See also AIR-SEA INTERFACE

TWO-PHASE FIOW, IIQUID-IIQUID

See IIQUID-IIQUID FIOW

TWO-PHASE FIOW, IITUID-VAPOR

Energy losses in flow of flashing fluid in horizontal pipe (6811) - 268

Interfacial waves on vertical condensate films (6111)-.... 59

Stability of interface to negative acceleration (6339)-.... 231 Vapor formation during water hammer (6141)--- 50 Weightlessness effect on liquid-vapor interface (6338) (6340) - 231 $(6341)$ 
TWO-PHASE FLOW, SOLID-FLUID

Elbow meter to measure flow and concentration in solid-liquid flows (6566)........- 65

Granular solids driven by compressed air

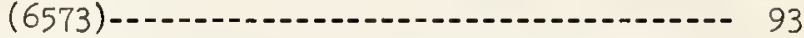

Momentum equation for solid-fluid system (6270)--..- 26

Motion of discrete particles in turbulent

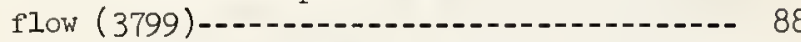

Motion of rigid spheres in a highly turbulent

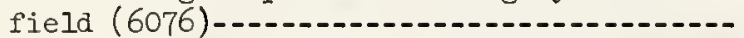

Particle volume determined from scattered light of laser radiation (6590)-........- 239

Solid-waste pipeline hydrodynamics (6470).... 96

Transport of solid suspensions in conduits (6564) - of See also SUSPENSIONS

$-\mathrm{U}-$

UNDERWATER SOUND

See HYDRODYNAMIC NOISE

See ACOUSTICS

UNDERWATER VEHICLES

Deep-submergence rescue vehicles (6179)-.-.-- 27

Hydrodynamic forces on fin-body combination (6375) UNSTFEADY FLOW

Group theory applied to three-dimensional

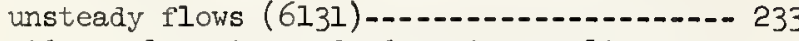

Rapid-acceleration hydrodynamics applied to rifle recoil (3740)

Three-dimensional rotational flow with vortex stretching but no diffusion (6126)-......-. 233

Three-dimensional rotational flows with vortex stretching and diffusion (6127)-.--- 233

See also VIRTUAI MASS

UPWEITING

Hurricane induced upwelling in ocean (6488)-- 244

$$
-\mathrm{V}-
$$

\section{VALVES}

Butterfly valves discharging into sudden enlargement; effect on cavitation (5336)-- 221

Containment structures for fixed-cone dispersion valves (6719)-... 247

Fixed-cone dispersion valves; aeration

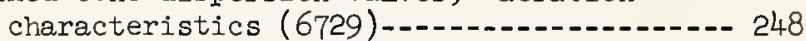

Operation tests of pressure regulating valve station (6441)-_.- 271

Reliability of backwater valves in plumbing

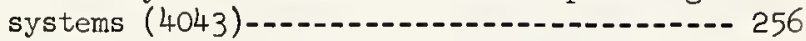

Tests on 12-in. butterfly and ball valves (6480)

VALVES, HEART

See BIOMEDICAI HYDRODYNAMICS

VALVES, HOWELL-BUNGER

Model study of valves for Sumersville Dam, W. Va. (6874)

Summersville Iake portotype tests on valve vibrations (6876) LVES, SERVO

Valve spool erosion evaluation (6373)-.....- 34

VAPOR CAVITIES

SEe CAVITATION

VAPOR-LIQUID FLOW

See TWO-PHASE FLOW

VECTOPLUVIOMETER

SEe HYDROLOGIC MEASUREMEINT

VEHICLES, AMPHIBOUS

See AMPHIBOUS

VEHICLES, MILITARY

Mobility related to characteristics of Alaska streams (6386)
VEHICLES, UNDERWATER

SEe UNDERWATER

VIBRATIONS

Effect on pipe-flow friction factor (6493)-..- 124

Nonlinear vibrations in hydraulic positioning systems (6577) -

of Howell-Bunger valve at Sumersville

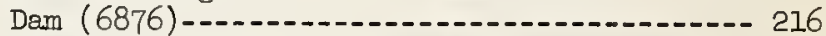

of hydroturbines at certain gate openings

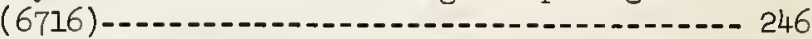

Propulsor blades; liquid effects on vibration (6557)

VIBRATIONS, FIOW INDUCED

At Old River spillway, La. (6032)--.-.-.-.-- 206

Circular cylinder at low Reynolds No.;

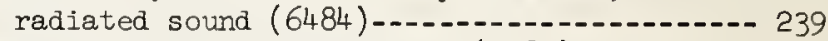

Flat plate in turbulent flow (5189)-........- 123

Flutter of hydrofoil craft with 3-dimensional unsteady foil loads (6538)............... 8

Flutter of supercavitating flat-plate hyarofoils (5500)-1..-109

In metal bellows, elastic tubes (6065)-.-.-.- 114 Low-crest spillway on elastic foundation

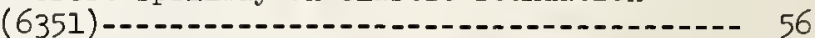

of a cylindrical centilever beam (6802)--.-.-- 267

Oscillations of D-section and circular cylinders (6576)......................... 255

Oscillations of flap gates (5950)-.......... 257

Self-excited vibration theory for propeller singing (5936)-....... I2]

Thin-plate flutter in narrow channel flow

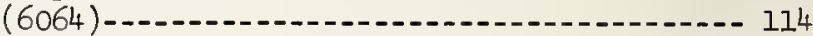

Thin-wall pipe, varying flow conditions (6118) 45

Training-wall vibration at Hells Canyon (5521) 144

Unstable oscillations of structural angle (6575)-...- 255

Wake oscillations and separation points of vibrating circular cylinder in uniform flow

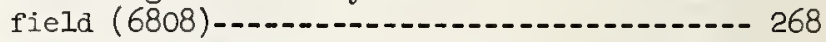

Wind-induced oscillations of elastic slender bodies (6060) VIRTUAL MASS

Circular cylinders oscillated in uniformly stratified salt water (6061)-............ 238

Hydrodynamic masses for floating and submerged bodies (6367)

of two-dimensional forms by conformal mapping (2091)

Spheres submerged in waves (6075)-....... 40 VISCOELASTIC FLOW

See NON-NEWTONIAN FLOW

VISCOSITY

Dependence between eddy and fluid viscosity (6201)-..... 102

Measurements at extreme shear in laminar flow of polymer solutions (6678)-1..-1 77

of polymer solutions, varying concentration

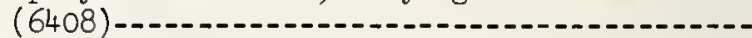
VISCOUS FLOW

Around blunt bodies in transition regime (6057)-1.... 263

Cylindrical tube containing line of spherical

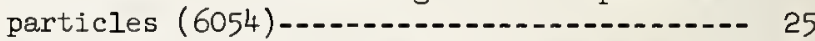

Numerical solutions for certain time-depen-

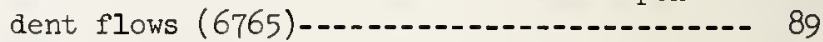

Stability over curved surfaces (6772)-.......- 105

Through sphere assemblages, fluidized and

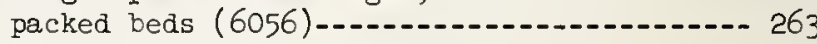

See also LAMINAR FLOW

VISCOUS SUBLAYER

Turbulence structure near wall studied with electrochemical technique (6824)..........

See also BOUNDARY IAYYER

See also TURBULENCE, WALI 
VORTEX MOTION

Anti-vortex system upstream of large power intake (6246)

Bathtub vortex, surge speed along centerline (6128)-.-1 233

Behind cylinder in oscillating flow (6381)-..- 40

Boundary layer beneath vortex (6616)-...-.-.-. 4

Breakdown in swirling tube flow with adverse

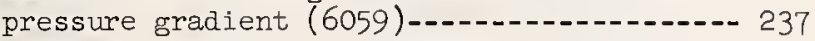

Breakdown of vortex, experiments supporting finite transition theory (6129)-........-. 233

Conducting-vortex-like flow between coaxial cylinders stabilized hydromagnetically (6569)-_... 90

Control of velocity distribution in vortex (6497)-1... 264

Critical submergence for vortexing during draining of vertical cylindrical tank (6797)-_.-...- 114

Dynamics of atmospheric vortices and boundary layer (6451)

Eddies in laminar separation zones (5909)--.-- 56

Formation at penstock entrances (6324)-.------ 226

In cavities in channel walls (6272)-.......- 26

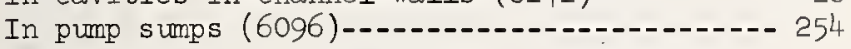

Interaction of two-dimensional submerged jet and vortex flow (6112)

Interaction with stationary surface (6570)-.-- 90

Literature survey on free-vortex internal velocities (6611) -

Mass transport in driven vortex (6274)-------- 26

Maximum rotational velocities in free vortices (6611)

Shed wing vortices and their decay (5590)--.-- 95

Stable eddies at pipe expansions (1875)---.--- 53

Steady vortex generated in a slot or cavity (6804)-....... 267

Thrust control in transonic nozzle with swirling flow (6062)-..................... 238 Vortex development at turbine intakes (6723)-- 247 Vortex sinks; behavior of pulse with origin

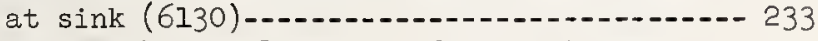

Vortex sinks, application of group theory

(6131)

VORTEX MOTION, TAYLOR
SEe TAYLOR VORTICES

VORTEX MOTION, WAKE VORTICES

See WAKES

VORTEX SINK FLOWS

See VORTEX MOTION

$$
-W-
$$

WAKES

Behind bodies of revolution with momentum addition (4099)-1.-. 20

Behind supercavitating wedge (4677)-...-.-.-. 94

Wake geometry during resonant oscillations

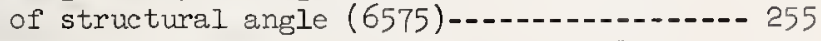

Wake oscillations of a vibrating circular

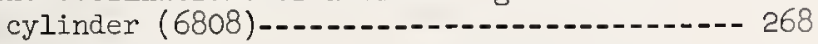
WAKES, COLIAPSE

Flow phenomena caused by collapse of mixed

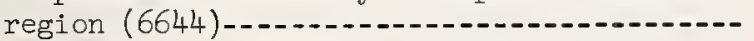

Mixed-region collapse in stratified liquids

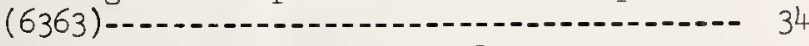

Two-dimensional wake behind cylinder in

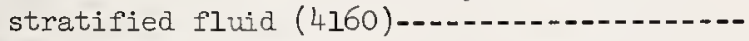

Wake of self-propelled body in stratified

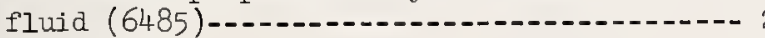

WAKES, KARMAN

See WAKES, VORTEX

SEe VORTEX MOTION

WAKES, STRATIFIED

Three-dimensional momentumless wakes (4160)---
WAKES, STRATIFIED (continued)

Two-and three-dimensional bodies in

stratified fluid (6173)

See also STRATIFIED FIOW
See also WAKES, COITAPSE

WAKES, TURBUTENT

Behind bodies of revolution (4974)--.....-.-.

Behind bodies of revolution with systematically

varied asymmetries (5311) -............... 119

WAKES, VORTEX

Behind circular cylinder in oscillating flow

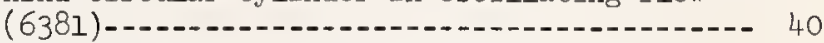

Behind elliptic cylinders (6574)--.---.-.-.-.- 254

Flow visualization behind circular cylinder

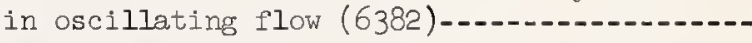

Karman street behind cylinder at low Reynolds No. (6484)

WALL JET

See JETS, WALL

WAII PRESSURES, FLUCTUATING

See TURBULENCE

WATER BUDGET

Analog and digital computers used in water budget studies $(6212)$ -

WATER ENTTRY

Drag, whip and cavity shapes (4867)--.------- 237

See also IMPACT

WATER HAMMER

Analog-computer analys is (6277)-............-.

Control by valve stroking (5917)...............

In irrigation pipe systems (6097) -......-.-. 254

Liquid column separation (4862)-...........- 78

Resonance in triplex pump suction and discharge

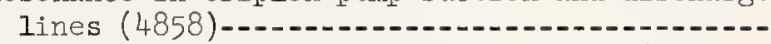

Surge attenuation due to line movement (6276)--

vapor formation during water hammer (6141)-...-

See also SURGES, PRESSURE

WATER IANDIIVG IMPACT

See IMPACT

WATER LEVEL

See HYDRAULIC MEASUREMENTS

WATER QUALITY

Chambers for mixing waters of different qualities (5865)

Coarse media effects on properties of

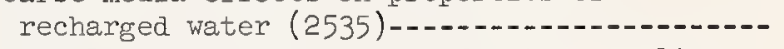

Control by conjunctive use of water supplies of different salt content (6665)-............

Cyclic changes of various water properties in deep stratified reservoirs (6712)-...... 246

Effect of logging on water quality of Alaska pink salmon streams (3535)-............. 146

Effect of pesticide residues (040W)-.-.-.-.-. 98

Effect of stratified flow in reservoirs on

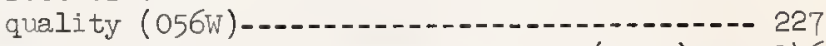

Effect on salmon in Duwamish estuary (050W)---- 146

Engineering-project effect on surface-water

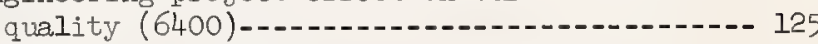

Feasibility of telemetry of water quality

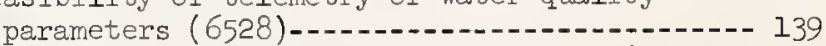

Groundwater change at Severance, Colo. (5880)-- 22

Land use effects in forested mountain watersheds (5413) -

Management; benefit-cost approach (6177)-..--

Physical and biological changes in ground and surface water from man's activities (002W)--- 24

Prediction for Wenatchee River, Wash. (6156)--- 144

Stream quality study in Arkansas (6152)-...-.-. 2

Surface-water hydrologic systems management for quality control (6223).................... 12

Watershed environment related to microbial dynamics (5407)-...... 22 WATER REQUIREMENTS

Agricultural water needs for State of Idaho (6704) (9)

\section{,} 5 . . , 
Supplying peak municipal demand with variable quality desalted water and artificial underground reservoir (04TW).................. 141

\section{WATER RESOURCES}

Arkansas and Oklahoma water resources

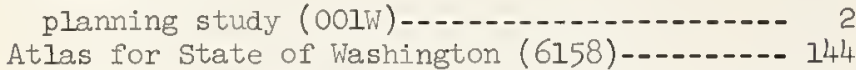
Atmospheric resources in Utah (5750)-........- 136 Benefit-cost inventory for treatment selection (6177)-1.-1 27

Conjunctive use of surface and groundwater; optimization (6665)-...................... 17

Effect of mineralized springs on Utah's water resources (048W)-.............................. 14

Hydrologic atlas of Utah (6531)-..........-. 140

In carbonate karst terrain (O3OW)-...-...-.-. 82

Integration of resources of Bear, Weber and Jordan Rivers, Utah (6518)-............-. 138

of Idaho streams (5167)................... 43

Preliminary inventory, state of Idaho (6705)-- 44

Similarity between rail-transport and waterresource systems (4543).................. 50

State water plan investigation, Utah (042W)--- 140

Systems analysis and mathematical models in

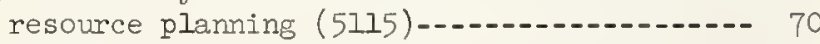

Systems analysis using operations research (4543) -

\section{WATER REUSE}

Feasibility of livestock waste disposal system involving reuse of water (034W) ..........

\section{WATER RIGHTS}

Engineering-hydrologic analysis of water

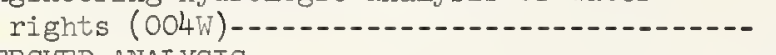

WATERSHED ANALYSIS

Alaska, Delta River drainage basin (6384)-..-- 180 Basins formed from glacial moraine (6604)-.-.- 257 Correlation and synthesis of watershed

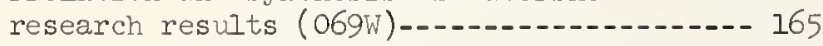

Effect of various vegetation on hydrology of No. Carolina watersheds (3306)-.......-. 249

Effects of gradual urbanization (6606)-------- 258

Forest management effect on hydrology of Citico Creek research watershed (4011)

Geophysical methods employed to find hydrologic properties of substrata (2658)-.- 175

Glenn Creek Basin, Fairbanks, Alaska (6385)--- 180

Hydrologic characterization of small water-

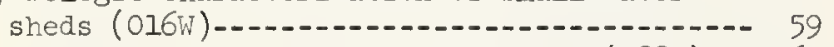

Hydrology of forested bog watersheds (3887)--- 165

Investigation of use of mathemaical models for small watersheds (5294)

Laboratory watershed system used for basic study of watershed hydraulics (4906)........

Mathematical model of lower reaches of Kansas River drainage system (026w)-..-.-.-.

Mathematical models of small watershed

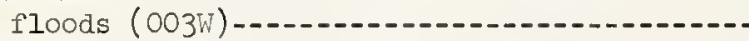

Models, see HYDROLOGIC MODELS

Northern Alaska, hydrology of small basin on

coastal plain (6383)

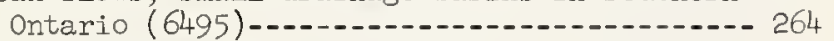

Physical and economic analysis as related to soil and water conservation (01TW) -.......-.

Prediction of small watershed performance by nonlinear systems analysis (5145) -......Reforestation and erosion control effects, Pine Tree Branch watershed, TVA (3309)--.--- 249

River basin hydrology, Kansas streams (021W)-- 61 Roughness of watersheds and conceptual river

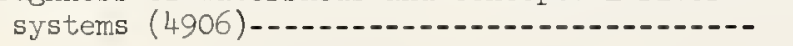

Soil type, slope and vegetation effects, Upper Bear Creek, (TVA) (4884)

Techniques and model laws for laboratory watersheds (3845) - 133

Vegetal cover effects, east Tennessee (3308)-- 249 See also HYDROLOGIC ANALYSIS

See also RUNOFF

See also WATERSHED MANAGEMENT

WATERSHED MAINAGEMENT

Determining water loss to phreatophytes (657B) -

Effect of timber and grassland controls on water yield, Arizona watersheds (657C)-...-- 174

Flood and sediment reduction in California conifer zone (4998)-_...- 171

Forest hydrology research in Mississippi (2914)-...- 178

Hawaii wildland watersheds (5001)-.........-. 173

Logging effect on streamflow, Oregon Cascades

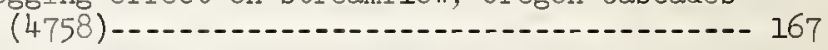

Practices affecting irrigation water supplies (5395)-.......... 21

Range-type watersheds in New Mexico (1969)---- 175

Research in Calif. and Hawaii forested

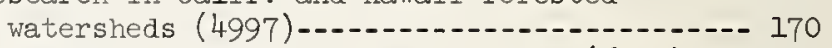

Research in chaparral zone, Arizona (657A)---- 173

Research in driftless area of southwestern

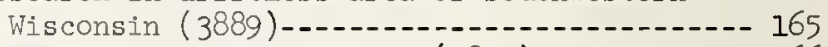

Research in lower Michigan (3890)-.........- 166

Research in northern Minnesota (3887)-......- 165

Research in Ozark-Ouachita Mts. forested

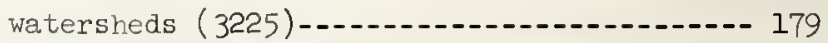

Research in southeastern U.S. forested watersheds (380)-_......-177

Sagebrush watersheds in Wroming (3569)-.--.--- 175

Southeast U.S. wetland forests (5813)-......- 178

Steep, unstable southwest brushlands (4999)--- 171

Techniques for mid-Columbia River forested areas (4757)--16-1 167

Water yield control in California snow zone (4996) - 169 WATER STORAGE

Feasibility of storing fresh water in saline

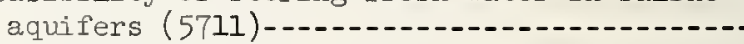

See also RESERVOIRS

WATER SUPPLIES

Construction of facilities in permafrost areas $(054 \mathrm{~W})$-.... 181

Farm water supplies in southern coastal plains (4841) WATER TEMPERATURE

Diffusion and exchange of heat discharged into

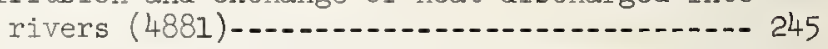

Effect of dam construction on downstream temperature (049w)-...................... 145

Factors affecting stream temperature (5787)-.- 92 Reservoirs and streams in TVA (769) See also COOIING WATER DISCHARGE

See also MODELS, RIVER

See also POLIUITON, THERMAL,

See also WATER QUAIITY

WATER TREATMENT

Benefit-cost approach (6177) Clarification with centrifugal acceleration (6498)

Electrophoretic control in filtration of

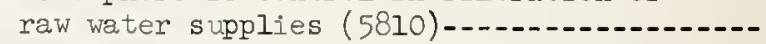

Removal of radioactive contaminants from condenser cooling water, Browns Ferry, TVA (6713) -...... 
WATER TREATMENT (continued)

See also FIIIRATION

Page

WATER TUNNELS

See FACILITIES

WATER USE

Bv vegetation, Calif. mountain watersheds

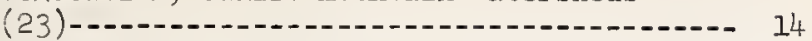

Determining water use by phreatophytes (657B)-- 174

Optimizing conjunctive use of surface and

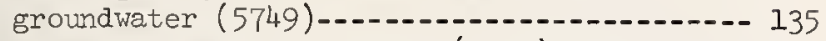

Selected cities and industry (005W)-......... 25

Sequential water use within a hydrologic complex (5748)

State water plan investigations, Utah (O42W)--- 140 WATER YIEID

Determination of yield using tracers (5395)-..- 21

Effect of different forest types (O70W)-------- 165

Effect of forest-cover controls (380)--.-.-.--- 177

Effect of timber and grassland controls on yield from Arizona watersheds (657C)-...-.-- 174

Flood and sediment reduction in California. conifer zone (4998)-..-171

Insuring maximm yield in watersheds denuded

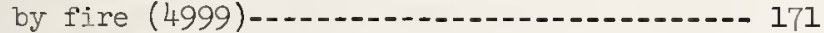

Mid-Columbia River forested areas (4757)-.-.-.-- 167

Prediction for high mountain watersheds based on physiography (5878)

Snowpack control research in Calif. (4996)-..-- 169

Vegetation effects in Chaparral zone, Arizona (657A) -

WATER YIEID, IMPROVEMENT OF

By decreasing evapotranspiration losses,

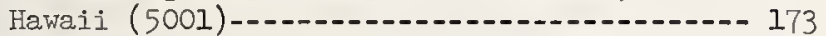

By snow deposition control, Colorado Alpine

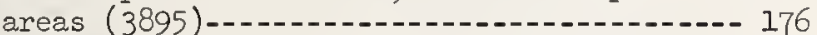

In glaciated mountain areas of New England

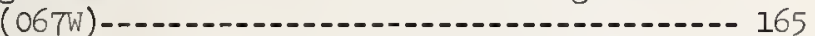

In northern Appalachian Mt. Region (068w)-.---- 165

In snowpack timber zone, central Rocky Mts.

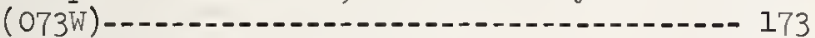

In southwest brushlands (5000)-..........- 172

In the Black Hills (2658)-.................- 175

WAVES

Interaction between gravity waves and turbulent

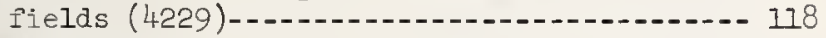

Scale effects in action through porous structures (5818)

WAVES, ABSORBERS

Beach to stop reflections in towing tank

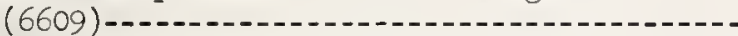

Fixed, pneumatic and hydraulic devices for minimizing reflections (6150)-..........- 145

Rubble-mound absorber characteristics (5635)--. 198

WAVES, BOTTOM PRESSURES

Power spectra of bottom pressures in near-shore

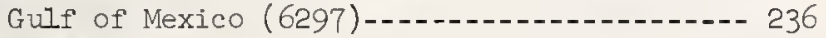

WAVES, BREAKINC

Characteristics of plunging breakers (5328)---- 184

Pressures on vertical wall (6335)-...-...-.- 236 (998) (4908)

WAVES, CAPIITARY

Interaction among capillary-gravity waves (3120)

WAVES, CLAPOTIS

Forces on vertical breakwater (998)-...-.-.-.- 187

See a.lso WAVES, STANDING

WAVES, CNOIDAI

Reflection over uneven bottom (6413)--.------- 72

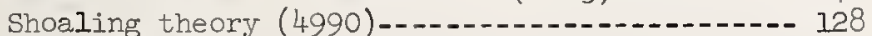

WAVES, DAMPING

Damping by screens and other permeable

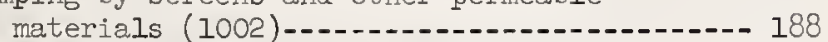

Damping with secondary flows (6274)-.-.--.--.-. 26
WAVES, DAMPING (continued)

Decay and reflection in ice floes (6537)-....-- 122

Effect of drag reducing polymers on wave

damping in tank (6829)

In channel with roughened sides (4128)

Interaction between gravity waves and

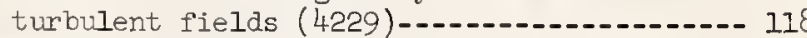

Sumary of viscous damping of shallow-water waves (6013)-

WAVES, DIFFRACTION

Long waves and tsunamis around islands (4866)- 124

Wind-wave diffraction by semi-infinite breakwater and by bottom discontinuities (4934)-- 10

WAVES, DISPERSIVE

Beach runup of waves impulsively generated

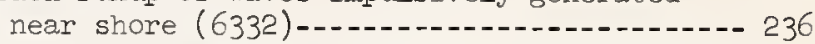

Model for numerical computation of propagation of waves generated by nuclear explosion (6795)-........- 105

Pressures on vertical wall (6335)-.-.-.-.-.-.- 236

Run-up on plane-faced walls (6333)-...-.-.-.-.- 236 WAVES, EDGE

Resonant edge waves on laboratory beaches ( 5326$)$

WAVES, ENERGY FLUX

Energy flux perpendicular to direction of propagation (4128) -......

WAVES, EQUIPMENT

Design criteria for wave filters in harbor

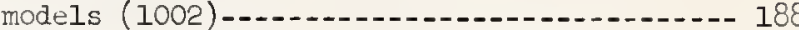

Generator and absorber studies (6281)-.-.-.-- 143 See also FACIIITIES

See also WAVES, ABSORBERS

See also WAVES, GENERATORS

WAVES, EXPLOSION GENERATED

See WAVES, DISPERSIVE

WAVES, FIEID DATA

Height and length data collected at east coast stations in U.S. (660)

181

WAVES, FIOATING BODIES ON

Damping effect of stabilizing plates on

floating vertical cylinder (6536)-......... 121

Motion of barge moored in ocean (5289)....... 51

Motion of spar-shape floats (6299)-.......... 14

Pressure distribution on heaving prolate

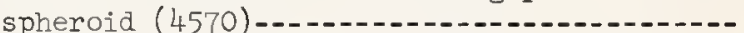

Stochastic hydrodynamic analysis of ocean wave action on moored platforms (5289) -.....-

WAVES, FORCES

Breaking waves and clapotis against vertical-

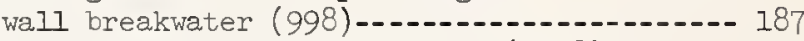

Breaking waves on vertical wall (4908)-...-.-. 51

Dynamic response functions of ocean struc-

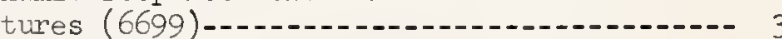

Dynamic response of offshore structures to random and periodic waves (3750)...........-

ocean wave simulation for engineering design (5439)-........................... 11

On breakwaters of varying permeability (6760)- 33 On drilling platforms, theoretical (6232)---- 259 On piles and pile groups, analytical methods

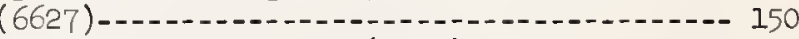

On piles and structures (5439)-......... 11

On platforms moored in ocean (5289).......- 51 Pressure on underside of pier (6334)-.......-. 236 Riprap stability under wave action (6486)----- 185 Spectral density for ocean wave forces (5439)- 11 Spheres submerged in waves, field study

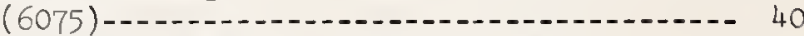
Stability of causeway profiles (6230)-...-...- 259 Submerged-pipeline experiments (6424)-.-.-.-.- 78 Tsunami surge forces (5439)............. 11 Uplift forces on dock (6584)............. 8 Vertical-wall pressure due to dispersive

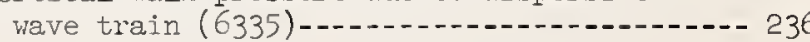


WAVES, FORECASTING

Automated prediction techniques on ocean-

wide basis (6454) -

Computer programs for surge prediction $(6477)$

Determination of scale at which synoptic analysis is feasib.le (6475)................ 244

Global forecasts using spacecraft data

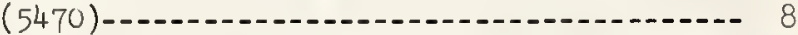

Improvement of techniques for sea, swell and

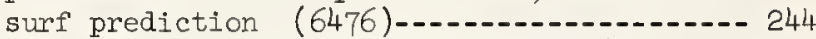

Pacific Ocean wave forecasting study (6412)-.. 66

WAVES, GENERATORS

A general purpose laboratory generator (5995)- 253

Generation of purely random seas (6609)-.-.-- 75

WAVES, GENERATION

Tsunamis generated by fault motion (6224)--.-- 12 WAVES, IN ICE FLOES

Wave decay and reflection in ice floes (6537)- 122 WAVES, IN HARBORS

See HARBORS

WAVES, INTERACIIONS

Between long and superposed short waves (5614) 218

Between waves and turbulent field (4229)-.-.-- 118 WAVES, INTERNAL

Annotated bibliography (6084)

Field study by temperature measurements

(6410) - 66

Generated by local disturbances (6644)--.----- 41

Generated by source or sink impulse (5613)-..- 218

Generated by spheres moving in linear density gradient (4400)-.................. 217

Generated by stratified flow over barriers

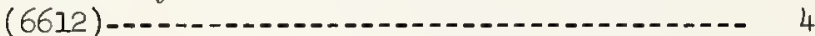

Generated by submerged body and its wake

(6173)

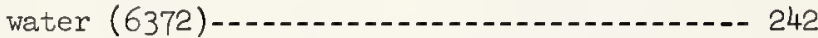

Internal tides off California (4500)-........ 113

Internal tides, waves and thermocline structure in coastal waters (6372)-.-.-.-.-- 242

Near-surface temperature and velocity effects of internal waves (6390)

sloshing in container with two liquids of different density (6543)-.................-.

Temperature and velocity correlations from vertically separated sensors in shallow water $(6220)$

WAVES, IONG

Amplification at small circular islands

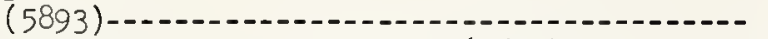

Penetration in narrow fiords (5685) -........

WAVES, MAPPING

World ocen mapped in special projection for wind-wave study (6411)

WAVES, MEASUREMEITS

See HYDRAULIC MEASUREMENTS, WAVES

WAVES, MODELS

See MODELS, WAVE ACTION

WAVES, OVERTOPPING

Effect of waves on proposed island site for combined nuclear power and desalting plant (6583)

of shoreline structures (5460)-..........-.- 129 WAVES, PEAK

The limiting height of ocean waves (6607).....

WAVES, PRESSURES

See WAVES, FORCES

WAVES, REFLECTION

Efficiency of fixed, hydraulic and pneumatic devices for minimizing reflection (6150)---- 145

From cylindrical pile arrays (5821)-........- 64

From vertical walls in Lake Washington (6149)- 145

Long waves over uneven bottom and obstacles, theory (6413)
WAVES, REFLECTION (continued)

Transmission and reflection by rubble and

floating breakwaters, beaches, absorbers (5635)-_... 198

WAVES, REFRACTION

Of wind waves (4934)-....... 10

qide-level and bottom-friction effect (6594)-- 238

Tsunami refraction at Crescent City, Calif.

(6865) -............ 214

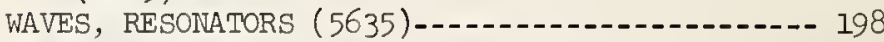

WAVES, RIPPLES

Liquid surface with impinging gas jet (6113)-- 59 WAVES, ROLL

On vertical films formed by condensing vapor (6111) -

See also OPEN CHANNEL FLOW

WAVES, ROSSBY

Hydrodynamics of rotating systems (4737)-...-. 150 WAVES, RUNUP

Analysis of field data at Nags Head, N.C.

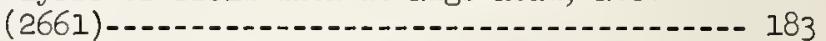

Beach runup, dispersive waves impulsively generated near shore (6332)-...........-. 236

Berms for protection of nuclear plant site

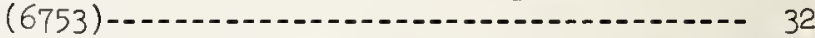

Comparison of laboratory run-up data from wind and mechanically generated waves (4155)-.-.- 124

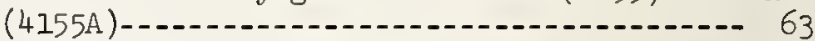

Effect of berms on run-up (4155)-..........- 124

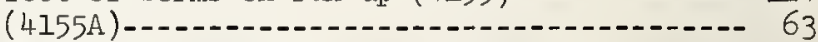

Impulsively generated waves, run-up on planefaced walls (6333)

On composite beaches (4155A)...........-.-. 63

Tsunamis at Oahu, Hawaii (5896)-..........- 40

Unusual standing wave in runup on laboratory beaches (5326) -

WAVES, SEDIMENT TRANSPORT BY

Beach scour at sea walls (5552)

(5552A) -

Duned beds under oscillatory flow (5545)-...- 35

Equilibrium profile of beaches and study of model scale effect (181)-.............-. 181

Erosion at foundations of concrete-crib breakwaters (6238) -.-1-260

Experiments on stability of beach fill

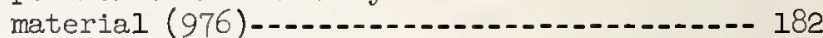

Radioactive tracers for beach studies (3897)-- 183

Sand movement by wind and waves, Northern

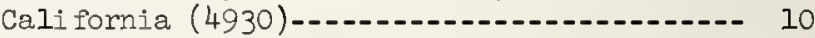

Transport by waves and currents in combination (4898) - 32

See also COASTAL SEDIMENT

WAVES, SEICHES

Hilo Harbor, Hawaii, seiching study (5894)-..- 40

Simulation and prediction with electrical analogs (6087) WAVES, SETUP

Model tests of wave setup, on beaches (3228)-- 183 WAVES, SHIP

See SHIPS, RESISTANCE

WAVES, SHOALING

Analysis with cnoidal-wave theory (4990)-...- 128

Deformation and breaking of solitary wave

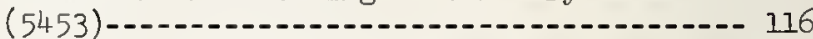
Model tests of wave setup on beaches (3228)--- 183 Theory and experiment up to and beyond breaking (1609) WAVES, SOLITARY

Experiments on deformation and breaking

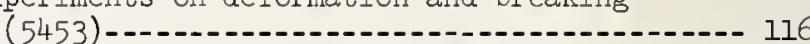

Theory applied to undular jump (1467)-...-.-. 189 WAVES, SPECTRA

Fetch-limited; from airborne sea-swell

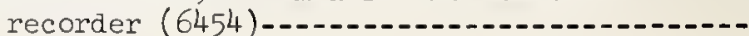


WAVES, SPECTRA (continued)

Shallow-water spectra from calm to

hurricanes in Gulf of Mexico (6297)-.....-. 132

Spectral density for ocean wave forces (5439)- 11

WAVES, STANDING

High-order theory for two-dimensional case

(5459)-129

See also WAVES, CIAPOTIS

WAVES, SURGES

See SURGES, STORM

WAVES, THEORY

High-order theory for deep water waves (5598)- 148

High-order theory for two-dimensional standing

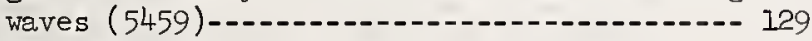

Profiles and trajectories from conformal mapping approach (6599)-_... 239

Ranges of validity of various theories for engineering use (6755)-..................... 33

Several theoretical problems in wave motion (6572)

WAVES, TIDES

See TIDES

WAVES, TRANSMISSION

Through cylindrical pile arrays (5821)-.....- 64

Through rubble breakwaters (5634)-.......-.- 198

See also WAVES, REFIECTION

VAVES, TSUNAMIS

Electric analog analysis (6132) -........... 233

Energy evaluation from tide gauge records using comparative analysis (6210).......... 235

Generated by horizontal fault moving nomal to channel (6224)

Numerical procedure for interaction with island (4866) - 124

Run-up on Oahu, Hawaii (5896)

Theoretical refraction studies for Crescent City, Calif. (6865)

Tsunami-barrier plans for Hilo, Hawaii; model (3903) -

Tsunami surge forces (5439) WAVES, WAVE TRAPS (5635) WAVES, WHITECAPS

Onset of whitecapping with increased surface wind speeds (6052)

WAVES, WIND

Characteristics observed in laboratory flume

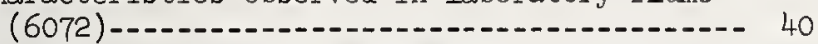

Directional spectra measurements; heights from stereo photos (6454)

Directional spectra of laboratory wind waves (4934)-...- 10 Dynamics of wind in vicinity of waves (5454)-- 116

Effect of waves at interface on turbulent

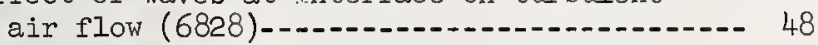

Experimental verification and extension of available generation theory (4917)-.-.---.- 116

Flow over moving boundary in relation to wind-generated waves (4917)............- 116

Laboratory simulation of sea waves (5454)...- 116 Model study for protection of nuclear power plant from storm waves (6505)-...-.-.-152

Numerical model to predict waves from extreme wind system over coastal area (6754)-.....- 33

observed particle motions (6465)-.......-.-. 243

Overtopping of shoreline structures (5460)---- 129

Reflection patterns in Lake Washington (6149)- 145 Wave climate study, St. Lawrence Gulf (6601)-- 263 Wind field near disturbed water surface (6389) 239 Wind speed and wave effect on evaporation

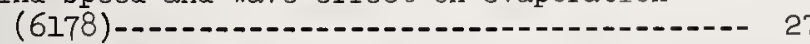

World ocean mapped in special projection for

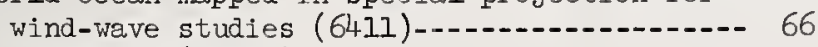

WAVY SURFACES (SOLID)

See ROUGHNESS, WAVY
WEIGHTLESSNESS

Effect on liquid-vapor interface

(6338) (6339) (6341)

Effect on outflow of liquids from space

vehicle (6340)

Liquid propellant sloshing in low-gravity environment (6063)-....... 114

Simulation and scaling of slosh (6655)-.-.--.- 230

sloshing in cylindrical flexible-bottom tanks

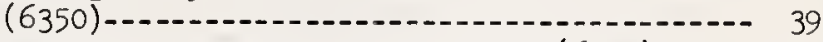

Sloshing problems with low gravity (6292)-.-.-- 132

Sloshing under reduced gravity (6341)-....... 232

Zero-gravity sloshing in partly filled tanks WEIRS

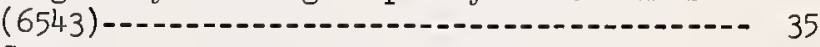

Broad crested; submergence effect on discharge

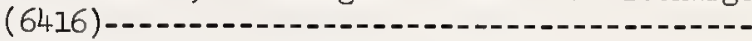

Discharge characteristics of side weirs (5740)-

Leaping-weir regulator for low interception

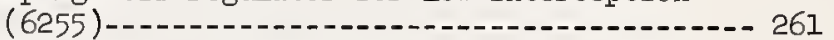

Model tests of riprap stability for low-water weirs (6871)-_... 215

Trapezoidal weir calibration for submerged flow $(6316)$

See also HYDRAUIIC MEASUREMENTS WELIS

Drawdown near wells in unconfined aquifers;

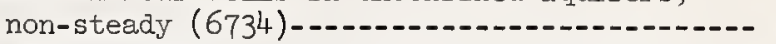

Seepage patterns of groundwater to wells for

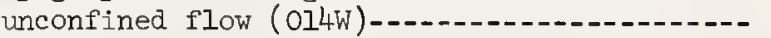

WIND FIELD

Near a wind-disturbed water surface (6389)-...- 239 WINDROWS

See CIRCULATION, LAKES

WIND TUNNELS

See FACILITIES

WIND WAVES

See WAVES, WIND WINGS

Shed wing vortices and their decay (5590)-...-.- 95 see also LTFTING-SURFACE THEORY WYES

See PIPE FLOW, FITTINGS
73 81 



\section{U.S. DEPARTMENT OF COMMERCE}

WASHINGTON, D.C. 20230

OFFICIAL BUSINESS

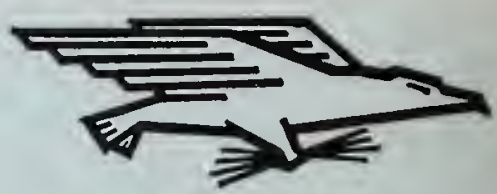

POSTAGE AND FEES PAID

U.S. DEPARTMENT OF COMMERCE 